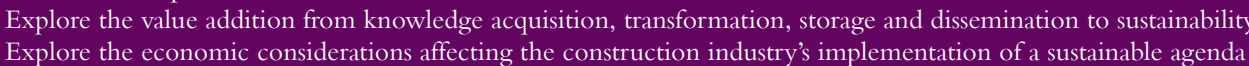
There have been noticeable developments and changes in recent years implecting on the built enviromment, as well On the debate on sustainabilityt As at writing, a number of devel oped and developing economies are beginning to come
out of the global recession. At the same time, a number of economies are employing austerity measures as part addressing the impact of recession. We continue to see major unrest and challenges in some parts of the world leading continues to be an issue in a number of countries and continents. Some countries are also experiencing real cut Higher Education funding, which invarable is bound to impact on research budgets. As built envirionnentent researchers these changes would have an impact on us
debate in our conference. For this international conference, the call for papers elicited 103 abstracts. The Scientific Committee have also worked tirelessly to uphold standard of quality and consstency of the papers. After the two stage blind review processes, we
have 53 accepted papers. This means that if your paper have been accepted for the conference, and is in the proceedings, then you should feel very proud of your achievement.

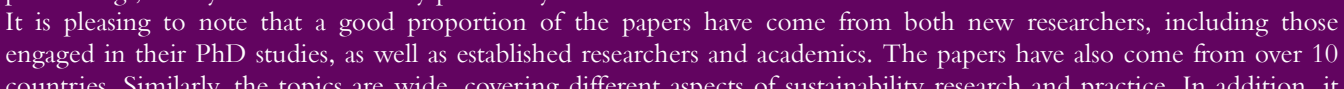
is noticeable that the content of the papers reflect the use of different research methodologies and philosophies.
I hope the the policy making, education and the construction industry in the wider areas of sustainability, in this very interesting ant

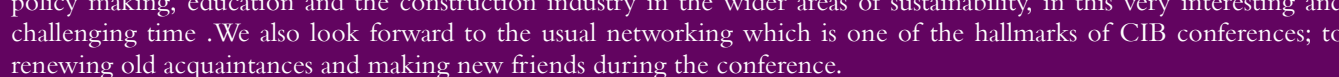
Prof. Charles Egbu PhD FRICS FCIOB FAPM FRSA FHEA Pro. 2015 Lorles Eon
Conference Chair

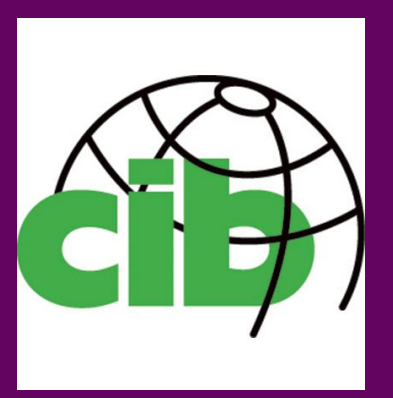

Leveraging Going North for Sustainability: Knowledge and Innovation for Sustainable Construction and Development

23-25 November 2015
London South Bank University, London, UK

Going north for sustainability: Leveraging knowledge and innovation for sustainable construction and development

School of the Built Environment and Architecture London South Bank University, UK 23-25 November 2015

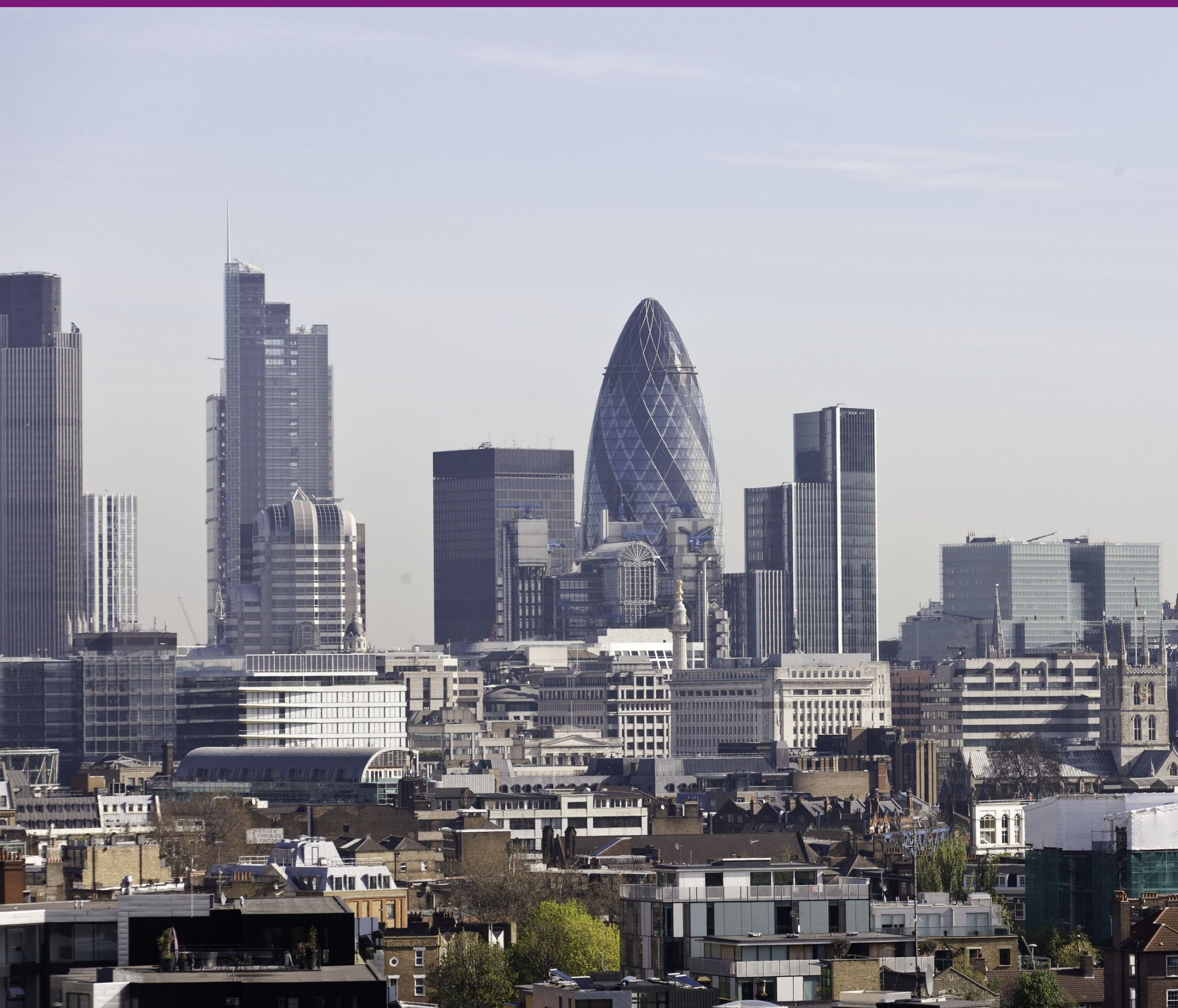


Going north for sustainability:

Leveraging knowledge and innovation for sustainable construction and development

23 - 25 November 2015

London South Bank University, London, UK

London South Bank University

International Council
for Research and Innovation
in Building and Construction 

(C) 2015 IBEA Publications Ltd.

Editor and Conference Chair: Professor Charles Egbu

Copy Editor: Dr. Mahtab Akhavan Farshchi

Published by IBEA Publications Ltd. London, UK

Printed by Lulu.com

All rights reserved. No part of this publication may be reproduced, stored in a retrieval system, or transmitted, in any form or by any means, electronic, mechanical, photocopying, recording or otherwise, without the prior permission in writing of the publishers.

British Library Cataloguing in Publication Data:

A catalogue record for this book is available from the British Library

ISBN- 978-1-326-47951-0 



\section{Contents}

$\begin{array}{ll}\text { Contents } & \text { iii } \\ \text { Foreword } & \text { vii } \\ \text { Acknowledgements } & \text { ix } \\ \text { Organising Bodies } & \text { x } \\ \text { Local Organising Committee } & \text { xi }\end{array}$

Theme 1 Procurement and Construction Economics

1. Developers' Compliance To The Delivery Of Basic Infrastructure To Housing Estates 3 Under The Public Private Partnership Arrangement In Abuja

2. Towards Sustainable Procurement Of Infrastructure At A South African University Of 13 Technology

3. Analysis Of Household Energy Consumption In Nigeria 23

4. Life Cycle Costing In Construction Projects: Professional Quantity Surveyors' Perspective 40

5. Using Soft System Methodology To Approach Social Value Outcomes In Public 50 Procurement

6. The Ce Meter; An Instrument To Assess The Circular Economy Capacity Of Buildings 60

7. An Investigation Of Psychological Contracts In Construction Procurement 70

8. Supply Chain Partnership In Construction A Field Study On Project Team Level Factors 81

9. Development Of The "Water-Specific P3 Risk Model”, Risks Identified 92

10. A Case For Target Value Design Towards Effective Low-Cost Housing Project Cost 104 Management And Performance In South-East Zone Nigeria

11. Stimulating The Bankability Of PFI/PPP Infrastructures Through The UK Government 115 Guarantees: Prospects And Challenges

12. Strategic Change In The Delivery Of Infrastructure

Theme 2 Culture and Human Resources

13. Perceptions Of Different Stakeholders Towards Sustainability: A Case Example From The Turkish Construction Industry

14. Women Professionals' Participation In The Construction Industry - Indian Scenario

15. Industry Culture As Causative Agents Of Construction Waste: A Need For Cultural Change 162

16. Interactions Of Culture And Person-Technology Fit In ICT Adoption In Construction 173

17. Determinants Of Employee Job Satisfaction In The Gauteng Province Of South Africa 184

18. Sustainability In Projects Requires Training In Managing As Designing 194

ii


19. Influence Of Host Organisation Culture In The Execution Of Construction Projects: A Case

Study Of Selected Higher Education Institutions In Nigeria

20. Implementation Of Early Conflict Management Measures In Construction Projects - The Case Of South Africa

Theme 3 Infrastructure Development and Management

21. An Evaluation Of Factors Influencing Compliance Of Construction Professionals To Ethical Standards

22. An Exploration Of Malaysian Public Listed Companies Diversifying Into Property Development

23. Beneficiary Housing Participation Defined - A South Africa Perspective

24. Environmental Impact And Energy Management Of Sports Stadia

25. Performance In Use: The Great Externality Of The Built Environment

26. Leveraging Concepts For Environmentally Sustainable Business Management In Construction - A Focused Review

27. Innovation In Offsite Manufacturing In The Field Of Housing: A Case Study Using Bourdivian And Actor-Network Approaches

28. Exploring Knowledge Management Principles For Decision-Making In Low-Energy 308 Building For Sustainability In Construction

29. Towards An Adaptability Rating For Buildings

30. Improving Housing Quality Through Client-Focused Information

31. Knowledge In The Decision-Making Process For Sustainable Renovation Of Multifamily Houses

32. Lessons For Specifying The System Boundaries Of An Asset Management Plan From Four Case Studies Of Failure

33. Reducing The Environmental Impact And Improving The Efficiency Of Construction Transport

Theme 4 Construction Industry and Global Economy

34. Building Sustainability And Building Health: An Inextricable Synergy

35. Research Trend Of Sustainability In Construction Journals

36. Corporate Factors Influencing Sustainable Construction Enterprise

37. A Framework For Growth Of Small And Medium-Size Construction Firms: A Literature Review

38. A New Theory-Based Typology For Construction Projects

39. Organizational Identification And Turnover Intention Of Employees In The Turkish 
Construction Industry

40. Research Programme On Innovative Learning Spaces And Their Development

41. Radical Circular Economy

42. Use Of Social Media In Construction Industry: A Case Study

44. Asbestos Free Fibrecement Components - Fifteen Years Of Joint Activities Between Industry And University

45. Using Life Cycle Assessment To Illustrate The Benefits Of Blinds As Passive And Sustainable Energy Saving Products In The Domestic Environment In The UK

46. A BIM-Centred System For Buffer Management

47. Re-Designing Project Management: Steps Towards A Project Management Curriculum For A Sustainable Built Environment

48. BIM Awareness And Readiness Of Postgraduate Built Environment Students In West Midlands Universities, UK

49. The Extent Of Integrating Sustainability Topics Into An MSc Quantity Surveying Course At London South Bank University In UK

50. Building Refurbishment Site Managers' Waste Management Practices

51. Challenges Of BIM Implementation In Sustainable Residential Projects In The UK And Future Perspective

52. Feasibility Study On Integration Of Low Carbon Technologies To Existing Domestic Dwellings In The UK

53. A Novel Dry Air Ground Source (DAGS) System For Heating And Cooling Buildings 


\section{Foreword}

This International Conference is about sustainability in its wider sense. It is an important area of discourse, as it pertains to how we work and how we lead our lives while considering the lives and workplaces of future generations. The conference particularly sets out to explore some of the developments and challenges taking place in academia and industry in both the Northern and Southern hemispheres. The conference is entitled "Going north for sustainability". The North signifies progress in technology, education and other areas of human endeavour to many people. Progress requires that people learn across continents and cultures. The conferences also hopes to celebrate the progress being made towards sustainability in construction and development in a developed world environment. Committed to the ideals of "meeting the needs of the current generation without undermining the ability of the next generation to meet their own needs", the CIB (International Council for Research and Innovation in Building and Construction) commissions and task Groups are joining forces to accelerate knowledge creation and sharing for sustainability in construction and development.

The international conference will deliberate broadly on the triple bottom line of people, planet and profitability related to the remits of the commissions (WC) and task groups (TG). The primary objectives of the conference are the following:

Explore the role of procurement in ensuring sustainability in construction and development projects

Explore the contribution of culture to construction and development and the implications of cultural competence to sustainability in construction

Explore the current trends in construction industry development

Present and demonstrate how research innovations can be/are being used to help companies and countries in sustainable construction and development

Explore the challenges and opportunities for public private partnerships in contributing to sustainable construction and national development

Explore the value addition from knowledge acquisition, transformation, storage and dissemination to sustainability

Explore the economic considerations affecting the construction industry's implementation of a sustainable agenda

There have been noticeable developments and changes in recent years impacting on the built environment, as well as on the debate on sustainability. As at writing, a number of developed and developing economies are beginning to come out of the global recession. At the same time, a number of economies are employing austerity measures as part of addressing the impact of recession. We continue to see major unrest and challenges in 
some parts of the world leading to massive immigration across countries and continents. Housing provisions, in terms of sustainability and affordability, continues to be an issue in a number of countries and continents. Some countries are also experiencing real cut in Higher Education funding, which invariable is bound to impact on research budgets. As built environment researchers, these changes would have an impact on us in one way or the other. No doubt, it would form an interesting area of debate in our conference.

For this international conference, the call for papers elicited 103 abstracts. The Scientific Committee have also worked tirelessly to uphold standard of quality and consistency of the papers. After the two stage blind review processes, we have 53 accepted papers. This means that if your paper have been accepted for the conference, and is in the proceedings, then you should feel very proud of your achievement.

It is pleasing to note that a good proportion of the papers have come from both new researchers, including those engaged in their $\mathrm{PhD}$ studies, as well as established researchers and academics. The papers have also come from over 10 countries. Similarly, the topics are wide, covering different aspects of sustainability research and practice. In addition, it is noticeable that the content of the papers reflect the use of different research methodologies and philosophies.

I hope that this conference affords us the opportunity to address some of the challenges that confront research, practice, policy making, education and the construction industry in the wider areas of sustainability, in this very interesting and challenging time .We also look forward to the usual networking which is one of the hallmarks of CIB conferences; to renewing old acquaintances and making new friends during the conference.

\section{Prof. Charles Egbu PhD FRICS FCIOB FAPM FRSA FHEA}

CIB 2015, London

Conference Chair 


\section{Acknowledgements}

A conference like this would be impossible to run without the help and assistance of a huge number of volunteers who have worked tirelessly to ensure its success. My special thank you to the Local Organising Committee, the National and International Advisory Board, and the Scientific Advisory Committee who have worked tirelessly to meet all deadlines for paper review and for upholding the high standard of quality.

A special mention is also due to Lynn Smith, Conference Administrator who took on the majority of the organisational and administrative burden for the conference. Thank you also to Dr. Mahtab Farshchi who was instrumental in the arrangement of papers for the conference proceedings and making sure that we were "ready to go" for the printers.

We are grateful for the support received from London South Bank University and from the CIB.

A huge thank you to the Vice Chancellor of London South Bank University, Professor Dave Phoenix OBE, for opening the conference and welcoming delegates. I am also grateful to Wim Bakens (CIB) for his welcome address to delegates.

We are grateful to Dr. Matthew Barac (LSBU) who moderated and chaired the debate during the "Industry Day". A number of industrialists and academics have supported the conference in a number of ways, including those who have acted as panellists in debates and question and answer sessions. We are thankful for their kind generosity and support.

A special thank you to the Keynote Speakers; Professor Ghassan Aouad (President of Applied Science University, Bahrain); Professor George Ofori (National University of Singapore), and Bridgett Bartlett (Deputy CEO, CIOB). We would also like to thank Cynthia Godley and the team at the Events and Marketing Departments at London South Bank University for their support with the conference.

Finally, we are also indebted to members of the CIB Student Chapter, LSBU, for their support in the organisation of the conference, and making sure that all who attended the conference had a worthwhile and enjoyable time during their stay in London. 


\title{
Organising Bodies
}

CIB is the world's foremost organization for construction researchers and practitioners. With its headquarters in Rotterdam, CIB is an international body dedicated to the research and documentation of the building industry. It brings together professionals from a broad spectrum of building organizations worldwide. The unrivalled collection of expertise of the more than 600 members is organized through a network of working commissions whose subject matter extends over every area of building and construction.

LSBU has been transforming lives, communities and businesses for over 120 years. We take a practical approach; professionally accredited and connected to industry. We offer some of London's best courses in engineering for cities, surveying, construction, architecture and design. The breadth and quality of our research and enterprise activities is widely acknowledged. Our applied research tackles real-world issues. We are the top modern university in London, UK, for world-leading and internationally excellent research in General Engineering (which includes The Built Environment and Architecture research). LSBU provides a highly applied academic environment which supports students into professional careers by providing them with the knowledge and skills that are attractive to employers.

\section{Participating Working Commissions and Task Groups}

\author{
W055 Construction Industry \\ W065 Organisation and Management of Construction \\ W089 Education in the Built Environment \\ W092 Procurement Systems \\ W096 Architectural Management \\ W102 Information and Knowledge Management in Building \\ W107 Construction in Developing Countries \\ W112 Culture in Construction \\ W117 Performance Measurement in Construction \\ TG72 Public Private Partnerships \\ TG81 Global Construction Data \\ TG83 e-Business in Construction
}




\section{Local Organising Committee}

Professor Charles Egbu, London South Bank University, UK - Conference Chair Professor Andy Ford, London South Bank University, UK Professor Graeme Maidment, London South Bank University, UK

Dr. Mahtab Farshchi, London South Bank University, UK

Dr. Alex Opoku, London South Bank University, UK

Dr. Matthew Barac, London South Bank University, UK

Ms Lynn Smith, London South Bank University, UK - Conference Secretary

\section{National and International Advisory Board}

Prof. Carlos Formoso, Federal University of Rio Grande do Sul, Brazil

Prof. Wilhelm Alfen, Bauhaus Universitat, Germany

Prof. Masahiko Kunishima, University of Tokyo, Japan

Dr Wim Bakens, CIB General Secretariat, Rotterdam, The Netherlands

Prof. Raymond Nkado, University of the Witwatersrand, South Africa

Mr German Mphahlele, Construction Industry Development Board, South Africa

Mr Boniface Muhegi, Contractors Registration Board, Tanzania

Mr Mike Sypsomos, The Mentor Group, Thailand

Prof. Stephen Ogunlana, Heriot-Watt University, UK

Prof. Akintola Akintoye, University of Central Lancashire, UK

Prof. Paul Olomolaiye, University of West of England, UK

Prof. Lukumon Oyedele, University of West of England, Bristol, UK.

Prof. Les Ruddock, University of Salford, UK

Prof. Chimay Anumba, Penn State University, USA

Prof. Obas Ebohon, De Montfort University, UK

Prof. Ghassan Aouad, Applied Science University, Bahrain

\section{Scientific Advisory Committee}

Dr Malik Khalfan, RMIT University, Australia

Prof. Sidney Newton, University of New South Wales, Australia

Prof. Alfredo Serpell, Pontifica Universidad Catolica de Chile, Chile

Prof. Wang Shouting, Tsinghua University, China

Prof. CM Tam, City University, Hong Kong, China

Prof. Mohan Kumaraswamy, University of Hong Kong, Hong Kong, China

Prof. Heng Li, Hong Kong Polytechnic University, Hong Kong, China

Prof. Anita Liu, University of Hong Kong, Hong Kong, China

Prof. Steve Rowlinson, University of Hong Kong, Hong Kong, China

Kähkönen Kalle, Tampere University of Technology, Finland

Prof. Banwet, Indian Institute of Technology Delhi, India

Prof. Arturas Kaklauskas, Vilnius Gediminas Technical University, Lithuania

Prof. Abdul Rashid, Universiti Sains Malaysia, Malaysia

Dr Emilia L.C. Van Egmond-De Wilde De Ligny, Eindhoven University of Technology, Netherlands

Dr Wilco Tijhuis, University of Twente, Netherlands

Dr Matthijs Prins, Delft University of Technology, Netherlands 
Prof. Hans Wamelink, Delft University of Technology, Netherlands

Prof. George Ofori, National University of Singapore, Singapore

Prof. PD Rwelamila, University of South Africa, Pretoria, South Africa

Prof. Alfred Ngowi, Central University of Technology, Free State, South Africa

Prof. Timothy Michael Lewis, University of the West Indies, Trinidad \& Tobago

Prof. Prasanta Kumar Dey, Aston Business School, UK

Prof Melvyn Lees, Birmimghamm City University, UK

Prof. Obas Ebohon, De Montfort University, UK

Prof. Stephen Ogunlana, Heriot-Watt University, UK

Prof. Andrew Dainty, Loughborough University, UK

Prof. Richard Fellows, Loughborough University, UK

Prof. Bob Giddings, Northumbria University, UK

Prof. Srinath Perera, Northumbria University, UK

Prof. Charles Egbu, South Bank University, UK

Prof. Akintola Akintoye, University of Central Lancashire, UK

Prof. Jack Goulding, , University of Central Lancashire, UK

Prof. Bimal Kumar, Glasgow Caledonian University, UK.

Prof. Mohammed Arif, University of Salford, UK

Dr Bingunath Ingirige, University of Salford, UK

Prof. Peter McDermott, University of Salford, UK

Prof. Les Ruddock, University of Salford, UK

Dr Stephen Gruneberg, University of Westminster, UK

Prof. Issaka Ndekugri, University of Wolverhampton, UK

Prof. Dean Kashiwagi, Arizona State University, USA

Dr Richard Burt, Auburn University, USA

Prof. Ben Uwakweh, North Carolina A\&T State University, USA

\section{International Scientific Review Committee}

Dr Tayyab Maqsood, RMIT University, Australia

Dr Roshani Palliyaguru, RMIT University, Australia

Prof. Sherif Mohammed, Griffith University, Australia

Dr Ajibade Aibinu, University of Melbourne, Australia

Dr Toong Khuan Chan, University of Melbourne, Australia

Dr Rizal Sunindijo, University of New South Wales, Australia

Dr Deepak Bajaj, University of Technology Sydney, Australia

Dr Connie Susilawati, Queensland University of Technology, Australia

Dr Joe Ssegawa, University of Botswana, Botswana

Dr Abdul Samad (Sami) Kazi, Technical Research Centre of Finland (VTT), Finland

Prof. Christian Brockmann, University of Applied Sciences, Bremen, Germany

Dr Prince Boateng, Koforodua Polytechnic, Ghana

Dr DeGraft Owusu-Manu, Kwame Nkrumah University of Science \&Tech, Ghana

Dr Ivan Fung, City University, Hong Kong, China

Dr Mei Yung Leung, City University, Hong Kong, China

Dr Isabelle Chan, Hong Kong University, Hong Kong, China

Dr Mei Yung Leung, City University, Hong Kong, China

Mr T O Oladinrin, Hong Kong Polytechnic University, Hong Kong, China

Dr Isabelle Chan, Hong Kong University, Hong Kong, China

Prof. Koshy Varghese, Indian Institute of Technology, Madras, India

Dr Gangadhar Mahesh, National Institute of Technology Karnataka, India

Dr Freddy Kurniawan, Narotama University, Indonesia

Dr Krishna S Pribadi, Institut Teknologi Bandung, Indonesia 
Dr Andi, Petra Christian University, Surabaya, Indonesia

Prof. Djwantoro Hardjito, Petra Christian University, Surabaya, Indonesia

Dr Peter Kaming, Atma Jaya University, Yogyakarta, Indonesia

Prof. Yoyong Arfiadi, Atma Jaya University, Yogyakarta, Indonesia

Dr Fuk Jin Oei, PT. Lippo Karawaci Tbk., Banten, Indonesia

Dr Arianti Sutandi, Tarumanegara University, Jakarta, Indonesia

Mr Jason Lim, PT. Sumarecon Agung Tbk., Jakarta, Indonesia

Dr Onnyxiforus Gondokusumo, Indonesia

Dr Martinus Abednego, PT Pertamina Hulu Energi, Indonesia

Dr Edward Susanto, PT. Susanto Ciptajaya, Indonesia

Dr Johnny Johan, PT. Kedoya Adyaraya, Jakarta, Indonesia

Mr Harijanto Setiawan, Atma Jaya University, Jogyjakarta, Indonesia

Prof. Takayuki Minato, University of Tokyo, Japan

Prof. Tsunemi Watanabe, Kochi University of Technology, Japan

Dr Abid Nadeem, Nazarbayev University, Kazakhstan

Dr Gerald Sundaraj, Construction Industry Development Board, Malaysia

Prof. Bala Kabir, Ahmadu Bello University, Zaria, Nigeria

Dr Obuks Ejohwomu, Bells University, Ota, Nigeria

Dr Jurbe Molwus, University of Jos, Nigeria

Prof. Iro Idoro, University of Lagos, Nigeria

Dr Martin Dada, University of Lagos, Nigeria

Prof. Sunday Oyediran, University of Lagos, Nigeria

Prof. Kole Odusami, University of Lagos, Nigeria

Prof. Timothy Nubi, University of Lagos, Nigeria

Prof. Ime Ikpo, Obafemi Awolowo University, Nigeria

Prof. Henry Odeyinka, Obafemi Awolowo University, Nigeria

Dr Timothy Ibironke, Federal University of Technology, Akure, Nigeria

Mr Julius Jibrin Adam, Federal University of Technology Akure, Nigeria

Mr Amos Adewusi, Federal University of Technology Akure, Nigeria

Dr Niyi Aje, Federal University of Technology Akure, Nigeria

Mr Pelumi Akinbogun, Federal University of Technology, Akure, Nigeria

Mr Festus Akinradewo, Federal University of Technology Akure, Nigeria

Mr Michael Alakinde, Federal University of Technology Akure, Nigeria

Dr Oluwaseyi Awodele, Federal University of Technology, Akure, Nigeria

Miss Kemi Ogundiran, Federal University of Technology Akure, Nigeria

Prof. Rufus Ogunsemi, Federal University of Technology Akure, Nigeria

Mr Deji Oke, Federal University of Technology Akure, Nigeria

Mr Michael Olukolajo, Federal University of Technology Akure, Nigeria

Mr Kayode Rotowa, Federal University of Technology Akure, Nigeria

Dr Dorcas Ayeni, Federal University of Technology, Akure, Nigeria.

Mr Gwom Peter, Kaduna State Polytechnic, Nigeria

Dr Isaac Ikediashi, University of Uyo, Nigeria

Dr Michael Oladokun, University of Uyo, Nigeria

Prof. Adnan Enshassi, University of Gaza, Palestine

Dr Vasantha Abeysekera, UNITEC, New Zealand

Dr Zehra Waheed, COMSATS Institute of Information Technology, Pakistan

Prof. Francisco Ribeiro, Instituto Superior Tecnico, Portugal

Prof. Rafiq M. Choudhry, King Faisal University, Saudi Arabia

Dr Ibrahim Falqi, King Khalid University, Saudi Arabia

Dr Abimbola Windapo, University of Capetown, South Africa

Dr Olatunji Aiyetan, Central University of Technology, Free State, South Africa

Prof. Ananda Jayawardane, University of Moratuwa, Sri Lanka

Prof. Ting Ya, National Central University, Taiwan

Dr Samsom Matiko, University of Dar es Salaam, Tanzania 
Dr Chotchai Chareonngam, Asian Institute of Technology, Thailand

Dr Bonaventura Hadikusumo, Asian Institute of Technology, Thailand

Dr Piyanut, Kasetsart University, Thailand

Dr Rathavoot Runthakhon, Siam University, Thailand

Dr Wannawit Taemthong, King Mongkut Institute of Technology, North Bangkok, Thailand

Dr Wutthipong Muongnoi, King Mongkut University of Technology, Thonburi, Thailand

Dr Sdhabhon Bokha, Ubon Ratchtani University, Thailand

Prof. Henry Alinaitwe, Makerere University, Uganda

Mr Wilfred Okello, Ministry of Works and Transport, Uganda

Dr Nuhu Braimah, Brunel University, UK

Mr Sani Akoh, Heriot-Watt University, UK

Dr Assem Al-Hajj, Heriot-Watt University, UK

Dr George Chen, Heriot-Watt University, UK

Mr Haniff Amos, Heriot-Watt University, UK

Dr Bilge Erdogan, Heriot-Watt University, UK

Dr Khamidi Faris, Heriot-Watt University, UK

Dr Ibrahim Motawa, Heriot-Watt University, UK

Dr Krisanthi Seneviratne, Heriot-Watt University, UK

Dr Benny Suryanto, Heriot-Watt University, UK

Dr Bayrak Turker, Heriot-Watt University, UK

Dr Aaron Anvuur, Loughborough University, UK

Dr Francis Edom-Fotwe, Loughborough University, UK

Mr Adeniyi Onaopepo, Northumbria University, UK

Dr Champika Liyanage, University of Central Lancashire, UK

Dr Marcus Jefferies, University of Newcastle, UK

Prof. David Proverbs, University of the West of England, UK

Dr Florence Phua, University of Reading, UK

Dr Tabarak Ballal, University of Reading, UK

Dr Dominic Ahiaga-Dagbui, Robert Gordon University, UK

Dr Ramesh Marasini, Southampton Solent University, UK

Dr Ezekiel Chinyio, University of Wolverhampton, UK

Dr Nii Ankrah, University of Wolverhampton, UK

Dr Subashini Suresh, University of Wolverhampton, UK

Dr. Suresh Renukappa, University of Wolverhampton, UK

Prof. David Proverbs, University of West of England, UK

Dr Andrew Brown, Edinburgh Napier University, UK

Mr Olubukola Tokede, Edinburgh Napier University, UK

Prof. Dilanthi Amaratunga, University of Huddersfield, UK

Prof. Richard Haigh, University of Huddersfield, UK

Dr Salman Azhar, Auburn University, USA

Prof. Benedict Ilozor, Eastern Michigan University, USA

Dr Nguyen Duy Long, Florida International University, USA

Dr Le Anh Dung, Hanoi University of Architecture, Vietnam

Dr Le Tien Dung, RMIT University, Vietnam

Dr Le Trung Thanh, Ministry of Construction, Vietnam 


\section{Theme 1 Procurement and Construction Economics}

1. Developers' Compliance to the Delivery of Basic Infrastructure to Housing Estates under the Public Private Partnership Arrangement in Abuja

2. Towards Sustainable Procurement Of Infrastructure At A South African University Of Technology

3. Analysis of Households Energy Consumption in Nigeria

4. Life cycle costing in construction projects: professional quantity surveyors' perspective

5. Using Soft System Methodology To Approach Social Value Outcomes In Public Procurement

6. The CE Meter; An instrument to assess the circular economy capacity of buildings

7. An Investigation of Psychological Contracts in Construction Procurement

8. Supply Chain Partnership in construction A field study on project team level factors

9. Development Of The "Water-Specific P3 Risk Model", Risks Identified

10. A case for Target Value Design towards Effective Low-cost Housing Project Cost Management and Performance in South-East zone Nigeria

11. Stimulating The Bankability Of PFI/PPP Infrastructures Through The UK Government Guarantees: Prospects And Challenges

12. Strategic change in the delivery of infrastructure 


\title{
DEVELOPERS' COMPLIANCE TO THE DELIVERY OF BASIC INFRASTRUCTURE TO HOUSING ESTATES UNDER THE PUBLIC PRIVATE PARTNERSHIP ARRANGEMENT IN ABUJA
}

\author{
AbdulAzeez, A-A. ; Owoicho, M. E. ${ }^{2}$ and Dahiru, D. ${ }^{3}$
}

\begin{abstract}
:
Infrastructure plays a vital role in housing development hence should be given much attention. The wellbeing of individuals in any community depends on the availability of basic infrastructure to support housing. Abuja as the capital of Nigeria is experiencing rapid population growth which has led to high demands in housing and infrastructure. The government went into partnership with estate developers in the provision of housing and infrastructure to the teeming population. The housing estates provided under this partnership suffer poor provision of infrastructure as cases of disputes between subscribers and developers have been recorded. The purpose of this study is to investigate the level of compliance of estate developers in the provision of infrastructure in public private partnership housing estates. It aims at identifying the basic infrastructure lacking in these estates as it would help relevant bodies play their roles efficiently in the provision of primary infrastructure and also ensure developers adhere to the agreement of partnership. A sample size of 56 estates was selected, a checklist was used for this purpose. From the findings, 75\% have paved access roads, 10.4\% have water supply, 79.2\% have drainages, $83.3 \%$ have streetlights, $0 \%$ have sewer lines, $95.83 \%$ have electricity, 14.6\% have shopping facility and $29.2 \%$ have recreational parks provided by the developers in the housing estates visited. In conclusion, there is poor provision of water supply, sewer lines, shopping facility and recreational parks in public private partnership housing estates. It is recommended that regulatory bodies ensure developers provide the required infrastructure through proper monitoring and supervision.
\end{abstract}

KEYWORDS: DEVELOPERS, HOUSING， INFRASTRUCTURE， ESTATES， PUBLIC PRIVATE PARTNERSHIP

\section{INTRODUCTION}

Majority of housing and urban challenges are associated with the concept of sustainability which can be handled in different ways (Council of Europe Development Bank, 2012). The delivery of basic infrastructure to urban communities constitutes one of the challenges in developing countries. Shelter is the basic need of humans as it protect us against harsh environmental conditions. Infrastructure provision forms an important ingredient to housing development and formal housing supply is dependent on relevant authorities delivering sufficient infrastructure (Kihato, 2012). Urban infrastructure and housing provision are closely related. Without infrastructures, housing cannot be sustainable and hence should be treated integrally (Otegbulu and Adewumi, 2009). One major aspect of urban problem with respect to housing is the poor state of the

\footnotetext{
${ }^{1}$ Department of Building, Ahmadu Bello University, Zaria, Nigeria. Email: Corresponding author: engraazeez@gmail.com; aabdulazeez@abu.edu.ng

${ }^{2}$ Department of Building, Ahmadu Bello University, Zaria, Nigeria. Email: msc22513mo13@gmail.com

${ }^{3}$ Department of Building, Ahmadu Bello University, Zaria, Nigeria. Email: drdaudadahiru@yahoo.com
} 
infrastructures (Ajanlekoko, 2001; Ajayi and Omole, 2012). Giddings (2007), observed that one of the most serious policy constraints to scaling up investments in housing and urban infrastructure in Africa is that in most countries in the region the sector is not accorded the priority it should command in national planning strategies and therefore receives short shrift in attracting budgetary resources.

In recent times, the development of cities and its infrastructural needs around the world is achieved by joint efforts of both the government and private individual efforts and initiatives. Nigeria operates a three tier system of government; the federal government, State government and local government, all required to provide affordable and comfortable housing and infrastructures to the people. Most rural communities suffer insufficient infrastructures and the existing infrastructures are deteriorating rapidly due to the pressure it suffers. These have also led to mass movement of people from rural areas in search of a better life. Government has embarked on mass housing schemes to cater for the ever growing demand of housing but only a little percentage has been achieved. This could be attributed to the fact that most government housing programs have been frustrated by corruption, politicization, insufficiency of technical staff at building sites, and lack of infrastructure (Ademiluyi, 2010).

The Federal Capital Territory Administration (FCTA) and the Federal Capital Development Authority (FCDA) decided in the year 2000 to embark on a new approach in order to meet the challenges. Private Public Partnership (PPP) concept was initiated to reduce the burden of providing housing and its needed infrastructures on the government and increase the participation of the private sector. Government provided parcels to private estate developers to housing estates. The developer enters into a 'Development Lease Agreement' with the FCTA/FCDA. This agreement states the term and conditions as well as the obligations of each of the two partners. According to Ibrahim and Kwankur (2012), Some the terms and conditions include on the part of the Authority: - The provision of Primary Infrastructure like, major road arterials, Power supply from the main grid line, Water supply from the main trunk line and Major sewer line connection. While on the part of the Developer they are expected to provide the Secondary Infrastructure like, Secondary roads and local streets within the estate, drainages and sewer lines, power supply to the individual units of house, local facilities for shopping and recreational activities. Cases of poor provision of infrastructure in estates provided under this partnership have been reported by house owners and residents. There was a publication on the internet by Code Wit news dated 7 December, 2013 reporting a dispute between a private estate developer and residents of Abuja Jubilation Bethel Estate, Lokogoma as regards the inability of the estate developer to provide the required infrastructure in the estate.

Cases of poor provision of infrastructure in estates have been reported by house owners and residents. There was a publication on the internet by Code Wit news dated 7 December, 2013 reporting a dispute between a private estate developer and residents of Abuja Jubilation Bethel Estate, Lokogoma, Abuja as regards the inability of the estate developer to provide the required infrastructure in the estate. Houses in public private 
partnership estates at Abuja remain unoccupied due to lack of infrastructure provision needed to ensure a comfortable and healthy environment.

This study intends to ascertain the compliance of developers as regards the provision of infrastructure agreed between the government and estate developers with a view proffer recommendation towards the provision of infrastructure in PPP housing estates.

\section{LITERATURE REVIEW}

\section{Infrastructure}

Infrastructure is widely defined as the system of services and facilities which provides for the basic wellbeing and quality of life (Ziara and Ayyub, 1996). The Longman online dictionary (2014) defines infrastructure as the basic systems and structures that a country or organization needs in order to work properly, for example roads, railways, banks etc. Infrastructure can be described generally as the set of interconnected structural elements that provide framework supporting an entire structure of development. Ziara and Ayyub (1996), further described infrastructure as facilities and basic systems on which the sustainability and growth of a community and state depends. The term typically refers to the technical structures that support a society, such as roads, water supply, sewers, electrical national grids, telecommunications, and so forth, and can be defined as "the physical components of interrelated systems providing commodities and services essential to enable, sustain, or enhance societal living conditions" (Fulmer, 2009). The major features in the above definition of infrastructure consists of facilities and utilities which are provided for the public to enhance living standards of the people. As the population of any society grows, the existing infrastructure suffers deterioration due to high demands.

Urban facilities are the necessary public facilities for maintaining people's lifestyle and city functions and refer to the framework for urban structure which may include transportation facilities such as roads and park lots, public spaces such as parks, green spaces and public squares, supply facilities such as water and electricity, waste disposal facilities such as sewers, waste treatment plants and garbage incinerators, educational and cultural facilities such as schools, libraries and research facilities, and medical and social welfare facilities such as hospitals and child care centres (Japan, 2004; Zakout 2006). Infrastructure is a very important aspect of housing development as it provides a conducive environment for inhabitants to live comfortably. Researchers have linked poverty to the deprivation of infrastructures, in essence any society that lacks basic infrastructure is impoverished. Amis and Kumar (2000) asserted that it is easier for individuals to cope with different levels of poverty due to the existence of infrastructure. It also follows that cities with the greatest number of poor people are those whose citizens lack infrastructure the most (Udoka, 2013).

Kumar (2005), classified infrastructure into two types, soft and hard infrastructure. Soft infrastructure refers infrastructure refers to all the institutions which are required to 
maintain the economic, health, and cultural and social standards of a country, such as the financial system, the education system, the health system, the governance system, and judiciary system, as well as security while the hard infrastructure Hard refers to the large physical networks necessary for the functioning of a modern industrial nation.

\section{Categories and Components of Infrastructure}

Zakout (2006), stated that infrastructure is important to attain adequate housing and good quality of life for individuals especially in the construction of low cost housing and therefore urban infrastructure should be classified into two main categories, namely:

i. Basic Infrastructure Components

ii. Supportive Infrastructure Components

\section{i. Basic Infrastructure Components}

The basic infrastructure components are defined as the key infrastructure components which are considered as a basic requirement for the basic life, health, safety and security of people. The provision of infrastructure which fall under this category should be provided simultaneously with the construction of houses and their costs added to the cost of housing. The provision of this infrastructure is the responsibility of the housing institution (owner/developer) in cooperation and coordination with the relevant national ministries and authorities. The basic infrastructure components are as follows: water supply, wastewater collection (sewerage system), wastewater treatment and reuse or disposal, power supply and security lighting, access and paving, storm water drainage and telephone lines.

\section{ii. Supportive Infrastructure Components}

This category of infrastructure includes all services which are considered to be supportive to the lives of the residents, but not necessary essential for their basic wellbeing. The provision of supportive infrastructure services within an estate or community is to provide proximity to services and facilitate the social life of residents. Thus, they are considered additional public facilities. Supportive infrastructure components include one or more of the following service facilities: parks and green areas, schools, health centre, worship area, public market and public service buildings

\section{Effects of Infrastructure on Property Values}

The state of infrastructure is an important parameter for assessment and indicator of status of any urban system (Ajibola et al., 2013). Olujimi (2010), asserted that the problems of deteriorated infrastructure are particularly peculiar in the old, indigenous core areas of the cities while the non-availability of infrastructure is peculiar to the outer spontaneous settlements that accommodate the low-income population. Public infrastructure when adequately provided offers multi-dimensional benefits within its operative network (Famuyiwa and Otegbulu, 2012). Real estate has no value if it has no utility, if it is not scarce and if it is not effectively demanded (Ajibola et al., 2013). 
Economies require the development of infrastructure, such as water, energy, roads development, transport networks, information, and communication technology for sustainability and these urban services also positively influence the value of real estate as they improve housing conditions and quality (Famuyiwa and Otegbulu, 2012). Odudu (2003), observed that housing values tended to peak in those locations that enjoyed one form of infrastructure or the other. (Johnson et al., 2005) stated that one of the determinants of property value is infrastructure, the presence of which leads to appreciation in property values.

\section{RESEARCH METHODOLOGY}

The research aims at ascertaining the level of compliance by estate developers in the provision of infrastructure in public private partnership housing estates recommended by government in Abuja. Essentially, the procedures by which researchers go about their work of describing, explaining and predicting phenomena is called research methodology (Rajasekar et al., 2013). A checklist was used as the data collection instrument. Checklist was used to take inventory of infrastructure available in existing estates. It was grouped into two sections, which consist; general information of estate and the list of infrastructure that should be available in estates as recommended by the FCTA/FCDA. The study is limited to public private partnership housing states in Abuja, Nigeria

With regards the sample size for the use of checklists in estates, all efforts to ascertain the number of estates from relevant authorities proved abortive. The sampling size was determined based on (Glenn, 1992) formula below considering the targeted population is unknown and large.

$n=\left(\left(z^{2} p q\right) / d^{2}\right)$

Where;

$\mathbf{n}=$ the desired sample size

$\mathbf{z}=$ the ordinate on the normal curve corresponding to aor the standard normal deviate.

For the purpose of this study, a confidence level of $90 \%$ will be adopted.

Usually a $90 \%$ level of confidence has $\alpha=0.10$ and critical value of $z_{\alpha / 2}=1.64$.

$\mathbf{p}=$ the proportion in the target population estimated to have a particular characteristics (normal between the range of $0.1-0.5$ )

$\mathbf{q}=1.0-\mathbf{p}$

$\mathbf{d}=$ degree of accuracy corresponding to the confidence level and $\mathrm{Z}$ selected.

The sample size is determined using the following parameters, $\mathbf{z}=1.64, \mathbf{d}=0.1, \mathbf{p}=0.3, \mathbf{q}=0.7$

Sample size $\mathrm{n}=\left[(1.64)^{2} \times 0.3 \times 0.7\right] /(0.1)^{2}=56.4$

Thus this study considered 56 estates. 
Housing estates were randomly selected in different districts allocated for PPP housing schemes, it was important that all districts were covered in this research. The data collected were analysed using bar chart, frequency tables.

\section{FINDINGS AND DISCUSSION}

From the research work, the following findings were discovered, and presented in figures and tables for easy articulation and interpretation. A percentage of $85.7 \%$ PPP housing estates were visited in different districts allocated for PPP housing scheme.

The chart in Figure 1 shows the year of establishment of estates visited in percentages. The highest number of estates visited were established between $2006-2010$ and the lowest number of estates visited fall under those established between $2000-2005$.

Figure 1: Year of Establishment of Estates

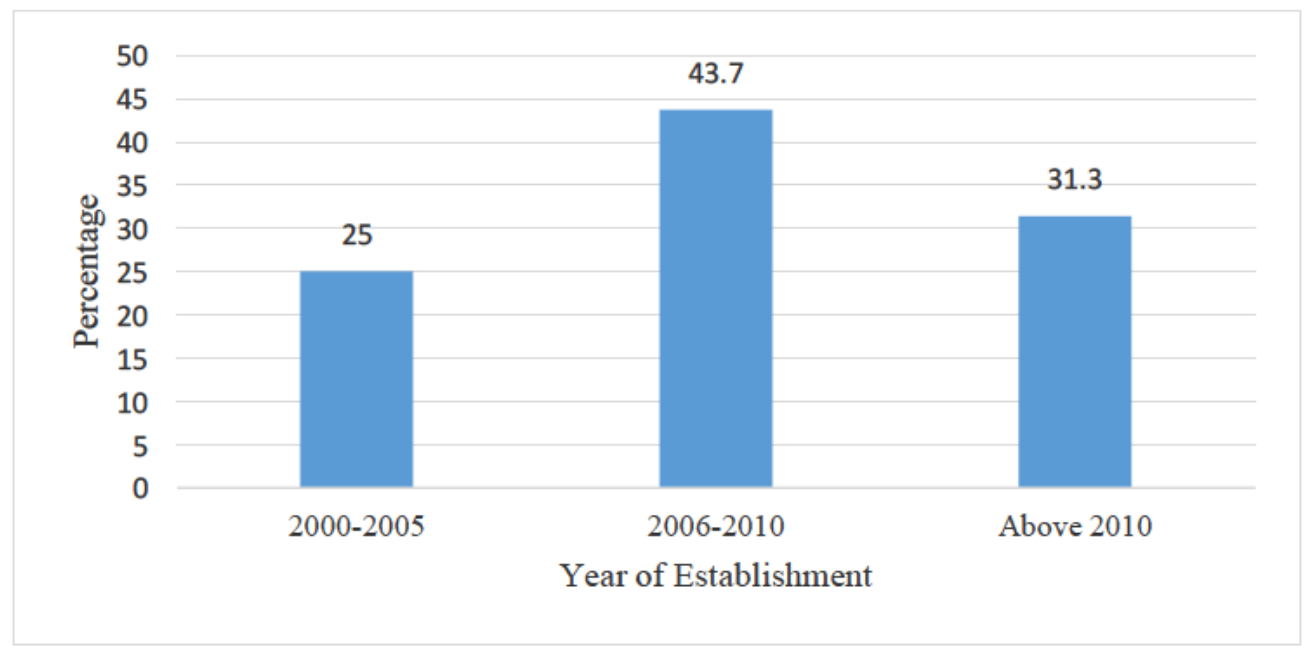

Source: Field Survey (2014)

Table 1 shows the type of residential buildings in the estates visited, $39.5 \%$ of the estates contained bungalows, $31.3 \%$ for duplexes, 22.9 for mixed buildings and 6.3 for mixed buildings. 
Table 1: Type of Residential Buildings in the Estates Visited

\begin{tabular}{lll}
\hline Type of Residential Building & Frequency & Percentage (\%) \\
\hline Bungalows & 19 & 39.5 \\
Duplexes & 15 & 31.3 \\
Block of flats & 3 & 6.3 \\
Mixed buildings & 11 & 22.9 \\
\hline Total & 48 & 100
\end{tabular}

Source: Field Survey (2014)

As shown in Table $2,75 \%$ of the estates have paved roads while $25 \%$ of the estates have their access roads unpaved. It was ascertained that $10.4 \%$ of estates have water provided by the developers and $89.6 \%$ do not have water provided by developers. The subscribers of estates without water supply provide alternative source of water for themselves by sinking boreholes and digging wells. The main reason for the poor provision of water in estates can be linked to government's inability to provide districts with water supply from the main trunk line. It was observed that $79.2 \%$ of the estates have drainages while 20.8 do not have drainages. From the results above a good percentage of estates have drainages provided by developers.

Based on the findings, $83.3 \%$ of the estates have streetlights while $16.7 \%$ do not have streetlights. The results shows that there is absence of street lights in few estates. It was ascertained that none of the estates have sewer lines and soak away are provided by developers. This is due to the absence of major sewer line connection that ought to be provided by the government. Also, $95.83 \%$ of the estates visited have electricity and $4.17 \%$ do not have electricity. This shows that most districts visited have power supply from the main grid line provided by the government hence the provision of electricity in estates.

Finally, $14.6 \%$ of the estates have shopping facility while $85.4 \%$ do not have shopping facility and $29.2 \%$ of the estates have recreational parks while $70.8 \%$ do not have recreational facility. Based on the findings, an appreciable percentage of estates lack shopping facility and parks for recreational activities. 
Table 2: Basic Infrastructure in Housing Estates under the PPP Housing Scheme

\begin{tabular}{lll}
\hline Basic Infrastructure & $\begin{array}{l}\text { Percentage } \% \\
(\text { Yes })\end{array}$ & $\begin{array}{l}\text { Percentage \% } \\
\text { (No) }\end{array}$ \\
\hline Paved Road & 75 & 25 \\
Water Supply & 10.4 & 89.6 \\
Drainages & 79.2 & 20.8 \\
Street Lights & 83.3 & 16.7 \\
Sewer lines & 0 & 100 \\
Electricity & 95.83 & 4.17 \\
Shopping facility & 14.6 & 85.4 \\
Recreational parks & 29.2 & 70.8 \\
\hline
\end{tabular}

Source: Field Survey (2014)

\section{CONCLUSION AND FURTHER RESEARCH}

From the findings, $75 \%$ have paved access roads, $10.4 \%$ have water supply, $79.2 \%$ have drainages, $83.3 \%$ have streetlights, $0 \%$ have sewer lines, $95.83 \%$ have electricity, $14.6 \%$ have shopping facility and $29.2 \%$ have recreational parks provided by the developers in housing estates visited. In conclusion, there is a poor delivery of sewer lines, water supply, shopping complexes and recreational parks respectively.

The poor participation of government in the partnership as regards the provision of main trucks for water supply and main sewer lines to districts has been attributed to the poor provision of these infrastructure to housing estates because secondary infrastructure in the estates depends on primary infrastructure to function. The low compliance to the provision of shopping complexes and recreational parks is due to the fact that developers convert land allocated for commercial and recreational purposes which is affirmed in the work of (Ibrahim and Kwankur, 2012).

It is recommended that government keep to its part of the partnership agreement by providing primary infrastructure to districts allocated for PPP housing estates. It is necessary to develop a master plan that incorporates working schedules of the government and estate developers in order to achieve synergy in the provision of infrastructure to districts and housing estates. There is also the need for proper supervision and monitoring of relevant bodies to ensure developers adhere to the master plan.

Adequate infrastructure delivery plays an important role in our day to day activities. This study has established the basic infrastructure lacking in PPP housing estates in Abuja. 
Further research should be carried out on the maintenance of infrastructure in public private partnership housing estates.

\section{REFERENCES:}

- ADEMiluYI, I. A. (2010). Public Housing Delivery Strategies in Nigeria: A Historical Perspective of Policies and Programmes. Journal of Sustainable Development in Africa, 12(6), 153-161.

- $\quad$ AGENCY REPORTER. (2013, December 7). Abuja Jubilation Bethel Estate Crisis Deepens. Code Wit World News. Retrieved from http://www.codewit.com/business/14614-abujajubilation-bethel-estate-crisis deepens.

- AJANLEKOKO, J. S. (2001). 'Sustainable Housing Development in Nigeria - The Financial and Infrastructural Implication', International Conference on Spatial Information for Sustainable Development Nairobi, Kenya.

- AJAYI, M. A. \& OMOLE, F. K. (2012). Sustainable housing development and communal provision of infrastructures in Asuwamo residential estate Akure, Nigeria. Procs $4^{\text {th }}$ West Africa Built Environment Research (WABER) Conference, 24-26, July 2012, Abuja, Nigeria, 191-201.

- $\quad$ AJIBOLA, M. O., AWODIRAN, O. O. \& Salu-KOSOKO, O. (2013). Effects of Infrastructure on Property Values in Unity Estate, Lagos, Nigeria. International Journal of Economy, Management and Social Sciences, 2(5), 195-201.

- $\quad$ AMIS, D. \& KUMAR. (2000). Urban economic growth, infrastructure, and poverty in India: Lessons from Visakhapatnam, environment and urbanization, 1(1).

- Council of Europe Development Bank. (2012). Sustainable Housing and Urban Development: The CEB's Contribution.

- FAMUYiWA, F. \& OTEGBUlU, A. C. (2012). Public water infrastructure in property prices: An environmental valuation approach. Elixir Infrastructure Mgmt. 51.

- Fulmer, J. (2009). What in the world is infrastructure? PEI Infrastructure Investor (July/August): 30-32.

- GLENN, I. D. (1992). Determining Sample Size, Agricultural Education and Communication Department, Florida Cooperative Extension Service, Institute of food and Agricultural Sciences, University of Florida.

- IBRAHIM, U. I. \& KWANKUR, T. G. (2012). The Challenges of Housing Development and Needs in Abuja. A paper May 2012. The FIG working week, Rome, Italy.

- JAPAN (2004). Seminar on public works administration in regional government II. City Planning System. October, 2004. JICA, Japan.

- JOHNSON, T., DAVIES, K. \& SHAPIRO, E. (2005) Modern Methods of Valuation of Land, Houses and Buildings. Estate Gazette, London.

- KIHATO, M. (2009). 'Infrastructure and housing finance': exploring the issues in Africa. Centre for affordable housing finance in Africa.

- KUMAR, D. (2005). Infrastructure in India. ICFAI Journal of Infrastructure. Retrieved from http://129.3.20.41/eps/urb/papers/0506/0506002.pdf.

- ODUDU, C. (2003). Significance of Infrastructure in Determining Land and Rental Values in an Urban Area-The Case of Lagos Metropolis. Land Management and Property Tax Reform in Nigeria-Proceedings of a National Workshop organized by the Department of Estate Management, University of Lagos, Nigeria.

- OLUJIMI, J. A. (2010). Analysis of the Relationships of Infrastructural Facilities in the determination of Rental Values of Residential Properties in Akure, Nigeria. Arts and Social Sciences Journal. 
- OTEGBulu, A. \& ADEWUNMI, Y. A. (2009). Evaluating the Sustainability of Urban Housing Development in Nigeria through Innovative Infrastructure Management. International Journal of Housing Markets and Analysis, 2(4), 334- 346.

- Rajasekar, S., Philominathan, S. \& Chinnathambi, V. (2013). Research Methodology. Retrieved from arxi.org/pdf/physics/0601009.

- THE LONGMAN ONLINE DICTIONARY. (2014). Retrieved from http://www.ldoceonline.com/spellcheck/?q=\%ednfrastructure

- UDOKA, I. S. (2013). The Imperatives of the Provision of Infrastructure and Improved Property Values in Nigeria. Mediterranean Journal of Social Sciences, 4(15),21-33.

- ZAKOUT, A. A. (2006). Provisions of Infrastructure for Low-Cost Housing Developments. MSc. Thesis Department of Infrastructure Engineering, the Islamic University of Gaza, Palestine.

- ZIARA, M. \& AYYUB, B. (1996). Methodology for construction reduced-cost Housing: System framework with decision analysis, Conference on Affordable Housing, Birzeit, Palestine. 


\title{
TOWARDS SUSTAINABLE PROCUREMENT OF INFRASTRUCTURE AT A SOUTH AFRICAN UNIVERSITY OF TECHNOLOGY
}

\author{
Awuzie, B.O. ${ }^{1}$; Emuze, F.A ${ }^{2}$. and Ngowi, A. ${ }^{3}$
}

\begin{abstract}
:
Higher Education Institutions (HEIs) are poised to serve as sustainability champions through embodied institutional activities in South Africa. Based on this premise, the Central University of Technology, Free Sate (CUT) has decided to mainstream sustainability in the delivery of its mandate as a university of technology. However, the procurement of capital infrastructure projects at CUT is proceeding in a manner akin to "Business As Usual" (BAU). As such, this study forms an appraisal of CUT's procurement business model to determine its suitability for delivering sustainability outcomes. This study adopts a qualitative, single embedded case study research design. A recently completed infrastructure project along with two ongoing projects was selected as case studies so as to observe replication and reliability of the findings. A mixture of semi-structured interviews with project stakeholders and policy documents were used to collect data. The data were analysed using themes. Preliminary findings observed no significant change in the manner through which projects were being delivered to reflect the sustainability agenda. This signalled the non-integration of sustainability principles into the delivery of infrastructure in the University. BAU appears to rein in the existing procurement model, and a major scope for its re-design is advocated through this exploratory evaluation.
\end{abstract}

KEYWORDS: CASE STUDY, HIGHER EDUCATION INSTITUTIONS, INFRASTRUCTURE, SOUTH AFRICA, SUSTAINABILITY.

\section{INTRODUCTION}

Sustainability has assumed a centre stage in contemporary times (Swilling, 2006, Fernández-Sánchez and Rodríguez-López, 2010). As such, governments and businesses alike have been admonished to apply their regulatory, legislative, and purchasing powers towards the implementation of the agenda (McCrudden, 2004, Arrowsmith, 2010). Furthermore, the inherent potential of Higher Education Institutions (HEIs) to contribute through a multifaceted approach to the integration of the sustainability ethos into societal fabric has been identified (Cortese, 2003). HEIs being the bedrock of knowledge creation and dissemination within societies as well as possessing a reputation as societal change agents have been looked upon by society to play a leading role in the quest for a sustainable society (Stephens et al., 2008). Scholars have identified teaching and learning, research, and operations as various media through which HEIs serving as a microcosm of a conventional society can spearhead the sustainable development challenge (McMillin and Dyball, 2009). The identified facets enable HEIs to serve as a platform for the

\footnotetext{
${ }^{1}$ Department of Built Environment, Central University of Technology, Bloemfontein, South Africa, Email: bawuzie@cut.ac.za

${ }^{2}$ Department of Built Environment, Central University of Technology, Bloemfontein, South Africa.

${ }^{3}$ Department of Built Environment, Central University of Technology, Bloemfontein, South Africa.
} 
challenge (McMillin and Dyball, 2009). The identified facets enable HEIs to serve as a platform for the development of the next generation of the graduates with the requisite skills for engendering sustainability within the society as well as the attendant knowledge base.

Extant literature reveals that several HEIs have picked up the gauntlet to provide leadership by example in society's quest to achieve successful implementation of the sustainability agenda (Svanström et al., 2012, Sharp, 2002). Within the South African context, HEIs more than ever before, seemed poised to serve as sustainability champions through embodied institutional activities. Whereas previous studies advocate for the adoption of a systems thinking approach for successful integration of the sustainability agenda across an HEI's institutional activities (Sharp, 2009, Velazquez et al., 2005), the procurement of infrastructure in South African HEIs appears left out. Such observation is premised on the paucity of literature concerning the sustainable procurement of infrastructure in South Africa HEIs. This is in contrast to a handful of their counterparts across the globe who have embarked upon the green campus initiative of which the sustainable procurement of campus infrastructure remains an integral part (Ferrer-Balas et al., 2008).

The Central University of Technology (CUT) belongs to the league of South African HEIs which have accepted the embodiment of the sustainability agenda into all of its institutional processes, particularly as it concerns the troika of teaching and learning, research, and operations, respectively. To buttress its determination to develop a local and international reputation as a sustainability champion, CUT unveiled its vision to achieve a full status of sustainability champion in 2010 (CUT, 2012). This vision is supported by a sustainability framework. The University is presently undergoing an infrastructural facelift across its campuses at Bloemfontein and Welkom. Expectedly, this vision should be embodied in the procurement of these infrastructure assets. Unfortunately, there is a shortage of information on this hence leading to assumptions that the procurement of infrastructure has continued on a Business As Usual (BAU) basis. Such assumptions have prompted this study. This study seeks to appraise CUT's Infrastructure procurement business model. It is expected that this would provide a clear picture of the goings-on within these projects from a sustainability perspective.

This study is structured into the following sections, namely; a review of the role of HEIs in Sustainable Development (SD), an exposé on the sustainability@CUT initiative, the research methodology utilized, discussion of preliminary findings, and conclusion.

\section{Higher Education Institutions (HEIs) and Sustainable Development}

Extant literature unanimously explicates the leadership role of HEIs in the quest of contemporary societies to achieve SD (Cortese, 2003, Sharp, 2002). SD is premised on the need to ensure that prime consideration is given to sustainability across several societal activities (Fernández-Sánchez and Rodríguez-López, 2010). Over the past decade, studies have sought to highlight the place of HEIs in spearheading SD. This has seen to the emergence of various aspects of the sustainability agenda in HEIs, of which 
the Education for Sustainable Development (ESD) assumes significant importance (Lozano-García et al., 2009). According to Cortese (2003), HEIs are expected to lead in the pursuit for a sustainable society by demonstrating the sustainability ethos through their daily activities as well as in the creation and dissemination of knowledge accordingly. This, he insists, would help in providing all students and staff alike with an educational experience which is aligned to the ethos of sustainability and/or SD. Furthermore, it has been observed that many HEIs seem to be focused on the mainstreaming of sustainability into its teaching and learning, and research activities hence relegating operations and procurement functions to the background (Velazquez et al., 2006). They reiterate the need for the adoption of a systematic approach in order to ensure the optimal integration of these principles into all facets of the HEI's institutional activities. McMillin and Dyball (2009) admit the complexity associated with the component parts of an HEI based on its mini-city status. They posit that HEIs should be able to ensure the uniform integration of these component parts into the sustainability agenda through the adoption of a systems approach.

The rate of successful SD implementation in the procurement of infrastructure within HEIs has remained largely under reported. However, from an infrastructure delivery perspective, Lim and Yang (2008) highlight the challenges confronting attempts to engender sustainable infrastructure delivery processes. Figure 1 showcases some factors which are responsible for these challenges.

Figure 1 Barriers to Sustainable Infrastructure Development

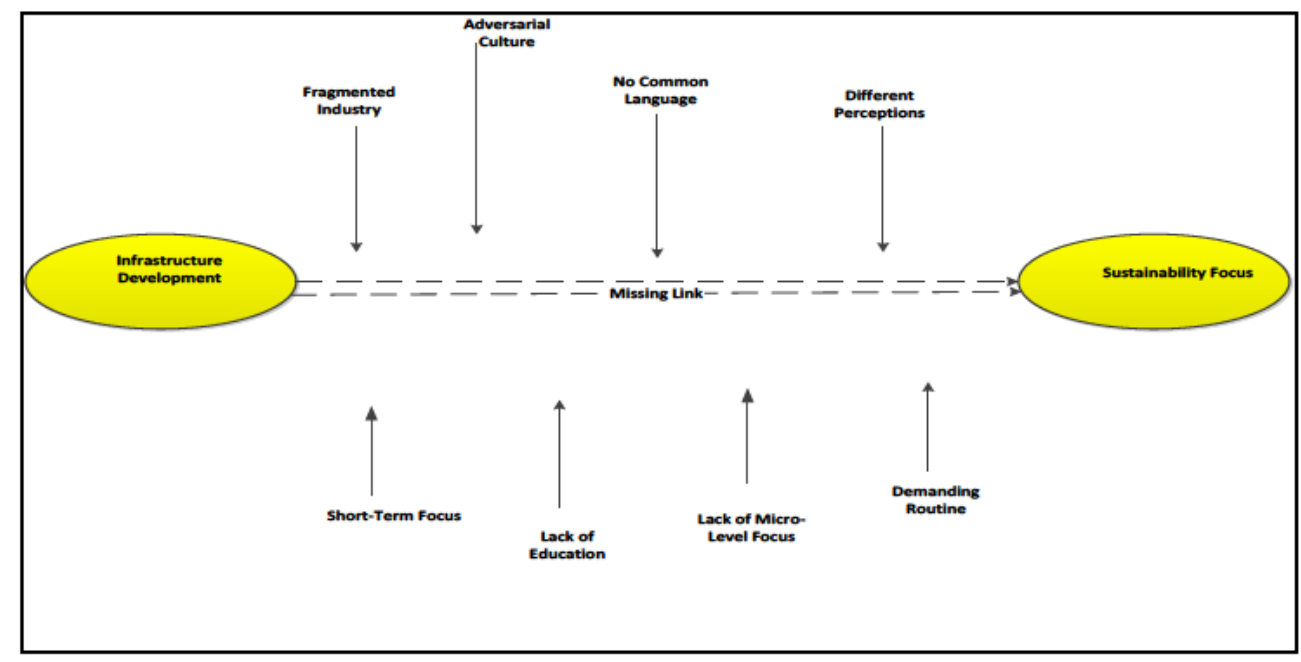

Source: Lim and Yang (2008)

Of particular interest to this study is the integration of sustainability ethos into the procurement of infrastructure in South African HEI campuses. Such interest is occasioned by the seeming paucity of studies on this phenomenon. As such, it seeks to 
appraise the infrastructure delivery business model of CUT to establish its inclination towards the sustainable procurement of infrastructure.

Expectedly, such HEIs desirous of achieving SU status will make attempts to ensure that the achieve SD ethos across the facets of the triple bottom line, namely; environmental, economic and social. A perusal of certain SD implementation policies/ strategies being executed by South African HEIs highlights an emphasis on the environmental and economic facet to the exception of the social. Obviously, this negates these institutions' ability to attain successful SD implementation.

\section{Sustainability@CUT}

The Central University of Technology (CUT) had in 2010, launched a decade long sustainability-oriented strategy tagged Vision 2020. According to the CUT sustainability development report (CUT, 2012), the strategy was centred on the desire to turn the university into a sustainable university focusing on the production of quality social and technological innovations in socio-economic development. Revolving around 4Ps namely; People, Plan, Product, and Pennies, the Vision statement sought to transform the university. Comprehensive implementation of the Vision 2020 commenced in 2012. To this effect, the University Sustainability Framework was developed as a guidance tool towards the attainment and measurement of the sustainable outcomes sought especially the creation and dissemination of sustainability-based knowledge, the development of the next generation of sustainability experts through teaching, learning and research and finally, the integration of sustainability principles into all procurement processes. Suffice to say that the effective implementation of the sustainability framework would position the institution as a sustainability champion.

Besides being an HEI of repute, CUT is also an Infrastructure Client Organisation (ICO) as it procures infrastructure to support its core business of teaching, learning and research. In this wise, the University is involved in the procurement, delivery and operation of various infrastructure projects within its campuses, amongst other services procured at a continuing basis. It is expected that as an ICO, CUT should be able to mainstream sustainability ethos into these activities using its leverage as a client (Dorée et al., 2011, Boyd and Chinyio, 2006).

Based on the foregoing, this study seeks to appraise the implementation of the sustainability agenda within CUT's infrastructure delivery business model, determining as it were, the degree of sustainability uptake among the various stakeholders across the projects. This will avail CUT with the opportunity to evaluate the impact of its present business model on the successful implementation of the sustainability components of its Vision 2020 strategy as it pertains to infrastructure procurement.

\section{RESEARCH METHODOLOGY}

A qualitative case study strategy is adopted for this study. The choice of the case study strategy comes across as a natural one given to the need to study the implementation of 
sustainability ethos (the phenomenon) within CUT's infrastructure procurement and delivery business model (its natural context)(Yin, 2009). Furthermore, qualitative data collection techniques such as interviews, focus groups and documents have been known to facilitate the collection of data reflecting the weltanschauung of the stakeholders involved in the procurement of infrastructure in at CUT (Blaikie, 2010). The potential of such techniques to lead to the creation of new knowledge has also been acknowledged (Barret and Sustrisna, 2009, Denzin and Lincoln, 2008). Three infrastructure projects within the CUT's Bloemfontein campus were selected to observe theoretical and literal replication hence guaranteeing reliability of findings. As such, whereas one of the projects, Project X (The Student Support Centre) was completed in 2012, Projects Y (The Teachers' Training Building) and Z (Engineering Building) were on-going at the time of reporting this study. The selection criteria for these projects were based on the study's central objective: an appraisal of CUT's infrastructure delivery business model with a view to establishing its ability to engender sustainability ethos, based on the triple bottom line, during project delivery. With the aid of the Viable Infrastructure Delivery Model (VIDM), a tool for modelling interorganisational relationships in infrastructure delivery based Temporary Multi-Organisations (Awuzie and McDermott, 2015); participants to the delivery of the three infrastructure projects within the CUT's Bloemfontein campus were identified. Various stakeholder representatives transcending the three projects and numbering eighteen (18) were approached by the authors for interviews through emails, telephone calls and face-to-face solicitations, however at the time of writing up this paper; only a handful had agreed to be interviewed. A total of five semi-structured interviews were conducted. For a list of interviewees and their designations, see Table 1 below.

Table 1: List of Interviewees

\begin{tabular}{llll}
\hline Stakeholder Group & Title & Code & Project \\
\hline Consultant & Infrastructure Delivery Partner & IDP & Y, Z \\
\hline FM Department & Director & FM1 & X,Y,Z \\
FM Department & Clerk of Works & FM 2 & Y,Z \\
FM Department & Assistant Clerk of Works & FM3 & Y,Z \\
Main Contractor (Site) & General Foreman & GF & Z \\
\hline Source: Authors' Fieldwork (2015) & & &
\end{tabular}

Source: Authors' Fieldwork (2015)

From Table 1 above, an uneven representation of the various stakeholder groups can be deciphered. Certain Main contractor and sub-contractor representatives as well as the HEI's sustainability manager were not available for interview at the time of preparing this paper. Hence, their views are not articulated in this particular study. Owing to this significant limitation, it is advised that the findings of this study should be treated with caution.

These interviews lasted for an average of thirty (30) minutes each. During these interviews, the interviewees were asked to describe their organisational roles within the infrastructure delivery system. Other questions asked included awareness about the 
concept of sustainability, their understanding and/or perception of the concept as enshrined in the Sustainability@CUT declaration and Vision2020 respectively, as well as the integration of the sustainability ethos into the projects within which they were participants. The data collected from these interviews were transcribed and subsequently analysed. Qualitative content analysis was adopted. The analysis proceeded initially from the use of pre-set themes (Taylor-Powell and Renner, 2003) accruing from the study's central objective; an appraisal of CUT's infrastructure delivery business model's suitability for driving sustainable procurement of infrastructure. As is the case with studies premised on the qualitative approach, other findings emerged from the dataemergent data.

\section{DISCUSSION OF PRELIMINARY FINDINGS}

A holistic appraisal of CUT's infrastructure procurement business model for sustainability is premised on the attainment of a credible description of the HEI's current project delivery system. Such credible description is dependent on the narratives of the stakeholder representatives about the goings-on in the delivery system. These goings-on alongside the level of awareness and knowledge concerning the concept of sustainability and the CUT's SD agenda, among the various stakeholders will be assessed. Such an assessment will assist in unravelling the degree of prominence accorded to the sustainability ethos espoused in CUT's agenda during the delivery of Projects, X, Y, and $\mathrm{Z}$ respectively. Accordingly, these topical issues were adopted as pre-set themes and data from the interview were analysed according to these themes.

The CUT's SD agenda clearly states its ambition to "to become a teaching, research, and learning environment which maximises and mainstreams environmental, economic and social sustainability in all its operations and educational activities". With this espoused ambition, it is expected that the procurement infrastructure in its campuses would follow processes which engender sustainability. It is also expected that the competencies required to drive the successful implementation of these ethos during project delivery would be readily available in-house at the institution. However, the responses garnered from the interviewees showed that the implementation of sustainability in CUT's infrastructure delivery system was underwhelming. In fact, the procurement of infrastructure has proceeded on a Business As Usual (BAU) basis. The understanding of what the sustainability concept connotes among interviewees leaves much to be desired. The following issues were also observed from the available data.

\section{Absence of Clear-Cut Policy}

According to IDP, the absence of a well-thought out policy at CUT was a probable cause of for the HEI's inability to successfully drive the sustainability integration into the infrastructure delivery process. He insists that such a policy was essential as it not only highlights the HEI's direction on SD but also provides guidance for doing so effectively alongside a set of incentives and penalties. Velazquez et al. (2005) corroborate this by reiterating the significance of policy in driving the implementation of sustainability in 
HEIs. However, it would appear that CUT's vision statement which is encapsulated in its Annual Sustainability Development Reports as well as the sustainability indicators listed therein does not have any bearing on the delivery of its infrastructure upgrade programme. The reports seem focused on energy conservation and other facets of environmental sustainability whilst neglecting other facets of sustainability.

However another interviewee (GF) reiterates that there was some element of sustainability implementation efforts going on in Project Z, particularly as it pertains to the employment of locally sourced tradesmen wherever practical. However, he maintains that this was as a result of the Main contractor's Corporate Social Responsibility obligations and not as a result of a clear cut policy directive from CUT. He also stated that he was unaware of the existence of the any CUT policy on sustainability.

From the foregoing, it is evident that the absence of a clear policy guideline on the sustainable procurement of infrastructure has led to a lack of structured approach to sustainable procurement of infrastructure in CUT.

\section{Poor Knowledge Flows}

Another issue observed during the course of the study was the high level of incoherence on what the sustainability@ CUT agenda entails. HEIs such as CUT have Facilities Management (FM) departments saddled with the responsibility for the procurement of infrastructure within their campuses. They also ensure that these projects are delivered in accordance with the HEI's overall objective. Often times, this task is done in conjunction with the HEI's Project Management Office (PMO) and procurement department. As such the FM department is an integral part of the delivery system and as such responsible for co-ordinating the implementation of these sustainability principles in these projects. However, from the interviews, it would appear that the degree of knowledge flow between the FM department and the procurement department (which is saddled with the responsibility of engendering sustainable procurement across the university) was at best, abysmal. Knowledge flows are defined as the series of processes that are utilised in the identification, capture, sharing and application of knowledge within and between organisations (Kumar and Ganesh, 2009, Laihonen, 2014, Nissen and Levitt, 2002). Knowledge flows are essential in engendering knowledge sharing and transfer within organisational and multi-organisational settings alike. Sustainable procurement of infrastructure requires effective knowledge flows within CUT's departments on one hand and between CUT and its supply chain members on the other. However, instances revealing poor knowledge flows were observed during the interviews, especially within the CUT. Asked to narrate their understanding of the sustainability @ CUT agenda, the interviewees from the FM department feigned ignorance of the concept. When prodded further, one of the interviewees (FM3) stated "Well...Just three weeks ago, I attended a workshop and sustainability...From what I gathered, it's all about reducing energy use on campus". FM3 is not alone in this regard as another interviewee, FM2 corroborated his statement. However, FM1 indicated his knowledge of the need to ensure that they inculcate socio-economic and environmental sustainability into the procurement, delivery and management of infrastructure at CUT. But he decried the funding regime which 
makes it imperative that they carry out maintenance works within a stipulated window hence not giving them time to carefully integrate these principles.

Another instance of poor information sharing was observed in the views espoused by two of the interviewees, IDP and GF on the issue of stipulations made by the CUT during the contract award. Whereas the IDP maintained that the CUT management had mandated them to ensure that contractors and tradesmen were recruited from the local environment for the delivery of infrastructure, GF stressed that he was unaware of such contractual stipulations but rather stated that the decision to engage local tradesmen by his organisation was dependent on the organisations CSR initiatives.

\section{CONCLUSIONS}

In response to the challenge by society for HEIs to lead the drive for a sustainable society, it appears that HEIs especially within the South African context have picked up the gauntlet. CUT is one of such HEIs. Accordingly, CUT has through its Vision2020 declaration and subsequent annual Sustainability Development Reports maintained its desire to become a sustainability champion within its immediate environment and beyond. However, the mainstreaming of sustainability principles into the HEI's activities has been largely under-investigated and under-reported especially as it pertains to the delivery of infrastructure projects. This has necessitated this particular study. It should be noted that this study forms an integral part of a wider study seeking to explore the degree of uptake of CUT's sustainability agenda across various facets of the HEI's endeavours. Some representatives of project stakeholders involved in the current upgrade of infrastructure at CUT were identified with the aid of the VIDM. Some of them were interviewed. Preliminary findings adumbrate that CUT is far off the mark in the implementation of its sustainability agenda in the procurement and subsequent delivery of infrastructure on its campuses. Also, no exceptional change was observed in the manner that infrastructure was being procured within the on-going projects when compared to the completed infrastructure project, hence indicating a continuance of the Business As Usual (BAU) regime. It was further observed that the absence of a clear cut policy on sustainability implementation and poor knowledge flows within the delivery system posed most daunting in the drive to achieve sustainable procurement of infrastructure at CUT.

This study is still on-going. As such, the findings espoused here are preliminary and should be regarded with caution. It is expected that more results will emerge upon the completion of the study.

\section{REFERENCES}

- $\quad$ ARROWSMITH, S. (2010). Horizontal policies in public procurement: a taxonomy. Journal of Public Procurement, 10, 149-186. 
- AWUZIE, B. \& MCDERMOTT, P. (2015). A conceptual model for evaluating infrastructurebased temporary multi-organisations. Built Environment Project and Asset Management, 5.

- BARRET, P. \& SUSTRISNA, M. (2009). Methodological strategies to gain insights into informality and emergence in construction project case studies. Construction Management and Economics, 27, 14.

- BLAIKIE, N. (2010). Designing social research, Polity.

- BOYD, D. \& CHINYIO, E. (2006). Understanding the construction client, London, John Wiley \& Sons.

- CORTESE, A. D. (2003). The critical role of higher education in creating a sustainable future. Planning for higher education, 31, 15-22.

- CUT (2012). Sustainability Development Report. Bloemfontein: Central University of Technology

- DENZIN, N. K. \& LINCOLN, Y. S. (2008). Collecting and interpreting qualitative materials, Sage Publications, Incorporated.

- DORÉE, A., VAN DER WAL, G. \& BOES, H. (2011) Client leadership in sustainability: How the Dutch railway agency created CO2 awareness in the industry. Proceedings 27th Annual ARCOM Conference, 2011. 5-7.

- FERNÁNDEZ-SÁNCHEZ, G. \& RODRÍGUEZ-LÓPEZ, F. (2010). A methodology to identify sustainability indicators in construction project management-Application to infrastructure projects in Spain. Ecological Indicators, 10, 1193-1201.

- FERRER-BALAS, D., ADACHI, J., BANAS, S., DAVIDSON, C., HOSHIKOSHI, A., MISHRA, A., MOTODOA, Y., ONGA, M. \& OSTWALD, M. (2008). An international comparative analysis of sustainability transformation across seven universities. International Journal of Sustainability in Higher Education, 9, 295-316.

- KUMAR, A. J. \& GANESH, L. S. (2009). Research on knowledge transfer in organizations: a morphology. Journal of Knowledge Management, 13, 161-174.

- LAIHONEN, H. (2014). A managerial view of the knowledge flows of a health-care system. Knowledge Management Research \& Practice.

- $\quad$ LIM, S. K. \& YANG, J. (2008) Understanding the need of project stakeholders for improving sustainability outcomes in infrastructure projects. Proceedings of the Performance and Knowledge Management Joint CIB Conference, 2008. 332-343.

- LOZANO-GARCÍA, F. J., HUISINGH, D. \& DELGADO-FABIÁN, M. (2009). An interconnected approach to incorporate sustainable development at Tecnológico de Monterrey. International Journal of Sustainability in Higher Education, 10, 318-333.

- MCCRUDDEN, C. (2004). Using public procurement to achieve social outcomes. National Resources Forum, 28, 19.

- MCMillin, J. \& DYBALL, R. (2009). Developing a whole-of-university approach to educating for sustainability linking curriculum, research and sustainable campus operations. Journal of Education for Sustainable Development, 3, 55-64.

- NISSEN, M. \& LEVITT, R. (2002). Dynamic models of knowledge-flow dynamics. Center for Integrated Facility Engineering CIFE, Stanford University, California USA.

- SHARP, L. (2002). Green campuses: the road from little victories to systemic transformation. International Journal of Sustainability in Higher Education, 3, 128-145.

- SHARP, L. (2009). Higher education: the quest for the sustainable campus. Sustainability: Science, Practice, \& Policy, 5, 1-8.

- STEPHENS, J. C., HERNANDEZ, M. E., ROMÁN, M., GRAHAM, A. C. \& SCHOLZ, R. W. (2008). Higher education as a change agent for sustainability in different cultures and contexts. International Journal of Sustainability in Higher Education, 9, 317-338.

- SVANSTRÖM, M., GRÖNDAHL, F., HOLMBERG, J., LUNDQVIST, U., SVANSTRÖM, M. \& AREHAG, M. (2012). The university and transformation towards sustainability: The strategy used at Chalmers University of Technology. International Journal of Sustainability in Higher Education, 13, 219-231. 
- SWILling, M. (2006). Sustainability and infrastructure planning in South Africa: a Cape Town case study. Environment and Urbanization, 18, 23-50.

- TAYLOR-POWELL, E. \& RENNER, M. (2003). Analyzing qualitative data. Wisconsin: University of Wisconsin--Extension, Cooperative Extension.

- VElazQueZ, L., MUNGuiA, N., PLATT, A. \& TADDEI, J. (2006). Sustainable university: what can be the matter? Journal of Cleaner Production, 14, 810-819.

- VELAZQUEZ, L., MUNGUIA, N. \& SANCHEZ, M. (2005). Deterring sustainability in higher education institutions: An appraisal of the factors which influence sustainability in higher education institutions. International Journal of Sustainability in Higher Education, 6, 383-391.

- YIN, R. K. (2009). Case study research design and methods, Thousand Oaks, Ca, Sage Publications. 


\title{
ANALYSIS OF HOUSEHOLD ENERGY CONSUMPTION IN NIGERIA
}

\author{
Kayode, R. ${ }^{1}$; Akhavan Farshchi ${ }^{2}$, M. and Ford, $\mathrm{A}^{3}$.
}

\begin{abstract}
:
Energy plays a vital role in the development of any country. In the context of the developing economies, the growth in energy consumption is associated with urbanisation and economic development through the transfer of mobile factors of production from rural to urban areas, and by the transition of the economy from a dominantly agricultural based economy to a relatively more industrialised type.

Nigeria as one of the key economies in the African continent faces many challenges in this transitionary path; population growth and the growing movement of population from rural to urban areas creates a challenge for policy makers in terms of planning energy and other infrastructure needs. Planning for future may involve accurate estimation of energy needs and while there are some attempts made at understanding the patterns of demand for energy in industrial sectors, there are scant amount of research into the patterns of consumption by households. Sources of energy for households are numerous and many traditional sources of energy are commonly used for their availability, low or no cost. However, such energy sources can be harmful for the environment and are gradually being replaced by the use of electricity due to its convenience and compatibility with the modern style of living in cities.

Following an initial literature review of the most commonly used estimation modelling techniques in the field of energy consumption this paper will report on the outcomes of a model of energy consumption for the residential sector, followed by a large survey of the household behaviour in selected parts of Nigeria. The research reported here challenges the use of traditional models used for estimation of energy consumption in developed countries for countries such as Nigeria. The existence and size of the black economy as relating to the use and abuse of electricity is highlighted and various hypotheses of this research reject the Energy Ladder theory which assumes a step wise transition into more sophisticated types of energy (i.e. electricity). The paper makes a number of contributions which are important in the debate on planning for energy in developing countries.
\end{abstract}

KEYWORDS: ENERGY MODELLING, BLACK ECONOMY, HOUSEHOLDS, GROWTH THEORY, NIGERIA

\section{INTRODUCTION}

Energy is essential to all human activities and, indeed is critical to social and economic development. Energy is only one of the many important inputs for production,

\footnotetext{
1 School of Built Environment and Architecture, London South Bank University, Emails: kayode3@1sbu.ac.uk

2 School of Built Environment and Architecture, London South Bank University, Emails: m farshchi@1sbu.ac.uk

3 School of Built Environment and Architecture, London South Bank University, Emails: andy.ford@1sbu.ac.uk
} 
conversion, processing and commercialisation in all sectors (FAO, 1992). It is generally recognised that energy, including electricity, plays a significant role in the economic development of a country as it enhances the productivity of the nation when inputs such as capital and labour are considered. In addition, the increased consumption is an indication of increase in economic activities, and by inference, an improvement in economic development of energy signifies that a country has high economic ranking.

Energy demand is important as it affects the economy which in turn affects people's lives (i.e. their income, health, happiness), and their ability to meet basic needs such as the need for infrastructure, education and so on. Access to electricity is particularly crucial to human development as electricity, in practice, is indispensable for certain basic household activities, such as lighting, refrigeration and the running of household appliances, and cannot easily be replaced by other forms of energy (IEA, 2002).

Energy demand unlike other consumption goods is a derived demand as it is not valued for itself but for what can be done with it, i.e. it is not wanted for its own sake but rather for the light and heat which it can provide. Energy consumption is also linked to urbanisation as any increase in urbanisation normally brings about changes to land use, causes increase in transportation, industry, infrastructure and the use of domestic appliances. It can be argued that an increase in urbanisation leads to an increase in energy consumption as the demand for goods and services may increase in due course. According to Medlock (2009), the exceptional economic growth and major improvements in standards of living in general over the last few decades have mainly come about because of the replacement of the work force with mechanical power through technological progress. Given the gap in socio-economic development in Africa, and in order to improve such standards in the Continent, better use of technology via electricity may need to be at the centre of long term planning.

The demand for energy (i.e. electricity) in a developing country raises some important issues due to the existence of the black economy and the growing rate of urbanisation, which exists in such nations. Many developing countries are still faced with the challenge of providing adequate and modern energy services to their communities, and the lack of such services may deter the improvements to the standard of living through increased income and employment opportunities.

Due to the nature of most developing countries, and because of the lack of understanding of household dynamics and other factors influencing its dynamics, it is difficult to fully identify the impact of insufficient energy consumption on the development of the various regions in the country and on the standard of living of people. There is difficulty in designing or evaluating policies and programmes intended to address the impact of the use of energy within households. The aim of this study is to be able to provide an appropriate analysis of the different factors that contribute to household energy demand with the objectives as follows:

Investigating the dynamics of demand of energy over time in Nigeria

Identifying the effects of the different factors on household energy demand 
Finding out the ultimate impact of such factors on energy demand

The rest of the paper will reveal steps taken to establish various factors that contribute specifically to the consumption of energy by households in Nigeria.

\section{LITERATURE REVIEW}

The importance of energy to development can be noted at the beginning of the industrial revolution (circa. 1771), when there was a sharp increase in demand for energy (i.e. coal). Coal was used to power the steam engines that changed the world. Such engines, which powered the manufacturing industries in the eighteenth century, were replaced by electricity powered engines in the nineteenth and twentieth centuries. The birth of the industrial revolution helped change the living standards in Europe and North America; higher standards of living helped improve income, health, life expectancy and population growth which in turn led to further increase in the demand for and use of natural and man-made resources and energy.

For the countries which did not follow the same path of growth as in Europe and North America, the question of economic growth and the role that energy consumption plays in it is critical. For policy makers it is important to understand the direction of the causality; does economic growth lead to the growth in energy consumption, or it is the energy consumption that generates the economic growth? Studies show that the lack of viable sources of energy is a contributing factor to the level of poverty experienced among individuals, communities, nations and regions. Various studies also show that there is a strong relationship between energy demand and economic growth (Ebohon, 1996; Masih and Masih, 1996; Asafu-Adjaye, 2000; Jumbe, 2004; Oh and Lee, 2004; Wolfe-Rufael, 2006; Akinlo, 2008, Odularu and Okonkwo, 2009 and Ozturk et al., 2010). However, most studies examining the causality between GDP (economic growth) and energy consumption on a general level show inconclusive results. Some theories also hold that rates of energy consumption and energy efficiency are linked causally to economic growth. The literature on energy also reveals other factors that may affect the economic growth of a country. These are productivity levels, demographic changes, political institutions and the degree of income equality.

In terms of causality methodology, this study identified four different hypotheses that can be used to describe the relationship between Gross Domestic Product (GDP) and energy consumption (EC), namely a) Conservation hypothesis (where Gross Domestic Product causes energy consumption), b) Growth hypothesis (where energy consumption causes Gross Domestic Product), c) Neutrality hypothesis (a case where there is no causal relationship between energy and economic development), and d) Feedback hypothesis (where there is a bi-directional causality between energy and economic development). The variances in these results have been attributed to the fact that economic activities and the human basic activities that take place differ from one country to another (Khanna and Rao, 2009) and the efficiency with which energy is used is also different. Wolde-Rufael (2006) also argued that there are possibly a number of factors, which may influence the 
demand for electricity, which differ significantly across countries and therefore cause the different directions of causality. The variations in results are generally known to be due to the differences in data sets, time lines, methodologies and variables used. According to Apergins and Tang (2013), the inconclusive evidence is potentially attributed to model specifications and the stage of economic development of the countries under investigation. Omri and Kahouli, (2014) who recently conducted an extensive review of the nexus between economic growth and different types of energy consumption, observed that the results from the studies were generally sensitive to methodology and type of energy considered. He concluded that the mixture and the non-conclusiveness of the results from previous studies are due to the different countries' characteristics, different datasets, and alternative econometric methodology. Apart from the cases of establishing the causality relationship between GDP and energy consumption, other research have identified different variables such as price (Haris and Liu, 1993, Beenstock et al.,1999; Amusa et al., 2009), temperature (Fatai et al, 2008; Hondrayiannis, 2004; De Vita et al, 2005), population (Liu et al, 1991; Rajan and Jain, 1999; and Mohamed and Bodger, 2005), rate of urbanisation (Adom et al, 2011), and education ( Heltberg, 2004 and Khattak et al, 2010).

Although the causality of the relationship between GDP and energy consumption is inconclusive, many of the studies reviewed show that the energy demand in any country is expected to be driven by various factors including the state of development of the country in question and both economic and non-economic factors. Based on the above findings this study focused on exploring different methodologies for estimating and analysing demand for energy in Nigeria.

\section{Modelling energy consumption}

Energy modelling involves understanding the energy world or process in a simpler way. The main intent of modelling is to help explain or predict some of the events in the energy world. Although there are a number of approaches to modelling energy demand, many studies have used the econometric modelling approach as this is thought to have a significant advantage in terms of identifying price responsiveness of energy demand and forecasting (Dilaver, 2012). Urban et al. (2007) in their work on developing Asian countries, discovered that the models used for estimating energy in industrialised countries find very little application in developing nations. They advised the need for energy systems and economies of developing countries to be modelled taking account of such factors as supply shortages, the poor performance of the power sector, electrification and the growing trend in urbanisation.

\section{Modelling techniques}

The main modelling techniques reviewed in this paper includes: a) Regression- whereby the relationship between a dependent variable and a number of independent variables is determined; b) Auto Regressive Distributed Lag-where the dependent variable is assumed to be dependent on its past value and the current and past values of some other variables. ARDL is used to capture the dynamic process of adjustment within the variables which may not be flexible to adjust to a new equilibrium in the short run; c) 
Error Correction model/Vector Error correction Model-Error Correction Models (ECMs) identify a long-run relationship between variables, while allowing for short-run deviations from this relationship. In other words, ECMs estimate how quickly a dependent variable returns to equilibrium after there has been a change to an independent variable. ECM is useful in estimating both long term and short term effects of the independent variable on the dependent variable and is an effective way of characterising the dynamic multivariate interactions of economic data. The use of ECM is to determine if there is a long run relationship between variables.

Our study showed that among research on modelling energy, different regression approaches have been used; for example: Liu et al. (1993) for Singapore; Rajan and Jain (1999) for India, Harlvosen and Larsen (2001) for Norway; Mohammed and Bodger (2005) for New Zealand; Tien and Pao (2005) for Taiwan, Louw et al., (2008) for South Africa; Egelioglu, (2001) for Northern Cyprus; Bianco, (2009) for Italy and Kankal et al. (2011) for Turkey. Whilst some used regression solely e.g. Rajan and Jain (1999), Egelioglu (2001), Louw et al. (2008), others like Liu et al. (1993), Tso and Yau (2007) and Kankal et al. (2011) compared regression to Artificial Neural Networks.

In forecasting the electricity consumption in Italy, Vincenzo et al. (2009) used multiple regression on annual data from 1970 to 2007. They included GDP, price of electricity, GDP per capita and population as independent variables on electricity consumption. They found that price elasticity was limited and therefore pricing policy could not be used to promote the efficient use of electricity in Italy. On the other hand, changes to GDP and GDP per capita had an effect on electricity consumption.

Narayan and Smyth (2005) analysed the residential demand for electricity in Australia. They carried this out using the ARDL bounds testing cointegration approach. They included annual data for 31 years from 1969 to 2000 for income, temperature, price of electricity and price of natural gas in the modelling and found income and price of electricity the most important factors in the long-run. Temperature was found to be significant to a small degree but gas price was not significant in the long-run. Amusa et al. (2009) also applied ARDL approach on data for the period between 1960 and 2007 in their work on South Africa and discovered that the price of electricity had an insignificant effect on aggregate electricity demand but changes in income had an impact. They however advised of the need for pricing policies that ensure electricity prices are cost reflective and that such policies should also enhance efficiency of electricity supply and use.

In an attempt to understand the electricity consumption in Taiwan, Holtedahl and Joutz, (2004) used ECM and included price of electricity as a determinant of its consumption, urbanisation (as a proxy variable to capture economic development characteristics and electricity-using capital stocks that are not explained by income), population, income, price of oil and weather. They found that there was an increase in the consumption of electricity as households in towns and cities were more likely to be connected to the grid than those in the rural areas and the result suggested that short- and long-term effects are separated through the use of an error correction model. Babatunde and Shaibu (2009), in 
examining the residential electricity demand in Nigeria, used annual data from 1970 to 2006 for income, price of electricity, price of substitute and population. As in the case of Narayan and Smyth (2005), income was found to be very significant in the long-run. The price of substitute and population were also very significant in the determination of the demand for electricity, but Babatunde and Shaibu (2009) found that, contrary to Narayan and Smyth's findings, the price of electricity was insignificant.

Reviewing the studies above showed consistency and confirmed income as being a very important determinant of consumption of energy but the price of energy may not necessarily have a significant effect on the aggregate demand for energy. This caused Ziramba (2008) in his study of residential electricity demand in South Africa to conclude that price increase alone will not discourage increases in residential electricity consumption.

It must be noted though that the different approaches to energy use and modelling, are all underlined by one or more different theories. They include sociological theory, psychological theory, educational theory and economic theory.

\section{Variables in energy modelling}

Some energy models have found different variables such as price and Gross Domestic Product significant in determining the demand for electricity (Atakhanova, 2007; Narayan et al., 2007). Others have included population (Liu et al., 1993; Mohamed and Bodger, 2005) and domestic exports and population (Fung and Tummala, 1995) while yet other studies have included climatic variables (Yan 1998, Rajan and Jain; 1999, Haris and Liu; 1993). Other variables that have also been used in modelling electricity consumption include income, price of substitute, and length of grid connection, appliances and size of household (Louw et al., 2008). Studies by Holtedahl and Joutz (2004) for Taiwan included urbanisation as a proxy for electricity-using equipment and Azam (2015) in his study on factors that affect energy consumption for ASEAN countries included urbanisation, foreign direct investment, human development index and real growth rate. Heltberg (2004) included education, size and composition of household, income, distance to suppliers and availability of natural resources as factors that influence the choice of fuels for households. Prasad (2006) on the other hand included the cost and availability of suitable appliances while Adom et al. (2012) considered real per capita GDP, industry efficiency, degree of urbanisation and structural changes in the economy as other important factors that influence decisions on the use of energy). Generally, the variables that have been used in energy modelling can be grouped into two main categories- endogenous and exogenous as seen in Table 1. 
Table 1: Summary of factors determining household energy choice

\begin{tabular}{|l|l|}
\hline \multicolumn{2}{|c|}{ Factors determining household energy choice } \\
\hline Categories & Factors \\
\hline Endogenous factors (household characteristics) & \\
\hline Economic characteristics & Income, expenditure \\
Non-economic characteristics & $\begin{array}{l}\text { Household size, gender, age, household } \\
\text { composition, education, labour }\end{array}$ \\
Behavioural and cultural characteristics & $\begin{array}{l}\text { Preferences (e.g. food taste), practices, lifestyle, } \\
\text { social status, ethnicity }\end{array}$ \\
\hline Exogenous factors(external conditions) & \\
\hline Physical environment & $\begin{array}{l}\text { Geographical location, climatic condition, } \\
\text { Policies }\end{array}$ \\
& $\begin{array}{l}\text { Public policy, energy policy, subsidies, market and } \\
\text { trade policies }\end{array}$ \\
Energy supply factors & $\begin{array}{l}\text { Affordability, availability, accessibility, reliability } \\
\text { of energy supplies }\end{array}$ \\
Energy device characteristics & Conversion efficiency, cost and payment method, \\
& complexity of operation \\
\hline
\end{tabular}

Source: Authors' compilation

\section{Theory in energy demand estimation}

The shortcomings of the above econometric models enticed this study to adopt an approach that goes beyond the assumptions of neoclassical economic theory by examining the wider socio-economic context of energy demand in a developing country. The need for such an approach was also driven by the lack of reliable and continuous data which is instrumental in conventional modelling techniques. Obtaining such data may not be easy as identified in the case of Nigeria. More so, there is no doubt that econometrics is subject to important limitations, which stem largely from the incompleteness of the economic theory and the non-experimental nature of economic data. Among developmental approaches to energy consumption, the 'energy ladder' and 'energy mix' models are found to be influential. These helped us study electricity as one part of the household energy mix which in turn is influenced by different factors such as the size of the household, the household income levels, the price of different fuels, and their availability to name a few.

\section{The Energy Ladder model}

The energy ladder is a concept used to describe the way in which households will move to more sophisticated fuels as their economic status improves. According to Leach (1992), the energy ladder model (ELM) process is strongly dependent on urban size and, within cities, on household income, since the main constraints on the transition are poor access to modern fuels and the high cost of appliances for using them.

Understanding household energy consumption, fuel choice and fuel switching behaviour is of vital importance in search for policies to support a transition process. In developing a conceptual framework, attention was given to the characteristics of households and models of energy consumption in developing countries. The framework in this study uses Energy Ladder hypothesis as a starting point. With this hypothesis comes the view that 
fuel substitution takes place in households. The framework facilitates the estimation of households' demand for energy.

Energy demand in households in developing countries is generally based on the concept of energy ladder or fuel substitution. Essentially, there are three steps in the energy ladder model (Heltberg, 2004):

1. There is universal reliance on biomass in the form of wood, dung and agricultural residues;

2. There is the use of transition fuels such as switch to fuels such as kerosene and coal;

3. The third and final phase is the adoption of fuels such as LPG, natural gas, electricity or other 'clean' sources of energy.

At the top of the list is electricity, while at the low-end of the range are fuel wood, dung and crop wastes. Figure 1 shows the relationship between income level and energy type. There is also the assumption that the energy ladder model operates both at the micro and macro levels. According to Hosier and Dowd, households at lower levels of income and development tend to be at the bottom of the energy ladder, using fuel that is cheap and locally available but not very clean nor efficient while at the macro level, energy consumption increases with development and accompany higher reliance on modern fuels (cited in van der Kroon et al, 2013).

Figure 1 Schematic illustration of energy ladder hypothesis

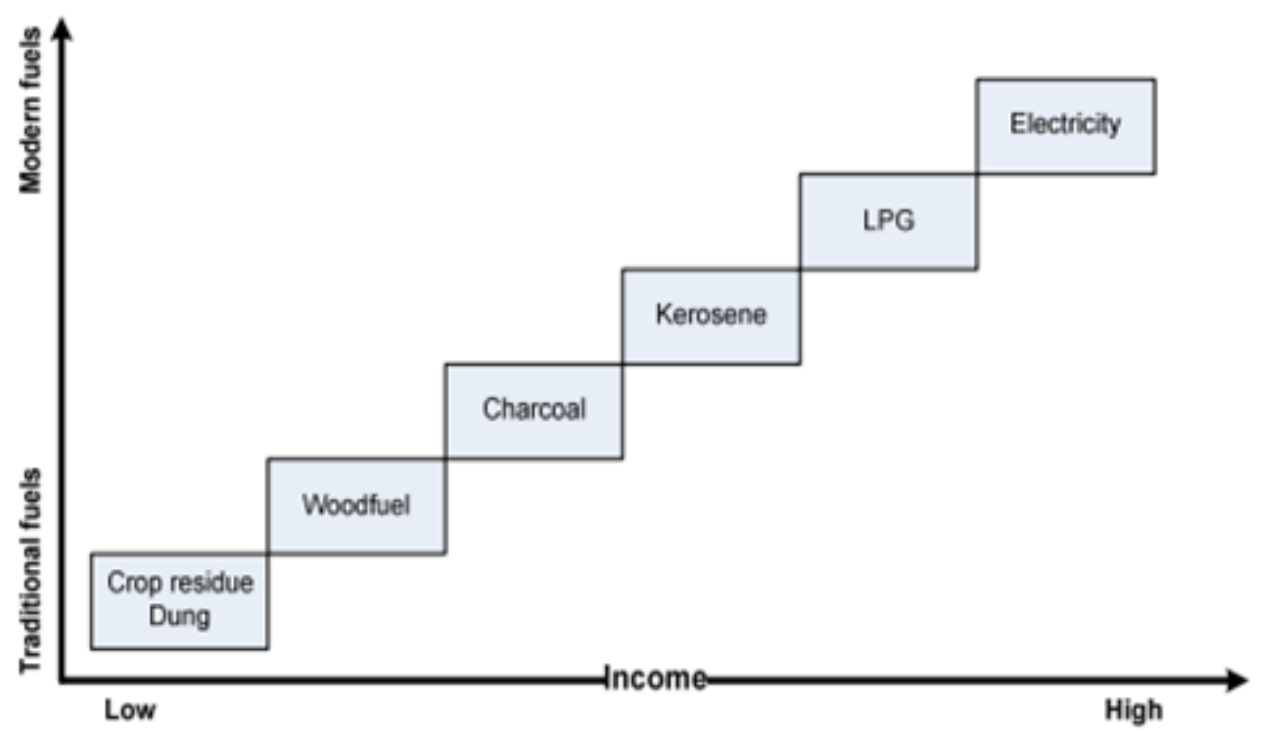

Source: Adopted from Holdren and Smith (2000)

However, Maun, Botswana, Hiemstra-van der Horst and Hovorka (2008) study examined the energy ladder for household energy use, and found that consumers do not follow the predictions of the energy ladder model; i.e. they do not simply switch from one fuel to 
another as their income improves; instead they found that households use multiple energy sources because the different fuels that they use are not entirely inter-substitutable. In fact, the results of the survey indicate that despite nearly universal use of commercial alternatives, fuel wood was chosen by households across the income spectrum as a strategic energy source important for particular applications.

Figure 2. Household energy transition in developing countries: Two alternative frameworks for analysis 2013 International Energy Workshop (IEW)

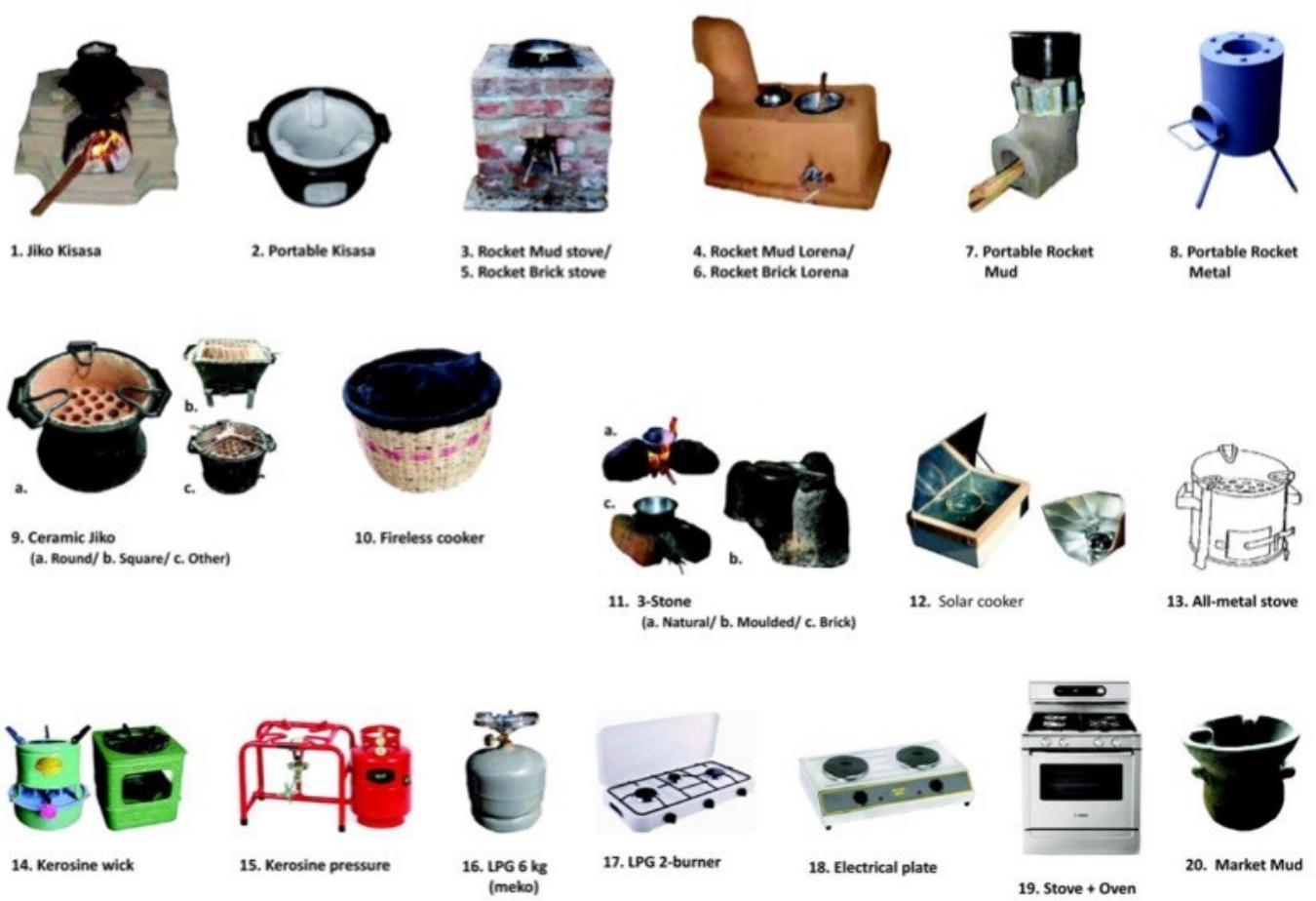

Source: Treiber, M. (IEA, Paris, 19 - 21 June) International Energy Agency

\section{Energy ladder model and energy mix}

The energy ladder model although noted mainly for its ability to explain the income dependency of fuel choices, has been criticised as being insufficient to represent actual energy consumption dynamics (Foster, 2000). This is due to the complexities of switching process as economic aspects are linked with social and cultural issues.

The framework of the energy mix model shows that households will therefore always allocate their disposable income among the different goods or combination of goods that will maximise utility (i.e. an assumption of neoclassical economic theory). A household expenditure may consist of three main categories namely: Food expenditure, clothing expenditure and energy expenditure. The energy expenditure is further broken into the expenditures associated with the different forms of energy: kerosene, Liquefied petroleum gas (LPG) and electricity. The characteristics of the energy ladder model and 
the energy mix model provide us with a basis by which we conceptualise our framework for household energy consumption in Nigeria - the energy mix model in this study is used as a framework to analyse and estimate the demand for electricity in Nigeria.

The use of energy ladder/energy mix allows us to include alternative variables to the widely used econometric modelling rooted in the neoclassical tradition, by considering variables such as the rate of urbanisation and the existence of informal economy. The shortcomings of such econometric models have been seen in the weakness of their predictions and therefore not being suitable as effective policy tools for developing countries. Urbanisation is a major contributor to energy consumption and as O'Neil et al. (2012) found urbanisation can influence economic growth and lead to a rapid transition away from traditional fuel use in developing countries. In sub-Saharan Africa only 46 per cent of the urban population uses electricity, compared to 85 per cent of the world urban population which has access to electricity (IEA, 2010). Furthermore, about 70 per cent of the population in developing countries use liquid fuels such as kerosene or bottled gas for cooking and heating (UNDP/WHO 2009).

The improvements in energy consumption may in turn lead to a growing population and growth of urbanisation and therefore it is important that developing countries have accurate information on the patterns of utilisation and factors driving consumption of urban household energy (Adegbulugbe and Akinbami, 2009). Between 1970 and 1980 the rate of urbanisation growth in Nigeria was between 16 and 20 per cent but by 2011, about 49.6 per cent of the total population was estimated as living in urban areas while the rate of urbanisation was given as 3.75per cent (2010-15 est., Index mundi, 2011). Although there has been tremendous increase in urbanisation over the years, the proportion of urban residents without electricity has also increased. Between 1970 and 1990, the number of urban inhabitants without electricity in Africa increased from less than 40 million to 100 million as reported by Karekezi and Majoro (2002). Although energy use patterns in developed and developing countries differ considerably, the evidence on urban energy use in developing countries suggests that it is common practice for poor urban households to use a mix of fuels for different end uses and to switch when fuel prices or household incomes change (Pachauri and Jiang 2008).

\section{Informal economy and energy}

Owing to the limited information available it is difficult to have an accurate estimate of the economic impact of the informal sector on the economy. In developing countries, some 60 per cent of the potential working population earn their living in the informal sector. Usually the income generated by the informal economy is not included in Gross Domestic Product calculation as the income is not often recorded for taxation purposes.

The fact that Nigeria has the largest informal sector in Africa stems from its stupendous population and decades of high unemployment rate. An attribute of the informal sector in Nigeria is the fact that the sector has a broad spectrum of activities that cuts across the entire segment of the economy. Such activities include manufacturing, construction, repair of cars and cycles, transportation, wholesale and retail among others. As reported 
by Nwaka (2005), information on the size and employment structure in the informal sector is hard to obtain, but estimates suggest that the sector accounts for between 45per cent and 60 per cent of the urban labour force with job creation in the informal sector averaging to 25,000 to 35,000 a year (Fapohunda, 2001). The informal economy contributes to over 35 per cent of the country's GDP and almost 60 per cent of the urban labour force. Studies have also shown that income effects on urban and rural household consumption patterns are crucial to understanding the evolution of household energy demand, and demand for other goods.

\section{RESEARCH METHODOLOGY}

The initial stage of this study was concerned with a considerable review of various theoretical and econometric modelling approaches to energy demand. The econometric models tend to explore a statistical relationship between various factors that determine energy. In our study we considered a mixed methodology including an econometric analysis using secondary data (40 years of data observations) and a survey based approach using a questionnaire survey (501 survey participants. By using triangulation in our study, we were able to offer a better understanding of what happens in the real world. Such knowledge and understanding can then be used for energy planning and setting up of policies that will help to improve the quality of life of the consumers and enhance the overall development.

We explored the relationship between demand for electricity and a number of economic and social factors based on lessons learnt from our review of literature on modelling studies. The survey of households adopted a door-to-door, semi-structured selfadministered questionnaire. These were used to collect data on socio-economic, demographic and housing characteristics. Questions such as household size, type of fuel, amount of fuel used, expenditure on energy, usage of electrical appliances, etc. enabled us to test some key hypotheses rooted in the energy mix/energy ladder as well as alternative ones.

\section{Energy Analysis}

\section{Regression analysis}

The first part of our study explored the use of the multiple regression in terms of modelling electricity, estimating the elasticities, and forecasting future electricity consumption In order to achieve this, the electricity demand function for the residential sector was estimated using secondary annual data for the period 1971-2011. Energy was considered as a commodity whereby its price act as a key determinant for energy consumption. This approach is quite common in models which use orthodox economy theory. Specifically, the demand for energy is supported by the consumer theory which is concerned with the rational behaviour of consumer with regard to their consumption decisions. This is because the consumer's choice sets are assumed to be defined by certain prices and the consumer's income or wealth. The consumers will therefore choose the set of goods that maximises their utility. In essence, individuals tend to make choices 
under income constraints while taking into account the value placed on the consumption of energy. The model tested is as follows: ${ }^{4}$

$$
\text { LREC }=-14.75+0.51 \text { LREC }_{(-1)}+0.53 \mathrm{LGDP}+0.41 \mathrm{LEDU}+0.83 \mathrm{LPE}-1.03 \mathrm{LCON}+\varepsilon \mathrm{t}
$$

Where REC is the residential electricity consumption level (MW)

GDP - Gross Domestic Product (constant 2005 US \$)

EDU - Secondary enrolment level (per cent gross population)

Pe - Price of electricity (Kobo)

Con - Rate of connectivity to the grid (per cent)

All data are transformed to $\log$.

Linear regression analysis shows that there is a statistically significant linear relationship between logged lagged values of residential electricity consumption and lagged values of GDP, price of electricity, education and rate of connectivity to the grid. While this model found some statistically significant results the predictions were not considered widely useful due to the limited number of observations (i.e. 40 years in total).

\section{Survey results}

One of the contributions of this study was in offering a better understanding of how the different sectors of the country use energy. Generally, rural consumption tends to rely strongly on fuel wood; charcoal, although there is increasing pressure to adopt electricity because of appliances like, fridges, washing machines as well as phones. Urban areas in contrast may use kerosene, fuel wood, electricity from the grid, gas and diesel generators. Therefore, in the context of a developing economy, the issue of urbanisation and transformation from rural to urban areas and the requirements of energy were rigorously explored. In other words, our survey results help revealed the economics of urbanisation and the demand for energy; which can help generate policies that will aid the development of both sectors.

By using the concept of energy ladder, we examined the differences in the pattern of energy use in households based on the economic status of the households. We also explored other factors that contribute to the consumption of energy by the residential sector in Nigeria. The interview/survey investigated the choice of energy for households and the ways of consumption, factors that affect people's behaviour plus collection of additional data which helped us fill the gap in secondary data.

\section{Sample size and characteristics}

A survey was carried out in the Ibadan metropolis in Nigeria in 2014-15. Questionnaires were issued at different locations within Ibadan to gather information. The questionnaire sought information from householders on the type of housing, housing demographics,

\footnotetext{
${ }^{4} \mathrm{~L}$ denotes natural log
} 
energy sources, energy appliances and the ownership of household appliances. The studies were conducted in a total of 560 residential buildings within five of the local government areas in Ibadan. There were, however, only a total of 501 respondents.

A general statistics of the subjects involved in the survey is indicated in Table 2.

Table 2 Summary statistics of variables used $(N=501)$

\begin{tabular}{|c|c|c|c|}
\hline Stratum & Sub-Stratum & Household & $\begin{array}{l}\text { Cumulative per } \\
\text { cent }\end{array}$ \\
\hline \multirow[t]{2}{*}{ Gender } & Male & 272 & 54.6 \\
\hline & Female & 226 & 45.4 \\
\hline \multirow[t]{6}{*}{ Age } & $18-25$ & 102 & 20.5 \\
\hline & $26-35$ & 165 & 33.2 \\
\hline & $36-45$ & 117 & 23.5 \\
\hline & $46-55$ & 73 & 14.6 \\
\hline & $56-65$ & 38 & 7.6 \\
\hline & $>66$ & 2 & 0.4 \\
\hline \multirow[t]{7}{*}{ Education level } & $\mathrm{PhD}$ & 56 & 11.9 \\
\hline & $\mathrm{MSc}$ & 88 & 18.7 \\
\hline & $\mathrm{BSc}$ & 177 & 37.7 \\
\hline & Secondary & 84 & 17.9 \\
\hline & Primary & 9 & 1.8 \\
\hline & $\begin{array}{l}\text { No Formal } \\
\text { education }\end{array}$ & 13 & 2.8 \\
\hline & Other & 43 & 9.1 \\
\hline \multirow[t]{3}{*}{ Income level (per annum) } & Low (0-29999) & 141 & 36.6 \\
\hline & $\begin{array}{l}\text { Medium (30000- } \\
\text { 99999) }\end{array}$ & 160 & 41.5 \\
\hline & $\begin{array}{l}\text { High ( } 100000 \text { and } \\
\text { above) }\end{array}$ & 84 & 21.8 \\
\hline \multirow{4}{*}{$\begin{array}{l}\text { Number of people living } \\
\text { as a family }\end{array}$} & Average & 4 & _ \\
\hline & Minimum & 1 & - \\
\hline & Maximum & 14 & - \\
\hline & Number of children & 2 & - \\
\hline \multirow[t]{3}{*}{ Type of house } & Bungalow & 102 & 22.4 \\
\hline & Duplex & 77 & 16.9 \\
\hline & Flat & 277 & 55.3 \\
\hline Electricity connection & Yes & 287 & 78 \\
\hline
\end{tabular}




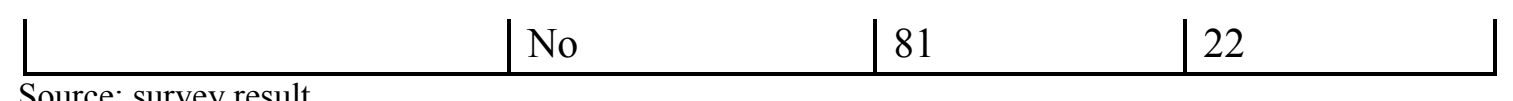

Source: survey result

Further analysis of the households indicated that most of the respondents were married (about 46.7 per cent). The sample area has people whose form of employment is mainly in the Civil service sector - 214 people employed with another 107 people being selfemployed. Of the civil servants, almost 38 per cent had first degrees whilst 17.3 per cent have PhDs. The level of education of the household was known to have an impact on the income level and, subsequently (according to the energy ladder hypothesis) an increase in energy consumption.

\section{Survey results: household income and expenditure}

Household income and expenditure are very important as many studies done have attributed energy demand to the income of the household. The energy ladder theory implies that people will only move up the energy ladder when there is an increase in their income. Obtaining data on such is therefore helped this study to test this hypotheis. However, it is important to note that issues centred on household finances are usually viewed with suspicion in Nigeria and it is therefore worth noting that some of the income declared by householders may be inaccurate. The chances, of course, are that the figures are more likely to be underestimated than overestimated, possibly for fear of tax implications.

\section{Figure 2 Distribution of income}

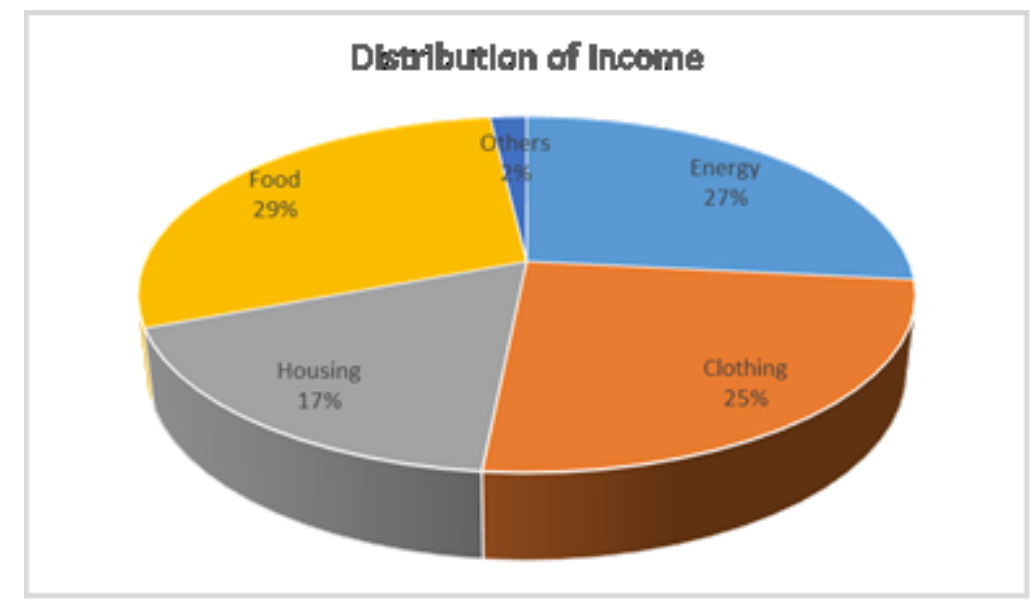

Source: Survey results

Figure 2 shows that the highest proportion of the households' income is spent on food (29 per cent). This is followed by energy ( 27 per cent) and clothing ( 25 per cent). Further, over 30 per cent of those who are classified as low income earners $(\mathrm{N} 0-29,999)$ and majority of those who earn over N150, 000 live in duplex houses. It is interesting to note that less than 20 per cent of the sampled size lived in flats. A correlation analysis on these 
two factors (household income and type of property) showed that there was no correlation between the two while the median household income level across the types of property is N50, 000-99,000.

Analysis of the data collected from the survey indicates that most households did not use just one form of energy but rather a combination of different types of energy for different purposes. For instance, a household may use electricity for lighting and cooling but use kerosene or gas mainly for cooking. The survey also revealed that the issue of availability was the most important factor to be considered when it comes to deciding whether to change from one energy type to another. This factor ranked highest with about 72 per cent followed by the issue of convenience ( 69 per cent). Other factors considered in making such decision include: efficiency (58 per cent), cost (52 per cent and marketing (29 per cent) in order for the respondents to switch from one energy type to another. In terms of deciding on a choice of fuel, respondents indicated that the following factors would be considered: the availability of the fuel, the efficiency, convenience and the cost.

\section{RESULTS AND DISCUSSIONS}

The analysis of the data collected did not show any statistically significant difference between the consumption of any of the energy fuels among the high-income earners and certainly there was not an abandonment of one form of energy in preference to another due to income. When asked about the factors that consumers consider important in choosing a fuel type or what would motivate them in switching fuels, only 10 per cent of the high income earners considered cost as important in choosing a fuel but the biggest motivating factor for them to change is the efficiency of the fuel type. Interestingly, too, the issue of cost was not paramount as a factor for those on low or medium income when choosing a fuel type; rather it is the availability, efficiency and convenience of the fuel that motivates them. The research results show that income is not the sole determining factor for household energy choice and so does not support the energy ladder theory which suggests that energy demand depends entirely on income as people move to more sophisticated form of energy as their income increases.

\section{Use of Ordinal logistic regression}

An ordinal regression model was evaluated to identify the determinants of energy choice; that is factors explaining the decision to consume a particular fuel. The ordinal regression was conducted as each of the fuel- kerosene, electricity and gas had three different levels of consumption.

It was discovered that the notion of the energy ladder did not hold in this instance as the increase in income which may have resulted in spending more on electrical appliances leading to increase in energy did not result in any significant corresponding effect. This is contrary to the perception that an increase in income may result into increase in the demand for a particular form of energy or abandoning one fuel for another. In the urban areas, more people tended to consume more electricity than gas or kerosene. Males consumed a higher level of electricity than females but within the sample population, 
there were more males that were heads of their households. The analysis also showed that education plays a major role in energy consumption and this study suggested that higher levels of education can be associated with a greater probability of the household using modern fuels. More of those with post-secondary education used more gas than electricity or kerosene. Although the increase in the proportion of income spent on any form of energy did not result in an increase in the number of consumers, the final model generated met the assumptions of the ordinal regression and statistically predicted the dependent variable over and above the intercept-only model. The results, however, did not indicate the use of one form of fuel type to satisfy households' energy needs.

\section{CONCLUSION}

This study aimed to investigate the importance of factors that contribute to the consumption of energy in households in Nigeria and in so doing, broaden the understanding of the concept of modelling energy consumption in general. The review of causality relationship between energy consumption and economic growth was the first step. A critical review of the literature on the energy modelling showed that econometric approach using orthodox economic theory may not be able to provide satisfactory explanation of the factors that affect the demand or consumption of energy in households in Nigeria as some other important factors are not usually considered with the econometric approach. The characteristics of the energy ladder model and the energy mix model provided the basis for a framework for household energy consumption in Nigeria. Under the assumptions of economic theory, households utilise the concepts of separability and multi-stage budgeting in maximising their utility. As disposable income is a constraint for most households in developing countries, many are inclined to firstly determine how much of their income will be spent on energy and in addition then determine the amount to be spent on the different types of the fuels and the quantity of such fuels.

Although, it had always been possible to forecast the use of energy using an econometric approach, the use of ordinal regression was beneficial as it was possible to analyse the data whilst taking into account that people consume energy at different levels. The strengths of the ordinal regression model lies in its ability to be able to identify significant independent variables that influence the ordinal response analysis for all levels of the ordinal outcome and subsequently evaluate and predict validity of the regression model. The impact of the factors on household energy consumption using data obtained from 501 households confirmed a positive and significant association between the locality of the property, ownership status, age, education status, the expenditure on electricity and consumption of energy.

This research highlighted the importance of the various socio-cultural factors that affects the consumption of energy within the household, and in the same vein, it was able to show that contrary to the hypotheses suggested in the energy ladder model, economic contribution is not the sole determinant in the choice of fuel energy. In addition, that movement to different forms of energy is not necessarily unidirectional and linear in 
progression and that movement on the energy ladder does not depend solely on the income of the household. However, only one of the hypotheses was supported suggesting that energy consumption depends on the preferences for particular fuel type. It will also be beneficial if the study is repeated for urban areas separately from peri-urban and rural regions and the results from the different areas compared. Future studies are also required to fully understand the main determinants of energy across the urban and rural regions as this will contribute to assisting the formation of relevant energy policies. It will also be interesting to compare the results of modelling the household energy consumption using different packages and methods in order to be able to establish whether the choice of modelling technique has an impact on results generated from analysis of primary data.

\section{REFERENCES}

- ADOM, P., BEKOE, W. and AKOENA, S. (2012) Modelling aggregate domestic electricity demand in Ghana: An autoregressive distributed lag bounds cointegration approach. Energy Policy 42, 530-537.

- BABATUNDE, A. and SHAUAiBU, I. (2009) The demand for Residential electricity in Nigeria: A Bound Testing approach [online], available: www.africametrics.org/documents/conference09 [accessed 11/03/2010].

- DILAVER, Z. (2012) Structural Times Series Modelling of Energy Demand. PhD Thesis, University of Surrey, Guildford.

- EBOHON, O.J. (1996) Energy, economic growth and causality in developing countries: A case study of Tanzania and Nigeria. Energy Policy, 24(5), 447-453.

- HOLTEDAHL, P. and JOUTZ, F.L. (2004) Residential electricity demand in Taiwan. Energy Economics 26(2), 201-224.

- $\quad$ KHANNA, M. and RAO, N.D. (2009). Supply and Demand of Electricity in the Developing World. Annual Review of Resource Economics. Vol. 1: 567-596.

- $\quad$ NARAYAN, P.K., SMYTH, R (2005). The residential demand for electricity in Australia: an application of the bounds testing approach to co integration. Energy Policy 33(4), 467-474.

- OMRI, A and KAHOULI, B. (2014) Causal relationships between energy consumption, foreign direct investment and economic growth: Fresh evidence from dynamic simultaneousequations models. Energy Policy 67, 913-922.

- $\quad$ VINCENZO, B., ORONZIO, M. and SERGIO, N (2009). Electricity consumption forecasting in Italy using regression models. Energy 34(9), 1413-1421.

- TREIBER, M. (2013) Household energy transition in developing countries: Two alternative frameworks for analysis 2013 International Energy Workshop (IEW) · International Energy Agency (IEA, Paris, 19 - 21 June) Michael Treiber, Available on: file://C:/Users/farshcm.LSBU/Dropbox/IEW\%202013_6A4Treiber.pdf

- VAN DER KROON B., BROUWER, R and VAN BËUKERING P.J.H. (2013) The energy ladder: Theoretical myth or empirical truth? Results from a meta-analysis. Renewable and Sustainable Energy Reviews; (20), 504-513.

- WOLDE-RUFAEL, Y. (2006). Electricity consumption and economic growth; a time series for 17 African countries, Energy Policy 34(10), 1106 - 1114.

- ZIRAMBA, E. (2008). The demand for residential electricity in South Africa. Energy Policy 36 (2008) 3460-3466. 


\title{
LIFE CYCLE COSTING IN CONSTRUCTION PROJECTS: PROFESSIONAL QUANTITY SURVEYORS' PERSPECTIVE
}

\author{
Chiurugwi, $\mathrm{T}^{1}$., Udeaja, $\mathrm{C}^{2}$., Babatunde, $\mathrm{S} . \mathrm{O}^{3}$., and Ekundayo, $\mathrm{D}^{4}$.
}

\begin{abstract}
:
Studies on life-cycle costing (LCC) in private finance initiatives (PFI)/public-private partnership (PPP) projects abound, particularly in the UK. But, there is a limited empirical study on the factors influencing the usage of LCC outside PFI/PPP context from professional quantity surveyors perspective. The purpose of this study is to identify the barriers to greater use of LCC and explore the factors responsible for professional quantity surveyors' disposition to LCC usage in construction projects outside PFI/PPP context in the UK. The primary data were collected through a questionnaire survey administered to professional quantity surveyors working in consultancy practices of varying sizes in the UK. The data obtained were analysed using frequency distribution, relative significant index (RSI), Analysis of Variance (ANOVA) and Posthoc test. The study identified eleven barriers influencing the usage of LCC outside PPPs context. Thus, the five highest ranked barriers include: lack of fiscal measures that encourage clients' use of LCC; clients are unwilling to pay for LCC; incompatibility with client's intangible or non-financial objectives and needs; difficulty in obtaining the appropriate, relevant and reliable information and data; and clients do not request for LCC. The study further revealed that the majority of professional quantity surveyors are not directly involved in the use of LCC in their organisations. This study would be beneficial as knowledge of the factors influencing the professional quantity surveyors' disposition to LCC usage would enlighten quantity surveyors, clients and other stakeholders in the construction industry.
\end{abstract}

KEYWORDS: BARRIERS, CONSTRUCTION ORGANISATIONS, LCC, PROFESSIONAL QUANTITY SURVEYORS, UK.

\section{INTRODUCTION}

Life-cycle costing (LCC) plays a significant role in supporting economic and natural resource sustainability goals. For instance, International Institute for Sustainable Development (IISD) (2009) reports that integrating LCC into most especially procurement policies would provide the procurers with the opportunity to demonstrate that the best value for money across the asset life cycle can only be assured by purchasing green and socially preferable alternatives. Thus, it is obvious that LCC helps towards achieving economic sustainability. In overall, LCC enhances the sustainability performance. LCC originated from North America in the 1960s when its use in defense industry procurement was encouraged by the government (Ashworth \& Hogg, 2000;

\footnotetext{
${ }^{1}$ National Institute of Agricultural Botany, Cambridge, CB3 0LE, UK. Email: tinashe.chiurugwi@niab.com

${ }^{2}$ Faculty of Engineering and Environment, Northumbria University, Newcastle upon Tyne, NE1 8ST, UK. Email: chika.udeaja@northumbria.ac.uk

${ }^{3}$ Faculty of Engineering and Environment, Northumbria University, Newcastle upon Tyne, NE1 8ST, UK. Email: solomon.babatunde@northumbria.ac.uk

${ }^{4}$ Faculty of Technology, Design and Environment, Oxford Brookes University, Oxford, OX3 0BP, UK. Email: dekundayo@brookes.ac.uk
} 
TRADATechnology, 2008). In the UK, the then Department of Industry's Committee of Terotechnology started promoting LCC concepts in the 1970s (Woodward, 1997). However, the construction industry operates in an increasingly uncertain business environment, characterised by increasing competitiveness, resource scarcity, sustainability requirements, and demand for value for money by its stakeholders (Swaffield \& McDonald, 2008; TRADATechnology, 2008). The built environment has wide-reaching economic and environmental implications: it is responsible for half of all $\mathrm{CO} 2$ emissions, half of water consumption, one-third of landfill waste, and one quarter of raw materials used in the UK (Woodward, 1997; Clift, 2003; BERR, 2008). As a result, there is mounting public interest and legislative requirement for sustainable construction, in addition to the need to conserve resources (Pasquire \& Swaffield, 2002). There is growing pressure on those that design, produce and operate constructed assets to predict and manage the assets' whole life performance; it is no longer enough only to consider initial capital cost (Woodward, 1997; Clift, 2003; Flanagan \& Jewel, 2005). There has been, therefore, a shift from addressing buildings 'as built' to 'in operation' (Pasquire \& Swaffield, 2002; Clift, 2003; Kirkham, 2007; TRADATechnology, 2008). Various life cycle approaches are employed to assess asset performance for the entire life cycle from conception to decommissioning (Pasquire \& Swaffield, 2002; Clift, 2003; Pelzeter, 2007).

Value improvement in the construction industry is imperative and will benefit all stakeholders in the industry such as the clients, contractors, consultants and the society as a whole (Ashworth \& Hogg, 2000; Flanagan \& Jewel, 2005). A number of novel techniques and practices which, if used properly, could lead to added value in design and construction of built assets have been proposed (Latham, 1994; Egan, 1997; Ashworth and Hogg, 2000; Kelly et al., 2002; Kelly et al., 2004). The Latham (1994) and Egan (1997) reports recommended LCC as a way through which the construction industry could deliver improved value for money (Pasquire and Swaffield, 2002). As the main promoter of LCC in the UK, the government considers value for money as 'the optimum combination of whole-life cost and quality to meet the users' requirements' (OGC, 2007). Previous studies on the use of LCC in the construction industry have been carried out from different professionals' perspective. For instance, Swaffield and McDonald (2008) investigate attitudes and opinions of quantity surveyors working for design and construction contractors regarding the use of LCC within PFI projects in the UK. In real estate professionals in Germany (Pelzeter, 2006 cited in Pelzeter, 2007), and a wider range of stakeholders in the construction industry in Sweden (Sterner, 2000) and the UK (Clift \& Bourke, 1999). It is important to note that no studies on LCC use among professional/consultant quantity surveyors have been carried out yet. Indeed, there is need to find out how the professional quantity surveyors view LCC and explore ways in which their use of the technique can be improved. This necessitated a study on LCC in construction projects from professional quantity surveyors' perspective. Thus, the aim of this study is to identify the barriers to greater use of LCC and explore the factors responsible for professional quantity surveyors' disposition to LCC usage in construction projects outside PFI/PPP context in the UK. The results of this study would be very useful and beneficial to all stakeholders in construction industry, especially contractors' 
quantity surveyors, clients, $M \& E$ engineers, facilities managers among others as value improvement in this sector is imperative.

\section{Difficulties with LCC Application in Construction}

The shortcomings of the LCC application in construction industry have been identified by a number of earlier researchers (Ashworth, 1996; Flanagan et al., 1989; Ferry \& Flanagan, 1991; Bull, 1993) among others. For instance, Ashworth (1993) asserts that the acquisition of LCC knowledge and skills are still in its infancy, with a considerable gap between theory and practice. Arditi \& Messiha (1996) state that in the United States $60 \%$ of the municipalities did not use LCC due to the following reasons: lack of formal guidelines, difficulty of estimating future costs and incomes, and criteria used in selecting projects for LCC implementation appear to be arbitrary. Kishk \& Al-Hajj (1999) summarise the difficulties in the application of LCC as a decision-making tool in the construction industry on the parts of the client, the analyst and the industry practices. The difficulties on the part of the industry (i.e. construction industry) include the separation of the capital cost of construction from the running cost; and lack of motivation in cost optimisation. In the same vein, the difficulties associated with LCC on the part of the client includes; lack of understanding, and the presence of multiple aspects of needs desired by clients (Kishk \& Al-Hajj, 1999). The difficulties on the part of the analyst include the difficulty in obtaining the proper level of information upon which to base LCC (Flanagan et al., 1989; Ferry \& Flanagan, 1991; Kishk \& Al-Hajj, 1999). Bull (1993) identifies lack of appropriate, relevant and reliable historical information and data as a major threat to the application of LCC technique by the analysts in the construction industry. Cost estimating methods are also identified as an obstacle to LCC technique. For instance, Mason \& Kahn (1997) argue that cost estimating may be difficult at an early stage of the design, due to lack of data or insight. Sparks \& McHugh (1984) assert that many companies use judgement in their predictions as they found statistical methods to be far more cumbersome, expensive, and no more accurate. Therefore, it can be deduced that LCC concept is difficult to apply in practice. While cost forecasting is not a new concept in construction, LCC presents a new set of challenges for the industry's costs experts (Hunter et al., 2005; Boussabaine, 2007).

\section{RESEARCH METHOD}

The target population for this study was professional quantity surveyors working for consultancy practices of varying sizes in the UK. The rationale for selecting only professional quantity surveyors was to achieve the research question of 'how the professional quantity surveyors view and use LCC'. Prior to data collection, the questionnaire was pre-tested. Thus, the questionnaire was electronically sent to three quantity surveyors consultancy firms with the purpose of testing and improving the questionnaire. This is supported by Fellows \& Liu (2008) who assert that questionnaires should initially be piloted, i.e. completed by a small sample of respondents, before data collection. The feedback of pre-testing indicated that there was a potential difficulty in carrying out research into the application of LCC due to its wide range of possible 
interpretations. In order to address this challenge, the definition of LCC was included in the cover email as 'a methodology for systematic economic evaluation of life-cycle costs (cost of an asset or its parts throughout its life cycle, while fulfilling the performance requirements) over a period of analysis, as defined in the agreed scope' (BSI, 2008). The participants of the study (i.e. professional quantity surveyors) were randomly selected from consultancy firms of varying sizes in the UK. The list from which the participants were randomly chosen allowed the inclusion of quantity surveyors of varied levels of experience, belonging to firms of varying sizes. Adopting random sampling technique eliminated possible bias (Perera et al., 2011). The data for this study were collected through questionnaire survey distributed electronically; this method of questionnaire administration has been adopted in prior construction management research (Swaffield \& McDonald, 2008; Perera et al., 2011) among others. The designed questionnaire was a multiple-choice type questionnaire on a five-point Likert scale. The questionnaire was divided into two sections: the first section focused on background information, while the second section was structured in relating to professional quantity surveyors' disposition to LCC, barriers to LCC and factors responsible for their disposition to LCC. The questionnaire was administered to 50 randomly selected professional quantity surveyors working in consultancy firms of varying sizes in the UK. Out of 50 questionnaires administered, 34 (representing 68\%) were returned and found appropriate for the analysis. The data collected for the study were analysed using descriptive and inferential statistics.

\section{RESULTS AND ANALYSIS}

Table 1 indicates that most of the respondents (50\%) were from large organisations possessing more than 400 employees. $29.4 \%$ of the respondents were from organisations employing 150 employees or less, and $20.6 \%$ of respondents were from organisations with 151 to 400 employees. A considerable percentage of the respondents $(47.1 \%)$ had 5yrs or less experience in the QS profession, 32.4\% of the respondents had 6 to 10 years of experience, and $20.6 \%$ had more than $10 \mathrm{yrs}$ of experience. It can be safely assumed that the respondents had adequate experience to supply reliable data for this study. Table 1 further reveals that $32.4 \%$ of the respondents were directly involved in the use of LCC in their organisations while $67.6 \%$ of respondents were not directly involved in LCC. This indicates that not all construction organizations in the UK are using LCC application on construction work. 
Table 1: Background information of respondents

\begin{tabular}{llcc}
\hline Variables & \multicolumn{1}{c}{ Levels } & Frequency & Percent \\
\hline Size of organisation & 150 employees or less & 10 & 29.4 \\
(approximate number of & 151 to 400 employees & 7 & 20.6 \\
employees in UK) & More than 400 employees & 17 & 50.0 \\
& Total & 34 & 100.0 \\
& & & \\
Years of experience in the & 5yrs or less & 16 & 47.1 \\
QS profession & 6 to 10 yrs. & 11 & 32.4 \\
& More than 10 yrs. & 7 & 20.6 \\
& Total & 34 & 100.0 \\
Involvement in LCC & Directly involved & 11 & 32.4 \\
exercise & Not directly involved & 23 & 67.6 \\
\hline
\end{tabular}

Table 2: Barriers to greater use of $L C C$

\begin{tabular}{|c|c|c|c|c|c|c|}
\hline Item & $\begin{array}{l}\text { Barrier } \\
\text { Freq. }\end{array}$ & $\begin{array}{l}\text { May be } \\
\text { Freq. }\end{array}$ & $\begin{array}{l}\text { Not a } \\
\text { barrier } \\
\text { Freq. }\end{array}$ & $\begin{array}{l}\text { Don't } \\
\text { know } \\
\text { Freq. }\end{array}$ & RSI & Rank \\
\hline $\begin{array}{l}\text { Lack of fiscal measures } \\
\text { that encourage clients' use } \\
\text { of LCC }\end{array}$ & 27 & 6 & 1 & 0 & 0.941 & 1 \\
\hline $\begin{array}{l}\text { Clients are unwilling to pay } \\
\text { for LCC }\end{array}$ & 23 & 10 & 1 & 0 & 0.912 & 2 \\
\hline $\begin{array}{l}\text { Incompatibility with client's } \\
\text { intangible or non-financial } \\
\text { objectives and needs }\end{array}$ & 18 & 12 & 3 & 1 & 0.846 & 3 \\
\hline $\begin{array}{l}\text { Difficulty in obtaining the } \\
\text { appropriate, relevant and } \\
\text { reliable information and }\end{array}$ & 17 & 14 & 2 & 1 & 0.846 & 3 \\
\hline & 20 & 7 & 3 & 4 & 0.816 & 5 \\
\hline $\begin{array}{l}\text { LCC } \\
\text { Lack of procurement and } \\
\text { contract award incentives to }\end{array}$ & 15 & 15 & 2 & 2 & 0.816 & 5 \\
\hline $\begin{array}{l}\text { use LCC } \\
\text { Separation of }\end{array}$ & 17 & 10 & 5 & 2 & 0.809 & 7 \\
\hline & 14 & 14 & 4 & 2 & 0.794 & 8 \\
\hline projects & 19 & 5 & 6 & 4 & 0.787 & 9 \\
\hline $\begin{array}{l}\text { The results are difficult to } \\
\text { interpret and not directly }\end{array}$ & 17 & 5 & 9 & 3 & 0.765 & 10 \\
\hline $\begin{array}{l}\text { useful } \\
\text { LCC skills are unavailable } \\
\text { There is insufficient time to } \\
\text { carry it out } \\
\text { Lack of a standard method } \\
\text { of life cycle costing }\end{array}$ & 13 & 11 & 6 & 4 & 0.743 & 11 \\
\hline
\end{tabular}


Table 3 reveals the categories of professional quantity surveyors' disposition to the use of LCC. It shows that $52.9 \%$ of professional quantity surveyors were indifferent to the use of LCC, $26.5 \%$ were unfavourably disposed to the use of LCC, and $20.6 \%$ were favourably disposed to the use of LCC in their various organisations. It can be deduced that there is a general lack of understanding of LCC principles among quantity surveyors because few public sector building clients in the UK are making decisions based on LCC. The lack of appreciation of LCC translates to reduced demand for LCC from construction clients except in PFI/PPP projects when LCC is mostly carried out at the early stage of procurement.

Table 3: Disposition of professional quantity surveyors to LCC

\begin{tabular}{lll}
\hline & Frequency & Percent \\
\hline Unfavourably disposed to the use of LCC & 9 & 26.5 \\
Indifferent to the use of LCC & 18 & 52.9 \\
Favourably disposed to the use of LCC & 7 & 20.6 \\
Total & 34 & 100.0 \\
\hline
\end{tabular}

Table 4 indicates the ANOVA results, thus, ANOVA was used in determining and comparing the statistical significance among size of the organizations, proportion of projects in which LCC was used, and years of experience, on the quantity surveyors' disposition to LCC. The result of ANOVA indicates that size of the organization $(\mathrm{F}(2,33)$ $=7.032, \mathrm{p}<0.05)$ and the proportion of projects in which LCC was used $(\mathrm{F}(3,33)=$ $3.254, \mathrm{p}<0.05)$ had significant influence on professional quantity surveyors' disposition to LCC. While the years of experience of quantity surveyors $(F(2,33)=0.128, p>0.05)$ has no significant influence on quantity surveyors' disposition towards the use of LCC. Thus, Posthoc test of multiple comparisons was conducted on the size of the organizations and the proportion of projects in which LCC was used, because both have significant influence on professional quantity surveyors' disposition to LCC and with a view to understanding the sources of the differences observed. The results are presented in Table 5 and 6 respectively.

Table 4: ANOVA result on factors responsible for professional quantity surveyors' disposition to $L C C$

\begin{tabular}{|c|c|c|c|c|c|c|}
\hline Variables & $\begin{array}{l}\text { Statistical } \\
\text { comparison }\end{array}$ & $\begin{array}{l}\text { Sum of } \\
\text { Squares }\end{array}$ & $\mathrm{df}$ & $\begin{array}{l}\text { Mean } \\
\text { Square }\end{array}$ & $\mathrm{F}$ & Sig. \\
\hline Size of the organisation & $\begin{array}{c}\text { Between groups } \\
\text { Within groups } \\
\text { Total }\end{array}$ & $\begin{array}{l}57.386 \\
126.497 \\
183.882\end{array}$ & $\begin{array}{l}2 \\
31 \\
33\end{array}$ & $\begin{array}{r}28.693 \\
4.081\end{array}$ & 7.032 & 0.003 \\
\hline $\begin{array}{l}\text { Proportion of projects in } \\
\text { which LCC was used }\end{array}$ & $\begin{array}{c}\text { Between groups } \\
\text { Within groups } \\
\text { Total }\end{array}$ & $\begin{array}{l}45.146 \\
138.737 \\
183.882\end{array}$ & $\begin{array}{l}3 \\
30 \\
33\end{array}$ & $\begin{array}{r}15.049 \\
4.625\end{array}$ & 3.254 & 0.035 \\
\hline $\begin{array}{l}\text { Years of experience as a } \\
\text { QS }\end{array}$ & $\begin{array}{l}\text { Between groups } \\
\text { Within groups } \\
\text { Total }\end{array}$ & $\begin{array}{l}1.509 \\
182.373 \\
183.882 \\
\end{array}$ & $\begin{array}{l}2 \\
31 \\
33\end{array}$ & $\begin{array}{l}0.754 \\
5.883\end{array}$ & 0.128 & 0.880 \\
\hline
\end{tabular}


Table 5 reveals the result of Posthoc test of multiple comparisons carried out on the respondents' disposition on the basis of the size of the organisations. Table 5 indicates that the larger the size of the organisation, the better the disposition of the quantity surveyors. For instance, those in organisations with more than 400 employees had better disposition than those in organisations with 151 to 400 employees (mean difference = $2.78, \mathrm{p}<0.05$ ) and also than those in organisations with 150 or fewer employees (mean difference $=2.45, \mathrm{p}<0.05)$. The differences in the disposition of QSs in organisations with 151 to 400 employees and those in organisations with 150 or less employees were not significant $(\mathrm{p}>0.05)$. This test was also conducted for the proportion of projects in which LCC was used (see Table 6).

Table 5: Posthoc test of multiple comparison of professional quantity surveyors' disposition on the basis of size of organisations

\begin{tabular}{|c|c|c|c|c|c|c|}
\hline \multirow[b]{2}{*}{ (I) Size } & \multirow[b]{2}{*}{ (J) Size } & \multirow{2}{*}{$\begin{array}{l}\text { Mean } \\
\text { diff. } \\
(\mathrm{I}-\mathrm{J})\end{array}$} & \multirow{2}{*}{$\begin{array}{l}\text { Std. } \\
\text { error }\end{array}$} & \multicolumn{3}{|c|}{$95 \%$ conf'd interval } \\
\hline & & & & Sig. & Lower bound & Upper bound \\
\hline \multirow{2}{*}{$\begin{array}{l}150 \\
\text { employees or } \\
\text { less }\end{array}$} & $\begin{array}{l}151 \text { to } 400 \\
\text { employees }\end{array}$ & 0.32857 & 0.995 & 0.942 & -2.1215 & 2.7786 \\
\hline & $\begin{array}{l}\text { More than } \\
400 \\
\text { employees }\end{array}$ & $\begin{array}{l}- \\
2.45294 \\
*\end{array}$ & $\begin{array}{l}0.805 \\
0\end{array}$ & 0.013 & -4.4343 & -0.4716 \\
\hline $\begin{array}{l}151 \text { to } 400 \\
\text { employees }\end{array}$ & $\begin{array}{l}150 \\
\text { employees or } \\
\text { less }\end{array}$ & -0.32857 & $\begin{array}{l}0.995 \\
4\end{array}$ & 0.942 & -2.7786 & 2.1215 \\
\hline \multirow{4}{*}{$\begin{array}{l}\text { More than } \\
400 \\
\text { employees }\end{array}$} & $\begin{array}{l}\text { More than } \\
400 \\
\text { employees }\end{array}$ & $\begin{array}{l}- \\
2.78151 \\
*\end{array}$ & $\begin{array}{l}0.907 \\
1\end{array}$ & 0.012 & -5.0142 & -0.5488 \\
\hline & 150 & & & & 0.4716 & 4.4343 \\
\hline & $\begin{array}{l}\text { employees or } \\
\text { less }\end{array}$ & $\begin{array}{l}2.45294 \\
*\end{array}$ & $\begin{array}{l}0.805 \\
0\end{array}$ & 0.013 & 0.5488 & 5.0142 \\
\hline & $\begin{array}{l}151 \text { to } 400 \\
\text { employees }\end{array}$ & $\begin{array}{l}2.78151 \\
*\end{array}$ & $\begin{array}{l}0.907 \\
1\end{array}$ & 0.012 & & \\
\hline
\end{tabular}

*The mean difference is significant at the 0.05 level 
Table 6 indicates the result of Posthoc test of multiple comparisons conducted on the respondents' disposition on the basis of the proportion of projects in which LCC was used. It shows that the mean difference in quantity surveyors' disposition to the use of LCC is significant when the proportion of projects in which LCC was used is 11 to $50 \%$ (mean difference $=3.64, \mathrm{p}<.05$ ) compared with mean differences for 6 to $10 \%$ and $5 \%$ or less; their mean differences were not significant ( $p>0.05)$. It can be deduced that the larger the proportion of projects in which LCC was used, the better the disposition of the quantity surveyors (see Table 6 for details).

Table 6: Posthoc test of multiple comparison of professional quantity surveyors'

\begin{tabular}{|c|c|c|c|c|c|c|}
\hline \multirow[b]{2}{*}{$\begin{array}{l}\text { (I) Proportion } \\
\text { Used }\end{array}$} & \multirow[b]{2}{*}{$\begin{array}{l}\text { (J) Proportion } \\
\text { Used }\end{array}$} & \multirow{2}{*}{$\begin{array}{l}\text { Mean diff. } \\
(\mathrm{I}-\mathrm{J})\end{array}$} & \multirow{2}{*}{$\begin{array}{l}\text { Std. } \\
\text { error }\end{array}$} & \multicolumn{3}{|c|}{$95 \%$ conf'd interval } \\
\hline & & & & Sig. & Lower bound & Upper bound \\
\hline \multirow[t]{3}{*}{ None } & $5 \%$ or less & -1.44444 & 0.93251 & 0.422 & -3.9800 & 1.0912 \\
\hline & 6 to $10 \%$ & -2.01587 & 1.08374 & 0.266 & -4.9627 & 0.9309 \\
\hline & 11 to $50 \%$ & $-3.64444^{*}$ & 1.19948 & 0.024 & -6.9060 & -0.3829 \\
\hline \multirow[t]{3}{*}{$5 \%$ or less } & None & 1.44444 & 0.93251 & 0.422 & -1.0912 & 3.9800 \\
\hline & 6 to $10 \%$ & -0.57143 & 1.00816 & 0.941 & -3.3127 & 2.1699 \\
\hline & 11 to $50 \%$ & -2.20000 & 1.13166 & 0.232 & -5.2771 & 0.8771 \\
\hline \multirow[t]{3}{*}{6 to $10 \%$} & None & 2.01587 & 1.08374 & 0.266 & -0.9309 & 4.9627 \\
\hline & $5 \%$ or less & 0.57143 & 1.00816 & 0.941 & -2.1699 & 3.3127 \\
\hline & 11 to $50 \%$ & -1.62857 & 1.25919 & 0.574 & -5.0524 & 1.7953 \\
\hline \multirow[t]{3}{*}{11 to $50 \%$} & None & $3.64444 *$ & 1.19948 & 0.024 & 0.3829 & 6.9060 \\
\hline & $5 \%$ or less & 2.20000 & 1.13166 & 0.232 & -0.8771 & 5.2771 \\
\hline & 6 to $10 \%$ & 1.62857 & 1.25919 & 0.574 & -1.7953 & 5.0524 \\
\hline
\end{tabular}

disposition on the basis of the proportion of projects in which LCC was used

*The mean difference is significant at the 0.05 level

\section{CONCLUSIONS}

The study revealed low levels of direct involvement of professional quantity surveyors in the use of LCC application in consultancy firms of varying sizes in the UK. The study, therefore, identified prevalent barriers to greater use of LCC outside PFI/PPP context by professional quantity surveyors in consultancy firms. This includes: lack of fiscal measures that encourage clients' use of LCC; clients are unwilling to pay for LCC; incompatibility with client's intangible or non-financial objectives and needs; difficulty in obtaining the appropriate, relevant and reliable information and data; and clients do not request for LCC. The study found that there is a general lack of understanding of LCC principles among professional quantity surveyors because few public sector building clients in the UK are making decisions based on LCC outside PFI/PPP projects. The study further revealed that size of the organisations and the proportion of projects in which LCC was used had a significant influence on quantity surveyors' disposition 
towards the use of LCC. The study through Posthoc test found that professional quantity surveyors in organisations with more than 400 employees had better disposition to LCC than those in organisations with 151 to 400 employees, and also than those in organisations with 150 or fewer employees. The Posthoc test result further revealed that professional quantity surveyors have better disposition to LCC when a larger proportion of projects use LCC (for example 11 to $50 \%$ of projects compared with 6 to $10 \%$ and 5\% or less). The study concludes that the larger the size of organisations and the bigger the proportion of projects in which LCC was used, the better the disposition of the professional quantity surveyors to LCC. Therefore, the study recommends internal and external short courses on LCC principles and applications for professional quantity surveyors with a view to improving their understanding on LCC. Also, professional bodies such RICS, CIOB among others should sensitise the public clients in adopting LCC for construction works outside PFI/PPP context. The limitation of this study was the small sample size, as a larger number of respondents from questionnaire survey would have increased the credibility of the results. But the study findings are very useful and beneficial to all stakeholders in the construction industry, as value improvement in this sector is imperative. Also, LCC helps towards achieving economic sustainability. Therefore, knowledge of the factors influencing the professional quantity surveyors' disposition to LCC use will enlighten quantity surveyors, clients and other stakeholders in the construction industry. It will help quantity surveyors among others, to be trained in the practicalities of LCC, including how to use standardised LCC methods in construction organisations. Further studies need to be carried out on LCC perception among construction clients, besides the government and quasi-public clients.

\section{REFERENCES}

- $\quad$ ARDITI, D. and MESSIHA, H. (1996) Life-cycle costing in municipal construction projects. Journal of Infrastructure System, 2(1), 5-14.

- $\quad$ ASHWORTH, A. (1993) How life cycle costing could have improved existing costing. In Bull, J. W. (ed.). Life cycle costing for construction. Glasgow, UK: Blackie Academic and Professional.

- ASHWORTH, A. (1996) Assessing the life expectancies of buildings for life cycle costing. Proceedings of the COBRA Conference, University of West of England, Bristol, UK.

- ASHWORTH, A. and HOGG, K. (2000) Added value in design and construction. Harlow: Longman.

- BERR, (2008) Strategy for sustainable construction. London: Department for Business, Enterprise \& Regulatory Reform.

- $\quad$ BOUSSABAINE, A. (2007) Cost planning of PFI and PPP building projects. London: Taylor \& Francis.

- $\quad$ BSI, (2008) BS ISO 15686-5:2008- buildings and constructed assets - service life planning Part 5: life cycle costing. London: British Standards Institution.

- BULL, J. W. (1993) The way ahead for life cycle costing in the construction industry, In Bull, J. W. (ed.). Life cycle costing for construction. Glasgow, UK: Blackie Academic and Professional.

- CLIFT, M. (2003) Life-cycle costing in the construction sector. UNEP Industry and Environment, April - September, 37-41

- CLIFT, M. and BOURKE, K. (1999) Study on whole life costing. London: Building Research Establishment Ltd. 
- EGAN, J. (1997) Rethinking Construction. London: HMSO.

- FELLOWS, R. R. and LIU, A. (2008) Research methods for construction. London: WileyBlackwell Science.

- FERRY, D. J. O. and FLANAGAN, R. (1991) Life cycle costing - a radical approach. London: CIRIA Report 122.

- FlANAGAN, R. and JEWEL, C. (2005) Whole life appraisal. Oxford: Blackwell Publishing Ltd.

- FlanAGAN, R., NORMAN, G., MEADOWS, J. and ROBINSON, G. (1989) Life cycle costing: theory and practice. Oxford: BSP Professional Books.

- HUNTER, K., HARI, S. and KELLY, J. (2005) A whole life costing input tool for surveyors in UK local government. Structural Survey, 23(5), 346-358.

- IISD, (2009) Life cycle costing in sustainable public procurement: a question of value [Online]. Available from: https://www.iisd.org/pdf/2009/life_cycle_costing.pdf. [Accessed: 16 September 2015].

- KELly, J., MORLEDGE, R. and WILKINSON, S. (2002) Best value in construction. Oxford: Blackwell Science Ltd.

- KELLY, J., MALE, S. and GRAHAM, D. (2004) Value management of construction projects. Oxford: Blackwell.

- KIRKHAM, R. (2007) Ferry and Brandon's cost planning of buildings. Oxford: Blackwell Publishing Ltd.

- KISHK, M. and AL-HAJJ, A. (1999) An integrated framework for life cycle costing in buildings. Proceedings of RICS Construction and Building Research Conference, University of Salford, UK.

- LATHAM, M. (1994) Constructing the team, final report of the government / industry review of procurement and contractual arrangements in the UK construction industry. London: HMSO.

- MASON A. K., and KAHN D. J. (1997) Estimating costs with fuzzy logic. AACE International Transactions, 3: EST.03.1-EST.03.6.

- OGC, (2007) Whole-life costing and cost management: achieving excellence in construction procurement guide 7. London: Office of Government Commerce.

- PASQUIRE, C. and SWAFFIELD, L.M. (2002) Life-cycle/whole-life costing. In KELLY, J., MORLEDGE, R. \& WILKINSON, S. (eds.). Best value in construction. Oxford: Blackwell Publishing.

- PELzETER, A. (2007) Building optimisation with life cycle costs - the influence of calculation methods. Journal of Facilities Management, 5(20), 115-128.

- PERERA, S., HAYLES, C. S., and KERLIN, S. (2011) An analysis of value management in practice: the case of Northern Ireland's construction industry. Journal of Financial Management of Property and Construction, 16(2), $94-110$.

- SPARKS, J. R. and MCHUGH, A. K. (1984) Awareness and use of forecast techniques in British industry. Journal of Forecasting, 3, 37-42.

- SWAFFIELD, L.M. and MCDONALD, A.M. (2008) The contractor's use of life cycle costing on PFI projects. Engineering, Construction and Architectural Management, 15(2), 132-148.

- TRADA TECHNOLOGY (2008) Life cycle costing, Wood Information Sheet. London: Wiley-Blackwell Science.

- WOODWARD, D.G. (1997) Life cycle costing- theory, information acquisition and application. International Journal of Project Management, 15(6), 335-344. 


\title{
USING SOFT SYSTEM METHODOLOGY TO APPROACH SOCIAL VALUE OUTCOMES IN PUBLIC PROCUREMENT
}

\author{
Farag, F. ${ }^{1} \&$ McDermott, P. ${ }^{2}$
}

\begin{abstract}
:
Social value in recent years have been attracting increased attention from public clients where policy documents encouraged clients to maximise their additional outcomes when procuring goods and services. However, social value studies in recent times show how there are problems accompanying its delivery with publicly procured projects, where confusion of definition among public procurers, the lack of methodologies and mechanics to calculate and implement the delivery processes and the absence of assessment and measurement methods caused hindrance to social value inclusion.

This paper discusses how using Soft Systems Methodology (SSM) would improve the delivery of social value outcomes for publicly procured projects. Since social value as a subject is considered to be of vague it cannot be approached in a similar way of well-defined construction deliverables, therefore SSM is adopted to accommodate its characteristics. The inability to define social value outcomes can be dealt with using the culture stream of inquiry specifically rich picture building which includes multiple stakeholder perspectives of reality. On the other hand, lacking methodologies and mechanisms to implement social value can be improved through logic based inquiry stream and Human Activity System modelling where stakeholders can have their input conceptualised into models which is compared to the real world situation to find most suitable answers. Measurement and assessment of social value can improve through improving the definition and the implementation processes.

This research does not claim to be empirical and could be seen as an explorative nature research of qualitative observational opinion. With the acknowledgment of this research limitation it can be viewed as a grounding base to a suitable research methodology approach used to explore a new subject such which is social value.
\end{abstract}

KEYWORDS: PUBLIC CLIENTS, PUBLIC PROCUREMENT, SUSTAINABLE PROCUREMENT, SOFT SYSTEM METHODOLOGY, SOCIAL VALUE.

\section{INTRODUCTION}

Thai (2001) argued that there are two types of goals for public procurement activities. Firstly, procuring goods and services, similar to commercial goals of any organisation. This can be achieved through reducing costs, managing financial, business and technical risks and maintaining probity and transparency. Secondly, non-procurement goals, which differentiates between public and private organisations. This type of goals supports creating socioeconomic benefits, elevating poverty, supporting local markets, the inclusion of ethnic minorities and improving educational standards. To clarify, historically the USA and Europe used their procurement policies to promote these secondary goals which have a social nature, exceeding the initial delivery of goods and

\footnotetext{
${ }^{1}$ School of the Built Environment (SoBE), University of Salford. f.f.farag@edu.salford.ac.uk

${ }^{2}$ School of the Built Environment (SoBE), University of Salford. P.McDermott@salford.ac.uk
} 
services (McCrudden, 2004). Similarly, the UK government have been encouraging the use of public procurement to deliver social value outcomes through their procurement activities where central government expenditure is $£ 13$ billion and local authorities' expenditure is $£ 40$ billion (Preuss, 2009).

The issuance of the National Infrastructure Plan (2013), the Public Services (Social Value) Act (2012) and the House of Commons' report on local procurement reforms (2014) suggested that public clients, local and central, should consider delivering Social Value (SV) through the strategic procurement of their goods and services. The Public Services (Social Value) Act (2012) was promoting SV benefits through encouraging public clients to maximize any additional outcomes which would surpass the delivery of procured goods and services delivery. The EU procurement directive (2014) stated that member states should deliver SV by using their buying power to deliver benefits to local communities and to create socioeconomic return on their investment.

Out of the variety of goods and services procured by the public sector clients, construction products were placed at the centre of government policy to stimulate economic growth through its 6.1\% share of the GDP (Murray, 2014). Construction industry is used to revitalize stagnated economies, through fiscal policies focusing on public expenditure to stimulate markets. This is achieved through employing semi and unskilled workers and collaborating with more than 200 industries making it a tool to include unexperienced workforce into the employment market (Preuss, 2009 \& Ozkan, Ozkan \& Gunduz, 2011).

\section{Background to Social value as a business requirement}

The growing gap between what is offered to solve human needs and how fast these needs are growing resulted in the change of perceiving business success as more than just monetary performance and profit increase. In the neoclassical theory of economics, value is created when the price of services or products sold to clients exceeds the cost of producing them, making organisational profits the main focus of strategies and business models (Mulgan et al, 2013). Therefore, since the emergence of the term capitalism 170 years ago the most dominant factor of measuring business success was creating and maximising profit. Because capitalism and free markets were the conquering ideologies across the globe, profit was the most significant outcome of any business at the time (Mulgan et al, 2007).

Nevertheless, Elkington (1999) expected that due to a shift in societal expectations and increased complexity of the business world, success criteria will shift towards having environmental and social success factors along with economic ones to measure businesses' sustainability, which would be accompanied by adopting new performance management mechanisms. He pointed out that since the issuance of the Brundtland Report in 1987 drastic changes to public and private business models were sought after to deliver goods and services. This was confirmed by Erridge and Mcllroy (2002) who stated that non-commercial criteria, which business success is measured against, were emerging. Finally, Mulgan (2013) stated that the economic crisis of 2008 shed light on 
the failure of prevailing business models to provide balance and stability for society's needs, where corporate monopolies, striving for profit maximisation, were hindering the delivery of societal benefits. He added that the crisis displayed the need for change in business models for both the public and private sector.

\section{Definition of social value}

The Public Services (Social Value) Act drew attention towards the term Social Value and its definition, where it was increasingly used within the public procurement context (Westall, 2012). SV was identified as business outcomes, which have a subjective nature because it depended on how different groups of stakeholders value an object, a service or a product, differently from each other because of having a different perspective (Woods \& Legihton, 2010). Therefore, SV can be defined according to the way it is interpreted and understood, as a unified definition cannot cover all its possible perspectives. This made the creation of a unified strong definition and/or term for different groups, businesses and/or organizations challenging. Several attempts were made to define SV such as:

1.Westall (2012) defined it as the outcomes of certain organisational activities which occur by creating positive and/or preventing negative social changes in people's lives and impacting even after the initial activities durations were finished;

2. MacLaren (2011) defined it as socially derived procurement/commissioning outcomes which are wider than fiscal interpretations of the value for money concept;

3. The Social Value Act (2012) defined it as the notion of maximising additional outcomes developed through procuring goods and services which surpasses the initial benefit of the goods and services themselves;

4. Russell (2013) defined it as outcomes of certain activities with non-fiscal nature, performed by any organisation, which are important to key stakeholders of the project.

Accordingly, for this research SV can be defined as the 'soft' non-financial outcomes of projects and/or programmes of investments, which may include, but are not limited to, communities' and individuals' social wellbeing. The soft nature in the definition indicates that it is more than cost saving or just monetary representation of the outcomes.

\section{Problems with social value in public procurement context}

Despite the rise of interest in SV, its delivery through public procurement was not an easy or straight forward task, regardless of the effort made to promote it as additional procurement outcomes. This was due to the confusion and misunderstanding of public procurers when dealing with SV delivery (The Public Services (Social Value) Act Year on Report, 2014). Brat et al (2013) argued that despite the initiatives developed in the EU procurement directives, member states did not achieve the success anticipated to deliver sustainable products or services procured by the public sector. It was found that the hindrance of SV delivery was due to three different reasons: 


\section{The Failure to Define Social Value in a Robust Fashion}

Public procurers were unable to define what outcomes can be delivered because of their confusion in defining which outcomes are most suitable for their projects and local contexts (Westall, 2012). The conflict between the soft unquantifiable qualitative characteristics of SV and public clients' predominantly quantitative goals, expressed in cost, time and quality, minimized the ability of public clients to identify SV outcomes for their capital investment programs. Project benefits were still dominated by low cost culture, leaving less room to other benefits with soft nature (Arvidson et al., 2010).

To clarify, for any public project there are three types of results, which are outputs, outcomes and impacts. Firstly, outputs of a project or a program are the direct results of the investment, such as products and the services. In a school project output could be the building, hiring supply chains and employing new teachers. Secondly, outcome of a project or a program is the added value in people and/or communities, which may have problems that can be solved through projects. Outcome can be increasing employability to reduce crime rate in a certain area and improving living wages by hiring local suppliers. Finally, impacts are the long term changes that the project outcomes can create. For example, impacts can be a significant reduction of crime rates or economic recovery implementation (Wood \& Leighton, 2010). Hence, the problem with defining SV is that procurers tend to confuse outputs with outcomes and justify them retrospectively without identifying what impacts are there for local communities (Russel, 2013).

\section{Insufficient Mechanisms and Methodologies for Implementation}

Public clients claim to have SV in their strategic objectives. However, they do not have the adequate mechanisms to deal with operational obstacles for different project phases. The reason for that was a detachment between higher level agendas and project level practicalities Brat et al (2013) concluded from their case study that strategic objectives of SV were not articulated to ease implementation on operational levels. For example, in a case study in the Northern Ireland investigating methods of delivering sustainable procurement it was found that most procurement officers could not find enough guidance about sustainable procurement and how it would be compatible with the OJEU rules and regulations (Erridge \& Hennigan, 2012).

Furthermore, MacLaren (2011) investigated the lack of methodologies to SV implementation, finding that it was not easily applied without sound theoretical basis, which can be used by stakeholders. Mulgan et al (2007) explained that despite having vast amounts of money invested in R\&D projects for technologies and business research, there are negligible amounts invested in social delivery innovation. Even governments do not spend the same amounts of money to provide answers for common public needs. Finally, the lack of organisational champions or key individual who could politically support the delivery of sustainable procurement, using their position in higher management in client organisations was hindering the delivery of sustainable procurement. Champions attempt to reduce the gap between higher level objectives and project level problems by using their political power on organisational and project level to implement and support SV (Preuss, 2009, Seuring \& Müller, 2008). 


\section{Inability to Assess and/or Measure Social Value}

SV measurement is an effort made to assess what is valued according to different stakeholders' perspectives and priorities, leading to an accurate evaluation of SV. Therefore, SV outcomes cannot be easily measured, quantified or assessed, causing problems for public clients who try to justify procurement choices to include SV goals (MacLaren, 2011). Arvidson et al (2010) indicated that since the late 1990s the UK government has been encouraging the measurement of public services outcomes in new methods, which would include social and environmental outcomes, but without success. Murray (2014) stated that despite having good procurement practices and skilled practitioners, solid evidence to base best practice upon were missing, where opinions as a source of evaluating outcomes of procurement strategies caused scepticism of any acclaimed benefits. Having no bench marking information or track record of SV weakens the ability to assess it. Also, in some practices, assessing SV outcomes was wrongfully perceived as attempts to prove that all project activities had SV outcomes which needed retrospective validation. Russell (2013) argued that SV and its measurement cannot only be quantitative because it will always have subjective judgement to assess and justify it. Finally, elements of assessing SV might improve if they were sector related, when they include characteristics of certain sectors. For example, the NHS model for measuring SV had elements such as; respect of patients, patient advocacy, and quality of care, reducing care inequalities and framing of ethics as outcomes measured for SV impact (Wood \& Leighton, 2010).

\section{SOFT SYSTEM METHODOLOGY BACKGROUND}

Checkland and Scholes (1999) stated "to manage anything in everyday life is to try to cope with a flux of interacting events and ideas which unrolls through time". Hence, because public procurement includes different views from different stakeholders with each of them influencing the outcomes, several perceptions of reality should be examined in order to include the key influencers on a situation. Soft Systems Methodology (SSM) was developed as a response to soft, ill-defined issues with multiple socially constructed realties which are difficult to solve and more difficult to define, thus, similar to SV definitions, being ambiguous and unclear. SSM is about producing different stakeholder's perspectives of the problem situation by developing models of human activities systems in order to debate the intervention needed to improve current situations (Durant-Law, 2005, Checkland \& Winter, 2006).

\section{Soft System Methodology Description}

In SSM, history has a significant role. Different historical perspectives based on different cultural and contextual backgrounds are important in exploring and learning about the problem situation. Facing this problem are 'would be improvers', who are interested in improving the situation through day to day Following the introduction of the history and the 'would be improvers' there are two structured streams of inquiry to navigate through 
to develop an intervention. Both streams interact with each other along the process of inquiry, feeding interconnected inquiry processes.

First is the logic based stream of inquiry, on the right hand side of Figure 1, which consists of multiple models of Human Activity Systems (HAS). It was developed and used to illuminate the problem situation by comparing relevant HAS models with real world perceptions. In this way they support having a debate about possible changes and improvements, which accommodate different points of view. The logic based stream has different stages of inquiry, which are:

-Selecting relevant systems from a continuum of tasks which vary from organisational description to issues arising freely from problem description;

-Naming relevant systems using Root definitions which represent the core of what is being transformed from inputs to outputs and CATWOE analysis, which allows to specify that system through identifying its Customers, Actors, Transformation process, Weltanschaungen or world views, Owners of the problem and Environment of the system;

-Modelling relevant (HAS) systems through developing models, representing activities of the system with emphasis on efficacy, efficiency and effectiveness;

-Comparing relevant systems with reality.

The logic based stream of inquiry selects, names and models HAS based on different perspectives. The cultural sources of these perspectives are investigated through the culture stream of inquiry on the left hand side of Figure 1. Since human activity systems are shaped by human beliefs, meanings and experiences, they should be examined in order to gain an understanding of where these systems emerge from. This is achieved through analysing the cultural context to define and structure the problem continuously for the duration of the research process and support the logic stream inquiry as well. The cultural stream of inquiry's different stages are:

-Rich picture building, which represents collective human affairs and its surroundings and interactions with each other pictorially;

-Analysis of the intervention, which identifies, who the intervention should be modelled for through differentiating between 'problem solver', 'problem owner' and the 'client';

- Social system analysis, which links through social systems' interpretations of roles, norms and values impact on the problem situation and logic based stream;

- Political systems analysis, which deals with the problem situation through identifying it as a power system and attempts to identify the power sources which affect the problem and its intervention (Checkland \& Scholes, 1999, Checkland, 1999 \& Winter \& Checkland, 2003). 
Figure 1: Soft System's methodology approach for real life situations (Source: Checkland \& Scholes, 1999).

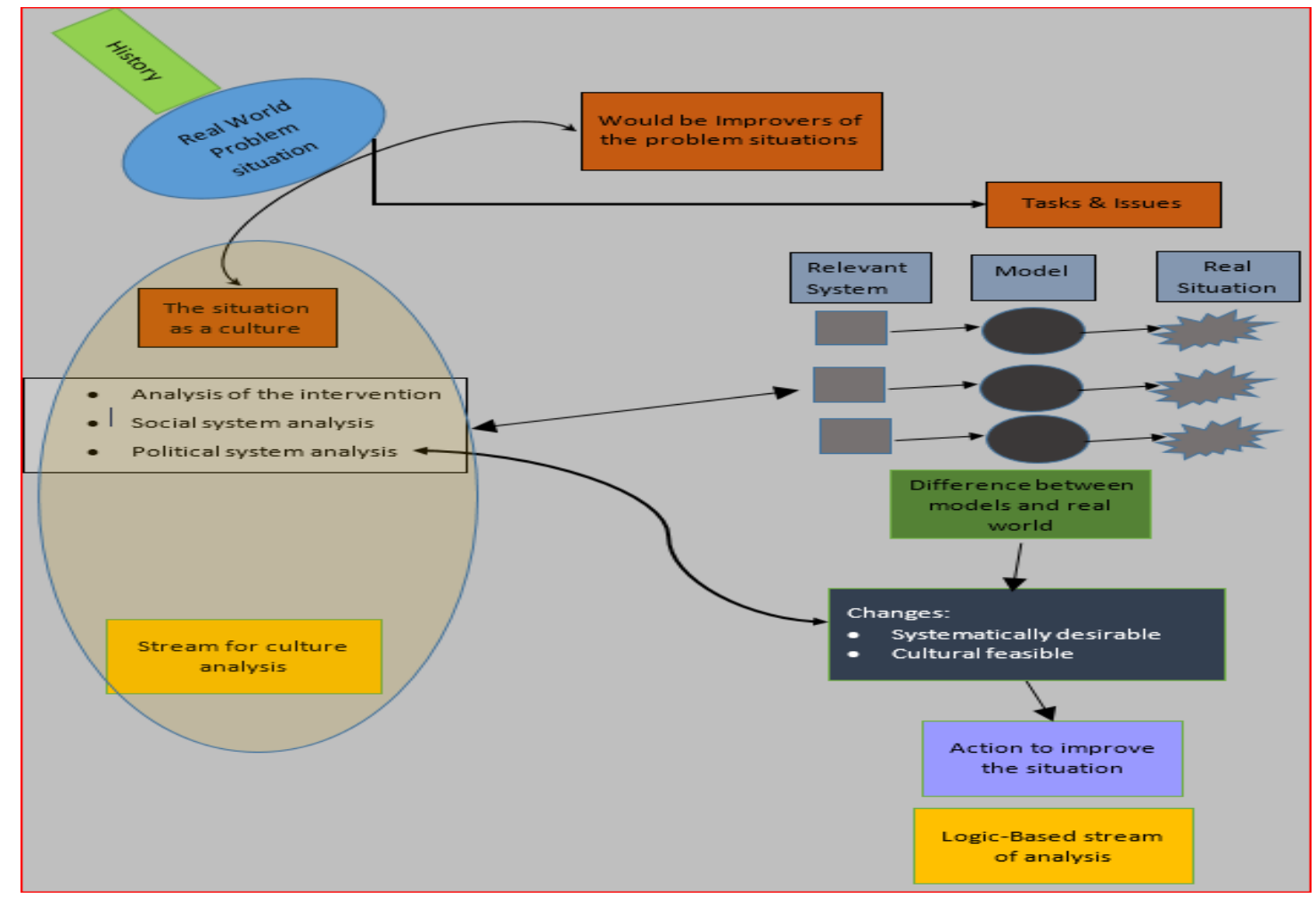

\section{DISCUSSION}

Out of the cultural stream of inquiry, rich pictures can be used to define factors and relations affecting the SV outcomes definition. Engaging in rich picture building can improve the ambiguous definition of SV through collectively describing the problem situation from different perspectives of project stakeholders. As multiple stakeholders are describing the problem situation for the rich picture building exercise, emotions and soft issues can be included without being standardised; and allow the inclusion of any representation that might be important. In-depth interviews are used to obtain the information needed from different stakeholders to create rich pictures, which allows them to express their views of the problem situation and therefore enriches the process of definition (Walker, Stinfort \& Maqsood, 2014). The conflicting opinions in defining SV can be improved when they are collectively included in one picture, with elements of the story being concluded out of the dialogue with stakeholders. During the process of sketching elements of the situation, a deeper understanding of the issue emerges as the whole picture unfolds until there is sufficient satisfaction with the portrayal accuracy.

During the interaction with the stakeholders two types of conversations arise. The first one with the stakeholders themselves, where they prepare their minds about what to say and how to illustrate it to other people, making it clear and well structured. This would 
help them form a reality check about what to say and improve poorly formed elements of their thoughts. The second conversation is with the researcher, where the latter will embark on a self-reflection of the dialog. This allows building a creative meaning of construction (Walker \& Stinfort, 2013, Checkland \& Scholes, 1999).

On the other hand, in the logic based stream of inquiry, developing HAS models which are relevant to the problems, conceptually will assist in outlining how the problems situation can be theoretically solved (Wilson, 2001). Selecting these relevant systems can be based on different stakeholders' perspectives, such as public clients, main contractors, supply chain members and local communities, where they can conceptualise how the delivery of SV can improve through publicly procured construction projects. The use of Root definition, which describes the system as means of transformation from a world view along with the assistance of CATWOE elements analysis of the model can assist in the emergence of new methods of delivery, which was identified earlier as the missing mechanisms of SV implementation on operational levels. These models can then be compared with the reality of the situation, built through rich picture to assess whether the improvements are socially and culturally viable or not. If so improved, the method can be implemented in future projects with the SSM being utilised to further investigate the success of such models. With HAS models having the activities of control and monitoring for each element of the CATWOE analysis the third and final issue with having no robust method of measuring or assessing SV can be solved. WIn this way activities of monitoring and controlling can assist in measuring and assessing SV performance.

\section{CONCLUSIONS}

Evidence in National and EU policy documents SV is getting increasingly rooted in public procurement activities, where it attracted attention on different levels, varying from central government to small boroughs in recent years. Despite that SV remains an ambiguous and vague subject which is hard to achieve due to multiple reasons. The main problems lie in defining and choosing additional outcomes which are considered successful in a SV context. Also, the inability to overcome implementation processes because of the lack of mechanisms and methodologies which would help to overcome obstacles of social value delivery on the project level. Finally, the confusing and nonrobust ways that are being used to assess and measure.

Nevertheless, the use of SSM and its two streams of inquiry can improve how SV is approached on research and practical levels, where it was developed to approach vague issues which are hard to track or define. Culture stream inquiry can be used to define SV where Rich picture building as a tool represents information which can be viewed parallel and not serially as written information which is essential for relationship information. The understanding created by the rich pictures is what leads to a definition of the problem situation and the choices made for the relevant systems which ought to be modelled. Furthermore, the logic based stream of inquiry and the use of relevant human activity systems used along with Root definitions and the CATWOE analysis can be used to 
formulate conceptual models representing different stakeholder's perspectives in improving current problems situation.

\section{REFERENCES}

- $\quad$ ARVIDSON, M, LYON, F., MCKAY, S. \& MORO, D. (2013). Valuing the Social? The nature and controversies of measuring Social Return on Investment (SROI), Voluntary Sector Review. 4(1). 3-18.

- $\quad$ ARVIDSON, M., LYON, F., MCKAY, S \& MORO, D. (2010). The ambitions and challenges of SROI, Third Sector Research Centre Working Paper 49.

- $\quad$ BRATT, C., HALLSTEDT, S., ROBÈRT, K. H., BROMAN, G. \& OLDMARK, J. (2013). Assessment of criteria development for public procurement from a strategic sustainability perspective, Journal of Cleaner Production. 52. 309-316.

- CHECKLAND, P. \& SCHOLES, J. (1999). Soft Systems Methodology in Action: Includes a 30 Year Retrospective. West Sussex: John Wiley \& Sons.

- CHECKLAND, P. (1999). Systems Thinking, System Practice: Includes 30 - Years Retrospective. John Wiley \& Sons: Chichester.

- CHECKLAND, P. \& WINTER, M. (2006). Process and Content: Two Ways of Using SSM, The Journal of the Operational Research Society. 57(12). 1435-1441.

- DURANT-LAW, G. (2005). Soft Systems Methodology and Grounded Theory a Knowledge Management Research Approach?, actKM Online Journal of Knowledge Management. 2(1). 14-23.

- ELKIngTON, J. (1999). Cannibals with forks: The Triple Bottom Line Theory of 21st Century Business. Oxford: Capstone Publishing Limited.

- $\quad$ ERRIDGE, A. \& MCllROY, J. (2002). Public Procurement and Supply Chain Management Strategies, Public Policy and Administration. 17(1). 52-71.

- $\quad$ ERRIDGE, A. \& HENNIGAN, S. (2012). Sustainable procurement in health and social care in Northern Ireland, Public Money \& Management. 32(5). 363-370. DOI: 10.1080/09540962.2012.703422.

- $\quad$ EU PROCUREMENT DIRECTIVE. (2014). Official Journal of the European Union. Volume 57, L 94. Luxembourg: Publication Office of the European Union.

- HM GOVERnMENT. (2012). The Public Service (Social Value) Act. London: The Parliamentary Book Shop.

- HM GOVERnMENT. (2014). The Public Services (Social Value) Act 2012: One Year On. London: The Parliamentary Book Shop.

- HM TREASURY. (2013). National Infrastructure Plan. London: Crown Publishing

- HOMMEL, U., \& SCHNEIDER, H. (2003). Financing the German Mittelstand. EIB Papers, 8(2), 53-90.

- HOUSE OF COMMONS. (2014). Local government procurement, Communities and Local Government Committee: Sixth Report of Session 2013-14. The Stationery Office Ltd.

- $\quad$ LINTON, J. D., KLASSEN, R. \& JAYARAMAN, V. (2007). Sustainable supply chains: An introduction, Journal of Operations Management. 25(6). 1075-7082.

- MACLAREN, V. (2011). Briefing 1: Introduction to Social Value, NAVCA's Local Commissioning and Procurement Unit.

- MCCRUDDEN, C. (2004). Using public procurement to achieve social outcomes, Natural Resources Forum. 28(4). 257-267.

- $\quad$ MUlGAN, G., TUCKER, S., ALI, R. \& SANDERS, B. (2007). Social Innovation: What it is, Why It Matters and How It Can Be Accelerated? Oxford: SAID Business School.

- MUlgAN, G. (2013). The Locust and the Bee: Predators and Creators in Capitalism's Future, Oxfordshire: Princeton University Press. 
- MURRAY, J. G. (2014). Debate: Public procurement needs outcome evaluations, Public Money \& Management. 34(2). P141-143. DOI: 10.1080/09540962.2014.887548.

- OZKAN, F., OZKAN, O. \& GUNDUZ, M. (2011). Causal relationship between construction investment policy and economic growth in Turkey, Technological Forecasting \& Social Change. 79, 362-370.

- PREUSS, L. (2009). Addressing sustainable development through public procurement: the case of local government, Supply Chain Management: An International Journal. 14(3). 213 223. DOI: / $10.1108 / 13598540910954557$.

- RUSSEL, S. (2013). Journey to Impact: A practitioner perspective on measuring social impact. Midland Heart.

- $\quad$ SEURING, S. \& MÜLLER, M. (2008). From a literature review to a conceptual framework for sustainable supply chain management, Journal of Cleaner Production. 16. 1699-1710.

- THAI, K. V. (2001). Public Procurement Re-Examined, Journal of Public Procurement. 1(1). 9-50.

- WALKER, D. H. T. \& STEINFORT, P. (2013). Using an improved rich pictures approach to improve project situational analysis in complex aid reconstruction development projects, International, Journal of Disaster Resilience in the Built Environment. 4(2). 182 - 198.

- WALKER, D., STEINFORT, P. \& MAQSOOD, T. (2014). Stakeholder voices through rich pictures, International, Journal of Managing Projects in Business. 7(3). 342 - 361

- WESTALL, A. (2012). Briefing 2: Measuring social value, social outcomes and impact, NAVCA's Local Commissioning and Procurement Unit.

- WILSON, B. (2001). Soft system methodology conceptual model building and its contribution. London: John Wiley \& Sons Ltd.

- WOOD, C. \& LEIGHTON, D. (2010). Measuring Social Value: The Gap between Policy and Practice. London: Demos. 


\title{
THE CE METER; AN INSTRUMENT TO ASSESS THE CIRCULAR ECONOMY CAPACITY OF BUILDINGS
}

\author{
Geraedts, R.P ${ }^{1}$ and Prins, $\mathrm{M}^{2}$.
}

\begin{abstract}
:
A direct connection can be made between adaptive building and sustainability (Wilkinson 2011). Market developments show increased demands by for flexibility and sustainability by users and owners as well as a growing understanding of the importance of a circular economy (Eichholtz 2009). Circular Economy (CE) is a rather recent way of looking at sustainability, based on thinking in circular supply chains, maximizing the value of materials in which products can be re-used, re-manufactured or/and re-cycled (Ellen MacArthur Foundation 2012). In 2014 a paper was presented at the International Union of Architects World Congress UIA2014 in Durban SA, titled Adaptive Capacity of Buildings (Geraedts 2014). A report was given of an extensive international literature survey and the development of a method to determine the adaptive capacity of Buildings. In total 147 indicators were described with accompanying assessment values. The most important recommendation for the next step was the development of an easy to use assessment method with a limited number of important flexibility performance indicators (FPI). This paper will explore the further development of this easy to use instrument with a limited number of important assessment criteria. These criteria will also be related to the concept of circular economy. The final result is an easy tool to assess the adaptive capacity of a building, and will also be the first tool to assess the circular economy level of a building as well.
\end{abstract}

KEYWORDS: ADAPTABLE, FLEXIBLE, ASSESSMENT INSTRUMENT, CIRCULAR ECONOMY, SUSTAINABLE, OPEN BUILDING.

\section{INTRODUCTION}

Wilkinson states that a direct connection can be made between adaptive building and sustainability (Wilkinson 2011). Local authorities worldwide are encouraging adaptation as a means of reducing building related urban energy consumption and greenhouse gas emissions. The City of Melbourne for instance is promoting the retrofit of 1,200 CBD properties before 2020 with sustainability measures as part of their policy to become a carbon neutral city. Australian cities date from 1837 to the present day whereas some European cities have been inhabited for over two millennia. The concepts of adaptation and evolution of buildings and suburbs is well developed in Europe, though the scale of some of the post war developments has created different forms of building perhaps less adaptable or suited to change. The need to adapt buildings and to reduce environmental footprints becomes more pressing over time as global concentrations of carbon dioxide increase.

Market developments show increased demands by for flexibility and sustainability by users and owners as well as a growing understanding of the importance of a circular economy (Eichholtz 2009). Circular Economy (CE) is a rather recent way of looking at

\footnotetext{
${ }^{1}$ Delft University of Technology, Faculty of Architecture, The Netherlands. Email: r.p.geraedts@tudelft.nl

${ }^{2}$ Delft University of Technology, Faculty of Architecture, The Netherlands. Email: m.prins@tudelft nl
} 
sustainability, based on thinking in circular supply chains, maximizing the value of materials in which products can be re-used, re-manufactured or/and re-cycled (Ellen MacArthur Foundation 2012).

This paper will explore the relation between the adaptability of a building on the one hand and at the same time the level of circular economy of that building on the other hand. What do we mean by circular economy and adaptability, and which criteria or indicators can be used to assess the quality of buildings? What are the priorities and can we weight the different indicators? As a final result an easy to use tool will be presented to assess the adaptive capacity of a building, and therefore also the first tool to assess the circular economy level of a building as well: the CE Meter.

\section{CIRCULAR ECONOMY}

\section{From linear to circular}

Since 150 years industrialization created a linear production and consumption model. This linear model assumes a take-make-waste pattern in which with energy, labour and capital produce products out of natural resources with a single life cycle. Resources are withdrawn from the earth (take), processed to components (make) and after the use phase thrown away (waste). This is called the cradle-to-grave principle (Braungart 2002). This linear consumption pattern in which the end user is responsible for the removal of the product, seemed to be successful to provide affordable products and global welfare, but was totally based on waste of resources and the creation of garbage (Ellen MacArthur Foundation 2013).

The circular economy concept stems from the believe that linear consumption will reach its limits in the foreseeable future, and builds upon different earlier concepts like for instance cradle-to-cradle theory (Ellen MacArthur Foundation 2012, Van Dijk 2014). The believe that linear consumption is reaching its limits originates for instance from the fact that the amount of resources that are available for use will decline steadily over the next years and decades leaving little to play with for future use. Especially since the rate of recycling is low for most resources (Ellen MacArthur Foundation 2014, Mentink 2014). The reason that the rate of recycling is low under a linear consumption pattern is that there in general is no premium or gain on re-using materials, this leads to the take-makedispose model that is used by most manufacturers nowadays (Ellen MacArthur Foundation 2012). In this research, their circular system diagram by the Ellen MacArthur Foundation is used to show how the circular economy works by closed-loop thinking. Circular economy attempts to create value by letting products 'ride the cycle', or in other words by adapting products when they no longer deliver the requested performance instead of disposing of them. An important driver behind this thinking is that in the future this would be a cheaper alternative than starting with fresh new products as the commodity prices would be a lot higher given their finiteness (Ellen MacArthur Foundation 2014). The construction sector has a high level of raw material consumption. In the Netherlands $50 \%$ of the national raw material consumption is caused by the 
construction industry and $40 \%$ refers to demolition waste. The dynamic and worldwide process of unlimited growth, characterized by rapid urbanization and fast consuming economies, will lead in the next decades to an explosive demand of construction materials (Van Timmeren 2013, Schoolderman 2014).

\section{Circular building: building in layers}

To structure and cluster the large number of different construction components with different functional life cycles, several possible arrangements were developed in the past. According to Habraken a certain level of wanted flexibility has impact on a building or at least on a part of a building. That's why it is good to know on which level in the building a certain adaptation takes place and how far its influence reaches. He already proposed in 1961 a subdivision of a building in different layers or levels: the support level with construction components with a long lifespan and the infill level with construction components with a short life span. A distinction between collective components for the community to decide (support level) and individual components for the individual user to decide (infill level) (Habraken 1961, Habraken 1998). To be able to disconnect these two levels and to make changes very easy for the individual users, Habraken also introduced together with Van Randen a preliminary form of modular coordination with agreements about the position, connection and measurements of the different construction components (Van Randen 1976). This was also an initiative to a more standardized and industrialized construction industry with the manufacturing of flexible and project independent (infill) construction components.

Duffy (Duffy 1998) and Brand (Brand 1994) defined six functional levels within a building in order to identify functions with different changing life cycles in a building. Each layer and the components within have their own technical, functional and economic lifespan. In order to comprehend to circularity, only construction components that are well suited to be reused using the six loops should be selected: site, structure, skin, services, space plan, and stuff.

1. Site: the urban location; the legally defined lot whose context lives longer than buildings. According to Brand and Duffy, the site is eternal.

2. Structure: the foundation and load-bearing elements, which last between 30-300 years. However, few buildings last longer than 50 years.

3. Skin: the exterior finishing, including roofs and façades. These are upgraded or changed approximately every 20 years.

4. Services: the HVAC (heating, ventilating, and air conditioning), communication, and electrical wiring. They wear out after 7-15 years.

5. Space plan: the interior layout including vertical partitions, doors, ceiling, and floors. According to Brand, commercial space can change every 3 years.

6. Stuff: the furniture that is moved daily, weekly or monthly. Furniture, in Italian is called mobilia, for good reason. 
Within a circular economy it is important to maximize the conservation of the different value resources. Therefore with circular building it is necessary to reflect on which resources and components are most suitable for this objective and for which life cycle. This distinction of a building in different layers with different life cycles will be used for the development of an instrument to assess the circular economy capacity of a building.

\section{Adaptability and flexibility}

Adaptive building or the adaptive capacity of a building is relatively new concept and can hardly be found in a large-scale international literature survey to similar concepts like flexible, extendible, multifunctional, reusable or removable. These concepts often have strongly overlapping meanings (Geraedts 2013). Schuetze defines the concept as easily adaptable to different functions or changing requirements, constructed with components and products, which allow re-use and recycle with a minimum of effort and loss of quality. It mainly concerns function neutral buildings, which have user related transformation potency. Use has been made of reusable construction components, based on the different life cycle of the different components (Schuetze 2009). Richard states the following: nobody can predict the demands, wishes or different tastes of the current and the future users of a building during its lifespan. Adaptable systems are necessary to taking up this challenge, to develop user friendly buildings open to change with freedom of choice for the first generation of users and possibilities to adapt for next generations of users (Richard 2010).

\section{Sustainability depending of the long-term utility value of buildings}

A building that can accommodate different types of users during its whole life cycle has a long-term utility value. The long-term utility value is a crucial precondition for sustainability. The adaptive capacity of a building represents this utility value, the future attractiveness of the building. The adaptive capacity is not the goal itself, but the means to ensure the future use of the building. To consider the adaptive capacity of a building the main focus is its future value. From this perspective not only the present user or owner of the building is important, but also to a large extent the attractive force of the building for next generations of users (Geraedts 2014). In this paper the following definition is used for adaptability or the adaptive capacity of a building: the adaptive capacity of a building includes all characteristics that enable it to keep its functionality during the technical life cycle in a sustainable and economic profitable way withstanding changing requirements and circumstances. The adaptive capacity is considered a crucial component when scrutinizing the circular economy value of the real estate stock (Hermans 2014).

The adaptive capacity can be split into three different appearances (Geraedts 2014):

1. Organizational flexibility. The capacity of an organization or user to respond adequately to changing demands of the built environment; 
2. Process flexibility. The capacity to react to changing circumstances, wishes or demands during the initiative, the design and the construction phase.

3. Product flexibility. The capacity of a building (the product) to respond to changing circumstances, wishes or demands during the use phase of the building.

Adaptability and sustainability (circular economy) are considered to be values. An adaptable building includes all characteristics that enable it to keep its functional value during the technical life cycle in a sustainable and circular economic way withstanding changing requirements and circumstances. Flexibility is considered to be a set of possible measures that could be taken to create these values. Flexibility measures are characteristics of a building that enable the building to be adaptable.

\section{The demand: use dynamics and transformation dynamics}

The focus of this paper to relate adaptability and circular economy is exclusively the product flexibility during the use phase of buildings. Target here is the translation of the demand into so-called transformation dynamics and use dynamics on three different levels: location, building and unit (see figure 1).

Figure 1: Framework to position the demand (for use and transformation dynamics), and the supply (of rearrange, extension and rejection flexibility) on three different levels

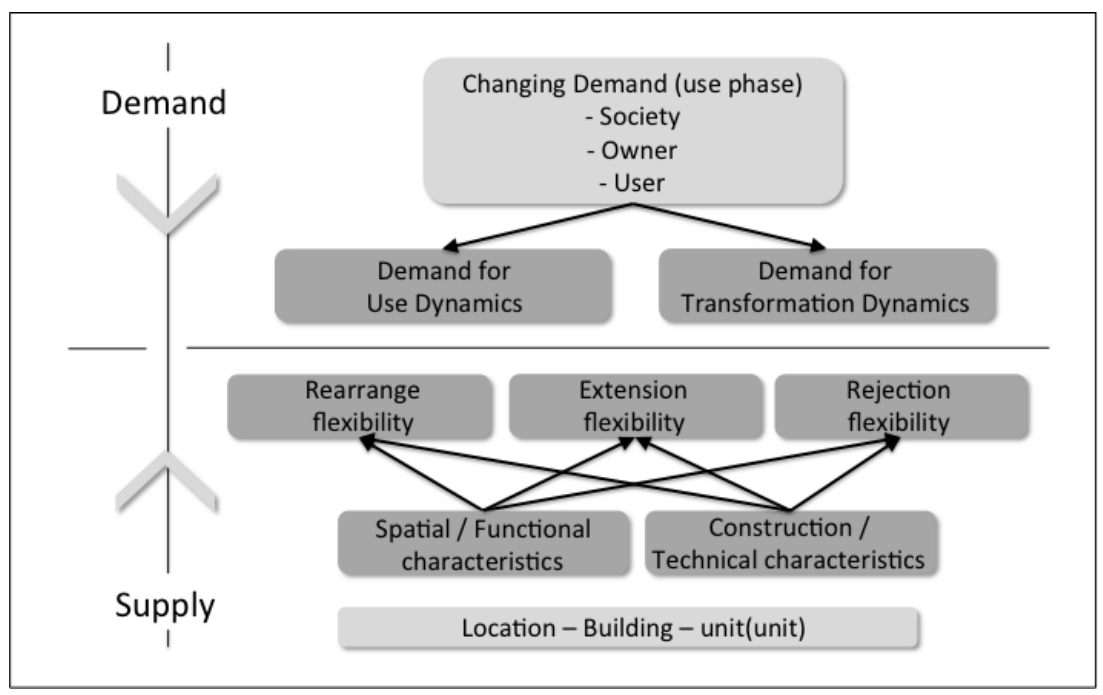

The demands for a building can be formulated by the demands of the users. The building must be able to move along in time with these (changing) demands. This may lead for instance to the demand that the building must be parcelled into smaller or bigger units or that specific facilities can be added to the units or building. This is called use dynamics. This concerns the demands for a building that should be able to accommodate totally different user groups or different functions in the near future. This may lead to specific demands for rearranging the building for different user groups. This is called transformation dynamics. 
The supply: rearrange, extension and rejection flexibility

Within the framework the flexibility of the supply is translated into three spatial/functional and construction/technical characteristics. They determine if a building can meet the requirements: rearrange flexibility, extension flexibility and rejection flexibility.

- Rearrange flexibility: to which degree the location, the building or the unit can be rearranged or redesigned.

- Extension flexibility: to which degree the location, the building or the unit can be extended.

- Rejection flexibility: to which degree (part of) the location, the building or the unit can be rejected.

\section{Supplied by spatial/functional and construction/technical characteristics}

Two types of characteristics influence the three possible flexibilities of a building as described: spatial/functional and construction/technical characteristics. Furthermore three different levels of scale will be taken into account: the whole building as the collection of all user units, the units within the building and the location of the building as far as it influences the use and the adaptability of the building. On top (see figure 1), the demand for change is shown and at the bottom the supply with the characteristics of the building, which determine if the building can meet the flexibility demands.

\section{DEVELOPMENT OF THE CE METER LIGHT}

The lack of a widely accepted method with assessment criteria for measuring the potential for adaptation into other possible functions during the life cycle of a building lead to an extensive international literature survey, resulting in totally many indicators more or less connected to the flexibility of buildings. In 2014 a paper was presented at the International Union of Architects World Congress UIA2014 in Durban SA, titled Adaptive Capacity of Buildings (Geraedts 2014). A report was given of this literature survey and the development of a method to determine the adaptive capacity of Buildings. In total 143 indicators were described with accompanying assessment values. The steering group behind this research project and the two already engaged expert panels one with representatives of the clients (demand side) and one panel with representatives of construction companies and suppliers (supply side) - asked for the further development of this instrument to a more practical usable instrument in construction practice. This resulted in a renewed condensed method called Flex 2.0 that will be briefly described in the next paragraphs.

\section{Layers}

To structure and cluster the large number of possible indicators, use has been made of the distinction in different layers of the building and its environment according to Brand (Brand 1994). 


\section{Structure of FLEX 2.0}

General requirements

To be able to actually use the adaptive capacity of a building to change the use of a building is it necessary to recognize a number of common important preconditions. Especially some legal, organizational and common constructional preconditions have to be mapped before further actions can take place. Is it possible to change the function of the building or to extend the building according to the actual development plan of the local government? What is the general technical condition of the building, what is the age, when was the last renovation of the building, what type of user utilized the building?

\section{Specific requirement, structured in 5 Layers}

By analogy with the model of Brand, five different levels were created in FLEX 2.0 to structure, locate and cluster all possible flexibility indicators that were previously found. The last page shows an overview (figure 4) of the 83 flexibility performance indicators that influence the adaptive capacity of buildings. Next to this a column is shown to give a personal weight to the various indicators (varies from $1=$ not important to $3=$ very important) and a column to mark the score or level of the specific indicator concerned.

\section{Scores or assessment level}

In this method values are given for each assessment aspect of flexibility performance indicators. There are four possible values for the score: $1=\mathrm{Bad}, 2=$ Normal, $3=$ Better, $4=$ Best. Figure 2 shows an example of the four assessment values of indicator nr.11: Surplus of free floor height. The final score is calculated by multiplying the assessment value and the weighting factor for that indicator.

Figure 2: example of the four assessment values of the indicator nr.11: Surplus of free floor height

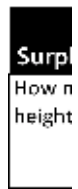

\section{FLEX 2.0 Light: the 17 most important indicators}

After the clustering of 143 indicators to 83 indicators, in the next step a second clustering was carried out to find a limited number of the most crucial indicators. This lead to FLEX 2.0 Light with 17 indicators in total, a very easy and fast to use instrument to assess the adaptive capacity of buildings (see figure 3 ).

Figure 3: FLEX 2.0 Light, a practical and easy to use light version of the assessment method with a limited number (17) of the most important indicators 


\section{CONCLUSIONS AND RECOMMENDATIONS}

As shown in the previous examples, the Flex adaptive capacity method is a first important step in the development of an instrument to formulate adaptive demands and to assess adaptive supplies of buildings, as part of the circular economy assessment of buildings. In the next steps this method has to be evaluated in practice with building owners, users and construction companies.

Further research will be needed to answer questions as: does the assessment method need to be specified for different sectors within construction? Different building types like hospitals, schools, office buildings or residential housing may lead to the use of a selected and specific group of assessment aspects.

Finally it is not unlikely that professional owners and clients in construction feel the urge for a standard describing the adaptive capacity of buildings, very much like the energy labels and sustainability certificates of BREEAM and Greenstar that are currently in use. Can we develop one similar standard on circular economy or circular buildings? 
Figure 4: 83 flexibility performance indicators

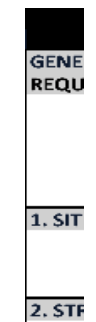

3. SKI

2. STF 


\section{REFERENCES}

- $\quad$ BRAND, S. (1994). How buildings learn; what happens after they're built. New York, Viking.

- BRAUNGART, M., McDONOUGH, W. (2002). Cradle to cradle remaking the way we make things. New York.

- $\quad$ DUFFY, F. (1998). Design for change, The Architecture of DEGW. Basel, Birkhauser

- $\quad$ EICHHOLTZ, P., KOK, N., QUIGLEY, J. M. (2009). "Doing Well by Doing Good?" Green Office Buildings; Berkeley Program on Housing and Urban Policy: W08.

- $\quad$ ELLEN MACARTHUR FOUNDATION (2012). Towards the Circular Economy; Economic and business rationale for an accelerated transition., Ellen MacArthur Foundation.

- ELLEN MACARTHUR FOUNDATION (2013). Towards the circular economy, opportunities for the consumer goods sector.

- ELLEN MACARTHUR FOUNDATION (2014). Accelerating the scale-up across global supply chains.

- GERAEDTS, R. (2013). Adaptief Vermogen; brononderzoek - literatuurinventarisatie. Delft, Centre for Process Innovation in Building \& Construction: 62.

- $\quad$ GERAEDTS, R., REMOY, H., HERMANS, M., Van Rijn, E. (2014). Adaptive Capacity of Buildings; a determination method to promote flexible and sustainable construction. UIA 2014 Architecture Otherwhere. A. Osman, Bruyns, G., Aigbavboa, C. Durban, UIA 2014 Durban: 1054.

- HABRAKEN, N. (1961). De dragers en de mensen, het einde van de massawoningbouw. Eindhoven, Stichting Architecten research.

- $\quad$ HABRAKEN, N. (1998). The Structure of the Ordinary. Boston, First MIT Press.

- $\quad$ HERMANS, M., GERAEDTS, R., VAN RIJN, E., REMOY, H. (2014). Bepalingsmethode Adaptief Vermogen van gebouwen ter bevordering van flexibel bouwen. Leidschendam, Brink Groep.

- MENTINK, B. (2014). Circular business model innovation: a process framework and a tool for business model innovation in a circular economy. Delft, Delft University of Technology.

- RICHARD, R. B. (2010). Four Strategies to Generate Individualised Buildings with Mass Customisation New Perspective in Industrialisation in Construction; A state of the art report. S. F. Girmscheid Gerhard. Zürich, IBB Institut für Bauplanung und Baubetrieb: 10.

- $\quad$ SCHOOLDERMAN, H., VAN DEN DUNGEN, P., VAN DEN BEUKEL, J., VAN RAAK, R., LOORBACH, D., VAN EIJK, F., JOUSTRA, D.J. (2014). Ondernemen in de circulaire economie, nieuwe verdienmodellen voor bedrijven en ondernemers. Amsterdam.

- $\quad$ SCHUETZE, T. (2009). Designing Extended Lifecycles. 3rd CIB International Conference on Smart and Sustainable Built Environment. A. v. d. Dobbelsteen. Delft, The Netherlands, Delft University of Technology.

- $\quad$ VAN DIJK, S., TENPIERIK, M., VAN DEN DOBBELSTEEN, A. (2014). "Continuing the building's cycles: a literature review and analysis of current systems theories in comparison with the theory of cradle to cradle." Resources, conservation, and recycling 82: 21-34.

- VAN RANDEN, A. (1976). Nodes and Noodles. Delft, Delft University of Technology.

- VAN TIMMEREN, A. (2013). Reciprocities, a dynamic equilibrium. Delft, Delft University of Technology (TUD).

- WILKINSON, S. J., REMOY, H. (2011). Sustainability and within use office building adaptations: A comparison of Dutch and Australian practices. Pacific Rim Real Estate Society Conference, Pacific Rim Real Estate Society; Bond University AUS. 


\title{
AN INVESTIGATION OF PSYCHOLOGICAL CONTRACTS IN CONSTRUCTION PROCUREMENT
}

\author{
Jefferies, M.C. ${ }^{1}$; Davis, P.R. ${ }^{2}$ and Ke, Y. ${ }^{3}$
}

\begin{abstract}
:
Purpose: A psychological contract $(P C)$ is an unwritten contract with mutual obligations as the central issue and it fills the gaps in a relationship and shapes employee behaviour. To date, there has been limited research that has examined $P C$ with respect to procurement methods in construction projects. There is a lot written about PCs, as a theoretical framework in areas such as strategic supplier partnering and relationships, but little research has been undertaken within a construction management context. An increased understanding of PC would enable procurement teams to identify the nuances associated with relationships in procurement and stakeholder selection.
\end{abstract}

Aim/Objectives: This research aims to examine social exchanges in construction contracts so that partners can better manager their relationships in projects. Specific objectives of the broader research are to: identify the presence of psychological contracts in construction projects; identify and catalogue the affect that the PC's has on the teams in various procurement models currently utilised within construction management and deliver a conceptual model of the PC in traditional and relationships style procurement scenarios.

Method: This paper reports on the first stage of a broader research project. To check and maintain currency of the topic, focus groups are held with key industry players and this is followed by the development of a survey instrument administered to a large sample of construction professionals involved with project delivery $(n=100)$.

Results: PCs are clearly present in the construction delivery team and they have considerable effect on the interaction between the project stakeholders. It appears that the PC variables underpin behaviours to a considerable extent. The next stage of the research is to use the output from the triangulated survey to develop a conceptual model of the PC in traditional and relationships style procurement scenarios.

KEYWORDS: PSYCHOLOGICAL CONTRACTS; TRADITIONAL PROCUREMENT; ALLIANCE CONTRACTING; FOCUS GROUPS.

\section{INTRODUCTION}

The Australian construction industry was the third largest contributor to the nations GDP and the third largest employer in the year 2010-11, with the value of construction completed work valued at A $\$ 167$ billion (Australian Bureau of Statistics 2012). The quality of the product is closely linked to the performance of building and property in the wider socio-economic community it serves and yet the Australian construction industry appears inefficient when compared to countries such as the US and UK. A major contributing factor to this inefficiency is due to relationships that exist within the industry

\footnotetext{
1 School of Architecture \& Built Environment, University of Newcastle, Australia. Email: marcus.jefferies@newcastle.edu.au

2 School of Architecture \& Built Environment, University of Newcastle, Australia. Email: peter.davis@newcastle.edu.au

3 School of Architecture \& Built Environment, University of Newcastle, Australia. Email: yongjianke@newcastle.edu.au
} 
(Davis and Love 2011, Davis and Walker 2009). Effective participation in relationship development and the avoidance of traditional 'business as usual' thinking has the potential to significantly enhance project outcomes (Davis 2010). Despite relationship and integrated procurement opportunities being available for some time, it is clear that Australian firms have been slow to adopt them and those that have participated have problems in articulating significant benefits. To examine how relationships are being nurtured in Australian construction projects we investigate psychological contracts, or the personal deal, analysing the impact of trust and commitment associated with a psychological contract in a strong procurement relationship. Outcomes reported could be used as a management tool to guide and support the adoption of relationship style contractual arrangements that reduce the likelihood of firms together with their clients experiencing losses in relationships that affect productivity and project success.

A psychological contract (PC) is an unwritten contract with mutual obligations as the central issue. It fills the gaps in a relationship and shapes employee behaviour (Anderson and Narus 1998), it highlights unwritten expectations as opposed to conscious expectations. An example is 'long term... prospects' which are articulated outside a contract or written agreement. PC's are analogous to an internal motivator and they drive individuals to determine a perceived or institutional contract that is often a departure from a written or more formal document of governance or contract. The characteristics of a PC can be either transactional or relational over a number of dimensions: their focus, a time frame, inherent stability, overall scope, and tangibility (Anderson and Narus 1998).

To date, there has been limited research that has examined PCs with respect to procurement structures in construction projects. There is a lot written about PCs, as a theoretical framework in areas such as strategic supplier partnering (Blancero and Ellram 1997), buyer- supply relationships (Hill, Eckerd et al. 2009), supplier distribution relationships (Kingshott and Pecotich 2007), customer service relations strategy (Cutcher 2008), performance management (Stiles, Gratton et al. 1997) and workplace safety (Walker and Hutton 2006), but little research has been undertaken within a construction management context. Dainty (2004) in research limited to construction organisations identified a PC of a reciprocal nature containing variables that underpinned relationshipbuilding. We suggest that increased understanding of PC would enable procurement/ delivery teams to identify more successfully the nuances associated with relationship development in construction procurement and stakeholder interaction. This research aims to examine social exchanges in project procurement so that partners can better manager their relationships.

\section{Psychological contracts (PC)}

The term 'psychological contract' (PC) first gained popularity in human resource studies during the 1990s (Guest and Conway 1997, Rousseau 1990, 1995, Sparrow 1998). In 2004 Dainty first wrote about psychological contracts displayed by construction project managers (Dainty, et al. 2004), investigating the dynamics that govern the PC between construction project managers and employees in order to understand its influence on 
employee turnover. They identified that the understanding based on trust in the traditional PC was being undermined at the time by "widespread organizational expansion and flattening organizational structures" (Raiden et al 2009 p.78). Crucially, the aforementioned 2009 UK study relating to strategic human resource management in the construction industry found that "employee resourcing practices often rely on the personal assessments of line management, which have the potential for inconsistencies, poor allocation decision and hence, disillusion employees through a violation of the psychological contract" (Raiden 2009 et al p.84). As a result, the authors recommended that a more flexible approach to the employee resourcing function in construction organizations be adopted where "the individuals" preferences and expectations are taken into account throughout the resourcing process" (Raiden 2009 et al p.83).

Subsequently, Dainty reiterates that because individualization of the employment relationship is vital to ensure maximum productivity, that the $\mathrm{PC}$ is more relevant than ever (Dainty 2012 p.24). They note that intrinsic rewards are becoming more important in the job market and cite an example from their case study where individuals involved on a construction project suggested that the PC "at its best it may offer scope for creativity, innovation and a feeling of long-term impact on the environment 'the desire to make something that will last' (Project Director)" (Dainty 2012 p.258).

Beyond this limited body of scholarly writing, studies centered on the application of the $\mathrm{PC}$ in the construction industry have been largely unexplored, with the exception of recent interest specifically in PC and workplace safety in the construction industry (Walker 2010, 2013, Walker and Hutton 2006).

\section{The intra-organisational PC}

The basis of the PC relationship within a firm is reciprocity between the organization and employees on the perceived obligations and expectations from one another (Guest 2002). The main theoretical underpinnings of the concept are generally attributed to Rousseau (Rousseau 1990, 1995) who distinguishes between two types of PC:

1. Transactional contracts: involve specific, monetizable exchanges between parties over a finite and often brief period of time. For example, competitive wage rates and the absence of long-term commitments. (Robinson et al. 1994)

2. Relational contracts: which in contrast, involve open-ended, less specific agreements that establishes and maintains a relationship. These contracts involve both monetizable and non-monetizable exchanges. For example inducements in relational contracts characteristically include training and development opportunities and a long-term career path within a firm. (Robinson et al. 1994)

Relational contracts provides a well-matched perspective for the organisation focus that forms the focus of this research. What is clear is that as the PC evolves around individual beliefs and perceptions, it is highly subjective and can be particular to each employee (Rousseau 1995). In essence, the PC constitutes an unwritten agreement between the organization and employees based on mutually accepted promises and obligations among the organization and the employees (Sparrow 1998). 


\section{The PC as a Personal Deal}

The view of the PC as an analytical HR tool to examine complex changes that occur throughout an organization when new employment practices are adopted and Sparrow (1998), Rousseau (1998) together with Guest and Conway (1998) suggest the PC is a means to understanding the overall state of the employment relationship within an organization. They argue that the PC should be regarded as a tool through which management can establish and maintain a 'healthy' $\mathrm{PC}$, and that change could subsequently be instituted more easily, with increased levels of commitment and satisfaction (Guest and Conway 1998). They used employee perceptions of trust in management and whether employees felt they were fairly treated to measure the extent to which employees believed that promises by the organization had been fulfilled.

In the context of the study, they concentrated not on pinpointing the "who, what and when' of original promises made but on confirming that the important outcome was that employees believed promises had been made. Guest and Conway (2005) offered a model built on the existing literature and the relationship between the type of contract and other background factors, for example, the state of the PC and a range of relevant outcomes including motivation, innovative behaviour and commitment. This model was from an employee's perspective and showed the outcome of an individual's evaluation to an exchange between and organisation and an employee. The key being that it assessed the extent to which employees believed that the organisation had met his promise and obligations and had treated them fairly. Background variables include a range of individual biographical and occupational factors, including possible variations in orientations to work and levels of job involvement. The other key background variable is the type of employment contract, while a simple distinction between permanent and fixed term/temporary can be made, in practice this distinction may need to be refined from study to study.

\section{RESEARCH METHOD}

A preliminary review of literature identified a gap in PC knowledge, being the affect the PC has on the implementation of construction project delivery (Gundlach et al. 1995, Leuthesser and Kohli 1995, Morgan and Hunt 1994a, Rousseau 1996). To check and maintain currency of the topic a focus group with key industry stakeholders from 2 major contracting organisations was facilitated and a pilot survey instrument was delivered to a purposive sample of stakeholders for verification and final amendment. The final survey was electronically administered to a large sample of construction professionals involved with project delivery $(\mathrm{n}=100)$ (Krueger and Casey 2000).

The research instrument contained four sections: issues specifically examined were relational orientation, trust, commitment and the $P C$ itself. Relational orientation was measured using a scale adapted from Leuthesser and Kohli (1995) to determine the extent of initiating, signaling and disclosing behaviours within a relationship. The items in the scale reflect perceptions about the partner across these aspects. An additional section determined satisfaction with the partners. Trust items were measured using the Morgan 
and Hunt (1994a) scales specifically developed to understand perceptions of suppliers in a procurement relationship. The measure of trust captures the level of reliability, integrity and confidence within the relationship. Commitment represents the importance of and belief about, maintaining the relationship and this measure reflects the attitudinal element of commitment proposed by Gundlach et al. (1995). Psychological contracts were measured with four factor scales adapted from Rousseau's extensive work to examine the extent that employees believed certain intrinsic/extrinsic promises are made in dealing with their major partners. The four factors were: good faith and fair dealing, relational benefits, relational conditions and intrinsic relational characteristics. All items in these measures use a 5-point Likert scale with strongly disagree and strongly agree as anchors (Bryman 2004).

The analysed results of the survey used a mixed method of both quantitative and qualitative techniques that were triangulated with a further industry focus group (Creswell 1994). Analysis of the results using SPSS supports its reliability and consistency. The main statistical methods used were descriptive statistics and one-sample $t$ test. The one-sample $t$ test procedure was performed on the items to determine if they were embraced to a significant extent.

\section{RESULTS}

Survey questionnaires were sent to a broad sample of industry practitioners. A total of 53 valid responses were returned. With regard to the sample validity, it is observed that 53 sets of valid responses were received. The general convention is that when the sample size is over 30, it is considered to be large by the Central Limit Theorem (Nunnally 1978). Moreover, Cronbach's alpha value of research instrument is 0.961, suggesting that the responses have a high internal consistency (Nunnally 1978). It is concluded that this data is reliable and further statistical analyses may be conducted.

The following identifies the characteristics of the sample and their project environment. It was observed that a large majority of respondents were male, with less than $10 \%$ of the respondents being female $(9.4 \%)$. Most of the respondents were between 40 and 59 years of age $(54.7 \%)$, next were 21 to 39 years old respondents $(35.8 \%)$, followed by respondents 60 year old and over representing 9.4\% of the sample. The majority of respondents had in excess of 30 years experience in project delivery $(22.6 \%), 15.1 \%$ of the respondents had over 26 years experience and a further $11.3 \%$ had over 21 years experience. So it can be seen that the respondents were experienced in their roles. The majority (42\%) were described as Project Managers with a further $17 \%$ identifying themselves as general managers the balance were contracts administrators, engineers, site managers or buyers, a large proportion (58\%) worked from their headquarters with $26 \%$ working from a regional office and 14\% working on site. A large proportion of the respondents were from the private sector $(62 \%)$ with the balance from the public sector. When asked about their organisations turnover nearly $60 \%$ indicated that their organisation turned over more that $\$ 200$ million per annum operated in organisations that employed over 100 but not exceeding 500 staff. 


\section{Satisfaction}

The focus of the questions revolved around the respondent's perception of their procurement partner's satisfaction whilst working with them on a recent project. All subsets of the primary question were identified as significant in the context of the survey. The subset questions may be synthesized as a commitment to an overall relationship that would continue in the forthcoming years, identified as a pleasurable experience with few problems. The questions followed Leuthesser and Kohli (1995) and were adapted with reference to Morgan and Hunt's (1994b) earlier survey instrument that was originally utilised in a study of the nature of relationship marketing. The link between relational behaviours and satisfaction are likely to be stronger when the output is important and there is a notably dynamic environment. $39 \%$ of the projects that the sample identified ranged between the value of more than $\$ 1$ million and less than $\$ 25$ million. Assuming that project cost has a relationship to importance to the client and overall dynamics of the project environment it is of little surprise that the sample in this survey identified these factors as significant. Leuthesser and Kohli (1995) suggest that relational behaviours that include initiating, signalling and disclosing behaviours improve buyer satisfaction.

\section{Trust}

The series of questions under the construct of trust were derived from Morgan and Hunt's (1994) scales specifically developed to tap perceptions of procurement partner's trust whilst working on a recent project. The measures of trust captured the level of reliability (they do what they say) and integrity. Trusting behavior may manifest in psychological contracts or the 'personal deal' that has been extensively researched by the likes of (Dabos and Rousseau 2013) and others who suggest that PCs may exist between an individual and groups or interdependent organisations, however, despite extensive research the relationship between an individual and an organisation is somewhat uncertain (Conway \& Briner 2005). In a trusting relationship such as a PPP or an alliance, which represent the most integrated of delivery systems in a procurement continuum (Davis and Love 2011), stakeholders are able to focus on essential long-term benefits. These long-term benefits are suggested to provide amongst other things, enhanced competitiveness/ innovation and lift productivity.

Interestingly, trust is aligned very closely with commitment and scales in the survey were designed to measure commitment and the parties belief about maintaining the relationship. Morgan and Hunt (1994b) suggest that in alignment commitment and trust maintain relationship investments that in this study are crucial to complex integrated project environments, engendering cooperation within the team. Commitment and trust supports long-term engagement typically required in more advanced/ mature project delivery methodologies similar to Alliance or PPP delivery systems which are inherently long-term in their nature. Essentially the combination of commitment and trust promotes efficiency, productivity and effectiveness that lead directly to behaviours that are conducive of long-term relationships and process success.

\section{Commitment}

Commitment scales were adapted from Gundlach, Achrol et al. (1995) and designed to measure perceptions of partnership commitment, as it is suggested that opportunism 
moderates the process of commitment. It would be clear to a reader of construction research that much is written that catalogues the adversarial nature of the construction industry. A review of several sources of academic work identifies many papers that highlight problems derived from the adversarial nature of construction - for example see (Boukendour and Hughes 2014, Eriksson 2010, Rose and Manley 2014, Smiley, Fernie et al. 2014)

As discussed earlier commitment is closely aligned to trust, it is essential to long-term relationships and follows the desire of contracting parties that remaining in the relationship would provide better outcomes than not. It is said to be close to mutuality, loyalty and the forsaking of others and is clearly distinguishable in long-term relationships (Gundlach, Achrol et al. 1995). In focus group meetings, where the findings of the quantitative survey were explain, participants indicated that to them commitment was linked closely to future work. Upon reflection with regard to the likes of opportunism they referred to a three tender rule. This was described as a rational check, for example; after a period of time by those within the team, most particularly the lead client may require a more stringent tender process after a period of relationship to check on aspects of value for money. In his research into Alliance relationship building Davis (2005) establish similar traits in catalogued relationship building models.

\section{Relational Benefits}

A series of questions considered relational benefits, the questions were adapted from Rousseau's (1996) measures to determine the extent that perceived future tangible relational outcomes, for example future projects, were promised by a major partner. In particular the sample were asked to reflect on incentives linked to their organisations performance. Determined as significant by the respondents and subsequently referred to in the focus group it was suggested that the term "promise" was too strong a word used in a construction industry context; it was suggested by one of the focus group participants that a promise "is more implied rather than stated - an 'implied undertaking' if you like". He used the example that "Giving a good price is still a long way from any guarantees to win future work". The implication being that future work is still going to be measured against performance and competition - and this relates back to the point made above on commitment.

\section{Intrinsic relationship characteristics}

This final set of questions that were deemed to be of significance by the sample considered autonomy and overall responsibility in the value chain. Using an adaptation of a survey instrument from Rousseau's previous work (1996) the sample were directed to reflect on constructs including: interesting (...a relationship role that is interesting to our organisation...), meaningful (...major partner promised a meaningful role for our firm within the overall relationship.), challenging (...promised a role that is challenging to our organisation) and responsible (...major partner promised a role that has high levels of responsibility).

At its core a personal deal is essentially an individual's motivation, providing a meaningful, challenging and responsible role drives the motivation to a stimulating 
outcome, as indicated in Dainty's research a positive PC will offer scope to an individual to be creative, innovate and be part of something that is of long term impact and will last (Dainty 2012 p.258). Take for example the oft-used expression 'yes, that's one of my buildings' an expression that whilst used widely, given consideration, serves to support this argument. In addition Guest and Conway have shown growing evidence that the use of a set of "high commitment" practices is likely to be associated with a range of positive outcomes (Guest and Conway 1998) that lead to better than business as usual outcomes, overall process and relational success that often would be seen to manifest in higher levels of productivity and reduced cost in the process consequent of good levels of quality and accountability.

\section{CONCLUSIONS}

It is noteworthy that the differences among the two schools of thought caused arguments between two of the most important representatives: Rousseau and Guest, whose publications contrast each other's views on a personal level, with particular emphasis in the terminology of using implied 'obligations' (Rousseau 1998) or 'expectations' (Guest and Conway 1998) in the definition of the PC. Eventually, there was a definition adopted that comprised both aspects (Guest 2002). There is no clear consensus on the definition of the psychological contract, however, most researchers accept that it should be viewed as a two-way exchange of perceived promises and obligations. Slightly adapting the definition provided by Herriot \& Pemberton (1997), we define the psychological contract as:

\section{"the perceptions of both parties to the employment relationship - organisation and individual - of the reciprocal promises and obligations implied in that relationship".}

As Schalk and Raeder (2011) and Rousseau (2001) suggest, there are interesting issues about who speaks for the organisation. There are also questions about how feasible it is to draw a clear line between expectations, promises and obligations. Although literature makes important conceptual observations about the PC and its place within organizations, there is little knowledge of whether organizations take the concept into account and if any apply it in practice (Conway \& Briner 2005). Due to its subjective nature and the numerous factors influencing its course, the PC is highly fluid and frequently merits redefinition and renegotiation (Guest 2002, Rousseau 1995).

At the outset of this research we aimed to identify the presence of psychological contracts in construction projects and identify and catalogue the affect that the PC has on the teams in various procurement models currently utilised within construction management. It is apparent that through the lens of PC constructs that include disclosing behaviours, satisfaction, trust, commitment, professionalism, relational benefits, resources and support and intrinsic relational characteristics, important aspects of the PC or personal deal manifest in project delivery. Future research is proposed that will compare traditional procurement models with relationships style procurement models and develop a PC model of construction project delivery. Ongoing research into this area is vital to 
ensure the development of sustainable procurements methods and that greater rewards are provided for all project stakeholders, no matter the procurement model used.

\section{REFERENCES}

- ANDERSON, J. C. and NARUS, J. A. (1998). "Ideas at Work: Business Marketing: Understand What Customers Value." Harvard business review 76(6): 53.

- $\quad$ BLANCERO, D. and ELLRAM, L. (1997). "Strategic Supplier Partnering: A Psychological Contract Perspective." International Journal of Physical Distribution \& Logistics Management 27(9/10): 616.

- BOUKENDOUR, S. and HUGHES, W. (2014). "Collaborative Incentive Contracts: Stimulating Competitive Behaviour without Competition." Construction Management and Economics 32(3): 279-289.

- $\quad$ BRYMAN, A. (2004). Social Research Methods. Oxford;, Oxford University Press.

- CONWAY, N. \&. BRINER., R. (2005). Understanding Psychological Contracts at Work: A Critical Evaluation of Theory and Research. Oxford, Oxford University Press.

- CRESWELL, J. (1994). Research Design - Qualitative and Quantitative Approaches. Thousand Oaks, California, Sage Publications, Inc.

- CUTCHER, L. (2008). "Service Sells: Exploring Connections between Customer Service Strategy and the Psychological Contract." Journal of Management and Organization 14(2): 116-126.

- DABOS, G. E. and ROUSSEAU, D. M. (2013). "Psychological Contracts and Informal Networks in Organizations: The Effects of Social Status and Local Ties." Human Resource Management 52(4): 485-510.

- DAINTY, A. R. J., RAIDEN, A. B. and NEALE, R. H. (2004). "Psychological Contract Expectations of Construction Project Managers." Engineering, Construction and Architectural Management 11(1): 33 .

- DAINTY, A. R. J. and LOOSEMORE., M. (2012). Human Resource Management in Construction: Critical Perspectives, Routledge.

- $\quad$ DAVIS, P. and LOVE, P. (2011). "Alliance Contracting: Adding Value through Relationship Development." Engineering, construction and architectural management 18(5): $444-461$.

- $\quad$ DAVIS, P. R. (2005). The Application of Relationship Marketing to Construction. Doctor of Philosophy PhD, Royal Melbourne Institute of Technology.

- DAVIS, P. R. (2010). Competitive Verses Traditional Alliance Procurement. Construction, building and real estate research conference of the Royal institution of chartered surveyors, COBRA 2010, Paris France, RICS.

- DAVIS, P. R. and WALKER, D. H. T. (2009). "Building Capability in Construction Projects: A Relationship-Based Approach." Engineering, Construction and Architectural Management 16(5): 475.

- $\quad$ ERIKSSON, P. E. (2010). "Partnering: What Is It, When Should It Be Used, and How Should It Be Implemented?" Construction Management and Economics 28(9): 905-917.

- GUEST, D. E. and CONWAY, N. (1997). Employee Motivation and the Psychological Contract. London, Institute of Personnel and Development (IPD).

- GUEST, D. E. and CONWAY, N. (1998). Fairness at Work and the Psychological Contract. London, Institute of Personnel and Development (IPD).

- $\quad$ GUEST, D. E. and. CONWAY., N. (2002). "'Communicating the Psychological Contract: An Employer Perspective'." Human Resource Management Journal 12(2): 22-38.

- GUEST, D. E. and CONWAY, N. (2005). The Impact of New Forms of Employment Contract on Motivation and Innovation. Swindon UK, Economic and Social Research Council. 
- GUNDlaCH, G. T., ACHROL, R. S. and MENTZER, J. T. (1995). "The Structure of Commitment in Exchange." Journal of Marketing 59(1): 78.

- HERRIOT, P. \&. PEMBERTON., C. (1997). "Facilitating New Deals." Human Resource Management Journal 7(1): 45-56.

- HILL, J. A., ECKERD, S., WILSON, D. and GREER, B. (2009). "The Effect of Unethical Behavior on Trust in a Buyer-Supplier Relationship: The Mediating Role of Psychological Contract Violation." Journal of Operations Management 27(4): 281-293.

- KINGShOTT, R. P. J. and PECOTICH, A. (2007). "The Impact of Psychological Contracts on Trust and Commitment in Supplier Distributor Relationships." European Journal of marketing 41(9/10): $1053-1072$.

- KRUEGER, R. A. and CASEY, M. A. (2000). Focus Groups : A Practical Guide for Applied Research. Thousand Oaks, Calif., Sage Publications.

- LEUTHESSER, L. and KOHLI, A. K. (1995). "Rational Behavior in Business Markets: Implications for Relationship Management." Journal of Business Research 34(3): 221.

- MORGAN, R. and HUNT, S. (1994a). "The Commitment-Trust Theory of Relationship Marketing." Journal of Marketing 58(July): 20-38.

- MORGAN, R. M. and HUNT, S. D. (1994b). "The Commitment-Trust Theory of Relationship Marketing." Journal of Marketing 58(3): 20.

- NUNNALLY, J. C. (1978). Psychometric Theory. New York.

- RAIDEN, A., DAINTY., ARJ.; NEALE, RH. (2009). Employee Resourcing in the Construction Industry: Strategic Considerations \& Operational Practice, Routledge.

- $\quad$ ROBINSON, S. L., KRAATZ, M. S. and ROUSSEAU, D. M. (1994). "Changing Obligations and the Psychological Contract - a Longitudinal-Study." Academy of Management Journal 37(1): 137-152.

- ROSE, T. M. and MANLEY, K. (2014). "Revisiting the Adoption of Innovative Products on Australian Road Infrastructure Projects." Construction Management and Economics 32(9): 904-917.

- ROUSSEAU, D. M. (1990). "New Hire Perceptions of Their Own and Their Employers Obligations - a Study of Psychological Contracts." Journal of Organizational Behavior 11(5): 389-400.

- ROUSSEAU, D. M. (1995). Psychological Contracts in Organisations. Thousand Oaks, California, Sage Publications Inc.

- ROUSSEAU, D. M. (1996). Psychological Contract Measures. Pittsburgh PA, Carnegie Mellon University.

- ROUSSEAU, D. M. (1998). "The Problem of the Psychological Contract Considered." Journal of Organizational Behavior 19(S1): 665-671.

- ROUSSEAU, D. M. (2001). "Schema, Promise and Mutuality: The Building Blocks of the Psychological Contract." Journal of Occupational and Organizational Psychology 74: 511541.

- SCHALK, R. and RAEDER, S. (2011). "Flexicurity Assessed. A Questionnaire for Organizational and Employee Flexibility and Security." Gedrag \& Organisatie 24(3): 286303.

- $\quad$ SMILEY, J.-P., FERNIE, S. and DAINTY, A. (2014). "Understanding Construction Reform Discourses." Construction Management and Economics 32(7-8): 804-815.

- SPARROW, P. R. a. M., M. (Eds.) (1998). Human Resource Management: The New Agenda. London, Financial Times Pitman Publications

- $\quad$ STILES, P., GRATTON, L., TRUSS, C., HOPE-HAILEY, V. and MCGOVERN, P. (1997). "Performance Management and the Psychological Contract." Human Resource Management Journal 7(1): 57-66.

- WALKER, A. (2010). "The Development and Validation of a Psychological Contract of Safety Scale." Journal of Safety Research 41(4): 315-321.

- WALKER, A. (2013). "Outcomes Associated with Breach and Fulfillment of the Psychological Contract of Safety." Journal of Safety Research 47: 31-37. 
- WAlKer, A. and HUTTON, D. M. (2006). "The Application of the Psychological Contract to Workplace Safety." Journal of Safety Research 37(5): 433-441. 


\title{
SUPPLY CHAIN PARTNERSHIP IN CONSTRUCTION A FIELD STUDY ON PROJECT TEAM LEVEL FACTORS
}

\author{
Koolwijk, J.S.J. ${ }^{1}$, Oel, van, C.J. ${ }^{2}$, and Wamelink, J.W.F. ${ }^{3}$
}

\begin{abstract}
:
People and their relationship are at the heart of supply chain partnerships, however there is a lack of qualitative studies focusing on how integrated relationships may be developed. Therefore, the purpose of this study was to conduct field research to deepen our understanding of team level variables that might help or inhibit a project team to perform in a SCP setting. To guide us in our study, we used a team effectiveness framework. Taking the role as a team coach, the first author conducted field research in four different project teams that were working in a SCP setting for the first time. These teams worked on housing refurbishment projects (2-12M construction costs) initiated by housing associations. All four were delivered through a strategic partnership. We found that SCP project teams are structured differently than conventional project teams. When we look at team level factors, we see that team members need time to understand their role and responsibilities within the project team and to build a shared mental model. The smallest problems in regard of team inputs (i.e. resources) can harm the team's performance. Trust and psychological safety are important mediators between the input-output relation. Our main conclusion is, if we want supply chain partnerships to work, much more attention should be given to team level variables instead of merely relying on tools and techniques.
\end{abstract}

KEYWORDS: SUPPLY CHAIN PARTNERSHIP, PROJECT TEAM LEVEL, PARTICIPATIVE OBSERVATION, CONSTRUCTION INDUSTRY

\section{INTRODUCTION}

The construction industry $(\mathrm{CI})$ is often blamed for its poor learning environment which in turn leads to its poor performance. To overcome these problems, supply chain partnership (SCP) is often promoted as means of improving performance by establishing close relationships and integrating activities between supply chain actors (O'Brien et al., 2008). While the application of supply chain partnerships (SCP) seems like a logical step forward for the construction industry $(\mathrm{CI})$, this industry is having problems in managing these partnerships and obtaining the intended improvements (Briscoe \& Dainty, 2005). A reason for this could be hidden in the top down approach on how to build a successful partnership in CI. Many different studies approach SCP as a technical-managerial problem, mainly involving the application of appropriate tools and techniques (Venselaar et al., 2015). By implementing these tools, it is thought that professionals will start to perform in line with the intended strategies. However, various studies have shown how

\footnotetext{
${ }^{1}$ Department of Management in the Built Environment, Faculty Architecture and The Built Environment, Delft University of Technology, The Netherlands. Email: j.s.j.koolwijk@tudelft.nl

${ }^{2}$ Department of Management in the Built Environment, Faculty Architecture and The Built Environment, Delft University of Technology, The Netherlands. Email: c.j.vanoel@tudelft nl

${ }^{3}$ Department of Management in the Built Environment, Faculty Architecture and The Built Environment, Delft University of Technology, The Netherlands. Email: j.w.f.wamelink@tudelft.nl
} 
strategies may be translated and transformed by people, artefacts and events when they are implemented in the various levels of an organisation (i.e. Sage, 2012). In addition, we know that if the human factor is ignored the impact of tools that are intended to motivate people to work together might be compromised (Rose \& Manley, 2010). Some researchers have taken a more bottom up approach and looked at team level phenomena that influence the performance of a construction project team. However, almost none of these studies really took a look at the actual workfloor were SCP principles are applied (Venselaar et al., 2015). Hence, this study aims in getting a better understanding of team level factors that help or inhibit a construction project team to perform in a SCP setting.

To capture this dynamic, time sensitive and complex nature of a construction project team that works in a supply chain partnership, we conducted participative observation research. The first author of this paper participated in four different project teams as an independent team coach. This role gave the researcher the opportunity to get real close to the project teams and individual team members. As a result, not only their behaviour in the team could be observed, but also their thoughts, feelings and problems could discussed in telephone conversations, e-mails and informal talks outside the team meetings.

Four Dutch housing associations that are implementing SCP as a key strategy in their asset management served as the cases in our study. This paper is structured as follows. In the next section, a theoretical framework is developed, based on general team-effectiveness and SCP literature. Then the observation research approach, including four case studies, is described. After that, empirical findings from the case study projects are presented. At the end, conclusions are drawn.

\section{THEORETICAL FRAMEWORK}

Construction involves cross-functional project teams. They comprise different specialists from different divisions or organizations, who have been brought together to form a temporary organization aimed at delivering a project. Because team members come from different organisations, this team has an inter-organisational context. This poses relational and performance risks (Das and Teng, 2001). Relational risk encompasses problems that occur when a partner firm does not commit itself to the partnership in the desired manner. Performance risks encompass factors such as a lack of competence on the partner's part. When we take a look at the team level, we see that a team needs a specification of its overall purpose (Hackman et al., 2000). Without clear goals the team won't be able to see were to aim for. Clear, measurable, challenging, but reachable goals are critical to energize the team (Hackman et al., 2000; Robbins and Coulter, 2012, P.359). It has been found that when the client's goals shift regularly this has a detrimental impact on the team spirit and has a positive impact on interpersonal conflicts (Liu et al., 2011). Several studies have shown that project team's success depends on the acquisition of sufficient and relevant resources (Carbonell and Rodriguez-Escudero, 2009). These resources need to be retained while other projects compete for these same scarce resources at the same time (Ancona and Caldwell, 1992). Team stability is an important factor that is related 
positively to team learning (Sivassubramaniam et al., 2012); team's innovativeness (Gibson and Gibbs, 2006) and, interpersonal trust (Zheng et al., 2008). Additionally, teams characterized by a lack of group longevity experience greater difficulty recognizing and integrating their knowledge for efficient task completion (Liang, Moreland, \& Argote, 1995). High level of functional diversity within a team should lead to beneficial effects on team performance, because team members with differences in the functional backgrounds should spur more creative outputs (Van Knippenberg \& Schippers, 2007); search for new information more broadly (Jackson \& Joshi, 2011); are more effective in handling non-routine problems (Van Knippenberg \& Schippers, 2007). However, team members that have diverse knowledge, abilities and experiences can have a different view on how specific tasks should be handled. As a result, diversity appears to increase group conflict in cross functional teams (Pelled et al., 1999). Mental models are perceived as internal representations of (aspects of) the environment that provide a conceptual framework for describing, explaining and predicting future system states (Rouse and Morris, 1986). In other words, a mental model is a person's understanding of 'how something works'. A team communicating about its goals, tasks, artefacts, (distributed) cognitions, working relationships and situations, on how the different team members understand them, will built a shared mental model (Mathieu et al., 2000). Shared team mental models help team members to predict what their teammates are going to do and are going to need, and facilitate coordinating actions between team mates (Harbers et al., 2012). Probably all types of knowledge about tasks, working relations and so on need to be shared and understood adequately in order for teams to become effective (Mohammed and Dumville, 2001). What helps a team to develop its collective knowledge and understanding of 'how something works' is team learning behaviour. Examples of such behaviour have to do with speaking up, communicating openly about concerns and errors, evaluating different opinions and views, openly discussing opinions, adjusting processes in on team members behaviours (Edmondson, 2004). Before people are willing to perform such learning behaviours, requires an environment in which this behaviour is accepted by the team and where people feel psychologically safe to really speak up (Edmondson, 2004). Psychological safety is defined as a shared belief that the team is safe for interpersonal risk taking (Edmondson and Lei, 2014). Chandrasekaran and Mishra (2012) found that an increase in psychological safety lowered team turnover and improved performance. Furthermore, psychological safety has been found to moderate between team diversity and team innovation and performance (Bradley et al., 2012). A closely related construct to psychological safety is interpersonal trust. Inter personal trust is "the willingness to take risk in a relationship" (Schoorman et al., 2007) or put in other words "the willingness of a party to be vulnerable" to another party (Mayer et al., 1995). Inter personal trust is a multidimensional construct with both cognitive and affective foundations. Cognition based trust is based on an individual thinking about and having confidence in the other based on good reasons as evidence of trustworthiness (Renzi, 2006). Higher levels of trust increases an individuals' willingness to share knowledge or to take risks in a relationship (Mayer et al., 1995; Schoorman et al., 2007). Interpersonal trust also reduces the need to monitor each other's' behaviour (Robbins and Judge, 2013). Luhmann (1979) argues that trust involves learning and that such learning processes are only complete when the person to be trusted has had the 
opportunity to betray trust, but not taken it. In a project team, trust or distrust between the different team members can exist from the beginning of a project when the team members already know each other and had a prior collaboration experience on which they could ground their expectations and predictions (Gulati, 1995). However, in a construction project setting, partners often lack this collaboration experience with each other. Therefore, the confidence in each other needs to grow with experience. Leadership has been identified as one of the most important ways of directing and steering a team successfully and efficiently through the process. The behaviour of a leader can have a large effect on the team members, on how they relate both to the leader as well as to each other (Bass, 1990). At the moment, there is a debate going on in the academic leadership community about the conceptual definitions of different leadership styles and how dimensions are selected for inclusion or exclusion (Van Knippenberg and Sitkin, 2013).

\section{METHOD}

The purpose of this study is to analyse processes within a construction project team that is working in a SCP setting. We want to study these processes while they are actually occurring in their natural context. Therefore, we've taken an participative observation approach in which the researcher (1st author) became part of the project team. As a participative observer you collect data by participating in the daily life of those he or she is studying for a considerable period of time (Bryman, 2008). Because the observer is so closely involved, it 'permits the investigator to experience and observe the group's norms, values, conflicts and pressures, which (over a long period) cannot be hidden from someone playing an in-group role.' (Hargreaves and Hargreaves, 2006, p. 139). There are various ways of characterising participant observation (Kawulich, 2005). In our cases the researcher took the role of team coach who works for a consultancy firm. Together with one of the directors of this firm, he coached the strategic partnership. The director coached the management team and the researcher coached the project and construction team. Through his role the researcher became a full and active member of the project team. To guide us in our study, we used the theoretical framework as presented in the previous chapter. We used the concepts from this framework as sensitizing concepts to provide a starting point for this study.

\section{Case selection and description}

We were able to participate in four projects (see table 1 on next page) that are delivered through four different strategic partnerships which are setup by Dutch housing associations (HA). These HA's are implementing SCP as a key strategy in their asset management. In our cases, SCP means that a housing association will partner with multiple (specialty) contractors to perform refurbishment projects. This HA has the intention to cooperate with these partners for two or more projects; involve multiple (specialty) contractors in an earlier stage in the (design) process; set up a new (project) organisation to integrate multiple hierarchy levels of each organisation (from higher management to blue collar workers); apply open book accounting and measure 
performance. For more information about the level of integration in each of these cases, we would like to refer to Koolwijk et al. (2015).

\section{DATA COLLECTION}

The researcher (first author) was an active member of the project team. Every team meeting the researcher was present. As a member of the team, the researcher received the project team e-mails and had access to the documents on the projects' websites. Therefore, the researcher was able to follow the project and the project team on a daily basis. The researcher spent a considerate amount of time with the team members to gain their trust. This position gave the researcher the opportunity to get their reflection on observations and to gain insight in their real ideas, thoughts and intentions. The researcher made field notes of the team meetings, personal insights that were discussed in personal talks, and also all project data (e-mails, et cetera) was collected. Together with another (professional) coach, the researcher gave workshops, did evaluations and executed specific interventions to help the project team to develop mutual goals, team spirit and a joint process. It also gave us a deeper understanding about the meaning people give to situations and behaviours of people, and it gave the opportunity to deepen our understanding of several concepts. One example of such an intervention are the evaluations that have been done with the project teams after every design phase. By evaluating the process, it became clear that team members would structure the design process differently in a follow up project based on their experiences. Both the discussions and the outcomes (new process design) of these interventions have been documented.

\section{Data analysis}

To analyse our findings, we first categorised the findings using the theoretical framework. After this we started to look for events that occurred in more than one project or events that are rare to be recorded and are noteworthy to be mentioned. One of the latter is noted in this paper (see relational risks). We also tried to see if we could find (possible) cause and effect relations in the data. Based on this analysis we've selected the major lessons for this paper. 
Table 1 Project description

\begin{tabular}{|c|c|c|c|c|}
\hline & Project A & Project B & Project $\mathrm{C}$ & Project D \\
\hline Size of HA / & 8.500 houses & 10.500 houses & 32.700 houses & 27.500 houses \\
\hline location in NL & North/East & South & North/West & South/West \\
\hline Type of houses & row houses & row houses & apartments & row houses \\
\hline Year or constr. & 1920’s & 1965 & 1940’s & 1940’s \\
\hline Project size & 26 & 100 & 189 & 79 \\
\hline Year project & 2012 & 2012 & $2013 / 2014$ & $2014 / 2015$ \\
\hline Constr. work & $\begin{array}{l}\text { Insulation of } \\
\text { facades, new } \\
\text { roofs, } \\
\text { restoration of } \\
\text { window frames } \\
\text { and window } \\
\text { shutters, } \\
\text { specialist re- } \\
\text { pointing and } \\
\text { brick } \\
\text { restoration, new } \\
\text { chimneys and } \\
\text { new glazing. }\end{array}$ & $\begin{array}{l}\text { Abatement of } \\
\text { asbestos, } \\
\text { renovation of } \\
\text { chimneys, } \\
\text { roofing, new } \\
\text { insulating glass } \\
\text { with ventilation } \\
\text { grilles, } \\
\text { insulation of } \\
\text { floors, painting } \\
\text { of windows and } \\
\text { doors. Tenants } \\
\text { could choose for } \\
\text { new bathrooms, } \\
\text { kitchens and/or } \\
\text { toilets. }\end{array}$ & $\begin{array}{l}\text { Insulation of facades, } \\
\text { new aluminium } \\
\text { window frames, new } \\
\text { roof finishing, PV- } \\
\text { cells, restoration of } \\
\text { concrete balconies, } \\
\text { new mechanical } \\
\text { ventilation and } \\
\text { central heating. } \\
\text { Tenants could choose } \\
\text { for a new kitchen } \\
\text { and/or bathroom. } \\
\text { Layout of the } \\
\text { apartment could be } \\
\text { changed. }\end{array}$ & $\begin{array}{l}\text { Chimneys, roofing, } \\
\text { new window frames } \\
\text { with ventilation } \\
\text { grilles, insulating } \\
\text { glass, new doors, } \\
\text { new mechanical } \\
\text { ventilation and } \\
\text { central heating, } \\
\text { impregnation and } \\
\text { insulation of } \\
\text { facades. Tenants } \\
\text { could choose for } \\
\text { new bathrooms, } \\
\text { kitchens and toilets. } \\
\text { Layout of the houses } \\
\text { could be changed. }\end{array}$ \\
\hline Remark & Monumental & & $\begin{array}{l}\text { Regarded as } \\
\text { monumental }\end{array}$ & \\
\hline $\begin{array}{l}\text { Delivery } \\
\text { method }\end{array}$ & $\begin{array}{l}\text { Strategic } \\
\text { partnering }\end{array}$ & $\begin{array}{l}\text { Strategic } \\
\text { partnering }\end{array}$ & $\begin{array}{l}\text { Strategic } \\
\text { partnering }\end{array}$ & $\begin{array}{l}\text { Strategic } \\
\text { partnering }\end{array}$ \\
\hline
\end{tabular}

\section{EMPIRICAL FINDINGS}

\section{Team structure}

Before we go into the team level factors, it needs to be noted that the structure of the SCP project teams that we've encountered in project A-D is different from the conventional structure one would normally encounter in housing refurbishment projects (see table 2). One of the main differences is the involvement of a general contractor and several specialty contractors in design development. Consequently, we see that the role of engineers is diminished and that the role of architects has become much less central; design development is a task of the project team with the architect or a drawing office integrating all the information into the drawings and specifications. 
Table 2 Project team structure in project A-D

\begin{tabular}{lllllll}
\hline & Project A & Project B & Project C & Project D & Conventional \\
\hline Project & Design and & Design and & Design and & Design and & Design: C-PM, \\
team & construction: & construction: & construction: & construction: & C-BS, A or D- \\
structure & C-PM, C-BS, C- & C-PM, C-BS, C- & C-PM, C-BS, & C-PM, C-PrM, T- & O, E-bs, E-s, \\
& PrM, T- & PrM, GC, SC-E, & C-PrM, A, & R-tenant and b, GC, & ECO, Cost \\
& R_client, T- & SC-HVAC, SC-P, & BIM, E-bs, E- & SC-E, SC-HVAC, & Construction: \\
& R_tenant & SC-R, SC-A/D & s, GC, SC-E, & SC-P, SC-P/G/W & GC \\
& GC, SC-P/G/W, & partially involved: & SC-HVAC, & partially involved: & \\
& SC-M, Mun-M & ECO, Cost, D-O & SC-P, SC-A/D & SC-A/D, Cost, A, D- & \\
& partially & & partially & O, E-BS & \\
involved: ECO, & & involved: & & \\
& & ECO, Cost, T- & & \\
\hline
\end{tabular}

Abbreviations: C-PM: client project managers, C-BS: client building supervisor, C-PrM: client property manager, T-R_client: tenant representative client (i.e. Tenant consul), T-R_tenant: tenant that lives in one the houses, T-R_b: tenant representative board, A: architect, D-O: drawing office, BIM: bim consultant, ECO: ecologist, Cost: Cost consultant, E-bs: engineer building services; E-S: structural engineer, GC: general contractor, SC-E: specialty contractor electrical, SC-HVAC: spec. contr. HVAC, SC-P: spec. contr. Plumbing, $\mathrm{SC}-\mathrm{P} / \mathrm{G} / \mathrm{W}$ : spec. contr. painting/ glazing/ and window frame renewal, SC-T: spec. contr. tiling, SC-R: spec. contr. roofing, SC-M: spec. contr. Masonry, SC-A/D: spec. contr. Asbestos abatement and demolitioner. Mun$\mathrm{M}$ : inspector monuments, Mun-BR: inspector building regulations.

The choice for a particular project team members is mainly determined on the type of (specialists) works that need to be performed and the expert knowledge that is required to make the design or to identify and manage potential risks. We see in our cases that contractors are selected by the client based on past experiences in earlier projects. The selection of specialty contractors is often a combination of the past experience of the client and the general contractor together.

\section{Overstretching resources is common in this new setting}

In all cases we've seen examples of team's having problems due to team members that were not capable of performing their tasks or that were overstretched at certain moments in the project. In a SCP team members are confronted with a lot of changes: a different team setting, new tasks, new (team) norms, new tools et cetera. In this setting, some team members take on too much work, because they simply do not see what's coming. Eventually this can lead to team members that are overstretched which eventually can lead to underperformance of the whole team. In project D for instance we saw a general site manager that took on too many tasks and thought he could handle it (even when he was warned multiple times by the team coach). When is manager did not back him up when things went wrong, the project got into trouble due to a lack of resources.

\section{Building a shared mental model and team learning behaviour}

We see in our cases that most specialty contractors are not used to work in a design team from a very early phase. In this new setting, it takes time for (specialty) contractors to see their own role and tasks, and to get to know the other team members personally and their capabilities. Additionally, we found that it takes time for contractors, who mainly focus 
on technical issues, to really start to understand the priorities of a client who is mainly concerned with the value-in-use of their houses and the satisfaction of their tenants. We found that tools and interventions can help the team in developing this shared mental model faster. Setting clear project team goals, planning the design phases together as a team, discussing what needs to get done and why, discussing who can do what best are activities that help the team in building a shared mental model. Team learning behaviour can help the team to explore its capabilities and to structure the work faster and to come up with new ideas and smart design solutions. Project leaders that foster this team learning behaviour, encouraging team members to speak up and to be open about their ideas and problems, help the team to excel. Project leaders also need to look after the team values, shielding the team from team members that show disrespectful behaviour or do not deliver on time. We found that team members in all projects would structure the team's tasks differently in a follow up project based on their experience in this first pilot project. From this we can infer that building a shared mental model takes experience and that having experience in traditional projects is not enough to do it right the first time in a SCP setting.

\section{Feeling safe to speak up}

Most team members are also not used to work with a client and (in some cases) a tenant in a design team. In all projects we found that some team members did not feel comfortable in this setting; they don't feel safe and to speak up while the general contractor, client and/or a tenant are present. In project A and D for instance, the presence of a tenant in the design team led to situations where other team members did not participate in certain discussions because they did not feel safe to share their sensitive knowledge on particular issues with a tenant.

\section{Trust}

Cognition based trust is an important aspect for project teams to perform. We've seen in multiple cases that having trust in the competence and trustworthiness of the partner leads to less buffer time in the project planning, because the other partners are more confident that this partner will deliver his (design) products on time. In projects where the team members where less familiar with each other, we see that it takes time for the team members to build trust in each other. Interventions like building prototypes can help the team to build trust in each other's capabilities.

\section{Breaking with old behaviour}

Specialty contractors are not used to share their knowledge with a client or a general contractor. Furthermore, in traditional projects keeping particular knowledge to themselves can be beneficial (for instance in claiming additional work). It looks like this past experience conditioned specialty contractors in this behaviour. We found that project leaders can help in breaking this behaviour by asking open questions and making it clear that they will only remain a partner when they bring their knowledge to the design table. Other team members that show the right behaviour, i.e. being open about problems and raising questions, can also act as an example to the other team members. 


\section{Relational risk}

In one case we've seen a relational risk come to light. One of the general contractors tried to abuse its position as a partner by making backdoor dealings with some of the other partners. The general contractor tried to raise its turnover by putting more men on the job than needed. To conceal his actions, the contractor also forced some of the other partners, who could do the same tasks, not to raise any questions about this in the project team. Eventually his misconduct was detected by the open book accountant and because one of the other partners broke the silence. This relational risks is present in every partnership were turnover and even (extra) profit can be hidden in the direct costs and (external) control is lacking.

\section{CONCLUSION}

Many different studies approach SCP as a technical-managerial problem, mainly involving the application of appropriate tools and techniques (Venselaar et al., 2015). By implementing these tools, it is thought that professionals will start to perform in line with the intended strategies. In our cases we've found that much more attention should be given to the project team; to the people that have to work together in a new setting. There are many different team related variables can hinder a project team in reaching its goals.

\section{LIMITATIONS}

The participative observation approach has some drawbacks. First of all the observations are done in four different project teams which form social groups on their own which have their own characteristics. Also, the context in which these teams have to work might look similar (housing associations, renovation projects) but when you look close there are many differences. Second, these teams are being guided by a group of consultants in a multi-site supply chain partnering program. This program puts the team members in a new organisational setting, requires team members to get early involved in the design, guides the team members on their interpersonal skills, and helps to structure the process by using several tools (i.e. value stream mapping). This program is rather unique in its holistic approach. It is therefore difficult to generalise the findings of this research to other project teams that are working in a supply chain partnership setting. However, some findings might be applicable to construction project teams that are working in a similar setting.

Another limitation is the researcher himself. In participative observation the researcher is the main instrument to record what is going on and finally to analyse all findings. To be a participative researcher, the researcher must fit in with the people being studied. He must also be able to communicate with group members on their level and terms. It also takes experience to sense what is going on in the group. If the researchers is not able to sense what is going on, there is a big chance he will miss interesting lessons. For instance he will not ask a team member is he feels comfortable with tenant sitting on the design table if he misses the nonverbal communication of this team member. In this case the 
researcher has more than 12 years of experience in working in design teams as a project manager and as a project team coach.

\section{REFERENCES}

- ANCONA, Deborah G.; CALDWELL, David F. Bridging the boundary: External activity and performance in organizational teams. Administrative science quarterly, 1992, 634-665.

- BASS, Bernard M. Theory of transformational leadership redux. The Leadership Quarterly, 1996, 6.4: 463-478.

- $\quad$ BRADLEY, Bret H., et al. Reaping the benefits of task conflict in teams: the critical role of team psychological safety climate. Journal of Applied Psychology, 2012, 97.1: 151.

- BRISCOE, Geoffrey; DAINTY, Andrew. Construction supply chain integration: an elusive goal?. Supply chain management: an international journal, 2005, 10.4: 319-326.

- BRYMAN, Alan. Of methods and methodology. Qualitative Research in Organizations and Management: An International Journal, 2008, 3.2: 159-168.

- CARBONELL, Pilar; RODRÍGUEZ-ESCUDERO, Ana I. Relationships among team's organizational context, innovation speed, and technological uncertainty: An empirical analysis. Journal of Engineering and Technology Management, 2009, 26.1: 28-45.

- CHANDRASEKARAN, Aravind; MISHRA, Anant. Task design, team context, and psychological safety: An empirical analysis of R\&D projects in high technology organizations. Production and Operations Management, 2012, 21.6: 977-996.

- DAS, Tushar Kanti; TENG, Bing-Sheng. Trust, control, and risk in strategic alliances: An integrated framework. Organization studies, 2001, 22.2: 251-283.

- DEWICK, Paul; MIOZZO, Marcela. Networks and innovation: sustainable technologies in Scottish social housing. R\&D Management, 2004, 34.3: 323-333.

- EDMONDSON, Amy C. Learning from failure in health care: frequent opportunities, pervasive barriers. Quality and safety in Health Care, 2004, 13.suppl 2: ii3-ii9.

- $\quad$ EDMONDSON, Amy C.; LEI, Zhike. Psychological safety: The history, renaissance, and future of an interpersonal construct. Annu. Rev. Organ. Psychol. Organ. Behav., 2014, 1.1: 23-43.

- $\quad$ GIBSON, Cristina B.; GIBBS, Jennifer L. Unpacking the concept of virtuality: The effects of geographic dispersion, electronic dependence, dynamic structure, and national diversity on team innovation. Administrative Science Quarterly, 2006, 51.3: 451-495.

- GULATI, Ranjay. Does familiarity breed trust? The implications of repeated ties for contractual choice in alliances. Academy of management journal, 1995, 38.1: 85-112

- HACKMAN, J. Richard, et al. Team effectiveness in theory and practice.Industrial and organizational psychology: Theory and practice, 2000.

- HARBERS, Maaike; RIEMSDIJK, MB van; JONKER, C. M. Measuring sharedness of mental models and its relation to team performance. In:Proceedings 14th International Workshop on Coordination, Organisations, Institutions and Norms. 2012. p. 106-120.

- HARGREAVES, David H.; HARGREAVES, David. Social relations in a secondary school. Routledge, 2006.

- JACKSON, Susan E.; JOSHI, Aparna. Work team diversity. 2011.

- KAWULICH, Barbara B. Participant Observation as a Data Collection Method. Forum: Qualitative Social Research, 2005, 6.2.

- $\quad$ KOOLWIJK, Jelle S. J.; VAN OEL, Clarine J.; WAMELINK, Johannes W.F.; VRIJHOEF, Ruben. Partnering in construction, a field study to further develop the framework of supply chain integration. Proceedings of the 31st annual ARCOM conference, 2015.

- $\quad$ LIANG, Diane Wei; MORELAND, Richard; ARGOTE, Linda. Group versus individual training and group performance: The mediating role of transactive memory. Personality and Social Psychology Bulletin, 1995, 21.4: 384-393. 
- LIU, Julie Yu-Chih, et al. Relationships among interpersonal conflict, requirements uncertainty, and software project performance. International Journal of Project Management, 2011, 29.5: 547-556.

- LUHMANN, Niklas. Trust and power Chichester. United Kingdom: John Wiley and Sons, Inc, 1979.

- MATHIEU, John, et al. Team effectiveness 1997-2007: A review of recent advancements and a glimpse into the future. Journal of Management, 2008, 34.3: 410-476.

- $\quad$ MAYER, Roger C.; DAVIS, James H.; SCHOORMAN, F. David. An integrative model of organizational trust. Academy of management review, 1995, 20.3: 709-734.

- MOHAMMED, Susan; DUMVILlE, Brad C. Team mental models in a team knowledge framework: Expanding theory and measurement across disciplinary boundaries. Journal of organizational Behavior, 2001, 22.2: 89-106.

- O'BRIEN, William J., et al. (ed.). Construction supply chain management handbook. CRC press, $2008 \mathrm{O}$

- $\quad$ PELLED, Lisa Hope; EISENHARDT, Kathleen M.; XIN, Katherine R. Exploring the black box: An analysis of work group diversity, conflict and performance.Administrative science quarterly, 1999, 44.1: 1-28.

- $\quad$ ROBBINS, Stephen, et al. Organisational behaviour. Pearson Higher Education AU, 2013.

- ROSE, Timothy; MANLEY, Karen. Motivational misalignment on an iconic infrastructure project. Building Research \& Information, 2010, 38.2: 144-156.

- $\quad$ ROUSE, William B.; MORRIS, Nancy M. On looking into the black box: Prospects and limits in the search for mental models. Psychological bulletin, 1986, 100.3: 349.

- $\quad$ SAGE, Daniel; DAINTY, Andrew; BROOKES, Naomi. A 'Strategy-as-Practice'exploration of lean construction strategizing. Building Research \& Information, 2012, 40.2: 221-230.

- $\quad$ SCHOORMAN, F. David; MAYER, Roger C.; DAVIS, James H. An integrative model of organizational trust: Past, present, and future. Academy of Management review, 2007, 32.2: 344-354.

- $\quad$ SIVASUBRAMANIAM, Nagaraj; LIEBOWITZ, S. Jay; LACKMAN, Conway L. Determinants of New Product Development Team Performance: A Meta-analytic Review. Journal of Product Innovation Management, 2012, 29.5: 803-820.

- VAN KNIPPENBERG, Daan; SCHIPPERS, Michaela C. Work group diversity.Annu. Rev. Psychol., 2007, 58: 515-541.

- VAN KNIPPENBERG, Daan; SITKIN, Sim B. A critical assessment of charismaticTransformational leadership research: Back to the drawing board?. The Academy of Management Annals, 2013, 7.1: 1-60.

- VENSELAAR, Marieke; GRUIS, Vincent; VERHOEVEN, Fenne. Implementing supply chain partnering in the construction industry: Work floor experiences within a Dutch housing association. Journal of Purchasing and Supply Management, 2015, 21.1: 1-8.

- $\quad$ ZHENG, Yanfeng. Unlocking founding team prior shared experience: A transactive memory system perspective. Journal of Business Venturing, 2012, 27.5: 577-591. 


\title{
DEVELOPMENT OF THE "WATER-SPECIFIC P3 RISK MODEL”, RISKS IDENTIFIED
}

\author{
Korayem, I.M. ${ }^{1}$, Ogunlana, S.O. ${ }^{2}$ and Boateng, P. ${ }^{3}$
}

\begin{abstract}
:
Risk assessment is one of the key success factors of public-private partnerships (PPP) water projects. Factors such as utility condition problems, unsustained increase in water supply requirements, sociotechnical issues and changes in government policies can cause such capital intensive projects to overrun planned budget and schedule allocations. Where the project is a commercial asset, delayed completion time and cost overruns usually have significant impact on the profitability of the project as well as the estimated returns on investment over the operational phase of the project. Understanding the specific risks involved in PPP water projects can be very crucial in designing containment measures to deal with their likely impact on the projects. Through review of literature and non-participant observation, different risk factors in PPP water projects can be identified. The identified factors can then be rated and prioritized through questionnaires using the Analytical Network Process (ANP) to demonstrate the complex interactions among those risks and to establish the most salient Value-for-Money (VFM) variables on PPP water projects. The outcome of the proposed research is an innovative ANP-based model known as "Water-Specific P3 Risk Model" that offers a platform to incorporate tangible and intangible risk variables into a risk assessment process in water infrastructure projects.
\end{abstract}

This paper presents the overall research methodology and the literature review undertaken for the identification of the risk factors associated with Water PPP Projects. Subsequent stages of the research are currently under progress.

KEYWORDS: PUBLIC-PRIVATE PARTNERSHIPS, WATER INFRASTRUCTURE, PPP WATER PROJECTS, RISK ASSESSMENT, VALUE FOR MONEY, ANALYTIC NETWORK PROCESS.

\section{BACKGROUND}

In the early 1990s, market-driven approaches for water resources management started to gain acceptance. Water was recognized as an economic good i.e. a commodity that should be priced at its cost of provision and its true value to society (Ouyahia, 2006). For developed countries, the United Nations in its 2000 Millennium Declaration, set eight goals for development, called the Millennium Development Goals (MDGs). These goals set an ambitious agenda for improving the human condition by 2015. In support of these goals, the Millennium Project was launched to recommend the best strategies for achieving the MDGs. Privatization and decentralization have become the main reform policies of the major international organizations (World Bank, International Monetary

\footnotetext{
${ }^{1}$ School of the Built Environment, Heriot-Watt University, Edinburgh, United Kingdom, imk5@hw.ac.uk

2 School of the Built Environment, Heriot-Watt University, Edinburgh, United Kingdom, s.o.ogunlana@hw.ac.uk

${ }^{3}$ Scott Sutherland School of Architecture and Built Environment, Robert Gordon University, Aberdeen, United Kingdom, p.boateng@rgu.ac.uk
} 
Fund, Organization for Economic Cooperation and Development). Public-Private Partnerships (abbreviated as PPP, or P3) have been introduced as the most common scheme of project development.

The involvement of the private sector in water infrastructure projects is a subject of much debate, which is currently far from being settled. Statistically, water projects undertaken under private sector are experiencing cancellation/distress at a much higher rate than other infrastructure projects under the same procurement scheme. Both proponents and opponents of water privatization support their claims with figures that should strengthen each party's argument. However, in lack of a common base of comparative analysis, these numbers were not indicative and could be considered as outliers.

The case was clearly summarized by Karen Bakker (2010):

"Most of the debate has centered on the relative merits of the public and private sector in managing large-scale reticulated water-supply networks. Unbiased research is rare; an examination of comparative performance is often influenced by ideological commitments. It is thus somewhat predictable that proponents and opponents of water privatization rarely agree on research strategies."

\section{RESEARCH METHODOLOGY}

A research on Water PPP is not expected to conclude on the debate on this matter. However, a better understanding of the risks involved in water PPP projects can significantly assist in designing containment measures to deal with their likely impact on the projects.

In order to achieve this aim, a research plan was set which comprises of identifying the risks associated with water PPP projects through the review of literature. The identified factors can then be rated and prioritized through questionnaires and non-participant observation utilizing the Analytical Network Process (ANP) to demonstrate the complex interactions among those risks and to establish the most salient Value-for-Money (VFM) variables on PPP water projects. The outcome of this research will be an innovative ANP-based model known as "Water-Specific P3 Risk Model" that offers a platform to incorporate tangible and intangible risk variables into a risk assessment process in water infrastructure projects.

\section{Critical Review of Literature}

This stage was considered necessary as a primary stage prior to identifying of risks in water PPP projects through a subsequent stage of literature review. The aim of this primary stage was to better understand the ongoing debate on this matter, and for getting a comprehensive grasp of existing knowledge that would allow making an original contribution to knowledge in this research area as advised by Naoum (1998). The research included investigating the various 
disciplines related to water infrastructure including construction, rehabilitation, asset management, and financing.

\section{Proponents and Opponents of Water Privatization}

Both proponents and opponents of water privatization supported their claims with figures that should strengthen each party's argument. A critical review of the most common assumptions/allegations made by each party is presented in this section.

The proponents of water privatization have always linked the poor political condition in some countries to the deficiency in water supply management especially in third world countries. This is a very general assumption, besides it ignores the fact that the same political bodies are responsible for engaging private sector parties in new water infrastructure projects. Accordingly, the assumption that the mis-management of political parties of water resources would only change if we switch to engaging the private sector is invalid. The assumption that private corporations will endeavour to lower their prices to gain more costumers is not always valid. After a certain point, the increase in water supply may require additional resources (facilities, equipment, services, etc.) to maintain the same level of service, which will result in additional cost to the Private corporation. The claimed success of water PPP projects in some developed countries cannot be considered as a proof of the success of such schemes in every country, especially in developing countries with significantly different conditions. It only proves that a proper setup of such scheme is a necessity of such procurement model. The assumption that poor people are ready to pay more for an improved service does not explain the social and political tension that water privatization face in first world countries like in Canada.

On the operation side, the assumption that the engagement of private sector will action an immediate improvement to the service is not valid. The fact is that water spillage from pipes are mostly attributed to aging infrastructure where available records of previous maintenance activities either does not exist or is not made available. Even with the availability of such records, the rehabilitation/maintenance of water pipes is facing limited budgets allocated for maintenance. The engagement of private sector is not foreseen to change things dramatically in this regard. The assumption that private corporations will have more tendency to handle water with care is not always accurate given that the private sector is engaged in a pre-determined contract value over a certain period of time with a pre-agreed level of performance. The increase of water supply may lead to more effort (and cost) to comply with the stakeholders' requirements and maintain the same quality level. Assuming that private sector will allow for more investment in research and development is not always accurate. A relatively large amount of research is taking place in developing improved strategies for water pipes maintenance and rehabilitation; however, governments mostly fund this research according to our observations.

The assumption that users, under the free water-pricing model, will have the option to seek an alternative in case of improper service is clearly not valid given the monopolistic 
nature of the water sector. Also, the assumption that private entities will seek an improvement to their service for an increased use and earnings is not always accurate. The additional use of resources can lead to more investments in facilities so as to handle such increase and maintain an acceptable operational/environmental level of service. The proponents typically ignored the necessity of developing a water policy based on available resources and target achievements with respect to water access and quality. The arrangement and coordination of new proposed projects should follow such policy. The allegation made that building major infrastructure facilities like dams is not always a necessity forms an unsubstantiated claim unless the associated engineering studies are examined. The indication by Segerfeldt (2005) that World Bank on investments on public works like building large dams have lead to many spectacular failures is very general, and is, therefore, not acceptable. Building dams, like any other engineering project, should have the typical engineering studies starting from preliminary design till detailed design to allow for a proper assessment, analysis, and execution. Moreover, the reference by Segerfeldt (2005) to a major public works failure like in the Soviet Union that took place during the 1950s does not offer a scientifically acceptable basis for evaluation (P21). Linking a proper water policy to market-driven policies is not valid. In Chile, private ownership was introduced where landowners were given the right to own water and sell it at freely determined prices. The success of such model in Chile does not necessarily guarantee that the same model is valid everywhere as engineering requirements beside political and social conditions should be studied well for each case. In any case, the overall planning of water supply is not expected to be handled by local residents but rather by responsible organizations.

On the other side, the opponents have put most of their efforts opposing the concept. Brubaker (2011) considers that many municipal utilities are ill-equipped to deal with new challenges in the industry and lack the necessary expertise at all levels. In-depth research on the matter is very limited. The most notable effort towards a more rational assessment of the situation was conducted by Bakker (2010). Bakker's analysis came from a different starting point of the debate, through focusing on issues of governance, where many are common between public and private parties. However, in our opinion, Bakker generally implied a shared responsibility between the public and private sectors for the current on-going deficiencies in this sector. As an example, while the reported overall market share of private sector is around 3\%, Bakker still note that the private sector is handling $20 \%$ of the market in urban areas with its current known deficiencies. While this may be true, it ignores the fact that the majority of services at its current conditions is offered by the public sector with its currently known deficiencies.

\section{Declination of the Number of Water PPP Projects}

According to World Bank data, a severe drop in the number of water PPP projects has occurred. The number of new projects with private participation that reached financial or contractual closure in 2009 declined by $46 \%$ compared to 2008. Annual investment commitments fell by $31 \%$ within the same period (Refer to Figure 1 below). Based on the Word Bank data, by 2009, the percentage of cancelled/distressed projects in water infrastructure forms $34 \%$ of the total committed investment, compared to $8 \%$ in 
electricity, $3 \%$ in telecom, and $8 \%$ in transport. The subject is not well-addressed in the research as of the reasons for such drop. In general, Ouyahia (2006) presented the water sector specific nature. Several case studies of such failures have been presented but in our opinion, most of this work was driven by the ideological concepts of the authors, or at least limited to the cases in hand. There is a need for an overall assessment of the situation where the reasons for such drop are assessed and delineated by industry experts to a list of risks associated with the water sector.

Figure 2: Private Participation in Infrastructure Projects between 1990 and 2009

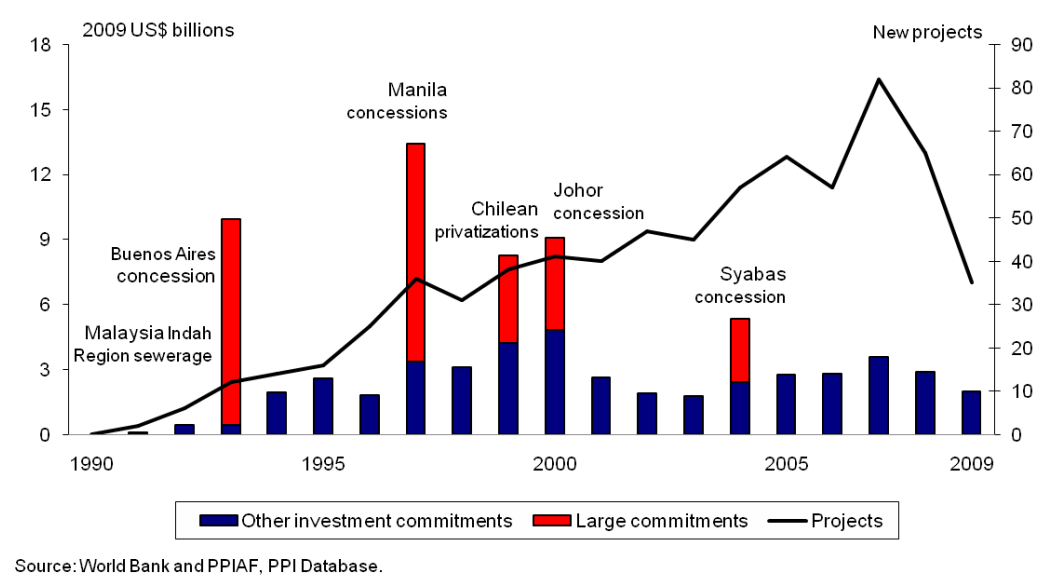

Source: World Bank and PPIAF, PPP Database (2010)

\section{The "Water-Specific P3 Risk Model", Risks Identified}

Considering the knowledge obtained from the primary stage of the literature review, the authors conducted an extensive review of water PPP projects cancellation including studying several published case studies. Presented in this section are the water-specific risks identified throughout this review which was found to be the common causes of cancellation of many water PPP projects.

\section{A. Absence of Facility Records}

Inadequate performance records for years in the past would prevent having meaningful comparisons between the public operator and its private successors. In Halifax, the disagreements between the public and private parties arose months after the initial agreement was signed. The private party claimed that potential problems with influent quality came to light only when the federal government issued its environmental screening report for the project. Prior to that, it relied on out-of-date data provided by the city and by local industry. Halifax insisted that it provided ample opportunities for testing and that it would have been reasonable for the consortium to do due diligence. 


\section{B. Asset Condition}

Asset Valuation: Obtaining solid information about the state of infrastructure is significant for a proper project evaluation and risk assessment of new investments. A clear identification of the asset condition is a major technical challenge. Besides, the lack of records of the previous activities relevant to existing systems is very common and does not make the issue any easier. Without such information, it difficult to establish a baseline to enable private firms to accurately bid on the work. This has been constantly a source of disputes. In the case of Atlanta, where some parts of its Infrastructure dates back to 1875 , the private partner "Suez" complained that the initial contract as it was signed did not reflect the actual status of the system. The Reason Foundation explained, "Some of the blame must fall on UWSA (Public owner). All of the bidders knew about the lack or quality of data ahead of time before they bid. Furthermore, USWA has a lot of experience running old systems and it should have built that expertise into its proposal." In the case of Buenos Aires, the unexpected poor performance of the buried assets was one of the reasons that lead to project cancellation at the end. In the case of Hamilton, the municipal staff confirmed that for the Contractor to meet the required performance standards, the system requires investment of hundreds of millions of dollars, which does not form part of the Contractor scope of work. The assessment of infrastructure conditions by requiring several competing firms to study a system extensively would be inefficient. Producing numerous feasibility studies would push up the costs of the bids and, by making the bidding process too expensive for small firms and will reduce competition. The most basic valuation problem in valuing assets-in-place is the use of discounted cash flow (DCF) techniques (Hertz, 1964). Regardless of the individual strengths and limitations of the various valuation methods, a common deficiency is that there is no indication of the confidence level on the determined capitalization rates (Ye and Tiong, 2000). The Asian Development Bank guidelines (1999) provides recommended financial evaluation methodologies for water supply projects.

Asset Management: Significant research has been conducted on the rehabilitation of distribution networks. The traditional strategies for rehabilitation varies between: Operative, inspection, Condition based, Proactive, and Predictive (Ugarelli, 2008). Numerous numbers of models were developed to assist in developing a strategy that reduce leakage for improved operative costs and enhance the environmental records. However, without a solid knowledge of the asset condition, the assessment of the operation component becomes very hard. Gathering and documenting information about the system will entail some expenditure for sure, but this initial cost will help not just to reduce unwanted expenses in the future, but also enable a services provider to manage the asset better.

\section{Expansion Potential}

It is essential that the relevant major construction projects, in particular those for water production and transmission, are well identified during the preparation stage. Early (or late) expansion of the system may cause disturbance to the overall planning and may result in the Contractor's inability to meet the contract requirements. The following factors typically cause the need for facility upgrade and/or expansion: 
Increase in Population: In Atlanta, the private partner inherited from the city a backlog of between 4,000 and 7,000 outstanding requests for service. This was accompanied with a construction boom in the service area, which created additional demands that was not accounted for during bidding stage. Additional investment to meet the increase in demand was not envisioned during the bidding process.

Increase in Usage: In some cases, the improvement of service have encouraged more use in water while the company may not be prepared for investing on this direction. In some cases, the contract is only set for providing service. Inability to meet the stakeholders' expectation can draw major negative political implications on the project. In some other cases, preventing the use of private wells led to an unexpected increase in usage.

Improvement in Quality: The private operator is obliged to follow the minimum performance criteria set in the contract. This may require replacement of inappropriate connections (which is considered as the most common source of physical leaks), which in some cases does not form part of the private sector scope of work. Also, it may have not been foreseen as a consequence of years of limited or inappropriate data collection. The timely implementation of such improvement has been a key factor in success. If not considered in the original private sector planning, the process may be delayed causing problems in the project delivery. In some instances, the involvement of a locally experienced Contractor have helped improved the process like in the case of Côte d'Ivoire (Martin, 2009). SODECI, a governmental entity, has always been in charge of regular extensions of distribution networks which assisted when it became responsible for identifying and preparing the capital investment program.

\section{External Impact}

Close coordination between the proposed project objectives and other inter-related projects is essential. Disruption on the program may have negative implications on the PPP project, due to one (or more) of the following factors:

A Party not Performing The Promised Investments: The delay in awarding (or completing) a relevant project may have a severe impact on the PPP project in hand. The delay may result in the contractor not being able to meet the contract specifications in terms of production or in terms of meeting the contract specified environmental regulations. The case of Manila is the most revealing, one of the reasons that led to the cancellation of the project was the government inability to complete the relevant riverbasin project. In the case of Atlanta, the public partner responsibility included flushing of the wastewater system which the private operator claimed was not performed as planned preventing them from meeting the environmental criteria. The City of Atlanta denied the accusation yet the city auditor confirmed that the city had indeed failed to reinvest savings in its utility by charging its water department an annual franchise fee, the city had transferred US\$9.8 million a year to its general fund (Reinhardt, 2003). A study conducted by the World Bank (2009) advises that the experience in Africa evolved to forming the so-called Public Assets-Holding Companies (AHCs) to act as owner of the water supply assets. However, the delay in implementing extension programs by AHCs 
have, in some cases, caused major problems to the operator. In Guinea, the AHC's delays in implementing extension programs frustrated the operator, and was encouraged to seek financing for implementing its own projects with adversely impacted the operational performance. In Senegal, initial delays in implementing rehabilitation programs meant that the $\mathrm{AHC}$ had to compensate the operator for loss of revenues.

Project Affected by Others' Underperforming Facilities: In Halifax, the contract was set so that the city controls what goes into its sewer system. The city enforced a seweruse bylaw to prevent hard-to-treat industrial pollutants from contaminating the influent but the city's regulation of discharges from some 5,000 sources will only be as effective as the monitoring and enforcement behind it with no clear identification in the contract. The latest information on influent quality was due to the inability to control over 5000 sources, which does not form part of the Contractor's scope of work.

\section{E. Commercial and Law}

Unsuitable Commercial Model: A suitable commercial model is essential for the successful delivery of the PPP project. Experience shows that the transfer of significant financing responsibilities to the private partners may create problems. This was obvious in the case of Cochabamba, Bolivia. The private investor - quickly after award increased supplied water by 30 percent, simply through repairs and technical enhancements. However, the concession included operation of the existing water supply system and construction within two years of the US \$214 million Misicuni Multipurpose Project (MMP), which used the River Misicuni for electricity generation, irrigation and water supply to the city. In order to meet these requirements, an average tariff increase of $35 \%$ was agreed upon during contractual negotiations. The government committee that negotiated the contract did not appreciate the financial implications when it insisted on the construction of the Misicuni dam, a project that was not deemed financially viable by the World Bank and international water companies. The government also insisted that the private sector sign and execute a contract for construction of a treatment plant that the consortium thought expensive and unnecessary (UNDP, 2012). In developing countries, the risk is more pronounced, as noticed in failed PPPs in Gambia and Chad, where the design of the capital budget was ill-matched with the PPP objectives (World Bank Group, 2009). In the case of Gambia's joint power/water operation, 85 percent of the revenues were generated from the sale of electricity, but no financing was available for rehabilitating and extending the power production and distribution infrastructure, in particular to replace a generator that collapsed the day before the operator mobilized (World Bank Group, 2009).

Skewed Tariff Structure: This may have significant implications on the satisfaction of stakeholders and in turn the overall delivery of the project. In the case of Cochabamba, Bolivia, an "Increasing Block Tariff (IBT)" was issued to ensure that high-income households would pay around twice the amount per cubic meter for consumption above $12 \mathrm{~m}^{3}$ that low-income users would pay. While the average tariff increase was 35 percent, the actual increase varied; lower-income consumers for increases of as little as 10 percent 
while higher-income consumers experienced tariff increases as high as 106 percent due to the increased tariff for their high level of consumption (UNDP, 2012).

Billing: In Africa, billing to public agencies represents 15 to 25 percent of the total billing. Water bills owed by public agencies have been a constant source of conflict between private operators and governments. In Côte d'Ivoire, this has been a recurrent problem, solved only temporarily by the sector adjustment in the late 1980s. Some countries have introduced special arrangements to mitigate the associated financial risk to water utilities and protect the revenues. In some countries like Senegal and Niger, an upgrade of the internal plumbing of public buildings to limit water consumption has been introduced. However, the improvement in billing administration has several faces. It may lead to a reduction in consumption as a result of water rationing. However, in some cases, the opposite may occur, when the greater availability of water lead many consumers to increase their consumption, which creates an increased water bills not only because of an increase in price but also because of an increase in volume.

Exchange Rate and Fixed Assets: Water Projects include considerable fixed assets that are considered irreversible. It is therefore prudent to ensure the commercial scheme has reduced the exposure to the risk of increase in exchange rates. Even in PPP where the investment program is financed by the partner government, the operator must still finance operating expenses to cover the expatriate staff and imported inputs (chemicals, spare parts, hardware, and software). These costs are in foreign currency, while the operator's revenues are in local currency only. Financial problems plagued privatization in Buenos Aires, where a private investor won a 30-year water and wastewater concession in 1993. The private investor increased water coverage, billing collection, operating efficiency. Although it initially promised to reduce tariffs by almost 27 percent, over the years it obtained a number of price adjustments, the first because of the city's inadequate records and the unexpectedly poor condition of the water distribution network. However, the Argentine financial crisis of early 2002 wreaked havoc on the concession. The peso was "de-pegged" from the dollar and devalued, the private investor had trouble servicing its debt, most of which was denominated in U.S. dollars. When the government refused to raise prices to offset the devaluation, the consortium announced its desire to pull out of the agreement, and the matter went into arbitration (Brubaker 2003). Guaranteed foreign exchange rate is typical where the foreign exchange risk is limited as the exchange rate to the Euro (or USD) is fixed, and the difference between inflation rates can easily be taken care of through cost index formula. A study by the World Bank (2009) of seven African countries in the sample of PPP showed Cape Verde, Ghana, and Guinea-countries with floating local currencies - have faced a higher foreign exchange risk.

Exclusive Right to Water Resources: To make the project financially viable in the case of Cochabamba, Bolivia, the private sector was granted the exclusive right of water resources in Cochabamba as well as any future sources required for the supply of water to the consumers in the city. As a consequence, many private wells were shut down. This decision carried significant negative political implications (UNDP, 2012). 


\section{F. Stakeholder Management}

Poor Involvement of Stakeholders: Considering the use of PPPs for water supply services always leads to an emotional debate. Consulting local stakeholders helps to clarify the objectives of PPPs. At the design stage, several of the PPPs documents have paid particular attention to consulting with stakeholders, including various government departments, management and staff of the public utility, and the media. Typical fears include steep tariff increases, massive staff reduction, heavy foreign presence, or exclusion of the poor. Expanding the customer base has often been a key factor for contracts to achieve financial sustainability. In Cochabamba, it was concluded that public officials should have better informed the public about the size and rationale for the tariff increase. Only after three months into the operations, significant public opposition emerged. A series of protests against the contract and the increase in water tariffs took place. Within weeks, public demonstrations prompted the government to roll back the rates and force a refund of the difference paid. The protests continued and escalated to the point that the military was sent into Cochabamba to restore calm. In the deteriorating situation, the working personnel abandoned their offices and the government cancelled the contract (UNDP, 2012).

Public Sector Involvement: The operator should be closely associated with defining the rehabilitation and extension of distribution networks and key plants. Experience shows that even for PPP with public funding for investment, operators should play a role in implementing civil works. The involvement of local private operators managed by nationals typically helps in dissipating the perception of foreign involvement in a socially sensitive sector and increases the acceptability of PPPs. This was witnessed in Côte d'Ivoire and Senegal. At the opposite extreme, the perception of foreign-managed operator was strong in Gambia, Chad, and Mali and was one reason that led to termination of the contracts (World Bank, 2009). In Côte d'Ivoire, the asset capital became public in 1978 and became one of the largest companies quoted at the Abidjan stock exchange. Shares of the private operators in Senegal, Niger, and Gabon are also held by local partners and by staff. Guinea's failure to foster local private management at SEEG was largely due to the structure of the company's ownership, with a 49 percent minority share held by the government.

Poor Selection of Local Partner: In Chad, the PPP ran into early trouble partly because financing for a new power plant had not been secured on time and the construction contracts that were awarded to inexperienced contractors for a $350 \mathrm{~km}$ pipeline and power plant had to be terminated for poor performance (World Bank, 2009).

\section{SUMMARY OF WATER SPECIFIC P3 RISKS}

In the light of the above discussion, the main risks factors associated with water PPP projects are summarized in Table 1 below.

Table 2: Water-Specific P3 Risks 


\begin{tabular}{ll}
\hline Group & Description \\
\hline $\begin{array}{l}\text { A: Difficulties in } \\
\text { Obtaining/Verifying Existing } \\
\text { Facility Records }\end{array}$ & $\begin{array}{l}\text { A1: Absence of maintenance records } \\
\text { A2: Absence of environmental data sampling records }\end{array}$ \\
\hline $\begin{array}{l}\text { B: Difficulties in Verifying the } \\
\text { Asset Condition }\end{array}$ & B1: Uncertainty of value of assets \\
B2: Uncertainty of cost of maintenance \\
$\begin{array}{l}\text { Cxpeed for Unsustainable } \\
\text { Expansion of Facility/Utilities }\end{array}$ & $\begin{array}{l}\text { C1: Potential increase in served population } \\
\text { C2: Potential increase in usage } \\
\text { C3: Increase in resources to meet environmental guidelines }\end{array}$ \\
\hline D: Adverse Impact from & D1: Improper planning of interrelated projects \\
Interdependent Facilities & D2: Uncontrolled performance of interrelated projects \\
\hline E: Enforcement of New & E1: Overly complicated commercial model \\
Commercial and/or Legal & E2: Potential excessive increase in tariff structure \\
Regulations & E3: Enforcement of right to water resources \\
& E4: Significant change in current billing practice \\
& E5: Potential change in currency exchange rates \\
\hline F: Mis-managemnt of & F1: Poor communication with stakeholders \\
Stakeholders & F2: Potential disruption to current local businesses \\
& F3: Underperformance of a local partner \\
\hline
\end{tabular}

\section{SUMMARY}

In the early 1990s, market-driven approaches for water resources management started to gain acceptance. Water was recognized as an economic good. Privatization and decentralization have become the main reform policies of the major international organizations (World Bank, International Monetary Fund, Organization for Economic Cooperation and Development). Public-Private Partnerships have been introduced as the most common scheme of project development. The involvement of the private sector in water infrastructure projects is a subject of much debate, which is currently far from being settled. Statistically, water projects undertaken under private sector are experiencing cancellation/distress at a much higher rate than other infrastructure projects under the same procurement scheme. This is not acceptable if PPP projects are to contribute to sustainable water supply. Both proponents and opponents of water privatization support their claims with figures that strengthen each party's argument. However, in view of the current lack of a common base of comparative analysis, these numbers are not indicative and can be considered as outliers.

A research on Water PPP is not expected to conclude on the debate on this matter. However, a better understanding of the risks involved in water PPP projects can significantly assist in designing containment measures to deal with their likely impact on projects. As such, a research plan was set to develop the "Water-Specific P3 Risk Model" which offers a platform to incorporate tangible and intangible risk variables into a risk assessment process in water infrastructure projects.

This paper presented the literature review undertaken for the identification of the risk factors associated with water PPP projects. As a primary stage, a critical review was undertaken for the arguments raised by both sides of the debate on water PPPs. The 
review showed that most arguments are driven by ideological pre-set opinions that led to making invalid assumptions, exaggerated claims, omission of facts, or was found to be contradictory in some cases. Subsequently, the authors conducted an extensive review of water PPP projects cancellation including studying several published material and case studies. This paper presents the outcome of the literature review process where a summary of identified risks is presented as the outcome. The subsequent research stage will seek industry experts to evaluate the identified risks through a questionnaire survey, where the outcome of the survey will be analyzed using the Analytic Network Process (ANP) to demonstrate the complex interactions among those risks. The "Water-Specific P3 Risk Model" resulting from this research remains limited to the cases in hand and the opinions of the experts who have contributed to this research. However, the proposed model offers an opportunity for future research to build on what has been achieved.

\section{REFERENCES}

- ASIAN DEVELOPMENT BANK (1999). Handbook for the economic analysis of water supply/projects, ADB, 1999. (http://www.adb.org/Documents/Handbooks/ Water Supply Projects/default.asp).

- BRUBAKER, E. (2003). Revisiting Water and Wastewater Utility Privatization. Presentation from Faculty of Law, University of Toronto (2003): 'Public Goals, Private Means`Research Colloquim.

- BAKKER, K. (2010). Privatizing Water. Governance Failure and the World's Urban Water Crisis. Ithaca, United States

- HERTZ, D.B. (1964). Risk analysis in Capital Investment, Harvard Business Rev.42(1), 95.

- MacGillivray, B.H., Hamilton, P. D., Strutt, J. E. \& Pollard, S. J. T. (2006). Risk Analysis Strategies in the Water Utility Sector: An Inventory of Applications for Better and More Credible Decision Making. Critical Reviews in Environmental Science and Technology, 36:85-139, 2006.

- MARTIN, P. (2009). Public-Private Partnerships for Urban Water Utilities. A Review of Experiences in Developing Countries. Trends and Policy Options No. 8, The International Bank for Reconstruction and Development / The World Bank.

- NAOUM, S. G. (1998). Dissertation Research and Writing for Construction Students,

- Boston, USA: Butterworth-Heinemann, Elsevier Science.

- OUYAHiA, M. (2006). Public-Private Partnerships for Funding Municipal Drinking Water Infrastructure: What are the Challenges? Discussion Paper May 2006, PRI Project Sustainable Development, Government of Canada.

- REINHARDT, W. (2003). "How Atlanta Lost its Low-Bid Bet on Water Ops," Public Works Financing, Volume 169, January 2003, p. 2.

- SEGERFELDT, F. (2005). Water for sale: How business and the market can resolve the World's water crisis. Washington D.C.: Cato Institute.

- UNDP, Special Unit for South-South Cooperation (2012). Cochabamba, Bolivia, Urban Water Expansion Case Study (Water) Project.

- WORLD BANK GROUP, Fall, Marin, Lcussol, Verspyck (2009). Reforming Urban Water Utilities in Western and Central Africa: Experiences with Public-Private Partnerships, Volume 1: Impact and Lessons. Water Sector Board Discussion Paper Series, Paper No. 13, June 2009.

- YE, S., and TIONG, R.L.K. (2000). NPV-at-risk method in infrastructure project investment valuation, J. Constr. Engg. Manage. 126(3), 227. 


\title{
A CASE FOR TARGET VALUE DESIGN TOWARDS EFFECTIVE LOW-COST HOUSING PROJECT COST MANAGEMENT AND PERFORMANCE IN SOUTH-EAST ZONE NIGERIA
}

\author{
Obi, L.I. ${ }^{1}$ and Arif, M. ${ }^{2}$
}

\begin{abstract}
:
Reports over the past decade, reveal the trend of poor cost performances of many Low-cost Housing (LcH) projects. This have apparently resulted in huge monetary losses to the government as the client, declining housing supply and undermined affordability of many Low and Low-medium incomes particularly in developing countries like Nigeria. In spite of the changes with contemporary trends in Nigeria, it would appear that the techniques employed in the management of the delivery costs of the LcH projects particularly in the South-east zone are yet similar to those used over a century ago. This necessitates urgent and appropriate sustainable intervention strategies adopting cost-effective techniques. Prior studies affirms the implications of modern cost management techniques such as Target Value Design (TVD) in improving delivery cost performances on construction projects. For this reason this paper which forms an integral part of an ongoing doctoral study, aim to identify the efficacy and applicability of TVD in the context of LcH project delivery cost management. A review of relevant and extant literature identifies peculiarities on the concept of TVD and LcH projects. Findings from literature and data collected via questionnaires further identify constraints on current LcH project delivery cost management system and clearly indicates the possible applicability and integration of TVD in the system. These findings provide a platform for the next phase of the research towards developing an improved delivery cost management model for LcH projects. This is expected to engender effective government-led LcH projects delivery particularly in in South-East zone Nigeria.
\end{abstract}

KEYWORDS COST MANAGEMENT, LOW-COST HOUSING, PROJECT COST PERFORMANCE, SUSTAINABILITY, TARGET VALUE DESIGN.

\section{INTRODUCTION}

The problem of housing is universal but apparently more critical in the developing countries (Olotuah \& Bobadoye, 2011). The prevailing housing situations evident in many developing countries, has attracted considerable attention given the declining quantity, quality and high costs of Low- cost Housing (LcH) supplied to target beneficiaries ( United Nations Human Settlements Programme (Un-Habitat), 2012; Assaf, Bubshaitr, \& Al-Muwasheer, 2010). Nowadays, with the prevailing situations of housing inadequacies, governments particularly in many developing countries have recognised the need for sustainable supply of $\mathrm{LcH}$, affordable to the low and low-middle incomes population.

Nigeria as a developing country is apparently geared towards such achievements though, several efforts which are yet to yield appreciable result. Trends of previous Government-

1 School of the Built Environment, University of Salford England United Kingdom. L.i.Obi@edu.salford.ac.uk

${ }^{2}$ School of the Built Environment, University of Salford England United Kingdom. M.Arif@salford.ac.uk 
led LcH schemes in Nigeria have been characterised with inadequate supply, abandoned projects, high supply cost, and poor quality houses (Akinde, 2012; FMLHUD, 2012; Olotuah, 2010 cited in Akinde, 2012; Balogun, 2005; Ogu 1999). Consequently, such impact are presumed to ripple inadvertently on declining housing stock, high sale prices of available stock, undermining affordability of the low and low-middle incomes and growing slums (Ogu, 1999; UN-Habitat, 2011). One of such identified drivers to this situation is the poor delivery cost performances experienced at the $\mathrm{LcH}$ project delivery level (Obi , Arif, Awuzie, 2015; Ubani, Okorocha, \& Emeribe, 2013; Akinde, 2012). This challenge have been identified to apparently lead to colossal loss of scarce resources, affecting client (government) budget projections impacting on project delay and abandonment resulting in declining supply (Smith, 2014). It's no wonder improving the delivery cost performances of $\mathrm{LcH}$ projects has attracted considerable attention across the globe. This will in no doubt, facilitate the realisation of FMLHUD, 2012 policy objective on sustainable LcH housing supply and affordability and particularly in South-East zone Nigeria (Obi et al., 2015;FMLHUD, 2012).

With the ongoing and future projections towards improving sustainable $\mathrm{LcH}$ supply, the construction and housing industry key players seek several survival rather than sustainable and effective strategies that can deliver effective $\mathrm{LcH}$ project cost performances (Urbani, et al., 2013). Therefore it has become imperative that urgent intervention be proffered by investigating cost effective techniques that can be adapted to deliver expected cost performances of $\mathrm{LcH}$ projects. Owing to the affirmed benefits of a modern cost-effective technique TVD that can facilitate improved delivery cost performances on LcH projects (Jacomit \& Granja 2011), this paper aim to identify the efficacy and applicability of TVD in the delivery cost management of LcH project in South-East zone Nigeria. Thus the paper is based on findings from a questionnaire survey and literature based case studies that examines the efficacy of current delivery cost management techniques on $\mathrm{LcH}$ projects cost performances. Furthermore, a systematic review of literature exploring the concept and identifying possible benefits of TVD. Thereby making a case for integrating TVD technique in current cost management system for improved delivery cost performances towards the sustainable LcH supply particularly in South-east zone Nigeria.

\section{LITERATURE REVIEW}

\section{Low-cost Housing (LcH)}

Housing a fundamental need to human existence which no government can ignore (UNHABITAT, 2011). However a vast majority particularly within the low and middle incomes in many countries without any form of assistance cannot live in adequate housing. Therefore $\mathrm{LcH}$ apparently evolved as an intervention strategy by many governments to address the housing needs of the portion of the population who without assistance cannot afford the cost of adequate housing at prevailing market rates in developed and developing countries ( Assaf et. al., 2010; Davis, 1997). LcH is defined by the UN-HABITAT (2011) and World Bank (1975) as housing developed within 
adequate or basic standard quality and target costs affordable to the poor and low income group in the country. However, since the concept of income group classification is not presumed to have a universal definition as contextualised in different countries reflecting differing national economies thus, the concept of $\mathrm{LcH}$ (Ogbu \&Adindu, 2012). Jingchun, (2011) revealed some peculiarities of Low-cost Housing which makes it differ from market housing. In same vein McNelis (2014) espoused that considerations on government involvement, production cost and the capability to afford by the beneficiaries are very important peculiarities characterising the concept of $\mathrm{LcH}$.

Low cost housing in Nigeria is targeted at the low and low-middle incomes (FMLHUD, 2012). Extant records reveals that many LcH supply schemes focused on new-build $\mathrm{LcH}$ projects seem not to meet government projections because of varying challenges.

Table 1: Trajectory of Low-cost Housing Supply in Nigeria

\begin{tabular}{lcll}
\hline LcH Schemes & Scheme Location & $\begin{array}{l}\text { Proposed } \\
\text { Number of } \\
\text { Units }\end{array}$ & $\begin{array}{l}\text { Number of units } \\
\text { Produced and } \\
\text { supplied }\end{array}$ \\
\hline First NDRP 1961 -1970 & Housing estates in Lagos & 61,000 & 500 \\
Second NDRP 1971- 1975 & LcH across the country & 120,000 & 7,080 \\
Third NDRP 1976- 1980 & LcH across the country & 202,000 & 28,500 \\
NHP 1986-1999 & LcH across the country & 121,000 & 1014 \\
NHP 1999- 2007 & LcH across the country & 148,000 & 8585 \\
NHP 2010- 2014 & LcH across the country & 700,000 & 43,126 \\
\hline
\end{tabular}

*NDRP $=$ National development Rolling Plan, NHP= National Housing Programme

Source: Adapted from FMLHUD (2012) and Akinde (2012)

One of such main challenges is the poor cost performances experienced on many LcH projects (See Table 1). Akinde (2012) further compiled a trajectory of poor cost performances of $\mathrm{LcH}$ projects in previous schemes as shown in Fig. 1. (Where NDRP= National development Rolling Plan; $\mathrm{NHP}=$ National housing programme; Using $£ 1=$ N303.00 at April, 2015 exchange rate). Yet this challenge has not been given considerable attention. 
Fig. 1: Low-cost Housing Project Delivery Cost Performance in Nigeria

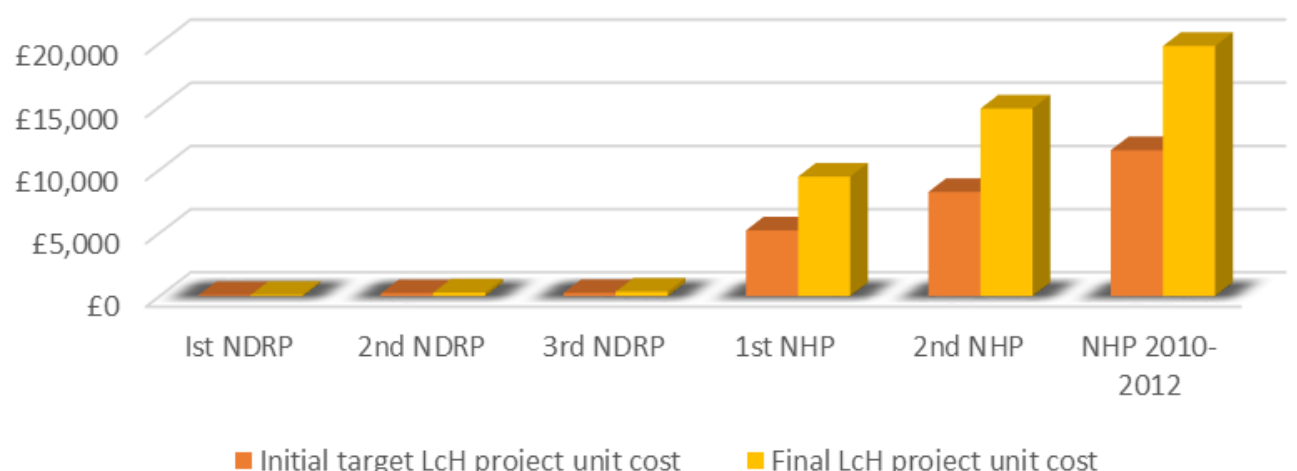

Source: Adapted from FMLHUD (2012) and Akinde (2012)

As a result, the unsuccessful realisation of many $\mathrm{LcH}$ schemes in Nigeria, given rise to prevailing housing deficit estimated at 17 million units with ripple effects on unaffordability by target beneficiaries (Obi et al., 2015; Akinde, 2012; FMLHUD, 2012; Ogu, 1999). This situation is most critical in the South-east zone where the severe poor cost performances of $\mathrm{LcH}$ projects have given rise to the prevailing housing crisis situation (Urbani et al., 2013). However to improve LcH supply, the projections are that an annual average production of 1.5 million units need to be sustainably supplied from 2015- 2025 in following rapid population growth and existing housing dearth (Global construction perspective \& Oxford economics report, 2013; FMLHUD, 2012). To this effect, the Nigerian government seek strategies to sustainably improve LcH supply for the populace which in no doubt is a salient feature of achieving its quest to become one of the top 20 economies by 2020 (FMLHUD, 2012). This is given that the income group which depend on $\mathrm{LcH}$ for adequate housing constitute a vast majority of the population particularly in South-East zone Nigeria.

\section{Sustainability}

The pragmatic term 'sustainability' has many definitions, adaptations and applications, however, the most common and widely accepted meaning was first conceptualised in the World Commission on Environment and Development (WCED) summit (Un-Habitat, 2008; Bruntland, 1987 in Un-Habitat, 2008). It provided that a sustainability in the context is "development that meets the needs of the present without compromising the ability of the future generations to meet their own needs" (Bruntland, 1987, cited in Iwuah et al. 2014). Sustainability is conceived predominantly in the classical context of environmental, social and economic development (Ding, 2008). In simple terms the general goal is to meet the essential needs of the world's poor while ensuring that future 
generations have adequate resources base to meet theirs (Adedeji et al 2011cited in Taiwo \& Adeboye 2013).

Sustainability in the context of housing as defined in relation to the quality of construction embracing social factors as regards psychological impact, economic factors as regards to affordability and eco-efficiency such as efficient use of non-renewable resources in the built environment (VROM, 2005 in Ihuah, et al., 2014). The understanding and implementation of Sustainability in housing takes a different approach in developing countries. Shelter initiative for climatic change (2008), argue that the concept of sustainability in most developing countries is limited to an understanding of economic sustainability. This is because the approach to sustainability in many developing countries owe to the background of improving existing trend of housing dearth and unaffordability particularly for the vast majority of the Low and Middle incomes (Taiwo \& Abeboye, 2013). Therefore, sustainability in the context of LcH from a developing country perspective will refer to the gradual, continual and replicable process of supplying housing that is affordable and that meet the needs of the populace (Adedeji et al., 2011).

It is then no surprise that the goals and objectives of National Housing policy (Federal Ministry of Lands Housing and Urban Development (FMLHUD), 2012) in Nigeria have remained emphatically focussed on improving sustainable production and supply of $\mathrm{LcH}$ to meet the housing need of many low and low- middle incomes in Nigeria. As a result, incorporating sustainable strategies at the $\mathrm{LcH}$ project level will not only make a significant contribution to the achievement of general sustainability objectives, but will also provide important advances in achieving cost effective $\mathrm{LcH}$ project delivery towards improved supply within the confines of beneficiary affordability.

\section{Poor Cost Performances and Effective Cost Management}

Poor cost performances on construction projects have become a global concern affecting client budgets, and end-user affordability and project team level of competency (Obi et al., 2015; Memon et al., 2014; Smith, 2014; Mbachu \&Nkado 2002). The incidences of this challenge have been reported in various studies across several countries around the globe. However, the trend is more severe in developing countries (Odediran \& Windapo, 2012; Reina \& Angelo, 2002). The construction and Low-cost housing sector in Nigeria is severely faced with this problem as earlier highligted (Obi et al., 2015; Odediran \& Windapo, 2012; Balogun, 2005).

Dell'Isola (2002), has argued that poor delivery cost performances can be mitigated by effective cost management. However, in achieving effective cost management $\mathrm{He}$ espoused that emphasis should be at the early stages before the end of design development. Hence, suggesting the need for effective cost management techniques employed particularly at the pre-design and design stages of $\mathrm{LcH}$ project delivery. Studies by Akintoye (1992 in Iroegbu, et al., 2010) have revealed that cost estimating methods are to a large extent mainly employed at these stages. According to Iroegbu et al. (2010) effective project cost planning despite it very important role is highly neglected in many construction project cost management in Nigeria. Thus planning the project 
delivery cost become an outcome of estimates most often found to be greater than what the client is willing to pay nor target beneficiaries able to afford. Such lack of effective technique could be considered a main factor challenging the efficacy of the project cost management system employed towards expected project cost performances (Iroegbu et al., 2010).

Apparently, studies by Zimina, Ballard, \& Pasquire (2012) and Langston (2002) have argued the inefficiency and inadequacy of traditional cost planning for effective cost management and to deliver value for money. This is their view is due to initial decision making, solely dependent on the architect rather than the project team is one of the main challenges. Rather they promulgate the need for more effective techniques as Target value design (TVD) towards achieving the desired output. Thus, it is presumed that the poor cost performances experienced on $\mathrm{LcH}$ projects could be as a result of the lack of adequate techniques employed that can serve as criteria for acceptable cost effective design development and control. To this regards, devising and adopting appropriate techniques such as TVD could facilitate improved delivery cost performances of $\mathrm{LcH}$ project towards sustainable LcH supply at affordable costs.

\section{Target Value design (TVD)}

TVD is a modern technique originating from target costing and adapted into the construction industry (Zimina et al., 2012). It is a technique employed to make a client's value (specific design criteria, cost, schedule) a driver of design, thereby reducing waste and satisfying or even exceeding the client's expectations. It is viewed as a waste elimination technique most suitable at the pre design and design stage during cost setting and planning in the project. By assisting in design and constructing to what is within the client capability to afford (Do, et al., 2014; Zimina, et al., 2012). It could also be view as a technique driving achievement of affordability while improving quality towards effective project performance (Jacomit \& Granja, 2011) Given financial budget constraints for $\mathrm{LcH}$ projects, and economic recessions challenging many countries across the globe including Nigeria, the less amount spent on each unit means a greater number of units can be built and supplied at affordable costs (Smith, 2014; Jacomit \& Granja 2011). To this regards target value design has been identified as a technique particularly effective at the early stages and can be used to deliver effective project cost performance in both large and small construction projects (Do et al., 2014; Zimina et al. 2012). Ballard and Reiser (2004) and Robert and Granja (2006) have reported its successful implementations on various construction projects while Jacomit and Granja (2011) have also espoused its possible application in the context of $\mathrm{LcH}$ project delivery. Thus, exploring the benefits TVD could be a positive direction to improve project delivery cost management and cost performances in view of sustainable supply and affordability.

\section{RESEARCH METHODOLOGY}

This study employed an explanatory sequential mixed method strategy carried out in two stages (Creswell, 2014). However, it adopted, purposive sampling strategy in both stages. This was mainly due to the nature of issues to be investigated that required respondents 
who have knowledge and experience related cost management of $\mathrm{LcH}$ projects and investigating cases were TVD has been applied or espoused for potential benefits. In order to collect such necessary information, in the first stage, a 254 questionnaire survey was administered to purposively selected eighty three $(83 \mathrm{Nr})$ project team organisations with direct managerial influence on the cost management practice on $\mathrm{LcH}$ project in South-East Zone. The project team members comprised of consultancy, contracting and client organisations. The researcher identified the organisations who have been involved in ongoing and completed LCH projects situated in the South-East zone of Nigeria within the past five years from a list of registered organisations available with the housing agencies. Respondents were required to identify the influence of poor cost management on poor cost performances. In addition, identify the frequency of use of a list of techniques at the predesign and design stages of $\mathrm{LcH}$ project delivery. The frequency and percentage and Kendall's W test used to rank the frequency of their use. Thus, the first stage involved the identification of the current system and main techniques employed on the delivery cost performances of $\mathrm{LcH}$ projects. In the second stage, an exploratory literature based case study of two studies that have examined TVD application in construction projects including $\mathrm{LcH}$ projects were investigated. This is to identify the benefit and impact of TVD on the project cost performance.

\section{DATA ANALYSIS}

\section{Analysis from questionnaire data}

From the data analysis, from a total of 245 questionnaires distributed and 144 (Client 26, Consultancy 57 and contracting 61) were returned representing a total response rate of 59 percent. A Cronbach alpha test was conducted which yielded an acceptable co-efficient of 0.808 showing the data was reliable and can therefore be used to conduct further analysis. The analysis of the questionnaires are further presented:

Fig 2: Extent of agreement on influence of poor delivery cost management and efficacy of current cost management system.

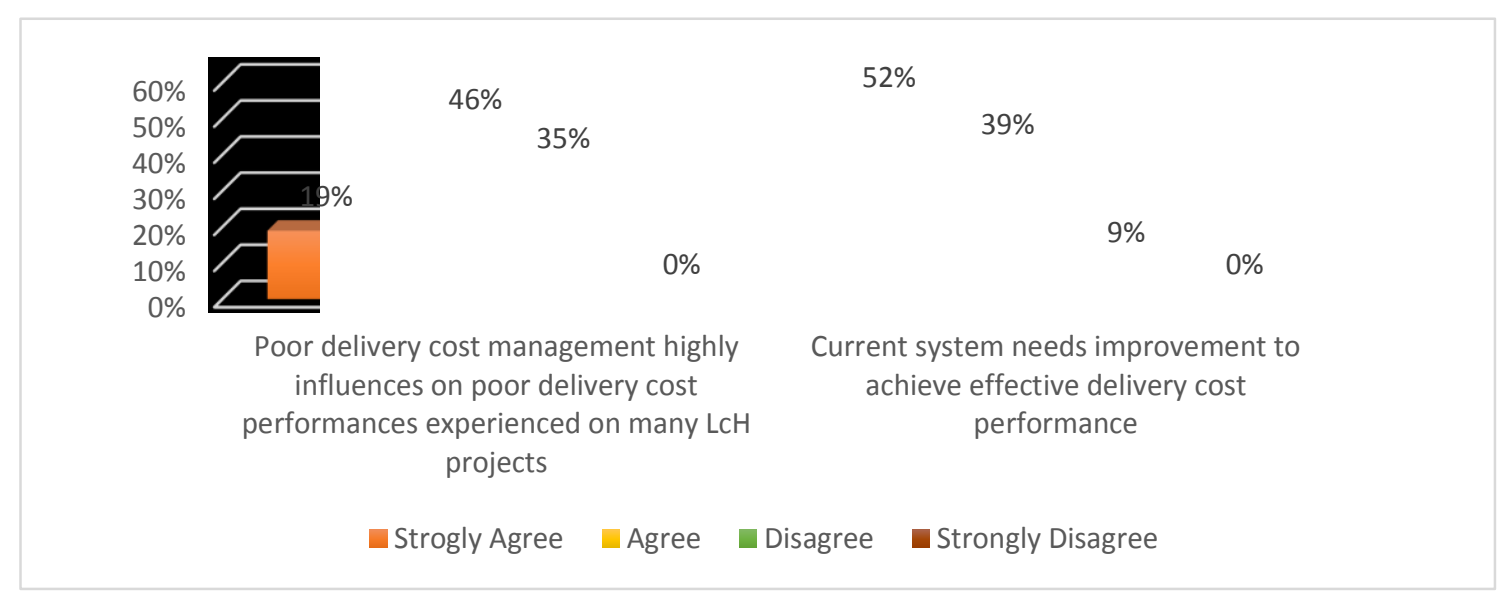


Findings from the responses documented in Fig 2 above $19 \%$ and $43 \%$ have a level of agreement that poor delivery cost management is one of the main factor influencing poor delivery cost performances experienced on many $\mathrm{LcH}$ projects while $35 \%$ disagrees to this. It was also revealed that there is a need to improve on the current cost management system with $52 \%$ and $39 \%$ in a level of agreement and only $9 \%$ of the respondents in disagreement. From the findings, the cost management system poses a challenges towards the achievement of effective delivery cost performance of $\mathrm{LcH}$ project corroborating previous studies.

Drawing from views by Dell'Isola (2002) on achieving effective cost management, techniques employed particularly at the predesign and design stage was investigated and findings presented in Table 2.

Table 2: Frequency of current techniques used particularly in the predesign and design stages of Low-cost Housing project cost management

\begin{tabular}{lll}
\hline Techniques & Kendall W Mean rank & Interpreted Ranks \\
\hline Traditional cost estimating & 7.95 & 1 \\
Cash flow forecasting & 7.10 & 2 \\
Cost scheduling & 6.93 & 3 \\
Cost budgeting & 5.95 & 4 \\
Traditional cost Planning & 4.89 & 5 \\
Cost reporting & 4.73 & 6 \\
Target Value Design & 2.53 & 7 \\
\hline
\end{tabular}

From Table 2, Cost estimating, cash flow forecasting and cost scheduling techniques with means 7.95, 7.10 and 6.93 ranking 1 st, 2 nd and 3rd are frequently employed while TVD of mean 2.53 ranking 7 th, is least employed in the delivery cost management system of $\mathrm{LcH}$ projects in the zone. This corroborates previous findings by Iroegbu et al., (2010). As such, the techniques employed are not sufficient to facilitate effective delivery cost management on the project.

\section{Case analysis}

This section presents a case study of a case A and B on TVD implementation in construction projects that cut across large and small projects in the USA and applicability in $\mathrm{LcH}$ projects in Brazil. Case A is a study from the findings cost performances on 47 projects in the United States of America (USA). Case A identified the demand for improved cost performances on construction projects (Large and small) owing to clients budget constraints and where possible cost reduction and improved value. In order to achieve such, case A came to the conclusion that implementation of TVD reduces the likelihood of poor project cost performances with delivery at $25-42 \%$ below client budget. Furthermore Case A concluded that TVD can be applied to projects of all sizes. Hence a cost effective technique particularly when applied from early stages of project delivery. 
Case B is a study from the findings on possible applications of TVD in LcH projects a developing country- Brazil. Case B identified the demand for improved LcH. However, in order to develop and supply $\mathrm{LcH}$ at affordable costs to the Low incomes responsive in terms of cost and quality effectiveness, case B came to the conclusion that TVD could be more successful in an $\mathrm{LcH}$ project delivery context adopting the design-build delivery system. Further findings revealed that TVD can also promote an increase in LcH project cost performances, quality and value delivery to end-users and clients.

\section{DISCUSSIONS AND CONCLUSION}

Given that the less amount spent in the production on each $\mathrm{LcH}$ unit means a greater number of units can be built and supplied to the target beneficiaries (Jacomit \& Granja 2011), effective LcH project delivery cost performances is a strategic approach to facilitating improved $\mathrm{LcH}$ supply. This is a positioning paper which establishes the feasibility of target value design in delivery cost management of $\mathrm{LcH}$ projects towards a sustainable LcH supply particularly in South- East zone Nigeria. Delivery cost performances experienced on the $\mathrm{LcH}$ projects in the zone have been identified to challenge effective supply and affordability. One of the reasons for such occurrences is traceable to the choice of techniques employed at the predesign and design stages of the project. Analysis from the questionnaires show that traditional cost estimating is mostly employed whereas TVD is least employed techniques at the pre-design and design stages of the $\mathrm{LcH}$ project delivery process. Findings from case analysis further demonstrates how the integration of TVD have improved the performances of projects including expected outcomes on LcH projects. It reveals TVD can be applied to projects of all sizes, however identified to be more successful when adopted with the design-build delivery system. It further reveals that TVD provides a platform to deliver effective value for money meeting cost budgets within the confines of affordability at improved quality.

From this discourse, implementing techniques strategic for cost effective performances at the project level will help deliver value for money both to government as the client and target beneficiaries alike and promote sustainable $\mathrm{LcH}$ production and supply. The move towards sustainable LcH supply at affordable costs can be achieved by integrating cost effective planning techniques particularly at the early stages of $\mathrm{LcH}$ project delivery process. This creates an opportunity for TVD to be integrated in the $\mathrm{LcH}$ cost management system to meet such expectations. Indeed, integrating TVD in the cost management system for $\mathrm{LcH}$ project delivery in particularly South-East zone Nigeria seems to be an idea whose time has come. Following espoused benefits offered by TVD towards the realisation of sustainability objectives it is clear that this technique if employed in the $\mathrm{LcH}$ project cost management system, particularly at the early stages, can drive the achievement of affordability, value enhancement, resource efficient use and cost effectiveness, improving delivery cost performances. The feasibility of its expected outcomes points towards the realisation of improvement at the project level, to facilitate effective LcH production and supply across the zone. (Zamin a et al, 2012; Jacomit \& Granja, 2011). This will call for the strong strategic involvement of the $\mathrm{LcH}$ project cost management team members; client, consultant and contractor teams alike. This study 
findings provide the needed platform to for developing a $\mathrm{LcH}$ delivery cost management model integrating TVD which is the next phase of the research. However, its integration will require examination of contextual peculiarities, a shift in the process and procurement system that may be currently adopted on such projects. This is expected to engender effective project delivery cost performance of $\mathrm{LcH}$ projects towards sustainable production and supply in the South-East zone Nigeria.

\section{REFERENCES}

- $\quad$ AKINDE, S. B. (2012). Lean Implementation towards Effective Low cost Housing Design and Construction Delivery in Nigeria. BSc. Diss. Unpublished. Salford Uni.

- $\quad$ ASSAF, S. A., BUBSHAITR, A. A., AND AL-MUWASHEER, F. (2010). Factors Affecting Affordable Housing Cost in Saudi Arabia. International Journal of Housing Markets and Analysis, 3(4), 290-307.

- BAllard, G., AND REISER, P. (2004). The St. Olaf College Fieldhouse Project: A Case Study in Designing to Target Cost. In 12th Annual Conference of the International Group for Lean Construction. 234-249.

- BALOGUN, O. M. (2005). Clients' Perception on Measure of Indigenous Contractors Performance in the Construction Industry. The Professional Builders, Journal of Nigerian Institute of Building, July edition, 42-48.

- DAVIS, S. (1997). The Architecture of Affordable Housing: London. Univ. of California Press Ltd.

- $\quad$ DELL'ISOLA, M. D. (2002). Architect's Essentials of Cost Management (Vol. 8): New York. John Wiley and Sons.

- DING, G. K. (2008). Sustainable Construction - the Role of Environmental Assessment Tools. Journal of Environmental Management, 86(3), 451-464.

- $\quad$ DO, D., CHEN, C., BALlARD, G., AND TOMMELEIN, D. (2014). Target value Design as a Method for Controlling Project Cost Overruns. In Proceedings of 22nd Annual Conference of the International Group for Lean Construction Oslo.

- FEDERAL MINISTRY OF LANDS HOUSING AND URBAN DEVELOPMENT (FMLHUD). (2012). National Housing Policy. Nigeria.

- $\quad$ GLOBAL FORECAST FOR THE CONSTRUCTION INDUSTRY TO 2025 Report. (2013) (Online). Available http://www.arcadis.com/Content/ArcadisGlobal/docs/publications/Research/Global_Perspecti ves_2025_Exec_Summary.pdf(Accessed 10th March, 2015)

- $\quad$ IHUAH, P. W., KAKULU, I. I., AND EATON, D. (2014). A review of Critical Project Management Success Factors (CPMSF) for Sustainable Social Housing in Nigeria. International Journal of Sustainable Built Environment, 3(1), 62-71.

- $\quad$ IROEGBU, A., NWAFO, K., WOGU, C., AND OGBA, S. I. (2010). Application of Project Cost Planning Techniques in the Nigeria Project Cost Management System. The Coconut: A Multidisciplinary Journal of Environment, Agriculture, Science and Technology, 2(1), 1-8.

- JACOMIT, A. M., \& GRANJA, A. D. (2011). An Investigation into the Adoption of Target Costing on Brazilian Public Social Housing Projects. Architectural Engineering and Design Management, 7(2), 113-127.

- JINGCHUN, L. (2011). The Development of Affordable Housing A case Study in Guangzhou, China. MSc. Diss. KTH Architecture and Built Environment..

- LANGStON, C. (2002). A New Era in Cost Planning. In Design and Construction: Building in Value. Oxford, Elsevier Science Ltd, 59-74.

- $\quad$ MBACHU, J., AND NKADO, R. (2004). Reducing Building Construction Costs; the Views of Consultants and Contractors. Paper presented at the Proceedings of the International 
Construction Research Conference of the Royal Institution of Chartered Surveyors, Leeds Metropolitan University.

- McNELIS, S. (2014). Making Progress in Housing: A Framework for Collaborative Research: London. Routledge.

- MEMON, A. H., RAHMAN, I. A., ABDUllaH, M. R., AND AZIS, A. A. (2014). Factors Affecting Construction Cost Performance In Project Management Projects: Case of MARA large projects. International Journal of Civil Engineering and Built Environment, 1(1).

- $\quad$ OBI, L.I., ARIF, M. AND AWUZIE, B. (2015). Waste Factors Impacting on Delivery Cost Performance of Design and Build Low-cost Housing Projects in Nigeria. In proceedings of 12th International Post graduate Conference University of Salford, Manchester, 10-12th June.

- ODEDIRAN, S. J., AND WINDAPO, A. O. (2014). Systematic Review of Factors Influencing the Cost Performance of Building Projects. Paper Presented at the Postgraduate Conference.

- OGU, V. I. (1999). Housing Enablement in a Developing World City: The Case Study of Benin City, Nigeria. Habitat International, 23(2), 231-248.

- OLADAPO, M. A. (2001, October). A framework for cost management of low cost housing. In International Conference on Spatial Information for Sustainable Development, Nairobi, Kenya 2-5.

- OlOTUAH, A. O., BOBADOYE, S. A. (2011). Sustainable housing provision for the urban poor: a review of public sector intervention in Nigeria. The Built \& Human Environment Review, 2.

- OZURUMBA, B. A. (2011). Urban Housing Financing in the South-Eastern States of Nigeria: Problems and Prospects. Journal of Sustainable Development in Africa, 13(8), 268 -282.

- $\quad$ REINA, P., AND ANGELO, W. J. (2002). Megaprojects Need More Study upfront to avoid cost overruns. ENR, 249(3).New York. McGraw-Hill, Incorporated

- $\quad$ ROBERT, G. T., AND GRANJA, A. D. (2006). Target And Kaizen Costing Implementation In Construction. In Annual Conference of the International Group for Lean Construction (Vol. 14).

- $\quad$ SMITH, P. (2014). Project Cost Management - Global Issues and Challenges. Procedia Social and Behavioral Sciences, 119, 485--494.

- $\quad$ UBANI, E., OKOROCHA, K., AND EMERIBE, S. (2013). Analysis of Factors Influencing Time and Cost Overruns on Construction Projects in South-Eastern Nigeria. International Journal of Mgt Sciences and Business Research, 2(2), 73.

- $\quad$ UNITED NATIONS HUMAN SETTLEMENTS PROGRAMME (UN-HABITAT), (2012). Affordable land and housing in Africa.(Online) Available at http://mirror.unhabitat.org/pmss/listItemDetails.aspx?publicationID=3376 (Accessed 28th June, 2014).

- $\quad$ UNITED NATIONS HUMAN SETTLEMENTS PROGRAMME (UN-HABITAT), (2008). Low-cost Sustainable Housing in Developing Countries 1-35.

- ZIMINA, D., BALlARD, G., AND PASQUIRE, C. (2012). Target value design: using collaboration and a lean approach to reduce construction cost. Construction Management and Economics, 30(5), 383-398. 


\title{
STIMULATING THE BANKABILITY OF PFI/PPP INFRASTRUCTURES THROUGH THE UK GOVERNMENT GUARANTEES: PROSPECTS AND CHALLENGES
}

\author{
Owolabi H. A. A. ${ }^{1}$; Oyedele L.O.C. ${ }^{2}$; Alaka A.H.A. ${ }^{3}$; Ajayi O. S A ${ }^{4}$; Akinade O.O A. ${ }^{5}$ and Muhammad \\ Bilal $^{6} \mathrm{~A}$
}

\begin{abstract}
:
The significance of public sector guarantees in stimulating PFI/PPP development has considerably increased since the recent global financial crisis in 2007-08. A Major reason for this is the drastic decline in availability of bank lending, bonds and capital markets finances for long term PFI infrastructure projects. Despite the introduction of the UK Guarantee Scheme for Infrastructure in July 2012 which was designed to attract private investments for new public infrastructures, investors in PFI have only managed to guarantee few projects so far. The overall goal of this study explores the impact of the scheme on the industry, its challenges and critical parameters for securing approval for Government Guarantee in PFI projects. Using a methodology of phenomenology, literature review and unstructured interviews were conducted with construction contractors, public sector employees, equity investors and lenders in UK construction industry. The study discusses five critical parameters necessary for guaranteeing government approval in PFI projects. These factors include (1) project compliance with UK National Infrastructure Plan, (2) demonstration of project bankability and risk management, (3) certainty in planning approval, (4) prove of dependence on guarantee and (5) value for money to taxpayers. Evidently, in-depth understanding of these necessary criteria will enable industry players (equity sponsors, banks, contractors and subcontractors) access such guarantee and improve the bankability of prospective PFI/PPP Projects.
\end{abstract}

KEYWORDS: CONSTRUCTION INDUSTRY, GOVERNMENT GUARANTEE SCHEME, PRIVATE FINANCE INITIATIVE (PFI), PROJECT FINANCE, PUBLIC PRIVATE PARTNERSHIPS (PPP)

\section{INTRODUCTION}

Since the recent global financial crisis (GFC) in 2007/2008, raising senior debt to finance PFI/PPP projects has become more difficult for most project sponsors (Demirag et al., 2011, Hampl et al., 2011). The huge financial loss suffered by many active lenders (Banks) to PFI projects at the wake of the GFC led to drastic reduction in capital available for financing many project finance contracts (Hampl et al., 2011). According to

\footnotetext{
${ }^{1}$ Director of Bristol Enterprise, Research and Innovation Centre (BERIC), Bristol Business School University of West of England, Bristol, Frenchay Campus, Coldharbour Lane, Bristol, BS16 1QY, United Kingdom, Hakeem2.owolabi@live.uwe.ac.uk

2 Bristol Enterprise, Research and Innovation Centre (BERIC) Ayolook2001@yahoo.co.uk; L.Oyedele@uwe.ac.uk

${ }^{3}$ Bristol Enterprise, Research and Innovation Centre (BERIC) Hafiz2.Alaka@live.uwe.ac.uk

${ }^{4}$ Bristol Enterprise, Research and Innovation Centre (BERIC) Saheed2.Ajayi@live.uwe.ac.uk

${ }^{5}$ Bristol Enterprise, Research and Innovation Centre (BERIC) Olugbenga2.Akinade@live.uwe.ac.uk

${ }^{6}$ Bristol Enterprise, Research and Innovation Centre (BERIC) Muhammad2.Bilal@live.uwe.ac.uk
} 
Meng and McKevitt (2011), the financial meltdown saw most banks becoming more stringent in criteria for granting project finance loans. The situation also led to a new culture of selectivity among project lenders in the industry, as banks began to cherry pick only bankable projects for financing (HM Treasury, 2014). With the borrowing powers of investors being eroded in the Inter-Bank market amidst escalated loan margins (Demirag et al., 2011); the need to meet growing infrastructural demands among many European nations propelled government interventions, especially in the UK.

Realising the need to raise private sector investments for new UK public infrastructures valued at $£ 250$ billion in the 2011 National Infrastructure Plan (NIP), the HM Treasury introduced an infrastructure stimulus package known as UK Guarantee Scheme for Infrastructures (UKGSI) in July 2012 (NAO, 2015). The primary objective of this scheme was to avoid delays to private investment in viable UK infrastructures that may have been hindered by the credit crunch. As part of its mandate, the scheme provided a $£ 40$ billion sovereign-backed guarantee that makes priority projects within the UK bankable to lenders, while stimulating market growth. The guarantee therefore aimed at facilitating access to bank credit and reduces the risks associated with financing large scale infrastructure projects to lenders. However, despite the laudable objectives behind the UKGSI, a recent report by the National Audit Office (NAO, 2015) revealed that sponsors in UK infrastructure projects have only managed to guarantee few projects so far. According to NAO (2015), out of the 200enquiries for government guarantee received by the Treasury Department, only 7 projects have been guaranteed while another 39 other projects were pre-qualified.

According to HM Treasury (2014), chief among the factors militating against projects sponsors from assessing the facility, is the poor structuring of potential projects' business cases. Many projects applications that were submitted for guarantee failed to prove commercial viability, in spite of efforts to use the scheme to give UK investors opportunity to raise cheaper long term private finances for projects using the strong sovereign credit risk rating of the UK government. Recent trend in the global financial market may have seen a resurgence of bank lending especially from year 2013 (NAO, 2015). Yet most banks have not been lending on long term basis (Johal et al., 2012). Bonds issuance still remained very limited with banks' lending being concentrated in few large projects (Johal et al., 2012). In effect, the UK is still faced with massive challenges in attracting private investments into PFI projects on the long-term, as an aftermath of the credit crisis (HM Treasury, 2014). The graph in Fig. 1 below shows the trend in private finance lending to new UK infrastructures between $2006-2014$. 
Figure 1. Volume of Bank and Bond Financing to PFI Projects (£bn), 2006-2014

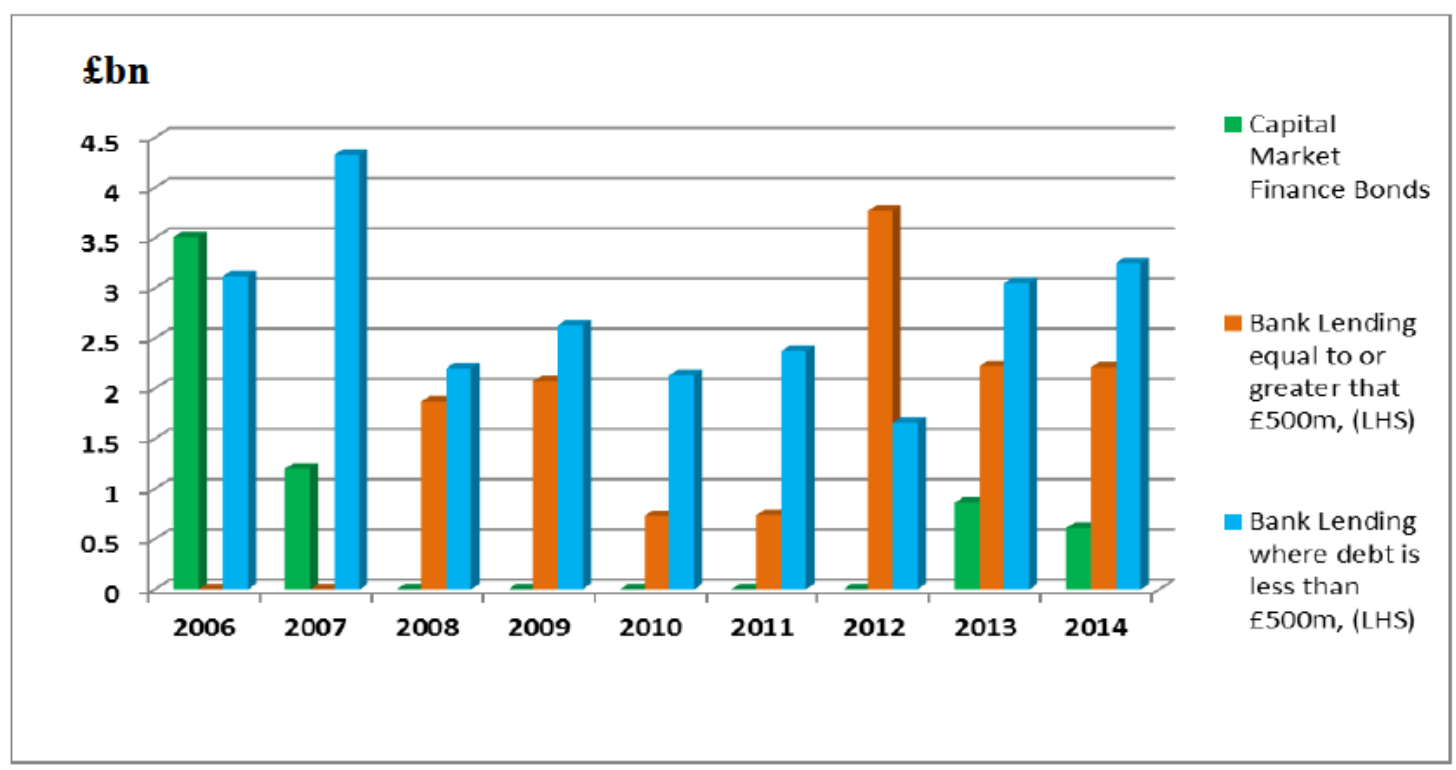

Adapted From National Audit Office (2015)

The graph reveals that banks lend to fewer PFI projects with value above $£ 500 \mathrm{~m}$, compared to PFI projects of value below $£ 500 \mathrm{~m}$ over the 9 year period.

Considering that UK currently values her infrastructural needs at about $£ 466$ billion based on the revised 2014 NIP policy, it expects much of it to be financed with private investment. Therefore, the major question before PFI stakeholders is, to what extent has the stimulus package encouraged bankability of UK PFI infrastructures? It is from this background that this study emerged with the overall aim of exploring the impact, critical parameters and challenges militating against investors' access to the UK Government Guarantee for PFI projects. In other to achieve the above aim study, the following objectives have been identified for the study:

1. To investigate stakeholders opinions regarding challenges of PFI sponsors in accessing the UK Guarantee Scheme for Infrastructure.

2. To examine the critical parameters that is necessary for UK PFI/PPP investors in infrastructures towards exploiting the UKGSI.

3. To examine the industry perception of the UK Guarantee Scheme for Infrastructures with regards to its overall impact and accessibility by PFI investors.

This study explores the perspectives of stakeholders in the UK project finance industry regarding challenges, critical parameters and opportunities that abound in the UK Guarantee Scheme for Infrastructure (UKGSI). Using phenomenological methodology, unstructured interviews with PFI industry stakeholders such as public sector assessors, lenders, equity investors etc. were carried out for data collection. This paper is structured as follows. The next section reviews the UK Guarantee Scheme for Infrastructure (2012) policy. It discusses the fundamental objectives of the stimulus package, as an extension 
of the 2011 UK National Infrastructure Plan (NIP). The third section examines the research methodology. The fourth section presents the findings from experts' opinions. The final section concludes the paper.

\section{LITERATURE REVIEW}

Despite the importance of project finance towards financing public-oriented projects (i.e. as roads, rail network, hospitals etc.), the current global financial crisis created drastic reduction in loan capital available for numerous project finance contracts (Meng and McKevitt, 2011; Hampl et al; 2011; Demirag et al; 2011). The global project finance market which attained a record high $\$ 68.6$ billion in 2008 suddenly plummeted by the end of 2009 to about $\$ 55.5$ billion due to the effect of the economic meltdown (Demirag et al, 2011). By the beginning of 2010, the value of bank lending to UK infrastructural projects had fallen from £6billion pre-crisis level to $£ 3$ billion (NAO, 2015). Due to this massive impact on major global economies, the need to reverse the ugly trend and ensure access to finance for critical infrastructures became imperative. Countries like US, Japan, Australia, China etc. began massive roll out of various economic and fiscal stimulus packages (Drew, 2010), with the Obama administration injecting about \$US800 billion in fiscal stimulus package, into the US financial system (Hampl, 2011).

Following this trend, the UK Government in 2012, passed into law the Financial Assistance Act. This act empowered the Treasury Department to provide financial guarantees for critical infrastructural projects in the UK (NAO, 2015), hence, the introduction of the 4year UK Guarantee Scheme for Infrastructures (UKGSI). The UKGSI was designed to provide an unconditional government cover for risks as well as other liabilities associated with financing large scale infrastructures in the UK. This HM Treasury’s policy was backed by a £40billion cover and was made accessible to private investors in UK infrastructures. The policy was to further facilitate successful implementation of the 2011 National Infrastructure Plan (NIP). The NIP itself is a 5year infrastructure master plan coordinated by Infrastructure UK (IUK); a department in the Treasury. It is the UK government's mid-term infrastructural plan that highlights 500 infrastructure projects requiring investment to the tune of $£ 250$ billion in priority sectors. Two-third of such investment is to be privately financed using schemes such as the PFI/PPP. But with the country facing challenges in attracting long term bank lending for project finance contracts owing to market instability, the guarantee scheme became necessary to stimulate market confidence.

As part of procedures for accessing the guarantee facility, the treasury department conducts due diligence appraisals for project proposals similar to commercial practice by project finance banks. Such appraisal involves risk assessments, economic and technical feasibility as well as value for money assessment. The treasury also ensures that, potential PFI investors are charged a non-refundable fee that is calculated based on market oriented bench mark on prices of risk margins. This fee, it considers as value for money to tax payers, given that the likelihood of making a call on such guarantee is low. However, inspite of the laudable objectives behind the UKGSI, report of the National 
Audit Office (2015) discovered that sponsors in UK infrastructures have only managed to guarantee few projects so far. Although the Treasury recorded her first guarantee in April, 2013; by December, 2014, only $£ 1.7$ billion of the $£ 40$ billion guarantee facility had been accessed (NAO, 2015). But with the facility due to terminate by December, 2016; the big question remains, to what extent had the UKGSI justified its primary objective.

\section{RESEARCH METHODOLOGY}

This study is exploratory in nature and adopts a phenomenological methodology which examines the common understanding of participants regarding a phenomenon, without relying on a priori theory (Fraassen, 2006). As such, evidence-based generalisation is considered capable of building theory (Lincoln and Denzin, 1994). The study therefore investigates the shared experiences of participants with respect to critical parameters, prospects and challenges militating against PFI sponsors in accessing the UK Government Guarantee. Literature review and unstructured interviews with UK PFI/PPP industry stakeholders (i.e. public sector assessors, lenders, equity investors and construction contractors) were conducted. The adoption of unstructured interviews was aimed at facilitating in-depth representation of the views and experiences of the research participants, as well as the meanings they subjectively ascribed to the phenomena (Alversson and Deetz, 2000). The sampling strategy adopted in the study is a purposive sampling approach based on the need to identify information-rich participants. Similar studies on project finance (see Bing et al., 2005; Li et al., 2005; Meng and McKevitt, 2011) have adopted this sampling method. The adoption of purposive sampling method in this study ensured the research team uses network of contacts within the UK PFI/PPP industry.

\section{Unstructured Interviews}

In order to enhance the generalisability of the research findings, a total of fourteen unstructured interviews were conducted in all. Twenty two participants were involved in the interviews comprising, four public sector assessors, four representatives of banks, six representatives of equity investment firms and eight construction contractors. In total, all the interview participants have been involved in an average of $36 \mathrm{PFI} / \mathrm{PPP}$ project finance deals in their career. Additionally, the average number of UKGSI applications personally involved in by all participants is 18 . The entire interviews duration lasted $467 \mathrm{mins}$. Below is the table showing the particulars of the interview participants: 
Table 1: Particulars on Interview Participants

\begin{tabular}{|c|c|c|c|c|c|}
\hline & $\begin{array}{l}\text { Public } \\
\text { Assessor }\end{array}$ & Lenders & $\begin{array}{l}\text { Equity } \\
\text { Firms }\end{array}$ & contractors & Total \\
\hline $\begin{array}{l}\text { No. of Interview } \\
\text { Participants }\end{array}$ & 4 & 4 & 6 & 8 & 22 \\
\hline $\begin{array}{l}\text { No. of Interviews } \\
\text { conducted }\end{array}$ & 2 & 4 & 6 & 2 & 14 \\
\hline $\begin{array}{l}\text { Average experience of } \\
\text { participants in PFI/PPP }\end{array}$ & $7 \mathrm{yrs}$ & 9yrs & $8 y r s$ & $10 \mathrm{yrs}$ & $34 \mathrm{yrs}$ \\
\hline Project financing & $75 \mathrm{mins}$ & $112 \mathrm{~min}$ & $160 \mathrm{~min}$ & $120 \mathrm{~min}$ & $467 \mathrm{~min}$ \\
\hline $\begin{array}{l}\text { Duration of interviews } \\
\text { conducted }\end{array}$ & $\begin{array}{l}\text { 3mid- } \\
\text { level,1 }\end{array}$ & $\begin{array}{l}\text { 4manage } \\
\text { rs }\end{array}$ & $\begin{array}{l}\text { 4manage } \\
\text { rs, } 2\end{array}$ & 2 managers & \\
\hline $\begin{array}{l}\text { Job Title of interview } \\
\text { participants }\end{array}$ & $\begin{array}{l}\text { senior } \\
\text { staff }\end{array}$ & 9 & $\begin{array}{l}\text { junior } \\
\text { staffs }\end{array}$ & 6 & 36 \\
\hline Average No. of & 9 & & 12 & 1 & \\
\hline $\begin{array}{l}\text { PFI/PPP projects } \\
\text { involved } \\
\text { Av. No. UKGSI } \\
\text { application involved }\end{array}$ & 10 & 4 & 3 & & 18 \\
\hline
\end{tabular}

Interview discussions in each group explored the experiences of various participants regarding the UKGSI applications that they have been involved in. Issues such as the basis for approaching the scheme, critical parameters for potential projects applications for guarantee and the challenges encountered in the course of applying for the guarantee were examined. Stakeholders were also asked about their perceptions regarding the general accessibility and impact of the scheme on the UK PFI market. Data collected from unstructured interviews were later transcribed. The qualitative data analysis was carried out using Nvivo10 software. Perspectives of various segments of stakeholder participants were thematically analysed and were cross-validated to arrive at valuable findings that are generalizable within the UK PFI/PPP industry.

\section{DISCUSSION OF FINDINGS}

This section discusses findings from unstructured interviews conducted with UK PFI industry stakeholders such as public sector assessors, lenders, equity investors and construction contractors. The various findings are grouped under three distinct themes i.e. (1) PFI industry stakeholders' perception of the UKGSI in terms of impact and general accessibility, (2) challenges encountered in accessing the guarantee scheme, (3) Critical parameters for securing UK government guarantee for infrastructures.

\section{Stakeholders' Perception of Impact and Accessibility of the Scheme}

Evidences emerging from the interviews revealed differences of opinion between the public sector participant and their private sector counterparts regarding the impact of the 
UKGSI. From the private sector perspective (i.e. representative of equity investment firms, banks and construction contractors), there is a consensus of opinion that:

"Going by the number of projects covered so far, the UKGSI is yet to encourage bankability of PFI projects in UK, speaking generally from the industry's point of view. At best, it has only allowed the execution of few numbers of projects that the treasury considered as priority. Many investors in PFI projects in UK have found it practically impossible to access the guarantee".

This views are in line with the study of LaBelle, (2012) who argued that, asides the major projects covered by the current UK guarantee scheme, there are limited project finance deals backed by institutional investors.

Despite the criticism of the UKGSI by most private sector interview participants, public sector assessors argued that:

"The scheme was not designed for every PFI project across all levels, (i.e. from counties to the national level). In that case not many of the PFI initiatives will be able to access the guarantee. But even at that, it doesn't indicate poor accessibility to the funds. The projects that receive most attention are the infrastructure projects with high construction risk and are likely to be non-investment grade”.

Public sector participants further argued that the impact of the scheme must be examined from a holistic point of view rather than based on the statistics of the number of projects that qualified for the guarantee. This perspective was also echoed by HM Treasury (2014) who argued that, an estimated 50 institutional investors have provided long and medium term finance for PFI infrastructure projects due to the impact of the guarantee scheme.

\section{Challenges Encountered in Accessing the Guarantee Scheme}

Based on findings from interview participants from the public sector (assessors), the major bane of the administrators of the scheme is poor structuring of many guarantee applications. Assessors unanimously argued that:

"One of the major reasons for the poor cover rate of the guarantee is that, most guarantee applications received by the UKGSI often have weak business cases. The UKGSI requires applicant to put together a water tight case for the commercial approach to their proposed projects. However, this is often lacking in many applications."

This perspective had once been highlighted by Ahadzi and Bowles (2004) who argued that, the exercise to secure guarantee for PFI project is as rigorous as securing the actual bank funding. Guarantors will require almost similar information as lenders, and chief among it is the extensive prove of financial as well as technical viability of the proposed project (Glaister, 1999). 
From private sector participants' point of view, transparency guarantee assessment was a big issue. Most participants from equity investments firms and the contractors,

"A number of criteria for accessing the scheme are subjective and difficult to address by investors. Project sponsors are required to demonstrate how their proposed PFI projects increased economic growth. This aspect tends to create bias in favour of large scale infrastructure projects, as against regional level or medium scale PFI projects."

Bing et al. (2005) agreed with this perspective in the role of public sector in PFI/PPP procurements. The study argued efficient PPP procurements rest on transparent and competitive bidding process; hence the public sector is expected to ensure that its rules and criteria are devoid of ambiguity.

Most private sector interview participants further argued that:

"The additional fee charged by the Treasury for providing the guarantee indirectly increases the cost of procurement. And this may work against the project sponsors during competitive bidding with other bidders who may leverage on lower project cost".

This perspective echoed the study of Boussabaine (2013) who argue that, PFI/PPP model allows government to finance a project on lower cost basis. This criticism was however countered by participants from public sector who argued that the scheme provides opportunity for private investors in infrastructures to raise long term bank lending on cheaper terms due to the strong sovereign credit rating of the UK government.

Additionally, most private sector participants highlighted the value for money assessment in the UKGSI scheme as defective. Participants argue that:

"Current UK PFI procurement policy had integrated value for money assessment in most project procurement in the UK. This is inescapable. So the justification that the treasury refers to its fee charge as value for money for the tax payers is a bit contradictory."

\section{Critical Parameters for being guaranteed under the UKGSI}

Based on findings from most participants from unstructured interviews, there are five critical requirements considered for being guaranteed under the UKGSI. According to most participants:

(1) "One of the first requirements is for the project to fall within the priority areas highlighted in the National Infrastructure Policy plan".

According to HM Treasury (2013), the UK 2011 NIP policy is targeted at nationally significant projects. Such project must therefore be large scale and be defined as infrastructure under the NIP policy (HM Treasury, 2014). Sectors such as road, rail, aviation, energy, local authority transports etc. are given preferences with regards to the scheme (HM Treasury, 2013). 
However, most private sector participants argued this criterion has made many medium size and small PFI investments to fall out of the scope of the scheme.

Another important parameter discussed by participants is:

(2) "Such project must have been approved by planning commission for construction works to start."

Stakeholders differed on this criterion. While the equity and construction contractors believed that such requirement is an unnecessary bureaucracy to the process due to the length of time to secure approval in many cases. Lenders and public sector assessors argued that:

"Having a planning commission permit is crucial to raising bank loan for such PFI project, as much as for the guarantee".

This view is supported by Meng and Mckevitt (2011) who argue that the operational permits and approval of projects is an important bankability criterion for winning PFI funding approval.

Interviews participants also agree that a strong business case of proposed project is an important guarantee criterion. Participants argue that:

(3) "The crucial thing here is that the project must demonstrate bankability (commercial and technical viability). Such project must also be non-investment grade."

This supports views in the study of Hampl et al. (2011) who argue that, investors must convincingly argue the financial viability and technical feasibility of their proposed PPP project, before any guarantee cover can be agreed.

Additionally, further evidences from interview participants suggest that, part of the requirement for being guaranteed is:

(4) "Project investors must demonstrate the project's dependence on the guarantee. The scheme will only consider projects that prove how it cannot go ahead without the backing of UKGSI guarantee. And this is a bit of a challenge for many project sponsors".

This view confirmed information from the National Audit Office Report (2015), where the Treasury argued that, proving the need for the guarantee is critical to consideration, to avoid investors' undue exploitation of the scheme.

Furthermore, most participants also argue that, another critical parameter for receiving the UKGSI cover is the demonstration of value for money (VFM). Although, participants 
differed on the appropriateness of such VFM in the scheme, but they collectively agree that:

(5) "It is essential to the scheme for project sponsors to demonstrate how such potential project represents value for money to tax payers. This is a bit confusing though considering that, not only must the project pass the VFM test to public sector client and the guarantee scheme, it must also demonstrate how it contributes to economic growth".

Public sector assessors argue that:

"It is important for the treasury to ensure that such project does not only have acceptable credit rating, but must not also present any fiscal or economic risk to the financial system”.

This view is vigorously contested however, by many private sector interview participants (lenders, equity and construction contractors) who argued that, the Treasury's definition of value for money under the guarantee scheme is complex and confusing. A number of studies such as Li et al. (2005), Demirag et al. (2004), Bing et al., (2005) have highlighted the significance of VFM in public procurement. According to Li et al. (2005) VFM in PFI/PPP emphasizes quality, efficiency/effectiveness, affordability and performance standards. The UK HM Treasury (1997: para. 3.10) has mandated that 'value for money will need to be demonstrated for every PFI projects right from the bidding stage.

\section{CONCLUSIONS}

This study examined the perspectives of UK PFI/PPP industry stakeholders regarding the impact, challenges and critical parameters for securing guarantee under the UK guarantee scheme for infrastructures. A phenomenological approach using literature review and unstructured interviews was conducted among industry experts involving public sector assessors, lenders, equity investors and construction contractors. After an in-depth exploration of issues, findings from unstructured interviews revealed that (1) the UK PFI/PPP industry stakeholders' perception differs regarding the impact of the UKGSI in terms of encouraging bankability of PFI/PPP project within the wider sector. Few projects that had been guaranteed are large projects having national appeal. This makes other medium sized projects unable to access the scheme. (2) The study also identified five factors that critical parameters for securing the UKGSI guarantee, (i) project alignment with UK NIP policy in terms qualifying as infrastructure and falling within priority sectors (i.e. roads, rail, aviation, renewable energy etc.) (ii) projects must secure planning commission's approval and permits to be considered for guarantee (iii) project must strongly demonstrate commercial and technical viability with regards to credit quality (iv) project must also justify the need for the guarantee and prove that it cannot commence without the guarantee (v) Project must demonstrate value for money as well 
as contribution to economic growth. Evidence from the study suggests sharp differences of opinion regarding the appropriateness of the most of the criteria between private sector and the public sector participants. This difference of perspectives must therefore be addressed by policy regulators to consider accommodating the implementation of various PFI projects with local and regional appeal. Additionally a robust engagement with industry stakeholders regarding clearer and transparent assessment and criteria for evaluating guarantee applications is also crucial for the public sector to consider.

The outcome of this study has been limited to the impacts and criteria for accessing the UK Guarantee Scheme for Infrastructures, particularly on PFI/PPP project financing. Further empirical research might also be required to examine the impact of the UKGSI on green field and brown field infrastructure investments in the UK. To achieve more generalisation in this research area, a questionnaire-based survey may also be carried out to examine the impact of the scheme from various stakeholders in the UK infrastructure sector. This study will no doubt be useful to policy makers, investors, financiers and other industry stakeholders regarding reorganising the scheme as well as exploiting maximum benefits from such kinds of government policies.

\section{REFERENCES}

- AHADZI, M., AND BOWLES, G. (2004) Public-Private Partnerships and Contract Negotiations: An Empirical Study. Construction Management and Economics. 22(9), 967978.

- Alvesson, M., AND DEETZ, S. (2000) Doing Critical Management Research. London: Sage Publications Ltd.

- BING, L., AKINTOYE, A., EDWARds, P. J., AND HARDCASTlE, C. (2005) The Allocation of Risk in PPP/PFI Construction Projects in the UK. International Journal of Project Management, 23(1), 25-35.

- $\quad$ BOUSSABAINE, A. (2013) Cost Planning of PFI and PPP Building Projects. Routledge.

- $\quad$ DEMiRAG, I., KHADAROO, I., STAPletON, P., AND STEVENSON, C., (2011) Risks and the Financing of PPP: Perspectives from the Financiers. The British Accounting Review. 43 (2011) 294-310.

- $\quad$ DREW, M. E. (2010) The Future of Financial Regulation: Lessons from the Global Financial Crisis. Griffith Law Review, 19(1), 1-5.

- GLAister, S. (1999) Past Abuses and Future uses of Private Finance and Public Private Partnerships in Transport. Public Money and Management. 19(3), 29-36.

- $\quad$ HAMPL, N., LUDEKE-FREUND, F., FLINK, C., OLBERT, S., AND ADE, V., (2011) “The Myth of Bankability - Definition and Management in the context of Photovoltaic Project Financing in Germany". (Online) Available at: https://www.alexandria.unisg.ch/export/DL/210237.pdf. [Accessed: 14th Feb, 2014]

- HM TREASURY, INFRASTRUCTURE PLAN, (2014) pp108, 10926.

- HM TREASURY (2013) National Infrastructure Plan. (Online) Available at [www nationalarchives.gov.uk/doc/open-government-licence.].[Accessed on 12th July, 2015].

- HM TREASURY (1997) 'Partnerships for Prosperity', Treasury Taskforce Guidance, www.ogc.gov.uk, 29 January 2004. Online [Accessed on 3rd April, 2015].

- JOHAL, S., MORAN, M., AND WILliAMS, K. (2012) The Future has been Postponed: The Great Financial Crisis and British Politics. British Politics. 7(1), 69-81. 
- LABElle, M. (2012) Constructing Post-Carbon Institutions: Assessing EU Carbon Reduction Efforts through an Institutional Risk Governance Approach. Energy Policy. 40, 390-403.

- $\quad$ LI, B., AKINTOYE, A., EDWARDS, P. J., AND HARDCASTLE, C. (2005) Critical Success Factors for PPP/PFI Projects in the UK Construction Industry. Construction Management and Economics. 23(5), 459-471.

- LINCOLN, Y. S. AND DENZIN, N. K. (1994) The Fifth Moment. Handbook of Qualitative Research. 1, 575-586.

- NATIONAL AUDIT OFFICE, (2015) UK Guarantees scheme for infrastructure, p6.

- MENG, X. AND MCKEVITT N., (2011) "Improving the Bankability of a PFI Financing Application". The Journal of Structured Finance. Vol.17 (3), pp 78-87. 


\title{
STRATEGIC CHANGE IN THE DELIVERY OF INFRASTRUCTURE
}

\author{
Potts, M. ${ }^{1}$; McDermott, P. ${ }^{2}$, and Stephenson, A. ${ }^{3}$
}

\begin{abstract}
:
This paper discusses a socio technical systems approach to the strategic delivery of infrastructure in the regulated UK water sector as part of a participatory focused research project. Part of an ongoing PhD programme, this paper highlights the value of a structured approach toward the facilitation of change within an Infrastructure Client Organisation (ICO). Engaged with a single UK based Water and Wastewater ICO (UKWASC), this project has been able to enact real world change through a framework of participatory change management enhanced by the application of strategic procurement management principles. What this paper highlights is the context through which interventions can be defined within a practical setting jointly optimise an ICO and its delivery arrangements to work towards achieving effective project delivery.
\end{abstract}

KEYWORDS: CHANGE MANAGEMENT, INFRASTRUCTURE DELIVERY, PARTICIPATORY RESEARCH, SOCIO TECHNICAL SYSTEMS.

\section{INTRODUCTION}

This paper outlines the creation of a Strategic Change Model concerned with the enactment of real world change within an Infrastructure Client Organisation (ICO). Utilising a Three Phase Change Approach (TPCA), the project is concerned with the optimisation of construction programmes and portfolios delivered by Temporary Multi Organisations (TMO) within a Multi Project Environment (MPE). Engaged with a single UK based Water and Wastewater ICO (UKWASC), this paper outlines the theoretical constructs which led to the formation and implementation of a change strategy within UKWASC. The resultant Change Management Protocol (CMP) served as a bridge between theory and action and allowed the formation and enactment of interventions utilising participatory methods.

\section{The Delivery of Infrastructure}

The delivery of infrastructure is characterised by its almost constant proclivity toward cost overruns, failure to deliver intended outcomes, a lack of skills and ability within clients, and their high management costs (Cantarelli et al.,2010; HM Treasury, 2010,

\footnotetext{
${ }^{1} \mathrm{PhD}$ Candidate, School of the Built Environment, University of Salford; England, UK. Email: m.potts@edu.salford.ac.uk (Corresponding author)

${ }^{2}$ Professor of Construction Management, School of the Built Environment, University of Salford, England, UK. Email: p mcdermott@salford.ac.uk;

${ }^{3}{ }^{3}$ Industry Supervisor, UK WASC, Greater Manchester, England, UK. Email: mr_a_stephenson@hotmail.com.
} 
2013; EC Harris and TRL, 2009). Indeed, the Infrastructure Cost Review (ICR) (HM Treasury 2010) identified that areas of general concern lay primarily with the managing client organisation. Importantly, infrastructure delivery characteristically exists within a Multi-Project Environment (MPE) (Aritua et al., 2011), with Payne (1995) suggesting that the multiple project context accounts for up to $90 \%$ of all projects by value. Artto et al. (2009) present the importance of understanding the difference between single and multi project management, with Pellegrinelli (1997) arguing that organisations that forcefit programmes into 'project-level thinking', lose sight of the initial benefits of the creation of programmes in the first instance. The common misconception that programme management is essentially project-based is highlighted by Pellegrinelli and Partington (2006), leading to authors such as Lycett et al. (2004) identifying a number of inadequacies in standard programme management approaches, arguing their basis on two flawed assumptions that programme management is essentially scaled-up project management, and that a "one size fits all" approach is appropriate.

Project delivery essentially exists within a Temporary Multi Organisation (TMO) setting (De Blois, 2013), and that understanding the context within which delivery exists is vital for Infrastructure Client Organisations (ICO). Mead and Gruneberg (2013) present successful delivery is via the management of a number of projects across a 'programme level procurement function matrix organisation'. In effect, the 'formal' structuring of programme procurement functions inclusive of strategy and governance; operations and support; assurance; and supply chain management; which are then 'crossed' by 'informal' project delivery environments, or TMOs who are intrinsically self-organising with informal decision making (De Blois, 2013).

Understanding the optimisation of TMOs within a MPE setting is vital to the effective delivery of infrastructure and the sustainable operation of supply markets, an issue suitably applicable to the UK water sector. Following Royal Assent of the Water Act in 2014, the legislative framework has been put in place to provide non-household customers with a choice of supplier, corresponding to the Government's Water for Life vision; resulting in works by ancillaries such as the Market Operator Services' preparation for the market opening in (MOSL, 2015). In effect, the holistic regional monopoly approach to date is being replaced by a divided strategy that breaks the sector into monopolistic wholesale activities and competitive retail activities (to an extent). This model of change, more akin to other utility sectors such as energy, represents a significant change to the operation of the water sector and provides a substantial challenge to the delivery of future works.

\section{Strategic Procurement Management}

To deliver any significant programme of works one must consider the environment into which those works are being placed, allowing for the full analysis of the relevant project contexts. Emmett and Crocker (2008) present that in taking a strategic approach, we are inherently moving away from a tactical approach that does not consider either market conditions or environmental variables etc. Understanding market conditions is vital in the formation of sustainable and competitive contractor conditions (Tan and Yao, 2011). Cox 
and Townsend (1998) however suggest that a strategic approach is more akin to understanding appropriateness, and thus being able to deploy and understand an array of tools and techniques, from tactical to strategic that suit a particular set of circumstances. Strategic thinking concepts inform us that we must consider the wider direction of a business in the long term, utilising embedded decision making environments and defining a profitable position within a marketplace (Mintzberg, 1987; Johnson and Scholes, 1997; Church and Ware, 2000).

Morledge and Smith (2013) suggest that a strategic approach to procurement, in response to the barefoot empiricism argument of Cox and Townsend (1998), needs to encompass all the project objectives required with an appropriate strategy presented of how to achieve them in the most effective way. A strategic approach is thusly focused on the appropriate use of decision making to suit the firms' needs in a holistic manner; and as such, procurement strategy is concerned with the appropriate design of sustainable market supply chains. As construction industry supply chains are typically converging, temporary, and made-to-order (Vrijhoef and Koskela, 2000), Arbulu and Tommelein (2002) suggest that clients need to understand their relative supply chain in terms of its structure, function and behaviour in order to be effective, thusly appreciating that the management of tactical relationships varies significantly from the management of strategic approaches. Cox (1999) presents that procurement competence ultimately originates from an understanding of contingent circumstances, the full repertoire of tools and techniques available and the application and understanding of appropriateness linked to organisational strategic vision. The underlying principle of this strategic view is not the application of either a collaborative or adversarial approach as a business goal, in so much that any business to business relationship is potentially adversarial, but the application of either a collaborative or more arm's length approach to leverage maximum value from the supply chain to attain one's strategic goals.

\section{A SPM FRAMEWORK}

In accordance with the three competence principles espoused by Cox (1999) it is proposed that the application of a strategic approach can similarly be broken into three constituent parts. The first component of tools and techniques is well espoused through using the work of Peter Kraljic (1983) and his Purchasing Portfolio Matrix as a lens. This seminal four box model suggests that sourcing strategies and supplier relations by proxy can be plotted against cost and complexity (and inherently risk). This form of approach is akin to that applied to the IPR (IUK, 2013) that plots procurement systems on a similar matrix. Kraljic, Cox and IUK make clear however that successful delivery comes via an alignment of organisational delivery processes to appropriately selected delivery strategies. Importantly, the strategic management and programme management literature, tells us that there is no one best way and in fact, multiple options may be simultaneously appropriate to create a sustainable and competitive delivery environment. It is therefore important to frame the use of delivery strategies as plotted against such matrices in terms of a 'broader' strategic approach, and thus it is proposed that the contingent application of the available procurement methodologies can be done via understanding of five strategic 
procurement principles outlined below, and that varying delivery components and attitudes are required across all five principles in order to enact delivery appropriately:

Risk exists throughout the delivery process and is concerned with the apportionment of responsibility and control throughout the life cycle of an endeavour.

Selection is concerned with the alignment of organisational goals and supply chain capability to achieve effective delivery.

Innovation is concerned with the alignment of processes, procedures and activities within the delivery chain to achieve increased profitability, sustainability, productivity, reliability, quality, safety and ultimately, efficiency.

Cost and the management of it is inherently the cornerstone of delivery. Whether it is the actual cost of a project, or the relative costs in delivering particular outcomes, cost should play a part in all aspects of the delivery chain.

Governance is concerned with, primarily, the post award relationship a purchasing organisation has with its supply market, especially with regard to the maintenance and improvement of contractual relationships.

\section{Socio Technical Systems}

The socio technical systems (STS) approach represents an important theoretical foundation through which to understand, assess and implement a SPM approach toward the delivery of infrastructure. The STS approach teaches that through joint optimization of both social and technical organisational aspects (Fox, 1995; Bradbury et al., 2011), opposed to optimisation in isolation (Trist et al., 1963), an organisation can employ a range of delivery strategies in a contingent manner to suit their respective needs and maximise their delivery activities. The STS approach with its foundations in the work of Trist and Bamforth (1951) presents that efficiency is found through understanding the social characteristics of work. Fox (1995) presents that the success of the STS approach comes from its reliance on a structured process involving a systems scan; a technical analysis; a social analysis; and a quality of working life consideration. The inherently strategic organisational analysis of STS aligns to recent work undertaken by Infrastructure UK via the Infrastructure Procurement Routemap (IPR) and Project Initiation Routemap (PIR) (IUK, 2013, 2014) that deploy an abridged form of the STS approach.

Such espousal of the STS framework can in fact be traced back to the work of Bridger (1977) and his STS 'pentagram' that built on the work of Leavitt's Diamond (1965). Bridger's model, drawing on the foundational principles of von Bertalanffy's General Systems Theory (1950), is seen by Leonard et al. (2013) as the only articulated model of the STS to be formed from the pioneering work of the Tavistock Institute. Importantly, there are two key characteristics of these STS models so far as they distinguish between organisation and environment via a semi-permeable boundary, and that interaction across STS elements is done via some form of optimizing / balancing managerial process / 
activity. Importantly then, the application of the STS approach, in support of the basic systems principles of organisations as transformation systems (Kast and Rosenzweig, 1985), is that one must consider the environmental and organisational systems, as well as the optimisation of the social and technical systems to align to organisational strategy. Nadler and Tushman's (1977) congruence (or fit) model is a prime example of the integration of inputs in forming a strategy that is applied across organisational sociotechnical parameters that lead to outputs. Congruence is then the identification of gaps or differentiation between organisational 'components' that do not serve the broader purpose of optimisation.

\section{A STS Approach Toward Change Management}

The issue is thus that in order to identify with, understand and then address such gaps (or incongruence), one must enact and operate within a framework of change management. Furthermore, a core tenet of the strategic procurement approach is the application and understanding of appropriateness rather than benchmarking. The underlying philosophy is the balancing and optimising of the socio-technical components of the organisation, and for the purpose here, the organisational model synthesised by Kast and Rosenzweig (1985) is utilised as an espousal of the STS approach (Figure 1). It encompasses the components identified by Miller (1967), Bridger (1977), Leavitt (1965), Zobrist and Enggist (1984) and others, whilst the managerial subsystem is developed for the purposes here in the latter sections. This model represents the transformative system of organisation and aligns to the second phase of the Three Phase Change Approach (TPCA) detailed by Potts et al. (2015) which in turn finds basis in Lewin's (1947) unfreeze stage for organisational change.

Figure 1: The organisational system (Adapted from Kast and Rosenzweig, 1985)

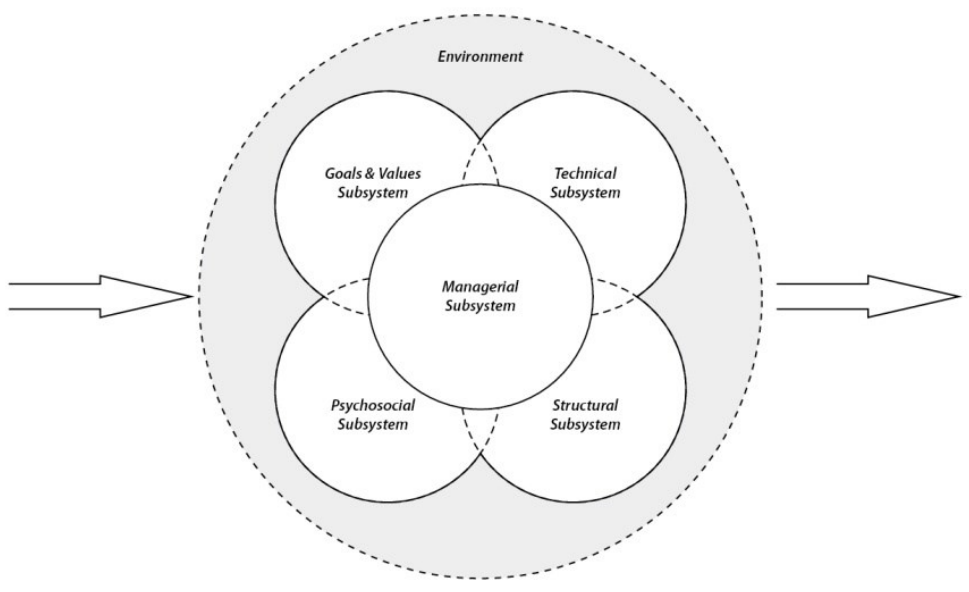




\section{RESEARCH METHOD}

Pasmore (2006) presents that the study of the workplace through the socio-technical school amalgamated the work of Kurt Lewin $(1947,1951)$ and action research, with Bion's theories on leaderless groups and von Bertalanffy's work on systems thinking to focus on organisational effectiveness. Lewin's early work had been enhanced by Coch and French (1948) as they showed that participation was a core tenet of reducing organisational change resistance. This work showed that participation and the 'learning organisation' of today, encompassing the involvement of workers into practice design, could engender significant performance improvements. The TPCA deployed for this project (readers are directed toward the detailed description outlined in Potts et al., 2015) is a phased approach to both research and change that builds on Lewin's Unfreeze, Move and Re-freeze (Lewin, 1947, 1951), which aligns to the inputs / transformation / outputs (open systems view) purported by Kast and Rosenzweig (1985) and Nadler and Tushman (1977). Figure 2 highlights the alignment of change within the three pronged competency framework outlined by Cox (1999).

Figure 2: A competency framework for change

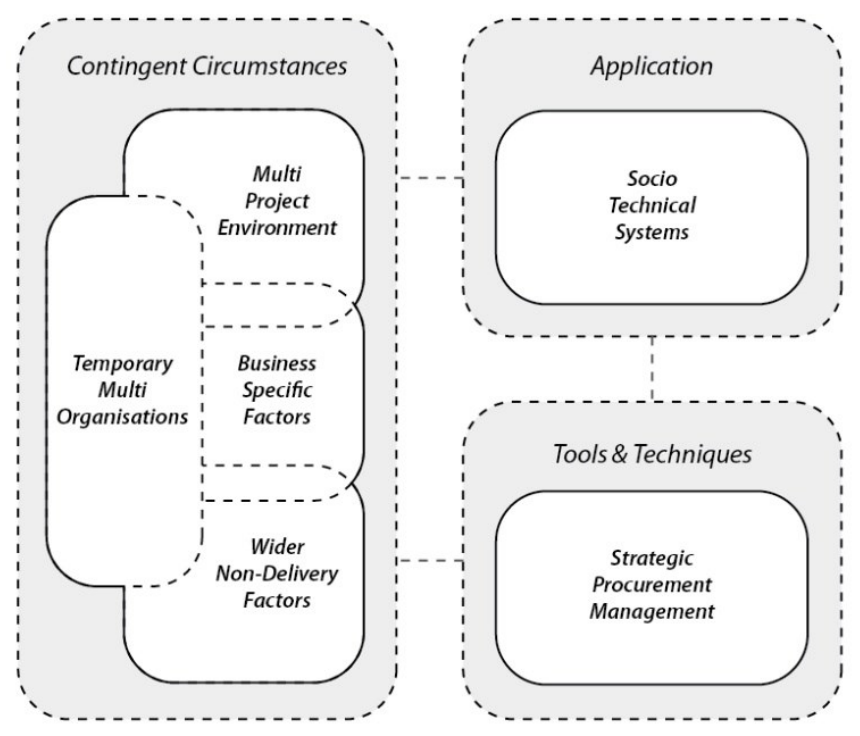

\section{A STRATEGIC SOCIO TECHNICAL CHANGE MODEL}

What this results in is the formation of the Strategic Socio Technical Change Model (Figure 3). Inputs and the environment are determined by the contingent circumstances highlighted within figure 2, while the application of the SPM approach is done within a framework of STS. The result is the modification of the transformative organisational environment into outputs which is determined by the delivery environment, characterised simply for the purposes here as design, construction and use. In accordance with systems principles the model then has an element of feedback, whilst also presenting that it is in 
fact in a state of transient flux as the organisation constantly changes and re-affirms within its environment. The five principles of SPM form the managerial balancing / optimising core of the model surrounding the quadrant matrix at its heart. This in effect outlines the alignment of contingent tools to suit delivery variables in order to manifest effective delivery. An additional component is added at the edge of the managerial space, that being an adaptation of Charles Perrow's (1967) work in the alignment of knowledge technology opposed to production technology. His model is highlighted to bring a further dimension to the skillset alignment argument proffered here that configuration of organisational skillset and delivery approaches to chosen procurement strategies is vital to the effective delivery of infrastructure (IUK, 2013, 2014), especially if those relationships are to be mutually beneficial to maintain sustainable competitive advantage (Holt et al. 2000), maintain a sustainable market position (London and Kenley, 2001), and foster progressive socially and economically sustainable construction solutions (Bourdeau, 1999) .

\section{Figure 3: The Basic Strategic Socio Technical Change Model}

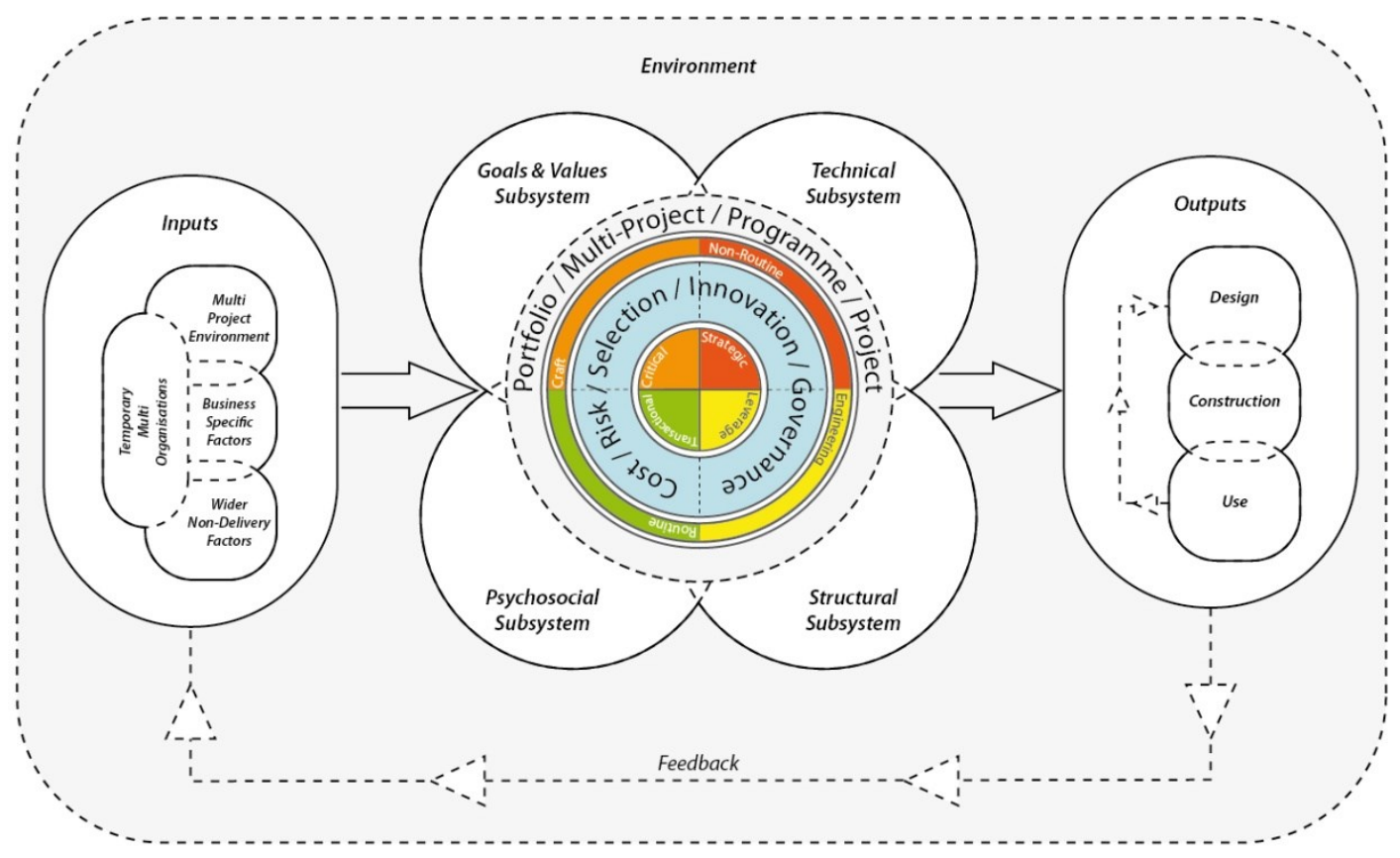

\section{Application of The SSTC Model}

Within the umbrella of the TPCA, a number of interventions were enacted that focused on each of the SPM principles. To define the areas through which to intervene as part of the SSTC model and begin to break down barriers to implementing sustainable and competitive practices (Sourani, 2011), a Change Management Protocol (CMP) was formed to act as a bridge between the theoretical underpinnings of the approach as part of the wider PhD project, and the practical needs and demands of the focus organisation. 
This meant outlining the context of the five principles and finding applicable focus areas in relation to them to allow the project to take a systems approach toward change, such that change in one area will be ultimately unsuccessful unless applied universally across the model. The result was the identification of a number of differing interventions that served the core focus of the SPM approach, whilst representing a form of utility and importance to the focus organisation to make their impact worthwhile. The interventions were as follows:

Risk: Delivery Route Allocation and Client Skills Assessment

Selection: Behavioural Assessment Programme

Governance: Framework Governance / Incentives / Performance Measurement and KPIs Cost: Organisational Re-Design

Innovation: Programme Optimisation

Each of these interventions served as an action oriented piece of work with a loosely definable aim and finish point initially. Each utilised participatory methodologies and took on board the wider impact of the elements as defined by the SSTC model. For example, Programme Optimisation as part of the Innovation tenet, focused on all four socio technical subsystems (as is vital to this approach) to form an appropriate engagement tool for use in conjunction with a Leverage type procurement strategy influenced by the factors outlined as inputs (and the environment) from the SSTC model. The intervention primarily focused on tasks, work flow, perceptions, knowledge and culture (Kast and Rosenzweig, 1985) to facilitate this goal, with the resultant action serving to help jointly optimise both delivery strategies and organisational practices to influence and improve the relative (delivery) outputs.

\section{CONCLUSIONS}

A whole host of change tools are applicable within the implementation of change, from double-loop learning (Argyris and Schon, 1974), Crosby's (1979) perceptions of organisational maturity, innovation diffusion (Rogers, 1995), and even the change curve (Kubler Ross, 1973) to name but a few. The key issue is the appropriate identification and use of change tools to identify with and implement SPM tools to suit contingent circumstances, utilising an appropriate change framework to facilitate their implementation. In accordance with the intervention above, an optimised programme, resulting in a committed (and funded) pipeline of construction activity with associated procurement and implementation strategies (with defined needs and budgets), aligns to the concept of demand management and market engagement as part of the SPM approach. This allows for the development of supply chains and the standardisation of components with sustainable supply strategies; all key supportive elements of the innovation tenet.

What this model and paper has aimed to highlight is that the application of a SPM approach toward infrastructure delivery can be successfully implemented (and identified) through a framework of STS, coupled with an appropriate methodology of 
implementation, namely, the TPCA. The methodology, model and framework have been successful in implementing change, especially around breaking down barriers to implementing a sustainable and strategic approach. Change that is focused on optimisation of the client organisation, but jointly with its environment and delivery arrangements should be a foundation upon which to build more competitive, appropriate, strategic and ultimately sustainable procurement and delivery relationships.

\section{REFERENCES}

- ARBulu, R. J., \& TOMMELEIN, I. D. (2002, August). Alternative supply-chain configurations for engineered or catalogued made-to-order components: case study on pipe supports used in power plants. In Proc. 10 th Annual Conference of the International Group for Lean Construction (pp. 6-8).

- ARGYRIS, C., \& SCHON, D. A. (1974). Theory in practice: Increasing professional effectiveness. Jossey-Bass.

- $\quad$ ARITUA, B., SMITH, N. J., \& BOWER, D. (2011). What risks are common to or amplified in programmes: Evidence from UK public sector infrastructure schemes. International journal of project management, 29(3), 303-312.

- $\quad$ ARtTo, K., MARtinsuO, M., GEMÜNDEN, H. G., \& MURTOARO, J. (2009). Foundations of program management: A bibliometric view. International journal of project management, 27(1), 1-18.

- BOURDEAU, L. (1999). Sustainable development and the future of construction: a comparison of visions from various countries. Building Research \& Information, 27(6), 354366.

- $\quad$ BRADBURY, H., MIRVIS, P., NEILSEN, E., \& PASMORE, W. (2008). Action research at work: Creating the future following the path from Lewin. The SAGE handbook of action research: Participative inquiry and practice, 2, 77-92.

- BRIDGER, H. (1977). The value of the organization's own systems in coping with stress. Proceedings of the International Committee on Occupational Mental Health Congress, New York, 1977

- CAntarelli, C. C., Flyvbjerg, B., MOLin, E. J., \& VAN WEe, B. (2010). Cost overruns in large-scale transportation infrastructure projects: explanations and their theoretical embeddedness. European Journal of Transport Infrastructure Research, 10(1), 5-18.

- CHAllengeR, W., ClEGG, W. C., \& ROBINSON, A. M. (2009). Understanding crowd behaviours: Guidance and lessons identified. UK Cabinet Office.

- $\quad$ CHURCH, J. R., \& WARE, R. (2000). Industrial organization: A strategic approach.

- CLEGG, C. W. (2000). Sociotechnical principles for system design. Applied ergonomics, 31(5), 463-477.

- $\quad$ COCH, L., \& FRENCH JR, J. R. (1948). Overcoming resistance to change. Human relations.

- COX, A. (1999), 'Improving procurement and supply competence", in Lamming, R. And Cox,A.(Eds),Strategic Procurement Management: Concepts and Cases, Earlsgate Press, Boston, UK.

- COX, A., \& TOWNSEND, M. (1998). Strategic procurement in construction. Thomas Telford Limited.

- CROSBY, P. B. (1979). Quality is free: The art of making quality certain. New York.

- DAVIS, M.C., CHALlENGER, R., JAYEWARDENE, D.N.W. \& CLEGG, C.W. (2014). Advancing socio-technical systems thinking: A call for bravery. Applied Ergonomics, 45 (2A), 171-180. doi: 10.1016/j.apergo.2013.02.009

- DE BLOIS, M (2013): The "self-organizing" project": a "systemic" view of the design and project processes. Relating Systems Thinking and Design 2013 Working paper. 
- DEWALT, K. M., \& DEWALT, B. R. (2010).Participant observation: A guide for fieldworkers. Rowman Altamira.

- EC HARRIS AND TRANSPORT RESEARCH LABORATORY (2009); Project Report CPR596, European Cost Comparison - Cost Differences between English and Dutch Highway Construction. EC Harris and TRL

- EMMETT, S., \& CROCKER, B. (2008). Excellence in Procurement: How to optimise costs and add value. Cambridge academic.

- FOX, W. M. (1995). Sociotechnical system principles and guidelines: past and present. The Journal of Applied Behavioral Science, 31(1), 91-105.

- HOLT, G. D., LOVE, P. E., \& LI, H. (2000). The learning organisation: toward a paradigm for mutually beneficial strategic construction alliances. International journal of project management, 18(6), 415-421.

- INFRASTRUCTURE UK (2013). Infrastructure procurement route map: a guide to improving delivery capability. HM Treasury, $U K$

- INFRASTRUCTURE UK (2014). Improving Infrastructure Delivery: Project Initiation Routemap. HM Treasury, UK

- JOHNSON, G. \& SCHOLES, K. (1997), Exploring Corporate Strategy: Text and Cases (London: Prentice-Hall, 1989).

- $\quad$ KAST, F. E., \& ROSENZWEIG, J. E. (1985). Organization and Management: A Systems and Contingency Approach. New York: McGraw-Hill

- KRALJIC, P. (1983). Purchasing must become supply management. Harvard business review, 61(5), 109-117.

- KÜBLER-ROSS, E. (1973). Coping with Death and Dying. Ziff-Davis.

- LEAVITT, HJ (1965). Applied Organisational Change in industry. In March, J.G. (Ed) Handbook of Organisations. New York: Rand McNally

- $\quad$ LEONARD, H. S., LEWIS, R., FREEDMAN, A. M., \& PASSMORE, J. (Eds.). (2013). The Wiley-Blackwell handbook of the psychology of leadership, change and organizational development. John Wiley \& Sons.

- LEWIN, K. (1947). 'Group decisions and social change'. In Newcomb, T.M. and Hartley, E. L. eds. Readings in Social Psychology. New York: Henry Holt.

- LEWIN, K. (1951). Field theory in social science: selected theoretical papers (Edited by Dorwin Cartwright.).

- LONDON, K. A., \& KENLEY, R. (2001). An industrial organization economic supply chain approach for the construction industry: a review. Construction Management \& Economics, 19(8), 777-788.

- $\quad$ LYCETT, M., RASSAU, A., \& DANSON, J. (2004). Programme management: a critical review. International Journal of Project Management, 22(4), 289-299.

- MEAD, J., \& GRUNEBERG, S. (2013). Programme procurement in construction: Learning from London 2012. John Wiley \& Sons.

- MILLER, E (1967). Systems of Organisation. London, Tavistock: 1967

- MINTZBERG, H. (1987). Crafting strategy (pp. 66-75). Boston, MA: Harvard Business School Press.

- MORLEDGE, R., \& SMITH, A. (2013). Building procurement. John Wiley \& Sons.

- MOSL (2015). Market Operator Services Limited: Our Work (Online). Available from: http://mosl.co.uk/ (Accessed: 1st August 2015).

- NADLER, D., \& TUSHMAN, M. L. (1977). A congruence model for diagnosing organizational behavior. Columbia University, Graduate School of Business.

- PASMORE, W. (2006). Action research in the workplace: The socio-technical perspective. Handbook of action research, 2, 38-48.

- PAYNE, J. H. (1995). Management of multiple simultaneous projects: a state-of-the-art review. International journal of project management, 13(3), 163-168.

- PELlEGRINELLI, S. (1997). Programme management: organising project-based change. International Journal of Project Management, 15(3), 141-149. 
- PELlEGRINELli, S., \& PARTINGTON, D. (2006). Pitfalls in taking a project-based view of programmes. In Proceedings of PMI Global Congress EMEA.

- PERROW, C. (1967). A framework for the comparative analysis of organizations. American sociological review, 194-208.

- $\quad$ POTTS, M., AWUZIE, B., MCDERMOTT, P., \& STEPHENSON, A.(2015) Engendering Change within a Water Infrastructure Client Organisation: A Participatory Action Research Approach. Journal of Engineering, Project, and Production Management 2015, 5(2), 71-81

- ROGERS EVERETT, M. (1995). Diffusion of innovations. New York.

- SOURANI, A. (2011). Barriers to addressing sustainable construction in public procurement strategies.

- TAN, Y, L., \& YAO, H. (2011). Sustainable construction practice and contractors' competitiveness: A preliminary study. Habitat International, 35(2), 225-230.

- TREASURY, H. M., \& UK, I. (2010). Infrastructure Cost Review: Technical Report. HM Treasure and Infrastructure UK, London, UK.

- TRIST, E. L. (1963) Organizational choice: capabilities of groups at the coal face under changing technologies: The loss, re-discovery. London: Tavistock

- $\quad$ TRIST, E. L., \& BAMFORTH, K. W. (1951). Some social and psychological consequences of the Longwall method. Human relations, 4(3), 3-38.

- VON BERTALANFFY, L. (1950). An outline of general system theory. British Journal for the Philosophy of science.

- VRIJHOEF, R., \& KOSKELA, L. (2000). The four roles of supply chain management in construction. European journal of purchasing \& supply management, 6(3),169-178.

- ZOBRIST, A., \& ENGGIST, R. (1984). Social technical systems thinking in management consulting: a holistic concept for organization development. The 1984 Annual: Developing Human Resources, 216-26. 


\section{Theme 2 Culture and Human Resources}

1. Perceptions Of Different Stakeholders Towards Sustainability: A Case Example From The Turkish Construction Industry

2. Women Professionals' Participation In The Construction Industry - Indian Scenario

3. Industry Culture As Causative Agents Of Construction Waste: A Need For Cultural Change

4. Interactions Of Culture And Person-Technology Fit

5. Determinants Of Employee Job Satisfaction In The Gauteng Province Of South Africa

6. Sustainability In Projects Requires Training In Managing As Designing

7. Influence Of Host Organisation Culture In The Execution Of Construction Projects: A Case Study Of Selected Higher Education Institutions In Nigeria.

8. Implementation Of Early Conflict Management Measures In Construction Projects - The Case Of South Africa" 


\title{
PERCEPTIONS OF DIFFERENT STAKEHOLDERS TOWARDS SUSTAINABILITY: A CASE EXAMPLE FROM THE TURKISH CONSTRUCTION INDUSTRY
}

\author{
Akgul, G. ${ }^{1}$ and Giritli,F.H. ${ }^{2}$
}

\begin{abstract}
:
The sustainability concept has been regularly experienced in the construction industry as well as in other industries over the last decades. This research includes the certification systems among the world to comprehend the headlines and assessment criteria. Local environment, culture, economy and technology factors are changing from country to country, however some certification systems have international criteria. The most popular certification systems are BREEAM (England), LEED (USA), Green Star (Australia), CASBEE (Japan), SB Tool (Canada) and DNGB (Germany). Nearly whole certification systems include similar subjects as; sustainable sites, water and energy efficiency, material and resources.

The aim of this research is to assess the sustainable project stakeholders' perception in Turkish construction industry from the point of occupation, job title and years of experience. Therefore, a questionnaire survey was made to assess the perceptions of each attendant with respect to LEED sustainability criteria. Headlines of LEED certification criteria; sustainable sites, water efficiency, energy and atmosphere, material and resources, indoor environmental quality and innovation in design were indicated to assess the perceptions of survey participants. In addition, only surveying of LEED criteria were inadequate to measure awareness; so the equipment, methods, risks and benefits also considered. The utilized equipment and methods, which had inquired about, were; credit responsibility matrix, LEED project book, cost-efficiency analyses, energy simulation, light analyses, air condition analyses and whole lifecycle costing. After the methods, assessed risks were financial risk, complex of building, lack of design planning, lack of construction planning, lack of advanced supplier, inexperienced contractor and inexperienced organization. And benefits mentioned in the survey were; decrease of capital cost, decrease of operational cost, marketing benefits, improve of responsibility to environment, health and productivity and new job sources.

We have a blind review process. Thus, please do not include author details on your paper. The conference organisers will insert these at the final editorial stage. Please ensure that you state your PAPER Reference ID on your paper.
\end{abstract}

KEYWORDS: CONSTRUCTION, LEED, MANAGEMENT, PERCEPTION, STAKEHOLDERS, SUSTAINABILITY

\section{INTRODUCTION}

In many countries, the construction industry is a primary driver of the national economy, and has significant contributions to the creation of new environments. It is at the forefront of how we shape our future and the sustainability of this future (Du Plessis, $2002 \mathrm{pi}$ ). But it also creates significant environmental and social impacts. Du Plessis (2007) stated that the challenge for the construction sector is not just responsible for providing and maintaining physical assets, but to do it in a more social and ecological way. However,

\footnotetext{
${ }^{1}$ Institute of Science and Technology, Istanbul Technical University, Turkey. Email: gizakgul@gmail.com

${ }^{2}$ Faculty of Architecture, Istanbul Technical University, Turkey. Email: giritli@itu.edu.tr
} 
the industry's sustainability performance has long been a subject of criticism, mostly due to the factors such as consumption of energy resources, environmental pollution and global warming (Moodley et al., 2008; Asif et al., 2007; Ahn et al., 2010). UNEP (2011) estimates that over their lifespan, buildings are responsible for $25-40 \%$ of the world's energy use, $30-40 \%$ of the world's solid waste generation, $30-40 \%$ of the world's global greenhouse gas emissions, $33 \%$ of the world's resources, and $8-12 \%$ of water use. The question now becomes how we can shape our strategies for raising the level of sustainability in construction. To move towards sustainable construction, more efforts are needed and should be directed towards realizing the sustainable development agenda of the industry.

All of this is to say that sustainable development and construction must be an uppermost priority for researchers (Myers, 2005; Tam, 2009; Sakr et al., 2010). But it also requires concerted action by all stakeholders involved in the creation and use of the built environment. This is particularly relevant due to the public perception of the industry. It is blamed for being "worst, wasteful, inefficient and ineffective" (Beatham et al, 2004) and perceived as a "dirty, dangerous and old fashioned" industry (Fairclough, 2002p.30).

Additionally, the construction industry has been identified as a slow adopter of sustainability, while sustainability has been considered as an effective enabler for process improvement in other industries. Accordingly, the study presented in this paper focuses on how the sustainability concept is perceived by the construction project stakeholders in Turkey. The main purpose of the study is to assess perceptions towards construction sustainability. It also investigates the awareness and understanding towards environmental aspect of sustainability among project stakeholders in the Turkish construction industry. A questionnaire survey has been conducted to understand perceptions of sustainability in the construction industry.

\section{Sustainable construction}

There is no standard definition for sustainability in the construction industry. The diversity of the construction industry also makes it more complicated to define sustainability. Sustainable construction is generally described as "the creation and responsible management of a healthy built environment based on resource efficient and ecological principles" (PAC, 2009). Agenda 21, introduced in 1992 by the UN summit on environment and development, defines it as "a holistic process aiming to restore and maintain harmony between the natural and built environments, ...". Sustainable construction involves "creating construction items using best-practice clean and resourceefficient techniques from the extraction of the raw materials to the demolition and disposal of its components" (Ofori 2000, p. 196).

Despite the lack of a standard definition of sustainable construction, it governs three main pillars: (environmental, social and economic sustainability) (Addis \&Talbot, 2001; Brownhill \& Rao, 2002). Environmental sustainability involves making responsible decisions by focusing on preservation of natural resources to achieve long-term environmental quality. Social sustainability concerns the human feelings: security, 
satisfaction, safety and comfort (Lombardi, 2001) and human contributions: skills, health, knowledge and motivation (Parkin, 2000). Finally, economic sustainability is concerned with the monetary gains from the project for the benefits of stakeholders (Zainul Abidin, 2007b). And it's important to be aware that the environmental and economic aspects of sustainability are intertwined.

Many countries have developed their green tools and practices which were accepted as $\mathrm{SC}$ practices. However, most of these tools concentrate more on the environmental aspects of SC. The widely known environmental accreditations are GBC (Green Building Challenge), LEED (Leadership in Energy and Environmental Design), BREEAM (Building Research Establishment Environmental Assessment Method), GREENSTAR (developed based on LEED and BREEAM by Australia Green Building Council), BEES (Building for Environmental and Economic Sustainability), SBtool (Sustainable Building Tool) from Canada, ECO-QUANTUM (a simulation based tool), ECOPROFILE (for existing office buildings), LCAid (based on Life Cycle of a building), and CASBEE from Japan. (Lee,2012; Alyami \& Rezgui; 2012). Among these, LEED and BREEAM are the world's most recognized and rigorous tools for the assessment and recognition of "green" buildings. BREEAM was the first environmental assessment method in the world.

LEED, developed by the United States Green Building Council (USGBC), is a green building rating system that assesses the sustainability of green buildings based on their design, construction, and operation. Additionally, LEED is the most popular and widely used green building rating system globally. There are currently more than 72,500 LEED building projects located in over 150 countries and territories (as of August 2015). Among these countries, Turkey is ranked as 9th with a total of 237 Leed certified projects.

Based on the foregoing, this paper seeks to explore and compare project stakeholders' perceptions on the adaptability and applicability of LEED in the Turkish construction industry.

\section{RESEARCH METHODOLOGY}

\section{Sample and data collection}

The main purpose of the study presented here is to assess the project stakeholders' sustainability perceptions in the Turkish construction industry. In order to reach this purpose a questionnaire accessible through Internet has been developed to collect data. The questionnaire was conducted with professionals who have enough experience in a LEED certificated project. Initially, 74 professionals who were identified among the members of Turkish Green Building Association were contacted, but 37 professionals did not participate, giving a response rate of $50 \%$.As a result, 37 effectively completed questionnaires were returned. The respondents surveyed represents a spectrum of different professions 
including 35.1\% architects, interior architects and city planners, followed by $32.4 \%$ mechanical and electrical engineers, $13.5 \%$ civil engineers and $18.9 \%$ other professionals.

\section{Questionnaire Format}

The questionnaire consisted of five parts. The first part covered data about the respondents' background. The second part covered data regarding level of significance of $\mathrm{LEED} \mathrm{BD}+\mathrm{C}$ rating system, which was organized into six credit categories. These categories are (1) Sustainable Sites, (2) Water Efficiency, (3) Energy and Atmosphere, (4) Materials and Resources, (5) Indoor Environmental Quality and (6) Innovation and Design.

The respondents were asked to state their personal opinions of the applicability for each of the above cited categories on a five-point scale ranging from "easily applicable" to "absolutely inapplicable". The third part of the questionnaire solicits information regarding tools and techniques used for assessment of sustainability. The fourth and fifth parts solicit information for testing the influence of risk and utility on sustainable construction strategies, respectively.

\section{Research Findings}

Table 1 shows applicability levels of LEED rating system of all groups of stakeholders. Level of applicability of LEED evaluation criteria was indicated into five levels. Level 5 referred to the highest level of applicability (4.21-5.00), Level 4 for high level of applicability (3.41-4.20), Level 3 for medium level of applicability (2.61-3.40) and Level 2 for low level of applicability (1.81-2.60) and Level 1 for inapplicability (1.00-1.80).

According to the findings of this research, most of the credits tend to possess low levels of applicability in the context of Turkish Construction industry. They have achieved mean ratings of less than 2.60 (low applicability level) based on the scale used. Furthermore, 'water efficient landscaping (1.76)' and 'water use reduction (1.76)' under the Water Efficiency Category were identified as difficult to achieve as they include high initial costs for their implementation. According to the respondents, achieving adequate 'thermal comfort (1.70)' and 'daylight and views (1.70)' received the lowest ratings due to the high initial costs for their implementation. 'Regional materials' under the Materials and Resources category was the only credit given a very low rating (1.62) by the respondents. The reason for the inapplicability of this credit item could be identified as such materials are locally impossible to find in the Turkish construction industry. 


\begin{tabular}{|c|c|c|}
\hline Applicability Levels of Leed Rating System & \multicolumn{2}{|c|}{ Results of all groups } \\
\hline 1. Sustainable Sites & 2.24 & Low \\
\hline 1.1 Site selection & 2.11 & Low \\
\hline 1.2 Development density and community connectivity & 1.92 & Low \\
\hline 1.3 Brownfield redevelopment & 2.54 & Low \\
\hline 1.4 Alternative transportation - public transportation access, & 1.86 & Low \\
\hline 1.5 Alternative transportation - bicycle storage and changing rooms & 2.46 & Low \\
\hline 1.6 Alternative transportation - low-emitting and fuel-efficient vehicles & 2.49 & Low \\
\hline 1.7 Alternative transportation - parking capacity & 2.14 & Low \\
\hline 1.8 Site development - protect or restore habitat & 2.05 & Low \\
\hline 1.9 Site development - maximize open space & 2.24 & Low \\
\hline 1.10 Storm water design - quantity control & 2.11 & Low \\
\hline 1.11 Storm water design - quality control & 2.35 & Low \\
\hline 1.12 Heat island effect & 2.49 & Low \\
\hline 1.13 Light pollution reduction & 2.35 & Low \\
\hline 2. Water Efficiency & 1.79 & Inapplicable \\
\hline 2.1 Water efficient landscaping & 1.76 & Inapplicable \\
\hline 2.2 Innovative wastewater technologies & 1.86 & Low \\
\hline 2.3Water use reduction & 1.76 & Inapplicable \\
\hline 3. Energy \& Atmosphere & 2.24 & Low \\
\hline 3.1 Optimize energy performance & 2.05 & Low \\
\hline 3.2 On-site renewable energy & 2.24 & Low \\
\hline 3.3 Enhanced commissioning & 2.35 & Low \\
\hline 3.4 Enhanced refrigerant management & 2.11 & Low \\
\hline 3.5 Measurement and verification & 2.08 & Low \\
\hline 3.6 Green power & 2.62 & Medium \\
\hline 4. Material \& Resources & 2.17 & Low \\
\hline 4.1 Building reuse & 2.08 & Low \\
\hline 4.2 Construction waste management & 1.97 & Low \\
\hline 4.3 Materials reuse & 2.30 & Low \\
\hline 4.4 Recycled content & 2.22 & Low \\
\hline 4.5 Regional materials & 1.62 & Inapplicable \\
\hline 4.6 Rapidly renewable materials & 2.35 & Low \\
\hline 4.7 Certified wood & 2.65 & Medium \\
\hline 5. Indoor Environmental Quality & 1.97 & Low \\
\hline 5.1 Outdoor air delivery monitoring & 2.19 & Low \\
\hline 5.2 Increased ventilation & 1.81 & Low \\
\hline 5.3 Construction IAQ management plan & 1.97 & Low \\
\hline 5.4 Low-emitting materials & 2.24 & Low \\
\hline 5.5 Indoor chemical and pollutant source control & 2.30 & Low \\
\hline 5.6 Controllability of systems & 1.89 & Low \\
\hline 5.7 Thermal comfort & 1.70 & Inapplicable \\
\hline
\end{tabular}


5.8 Daylight and views - daylight

1.70

1.89

napplicable

6. Innovation

1.80

1.84

Inapplicable

6.1 Innovation in design

1.76

Low

6.2 LEED Accredited Professional

Inapplicable

Table 1. Mean applicability levels of LEED Rating System of all groups of stakeholders

In this study, the weighted ratings from the specialists have examined with Kendall's coefficient of concordance. The values gained from assessments of risk factors have analysed with Kendall's coefficient of concordance to reveal the degree of consistency and shown below.

Figure 1 and Table 2 have shown that managers, consultants and workers have no statically meaningful concordance with each other $(\mathrm{W}=0,72 ; \mathrm{p}=0,044)$.

Figure 1: Rank of risk criteria by position

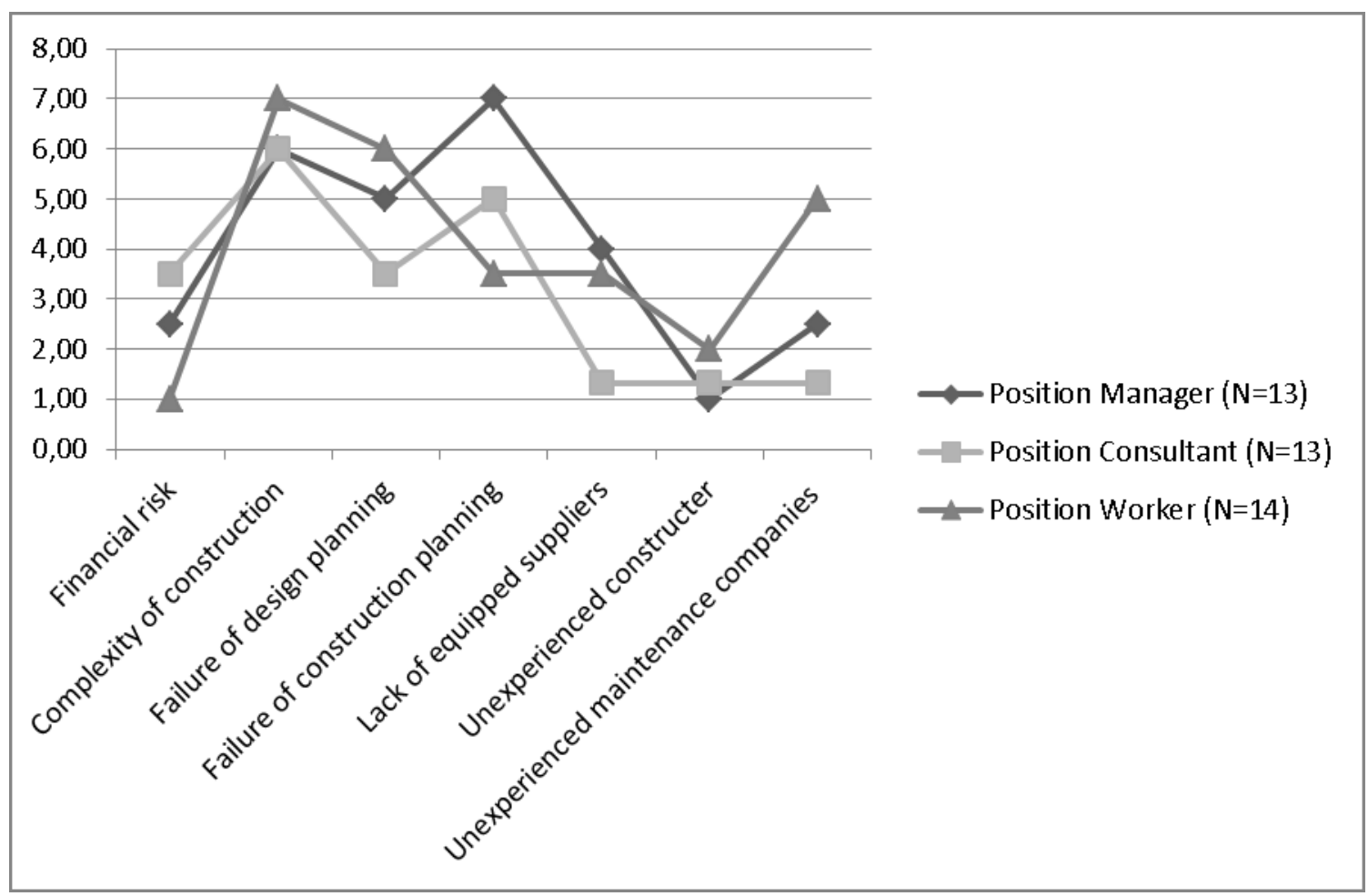


Table 2: Concordance of risk criteria by position.

\begin{tabular}{|c|c|c|c|c|c|c|}
\hline \multirow[b]{2}{*}{ Risk Criteria } & \multicolumn{3}{|c|}{ Position } & \multirow[b]{2}{*}{$\sum_{\Sigma}^{\mathbb{\Xi}}$} & \multirow[b]{2}{*}{$\begin{array}{l}3 \\
\infty \\
\overline{\bar{\sigma}} \\
\overrightarrow{0} \\
0 \\
\mathbb{0}\end{array}$} & \multirow[b]{2}{*}{$\therefore$} \\
\hline & 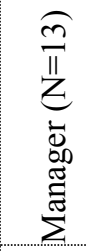 & 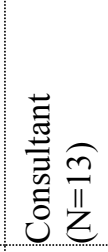 & 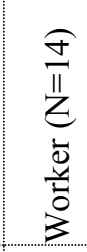 & & & \\
\hline Financial risk & 2,50 & 3,50 & 1,00 & 2,33 & \multirow{7}{*}{0,72} & \multirow{7}{*}{0,044} \\
\hline Complexity of construction & 6,00 & 6,00 & 7,00 & 6,33 & & \\
\hline Failure of design planning & 5,00 & 3,50 & 6,00 & 4,83 & & \\
\hline Failure of construction planning & 7,00 & 5,00 & 3,50 & 5,17 & & \\
\hline Lack of equipped suppliers & 4,00 & 1,33 & 3,50 & 2,94 & & \\
\hline Unexperienced constructer & 1,00 & 1,33 & 2,00 & 1,44 & & \\
\hline Unexperienced maintenance companies & 2,50 & 1,33 & 5,00 & 2,94 & & \\
\hline
\end{tabular}

Figure 2 and Table 3 have shown that occupation groups have statically meaningful concordance with each other $(\mathrm{W}=0,832 ; \mathrm{p}=0,003)$. The concordance is defined by value's proximity to 1 .

Figure 2: Rank of risk criteria by occupation

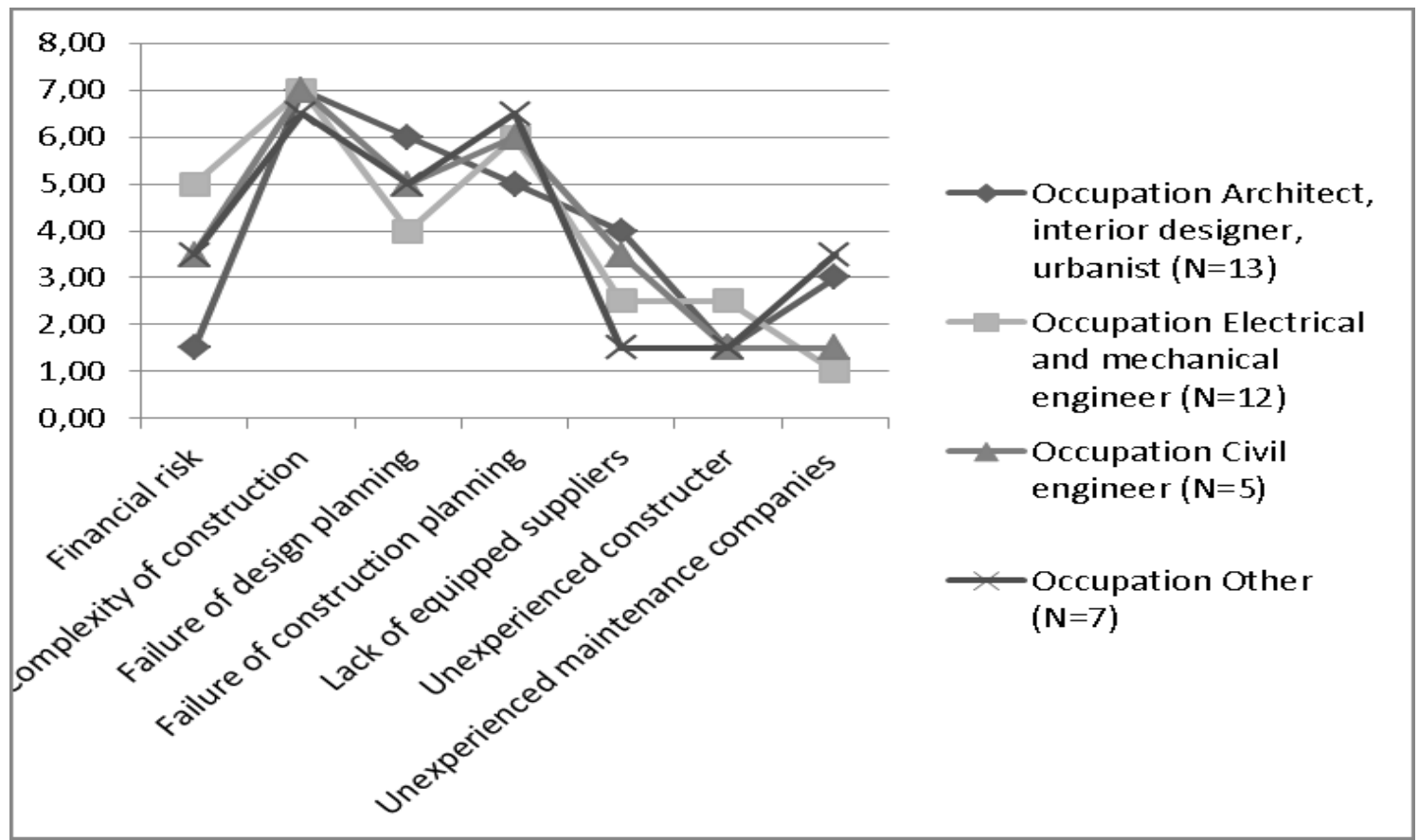


Table 3: Concordance of risk criteria by occupation

\begin{tabular}{|c|c|c|c|c|c|c|c|}
\hline \multirow[b]{2}{*}{ Risk Criteria } & \multicolumn{4}{|c|}{ Occupation } & \multirow[b]{2}{*}{$\sum_{\Sigma}^{\Xi}$} & \multirow[b]{2}{*}{$\begin{array}{l}3 \\
\infty \\
\overline{\bar{J}} \\
\underline{0} \\
\underline{D} \\
\underline{v}\end{array}$} & \multirow[b]{2}{*}{0} \\
\hline & 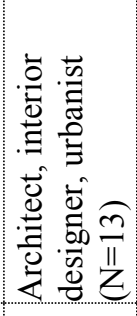 & 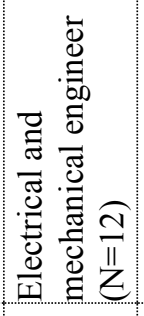 & 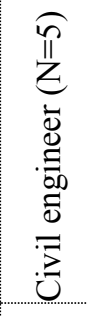 & 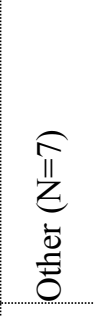 & & & \\
\hline Financial risk & 1,50 & 5,00 & 3,50 & 3,50 & 3,38 & \multirow{7}{*}{0,832} & \multirow{7}{*}{0,003} \\
\hline Complexity of construction & 7,00 & 7,00 & 7,00 & 6,50 & 6,88 & & \\
\hline Failure of design planning & 6,00 & 4,00 & 5,00 & 5,00 & 5,00 & & \\
\hline Failure of construction planning & 5,00 & 6,00 & 6,00 & 6,50 & 5,88 & & \\
\hline Lack of equipped suppliers & 4,00 & 2,50 & 3,50 & 1,50 & 2,88 & & \\
\hline Unexperienced constructer & 1,50 & 2,50 & 1,50 & 1,50 & 1,75 & & \\
\hline Unexperienced maintenance companies & 3,00 & 1,00 & 1,50 & 3,50 & 2,25 & & \\
\hline
\end{tabular}

Figure 3 and Table 4 have shown that experience have no statically meaningful concordance $(\mathrm{W}=0,628 ; \mathrm{p}=0,004)$.

Figure 3: Rank of risk criteria by experience

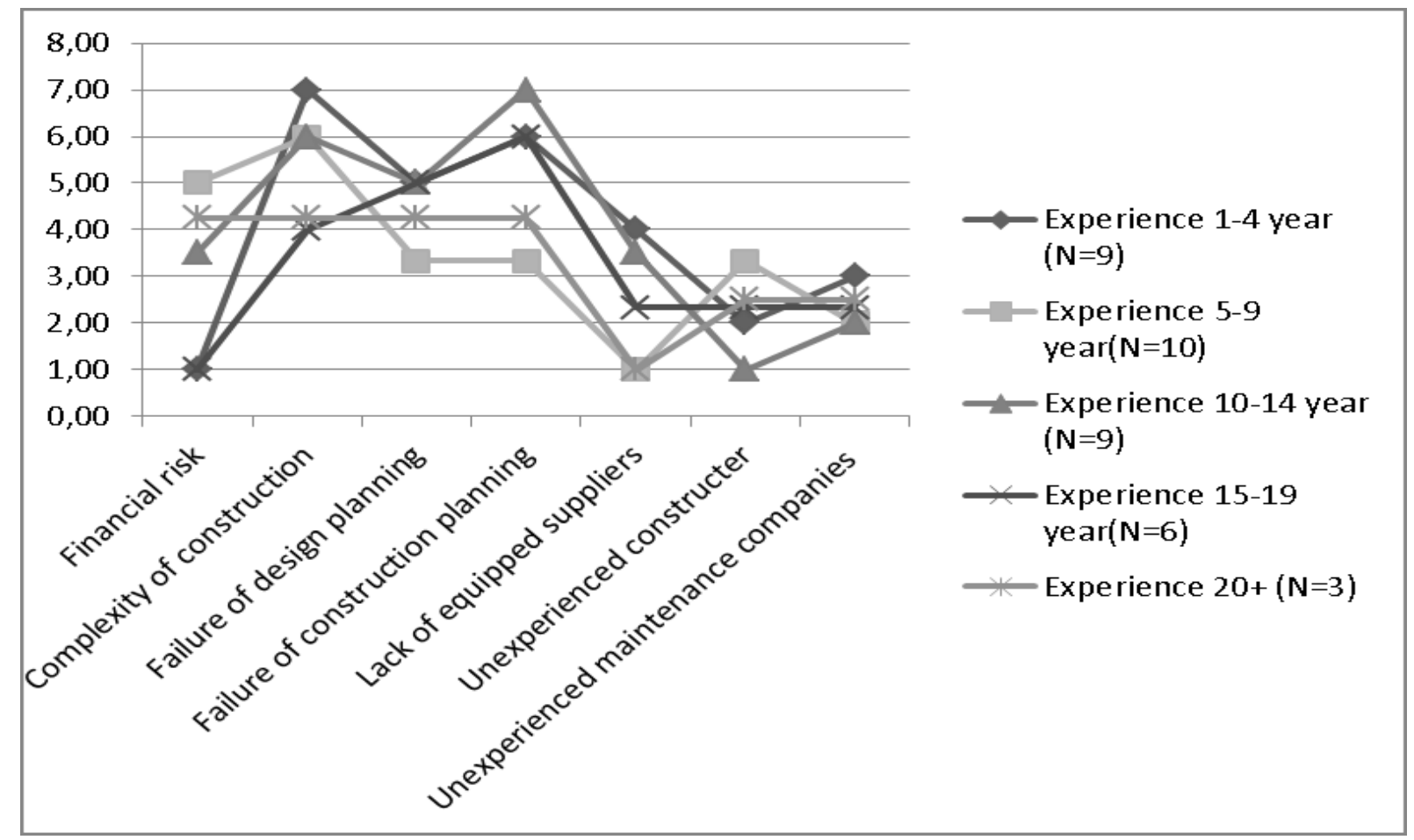


Table 4: Concordance of risk criteria by experience

\begin{tabular}{|c|c|c|c|c|c|c|c|c|}
\hline \multirow[b]{2}{*}{ Risk Criteria } & \multicolumn{5}{|c|}{ Experience } & \multirow[b]{2}{*}{ 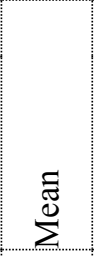 } & \multirow[b]{2}{*}{$\begin{array}{l}3 \\
0 \\
=\bar{\pi} \\
\overline{0} \\
\underline{0}\end{array}$} & \multirow[b]{2}{*}{ 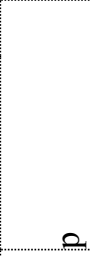 } \\
\hline & 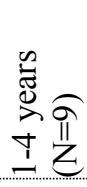 & 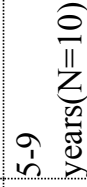 & 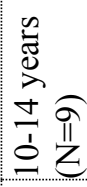 & 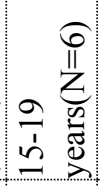 & 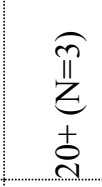 & & & \\
\hline Financial risk & 1,00 & 5,00 & 3,50 & 1,00 & 4,25 & 2,95 & \multirow{7}{*}{0,628} & \multirow{7}{*}{0,004} \\
\hline Complexity of construction & 7,00 & 6,00 & 6,00 & 4,00 & 4,25 & 5,45 & & \\
\hline Failure of design planning & 5,00 & 3,33 & 5,00 & 5,00 & 4,25 & 4,52 & & \\
\hline Failure of construction planning & 6,00 & 3,33 & 7,00 & 6,00 & 4,25 & 5,32 & & \\
\hline Lack of equipped suppliers & 4,00 & 1,00 & 3,50 & 2,33 & 1,00 & 2,37 & & \\
\hline Unexperienced constructer & 2,00 & 3,33 & 1,00 & 2,33 & 2,50 & 2,23 & & \\
\hline Unexperienced maintenance companies & 3,00 & 2,00 & 2,00 & 2,33 & 2,50 & 2,37 & & \\
\hline
\end{tabular}

According to figure 4 and table 5, while assessing the risk criteria, there is a high concordance in position and occupation groups. However, experience group have average concordance in between. Likewise, while assessing the benefit criteria, average concordance in experience groups; high concordance in position groups and rare high concordance in occupation groups have determined.

Figure 4: Kendall $W$ of the rank from respondents about risk and benefit criteria

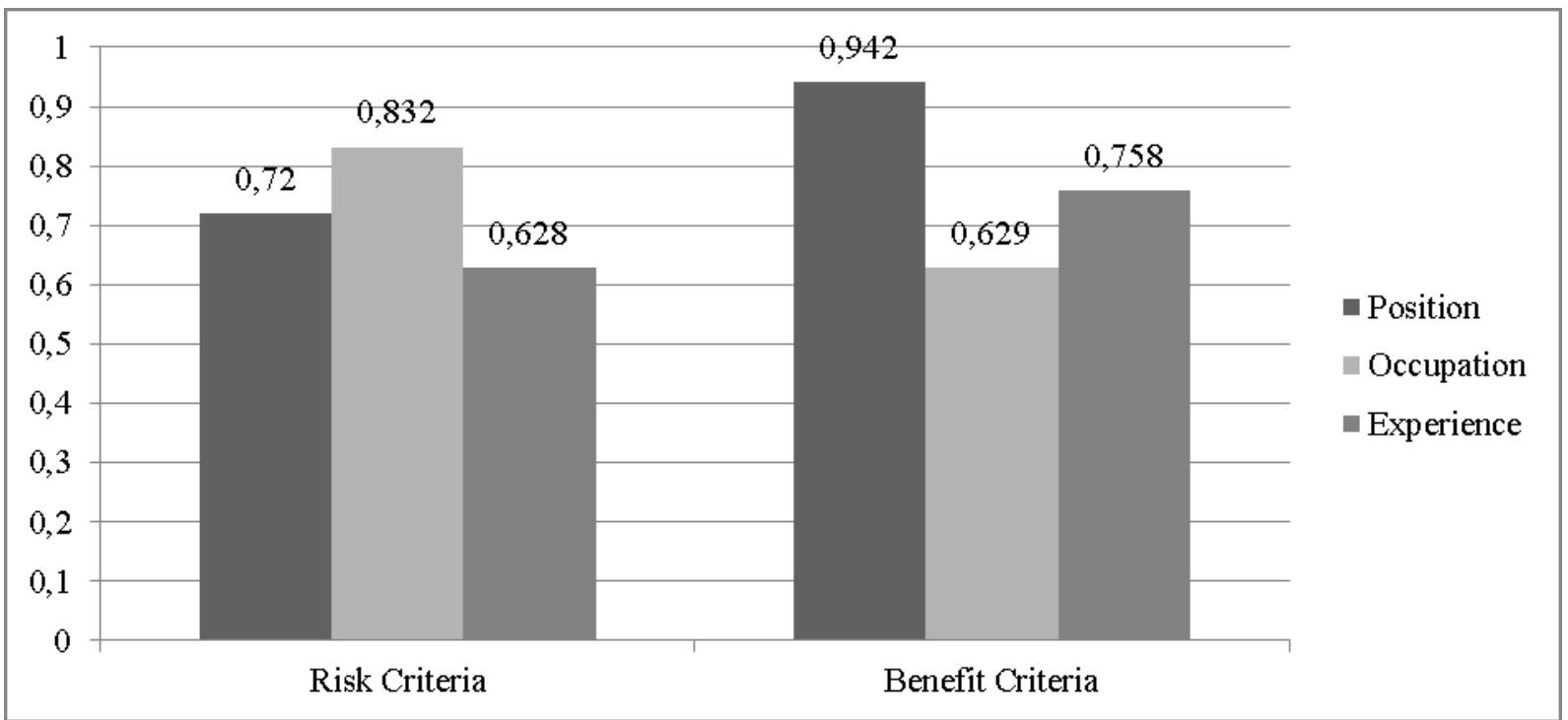


Table 5: Kendall's W Means (Caffey, Kazmierczak ve Avault, 2001, p.31).

\begin{tabular}{|l|l|l|}
\hline W & Explanation & Degree of Concordance \\
\hline 0,1 & Very low concordance & None \\
\hline 0,3 & Low concordance & Low \\
\hline 0,5 & Concordance & Average \\
\hline 0,7 & High Concordance & High \\
\hline 0,9 & Rare High Concordance & Very High \\
\hline
\end{tabular}

\section{CONCLUSIONS}

From the results of tests, the project stakeholders, who had participated in a LEED certificated project, knew the most of sustainability criteria well and had no complication to execute the criteria. On the other hand, according to the experience of respondents, brownfield development, bicycle storage and changing rooms, low-emitting and fuelefficient vehicles, green power and certified wood criteria were detected as the option of "have no idea". Therefore, due to the respondents, these criteria were commented as may not be used or may not be practiced much. Besides, the differences were observed between the ratings of architects and civil engineers. And also variations were clearly seen between different job titles. After the sustainability criteria; used equipment and methods part of the survey had analysed. Managers were indicated as using equipment and methods like heat control, energy efficiency, light assessment, budget and cost management more than workers were. Since the managers have been in a position that gives the last significant decisions.

Because of the limited number of practiced green buildings in Turkey, risks were assessed majorly effective. Risk categories were evaluated incompatible among managers and workers; also between job titles. The risks of execution, financial risk and design and construction planning problems, advanced supplier, inexperienced contractor and organization were all found effective by respondents. All kinds of construction projects contain financial risk. In addition, design and construction planning risks can be solved by experienced team members. On the other hand, the lack of advanced supplier risk has originated from the construction industry. Material suppliers must improve themselves to serve the alterations in the sector by researches and developing teams. If green building production becomes more common, the sector will need to supply the materials that are demanded.

Consequently, in Turkish construction industry people should focus on the benefits of green building and improve the sector by seeing construction sector as a strategic sector, valuing customer, removing dishonest trading, improving and marketing scientific researches, sharing knowledge between universities and industry, defining long term strategies, improving cooperation before competition, making long term benefit-cost analyses, enhancing awareness, evaluating the opportunities and encouraging researches. 


\section{REFERENCES}

- $\quad$ ALWAER H., CLEMENTS-CROOME D.J. (2009) Key Performance Indicators (Kpıs) And Priority Setting In Using The Multi-Attribute Approach For Assessing Sustainable Intelligent Buildings, Elsevier Ltd.

- $\quad$ CAFFEY, R. H., KAZMIERCZAK, R.F., and AVAULT, J.W. (2001) Developing Consensus Indicators of Sustainability for Southeastern United States Aquaculture, Louisiana Agricultural Experiment Station Bulletin No. 879, 31 p.

- GBCA- Green Building Council Of Australia (2013) Introducing Green Star, http://www.gbca.org.au/resources/gbca-publications. [Accessed: 9th April 2014]

- HEPBASLI, A. (2012) Low Exergy (LowEx) Heating and Cooling Systems for Sustainable Buildings, Renewable and Sustainable Energy Reviews 16.

- KATS, G. (2003). The Costs and Financial Benefits of Green Buildings, A Report to California's Sustainable Building Task Force

- KATZ, A. (2012). About USGBC, http://www.usgbc.org/articles. [Accessed: 15th March 2014].

- LEED- Leadership In Energy Environmental Design (2009). 2013 LEED for New Construction and Major Renovations Scorecard, USGBC- U.S Green Building Council

- LEED- Leadership In Energy Environmental Design (2013). 2013-2015 Strategic Plan, USGBC- U.S Green Building Council

- LEED- Leadership In Energy Environmental Design (2014). Why Leed Certification Matters, USGBC-U.S Green Building Council

- $\quad$ MALIN, N. (2004). Environmental Building News, Vol.13 No.11

- PYKE, C. (2014). IPCC Report: Building Sector Emissions Growing, Green Buildings Can Be Solution, http://www.usgbc.org/articles, [Accessed: 15th April 2014].

- $\quad$ RICS- Royal Institution Of Chartered Surveyors (2005). Green Value 


\title{
WOMEN PROFESSIONALS' PARTICIPATION IN THE CONSTRUCTION INDUSTRY - INDIAN SCENARIO
}

\author{
Ahuja, V. ${ }^{1}$ and Kumari, S. ${ }^{2}$
}

\begin{abstract}
:
Construction industry is an integral part of a country's infrastructure and industrial development. But, it is typically a male dominated industry and presents a major challenge for equal opportunities for women. India, one of the fastest growing economies in the world, is facing the global phenomenon of shortage of skilled workforce. To make up this shortage, it becomes imperative to convert untapped women resource. Paper presents a component of the work of a PhD research conducted to study the status of women workforce participation in Indian construction industry, issues and challenges faced by them and recommendations for improving working environment for them. Discussion focusses on issues and participation of women executives or professionals. Literature review from global research forms the base for identifying research variables and leads to data analysis from questionnaire survey conducted in the National Capital Region of India which includes capital city New Delhi and surrounding areas. Survey sample included men and women executives and representatives of organizations. Results indicate that women join the construction industry because of its challenging character, but their perception is that they do not get adequate opportunities and one of the identified barriers is work culture of long and inflexible working hours that does not support their requirement of devoting time for family responsibilities. Government level initiatives are required to address these issues and due to changing social demography, periodically studies need to be conducted to address these issues. Though the study is focussed for Indian Construction Industry, it has a global relevance and specific relevance for other developing countries.
\end{abstract}

KEYWORDS: INDIAN CONSTRUCTION INDUSTRY, ISSUES AND CHALLENGES, WOMEN WORKFORCE

\section{INTRODUCTION}

Construction sector is the world's largest industrial employer (Improving Working and Living Conditions in Construction, 2004). In India, it is one of the fastest-growing sectors and the second-largest generator of employment after agriculture. The Indian construction industry employs about 31 million people (India infra guru jobs, 2008) and by 2022 the workforce is expected to increase to 92 million (Government of India, 2011). More than half of the 31 million construction workers in India are women, but their potential is not utilised to the maximum (Government of India, 2008). The status of women is one of the determinants in overall development of any country. This issue is comparatively more serious in developing countries and specifically in construction industry.

\footnotetext{
${ }^{1}$ School of Construction, RICS School of Built Environment, Amity University, Noida, INDIA. Email: vahuja@rics.org

2 Faculty of Management Studies (WISDOM), Banasthali University, Rajasthan, INDIA. Email: savita2006.kumar@gmail.com
} 
The predominant image of construction is that of a male-dominated industry (Agapiou, 2002 cited in Amaratunga et al., 2006) and researchers have acknowledged the worldwide phenomenon of underrepresentation of women in the construction industry (Othman and Jaafar, 2013). Educating and recruiting more women in the construction industry is as important as retaining them (Gurjao, 2006). Researchers have highlighted the issue of low number of women holding managerial positions in the industry (Othman and Jaafar, 2013), gender divisions and vertical segregation (Fernando et al., 2014). This is a global phenomenon and is a case for global research. Globally construction industry is experiencing shortage of skilled workforce. Researchers have highlighted the requirement to attract more women to construction industry in order to fill the skills gaps and to make changes within the industry in terms of gender segregation and enhanced productivity (Fernando et al., 2014).

Job satisfaction as a result of opportunities and promotion is more likely to retain staff (Gurjao, 2006). But, majority of women face myriad issues and researchers have highlighted issues like societal perceptions, work-life balance issues, glass ceiling, low skills set. Primarily women bear the primary responsibility for domestic duties (Amaratunga et al., 2006). Thus, women in older age groups/mature women require parttime working and flexible working time options (Gurjao, 2006). But, construction industry globally does not attend to issues like balancing the work and family commitments (Fielden et al., 2000 cited in Amaratunga et al., 2006), leading to construction women adopting 'either or' approach to career and family (Amaratunga et al., 2006).

Women in the construction industry could be categorized in three groups: Women working in professional/technical positions; Women in administrative positions; and Women as construction labour working at sites (Ahuja \& Kumari, 2012). It is rare to find women contractors and site engineers in the construction sector in India, though there are women architects and designers. Negligible presence of women in construction industry has attracted both government and industry players' attention with focus on studying the issues leading to less participation of women in the sector and in finding ways to resolve these issues (Ahuja \& Kumari, 2013). But, in India studies are primarily conducted pertaining to the women of the third group i.e construction workers or labour which are large in number.

This paper discusses a component of the work of a $\mathrm{PhD}$ research conducted to study the status of women workforce participation in Indian construction industry, issues and challenges faced by them and recommendations for improving working environment for them. Study was conducted for women executives or professionals as well as workers at site. This discussion is focused on issues related to women professionals or executives. Literature review from global research forms the base for identifying research variables and leads to data analysis from questionnaire survey conducted in Indian Construction Industry. Study has global relevance in terms of social sustainability factor of women having equal work opportunities and economic sustainability factor of improving social productivity for all sectors. It has specific relevance for other developing countries. 


\section{CHARACTERISTICS OF CONSTRUCTION INDUSTRY}

Construction industry is known as a demonstrably male-dominated economic activity (Othman and Jaafar, 2013). Researchers have highlighted construction industry's over emphasis on "male values" which include long working hours, working away from home and geographical instability, a highly competitive culture (Amaratunga et al., 2006) and a high level of stress (Othman and Jaafar, 2013). Researchers have named it as culture of 'competitive presenteeism' (Watts, 2009). Construction industry work environment leads to conflicts in balancing work and family (Othman and Jaafar, 2013) and has not kept pace with social and demographic changes occurring within the industry workforce (Lingard \& Francis, 2008). Generic problems of inflexible working practices are experienced by women in all investigated areas of the supply chain (Gurjao, 2006 cited in Worrall et al., 2010).

Women encounter barriers at every stage of their progression (Gurjao, 2006). Working arrangements such as part time working, career breaks, and job sharing are considered as feminine and unfeasible in the industry (Amaratunga et al., 2006). Site conditions are not conducive for women and contractors have to invest extra finances in arranging basic facilities like toilets and guest houses specifically for them. Also, sometimes it is considered difficult to maintain discipline at site with male and female employees working together (Chittibabu, 2007). Such issues are faced by women executives as well as workers at site. In a survey of Indian Construction industry it was found that at many sites, duty to provide basic sanitation, first-aid facilities and child care facilities is completely ignored. Amongst the surveyed sites, $64 \%$ had no toilet facilities and $45 \%$ did not even provide drinking water (Baruah, 2010). Women who are at managerial positions at site feel negative about varying degrees of confrontation, close surveillance due to heightened visibility, sexual harassment, intimidation and wider safety issues, all experienced as emotionally draining and sometimes reasons for leaving (Watts, 2009).

Globally construction industry is facing an ongoing skills shortage and diversity-based recruitment levels are currently inadequate in meeting this severe skills gap (ConstructionSkills, 2008 cited in Worrall et al., 2010). Researchers have suggested that facilitating "untapped resource" of women participation could expand inclusivity and significantly improve the current skills' shortage faced by the industry (English and Hay, 2015; Gurjao, 2006; Worrall et al., 2010).

\section{Status of Women in Construction Industry}

Researchers have reported that wide range of global legislations emerged in the late 1990s to support women, but still the approximate proportion of women in construction industry is 10 per cent (Gurjao, 2006) and 66 per cent of women are employed in clerical roles (Gurjao, 2006; Fielden et al., 2000) rather than in a construction role (English and Hay, 2015). Since 1997, percentage of women in the UK construction industry, has remained relatively unchanged at between 10 and 14 per cent (Fernando et al. 2014). Women are seriously underrepresented in the construction sector in the European Union even though their representation in other sectors of the economy has increased (Byrne et 
al., 2005 cited in Haupt and Fester, 2012). In South Africa, women represent only 20 per cent of architects, 12 per cent of quantity surveyors, 2 per cent of civil engineers, 3 per cent of construction project managers and 0.6 per cent of construction managers (Worrall et al., 2010). In Cuba, published statistics show women's employment in construction at 20.3 per cent of the workforce (Ramirez, 2004), and it is increasing rapidly (Fortune, 2010). Family-friendly practices were not evident in the Australian construction industry (Haupt \& Fester, 2012). In a survey conducted in Thai construction industry, it was studied that women engineers in contractor companies were much more affected by problems such as sexual harassment, work-life conflicts and equal opportunity than women engineers in non-contractor companies (Kaewsri \& Tongthong, 2011). In India, $50 \%$ of workforce in construction industry is women (Government of India, 2008), but only about $1.4 \%$ are engineers, architects, designers and administrators (Chittibabu, 2007), rest work as construction labour. In a longitudinal study conducted in India, findings were: During last decade of 20th century there was a significant drop in preference for civil engineering and electrical engineering; Women engineers strongly perceive that they do not get what they deserve in terms of jobs, promotions, salaries as well as professional recognition; 'Unsatisfactory work opportunities and environment' is perceived as the most important factor affecting their career (Parikh \& Sukhatme, 2004).

The under-representation of women at senior levels is attributed to several structural and attitudinal barriers which may be gender-centred or organization-centred (Fernando et al., 2014) and reflects the phenomenon of "glass ceiling" (Gurjao, 2006). Globally women in construction perceive that though they may not face major discrimination, but they have to work harder than their male colleagues and have to prove themselves all the time (English \& Hay, 2015; Parikh \& Sukhatme, 2004). Studies focused on women entrepreneurs in construction industry have shown that financial institutions consider women - owned businesses high-risk enterprises and thus women have difficulty in finding capital to finance their projects (Maharaj \& Edigheji, 1999). EOC (Equal Opportunities Commission) research in UK shows that about 30,000 women leave their jobs annually on account of poor maternity rights and women from construction industry form a major component (Gurjao, 2006).

Women in different stages of profession in construction industry can be categorized as: Young women joining after completing education; Women starting on with family responsibilities and to be retained in the workforce; Women trying to return or returning to work following a career break; and Women who may join construction industry seeking a career change. Different issues are relevant at each stage of their professional career and are being studied globally.

The UK construction industry recently has become more proactive in making effort to retain women in order to avoid the 'revolving doors syndrome' that is attracting people only for them to exit shortly (Gurjao, 2006). In UK, Salford University has also conducted a study 'Developing Female Engineers' and brought forth the concept of 'leaky pipeline' which explains that though number of women entering the construction industry is increasing, but still the overall percentage was not increasing because losses were experienced along the way (Gurjao, 2006). Safa (1995) describes equality rights for 
women in the Cuban Constitution - such as equal pay, affirmative action in the workplace, one year's maternity leave on full pay, free day care centres for children, promotion of equality in education and affirmative action in the home through the Family Code (Fortune, 2010). As reported above, this has helped in increasing participation of women in Cuban construction industry. Galea \& Loosemore (2006) have discussed gender specific way of communication in the construction industry i.e. genderlect. The study finds that the main cause of interpersonal conflicts is the difference in way of negotiation by men and women. And genderlect in the construction industry is male centric and is the main reason of the conflict between male and female workers.

It would seem from models in Europe that political good will to encourage employment of women is insufficient to elicit change and that only when equal opportunity actions that targeted women were implemented was there a change (Michielsens, 2004 cited in English et al., 2006). 'Tokenism' approach needs to be avoided (Gurjao, 2006). Also, objective needs to shift from requirement to solve the labour resources crisis and skill shortages to improve equal opportunities for women (Agapiou, 2002 cited in Amaratunga et al. 2006).

In a study conducted in India regarding career goals of women engineers, identified goals were: Opportunity for personal growth and development of independent thought and action; feeling of security by being self-supporting and opportunity for financial growth (Parikh \& Sukhatme, 2004). From studies conducted to assess critical success factors as perceived important by professional women in construction industry, identified factors were: Educational qualification; Chartered qualification; Organisation support in the form of flexibility, having a good mentor and managers, ongoing training and development activities and personal development; Family support in the form of support from male partners or spouses and extended family; Support from peers; Opportunities and personal developments through training; Personal characteristics like personal ambitions, relationships with clients and co-workers, a positive attitude to responsibility; Soft skills like determination, quality of examinations, presentation skills, resilience, common sense, and sense of humour, hard work and other soft skills; and General management and Project management skills (Fernando et al., 2014; Haupt and Fester, 2012).

\section{Strengths of Women}

Women have inherent strengths that can positively contribute to the construction industry. Women are perceived to have better listening skills and soft skills (English \& Hay, 2015), they are perceived to be more creative than men, they pay more attention to detail, are more thorough, more organised, more precise and make a deeper and more thorough analysis (Fortune, 2010). Women are better at negotiating relationships and keeping the peace, while men tend to be more aggressive (English \& Hay, 2015). Traits like teamwork, politeness and multi-tasking that are considered feminine can have beneficial application on site (English and Hay, 2015). Women have stronger communication, empathy, and as compared to men they are able to response better to stress (Othman and Jaafar, 2013). Women are more likely to be innovative and flexible and adopt a participatory mode of working (Watts, 2009). Women project managers are 
found to have the ability to perceive warnings, stay alert when problems or conflicts arise, picture and analyse the problem to make an appropriate decision (Othman and Jaafar, 2013).

\section{DATA ANALYSIS OF STUDY CONDUCTED IN INDIAN CONSTRUCTION INDUSTRY}

Research was conducted in Indian construction industry to study the issues, challenges and prospects for women workforce participation in Indian Construction Industry. This research was conducted because there are very limited published studies in India addressing the issue. Research Methodology included qualitative as well as quantitative study. Issues that required urgent attention and study were identified through literature survey. Identified issues are: Perception and attractiveness of construction industry among women as a career opportunity; Discrimination faced by women on account of gender; Opportunities and challenges in career growth; Working conditions for women at construction site; and Social Security benefits to women.

Quantitative analysis was conducted on the data collected through structured questionnaire survey. The samples of study were both men and women professionals. This is because being a comparative study, the perception of men towards participation of women in construction industry and their working conditions was also considered important. Qualitative analysis was conducted on data collected from representatives of construction organizations through a semi-structured questionnaire survey. For these two distinct questionnaire surveys, the survey area was National Capital Region (NCR) that includes capital city New Delhi and regions of neighbouring States. Since last two decades, NCR of India has been witnessing high construction activity and is poised to continue as one of the fastest growing regions, both in per capita as well as population density (The Economic Times, 2011). Considering factors of high construction activity and presence of migrants from across the country, NCR was selected for survey. Quantitative data analysis was conducted through SPSS (Statistical Package of Social Sciences) using descriptive statistics. Survey sample for the professional category included 141 professionals comprising 48 (1/3rd of the total sample) women and 93 men. This indicates minimal presence of women as construction professionals. For Organizational category, 25 organizations of different staff strengths were studied. These organization were primarily of private sector.

Age and experience profile of men and women were distinct. None of the women respondents was above the age of 50 years, whereas 4 male respondents were older than 50 years. $85 \%$ women were less than 35 years of age whereas only $50 \%$ men were below 35 years of age. Majority of women (50\%) had 3-5 years of experience whereas only 4\% of them had 10 years' experience. Amongst men, $40 \%$ of them had experience of 10 years or above. Majority of women respondents were architects $(40 \%)$ and only $22 \%$ were engineers, though $40 \%$ of interviewed men were engineers. $50 \%$ of women respondents were employed at middle level management and only one third were at senior level of management. Amongst men, 56\% were working at middle level of 
management, whereas $25 \%$ were working at senior level of management. All women respondents were fulltime employees whereas, some of the male respondents $(15 \%)$ were either working part time or as consultants.

$44.8 \%$ women respondents and $84 \%$ men agreed that women face difficulties in securing employment in the construction industry. Among male respondents, reasons for joining the industry were almost equally divided between family background, challenging nature of the industry, better growth opportunity and better income. But, for $75 \%$ of the women respondents it was the challenging nature of the industry. While all female respondents perceived that women can experience career progression to the top managerial positions, 18 out of the 93 male respondents did not think so.

2/3rd of women respondents disagreed with the statement that there were equal opportunities for both genders in construction industry, whereas only one third of the male respondents disagreed. More than $10 \%$ of total respondents strongly agreed with the statement. 15 women and 47 men (total 63 i.e. 45\%) indicated that they had never witnessed any inequality/discrimination on account of gender. Remaining 78 respondents (55\%) had witnessed harassment (1 man); disrespect (1 woman and 4 men); lack of opportunity (32 women and 17 men); mistreatment/ill treatment (3 men).

Around $60 \%$ women as well as male respondents agreed or strongly agreed that construction industry is a male dominated industry. Also $73 \%$ women and $60 \%$ men perceived that the culture of construction industry is unfavourable for female employees. A staggering $92 \%$ of total respondents agreed that long working hours and inflexible working hours create unfavourable working condition for women. Only 31\% women respondents perceived that women are susceptible to verbal abuse in the construction industry as against 54\% men. On the other hand 56\% women respondents perceived that they are susceptible to sexual abuse as against 39\% men. $84 \%$ of total respondents perceived that the government should take initiatives to attract women into construction industry.

For study of organizations, sample included very young organizations established recently (2013), organizations having 10-15 years of operations and matured organization serving for last six decades. Executives at different job profiles (24 different types of jobs) were interviewed. Findings of the interviews through questionnaire survey revealed negligible presence of women in the construction industry. Most of the respondent organizations had only up to $10 \%$ female employees. None of the organizations had more than $20 \%$ female employees. Surprisingly, new and few older organizations stated female employees are not suitable for site work. Though for administrative work gender is not an issue, still they have a preference for male employees over female employees and the associated perceptions were that: Male employees are comparatively more skilled and are ready to handle different tasks; Male employees are ready to take hard and tough jobs; Females take more leaves and are irregular in duties; and Females are reluctant to migrate to remote sites or to work in night shifts. However few organizations' viewpoint was that women employees were more efficient for research \& development, design preparation and office work. Also, they are less motivated to form employee groups like unions. 


\section{CONCLUSIONS}

Survey results indicate that there is marginal presence of women in senior positions and at mature/older age. Women join the industry for its challenging nature, but there is strong perception that they do not get equal opportunities in the industry and they are also not able to effectively get involved in the site work.

Women are not adversely affected by the loud character of the industry and do not experience significant verbal abuse but they experience sexual harassment. This is an issue that is perceived differently by men. Compared to $56 \%$ women only $39 \%$ men perceive that women face sexual harassment. This indicates that women should be at senior positions so that issues pertaining to women can be addressed. Women perceive that they can achieve top managerial positions, but men have different perception. Further qualitative study is required to understand factors for such differing perceptions.

$78 \%$ respondents had witnessed gender discrimination in the form of harassment, disrespect, lack of opportunity and mistreatment. Survey data supports that long and inflexible working hours create unfavourable working conditions for women and culture of the industry is also not suitable for women. As discussed in literature survey, providing adequate maternity benefits results in retention of women or their return to the industry after sabbatical. Future research work includes a social study to understand the appropriate period and structure of maternity leave that would facilitate women to remain involved with organisational work during that period and further join back full time work.

Literature study is supported by survey as respondents perceive that government level initiatives are required to change the face of women participation. But, such interventions would be effective if general perception is changed regarding reasons for women taking leaves and their work preferences. Family support is needed so that women avail minimal leaves due to family commitments and can also travel to sites. Organizational support is needed with respect to supporting them with flexible working hours and work from home options. This would help in retaining women at the time when they need to devote time for family responsibilities and would also provide easy transition for their return. This would be in line with efforts made by Cuban government and society and reduce the 'Leaky pipeline' phenomenon.

Organizations perceive that women have better capabilities for research and design activities and do not involve themselves in groupism or other disruptive activities. Thus, along with above discussed affirmative actions, organizations should plan complimentary work assignments as per strengths of men and women employees and lead to benefit for the organization and the industry. At industry level, efforts are needed to increase use of IT and virtual working environment in the industry. This would further facilitate women in working from home.

The study highlights that addressing above discussed issues would bridge the skills gap in the industry and provide women equal opportunities, thus improving the work satisfaction among women. This would aid towards achieving economic and social 
sustainability in the society. Due to changing social demography, similar studies should be periodically conducted at global level to study and improve the working conditions and presence of women in construction.

\section{REFERENCES}

- $\quad$ AgAPIOU, A. (2002) Perceptions of Gender Roles and Attitudes towards Work among Male and Female Operatives in the Scottish Construction Industry, Construction Management and Economics, 20, pp 697-705.

- AHUJA, V. \& KUMARI, S. (2012) Issues and Challenges for Women in Construction Industry: Global as well as Indian Perspective, Proceedings of the Regional Conference of 'The International Network of Women Engineers \& Scientists (INWES), New Delhi, India, 12 th -13 th Oct., pp 11 .

- $\quad$ AHUJA, V. \& KUMARI, S. (2013) Indian Construction Industry - Training Needs and Issues, Proceedings of the 18th Annual Convention and Seminar on 'Training, Skill Upgradation and Competence Development in Building Industry' of Indian Buildings Congress, New Delhi, India, 20(1), pp 54-60.

- Amaratunga, D., HAigh, R., LEE, A., ShanmugAm, M. \& ElvitigAlA, G. (2006) Construction industry and women: A review of the barriers, Research Institute for the Built and Human Environment publication, The University of Salford, Salford, M5 4WT.

- BARYAH, B. (2010) Women and Globalization: Challenges and Opportunities Facing Construction Workers in Contemporary India, Development in Practice, 20(1), pp. 31-44.

- Byrne, J., Clarke, L. and Van Der Meer, M. (2005) Gender and Ethnic Minority Exclusion from Skilled Occupations in Construction: A Western European Comparison, Construction Management and Economics, 23(10), pp. 1025-34.

- ChitTiBabU, M. (2007) The Working Women in Contemporary Conditions and the Position of the Class Oriented Trade Union Movement, Presented in 16th Congress of World Federation of trade Unions, Brussels, Belgium, 13-14 Sep, 2007.

- ConstructionSkills (2008) Diversity within Construction, Available at: www.constructionskills.net/research/researchactivity/diversitywithinconstruction.asp

- $\quad$ ENGLISH, J., HAUPT, T.C. \& SMALLWOOD, J.J. (2006) Women, Construction and Health and Safety $(\mathrm{H} \& S)$ : South African and Tanzanian perspectives, Journal of Engineering, Design and Technology, 4(1), pp. 18-28.

- ENGLiSH, J. \& HAY, P. (2015) Black South African women in Construction: Cues for Success, Journal of Engineering, Design and Technology, 13(1), pp. $144-164$.

- $\quad$ FIELDEN, S. L., DAVIDSON, M. J., GALE, A. W. \& DAVEY, C. L. (2000) Women in Construction: The Untapped Resource", Construction Management and Economics, 18, pp. 113-121.

- $\quad$ FERNANDO, N.G., AMARATUNGA, D. \& HAIGH, R. (2014) The Career Advancement of the Professional Women in the UK Construction Industry, Journal of Engineering, Design and Technology, 12(1), pp. 53-70.

- FORTUNE, J. (2010) I am the Mother and the Father - Women in Construction in Cuba and the UK, International Journal of Cuban Studies, 2(1/2), pp. 147-156.

- GAlEA, N. \& LOOSEMORE, M. (2006) Men and Conflict in the Construction Industry. In: Boyd, D (Ed) Proceedings of 22nd Annual ARCOM Conference, 4-6 September 2006, Birmingham, UK, pp. 843-850.

- GOVERNMENT OF INDIA, PLANNING COMMISION (2008) Volume II: Social Sector, Chapter 6: Towards Women's Agency and Child Rights, Eleventh five year plan 2007 - 2012. New Delhi: Oxford University Press.

- GOVERNMENT OF INDIA, PLANNING COMMISSION (2011) Faster, Sustainable and More Inclusive Growth, An Approach to the Twelfth Five Year Plan. 
- GURJAO, S. (2006) Inclusivity: The Changing Role of Women in the Construction Workforce, Chartered Institute of Building, Ascot.

- HAUPT, T. \& FESTER, F. (2012) Women-owned Construction Enterprises: A South African Assessment, Journal of Engineering, Design \& Technology, 10(1), pp. 52-71.

- Improving Working and Living Conditions in Construction (2004) Draft Recommendations and Technical Guidance from the International Federation of Building and Wood Workers, Available from: www.ifbww.org/files/Improving Working and 84E5F.pdf [Accessed: 14th June 2013].

- India Infra Guru Jobs (2008) Construction, Available from: http://www.indiainfraguru.com/construction html [Accessed: 14th August, 2009].

- $\quad$ KAEWSRI, N. \& TONGTHONG, T. (2011) An Investigation of Women Engineers in Nontraditional Occupations in the Thai Construction Industry, Australasian Journal of Construction Economics and Building, 11(2), pp. 1-21.

- LINGARD, H. \& FRANCIS, V. (2008) An Exploration of the Adaptive Strategies of Working Families in the Australian construction industry, Engineering, Construction and Architectural Management, 15(6), pp. 562 - 579.

- MICHIELSENS, E., FRYDENDAL PEDERSEN, E. \& SUSMAN, B. (2004) The European Social Partners for Construction: Force for Exclusion or Inclusion?, Women in Construction, edited by Linda

- MAHARAJ, A. \& EDIGHEJ, S. (1999) Women in Construction: Breaking Ground Agenda, No. 42, Land and Housing: Women Speak Out (1999), pp. 82-87. Available on http://www.jstor.org/stable/4066045 [Accessed on 1st December, 2011].

- OTHMAN, N.L. \& JAAFAR, M. (2013) Personal Competency of Selected Women Construction Project Managers in Malaysia", Journal of Engineering, Design and Technology, 11 (3), pp. 276-287.

- PARIKH, P. P. \& SUKHATME, S.P. (2004) Women Engineers in India, Economic and Political Weekly, 10th January issue, pp. 193-201.

- RAMIREZ, R.M. (2004) Official Statistics of the National Direction of the Federation of Cuban Women. Cuba FMC 2004.

- $\quad$ SAFA, H .I. (1995) Economic Re-structuring and Gender Subordination, Latin American Perspectives, 22: 32.

- WATTS, J. H. (2009) Leaders of Men: Women 'Managing' in Construction, Work, Employment and Society, 23(3), pp. 512-530.

- $\quad$ WORRALl, L., HARRIS, K., STEWART, R., THOMAS, A. \& McDERMOTT, P. (2010) Barriers to Women in the UK Construction Industry, Engineering, Construction and Architectural Management, 17(3), pp. 268 - 281. 


\title{
INDUSTRY CULTURE AS CAUSATIVE AGENTS OF CONSTRUCTION WASTE: A NEED FOR CULTURAL CHANGE
}

\author{
Ajayi, S. O. ${ }^{1}$; Oyedele, L. O. ${ }^{2}$; Kadiri, K. O. ${ }^{3}$; Muhammad, B. ${ }^{4}$; Akinade, O.O. ${ }^{5}$; Owolabi, H.A. ${ }^{6}$ and \\ Alaka, H.A. ${ }^{7}$
}

\begin{abstract}
:
Owing to its contribution of largest portion of landfill wastes and consumption of about half of mineral resources excavated from nature, construction industry has remained a major target for achieving global sustainability. Despite an adoption of several waste management strategies, and introduction of various legislative measures, reducing waste generated by the industry remains challenging. In order to understand cultural factors contributing to waste intensiveness of the industry, as well as those preventing effectiveness of existing waste management strategies, this study examines cultural profile of construction industry. Drawing on four focus group discussions with industry experts, the study employs phenomenological approach to explore waste inducing culture.

Combining findings from phenomenological research with extant literatures, the study suggests that in order to reduce waste intensiveness of the construction industry, four waste inducing cultures need to be changed. These include (i) make-do understanding that usually result in make-do waste (ii) noncollaborative culture, which results in reworks and other forms of wasteful activities (iii) blame culture, which encourages shifting of waste preventive responsibilities between designers and contractors, and (iv) culture of waste behaviour, which encourages belief in waste inevitability. These sets of measures are not only important for engendering waste management practices; they are requisite for effectiveness of existing strategies. Thus, this paper advocates cultural shift as a means of enhancing sustainability and profitability of the construction industry.
\end{abstract}

KEYWORDS: CONSTRUCTION WASTE, COLLABORATION, MAKE-DO WASTE, WASTE BEHAVIOUR, LANDFILL

\section{INTRODUCTION}

Construction industry contributes significant portion of the global economy and employs large population across the globe. It accounts for $13 \%$ of the global economy and

\footnotetext{
${ }^{1}$ Bristol Enterprise, Research and Innovation Centre, University of the West of England, Bristol; UK. Email: saheed2.ajayi@live.uwe.ac.uk;

${ }^{2}$ Bristol Enterprise, Research and Innovation Centre, University of the West of England, Bristol; UK. Email: L.oyedele@uwe.ac.uk;

3 Department of Architecture, Obafemi Awolowo University, Ile-Ife, Nigeria. Email: imamkadiri@yahoo.com

${ }^{4}$ Bristol Enterprise, Research and Innovation Centre, University of the West of England, Bristol; UK. Email: muhammad2.bilal@live.uwe.ac.uk;

${ }^{5}$ Bristol Enterprise, Research and Innovation Centre, University of the West of England, Bristol; UK. Email: olugbenga2.akinade@live.uwe.ac.uk;

${ }^{6}$ Bristol Enterprise, Research and Innovation Centre, University of the West of England, Bristol; UK. Email: hakeem2.owolabi@live.uwe.ac.uk;

${ }^{7}$ Bristol Enterprise, Research and Innovation Centre, University of the West of England, Bristol; UK. Email: hafiz2.alaka@live.uwe.ac.uk.
} 
contributes annual amount of $\$ 12$ trillion, which is projected to reach $\$ 15$ trillion in 2025 , according to a year 2013 analysis by Global Construction Perspectives (GCP, 2013). As at the year 2008, the UK construction industry accounts for $8 \%$ of Gross Domestic Products (GDP), generates employment for over three million workers and contributes annual value of over £100billion (HM Government, 2008). However, the industry is highly fragmented as it seeks to meet demand of its customers within limited budget, resources and time-frame. As such, a typical project involves several numbers of drawings and different professional activities, whose successful coordination is important for completing the project within budget, expected time, and to the desired quality. Apart from the cultural profile of the industry, organisational culture within one business would not only have adverse effects on the others, it would also affect the collective outputs of the businesses (Hillebrant, 2000).

Meanwhile, apart from its consumption of more than half of mineral resources excavated from nature, construction industry contributes the largest portion of waste to landfill. For instance, the UK construction industry contributes about $44 \%$ of landfill waste, while the industry landfilled 44\% waste in Australia, $29 \%$ in the US and $35 \%$ across the globe (Solís-Guzmán et al., 2009; Oyedele et al., 2014). It has often been stated that achievement of the global sustainability agenda and prevention of impending negative environmental impacts depends on how well the construction industry is able to reduce its $\mathrm{CO} 2$ emission, virgin materials consumption and waste to landfill (Ajayi et al., 2015). As a result of its environmental and financial benefits, several strategies for tackling construction waste have been developed. In addition to these, various fiscal and legislative provisions have been made to engender waste minimization practices within the construction industry. However, despite increasing waste management research, strategies and legislative provisions, landfilling of construction waste remains a common practice. While other industries have substantially reduced their waste to landfill, proportion of C\&D waste landfilled remained alarming (DEFRA, 2013). According to Teo and Loosemore (2001), increasing waste intensiveness of the construction industry is not only as a result of ineffectiveness of the existing waste management strategies. Rather, waste intensiveness of the industry is enhanced by certain behavioural and cultural values that support construction waste generation (Teo and Loosemore, 2001). While it is clear that understanding such waste inducing culture could engender solutions to construction waste mitigation, there is paucity of study that evaluates construction waste from cultural perspective. This represents a gap that this study seeks to fill.

The overall aim of this study is to examine cultural profile of construction industry in order to understand cultural factors contributing to its waste intensiveness, as well as those preventing effectiveness of existing waste management strategies.

In order to gain in-depth exploration of the concept as understood by the industry's expert, this study employs phenomenological approach as its epistemological framework. As a theoretical background to the study, the next section of the paper established the relationship between organisational culture and its efficiency. This was followed by justification and description of the methodological approach to the study, which includes sampling, data collection and analytical procedures. The result of the findings are then 
presented and discussed before culminating the study with a conclusion and implications for practice. The study offers insights into the need for cultural change as a means of reducing waste intensiveness of the construction industry.

\section{Impacts of Culture on Organisations}

Organisational culture is an important phenomenon that determines how members of that organisation relates with one another and external community in comparison with other organisations. It often encompasses common belief and share assumptions that guide appropriate response and actions for various occurrence (Ravasi and Schultz, 2006). As it is usually taught or passed to new members through formal training or informal interaction, organisational culture shapes the way a group interact with one another, stakeholders, clients/customers and the general community (Sharifirad and Atei, 2011). Like other industries, construction industry is characterised by cultural differences across firm types, age and size (Oney-Yazici, et al., 2007). Understanding these cultural could therefore assist in planning how to manage and improve the industry (Schein, 1992). With increasing awareness of the impacts of organisational culture on its success, substantial research efforts have been devoted to empirical investigation of organisational culture across several industries and nations (cf. Cameron and Quinn, 1999; Oney-Yazici, et al., 2007). Evidence suggests that international construction firms often faced problems due to misunderstands caused by cultural and behavioural differences across organisations (Oney-Yazici, et al., 2007).

Albeit paucity of studies linking construction industry's culture with its waste intensiveness, studies are rife on the relationship between culture and achievement of organisational goals and development. For instance, Naranjo-Valencia et al. (2011) investigate the relationship between organisational culture and openness to innovation. The study suggests that organisational culture does not only determine employees' readiness for innovation, it determines strategy and approach to innovation. Since culture affects employees' behaviour and their disposition to various aspects of their job, it also determines whether they would accept innovation as fundamental value of their organisation or not. Meanwhile, both direct and indirect relationship have been established between organisational culture and performance. According to Denison (1984), cultural factors related to organization of work and decision-making is strongly correlated with financial performance of a firm. This means that an organisation with the right culture of work organisation and decision-making process tends to out-perform its competitors in terms of financial turnover. On a similar note, Kotter and Heskett (1992) suggest that an organisation with adaptive values tends to have superior performance over a long period of time. Echoing similar position, Lee and Yu (2004) posit that in several cases, cultural elements that distinguish various organisations are related to performance.

Studies specifically addressing construction industry suggest that several cultural profiles, which varies with firm type, organizational size and age, exist within the industry. According to Oney-Yazici, et al. (2007), firms operating within architectural services and contracting cherished and emphasised culture of stability and team working much more than innovation and productivity. A study of construction waste also suggests that an 
underlying culture of waste inevitability within the industry is a major cause of waste intensiveness of the construction industry (Teo and Loosemore, 2001). By believing that waste is unavoidable, waste management is perceived as low priority, thereby receiving less attention and inadequate incentives. These further corroborate the fact that organisational culture within an industry is an important phenomenon that determines levels of importance attached to an activity.

Summarily, while industry or organisational culture could be seen as indispensable norm within such industry, it could make or mar progress, sustainability and profitability of the industry (Cameron and Quinn, 1999). As such, it is important that organisations adequately evaluate their culture in a bid to determine their consequences on development. This is particularly important for the construction industry, which is large and complex, and covers a wide range of micro, small, medium sized and large business activities that are all united by their output (Hillebrant, 2000). In such case, organisational culture within one business would not only have effects on the others, it would also affect the collective outputs, which are usually buildings or other infrastructural facilities.

\section{METHODOLOGY}

This study is a part of an overall study seeking to develop holistic approach for minimizing waste generated by construction activities. It seeks to explore cultural factors that contribute to waste intensiveness of the construction industry. In order to achieve this, phenomenological approach was employed in collecting data from industry practitioners. From epistemological point of view, the use of phenomenology enhance exploration of lived experience of research participants with respects to the concept under investigation (Creswell, 2013). This helps in exploring construction industry's culture that are capable of inducing waste generation or preventing effectiveness of existing waste management strategies. According to van Manen (1990), the tenet of phenomenology is based on the belief that a wrongly understood or widely neglected phenomenon could not be well understood until all presuppositions and researchers' understandings are bracketed out. The methodological approach therefore avail the opportunity of getting first-hand information from the industry practitioners, thereby preventing potential biasness from the researcher.

According to Creswell (2013), a phenomenological research could be carried out through in-depth interview with individual participants or interview with multiple participants (focus group discussions). In this study, focus group discussions have been preferred to interview as it allows the research participants to build on each other's opinion through intersubjective interaction (Kvale, 1996). In order to get information-rich participants, purposive sampling was used for this study. This is in line with Merriam's (1998) position that purposive sampling is suitable in a situation whereby researchers seek to explore phenomenon. Selection criteria was therefore based on job position, interest in waste mitigation and years of experience within the construction industry. Based on Polkinghorne's (1989) recommendation that between five and 25 participants are expected to participate in phenomenological research, a total of 24 participants were 
involved in the study. This involved architects, civil/structural engineers, construction project managers, site waste managers, materials suppliers and supply chain managers of small to large design and construction firms across the UK. In addition to two members of the research team, who moderated the discussions, Table 1 shows the distribution of participants in the four focus group discussions used for the study.

Table 1: Overview of the focus group discussions and the participants

\begin{tabular}{llll}
\hline FG & Categories of the Participants & $\begin{array}{l}\text { Number of } \\
\text { participants }\end{array}$ & $\begin{array}{l}\text { Average years } \\
\text { of experience }\end{array}$ \\
\hline 1 & Architects and Design Managers & 7 & 13 \\
2 & Materials suppliers and supply chain managers & 6 & 16 \\
3 & Project managers and site waste managers & 6 & 14 \\
4 & Civil and structural engineers & 5 & 15 \\
TOTAL & & 24 & \\
\hline
\end{tabular}

More specific to this study, the research participants were asked to evaluate cultural profile of the construction industry. This is aimed at determining the industry's culture contributing to its waste intensiveness. As part of a study seeking to explore the whole aspect of construction waste mitigation, each of the discussions lasted between 75 and 90 minutes and were all recorded with permission of the participants.

\section{ANALYSIS AND FINDINGS}

Phenomenological data analysis usually follow a systematic process where analysis is done from narrow to broader unit of analysis (Creswell, 2013). In order to achieve this, the voice data was transcribed into a written script, which was read several times to identify significant themes that are commonly shared by the participants. This was achieved through a content driven thematic analysis that helped in exploring both implicit and explicit statements stemming from the data (Braun and Clarke, 2006). In all, a total of four waste inducing culture were identified from the analytical process. These are:

1. Make-do understanding that usually result in make-do waste

2. Non-collaborative culture

3. Blame culture, which encourages shifting of waste preventive roles between parties

4. Culture of waste behaviour

The research participants posit that in order to reduce waste intensiveness of the construction industry, the four cultural beliefs should be addressed.

\section{DISCUSSION}

Based on the findings from focus group discussions, as enumerated above, this section focus on the common experience of the research participants concerning waste inducing 
culture. The discussion considers both essential and invariant structures that emanated from the data collection process. The findings point out that although the industry seek to ensure environmental sustainability, there are certain culture impeding its social and environmental sustainability. As earlier itemised, the industry's culture that enhances waste generation are discussed under four headings.

\section{Make-do Understanding}

Unlike manufacturing industry where manufacturing, assembly and disassembly processes are carried out with the aid of carefully and completely prepared design, construction activities often start with incomplete design information (Koskela, 2004). According to the focus group discussants, construction procurement routes often allows commencement of construction activities before completion of design documents. This means that those that should carry out the construction work lack adequate information or have wrong information to do the job, thereby resulting in waste due to reworks (Alarcon and Mardones, 1998). This echoed findings by Dainty and Brooke (2004), which suggests that most error at construction stage is usually due to incomplete design document or contractors' poor knowledge of the design and its documentation. The kind of waste generated as a result of such process is what Koskela (2004) referred to as makedo waste. As such, the overall process and provisions that allows construction activities with incomplete documentation is termed make-do understanding, which affects sustainability of the industry. This occurs as a result of construction activities that is commenced while design, construction documents and specifications are yet to be completed or when there are unresolved design issues. Apart from being a potential cause of reworks and subsequent waste generation, incomplete design and contract documents at the time of construction or contract award increase the risks of cost and time over-run in construction projects. This means that apart from environmental sustainability, such activities also threaten economic sustainability of the construction activities.

In order to prevent waste generation, cost over-run and project delays that could be caused by the make-do understanding, the focus group participants recommended a more collaborative project delivery process. This could be achieved through early involvement of contractors during the design process, use of Integrated Project Delivery (IPD) and collaborative BIM environment. Owing to involvement of all major stakeholders in the design process (Isikdag and Underwood, 2010), the use of IPD as a procurement route is capable of preventing errors that could be due to information delay and make-do understanding.

\section{Non-collaborative culture and over-the-wall syndrome}

Inadequate collaboration between designers, procurement team and contractors is a key feature that compromises profitability and effectiveness of the construction industry (Hughes et al., 2012). Traditionally, a client commissions the design team, which will subsequently involve engineers and building service consultants. As a result of fragmented nature of the industry, the drawings are passed from one trade to another, without necessarily working collaboratively. The design documents are then passed to the 
contractor who undertakes the actual work onsite. This results in what is regarded as over-the-wall syndrome, which is a difficulty that arise when different professionals are working independent of one another towards the same goal. It therefore results in late detection of errors and the need for reworks that subsequently result in construction waste generation and subsequent likelihood of negative environmental impacts. It has often been evident that the major causes of construction waste are ineffective project communication and coordination, inconsistent procurement documentation, unclear allocation of responsibilities (Osmani, 2012), document delay, and non-involvement of contractors in design decisions (Arain et al., 2004). All these occur as a result of poor collaboration among the project team.

In a bid to reduce construction waste due to rework, the focus group discussants suggest that there is need for increasing collaboration throughout project lifecycle stages - design to completion. This requires an environment for effective communication, information sharing, early warning system and early contribution of expertise by all parties (Hughes et al., 2012). As such, every ambiguity and inaccuracies would have been resolved before design completion, thereby preventing construction errors, reworks and waste. Similarly, collaborative working between the designers and contractors would assist in addressing constructability of the design, which could otherwise result in error and waste. Cultural change from over-the-wall approach is as such requisite to improving sustainability of the construction industry.

\section{Blame Culture}

Construction industry is known for its inadequate interdisciplinary communication. Although the designers do the design, they do not necessarily think about construction methodology and they are not prepared to take responsibility for problems regarding buildability or errors in design. On the other hand, cost saving achieved through innovative design is not necessarily shared with the designers in the same way as they do not share in problems emanating from buildability of their design. Rather, the whole process is interested in passing blame to another party (Fewings, 2013). This shifting of blame is one of the major factor contributing to ineffectiveness of construction waste management strategies. While the contractors believe that designers contribute to waste generation, designers posit that their activities have nothing to do with waste (Osmani et al., 2008). With the industry being characterised by blame culture as in this case, collaborative working environment could not be more important for its economic and environmental sustainability.

\section{Culture of Waste Behaviour}

This study found that a deep-rooted wasteful culture exists within the construction industry. The focus group discussants argued that it is widely held belief within the industry that since the client paid for waste management, it is better to generate waste than allowing waste management to delay further construction activities. This questions integrity of the construction industry with respects to social aspect of sustainability, which seeks to ensure quality and save society. This behaviour is also evident in the 
concept of waste allowance, which is the potential proportion of waste that is added to the required quantity of materials. According to Buchan et al. (1991), this allowance is usually in the range of 2.5 to $10 \%$ of the quantity of materials. It is believed that a certain proportion of waste is inevitable due to current practices.

In line with this study, Teo and Loosemore (2001) illuminated the prevailing culture of waste inevitability that characterised the construction industry. The study stressed that construction operatives usually believe that since waste is inevitable, there is no need for excessive preventive efforts. In addition, since the cost of wasted materials and the cost of landfilling the waste is already paid by the client, little effort is usually made by the site management. The same opinion was echoed by Ikau et al. (2013) and Osmani et al. (2008) who reiterated that a major reason for insurmountable waste intensiveness of the construction industry is that workers believe that waste is inevitable thereby giving less attention to waste management. Waste management effort is rather driven by environmental policies and various fiscal measures that are usually put in place by the government (Al-Hajj and Hamani, 2011). In order to drive the necessary cultural change in the industry, there is need for more dedication on the part of workers, clearly defined and communicated waste management approach and top management's commitment to waste management (Teo and Loosemore, 2001).

\section{CONCLUSION}

Construction industry has remained a major target for achieving global sustainability, as it consumes about half of mineral resources, and contributes largest portion of landfill wastes. Despite an adoption of several waste management strategies and introduction of various legislative measures, reducing waste generated by the industry remains challenging. This suggests that there are underlying culture that enhance waste intensiveness of the industry. Using phenomenological approach, this study examines cultural profile of construction industry in order to understand cultural factors contributing to waste generation, as well as those preventing effectiveness of existing waste management strategies.

The study suggests that a non-collaborative culture within the industry is a major factor contributing to waste intensiveness of the industry. This is usually as a result of over-thewall syndrome, which is a difficulty that arise when design and construction professionals lack collaboration. This results in late detection of errors and the need for reworks that subsequently result in construction waste generation and tendency of materials depletion and negative environmental impacts. Similarly, the culture of "makedo" that allows commencement of construction activities with incomplete design document is another organisational culture that contribute to waste intensiveness of the industry. To effectively mitigate construction waste, it is not only required that design and contract documents are completed before the construction process, early involvement of contractors during design stage is expected of the industry. By involving all parties in design and construction decision in more collaborative system, the blame culture that enhances shifting of waste mitigation responsibility would be prevented. In addition, this 
study suggests that a major factor contributing to waste generation in the industry is the belief of waste inevitability. It prevents implementation of effective waste management strategies and encourages waste causative activities such as lack of management support of waste management efforts, excess waste allowance and over ordering of materials, among others.

This study implies that apart from change in the way waste is managed within the industry, there is need for improved collaboration within the industry. The study evident that the blame culture and make-do understanding are as a result of non-collaborative culture within the industry. By shifting from the traditional procurement route to a more collaborative system such as Integrated Project Delivery (IPD), more interdisciplinary relationship and communication would be enhanced in the industry. This requires early involvement of key stakeholders, use of BIM, free sharing of project information, risks and rewards sharing, among others. Rather than shifting blame and risk, performance based rewards and penalties would enhance waste effectiveness, productivity and overall profitability of the industry.

As a result of paucity of study examining impacts of industry's culture on construction waste, this study has been limited to exploration of factor through qualitative approach. Other studies employing quantitative approach could determine generalizability of the findings of this study by using larger sample. This would assist in studying at length rather than depth that is investigated in this study. In addition, as this study has been carried out within the UK context, transferability of its findings to other regions could also be investigated. With organisational culture recognised as a key driver of work ethics and relationship, it is important that cultural profile of the construction industry is investigated for its impacts on time and cost over-run, which are rife in the industry.

\section{REFERENCES}

- $\quad$ AJAYI, S.O., OYEDElE, L.O., BILAL, M., AKINADE, O.O., ALAKA H.A., OWOLABI, H.A., \& KADIRI, K.O. (2015). Waste effectiveness of the construction industry: Understanding the impediments and requisites for improvements. Resources, Conservation and Recycling, 102, pp. 101-112

- ALARCÓN, L. F., \& MARDONES, D. A. (1998). Improving the design-construction interface. In: Proceedings of the 6th Annual Meeting of the International Group for Lean Construction, Guaruja, Brazil, 13-15 August, 1998.

- AL-HAJJ, A., \& HAMANI, K. (2011). Material waste in the UAE construction industry: Main causes and minimization practices. Architectural Engineering and Design Management, 7(4), pp. $221-235$.

- $\quad$ ARAIN, F. M., ASSAF, S., \& PHENG, L. S. (2004). Causes of discrepancies between design and construction. Architectural Science Review, 47(3), pp. 237-249.

- $\quad$ BRAUN, V., \& CLARKE, V. (2006). Using thematic analysis in psychology. Qualitative research in psychology, 3(2), pp. 77-101.

- $\quad$ BUCHAN, R. D., FLEMING, F. W., \& KELLY, J. R. (1991). Estimating for builders and quantity surveyors. Oxford: Newnes.

- CAMERON, K.S., \& QUINN, R.E. (1999). Diagnosing and changing organizational culture: Based on the competing values framework. New York, NY: Addison-Wesley. 
- CRESWELL, J. W. (2013). Qualitative inquiry and research design: Choosing among five approaches, 3rd edition. Thousand Oaks: Sage.

- DEFRA, (2013). Waste Prevention Programme for England: Overview of Evidence - A rationale for waste prevention in England. London: Department for Environment, Food and Rural Affairs (DEFRA).

- DENISON, D. (1984). Corporate culture and organizational culture and effectiveness. Organization Science, 6(2), pp. 204-223.

- FEWINGS, P. (2013). Construction Project Management: An integrated approach, 2nd edition. London and New York: Routledge.

- GLOBAL CONSTRUCTION (GC, 2013). "A global forecast for construction-2025" [online]. Available through: http://www.globalconstruction2025.com/. [Accessed: 16th July, 2014].

- HILLEBRANT, P.M. (2000). Economic theory and the construction industry, 3rd edition. London: Macmillan.

- HM GOVERNMENT (2008). Strategy for sustainable construction. London: Department for Business, Enterprise and Regulatory Reform.

- $\quad$ HUGHES, D., WILLIAMS, T., \& REN, Z. (2012). Differing perspectives on collaboration in construction. Construction Innovation, 12(3), pp. 355-368.

- IKAU, R., TAWIE, R., \& JOSEPH, C. (2013). Initial findings on perspectives of local contractors on waste minimization barriers and incentives. In: Proceeding of IEEE Business Engineering and Industrial Applications Colloquium, pp. 506 - 509.

- ISIKDAG, U., \& UNDERWOOD, J. (2010). Two design patterns for facilitating Building Information Model-based synchronous collaboration. Automation in Construction, 19(5), pp. 544-553.

- KOSKELA, L. J. (2004). Making do-the eighth category of waste. In: Proceedings of the 12th annual conference of the International Group for Lean Construction, 3-5 August 2004, Helsingor, Denmark.

- KOTTER, J., \& HESKETT, J. (1992). Corporate culture and performance. New York, NY: Free Press

- KVALE, S., (1996). Interviews: An introduction to qualitative research interviewing. Thousand Oaks, California: Sage Publications

- LEE, S.K.J, \& YU, K. (2004). Corporate culture and organizational performance. Journal of managerial psychology, 19(4), pp. 340-359.

- MERRIAM, S. B. (1998). Qualitative research and case study applications in education. Revised and expanded from" case study research in education. San Francisco, CA: JosseyBass Publishers

- NARANJO-VALENCIA, J. C., JIMÉNEZ-JIMÉNEZ, D., \& SANZ-VALLE, R. (2011). Innovation or imitation? The role of organizational culture. Management Decision, 49(1), pp. $55-72$.

- ONEY-YAZICI, E., GIRITLI, H., TOPCU-ORAZ, G., \& ACAR, E. (2007). Organizational culture: the case of Turkish construction industry. Engineering, Construction and Architectural Management, 14(6), pp. 519-531.

- OSMANI, M., GLASS, J. \& PRICE, A.D.F. (2008). Architects' perspectives on construction waste reduction by design. Waste Management, 28(7), pp. 1147-1158.

- OYEDELE, L. O., AJAYI, S. O., \& KADIRI, K. O. (2014). Use of recycled products in UK construction industry: An empirical investigation into critical impediments and strategies for improvement. Resources, Conservation and Recycling, 93, pp. 23-31.

- POLKINGHORNE, D. E. (1989). Phenomenological research methods. In: Hailing, S., \& Valle, R. (Eds.). Existential-phenomenological perspectives in psychology, pp. 41-60. New York: Springer.

- RAVASI, D., \& SCHULTZ, M. (2006). Responding to organizational identity threats: Exploring the role of organizational culture. Academy of management journal, 49(3), pp. 433458. 
- SCHEIN, E. (1992). Organizational culture and leadership, 2nd edition. San Francisco, CA: Jossey-Bass.

- SHARIFIRAD, S. M., \& ATAEI, V. (2012). Organizational culture and innovation culture: exploring the relationships between constructs. Leadership \& Organization Development Journal, 33(5), pp. 494-517.

- SOLÍS-GUZMÁN, J., MARRERO, M., MONTES-DELGADO, M.V., \& RAMÍREZ-DEARELLANO, A. (2009). A Spanish model for quantification and management of construction waste. Waste Management, 29(9), pp. 2542-2548.

- TEO, M. M. M., \& LOOSEMORE, M. (2001). A theory of waste behaviour in the construction industry. Construction Management \& Economics, 19(7), pp. 741-751.

- VAN MANEN M. (1990). Researching lived experience: Human science for an action sensitive pedagogy. London, Ontario: Althouse. 


\title{
INTERACTIONS OF CULTURE AND PERSON-TECHNOLOGY FIT IN ICT ADOPTION IN CONSTRUCTION
}

\author{
Hua, Y.Y. ${ }^{1}$, Liu, A.M.M. ${ }^{2}$, and Tijhuis, W. ${ }^{3}$
}

\begin{abstract}
:
Substantial hidden innovations exist in the construction sector, such as information and communication technology (ICT), however, innovation adoption processes are embedded in organizational culture, which varies among organizations. ICT innovation in this research is considered as the interaction process between technology, culture, task and person across individual and organizational levels, instead of a linear stage-by-stage process as in traditional ICT adoption research. Technology-culture fit, tasktechnology fit, person-task fit and person-culture fit are all interlinked in an interaction framework. Due to the dual nature of technology and the dynamic nature of culture, the relationship between technology and culture is also bidirectional. This paper develops a conceptual framework for the interaction between technology, culture, task and person across organizational level and individual level. The organizational level interaction is technology centered, focusing on the fit between values embedded in organizational culture and in technology. The individual level interaction is task centered, which focuses on the fit between technology and task requirements, and the fit between competency of an individual and task requirements. Based on the deductive inferences of theories and empirical findings, two propositions are put forward: i) technology-culture fit is associated with task-technology fit ; ii) person-culture fit and person-task fit influence individuals' adoption behaviour through the mediation effect of task-technology fit.
\end{abstract}

KEYWORDS: CONSTRUCTION, INFORMATION AND COMMUNICATION TECHNOLOGY, INNOVATION, TASK-TECHNOLOGY FIT, TECHNOLOGY-CULTURE FIT

\section{INTRODUCTION}

Information and communication technology (ICT) has recently been identified as an essential innovation for improving communication in construction processes. ICT has been found to add value to information management in construction through shortened project duration, enhanced processing of progress claims, contract administration, organizational image and user satisfaction (Stewart and Mohamed 2003). To keep up with the technology development and to enhance sustainability, many organizations in the construction industry have adopted ICT. However, in practice, many construction enterprises differ greatly in performance of using ICT. Technology adoption problems remain in the construction industry such as users' resistance because people are changeaverse toward new technologies (Love et al., 2001), but "sustainability enabled"

\footnotetext{
${ }^{1}$ Department of Real Estate and Construction, The University of Hong Kong, Hong Kong. Email: huayy@hku.hk

${ }^{2}$ Department of Real Estate and Construction, The University of Hong Kong, Hong Kong. Email: ammliu@hku hk

${ }^{3}$ University of Twente, Netherlands. Email: w.tijhuis@utwente.nl
} 
organizations need the capacity for change and the related process of continuous innovation and organizational transformation. Therefore, the key question is how to ensure that expected users accept and use ICT in their work processes.

The relative invisibility of the ICT implementation process is also identified as the major cause of ICT implementation failures. Markus and Robey (1988) attributed such invisibility to the unpredictably complex social interaction of ICT and organization. Socio-technical system theory provides a perspective to understand the invisible process of ICT implementation. Socio-technical system theory is used to study the interaction between people and technology in workplaces, or the interaction between society's complex infrastructure and human behaviour. The socio-technical system contains several components, including technology, task, actors, culture and structure. These elements are highly interdependent and a change in any one of them results in a compensatory (or retaliatory) change in the other elements so that the system maintains equilibrium (Lyytinen and Newman 2008). Therefore, these elements should be considered jointly.

In the socio-technical system, the elements should fit each other to maintain the system equilibrium. The impacts of these 'fits' on technology adoption have been considered individually by researchers. For example, technology-culture fit (e.g. Leidner and Kayworth, 2006) and task-technology fit (e.g. Zigurs and Buckland, 1998) have been shown to affect technology adoption. Person-culture fit and person-task fit are two mature constructs in human resource management theory (Caldwell and O' Reilly 1990). Although these two constructs are not directly related to technology adoption, they are found to be related to commitment for organization change (Meyer et al. 2010) and creativity (Livingstone et al. 1997), both of which play key roles in technology adoption.

The above-mentioned 'fits' lay ground for the development of a comprehensive system which links culture, technology, task and person. The conceptual relationships between culture, technology, task and person are shown in Figure 1.

Figure 1: Conceptual model of the fit between culture, technology, task and person

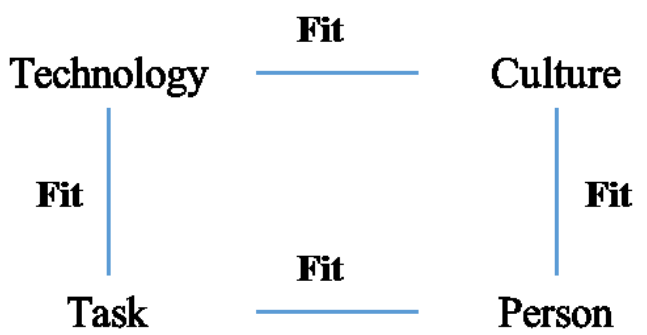

The conceptual model lays ground for the following research questions regarding the underlying relationships between these fits:

1) How does technology fit culture and task? 
2) What is the role of person in the fit between technology, culture and task?

3) What is the relationship between organizational level fit and individual level fits?

In response to the above research questions, this paper aims at i) developing a comprehensive theoretical model for the fit between culture, technology, task and person; and ii) deriving propositions based on the theoretical model for future testing.

The research method adopted is critical review of theory and literature. The topic covers the themes of socio-technical system, organizational culture, strategic fit, organizational behaviour and innovation adoption, so literature is selected according to the following criteria: 1) the literature should mention the above themes, especially in the scope of ICT adoption; 2) the literature appearing in top-ranking journals is prioritized.

\section{DUALITY OF TECHNOLOGY}

Before introducing the cultural approach to technology, the duality nature of technology should be acknowledged. From the duality perspective, technology is not only an objective force, but also a socially constructed product. That is, technology is physically constructed by actors working in a given social context, and technology is socially constructed by actors through the different meanings that they attach to it and the various features they emphasize and use (Orlikowski 1992).

Previous research has also indicates that information technology is not value-neutral; rather, it is inherently symbolic and value-laden (Robey and Markus 1984; Scholz 1990). These particular values might be used to explain why some organizations conduct excessive information searches beyond what is necessary in order to reflect these values. Likewise, Scholz (1990) argues that firms' computerized information systems are highly symbolic, representing such values as equality versus subordination, progressivism versus conservatism, community versus isolation, sympathy versus antipathy, and emotionality versus insensibility. Robey and Markus (1984) argue that information system development and user involvement activities represent organizational rituals symbolizing the underlying value of rationality that people attribute to information technology. These values are formed over time through individuals' use of technology and lead to standardized ways of organizational data collection and processing, communication, and information and knowledge distribution. Understanding these information technology values may provide a much clearer picture for predicting how technology interacts with culture.

According to the cultural approach, technology contains a script that influences not only people's perception of the world but also human behaviours, and there is no fundamental distinction between humans and non-humans, including technological artefacts (Latour 1992, 1993). Some researchers claim that technology enables (or even invites) and constrains (or even inhibits) certain human actions and the attainment of certain human goals and, therefore, is, to some extent, value-laden. 


\section{Organizational Culture Dynamics}

Researchers perceive and define organizational culture in different ways (Hatch, 1993). According to Schein (1990), culture is "the pattern of basic assumptions that a given group has invented, discovered, or developed in learning to cope with its problems of external adaptation and internal integration, and that have worked well enough to be considered valid, and, therefore, to be taught to new members as the correct way to perceive, think, and feel in relation to these problems." Schein (1990) proposes that culture exists simultaneously on three levels: artefacts on the surface, values lie underneath artefacts, and basic assumptions at the core.

The term cultural dynamics originated in cultural anthropology. It refers to such issues as the origins and evolution of cultures, enculturation processes, and the problem of change versus stability. Schein (1990) describes four stages of culture development, namely creation, preservation, natural evolution and guided evolution. Culture is constituted by local processes involving both change and stability. Hatch (1993) developed a culture dynamics model, reformulating Schein's original organizational culture model in procedural terms. Four processes are examined, namely manifestation, realization, symbolization, and interpretation. These processes are defined and presented in a new model called culture dynamics. All of the processes co-occur in a continuous production and reproduction of culture in both its stable and changing forms and conditions. In other words, numerous instances of the cultural processes occur and recur more or less continuously.

\section{Technology-Culture Fit}

Due to the dual nature of technology and the dynamic nature of culture, the relationship between technology and culture is bi-directional. Which means that the organizational culture will influence the ICT adoption and, in turn, the ICT adoption will also change organizational culture to some extent. Previous studies, investigating various types of organizational culture, provide empirical support for the influence of organizational culture on the adoption and outcomes of innovative technology. For instance, Hoffman and Klepper (2000) found that organizations with high mercenary cultures (low in sociability and high in solidarity) experience more favourable outcomes from technology assimilation than those with networked culture (high sociability and low solidarity). Ruppel and Harrington (2001), drawing on the competing values framework, concluded that intranet adoption is much more likely to succeed in development cultures (values emphasizing flexibility and innovation). Research on backward influence from ICT adoption to organizational culture is comparatively less and conducted later than the forward influence from organizational culture to ICT adoption. ICT has been found to have the potential for re-engineering organizational culture and that different types of technology artefacts may influence certain types of values (Leidner and Kayworth, 2006).

The concept of 'fit' emerges along with the studies on the bidirectional relationship between technology and culture. Technology-culture fit refers to the level of congruence between the general values of a given group of members and the values embedded in a 
given system; the fit will determine how the social group perceives and ultimately uses the system (Leidner and Kayworth, 2006). The concept of 'fit', rooted in the population ecology model and in the contingency theory tradition, has served as the central thrust to the development of middle range theories in many management disciplines, especially in the organization theory and strategic management fields.

A poor fit will lead to negative perceptions and behaviours regarding the system while a better fit will lead to more favourable responses (Cabrera et al. 2001, Leidner and Kayworth, 2006) In traditional organizational culture and information technology research, organizational culture is considered as a human-related or social entity, while information technology is considered as a technological entity. However, the concept of technology-culture fit stands on the view that information technology is also laden with certain values according to the organizational culture, and considers that culture and technology have some common properties to 'fit' each other.

\section{Task-Technology Fit}

A group task is defined here as the behavioural requirements for accomplishing stated goals, via some process, using given information. Information technology can be seen as information processing tools that are designed to work together to support the accomplishment of group tasks (Zigurs and Buckland, 1998). There are different definitions of task-technology fit. For example, Zigurs and Buckland (1998) define tasktechnology fit as ideal profiles composed of an internally consistent set of task contingencies and technology's elements that affect group performance. Dishaw and Strong (1998) operationalized task-technology fit as a computed interaction which predicts utilization. Goodhue (1995) operationalized task-technology fit as user evaluation, which is predicted by the interactions.

From these definitions, the differences between these three kinds of operationalization of task-technology fit are clearly demonstrated. In Zigurs and Buckland's (1998) model, task-technology fit is a matched fit profile. For example, simple tasks should result in the best group performance when done using a technology that emphasizes communication support, while decision tasks should result in the best group performance when done using a technology that emphasizes information processing and process structuring. In Dishaw and Strong (1998) model, fit was conceptualized as an interaction and is computed as product of tool functions and task activities. There are two dimension of fit: production fit and coordination fit. However, in Goodhue's (1988, 1995) model, tasktechnology fit is conceptualized as user evaluation, and it mainly assess eight aspects: quality, locatability, authorization, compatibility, production timeliness, system reliability, ease of use/training, relationship with users. The heart of the task-technology fit model are the assumptions that information systems give value by being instrumental in some task or collection of tasks, and that users will reflect this in their evaluations of the systems. The focus of this research is on individuals' adoption behaviour, and individuals' perceptions and evaluations of the technology as more relevant with the adoption behaviour, therefore, Goodhue's definition was adopted. 


\section{Person-Culture Fit and Person-Task Fit}

The match, or compatibility, between employees and various aspects of their workplace environment (person- environment fit) has proven to be a useful concept for explaining a variety of employee and organizational outcomes (O'Reilly, Chatman, \& Caldwell, 1991). Person-culture fit and person-task fit are two mature constructs in the theory of the person-environment fit. Person-culture fit is defined as the congruence between individual's values and those of an organization (O' Reilly et al. 1991). Basic values may be considered as internalized normative beliefs which guide behaviour. Person-culture fit has been found to predict job satisfaction and organizational commitment. O'Reilly et al. (1991) developed the organizational culture profile (OCP), an instrument for assessing person-culture fit, which covers seven factors, namely innovation, stability, respect for people, outcome orientation, attention to detail, team orientation, and aggressiveness. Person-task fit refers to the congruence between individual competencies and the job requirements (Caldwell and O' Reilly 1990). Results of a series of studies have shown that person-job fit predicts efficiency, effectiveness, quality, and overall performance improvement.

Previous researches on person-culture fit and person-task fit focus on organizational entry, early socialization of employees, and work performance. However, less is known about the role of person-culture fit and person-task fit in the technology adoption process. The introduction of a new ICT may change the values of organizational culture and task requirement, so individual's person-culture fit and person-task fit is also changed. Although these two constructs are not directly mentioned to affect technology adoption, they are found to be related to commitment to organization change (Meyer et al. 2010) and creativity (Livingstone et al. 1997), which have close relationships with ICT adoption. Therefore, the role of person-culture and person-task fit in ICT adoption process is worth investigating.

\section{DEVELOPMENT OF THEORETICAL FRAMEWORK AND PROPOSITIONS}

From the above review, it is evident that technology, culture, task and person are linked with each other and technology-culture fit, task-technology fit person-culture fit and person-task fit are all pointing to ICT adoption. It means that the whole socio-technical system affects the adoption of ICT. The socio-technical system operates at two levels. It is clear that technology-culture fit is an organizational level construct, while personculture fit and person-task fit are individual level constructs. Here, task-technology fit is across two levels: at the organizational level, it means the fit between the technology and organizational task design, but at the individual level, it means the individual's perception of task technology fit. Since each of the sociotechnical components can become the source of the system's misalignment, these 'fits' depend on each other.

Drazin and Van de Ven (1985) argue that the overall effect of multiple fits is not the sum of their individual effects and so, is not additive, but geometric/synergetic. They advance 
a model of combination of multiple fits as being a system fit. In a system fit, the effect of multiple fits on organizational performance is not just the sum of the effect of each fit on performance. Instead, there is some holistic property that is not captured by an atomistic analysis of each fit separately that just combines them. Thus, they argue, the effect of multiple fits cannot be calculated by simply adding up the effect of each fit on the performance. In the social-technical system of ICT adoption, how technology-culture fit, task-technology fit, person-culture fit and person-task fit interact with each other, and affects the system's performance together needs be explored.

Figure 2: Theoretical framework of socio-technical system and ICT adoption

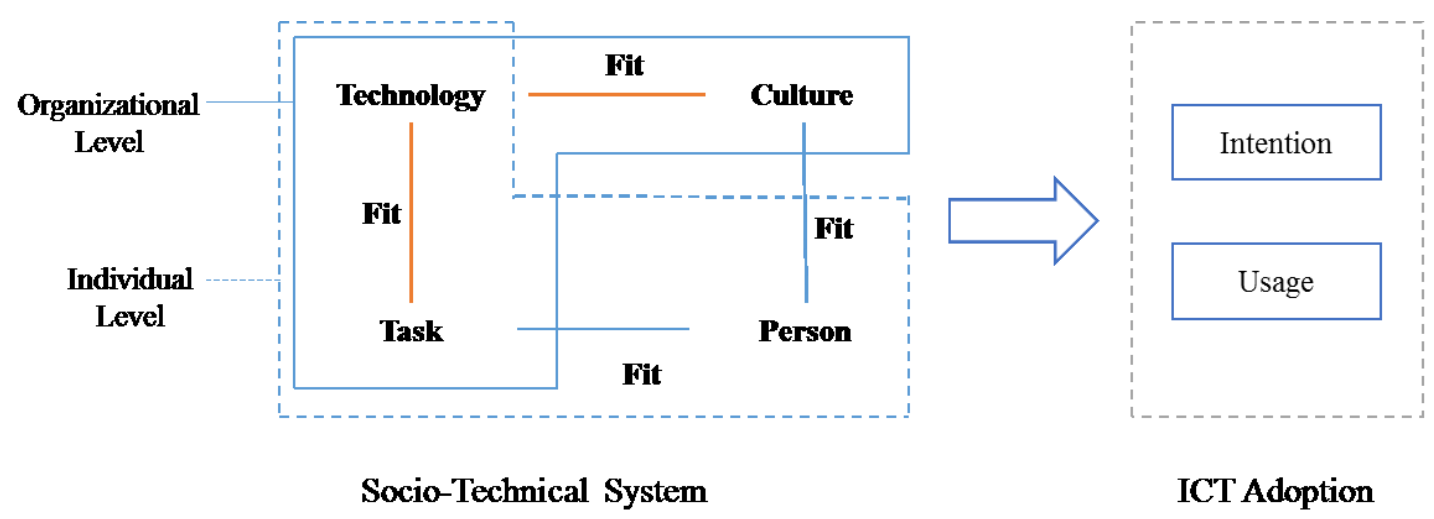

In order to validate the theoretical model (shown in Figure 2), a subset of the theoretical model is developed for empirical study to be conducted in the next stage. The relationships hypothesized between these 'fits' and ICT adoption are illustrated in Figure 3 and two propositions are developed as below.

Proposition 1: Technology-culture fit associating with task-technology fit

Based on Hatch's (1993) culture dynamic framework, manifestation permits cultural assumptions (the essence of culture in Schein's theory) to reveal themselves in the perceptions, cognitions, and emotions of organizational members. Cultural realization makes values real by transforming expectations into social or material reality and by maintaining or altering existing values through the production of artefacts. The technology-culture fit is derived by value comparison under cultural assumptions, which should be manifested into reality, demonstrated in the task design. Therefore, it could be proposed that technology-culture fit is associated with task-technology fit. Tasktechnology misfit is, apparently, caused by vague task requirements or insufficient technology capability, but simple redesign of task or technology is not sufficient for tasktechnology fit and changing the values of organizational culture may be the root. 
Proposition 2: Person-culture fit and person-task fit influence individuals' adoption behaviour through the mediation effect of task-technology fit.

Articulated by Goodhue and Thompson (1995), "task-technology fit" has been used to provide a conceptual basis for user evaluation instruments for organizational assessment and decision making in information systems. The core of the task-technology fit model is the assumption that information systems give value by being instrumental in some task or collection of tasks and that users will reflect this in their evaluations of the systems. The antecedents of task-technology fit are the interactions between task, technology, and person. Person-culture fit and person-task fit are two important organizational attributes of individuals so, they could be seen as the antecedents of task-technology fit. All new technologies have material properties, 'which afford different possibilities for action, based upon the contexts in which they are used' (Leonardi, 2011; p. 153). Such 'affordances' occur through the situated interaction of a user and a technology so, different individuals may have different interpretations of affordance and, further, have different evaluations of task-technology fit. Since pervious research work has shown that task-technology fit affects individuals' adoption behaviour, it is proposed that personculture fit and person-task fit influence individuals' adoption behaviour through the mediation effect of task-technology fit.

Figure 3: Logical links between the propositions

Organizational Level

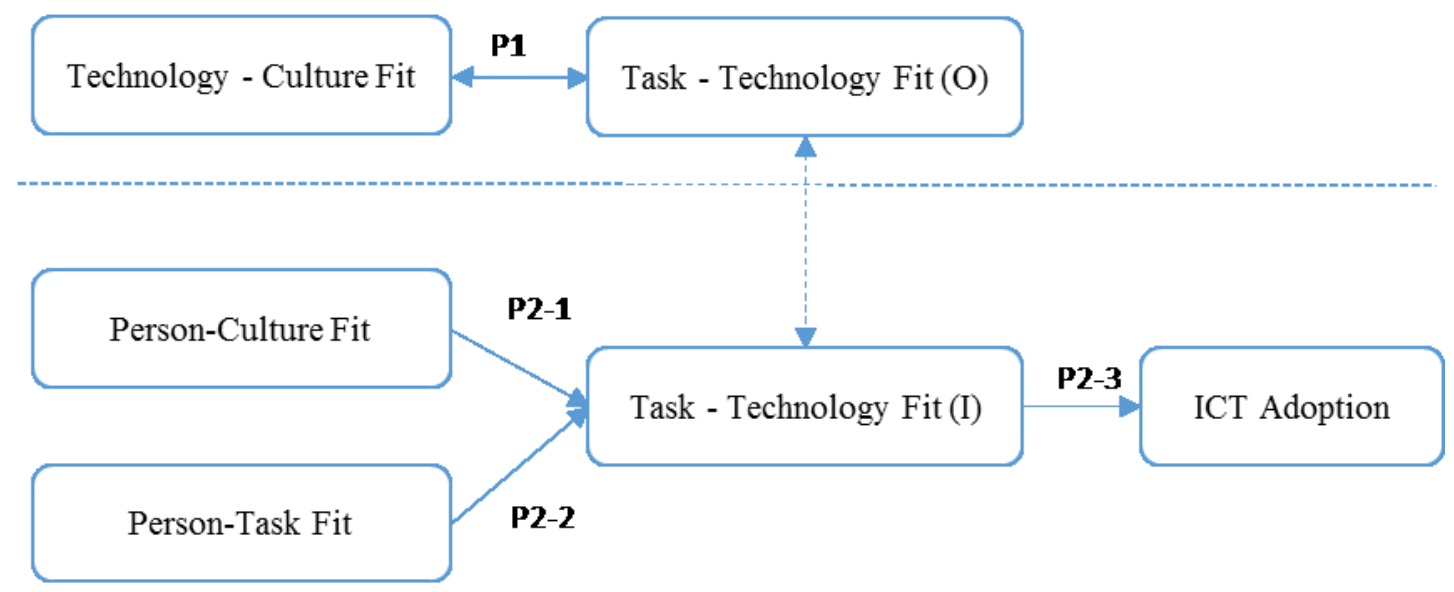

Individual Level 


\section{DISCUSSION}

This research adopted the socio-technical approach to study the ICT adoption process in construction companies. For the construction research field, although researchers have addressed the importance that organization culture and human factors have in ICT adoption (e.g. Peansupap et al. 2003), research focusing on the underpinnings of ICT adoption and implementation, and theories that reveal the integrated relationship between culture, technology, task and person, is rare. The socio-technical approach provides a new lens to look at culture, technology, task and person, and also offers thorough explanations for their recursive relationship

The ICT adoption process in this research is considered as the interaction between technology, culture, task and person across individual and organizational levels, instead of linear stage by stage process as in the traditional ICT adoption research approach. In this interaction framework, the technology-culture fit, task-technology fit, person-task fit and person-culture fit are all linked together, which supplements the previous fragmented findings and acts as a foundation for further studies on the relationship of these fits. These fits also further elaborate the relationship between culture, technology task and person in socio-technical theory to an operational level, which allow the empirical validation of the theory.

In future study, the theoretical framework will be tested by mixed methods. At the organizational level, the relationship between technology-culture fit and task-technology fit will be analysed by qualitative study, because the technology-culture fit is an abstract phenomenon and cannot be assessed by measurement instruments directly. However, at the individual level, the person-task-technology interactions are more observable and will be analysed through a quantitative approach.

\section{CONCLUSIONS}

A conceptual framework is developed for the interaction between technology, culture, task and person. The framework is developed across two levels: organizational level and individual level. The organizational level interaction is technology centered, focusing on the fit between values embedded in organizational culture and in technology. The individual level interaction is task centered, which focuses on the fit between technology and task requirements, and the fit between competency of an individual and task requirements. Under this framework, two propositions are put forward: i) technologyculture fit at the organizational level is associated with task-technology fit ; ii) personculture fit and person-task fit influence individual's adoption behaviour through the mediation effect of task-technology fit. 


\section{ACKNOWLEGEMENT}

The work described in this paper was fully supported by a grant from the Research Grants Council General Research Fund (Project No. HKU 715111).

\section{REFERENCES}

- CABrera, A., CABrerA, E. F., and BARAJAS, S. (2001) The Key Role of Organizational Culture in a Multi-System View of Technology Driven Change, International Journal of Information Management, 21(3), 245-261.

- CAldwell, D. F. and O' REILly C. A. (1990) Measuring Person-Job Fit with a ProfileComparison Process, Journal of Applied Psychology, 75(6), 648-657.

- DISHAW, M. T., and STRONG, D. M. (1998). Supporting Software Maintenance with Software Engineering Tools: A Computed Task-Technology Fit Analysis, Journal of Systems and Software, 44(2), 107-120.

- DRAZIN, R. and VAN DE VEN, A. H. (1985). Alternative Forms of Fit in Contingency Theory, Administrative science quarterly, 514-539.

- DUBE, L., and ROBEY, D. (1999) Software Stories: Three Cultural Perspectives on the Organizational Context of Software Development Practices, Accounting Management and Information Technologies, 9(4), 223-259.

- ERdogan, B., ANUMBA, C. J., BOUCHLAGHEM, D., NIElSEN Y. (2008) Collaboration Environments for Construction: Implementation Case Studies, Journal of Management in Engineering, 24 (4), 234-244.

- FELDMAN, M. S., and MARCH, J. G. (1981) Information in Organizations as Signal and Symbol, Administrative Science Quarterly, 26(2), 171-86.

- GOODHUE D. L. and THOMPSON R. L. (1995) Task-Technology Fit and Individual Performance, MIS Quarterly, 19(2), 213-236.

- GOODHUE, D. L. (1998) Development and Measurement Validity of a Task-Technology Fit Instrument for User Evaluations of Information System, Decision Sciences, 29(1), 105-138.

- HARPER, G. R. and UTLEY, D. R. (2001) Organizational Culture and Successful Information Technology Implementation, Engineering Management Journal, 13(2), 11-15.

- HATCH, M. J. (1993) The Dynamics of Organizational Culture, Academy of Management Review, 18(4), 657-693.

- HATCH, M.J. and CUNLIFF, A.L. (2013) Organization Theory: Modern, Symbolic and Postmodern Perspective. Oxford, UK: Oxford University Press.

- HOFFMAN, N. and KLEPPER, R. (2000) Assimilating New Technologies: The Role of Organizational Culture, Information Systems Management, 17(3), 36-42.

- HOFSTEDE, G. H. (2001) Culture's Consequences: Comparing Values, Behaviors, Institutions, and Organizations across Nations (2nd edn.), Thousand Oaks, CA: Sage.

- KITCHELL, S. (1995) Corporate Culture, Environmental Adaptation, and Innovative Adoption: A Qualitative/Quantitative Approach, Journal of the Academy of Marketing Science, 23(3), 195-205.

- LATOUR, B. (1992) Where Are the Missing Masses? In Shaping Technology/Building Society: Studies in Sociotechnical Change, edited by W. Bijker and J. Law. Cambridge, MA: MIT Press, pp. 225-258.

- LEIDNER, D. E. and KAYWORTH, T. A. (2006) Review of Culture in Information Systems Research: Toward a Theory of Information Technology Culture Conflict, MIS Quarterly, 30(2), 357-399.

- LEONARDI, P. M. (2011) When Flexible Routines Meet Flexible Technologies: Affordance, Constraint, and the Imbrication of Human and Material Agencies, MIS quarterly, 35(1), $147-$ 167. 
- LIVINGSTONE, L. P., NELSON, D. L. and BARR, S. H. (1997). Person-Environment Fit and Creativity: An Examination of Supply-Value and Demand-Ability Versions Of Fit. Journal of Management, 23(2), 119-146.

- LOVE, P. E. and IRANI, Z. (2001). Evaluation of IT costs in construction. Autom. Constr., 10(6), 649-658.

- LYYTINEN, K. and NEWMAN, M. (2008). Explaining information systems change: a punctuated socio-technical change model. European Journal of Information Systems, 17(6), 589-613.

- MARKUS, M. L. and ROBEY D. (1988) Information Technology and Organizational Change: Causal Structure in Theory and Research. Management Science, 34(5), 583-598.

- MEYER, J. P., HECHT, T. D., GILL, H., and TOPLONYTSKY, L. (2010). PersonOrganization (Culture) Fit and Employee Commitment Under Conditions Of Organizational Change: A Longitudinal Study. Journal of Vocational Behavior,76(3), 458-473.

- O'ReILly, C.A., CHATMAN, J., and CALDWELL, D.F. (1991) People and Organizational Culture: A Profile Comparisons Approach to Assessing Person-Organization Fit, Academy of Management Journal, 34(3), 487-516.

- O'REILly C.A. and CHATMAN J. (1996) Culture as Social Control: Corporations, Cults, and Commitment, Research in Organizational Behavior, 17, 157-200.

- ORLIKOWSKI W. J. (1992) The Duality of Technology: Rethinking the Concept of Technology in Organization, Organization Science, 3(3), 398-427.

- PEANSUPAP, V. and WALKER, D. (2005) Factors Affecting ICT Diffusion-A Case Study of Three Large Australian construction Contractors, Engineering, Construction and Architectural Management, 12 (1), 21-37.

- ROBEY, D. and MARKUS, M. L. (1984) Rituals in Information Systems Design, MIS Quarterly, 8(1), 5-15.

- RUPPEL, C. P. and HARRINGTON, S. J. (2001) Sharing Knowledge through Intranets: A Study of Organizational Culture and Intranet Implementation, IEEE Transactions on Professional Communication, 44(1), 37-52.

- SCHEIN, E.H. (1990) Organisational Culture, American Psychologist, 45, 109-119.

- Scholz, C. (1990) The Symbolic Value of Computerized Information Systems, in Symbols and Artifacts: Views of the Corporate Landscape, P. Gagliardi (ed.), Aldine de Gruyter, New York, 233-254.

- STEWART, R. A. and MOHAMED, S. (2003) Evaluating the Value IT Adds to The Process of Project Information Management in Construction, Automation in Construction, 12, 407417.

- STRONG, D. M. and VOLKOFF, O. (2010) Understanding Organization-Enterprise System Fit: A Path to Theorizing The Information Technology Artifact, MIS Quarterly, 34(4), 731756.

- ThOMPSON, R. L., HIGGins C. A. and HOWELl J. M. (1991) Personal Computing: Toward a Model of Utilization, MIS Quarterly, 3, 125-43.

- WILSON, T. D. (2000) Human information behavior, Informing science, 3(2), 49-56.

- ZIGURS, I. and BUCKLAND, B. K. (1998) A Theory of Task/Technology Fit and Group Support Systems Effectiveness, MIS Quarterly, 22(3), 313-334. 


\title{
DETERMINANTS OF EMPLOYEE JOB SATISFACTION IN THE GAUTENG PROVINCE OF SOUTH AFRICA
}

\author{
Lesailane, P. ${ }^{1}$; Aigbavboa, C. ${ }^{2}$ and Thwala, W.D. ${ }^{3}$
}

\begin{abstract}
:
This study examines the determinants of construction employees' job satisfaction in the South Africa construction industry. This is because it has been observed in many studies that, when employees are satisfied with their jobs, they tend to perform at peak all the time, which lead to increase in the productivity of the construction industry. The study was conducted with reference to existing theoretical literature and the use of a structured questionnaire survey. The questionnaire survey was distributed to 50 professional team members in the South African construction industry. From the 50 questionnaires distributed, 40 usable questionnaires were received back, which formed the basis of the analysis for the study. The findings from this study revealed that the dominant determinants of construction employees' job satisfaction are: work that allows personal growth; work that allows development; employment security; adequate salary; feedback from boss on task performance; opportunity for promotions and challenging work. This study carries a greater value in contributing to the existing literature of job satisfaction of construction workers based on younger construction professional members, since the majority of the participants in this study were respondents within under the age group of 21-25 years of age.
\end{abstract}

KEYWORDS: ABSENTEEISM, CONSTRUCTION, EMPLOYEE TURNOVER, JOB SATISFACTION, JOB DISSATISFACTION

\section{INTRODUCTION}

Within each and every sector in South Africa, new companies are established every year and this may lead to an increase in competition within those sectors. Therefore, it is the manager's task to ensure that employees within a given organization have the drive to perform their tasks to reach the organizational goals in order to have a competitive advantage over other organizations. According to Deeprose (2003), as a manager, there are many ways that one can use to create an environment where employees are most likely to feel motivated to take actions that contribute to organizational goals. However, senior management in a given organization tends to ignore the issue of motivation of employees in the workplace. Moreover, some find it difficult to address the issue of employee motivation in their organization since it entails studying behavior of each and every employee and identifying causes of such behaviors.

Bernold and AbouRizk (2010) emphasized that construction is performed by different employees including labourers, engineers, specialists, etc which have their own reasons

\footnotetext{
1 Department of Construction Management \& Quantity Surveying, University of Johannesburg, Johannesburg, Doornfontein Campus, Johannesburg, 2028, South Africa. Email: portles@webmail.co.za Department of Construction Management \& Quantity Surveying, University of Johannesburg, Johannesburg, Doornfontein Campus, Johannesburg, 2028, South Africa. Email: caigbavboa@uj.ac.za

3 Department of Construction Management \& Quantity Surveying, University of Johannesburg, Johannesburg, Doornfontein Campus, Johannesburg, 2028, South Africa. Email: didibhukut@uj.ac.za
} 
to perform in a particular way with varying degrees of energy and enthusiasm. The ability to have a comprehensive understanding of basic things that keep an employee motivated thereby improving their level of satisfaction, will have a significant positive impact in their performance of job tasks. The study illustrates that when employees are happy and satisfied in their jobs, their level of motivation is high and they perform at peak all the time (Tyilana, 2005).

Moreover, an employee will only be committed to their job if they are happy about their duties and feeling content with rendering job tasks. If employers want to inspire people to give their best and most committed effort in support of the organizational goals, they should relate those goals to something more compelling than simple satisfaction, something that people spend a lifetime pursuing: happiness (Walters, 2010). In their book, Bernold and AbouRizk (2010) argue that personal desires are the fundamental motivation behind all human actions. In that regard, it can be said that individual needs, serve as a form of motivation that will determine a level of satisfaction an employee may have with regard to their job. This is because Lavender (1996) has argued that an individual's behavior is affected by their motivation. Hence, it is important to fulfill those needs as this will help to stimulate an individual's interest in their job and it will in turn serve as motivation.

In the research conducted by CIDB (2013), it was observed that many construction projects in South Africa are still facing challenges such as client's dissatisfaction with work rendered by contractors in respect of delivering defective work not completed within budget and on time. This may be due to experiences of absenteeism and employee turnover within a given project. As a result; these two factors according to Rojas (2008) tend to reduce productivity as construction industry has traditionally paid little attention to these problems.

Rojas (2008) mentioned job satisfaction among other factors as determinants of absenteeism and turnover. In that regard, Schaffer (2001) argued that in order to achieve high productivity, members of management as well as the entire workforce, need to be highly motivated, positive, and totally committed. It is because of the aforementioned challenges that this paper attempts to explore the concept of motivation and job satisfaction.

The aim of this paper is to explore the determinants of job satisfaction in the construction industry as well as the influence of factors leading to dissatisfaction on absenteeism and employee turnover. Firstly, this paper starts with an overview of determinants of job

satisfaction. Subsequently, a brief discussion of the influence of dissatisfaction on absenteeism and employee turnover will be provided.

\section{THEORETICAL OVERVIEW OF THE DETERMINANTS OF JOB SATISFACTION IN THE CONSTRUCTION INDUSTRY}

There is an abundance of empirical studies in the area of job satisfaction in the construction industry. For instance, in the research conducted by Thwala et al (2012), the 
findings reveal that the construction workers highly ranked physiological needs (such as tea or lunch break), esteem needs (such as self-respect, autonomy, achievement and recognition) and safety needs (such as job security, shelter and protection against danger ) as motivators which led to high level of their job satisfaction. However, this does not agree with the findings of the research conducted by Bowen and Cattel (2008), where respondents (quantity surveyors) ranked self-esteem needs (such as achievement, promotions, opportunity to do challenging and creative work, opportunity to do varied and non-repetitive work) the least as the determinants of job satisfaction. Surprisingly, the findings of Thwala et al. (2012), the workers ranked social needs (such as a feeling of being a member of the team and assisting co-workers) the least as determinant of job satisfaction. However, in the study of Bowen and Cattel (2008), respondents' highly ranked social need (such as feeling a member of a team and participating in decision making) as determinants of job satisfaction

Nevertheless, the study of job satisfaction of professionals within the construction industry conducted by Yirenkyi-Fianko and Chilese (2012), agreed with the findings of Thwala et al. (2012), whereby the construction professionals ranked physiological needs (quality of life), safety needs (personal health) and self-actualization needs (personal development) as the most important determinants of job satisfaction, however, selfesteem (work itself including autonomy, recognition and achievement) was being ranked the least, together with social needs (relationship with supervisor and workmates). Again, the study of Bowen and Cattel (2008), contradicts with these findings, whereby the respondents (quantity surveyors) highly ranked social needs (low degree of supervision by supervisor, and feedback from supervisor on performance) as determinants of job satisfaction.

Kanderee and Chaudhry (2012), found that respondents ranked salary, nature of the job, job flexibility, job security, direct manager's behavior and company leadership as factors that strongly influence their job satisfaction, while other factors such as place of work, other benefits, living environment and name of company, were ranked the least. Highly ranked factors such as: nature of job, salary and job flexibility as esteem needs and job security as security needs, seem to be agreeing with the findings of the study of Thwala et al. (2012). But, direct manager's behaviour as social needs, contradicts their findings. Moreover, the factors that were ranked the least such as living environment and place of work as physiological needs and other benefits as esteem needs, contradict with the findings of Thwala et al. (2012), whereby physiological needs were ranked as the strongest determinants of job satisfaction.

In the study by Onukwube (2012) the findings show that job satisfaction increases with age and it was concluded that older quantity surveyors experience greater job satisfaction than younger quantity surveyors, since they have job experience, tenure, job security and high income. Also, the findings showed that male quantity surveyors were more satisfied with their job than were their female counterparts (Onukwube, 2012). Similarly, the findings show that difference in educational level also affects job satisfaction, whereby quantity surveyors with postgraduate degrees were significantly more satisfied with their present job, promotion, co-workers, supervision, pay and overall job satisfaction than were quantity surveyors with bachelor's degree (Onukwube, 2012). 


\section{Determinants of Job Satisfaction}

According to Hodson and Sullivan (1990:100), the factors that determine the degree of satisfaction include the nature of job tasks, technology, organizational characteristics, and worker's participation in decision making, individual differences, and prior expectations. These factors are individually discussed below:

\section{Nature of Job Tasks}

Work that has autonomy, complexity, and diversity can be self-actualizing (Hodson and Sullivan, 1990:100). Job autonomy is the extent to which the worker controls his or her own work and relations with others at work, including both co-workers and supervisors (Hodson and Sullivan, 1990:100). Diversity of tasks, as informed by Hodson and Sullivan (1990:101), is a significant factor because repetitive work, lacking in variety and done at a forced pace, is perhaps the most brutally alienating work. Self-actualization may also depend on the level of meaningful interaction allowed on a job (Hodson and Sullivan, 1990:101). Other than working as a team, Matutuane (2009:26) has identified relationship with co-workers as one of determinants of job satisfaction. As argued by Hodson and Sullivan (1990:101), a noise, dirt and dangerous working conditions are also important sources of dissatisfaction. This is because employees prefer physical surroundings that are not dangerous or uncomfortable (Hadebe, 2001:24).

\section{Organizational Structures and Policies}

Job tasks and technology are important determinants of alienation, but workers are also strongly influenced by the characteristics and policies of the organization in which they work (Hodson and Sullivan, 1990:103). As a result, the size of the organization as well as its policies on promotion and wages are also important. Large size organizations produces feelings of powerlessness and isolation, because workers have difficulty in sensing the overall purpose and direction of their organization and in feeling that they are a significant part of that purpose (Hodson and Sullivan, 1990:103). Being paid a living wage for one's work is also a necessary condition for self-actualization (Hodson and Sullivan, 1990:103). Therefore, it is important for employees to be paid reasonable income as, according to Hadebe (2001:24), when pay is seen as fair based on job demands, individual skill level, and community pay standards, satisfaction is likely to result. Additionally, according to Hadebe (2001:24), employees seek fair promotion policies and practices. Hence, workers who have a low likelihood of promotion often come to feel disenchanted with their jobs (Hodson and Sullivan, 1990:104).

\section{Participation}

Organization can also facilitate self-actualization through their style of supervision and through encouraging workers to participate in making decision (Hodson and Sullivan, 1990:104). Moreover, if managers allow workers to make decision about their jobs and also to assist in decision making process about the organization, workers will experience a greater self-actualization. And this includes formal participation in determining the direction of an organization, as among the members of a worker-owned cooperative or a volunteer organization (Hodson and Sullivan, 1990:104). In addition, Matutuane 
(2009:25) has informed that the amount of technical and social support extended by the supervisor to the employee influences job satisfaction.

\section{Individual Differences in the Experience of Work}

Whether workers are satisfied with a given job thus depends to some extent on what they hope to get out of it (Hodson and Sullivan, 1990:105). Gender, race, age, and education are important differences between individuals that influence the needs and values they bring to the workplace (Hodson and Sullivan, 1990:105). Hence, Hodson and Sullivan (1990:105), see it necessary to ask if workers of different genders, races, ages and educational groups have different experiences at work. For instance, Ross (2005:182) has concluded that difference in age, gender, tenure, education level, and seniority of employees influence employee motivation, job satisfaction and corporate culture.

\section{RESEARCH METHODOLOGY}

The study was conducted with reference to existing theoretical literature and the use of a structured questionnaire survey. The existing literature was obtained from published and unpublished sources. Since the population surveyed was already identified, the researcher adopted the stratified sampling. In this type of non-random sampling, a researcher first divides the population into subpopulations (strata) on the basis of supplementary information and subsequently, the researcher draws a random sample from each subpopulation (Neuman, 2000). The researcher divided the population into strata according to the types of professions, such as: construction management, construction project management, quantity surveying, structural engineering and architecture. This allows each member within each subpopulation to have equal chance to be selected. The population comprised of professional team members within both consulting and contracting firms, working in Johannesburg, South Africa. The respondents were randomly selected from each subpopulation to make up a sample of 50. However, due to limitation of time and low response rate, the final sample size used for analysis purpose, based on the acceptable questionnaires completed by the respondents, was 40. A five

point Likert scale was used to determine the factors that have influence on the construction job. For the purpose of this study, frequency and mean item score (from central tendency) will be used to analyze data.

\section{FINDINGS}

\section{Biographical Data}

From the surveyed 40 respondents, the findings reveal that more than half $(52.5 \%)$ of the total number of the respondents were female while the male respondents were $47.5 \%$. Also, in terms of age group, it was found that that the majority $(47.5 \%)$ of respondents were between the age of 21 and 25 years; $20 \%$ were between $26-30$ years; $17.5 \%$ were between $31-35$ years with $17.50 \% ; 2.5 \%$ were between $41-45$ years ; and $5 \%$ were above 55 years. There were no respondents that fall under the age group of 46-50 and 51-55 
years. Furthermore, the findings reveal that half $(50 \%)$ of respondents have diploma degrees while $45 \%$ have bachelor's degree, and 5\% have master's degree. In terms of the years of experience, $7.5 \%$ have less than a year of experience working in the construction industry, $62.5 \%$ have $1-5$ years of experience, $17.5 \%$ have $6-10$ years of experience, $5 \%$ have $11-15$ years of experience and $17.5 \%$ have more than 16 years of experience. Lastly, of 40 respondents that participated, $70 \%$ of them were quantity surveyors, 5\% were construction managers, 5\% were construction project managers, $2.5 \%$ were structural engineers, $10 \%$ were construction project managers and $7.5 \%$ were architects.

\section{Determinants of construction job satisfaction}

Table 1 indicates that the most important determinant of employee construction job satisfaction in South Africa (Greater Johannesburg) is, "work that allows personal growth. The other top ten factors which the respondents have ranked in order of their importance as contributors to construction workers job satisfaction are: work that allows development; employment security; adequate salary; feedback from boss on performance; opportunity for promotions; opportunity for challenging work; recognition from boss for doing a good job; good working conditions; and having control over own work.

Table 1: Determinants of construction employee job satisfaction.

\begin{tabular}{lll}
\hline Determinants of job satisfaction & MIS & Rank \\
\hline Work that allows personal growth & 4.83 & 1 \\
Work that allows development & 4.80 & 2 \\
Employment security & 4.70 & 3 \\
Adequate salary & 4.70 & 3 \\
Feedback from boss on task performance & 4.45 & 4 \\
Opportunity for promotions & 4.35 & 5 \\
Opportunity for challenging work & 4.34 & 6 \\
Recognition from boss for doing a good job & 4.33 & 7 \\
Good working conditions & 4.31 & 8 \\
Having control over own work & 4.30 & 9 \\
\hline
\end{tabular}

These findings concurs with the findings of Thwala et al. (2012) where it was found that construction workers highly ranked motivators such as physiological needs (working environment, food, amongst others), esteem needs (autonomy, recognition, feedback from boss, challenging work, promotions) and security needs (job security, shelter and protection against danger) as the most important factors that determine their level of job satisfaction. Also these findings agrees with the findings of the study by Yirenkyi-Franko and Chilese (2012) where construction professionals highly ranked self-actualization needs (personal development, career growth, amongst others) as one of the most 
important determinants of construction job satisfaction. Also, the findings further harmonises with the findings of the study done by Kanderee and Chaudhry (2012), whereby it was found that construction workers (professional) ranked salary as one of the most important determinants of job satisfaction.

However, going by the ideal of social sustainability, which is the ability of corporations or any entities to develop processes and structures which not only meet the needs of its current members, but also support the ability of future generations to maintain a healthy community; it can be infer that the construction industry based on the above findings is not faring very well. According to McKenzie (2004), a life-enhancing condition within corporations, and a process within companies or entities that can achieve that condition is where social-sustainability should be approached from.

Defining social sustainability can be tough, but defining what a healthy industry (for instance the construction industry) is and should contribute is a good way to understand the concept. However, one approach is to base this on research on human needs. For instance, Manfred Max-Neef, a Chilean economist, along with his colleagues researched on the nine human needs that were consistent across different cultures. These nine needs (subsistence, protection, affection, understanding, participation, leisure, creation, identity and freedom), Max-Neef found, always showed up despite different social norms, conventions or locations or industry. The way these needs are satisfy he concluded, is what defines the differences from culture to culture. So this model helps us to see past our differences and understand what is at the core of human behaviour and how to achieve a meaningful job satisfaction by construction employees.

Also, there are a number of different issues to consider regarding how construction activities and operations might harm the employees. Some seem obvious, for instance, safety problems and lack of access to health care or a living wage. But Max-Neef's research encourages institutions to dig a little deeper. The model encourages that corporations should do no harm to the employees by undermining the need of the workers; whilst they should make a positive difference by contributing to meeting these needs in a sustainable way.

It should be noted that Max-Neef's list is not ordered like the one John Maslow postulated. One of Max-Neef's insights is that a deficit in meeting any of these needs is a type of poverty that in turn generates pathologies which if not dealth with in the right manner hurts and disadvantages the workers. Some of these needs are obvious. For instance, when the workers do not have enough to eat (subsistence), you have hunger or starvation. Whilst in some workers, the lack of affection o their jobs leads to what is known as "failure to thrive," sometimes even leading to death of their careers and zeal to be creative. Also, if there is no enough leisure, workers become workaholic who suffers from stress and stress related maladies. But it is also true that when workers do not have enough opportunities to influence matters that affect them (participation and freedom), they often get passive aggressive or even aggressive. This support the research findings that workers in Johannesburg are satisfied with construction jobs that offer this opportunities. In some organisations for instance, there is often the incidence of 
'malicious obedience,' which is disgruntled employees doing exactly what they are told even though they know it is not the right thing to do. Another of Max-Neef's insights which supports the present research findings is that these needs as identified cannot be substituted for one another. For instance, if you compensate for a lack of affection with food (subsistence) you have another well recognized problem: obesity. These needs are all important for a healthy worker(s) involvement and satisfaction with construction jobs.

\section{CONCLUSIONS}

Many construction projects upon completion are not being delivered to the client's satisfaction, due to poor performance throughout the construction process; and, among other factors, job satisfaction has been identified as the factor that influences the performance of these projects, through experiences of absenteeism and employee turnover. In that regard, this paper shows the importance of maintaining job satisfaction of employees involved in the construction industry, in order to improve the performance of construction projects. The literature on determinants of job satisfaction has been reviewed; and subsequently, a survey was conducted based on the literature provided. The findings reveal that the most important determinants of construction job satisfaction are: work that allows personal growth; work that allows development; employment security; adequate salary; feedback from boss on task performance; opportunity for promotions and challenging work.

The implications of these findings is that top management within the organizations in the construction industry should provide employees with job tasks that encourage them to apply their skills and creativity, which will allow them to become more innovative and valuable to the organizations they are employed in. And this will not only benefit the employees by provision of job satisfaction, but, the organization as a whole, because such kind of job tasks will interest employees, thereby motivating them to perform their job to the expectation of the management at the top. And, the top management should as well recognize employees when performing well at work by provision of salary increase, job title or promotions. Also, difference in age, educational level and gender are concluded to be other determinants of job satisfaction of employees. The implications of these findings show that the top management should also provide employees that are young and with low educational levels, with training programs, workshops as well as sponsorships in order to encourage them to further their studies; thereby improving their educational qualification level. Furthermore, level of job satisfaction of female employees within the construction industry can be improved by modifying and improving the working environment to suit both genders, and also by enforcement of fair policies in respect of promotions and wages.

The majority of the respondents were younger as well as female members of construction professional team. Therefore, this study carries a greater value in contributing to the existing literature of job satisfaction based on individuals of rather different characteristics as mentioned above. These younger respondents may become the future seniors and leaders within the industry. Therefore, it is crucial to invest in them, in order to create and retain potential candidates as ideal leaders and seniors that the construction 
industry needs to have in future. By investment, it implies that, with the guidance of these present findings of this study, the management and employers can be able to address and maintain the issue of job satisfaction of these aforementioned individuals.

\section{REFERENCES}

- $\quad$ BERNOLD, L.E \& ABOURIZK, S.M. (2010). Managing Performance in Construction: The Complexity of HumanMotivation. New Jersey: John Wiley and Sons, Inc.

- BOWEN, P \& CATTELL, K.(2008). Job satisfaction of South African Quantity Surveyors, Engineering, Construction and Architectural Management. 15 (3), pp.260 269

- CIDB \& University of Free State. (2013). The CIDB Construction Industry Indicators: Summary Results.Available: http://www.cidb.org.za/Documents/KC/cidb_Publicatins/Ind_RpsOther/ind_reps_cii_2013.pd $\mathrm{f}$.

- $\quad 27$ March 2014].

- $\quad$ DEEPROSE, D. (2003). Smart Things to Know about Motivation. UK: Capstone Publishing Limited.

- HADEBE, (2001). The Relationship between Motivation and Job Satisfaction of Employees at Vista Information Services. Degree of Masters in Administration. University of Johannesburg.

- $\quad$ HODSON, R \& SUlLIVAN, T.A. (1990). The Social Organization of Work: Seeking Job Satisfaction. United State of America: Wadsworth

- KANDEREE, K \& CHAUDHRY, A.G. (2012). Leadership - Style, Satisfaction and Commitment: An Exploration in the United Arab Emirates Construction Sector, Engineering, Construction and Architectural Management. 19 (1), pp.61 85.

- $\quad$ LAVENDER, S. (1996). Management for the Construction Industry: Individual Motivation. Addison Wesley Longman. Limited. England.

- MATUTUANE, L.P. (2009). A Study of Employee Satisfaction in Two Manufacturing Facilities of General Motors, South Africa. Degree of Masters in Business Administration. Rhode University.

- NEUMAN, W.L. (2000). Social Research Methods: Qualitative and Quantitative Approaches. USA: A Pearson Education Company.

- $\quad$ ONUKWUBE, H.N (2012). 'Correlates of Job Satisfaction amongst Quantity Surveyors in Consulting Firms in Lagos', Nigeria, Australian Journal of construction Economics and Building, 12(2), pp. 43-54.

- $\quad$ ROJAS, E.M. (2008). Construction Productivity: Absenteeism and Turnover. United State of America: ELECTRI International.

- ROOS, W. (2005). The Relationship between Employee Motivation, Job Satisfaction and Corporate culture. Degree of Master of Science. University of South Africa.

- $\quad$ Schaffer, R.(2001). Managing Productivity. Mumbai: Jaico Publishing House.

- THWALA, W.D., MONESE, L. \& NTHABISENG, L. N. (2012). 'Motivators of Construction Workers in the South African Construction Sites: A Case Study', Journal of Economics and Behavioral Studies. 4(11), pp.625-643.

- $\quad$ TYILANA, EX. (2005). Impact of Motivation On Job Satisfaction Amongst employees Of A National Broadcaster. Degree of Master Commerce. University of Johannesburg.

- WALterS, J. (2010). Positive Management: Increasing Employee Productivity: Positive Management, Strategy, and Productivity. New York: Business Expert Press.

- YIRENKYI-FIANKO, A.B \& CHILESE, N. (2012). 'Job Satisfaction of Professionals within Ghanaian Construction Industry', In: Smith, S.D (Ed). Proceedings Of The $28^{\text {th }}$ Annual 
ARCOM Conference. 3-5 September 2012. Edinburgh, UK: Association Of Researchers. In Construction Management, pp.589-599. 


\title{
SUSTAINABILITY IN PROJECTS REQUIRES TRAINING IN MANAGING AS DESIGNING
}

\author{
Lousberg, L.H. ; Heintz, J.L. and Prins, M.
}

\begin{abstract}
:
Problems that present project managers have to deal with are more and more concerning complexity, i.e. unexpected, uncertain, unstable or unique situations. This seems also the case with sustainable building projects. It is therefore necessary that project managers are trained to deal with these problems, especially by learning from their performance. In this article we motivate why and propose how.

Based on literature study we elaborate on the concepts of reflection-in-action, design-thinking and managing as designing. In sustainable building projects the problem occurs on a regular basis that the often big ambitions in the initiative phase are not realised in the realisation phase. These ambitions perish because of a lack of substantial knowledge regarding the quality-, time- and cost-aspects of sustainable building projects. More important than this sufficient substantial knowledge is an integral approach of the entire building process. Exactly this integral approach of the process with its characteristic of working from sketch to detail -and backwards-appears to be very suitable for sustainable building projects and requires a management approach that allow, support and stimulates this; an approach that can be characterised as designing project management.

Where the concepts of reflection-in-action, design-thinking and managing as designing are interrelated in the concept of learning we introduce the project management design cycle. Project managers do not only need to use this searching and experimenting approach with awareness in order to learn from their performance, but students in project management will also have to be trained in how they can learn from their performance as a project manager. We propose that training related to cases e.g. as in management games seems to be the most suitable.
\end{abstract}

KEYWORDS: SUSTAINABILITY， TRAINING， REFLECTION-IN-ACTION， DESIGNTHINKING, PROJECT MANAGEMENT

\section{INTRODUCTION}

Despite all good intentions, ambitions in sustainable building projects often fail or go under in the course of the process, usually as a result of budget cuts. Instead of integral designing from the first sketch on, the building is designed as a Mr. Potatohead in which all sustainable solutions are pinned, making them an easy target for budget cuts. The key to creating a sustainable building is in customizing the underlying design process (Van Doorn, 2012:6).

Adjusting underlying processes is a project management task, whether this is carried out by a project manager or an architect is not in question. In addition, the problems that a manager of a sustainable building project has to cope with, can be characterised as

\footnotetext{
${ }^{1}$ Department of Management in the Built Environment, Delft University of Technology, Netherlands. Email: L.H.M.J. Lousberg@tudelft nl
} 
complex i.e. uncertain, instable and/or unique. Since about a decade coping with these kinds of problems has special attention in project management literature (e.g. Cicmil et al., 2006, Blomquist et al., 2010). However, it is but relatively little attention that has been paid to a line of thought that begins with Donald Schön's 'The Reflective Practioner' from 1983. In this article we pick up this line and develop it further through Design Thinking, Innovation and Managing as Designing. We will discuss these concepts extensively. We then reflect from this theoretical framework on the problems faced by sustainable building projects and describe how solutions from a searching and experimenting approach can be achieved. Finally we propose how project managers and students in project management can be trained in this approach that seems to be conditional for successful sustainable building projects.

\section{REFLECTION-IN-ACTION}

Schön starts with the determination of 'a gap between professional knowledge and the demands of real-world practice' (Schön, 1983: 45), a gap that, although ever smaller, still exists (cf. Koskola \& Howell, 2002, Cicmil et al., 2006, Gustafsson \& Lindahl, 2015). Where professional knowledge is 'convergent', practice is 'divergent' (Schön, 1983: 45). For project management, this means that where project managers are taught to converge in a project to result in terms of quality, time and money, practical experience shows that this guidance in particularly complex projects is not enough, and that here is a quest for means to mitigate the 'chaos of practice'. Schön then introduces the concept of Reflection-in-action, defined as thinking about doing something while doing it (ibid. 54). He then describes a number of professional practices including those of architectural design, but is limited in that because it is only about the reframing of the (design) problem. In the next section on Design Thinking we will come back to that. More extensively Schön discusses the structure of reflection-in-action. At first framing and next reframing of the problem is discussed as in a conversation between a student and practitioner. The practitioner then takes the reframed problem and conducts an experiment to discover what consequences and implications can be made to follow from it (ibid. 131). 'In this reflective conversation, the practitioner's effort to solve the reframed problem yields new discoveries which call for new reflection-in-action. The process spirals through stages of appreciation, action, and re-appreciation. The unique and uncertain situation comes to be understood through the attempt to change it, and changed through the attempt to understand it. Such is the skeleton of the process'.(ibid. 132). Schön even writes about ' reflection-in-action as an epistemology of practice ' (ibid. $133)$.

The chapter on management starts Schön with a two-tier management approach to professional knowledge that shows similarities with the dichotomy in project management approaches as still discussed in the literature (cf.. Blomquist et al., 2010, Gustafsson \& Lindahl, 2014). In the first approach, the manager is a technician whose practice consists in applying to the everyday problems of his organization the principles and methods derived from management science (ibid. 236). Taylor was the first to coin ' scientific management' were 'work was treated as a man/machine process which could be 
decomposed into measurable units or activity (ibid. 237). Further on Schön notices that 'Taylor saw the industrial manager as a designer of work (-). Above all, he saw the manager as an on-line experimenter, a scientist in action, whose practice would consist in the trial and measurement of designs and methods aimed at the discovery and implementation of the one best way'.

The second approach differs in this with the first, because it contains 'the manager is a craftsman, a practitioner of an art of managing that cannot be reduced to explicit rules and theories. Managers do reflect in action. (-) Whatever the triggering condition, a manager's reflection-in-action is fundamentally similar to reflection-in-action in other professional fields. It consists in on-the-spot surfacing, criticizing, restructuring, and testing or intuitive understandings or experienced phenomena'. (ibid. 241). Then Schön describes a number of examples from practice from which this reflection-in-action should turn out.

\section{Design Thinking}

Schön wrote referring to Herbert Simon's 'The Sciences of the Artificial' (1969) 'Simon believes that all professional practice is centrally concerned with what he calls 'design', that is, with the process of 'changing existing situations into preferred ones'.' (Schön, 1983:46). In line with this is the concept of design thinking. Design thinking can be interpreted as 'thinking as a designer'. Many of the design models described in literature have the following activities in common: analyse (getting to know the problem), synthesize (to find a solution to the problem) and evaluate (testing the solution against the problem) (Van Doorn, 2004: 32, Van Doorn, 2012:130). Contrary to the usual induction and deduction for analysing problems, design thinking characterizes itself by abduction. In the three step cycle outlined, the first step remains 'conventional' induction and deduction analysis, it is the second step that is characterised by abduction. Here we touch something basic: design thinking is solution-oriented (Dorst, 2010:133). At abduction, we know where we want to go, what we want to have as an outcome merely than a result, what the desired situation is, but we don't yet know exactly what the problem is from the given situation and we don't know how we may come from the given situation to the desired situation. That is selected by searching and experimenting, where in a coevolutionary process the problem is reframed (Dorst, 2010:133) and is experimented with a number of possible solutions to see if they meet.

Meanwhile, Design Thinking has many application areas for example in IT and Business (Dorst, 2010:131), but also in Innovation (cf.. Smulders, 2012). What these applications seem to have in common is that they are applying the searching and experimenting nature of design thinking in their field and know the benefit. It is precisely this searching and experimenting nature of design thinking which we assume that it can be the distinctive feature for managing in complex i.e. unexpected, uncertain, instable and/or unique situations. 


\section{Managing As Designing}

Although, contrary to the work of Dorst and Smulders, examined in only one case, this seems to be confirmed in Managing as Designing (Boland et al., 2008). Based on the observation that 'A design attitude, with its expectation to shape a better world, is a neglected but centrally important cognitive mode that should be nurtured in management practice and education' (ibid. 12), a research into Frank Gehry's practice of design is discussed, including lessons to be learned for management practice. These lessons are about organizational design and are first 'The possibilities for transformation in organizational leadership beginning with the adoption of a design attitude', second 'The design attitude includes an expectation that an organization's familiar language will be subject to scrutiny, and that new vocabulary elements are expected as an emergent outcome or seeking to create a more desirable state of affairs', third 'Part of the design attitude for leaders is to make a conscious effort to resist closure of a design problem and to maintain an open and liquid flow of design ideas', fourth 'Our study also shows that, like the search for functionality, organizational designs are never complete' and finally 'The design of large software systems is representative of the design type or complex organization attempted by their leaders today. The software design literature clearly shows that the design time spent in a liquid state, exploring alternatives and requirements early on in the process, results in fewer "bugs" and software repairs later on.' (ibid. 22, 23). The lessons for the management practice concern apparently only organizational design, not the daily management.

This day-to-day management of complex projects can be seen as a form of problem solving (Ahern, et al., 2014), where problem is the determination of courses of action to change present states into more desirable states, then it follows that design and design thinking are necessary tools. Projects present managers with design problems at several scales. The overall organization of the project, selection of partners, forms of contracts and tendering, structures of reporting and meeting is a large scale design problem facing any project manager at the outset. One might call this the strategic level. Resolving a scheduling conflict between two agents or a question of how to structure a BIM database would be examples of tactical problem solving.

Seen this way, it becomes easy to recognize that project management is a form of problem solving. These problems may be planning problems, or they may be problems requiring interventions in already ongoing events. We are used to thinking of the design and construction of buildings as requiring the solution to many kinds of problems: what forms will best accommodate the project brief, what materials will best realize these forms, what techniques are the best for assembling the chosen materials in the desired form. Problems in architectural and engineering design, and problems relating to the many crafts required for the assembly of buildings.

While one may consider these issues as matters of choice, the interrelation between the different choices to be made (each representing a different frame), the multiplicity and ambiguity of project goals and resources (typically seen differently by different stakeholders) raises the complexity of the network of choices to the level of a wicked 
problem (Coyne, 2005; Rittel \& Webber, 1973) - i.e. a problem where there is no possibility of optimization or algorithmic approaches to decision making. This is a problem type for in which design thinking has been found to be very useful.

A variety of researchers have proposed that these sorts of problems are best addressed by design. Among them Boland and Collopy describe the advantages of design thinking in management contexts as follows:

"A decision attitude toward problem solving is used extensively in management education. It portrays the manager as facing a set of alternative courses of action from which a choice must be made. The decision attitude assumes it is easy to come up with alternatives to consider, but difficult to choose among them. The design attitude toward problem solving, in contrast, assumes that it is difficult to design a good alternative, but once you have developed a truly great one, the decision about which alternative to select becomes trivial. The design attitude appreciates that the cost of not conceiving of a better course of action than those that are already being considered is often much higher than making the 'wrong' choice among them." (Boland \& Collopy, 2004, p. 4)

It is our contention that design and design thinking are particularly useful in design and construction management, especially in managing sustainable projects.

\section{SUSTAINABLE BUILDING PROJECTS}

The two in the previous section described characteristics of managing as designing, namely looking in a different way at the organisational design and looking in a different way at daily management, can be made concrete in sustainable building projects, in particular in relation to the design process.

The 'classic'/'traditional' design process is in the Netherlands and similar in other countries is phased in a preparation/ definition phase (appraisal and design brief), design phase (concept, preliminary, final and technical design). 'The nature of the sustainable design brief asks for a recast. There must be time and space for the joint definition of the project meaning of sustainability, in order to create integrated architectural design proposals and for developing innovative solutions (Van Doorn, 2012:129). This calls for a redesign of the design process, on the basis that the overall design process doesn't longer than the traditional design process.

Two possibilities are conceivable in this light (ibid. 129, 130). The first is that the phase of the structure design is integrated with the definition phase. Defining the sustainable design ambition plays a key role in the success of the sustainable design project. There are two reasons for integrating the definition of the sustainable brief with the design phase and hence involve the members of the design team in it. First, it can better be used in this way by their creativity, insight and experience. 'It makes sense that the sustainable ambition often arises only during the design process and not before that. The preparation of the sustainable project ambition in the form of a sketch design is therefore effective for a sustainable project. Secondly, a shared understanding of the meaning of sustainability 
in the project is important to the success of it. That is also why it is valuable to do this again in the design phase and to define it together. ' (ibid. 130).

The second possibility to redesign the sustainable design process is extending the preliminary design phase. 'The preliminary design phase is the moment where the main design decisions are made and the design concept takes shape. From the point of view of sustainability, this is the phase where design choices are made, such as the orientation and location of the functions, which have the greatest effect on the final building performance (while often being the cheapest to implement).

The need for looking differently at the daily management of a sustainable project, appears from the question for a higher degree of iteration, for repeating the design cycle of analysis, synthesis, and evaluation and for working from coarse to fine - and back again - then in a 'traditional' design process. This concerns specifically an early contribution of technical know-how and forward integration of architectural knowledge (ibid. 132).

However, besides the forward integration of architectural knowledge, it is also about giving space to research and experiment and to constantly, until with the preparation of the implementation, testing of (in between) results to sustainable criteria. In this way is 'the traditional management cycle of analysis, diagnosis, goal setting, planning and execution embedded as an iterative routine in each iteration instead of being executed only once throughout the project. The management cycle is repeatedly executed by the team of well-educated knowledge workers instead of an individual manager who predicts and controls the team. ' (Stettina, 2015:43)

\section{Learning}

If we compare the elaboration of the concepts of reflection-in-action, design thinking and managing as designing, they seem to show much similarity with the concept of experiential learning (Kolb, 1984), a concept that origins in the experiental works of Dewey, Lewin, and Piaget and is extensively studied in practice. The experiential learning cycle consists of respectively the phases of the Concrete experiencing of an experience, Reflective observation, the Abstract conceptualizing and the Active experimentation, hence so forth. This experiential learning matches with the cognitive structure by which people can achieve the highest stages of learning (cf. Moon, 1999:24, 110). Key concept in this is reflection (Moon, 1999), but then as reflective habit (Smith, 2001:31), a reflective habit that turns out to be inherent to design thinking.

To the in the section Design Thinking cited quote about the definition of design as 'changing existing situations into preferred ones' adds Schön: 'But design in this sense is precisely what the professional schools do not teach.' (Schön, 1983:46). Our proposal is to pick up this challenge (cf. Dun \& Martin, 2006) and develop a cyclic model by which project managers or students in project management can learn how to cope with complex, i.e. unexpected, unstable, insecure and unique situations. We have named this cyclic 
model the Project Management Design Cycle and it consists of the stages Awareness/Recognition, Design, Performance and Reflection.

Project managers with their busy agenda's and often seemingly necessary daily fixation on end goals that must be met, seem to have little time for a reflective practice, while in fact their behaviour is accordingly to it (cf. Kolb, 1984, Moon, 1999), only they are just not aware of it. The first step that we propose to train (prospective) project managers in reflective practice is that of Awareness/recognition. This awareness encompasses not only the formal project as captured in so called "project information", but also, and importantly, the social situation (situational awareness), including the status and state of the various actors and stakeholders in the project. Awareness of what is going on, who is doing what, etc. Also of intentions, goals, and plans. Awareness also encompasses the determination that 'something needs to be done' i.e. deviation from the intended course of the project in some why. Awareness has a very significant component of sensemaking.

Out of this awareness flows an understanding of both the current state and a desired outcome. Having determined that action is required, design refers to the shaping of a course of action. Design thinking here is important in its open and free approach to generating alternatives and possibilities. But Design should include both generate and test. A designed course of action is also one that has been in some sense tested.

This course of action will naturally consist of a list of things for the actors in the project to do, but equally important it will include things which the project manager him or herself must to in order to initiate and guide the other actors in the actions they must carry out.

This second set of actions must then be performed by the project manager. And this performance constitutes the second main set of activities of the building project manager. The choice of the word performance refers to the performative aspect of management. It is not just a matter of carrying out the design. A Performance is required in that management, especially Design \& Construction Management, requires that one changes people's minds and actions. This requires that one reach them in the same way an actor does.

Finally, there is a reflection upon the outcome, attempting to draw any lessons about the designed course of action or its performance that may be useful in the future.

Coping with complex managerial problems in a way as described above can be trained in a simulation of 'real life' situations as in management games. There are practical challenges, of which the least seems: "How do we know whether the simulation is 'real as life '?" In the literature enough material can be found to construct a reasonably similar simulation (cf. Duke \& Geurts, 2004, Gaffney et al., 2007).

However, the most important practical challenge seems to be: "How do we know whether the trainees have gone through the cycle of Awareness/ Recognition, Design, Performance and Reflection in their daily management 'while doing it "?". We think that 
this can be solved by subsequently on the one hand discuss with the trainee whether he/ she recognizes the different steps, looking back on his/ her daily functioning as a project manager, but above all by assessing whether he/ she during the exercise of his/her function works ' designerly ', i.e. focussed is on analysing the problem by developing various solutions. Because that determines the searching and experimenting nature nature of managing as designing contrary to the common view on managing as choosing between ready-made options presented. By observing and subsequently evaluating the behaviour of the trainee at his/her daily management, we expect it is possible to train project managers and students in project management in learning from themselves.

\section{RESEARCH METHODOLOGY}

Even though the paper is solely based on a literature review it is an important question to which extent the concepts covered in this paper are based on sound research. Scientifically speaking, Schön's operationalisations of the concept of Reflection-inaction are not very convincing. They are examples such as a lecturer uses to illustrate a theory, but it is unclear whether theyt are systematic case studies on the basis of which a theory is proposed. Also Moon (1999) states that Schön's concept is established, without ever been tested to be substantial and that there has been a tendency to adopt Schön's model as a 'fact' and theorize on this basis rather than treat the model as speculative (Moon, 1999:14, 54). There have been attempts to operationalize the concept (ibid. 49). One example is the reflexive practice of design teams (Valkenburg \& Dorst, 1998). In an explorative study Valkenburg and Dorst investigate whether by means of Schön's reflective practice the nature of team designing can be described. This seems to be the case; reflection-in-action can be operationalized as reflection that guides the development of one's knowing-in-action habits (ibid. 251).

The concept of Design Thinking has been extensively researched in different practices (cf. Dunne \& Martin, 2006, Dorst, 2010, Smulders et al., 2014).

The concept of Managing as Designing however seem to be grounded in only one case study, but is very well received (cf. Sebastian, 2007, Winch, 2008,).

Although there is evidence on the basis of the literature about the uncertain, searching and experimenting nature of the integral development process of sustainable building projects (cf. Van Doorn, 2012), operationalisations of Reflection-in-action, Design Thinking and Managing as Designing in these projects are, also as far as we know, not tested.

However, because these concepts seem to be very near to the concept of experiential learning and motivated by the extensive research on this concept (cf. Kolb, 2000), we believe on the basis of our literature review in this paper that it is very worthwhile to test the operationalisation of these concepts in the management practice of sustainable building projects. 


\section{CONCLUSION}

In the foregoing we argued on the basis of a literature review that it is appropriate/specific to sustainable building projects that students and professionals are trained in managing as designing. We started at the concept of Reflection-in-action defined as thinking about doing something while doing it. This was then associated with Design thinking of which the searching and experimenting nature seemed suitable for managing complex i.e. unexpected, uncertain, instable and/or unique situations. Although concerning only one case this seemed to be confirmed in a study that introduced the concept of Managing as Designing. The two characteristics or managing as designing, namely looking in a different way at the organisational design and looking in a different way at daily management, were made concrete for sustainable building projects. Finally we specified based on the concept of experiential learning this daily management into personal awareness, design, performance and reflection to support the training of students and professionals in managing as designing.

The education of (future) managers of sustainable building projects should therefore, focus in particular on the actions of individuals. This focus on personal awareness, design, performance and reflection makes the approach ideal for the education of students and professionals. By focusing on the higher level actions of a project manager we avoid losing ourselves in chasing the ever changing body of management tools and techniques which will face anyone in the field, and concentrate on those cognitive and social skills that will be required for making sustainability in building projects possible.

\section{REFERENCES}

- $\quad$ AHERN, T. LEAVY, B. \& BYRNE, P. (2014). Complex project management as complex problem solving: A distributed knowledge management perspective. International Journal of Project Management, 32(8), 1371-1381.

- $\quad$ BlOMQUiST, T. , HÄLlgREN, M., NILSSON, A. \& SÖDERHOLM, A. (2010) Project-asPractice: In Search of Project Management Research That Matters. Project Management Journal. Vol. 41, No. 1, 5-16

- BOlAND, R. \& COLlOPY, F. (2004). Managing as Designing. Palo Alto: Stanford University Press

- BOLAND, R., COLlOPY F., LYYTINEN K. \& YOO, Y. (2008) Managing as Designing: Lessons for Organization Leaders from the Design Practice of Frank O. Gehry. Design Issues: Volume 24, Number 1

- $\quad$ CICMIL, S., WILliAMS, T., THOMAS, J. \& HODGSON, D. (2006) Rethinking Project Management: Researching the actuality of projects. International Journal of Project Management 24 (2006) 675-686

- $\quad$ COYNE, R. (2005). Wicked Problems Re-Visited. Design Studies, 26(1), 5-17.

- $\quad$ DORST, K. (2010) The Nature of Design Thinking. DTRS \& Interpreting Design Thinking.

- $\quad$ DUKE, R.D., GEURTS, J. L. (2004) Policy games for strategic management - Pathways into the unknown, Amsterdam, Dutch University Press

- $\quad$ DUNNE, D. \& MARTIN, R. (2006) Design Thinking and How It Will Change Management Education: An Interview and Discussion. Academy of Management Learning \& Education. Vol. 5, No. 4, 512-523. 
- GeurTs, J.L., DUKE, R.D., VERMEUlen, P.A. (2007) Policy Gaming Strategy and Change, Long Range Planning 40 (2007) 535-558, Elsevier

- GUSTAFSSON, C. \& LINDHAL, M. (2015) Improvisation - an emergency theory perspective. Culture and Organization 2015.

- KOLB, D. (1984) Experiential Learning as the Science of Learning and Development. New Jersey: Prentice Hall

- KOLB, D., BOYATZIS, R., MAINEMELIS, C. (2000) in: R. J. Sternberg and L. F. Zhang (Eds.), Perspectives on cognitive, learning, and thinking styles. NJ: Lawrence Erlbaum

- KOSKOLA, L. \& HOWELL, G. (2002) The underlying theory of project management is obsolete. In: SLEVIN, D., PINTO, D. \& Cleland d. (eds) Proceedings PMI Research Conference 2002, Project Management Institute, Newtown Square, PA, 293-302.

- MOON, J. (1999) Reflection in Learning \& Professional development. London: Kogan Page Limited

- RITTEL, H. \& Webber, M. (1973). Dilemmas in a general theory of planning. Policy Sciences, 4(2), 155-169.

- SCHÖN, D. (1983) The Reflective Practioner - How professionals think in action. USA: Basic Books

- SEBASTIAN, R. (2007) Managing Collaborative Design. Delft: Delft University of Technology

- SMith, P. (2001) Action Learning and Reflective Practice in Project Environments that are Related to Leadership Development. Management Learning Vol. 32 (1): 31-48.

- SMULDERS, F. (2006) Get synchronized! Delft: Delft University Press

- SMUlDERS, F. \& BREMER, M. (2012) Innovating Innovation: Towards a NPDManagement Taxonomy. ISBN 978-90-77360-15-6

- SMUlders, F., DORST, K. \& VERMAAS, P. (2014) Applying Design Thinking Elsewhere: Organizational context matters. 19th DMI: Academic Design Management Conference

- STETTINA, C. (2015) Governance of innovation project management : necessary and neglected. Available from: http://hdl handle.net/1887/33081 [Accessed: 4th June 2015].

- VALKENBURG R. \& DORST K. (1998) The reflective practice of design teams. Design Studies 19 (1998) 249-271.

- VAN DOORN, A. (2004) Ontwerp/ proces. Amsterdam: Uitgeverij SUN

- VAN DOORN, A. (2012) Het duurzame ontwerpproject. Zeist: AD Druk

- WINCH, G., (2008) Managing as designing?, Building Research \& Information, 36:2, 203205. 


\title{
INFLUENCE OF HOST ORGANISATION CULTURE IN THE EXECUTION OF CONSTRUCTION PROJECTS: A CASE STUDY OF SELECTED HIGHER EDUCATION INSTITUTIONS IN NIGERIA
}

\author{
Olowoake, M.A. ${ }^{1}$
}

\begin{abstract}
:
Crotty (2005) asserts that, culture predetermines actions and therefore it becomes important to know the culture of all the project team members for appropriate action during the management of the project. The philosopher Francis Bacon once said men commonly think according to their inclination, speak according to their learning and imbibed opinions, but act according to custom (Harris, 2003).

The cultures of different Organisations go a long way in determining the efficiency, effectiveness, and the overall success of executing construction projects. The researcher studied the different cultures of twelve different Higher Education Institutions in Nigeria vis-a vis project execution. It is observed that, well maintained Higher Education Institutions (HEIs) buildings connote better and effective teaching and learning environment for students and other faculty staff, and will impact on staff and learners' performance and improve their productivity levels.

A cursory look at some of the HEIs buildings being studied suggests that, they are not well maintained in the last five years as due to the influence organisational cultures as revealed by the current interviews conducted for the Directors of the twelve HEIs being considered in this study.

Research Objectives: To investigate and review the current theoretical approaches to the influence of culture on project execution strategies.

To evaluate Works and Services Departments culture in relation to the adoption and use of Procurement strategies; Maintenance methods; Maintenance budgets; Post occupancy evaluations; Quality control; and Sustainable programme. To develop a strategic framework to support maintenance.

Research Methodology: The researcher conducted semi-structured interviews (qualitative) for the twelve Directors of works and services departments of the selected HEIs in Nigeria, and questionnaire survey (quantitative) for twelve senior technical staffs of the same sites.

Results: The study confirmed that: Majority of the HEIs do not have full complements of technical staffs, and most projects are outsourced. In most HEIs in Nigeria, the use of curative maintenance method is prevalence. Budgets are derived from in-appropriate data collection techniques, and there is over-reliance on letters of complaints from the facilities users. None of the studied HEIs in Nigeria have project quality control unit within the works and services departments. Only a few of them prepare and use sustainable programmes for their built environments.
\end{abstract}
KEYWORDS:
PROJECT
BUDGET,
COUNTRY
CULTURE,
SUSTAINABLE ENVIRONMENT, SUSTAINABLE PROGRAMME, QUALITY CONTROL
1 Moshood
Abiola
Polytechnic,
Abeokuta,
Ogun
State,
Nigeria, Olowoake.mohamed.mapoly.edu.ng@gmail.com 


\section{INTRODUCTION}

According to Chika (2008), restoration of facilities or buildings into appropriate and acceptable standards at a reasonable cost with little inconveniences to the occupiers is the core of property or facilities management. David (1999) classifies assets management into five types, such as: physical assets, human assets, financial assets, information assets, and intangible assets. However, for the purpose of this study, emphasis shall be placed on physical assets.

\section{Influence of Culture on Project Execution}

Feldman (1995) argues that, "one cannot describe a culture without also interpreting it. Men only think according to their inclination, speak according to their learning and imbibed opinions, but act according to custom (Harris, 2003). Culture predetermines actions and therefore it becomes important to know the culture of all the project team members for appropriate action during the management of any foreign project. The cultural differences in project management risk perception are essential (Camprieu et al., 2000). Cultural policy should not be considered in isolation for it transmits values, ideology, global standards and organizational principles (Mo, 2007). International activities are influenced by national cultures and globalization which entails inter-cultural management (Neelankavil et al., 2000)

Table 1: Semi-Structured Interviews Conducted For The Directors Of Twelve Heis Works And Services Departments In Nigeria

\begin{tabular}{|c|c|c|c|}
\hline $\begin{array}{l}\text { Serial } \\
\text { Number }\end{array}$ & Name of the Institutions & & $\begin{array}{l}\text { Number of } \\
\text { Respondents }\end{array}$ \\
\hline 01 & Abraham Adesanya Polytechnic, Nigeria & A & 1 \\
\hline 02 & Federal Polytechnic Ilaro, Nigeria & B & 1 \\
\hline 03 & Federal University of Agriculture, Abeokuta, Nigeria & $\mathrm{C}$ & 1 \\
\hline 04 & Lagos State Polytechnic, Ikorodu, Nigeria & $\mathrm{D}$ & 1 \\
\hline 05 & Moshood Abiola Polytechnic, Abeokuta, Nigeria & $\mathrm{E}$ & 1 \\
\hline 06 & Obafemi Awolowo University, Ile-Ife, Nigeria & $\mathrm{F}$ & 1 \\
\hline 07 & Olabisi Onabanjo University, Ago-Iwoye, Nigeria & $\mathrm{G}$ & 1 \\
\hline 08 & University of Ibadan, Nigeria & $\mathrm{H}$ & 1 \\
\hline 09 & University of Lagos, Nigeria & I & 1 \\
\hline 10 & Tai Solarin University, Ijebu-Ode, Nigeria & $\mathrm{J}$ & 1 \\
\hline 11 & The Polytechnic Ibadan, Ibadan, Nigeria & K & 1 \\
\hline 12 & Yaba College of Technology, Lagos, Nigeria & $\mathrm{L}$ & 1 \\
\hline Total & & & 12 \\
\hline
\end{tabular}




\section{RESULTS OF INTERVIEWS CONDUCTED FOR DIRECTOR OF WORKS AND SERVICES IN NIGERIA}

\section{Procurement Strategies}

Use of Outsourcing: Outsourcing involves contracting out of either capital projects or maintenance projects to qualified and competent contractors to execute because of the largeness and complexity of such projects.

\section{Use of In-house Technical Staff}

The use of in-house technical staff to handle simple and small maintenance projects is desirable. Such projects can be more expensive if executed via outsourcing. These types of jobs are minor repair or replacement in nature, and they can be completed by the inhouse technical staff within three- to-four days, and attracted little costs. In addition, the designs of such jobs could be handled by Consultants or by in-house technical staff (HEIs-Planning and design unit).

A, 2012; and D, 2012) preferred routine and curative maintenance methods (K, 2012; and $B$, 2012) preferred the use of curative maintenance method due to paucity of funds $(H$, 2012; G, 2012; and E, 2012) preferred the use of predictive, curative, and preventive maintenance methods.(L, 2012; J, 2012) preferred the use of predictive and corrective maintenance methods instead of planned preventive method due to paucity of funds $(\mathrm{F}$, 2012; and C, 2012) preferred the use of planned preventive maintenance method in order to reduce maintenance costs, prevent assets failures, prolong assets durability, and increase assets productivity levels.

Most HEIs prefer the use of curative method (restoration back to normal position), some combine conditions survey with curative method (that is, predictive with corrective methods).However, the best approach as confirmed from the interviews responses and the literature review is "Planned Preventive Maintenance" method. (A, 2012; and E, 2012) preferred budget to be prepared based on the previous year budget plus the current market prices of materials and components, and an additional percentage.(K, 2012; H, 2012) preferred to use open budget.(G, 2012; and C, 2012) preferred the use of data collected from reconnaissance survey to prepare maintenance budget. B (2012) uses "forecast" to prepare maintenance budget. F (2012) uses "Centralised budgeting System".(L, 2012; and J, 2012) prepare maintenance budgets based on condition surveys of the assets. D (2012) uses the Institution annual overall budget to prepare the maintenance budgetwhich is a ten per cent of the overall of the Institution annual budget. 
Diagram 1 Budget preparations techniques by various works and services departments:

MAINTENANCE BUDGET

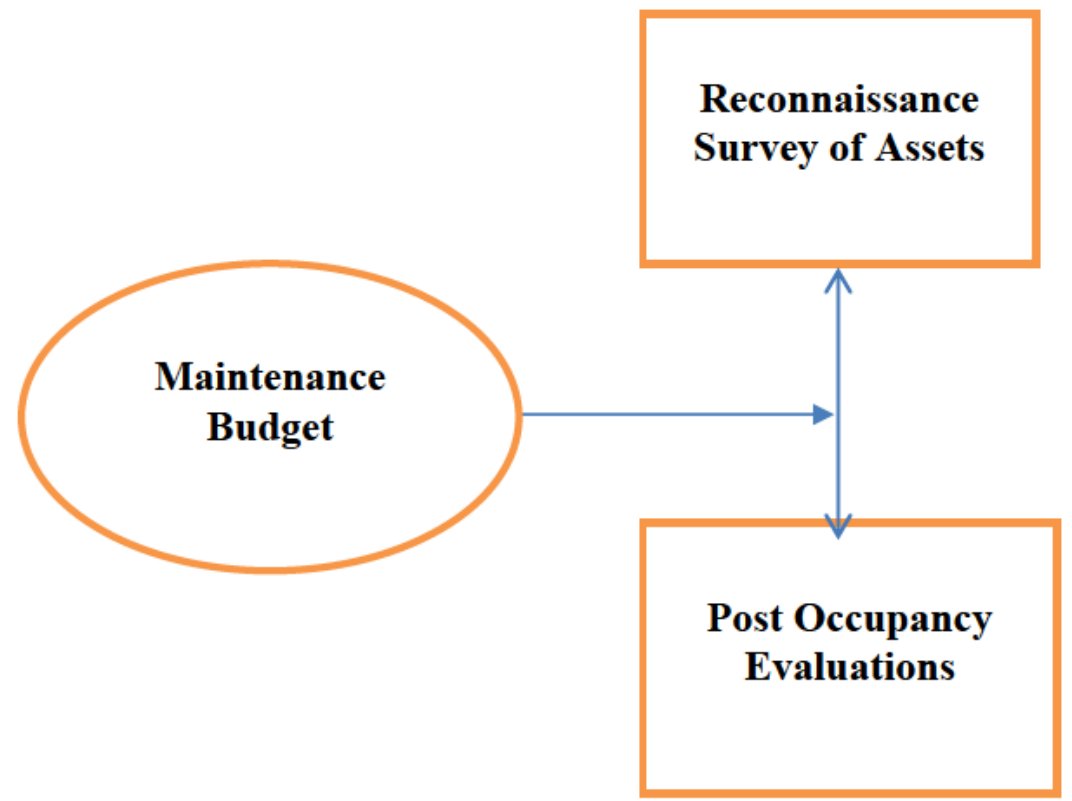

Previous year budget plus a percentage: Many HEIs works and services departments use the previous year maintenance budget to prepare the current year budget with only a percentage increase, and the current prices of components and materials. Some HEIs based the budget preparations on forecasts. However, the best approach is to conduct reconnaissance surveys of the built environment (to identifying the existing defects, and possible future defects). The defects identified are measured and priced in order to give accurate budget figures.

(A, E, H, J, K, L, W, 2012) rely on letters of complaints from the assets users. J(2012) carries out users' satisfaction surveys regularly. C (2012) carries out the survey once in a year. B (2012) carries out users' survey periodically. In all built environments of higher education institutions, the end users of the assets are the academic staff, administrative staff, technical staff, and the students.

(A, C, D,F, G, H,2012) agreed that, there should be a quality control unit within Works and Services departments with the responsibilities of monitoring, controlling, and supervision of all maintenance projects. G (2012) asserted that, carrying out of all important site tests are very essential (B, C, E, J, L, 2012) agreed that, all Contractors must adhere strictly to all schedules, and all project specifications.

Project quality control is germane to the success of project delivery. In every works and services department of each HEI, there is the need for the establishment of a "Quality Control Unit" (comprising of seasoned professionals from the consulting firms and from works and services department). In addition, the duties of the unit is to ensure quality in 
all ramifications (that is, in designs, planning, execution, components, materials, and production of maintenance manuals).

$H$ (2012) emphasised the qualities of construction materials and workmanship (A, 2012) emphasised regular checks on the assets for maintainable defects. G (2012) emphasised boosting of the HEIs built environments, regular and adequate supply of water, electricity, and improved waste treatment.(C, 2012; and B, 2012) emphasised five years developmental plans. F (2012) called for improved quality of labour.

(L, 2012; and J, 2012) emphasised regular maintenance of HEIs built environments to avoid dilapidation. D (2012) asserted that, the whole built environment under the works and services department were divided into zones, and manned by maintenance officers for ease of administration. Sustainability of HEIs built environment could be treated in three integrated principal ways, such as: environmental; economic; and social. Most HEIs in Nigeria are characterised with irregularities, such as: epileptic supply of electricity, poor drinkable water supply, poor waste collection, treatment, and disposal system, poor drainage system, poor maintenance budgeting system, and poor maintenance method. In spite of the erratic supply of electricity, majority of the HEIs use direct current (use of generating plants), only that poor budgeting system and the delay in releasing maintenance cash hinder the efforts. In addition, only a few of the HEIs in Nigeria are residential, and those that do, can only accommodate a few students due to limited numbers of bed spaces. Due to increasing numbers of candidates seeking admissions, and students' population explosion, more academic programmes were introduced. As a result, a few students admitted to existing programmes increased astronomically, with little or no improvement on the existing teaching and learning facilities.

\section{Cultural Influence}

Most Higher Education Institutions works and services departments don't have full complement of in-house technical staff. In addition, majority of the technical staff on the pay roll need to attend more in-service training to be qualified and skilful. Also, the attitudes of the technical personnel to their duties may likely reduce the level of productivity, and cause conflicts. (Brian and Brook, 2009) assert that, "one of the reasons why projects fail is that, there could be a real weakness in the understanding of cults or workforces". Therefore, foreign organisations should do well to increase the time and resources allocated to planning, consider the needs of foreign workers, and the impact of conflict on work progress arising from different cultures.

Table 2 Response rate to complaints from the facilities users are always delayed

\begin{tabular}{|l|l|l|l|}
\hline Likert scale & Results & $\%$ & Remarks \\
\hline S.A(1) & 70 & 58.34 & \\
\hline A(2) & 34 & 28.33 & \\
\hline D(3) & 04 & 3.33 & \\
\hline S.D(4) & 12 & 10 & \\
\hline Total & 120 & 100 & \\
\hline
\end{tabular}

Source: Field Survey 2013 
As in Table 2, about $86.67 \%$ of them agreed that, response rates to complaints from the assets users are always delayed. While about $13.33 \%$ of them disagreed. Majority of the respondents agreed, that response rate is delayed. As explained in Question above, the data collection techniques are faulty, coupled with faulty processes and human faults (Cultural influence) in the budget implementation could cause delays in restoring assets back to acceptable standards.

Table 3 Maintenance works are carried out regularly on existing building

\begin{tabular}{|l|l|l|l|}
\hline Likert scale & Results & $\%$ & Remarks \\
\hline S.A (1) & 20 & 16.67 & \\
\hline A (2) & 12 & 10 & \\
\hline D (3) & 64 & 53.33 & \\
\hline S.D (4) & 24 & 100 & \\
\hline Total & 120 & \\
\hline
\end{tabular}

As in Table 3, about $26.67 \%$ of the entire respondents agreed that maintenance works are carried out regularly on existing buildings. Also, about $73.33 \%$ of the participants disagreed. In Nigeria, majority of the HEIs do not carry our regular maintenance works on their existing buildings. Immediate causes of this could be the following factors: lack of maintenance budgets; where budget exists it could be faulty preparations of maintenance budget; delays in releasing maintenance cash; human faults in implementing maintenance budget; use of in-effective in-efficient maintenance methods; and inappropriate use of procurement strategies. A cursory look at those buildings, especially those built more than five years ago, indicate that they are in dilapidated conditions.

Table 4 To avoid keeping of backlogs of maintenance, works and services department could use maintenance control toolkit

\begin{tabular}{|c|c|c|c|}
\hline Likert scale & Results & $\%$ & Remarks \\
\hline S.A (1) & 76 & 63.33 & \\
\hline $\mathrm{A}(2)$ & 24 & 20 & \\
\hline $\mathrm{D}(3)$ & 12 & 10 & \\
\hline S.D (4) & 08 & 6.67 & \\
\hline Total & 120 & 100 & \\
\hline
\end{tabular}

Source: Field Survey 2012

As in Table 4 about $83.33 \%$ of the entire respondents agreed that, the use of maintenance control toolkit helps in preventing keeping of backlogs of maintenance. However, the remaining $16.67 \%$ of the whole participants disagreed. The use of maintenance control toolkit, such as, maintenance schedule; maintenance programme; jobs specification; history record; and facility register help to avoid keeping of backlogs of repairs and replacements of existing buildings. The use encourages prompt and adequate release of maintenance budget (cash). 


\section{INFERENCES}

In most HEIs, response rate to Users' Complaints about defects are delayed due to delays being suffered by the works and services departments from the HEIs management in approving and releasing maintenance cash. In addition, previous year maintenance projects in which maintenance cash was approved and released still re-appear in the following year (cultural influence) budget for implementation.

Most of the HEIs Works and Services Departments Technical staff lacks necessary technical skills and knowledge to perform their official duties satisfactorily (cultural influence), and prefer to keep backlogs of repairs and replacements of defects.

Most HEIs Chief Executives are not maintenance or technically inclined, and view regular maintenance of existing built environments as waste of revenue. They always favour erecting of new staff offices and lecture rooms for personal gains (attitudes).

Most HEIs works and services departments do prefer existing buildings to be in dilapidated conditions or collapse before carrying out maintenance works on them (curative method), and do not prepare and use maintenance control toolkit. And, the absence of its use prevents the timely approval of maintenance budget, and adequate release of maintenance cash.

\section{REFERENCES}

- CAMPRIEU, R., DESBIENS, J. and FEIXUE, Y. (2007) “Cultural Differences in Project Risk Perception: An Empirical Comparison of China and Canada', International Journal of Project Management, Vol.25, pp. 683-693

- CHIKA, E.U. (2008) Professional Practice for Real Estate, TREEM NIGERIA LIMITED, Lagos. Nigeria, p. 34

- DAVID, G.C. (1999) The Facility Management Hand book, American Management Association, New-York

- FELDMAN, M.S. (1995) Strategies for Interpreting Qualitative Data Sage Publication, vol.33, London

- HARRIS, P.R. (2003) New Work Culture: A Hand Book, HRD Transformational Management Strategies, Jaico Publishing House, Mumbai

- MO, P.H. (2007), The Nature of Chinese collective Values: Formation and Evolution, International Journal of Chinese Culture and Management, Vol. 1, No. 1, pp. 108125

- $\quad$ MULlER, R. and TURNER, R. (2007), The Influence of Project Managers on Project

- Success Criteria and Project Success by Type of Project, European Management Journal, Vol. 25, No. 44, pp. 298-309

- NEELANKAVIL, J.P., MARTHUR, A. and ZHANG, Y. (2000) Determinants of Managerial Performance: A Cross-Cultural Comparison of Perceptions of Middle Level Managers in Four Countries', Journal of International Business Studies, Vol. 31, No. 1, pp. 121-140. 


\title{
IMPLEMENTATION OF EARLY CONFLICT MANAGEMENT MEASURES IN CONSTRUCTION PROJECTS - THE CASE OF SOUTH AFRICA
}

\author{
Rwelamila, P. D. ${ }^{1}$ and Brown, S. T. ${ }^{2}$
}

\begin{abstract}
:
This paper reports on the study which sought to address construction conflict, reviewing in particular the development of 'conflict', rather than 'dispute' within the South African construction industry (SACI) and the measures taken to address it. A comprehensive survey undertaken within the South African market identified that the success rate in resolving conflict at an early stage was notably low and that conflict often escalated into disputes and was thereafter resolved by third party intervention, such as a mediator or an arbitrator. The survey identified that the majority of conflicts originated within the construction 'site' environment, with client reluctance to entertain claims being noted as the most common cause of conflict. Formal processes for Early Conflict Management were found to be seldom implemented or planned. The lack of skills to address and deal with conflict on construction projects in South Africa was readily demonstrated by the survey findings and it was noted that the industry could benefit enormously from the introduction of training to enable personnel to better manage conflict.
\end{abstract}

KEYWORDS: EARLY CONFLICT MANAGEMENT, PROJECTS, DISPUTES, CONSTRUCTION INDUSTRY, SOUTH AFRICA

\section{INTRODUCTION}

Disputes are common in the construction industry, to the extent that they are often viewed as a part of the construction process (Hellard 1992). Most commonly used standard forms of contract include dispute resolution clauses, or more accurately 'alternate' dispute resolution clauses. While Zach and Peters (2011) noted that construction industry professionals are routinely taught to plan their work diligently, it is not often in the construction industry that any effective planning is carried out relating to the management of disputes. More often the industry relies on pre-existing dispute clauses to address potential conflict or disputes. Such clauses are generally viewed as beneficial, but are often also regarded as the only means to resolve disputes in the construction industry. They are most often applied only once a dispute has reached an advanced stage (Groton and Lawrence 2010). Processes, such as adjudication, have more recently been introduced into the South African construction industry (SACI), as an optional means of dispute resolution. Mediation is another commonly used form of dispute resolution in the SACI, although Povey (2005) shows it to be defectively implemented in the South African context. Nonetheless, measures such as adjudication

\footnotetext{
${ }^{1}$ Graduate School of Business Leadership, University of South Africa, Pretoria, South Africa. Email: rwelapmd@unisa.ac.za

${ }^{2}$ PAD \& Company, Motorway M3, Riche Terre, Terre Rouge, Mauritius. Email: tb@padconstruction.com
} 
and mediation address 'dispute' rather than 'conflict' resolution and as such are implemented once conflict has developed into a dispute (Maiketso and Maritz 2012).

According to Yiu and Cheung (2007): "Escalating conflict level may turn into psychological struggles between the contracting parties and manifests as dispute."

While this view is well supported, the construction industry's focus remains on dispute resolution rather than conflict avoidance. Fellows (1992) noted that this focus addressed the symptoms rather than the causes of disputes. Simmons (1992) suggested that the 'inventive' management of conflict could reduce the prevalence of conflict in the construction industry. Early Conflict Management (ECM) is the principle that, as conflict on construction projects is predictable and commonplace; measures should be implemented to ensure that such conflict is addressed at its early stages, as it arises, rather than being allowed to develop into disputes. Often the 'golden hour' or the period when a conflict remains most manageable, is allowed to elapse with little or no attempt to address the conflict in an effective manner (Lewis, Cheetham and Carter 1992). Processes or procedures for Early Conflict Management are most often not comprehensively addressed in construction contracts and the effect of this is recognised by major dispute resolution organisations.

Research reported in this paper reviews conflict cycles in the context of the SACI to identify at which point in this cycle early conflict resolution is regularly implemented, could be implemented and should be implemented, as a preventative measure to prevent conflicts from escalating into disputes (McKipllop 2003). This is reviewed in the context of the South African construction industry. The research intended to identify the pervasiveness of Early Conflict Management in the construction industry in South Africa and assessed the processes employed to manage conflict.

This paper is divided into five sections: Problem statement and research questions; Theory and practice of conflict management; Summary of research methodology; Results, synthesis and analysis of results; and Conclusions and recommendations.

\section{PROBLEM STATEMENT \& RESEARCH QUESTIONS}

\section{Problem statement}

Although, as noted by El-adaway and Kandil (2010), disputes are often considered inevitable, disputes within the construction industry are certainly noted to be excessive and are often a major negative factor in the industry (Panagiotis and Howell 2001:223). Gaitskell (2005) emphasised the many alternate dispute resolution processes currently employed within the industry. Despite the prevalence of such processes, and while disputes have reduced somewhat in number wihin the industry, they remain extensive. This is a global trend as noted in EC Harris (2013) and the South African industry has not been spared from this international phenomenon. There is often a debate over the difference between the terms 'conflict' and 'dispute', as they relate to the construction industry. A useful reference was made by Brown and Marriott (1999) which identified a 
dispute as 'a conflict made public and requiring resolution'. This is the point at which disputes are most often addressed, when the opportunity to resolve the conflict within the stakeholder group has failed and intervention by an external party is required. It is this period between the development of a conflict and its progression to a dispute that perhaps need greater industry focus, better education and more statutory support that may improve outcomes; resolving and managing conflict before it develops into a dispute (Cheung \& Suen 2002).

\section{Research questions}

The research reported in this paper addresses the issues above within the context of the South African construction industry, and seeks to answer the following research questions:

RQ1 - Are Early Conflict Management (ECM) procedures or processes routinely used in the South African construction industry as a means to prevent disputes?

RQ2 - What conflict management processes and procedures are commonly used in theSouth African construction industry?

RQ3 - What is the rate of success of early conflict resolution within the South African construction industry?

RQ4 - What is the level of training and education relating to conflict and dispute resolution within the South African construction industry?

RQ5 - What industry advancements can be introduced to improve conflict management in the South Africa construction industry?

\section{THEORY AND PRACTICE OF CONFLICT MANAGEMEMNT}

This differentiation between 'conflict' and 'dispute' is significant when referring to these issues in a construction context. It differs from the distinction commonly made in a conventional social context, where conflict is often noted as referring to longer-term more entrenched issues, while disputes are noted to be short-term issues readily resolved (Burton 1990). Ayodeji (2009 :2) describes construction disputes as: "...a manifest conflict - a form of conflict that comes to the awareness of parties involved and that requires a resolution. It is the activity dimension of conflict."

In the construction environment it is accepted that disputes arise from unresolved conflict and there is therefore a growing awareness that conflict should be better managed in order to prevent disputes (RICS 2012). The most commonly employed means of resolving construction conflict internationally remains via party to party negotiations. Bvumbwe and Thwala (2011) confirmed mediation as being widely used in the South African industry; however Povey (2005) identified that mediation in the South Africa context did not comply with the recognised mediation practices and principles. 
The examination of the failings of conventional legal processes spurred the creation of task forces such as that established in 1987 by the Construction Industry Institute in the USA, which set about answering Burger's (1982) question from a construction industry perspective. AAA (2009) noted a worsening negative construction environment, rife with conflict and mired in endless litigation. In the 1990's in the United Kingdom there was clear evidence that the industry was underachieving and similar task groups to that of the Construction Industry Institute (CII) were formed and produced influential reports such as the Latham Report (1994) and the Egan Report (1998).

\section{Managing construction conflicts}

The role of conflict management on projects is often considered a Project Management role, interrelated with the Project Manager's role of managing stakeholder relations. EC Harris (2012) reported that the unconstructive actions of project managers are often a negative influence in disputes; recognising the failure to act impartially, inadequate knowledge of contractual processes and insufficient authority, as the key issues. Rwelamila and Purushottam (2012) highlighted the failings in Project Management in Africa, supporting the submission by Ssegawa and Ngowi (2009) that most Project managers in Africa are not in their role by design. The lack of training to effectively manage conflict, or the perception that training in another role will provide the requisite skills to manage conflict, is primary a cause for the lack of success in this area (Pinto 1989). Some environments have seen far more marked improvements in other areas of construction, such as safety, quality and sustainability.

While not universally accepted, advances in these areas have been reported globally (for example, Rwelamila 2002; CIDB 2009). When making comparisons with improvements in these areas of the construction industry, it is notable that there has not been any significant reciprocal improvement or focus in the field of conflict management.

\section{Nature of construction disputes}

Botha (2000) observed that conflict should be managed to prevent its development into disputes. Effective conflict management can further avoid the breakdown of stakeholder relationships, prevent projects from suffering delays, address quality issues; and limit the expense of resolving disputes. What causes conflict in the construction industry, and why is the industry so exposed to conflicts and disputes? Smith (1992) noted the abundance of disputes within the industry, while Cheung and Suen (2001) supported the hypotheses that the very nature of the industry makes conflict unavoidable.

The complexity of construction disputes and the susceptibility of the industry to conflict have been reviewed for some time (Feldman 1972). Mitropoulos and Howell (2001) identified that a blend of 'environmental' and 'behavioural' issues often result in contractual difficulties. These can be exacerbated by further factors such as 'uncertainty' and 'opportunism'. The combination of these elements is often present in construction contracts. 


\section{Construction conflicts - causation}

Dalton and Shehadeh (1992) confirmed the causes of construction conflict reported internationally to be in line with those noted in Bvumbe and Thwala (2011), which ascertained the five leading causes of disputes in the South African industry as: Clients' failure or refusal to settle any claims brought on by the contractor; Use of improperly or poorly drafted contracts; Extension of time claims; Variations; and late completion.

Additional factors include the project type and complexity and the attributes of the dominant stakeholders (Revay 1992). It is a combination of these factors that contributes to 'the germination and manifestation' of construction disputes, the settlement of which may be hindered by the personalities of those involved in negotiations (Cheung, Yiu \& Yeung 2005). Bristow and Vasilopoulos (1995) further identified impractical expectancies as a key cause of conflict. This is particularly notable relative to contract programs, where at tender stage contractors are pressured into agreeing to impossible programs.

\section{Construction disputes resolution - current trends}

Jennings and Stebbings (2006) identified the failure to properly prepare dispute resolution provisions as a key issue and notes that the means of dispute resolution should be decided based on the specific project parameters.

This opposes the common reality, where what is in the standard contract is deemed sufficient or what has been used previously is simply inserted as an ADR provision (Zach \& Peters 2011). Levine (2009) reiterated the importance of carefully constructed contract documents as a means to avoid disputes. The importance of this underlines a key failing in commonly used ADR contract clauses, in that resolution by the parties is often given inadequate emphasis. At an industry round table review of construction dispute resolution practises, reported in AAA (2009), the advantages of early conflict resolution, addressing conflict before develops into difficult disputes, were reviewed. It is noteworthy that in 2007, with the myriad of ADR solutions available; the need to resolve conflict early, as a means to minimise disputes, was still widely supported. Clearly current practices are failing to address the issues (Cheung and Pang 2013) .

\section{The construction conflict cycle}

FFC (2007:13) identified construction conflict as a process, with a defined 'cycle' and notes the importance of the parties in understanding of this cycle, when addressing disputes. This is demonstrated to be applicable to most construction conflicts. Conflict crystallises when the difference between two or more parties becomes defined (Gerber and Ong 2013). In construction conflict this initial stage of conflict is often notable by the division of the parties and the development of an 'us v them' stance. Hart (1992) defines the conflict cycle as indicated in Table 1. 
Phases

(1) Anticipation - The expectation that conflict will arise.

(2) Wait and see - Once conflict arises parties take time to stand back assess the situation.

(3) Growing - Conflict can grow rapidly or can develop over an extended period.

(4) In the Open - At this stage resolution of the conflict can be reviewed.

(5) Application - Implementation of the resolution.

(6) Settlement - Agreement and conclusion.

(7) Refection - Analyzing the conflict.

Source: Hart (1992)

At this early stage conflict remains manageable and is often noted as being positive (Bercovitch and Langley 1993). However, left improperly managed conflict can enter a development' or 'growth' phase.

Fenn and Gameson (1992) suggested that the use of standard forms of contract in construction produced repeated conflict, similar in nature and progression. The parties become more entrenched in their positions and communication becomes more strained. In construction conflicts this is noted to be a key stage, as conflict can be noted to rapidly escalate during this phase.

Where there is a failure to address conflict, it escalates into a dispute which inevitably required the inputs of a third party to resolve (John and Srivastava 1999). Where resolution is achieved the final phase is 'settlement of the conflict', which in construction conflict may often involve the implementation of an agreed solution or 'way forward.' Where conflict develops into dispute, the settlement may come via alternate dispute resolution or litigation; but it will undoubtedly come at a far greater expense to the parties and the project.

\section{The South African perspective}

The South African industry has certainly not been spared from the global phenomenon of construction disputes, and this is perhaps worsened by the prevalence of corrupt practices in the industry (Bowen et al. 2007). Abundant research has focused on the need to address and avoid conflict (Smith 1992). Considerable focus in this area has remained in the use of ADR or Alternate Dispute Resolution methods (Cheung and Suen 2002).

Bvumbwe and Thwala (2011) identified the pervasiveness and types of ADR commonly employed in the South African construction industry, identifying mediation as a popular ADR process; supporting the findings of Povey (2005). This trend differs from several international markets, such as the United Kingdom, where although mediation is used and is noted to be generally successful, statutory adjudication has developed into the most widely used form of ADR; seen by many to have replaced the more cumbersome arbitration process (Gaitskell 2005). Adjudication was demonstrated not to be a widely used process within the South African industry, but one that is gaining in popularity (Maiketso and Maritz 2012). The adjudication process and 
practices such as the appointment of Dispute Adjudication Boards, have existed for some time, and have sought to address disputes at an early stage, in order to minimise the impact of disputes on projects; particularly during the project construction phase (McKillop 2003).

\section{Summary}

There is a significant body of research that confirms both the pervasiveness of conflict within the SACI, but also the lack of adequate measures to manage conflict at the early stages of its development.

\section{RESEARCH METHODOLOGY - BRIEF}

The selection of the research methodologies took detailed account of the research requirements and any limitations that may be applicable to the collection of the required data. This enabled the selection of the research instruments and defined the scope of the research (Fellows and Liu 2008).

Two methods for collecting data were employed. Firstly, the theory and practice literature review briefly described above. The literature review allowed a thorough investigation of current and previous research into the study area and offered a good platform for the study. The second data collection method was a comprehensive questionnaire, which was hosted online. Invitations to partake in the survey were forwarded to a predetermined list of recipients, each participant in the South African construction industry. The survey targeted a range of participants, including contractors, developers, consultants, project managers and quantity surveyors. The research intended to evaluate the use of early measures employed to address conflict as it arises within the South African construction industry. The combination of the literature review and the conclusions drawn in that study and the results of the questionnaire, were rounded and variable research approach, which produced a consistent, complementary sequence of findings from which strong conclusions were extricated (Pettigrew 1997). The variability of the processes employed allowed for such a dynamic process, while the analysis of the results met the submission of Pettigrew (1997:340) that the analysis process should: "account for and explain the what, why and how of the links between context, process and outcomes."

\section{Research instrument - the questionnaire}

The questionnaire was designed as follows:

Introduction: The introduction provides respondents with a brief overview of the study and the detail of the researcher and the supervisor; submission date and highlights the anonymity of the respondents.

Section A: The questions were designed to establish data about the respondent and their participation in the construction industry. The area of the industry in which the 
responded was involved, the respondent's designation within the industry, length of service and level of education.

Section B: Insight into the respondent's general knowledge and understanding of conflict in the construction industry. The respondent's perception of conflict in the South African construction industry, noting its prevalence and cause. Additionally an examination of the respondent's views on key elements of construction conflict and answers to questions commonly raised by researchers in the field of construction conflict and dispute.

Section C: The respondent's knowledge of commonly employed dispute and conflict resolution and management processes.

Section D: Questions were designed to establish the respondent's level of training in the field of construction conflict management, their understanding of training needs, and their perspective on improvement in training in the field.

The questionnaire was sent to Construction companies registered by the South African Construction Industry Development Board (CIDB); Construction project managers registered by the South African Council for project and construction management professions (SACPCMP); public and private clients. Details of these respondents are given in the next section of this paper.

\section{RESULTS, SYNTHESIS AND ANALYSIS OF RESULTS}

The literature review enabled the comprehensive examination of conflict management in the construction industry, both internationally and within the South African environment. The analysis of the literature enabled the development of a research instrument as described in the preceding section. The questionnaire sought to attain data relating to conflict management within the South African construction industry to enable the research questions to be answer. The objective of this study was to review and analyze the Implementation of Early Conflict Management measures in the South Africa Construction Industry. This section, briefly presents the results of the research data obtained from the research instrument, in a manner, which enables the extrapolated data to be analyzed to answer the research questions. Detailed results and synthesis and analysis of results are described elsewhere (Brown \& Rwelamila 2013).

The questionnaire was forwarded to a large number of potential respondents, representing six construction industry stakeholder groups in South Africa. The response, while considered low, was adequate to enable sufficient data to be extrapolated to meet the requirements of the study. The data obtained was evaluated and applied to address the research questions. Importantly there was a cross section of respondent groups which enabled a more thorough and detailed study results. Survey questions sought to examine the respondent's knowledge of, and experience with, the subject of construction conflict management, and to present the responses in a manner that could provide valid 
data with which to address the requirements of the study. As indicated above, only summaries of results are provided in this paper due to lack of space and brevity.

Table 2 summaries the questionnaire target population and the randomly selected sample from each stakeholder group; and identifies the response rate for each group.

Table 2: Questionnaire response analysis

\begin{tabular}{|c|c|c|c|}
\hline Description & Randomly Selected From & $\begin{array}{l}\text { Total Number of } \\
\text { registered } \\
\text { organisations or } \\
\text { individuals }\end{array}$ & $\begin{array}{l}\text { Randomly } \\
\text { selected sample }\end{array}$ \\
\hline Large Scale Contractors & CIBD Membership Register & 177 & 60 \\
\hline Medium Sized Contractors & CIBD Membership Register & 1273 & 60 \\
\hline Project Managers & $\begin{array}{l}\text { SACPCMP Membership } \\
\text { register }\end{array}$ & 633 & 60 \\
\hline \multirow[t]{3}{*}{ Clients } & SAPOA Membership & 1200 & 30 \\
\hline & SALGA Membership & 278 & 30 \\
\hline & South African Parastatal list & & \\
\hline \multirow[t]{2}{*}{ Consultants } & SAIA Membership & 2094 & 60 \\
\hline & CESA Membership & 908 & \\
\hline Quantity Surveyors & ASAQS Membership & 1000 & 40 \\
\hline
\end{tabular}

Source: Brown \& Rwelamila (2013)

\section{Answering research question}

RQ1 - Are early conflict management procedures or processes routinely used in the

South African construction industry as a means to prevent disputes?

As is shown in detailed analysis or results (Brown and Rwelamila 2013), early conflict management (ECM) as a formal process is not well understood or implemented in the South African construction industry. ECM processes are not routinely used and there is a perception that industry participants rely more on established alternative dispute resolution (ADR) processes to deal with conflict; in a high percentage of cases, after it has developed into a dispute. It was also demonstrated that conflict was not often addressed in the project startup process; and construction conflict in South Africa remains poorly managed and this strongly suggests that early conflict management procedures or processes are not routinely used.

RQ2 - What conflict management processes and procedures are commonly used in the South African construction industry?

Several standard ADR processes such as arbitration, adjudication and mediation were noted to be employed as ECM measures. Mediation was found to be the most widely employed process, while conciliation and negotiation were also noted to be somewhat successfully employed as ECM processes; however formal conflict management processes remain limited. 
RQ3 - What is the rate of success of early conflict resolution within the South African construction industry?

There was a clear level of disparity between the stakeholder groups regarding the success of early conflict resolution in the South African industry. The client-side parties, the Client/Project Manager/Consultant/Quantity Surveyor cohorts, were noted to be more positive regarding the outcome of conflict management processes, while the Contractor cohorts, were less positive. Overall, there was a strong indication that formal Early Conflict Management processes are seldom or successfully employed in the South Africa industry. To a notable extent, processes such as mediation, conciliation and negotiation were found to be successfully applied to address conflict, however overall the success of early conflict resolution in the South African industry remains limited.

RQ4 - What is the level of training and education relating to conflict and dispute resolution within the South African construction industry?

The study indicated that the level of training relating to conflict or dispute resolution in the South African industry was relatively low, with formal training specific to conflict or dispute management being limited. It was notable that the Project Manager cohort had a higher frequency of training in this area and incongruously, the Contractor groups had a lower level of training. The greater percentage of the training noted was as part of a higher education study program and not specific to conflict management.

RQ5 - What industry advancements can be introduced to improve conflict management in the South Africa construction industry?

The study revealed that formal Early Conflict Management processes were seldom employed and that the industry relied more greatly on standard ADR processes. The formalization of Early Conflict Management processes employing ADR processes noted to be successful in addressing conflict in the South Africans construction industry, such as mediation, conciliation, or negotiation; combined with improved training for project participants, in particular those noted to be likely to be involved in conflict, would bring improvements to conflict management in the industry. Processes should be routinely addressed and incorporated in the project procurement phase. The project participants should clearly understand their role in addressing conflict. The ECM process should be implemented as early in a conflict situation as possible, ensuring that the correct stakeholders are included in the resolution process.

\section{Summary research outcome}

As with most construction industries, conflict is noted in the South African industry to be widespread and not effectively managed. In contracts, conflict management is seldom properly planned for and when it arises, it is often left to escalate, until a dispute crystalizes and Alternate Dispute Resolution measures are applied to address it. A key influencing factor in this is the lack of training with regards to conflict management. 


\section{CONCLUSIONS AND RECOMMENDATIONS}

The central goal of the study briefly reported in this paper was to gather data which would enable the research questions formulated from the research statement to be validly addressed. The literature review and the study questionnaire enabled the presentation of results relative to the study and these results were analyzed in detail in Brown and Rwelamila (2013). This section provides a summary of conclusions determined from the synthesis and analysis of the research results and identifies recommendations for the South African construction industry and recommendations for possible future research into the study area.

\section{Conclusions}

\section{Construction conflict resolution}

In the modern construction era, the suggestion that personnel could enter a construction site, even one of moderate size, without having at least a basic level of training relative to safety, is unthinkable. For construction supervisors not to possess an adequate knowledge, understanding and in many cases education in safety management, would be considered in many markets to be implausible. Such factors relating to construction safety have not been applied for an extensive period and the past twenty years has seen notable and substantial improvements in the area of construction safety. These advances have been, in many cases, driven by government intervention including considerable statutory support and a focus on grass roots training.

\section{Selecting early conflict management measures}

Conflict management is not regularly addressed in the project procurement or start up phases. Terms in standard forms of contract are most often considered to be adequate to address conflict as it arises. When drawing comparisons once again with construction safety procedures, it is notable that at project start up phases, there is a deliberate and sustained focus on safety, with a bespoke safety management plan often being required for projects, and risk assessments and method statements being regularly applied tools to management construction safety. Despite the prevalence of construction conflict and the adverse effect of such conflict on the industry, there is rarely any reciprocal focus on conflict management during early project phases.

\section{Construction conflict in the South Africa context}

The study concluded that in line with international trends, conflict on South African projects most often arose on sites. While a substantial percentage of conflict was noted to escalate into disputes, there was a noteworthy finding that to a reasonable degree, conflict was often effective addressed and resolved.

\section{Construction conflict - training for success}

The research identified that adequate training in conflict management, both internationally and in the South African environment was rare and that there are few reported prerequisites for industry participants to undertake such training. Considering the enormity of the problem and the apparent difficulties in finding 
satisfactory means to address the challenges posed by construction conflict, improvements in training conflict management is noted to be an obvious requirement. This is hampered by the lack of availability of such training. Where industry participants are noted to have training in conflict management, it is determined that such training is predominantly as a secondary unit of a related subject.

\section{Stakeholders role in conflict resolution}

There is a notable lack of concurrence in agreeing which stakeholders have a role to play in addressing and resolving construction conflict. The hesitance of industry participants to become embroiled in conflict once it has developed is determined to be a factor in the regular escalation of conflict into dispute. Defining the conflict management process in the project startup and improving the skill levels of industry participants, particularly those predominantly located in environments where conflict is most often noted to develop, will bring about substantial advancements.

\section{Recommendations}

\section{Construction conflict - facing up the challenge}

Planning to deal with the problem should it arise, is essential and the reliance on standard contract clauses to provide the means to address conflict is seldom effective. Early Conflict Management should be planned to be project specific, taking account of the particular features of the project, and the characteristics of the project stakeholder group. Such planning should be seen as a positive step in the best interest of the project and the project participants.

\section{Training to acquire knowledge base in conflict management}

The skills which stakeholders possess to ensure that they are able to effectively deal with conflict are seldom questioned. Training in conflict management is not often noted to be a requirement for any construction personnel. Increased and better-quality training in conflict management would certainly bring improvements, and the industry should take steps to develop and encourage such training.

\section{Focus on 'conflict' and not 'dispute'}

The construction industry is notably focused on dispute resolution rather than conflict resolution, and research in this filed is extensive. However, this concentration on dispute detracts from conflict resolution and the industry should give greater emphasis to addressing conflict. Such a revised focus can reduce conflict, or ensure that it is resolved before becoming a dispute.

\section{Future research}

Conflict Management Processes - the focus on Alternate Dispute Resolution measures has detracted from the development of processes specific to resolving conflict and not dispute. A study reviewing the development of processes designed to be applied as Early Conflict Management measures would be beneficial.

Addressing Conflict in Early Project Phases - conflict Management is often seen as a negative issue and a focus on the topic in the early project stages is therefore often 
overlooked, with parties considering the standard contract clauses to be sufficient in dealing with the matter. A study assessing the inclusion of conflict management measures in project start up processes would be constructive.

Training for Conflict Management - training is a significant aspect of conflict management and one often disregarded. A study evaluating such training in the industry, investigating the prevalence and availability of such training would

\section{REFERENCES}

- $\quad$ AMERICAN ARBITRATION ASSOCIATION (2009) The Construction Industry's Guide to Dispute Avoidance and Resolution, Accessed 5th May 2015 at: $<$ http//:www.adr.org/aaa.

- AYODEJI, A.A. (2009) Reducing Disputes in Construction Claims: The Role of the Decision-Making Process. AACE International Transactions, CDR.S02.1 to CDR.S02.19.

- BERCOVITCH J. and LANGLEY J. (1993) The Nature of the Dispute and the Effectiveness of International Mediation, Journal of Conflict Resolution, 37(4), pp. 670-691.

- BOTHA, H. (2000) Conflict in the Construction Industry. Bellstone Training (International) Limited, London.

- $\quad$ BOWEN, P., AKINTOYE, A., PEARL, R and EDWARDS, JP (2007) Ethical behaviour in the South African construction industry, Construction Management and Economics, 25, pp. 631-648.

- BRISTOW D. and VASILOPOULOS R. (1995) Facilitating Dispute Resolution of Construction Projects, Construction Law Journal, 11(2), pp. 95 to 117.

- BROWN, H.J. and MARRIOTT, A.L. (1999) ADR Principles and Practice (2nd ed.), Sweet and Maxwell, London.

- BROWN, S and RWELAMILA P. D. (2013) Review \& Analysis of Early Conflict Management in the South African Construction Industry (SACI), Unpublished research report, Graduate School of Business Leadership, University of South Africa.

- BURGER, W.E. (1982) Isn’t there a batter way? American Bar Association Journal, Volume 68 page 274. Burton, J.W., 1990, Conflict: Resolution and Prevention, Macmillan, London.

- $\quad$ Burton, J. (1990) Conflict: Resolution and prevention. New York: St. Martin's Press.

- BVUMBWE, C and THWALA, D.W. (2011) An exploratory study of dispute resolution methods in the South African construction industry, International Conference on Information and Finance, IPEDR, volume 21, IACSIT Press: Singapore. Viewed 2nd April 2014 at: < https://ujdigispace.uj.ac.za/handle/10210/10446>.

- CHEUNG, S. and SUEN, H.C.H. (2002) A multi-attribute utility model for dispute resolution strategy, Construction Management and Economics Journal, 20, pp. 557 - 568.

- CHEUNG, S. and PANG, K. (2013) Anatomy of Construction Disputes, Journal of Construction Engineering and Management, 139(1), pp. 15-23.

- CHEUNG, S.O., YIU, T.W., and YEUNG S.F. (2005) A Study of Styles and Outcomes in Construction Dispute Negotiation, Journal of Construction Engineering and Management, 132(8), pp. 805 to 814.

- CONSTRUCTION INDUSTRY DEVELOPMENT BOARD (CIDB) (2009) Annual Report 2008-2009, CIDB, Pretoria.

- DALTON, D. and SHEHADEH, N. (1992) Statistical modelling of claim procedures and construction conflicts, Proceedings of the first international conference on construction conflict: Management and Resolution. Manchester: UMIST, pp. 276-88.

- $\quad$ EC HARRIS BUILT ASSET CONSULTANCY (2013) Global Construction Disputes: A Longer Resolution, viewed 8th April 2014 at $<$ http://www.echarris.com/pdf/EC\%20Harris\%20Construction\%20Disputes\%202013Final.pdf $>$ 
- EGAN, J. (1998) Rethinking Construction: Report of the Construction Task Force, London: HMSO.

- EL-ADAWAY, I.H. and KANDIL, A.A. (2010) Multiagent System for Construction Dispute Resolution (MAS- COR), Journal of Construction Engineering and Management, 136(3), pp. 303 to 315 .

- FEDERAL FACILITIES COUNCIL (FFC) (2007) Reducing Construction Costs: Uses of Best Dispute Resolution Practices by Project Owners, Federal Facilities Council Technical Report 149, National Academic Press, Washington.

- FELDMAN, M. (1972) A Contractor looks at the Causes of Construction Contract Disputes, The Arbitration Journal, 27(3), pp. 145 to 168.

- FELLOWS, R. (1992) Karming conflict, Proceedings of the UMIST Conference (no more details)

- FELLOWS, R. and Liu, A. (2008) Research Methods for Construction. 3rd edition, Chichester: John Wiley and Son.

- FENN, P. and GAMESON, R. (1992) Construction Conflict Management and Resolution: Proceedings of the First International Construction Management Conference, Manchester, Spon press, Abingdon.

- FUlbright, R. C. and JAWORSKI, L. P. (2006) The Third Annual Report of the LTSF, Report No. 3, Litigation Trends Survey Findings LTSF 11-12. Accessed 8th April 2014 at http://aryme.com/docs/adr/2-2-1018/informe-fulbright-2006-fulbright-jaworskilitigation-survey.pdf.

- GAITSKELL, R. (2005) Trends in Construction Dispute Resolution, Society of Construction Law, London. Gardiner, P.D. and Simmons, J.E.L., 1992, Analysis of conflict and change in construction projects, Construction Management and Economics, 10, pp. 459-78.

- GERBER, P. and ONG, B.J. (2013) Best Practice in Construction Disputes, Lexis Nexis:

- GROTON, J.P. and LAWRENCE, K.C. (2010) Real Time prevention and resolution of construction disputes: varieties of standing neutral and what they do, Dispute Resolution Journal, 65(3), pp. 128-133.

- HART, R.R. (1992) Improving Your Chance of Success during Construction Mediation, Arbitration Journal, December issue, pp. 14 to 20.

- HELlaRD, R. (1992) Construction conflict: management and resolution, Proceedings of the first international conference on construction conflict: management and resolution. Manchester: UMIST, pp. 39-46.

- JENNINGS J. and STEBBINGS S. (2006) International Construction: Dispute Resolution Comes in Tiers. Kluwer Law International, The Netherlands.

- JOHN, O. P., \& SRIVASTAVA, S. (1999) The big five trait taxonomy: History, measurement, and theoretical perspectives. In L. Pervin \& O. John (Eds.), Handbook of personality: Theory and research (pp. 102-138). New York: Guilford.

- LATHAM, M. (1994) Constructing the Team, London: HMSO.

- LEVINE, J. (2009) Constructing the Construction Case: Tips, Traps and Tricks, Dispute Resolution Journal, August/October issue, pp. 62 - 72.

- LEWIS, J., CHEETHAM, D and CARTER, D. (1992) Avoiding conflict by risk management - the role of the client's Project Manager. Proceedings of the first international conference on construction conflict: management and resolution. Manchester: UMIST pp.72-94.

- MAIKETSO, N.C. and MARITZ, M.J. (2012) Adjudication as an alternative dispute resolution method in the South African construction industry, Journal of the South African Institution of Civil Engineering, 54(2), pp. 65-70.

- MCKILlOP, A. (2003) Dispute Review Boards Help Settle Disputes During Construction. AACE International Transaction, Accessed 12th April

2015 at, $<$ http://connection.ebscohost.com/c/articles/52475933/pros-cons-using-disputereview-boards 
- Mitropoulos, P. and HOWELL, G. (2011) Model for Understanding, Preventing and Resolving Project Disputes, Journal of Construction Engineering and Management, 127(3) pp.223 to 231 .

- PANAGIOTIS, M. \& HOWELL, G. (2001)Model for understanding, preventing and resolving project disputes", Journal of Construction Engineering and Management, 127(3), pp. 223-231.

- PETTIGREW, A.M. (1997) What is Processual Analysis? Scandinavian Journal of Management, 13(4), pp.337-348.

- PINTO, J.K. (1989) Critical factors in project implementation: a comparison of construction and R\&D projects, Technovation, 9(1), pp. 49-62.

- POVEY, A.L. (2005) An investigation into the mediation of disputes in the South African construction industry, Journal of the South African Institution of Civil Engineering, 47 (1), pp. 2-7.

- REVAY, S.G. (1992) Can construction claim be avoided? Proceedings of the first international conference on construction conflict: management and resolution. Manchester: UMIST, pp. 202-208.

- REVEll A. and BLACKBURN R. (2007) The business case for sustainability? An examination of small firms in the UK's construction and restaurant sectors, Business Strategy and the Environment, 16 (6), pp. 404-420.

- RWELAMiLA, P.D. (2002) Creating an Effective Construction Industry Strategy for South Africa, Building Research and Information, 30 (6), pp.435 to 445.

- RWElamila, P.D. and PURUShOTTAM, N. (2012) Project Management Trilogy Challenges in Africa - Where to From Here? Project Management Journal, 43(4), pp. 5-13.

- SMITH, M. (1992) Facing up to conflict in the construction industry. Proceedings of the first international conference on construction conflict; management and resolution, Manchester: UMIST, pp. 27-34.

- SSEGAWA, J.K., \& NGOWI, A.B. (2009) Challenges in delivering public construction projects: A case of Botswana. Germany: Lambert Academic Publishing.

- YIU T.W. and CHEUNG S.O. (2007) Behavioral Transition: A Framework for the Construction Conflict- Tension Relationship, IEEE Transactions on Engineering Management, 54 (3), pp. 498-505. 


\section{Theme 3 Infrastructure Development and Management}

1. An Evaluation Of Factors Influencing Compliance Of Construction Professionals To Ethical Standards

2. An Exploration Of Malaysian Public Listed Companies Diversifying Into Property Development

3. Beneficiary Housing Participation Defined - A South Africa Perspective

4. Environmental Impact And Energy Management Of Sports Stadia

5. Performance In Use: The Great Externality Of The Built Environment

6. Leveraging Concepts For Environmentally Sustainable Business Management In Construction - A Focused Review

7. Innovation In Offsite Manufacturing In The Field Of Housing: A Case Study Using Bourdivian And Actor-Network Approaches

8. Exploring Knowledge Management Principles For Decision-Making In Low-Energy Building For Sustainability In Construction

9. Towards An Adaptability Rating For Buildings

10. Improving Housing Quality Through Client-Focused Information

11. Knowledge In The Decision-Making Process For Sustainable Renovation Of Multifamily Houses

12. Lessons For Specifying The System Boundaries Of An Asset Management Plan From Four Case Studies Of Failure

13. Reducing The Environmental Impact And Improving The Efficiency Of Construction Transport 


\title{
AN EVALUATION OF FACTORS INFLUENCING COMPLIANCE OF CONSTRUCTION PROFESSIONALS TO ETHICAL STANDARDS
}

\author{
Adeyinka, B. F. ${ }^{1}$; Jagboro, G.O. ${ }^{2}$ and Ojo, G.K. ${ }^{3}$
}

\begin{abstract}
:
Physical infrastructure built through construction activity is the nation's economic backbone as it forms the arteries for the facilitation of productive activity by enabling goods and services to be distributed within and outside the country (Hillebrandt, 2000). The industry contributes between 5 and 10\% of gross domestic product (GDP) in all countries, employs up to $10 \%$ of the working population and also responsible for about half of the gross fixed capital formation as established (Lopes, 2012). Empirical studies have established that the industry is tainted with various unethical practices which span over project owners, funding agencies or sponsors, consultants, contractors, subcontractors etc (Tahir and Amjad, 2013). Common unethical practices that combat with economic growth include corruption, bid shopping, front end loading, conflicts of interests, cover pricing, payment game, compensation of tendering costs and negligence, collusive tendering, bribery, professional negligence, fraudulent behaviour, unfair conduct and a breach of professional responsibilities among architects, quantity surveyors, consulting engineers and contractors (Pearl, et al., 2007 and Tahir and Amjad, 2013). The nature of the industry have created many complex linkages between the industry and other sectors of the economy (Ofori, 2012). Construction professionals should therefore have the sole responsibility to discharge their duties with utmost care and diligence. These can be achieved by seen a need for heightened standards of ethics for construction professionals who among others are architects, quantity surveyors and engineers because their actions can have effects on lives and properties of the general public. Therefore, ethical behaviour of construction professionals is essential for an industry that have been negatively stigmatized with poor ethical conducts (Tow and Loosemore, 2009).
\end{abstract}

RICS (2000a) identified nine core values as a set of moral principles expected to resolve professional ethical issues that can arise among the professionals, the client as well as the wider community. The codes on their own are not effective and no amount of control measures put in place can eradicate unethical behaviour if the people concerned are not willing to comply. There is a wide gap between theory and practice which show that there are factors that tend to influence compliance of construction professionals either positively or negatively to the established ethical standards (Knight and Morledge, 2005). In order to therefore protect the image of the industry, construction professionals should inculcate vital ethical standards and highest working standards to safeguard the reputation of the industry (Izzo, 2000). The menace of malpractices in construction sector can be curbed if the factors influencing compliance can be determined and worked upon. This needed urgent attention to optimally utilize the resources for the developmental works. Against this background, this paper seeks to establish an empirical study examining the factors influencing construction professionals' compliance to ethical standards with a view to improving ethical standards among the construction professionals.

\section{KEYWORDS: PROFESSIONAL ETHICS, CONSTRUCTION INDUSTRY, COMPLIANCE; ETHICAL STANDARDS}

\footnotetext{
${ }^{1}$ Department of Quantity Surveying, Obafemi Awolowo University, Ile-Ife, Nigeria. (corresponding author) funmilola20074life@yahoo.com

${ }^{2}$ Department of Quantity Surveying, Obafemi Awolowo University, Ile-Ife, Nigeria. graceo2010@yahoo.co.uk

${ }^{3}$ Department of Quantity Surveying, Obafemi Awolowo University, Ile-Ife, Nigeria. giagboro@yahoo.com
} 


\section{PROFESSIONAL ETHICS: PREVIOUS RESEARCHES EXAMINED}

Adeyinka, Jagboro and Ojo (2015) examined the level of usage of mechanisms for enforcement of ethical standards. The study found that individual related mechanism is the frequently used mechanism for enforcement of ethical standards in which the success of other mechanisms rely on. Ho (2011) investigated the ethics management for the construction industry. Findings showed that to develop an appropriate ethical decisionmaking relationship between individuals; situational/organisational, moral intensity and employees' must be determined. Dabson, Kenney, Flimmer and Waters (2007) in UK established that ethics is very subjective and what some consider being wrong and right are be very different. However the subjectivity, there should be standards in which the professionals should strictly follow. Hamzah, Saipo, Mohd, Mohammed and Yap (2007) in Malaysia investigated the correlation between the quality of construction works and professional ethics. Findings revealed that unethical practices displayed by construction professionals had adverse effect on the quality of construction works executed by the professionals. In addition to these, Tow and Loosemore (2009) identified 27 factors affecting ethical behaviour of construction professionals to include absence of ethics training programs, absence of reward systems for those who act ethically within the industry among others. Gbadegesin and Ojo (2011) only concentrated on property management and found that lack of ethical standards have eroded the significance of property management. From related completed researches, there are limited empirical studies against factors influencing compliance of construction professionals to ethical standards, which forms the gap filled by this paper.

\section{Factors Influencing Construction Professionals' Compliance to Ethical Standards}

From the literature, factors affecting ethical behavior included; individual, leadership, systems and procedures, structure and institution, cultural factors, legislations, system and work procedure, noble values and ethics, code of ethics, recognition, internal control. Other factors include individual, values in society, government roles and organizational practices as different spheres of ethical values and action which interact and reinforce each other (Lawton, 2005). Furthermore, to raise awareness of corporate and individual responsibilities in construction industry, the prerequisite aspects of professional education training, leadership, organizational systems and decision processes, auditing, controls, and penalties were outlined (Paine, 1994).

Fan and Fox (2009) established that when making ethical decisions, one's self, family and legal requirements were factors influencing decision making that must be taken to protect public interest. Individual knowledge and professional training have ethical implications and implies responsibility. Religious and moral education breeds and enhances individual knowledge which is a constitutive aspect of all social selforganization. In social systems, individual values, norms, conclusions, rules, opinions, 
ideas and beliefs can be seen as individual knowledge (Fuchs and Hofkirchner, 2005). Also, professional education and training were always been a major concern for our society, especially for academics and professional practitioners. There have been a dramatic increase in the interest in ethics as applicable to the construction industry which has always made ethics-related course to be an integral part of both the undergraduate and professional curriculum. Focus and awareness on the application of applied professional ethics in relation to the construction education program should be emphasized. Professional value, integrity and competence of construction professionals are developed during professional educational training in universities and tertiary institutions. Chan and Chan (2002) and Mohamad, Abdul Rahman, Usman and Tawil (2015) echoed that improving ethics in the industry should start from the way the professionals are educated. Process of learning ethics should not stop at colleges/universities but should continue during the professionals' working life.

Researchers have argued that the roles of organization and the influence of the industry cannot be over emphasized. Effective leadership in the organization articulates a vision that includes ethical principles, communicate the vision in a compelling way and demonstrate consistent commitment to the visions of the organization over time. Leadership is required to develop a culture where ethics and practice can evolve. Good leadership combined with integrity have positive impact on subordinates which ultimately improve effectiveness of the industry. Organizational influence get employees respond positively to the moral values and obligations (Mohamad, et al. 2015). For good project performance, managers must be honest, display integrity while the clients' interest are protected (Dainty, Cheng, and Moore 2003). Organizational ethics should be designed in accordance to the acceptable norms of both the business environment the general public and the culture of the state and the country where the business operate (Svensson and Wood, 2004). The system/procedure of the industry are means by which things are done by the professionals which is a key trust for upgrading ethics in the construction industry. Improvement on the existing industry practices and the procedure ultimately affect the performances of the professionals. One of the ways in dealing with ethical conflicts is fair treatment especially during recruitment and selection. Employers should check out for individuals who not only subscribe to the corporation's values but also values ethical standards (Townley, 1994). Ethical values should be evaluated among candidates along with other criteria in making selection as well as in promotional exercises. Contribution on values and behavior should be measured as well as employee's technical competence for performance assessment. Palalani (2000) emphasized that to ensure acceptable quality in industry, there should be insistence on enforcement of standards inform of monitoring strict adherence to specifications or building codes. Also, benchmarking as a tool provide means of monitoring progress of ethical behavior towards quality improvement.

The influence of government regulations and professional regulatory bodies are highly essential in controlling unethical practices. Lawton (2005) noted that to ensure uniformity in delivery, professionals must regulate themselves and support a performance-oriented culture. For long-term vision in the industry, Fox and Skitmore (2003) reflected the crucial role of government on behavioral pattern of the construction stakeholders through 
legislation and regulation. This can be inform of legality, for instance, in a case when a client asks a professional to act illegally, this can affect both the professional and the organizations' in which their license can be in jeopardy. However, when the industry is bound by a piece of regulations, unethical actions are rejected out rightly. (Holian, 2002). However, organizations have a duty to their shareholders in protecting public interest. Their ethical orientation is on the interests and needs of individual clients, their immediate colleagues and ultimately to make money. The ethical reasoning of managers should focus on the citizen, the public or the profession (Lawton, 2005). Also, professional bodies have great impact in influencing construction professionals. Satisfaction and accountability displayed by the duo are essential both as an example and for effectiveness in the construction industry. Velayutham and Perera (2004) noted that sense of accountability imbibed from professional bodies is a rational practice to ensure responsibility. Accountability should be implemented in all civil societies, economic institution and organizations and those who exercise the power of government or corporate office must be publicly accountable for their actions. Measurement of effectiveness by using key performance indicators and benchmarking are strategies to achieve excellence by the government construction client. There is a clear spread of benchmarking worldwide and across various industry sectors and organizational sizes (Jarrar and Zairi, 2000). Datta (2000) affirmed that the industry has no objective process for auditing clients' satisfaction which are expected to be echoed by the professional associations. A client uses customer satisfaction as an important performance indicator of professional services by construction consultants but this has not been given the necessity it deserved nor accorded the required importance by the professionals. Government can influence ethical standards by becoming involved continually in the process of tendering, project construction and delivery right from the inception of the contract till completion. These could be achieved through involvement and active participation in procurement practices, monitoring techniques and accounting procedures as established by Holt and Rowe (2000). Contractors who are technically competent both in manpower, personnel and ethical virtues should be selected for a long-term sustainability (House of Commons, 2001). Conclusively, fifty-one (51) factors from those identified from the literature were used for the purpose of assessment by the respondents for this research.

\section{RESEARCH METHODOLOGY}

The study assessed the factors influencing compliance of construction professionals to ethical standards. The study was carried out in Southwestern Nigeria using Lagos State due to the concentration of construction firms in the state Fagbemi (2008). The research employed questionnaire as data collection method administered on seven (7) construction professionals namely; Architects, Builders, Quantity Surveyors, Engineers, Estate surveyors, Town planners and Land surveyors. Responses from these professionals are expected to validate and strengthen the research findings. Total of two hundred and seventy (270) questionnaire was administered with only one hundred and ninety-three (193) suitable for analysis out of the two hundred and thirty four (234) retrieved. Thus the response rate represented by $64.07 \%$. The respondents rated the significance and the level 
of ethical compliance of professionals on likert scale where $5=$ most significant and $1=$ not significant. Method of data analysis was factor analysis.

Table 1: Result of Demographical Information of Respondents

\begin{tabular}{|c|c|c|c|c|}
\hline \multicolumn{5}{|c|}{$\begin{array}{l}\text { Type of Organization } \\
\text { Percentage }(\%)\end{array}$} \\
\hline Contracting & 66 & \multicolumn{3}{|l|}{$34.19 \%$} \\
\hline Consulting & 71 & \multicolumn{3}{|l|}{$36.78 \%$} \\
\hline Government & 43 & \multicolumn{3}{|l|}{$22.27 \%$} \\
\hline No response & 13 & \multicolumn{3}{|l|}{$6.73 \%$} \\
\hline Total & 193 & \multicolumn{3}{|l|}{$100 \%$} \\
\hline \multicolumn{5}{|c|}{ Year of Establishment of Firms } \\
\hline Years of Firms & Frequency & Mid-Point & $\mathbf{F x}$ & Percentage $(\%)$ \\
\hline $0-10$ years & 32 & 5 & 160 & 16.58 \\
\hline $11-20$ years & 57 & 14.5 & 826.5 & 29.53 \\
\hline 21-30 years & 41 & 24.5 & 1004.5 & 21.24 \\
\hline $31-40$ years & 25 & 44.5 & 1112.5 & 12.95 \\
\hline 40yearsand above & 23 & 40 & 920 & 11.91 \\
\hline No response & 15 & - & - & 7.77 \\
\hline Total & 193 & & 4243.5 & 100.0 \\
\hline Mean $=21.9$ years & & & & \\
\hline \multicolumn{5}{|c|}{ Respondents Profession } \\
\hline Profession & Frequency & \multicolumn{3}{|c|}{ Percentage (\%) } \\
\hline Architect & 35 & \multicolumn{3}{|c|}{18.13} \\
\hline Builder & 26 & \multicolumn{3}{|l|}{13.47} \\
\hline Quantity Surveyor & 31 & \multicolumn{3}{|l|}{16.06} \\
\hline Engineer & 48 & \multicolumn{3}{|l|}{24.87} \\
\hline Town Planner & 18 & \multicolumn{3}{|l|}{9.32} \\
\hline Estate Surveyor & 17 & \multicolumn{3}{|l|}{8.80} \\
\hline Land Surveyor & 15 & \multicolumn{3}{|l|}{7.77} \\
\hline No response & 3 & \multicolumn{3}{|l|}{1.55} \\
\hline Total & 193 & \multicolumn{3}{|l|}{100.0} \\
\hline
\end{tabular}

Academic Qualification of the Respondents

\begin{tabular}{|c|c|c|c|}
\hline Professional Qualification & Frequency & \multicolumn{2}{|c|}{ Percentage (\%) } \\
\hline OND & 13 & \multicolumn{2}{|c|}{6.73} \\
\hline HND & 52 & \multicolumn{2}{|l|}{26.94} \\
\hline B.Sc./B.Tech. & 77 & \multicolumn{2}{|l|}{39.89} \\
\hline M.Sc. & 17 & \multicolumn{2}{|l|}{8.80} \\
\hline Ph.D & 9 & \multicolumn{2}{|l|}{4.66} \\
\hline PGD & 19 & \multicolumn{2}{|l|}{9.84} \\
\hline No response & 6 & \multicolumn{2}{|l|}{3.10} \\
\hline Total & 193 & \multicolumn{2}{|l|}{100} \\
\hline \multicolumn{4}{|c|}{ Professional Qualification of Respondents } \\
\hline \multicolumn{2}{|l|}{ Professional Qualification } & \multicolumn{2}{|r|}{ Percentage $(\%)$} \\
\hline \multicolumn{2}{|c|}{ Nigerian Institute of Architects (NIA) } & 31 & 16.06 \\
\hline \multicolumn{2}{|c|}{ Nigerian Institute of Builders (NIOB) } & 23 & 11.91 \\
\hline \multicolumn{2}{|c|}{ Nigerian Institute of Quantity Surveyors (NIQS) } & 29 & 15.02 \\
\hline \multicolumn{2}{|c|}{ Nigerian Society of Engineers (NSE) } & 43 & $22.27 \%$ \\
\hline \multicolumn{2}{|c|}{ Nigerian Institute of Town Planners (NITP) } & 16 & 8.29 \\
\hline
\end{tabular}




\begin{tabular}{|c|c|c|c|c|}
\hline \multicolumn{3}{|c|}{ Nigerian Institute of Estate Surveyors and Valuers (NIESV } & 14 & 7.25 \\
\hline \multicolumn{3}{|c|}{ Nigerian Institute of Surveyors (NIS) } & 12 & 6.21 \\
\hline \multicolumn{3}{|c|}{ Non professionally qualified } & 15 & 7.77 \\
\hline \multicolumn{3}{|c|}{ No response } & 10 & 5.18 \\
\hline \multicolumn{3}{|l|}{ Total } & 193 & 100 \\
\hline \multicolumn{5}{|c|}{ Respondents' Years of Experience } \\
\hline Years & Frequency & Mid-Point & $\mathbf{F x}$ & Percentage $(\%)$ \\
\hline $0-10$ years & 45 & 5 & 225 & 23.31 \\
\hline $11-20$ years & 54 & 14.5 & 783 & 27.97 \\
\hline $21-30$ years & 35 & 24.5 & 857.5 & 18.13 \\
\hline $31-40$ years & 26 & 44.5 & 1157 & 13.47 \\
\hline 40 years and above & 20 & 40 & 800 & 10.36 \\
\hline No response & 13 & - & & 6.73 \\
\hline $\begin{array}{l}\text { Total } \\
\text { Mean=19.80 years }\end{array}$ & 193 & & 3822.5 & 100 \\
\hline
\end{tabular}

Table 1 described the demographical information of the respondents. The respondents surveyed cut across different construction organizations which include consultancy (36.78\%), contracting (34.19\%) and government firms/ministries $(22.27 \%)$. The average years of establishment of respondents firms were approximated to be 22years; they consisted of professionals in the construction industry. They included Architects (18.13\%), Builders (13.37\%), Quantity Surveyors (16.05\%), Engineers(24.87\%), Town Planners (9.32\% ), Estate Surveyors $(8.80 \%)$ Land Surveyors (7.77\%). Also, most of them $(66.29 \%)$ had minimum of B,Sc/B.Tech, other academic qualifications included M.Sc. and P.hD degrees. The respondents surveyed belong to different professional bodies, which were Nigerian Institute of Architects, (16.06\%), Nigerian institute of Builders $(11.91 \%)$, Nigerian institute of Quantity Surveyors(15.02\%), Nigerian Society of Engineers(22.275\% ), Nigerian Institute of Town Planners(8.29\%), Nigerian Institute of Estate Surveyor and Valuers (7.25\% a), and Nigerian Institute of Surveyors $(6.21 \%)$. Respondents' years of experience indicated the average of 19 years professional experience. From the biographical information of the respondents, they were well represented by professional classifications, they had required educational and professional experience and qualifications to supply reasonable and reliable data for the study.

\section{Factor Analysis Test}

In order to know the major components from the fifty-one factors identified from the literature, the variables were subjected to factor analysis. These significant components factors were labeled with a generic name that were used to explain the factors influencing compliance of professionals to ethical standards. Kaiser - Meyer-Olkin (KMO) measure of sampling adequacy (MSA) was used to test the appropriateness of the factors extraction and Bartlett's test of sphericity. The result of the appropriateness of the tools was presented in Table 2 which showed that KMO was 0.970 . For factor analysis to analysis to proceed, value of a set of scores should be closer to 1 and measure of sampling adequacy should be greater than 0.5 (Field,2005). In addition, Bartlett's test of sphericity showed that the result was highly significant $(\mathrm{X} 2=1.705 \mathrm{E} 4, \mathrm{P}<0.05)$. Based 
on these, factor analysis is best suitable for the data collected for this study. In addition, principal components analysis was carried out on the factors affecting ethical compliance of professionals, starting with the original data matrix, this is from where principal factors were extracted after iteration of communalities. Each factor with an Eigen values grater that 1 was retained for the rotation. However, the three reduced components and items loaded under each principal components were presented in Table 3.

Table 2: KMO and Bartlett's Test

\begin{tabular}{|c|c|c|}
\hline \multicolumn{2}{|c|}{ Kaiser-Meyer-Olkin Measure of Sampling Adequacy. } & .970 \\
\hline Bartlett's Test of Sphericity & Approx. Chi-Square & $1.705 \mathrm{E} 4$ \\
\hline & Df & 127 \\
\hline & Sig. & \\
\hline
\end{tabular}


Table 3: Extracted Factors from Factor Analysis

\begin{tabular}{|c|c|c|}
\hline Components Factors & Loaded Items & Loading Variables \\
\hline Component Factor 1: Individual & Individual values & .797 \\
\hline Related Factors/professional & Personal goals & .809 \\
\hline \multirow{2}{*}{ training } & Family upbringing & .764 \\
\hline & Respect for human right & .754 \\
\hline \multirow[t]{12}{*}{$(\%$ of variance $=66.94 \%)$} & Good sense of social responsibility & .790 \\
\hline & Personal integrity & .822 \\
\hline & Self concept & .781 \\
\hline & Personal value system & .778 \\
\hline & Faith/religious beliefs & .730 \\
\hline & Education training/background & .705 \\
\hline & Professional membership status & .741 \\
\hline & Years of experience & 678 \\
\hline & Type of organisation & .760 \\
\hline & Age & 669 \\
\hline & Gender & 694 \\
\hline & Organisational codes of practice & .729 \\
\hline Component Factor 2: Government & Penal code & .573 \\
\hline Regulations and Professional & Professional bodies regulatory system & .563 \\
\hline \multirow[t]{2}{*}{ Regulatory bodies } & Anti corruption crusade & .574 \\
\hline & Penalty system & .584 \\
\hline \multirow[t]{14}{*}{$(\%$ of variance $=8.06 \%)$} & Legal administrative agencies & 668 \\
\hline & Societal values & .791 \\
\hline & Cultural values & .831 \\
\hline & Humanity values & .820 \\
\hline & Religious values & .839 \\
\hline & Societal status & .817 \\
\hline & Professional value & .757 \\
\hline & Respect for ones professional status & .825 \\
\hline & Professional codes of conduct & .833 \\
\hline & Employees performance review & .796 \\
\hline & Employment guidelines & .831 \\
\hline & $\begin{array}{l}\text { Employers awareness campaign against unethical } \\
\text { practices }\end{array}$ & .778 \\
\hline & Job security & .811 \\
\hline & Unsatisfied salary & .752 \\
\hline Component Factor 3: System and & Reward for exemplary character & .540 \\
\hline \multirow[t]{2}{*}{ Procedure of the Industry } & Condition of service & .560 \\
\hline & Remuneration/Motivation & .584 \\
\hline \multirow[t]{10}{*}{$(\%$ of variance $=2.85 \%)$} & Work environment influence & .522 \\
\hline & Superior and Boss relationship & .540 \\
\hline & Firmness of practice procedures & .576 \\
\hline & Justice delivery procedures & .662 \\
\hline & Sanctions on violators & 607 \\
\hline & Chain of communication in the system & 639 \\
\hline & Level of control from superior & .645 \\
\hline & Nature of job & .652 \\
\hline & Procurement processes & .665 \\
\hline & Clients category e.g government as a client & 639 \\
\hline
\end{tabular}

Note: Only items with factor loadings above 0.500 only were included in this table 


\section{INTERPRETATION AND DISCUSSION OF FINDINGS}

The first component factor was individual related factors/professional training which ; this represented $66.94 \%$ of the observed variance loaded with other sixteen (16) items. The factors included individual values, family upbringing and respects for human right, faith or religious beliefs etc. The least items were age and gender. This component factor indentified the roles of individual as regards compliance to ethical standards. The roles of individual can be traced to the family background, personal values and norms, educational training such person was exposed to. Each of these factors influences individuals' behavioral pattern, that will falls back on the industry at large. The resultant effect that will be reflected in their professional services. This is in conformity with Fuchs and Hofkirchner (2005) established that religious and moral education breed and enhance individual knowledge which is a constitutive aspect of all social selforganization. In social systems, individual values, norms, rules, opinions, ideas and beliefs can be seen as individual knowledge. Through education training in universities, professional values, integrity and competence of construction professionals are nurtured. Chan and Chan (2002). opined that educational training is not only important but equally inculcating ethical values into the professionals. Ethical values inform of morals define personal character, show how an individual should live in society and serve as code for individual survival. In fact, Kayne (2010) asserted that ethics are standards or codes of behavior expected by the group to which the individual belong for example they include nation, social, company, professional or even family ethics. Gibson (2011) was of the opinion that when personal values and moral are recognized by the professionals, protection of the public and environment will be highly essential in their professional services. Therefore this study agreed that individual related factors and professional training influenced compliance of individual professional to ethical standards.

The second component factor is government regulations and professional regulatory bodies with $8.06 \%$ of the observed variance, with eighteen (18) loading items. Among the items loaded include; penal code, professional regulatory system, employers guidelines, job security, professional codes of conduct, anticorruption crusade, employees' performance review. This shows that legislations and regulations have roles to play in influencing professionals either positively or negatively. Government at the realm of instituting laws and regulations for the stakeholders should influence them positively through different regulations put in place (Fox and Skitmore,2003). For example, anticorruption crusade, transparency initiatives can also be organized by the governments to encourage the stakeholders in acting ethically. Also, Holian (2002) affirmed the need for legality to be in action; when this is active and alive, punished professionals will serve good examples for others to say no to unethical actions. For example, firm justice inform of penal code, serves as warnings for professionals to abstain from unethical practices. This will invariably influence the professionals to comply positively with ethical standards. Also, code of practice is a code of professional responsibilities that must be implemented by the government in which failure to comply attracts penalties like suspension from practice, withdrawal of license or total expulsion from the professional bodies. According to Fan and Fox (2009), these will promote the awareness 
of social responsibility and public interest. However, in a situation where the rule of law is weak, corruption will thrive in such opportunistic environment which will results into unethical practices among professionals in the industry. Therefore, system of government administration must be fair and firm to administer justice as at when due, otherwise, if professionals acts contrarily.

The third major component factor is system and procedure of the industry with $2.85 \%$ of the observed variance with thirteen (13) loading items. The items included procurement processes, client category, justice delivery processes, remuneration and motivation, condition of service, firmness of practice procedures, level of control from superior and nature of job. The least loaded items were superior boss relationship, reward for exemplary character and work environmental influence. Key trust for upgrading ethics in the construction industry is to improve existing industry practices that ultimately affect performance. System of the industry should be firm and fair in tendering processes, project construction and delivery as well as fairness in justice delivery processes. In procurement practices, there is need for adequate control and monitoring. Holt and Rowe (2000) affirmed that there should be fairness in the award and procurements processes of contracts. Contracts should strictly be awarded only to qualified and experienced contractors not to relatives or family members that did not have experience in construction activities .Job security and unsatisfied salary goes hand in hand to determine the attitude of professionals to ethical standards either positively or negatively. An employer with sense of job security and good salary will not likely damage his reputation by acting unethically while an employer might act contrary if there is no sense of job security and good pay especially in an opportunistic environment. This can occur if especially approached by clients to acts unethically, e.g approving building plans not conformed to design standards, which could be harmful and be threats to life, or construction in danger prone zones. Organization constitutes a climate and a culture within which professionals operate. The system and procedures therefore, represent collective acceptances and operations of ethical norms adopted by the groups concerned and as such, constitute powerful influences over individuals' behavior. (Cohen 1993). Employers therefore have prevailing perceptions of organizational signals regarding norms in making decisions which have moral components. Also, employments guidelines must be designed to guide the conducts of their employees which makes the employees understand the goal and dos and don'ts of the company. Velayutham and Perera (2004) opined that accountability is a practice to ensure responsibility by individuals and institutions, which should be implemented among other civil societies, economic institution and organizations. This gives the sense of accountability to all professionals as it guides their daily activities.

In addition, the work environmental influence is important. System and procedures of the industry should focus on clients' satisfaction. The professionals should note that the industry is interested in clients' priorities as affirmed by Datta (2000) that the industry has no objective process for auditing clients' satisfaction. Client satisfaction should be monitored because it is a good performance indicator of professional services delivered by construction consultants used by clients. Also, setting standards and benchmarking for practicing the profession improves compliance. These conformed to Jarrar and Zairi 
(2000) that industries should adopt a clear spread of benchmarking worldwide and across various industry sectors and organizational sizes. The least loaded item was reward for exemplary character. Tow and Loosemore (2009) confirmed that absence of reward systems for those who act ethically within the industry from the government, professional bodies or the industry will serve as an encouragement for other professionals. Finally Professional regulatory bodies and institutions in collaboration with government and other prominent stakeholders should address the ethical challenges facing the construction industry as agreed by Adjei, Sarfo and Sam (2015).

\section{CONCLUSIONS}

Findings showed that factors influencing compliance of professionals to ethical standards were significant. It was thereby concluded that individual related factors/professional training, government regulations and professional regulatory bodies and; system and procedure of the industry have high influence on the level of compliance of construction professionals to ethical standards. For the construction industry to act optimally to the interest of the general public, highest level of ethical behaviour must be effective, apparent and become a reality among the individuals practicing that profession.

\section{REFERENCES}

- ADEYINKA, B. F, JAGBORO G.O and OJO G.K. (2015) Enforcement Mechanisms of Ethical Standards among Nigerian Construction Professionals: Factor Analysis Approach, Environmental Design and Management International Conference (EDMIC) 2015.

- ADJEI, K.O., SARFO, M., and SAM, A. (2015) Challenges Facing Members of Ghana Institution of Surveyors in Complying with Code of Ethics, African Journal of Applied Research (AJAR) Journal, Vol.1,No.1 ISSN 2408-7920 January 2015, Cape Coast, Ghana. 219-235.

- CHAN, E.H.H., and CHAN A.T.S., (2002) Developing of Professional System in the Construction Industry in China", Journal of construction Research, vol. 3 No. 21, 271-284).

- COHEN, D. (1993) Creating and Maintaining Ethical Work Climates: Anomie in the Workplace and Implications for Managing Change, Business Ethics Quarterly pp.343-358.

- DABSON, A., KENNY S., FLIMMER F., and WATERS M.(2007) Ethics for SurveyorsWhat are the Problems? Strategic Integration of Surveying Services FIG Working Week 2007, Hong Kong SAR, China, 13-17 May 2007.

- $\quad$ DAINTY, A.R.; CHENG, J.M. and MORE D.R. (2003) Redefining Performance Measures and a Phenomenon, it's time to Accept Other Success Criteria, International Journal of Project Management 17(66), 337-342.

- DATTA, M. (2000) Challenges Facing the Construction Industry in Developing Countries " $2^{\text {nd }}$ International Conference on Construction in Developing Countries, $15^{\text {th }}-17$ November 2000, Gabarone Bostwana

- FAGBEMI, A. O. (2008) Assessment of Quantity Surveyors Service Quality in Lagos State, Nigeria "Unpublished M.Tech. Thesis, Department of Quantity Surveying, Federal University of Technology, Akure, Nigeria.

- FAN, L.C.N. and FOX,P.W. (2009) Exploring Factors for Ethical Decision Making: Views from Construction Professionals Journal of Professional Issues in Engineering Education and Practice (C) ASCE / April 2009, pg 61-69. 
- FOX, P.W. and SKITMORE, R.M. (2003) Developing the Hong Kong Construction Industry, Knowledge Construction "Proceedings of the Joint International Symposium of CIB Working Commission W55, W65, W107” 22-24 October 2003, National University of Singapore vol. 2, 711-727.

- FUNCHS, C. and HOFKIRCHNER, W. (2003) Self Organisation, Knowledge and Hall, New Jersey: USA.

- GBADEGESIN J.T. and OJO O. (2011) An Appraisal of Property Management Practice in Metropolitan Ibadan, Nigeria. The Built \&Human Environment Review, Volume 4, Special Issue 1, 2011.

- GIBSON, J. (2011) Jackson GIBSON Construction Company. wwwjackgibsonconstruction.com/safety.asp-united states- retrieved on 23/4/2011.

- HAMZAH, A., SAIPO, B.A., MOHD. S.M., MOHAMMED A. B. and YAP X.W.(2007) Does Professional Ethics Affect Quality? Center for Project and Facilities Management, Faculty of the Built Environment. University of Malaysia.

- HILlEBRANDT, P.M. (2000) Economic Theory and the Construction Industry, 2nd Edition. Macmillan, Basingstoke.

- HO, C.M F. (2011) Ethics Management for the Construction Industry,Construction and Architectural Management, Vol. 18 Iss $5 \quad$ pp. 516 - 537.

- HOUSE OF COMMONS, (2001) Modernizing Construction, Controller and Auditor" General HC87 Session 2000-2001, $11^{\text {th }}$ January 2001, Available from: London. www.nao.org.uk/idoc.ashx?docId=d07a89e0-cflf-4edd... [accessed on 18 March 2011].

- HOLIAN, R. (2002) Management Decision Making and Ethics: Practices, Skills and Preferences Management Decision, Available from: $\underline{862-}$ 870 rmit net.au/browse; $\mathrm{D}=4421 \mathrm{k} 7 \mathrm{gad} 7907 \mathrm{qo}$ [accessed 7 April 2001]

- HOLT, R. and ROWE, D.(2000) Total Quality Public Management and Critical Leadership in Construction Project", International Journal of Quality \& Reliability 7 (415), pp.541-553.

- IZZO, G. (2000) Cognitive Moral Developments and Real Estate Practitioners". JRER. Vol. 20, No.1/2 - 2000.

- JARRAR, Y. F. and ZAIRI. (2000) Internal Transfer of Best Practice for Performance Excellence: A global survey, Benchmarking' An International Journal, 7(4), pp. 239-246.

- KAYNE, R. (2010) What is the Difference Between Ethics and Morals"? Available from: http://www.wisegeek.com/what-is-the- difference-between-ethics-and-morals htm. [assessed 25 May 2011].

- KNIGHT, A. and MORLEDGE, R. (2005), Professionalism and Ethical Decision Making. Paper published in the conference proceedings of the QUT Research Week, Brisbane. 37, 231-2434-5 July.

- LAWTON, A.(2005) Public Services Ethics in a Changing World, Future Leadership in Construction" Project, International Journal of Quality \& Reliability, Available from: www2.hull.ac.uk > HUBS home > About us > Our staff. 7 (415), 541-553) [accessed 18 March 2011].

- LOPES, J. (2012) Construction in the Economy and its Role in Socio-Economic Development. In Ofori, G. (Editor) New Perspectives on Construction in Developing Countries. Spon, Abingdon, pp. 40-71.

- MOHAMAD, N., ABDUL RAHMAN, H., USMAN, I. M. and TAWIL, N. M. (2015) Ethics Education and Training for Construction Professionals in Malaysia, Asian Social Science; (11) 4, 2015.

- OFORI, G. (2012) Developing the Construction Industry in Ghana: The Case for a Central Agency", National University of Singapore, Singapore.

- PAINE,L.S.(1994)Managing for Organisational Integrity, Harward Business Review, Available from: www.economist.com/media/globalexecutive/issues in leadership e.pdf. [accessed 18 March2011].

- PALALANI, K., (2000), "Challenges Facing the Construction Industry: A Botswana Perspective" Challenges facing the Construction Industry in Developing Countries, "2 ${ }^{\text {nd }}$ 
International Conference on Construction in Developing Countries. pp. 15-17 November 2000, Gabanna, Bostwana.

- PEARL, R., BOWEN, P., MAKANJEE, N., AKINTOYE, A. and EVANS. (2007) Professional Ethics in the South African Construction Industry. A Pilot study, Journal of Construction Management and Economics Volume 25, Issue 6, pages 631-648.

- $\quad$ RICS (2000a). Professional Ethics Guidance Notes.

- SVENSSON, G. and WOOD, G. (2004) Codes of Ethics: Best Practice in the Swedish Public sector: a PUBSEC-scale, the International Journal of Public Sector Management, (17) (21, 178-195).

- $\quad$ TAHIR N. and AMJAD, A.I.(2013) Unethical Practices in Pakistani Construction Industry, European Journal of Business and Management, Vol.5, No.4, 2013.

- $\quad$ TOW, D. and LOOSEMORE, M. (2009) Corporate Ethics in the Construction and Engineering Industry." Journal of Legal Affairs and Dispute Resolution in Engineering and Construction , August 2009, Vol. 1, No. 3 : pp. 122-129.

- TOWNLEY,B.(1994) Reframing HRND: Power Ethics and the Subject at Work London: Available from: Sage.www modszone.com/.../OWT 208 Spirituality in the Workplace.ppt. [assessed 18 March 2011].

- VELAYUTHAN, S. and PEREA, M.H.B., (2004) The Influence of Emotion and Culture on Accountability and Governance, Corporate Governance" 4(1), 52-64. 


\title{
AN EXPLORATION OF MALAYSIAN PUBLIC LISTED COMPANIES DIVERSIFYING INTO PROPERTY DEVELOPMENT
}

\author{
Abdul-Rashid, A-A. ${ }^{1}$ and Chow, W. W. ${ }^{2}$
}

\begin{abstract}
:
Property development is perceived as a lucrative industry in Malaysia. There is a notable trend of nonproperty related companies, small and large, diversifying into this industry. A study was conducted to examine the rationale of non-property related public-listed companies diversifying into property development and the tactics adopted to overcome liabilities of newness. Public-listed companies were selected as the challenges of diversification are greater in that they are highly regulated and answerable to many parties including shareholders and financiers. A qualitative research method using the interview technique was adopted for this exploratory study. Chief executive officers of 25 non-property related public listed companies known to have diversified into property development were contacted. Five senior managers agreed to participate in this research. Interestingly while for four of the companies, diversification was a conscious move by top management, the last diversified serendipitiously. Market growth and entering into a new market were the main reasons behind the diversification move. To overcome liabilities of newness the companies either joint ventured with, or acquired established smaller property development companies. Interestingly, one chose to do it alone, by engaging various consultants to undertake various activities throughout the property development on its behalf. The last observation affirms a previously conducted study that shows human resource is not key to success in property development.
\end{abstract}

KEYWORDS: DIVERSIFICATION, HOUSING DEVELOPMENT, LIABILITY OF NEWNESS, SERENDIPITY

\section{INTRODUCTION}

The private sector is the main provider of housing in Malaysia. With rising population, urbanisation, household formation, property developers have not been able to keep pace with housing demand. This supply-demand gap ensures that the players get healthy returns. Thus it continues to attract new market entrants, small and large, from nonproperty related companies, in addition to new start-up companies. Over the last decade or so, several public listed companies have diversified into property development Selangor Dredging Bhd (2004), Eksons Corp Bhd (2006), Weida (M) Bhd (2007), Fitters Diversified Bhd (2008), Caely Holdings Bhd (2011), Digistar Corp Bhd (2013). A study was conducted to investigate the rationale of such companies diversifying into property development, and the tactics adopted to overcome their liabilities of newness. Publiclisted companies were selected as the challenges of diversification are greater in that they are highly regulated and answerable to many parties including shareholders and financiers. The case study approach was adopted for this preliminary study. To the best

\footnotetext{
${ }^{1}$ School of Housing Building and Planning, Universiti Sains Malaysia, Malaysia, arashid@usm.my

2 School of Housing Building and Planning, Universiti Sains Malaysia, Malaysia, wy_chow88@hotmail.com
} 
knowledge of the authors, no study has yet been conducted to look into diversification of public-listed companies in Malaysia into property development.

\section{LITERATURE REVIEW}

In 1979, Mintzberg published a paper in the Administrative Science Quarterly to propose that strategy as a pattern in a stream of decisions can be either deliberate (i.e. intended before realised) and emergent (i.e. patterns realised despite or in the absence of intentions). Over the years, his idea was accepted by many. Studies continue to investigate the two types of strategies in specific contexts, such as Australian SMEs (Wiesner and Millet, 2012) Brazilian hospital (Junior et al., 2012) and pricing strategy. Church and Clark (2003) label the two types of strategies as purposive strategy and serendipity.

There is the view that firms diversify when internal growth opportunities become exhausted (Arikan and Stulz, 2011; Andres et al., 2014). Hence firms enter markets which offer growth opportunities or are new to them (Hulbert et al., 2013; Yeh et al., 2013). Firms diversify into new activities through various modes. Some firms choose to diversify through internal development (Lee and Lieberman, 2010; Toschi and Munari, 2012), others through acquisition (Brueller et al., 2014; Ekkayokkaya and Paudyal, 2015). While the rest do so by joint venturing with other parties (Reuer and Ragozzino, 2012).

In 1965, Arthur Stinchcombe introduces the 'liability of newness' construct. He postulates that organisations face the highest mortality rates within the earliest stages of their life cycle because of liability of newness. Over the last fifty years, his construct was widely accepted by management scholars (Abatecola, et al., 2012). In the context of the property development, the liabilities of newness include unfamiliarity with land market, finance, weak housebuyer confidence and complicated approval process. Having land in prime locations provides property development companies the edge over others (Abdul Aziz et al., 2005). For newcomers into the sector, obtaining this vital resource would certainly be challenging in terms of where to source and how much to pay for it. Finance is a major barrier to real estate development in Ghana (Owusu-Manu et al., 2015) and most likely elsewhere too. Not having legitimacy is another liability for new business enterprises (Zimmerman and Zeitz, 2002). Navigating the complicated approval process by various authorities is another challenge (Abdul-Aziz et al., 2005).

Actions taken to overcome the liability of newness include forming joint ventures with established partners (Das and He, 2006). By extension this logic can also apply to resource-rich partners. There are various financial options which newcomers to real estate development can explore (Ebrahim and Hussain, 2010). To overcome the lack of legitimacy, Hannan and Freeman (1984) recommend that management strive to create the perception that their organisations are legitimate and trustworthy whereas Rao et al. (2008) suggest having reputed executives. 
New business start-ups ensure that entrepreneurial economies are generative and selfrenewing (Schramm, 2004). Established firms innovate, but within their existing lines of business. New business start-ups do not suffer from such organisational constraints and can therefore be more innovative. Continuous stream of newcomers also ensure that the industry remains healthy by alleviating incumbent inertia (Miller and Friesen, 1980) and displacing the least efficient firm (Geroski, 1989). Sustainability of industries therefore rely very much on the emergence of new competitors. At the heart of Schumpeter's (1942) articulation of creative destruction is the challenge that entrenched competitors face when confronted with more innovative newcomers.

\section{RESEARCH METHOD}

The case study approach was adopted for this preliminary study. The case study research method as an empirical inquiry example relying on or derived from observation involving the investigation of a contemporary phenomenon within its real-life context; when the boundaries between phenomenon and context are not clearly evident; and in which multiple sources of evidence are used (Yin, 1984). Out of the 15 public-listed nonproperty related companies known to have diversified into property development that were approached, only five agreed to participate. The details of the five companies are shown in Table 1. The interviewees were well qualified to answer the questions that were posed - General Manager (Company A), Group President (Company B), Chief Financial Officers (Companies C and D) and Senior Quantity Surveyor (Company E). The interviews were based on a prepared list of questions based on literature review. But the interviewees were given full latitude to express their opinions. Apart from interviews, data were sourced from company annual reports and news media. Data were analysed according to themes (Greg, 2012).

\section{FINDINGS AND DISCUSSIONS}

Table 1 provides some details about the five case companies. Company B took the shortest time to diversify into property development whereas Company $\mathrm{E}$ the longest time. Yet the latter has core business that was the closest related to this activity. 
Table 1: Some details of the case companies

\begin{tabular}{|c|c|c|c|c|c|}
\hline & Company A & Company B & Company C & Company D & Company E \\
\hline Core business & $\begin{array}{l}\text { Precision metal } \\
\text { components; } \\
\text { precision } \\
\text { tooling and } \\
\text { equipment; } \\
\text { metal } \\
\text { fabrication }\end{array}$ & $\begin{array}{l}\text { Electronic data } \\
\text { capture and } \\
\text { collation } \\
\text { (EDCC) } \\
\text { systems } \\
\text { provider }\end{array}$ & $\begin{array}{l}\text { Manufacturing } \\
\text { and marketing } \\
\text { furniture } \\
\text { webbing }\end{array}$ & $\begin{array}{l}\text { Construction; } \\
\text { trading; } \\
\text { manufacturing; } \\
\text { plantation and } \\
\text { timber }\end{array}$ & $\begin{array}{l}\text { Construction \& } \\
\text { civil } \\
\text { engineering } \\
\text { works; ready- } \\
\text { mix concrete; }\end{array}$ \\
\hline $\begin{array}{l}\text { Year } \\
\text { established }\end{array}$ & 1984 & 2003 & 1983 & 1994 & 1960 \\
\hline $\begin{array}{l}\text { Year listed } \\
\text { No. of } \\
\text { workers }\end{array}$ & $\begin{array}{l}1997 \\
>2000\end{array}$ & $\begin{array}{l}2012 \\
>200\end{array}$ & $\begin{array}{l}2003 \\
>2000\end{array}$ & $\begin{array}{l}1999 \\
<50\end{array}$ & $\begin{array}{l}1991 \\
>120\end{array}$ \\
\hline $\begin{array}{l}\text { Year } \\
\text { diversified } \\
\text { into property } \\
\text { development }\end{array}$ & 2013 & 2013 & 2014 & 2007 & 1999 \\
\hline $\begin{array}{l}\text { Mode of first } \\
\text { foray into } \\
\text { property } \\
\text { development }\end{array}$ & $\begin{array}{l}\text { Joint venture } \\
\text { with land owner }\end{array}$ & $\begin{array}{l}\text { Acquisition of } \\
\text { company }\end{array}$ & $\begin{array}{l}\text { Joint venture } \\
\text { with land owner }\end{array}$ & Sole venture & Sole venture \\
\hline
\end{tabular}

On the 21st October 2013 Company A announced to Bursa Malaysia its intention to seek shareholders' approval for its proposed diversification into property development. Before that announcement, two of its subsidiary had been independently building up land banks in Tanjung Bungah on Penang Island (1.5 acres) and Langkawi (6.9 acres) respectively. One of the non-executive directors had already been involved in property development for the past 18 years. The company was hoping that it could leverage on this director's property development expertise. Company A's first real development project was in Sungai Renggam, Selangor, where it entered in a joint venture with a landowner in May 2013 to develop his 1.3 acres piece of land into residential units. Subsequently in May 2014 in Lumut, Perak, the company via its subsidiary company entered into another joint venture with another land-owner to develop his 4.7 acre piece of land for mixed residential development. The diversification was part of Company A's plan to diversify its revenue and to mitigate the Group's sole dependency on its existing core business in manufacturing sector. With stable and strong growth prospects, Company A believed the diversification into the property development would be beneficial to the Group's future earnings.

In August 2013, Company B purchased a 52\% stake in a smallish property development company based in Penang for RM2.44 million. It did so from the RM15.9 million proceeds from the part-disposal of its Thai technology company which was expected to face tough times for the next few years. A month after the acquisition, the acquired company launched a high-end residential development comprising of 77-units of semidetached and bungalow houses in Bukit Mertajam, Penang. According to the Group President in an interview with the media, the purchase of the particular developer 
company had turned out to be a sweet deal as it provided easy entry into the property market at low price and with low risk. He added that it had always been his company's strategy to acquire companies for mutual growth. In August 2014, Company B acquired $51 \%$ share in a Penang-based property company for RM15 million which held the rights to develop a business park in Tambun, Perak, which featured a total of 112 units of properties, comprising 60 units of 4-storey semi-detached shop offices and 52 units of 4storey light industrial factories. Though the Group President had no intention to be a fullfledged property player, his company was nonetheless scouting for good parcels of land to grow its landbank, preferably in the Klang Valley and other growth areas.

After obtaining shareholder approval in an extraordinary meeting in April 2014, Company $\mathrm{C}$ diversified into property development. Its maiden project in Kuala Lumpur was a joint venture with a landowner comprised of two 38-storey condominium blocks with 472 units of homes was launched in the third quarter of 2014. Its Chief Financial Officer explained:

"Joint venture means you find a joint venture partner to contribute the land, then we do the development so the gearing is low. These landowners don't know what to do with the land, so they need a partner to help them to develop. So they contribute their land and the developer would do the rest of the work.

When interviewed following shareholder approval, its Group Managing Director said in a press release, "Our core business is doing well and we are diversifying our business activity to grow the company and bring it to the next level. We choose to be involved in the property sector because the demand is always there and we see opportunities for growth in this sector." Following the success of its maiden project, Company C apparently received many parties keen to enter into joint ventures with. But its chairman said, "Our approach is careful and selective, not only on location and type of development - we want to do something with quality and do it well." He also said that establishing joint ventures especially with landowners was the company's "prime strategy" in property development.

In November 2006, Company D appointed someone with 25 years' experience in property development as its Managing Director to spearhead the property development diversification. In 2014, he was redesignated as Executive Chairman. In 2007, Company D's subsidiary launched its maiden residential project in Bangsar South, Selangor, comprising of 37 high-end houses on a 3.9 acres site with a gross development value of RM43 million. Construction work was undertaken by the Group's in-house construction arm. There have been several development projects since then, to the extent that effective $1^{\text {st }}$ July 2013, Company D was reclassified from 'industrial products' to 'properties' sector by Bursa Malaysia.

Company E entered property development serendipitously. Among the oldest and largest construction firms in the country, it came to possess a large tract of land after the Federal Government could not pay it for the construction of a sports complex in the 1990s. The Federal Government alienated 154 acres of freehold land to the company. Company E's 
maiden project was a three-blocks low-cost flat development comprising of 1,098 units which it launched in the last quarter of 1999 and handed to buyers in 2004. It was a painful lesson as for financial year 2001, the company unexpectedly incurred losses of RM7.3 million arising from the project. Over the years, the company had disposed about 90 acres of this land to raise funds (it was slapped with PN17 status in 2008 by Bursa Malaysia for being in financial distress and which was only lifted in March 2014). With Kuala Lumpur expanding south, the remaining land became ripe for development. In 2009 , it had mapped out plans to develop a 10-acre site into mixed commercial development with a total GDV of more than RM1 billion through its $100 \%$ wholly owned subsidiary company, while the remaining land would be developed into an integrated development of RM3.5 billion in joint venture with a reputable developer. The former was launched in 2003 and expected to be completed in 2017, while the latter launched in 2015 would unfold in four phases and scheduled for completion in 2019. As these two developments were gathering momentum and PN17 status lifted, Company E was looking to replenish its land bank mainly in the Klang Valley, Penang and Kota Kinabalu.

To sum up, as elaborated above four case companies diversified due to deliberate top management decision while the last one diversified serendipitously, which cohered with past literature (Mintzberg, 1979).

Table 2 shows the rationale of diversification into property development by the five case companies. All five companies diversified into property development because of market growth and new market, which again cohere with past literature (Hulbert et al., 2013; Yeh et al., 2013). For Respondents B and C, the reason for diversification was the lure of steady increase in house prices, which cohere with literature (Liew, 2013). One analyst observed that for as long as property prices surge, companies will continue to diversify into property development (Property Report, 2010).

Table 2: Rationale for diversifying into property development

\begin{tabular}{cccc}
\hline Respondent & $\begin{array}{c}\text { Market } \\
\text { growth }\end{array}$ & $\begin{array}{c}\text { Continuous rise in } \\
\text { local house prices }\end{array}$ & $\begin{array}{c}\text { New } \\
\text { market }\end{array}$ \\
\hline A & $\checkmark$ & $\checkmark$ & $\checkmark$ \\
B & $\checkmark$ & $\checkmark$ & $\checkmark$ \\
C & $\checkmark$ & & $\checkmark$ \\
D & $\checkmark$ & & $\checkmark$ \\
E & $\checkmark$ & & $\checkmark$ \\
\hline
\end{tabular}

In order to uncover the tactics adopted to overcome liabilities of newness, these liabilities would have to be firstly identified. These liabilities were obtaining land in attractive locations, raising finance, weak housebuyer confidence and complicated approval process.

All the case companies intimated that their main liability was securing good pieces of land in prime locations at what should be reasonable prices, which resonates with Abdul Aziz et al. (1995). Respondent A explained that the property development business is unique in that a location can only fit one project. According to Respondent B, land in Klang Valley especially has become scarce due to rapid development. MPI Report (2011) 
notes that replenishing land banks to sustain business is challenging for many developers. The report goes on to say that rising land prices in prime urban areas are beyond the reach of many developers.

The next liability was raising finance, which resonates with (Owusu-Manu et al., 2015). Company E's bank provided bridging loan only after $60 \%$ of the properties of its development were sold. Developers have to find house buyers before they can obtain bridging loans $(\mathrm{Ng}, 2007)$. Like Company E, Company B also rated financial capability as the second most important liability of newness. Fortunately for Company B, the partdisposal of its Thai company gave it a firm financial footing to diversify into property development. Its respondent B opined that small size developers tend to be ignored by bankers. Hence, companies that have adequate resources and of sound financial status have an edge over others $(\mathrm{Ng}, 2007)$.

The third liability of newness is lack of housebuyers confidence, which resonates with Zimmerman and Zeitz (2002). Respondent B said that housebuyers are not familiar with new players in the property industry. Respondent $\mathrm{E}$ observed that house-buyers have more confidence in players with strong financial resources, vast experience and good reputation. Homebuyers are smarter now and will do background checks on the property developers before they buy a property (Liew, 2013). Company $\mathrm{E}$ found it challenging to get approvals from the various authorities throughout the development, which can take more than five years for a medium-sized development. Perseverance is therefore crucial in property development. A study conducted by Balen (2006) notes that obtaining planning permission has always been a lengthy and bureaucratic process.

How did these sampled companies overcome the liabilities of newness? With regards to obtaining prime land, one effective way as demonstrated by Companies $\mathrm{A}$ and $\mathrm{C}$ was to joint venture with landowners, which cohere with Das and He (2006). Company B's strategy was to avoid purchasing large tracts of land to avoid over-committing financially. As for raising finance, Company $\mathrm{C}$ was open to various financing options from the capital market, financial banking institutions or other credit facilities, which is what the literature suggests (Ebrahim and Hussain, 2010). Regardless of the option selected, careful assessment of cash flow and debt obligation was Company C's priority. Its Chief Financial Officer added this was the reason the company started off by joint venturing with a landowner as it saved on the cost of landownership:

The land owner contributed the land and we did the development. Then we shared the profit."

Company D was able to lower development cost because it manufactured its own building materials. Respondent D said:

"Cement is one of the major cost components of our property development segment. By setting up our own plant, we can save up to $20 \%$ on our raw materials, labour and logistic costs."

Additionally construction work was undertaken by its construction arm. Respondent D continued:

"We do everything on our own unlike some developers who have to tender out their construction projects to third party companies." 
Hence, the requirement for borrowing was lower for this company. According to Respondent E, once the concession agreement was signed between his company and the government, it quickly launched the low-cost housing development to reduce the holding costs of the land bank, and allowed for sufficient time to generate revenue from property development during the Asian Economic Crisis of 1997.

To overcome housebuyers' lack of confidence, Company $\mathrm{C}$ positioned itself as a niche property developer by looking at all aspects of the company's product offerings from product features to styling, design and layout to meet the needs of today's home-buyers. As an example, for its maiden project, the glass-encased gymnasium overlooking the swimming pool was introduced. Company A emphasised the need to be innovative in all operational aspects in order to be a successful property developer. For this, according to its respondent, the company draw inspiration from established players in term of:

"how much they sell, what they give to the market, the strategy plan that they have, how they do the planning here and there, why they can do it and we cannot do it. Our main aim is to make the buyer the winner. Buyers must always be the winner, not us. If the champion is the developer, the buyers will have the perception that the developer is not giving them value for money property because it earns more than them, and you are just making them an earning machine. So the buyers will run.

For Company D, its principle was to develop quality houses.

One of the ways to increase housebuyer confidence was to assemble a competent management team with the right track record and expertise, said Respondent A. Company D did so, by firstly appointing a new Managing Director with more than two decades of property development experience. Company D's headhunted the right candidates "through advertisement, by word of mouth through business associates, family and friends and by recommendation." Its respondent was aware of the perils of being overly dependent on any one personnel. These companies echo the observation made in literature pertaining to competent manpower (Rao et al. (2008). However Respondent B, provided an opposite view to the notion that diversification move into property development requires an assembly of experience staff

On the Board of Director, we have a few key people who are familiar with property development. But being a board member, they are not full time staff. You still need to hire people to run but if you acquire existing company, they already have the management team around so we just monitor on top. It is much easier to do it this way compared to start looking for people.

For Company E, after a tumultuous period when it was tagged with PN17 stigma by Bursa Malaysia, the company now runs on a very lean team of 50-60 staff, explained its Chief Executive Officer to the media. Companies B and E cohere with Abdul Aziz et al. (2005)'s finding that property development companies can outsource a large proportion of knowledge-intensive activities to consultants and contractors. 


\section{CONCLUSIONS}

The study found that four case companies diversified into property development as planned. Discovering that one public-listed company did so serendipitously was unexpected as the presumption was that every action by such companies is predicated on careful deliberation by top management. Furthermore the liabilities of newness is not as insurmountable as one might imagine. Joint venture with land owner or corporate acquisition were the uncovered tactics to overcome these liabilities. Another interesting observation, and one which cohered with a past study, is that a newcomer does not need to assemble a large team of knowledgeable staff that would add on to the company's fixed overheads. There are plenty of independent service providers such as consultants and contractors that can carry knowledge-intensive work on its behalf on project basis.

The literature states that for an industry to sustainable, there must be continuous inflow of newcomers with enthusiasm and possibly fresh ideas. For Malaysia which still has a growing and young population as well as undergoing rapid urbanisation and household formation, it is important that a vibrant and competitive property development sector is sustained so that housebuyer welfare is preserved. Certainly on the basis of this study, market growth, new market and continuous house price rises will continue to draw nonproperty-related companies to diversify into this market sector. Also, some may make the move early in their corporate history while others later. Some may have core businesses that are closely tied to property development, others not so. These findings can be used as the basis for a much more extensive and rigorous study.

\section{REFERENCES}

- ABATECOlA, G., CAFFERATA, R. and POGGESI, S. (2012) Arthur Stinchcombe's 'liability of newness'. Contribution and impact of the construct, Journal of Management History, 18(4), 402-418.

- $\quad$ ABDUL AZIZ, A. R., HO, S. Y. and JAAFAR, M. (2005) Valuable resources of Malaysian housing developers: the resource-based view, Journal of Valuation and Property Services, 5(1), 1-14.

- $\quad$ ANDRES, P., FUENTE, G. and VELASCO, P. (2014) Growth opportunities and the effect of corporate diversification, The Spanish Review of Financial Economics, 12(2), 72-81.

- $\quad$ ARIKAN, A. M. and STULZ, R. M. (2011) Corporate acquisitions, diversification, and the firm's lifecycle, Working Paper 17462, National Bureau of Economic Research. Available from: http://www.nber.org/papers/w17463.pdf. (Accessed 4 April 2015)

- $\quad$ BALEN, M. (2006) Land Economy, London: Institute of Economic Affairs.

- $\quad$ BRUELLER, N. N., CARMELI, A and DRORI, I. (2014) How do different types mergers and acquisitions facilitate strategic agility, California Management Review, 56(3), 39-57.

- $\quad$ CHURCH, R. and CLARK, C. (2003) Purposive strategy or serendipity? Development and diversification in three consumer product companies, 1918-39: J. \& J. Colman, Reckitt \& Sons, and Lever Bros./ Unilever, Business History, 45(1), 23-59.

- DAS, T. K. and HE, I. Y. (2006) Entrepreneurial firms in search of established partners: review and recommendations, International Journal of Entrepreneurial Behaviour \& Research, 12(3), 114-143.

- $\quad$ EBRAHIM, M. S. and HUSSAIN, S. (2010) Financial development and asset valuation: the special case of real estate, Journal of Banking \& Finance, 34(1), 150-162. 
- EKKAYOKKAYA, M. and PAUDYAL, K. (2015) A trade-off in corporate diversification, Journal of Empirical Finance, doi: 10.1016/j.jempfin.2015.07.005

- GEROSKI, P. (1989) Entry, innovation, and productivity growth, Review of Economics and Statistics, 71, 572-578.

- GREG, G. (2012) Applied Thematic Analysis. Thousand Oaks, California: Sage

- HANNAN, M. and FREEMAN, J. (1984) Structural inertia and organizational change, American Sociological Review, 49, 149-164.

- HUlbert, B., GILMORE, A. and CARSON, D. (2013) Sources of opportunities used by growth minded owner managers of small and medium sized enterprises, International Business Review, 22(1), 293-303.

- JUNIOR, V. M., PASCUSSI, L. and MURPHY, P. (2012), Implementing strategies in complex systems: lessons from Brazilian hospitals, Brazilian Administrative Review, 9 (special), http://dx.doi.org/10.1590/S1807-76922012000500003

- LEE, G. K. and LIEBERMAN, M. B. (2010) Acquisition vs. Internal development as modes of market entry, Strategic Management Journal, 31 (2), 140-158.

- LIEW, J. T. (2013) Good idea to jump on the property bandwagon? The Sun Daily, Nov 25. Available from http://www.thesundaily.my/news/889057 (Accessed: 12 March 2015).

- LOPES, T. S. (2015) A systems view of corporate diversification, International Studies of Management \& Organisation, 45(4), 342-358.

- MILlER, D. and FRIESEN, P. H. (1980) Momentum and revolution in organisational adaptation. Academy of Management Journal, 23, 591-614.

- MINTZBERG, H. (1979) An emerging strategy of 'direct' research. Administrative Science Quarterly, 24(4), 582-589.

- MPI Report: Property Quotient. (2011) Developers should venture overseas to ensure sustainability, 17 February. Available from: http://www.iproperty.com my/news/3376/mpireport-property-quotient. (Accessed: 2 Feb 2015).

- NG, L. F. (2007) Determinant Factors of Implementing Build Then Sell in Malaysia: Housing Developers Point of View, unpublished MSc thesis, Universiti Sains Malaysia, Penang, Malaysia.

- OWUSU-MANU, D., EDWARDS, D. J., BADU, E., DONKOR-HYIAMAN, K. A. and LOVE, P.E.D. (2015) Real estate infrastructure financing in Ghana: sources and constraints, Habitat International, 50, 35-41.

- PROPERTY REPORT (2010) New developers see the light in Malaysian property, November 12. Available from: http://www.property-report.com/new-developers-see-the-light-inmalaysian-property/. (Accessed: 23 March 2015).

- RAO, R. S., CHANDY, R. K. and PRABHU, J. C. (2008) The fruits of legitimacy: why some new ventures gain more from innovation than others, Journal of Marketing, 72(4), 58-75.

- REUER, J. J. and RAGOZZINO, R. (2012) The choice between joint ventures and acquisitions: insights from signaling theory, Organization Science, 23(4), 1175-1190.

- SCHRAMM, C. J. (2004) Building entrepreneurial economies, Foreign Affairs, 83(4), 104 115.

- SCHUMPETER, J. A. 1976. Capitalism, Socialism and Democracy (Eighth impression, George Allen \& Unwin (Publishers) Ltd, London.

- SMITH, G. E. (2012) Emergent pricing strategy. In G. E. Smith (ed.) Visionary Pricing: Reflections and Advances in Honor of Dan Nimer, Bingley, London, Emerald Group Publishing Limited, pp. 103-126.

- STINCHCOMBE, A. L. (1965) Social structure and organizations. In March, J. (Ed), Handbook of Organizations, Rand McNally, Chicago, IL, pp. 142-193.

- TOSCHI, L. and MUNARI, F. (2012) Mix and match: corporate diversification and CVC portfolio, paper presented at the DRUID 2012, 19-21 June, CBS, Copenhagen, Denmark.

- WIESNER, R. and MILLETT, B. (2012) Strategic approaches in Australian SMEs; deliberate or emergent, Journal of Management \& Organisation, 18(1), 98-122. 
- YEH, C.-T., HUNG, C.-C. and JHANG, Y.-S. (2013) The impacts of growth opportunities, information asymmetry, and free cash flow on corporate diversification, International Journal of Business and Management, 1(1), 29-41.

- $\quad$ YIN, R. K. (1984) Case Study Research: Design and Methods. Newbury Park, CA.: Sage.

- ZIMMERMAN, M. A. and ZEITZ, G. J. (2002) Beyond survival: achieving new venture growth by building legitimacy, Academy of Management, 27(3), 414-431. 


\title{
BENEFICIARY HOUSING PARTICIPATION DEFINED - A SOUTH AFRICA PERSPECTIVE
}

\author{
Aigbavboa, C. O. ${ }^{1}$ and Thwala, W. D. ${ }^{2}$
}

\begin{abstract}
:
Beneficiaries' participation is a rich concept that varies with its application and definition. The way participation is defined, depends on the context in which it occurs. For some scholars, it is a matter of principle; for others, a matter of practice; for even more it is an end in itself. Hence, in this paper a South Africa perspective on the definition of participation will be discussed in relation to subsidised low-income housing beneficiaries. The data used in this research were derived from secondary sources only; through a detailed review of related literature on the subject in order to meet the research objectives. The study is a South Africa perspective on the definition of participation. From the review of the extant literature, it was found that participation is a stereotyped word like children use Lego pieces. Like Lego pieces, the words fit arbitrarily together and support the most fanciful constructions. They have no content but do serve a function. As these words are separate from any context, they are ideal for manipulative purposes. Hence, it was found that 'Participation' belongs to this category of word. Therefore, because involvements in projects and other ventures gives people a better understanding of their interests and the interests of others, and, in some cases, brings them to see what would be best for the entire group, this study thus contribute to the body of knowledge in the conceptualisation of subsidised low-income beneficiary participation in South Africa.
\end{abstract}

KEYWORDS: BENEFICIARY PARTICIPATION, HOUSING, HOUSING POLICY, LOWINCOME, LOW-INCOME HOUSING

\section{INTRODUCTION}

Theories of beneficiary participation have received considerable academic attention particularly since the early 1900's, but have been a source of debate since at least the early 1960s. However, the influential theoretical work on the subject of participation was done by Arnstein (1969). The precise importance of Arnstein's work comes from the obvious recognition that there are different levels of participation, from manipulation or therapy of citizens; through to consultation, and to what we now view as genuine participation, that is the levels of partnership and citizen control. The fundamental point in Arnstein's model (is) that "participation without redistribution of power is an empty and frustrating process for the powerless. It allows the power holders to claim that all sides were considered, but makes it possible for only some of those sides to benefit, thus maintaining the status quo" (Arnstein, 1969).

Beneficiary's participation in a housing process for instance, offers an opportunity to engage those who are affected by housing issues in a dialogue; defining problems and

\footnotetext{
${ }^{1}$ Department of Construction Management \& Quantity Surveying, University of Johannesburg, Doornfontein Campus, Johannesburg, 2028, South Africa, caigbavboa@uj.ac.za

${ }^{2}$ Department of Construction Management \& Quantity Surveying, University of Johannesburg, Doornfontein Campus, Johannesburg, 2028, South Africa, didibhukut@uj.ac.za
} 
creating solutions. The inclusion of community stakeholders in a housing development process helps ensure appropriate housing strategies and policies are developed through more efficiently evaluation, development and implementation to guarantee the satisfaction of the beneficiaries'. Inadequate beneficiaries' participation in the process can lead to community conflict or as a worst case scenario, anti-development initiatives and ultimately housing dissatisfaction, which impacts on the quality of life of the final beneficiaries. Successful beneficiaries' participation is important because a mixed cross section of the population that has a housing need can be involved in defining the housing problem and in crafting community sensitive solutions. However, there is disagreement among planners and professionals about the contribution of beneficiaries' participation in improving the lives of the people, particularly the poor and disadvantaged (Rifkin \& Kangere, 2002). Some completely dismiss its value altogether, while others believe that it is the "magic bullet", (Rifkin \& Kangere, 2002), that will ensure improvements especially in the context of poverty alleviation, and community ownership. Hence, the objective of this paper is to present a South Africa perspective on the definition of participation in relation to subsidised low-income housing beneficiaries. Too frequently, development initiatives have been designed by those who have no real knowledgeable understanding of the real needs of a specific community. Most times, the produced 'housing plan' is based on the different stakeholders' perceived needs of the low-income groups instead of the beneficiaries' true needs (Davy, 2006). Kotze and Kellerman (1997) attribute this to the fact that the idea that development consists of a transfer of skills or information creates a role for the expert as the only person capable of facilitating the transfer of these skills from them to the community or society. In order to create developmental efforts that echo the real needs and expectations of specific groups, inclusive of development that will satisfy the people, a paradigm shift is needed in the current conceptualization of participation in housing development studies. This is a shift from the so-called blue-print approach to development toward a more process and people-centered development that should produce beneficiaries' participation. According to Oakley (1991) the role of beneficiaries' participation in South Africa cannot be undermined or may not override economic, personal or technological aspirations in the South Africa public sector as the country's past governance situation should compel the government to correct injustices by actively involving the affected in policy development. The data used in this research were derived from secondary sources only; through a detailed review of related literature on the subject in order to meet the research objectives.

\section{ORIGIN OF BENEFICIARY PARTICIPATION}

Beneficiary participation in the public sector organisation has undergone a significant change. Prior to this, people were more tolerant of poor service deliveries; more patient in long queues and enduring inefficient public administration than they are now (Olivier, 2003). Nowadays, people are expecting quality delivery of public services and are beginning to hold elected representatives increasingly accountable, when their expectations are not met. Hence, the origin of beneficiary participation can probably be 
traced to three root sources, which are: participation as good development project practice (Abbot, 1996); participation as good governance (Kooima, 1993) and participation as political empowerment (Bond, 2001). These concepts are discussed below in detail.

\section{Participation as Good Development Project Practice}

According to Rahnema (1992), participation was first used in the early 1950's by social activists and project field workers, as a necessary facet of development. Also, the World Bank, and other international agencies, as well as the Development Bank of Southern Africa (DBSA) have since taken the notion of participation as a requirement for successful project implementation in the society. Hence, it has become a common practice to include some or other form of public participation in the implementation of infrastructure projects within development initiatives. A large amount of development work case studies tend to focus on project specific participation and it is arguably the most well-known participation framework of reference (Olivier, 2003).

\section{Participation as Good Governance}

The United Nations Development Programme (1998) defines governance as the exercise of economic, political, and administrative authority to manage a country's affairs at all levels and the means by which states promote social cohesion and integration, to ensure the well-being of their population. This entails all methods used to distribute power and manage public resources, and the organizations that shape government and the execution of policy. Governance also encompasses the mechanisms, processes and institutions, through which citizens and groups articulate their interests, exercise their legal rights, meet their obligations and resolve their differences. According to this definition, good governance therefore depends on public participation to ensure that political, social and economic priorities are based on a broad collective agreement and that the poorest and most vulnerable populations can directly influence political decision making, particularly with respect to the allocation of development resources. Good governance is also effective and equitable, and promotes the rule of law and the transparency of institutions, officials, and transactions (UNDP, 1998). Participation by the citizens of a state is a key cornerstone of good governance. Participation could be either direct or through legitimate intermediate institutions or representatives. However, it should be noted that representative democracy does not necessarily mean that the concerns of the most vulnerable in society would be taken into consideration in decision making, but it does create a platform for participation with the vulnerable in the society. Participation needs to be informed and organized. This means freedom of association and expression on the one hand and an organized civil society on the other hand. Good governance has eight major characteristics. It is participatory, consensus oriented, accountable, transparent, responsive, effective and efficient, equitable and inclusive and follows the rule of law. It guarantees that corruption is curtailed, the views of minorities are taken into account and that the voices of the most vulnerable in society are heard in decision-making process. It is also responsive to the present and future needs of society. 
Lastly, participation as good governance refers to a high quality of processes by which decisions affecting public affairs are reached and implemented. This process ensures that all, including the poor and other disadvantaged groups, are included and have the means to influence the direction of development in particular as far as it affects their lives. Also, to make contributions to development and have these recognised and to share in the benefits of development and to improve their lives and livelihood. Participation as good governance helps to ensure that all people have adequate access to basic services.

\section{Participation as Political Empowerment}

The empowerment approach to participation is located within the radical paradigm of alternative development and is manifested in the mobilization of popular political power. This originated from the economic development theory and theories of development. This approach positions participation within a broader political struggle that links the condition of under-development with access to political power. Originally, this tradition found expression in popular resistance movements within South America, Asia and South Africa (Bond, 2001).

These three approaches to participation sometimes intermingle and sometimes are confusing in practical engagement between the government and communities. From the above, it should be noted that there is no single universally applicable or perfect model of participation. It is important to recognize different circumstances require a different style of participation from authorities. However, the responsibility is to understand the context within which communities are engaged, so as to design the most appropriate participative mechanism and process. Participation in the current study is positioned on the good governance approach because good governance depends on public participation to ensure that civil, societal and cost-effective priorities are based on a broad collective agreement and that the poorest and most vulnerable populations can directly influence political decision making, particularly with respect to the allocation of development resources. Also, since the current study is based on South Africa, where public participation is considered to be one of the key tenets of democratic governance, the concept of participation as used, in this study, inclines towards this approach.

\section{BENEFICIARY PARTICIPATION DEFINED}

Participation is a rich concept that varies with its application and definition. The way participation is defined, depends on the context in which it occurs. For some scholars, it is a matter of principle; for others, a matter of practice; for even more it is an end in itself as described above. However, Rahnema (1992) informs that participation is a stereotyped word, like children use Lego pieces. Like Lego pieces, the words fit arbitrarily together and support the most fanciful constructions. They have no content, but do serve a function. As these words are separate from any context, they are ideal for manipulative purposes. 'Participation' belongs to this category of word. 
Most times, the term participation is modified with adjectives, resulting in terms such as community participation, citizen participation, people's participation, public participation, popular participation or even beneficiary participation as used in the current study. However, the Macmillan English Dictionary (2002:1032) defines participation as "to have a share in" or "to take part in," thereby emphasising the rights of individuals and the choices that they make in order to participate. Whilst, Arnstein (1969) claims that the idea of citizen participation is a "little like eating spinach: no one is against it in principle because it is good for you". But there has been little analysis of the content of citizen participation, its definition, and its relationship to social imperatives such as social structure, social interaction, and the social context where it takes place. Bearing this in mind, the present study hopes to advance the concept further by incorporating it into the definition and object of beneficiary satisfaction with their housing unit. However, it can also be a method to co-opt dissent, a mechanism for ensuring the receptivity, sensitivity, and even accountability of social services to the users, as is the case of satisfaction with publicly provided houses by the South African government to the poor and low-income groups.

Mathbor (2008) defined citizen participation as a process by which citizens' act in response to public concerns, voice their opinions about decisions that affect them, and take responsibility for changes to the community. Likewise, citizens' participation may also be referred to as a response to the traditional sense of powerlessness felt by the general public when it comes to influencing government decisions. This is because citizens often feel that housing development issues are beyond their control because the decisions are made outside their community by unknown bureaucrats and technocrats. Furthermore, participation is a collective efforts to increase and exercise control over resources and institutions on the part of groups and movements of those hitherto excluded from control. This definition points towards a mechanism for ensuring community participation. Williams (2006) further informs that beneficiary participation is the direct involvement of the citizenry in the affairs of planning, governance and overall development programmes at local or grass roots level. Likewise, Davidson et al. (2007) inform that it involves how and why members of a community are brought into these affairs. Likewise, Meyer and Theron (2000) inform that participation is a social learning process linking the building blocks of development. A vivid definition of participation programmes would indicate the involvement of a significant number of persons in situations or actions that enhance their well-being, for example, their housing, income, security, or self-esteem (Chowdhury, 1996). Chowdhury further states that the ideal conditions contributing towards meaningful participation can be discussed from three aspects which are: What kind of participation is under consideration? Who participates in it? How does participation occur? Mathbor (2008) also points out the importance of the following issues in order to assess the extent of community participation: Who participates? What do people participate in? Why do people participate? There are: a) Cultural explanations (values, norms, and roles, etc.); b) Cognitive explanations (verbal skills and knowledge about the organizations); and c) Structural explanations (alternatives, resources available, and the nature of benefit sought) Implications (how the benefit contributes to the ends or principles they value). 
The significance of beneficiary participation is said to draw from three main factors. Primarily, it is alleged to allow for cost reduction through the utilization of local labour and expertise (Davidson et al., 2007). Secondly, it potentially leads to the implementation of appropriate responses through the involvement of locals in collective decision-making, through the assessment of their needs and expectations, (Davidson et al., 2007) thus guaranteeing housing satisfaction. Thirdly, it helps in directing scarce resources towards the more needy, identified by fellow locals (Davidson et al., 2007). Beneficiary participation is perceived as an undertaking that results in the empowerment of the local population. However, it also has numerous non-benevolent political significances. It is referred to as a curious element in the democratic decision-making process. While the roots of beneficiary participation can be traced to ancient Greece and colonial New England, its significance reflects a contemporary recognition that societies are simply too remote to be truly "of, by and for the people" without their involvement in the development that affects them. Nevertheless, in principle, beneficiary participation requires the involvement of local actors in the conceptualization, implementation, monitoring and evaluation of projects. In practice it sometimes tends to be confined to specific activities (Mafukidze \& Hoosen, 2009). As such, beneficiary participation can further be referred to as local involvement within a continuum of possibilities where locals may participate only as providers of labour, in decision-making or at all levels (Davidson et al., 2006; Mafukidze \& Hoosen, 2009). The level of local involvement is most times conditional since there are no rules that prescribe the levels of involvement. In some development, beneficiary participation could be confined to the discussion of a proposed idea of building low-income houses. For instance, the Reconstruction and Development Programme (RDP) capital subsidy low income housing under consideration in this present study considers a minimal involvement from the local population as most participatory process is simply aimed at bringing them together to endorse an idea rather than to achieve empowerment, contribution of ideas and capacity building. Beneficiary participation in housing delivery, and as used in this study, agrees with the aforementioned definitions and can be summarized as a localized collective learning process. This is where all stakeholders acquire and share information and learn to accept responsibility for decisions, whilst working towards achieving the shared objective of improving housing delivery. The definition acknowledges and tolerates the interest of different knowledge, pursuit of cooperation and deliberate minimization of clashes along interest, knowledge and power lines, which reinforces beneficiary participation. Thus, enabling the eventual satisfaction of the beneficiaries with the subsidised houses being constructed and allocated to them by the government.

\section{THE LEGISLATIVE AND POLICY FRAMEWORK FOR PARTICIPATION IN SOUTH AFRICA}

Since 1994, the South African government has put in place policy and legislative frameworks that seek to promote participatory governance. The notion of beneficiary participation is embedded in the South African Constitution. Recognizing the adverse impact of Apartheid on the settlement of the majority of South African citizens, the 
incoming democratic government in 1994, from the outset, placed emphasis on the provision of housing, as a basic human right. The 1994 Housing White Paper asserted that the government was under a duty to take steps and create conditions which will lead to an effective right to housing (Tapscott \& Thompson, 2010) and other social benefits for all. It is alleged in South Africa that a person has a right to live in dignity, in habitable conditions, and that government will vigorously promote an effective right to housing for all, within the resources and other limitations applicable to it (Republic of South Africa Constitution, 1996, Section 4.4.2). The principles of citizen participation was clearly articulated in the Housing White Paper and further advanced in the Development Facilitation Act of 1995, of which the policy goals were later given legal effect by the 1996 Constitution (Tapscott \& Thompson, 2010). Enshrined in the Constitution's Bill of Rights (Section 26) is the declaration that: "Everyone has the right to have access to adequate housing. The State must take reasonable legislative and other measures within its available resources, to achieve the progressive realisation of this right". Following this edict, was a new National Housing Act promulgated in 1997, committing the state, inter alia, to prioritize the needs of the poor in the design and delivery of housing development programmes.

In harmony with the Reconstruction and Development Policy emphasis on beneficiary consultation, the 1994 Housing White Paper committed the government "to a development process driven from within the communities" (Section 4.4.4.), which would promote "the participation of affected communities in the planning and implementation of new developments" (Section 4.5.1). This viewpoint was also advanced in the 1997 National Housing Act which emphasizes, in Section 2(1) that national, provincial and local spheres of government must: "give priority to the needs of the poor in respect of housing development; consult meaningfully with individual and communities affected by housing development; ensure that housing development ... is administered in a transparent and equitable manner, and upholds the practice of good governance". The South Africa Government's commitment to consultation, public participation transparency, and the adherence to agreed norms and standards is further evident in the 2008 Social Housing Act (Act No. 16 of 2008), which, in Section 2.1, states the need to: "consult with interested individuals, communities and financial institutions in all phases of social housing development. Facilitate the involvement of residents and key stakeholders through consultation, information sharing, education, training and skills transfer, thereby empowering residents;..." (Department of Human Settlement, 2009).

Moreover, the South Africa constitutional requirements for beneficiary participation is found in its mandate for local government, but more specifically in Chapter 10, Section 195, which states that: "public administration must be development-oriented; people's need must be responded to, and the public must be encouraged to participate in policy making and good human resource management and career development practices must be cultivated to maximize human potential". Also, on a national level, the South Africa government introduced, what is commonly known as the Batho Pele Principles, which are found in the White Paper on Transforming Public Service Delivery of 1997 and embodies the evolution of public participation in South Africa. Batho Pele means 'people first'. Through this principle, the government established the importance of the South African 
public (citizens) and their valued input through participatory means, and called "for a shift away from inward looking, bureaucratic systems, processes and attitudes, and a search for new ways of working which put the needs of the public first, better and sustainable development, which is faster, and more responsive to the citizen's needs and expectations" as enshrined on the White Paper on Transforming Public Service Delivery of 1997.

\section{BENEFICIARY PARTICIPATORY PROCESS IN SOUTH AFRICA}

In the delivering of public housing projects and in giving effect to the rules of national policy in South Africa, a municipality is mandated to work with community representatives through what are called beneficiary committees (Tapscott \& Thompson, 2010). Beneficiary committees are understood to be elected by communities, and it is evident that they are established in different ways by different municipalities and in some cases in different ways by the same municipal authority, depending on the community dynamic, or nature of the project. As such beneficiary committees cannot be expected to serve the communities they are purported to represent in similar ways. For instant, in the Department of Human Settlement capital subsidy projects, in which beneficiaries are selected from a general waiting list, this differs substantially from a committee established in an, in situ, upgrade area (where shacks are replaced by houses on site) where a sense of community is likely to be stronger. The effectiveness and legitimacy of the beneficiary committees as seen by the representatives themselves is markedly different between the different types of projects, in spite of the signed agreement between beneficiary representatives, the municipality and the housing developer (Tapscott \& Thompson, 2010).

In giving influence to the idea of people-centered development, the South Africa Housing Code stresses the need for a structured agreement (also referred to as a 'social compact' or 'contract') between a municipality and the community in the delivery of housing projects. This agreement ensures that community members assume ownership of their own development and project. The involvement of the beneficiaries from the onset is of vital importance. Hence, beneficiary participation is undertaken within the context of a structured agreement between the municipality and the community.

Beneficiary participation is generally more successful when the community ('beneficiaries') takes on much of the responsibility, as compared to situations in which the government attempt to assess beneficiaries' preferences for housing through surveys or meetings. In order for beneficiary participation to work, projects must include special components that address it directly. Beneficiaries should be recruited to help in all phases of designing, implementing, maintaining, supervising, and evaluating a new housing construction, but only if the time, effort, and money are spent to do it correctly (Thwala, 2009). Despite these constraints, when the process is started early enough, this aspect will enhance the production of a housing product that would have be specifically designed to meet the needs of the community in all aspects. Also, special consideration must be given 
to the development of local committees and governance structures to adequately oversee local participation. These local committees and governing structures when developed will direct and execute development (housing) projects, rather than merely receiving a share of project benefits.

\section{METHOD}

The data used in this research were derived from secondary sources only; through a detailed review of related literature on the subject in order to meet the research objectives. The study is a South Africa perspective on the definition of housing process participation.

\section{Lesson Learnt}

From extant review of literature, it was found that participation is a rich concept that varies with its application and definition. The way participation is defined, depends on the context in which it occurs. For some scholars, it is a matter of principle; for others, a matter of practice; for even more it is an end in itself. The literature reviewed further found that participation is a stereotyped word like children use Lego pieces. Like Lego pieces, the words fit arbitrarily together and support the most fanciful constructions. They have no content but do serve a function. As these words are separate from any context, they are ideal for manipulative purposes. Hence, it was found that 'Participation' belongs to this category of word. Also, it was found that beneficiary participation can probably be traced to three root sources, which are: participation as good development project practice (Abbot, 1996); participation as good governance (Kooima, 1993) and participation as political empowerment (Bond, 2001).

Likewise, it was revealed that the South Africa Government's commitment to consultation, public participation transparency, and the adherence to agreed norms and standards is evident in the 2008 Social Housing Act (Act No. 16 of 2008), which, in Section 2.1, states the need for the State to: "consult with interested individuals, communities and financial institutions in all phases of social housing development.

Moreover, the South Africa constitutional requirements for beneficiary participation is found in its mandate for local government, but more specifically in Chapter 10, Section 195, which states that: "public administration must be development-oriented; people's need must be responded to, and the public must be encouraged to participate in policy making and good human resource management and career development practices must be cultivated to maximize human potential". Also, on a national level, the South Africa government introduced, what is commonly known as the Batho Pele Principles, which are found in the White Paper on Transforming Public Service Delivery (1997) and embodies the evolution of public participation in South Africa. Hence, the study revealed that the involvements in projects and other ventures gives people a better understanding of their interests and the interests of others, and, in some cases, brings them to see what would be best for the entire group which is the totality of participation. 


\section{CONCLUSIONS}

The study has assessed a South Africa perspective on the definition of participation in relation to subsidised low-income housing beneficiaries. Findings form the study revealed that since 1994, the South African government has put in place policy and legislative frameworks that seek to promote participatory governance. The notion of beneficiary participation is embedded in the South African Constitution. Also, it was found that the principles of citizen participation is clearly articulated in the Housing White Paper and further advanced in the Development Facilitation Act of 1995, of which the policy goals were later given legal effect by the 1996. Likewise, enshrined in the Constitution's Bill of Rights (Section 26) is the declaration that: "Everyone has the right to have access to adequate housing and that the state must take reasonable legislative and other measures within its available resources, to achieve the progressive realisation of this right". Overall, it was revealed that the South Africa Government's commitment to consultation, public participation transparency adheres to international norms and standards. While the roots of beneficiary participation can be traced to ancient Greece and colonial New England, its significance reflects a contemporary recognition that societies are simply too remote to be truly "of, by and for the people" without their involvement in the development that affects them.

\section{REFERENCES}

- ABBOTT, J. (1996). Sharing the city: community participation in urban management. London: Earthscan.

- $\quad$ ARNSTEIN, S.R. (1969). A ladder of citizen participation. Journal of the American institute of planners, 35(4):216-224.

- $\quad$ BOND, P. (2001). Against Global Apartheid: South Africa meets the World Bank, IMF and International Finance. London and New York: University of Cape Town Press. p. 239.

- CHOWDHURY, A.N. (1996). Let Grassroots Speak: People's Participation, Self-Groups and NGOs in Bangladesh. University Press Limited: Bangladesh.

- DAVIDSON, C.H., Johnson, C., Lizarralde, G., Dikmen, N. \& Sliwinski, A. (2007). Truths and myths about community participation in post-disaster housing projects. Habitat International, 31(1):100-115.

- DAVY, J. (2006). Assessing public participation strategies in low-income housing: The mamre housing project. Stellenbosch University, Stellenbosch.

- DEPARTMENT OF HUMAN SETTLEMENT (2009). Technical and General Guidelines Part A of Part 3 Vol 2 of the National Housing Code (2009) 21. Pretoria: Department of Human Settlement.

- $\quad$ KOTZE, D.A. \& KELLERMAN, G.E. (1997). Participation and managerial approaches to development. Development, administration and management: A holistic approach, ed. D.A. Kotze, Pretoria: Van Schaik.

- MATHBOR, G.M. (2008). Effective Community Participation in Coastal Development. Chicago, IL: Lyceum Books.

- MAFUKIDZE, J.K. \& HOOSEN, F. (2009). Housing shortages in South Africa: A discussion of the after-effects of community participation in housing provision in Diepkloof. Urban forum, 20:379-396.

- $\quad$ MEYER, I. \& THERON, F. (2000). Workbook: Public participation in local government. A framework for action. Bellville: SOPMP. 
- OAKLEY, P. (1991). Projects with people: The practice of participation in rural development Geneva: International Labour office.

- OLIVIER, A. (2003). A critical review of public participation in development planning within South African local governments. Organisation Development Africa.

- RAHNEMA, M. (1992). Participation in The development dictionary - A guide to knowledge and power, ed. W. Sachs, Zed Books Ltd: London, pp. 116-131.

- $\quad$ RIFKIN, S.B. \& KANGERE, M. (2002). What is participation? A participatory strategy in Africa, ed. S. Hartley, London: University College London.

- $\quad$ TAPSCOTT, C. \& THOMPSON, L. (2010). Participatory Development in South Africa Between Rhetoric and Practice. 14th International Research Society for Public Management Conference. Berne Switzerland: 1-19.

- THWALA, W.D. (2009). Experiences and challenges of community participation in urban renewal projects: The case of Johannesburg, South Africa. Journal of construction in developing countries, 14(2):37-54.

- UNITED NATIONS DEVELOPMENT Programme (1998). Governance for Sustainable Human Development. New York: United Nations.

- WILliamS, J.J. (2006). Community participation: Lessons from post-apartheid South Africa. Policy studies, 27(3):197-217. 


\title{
ENVIRONMENTAL IMPACT AND ENERGY MANAGEMENT OF SPORTS STADIA
}

\author{
Chilvers. S. ${ }^{1}$; Chaer, I. ${ }^{2}$ and Ford, A. ${ }^{3}$
}

\begin{abstract}
:
Worldwide focus on energy has sharpened in the last 15 years. Political, sociological, financial and environmental factors cause concern at various global, regional and domestic levels of authority and within the public's consciousness. The built environment within the UK is a high energy user and is increasingly regulated within the UK. 'Energy Management Systems' allow organisations to understand their energy usage and develop strategies to reduce it. Published data from industry and academia contain data that can be utilised to set benchmarks and gain an indication on proven strategies to reduce energy within particular building types. However, the sports industry seems to have little or no mention in such literature. The finances, brand awareness and infrastructure within sport present an opportunity to not only drive its own energy consumption down, but help smaller clubs, and inspire the viewing public and other industries to bring about change through the implementation of procedures and investment in sustainable technology. The current measures being taken by sporting associations and individual clubs to reduce energy use and carbon emissions are investigated via direct contact and also through analysis of published and gathered data the cost of energy consumption is identified as $0.49 \%$, relative to the financial outgoings of a typical English football club. It is concluded that the drive for sustainability is overly reliant on the individual club and what measures that are put in place are hampered by the increased requirements put upon them and lack of future planning in regards to ownership and payback. The example of USA and Canadian sports associations and franchises should be used as one to strive for with regards to engagement with environmental sustainability and wide reporting of issues and measures through Corporate and Social Responsibility.
\end{abstract}

KEYWORDS: ENERGY MANAGEMENT, REGULATIONS, SPORTS STADIA, STADIUM DESIGN, SUSTAINABILITY.

\section{INTRODUCTION}

The UK building services sector tends to focus on the commercial sector with the most common building types being concentrated on with regards to case studies, research, benchmarking and regulation. Specific drivers applicable to the sports industry (such as the British Association for Sustainability In Sport (BASIS)) are reviewed, as are existing attempts by the various national sporting associations in the UK (e.g. the Football Association (FA), Rugby Football Union (RFU) and English and Wales Cricket Board (ECB)) to put measures in place. What mention there is of sustainability is largely in relation to the financial sustainability of the sport, especially at what is called 'grass roots' level. Any mention of environmental sustainability is where the main sporting

\footnotetext{
${ }^{1}$ ME Engineers Ltd - simonc@me-engineers.co.uk

${ }^{2}$ School of the Built Environment and Architecture, London South Bank University, England UK. Email chaeri@1sbu.co.uk

${ }^{3}$ School of the Built Environment and Architecture, London South Bank University, England UK. Email andy.ford@lsbu.ac.uk
} 
associations detail inward looking initiatives within the operation of their respective national stadiums that they have implemented themselves.

There are several English football clubs that issue annual reports on 'Corporate and Social Responsibility' (CSR) which do contain some elements of energy and waste reduction and describe steps being made to reduce their environmental impact. However these tend only to be the richest clubs or those with a stable financial position in regards to long term ownership; which in the modern game is a rarity when many clubs are in precarious financial positions and have had many different owners in recent years. Financial stability and investment in a club tends to concentrate on short term goals like immediate survival or promotion within their association's league structure.

\section{EXISTING ACADEMIC WORKS ON CSR WITHIN SPORT}

Existing Literature on the subject of sustainability in Sports Stadia is sparse and what does exist tends to be predominantly US centric. With a far further reaching academic base to draw upon within 'Sports Management' departments from such notable Universities as Michigan and Tennessee; the US has been analysing and critiquing the sustainability credentials of popular North American sports such as Football, Basketball, Ice Hockey and Baseball for some time. This is seemingly due to a number of factors. There is a high level of integration of sport within the collegiate and university academic system within the US and an emphasis put upon it within the scholarships that are available to students who excel at sport. So much so that the inter-college/university games of some sports are internationally televised and draw just as large crowds as the professional equivalent. This popularity has meant that some University owned stadiums dwarf their professional equivalents in size, leading to some instances of professional sports franchises taking up shared residency within stadiums with a local University.

The University of Michigan's Stadium is the second largest stadium in the world and largest within the US. A further six university owned stadiums make up seven out of the ten largest stadiums in the world. This means that universities within the US have a clear interest in running these facilities as cost effectively and sustainably as possible. The departments within these universities are clearly well placed and funded to be able to research and put into practice the knowledge in this subject area.

Another driving factor is that the majority of National Football League (NFL) stadiums are entirely or part owned by the local authority and the NFL franchises in question are effectively tenants. Therefore the local authority has a vested interest in the cost of running these facilities and will likely be publicly held to account for the environmental impact of these facilities on the surrounding area.

Babiak of the University of Michigan has written several papers on the extent and effectiveness of CSR throughout professional sport in North America (including Canada where she studied). A paper that she co-authored with Wolfe of Brock University discusses the internal and external determinates that effect CSR's within professional 
sports franchises. It uses several data collection techniques including in-depth interviews with eight executives from the four major American sports and it concludes that the external drivers like interconnectedness with sponsors, fans and local authorities plus pressure from their relevant sporting association were key drivers in the development of the CSR strategy. It concludes that a framework should be put in place for the adoption of CSRs and that the determinants that influence individual sports and organisations be investigated further (Babiak \& Wolfe, 2009).

Within another paper by Babiak co-authored with Trendafilova of the University of Tennessee, the motives and pressures to adopt sustainable management practices within sport were investigated and concluded that:

"environmental responsibility has become an important component of business operations for these teams." and

"found environmental practices are diffusing rapidly through professional sports." (Babiak \& Trendafilova, 2011)

A further work by Babiak and Trendafilova investigated the extent of environmental sustainability and CSR using data mining and keyword search techniques on sports organisations, franchises and media outlet websites throughout North America, in an attempt to extrapolate the extent of and influencing factors that such subjects are discussed and communicated. It found that evidence indicated attitudes among the sport organizations, with respect to environmental management were associative and that it also concluded that the media played a key role in:

"...driving and defining the type and extent of involvement in professional sport teams' environmental sustainability efforts." (Babiak, et al., 2013)

\section{UK STADIUM MANAGERS SURVEY}

This research paper has two streams of research. The first was an attempt to get facilities managers of sports stadiums (or their nearest equivalent) to respond to a brief online survey about their clubs current stance on sustainability. This took the form of questions that assessed how energy was monitored, managed and consumed. 75 persons were contacted directly via email. Only three survey responses resulted therefore, after another attempt at contact via email, a social media campaign was initiated and every top level sports club and association in the UK contacted via their official twitter handles (demonstrated within

Figure 3). This resulted in another seven responses, bringing the total responses to ten which included most major UK and Ireland sports associations for Rugby, Football and Cricket.

Figure 3: Twitter Message to UK Sports Clubs and Associations 


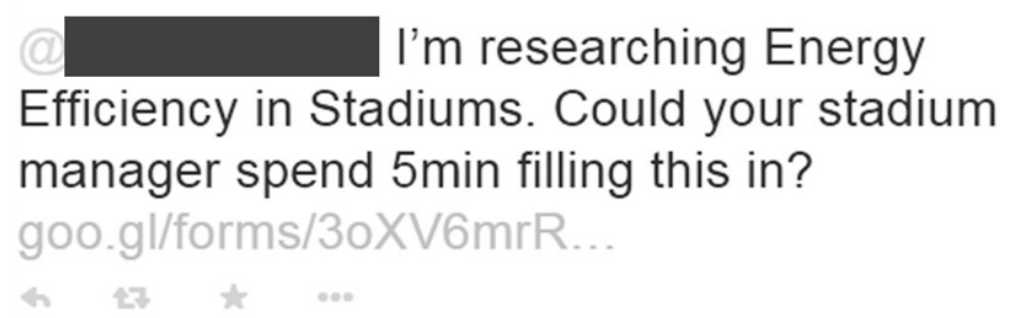

Despite the poor response rate experienced at club level the responses given by the various associations to particular questions regarding management procedures and accreditation yielded the conclusion that there is a distinct lack of any association-led sustainability initiatives throughout each sport with one exception; Cricket. Within the respondents the only sport clubs that could make a claim to be driving sustainability initiatives forward were the County Cricket Clubs. They responded fairly positively regarding a dedicated energy manager and themselves or their venues holding current accreditation to internationally recognised Environmental or Event Management Systems ISO:15001 and/or ISO:20121. With Lords'/ECB's home cricket ground's current energy manager being the current chair of BASIS, it seems that there is a positive attitude to sustainability and energy management throughout the sport.

Within the responses to an open question regarding what sustainability initiatives there are within the sports venues, there was no mention of renewable technologies. Due to the poor response rate, further investigation would be required to determine whether such technology and initiatives may have been included within the original design. This means that the majority of effort with respect to energy reduction is going into reducing energy demand and controlling systems more efficiently. Shown within Figure 4 is a word map displaying the key terms used within the response. The more the term was used within the dataset of responses the larger the font used within the word map.

Figure 4: Word Cloud responses to Sustainability Initiatives

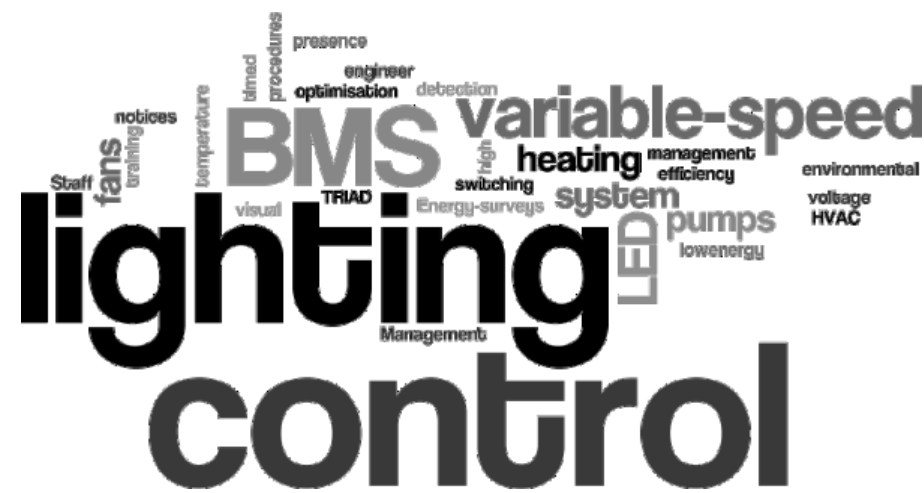




\section{ENERGY CONSUMPTION ANALYSIS}

A paper on the implementation of 'BS EN ISO 50001' and the creation of an 'Environmental Management System' co-authored by the Aviva Stadiums Energy Management team states that the bulk of the energy use within the stadium is from "MICE" (Meetings Incentives Corporate Events).

"Despite the Aviva Stadium being a state-of-the-art facility, encompassing some of the best plant and equipment available at the time of construction, the designer's main priority was to create a stadium which could cater for up to 50,000 people, up to 25 times a year, and not for the hosting of meetings, incentives, conferences and events (M.I.C.E). But M.I.C.E are the second most essential revenue stream for the stadium, and are much more frequent throughout the year. As a result, the stadium consumed over 19,000MWH of energy during its opening year." (Byrne, et al., 2014, p. 6)

The challenge of controlling plant effectively and efficiently for partial occupancy in a stadium is clearly an issue that the energy management team at the Aviva struggled with initially. Such occupancy schedules ideally need to form the original client brief and can even be collaboratively decided upon by the designer, architect, end-users and client as part of final commissioning if need be. Byrne, et al clearly state that this was not the case. However, good industry practice dictates that HVAC plant and Lighting be designed zonally to allow a degree of independent control and efficiency at part load. No mention within the paper is made of additional expenditure on plant or infrastructure, so it can only be assumed that the process that the energy management team went through was iteratively overlaying a control strategy across the HVAC plant.

It is assumed that the plant and controls were left in place for the maintenance and facilities team to develop their own scheduling of plant based on the sporadic occupancy that comes from individually hiring out multitudes of areas within the stadium for 'M.I.C.E'. The nature of such activities in regards to numbers of people in attendance, type of event (catered/non-catered), setup/decant and start/stop times results in large variances on the demands of the stadium's building services system.

Even simpler buildings require a period of time for the occupant to settle into and get an understanding of how they work and how their operations should best translate into buildings management in their new environment. Their day-to-day operations change and, according to the new opportunities their new building affords them, they slowly expand their business into the new or refurbished infrastructure. This dynamic puts a fundamental constraint on how designers of all types of buildings struggle to anticipate the exact usage of a given building, something that is exacerbated within the design of a complex sports stadium with many groups of end users, sometimes with conflicting aspirations for their new working environment.

These usage changes as well as other factors contribute to a phenomenon that has become known as 'The Performance Gap'. This is seen as the difference between the predicted energy use of a building during its design and procurement stages compared to the actual 
energy use of a building once it becomes occupied. This is identified within CIBSE's Technical Memorandum 'TM54: Evaluating operational energy performance of buildings at the design stage'

As explained within 'TM54' there are two main reasons for this performance gap;

"The first is that the method of calculating energy use for the purposes of compliance does not take into account all the energy uses in a building. In particular, it does not address energy used by lifts and escalators, for catering facilities, or for server rooms. This energy use can be substantial: in one case study, the National Trust HQ at Swindon, it was found that 60\% of the energy use, that for the server room and the catering, was used in just 3\% of the floor area, and more than doubled the operational energy use over the design estimates.

The second reason for the performance gap is related to site practice. To deliver a building that uses as much energy as expected requires that the design is built as intended, the engineering systems are commissioned effectively and the operators and occupiers of the building understand how to operate and maintain the building so that it delivers the expected performance." (Menezes \& Cheshire, 2013, p. 4)

The Building Services Research and Information Association (BSRIA) have developed guidance in order to mitigate the effects of the second reason given within the above statement and attempts to quantify and explain this phenomenon. Collectively this suite of guidance is called the 'Soft-Landings' approach to completion of construction projects and handing over of buildings/systems to a client (BSRIA, n.d.).

Designing an environment that is to cater for thousands of people is clearly at odds with M.I.C.E that may only require a tiny fraction of the accommodation space available. Such scenarios would still require HVAC, HWS and catering plant to be energised. An attempt within the article is made to quantify the energy use associated with this and, through implementing 'BS-EN-ISO-50001', measures have been put in place to reduce the energy consumption. This is clearly shown in the year on year energy reduction shown. With the Aviva being a new stadium and the average age of football stadia in the UK being 76 years, it is easy to conclude that there are clearly going to be opportunities to reduce energy within the existing stock of sports and arenas in the UK.

\section{Objective}

Developing upon the above the second stream of work uses published energy consumption data along with data gathered directly by the author to quantify the energy use and expenditure of a typical UK sports club and compared it to the typical total outgoings of a club. Actual energy consumption data from a recently built stadium was gathered by the author and blended with published data from the Aviva Stadium within the paper by Byrne et al and data from Wembley (Wembley, 2014, p. 15). The aim would be to extrapolate this energy trend across the whole of the English Premier League (EPL). 


\section{Data Gathering}

Several issues were experienced when gathering the energy consumption data as it was found that, despite the stadium in question being built only a few years ago and to fairly current regulations, the energy metering was lacking in several instances. Due to the sheer volume and complexity of the stadium the number of Building Management System (BMS), points returning to the BMS head-end was overwhelming the data network and also quickly clogging the hard-disk-drive. Part of a rationalisation procedure, post occupation, was to reduce the energy metering to report twice daily rather than every thirty minutes. Also as part of this, lots of the older data had been archived but couldn't be found. Other more critical issues were that the mains gas meter had been changed since the stadium had been built and was no longer reporting to the BMS also several of the gas sub-meters were either not working or not connected. Most of the nonreporting BMS points were attributed to the black buildings tests that the stadium has to regularly undergo as part of emergency system testing. The BMS outstations would lose power and disconnect from the network and require BMS engineer intervention in order to re-engage within the head-end. This resulted in long periods where nothing was reported and the man hours required to keep reconnecting the outstations was overwhelming. The importance of performing regular health checks of such complicated systems like BMS, metering and other control systems cannot be underestimated. This will ensure that any building is performing as it should do and ensures effective maintenance procedures are carried out as required. Further energy saving measures can also be investigated using the data that is collated.

\section{RESULTS}

Regardless of the issues experienced above, some very useful data on the electrical energy consumption was blended with two sets of published data from the Aviva Stadium in Dublin and Wembley Stadium to produce a gas and electricity usage per square metre of hospitality space.

Using the Site wide electrical consumption data within Error! Not a valid bookmark self-reference. an average of each month was created from the dataset and totalled (shown in italics within the far right hand column) in order to give a typical year consumption of $4,991,831 \mathrm{kWh}$ 
Table 3: Stadium A's site wide Electrical Consumption

\begin{tabular}{llllll}
\hline & 2011 & 2012 & 2013 & 2014 & Average \\
\hline Month) & $(\mathrm{kWh})$ & $(\mathrm{kWh})$ & $(\mathrm{kWh})$ & $(\mathrm{kWh})$ & $(\mathrm{kWh})$ \\
\hline January & & 461164 & 582701 & 564314 & 536060 \\
\hline February & 528747 & 526870 & 473654 & 509757 \\
\hline March & 419303 & 477651 & 453576 & 450177 \\
\hline April & 318359 & 382891 & & 350625 \\
\hline May & 297624 & 335746 & & 316685 \\
\hline June & 306538 & 290902 & 265919 & 287786 \\
\hline July & 328795 & 293639 & 363975 & & 328803 \\
\hline August & 349285 & 374843 & 364080 & 362736 \\
\hline September & 397752 & 349687 & 355142 & 397527 \\
\hline October & 332541 & 440037 & 425798 & & 512681 \\
\hline November & 537459 & 498678 & 501905 & & 569535 \\
\hline December & 630609 & 582701 & 495295 & & \\
\hline Cost (£) & $231,214.91$ & $394,320.55$ & $449,908.41$ & $132,150.80$ & \\
\hline $\begin{array}{l}\text { Average } \\
\text { Monthly (£) }\end{array}$ & 33030 & 32860.05 & 37492.37 & 44050.27 & \\
\hline
\end{tabular}

Table 4: Calculation of Energy Intensity for Gas and Electricity

\begin{tabular}{lllll}
\hline & Aviva & Wembley & Stadium A & Intensity \\
\hline Capacity (seats) & 51,700 & 90,000 & 31,000 & \\
\hline GIA (m2) & 66,460 & 174,000 & 21,000 & \\
\hline Hospitality Area (m2) & 6,160 & 8,905 & 3,650 & \\
\hline Gas $(\mathrm{kWh} / \mathrm{yr})$ & $7,040,800$ & $8,311,993$ & - & \\
\hline Elect. $(\mathrm{kWh} / \mathrm{yr})$ & $8,212,400$ & $22,191,401$ & $4,991,831$ & \\
\hline Gas $(\mathrm{kWh} /[\mathrm{seat}] . \mathrm{yr})$ & 136.185687 & 92.355478 & & \\
\hline Elect. $(\mathrm{kWh} /[\mathrm{seat}] . \mathrm{yr})$ & 158.847195 & 246.571122 & 161.026806 & \\
\hline Gas $(\mathrm{kWh} / \mathrm{m} 2[\mathrm{gia}] . \mathrm{yr})$ & 105.940415 & 47.770075 & - & 1038.19721 \\
\hline Elect. $(\mathrm{kWh} / \mathrm{m} 2[\mathrm{gia}] . \mathrm{yr})$ & 123.569064 & 127.53679 & 237.70624 & \\
\hline Gas $(\mathrm{kWh} / \mathrm{m} 2[\mathrm{hosp} \cdot \mathrm{yr})$ & 1142.98701 & 933.40741 & - & 1350.40337 \\
\hline Elect. $(\mathrm{kWh} / \mathrm{m} 2[\mathrm{hosp}] . \mathrm{yr})$ & 1333.18182 & 2492.0158 & 1367.6249 &
\end{tabular}

The Consumption from the data available for the Aviva and Wembley was averaged for gas and electricity to represent a typical year. No particular year was targeted due to the 
general aim of this methodology is to create a typical baseline for any given stadium and to ignore the fact that the Aviva and Wembley stadiums were attempting to demonstrate energy reductions year-on-year.

\section{ANALYSIS}

The Gross Internal Area (GIA) of Wembley is questionable and is taken from published Display Energy Certificate data. It is suspected that this is taking into account concourse area instead of conditioned (heated) area within the 'thermal envelope' of the stadium. Also the electrical demand is vastly disproportionate to the other electrical consumptions. This is due to the fact that Wembley has a relatively small roof 'oculus' in order to facilitate a retractable roof, requiring extensive use of grass growth lamps in order to nourish the grass all year round. Therefore the electrical consumption is ignored in this instance. The remaining values when calculated per square area of hospitality are roughly proportionate with one another with the electrical consumption of the Aviva and Stadium A at approximately $2.5 \%$ variance from each other.

Using the gas consumption rate of $\mathbf{1 0 3 8 . 2} \mathbf{k W h} / \mathbf{m}^{2}[\mathbf{h o s p}] . \mathbf{y r}$ and electricity consumption rate of $1350.4 \mathrm{kWh} / \mathbf{m}^{2}[\mathbf{h o s p}] . \mathbf{y r}$ the potential energy consumption of the stadiums within the EPL were inferred from the Hospitality areas for each stadium. These areas were extracted from the clubs hospitality sections of their websites that give booking and layout details of their conferencing facilities. Along with the inferred energy consumption for each stadium within the EPL, basic financial information was gathered for each club giving total incomings and outgoings for 2014/15. This work finds that on average $\mathbf{0 . 4 9 \%}$ of an EPL club's total annual outgoings are potentially spent on the energy consumed by their stadiums.

\section{DISCUSSIONS}

More leadership and transparency is required within the industry and an opportunity exists to leverage the financial strength of the EPL, but this requires the sports associations to take note of this fact and enforce such an attitude downwards.

The USA and Canada have a comparatively more engrained and positive ethos towards sustainability of stadiums and sport management within their league structures. This could possibly be replicated within the UK. 10 years ago academic papers within North America were calling for better leadership from the major sports leagues and now there are papers and journals praising the steps that have been made. One element of the success within North America has been strong city and authority governance on these issues, with progressive attitudes towards planning and what is expected of large commercial franchises with global images and far reaching social implications within their community. Corporate Social Responsibility within sports associations and franchises are the norm rather than the exception in the US and Canada, something that is lacking in the UK. 
Leadership within the UK is weak, with the ECB being the only sport association that is actively a member of an organisation for change. Other associations are making attempts to maintain a good attitude towards sustainability but the approach seems to be very insular and only really interested in what the association can do themselves rather than attempt to enforce a top down approach throughout their respective sports.

Several EPL clubs are in the process of heavily redeveloping, increasing or moving their Stadiums including Tottenham, Liverpool, Chelsea, Manchester City and West Ham. The increasing capacity and technical specification of modern grounds with ever increasing hospitality space and broadcast facilities means that despite clubs sustainable initiatives the trend is that energy consumption of stadiums is only going to increase. Exacerbated further by the recent trend of modern football clubs developing structured academies within dedicated training grounds separate to their main stadium in order to comply with the EPL's 'Elite Player Performance Plan' (EPPP) (The Premier League, 2011).

Two recent instances highlight this; a widely publicised requirement of an additional substation to feed Manchester City's new training ground despite its lauded sustainable credentials and Chelsea's newly upgraded LED sports lighting system as an example of energy savings that have been negated due to a recent increase in EPL's sports lighting requirements for improved broadcasting quality.

\section{CONCLUSIONS}

It is easy to conclude that energy cost cannot be at the forefront of UK clubs financial management, with only $\mathbf{0 . 4 9 \%}$ of their outgoings being spent on Gas and Electricity. Financial Fair Play (FFP) is now being enforced by UEFA across Europe with mechanisms to stop clubs over spending and risking financial difficulties. The reaction from clubs seems to be that income needs to be boosted and the lucrative nature of matchday hospitality and non-matchday MICE are driving the clubs towards investment in upgrading existing stadia or building new ones. Although new stadia that are built to current regulations and sustainable agendas should be welcomed, the energy consumed by stadia that are going to be larger and vastly more complex and heavily serviced than those they replace is not going to bring about a net reduction in energy and may risk the reverse.

As found within the survey, there is a drive towards energy reduction and energy efficiency through adapting and improving controls on Lighting and HVAC equipment, but this is likely to only be part of a good practice maintenance regime using current technology and techniques where possible, rather than a concerted initiative driven by a wider sustainability agenda. It's also noted that none of the respondents stated that they had installed renewable energy technologies. This is likely to remain the case while there are so many other complicating factors that need to be addressed within a building as complex as a stadium and with ever increasing commercial requirements put upon a stadium's services. 


\section{REFERENCES}

- $\quad$ BABIAK, K., HEINZE, K. \& TRENDAFILOVA, S., 2013. Corporate social responsibility and environmental sustainability: Why professional sport is greening the playing field. Sport Management Review, 16(13), pp. 298-313.

- $\quad$ BABIAK, K. \& TRENDAFILOVA, S., 2011. CSR and environmental responsibility: motives and pressures to adopt green management practices. Corporate Social - Responsibility and Environmental Management, 18(1), p. 11.

- BABIAK, K. \& WOLFE, R., 2009. Determinants of Corporate Social Responsibilty in Sport: Internal and External Factors. Journal of Sport Management, Issue 23, pp. 717-742.

- BSRIA, n.d. Soft Landings.

[Online] Available at:

https://www.bsria.co.uk/services/design/soft-landings/ [Accessed 1804 2015]

- $\quad$ BYRNE, A. M., BARRETT, M. D. \& KELLY, R. M., 2014. Implementation of ISO 50001 Energy Management System in Sports Stadia. SDAR* Journal of Sustainable Design \& Applied Research - Issue 1: Volume 2: Article 1, pp. 6-13.

- MENEZES, A. C. \& CHESHIRE, D., 2013. Foreword. In: K. Butcher, ed. TM54: Evaluating operational energhy performance of bilding at the design stage. London: CIBSE, p. 4.

- THE PREMIER LEAGUE, 2011. Elite Player Performance Plan. [Online] Available at: http://www.premierleague.com/content/premierleague/en-gb/youth/elite-playerperformance-plan html [Accessed 3103 2015].

- WEMBLEY, 2014. Going Greener: Our Journey to Environmental Sustainability 2012-13. [Online] Available http://view.vcab.com/?vcabid=geaSenhgpScnahcag\&count=23/12/2014\%2012:02:56-2 [Accessed 2304 2015]. 


\title{
PERFORMANCE IN USE: THE GREAT EXTERNALITY OF THE BUILT ENVIRONMENT
}

\author{
Gillich, A. ${ }^{1}$ and Ford, A. ${ }^{2}$
}

\begin{abstract}
:
In economics, negative externalities occur when production or consumption impose external costs on third parties outside of the market, for which no appropriate compensation is paid. Prices seldom capture all costs. Pollution is the most commonly acknowledged externality associated with the built environment. Regulations and taxes therefore attempt to internalise the externality and force the polluter to own that cost. Existing mechanisms that attempt this for building performance are inadequate. Even exemplar buildings routinely consume 200-300\% more energy than their design intent, and many designs are not fit for purpose. This leads to the question: who owns building performance? And more specifically, who is accountable when a building does not perform as promised?

This paper argues that due to institutional barriers in the building industry, in-use performance is an externality fundamentally no different from pollution. Both are 'public goods' that are non-excludable (the benefits of the public good can be enjoyed by many) and non-rival (consumption by some does not prohibit consumption by others).

This work uses data from case studies conducted through the Post-occupancy Review Of Buildings and their Engineering (PROBE) program from 1995-2002. PROBE defined 43 variables for building performance using building user and energy surveys. The findings argue that UK buildings suffer from reduced occupant satisfaction, perceived productivity, and poor energy performance in use. However, these grievances rarely become addressable priorities for buildings in use due to institutional barriers such as split incentives and the difficulties of collective action. Performance is a public good that is not suitably captured by price signals or market interactions between building designer/builders and building occupier/managers. Finally, PROBE results are compared to more recent case study evidence showing that a decade later, the findings of PROBE surveys have still not been sufficiently incorporated into policy efforts to internalise the externality of in-use performance.
\end{abstract}

KEYWORDS: BUILDING PERFORMANCE, EVALUATION, EXTERNALITY, INNOVATIVE PROCUREMENT, SOCIAL RESPONSIBILITY

\section{INTRODUCTION}

The idea that buildings do not perform as predicted is not new. Even exemplar buildings routinely consume $200-300 \%$ more energy than their design intent and too many designs are hardly fit for purpose. This statement is supported by decades of study, and yet the core of the issue has remained unchanged in that time.

This paper argues that building performance in use should be treated as an economic externality in the same way as pollution. Just as the past decade has seen a suite of

\footnotetext{
${ }^{1}$ Centre for Efficient and Renewable Energy in Buildings (CEREB), London South Bank University, gillicha@1sbu.ac.uk

${ }^{2}$ Centre for Efficient and Renewable Energy in Buildings (CEREB), London South Bank University, andy.ford@1sbu.ac.uk
} 
regulatory and market based policies designed to internalise carbon dioxide emissions into the cost of the building process, so must a similar set of policies internalise performance.

This work will build this argument first by exploring the literature context surrounding externalities in the building industry. The empirical portion of the paper will then reviews and compares findings from two different epochs of building performance evaluations. First, data from the PROBE building evaluation studies from 1995 to 2002 to explore the institutional barriers involved and how they impact performance in the context of both occupant satisfaction and energy use. Finally, this will be compared to a modern case study of the Sainsbury Lab in Cambridge to demonstrate how despite advances in many areas of building policy, performance remains an uncosted externality.

\section{LITERATURE ON EXTERNALITIES}

In perfect markets there would be no externalities (Meade, 1973). But it is long accepted that market failures hinder the optimal allocation of resources (Bator, 1958). Economics texts will define a market failure as a result of a negative externality. A typical example is the polluting factory that does not count the additional deterioration of the atmosphere that it causes as a cost of production. A suitable regulation or tax could create a Pareto superior position if the value of cleaner air to society is greater than the value of lost production to the factory (Levin, 1982).

We cannot rely upon voluntary action to internalise all important externalities. It is impossible to decentralize pollution externalities without direct intervention to control market trends (Hochman \& Ofek, 1979). Climate change and greenhouse gas emissions are frequently referred to as economic externalities (Rezai, et al., 2012), and buildings are responsible for one third of global greenhouse gas emissions (UNEP, 2009). The term externality is therefore commonly used for market failures in the built environment with regards to principal agent problems and information asymmetries limiting the implementation of cost effective energy efficiency. What is less accepted is the idea of applying this language of externalities directly to the performance of the building itself.

Externalities, market failures, and public goods are three closely interwoven issues, particularly when the environment is concerned (Merlo \& Rojas Briales, 2000). The issue of buildings as public goods is important. This paper will show that despite the apparent input of owners and occupants to the market, we occupy buildings as a collective and there are numerous barriers to collective action that hinder our ability to value in-use performance with any accuracy. This fits with economic literature on externalities, which escape being correctly priced in the market because they generally appear as public goods, meaning that their consumption is collective (Merlo \& Rojas Briales, 2000). 


\section{VALUE AND EXTERNALITIES IN BUILDINGS}

For buildings in the past, the broader human and environmental costs in planning, pricing and resource selection were simply ignored; or priced at zero (Ottinger, et al., 1990). These externalities or social costs are considerable, and yet:

"The building industry is large, multifaceted, and slow to adopt change and, as such, technical innovation and advance in building design is constrained by economic possibility and social expectation - their cost and perceived value. [...] New emphases to building - such as green performance - require an explicit acknowledgement and justification of the merits of the new requirements." (Cole, 2000)

This amounts to saying that the causes of poor performance lie at the heart of the way in which the building industry operates, but the building industry has few drivers for improving performance in use. As Bordass notes, it is not simply that developers seek to minimise construction costs, rather their focus is on maximising return on investment. This means considering the lettable area, the rental value, time to completion, and occupancy (Bordass, 2000). The distance from there to performance in use is separated by many silos, each of which has their own set of internally logical priorities.

Location, appearance, and specification features have been the main determinants of value, and provided that they are 'good enough' for their purpose, the in-use performance is not highly figured (Bordass, 2000). Many studies have found that sustainable buildings do not face a lack of technological solutions or assessment methods, but rather organisational and procedural difficulties that lead to a sub-optimal result (see e.g. (Hakkinen \& Belloni, 2011).

The specific context of the externality in economic theory has been used to explore the deeper causes of market failures in building energy efficiency markets (Ren, et al., 2009). However, as will be detailed throughout this paper, building energy efficiency markets today deal largely with design and neglect the more important issue of performance in use. Simply put, no regulation or tax affecting the UK building industry directly addresses achieved performance in use. Carbon pollution is internalised through both market mechanisms (e.g. carbon reduction commitment) and legislation (e.g. Part L of the building regulations). The Energy Performance of Buildings Directive has helped the quest for energy efficiency and low carbon buildings in the EU. However, there is no requirement under the EPBD to verify buildings' energy performance in-use (Burman, et al., 2014).

This has been pointed out in theory: "In the context of climate change, the social cost of excess in energy use over the regulatory limit is disproportionately high. Therefore, this excess in energy use could be considered a negative externality that must be measured and treated effectively. Integration of measurement and verification plan into the existing policy framework can facilitate this". (Burman, et al., 2014, pg 162). But in practice, there are no market or policy tools to internalise a building's comfort, functionality, and energy performance the way that is done for pollution. 
Part of the reason for this distinction is simply that carbon pollution is easily quantifiable (e.g. $\mathrm{kgCO} 2 / \mathrm{m} 2 /$ annum), whereas valuing performance in terms of energy, occupant satisfaction and functionality is less straightforward. There are however decades of progress towards creating a consistent and reliable framework for evaluating building performance.

\section{METHODOLOGY}

The methodology for this paper is to review the building performance evaluations of the PROBE (Post-occupancy Review Of Buildings and their Engineering) studies of the late 1990s and compare both their methods and their findings to a more recent evaluation of the Sainsbury laboratory in Cambridge. The methods will be compared along two themes, first the technical performance of the buildings in terms of energy and carbon consumption. This technical performance is measured in the context of both the design intent as well as against what is feasible or expected from exemplar buildings. The second theme is the practical performance of the buildings towards their design function. That is, are they fit for purpose?

These two sets of data are separated by over a decade of study, throughout which policies regulating externalities like carbon pollution have changed considerably. This paper will therefore analyse the degree to which performance in use continues to be an externality.

\section{Building Performance Evaluation Methods}

Post-occupancy surveys have broadened beyond single uses such as energy. A survey might measure the performance of the energy and technical systems, the efficiency space unitisation, occupant comfort and productivity, management, and perhaps environmental impact and cost-in-use (Bordass, et al., 2001). Comfort, health and productivity of building occupants are positively associated statistically, but are easily undermined by chronic, low-level problems (Leaman \& Bordass, 2001).

Logic suggests that building performance should be a self-correcting problem, with millions of precedents upon which to iteratively improve over the past decades and centuries. However, most buildings are considered one off, and when suitable feedback is recorded, it is frequently confidential and at best made available unattributably or anecdotally. (Cohen, et al., 2001)

The Probe studies improved the openness of post-occupancy evaluation studies by reporting them in the Building Services Journal produced by the Chartered Institution of Building Services Engineers (CIBSE). The project ran from 1995 to 2002 and published a total of 23 studies. Probe was part funded by a government grant and partly through the Building Services Journal editorial and publication costs. The Probe investigatory team also contributed much of their time in-kind.

There were three principal differences between Probe studies and other occupant studies (Leaman \& Bordass, 2001): 
- Each building was benchmarked against a broader dataset.

- Technical and energy assessment was combined with occupant satisfaction surveys and an exploration of the design and management context.

- The results were published with all buildings named.

The Probe methodology combines two established tools, the occupant survey method developed by Building Use Studies Ltd (BUS) to gauge occupant satisfaction, and the Energy Assessment and Reporting Method's (EARM) tool for analysis of energy use. The program is summarised across a series of five papers (Cohen, et al., 2001), (Bordass, et al., 2001) (Bordass, et al., 2001) (Leaman \& Bordass, 2001) (Bordass, et al., 2001).

The occupant surveys were based on the BUS methodology, but reduced to only two pages in order to avoid data fatigue among respondents and simplify the analysis for evaluators (Cohen, et al., 2001). The energy assessment methodology could not rely on extensive or intrusive monitoring. They created a spreadsheet based tool similar to CIBSE TM22 which provided the desired combination of precision and relevance and allowed for benchmarking of performance against individual end uses.

The PROBE buildings showed a high variability in gas consumption, from under 40 $\mathrm{kWh} / \mathrm{m} 2 /$ annum to $400 \mathrm{kWh} / \mathrm{m} 2 /$ annum (Bordass, et al., 2001). The results were compared for 17 of the case study buildings were measured against the ECON 19 benchmark buildings (DETR, 2000), with most falling between 'typical' and 'good practice'. In measuring the gas consumption, electricity consumption, and overall carbon dioxide emissions, the majority of buildings consume considerably more than the benchmarks, which is surprising given their design intent as energy efficient buildings (Bordass, et al., 2001).

The following factors were identified among the most common design issues (Bordass, et al., 2001):

- Excessive ventilation: Most buildings were well insulated but lost considerable energy due to gaps in the fabric. There were also problems with automated windows, and also unnecessarily high volumes of mechanical ventilation.

- Window design: Plans to use natural daylight frequently suffered from glare issues. Often control system issues kept lights on even when sufficient daylight was present. There were also control issues around unreachable handles. Automated controls of windows and blinds could also frustrate users.

- Novel advances underperform: Several buildings attempted novel energy saving designs that suffered from control issues, lack of accountability, and insufficient understanding by occupants, termed: the 'pitfalls of innovation'.

- Lighting and its controls: Lighting was often oversupplied and overused. Daylight-linked photoelectric controls seldom accounted for local operation of blinds and so were often re-set or over-ridden, diminishing savings.

- Common control and operation issues: Many control systems issues already noted for windows and lighting. This was common for HVAC systems as well. Poor boiler sequencing and poor or non-existent sequencing of chiller was an issue. Wasteful hours of pump running. Poor user interfaces. Poorly laid out plant 
rooms or services complicate the servicing, adjustments, and repairs process. Poor response to exceptional circumstances, or small local loads requiring large systems to operate at longer hours.

It is interesting to note that many of these items require solutions at the design stage and are difficult or costly to address later throughout the life of the building. More should be done to 'get it right the first time': The industry is not good at dealing with problems after completion (Bordass, et al., 2001). Even issues that can be addressed through operation were found to be problematic. Most buildings do not give sufficient resources for proper management, and as a result the building services and control systems require more than the building operators can meet.

Probe also measured occupant satisfaction, comfort, and health using a 43 point BUS Survey dataset. Selected results are summarised in Table 1, though the general findings of the Probe studies were: "that chronic occupant problems are widespread in British buildings. Many of these never come sufficiently high on anyone's priority list to get fixed, so slamming doors, and glare from sun and sky, hot offices, poor controls, noise disturbance and suchlike are the norms for occupants everywhere. They may seem trivial, but the effects on occupant satisfaction and perceived productivity are not." (Leaman \& Bordass, 2001) pg 142.

Even though problems such as noise can affect productivity and bottom lines, no one 'owns' the problem, and as a result, buildings are less comfortable, productive, and functional than they could be. In 2001 Probe raised two reasons there is interest in POE but little action: Who pays for the survey? And who pays to implement the findings? The fact that the industry has not satisfactorily addressed these questions was raised by Cooper (Cooper, 2001)Most designers are reluctant to fund POEs, and among those that received Probe evaluations, no funding was available to allow follow up improvements. Some buildings self-financed the improvements in response to Probe findings, but most did not even though minor changes could have made significant improvement (Bordass, et al., 2001).

It is also worth noting that the Spearman Rank coefficient for the comfort index score and the productivity ranking is rho $=0.84 \mathrm{p}<<.01$, suggesting a correlation between comfort and productivity among this sample.

A closing theme and recommendation from the Probe studies was that you shouldn't procure what you can't afford to manage. Most occupiers prefer simple buildings that don't get in the way and buildings that can respond to them. 
Table 1: Comfort and productivity rankings for Probe studies (Leaman \& Bordass, 2001).

\begin{tabular}{|l|l|l|l|l|}
\hline Rank & Initials & Building Name & $\begin{array}{l}\text { Comfort Index } \\
\text { Score }\end{array}$ & $\begin{array}{l}\text { Productivity } \\
\text { Ranking }\end{array}$ \\
\hline 1 & FRY & Elizabeth Fry Building & 5.12 & 6.2 \\
\hline 2 & TAN & Tanfield House & 4.73 & 8 \\
\hline 3 & C\&G & Cheltenham \& Gloucester Bldg Society & 4.66 & - \\
\hline 4 & RMC & Rotherham Magistrates Courts & 4.59 & 1.8 \\
\hline 5 & MBO & Marston Book Services Of® ce & 4.44 & 7.1 \\
\hline 6 & WMC & Woodhouse Medical Centre & 4.36 & 10.9 \\
\hline 7 & HFS & HFS Gardner House & 4.22 & 2.1 \\
\hline 8 & CAB & John Cabot City Technology College & 4.2 & 6.3 \\
\hline 9 & POR & The Portland Building & 4.17 & 4.8 \\
\hline 10 & CRS & Co-operative Retail Services & 4.08 & 1.1 \\
\hline 11 & ALD & 1 Aldermanbury Square & 4 & -4.2 \\
\hline 12 & Benchmark & & 3.96 & -2.6 \\
\hline 13 & DMQ & de Montfort University, Queens Building & 3.81 & -10 \\
\hline 14 & CAF & Charities Aid Foundation & 3.64 & -3.5 \\
\hline 15 & APU & Anglia Polytechnic University & 3.51 & -5.6 \\
\hline 16 & C\&W & Cable \& Wireless Training College & 3.27 & -8.1 \\
\hline
\end{tabular}

\section{ANALYSIS OF RECENT CASE STUDIES}

A research project recently considered the performance of the Sainsbury's Research Laboratory in Cambridge (Min Lee, et al., 2015). The Sainsbury Laboratory, completed in 2010 achieved a BREEAM Excellent rating for environmental performance in both the design and post-construction stage. It has an EPC rating of B46. It also received building services award for innovative use of daylight and won the Sterling prize for architectural design.

The energy and gas data given in Figure 3 show that a decade after the Probe studies, exemplar buildings can still fail to meet expectations. The study used a similar methodology to the Probe surveys in combining energy performance and POE studies. Despite $94 \%$ of the gas consumption going towards space heating ( $6 \%$ hot water), the most frequent complaint from the POE survey was that the space was too cold. Most took no actions to correct this because temperature controls were not available, or they didn't know how to take actions. The POE showed that most were happy with the lighting, and that where there were issues, it was again generally around controls and shading. (Min Lee, et al., 2015). 
Figure 3: Comparison between estimated and actual regulated and unregulated energy consumption of the Sainsbury Laboratory, as well as with the standards described in CIBSE TM46.The actual energy use is based on year 2013. (Min Lee, et al., 2015)

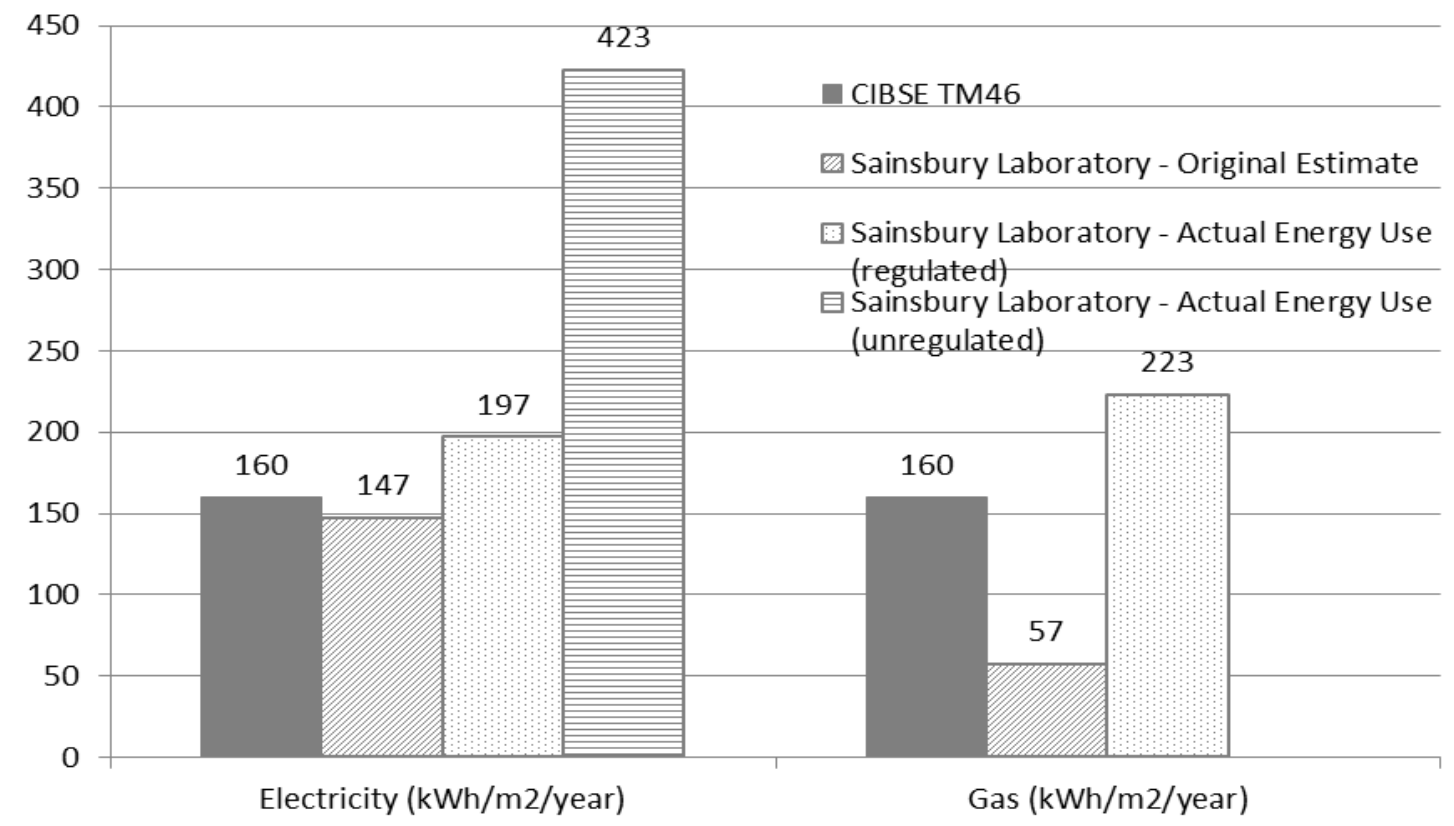

The Sainsbury Laboratory is not an isolated case. A recent review of fifty non-domestic buildings evaluated in the Innovate UK's Building Performance Evaluation programme produced similar results (Palmer \& Armitage, 2014), as does an analysis of CarbonBuzz data quantifying the gap between design and performance for 600 buildings (CarbonBuzz, 2013).

\section{DISCUSSION AND CONCLUSIONS}

This paper has defined externalities and shown that they are well recognised within the built environment for pollution, but not for performance. The building regulations, which internalise carbon emissions via Part L do not actually count performance at all. Even in a Carbon Trust document cautioning against assuming that regulations compliance modelling will indicate actual performance, they still refer to the Part L and EPC scores as 'Design Predictions' (Carbon Trust, 2011). This lazy use of language confuses the public and suggests that performance is included in design calculations when in fact no current regulations count performance at all, either through prediction or post hoc measurement. DECs do this for some public buildings, but without tying the measurement to a consequence.

This idea of designing for benchmarks not performance is deeply woven into the existing regulatory environment. The Probe studies emphasised this point over a decade ago and the idea of designing for operation is still not adequately addressed by policy. This observation is therefore not new. Studies have noted that leading causes of the 
performance gap include a reliance on calculated performance under standardised conditions rather than performance in use, and inadequate prediction of energy use during the design stages among other factors. (Burman, et al., 2014) (Carbon Trust, 2011).

Treating performance in use as an externality no different than pollution is an important step towards treating building performance as a public good to which we are all entitled. Fundamental to the definition of an externality is the idea that the external effect will be on parties that are not participants in the market being studied (Miller, 2006). The Probe case studies as well as the Sainsbury Lab showed that occupants and building managers either lack the means to influence the technical performance of the building to due design choices, or when they do have the technical means to intervene, barriers to collective action often prevent them from doing so. This is particularly true for buildings with transient occupancy, for which the public good aspect of externalities is very relevant.

Many of the technical issues above can be traced to a route problem that Probe termed: Diversity of usage. That is many modern buildings are less routinely occupied due to flexible working and out of use hours. However, most design processes assume more traditional usage patterns. This leads to services that cannot flexibly adapt to changes and buildings that are not designed for their users.

Finally, in reviewing commentaries on the Probe process, Bordass et. al., (2002) noted that there is wide consensus that the costs of POE were small compared to the likely benefits, but that despite this, POE is often difficult to justify. The reasons they cite include: a fragmented supply industry, uncertain benefits, the results may be threatening, and unclear ownership of the process. All of these factors are commonly acknowledged as market failures, and thus meet that basic criterion for policy intervention.

The central point of this paper is that the formality of language is not esoteric or abstract. There are a considerable number of built environment professionals that believe Part L models are design estimates and EPCs predict building energy in use. Even the word 'performance' in the acronym EPC only confuses the matter further. Building performance meets the conventional economic definition of an externality no different from pollution. If the UK is to have legally binding carbon pollution targets we must be equally ambitious about performance itself, which as the Probe studies showed is about far more than just energy. Nobody owns performance in use, and decades of evidence show that policy has not yet addressed this in a fundamental way. Recent efforts by the UK government to do away with environmental regulations and leave more to the construction industry are therefore unlikely to meet with success.

\section{REFERENCES}

- $\quad$ BATOR, F., (1958). The Anatomy of a Market Failure. The Quarterly Journal of Economics, 72(3), pp. 351-379.

- BORDASS, B., (2000). Cost and value: fact and fiction. Building Research and Information, 28(5-6), pp. 338-352. 
- $\quad$ BORDASS, B., COHEN, R., STANDEVEN, M. \& LEAMAN, A., (2001). Assessing building performance in use 2: technical performance of the Probe buildings. Building Research \& Information, 29(2), pp. 103-113.

- $\quad$ BORDASS, B., COHEN, R., STANDEVEN, M. \& LEAMAN, A., (2001). Assessing building performance in use 3: energy performance of the Probe buildings. Building Research \& Information, 29(2), pp. 114-128.

- BORDASS, B., LEAMAN, A. \& COHEN, R., (2002). Walking the tightrope: the Probe team's response to BRI commentaries. Building Research and Information, 30(1), pp. 62-72.

- $\quad$ BORDASS, B., LEAMAN, A. \& RUYSSEVELT, P., (2001). Assessing building performance in use 5: conclusions and implications. Building Research \& Information, 29(2), pp. 144-157.

- BURMAN, E., MUMOVIC, D. \& KIMPIAN, J., (2014). Towards measurement and verification of energy performance under the framework of the European directive for energy performance of buildings. Energy, Volume 77, pp. 153-163.

- CARBON TRUST (2011). Closing the Gap: Lessons learned on realising the potential of low carbon building design, London: Amsterdam University Press..

- $\quad$ CARBONBUZZ (2013). Summary of Audits Performed on CarbonBuzz by the UCL Energy Institute, London: CarbonBuzz.

- COHEN, R., STANDEVEN, M., BORDASS, B. \& LEAMAN, A., 2001. Assessing building performance in use 1: the Probe process. Building Research \& Information, 29(2), pp. 85-102.

- COLE, R. J., (2000). Editorial: Cost and Value In Building Green. Building Research \& Information, 28(5-6), pp. 304-309.

- COOPER, I., (2001). Post-occupancy evaluation - where are you?. Building Research and Information, 29(2), pp. 158-163.

- $\quad$ DETR (2000). Energy Efficiency Best Practice Programme, Energy Consumption Guide 19, energy use in offices, BRESCU for DETR, s.1.: s.n.

- HAKKINEN, T. \& BELLONI, K., (2011). Barriers and drivers for sustainable building. Building Research \& Information, 39(3), pp. 239-255.

- HOCHMAN, O. \& OFEK, H., (1979). A Theory of the Behaviour of Municipal Governments: The Case of Internalising Pollution Externalities. Journal of Urban Economics, Volume 6, pp. 416-431.

- $\quad$ LEAMAN, A. \& BORDASS, B., (2001). Assessing building performance in use 4: the Probe occupant surveys and their implications. Building Research \& Information, 29(2), pp. 129. 143.

- LEVIN, P., (1982). Pollution Externalities: Social Cost and Strict Liability. Cato Journal, 2(1), pp. 205-229.

- MEADE, J. E., (1973). The Theory of Economic Externalities: The Control of Environmental Pollution and Similar Social Costs, s.1.: Brill Archive.

- MERLO, M. \& ROJAS BRIALES, E., (2000). Public goods and externalities linked to Mediterranean forests: economic nature and policy. Land Use Policy, Volume 17, pp. $197-$ 208.

- $\quad$ MILlER, N., (2006). Notes on Microeconomic Theory: Chapter 8 Externalities and Public Goods. Chicago, Illinois: s n.

- MIN LEE, S., SOULTI, E. \& GUTHRIE, P., 2015. The energy performance gap in nondomestic buildings: a case study to evaluate the occupants' influence and a post-occupancy evaluation., University of Cambridge: Working Paper, Centre for Sustainable Development, Department of Engineering.

- $\quad$ OTTINGER, R. et al., (1990). Environmental costs of electricity, New York, NY (United States);: Oceana Publications.

- $\quad$ PALMER, J. \& ARMitAGE, P., (2014). Building Performance Evaluation Program: Early Findings from Non-Domestic Projects, s.1.: Innovate UK.

- $\quad$ REN, S.-m., GUO, H.-d. \& XU, Z.-y., (2009). Externality Feature Analysis of Building Energy Efficiency Market and Incentive Policies in China. Construction Conserves Energy, Volume 1, p. 26. 
- REZAI, A., FOLEY, D. K. \& TAYLOR, L., 2012. Global Warming and Economic Externalities. Economic Theory, 49(2), pp. 329-351.

- UNEP, 2009. Buildings and Climate Change - Summary for Decision Makers, Paris, France: United Nations Environment Program. 


\title{
LEVERAGING CONCEPTS FOR ENVIRONMENTALLY SUSTAINABLE BUSINESS MANAGEMENT IN CONSTRUCTION - A FOCUSED REVIEW
}

\author{
Huovinen, $\mathrm{P}^{1}$
}

\begin{abstract}
:
The main objective of this paper is to advance applied conceptual knowledge about environmentally sustainable business management (BM) in construction. Environmentally sustainable BM is herein defined to encompass the utilization and development of natural resources in ways which are compatible with the maintenance of these resources, and with the conservation of the natural and built environments, for current and future generations. In principle, concept designers can incorporate environmental sustainability into their BM concepts as a dimension, an element, or an attribute of managing, or as a criterion in decision making. Readily, the 71 construction-related BM concepts have been published between 1990 and 2013. A focused review resulted in the expected findings, i.e., only the 11 (15\%) construction-related BM concepts have been designed along the environmental sustainability dimension. Thus, it is posited that high-sustainability BM concepts be designed by coupling environmental sustainability with the three other necessary dimensions, i.e., content-free frames of reference on BM, schools of thought on generic BM, and focal contexts in construction, respectively. In turn, CIB-related researchers may adopt these couplings and engage themselves with cross-disciplinary BM conceptualization programs in collaboration with farsighted business managers in construction.
\end{abstract}

KEYWORDS: BUSINESS MANAGEMENT, CONCEPT DESIGN, CONSTRUCTION, ENVIRONMENTAL SUSTAINABILITY, RESEARCH REVIEW.

\section{INTRODUCTION}

The background involves this author's argument that business management (BM) is the most challenging, evolving, and critical area (or level) within strategic management in general, in research and practice as well as across all contexts (Huovinen 2003, 2015). Thus, generic and applied research on BM has been reviewed since 1999. So far, the reviewing has resulted in the identification of the 71 construction-related BM concepts that have been published in English mainly via journals between 1990 and 2013 (e.g., Huovinen 2015). Construction relatedness includes the ownership, financing, life-cycle, design, implementation, and servicing aspects of capital investments in natural resources usage, energy supply, manufacturing, telecommunications, transportation, infrastructure, real estate, and general building concerns. Later, the terms "construction" and "construction-related" are used to encompass all kinds of built environments and investment concerns. Besides the reviewing of construction-related BM concepts, many focused reviews have been conducted among the schools of thought on generic BM (e.g., Huovinen 2010) as well as along the four dimensions of the concept design, i.e., environmental sustainability (Huovinen 2011b), business ideation (e.g., Huovinen

\footnotetext{
${ }^{1}$ Department of Civil Engineering, Tampere University of Technology, Finland. pekka huovinen@tut.fi.
} 
2012a), collaboration (Huovinen 2012b), and international business (e.g., Huovinen 2011c).

The first focused review of the design of concepts along the environmental sustainability dimension addressed the 62 construction-related BM concepts published between 1990 and 2009 (Huovinen 2011b). No high-sustainability BM concepts were among them. Thus, this reviewer felt necessary to design the two such BM concepts (Huovinen 2011ab) in order to pave a way for other concept designers.

In turn, this paper serves as a 4-year update identifying and covering altogether the nine new BM concepts published between 2010 and 2013. The main objective is to advance applied conceptual knowledge about environmentally sustainable BM in construction. The four sub-objectives include (i) the introduction of the pioneering reviewing, (ii) the overview of the 71 construction-related BM concepts, (iii) the reporting on the focused review of the design of these 71 concepts along the environmental sustainability dimension, and (iv) the choice and coupling of the four necessary dimensions for the advancement of concepts for environmentally sustainable managing of businesses in construction. The four parts of the paper are unfolding as follows.

\section{71 CONSTRUCTION-RELATED BM CONCEPTS PUBLISHED BETWEEN 1990 AND 2013}

The independent reviewing serves as a way of learning and understanding vis-à-vis construction-related BM research. The four review rounds have been carried out in 19992003, 2006, 2010-2012, and 2014. The same limitations have been re-adopted in order to protect the validity against the five threats. Hart's (1998) literature review guidelines have been relied upon. The design of and reliance on the method for the reviewing of conceptual research, i.e. the documented, replicable ways of searching, browsing, in/excluding, retrieving, inferring, moderate coding, describing, analyzing, and interfering with the construction-related conceptual BM data have been reported upon in Huovinen $(2003,2006,2008)$.

The search for eligible construction-related BM concepts has been conducted comprehensively within the volumes of 21 journals in construction and those of 47 journals in business administration. Concerning the other formal channels, the degrees of the comprehensiveness of the search have varied markedly.

The 71-concept population is herein overviewed only via the three questions.

Question 1. What is the relatedness of 71 concepts to one or several of eight schools of thought on BM? Generic BM research involves the eight schools of thought: (1) Porterian school, (2) resource-based school, (3) competence-based school, (4) knowledge-based school, (5) organization-based school, (6) process-based school, (7) dynamism-based school, and (8) evolutionary school (Huovinen 2008). This reviewer could assign each $\mathrm{BM}$ concept to one of the eight schools based on the respective authors' rationales and replies to the fundamental question "What is the primary way (element) of managing that 
will enable managers to set challenging business goals and also to attain them?" The school relatedness appears in Table 1 . The combined share of the four schools is $80 \%$ or 57 concepts (16 Porterian, 16 dynamism-based, 15 organization-based, and 10 knowledge-based concepts). Since 1999, none of the schools has triggered a coherent flow of construction-related BM concepts.

Question 2. What is the relatedness of 71 construction-related BM concepts to disciplines within engineering sciences? $34(48 \%)$ concepts are primarily related to construction management (CM), $14(20 \%)$ concepts are related to industrial management and international marketing, $12(17 \%)$ concepts are related to project management (PM), and $11(15 \%)$ concepts are related to corporate real estate services. The scholars of these four disciplines have designed $62(87 \%)$ concepts. 9 (13\%) concepts have been designed by the scholars affiliated with the business schools. No traditions in research on construction-related BM exist in the OECD countries.

Question 3. For which focal business contexts have the authors designed 71 constructionrelated BM concepts? 25 (35\%) concepts address project-based, contracting, complex product systems, or engineering, purchasing, and construction (EPC) projects, 25 (35\%) concepts address construction or building broadly, 10 (14\%) concepts address real estate development and services, $5(7 \%)$ concepts address businesses based on capital investment markets, $4(6 \%)$ concepts address design and consulting services, and $2(3 \%)$ concepts address building products supply.

The pioneering reviewing has been protected only in part against the formal publishing channel bias, i.e. an increasing difference between a number of 71 identified construction-related BM concepts and a number of an existing population of such concepts published via all formal scientific channels. It is likely that in total 80-85 construction-related BM concepts have been published between 1990 and 2013.

\section{FOCUSED REVIEW AND THE ASSESSED DEGREES OF THE DESIGN OF 71 CONSTRUCTION-RELATED BM CONCEPTS ALONG THE ENVIRONMENTAL SUSTAINABILITY DIMENSION}

In general, OED (2011) defines sustainable "to be capable of, relating to, or designating forms of human economic activity and culture that do not lead to environmental degradation, especially avoiding the long-term depletion of natural resources". Oxford Reference (2015) condenses sustainable into "capable of being sustained or continued over the long term, without adverse effects", defines sustainability as "a concept that is used to describe community and economic development in terms of meeting the needs of the present without compromising the ability of future generations to meet their needs" and ecological sustainability as "the maintenance or restoration of the composition, structure, and processes of ecosystems" as well as couples sustainable management into "managing the use, development, and protection of natural resources in a way or at a rate 
which enables people and communities to provide for their social, economic, and cultural well-being and for their health and safety".

\section{Conduct of the focused review}

For the focused review, the four degrees of environmental sustainability were prespecified. A particular author may have designed a construction-related BM concept along the environmental sustainability dimension to:

- a high degree, i.e., environmental sustainability is one of the primary elements of BM such as one of business goals, a key attribute of offerings, a set of competitive advantages, a synergy among strategies, an edge of competitiveness, and a key performance indicator of business processes, organizations, project portfolios, etc.

- a medium degree, i.e., environmental sustainability is one of the supportive elements of BM

- a low degree, i.e., environmental sustainability is only an implicit part of a firm's offerings and underlying expertise in built environments and/or it is taken into account only as one requirement or one tendency in client chains' buying behavior, one criterion in stakeholders' decision making, one factor in environmental analyses, etc.

- no degree at all, i.e., an author is silent vis-a-vis environmental sustainability, no single 'thing' is explicitly written along this dimension in the reference.

The concept-specific assessments were compiled in the tables, school by school (except that none of the identified 71 concepts belong to the 8th evolutionary school). The corresponding sentences, phrases, or single terms were quoted with the page numbers, respectively. This reviewer will submit a complete list of 68 references containing 71 construction-related BM concepts on request.

Overall, the assessment revealed that $11(15 \%)$ construction-related BM concepts have been designed along the environmental sustainability dimension. Relatively, there are only indicative differences between the concepts belonging to the seven schools of thought on BM, i.e., $50 \%$ ( 1 out of 2 ) of the resource-based concepts have been designed along the environmental sustainability dimension, followed by $19 \%$ (3 out of 16) of the Porterian concepts, 19\% (3 out of 16) of the dynamism-based concepts, $14 \%$ ( 1 out of 7 ) of the process-based concepts, $13 \%$ (2 out of 15) of the organization-based concepts, $10 \%$ (1 out 10) knowledge-based concepts, and $0 \%$ (0 out of 5) competence-based concepts (Table 1).

Ex ante, this reviewer knew that there are at minimum $2(3 \%)$ high-degree constructionrelated BM concepts that he himself had designed (Huovinen 2011a-b). But it turned out to be erroneous to assume that the other authors had designed some recent high-degree concepts as well. So far, 2 (3\%) high-degree, 1 (1\%) medium-degree, and 8 (11\%) lowdegree construction-related BM concepts have been designed along the environmental sustainability dimension (Table 1). 
Table 1: Results of the four-degree assessment of the design of 71 construction-related BM concepts (published btw. 1990 and 2013) along the environmental sustainability dimension

\begin{tabular}{|c|c|c|c|c|c|c|c|c|c|}
\hline \multirow[t]{3}{*}{$\begin{array}{l}\text { School of thought on } \\
\text { generic BM }\end{array}$} & \multicolumn{2}{|c|}{$\begin{array}{l}\text { High-degree } \\
\text { concepts }\end{array}$} & \multirow{2}{*}{\multicolumn{2}{|c|}{$\begin{array}{l}\text { Medium- } \\
\text { degree } \\
\text { concepts }\end{array}$}} & \multicolumn{2}{|c|}{$\begin{array}{l}\text { Low-degree } \\
\text { concepts }\end{array}$} & \multirow{3}{*}{$\begin{array}{l}\text { No-degree } \\
\text { concepts } \\
\text { No. }(\%)\end{array}$} & \multicolumn{2}{|c|}{$\begin{array}{l}\text { All BM } \\
\text { concepts }\end{array}$} \\
\hline & No. & $(\%)$ & & & No. & $(\%)$ & & No. & $(\%)$ \\
\hline & & & No. & $(\%)$ & & & & & \\
\hline 1 Porterian & 1 & $(1 \%)$ & 0 & $(0 \%)$ & 2 & $(3 \%)$ & $13(18 \%)$ & 16 & $(23 \%)$ \\
\hline 2 Resource-based & 0 & $(0 \%)$ & 0 & $(0 \%)$ & 1 & $(1 \%)$ & $1(1 \%)$ & 2 & $(3 \%)$ \\
\hline 3 Competence-based & 0 & $(0 \%)$ & 0 & $(0 \%)$ & 0 & $(0 \%)$ & $(7 \%)$ & 5 & $(7 \%)$ \\
\hline 4 Knowledge-based & 0 & $(0 \%)$ & 0 & $(0 \%)$ & 1 & $(1 \%)$ & $9(13 \%)$ & 10 & $(14 \%)$ \\
\hline 5 Organization-based & 0 & $(0 \%)$ & 0 & $(0 \%)$ & 2 & $(3 \%)$ & $13(18 \%)$ & 15 & $(21 \%)$ \\
\hline 6 Process-based & 0 & $(0 \%)$ & 0 & $(0 \%)$ & 1 & $(1 \%)$ & $6 \quad(8 \%)$ & 7 & $(10 \%)$ \\
\hline 7 Dynamism-based & 1 & $(1 \%)$ & 1 & $(1 \%)$ & 1 & $(1 \%)$ & $13(18 \%)$ & 16 & $(23 \%)$ \\
\hline 8 Evolutionary & 0 & $(0 \%)$ & 0 & $(0 \%)$ & 0 & $(0 \%)$ & $0 \quad(0 \%)$ & 0 & $(0 \%)$ \\
\hline Sum & 2 & $(3 \%)$ & 1 & $(1 \%)$ & 8 & $11 \%)$ & $60(85 \%)$ & 71 & $100 \%)$ \\
\hline
\end{tabular}

Protection of the validity of the focused review against the four biases

Concept Inclusion Bias 1 involves this reviewer perceiving that an author has designed a concept along the environmental sustainability dimension even if this author has not done so. This bias has been minimized by assessing each reference in the same way and quoting only the necessary part of each of the references that contain $11(15 \%)$ construction-related BM concepts designed along the environmental sustainability dimension (Table 1). Future reviewers can test the inter-concept consistency of inclusion by repeating the assessments, i.e., reading the references and confirming my quotations or rejecting some of them and, thus, excluding the same.

Concept Exclusion Bias 2 involves this reviewer perceiving that an author has not designed a concept along the environmental sustainability dimension even if this author has done so. Twenty-two "no degree" assessments indicate that this reviewer did not identify any aspects on environmental sustainability. In turn, 38 "no degree" assessments coupled with the quotations, respectively, implies that these authors are using the terms sustainable, sustainability, and environment(al), but only within the scope of strategic, business, or project management. Future reviewers can test the inter-concept consistency of exclusion by repeating the assessments, i.e., reading the references and confirming the exclusions of 60 concepts or identifying sustainability elements in some of them and, thus, including the same.

After the inclusion, Degree Assessment Bias 3 is related to this reviewer's reliance on a pre-specified scale of the three analytical degrees instead of a quantitative scale. The 3degree lens corresponds to the explorative nature of the focused review. This reviewer could assign one of the three degrees to each of 71 BM concepts without hesitation. Future reviewers can request this reviewer to submit the concept-specific quotations and assessments to them and test the inter-concept consistency of degree assignments by reading the references and confirming the same degrees or assessing changes in some of them and justifying such changes with quotations. Or, they could re-specify a scale of degrees, e.g., by dividing each degree into two sub-degrees. 
Concept Author-Reviewer Bias 4 is related to a fact that this reviewer has designed 14\% or 10 out 71 construction-related BM concepts. This reviewer is a long-time member of the competence-based school of generic BM (the 3rd school). However, the school relatedness of these 10 concepts is not concentrated. Instead, it is spread between the five schools, i.e., this reviewer has designed 3 organization-based, 3 dynamism-based, 2 Porterian, 1 knowledge-based, and only 1 competence-based concept. Two (out of 3) organization-based BM concepts have been co-designed. Further, I have assessed that I have designed 2 high-degree and 2 low-degree concepts along the environmental sustainability dimension. Future reviewers can carefully test the inter-concept consistency of the assessment outcomes versus each of the three other biases in the case of these 10 concepts. Other reviewers can come up with some explanations for this reviewer being, so far, the only high-degree concept designer.

\section{Briefing of 2 high-degree, 1 medium-degree, and 8 low-degree BM concepts}

Concerning the 1st Porterian school with 16 BM concepts, only Huovinen (2011a: 6-12) has designed the high-degree managing of four businesses based on the multiplication of Porter's (1980) five forces framework and the design of the 8-arena framework for capturing complexity of managing businesses in arenas in construction, i.e., 1 Uses, 2 Ownership, 3 Life-cycle servicing, 4 Capital investing, 5 Contracting as Wholes, 6 Contracting as Parts, 7 Prefabrication, and 8 Materials. A high degree of environmentally sustainable BM is achieved by implanting 23 drivers into the four main business types coupled with 23 specified (sub-)arenas. In life-cycle contracting and development businesses (in Arena 4), the drivers include the coupling of object development ideas with sustainability advantages. In design-build contracting businesses (in Arena 5), the drivers include the re-engineering of value chains. In design businesses (in Arena 6), the drivers include the transformations of design firms into long viewers, path dependency breakers, stock programmers, object planners, impact blockers, and impact cause tracers. In supply businesses (in Arenas 6-8), the drivers include the adoptions of cradle-to-cradle certifications, product renewals, and responsibility takings over life-cycles. In turn, Veshosky (1994: 43-45) has used Porter's (1980) strategies as a basis for developing an low-degree, analytical framework and applying this to the design segment of the $\mathrm{A} / \mathrm{E} / \mathrm{C}$ industry in the USA. The cost leadership, differentiation, and niche strategies have been elaborated. A low degree of sustainability is indicated as environmental systems and facilities among a firm's project types as well as core competencies for managing hazardous waste. In turn, Huovinen (2001: 73) has designed a 4-area, competitive strategy framework for technology-intensive contractors. It is based on the idea of creating the best fit between the primary decision maker, i.e. the focal investor with its need and investment process and the most competent contractor with its solution and delivery process. A low degree of sustainability is designed as a criterion, i.e. clients take environmental impacts into account when choosing winning solutions or bids.

Concerning the 2nd resource-based BM school with 2 concepts, Lowendahl (1997/2000: 106) has designed a low-degree concept, i.e., the three generic strategies, the four resource types, the four dimensions for resource-based differentiation, and the three 
phases in the evolution of professional service firms. A low degree of sustainability is indicated as environmental protection among alternative markets.

Concerning the 3rd competence-based BM school with 5 concepts, the assessment resulted in the no-degree concepts only.

Concerning the 4th knowledge-based BM school with 10 concepts, Love et al. (2002: 12) have designed a low-degree model for long-term learning alliances, TQM, and supply chains. A low degree of sustainability is designed as alliances taking into account the ethical consideration of social and environmental responsibility.

Concerning the 5th organization-based BM school with 15 concepts, Flanagan (1994: $312,316,318$ ) envisioned that, by 2000 , a successful construction company will have many desired features of a low-degree service provider. A low degree of sustainability is designed as (i) environmental consciousness and sustainability driving strategies, (ii) energy, traffic, waste, and ecology becoming more important, and (iii) successful companies being concerned about the environment and the community. In turn, Huovinen and Hawk (2003: 158) have designed a collaborative client-supplier relationship model for globally operating building product suppliers. A low degree of sustainability is implanted as a product's environmental impacts among 11 decision making criteria that clients use for choosing winning bids.

Concerning the 6th process-based BM school with 7 concepts, Anderson and Merna (2005: 175) have designed a low-degree framework for managing new business development processes of PM services firms. A low degree of sustainability is implanted as environmental management among 11 domains in development.

Concerning the 7th dynamism-based BM school with 16 concepts, only Huovinen (2011b: 11-13) has designed a high-degree, 5-element business system, i.e., environmental sustainability is (1) customized into competitive strategies and offerings so that no/low negative impacts enable a firm to meet its high-sustainability goals, (2) leveraged into business processes to minimize carbon footprints, (3) crafted into a firm's core competitiveness, (4) fused into a business frame and governance, and (5) linked to an extended business frame in terms of collaboration with like-minded stakeholders. In turn, Chinowsky with Meredith (2000: 130, 142, 146) have defined an engineering organization's strategic management as a medium-degree, dynamism-based, 7-area feedback wheel. A medium degree of sustainability is incorporated as environmentally sensitive core designs, project-specific solutions, an environmental engineering competency, an environmental knowledge area, and an environmental testing competency. In turn, Mutka and Aaltonen (2013: 170-171) have built a low-degree, 8element business model framework for deepening the understanding of both relationships between and dynamics of business models as part of firm-level management and projectlevel management within project-based firms. A low degree of sustainability is indicated via the case firm providing life-cycle solutions, based on environment-friendly technologies. 


\section{ADVANCING CONCEPTS FOR HIGHLY-SUSTAINABILITY BM WITH CONTEXTS IN CONSTRUCTION}

The focused review revealed a white space with no high-sustainability constructionrelated BM concepts. Thus, this reviewer defines the five couplings necessary for advancing BM concept design processes and their outcomes. It is assumed that BM concepts are environmentally sustainable, content-freely framed, theoretically advanced, and contextually applicable in respective focal contexts in construction when they are designed, at minimum, along the four corresponding dimensions:

3. Environmental sustainability. A concept designer may adopt the existing definition (e.g., OED 2011) or define a new one as the core of this dimension.

4. Content-free frame of reference on BM. A concept designer may choose one of many references (from within strategic management and planning, systems design, etc.) framing BM as a whole and setting boundaries for a scope. More importantly, frames can be coupled with other content-laden dimensions.

5. School of thought on generic BM. A concept designer may prefer one or more school-specific dimensions from among the eight schools (Huovinen 2008).

6. Focal context in construction. A concept designer may prefer one or more contextual dimensions such as business types, environments, and dynamism.

Each of the five couplings involves the two dimensions of BM concept design, i.e., environmental sustainability is coupled theoretically with frames of reference and schools of thought on generic BM as well as contextually with business types, environments, and dynamism in construction. Geographically, each coupling may be bounded by an area inside a country, a country as a whole, or a group of countries.

Coupling 1. Environmental sustainability and frames of reference. Environmental sustainability in construction-related BM is herein defined to encompass the utilization and development of natural resources in ways which are compatible with the maintenance of these resources, and with the conservation of the natural and built environments, for current and future generations (applying OED 2011 and Oxford Reference 2015). The design of highly environmentally sustainable BM concepts begins with the choices and incorporation of the four necessary frame elements, i.e., (i) envisioning preferred states and ways in dealing with environmental sustainability issues (e.g., in 2025 and beyond), (ii) widening business goals management with the targeting and attainment of environmental sustainability levels and causal relations between sustainability, business performance, and social issues, (iii) adopting environmental sustainability as a decision making criterion, and (iv) adding the minimization of a business' negative impacts on natural and built environments onto agendas (Huovinen 2011b). The four frame elements need to be designed so that they accommodate variety in managing a business with focal contexts in construction.

Coupling 2. Environmental sustainability and schools of thought on generic BM. The design of theoretically advanced, high-sustainability BM concepts can be based on one or more of the eight schools of thought on generic BM (Huovinen 2008). The choice of a particular school can be based on a concept designer's knowledge about BM schools and 
perceptions on a fit between a particular school's assumptions on, generic concepts for, explanations of, and normative advice for (un)successful BM with focal context types as well as her or his pre-understanding of business types and information about status of real business contexts in construction. School-specific and environmental sustainability elements need to be designed so that they accommodate variety in managing of a business with focal contexts in construction.

Coupling 3. Environmental sustainability and business types in construction. In part, contextually applicable, high-sustainability BM concepts need to be designed along the business type dimension. There are nine broad business types in construction, i.e., (i) technology-intensive contracting, (ii) construction-related contracting, (iii) process engineering, design, and consulting services, (iv) construction-related design and consulting services, (v) building products, systems, and materials supply, (vi) machinery, components, etc. supply, (vii) construction machinery, equipment, and tools supply, (viii) real estate ownership, development, and management services, and (ix) life-cycle services related to stocks and objects in built environments. The choice of a particular business type may be based on the rationales of a concept designer and her or his stakeholders, respectively. Business type-specific and environmental sustainability elements need to be designed so that they accommodate variety in managing of this business type with focal contexts in construction.

Coupling 4. Environmental sustainability and business environments in construction. In part, contextually applicable, high-sustainability BM concepts need to be designed along the business environment dimension. This dimension consists of multiple sub-dimensions that cover political, economic, social, technological, and also environmental (so-called PESTE) sustainability developments in all countries, economies, societies, etc. across the globe. The choice of focusing on one, more, or all the five business environments may be based on the rationales of a concept designer and her or his stakeholders, respectively. Some concept designers may choose to deal with additional sub-environments such as law, digitalization, industrialization, or servicing. The high applicability of business environment-focused BM concepts needs to be ensured by using relevant techniques and services, e.g., foresight crafting, scenario building, business intelligence, market and social research, or risk management. PESTE-specific and environmental sustainability elements need to be designed so that they accommodate variety in managing of a business with focal contexts construction.

Coupling 5. Environmental sustainability and business dynamism in construction. In part, contextually applicable, high-sustainability BM concepts need to be designed along the business dynamism dimension, which involves all kinds of fast, moderate, and slow developments on the demand and supply sides with periods, cycles, stages, and states, typically named as chaotic, random, evolving, growing, increasing, stable, decreasing, downturn, stagnated, or recession. The choice of focusing on particular kinds of dynamism may be based on the rationales of a concept designer and her or his stakeholders, respectively. The high applicability of business dynamism-focused BM concepts needs to be ensured by using relevant forecasting models, market intelligence systems, risk management programs, etc. tools and services. Business dynamism-specific 
and environmental sustainability elements need to be designed so that they accommodate variety in managing of a business with focal contexts in construction.

\section{CONCLUSIONS}

It is recommended that principal stakeholders adopt the five couplings in concept design and engage themselves with cross-disciplinary, construction-related BM conceptualization programs as follows. (a) CIB-related researchers launch highsustainability BM programs concerning critical northbound and southbound contexts. (b) BM-related and sustainability-focused researchers jointly produce viable BM knowledge about how to avoid and minimize negative implications. (c) CIB-related researchers and farsighted business managers jointly craft breakthrough high-sustainability concepts for managing major business domains in construction.

\section{REFERENCES}

- ANDERSON, D. K. and MERNA, A. (2005) Project Management Is a Capital Investment Process. Journal of Management in Engineering, 21(4), 173-178.

- CHINOWSKY, P. S. with MEREDITH, J. E. (2000) Strategic Corporate Management for Engineering. New York: Oxford University Press.

- FlanAGAN, R. (1994) The Features of Successful Construction Companies in the International Construction Market. In WARSZAWSKI, A. (ed.). Etkin Int'l Seminar on Strategic Planning in Construction Companies (pp. 304-318). Tecnion. Haifa, Israel.

- $\quad$ HART, C. (1998) Doing a Literature Review. London: SAGE Publications.

- HUOVINEN, P. (2001) A Framework for Designing an International Competitive Strategy in the Case of Technology-Intensive Contractors. In PREECE, C. N. (ed.). Proc. of 2nd Int'1 Construction Marketing Conf. (pp. 68-75). University of Leeds, the UK.

- HUOVINEN, P. (2003) Firm Competences in Managing a Firm's Dynamic Business in Particular in Construction Markets. Unpublished Licentiate Thesis in Construction Economics and Management. Espoo: Helsinki University of Technology.

- HUOVINEN, P. (2006) Reviewing Conceptual Research on the Targeted Area of Construction-Related Management. In PIETROFORTE, R., DE ANGELIS, E., POLVERINO, F. (eds.). Proc. of Int'l Symposium of CIB W55, 65, 86 on Construct-ion in the XXI Century (pp. 1-12). CIB et al. Rome, Italy. Edizioni Scientifiche Italiane.

- HUOVINEN, P. (2008) Platform for Advancing Research in Competence-based Business Management: A Population of 84 Concepts Published between the Years 1990-2002. In SANCHEZ, R. \& HEENE, A. (eds.) A Focused Issue on Fundamental Issues in Competence Theory Development (pp. 175-218). Research in Competence-Based Management, Vol. 4. Emerald Group Publishing.

- HUOVINEN, P. (2010) Knowledge-Based Management of a Project-Based Business. In ARAMO-IMMONEN, H., NAARANOJA, M. \& TOIKKA, T. (eds.). Proc. of Scientific Track on Project Knowledge Sharing Arena (pp. 101-112). Project Days 2010. PMAF. Aalto University, Espoo, Finland.

- HUOVINEN, P. (2011a) Advancement of Sustainable Development, Contracting, Design, and Supply Businesses vis-a-vis Construction Markets. In WAMELINK, H., GERAEDTS, R. \& VOLKER, L. (eds). Proc. of MISBE2011 (pp. 1-15). Delft Univ. of Technology et al. Amsterdam, the Netherlands.

- HUOVINEN, P. (2011b) Managing of Construction-Related Businesses in Environmentally Sustainable Ways - a Focused Review of 62 Concepts. In WAMELINK, H., GERAEDTS, R. 
\& VOLKER, L. (eds). Proc. of MISBE2011 (pp. 1-16). Delft Univ. of Technology et al. Amsterdam, the Netherlands.

- HUOVINEN, P. (2011c) Review of 65 Construction-Related Business Management Concepts Published between the Years 1990-2010 - with an Assessment along the International Dimension. In Proc. of 11 th Vaasa Conference on International Business (pp. 1-25). Univ. of Vaasa, Finland.

- HUOVINEN, P. (2012a) Advancement of a Firm's Competence-Based Business Ideation in Particular for Contexts within Capital Investment Markets (CIMs) - Based on a Review of 67 CIMs-Related Business Management (BM) Concepts Published between the Years 19902011. In Proc. of First Int'l Conference on Competence-Based Strategic Management. Copenhagen Business School, Denmark.

- HUOVINEN, P. (2012b) Advancing Collaboration-Based Business Management within Project Engineering Organizations. In JAVERNICK-WILL, A. \& MAHALINGAM, A. (eds.). Proc. of EPOC 2012 (pp. 1-27). EPOS and Univ. of Twente. Rheden, the Netherlands.

- HUOVINEN, P. (2015) Theoretical 71-Concept Platform for Advancing ConstructionRelated Business Management. In KÄHKÖNEN, K., HUOVINEN, P. \& KEINÄNEN, M. (eds.). Proc. of 8th Nordic Conference on Construction Economics and Organization. Procedia Economics and Finance, 21 (pp. 80-87). Elsevier. RIL, Tampere Univ. of Technology/CME, and CREON. Tampere, Finland.

- HUOVINEN, P. and HAWK, D. L. (2003) Towards Collaborative Customer-Supplier Relationships in Global Building Product Businesses. In REPONEN, T. (ed.). IT-Enabled Global Customer Service (pp. 143-162). Hershey: Idea Group Publishing.

- LOVE, P. E. D., IRANI, Z., CHENG, E. and LI, H. (2002) A Model for Supporting InterOrganizational Relations in the Supply Chain. Engineering, Construction and Architectural Management, 9(1), 2-15.

- LOWENDAHL, B. (1997/2000) Strategic Management of Professional Service Firms. 1st/2nd Ed. Copenhagen: Copenhagen Business School (Handelshojskolens Forlag).

- $\quad$ MUTKA, S. and AALTONEN, P. (2013) The Impact of a Delivery Project's Business Model in a Project-Based Firm. Int'l Journal of Project Management, 31, 166-176.

- OED (2011) Oxford English Dictionary, 2nd Ed., OUP. Online Nov 2010. Available from: http://www.oed.com:80/Entry/195120. [Accessed: 15th Jan 2011].

- OXFORD REFERENCE (2015) A Dictionary of Environment and Conservation, 2nd Ed. (PARK, C. and ALLABY, M.). Oxford University Press. Online 2013. Available from: http://www.oxfordreference.com/view/10.1093/acref/... [Accessed: 6th July 2015].

- $\quad$ PORTER, M. E. (1980) Competitive Strategy. New York: The Free Press.

- VESHOSKY, D. (1995) Portfolio Approach to Strategic Management of A/E firms. Journal of Management in Engineering, 10(5), 41-47. 


\title{
INNOVATION IN OFFSITE MANUFACTURING IN THE FIELD OF HOUSING: A CASE STUDY USING BOURDIVIAN AND ACTOR- NETWORK APPROACHES
}

\author{
London, K. ${ }^{1}$ and Pablo, $\mathrm{Z}^{2}$
}

\begin{abstract}
:
The purpose of this paper is to apply the Bourdivian concepts of field, habitus, and capital as theoretical lenses to examine the Australian housing construction sector. Specifically, we demonstrate the usefulness of Pierre Bourdieu's approach in understanding specific factors that drive innovations in offsite manufacturing (OSM), an approach that involves the manufacture and assembly of parts, components, and/or systems in a controlled environment away from the traditional construction site. We begin by exploring field, habitus, and capital. We then explore how these lenses have been applied by Bourdieu and by various authors to analyse the field of housing and the built environment. We explain how an actornetwork approach can be mobilized methodologically to apply Bourdivian concepts to analyze the players and dynamics of innovative OSM housing supply chains in Australia. We then present our preliminary findings, one being the argument that the creation/ conversion of different species of capital forged a pathway to successful incremental change.
\end{abstract}

KEYWORDS: ACTOR-NETWORK THEORY, BOURDIEU, CAPITAL, INNOVATION, OFFSITE MANUFACTURING

\section{INTRODUCTION: FIELDS, CAPITAL, AND HABITUS}

Pierre Bourdieu $(1984,1986)$ argues that the modern social world is made up of a series of fields wherein actors, predisposed by habitus and in possession of capital in various forms, occupy different positions and struggle for ascendancy. In this paper, we examine how these Bourdivian concepts can be applied as analytical lenses for understanding innovation in the field of housing construction, in particular supply chains making use of offsite manufacturing (OSM) techniques.

Fields (culture, education, media, religion, economics etc.) are microcosms of mutually supporting "institutions, rules, rituals, conventions, categories, designations, appointments and titles which constitute an objective hierarchy, and which produce and authorise certain discourses and activities" (Webb 2002, p. 44). Fields exhibit varying degrees of differentiation and autonomy (Bourdieu 1986; Mahar et al. 1990; Swingewood 2000). Each field has its own stakes, interests, and practices, collectively defining "rules of the game" and crystallizing into an orthodoxy that is an official and legitimate version of how the good life should be at a given time. Anything outside of this is considered unorthodox, or as heterodoxa (Grenfell 2004, p. 28). The privilege of legitimating and

\footnotetext{
${ }^{1}$ School of Property, Construction, and Project Management, RMIT University, Melbourne, Australia. Email: kerry.london@rmit.edu.au

${ }^{2}$ School of Property, Construction, and Project Management, RMIT University, Melbourne, Australia. Email: zelinna.pablo@rmit.edu.au
} 
consecrating what is "good" in a field is a privilege linked to specific positions in a field, and not to others; thus positions in fields, which are occupied by actors, can be characterized as more powerful/ less powerful, or as dominant/ subordinated (Bourdieu and Wacquant 1992). The power relations between and among positions make up a field's structure. Fields are characterized by ongoing struggles among actors for these positions of legitimate authority.

One of the things driving these struggles is capital. Capital functions as both "weapons and stakes" for ascending in a given field (Emirbayer and Williams 2005, p. 691), and covers "all the goods, material and symbolic, without distinction, that represent themselves as rare and worthy of being sought out after in a particular social formation"' (Harker 1990, in Webb 2002, p. 22.). Capital therefore "symbolizes" things that are important in a given field. Symbolic capital can take three forms: economic, social, and cultural. Economic capital refers to money, as well as to goods that can be directly converted into money. Social capital refers to actual or potential resources linked to group membership, or to being part of a network of "more or less institutionalized relationships" (Bourdieu 1986, p. 88). Cultural capital can be embodied, objectified, or institutionalized. Embodied cultural capital is acquired by investing in resources that "form long-lasting dispositions in the mind and body" (Bourdieu 1986, p. 84). Objectified cultural capital (in forms like paintings, monuments, books) takes material form and becomes transmissible. Institutionalized cultural capital generally takes the form of recognized academic qualifications. Examples of each type, as well as the ways that they are distributed, depend on a given field. Bourdieu (1991, in Grenfell 2004, p. 28) claims that "agents possess power in proportion to their symbolic capital, i.e. in proportion to the recognition they receive from the group"; hence, agents struggle to accumulate more of certain types of capital, or to "convert" capital from one form to another.

Another trump card for ascendancy in a field is habitus (Mahar et al. 1990), the largely unconscious mechanism by which agents internalize the structures and patterns of a given field. Habitus is a set of predispositions implanted during childhood and deepened by social systems that agents participate in over time (Swingewood 2000). It overlaps with capital in the sense that some habitus "constitute a form of capital (symbolic) in and of themselves" (Mahar et al. 1990, p. 12), for example the way that art appreciation can be bred into children from certain classes at a very young age. One's habitus allows one access to multiple, though not necessarily an unlimited, number of choices of action, hence it cannot be described as deterministic.

\section{BOURDIVIAN CONCEPTS AND THE BUILT ENVIRONMENT}

Bourdieu has used the concepts of field, capital, and habitus to examine a broad range of issues: education, art, media, culture, even life in Algeria (Grenfell 2004). Notably, he also used his theory of fields to analyze the issue of housing in France in 1977, unpacking the complexities associated to the demand side of housing, the supply side of housing, and the role of the state. Based on his findings, he concluded that housing transactions 
and practices could not be reduced to economic laws of supply and demand, and that such economistic views tended to be oversimplified and limiting (Bourdieu 2005).

There is a growing body of work that has likewise sought to extend the application of Bourdivian concepts not just to housing, but also to different subfields of the built environment. Sang and Powell (2012), for example, explored the persistence of gender inequality in the construction industry, showing that the field was characterized by symbolic violence (a Bourdivian concept) towards women. Stevens (1998) explored how using the concepts of field, capital, and habitus (specifically socialization via the educational system) can yield insights into the field of architecture, which he claimed is split into the field of mass production driven mainly by economic (temporal) capital, and the field of restricted production driven mainly by cultural (intellectual) capital.

While Stevens (1998) focused primarily on two types of capital (temporal and intellectual), Skaates et al. (2002) built on Bourdieu's original conception of three species of capital (economic, social and cultural), and used this framework to propose a hierarchy of architectural firms occupying different positions. An important contribution by Skaates et al. (2002) as far as this paper is concerned is that they operationalized the definitions of different species of capital with respect to the field of architecture.

Other work has proposed new species of capital. Nahapiet and Ghoshal (1998, p. 245) argued that social capital can facilitate the creation of intellectual capital, defined as "the knowledge and knowing capability of a collectivity". They ground their argument by proposing that social capital has three dimensions: structural (for example, network ties and configurations), cognitive (shared language and narratives), and relational (trust and norms). A specific element of (structural) social capital like network ties can yield network benefits, for example quick access and referrals to sources of information. These benefits can then facilitate the process of combining and exchanging existing knowledge, leading to new intellectual capital. Nahapiet and Ghoshal's (1998) study is a conceptual one, and is not specific to the built environment, but their arguments have rich potential application in the sector. The link between social capital and knowledge has, in fact, been explored empirically in construction (see Stryhe 2009).

Apart from work exploring the link between capital and knowledge, research has also been done to explore the relationship between capital and innovation. London and Siva (2011) explored the diffusion of innovation across the construction industry by tracing the creation, development, and adaptation of a waffle pod footing system originally developed in South Australia. They argued that one way to address barriers to innovation was to build reflexive capability, which enabled actors to consciously identify stocks of social, cultural, and intellectual capital, to strategize on how to create, use, and maintain these, and if necessary, to change these strategies.

Having examined Bourdieu's concepts of field, capital, and habitus, as well as how these have been applied to analyses of issues in the built environment, we frame our research question as follows: 
How can the Bourdivian concepts of field, capital, and habitus be applied to understand innovation in the Australian housing construction industry, specifically in relation to offsite manufacturing?

\section{METHODOLOGY}

To address the research question, we are conducting five qualitative case studies in the Australian housing sector. The findings presented here are preliminary; they relate to an early-stage analysis of data involving our first case site, referred to here as Organization A.

\section{The case site}

Organization $\mathrm{A}$ is an Australian developer that has in recent years begun to focus specifically on the construction of medium-density, five-to-six storey dwellings, in response to the Australian governments' push for increased density in the inner and middle suburbs. In 2012, Organization A spearheaded efforts to design and construct a five-storey timber apartment building in the Australian state of Victoria, an initiative that we refer to here as The Project. Early into The Project, concerns emerged among key managers regarding the length of time required to lay the floors using traditional methods, along with the safety issue of possible fall from heights in the course of installation. In an early meeting with engineers, contractors, and suppliers, an executive from Organization A presented the idea of introducing prefabricated cassette floorings. The idea was taken up by the group, and gradually a team was formed to develop a prototype within a six-month period. The prototype development period involved intense collaboration, with members discussing and refining the idea in a series of weekly, then bi-monthly meetings. In the process, one contractor (Contractor B) brought another entity on board (Contractor $\mathrm{C}$ ) to lead the design and the initial fabrication of the cassette, with the understanding that Contractor B would later take up full-scale commercial fabrication. The cassette flooring that was eventually developed was made primarily from cross-laminated timber, although variations of the product are offered. One of these incorporates a floor joist made of a patented element, a composite of lightweight steel and timber. It was this variant that was used in The Project. Contractor B claimed these floor cassettes had the spanning capabilities of reinforced concrete, could be manufactured offsite, and, due to their lightness, could be craned into place. This meant that laying out floors could be carried out in a swifter, safer, cheaper manner. The first cassettes for The Project were craned into place towards the end of June 2013. Use of the cassettes allowed floors to be laid in shorter cycles, and allowed the simultaneous building of internal walls, leading to the building being completed one month early and with savings on built costs of $25 \%$ per apartment. Organization A is currently exploring more widespread use of the cassette in its upcoming projects in other states.

\section{Actor-network theory, data gathering, and data analysis}

Interview narratives suggest that the development of the cassette floor system was not a simple, linear process unilaterally executed by a single organization; it was the outcome of interactions among actors linked in complex webs. To understand the context of the 
cassette's development, it was necessary to map the players involved and their interactions with one another. To accomplish this, we used actor-network theory (ANT), a broad term covering theoretical and methodological approaches that assume that much of social reality is the outcome of actors interacting in heterogeneous networks (Law 1992). We employ ANT here as a methodological approach that provides an analytical toolkit for identifying both human and non-human actors involved in the innovation phenomenon we are seeking to unpack; scrutinizing the interactions that take place among them; and examining the network effects of such interactions.

Our ANT map suggests that Organization A was a central player managing multiple dyadic relationships with an architectural firm, a designer, and a variety of contractors, for example for flooring and framing. At this stage a total of five interviews have been conducted with managers from Organization A as well as two partners. Interviews lasted approximately one hour each, were recorded and then fully transcribed, then analysed thematically. Data was also obtained from document reviews in the form of industry reports, presentations, photographs provided by interviewees, and news articles related to The Project.

\section{FINDINGS}

The initial themes that were used for data analysis were drawn from Bourdieu's conceptual apparatus comprising field, habitus, and capital.

\section{Field: Innovation as a gradual "changing the rules of the game"}

In understanding the field of housing, we begin with the Bourdivian concept of doxa, which in this case sensitizes us to the idea that there are a number of prevailing orthodoxies in the field of Australian housing. Three are noted here: the market's strong inclinations towards large, detached houses (Santow 2009); an industry preference for concrete (Heaton 2015); and the widespread employment of craft-based techniques in construction (Loosemore et al. 2003).

Our preliminary analysis suggests that over the last few decades, Organization A has slowly sought to interrogate and redefine these so-called rules of the game. For more than a decade, Organization A has been making calculated departures from convention. First, it interrogated the "detached housing" rule by diversifying into medium-rise structures. Second, it interrogated the "concrete" rule by making use of timber. Recently, it has begun interrogating the dominance of onsite craft-based approaches by combining onsite techniques with offsite manufacturing.

There are two important things to note about what Bourdieu would call such "heterodoxy". The first point is that Organization A's interrogation of the orthodox involved changes introduced incrementally, and not in sweeping, dramatic ways. One manager described efforts this way:

I think to get to a lot of people want to go from A to $P$ immediately. I say let's get to $B, C, D, E$... If you try and jump straight to $P$ you'll fail. Yes we did hybrid 
which is lightweight timber frame. Okay, the next step for us was, how do we improve? Let's go to five storeys, let's introduce cassettes. All right, fantastic, that's worked. All right, what's the next step?

A second point is that changes introduced are multifaceted. As we will show later, changes introduced by Organization A involved technological innovations tightly coupled social change in the form of new ways of working and managing. The introduction of cassette floorings, then, is just one part (albeit a significant one) of a series of changes that the company has sought to implement in the field.

Our preliminary findings therefore suggest that innovation in this case is better understood not as the decontextualized introduction of a new technology like a new cassette floor, but as a systematic, multidimensional and gradual changing of the "rules of the game" in a field over time. This is not to say that innovations are always systematic and gradual, but the incremental, evolutionary approach appears in this case to have been favoured by Organization A. It is worth exploring if the success of this incremental approach to innovation is linked to the characteristics of the field of construction, a conservative arena that has historically been linked to low levels of innovation.

\section{Habitus: The need for a prime mover to go beyond habitus/preservation}

In seeking to rewrite (or at least "tweak") the rules in the field of housing and introduce change large-scale change, Organization A can be understood as the primum movens or prime mover. ANT uses this term to refer to the main actor that seeks to recruit other actors into a network, triggering a chain of interactions which in turn leads to certain network effects or outcomes (Callon 1999). ANT theorists would argue that Organization A was a primum movens in the sense that, as one manager put it, it "[brought] parties together and...made things happen." However, some ANT proponents would also go further by suggesting that a "prime moving" organization is a collectivity that can be further broken down into even more basic elements, for example individuals (Law 1992). If we drill down more deeply into the dynamics of Organization A, these will reveal that there were key managers within the company who pushed for much of the innovation of the cassette flooring. In particular, multiple interviewees made specific reference to one executive, referred to here Manager 1, who was described as the "key initiator" of the new technology and who mobilized the team to develop the prototype.

Manager 1 was described as having "insurmountable credentials" and a "reputation within the organization for getting the job done". An interviewee offered the opinion that the chain of events resulting from the cassette floor innovation would have taken place without this individual. The interviewee said,

He is a director himself but the general managers and the executive general managers of that level have that trust in him to say, right [Manager 1], if you think if you have bit of an inkling that this will work let's explore it.

The so-called "power" of Manager 1 to initiate (though not singlehandedly bring about) innovation can be accounted for in a number of ways. One possibility that we explore here is this person's so-called habitus. Habitus and field are linked in the sense that 
objective structures in a field tend to be subconsciously internalized by actors, and are often (not always) reproduced. Habitus thus has some structuring effects over individual actions (because of habitus, some possible actions are automatically left out), but these effects are by no means deterministic (Mahar et al. 1990). In the case of Manager 1, it is clear that he was all too aware of prevailing practices in the field of housing, practices that could for example erode the collaboration necessary for an initiative as complex as the cassette flooring. He stated,

I think we're in a very male dominated environment. I think because we've got such a high dominance of the male thinking, testosterone, the male thinking pattern which is very - I need to be disengaged from you because if emotionally I get too close it starts - that's vulnerability and all that sort of thing and I don't think there's an understanding that you can get actually close to someone and you don't need to be vulnerable to them.

A less reflective agent would internalize these rules then reproduce this tendency in work practices, perpetuating an arrangement where housing actors remain detached and aloof from one another. In this case, though, Manager 1 made an intentional decision not to adopt prevailing practices, and instead took on a very specific posture that carved out a space for trust and collaboration (social capital, discussed later), while still maintaining a significant level of accountability and task orientation:

I've got one of our external builders right now... he has fallen off the track and I noticed he was coming off the track. We went and had a talk to him. The general foreman's wife walked out on him... they didn't want to come and tell us. They were scared to come and tell us about it. [W] e're both commercial entities and we've both got outcomes we have to achieve. So that will come into it at some stage. But at this point in time they're not the place I want to be. Right now I want to work out how can we get you back on track, because if I can get you back on track I'm going to win, you're going to win and everyone is going to look good.

This is consistent with Bourdieu's argument that agents occupying positions in fields can, despite predispositions of habitus, mobilize a number of postures in non-deterministic ways (Mahar et al. 1990). At times this leads to fields being transformed.

An important lesson from this preliminary analysis, then, is that innovation (in varying degrees) can only take place if led by an initiator who is reflexive enough to move beyond "preservation strategies" that simply defend the orthodoxy of a field. In this case, we see that Manager 1 and Organization A mobilized what Bourdieu (1984) calls transformation strategies. This is interesting because it contradicts one of Bourdieu's (1984) arguments: that preservation strategies are usually mobilized by actors in dominant positions, while transformation strategies are usually mobilized by actors in dominated ones. In this case, Manager 1 (rich in credentials and expertise) and Organization A (rich in reputation and economic capital) were actors in powerful positions, yet they were mobilizing strategies of transformation. While this may initially seem like an outright contradiction, a more nuanced explanation that can be explored in future work is that both were mobilizing another type of strategy: navigating the fine line between "tradition and tempered 
innovation" (Bourdieu 1984, p. 15). This is a strategy often attributed to actors linked to the function of education in a field.

\section{Capital: A successful pathway of capital conversion in the construction industry}

Another important finding at this stage is that Organization A's ability to change the rules of the game (incrementally) while maintaining its position of power was due not only to its incremental approach, but also due to its ability to execute a series of capital conversions. As Organization A rewrote the rules of the game, it did so in ways that allowed itself to create and convert capital, ending in a state where it had more. Our findings suggest that the company employed a specific pathway of capital conversions, depicted below:

Figure 1: Organization A's pathway of capital conversion.

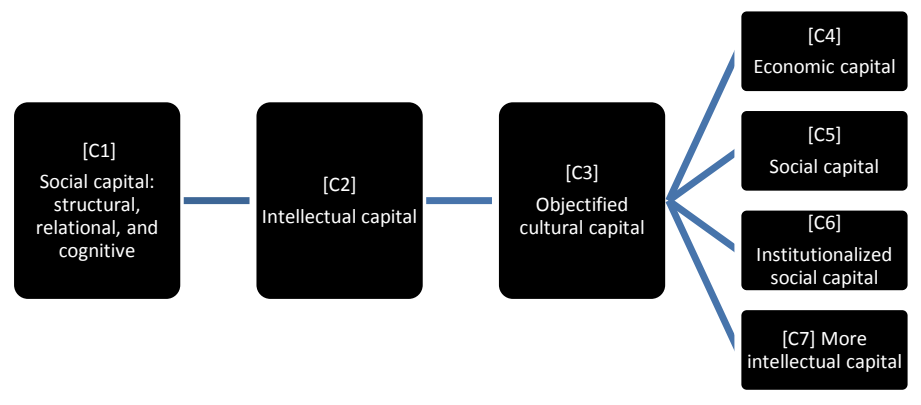

The intentional and deliberate creation of social capital appears to be the critical starting point for introducing changes in the field related to the cassette flooring. Using Nahapiet and Ghoshals' (1998) definition, we see evidence of structural, relational, and cognitive dimensions of social capital being managed. Efforts to develop the cassette flooring began by building the structure:

... we knew who our core subcontractors and suppliers needed to be. And in doing so we had to research on that company and make sure they were capable of doing what we needed as well. So we went out to the largest frame and truss manufacturers who had the best detailers in their, I guess, pool of employees. We went to a flooring company who had the ability and cashed up to be able to do all the independent testings that we wanted to be done. And we had the best engineers on board. All those things all clicked, that's all. So we knew who we needed to make it to work.

As work on the cassette floor progressed, the cognitive dimension of social capital emerged in the form of shared thinking and discourses:

...it's a momentum. It just builds moment and momentum and people catch on...Yeah, the positivity just really catches on. And people start becoming likeminded when you put that group together. 
...everyone was very narrow-minded but by the time you finished with the group after six months, everyone knew, okay, if I put this floor joist here it will do this to acoustic, it will do this to fire. Everyone becomes a little bit more understanding of how each other thinks.

The relational dimension was also evident:

...you've got to make the site fun. You've got to take them out for lunches. People in here are going out for lunches all the time. Get the guys off site, shut the site down for half a day and take them out for lunch and say to them, "Thanks, you're doing a great job."

Consistent with the proposition of Nahapiet and Ghoshal (1998), our findings highlight the close link between social capital and intellectual capital. The creation of a network of like-minded actors working in close proximity appears to have led to knowledge creation, or intellectual capital:

By us having everyone there at the table once we hit an issue we can ask that discipline, how do we get around it, what are my options, bang. Decision is made right there and then, you move on... that's why we have people around the table because I know I don't know engineering to the nth degree but I've got a fairly good understanding of it from a frame and truss point of view. But to draw on knowledge from these guys has given me a bit more confidence in making decisions in big meetings to say, guys I think we can do this.

There are three observations to make about this pathway of capital conversion. The first is that social capital appears to be an important foundation for capital accumulation, possibly because it addresses the fundamental problem of fragmentation in the construction field. A single primum movens, no matter how strong, thus appears to be a necessary but not sufficient condition for successful innovation.

A second point is that intellectual capital is not an automatic, unproblematic outcome of social capital - good networks can create invalid knowledge. One manager from Organization A discussed the case of a competitor company forming its own network with the aim of creating similar innovations for timber buildings. A network of partners was built up (good social capital); however, the effort was deemed a failure because the knowledge that was created had a misdirected focus on building around concrete standards, instead of on timber standards required to support the innovation.

A third observation is that in the case of the construction industry, it seems necessary to convert intellectual created into tangible forms in order to maximize its value, thus it is important in an industry dealing with tangible assets to convert intellectual capital into objectified cultural capital. In this case, brainstorming, discussing ideas about a cassette flooring prototype, and writing reports were important. However, it was not plans on paper that led to the creation of more capital; it was completed buildings showcasing the robustness of the cassette flooring that proved to be invaluable in the creation of more capital. Three interviewees repeatedly mentioned the importance of bringing doubtful 
partners to the completed project site, in order for them to "jump up and down" in the completed building to demonstrate how the timber flooring felt as strong as concrete. One interviewee mentioned that the walk-through strategy was being considered for doubting customers as well. Another also mentioned that very people who had designed the cassette came to appreciate their "intellectual capital" most fully only when they saw it in embodied form:

... on the very last day of lifting ... we took the fabrication team to the site and it wasn't until then that they realised... how critical it was to fit.

Objectified cultural capital thus appears to be a particularly potent and versatile capital base in the housing field. This is an important consideration given widespread discourses regarding economies being increasingly driven by "intangible" knowledge. Our findings suggest that it was objectified cultural capital that has led to the creation of at least four new forms of new capital. The cassette has led to (1) more economic capital:

Cassettes are a component of what we do. But yeah, the idea is strong. The momentum is still there and I guess the outcomes from it, from a financial timing, design and everything and meeting market expectations are all there. So...we've hit a lot of milestones and the rest of the business units have seen how this can work so it's spruiking a lot of interest in our other states.

It has also been linked to (2) more social capital, as contractors who formerly doubted the viability of the cassette flooring are now coming on board:

...in particular the sales and marketing manager, cause he was the one who I was going, oh guys be very careful, blah, blah, blah. He was the one, he's jumping up and down [on the cassette, to test it] going wow, I get this now.

It has also led to the creation of (3) institutional cultural capital, as the organizations involved in developing the cassette have recently received an industry award for innovation, and to (4) intellectual capital, as intellectual property in at least two forms has emerged and is now shared by three of the partners.

\section{CONCLUSIONS}

In this study, we have shown through our preliminary findings how the concepts of field, habitus, and capital can shed light on the process of innovation in the field of housing. Innovation is in this case is an incremental, socio-technical process of rewriting the "rules of the game", often led (but not completely controlled) by a prime mover who is reflexive enough to question a field's orthodoxy, and facilitated by strategic conversions of capital, with social and embodied cultural capital appearing critical in the field of housing and construction. 


\section{REFERENCES}

- $\quad$ BOURDiEU, P. (1984). Sociology in Question. London, Thousand Oaks, New Delhi: Sage.

- BOURDIEU, P. (1986) The Forms of Capital. In SADOVNIK, A.R. (ed.). Sociology of Education: A Critical Reader (2007). New York: Routledge.

- $\quad$ BOURDIEU, P. (2005) The Social Structures of the Economy. Cambridge: Polity Press.

- BOURDIEU, P. and WACQUANT, L.J.D. (1992) An Invitation to Reflexive Sociology. Chicago, London: The University of Chicago Press.

- CALlON, M. (1999) Some Elements of a Sociology of Translation: The Domestication of the Scallops and the Fishermen of St. Brieuc Bay. In BIAGOLI, M. (ed.). The Science Studies Reader. New York: Routledge.

- $\quad$ EMIRBAYER, M. and WILliAMS, E.M. (2005) Bourdieu and Social Work. Social Service Review, December, pp. 689-723.

- GRENFELL, M. (2004) Pierre Bourdieu: Agent Provocateur. London, New York: Continuum.

- HEATON, A. (2015) Is Concrete Still The Material of Choice? [Online] Available from https://sourceable.net/concrete-still-material-choice/\#. [Accessed 16 July 2015].

- LAW, J. (1992) Notes on the Theory of the Actor-Network: Ordering, Strategy and Heterogeneity. Systems Practice, 5, pp. 379-93.

- LOOSEMORE, M., DAINTY, A. and LINGARD, H. (2003) HRM in Construction Projects: Strategic \& Operational Approaches. London: Spon Press.

- LONDON, K AND SIVA, J. (2011) Housing Supply Chain Model for Innovation Research Report [Online]. Available from http://apo.org.au/research/housing-supply-chain-modelinnovation-research-report. [Accessed 16 July 2015].

- MAHAR, C., HARKER, R., and WILKES, C. (1990) The Basic Theoretical Position. In HARKER, R., MAHAR, C. \& WILKES, C. (eds.). An Introduction to the Work of Pierre Bourdieu: The Practice of Theory. Houndmills, Basingstoke, Hampshire: Macmillan.

- NAHAPIET, J. and GHOSHAL, S. (1998) Social Capital, Intellectual Capital, and the Organizational Advantage. The Academy of Management Review, 23(2), pp. 242-266.

- $\quad$ SANG, K. and POWELL, A. (2012) Gender Inequality in the Construction Industry: Lessons from Pierre Bourdieu. In SMITH, S.D (ed.). Proceedings of the 28th Annual ARCOM Conference, 3-5 September 2012, Edinburgh, UK, Association of Researchers in Construction Management, 237-247.

- $\quad$ SANTOW, S. (2009) Australians live in world's biggest houses. [Online] Available from http://www.abc net.au/news/2009-11-30/australians-live-in-worlds-biggest-houses/1162630. [Accessed 15 July 2015]

- $\quad$ SKAATES, M.A., TIKKANENB, H. and ALAJOUTSIJARVI, K. (2000) Social and Cultural Capital in Project Marketing Service Firms: Danish Architectural Firms on the German market. Scandinavian Journal of Management, 18 (2002), pp. 589-609

- STEVENS, G. (1998) The Favored Circle: The Social Foundations of Architectural Distinction. Cambridge, London: MIT Press.

- STRYHE, A. (2009) Managing Knowledge in the Construction Industry. Hoboken: Taylor and Francis.

- SWINGEWOOD, A. (2000) A Short History of Sociological Thought. $3^{\text {rd }}$ Ed. Houndmills, Basingstoke, Hampshire: Palgrave.

- WEBB, J., SCHIRATO, T. and DANAHER, G. (2002) Understanding Bourdieu. Crows Nest NSW: Allen and Unwin. 


\title{
EXPLORING KNOWLEDGE MANAGEMENT PRINCIPLES FOR DECISION-MAKING IN LOW-ENERGY BUILDING FOR SUSTAINABILITY IN CONSTRUCTION
}

\author{
Maduka, N.S. ${ }^{1}$ Udeaja, C. ${ }^{2}$ and Greenwood, D. ${ }^{3}$
}

\begin{abstract}
:
Low energy building retrofit presents important opportunities for reducing of greenhouse gas emissions in the environment. It has been considered as one of the key approaches to achieving sustainable development in construction industry. Nevertheless, such retrofitting proves challenging due to the fact that the industry has ignored the need to manage project knowledge in retrofitting these buildings. This has arguably made decision-making difficult for key stakeholders because lesson learned are not captured in low energy retrofit projects. Managing project knowledge has been established as essential in delivering low energy building retrofit projects through decision-making hence an informed decision support framework (IDSF) has been developed. The methodology employed in development of IDSF is through literature review covering, among other things, knowledge management (KM) principles and procedures. The IDSF will help improve decision-making capabilities of key stakeholders involved in low-energy building retrofit projects to make informed and appropriate decisions. It will also help to avoid post-decision mistakes in low energy building retrofit projects. Furthermore, IDSF will help in the development of decision support system (DSS) that will be used for making informed and sound decisions in achieving low-energy retrofit projects and also help in full uptake of retrofit projects
\end{abstract}

KEYWORDS: CLIMATE CHANGE, EXISTING BUILDINGS, KNOWLEDGE MANAGEMENT, LOW-ENERGY RETROFITS, DECISION SUPPORT.

\section{INTRODUCTION}

Climate change has imposed significant problems and risks worldwide. With the rapid increases in urbanisation and industrialisation more greenhouse gases (GHG) are emitted directly to the atmosphere. The built environment, particularly existing buildings and their operation contribute to a large extent amount of greenhouse gas emissions in the atmosphere (Asadi et al., 2012). This has necessitated the efforts of many governments and international organisations in the last decade in putting significant efforts toward energy efficiency improvement in existing buildings (Ma et al., 2012). For example the US government provided $\$ 30$ billion for General Service Administration and Department of Defense to invest in energy efficient upgrades to their existing buildings and facilities (ARRA, 2009). In Australia, the government in its 2009-2010 budget invested \$454

\footnotetext{
${ }^{1}$ Department of Mechanical and Construction, Northumbria University, Newcastle upon Tyne, NE1 8ST, United Kingdom. Email:ndy2k2001@yahoo.com

2 Department of Mechanical and Construction, Northumbria University, Newcastle upon Tyne, NE1 8ST, United Kingdom. Email: chika.udeaja@northumbria.ac.uk

${ }^{3}$ Department of Mechanical and Construction, Northumbria University, Newcastle upon Tyne, NE1 8ST, United Kingdom. Email: david.greenwood@northumbria.ac.uk
} 
million to progressively retrofit existing government buildings to increase the energy efficiency and reduce GHG (OEH, 2009). The United Kingdom (UK) government in 2010 made a significant contribution to upgrade the energy efficiency of existing buildings of about 7million homes by 2020 aimed at reducing GHG by $29 \%$ (DECC, 2011). This paper focuses on delivering low-energy building retrofit projects through a decision-making framework developed using knowledge management (KM) principles and procedures. The next section will further discuss the significance for low energy building retrofit.

\section{The Imperatives of Low-Energy Building Retrofit}

Existing buildings are responsible for half of the total greenhouse gas emission (GHG) in the UK with adverse impact on the global, environmental, human health and economy. It is recognised that $80 \%$ of the energy consumed throughout a building lifecycle occurs when it is occupied and in use and where the service life of the building ranges from 3070 years (Menassa and Baer, 2014). This fact compels the industry to produce buildings that will be energy efficient during their life-cycle through low-energy retrofitting of the existing buildings using modern sustainability principles (UNEP, 2009). It has been suggested that significant reduction of GHG emission can be achieved through lowenergy retrofitting of existing structures (Menassa and Baer, 2014). The important role existing buildings play in achieving energy reduction or GHG through low-energy retrofit can be part of a complete plan for sustainable corporate development (Hwang and $\mathrm{Ng}$, 2013). According to Kubba (2010), low-energy retrofits should be designed for optimal energy efficiency and constructed with a preference for natural, reclaimed, and recycled materials. These buildings provide healthier, more comfortable and productive indoor environments for occupants by maximizing the effective usage of resources like energy, water, and raw materials. However, low-energy retrofit has many challenges (such as finance, assumed high cost, lack of decision-making etc.) that come with it. Embarking on the retrofitting of buildings is quite difficult to undertake because a building and its environmental nature is complex (technical, technological, economic, social, ecological, social, comfort) and this has necessitated the need for informed decision-making through managing knowledge when undertaking the retrofit measures (Duah et al., 2014). The ensuing section will discuss further the relevance of managing project knowledge to delivering low-energy retrofit by first describing what knowledge and knowledge management means.

\section{Knowledge Management}

Different definitions of knowledge exist in the academic literature and these definitions are coined to each author's perspective. Knowledge has been referred to as information which has been used and integrated within a person's knowledge-based experience and behavioural patterns (DeTienne and Jensen, 2001). One of the most common classifications of knowledge are 'tacit knowledge' and 'explicit knowledge' (Nonaka and Takeuchi, 1995). Tacit knowledge deals with a personal knowledge about a specific context. It is part of personal experience and difficult to formulate, record or express clearly since it is stored in human brains and mind (Kanapeckiene et al., 2010). Explicit 
knowledge on the other hand is learned and acquired and it can be shared and transferred through a medium of systematic or formal language (Kanapeckiene et al., 2010). Explicit knowledge can be easily collected, documented, stored, and retrieved very independently of any single individual through technological means and systems (Hari et al., 2005). An organisation is bound to require elements of both approaches, and must integrate the two effectively to achieve maximum positive impact (Hari et al., 2005). In construction, knowledge cannot bring competitive advantage unless it is managed (Shellbourn et al., 2006). Egbu et al. (2004) define it as an important resource for construction organisations due to its capability to provide market leverage and contributions to organisational innovations and project success. Furthermore, Achieving success from KM depends on the effective and efficient deployment of different KM procedures within the context of specific organisation (Udeaja et al., 2008a, Maduka et al., 2015b).

\section{Knowledge Management Procedures/Approaches}

Success from KM depends on the effective and efficient deployment of different KM strategies and tools within the context of specific organisation (Udeaja et al., 2008a). It has been revealed that KM procedures have great influence on organisations achieving optimal performance in construction projects (Zack et al., 2009). Different studies have used different terms for KM procedure for example: knowledge sharing (Robinson et al., 2002, Egbu and Robinson, 2005); Knowledge utilisation (Asoh et al., 2007); Knowledge capture and reuse (Udeaja et al., 2008a); knowledge creation (Yang et al., 2010); knowledge organisation (Ramachandran, 2010); knowledge storage (Allameh et al., 2011). What differentiates each of these is the difference in viewpoint, application and level of details. For the purpose of this paper three KM procedures will be discussed which include knowledge capture, knowledge sharing/transfer and knowledge reuse.

Knowledge Capture: knowledge capture deals with the process of retrieving either explicit or tacit knowledge that is embedded in people, artefact or organisational entities (Hsieh et al., 2009). Knowledge capture prevents the loss of critical knowledge due to retirement, job downsizing and subcontracting. Egbu and Robinson (2005) reveal that a lot of organisations are concerned more with telephones, faxes, emails and internet and intranet. This is because they disregard the recording of valuable experience in electronic form in the area of documentation, data bases, webpages, which can assist in preventing the repetition of mistakes in construction activities. Tan et al. (2010) stated that knowledge capture involves three processes which include knowledge identification and location, knowledge representation and storage and knowledge validation. Identifying knowledge and locating it involves identification of the kind or type of knowledge to be managed and the location of learning situation (Kamara et al., 2003). This includes the creation of new knowledge and individuals with the relevant knowledge (Tan et al., 2007). Knowledge representation and storing comprises indexing, organising and structuring knowledge (Robinson et al., 2002) into theme-specific knowledge areas and authoring knowledge (Markus, 2001) in the standard or format specified. Knowledge validation deals with giving credibility to the captured knowledge by ensuring that knowledge captured and stored is fit for purpose. 
Knowledge Sharing/Transfer: this refers to the provision of the right knowledge to the right person at the needed time (Robinson et al., 2002). Effective knowledge sharing is supported by supportive organisational culture and trust between the people that are engaged (Newell et al., 2002). Markus (2001) argued that this procedure can be passive or active. The author further explained that it could be passive in the area of newsletter publication or population of knowledge repository for users or active in the area of publishing knowledge via electronic alert to those who needed it. Similarly, Egbu and Robinson (2005) stated that knowledge sharing/transfer has been argued to be achieved through mobile phones, pagers, telephones, faxes, storytelling, quality circles, mentoring and shadowing, coaching and job rotation are all considered to be effective in sharing and transferring knowledge.

Knowledge Reuse: reuse of knowledge is stated to involve both recall (that information has been stored, in what location, under what index or classification scheme) and recognition (that information that meets the users' needs (Lansdale, 1988). Szulanski et al. (2002) specified that knowledge reuse deals with the reapplication of knowledge such as best practice. Similarly, Majchrzak et al. (2004) argued that it is the reuse of knowledge for innovation with necessary integration or adaptation of best practice. The reuse of knowledge encompasses conceptualising the issue or problem and selecting the best reusable ideas (i.e. knowledge) and also by perusing and revaluating reusable ideas. Tan et al. (2007) stated the various kind of reusable knowledge to include: process knowledge; costing knowledge; legal and statutory needs; knowledge of the best practices and lesson learned; knowledge of who knows what etc.

\section{Managing Knowledge in Attaining Low-energy Building Retrofit}

Egan (1998) suggested that managing knowledge from people, culture, technology and training perspectives was important for the construction industry. The significance of knowledge management (KM) in construction projects has been documented by various researchers in academic literature (Carrillo et al., 2000, Kamara et al., 2000, Robinson et al., 2001, Egbu and Robinson, 2005, Anumba et al., 2005, Shellbourn et al., 2006, Tan et al., 2006, Udeaja et al., 2008a, Kanapeckiene et al., 2010) and this is necessary particularly in low-energy retrofit. KM has received a great deal of attention in recent years. The role and essence or relevance of KM as a key source of potential advantage for construction organisation has been addressed by numerous authors see for example: web prototype for live capture and reuse of project knowledge (Udeaja et al., 2008a); integrated knowledge management model and system for construction (Kanapeckiene et al., 2010); knowledge mapping in sustainability (Glimour et al., 2013); exploring KM principles to develop decision making framework for key stakeholders.

In Miller et al. (2008) study identified that whilst there is a genuine need for stakeholders to drive the uptake of low-energy retrofit, the level of managing knowledge in delivering low-energy retrofit projects and specific sustainability features remain disappointingly low. This is because professionals in the construction industry find it difficult to access core knowledge for highly knowledge-intensive activities, such as problem-solving, decision-making, etc. (Anumba et al., 2005, Egbu and Robinson, 2005). Construction organisations have been managing knowledge informally for years, but the challenges 
facing today's industry particularly in low-energy retrofit means that most organisations now need a more structured, coherent approach to KM to deliver projects (Kamara et al., 2002, Khalfan et al., 2002, Anumba et al., 2006, Udeaja et al., 2008a). Kamara et al. (2002) and Petri (2014) stated managing project knowledge in low-energy building retrofit projects will help in reducing of project timeline, including quality and customer satisfaction. Therefore there is a need to explore KM principles to develop a decision support framework which will assist in addressing lack of informed decision-making in attaining low-energy retrofit (Maduka et al., 2015a).

\section{Decision Support Models and Frameworks for Low-energy Building Retrofit}

Decision support tools are useful for identifying and determining optimal retrofit measures (Ma et al., 2012). The complexity that emanates from retrofitted building projects can be tackled through decision support framework that is knowledge driven. Brozova et al. (2008) stated that decision-making is a mental process leading to the selection of the best strategy among several alternatives, and as such every decisionmaking process produces knowledge for the successful solution to a given problem. However, many decision-making models and methods have been developed to help deliver solutions to low-energy retrofit projects. Juan et al. (2009) developed an integrated decision support system to recommend a set of sustainable refurbishment actions for existing office buildings. This was developed based on the consideration of trade-offs among refurbishment cost, improved building performance and environmental impacts. Doukas et al. (2009) developed a decision support model for evaluating energy saving measures in a typical office building. The model was developed in consideration of an experience data base through systematic incorporation of energy data collected from building energy management system to calculate building performance indicators. Brozova et al. (2008) in their research developed a knowledge mapping model for decision-making process for theoretical analysis and application.Goodacre et al. (2002) developed a cost-benefit analysis framework to use to access the potential scale of some benefit from the comprehensive upgrading of heating and hot water energy's efficiency in English building sector. These studies have indeed demonstrated the need for decisionmaking in delivering low-energy retrofit building projects and have been able to address some low-energy retrofit challenges. However, there is a gap in developing a decision support framework or system through $\mathrm{KM}$ to inform key stakeholders on making informed and appropriate decisions in delivering these projects. However, a theoretical decision support framework has been articulated and developed through relevant literature reviews and this is shown in Figure 1.This theoretical decision support framework will be essential for collection of empirical data that will result to development of a decision support system. 
Figure 1. Informed decision support framework (IDSF)

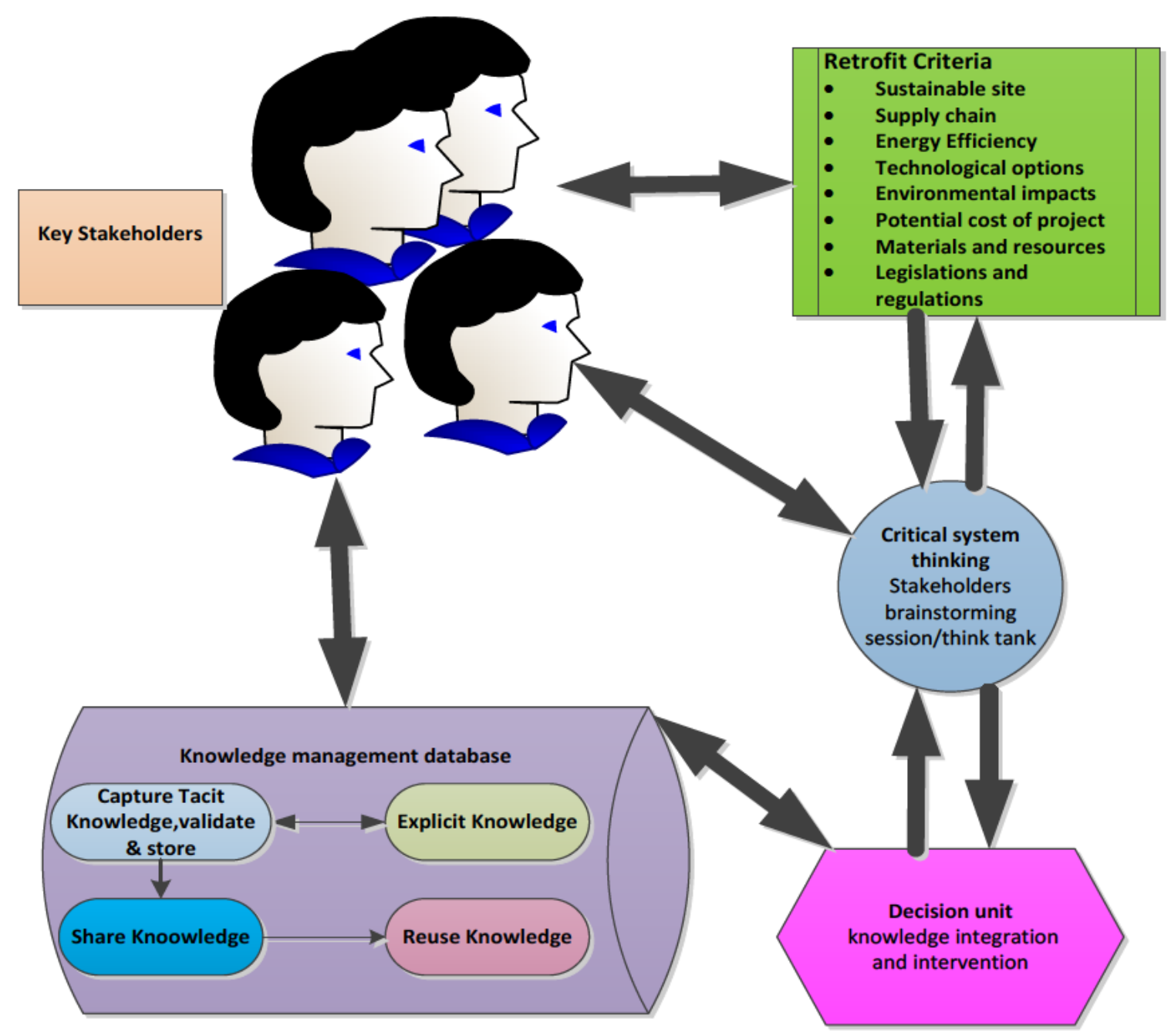

Informed Decision Support Framework (IDSF)

A theoretical decision support framework has been developed and illustrated in figure 1 . The framework is directed at the key stakeholders involved in low-energy retrofit building projects to enable them to make sound and informed decision in delivering these projects. The decision support comprises of Key stakeholders; Knowledge management database, retrofit criteria/measures; critical system thinking and decision unit.

The Key stakeholders are the decision makers with vested interests in low-energy building retrofit projects. These are considered to be clients, owners, tenants, and 
investors, building operators, designers (architectural, mechanical, civil and electrical) and project managers (Menassa and Baer, 2014). The knowledge management database (KMD), provides the central repository where the information of retrofit projects is captured, including the explicit knowledge which together is shared for reapplication or reuse. The KM database enables the key stakeholders in collecting information, diagnosing and analysing the existing circumstances. The information in KMD applies to relevant experience of stakeholders in a previous retrofit projects which can be reused in a current retrofit project decisions. KMD is established to help key stakeholders improve the utilisation rate of knowledge in terms of capture and share and increase the rate of knowledge reuse (Zhang and Lu, 2007, Udeaja et al., 2008b). At this stage, decision makers' wisdom and insight play a role by considering captured knowledge, shared knowledge and knowledge reuse or reapplication in decision-making and the need for these have been expanded in Section 4 of this paper. KMD will also assist in sharpening the intuition of the stakeholders and improve their mental capabilities in decision-making. This will help the stakeholders to avoid overconfident about their judgement, but rather set decision goals in order to make an informed decision. It will also enable them consider retrofit criteria and measures through critical thinking which involves brainstorming /think tank sessions. Retrofit criteria and measures (RCM), key stakeholders at this point will enable key stakeholders in considering sustainability criteria information, diagnosing and analysing the existing circumstances as regards to low-energy retrofit issues. RCM remains a key indicator that would help to inform and manage knowledge before appropriate decisions are made. Critical thinking system (CTS), the brainstorm/think tank session will assist the stakeholders to see through ostensible facts. This will help to reach a fundamental understanding of the apparent decision difficulties by integrating the knowledge in the database with the outcomes from brainstorming/think tank to enable an informed decision. Decision unit (DU) incorporates knowledge intervention and integration. Knowledge intervention (KI) is a mechanism which assists the stakeholders to surface hidden retrofit assumptions and reflects on them for a reflective thinking in making right decision about low-energy retrofit building projects. DU makes reference to KMD and integrates the outcome of the brainstorm/think tank session which will support them to make a sound and informed decision. At this point, knowledge reuse through KMD will be essential. Through knowledge reuse, proven solutions are integrated by learning from the use and failures of previous projects; avoid pitfalls and increase the chances to make right decision (Liu et al., 2015).

\section{CONCLUSION AND FUTURE WORK}

$\mathrm{KM}$ is likely to become more pervasive in various industries particularly in construction industry as delivering of low-energy retrofit continues to pose a challenge due to its complex nature and stakeholders' varied options. Managing project knowledge is needed to be adopted in low-energy building retrofit projects in order to surmount the existing decision challenges through the development of an informed decision-making framework. Decision-making is a complex process as established through the literature and most decision support frameworks ignore KM contribution in decision-making 
process. This paper has demonstrated the need and essence of a decision support through KM principles and strategies by developing IDSF. The framework incorporates knowledge management database, retrofit measures, critical system thinking and decision unit. These were introduced through theoretical formulations to enable an informed decision-making for key stakeholders in delivering low-energy building retrofit. The use of the framework will minimise retrofit decision mistakes and maximise informed decision-making capabilities of the key stakeholders in retrofit projects. IDSF will also enable the full up-take of low-energy building retrofit projects in the built environment due to knowledge strategies demonstrated in the framework. In achieving low-energy building retrofit projects for sustainable development KM remains a crucial element as have been revealed in numerous literatures. The developed a theoretical IDSF precedes the next stage of the research which will be the collection of empirical data from intended case organisations with the help of literature reviews and other published sources. The data collected and analysis will, in turn, precede the development of a decision support system (DSS) through data analyses.

\section{REFERENCES}

- ANumbA, C., EGBU.C. \& CARRILlO, P. M. 2005. Knowledge Management in Construction. Blackwell Publishing.

- ANUMBA, C. J., EGBU, C. \& KASHYAP, M. 2006. Avoiding Structural Collapses in Refurbishment: A Decision Support System. The Health and Safety Executive.

- ARRA 2009. The Recovery Act. American Recovery and Reinvestment Act. Available at: http://www.recovery.gov/arra/About/Pages/The_Act.aspx.

- $\quad$ ASADI, E., DA SILVA, M. G., ANTUNES, C. H. \& DIAS, L. 2012. A multi-objective optimization model for building retrofit strategies using TRNSYS simulations, GenOpt and MATLAB. Building and Environment, 56, 370-378.

- BROZOVA, H., SUBRT, T. \& BARTOSKA, J. 2008. Knowledge Mapping in Decisionmaking Process:Theoritical Analysis and Application. The 9th European Conference on Knowledge Management.

- CARrillo, P. M., ANUMBA, C. J. \& KAMARA, J. M. 2000. Knowledge Mnagement Strategy for Construction: Key IT and Contextual Issues. Construction Project Management, 35, 587-601.

- CHEN, L. \& MOHAMED, S. 2008. Impact of internal business environment on knowledge management within construction organisations. Journal of Construction Innovation, Emerald, 8, 61-81.

- CHIN-LOY, C., MUJTABA, B. G. \& DASTOOR, B. 2007. Organizational Knowledge Management Research and Practices for Developing Economies. Society of Afghan Engineers Journal, 58.

- DAVENPORT, T. H. \& PRUSAK, L. 2000. Working Knowledge: How Organisations Manage what they Know (2nd edition). Harvard Business School Press, USA

- DECC 2011. Homes and economy to benefit from energy and climate policies UK Department of Energy and Climate Change Available at: http://www.decc.gov.uk/ (Accessed on 10/07/15).

- DETIENNE, K. B. \& JENSEN, R. B. 2001. Intranets and Business Model Innovation: Managing Knowledge in Virtual Organisation. In Malhotra,Y.Edition Knowledge Management and Business Model Innovation. Idea Group Publishing,Hershey., 198-215. 
- $\quad$ DOUKAS, H., NYCHTIS, C. \& PSARRAS, J. 2009. Assessing energy-saving measures in buildings through an intelligent decision support model. Building and Environment, 44, 290298.

- DUAH, D., Y.A, K., F. \& SUAL, M. 2014. Expert Knowledge Elicitation for DecisionMaking in Home Energy Retrofits. Structural Survey, 32, 377-395.

- $\quad$ EGAN, J. 1998. Rethinking Construction. London UK.

- $\quad$ EgBU, C., HAYleS, C., QUINTAS, P., HUTCHINSON, V., CHIMAY, A. \& RUIKAR, K. 2004. Knowledge Management for Sustainable Construction Competiveness. Final BNE Report.

- EGBU, C. \& ROBINSON, H. 2005. Construction as a Knowledge Based Industry. In Anumba, C,Egbu, C. and Carrillo, P. (eds) Knowledge Management Construction, 31-49.

- FONG, P. S. W. \& CHOI, S. K. Y. 2009. The processes of knowledge management in professional services firms in the construction industry: a critical assessment of both theory and practice. Journal of Knowledge Management, 13, 110126.

- $\quad$ GOODACRE, C., SHARPLES, S. \& SMITH, P. 2002. Integrating Energy Efficiency with the Social Agenda in Sustainability. Energy and Buildings, 34, 53-61.

- HARI, S., EGBU, C. \& KUMAR, B. 2005. A Knowledge Capture Awareness Tool: An Empirical Study on Small and Medium Enterprises in the Construction Industry. Engineering,Construction and Architectural Management, 12, 553-567.

- HSIEH, P. J., LIN, B. \& LIN, C. 2009. The Construction and Application of Knowledge Navigator Model: An Evaluation of Knowledge Management Maturity. Experts Systems With Applicatiions, 36, 4087-4100.

- HWANG, B.-G. \& NG, W. J. 2013. Project management knowledge and skills for green construction: Overcoming challenges. International Journal of Project Management, 31, 272 284.

- JUAN, Y.-K., KIM, J. H., ROPER, K. \& CASTRO-LACOUTURE, D. 2009. GA-based decision support system for housing condition assessment and refurbishment strategies. Automation in Construction, 18, 394-401.

- $\quad$ KAMARA, J. M., ANUMBA, C. J. \& CARRILlO, P. M. 2000. Integration Of Knowledge Mnagement within Construction Business Processes. Proceeding of the UK National Conference on Objects and Integration for Architecture.,Engineering and Construction.London Building Research Establishment, 95-105.

- $\quad$ KAMARA, J. M., ANUMBA, C. J. \& CARRILlO, P. M. 2002. A CLEVER approach to selecting a knowledge management strategy. International journal of project management, 20, 205-211.

- $\quad$ Kamara, J. M., ANumba, C. J., CARrillo, P. M. \& BOUChlagheM, N. M. 2003. Conceptual Framework for Live Capture of Project Knowledge. Proceedings., CIB W078 International Conference on Information Technology for Construction - Construction IT: Bridging the Distance, CIB, Waiheke Island, New Zealand, 178- 185. .

- KANAPECKIENE, L., KAKLAUSKAS, A., ZAVADSKAS, E. K. \& SENIUT, M. 2010. Integrated knowledge management model and system for construction projects. Engineering Applications of Artificial Intelligence, 23, 1200-1215.

- $\quad$ KHAlfan, M. M. A., BOUChlaGhem, D. M., ANUMBA, C. J. \& CARRILlO, P. M. 2002. A Framework for Managing Sustainability Knowledge, The C-Sand Approach. ESm@rt 2002, Salford, UK.

- KUBBA, S. 2010. Green construction Project Management and Cost Oversight. Elsevier, U.S.A.

- $\quad$ LANSDALE, M. 1988. The psychology of personal information management. Applied

- $\quad$ Ergonomics, 19, 55-66.

- $\quad$ LIU, S., SMITH, M. H., TUCK, S., PAN, J., ALKURAJI, A. \& JAYAWICKRAMA, U. 2015. Where can can Knowledge-Based Decision Support Systems Go in Contemporary Business Management-A New Architecture for the Future. Journal of Economics, Business and Management, 3, 498-504. 
- $\quad$ MA, Z., COOPER, P., DALY, D. \& LEDO, L. 2012. Existing building retrofits: Methodology and state-of-the-art. Energy and Buildings, 55, 889-902.

- MADUKA, N. S., UDEAJA, C. E. \& GREENWOOD, D. 2015a. Managing Project Knowledge in Delivering Sustainable Retrofitted Buildings: A Decision Support Framework. Proceedings of 12th International Post-Graduate Research Conference, School of Built Environment,University of Salford,Manchester, June, 2015.

- MADUKA, N. S., UDEAJA, C. E. \& GREENWOOD, D. 2015b. The Use of Knowledge Management Approach in Delivering Sustainable Retrofitted Building Projects: A Conceptual Decision Support System for Key Stakeholders. Proceedings of 2nd International Sustainability Building Symposium (ISBS), April, 2015,Turkey.

- MAJCHRZAK, A., COOPER, L. P. \& NEECE, O. E. 2004. Knowledge Reuse for Innovation. Mangement Science, 50, 174-188.

- MARKUS, M. L. 2001. Toward a Theory of Knowledge Reuse: Types of Knowledge Reuse Situations and Factors in Reuse Success. Journal of Management Information Systems, 18, 57-93.

- MENASSA, C. C. \& BAER, B. 2014. A Framework to Access the Role of Stakeholders in Sustainable Building Retrofit Decisions. Sustainable Cities and Society, 10, 207-221.

- MILlER, S., HICKSON, D. \& WILSON, D. 2008. From Strategy to Action: Involvement and Influence in Top Level Decisions. Long Range Planning, 41, 606-628.

- NEWELl, S., ROBERTSON, M., SCABROUGH, H. \& SWAN, J. 2002. Managing Knowledge Work. Palgrave,Basingstoke,Hamsphire.

- NONAKA, I. \& TAKEUCHI, H. 1995. Knowledge Creating Company. Oxford University Press.

- OEH, A. 2009. New South Wales of the Environment. Available at: http://energy.gov/articles/doe-fund-454-million-retrofit-ramp-ups-energy-efficiency (Accessed on 10/07/2015).

- OMERZEL, D. G. 2010. The impact of knowledge management on SME growth and profitability: A structural equation modelling study. Africa Journal of Business Management, 4, 3417-3432. .

- PETRI, L. 2014. Engaging Construction Stakeholders with Sustainability through a Knowledge Harvesting Platform. Computers in Industry, 65, 449-469.

- $\quad$ ROBinson, H. S., CARRILlo, P. M., ANUMBA, C. J. \& AL-GHASSANI, A. M. 2001. Perceptions and Barriers in Implementing Knowledge Management Strategies in Large Construction Organisations. COBRA.

- ROBInSON, H. S., CARRILlo, P. M., ANUMBA, C. J. \& AL-GHASSANI, A. M. 2002. Knowledge Management for Continuous Improvement in Project Organizations. Proc., 10th International Symposium on Construction Innovation in Project Organizations, CIB 65, Ohio, US., 680-697. .

- ROLleT, H. 2003. Knowledge Management Processes and Technologies. Kluwer Academic,Boston.

- Shellbourn, M. A., Bouchlaghem, D.M., ANUMBA, C. J., CARillo, P. M., KHALFAN, M. M. \& GLASS, J. 2006. Managing Knowledge in the Context of Sustainable Construction Journal of Information and Technology in Construction 11, 57-71.

- $\quad$ SZULANSKI, G., WINTER, S. G., CAPELTA, R. \& VANDEN, C. 2002. Opening the Black Box of Knowledge Transfer: The Role of Replication Accuracy.

- TAN, C. M., CARRILlo, P. M., ANUMBA, C. J., M, A., NASREDDINE, D., BOUCHLAGHEM, J. M., KAMARA, J. M. \& UDEAJA, C. E. 2007. Development of a Methodology for Live Capture and Reuse of Project Knowledge in Construction Journal of management in Engineering, 23, 18-26.

- TAN, H. C., ANUMBA, C. J., CARRILlO, P. M., BOUCHLAGHEM, N. M. \& KAMARA, J. M., \& UDEAJA, C.E. 2010. Capture and Reuse of Project Knowledge in Construction. Wiley-Blackwell Publication, Oxford, United Kingdom. 
- TAN, H. C., ANUMBA, C. J., CARRILlO, P. M., BOUCHLAGHEM, N. M. \& KAMARA, J. M. U., C.E. 2006. Live Capture and Reuse of Project Knowledge in Construction Organisations. Journal of Operation Research Society Ltd., 4, 149-161.

- udeaja, C. A., KAMARA, J. M., CARRILlo, P. M., ANUMBA, C. J., N BOUCHLAGHEM, N. \& H.C., T. 2008a. A web-based prototype for live capture and reuse of construction project knowledge. 839-851.

- UDEAJA, C. E., OJIAKO, U., MAGUIRE, S. \& AND KOH, L. 2008b. Conceptual Framework for the Capture of Customer Experience Journey in the Housing Sector. COBRA Conference, Dublin,3-5 September 2008.

- UNEP, U. N. E. P. 2009. Buildings and Climate Change: Summary for Decision-Makers. Available at: www.unep.org/sbci/pdfs/SBCI-BCCSummary.pdfSummary.pdf (accessed, Jan, 2015).

- ZACK, M., MCKEEN, J. \& SINGH, S. 2009. Knowledge management and organizational performance: an exploratory analysis. Journal of Knowledge Management, 13, 392-409. .

- ZHANG, N. \& LU, W. F. 2007. A Framework for Manging Enterprise Knowledge for Collaborative Decision Support. Proceedings of 5th International IEEE Conference on Industrial Informatics (INDIN'07), 517-523. 


\title{
TOWARDS AN ADAPTABILITY RATING FOR BUILDINGS
}

\author{
Maltese, S. ${ }^{1}$ Kamara, J. M. ${ }^{2}$; Dejaco M. C. ${ }^{3}$ and Re Cecconi, F. ${ }^{4}$
}

\begin{abstract}
:
The changing needs of building owners and users over time requires that buildings are adaptable to these changing needs over the lifecycle of buildings. Changes to building regulations, demand for enhanced building performance (e.g. in energy use), and the inadequate supply of new building stock (among other factors) further exacerbate the need to adapt existing buildings to meet changes to demand. This paper introduces research, which is aimed at developing guidelines for assessing the adaptability of buildings at the design stage (to promote Design for Adaptability) and for existing buildings. A theoretical model, which is based on literature review, for an adaptability metric is proposed. The metric is based on theoretical indicators of adaptability of three elements of a building (fabric, services and spaces) in relation to six adaptability features: adjustability, versatility, refit-ability, convertibility, scalability and movability. A background into the meaning and need for adaptability is followed by an overview of related research in this area. Thereafter the underlying assumptions and method for developing an adaptability metric are described. The paper concludes with a discussion on the potential application, benefits and limitations of an adaptability metric for buildings and identifies areas for further research.
\end{abstract}

KEYWORDS: ADAPTABILITY, CHANGE, FLEXIBILITY, FUNCTION, KEY PERFORMANCE INDICATOR, NEW CONSTRUCTION, REAL ESTATE.

\section{INTRODUCTION}

Buildings are usually adapted over the course of their lifecycle, to meet the changing needs of owners and users. This includes refurbishment and/or maintenance and repairs, which are significant components in construction output in the UK and other countries such as Italy (ANCE, 2014; ONS, 2015). The adaptation of buildings is also necessary to: meet new performance requirements and regulations, save money and improve the overall sustainability, and also because the unavailability of suitable land for, and cost of new buildings (ISPRA, 2014).

Adaptability deals with change over time and the need for its active consideration in design (otherwise referred to as Design for Adaptability - DfAD) is based on the hypothesis that product life ends because a product is unable to adapt to change (Kasarda et al., 2007, Pinder et al., 2011). Schmidt III et al. (2010a) describes DfAD as "design for time" whereby physical characteristics and spatial, structural and service strategies are

\footnotetext{
${ }^{1}$ Department of Architecture, Built Environment and Construction Engineering, Politecnico di Milano, Italy I. Email: sebastiano maltese@polimi.it

${ }^{2}$ School of Architecture, Planning and Landscape, Newcastle University, Newcastle upon Tyne, UK. Email: johnkamara@ncl.ac.uk

${ }^{3}$ Department of Architecture, Built Environment and Construction Engineering, Politecnico di Milano, Italy I. Email: mario.dejaco@polimi.it

${ }^{4}$ Department of Architecture, Built Environment and Construction Engineering, Politecnico di Milano, Italy I. Email: fulvio.rececconi@polimi.it
} 
adopted to allow a building to respond to changing functional needs of users over the lifecycle of a building (Russell and Moffatt, 2001; Arge, 2005).

Adaptability, even if less known than other topics (i.e. energy efficiency, environmental impacts, etc.), has a relevant influence on the building life cycle, in terms of impacts/costs reduction and functional life, as people are more willing to use a building able to fulfil their needs with less changes (also over the years) (Russell and Moffatt, 2001; Beadle et al. 2008). This is why building adaptability should be measured and highlighted during design (and during operation, if not yet done before). Adaptability is also closely linked to all aspects of sustainability (i.e. social, economic and environmental), as an adaptable building could help in saving energy and money: less refurbishments, operations, construction products and pollution, with more comfort for final users.

This paper introduces the research, which is aimed at developing metrics for assessing the adaptability of buildings at the design stage (to promote DfAD) and for existing buildings. The intention is to push the assessment of adaptability, through the development of a metric, towards the early design stage, so as to provide a standardised instrument able to help designers while working and not only a posteriori, during operation. Many current researches are focused on existing case studies (i.e. Eguchi et al., 2011), while others (i.e. Schmidt et al., 2014), even if perfectly structured, provide instruments too complex for a dynamic use. The metric under development aims to fill the gap in current researches, by providing a preliminary assessment tool to be used during the design and not after (when modifications are expensive).

The paper starts with a literary review of adaptability to define the topic, describes the research methodology used, outlines a possible metric, and also outlines further developments and connections with sustainability.

\section{LITERARY REVIEW}

In these paragraphs relevant adaptability features, a possible way to measure them and the need of a metric are described, with the aim of clarifying objectives and boundaries of this research.

First of all, a definition of adaptability should be given, to fully comprehend potentials and limits of the metric under development. These citations are really useful to understand the context of this research. Here an extract from Kelly et al. (2011): "Beadle et al. (2008) argue that "adaptable buildings have the ability to change use with market conditions, enabling them to have a longer useful life"." Schmidt et al. (2010a) wrote that "adaptability as a design characteristic embodies spatial, structural, and service strategies which allow the physical artefact a level of malleability in response to changing operational parameters over time". Adaptability is different from flexibility, as written by Gijsbers (2006), as structural flexibility is "The capacity of the building structure to provide changes in other storeys, without the necessity to modify the bearing structure 
itself (Blok, 2005)". Even if it is related to the load bearing layer, this concept can be considered valid for all building components.

From what has been found in literature, adaptability in this research is the ability to accommodate changes over time through the response of the building (as a whole) and its components (fabric, services and spaces) to increasing needs.

Similar concepts related to adaptability include: a) flexibility - almost synonymous with adaptability, but with a reduced range of adoption; b) adaptive re-use - to use a land or a building for a purpose different from the original one; c) recyclable and connected concepts - the attitude of something of being reused after the end of its service life and not simply disposed. Other related concepts are described in the next paragraphs, as they are part of the adaptability features (key characteristics in which the adaptability is divided).

In general, for a building, adaptability is the ability to accommodate changes over time, hence a definition of change and time is required, as these two can be considered the boundaries of the adaptability metric. Brand (1994) expanded Duffy's (1990) concept of layers to include the total building. This classification of building layers, improved by Kelly et al. (2011) is reported here, with the aim of using it as the starting point for the creation of the metric.

Table 5 - Building layers and time, adapted from Kelly et al. (2011)

\begin{tabular}{llll}
\hline$\#$ & Layer & Description & Time scale \\
\hline 0 & site & geographic setting of building & Eternal \\
1 & structure & load bearing elements including foundations & $30-300$ years \\
2 & skin & exterior surfaces that provide a weather protecting layer & 20 years \\
3 & services & $\begin{array}{l}\text { working guts of a building - HVAC, electrical, plumbing, } \\
\text { sprinklers, etc. }\end{array}$ & $7-15$ years \\
& & internal layout - internal partitions, doors, etc. & $3-30$ years \\
4 & space plan & furniture, equipment, personal positions of occupants & Daily \\
\hline
\end{tabular}

In this work, the object of the assessment is the building, so at first the site is excluded: to dismantle/demolish the building and to move it in another place is not considered as an adaptable alternative. This also because spaces in which it is still allowed to build are constantly decreasing, at least in Italy (ISPRA, 2014).

The last layer ( 5 - Stuff) should be considered in this metric, but the main focus is related to the building and its spaces, and not the stuff itself; as instance a space should increase the possibility to move the furniture, reorganise the equipment arrangement and so on. But as the furniture does not last as long as the building, more importance should be given to spaces adaptability qualities.

Adaptable Futures research group (2012) added also a social and a surroundings layers, which influence building adaptability. Also these two layers are not considered in this first definition of the metric, as they are too subjective and also connected to the building under analysis, so specific and detailed analysis should be performed each time (a metric may not be able to properly capture these aspects). 
The following characteristics have been developed from the literature review (Fuster et al., 2009; Kelly et al., 2011, Pinder et al., 2011, Schmidt III et al., 2010) and they are considered as the major features of adaptability: a) adjustable (agile): to be used for more than one task without the need of (slowly and heavily) modifying it - i.e. office that turns into a meeting room, classroom into a playroom; b) versatile (flexible): to be quickly adapted for different purposes, even with some temporary shape changes - i.e. downsizing (temporarily or permanently) a space to get two independent (or at least separated) spaces; d) refit-able: to be adaptable in case of performance upgrades - i.e. to meet new energy requirements; e) convertible: to be adaptable in case of space functional change - i.e. turning permanently a balcony into an office; f) scalable: to be adaptable in case of space dimensions change - i.e. the load bearing should be designed to be able to bear an additional floor; g) moveable: to be moved in another place (at first step this characteristic is not applied to the whole building but only to its layers, if need be); h) reusable (after building life expired), related to construction products, at first step not considered in this metric as related to the end of life of the building; and i) recyclable (after building life expired), related to construction products, at first step not considered in this metric as related to the end of life of the building.

Adaptability has a key role for both new construction and existing buildings, even if in the former case there is a bigger possibility to positively influence building behaviour during the design stage. This assessment should not be neglected for existing buildings, as they represent the majority of the construction sector panorama.

In case of a new construction, adaptability (since the early design) can be assessed to (non-exhaustive): a) meet client's need; b) reduce impacts (economic and environmental) related to modifications occurring during building operation; and c) calculate construction costs for each adaptable alternative.

In case of an existing building, the assessment can help to (non-exhaustive): a) determine the adaptability potential; b) select possible refurbishment alternatives; and c) check requirements compliance.

Adaptability and related metrics developed are perceived differently depending on what they are focused on and on the objective. Schmidt et al. (2014) provided some different definitions, like specific adaptability (towards foreseeable changes) versus general adaptability (towards unforeseeable changes). Also segmentation is a way to analyse adaptability by decomposing the system into discrete and functional modules, consistent with the product architecture literature. So the metric under development is just a possible way to describe the adaptability behaviour of a building and its part; it is also to be considered a compromise between usability (of the metric) and detail (provided by the metric).

This research aims to give to stakeholders a way to objectively measure (even in a qualitative way) the adaptability potential of an asset and its parts. This metric comes to fill the lack of an instrument to evaluate this building characteristic, as many researches already pointed out main features, solutions and criticalities, but only few people concentrated on how to measure it (Conejos et al., 2013; AdaptableFutures, 2012). This 
metric is developed from their works, trying to cope with requirements given by both adaptability and measuring systems.

\section{RESEARCH METHODOLOGY}

The aim of this research is to answer to these questions: a) how can adaptability be conceptualised and objectively measured?; b) what are the most influencing factors?; c) how to manage adaptability implications?. This research wants to help stakeholders in dealing with adaptability of their projects and/or existing buildings. It builds on previous research by some of the authors of this paper, on the development of tools to help users in making strategic decisions about their portfolios, by providing some Key Performance Indicators (KPIs) about building condition, maintenance and requirements compliance (Dejaco et al., 2014).

First of all, a literature review on the topic has been performed (50 elements, considering papers, books, proceedings and websites). From this review all the relevant characteristics related to adaptability have been gathered and then assigned to the appropriate adaptability feature. This can be considered the former step for the creation of a metric. Then these characteristics have been associated to two different sets of weights: one considers the importance of each one of the 6 features while the second (still to be fully tested) considers the relative contribution of each characteristic to the specific feature(s) to which is connected. Then these characteristics have been inserted in a checklist to allow the user to simply check the fulfilment, with a qualitative scale from 1 (not adaptable) to 5 (fully adaptable). The calculation layer under the checklist is composed by a series of averages (both simple and weighted). The checklist, to be more comprehensible, is also divided in three parts: building (as a whole), spaces and technology (fabric and services).

In addition to this, the aim of this research is to provide a set of guidelines to be placed side by side to the metric, to be used both for new constructions and existing buildings. Both metric and guidelines are currently under development, so the following steps will be: a) to refine the system developed; b) to test the system with some case studies; and c) to improve the system according to findings.

\section{DEVELOPMENT OF AN ADAPTABILITY METRIC}

The need to measure the adaptability is born with the necessity of having an instrument able to guide designers in their choices, comparing alternatives and understanding the importance of each modification. An analysis of the stakeholders is necessary to understand to who address the metric. The actors in this assessment are mainly: a) asset managers: they receive information about their building and spaces, so they can act promptly to restore it, if need be; b) portfolio managers: they receive information about their building, so they can compare it with others, plan function change and allocate budget; c) designers: they can use this metric as a guideline during the design phase and 
update it since the beginning, to have a powerful instrument to control the future building. They are also meant to measure the adaptability level of their projects and strike a balance between costs and benefits; and d) clients: they can receive synthetic data on asset current condition, so to be aware of the situation and to discuss with professionals to get the most effective alternatives. In case of new constructions, they can receive from the designer the list of spaces with an adaptability evaluation, so to be prepared for future issues.

In addition to this, it is important to understand that this metric should be considered as a preliminary tool, with qualitative assessments to be filled in a checklist. Multiple series of weights are associated to this checklist, so to give to users a detailed result based on their choices.

As objectives and stakeholders have been defined, the next step to create a reliable metric is to define the object of the measurement. The main adaptability features are fulfilled by several different characteristics (explained in the next paragraph), which are connected to different parts of the building and even to spaces. That is the reason why the work has been divided into three different objects, connected to three separate checklists: a) building-related factors, intended as an entity, with a series of characteristics that cannot be associate to a single element or a part of it; b) spaces: some characteristics, relevant for adaptability, involve dimensions, location and features proper of a space; and c) fabric and services: this is the physical part of the building, including both building components, services, furniture and equipment. Building and space are considered two objects, while fabric and services are composed by two levels, called layers, according to Brand (1994) and technological units. Here in Table 6 there is the full list.

Table 6-Fabric and services

\begin{tabular}{|c|c|c|c|}
\hline LAYER & TECHNOLOGICAL UNIT & LAYER & TECHNOLOGICAL UNIT \\
\hline \multicolumn{2}{|c|}{ entire building and spaces } & \multirow[t]{3}{*}{ services } & HVAC \\
\hline structure & $\begin{array}{l}\text { foundations } \\
\text { under-ground load bearing elements } \\
\text { above-ground load bearing elements }\end{array}$ & & $\begin{array}{l}\text { DHW } \\
\text { electrical system } \\
\text { waste disposal system }\end{array}$ \\
\hline skin & $\begin{array}{l}\text { opaque envelope } \\
\text { transparent envelope } \\
\text { above-ground envelope } \\
\text { roof }\end{array}$ & & $\begin{array}{l}\text { transport } \\
\text { gas supply } \\
\text { communications } \\
\text { fire fighting system } \\
\end{array}$ \\
\hline space plan & $\begin{array}{l}\text { internal vertical partition } \\
\text { internal horizontal partition }\end{array}$ & stuff & $\begin{array}{l}\text { furniture } \\
\text { equipment }\end{array}$ \\
\hline
\end{tabular}

To connect this research to the international, main elements of Table 6 have been matched with the Italian standard UNI 8920-1:1981 (Ente Italiano di Normazione, 1981) and with the Uniclass2 - Table G (Construction Project Information Committee, 2013). Table G has not been used as the only reference because it does not fully match with the layers commonly used in literature when dealing with adaptability. 


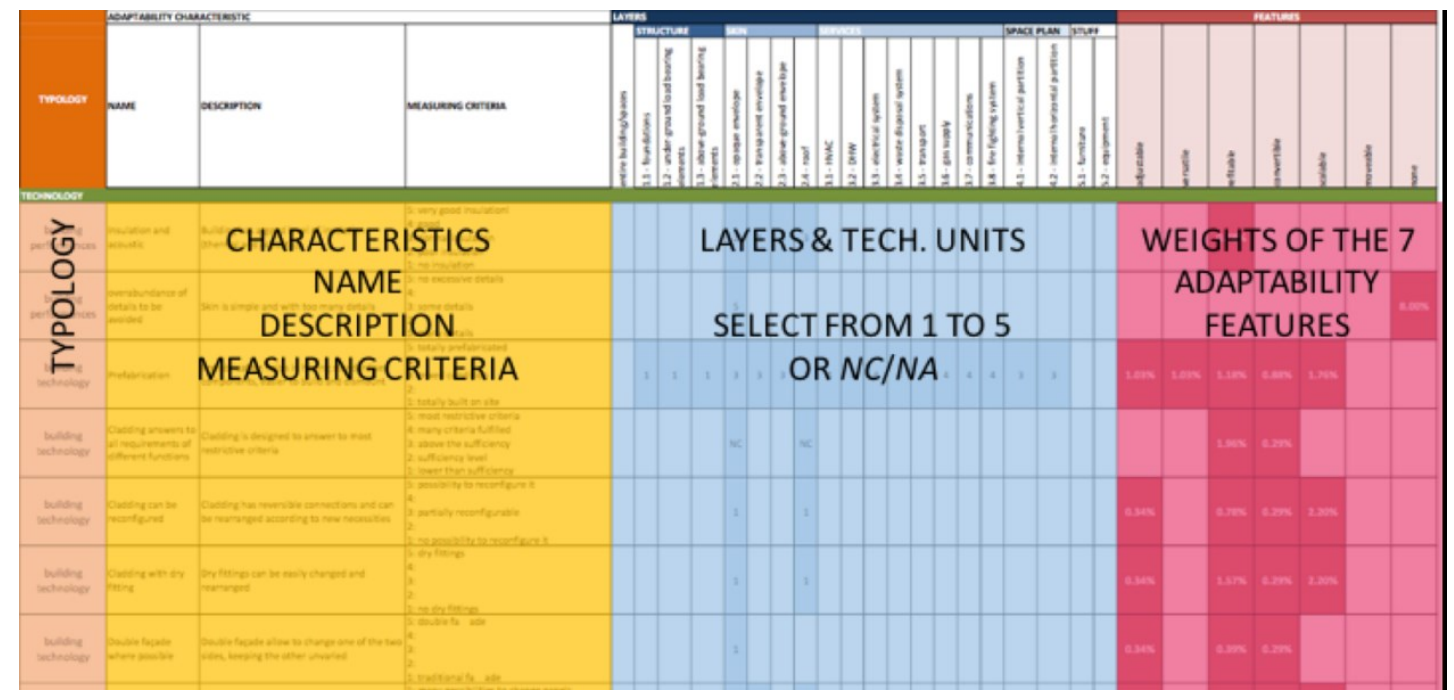

A metric is considered as such if it is precise and as objective as possible; here these two characteristics are even more relevant because the topic is not so commonly widespread (as instance as sustainability or energy efficiency) and so a clear understanding of both input and output is mandatory. Therefore, a list (of course not exhaustive) of the characteristics that make a building adaptable has been defined starting from a literature review on the topic (Beadle et al., 2008; Conejos et al., 2013; Davison et al., 2006; Eguchi et al., 2011; Fuster et al., 2009a; Manewa et al., 2009; Saari and Raveala, 2006; Schmidt III et al., 2010; Webster, 2007). Each characteristic, up to totally 111, has a name, a description, a measuring criteria (one of the most important value of the metric, as it explains how to deal with each characteristic), a typology (as it is mainly related to a particular aspect of the building) and it is connected with one or more adaptability feature(s). Figure 5 shows an extract of the checklist developed, containing all the characteristics gathered (the aim is just to show the main columns of the spreadsheet). After the completion of the checklist the system automatically gives to the users some Key Performance Indicators (KPIs) to guide users through their decisions and choices.

As can be seen from Error! Not a valid bookmark self-reference. the final rating is a weighted average of the six main adaptability features (a seventh feature, "general", has been added to collect all those characteristics not referring to one of the previous areas, but nevertheless considered important).

The relative importance of each feature must be calculated for each case study with the AHP (Saaty, 1980) technique (by simply filling a couple comparison matrix). This is important, because adaptability is not an absolute concept but a collection of several factors, which may lead to different choices, perfectly considered adaptable. As instance a client may want a building easily convertible (change of function) but not necessarily scalable (which can be increased in volume and surface). Therefore, the choice of the weights is demanded to the client or to the designer. 
Figure 6 - Overall building adaptability rating

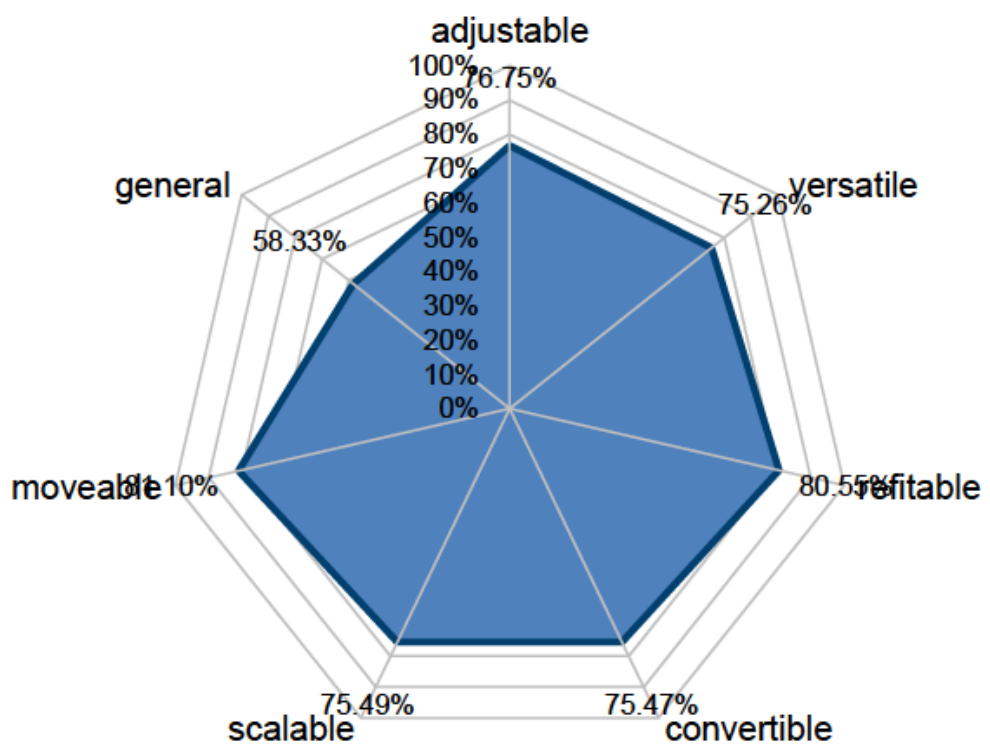

Figure 7 -Adaptability rating split in the three main objects

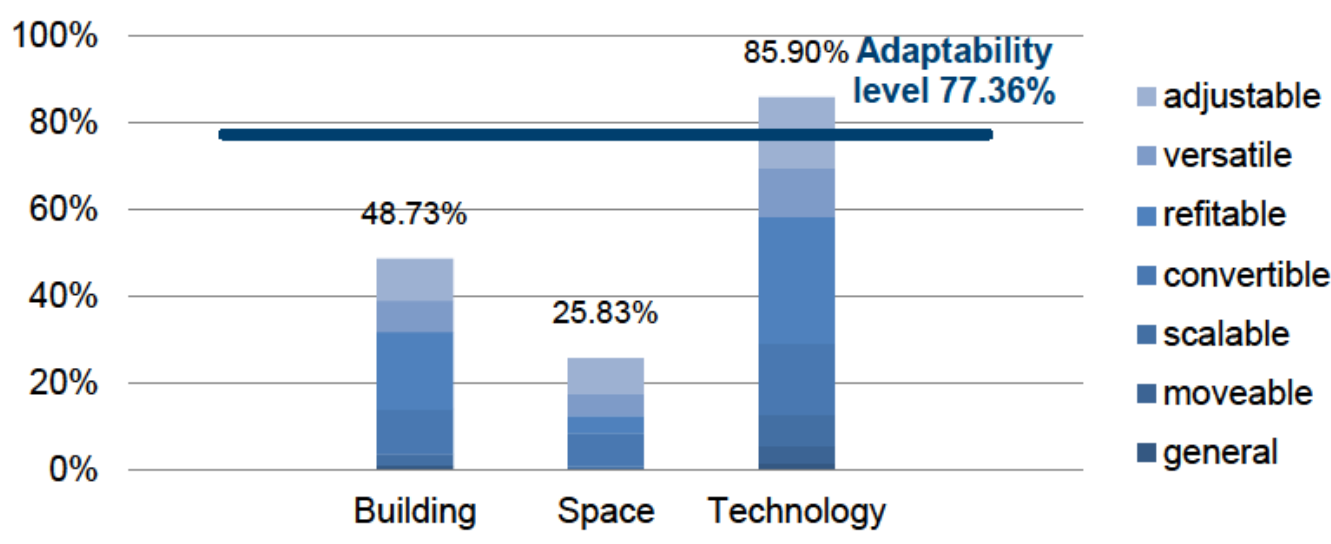

Figure 7 shows the single contribution of each the seven main adaptability features to each of the three objects. This is an interesting because it helps users in focusing on the criticalities encountered, trying to enhance missing/unfulfilled characteristics. Data in the summary are appositely presented with an increasing level of depth and complexity, to help users according to their needs. The summary contains other general data about the building and some interesting insights (i.e. the number characteristics fulfilled per each typology) that can help to understand the building adaptability level, not depending on the results. 


\section{POTENTIAL BENEFITS AND LIMITATIONS}

This paper tried to enhance the study on this topic by collecting main adaptability characteristics from other researches; the result is a preliminary metric, which can be used also as a guideline, to assess the adaptability level of a building. This is less detailed than other researches, as it tries to embrace the whole topic and not, as instance, just one specific feature. The result is more than a guideline to follow, as it gives to users a precise feedback based on their choices, with a score and the adaptability level split into the various components and spaces of the building. Now this rating system is under development but it helps in focusing on adaptability, while choosing design alternatives during the traditional design process. In the future it will be put side by side with an analysis of the implications of each choice over the life cycle: each adaptable alternative influences one or more aspects of the building (i.e. having a raised flooring helps in upgrading services, but it may reduce the useful height of the storey, increase construction costs, etc.); so implications should be assessed as well as the adaptable alternatives to achieve a complete system able to help designers and clients.

The metric is limited to the adaptability characteristics analysis, so it is a good help during the preliminary phase of selection of the design alternatives, which should be analysed in detail to strike a balance between costs and benefits over the life cycle. This is better in case of an existing building, as the analysis of the implications is really reduced in terms of effort: as the building is already in the operation phase, alternatives and adaptability implications are minimal.

As mentioned before, this is an ongoing work and it can be improved with some case studies (one has been performed to test the procedure) but the main objective is to provide a set of guideline to follow and a metric to measure the alternatives, so to design new buildings (or refurbishment) in an adaptable way. The demand of this tool is present, even if it does not come during the design, but during the operation phase, when the client notices that the asset does not fully answer to its needs.

It is acknowledged that the proposed adaptability rating can be seen as a set of characteristics associated to a weighting system; it may be not so easy to fill for some reasons: a) adaptability is still not well known; b) lot of data, not always available, are required to fill it completely; and c) actually it is a spreadsheet (even if quite handy) and not a tool/software. One of the major risks in the implementation of a system like this is that actually is not connected with the economic part: clients always need (want?) to decide on an economic basis, which should be in provided in the future together with the adaptability rating. Eventually, to ease the implementation process, these characteristics can be gradually implemented in a BIM model, so to provide a prompt update of the assessment. 


\section{CONCLUSIONS}

This paper shows the first results of the research, which has the aim of inserting adaptability in the panel of the design criteria, to be used in the early design stages. The adaptability metric is a qualitative and preliminary assessment tools that wants to enable stakeholders in assessing the adaptability level of their projects and assets, if dealing with the real estate, and it will contribute to the overall sustainability of buildings Future developments include deeper analysis, with life cycle calculation, to understand the implication of each choice, also because all the components, both fabric and services, are strictly connected, so each alternative has an influence on both the building response to changing needs and the operational parameters, like consumptions, comfort and usability. Another important aspect that the authors are currently investigating is the requirements analysis: this because each building function (and each space inside a building) has different requirements, given by law, standards, voluntary protocols and clients. So, before analysing the adaptability level of an existing building, it may be necessary to analyse what is missing and what current laws and regulations can allow. It can be also useful during the design of a new building, because this list of requirements can be used to check the compliance with both regulations and clients' needs.

\section{REFERENCES}

- ADAPTABLEFUTURES (2012), Extending the life of our built environment. [Online] Available from: www.adaptablefutures.com. Loughborough University. [Accessed: 19th April 2015].

- $\quad$ ARGE, K. (2005), Adaptable office buildings: theory and practice, Facilities, Vol. 23, Issue 3/4, pp. 119-127

- ASSOCIAZIONE NAZIONALE COSTRUTTORI EDILI (ANCE) (2014), Osservatorio congiunturale sull'industria delle costruzioni, July 2014, Roma, Italy.

- BEADle, K., GIBB, A., AUSTIN, S., FUSTER, A. \& MADDEN, P. (2008), Adaptable futures: setting the agenda? in Proceedings of the $1^{\text {st }}$ I3CON International Conference, Loughborough University, Loughborough, UK, 14-16 May.

- $\quad$ BRAND, S. (1994), How Buildings Learn: What Happens After They're Built, Viking Press, New York, USA.

- $\quad$ CONEJOS, S., LANGSTON, C. \& SMITH, J. (2013), AdaptSTAR model: A climate-friendly strategy to promote built environment sustainability, Habitat International, Vol. 37, pp. 95103.

- $\quad$ CONSTRUCTION PROJECT INFORMATION COMMITTEE (2013), Uniclass2 - Unified Classification for the Construction Industry.

- $\quad$ DAVISON, N., GIBB, A.G., AUSTIN, S.A., GOODIER, C.I. \& WARNER, P. (2006), The multispace adaptable building concept and its extension into mass customisation, in Proceedings of the Adaptables2006 - International Conference on adaptable building structures, Eindhoven, The Nederlands, 3-5 July 2016.

- DEJACO, M.C., RE CECCONI, F. \& MALTESE, S. (2014), A rating system for building condition ranking, in Proceedings of the CIB Facilities Management Conference, Copenhagen - DK - Technical University of Denmark, 21-23 May 2014, pp. 179-191.

- $\quad$ DUfFY, F. (1990), Measuring Building Performance, Facilities, Vol. 8 No. 5, pp. 17.

- $\quad$ EGUCHI, T., SCHMIDT III, R., DAINTY, A., AUSTIN, S. \& GIBB, A. (2011), The cultivation of adaptability in Japan, Open House International, Vol. 36 No. 1. 
- $\quad$ ENTE ITALIANO DI NORMAZIONE (1981), UNI 8290-1, Edilizia residenziale - Sistema tecnologico - Classificazione e terminologia.

- FUSTER, A., GIBB, A., AUSTIN, S., BEADLE, K. \& MADDEN, P. (2009), Adaptable buildings: three non-residential case studies, in Proceedings of the CIB Changing Roles: New Roles; New Challenges conference, Noordwijk, The Netherlands, 5-9 October.

- FUSTER, A., GIBB, A., BEADLE, K., AUSTIN, S. \& MADDEN, P (2009a) Newways: an industrialised kit of parts, In (Kazi, A., Hannus, M. and Boudjabeur, S.) Open building manufacturing: Key technologies, applications, and industrial cases, ManuBuild.

- GIJSBERS, I. R. (2006), Towards adaptability in structures to extend the functional lifespan of buildings related to flexibility in future use of space, in Proceedings of the Adaptables2006 - International Conference on adaptable building structures, Eindhoven, The Nederlands, 3-5 July 2016.

- ISTITUTO SUPERIORE PER LA PROTEZIONE E LA RICERCA AMBIENTALE (ISPRA) (2014), Il consumo del suolo in Italia, Edizione 2014, Roma, Italy (Rapporto 195/2014).

- KASARDA, M.E., TERPENNY, $\square$ J.P., INMAN, D, PRECODA, K.R., JELESKO, J., SAHIN, A \& PARK, J. (2007), Design for adaptability (DfAD) - a new concept for achieving sustainable design, Robotics and Computer-Integrated Manufacturing, Vol. 23, pp. 727-734.

- KELLY, G., SCHMIDT III, R., DAINTY, A. \& STORY, V. (2011), Improving the design of adaptable buildings through effective feedback in use, in Proceedings of the CIB Management and Innovation for a Sustainable Built Environment conference, Amsterdam, The Netherlands, 20-23 June.

- $\quad$ MANEWA, A., PASQUIRE, C., GIBB, A. \& SCHMIDT III, R. (2009), A paradigm shift towards whole life analysis in adaptable buildings, in Proceedings of the CIB Changing Roles: New Roles; New Challenges conference, Noordwijk, The Netherlands, 5-9 October.

- OFFICE FOR NATIONAL STATISTICS (ONS) (2015), Statistical bulletin - Output in the construction Industry, UK Office for National Statistics, February 2015

- PINDER, J., SCHMIDT III, R., GIBB, A. \& SAKER, J. (2011), Exploring the business case for more adaptable buildings: lessons from case studies, in Proceedings of the $C I B$ Management and Innovation for a Sustainable Built Environment conference, Amsterdam, The Netherlands, 20-23 June.

- SAARI, A. \& RAVEALA, J. (2006), Managing flexibility programming and overall design, in Proceedings of the Adaptables2006 - International Conference on adaptable building structures, Eindhoven, The Nederlands, 3-5 July 2016.

- SAATY, T. (1980), The Analytic Hierarchy Process: Planning, Priority Setting, Resource Allocation, McGraw-Hill, New York (USA).

- SCHMIDT III, R., EGUCHI, T. \& AUSTIN, S. (2010), Lessons from Japan: A look at the Century Housing System, in Proceedings of the $12^{\text {th }}$ International Design Structure Matrix Conference, Cambridge, UK, 22-23 July.

- $\quad$ SCHMIDT III, R., EGUCHI, T., AUSTIN, S. \& GIBB, A. (2010a), What is the meaning of adaptability in the building industry?, in Proceedings of the CIB $16^{\text {th }}$ International Conference on Open and Sustainable Building, Bilbao, Spain, 17-19 May.

- SCHMIDT III, R., SANCHEZ VIBAEK, K. \& AUSTIN, S. (2014), Evaluating the adaptability of an industrialized building using dependency structure matrices, Construction Management and Economics, Vol. 32 No. 1-2, pp. 160-182.

- WEBSTER, M. (2007) Structural Design for Adaptability and Deconstruction: A Strategy for Closing the Materials Loop and Increasing Building Value, New Horizons and Better Practices, pp. 1-6. 


\title{
IMPROVING HOUSING QUALITY THROUGH CLIENT-FOCUSED INFORMATION
}

\author{
Moreira da Costa, J. ${ }^{1}$ and Corvacho, M. H. ${ }^{2}$
}

\begin{abstract}
:
Housing is among the main drivers for the Construction Industry (CI) in most countries, providing the response to a fundamental need of people. This fulfilment usually involves a significant burden to the financial resources of individuals or families, extending for a considerable lapse of time. Nevertheless, the information that the CI provides to its housing customers is far behind what other industries do. The choosing of a home is mostly based on non-specialist direct analysis as any documents that might be available are generally technically-oriented. Several Design Quality Evaluation Methods (DQEM) have been developed and even implemented in some countries (i.e. Qualitel/France, SEL/Switzerland, HQI/UK, $M C$ FEUP/Portugal) but they have yet to achieve recognition as a suitable tool for Client-as-User decision. Unlike other industries which engage in making their clients more knowledgeable and able to choose wisely among the diverse offers in the market, CI seems unconcerned by this. Thus, a recollection of surveys concerning the impact of the Design stage of a construction project is presented, followed by an overview of some of the more widely known DQEM. This is followed by a discussion and proposal of a more user-friendly approach for the presentation of quality performance levels in housing design and how it might be used as an asset for a change in the way CI is perceived by public opinion, fostering user knowledge and client-induced industry improvement
\end{abstract}

KEYWORDS: CLIENT, DESIGN, EVALUATION METHODS, QUALITY, USER.

\section{INTRODUCTION}

The Construction Industry (CI) has always been quite peculiar about the way it deals with its Clients. Although CI's products count among the more expensive and long lasting in anybody's life span - just think of a house, an apartment - little effort has been devoted to "educate the Client" as it has been stated in the Rethinking Construction report (Egan et al, 1998). Ten years forward, the UK's CI seems to have yet to efficiently face this issue as it is again raised in the Never Waste a Good Crisis report (Wolstenholme et al, 2009), by identifying the lack of motivation from clients in demanding best value solutions for their projects and engaging in a true collaborative work. Although both of these considerations are of British origin, one may argue with some confidence that similar situations are typical in most countries CI's.

To put things into perspective, let's compare the ways in which two different industries, providing essential products for every day's life, usually deal with their customers.

\footnotetext{
${ }^{1}$ CONSTRUCT - Institute of R\&D in Structures and Construction, Faculty of Engineering (FEUP) - University of Porto, Porto, Portugal. Email: jmfcosta@fe.up.pt

${ }^{2}$ CONSTRUCT - Institute of R\&D in Structures and Construction, Faculty of Engineering (FEUP) - University of Porto, Porto, Portugal. Email: corvacho@fe.up.pt
} 
First, the purchase of a TV set. Starting from a budget and size constraints, probably it will make sense to have a look into the dozens of review sites available on the web or even some specialist print magazines; most of these are written in laymen language with limited technical jargon, therefore with little risk of scaring the potential customer. Afterwards, a catalogue to take home and analyse in more detail (or ask a friend) will also be available. Sometimes, chances are that the decision may fall on something a bit more expensive as the best value factor is understood by the costumer and the TV industry has made an effort in providing data he/she can understand.

On the other hand we have the need for buying or renting a home. While our TV set could cost, for instance, $€ 1000$, this undertaking will require the customer to go into the level of several tens or even hundreds of thousands euros of investment, often supported by a loan that will constrain a large part of the family's income for several years to come. Nevertheless, the way the CI producer presents its product to its potential costumer could hardly be more different from the example above.

The CI is, most probably, one of the most transversal industries in the modern world. Starting with the diversity of raw and processed materials that are required, any construction will engage a massive diversity of technical expertise and working crafts to carry the conceptual ideas to its physical completion and, finally, will also rely on an array of other trades and products to make the space or infrastructure liveable and serviceable. Even so, society looks at CI as a "black box", only really understood by insiders. It shouldn't be so and the constraints that the industry in facing in many European countries and not just might be a good opportunity to begin a most needed change.

A final point should be noted: in most construction projects, two Clients exist. First, the Client-as-Promoter, defining the brief and framework for the project, with business or social objectives; then, the Client-as-User, the one who is going to actually use the building or infrastructure and that will have to directly deal with its qualities and shortcomings.

\section{RESEARCH ON THE INFLUENCE OF DESIGN}

For any kind of construction, it is common sense that a comprehensive design should be developed upfront. Architectural, Structural, Electrical, Mechanical, Facilities Designs to mention just the more usual ones - are the basis for a successful production and the ever challenging pursuit of balancing the fundamental vectors of Quality, Cost and Time.

In some sense, to devote as much effort possible to Design is not only technically sound but also logical in the economic sense. Although this will vary somewhat from country to country, perhaps it will not be too wrong to say that the total fees for a full design team (that is, Architects, Engineers, etc.) may reach around $10 \%$ of the total cost of construction; however, the professionals paid by these $10 \%$ will be responsible for 
developing the ideas and specifications that will define how the remaining $90 \%$ of the investment is going to be spent.

On the other hand, the Design stage is also the most inexpensive stage of production in a project; very little needs to have any physical substance, besides models and provisional print-outs, as the modern design team relies on digital processes to carry out its work. Even the final printed output - drawings, documents - can be left almost to the deadline with the help of the current crop of fast printers and plotters. The time allowed for Design can be nearly totally devoted to exploring and discussing ideas, testing options, deciding over which way to go. Any change of mind, correction or even discard of work already done in this stage - no matter how psychological disturbing as it may be - will have an associated cost far lower than coming to that conclusion during the execution stage. The time for rethinking again and deleting bytes is much cheaper than inventing a last-minute solution to accommodate a forgotten $\mathrm{AC}$ duct or to force the users to deal with a poorly proportioned space for all the life span of a building.

The influence of Design in Building Quality has been addressed in several researches along the years but perhaps still at a level much below what it should have been. If wishing to point out one of the first major studies where this issue was raised, perhaps the report published by the Bureau Securitas in France might be a good selection (Bureau Securitas, 1979). This study was made possible by using an extensive database of complaints presented to insurance companies and concerning deficiencies arising from construction defects (around 10000 cases, 1968-1978), gathered by Bureau Securitas when acting as experts for identifying their causes (Fig.1).

Fig. 1 - Causes of deficiencies in buildings (Bureau Securitas, 1979)

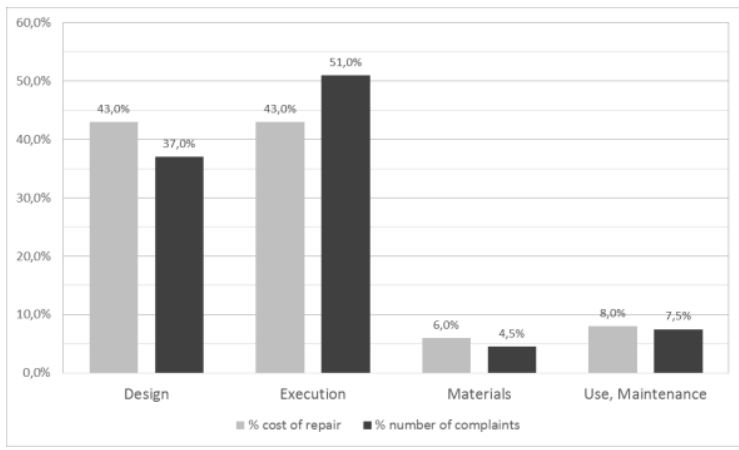

A. General causes of deficiencies

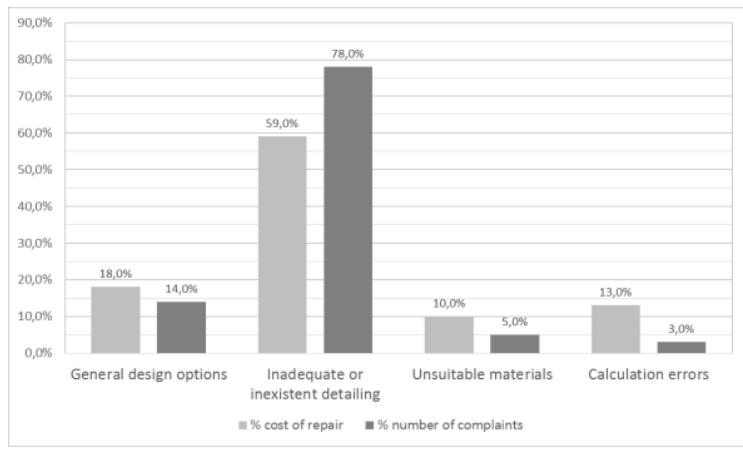

B. Specific causes of Design-related deficiencies

Two of the main findings of this report can be highlighted as: i. The identification of Design with a level of responsibility same as Execution for failures in buildings; ii. Almost 2/3 of the Design-related deficiencies were tracked back to flawed detailing.

Another research, conducted in the Chalmers University of Technology (Josephson and Hammarlund, 1999), refers a summary of several studies and shows similar conclusions (ranges of results shown in Fig.2). One relevant aspect is the fact that the largest part of 
design-related defects becomes apparent essentially after the Production stage, that is, when the building begins to operate and its elements begin to be endure the stresses and are asked to fulfil the requirements for which they were thought for.

A more recent study presents the causes at origin of specific types of defects and, again, Design takes the largest part of responsibility for almost all the investigated construction elements (Fig. 3, Chong and Low, 2005). A significant number of other research papers over this matter can be found and are cited in the references mentioned above. If comparing with the Bureau Securitas report, it is a fact that most of them were only able to study much smaller samples, sometimes also bound to CI environments with specific features or even focused on particular types of defects or failures.

Fig. 2 - Origin of defects in buildings as $\%$ of total defect cost (based on Josephson and Hammarlund, 1999)

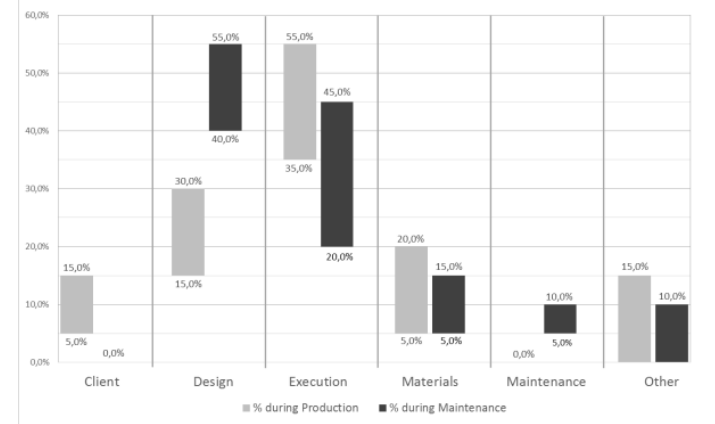

Fig. 3 - Root causes of defects at Occupancy stage (based on Chong and Low, 2005)

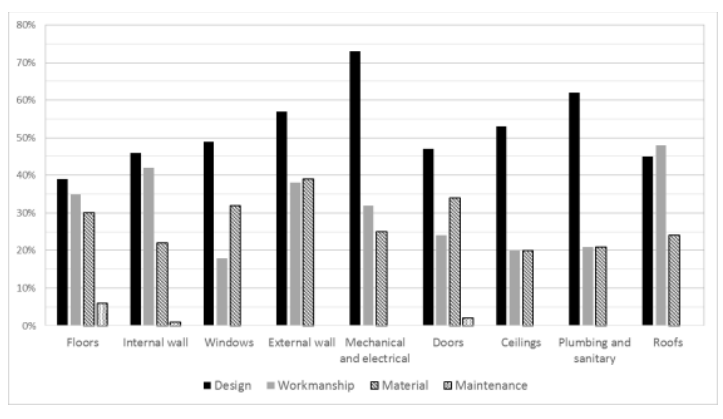

Whichever limitations may have existed, the overwhelming majority of the investigations agrees in identifying Design as being at the basis of failures or defects patent in buildings, with a share at times higher than $50 \%$.

Before closing this section it is important to draw the attention to a fact: the investigations over this issue refer to "defects" or "failures" that can be visually perceived as construction flaws - cracks, moisture, equipment failure, peeling of finishes, etc. Other type of failures, related to the inability of the designed spaces to fulfil adequately the purposes for which they were intended, are not represented in these researches. This is a relevant consideration as buildings are built for people to use in a regular basis; unlike a bridge, which is made for a specific and very well defined purpose - for people to get to the other side, a single objective fulfilled in a matter of seconds or minutes and from time to time - the people who use a building do it for continuous and long periods of time, to develop a multitude of different tasks in which also diverse ways are possible. A poorly organized room distribution in a home may constrain the living of a family for years and is not so easily solved as, for instance, a rain leakage. But it does not show as "construction defect" in most researches. 


\section{DESIGN QUALITY EVALUATION METHODS}

Notwithstanding the situation pictured previously, the fact is that comprehensive Design Quality Evaluation Methods (DQEM) are hard to find and, the existing ones, relatively unknown to both the professionals and the public. Here, DQEM are considered as organised procedures that grade the efficiency of a set of design options, according to an established framework of analysis. Some of these methods have a tree-like structure as shown in Fig.4, where general concepts are subsequently divided into more specific ones until a list of evaluation criteria is reached; an evaluation criterion is a grading process that allows that a measurable item - i.e. Total Energy Consumption in Winter or Area of a Bedroom - or observed situation - i.e. Type of wall finish in bathrooms or "L" shaped Living Room - may be compared to a scale of pre-defined solutions each associated with a corresponding quality performance mark level.

The DQEMs developed under this framework allow that the marks obtained at Evaluation Criteria level are combined through weights given to each criterion and provide a mark for the Global Criterion one level above; this can be extended through each level, leading to partial marks and an inclusive quality mark for the global design. This approach helps the designers to be aware of unbalanced quality levels and to identify the areas or components more suitable to a reanalysis, for instance when facing budget restrictions.

Fig. 4 - General framework of a Design Quality Evaluation Method (based on Moreira da Costa, 1995)

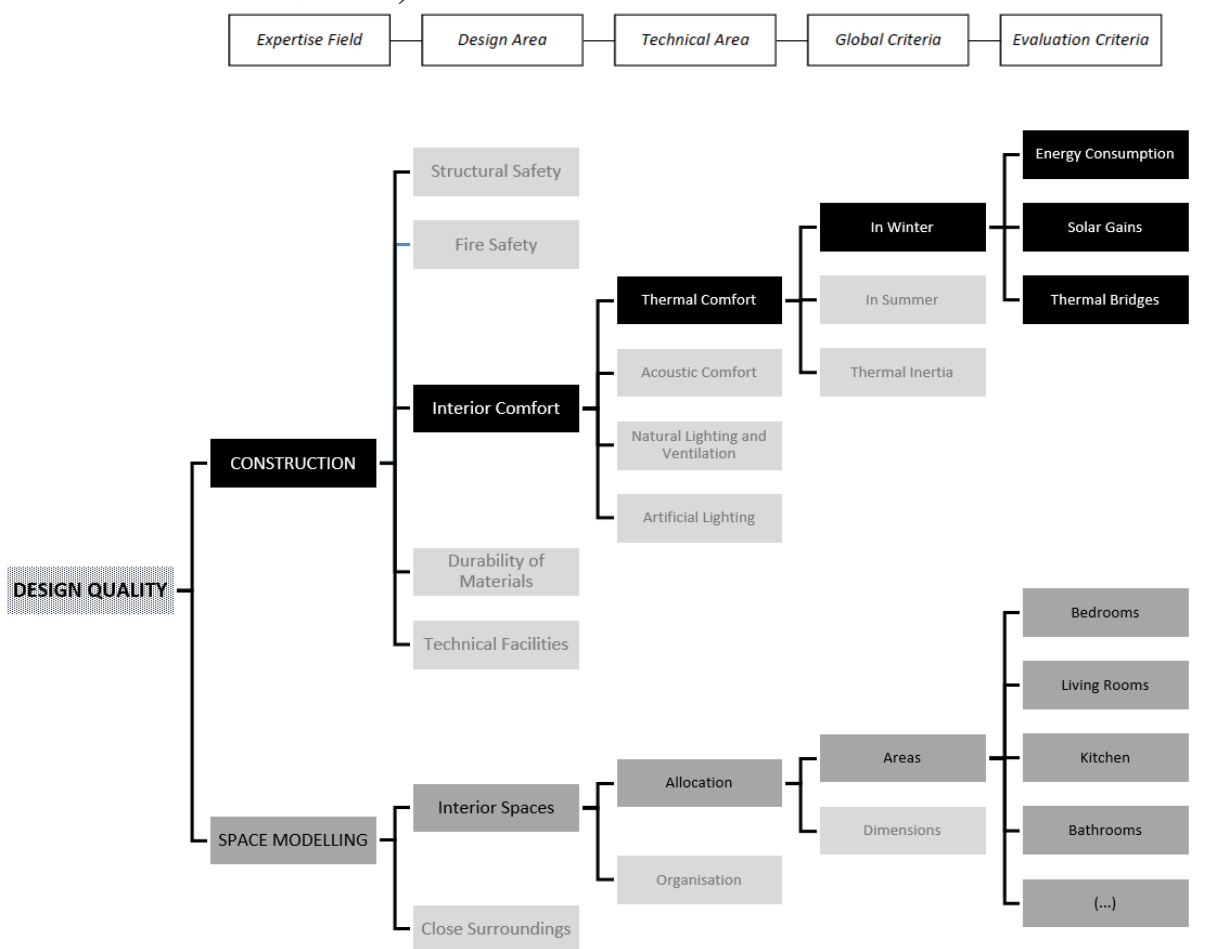

This Tree-structure is followed by some of the identified DQEM: (i) Système d'évaluation de logements SEL (Office Fédéral du Logement OFL, 2000) and (ii) 
MC_FEUP (Moreira da Costa, 1995). The French strategy, leaded by Association Qualitel (CERQUAL, 2013 and 2014a), is somewhat different as it doesn't follow a hierarchy as shown above but, instead, defines a Series of particular Technical Areas and corresponding Global/Evaluation Criteria which marks are then combined according to predefined rules (i.e. global mark blocked at lower level if any criteria is below medium level). In this case, the identification of the distribution of quality levels is less direct. In what concerns the British Housing Quality Indicators HQI (NAHA, 2008), both types of structure can be found. In Table 1 it is possible to see the main characteristics of these DQEM.

As it is apparent, all of these DQEM focus on housing buildings. This is not surprising, since a home is, most probably, one of the more complex units to design and build. Not only the recipient most of the times is unknown besides a general profile, but also it concerns a building unit that may have to adapt to the natural age evolution of the users (and consequent change in the ways the home is used, relevant in markets where the purchase of residence is preferred), and the designed technical solutions and materials ought to provide comfort but also be durable and reliable enough to ensure that maintenance can be done within acceptable intrusion in the household.

The attention to the Environmental Sustainability of Building Projects has also lead to other DQEM, an area where the following may be referred: (i) BREEAM (BRE Global Ltd, 2012), (ii) LEED (USGBC, 2015), (iii) HQE (CERQUAL, 2014b), (iv) LiderA (Pinheiro, 2011) and SBTool (iiSBE, 2012). An overview is shown in Table 2.

Table 1 - Overview of Design Quality Evaluation Methods - New and existing housing

\begin{tabular}{|c|c|c|c|c|}
\hline \multirow{4}{*}{$\begin{array}{l}\text { Country + Organisation } \\
\text { FR }(1980 \rightarrow) \\
\text { Association Qualitel }\end{array}$} & \multirow{2}{*}{$\begin{array}{l}\text { Quality Labels }+ \text { Scope } \\
\text { QUALITEL } \\
\text { New housing }\end{array}$} & \multicolumn{2}{|l|}{ Design / Technical Areas } & \multirow{2}{*}{$\begin{array}{c}\text { Structure } \\
\text { Series }\end{array}$} \\
\hline & & $\begin{array}{l}\text { - Energy Performance } \\
\text { - Durability of the building } \\
\text { envelope } \\
\text { - Water management }\end{array}$ & $\begin{array}{l}\text { - Exterior and Interior Acoustics } \\
\text { - Thermal Comfort in Summer } \\
\text { - Information for Maintenance } \\
\text { and Users }\end{array}$ & \\
\hline & $\begin{array}{l}\text { HABITAT \& ENVIRONMENT } \\
\text { New housing }\end{array}$ & $\begin{array}{l}\text { Same as Qualitel plus: } \\
\text { - Environmental-conscious } \\
\text { building site } \\
\text { - Electric Consumption }\end{array}$ & $\begin{array}{l}\text { - Selection of Materials } \\
\text { - Visual Comfort } \\
\text { - Communal Spaces and Rooms } \\
\text { - Quality of Interior Air }\end{array}$ & Series \\
\hline & $\begin{array}{l}\text { PATRIMOINE HABITAT } \\
\text { (\& ENVIRONNEMENT) } \\
\text { Renovation of housing }\end{array}$ & $\begin{array}{l}\text { - Environmental management of } \\
\text { the Project } \\
\text { - Clean Building Site } \\
\text { - Green attitudes } \\
\text { - Fire Safety } \\
\text { - Sanitary Quality of Dwellings }\end{array}$ & $\begin{array}{l}\text { - Building Envelope and Roof } \\
\text { - Facilities and Comfort in } \\
\text { Communal Areas } \\
\text { - Facilities of Dwellings } \\
\text { - Energy Performance }\end{array}$ & Series \\
\hline $\begin{array}{l}\mathrm{CH}(1986 \rightarrow) \\
\text { Office Fédéral du Logement } \\
\text { OFL }\end{array}$ & $\begin{array}{l}\text { SYSTEME D'EVALUATION DE } \\
\text { LOGEMENTS SEL } \\
\text { New housing }\end{array}$ & $\begin{array}{l}\text { Under Architectural perspective: } \\
\text { - Dwelling } \\
\text { - Close Surroundings } \\
\text { - Urban Location }\end{array}$ & & Tree \\
\hline $\begin{array}{l}\text { PT }(1995 \rightarrow) \\
\text { Faculdade de Engenharia da } \\
\text { Universidade do Porto FEUP }\end{array}$ & $\begin{array}{l}\text { MC_FEUP } \\
\text { New housing }\end{array}$ & $\begin{array}{l}\text { - Structural Safety } \\
\text { - Fire Safety } \\
\text { - Interior Comfort } \\
\text { - Durability of Materials }\end{array}$ & $\begin{array}{l}\text { - Technical Facilities } \\
\text { - Interior Spaces } \\
\text { - Close Surroundings }\end{array}$ & Tree \\
\hline $\begin{array}{l}\text { UK }(2000 \rightarrow) \\
\text { The National Affordable } \\
\text { Homes Agency }\end{array}$ & $\begin{array}{l}\text { HOUSING QUALITY } \\
\text { INDICATORS HQI } \\
\text { New housing }\end{array}$ & $\begin{array}{l}\text { - Location } \\
\text { - Site - Visual impact, layout and } \\
\text { landscaping } \\
\text { - Site - Open space } \\
\text { - Site - Routes and movement } \\
\text { - Unit - Size } \\
\text { - Unit - Layout }\end{array}$ & $\begin{array}{l}\text { - Unit - Noise, light, services \& } \\
\text { adaptability } \\
\text { - Unit - Accessibility within the } \\
\text { unit } \\
\text { - Unit - Sustainability } \\
\text { - External Environment - } \\
\text { Building for Life }\end{array}$ & $\begin{array}{c}\text { Series + } \\
\text { Tree }\end{array}$ \\
\hline
\end{tabular}


Table 2 - Overview of Evaluation Methods for Environmental Sustainability of Building Projects

\begin{tabular}{|c|c|c|c|c|}
\hline Country + Organisation & Quality Labels + Scope & \multicolumn{2}{|l|}{ Design / Technical Areas } & Structure \\
\hline $\begin{array}{l}\text { UK }(1990 \rightarrow) \\
\text { British Research } \\
\text { Establishment BRE Global }\end{array}$ & $\begin{array}{l}\text { BREEAM } \\
\text { All types of buildings, new and } \\
\text { existing }\end{array}$ & \multicolumn{2}{|c|}{$\begin{array}{ll}\text { For new construction: } & \\
\text { - Management } & \text { - Waste } \\
\text { - Water } & \text { - Transport } \\
\text { - Health and wellbeing } & \text { - Land use and ecology } \\
\text { - Materials } & \text { - Innovation } \\
\text { - Energy } & \text { - Pollution } \\
\end{array}$} & $\begin{array}{c}\text { Series }+ \\
\text { Tree }\end{array}$ \\
\hline $\begin{array}{l}\text { USA }(1998 \rightarrow) \\
\text { US Green Building Council } \\
\text { USGBC }\end{array}$ & $\begin{array}{l}\text { Several types of buildings, new } \\
\text { and existing }\end{array}$ & $\begin{array}{l}\text { - Location and Transportation } \\
\text { - Sustainable Sites } \\
\text { - Water Efficiency } \\
\text { - Energy and Atmosphere }\end{array}$ & $\begin{array}{l}\text { - Materials and Resources } \\
\text { - Indoor Environmental Quality } \\
\text { - Innovation } \\
\text { - Regional Priority }\end{array}$ & $\begin{array}{c}\text { Series }+ \\
\text { Tree }\end{array}$ \\
\hline $\begin{array}{l}\text { FR }(2004 \rightarrow) \\
\text { Association Qualitel }\end{array}$ & $\begin{array}{l}\text { HQE } \\
\text { New housing }\end{array}$ & \multicolumn{2}{|c|}{$\begin{array}{l}\text { - Energy and Economics - Maintenance, water, thermal, durability } \\
\text { - Comfort in use - Acoustic, hygrothermal, visual, odour } \\
\text { - Health and Protection - Spaces, air, water, equipment, accessibility } \\
\text { - Environment - Building integration, materials, building site, CDW }\end{array}$} & Series \\
\hline $\begin{array}{l}\text { PT }(2005 \rightarrow) \\
\text { Instituto Superior Técnico } \\
\text { IST }\end{array}$ & $\begin{array}{l}\text { LIDERA } \\
\text { All types of buildings, new and } \\
\text { existing }\end{array}$ & $\begin{array}{l}\text { - Site and Integration } \\
\text { - Resources } \\
\text { - Environmental loadings }\end{array}$ & $\begin{array}{l}\text { - Environmental Comfort } \\
\text { - Socioeconomic experience } \\
\text { - Sustainable use }\end{array}$ & $\begin{array}{c}\text { Series + } \\
\text { Tree }\end{array}$ \\
\hline $\begin{array}{l}\text { CAN }(2007 \rightarrow) \\
\text { International Initiative for a } \\
\text { Sustainable Built } \\
\text { Environment iiSBE }\end{array}$ & $\begin{array}{l}\text { SBTOoL } \\
\text { All types of buildings, new and } \\
\text { existing }\end{array}$ & $\begin{array}{l}\text { - Site location and characteristics, } \\
\text { Available services } \\
\text { - Site regeneration and } \\
\text { development, Urban Design } \\
\text { - Energy and Resource } \\
\text { consumption }\end{array}$ & $\begin{array}{l}\text { - Environmental loadings } \\
\text { - Indoor environmental quality } \\
\text { - Service quality } \\
\text { - Social, Cultural and Perceptual } \\
\text { aspects } \\
\text { - Cost and Economic aspects }\end{array}$ & $\begin{array}{l}\text { Series + } \\
\text { Tree }\end{array}$ \\
\hline
\end{tabular}

It should be referred that besides its use for obtaining the qualification label which may be associated with the DQEM, they may also be used as an internal quality control tool for the involved designers. In fact, the evolution to digital and the internet has presented designers with the possibility of choosing among many more options than it was possible just a few years ago. In the times of mostly hand-produced output and when the access to technical data relied on printed catalogues collected in offices, designers had to decide which options to follow based mostly on their vision, experience, instinct and available references. To test different spatial layouts, structural models or combination of finishes had to be made under a reasonable scope and depth as producing the drawings and bills of quantities needed for comparing them was a rather time-consuming task. As for new materials or systems, if specifications and details had yet to make its way to the office's archive, they were as good as inexistent.

Nowadays, software and digital models allow that this exploration of possibilities can be made much quicker and more extensively. Different but suitable room arrangements can be looked at side by side and an evaluation of, for instance, each one's ratio of useful/gross areas, can be performed in a few minutes. In the same way, several slab/beam/column frame models can be analysed under the points of view of architectural impact vs. cost vs. constructability, so that a balanced decision can be reached concerning the structural solution. The increasing number of expertise involved in design and the also increasing complexity of making a sound decision in regard to the wide available data makes the use of DQEM an important checking and control tool for an efficient and highly performant output of the design stage. 


\section{DEVELOPING CLIENT-AS-USER FOCUSED INFORMATION}

The Construction Industry has suffered from a poor public image for a long time. Some of the reasons that may help to understand this situation have been discussed widely and under diverse perspectives (Baldry, 1997; Rameezdeen, 2007; Wilkinson, 2014); nevertheless, still no substantial change is perceived, not only in what concerns the views of the industry's customers but also in the consequences for CI “... companies' abilities to recruit and retain the best talent." (HMG, 2013).

Virtually all of the DQEM previously referred have stated a goal of providing laypersons with information useful for making a more sound decision when buying or renting a home. But it seems obvious that this intention has yet to infiltrate through the technical layers of actors in the industry and reach the average consumer/user. In fact, even in the cases where specific quality labels claim a large dissemination in the housing market (Qualitel/CERQUAL being the most impressive case), it is rather unusual to find marketing by housing promoters referring the quality grade that was obtained by a project and/or its units under a scheme or, if so (i.e. the case of some Environmental Sustainability labels), are presented at such a macro level that make it hard for the final user to acknowledge it as relevant information. It can be said that, although many of these labels are achieving their objective of improving building quality, one can consider that CI keeps on being an industry where the Client-as-User finds it increasingly difficult to understand the various components that should be taken into consideration so that a balanced decision is made and, when presented, they concern just a few topics and leave out the major part of those components.

A good example is the now European-widespread Energy Performance Certificate (EPC) for buildings (see http://www.dfpni.gov.uk/sale rent epb leaflet.pdf for the British case), the outcome of a detailed and complex evaluation of the various parts that influence the anticipated cost of energy a user can expect to have to deal with. When looking at an EPC one may identify two contrasting features: (i) an unquestionably important characteristic of a building unit is presented in a simple and intuitive way for most people, similar to what has been around for a while in household appliances; (ii) on the other hand, this information is an isolated item as no other performance or quality ratings are usually provided for users in the same way. Making again a parallel to everyday life, the situation above is similar to asking a customer to decide on which car to buy based just on price, fuel consumption and an overall outside look.

It will be also appropriate to reflect on this matter of user information in the housing market under the view of what, in recent times, have been the changes of perception and of concern for the common citizen in many of their day-to-day routines. For instance, most people have begun to be more attentive to what they eat, to take more care with the contents of food, to do more exercise, in an effort to try to lead more healthy lives. The food industry has responded by including more detailed information in the packages and nowadays one can find shelves upon shelves of different types of offers with easy to understand data so that each one can choose what considers as the best for him/her. 
This extends to one of the most repeated word in the news of today: Sustainability. Electric cars, green spaces, recycling, re-usable packaging are just a few of the issues that obtain increased attention from most people and, in many cases, cause radical changes of attitude in their daily lives. During a recent interview featuring USA President Barack Obama and naturalist Sir David Attenborough (available at https://www.youtube.com/watch?v=NZtJ2ZGyvBI), Sir David mentioned that "...more than 50\% of people in the world are urbanized...", that is, live in urban areas. As residential buildings account for the largest share of all types of buildings, it is possible to say that the new conscience and consequent demand of consumers towards more long-lasting and sustainable practices and lifestyle could be reflected more deeply in the construction industry if information was provided in a more direct and understandable-by-all way.

This will require a change of attitude by promoters, surely, but it begins on the design board. The way DQEM have been developed has, unquestionably, a technical purpose, as a tool for helping designers to choose between the available options and to balance wisely the expected compromises yielding from a full-expertise global design. Nevertheless, an important share of the evaluation criteria included in these methods relates directly to aspects that are relevant for the choosing of users among the market offers; but, even so, the way these issues are referred in the original formulation of the methods are difficult to grasp by non-specialists.

Yielding from this, the transposition of the technical model of many DQEM to a Clientas-User oriented information is a step not overly complex and that may induce some much needed change in the way the CI relates to its customers and is perceived by public opinion. A tentative model of such a procedure is presented in Fig. 5, using as example a list of evaluation criteria extracted from several of the DQEM referred above.

\section{CONCLUSIONS AND RECOMMENDATIONS}

Sometimes, a good design can end up in a poor building; on the other hand, it is also reasonable to say that a bad design never leads to a good building.

Design is at the core of any successful construction project and, in particular for residential buildings, taking into account the impact on the economic and way of life aspects of families, the CI should consider as fundamental the provision of useful and easily understandable information so that purchase or renting decisions may be done as consciously as possible.

In several countries, in particular the ones where CI is having a difficult time, many design consulting practices are facing fierce competition, where fees are often the major factor in a successful bid for work and the quality of this - as perceived by the final user - is irrelevant in the process. The use of Design Quality Evaluation Methods may be an effective approach to allow the more efficient and capable designers to objectively show the result of their higher expertise to their direct clients; in parallel, by using these methods and providing the transposition to Client-as-User-oriented information, an asset 
for standing out in the market is given to the Client-as-Promoter and, at the same time, an improved image of the industry can be fostered.

The CI is frequently in the crosshairs of media and general public attention for all the wrong reasons. It deals with large sums of money, it is often used as political weapon, technical jargon is used profusely irrespective of the situations or involved parties; transparency, innovation and consumer awareness are hardly words that come to mind when speaking about CI.

Fig. 5 - Example of transposition of DQEM Criteria to Client-as-User-oriented information (based on the DQEM in Tables 1 and 2)

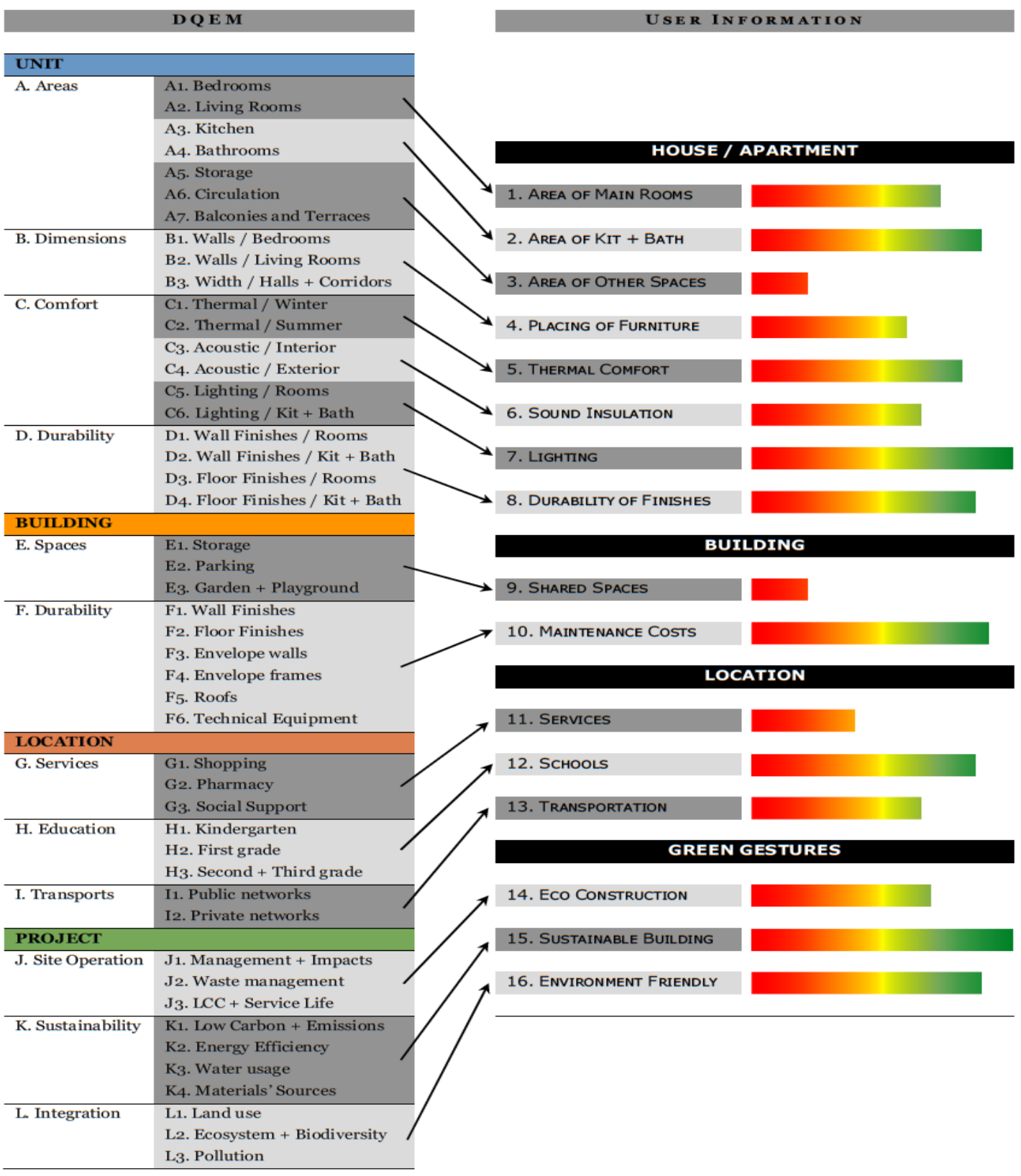


The tools for beginning a change in these matters already exist and can be used without requiring a great deal of effort. It will depend on the motivation and willingness of designers and direct clients to alter their attitude as seen by the market but, as it can be found in many other industries, it is also important to realize that the ones that stand out and make a difference are the ones who decided to do something new instead of just going with the pack. Clients-as-Users are increasingly more discerning and able to make their own decisions in all sorts of market offerings. In many other industries - IT probably at the forefront - it is costumer-driven demand that fosters innovation and growth. It is up to the CI to rise to the challenge and contribute so that Clients, and not only the ones who are familiar about the construction process (Egan et al, 1998), become more knowledgeable and demanding.

\section{REFERENCES}

- BALDRY, D. (1997) The image of construction and its influence upon clients, participants, and consumers. In: Stephenson, P (Ed.), 13th Annual ARCOM Conference, Vol. 1, p. 52-61, ARCOM, Cambridge, UK. Available from: http:/www.arcom.ac.uk/

- BRE GLOBAL (2012) BREEAM International New Construction. Technical Manual. BRE, Watford, UK. Available from: http://www.breeam.org/

- $\quad$ BUREAU SECURITAS (1979) Statistical Study of 10000 failure reports (in French). Annales de L'Institut Technique du Bâtiment et des Travaux Publics, no 378, Paris, France.

- CERQUAL (2013) The certifications of existing housing. Housing Patrimony. Housing Patrimony \& Environment Edition 2011 (in French). Association Qualitel, Paris, France. Available from: http://www.qualite-logement.org/

- CERQUAL (2014a) The certifications of new housing. Qualitel. Housing \& Environment Edition 2012 (in French). Association Qualitel, Paris, France. Available from: http://www.qualite-logement.org/

- CERQUAL (2014b) The certifications of new housing. NF Housing and NF Housing High Environmental Quality. Technical Reference v9.0 (in French). Association Qualitel, Paris, France. Available from: http://www.qualite-logement.org/

- ChOnG, W.-K. and LOW, S.-P. (2005) Assessment of Defects at Construction and Occupancy Stages. Journal of Performance of Constructed Facilities, Vol. 19, p. 283-289, ASCE, USA. Available from: http://ascelibrary.org/

- EGAN, J. et al (1998) Rethinking Construction: The Report of the Construction Task Force.. DETR, London, UK. Available from: < http://constructingexcellence.org.uk/ $>$

- HM GOVERnMENT (2013) Construction 2025 p. 40-43. Available from: https://www.gov.uk/government/uploads/

- INTERNATIONAL INITIATIVE FOR A SUSTAINABLE BUILT ENVIRONMENT (2012) SBTool 2012. iiSBE, Ottawa, Canada. Available from: http://www.iisbe.org/node/140

- JOSEPHSON, P.-E. and HAMMARLUND, Y. (1999) The causes and costs of defects in construction - A study of seven building projects. Automation in Construction, Vol. 8, $\mathrm{n}^{\mathrm{o}}$ 6, $\mathrm{p}$. 681-687, Elsevier, UK. Available from: http://www.sciencedirect.com/

- Moreira DA COSTA, J. (1995) Design Quality Evaluation Methods for Housing Buildings (in Portuguese). PhD Thesis, FEUP, Porto, Portugal. Available from: http://repositorio-aberto.up.pt/

- $\quad$ OFFICE FÉDÉRAL DU LOGEMENT (2000) System of Housing Evaluation SEL Edition 2000 (in French). Bulletin du logement, Vol. 69, OFL, Granges, Switzerland. Available from: http://www.bwo.admin.ch/dokumentation/ 
- Pinheiro, M. (2011) LiderA. Voluntary System for the Sustainability of Built Environments. LiderA, DEC/IST, Lisbon, Portugal. Available from: http://www.lidera.info/resources/ LiderA V2.00c1\%20sumario ingles.pdf

- RAMEEDZDEEN, R. (2007) Image of the construction industry. In: Sexton, M et al (Ed) CIB Report - Publication 313: Revaluing Construction, CIB, Rotterdam, The Netherlands, $p$. 77-87. Available from: http://site.cibworld.nl/dl/publications/CIB313.pdf

- THE NATIONAL AFFORDABLE HOMES AGENCY (2008) Housing Quality Indicators (HQI) Form. HCA, London, UK. Available from: https://www.gov.uk/

- US GREEN BUILDING COUNCIL (2015) LEED v4 for Building Design and Construction. USGBC, Washington DC, USA. Available from: http://www.usgbc.org/leed\#v4

- Wilkinson, P. (2014) Construction and Property. In: \#PR2015, CIPR, London, UK, p. 16. Available from: http://www.cipr.co.uk/

- WOlSTENHOLME, A. et al (2009) Never Waste a Good Crisis. Constructing Excellence, London, UK. Available from: $<$ http://constructingexcellence.org.uk $>$

- All online References Accessed 2015.07.27 


\title{
KNOWLEDGE IN THE DECISION-MAKING PROCESS FOR SUSTAINABLE RENOVATION OF MULTIFAMILY HOUSES
}

\author{
Persson, M. ${ }^{1}$ and Lyvall, A-C. ${ }^{2}$
}

\begin{abstract}
:
Background: Renovation of multifamily houses is a challenging process as a large number of requirements from stakeholders such as tenants, property owners, building contractors, architects and society has to be coordinated. As part of larger project aiming to develop a requirement driven model to support decisions for sustainable renovation of multifamily houses, our focus is on analysing requirements for knowledge sharing throughout the renovation process. New requirements due to a change from new production to maintenance and specialised services require new knowledge, new ways of collaboration and improved knowledge

sharing.

Objectives: The purpose is to study how and who requires cooperation and knowledge sharing during the renovation process. The basis for decisions within a renovation project is addressed research questions around Criteria for choice of which property to renovate, the Documentation of renovation decisions and Knowledge sharing in the renovation process - internally, externally and between projects.
\end{abstract}

Methodology: This field study has used interviews with representatives from property companies to investigate criteria for choosing which properties to renovate and the basis for renovation decisions. The knowledge implementation in the decision-making process is also analysed. On-going renovation processes and motivation and incentives for knowledge sharing within a project between stakeholders, from project to project within a property company and between property companies are analysed.

Results: Basis for renovation decisions varies from ocular inspection to intense use of spreadsheets and yield calculations. Though an outspoken need for knowledge sharing, neither incentives nor developed and structured processes for knowledge sharing are commonly used. Sustainability is one of the requirements considered in the decision-making process.

KEYWORDS: BASIS FOR DECISION, KNOWLEDGE MANAGEMENT, KNOWLEDGE TRANSFER, RENOVATION DECISION, RENOVATION ALTERNATIVES, SUSTAINABLE RENOVATION.

\section{INTRODUCTION}

This study is part of the Swedish Formas program: Sustainable rebuilding, renovation and renewal of residential and commercial Buildings 1950-1975. The project looks into how technical and operational solutions are achieved from requirements and incentives through the requirements for a building project as illustrated in figure 1.

Real estate organizations incorporate both project (temporary) and property management (permanent) operations and can be regarded as a project matrix organization in accordance with Hobday's classifications (Hobday 2000). The focus on real estate

\footnotetext{
${ }^{1}$ Faculty of Technology and Society, Malmö University, Malmö, Sweden. Email: mats.persson@mah.se

${ }^{2}$ Faculty of Culture and Society, Malmö University, Malmö, Sweden. Email: ann-charlotte.lyvall@mah.se
} 
organizations is of particular interest as the industry plays a major economic role in Sweden, which implies that efficient knowledge sharing/transfer and creation would most likely impact not only the companies, but the society as a whole.

Figure 1. The requirements and incentives for a building project are adapted to the demands set from owner, users, stakeholders and authorities to accomplish technical and operational solutions.

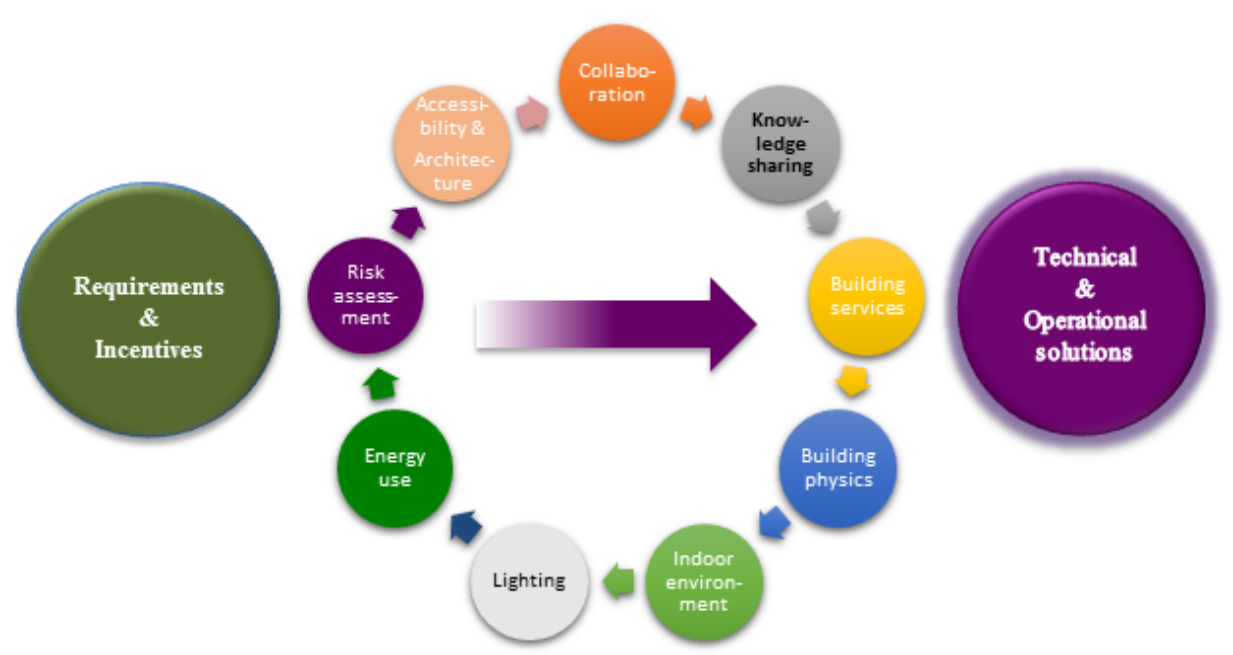

During the last decades, focus in real estate companies has shifted from production of new houses to maintenance and services. The new demands on renovations require new ways of organizing management functions in collaboration with tenants, building contractors and architects. Housing management focuses nowadays on e.g. allocation of decision-making powers and responsibilities in projects or local organizations (Blomé, 2010). Property-related services have become more specialized and a client-provider concept is now characterizing many organizations. This puts extra demands not only on creating new skills but also on: a) finding new forms of collaboration; b) improving knowledge sharing in projects as well as in day-to-day work.

Real estate organizations incorporate both project (temporary) and property management (permanent) operations and can be regarded as a project matrix organization in accordance with Hobday's classifications (Hobday, 2000). The focus on real estate organizations is of particular interest as the industry plays a major economic role in Sweden, which implies that efficient knowledge sharing and creation would most likely impact not only the companies, but the society as a whole.

During the last decades, focus in real estate companies has shifted from production of new houses to maintenance and services. The new demands on renovations require new ways of organizing management functions in collaboration with tenants, building contractors and architects. Housing management focuses nowadays on e.g. allocation of 
decision-making powers and responsibilities in projects or local organizations (Blomé, 2010). Property-related services have become more specialized and a client-provider concept is now characterizing many organizations. This puts extra demands not only on creating new skills but also on: a) finding new forms of collaboration; b) improving knowledge sharing in projects as well as in day-to-day work.

\section{Purpose}

Requirements on cooperation and knowledge sharing during the renovation process are studied. The basis for decisions within a renovation project is addressed with research questions on how decisions are developed, who is involved and what is the contribution in the different stages?

The criteria for choosing which property to renovate and the documentation of renovation decisions is studied as well as how knowledge is managed within projects, between projects and between property companies.

\section{METHOD}

To undertake the study interviews and study visits have been made. The interviewed (totally 9 people in 6 interviews) are employed by real estate companies and working with project management and project selection in renovation projects. The duration for each interview was between 2 and 6 hours and study visits and documentation from project decisions was provided by two of the companies. They all have insight in the decision-making process although they are not part of the company board or executive committee actually making the decision. The interviewed have knowledge of the work to prepare the decisions and evaluate project to renovate. The companies are 4 public property companies and one state owned commercial property company. Facts and key performance indicators for the studied companies are shown in table 1.

Table 1. Facts and Key Performance Indicators for the studied companies 2013.

\begin{tabular}{llllll}
\hline Company & Alpha & Beta & Gamma & Delta & Epsilon* \\
\hline Flats, no. & 2,281 & 23,163 & 22,700 & 11,644 & 192 (properties) \\
Leasable area, $1000 \mathrm{~m} 2$ & 140 & 1,636 & 1,699 & 875 & 2,562 \\
(premises) & $(57)$ & & $(157)$ & $(61)$ & \\
Revenue, million $€$ & 18 & 152 & 182 & 90 & 603 \\
Equity ratio & $19 \%$ & $23 \%$ & $29 \%$ & $25 \%$ & $39 \%$ \\
Dividend yield & $7.0 \%$ & $7.0 \%$ & $7.5 \%$ & $3.0 \%$ & $5.1 \%$ \\
Net operating income $€ / \mathrm{m} 2$ & 30 & 28 & 32 & 35 & 167 \\
Operating cost $€ / \mathrm{m} 2$ & - & 39 & 44 & 35 & 40 \\
Maintenance cost $€ / \mathrm{m} 2$ & $19 * *$ & 24 & 27 & 22 & 44 \\
Vacancy & - & $<1 \%$ & $0.6 \%$ & $0.3 \%$ housing & $6.6 \%$ \\
& & & & $(4.4 \%$ premises) & \\
\hline
\end{tabular}

* Premises only **Maintenance and operating cost

Table 1 shows that the studied companies are both big and smaller. This provides a variety in the resources the studied companies possesses. A smaller company has to rely 
on consultancy services to a larger extent than a bigger company who can have more developed project management competence. All companies are making a profit.

\section{TEORETICAL FRAMEWORK}

According to Lind and Muyingo (2013) it is important to adapt maintenance planning to the specific characteristics that exist in the real estate sector. It is almost impossible to predict the lifetime and degradation processes for various components of the unique and complex objects, which interact with the environment. A flexible planning system is needed where continuous adjustments of the plans are an integral part of the system. Just as important as the direct planning is a decision support system or a knowledge management system. (Lind and Muyingo, 2013)

One of the factors contributing to the low level of innovation is the adversarial relationships, and thus the lack of cooperation (Holmen et al, 2005). The construction industry (may well also be applied to renovation projects in the real estate industry) is characterized by shifting coalitions around the unique projects, which makes it difficult to introduce renewal processes from the perspective of "trial and error", that is based on learning from a range of projects (Holmen et al, 2005). The frequent change of partners' dominates over technological renovation project, which seems to lead to a low level for the creation of relationships between the involved companies, as "...every project represents cooperation around something new" (Holmen et al, 2005).

Thuvander et al (2012) reports that there is a need to clarify the process and the values that are more difficult to define. They suggest the development of a methodology for renovation with references to different tools. "In the building sector, renovation should be considered a service-minded process rather than a merely technical one as often is the case in new construction" (Thuvander et al, 2012). The different levels in valuation of a project (Persson et al, 2012) illustrate the complexity in defining a successful project from the process level to strategic level.

Although many in the industry are talking about the importance of experience feedback it has been slow to create such systems. One reason is lack of motivation for knowledge sharing, depending on the laws of procurement, which supports short-term economic optimization and relying on well-proven solutions (Dubois and Gadde, 2000)

Pemsel and Blomé (2012) concludes in their study of how knowledge contributes to value-added activities in the real estate organizations, that knowledge-sharing activities were considered poor between different subunits in the organization and the main motivation for learning was doing a good job for their customers. It is rare that real estate organizations use incentives to increase the frequency of knowledge sharing activities (Pemsel and Blomé, 2012).

The knowledge management of the sector and available information for personnel in real estate companies is not well organised to facilitate a transfer from explicit to implicit 
knowledge according to the SECI model of Nonaka and Takeuchi (1995), as pictured in Figure 2.

Figure 2. The SECI model of knowledge transfer with the process of internalising highlighted (adapted from Nonaka \& Takeuchi 1995).

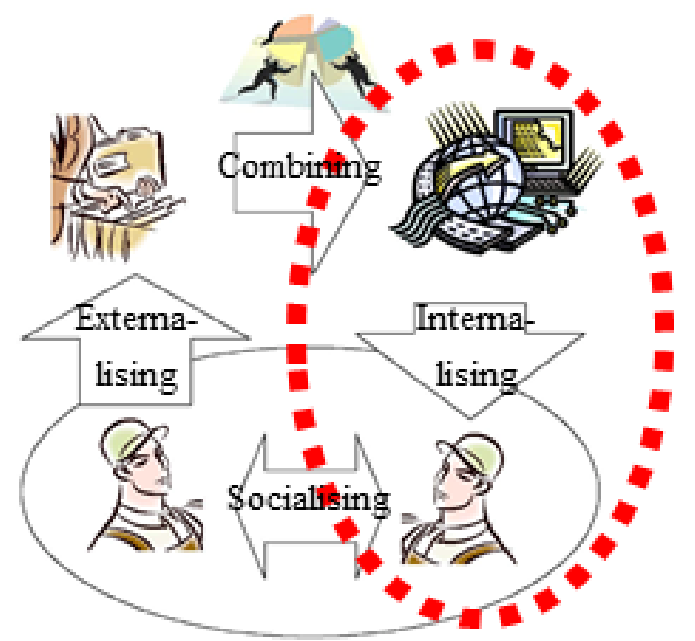

The bottom of figure 2 shows the process of socialising (tacit $\rightarrow$ tacit); on the left is externalising (tacit $\rightarrow$ explicit); at the top is combining of knowledge (explicit $\rightarrow$ explicit), and on the right side is the important process of internalising (explicit $\rightarrow$ tacit). Enabling internalising is a main objective of knowledge sharing (Persson 2006).

The construction industry is of a project-based nature and projects are described as the ideal form of learning and knowledge sharing, as problem solving often requires the creation of new knowledge (Hobday, 2000). Projects in the construction industry can be seen as knowledge-intensive units with actors with specialized skills, which must be used for the success of the project (Damgaard and Hansen, 2012).

It is often perceived that the level of innovation in construction real estate industry is low. There may be several reasons. Each project is in its own way unique and there are few customers who demand series of similar projects, therefore construction projects are intermittent and dependent on unpredictable and heterogeneous demand of different customers (Holmen et al, 2005; Easton and Araujo, 1997). Projects have temporary character, which means problems for accumulating knowledge and that a new learning curve must be initiated by the provider each time (Cox and Thompson, 1997). Individuals from different companies working together on a project rarely meet in other projects and individuals are additionally frequently replaced in on-going projects (Holmen et al, 2005; Welling and Kamann, 2001). Technological innovation projects are overtaken by the recurrent change of project partners and firms tend to act as if they will not benefit from relationships in coming projects, but as Holmen et al (2005) state, it is possible to reuse knowledge about the counterparts and how they work in other project, thus favouring actor bonds and not resource ties and activity links (Holmen et al, 2005). Within a project 
the design and construction processes is often segregated, which means that feedback from the construction process is not taken into account in the design process and the design is fixed within a specific project (Holmen et al, 2005). The lack of knowledge and knowledge sharing resulting in increased project costs of 10-25 per cent of the total project cost (Pemsel and Blomé, 2012).

However, it is worth studying initiatives that require collaboration and relationships even if the underlying theories and models are based on other industries (Holmen et al, 2005).

\section{FINDINGS}

\section{Criteria for choosing which property to renovate}

There are many criteria influencing the choice of property for renovation, however common aspects are profitability and the technical status of the building, based on some sort of inventory. The inventory is made every year or every three years according to predetermined criteria and result in points on a scale or a property profile, which are used together with a market-driven analysis. Ocular inspections resulting in a list of properties in need for renovation, are used in company Gamma, and simply result in choice of the property in worst condition. Due to legal obligations to adhere to market principles, the profitability aspect for public housing companies is also key criteria.

For Epsilon change of operations and user requirements are further criteria for choice of property. Since the consequences of a renovation lead to a raise of standards from the 1960 's and will result in increased rents, discussions with tenant are held before any decision is made.

Finally, directives from owners to contribute to the development of the city for one of the companies, Delta, result in taking the need for housing, mix of tenants and level of rents and costs for a specific area into account. Gamma on the other hand states that area specific or even social reasons are seldom factors for choice of renovation object.

\section{Legal obligations}

Total renovation of a building also brings along requirements to comply with present legislation for new buildings. The most discussed legal obligations, influencing choice and level of renovations, are accessibility, fire protection and energy conservation. Profitability is difficult to reach, as the legal obligations are mandatory for obtaining construction permits. In many cases the cost for renovation cannot be fully reimbursed by an increase in rents for the public housing companies. However, both Beta and Delta are of the opinion that the obligations have to be accepted, even if the cost for renovation increases. As one manager in Beta (2014) stated "we have to accept it, we complete the drawings and do our calculations based on it". Gamma does not implement any renovations, for example pipe replacements leading to refurbishment of bathrooms and wider door openings, which demand construction permits and subsequently cannot be motivated from a profitability aspect. In Epsilon customer requirements often lead to higher levels than the legal obligations stated and the customer is willing to pay for these 
levels. Sometimes it is difficult to reach targets, for example for indoor climate, since certain buildings may not be changed architectonically on the outside. It is of great importance to have a good dialogue with town planning authorities and a way of negotiating the fulfilment of legal obligations in the construction permit process.

\section{Legal obligations for fire, accessibility and fire conservation}

Accessibility and fire protection are perceived as more difficult to fulfil and necessitate careful planning since they lead to higher level of cost. Delta suggests different levels for accessibility as means for improving, for example accessibility with wheelchair for new properties and with walker for existing properties. For Alpha fire protection is more difficult as every flat has to be a fire compartment and elevators do not fulfil the legal obligations. Gamma does not make any refurbishments and decides about action after action, but does put in new elevators.

Regarding energy conservation Alpha means that energy requirements lead to something in return, i.e. lower energy consumption and accordingly lower energy cost. In Delta both national and city goals for energy consumption are to be met and what can be done to raise the building from an energy perspective and reach a cost, acceptable for all parties. In Beta a strategy for using heat exchange in ventilation is formulated, but this is not a decision of the company board, and no heat pumps are accepted because of dependence of electricity.

\section{Basis for decisions}

The basis for decision-making used for prioritising between objects for renovation differs from ocular inspections and fault reports, spreadsheet, calculations of investment, value and to demands for dividend yield. In Gamma the technical inventory, previously centred on one person, who has performed ocular inspections, together with fault reports form the basis for decision-making. In Alpha it is based on the inventory of properties and thereafter on a 21-point programme in the form of a spreadsheet, to analyse the need of actions and calculation of cost, i.e. a Life Cycle Cost analysis for a time period of 30 years. The income consists of rent and savings on energy conservation and renovation. To further explore and compare level for renovation Alpha benchmarks with the key performance indicators of SABO (Swedish Association of Public Housing Companies).

In Epsilon decisions are based on cash flow analysis, technical descriptions, financial calculations and planning for the area in question. Everything must meet profitability demands and the owner requires a dividend yield of $5.8 \%$. The calculations are not unique and based on experience and an overall view and an effort of finding balance between need and money in the end result. If not so profitable measures are put together with more profitable measures, a synergy effect is achieved.

With Delta investment and value calculations form the basis for decision-making documents presented to the company board and the goal is not to have any suggestions rejected. A dividend yield of $7 \%$ is required and the company works with investment calculations, operation costs and also yearly evaluations and market comparisons, i.e. a value calculation based on dividend yield. If a property is to be sold after a renovation the investment should pay off. 


\section{Connectivity with user/tenants}

The renovation decisions are anchored in a tenant dialogue with the users or tenants in all the companies, but the process takes a long time and action is needed well in advance. In Alpha the decision protocol is anchored with the Swedish Association of Public Housing Companies Tenants, and the tenants sign a letter containing information regarding the renovation. As in company Beta, meetings are held with the tenants, where they can influence the renovation process. Both companies have employees, who have contacts with tenants and coordinate temporary housing back and forth. In Delta tenants and accessibility advisors are involved in the renovation process, the later also review the construction permits. Project managers meet with tenants at times suitable for the tenants to discuss how they feel about their area and how to improve it. At the time for acceptance, representatives visit the tenants at their homes. In Epsilon the tenants have the possibility to influence and after every new stage communication and thereafter a referral round take place. "The more the customer is involved, the better" (project manager, Epsilon, 2014).

During the renovation all the tenants of the building in the Alpha company move out, whereas Delta wants the tenants to stay on during the renovation and is of the opinion that the contractors have found a way of spending as short time as possible in every flat and for whom a focus on the tenants is rational. For Epsilon remaining tenants is a working environment problem, since the tenants often cannot predict the impact of the on-going renovation on its own operations. However, remaining tenants has experienced an increased awareness of security regulations, which will benefit the tenant after the completion of the renovation.

Customer satisfaction after a renovation project is important according to Delta, even if not always done and is measured through a customer survey. Response rates are improved through lottery of two months' rent. Epsilon uses customer surveys and followup meetings in order to receive feedback; they do not want to have dissatisfied customers.

\section{Basis for renovation decisions within a renovation project}

Decisions within a renovation project are mostly about profitability and sustainability, but also technical status and market analysis. In Beta one project involves Corporate Social Responsibility, CSR, with close cooperation between the jobcentre and the contractor with the purpose of engaging unemployed people in the renovation project and at the same time raise the areas profile. Some unemployed people will find temporary unskilled work for the duration of the project and thus experience, some are eligible for training and will have acquired skills beneficial for future employment and others with a formal education from other countries, like engineers and architects, will learn the conditions for working in Sweden and be more employable. For Alpha the decisions are about safeguarding construction during the lifetime of the building. Beta is of the opinion that the maintenance plan is a "living" document and therefore the order of priorities can change. The company board has decided to differentiate levels of renovation to mini, midi and maxi, which the project managers mean will make it difficult to differentiate the rent. The same system is in place in Delta and partly in Gamma, where it is suggested not 
to be appropriate from a market view, since the company is responsible for the operational lifetime of the property, not only until the tenant move.

Technical solutions are chosen based on consultants with excellence and experience from other projects. Epsilon is the only studied company that is implementing environmental certification such as BREEAM or LEED. The reason for this is probably that Epsilon has business customers and no private tenants.

"The problems are not unique in these buildings. It is about ensuring the construction of the buildings." (Project manager, Alpha, 2013)

\section{Knowledge management in the decision-making process}

Knowledge management was noted as important and needed, but difficult. The studied public housing companies displayed a lack of structured processes for knowledge sharing and expressed that they were considering setting up systems to be better in this respect.

Knowledge sharing in a project

All studied companies described a normal project situation with new project team and new stakeholders in new projects. Stakeholders and project team also changes during the progress of a project. New team members are introduced to the project and other leaves the project. Knowledge sharing regarding project information is maintained in meetings and through project documents. New knowledge to the project is brought in mainly through the members of the project team and the knowledge processes that are present in their organizational environment.

Many obstacles that slow knowledge sharing were expressed in the study. As there is a business and competitive setting for the work in a project there is a lack of trust between consultants, entrepreneurs and property companies. In partnering projects there is generally a greater expression of trust between client and contractor but this does not often encompass all subcontractors and suppliers that are involved in the project. There is a risk that to much focus on tendering process (no incitements).

\section{Knowledge sharing from project to project within a property company}

The investigated companies displayed limited systems for sharing knowledge between projects. Main methods are having guidelines, policy document, presentation of reference projects and checklists. One example was found for a systematic way of documenting a project before project start decision.

Workshop (debriefing) after projects was a method recently introduced in a couple of the companies. There was limited experience from using this as input for new projects. The problem being how to structure lessons learned; what is new and what is confirmed knowledge? and how to present this?

\section{Knowledge sharing between property companies}

The public property companies are not competitors as they have municipal owners and only appear on their local market. They are also members of SABO (Swedish Association 
of Public Housing Companies) that is an organization that initiates research, development, publications, guidelines and seminars for housing companies. The studied companies mention SABO as an important source for information/knowledge and benchmarking for the Swedish public housing companies. It is therefore not surprising that there is an expressed preparedness to share experience and knowledge through study visits etc.

\section{CONCLUSIONS}

The criteria in the public property sector for choosing which property to renovate, are gradually moving from solely inventories of need for renovation and technical aspects, to more complex decision-making tools including life cycle cost analysis, profitability, market value, customer requests and directives from owners. Newer aspects for decisionmaking involves Corporate Social Responsibility as means of raising the status of an area and for public property companies and contractors to take an active responsibility for the social development of the community.

Sustainability was not used as a separate parameter in the decision-making process. As part of CSR sustainability was considered on strategic and project level by the investigated organizations. All of them work with long-term engagements and renovate with the intention to operate and maintain the buildings for a long periods of time.

There is an awareness of the benefits of knowledge sharing among the studied companies and a realisation that it is perhaps possible to reuse knowledge even though renovation projects are of a temporary character. One of the companies actually have some kind of system for registering knowledge, but due to its smallness feels a lack of partners to share it with. The other public property companies all seem to be in the process of searching for a system to help them share and reuse knowledge created in renovation projects among themselves and the actors involved. This process and different ways of handling knowledge in the sector is a field for further studies. The company acting commercially and only with premises seem to have accomplished more regarding knowledge sharing, which could be worth learning from for the public property companies.

\section{REFERENCES}

- BLOMÉ, G. (2010) Local housing administration models for large housing estates. In Property Management, 28(5) pp 320-338.

- COX, A. and THOMPSON, I. (1997) Fit for purpose' contractual relations: determining a theoretical framework for construction projects, In European Journal of Purchasing \& Supply Management, v3, September 1997, pp. 127-135.

- DAMGAARD, T. and HANSEN, A. P. (2012) Communities of Practice as a Learning Challenge in Construction Projects - How FM Knowledge can be integrated in the learning process. In JENSEN, P.A \& NIELSEN, S.B. (eds.) Facilities management research in the Nordic countries: past, present and future. Polyteknisk forlag. 
- DUBOIS, A. and GADDE, L-E. (2002) The construction industry as a loosely coupled system: implications for productivity and innovation. In Construction Management and Economics, 20:7, pp. 621-631.

- $\quad$ EASTON, G. and ARAUJO, L. M. (1997) Interfirm responses to heterogeneity of demand over time. In The Formation of Inter-organizational Networks. Oxford University Press, Oxford, pp. 66-94. ISBN 0-19-828948-0.

- HOLMEN, E., PEDERSEN, A. C. and TORVATN, T. (2005) Building relationships for technological innovation. Journal of Business Research. Vol. 58, No. 9, pp. 1240-1250.

- HOBDAY, M. (2000) The project-based organisation: an ideal form for managing complex products and systems? Research policy 29 (2000) pp. 871-893. Elsevier.

- NONAKA, I. (1991) The knowledge creating company, Harvard Business Review 69 (6 NovDec): 96-104.

- NONAKA, I., and TAKEUSHI, H. (1995) The Knowledge-creating Company, Oxford University Press, New York.

- PEMSEL, S. and BLOMÉ, G. (2012) Knowledge as a source of power in real estate organisations. In JENSEN, P.A \& NIELSEN, S.B. (eds.) Facilities management research in the Nordic countries: past, present and future. pp. 253-266 Polyteknisk forlag.

- PERSSON, M. (2006) Lessons Learned in Knowledge Management - the case of construction. ISRN LUTVDG/TVBP2006/1021--SE. Lund - Sweden: Division of Construction Management, Lund University.

- $\quad$ PERSSON, M., LARSSON, B. and SVETOFT, I. (2012) Decision Making for Sustainable Rebuilding: A Theoretical Approach. In proceedings from Retrofit 2012, Manchester.

- $\quad$ THUVANDER, L., FEMENIAS, P., NORLING MJÖRNELL, K. and MEILING, P. (2012) Unveiling the Process of Sustainable Renovation. In Sustainability (2071-1050). Vol. 4 (2012), 6, pp. 1188-1213.

- WELling, D. T. and KAMANN, D. J. F (2001) Vertical Cooperation in the Construction Industry: Size does Matter. The Journal of Supply Chain Management. Fall 2001, pp. 28-33. 


\title{
LESSONS FOR SPECIFYING THE SYSTEM BOUNDARIES OF AN ASSET MANAGEMENT PLAN FROM FOUR CASE STUDIES OF FAILURE
}

\author{
Tade O. S. ${ }^{1}$; Smith, $\mathrm{K}^{2}$.; Ali, A. ${ }^{3}$ and Opoku, A. ${ }^{4}$
}

\begin{abstract}
:
Managing knowledge is important to the construction industry because of the expense and duration of its projects. However, it is difficult to decide the scope of the knowledge base required for a design when sustainable ecosystem issues, which may originally appear to be tangential, become in the longer term primary negative influences. In such cases, how do we manage the risk of under-specifying the scope of a new asset management system at the design stage? And how do we justify the increased cost of a larger geographical or disciplinary catchment for the asset management plan? This paper gives a route to an answer by reporting four cases of failure of a project outside its original system boundaries that was otherwise successful within them. An implication of the low carbon agenda is that design lives will be longer and the likelihood of unforeseen ecosystem interactions will increase. And that the designer will need prompts in terms of new knowledge. Accordingly this paper reports on current $R \& D$ by the authors to create a computer package that addresses whole-life AMP issues at the design stage. This will be of significant impact in addressing the low carbon upgrade issues in urban buildings and infrastructure. Currently we call this Snake Eye.
\end{abstract}

KEYWORDS: ASSET MANAGEMENT, ENVIRONMENTAL, DESIGN, RISK MANAGEMENT, SUSTAINABILITY

\section{INTRODUCTION}

The major purpose of creating a sustainable Asset Management Plan (AMP) is to give optimal value to asset owners, the end users and most importantly fulfil the triple bottom line of sustainability. The ecosystem is a complex one. This complexity has made it difficult to decide the knowledge base scope required for engineering designs. Designs are in most cases based on the available information, technology and resources. The knock on effect of underspecifying the scope of design is sometimes catastrophic. More often than not, sustainability is inadvertently made the opportunity cost. We find that even before accounting for negative impacts on human, society and environment, the real construction costs of large dams are too high to yield a positive return (Ansar et al, 2014).

\footnotetext{
${ }^{1}$ School of the Built Environment and Architecture, London South Bank University, England UK. tadeo@lsbu.ac.uk

${ }^{2}$ School of the Built Environment and Architecture, London South Bank University, England UK Ken.smith@1sbu.ac.uk

${ }^{3}$ School of the Built Environment and Architecture, London South Bank University, England UK. alia76@1sbu.ac.uk

${ }^{4}$ School of the Built Environment and Architecture, London South Bank University, England UK. opokua@1sbu.ac.uk
} 
Asset management (AM) can help reduce the risks of catastrophic failures of the system as well as surprises in the budget (Vinnari and Hukka, 2009). There are lessons to be learnt from some case studies around the world. These lessons are very crucial to be considered in future designs. This is an application of Wood's forensic cycle. Designs have been improved over the years, nevertheless with the available technologies for sophisticated designs, case studies has showed often times that oversight does occur in deciding the knowledge base scope required. The will to improve and sustain the level of performance of assets in our dynamic world has made necessary to review our AMP. To achieve this, AMP must be considered in the initial design draft because AMP and the asset management cost (AMC) is a function of the design. Opportunity cost is inherent in all asset creation and one of the problems in design is identifying the real cost from the opportunity cost. In a bid to creating our built environment, the balance of our ecosystem which is naturally in a state of equilibrium has been disturbed. Designers try as much as possible to minimize upsetting the equilibrium which is sometimes impossible because of the complex system in the built environment.

It is high time we built not only a sustainable asset but also in a sustainable way. It is worth knowing that two sustainability issues arise in our built environment:

- Impact of the assets introduction on the sustainability of the community.

- Sustaining the asset throughout its life cycle.

Asset failure goes beyond structural defects or asset not fit for its intended purpose, but when an otherwise beneficial asset create a negative knock on effect, the asset has failed in terms of sustainability. Understanding the system dynamics of our environment is the key to avert some costly oversight in specifying the system boundaries of an AMP. System dynamics as defined by (Wolstenholme, 1990) is a rigorous method for qualitative description, exploration and analysis of complex systems in terms of their processes, information, organisational boundaries and strategies which facilitates qualitative simulation modelling and analysis for the design of their structure and control (Thurlby, 2013).

This paper conducts a literature review across a range of disciplines and international data bases for induced failures in adjacent assets outside the primary design's system boundary, and then examines the impact on the external ecosystem's sustainability. The cases discovered indicate there is a question to be addressed in future projects.

1. An otherwise beneficial dam, inducing Schistosomiasis in a river basin population by disturbing the prey-predator balance in microscopic river life.

2. Coastal land reclamation causing habitat loss for migratory birds as well as other intertidal biodiversity, and impacting the livelihoods of thousands of people who depend on the intertidal ecosystem beyond the national boundary. 
3. The mismanagement of an intra-continental lake such that its capacity reduced by over $90 \%$ with consequent profound implications for biodiversity and food production

4. The mining of tar sands for oil in one region that resulted in significant pollution and health issues outside the project's boundary.

\section{CASE STUDIES}

An otherwise beneficial dam for the people of Senegal induced Schistosomiasis in their river basin population by disturbing the Snail-Prawn balance in microscopic river life. The disease cause an annual loss of between 1.7 and 4.5 million disability (Steinmann et al, 2006). A critical look at this project indicated that it was not economically sustainable. The dam design had to be revisited and retrofitted to balance the disturbed Snail-Prawn balance. Apart from the environmental and social impact, the project also became unsustainable economically. The cost of drugs and vaccines for this pervasive disease treatment as reported by The Guardians was $\$ 20 \mathrm{~m}$ and the project to restore the disturbed ecosystem was estimated to cost $\$ 500,000$.

Recent analysis calculated that china and South Korea had reclaimed 51\% to $60 \%$ respectively of their coastal wetlands since 1980 (An et al .2007). This coastal land reclamation caused habitat loss for migratory birds as well as other intertidal biodiversity, and impacting the livelihoods of thousands of people who depend on the intertidal ecosystem beyond the national boundary. It became evident that regional reclamation construction on coastal area induced drastic land cover changes which led to changes in water quality (Choi 2013). The economic driven purpose of the reclamation resulted into social and environmental instability making the project socially and environmentally unsustainable.

The mismanagement of Lake Chad reduced its capacity by over $90 \%$ with consequent profound implications for biodiversity and food production (Odada et al, 2006). Lake Chad lies between the boundary of Chad, Nigeria, Niger and Cameroun in West Africa. The Lake experience this drastic changes due to poor water management practices during the last 50 years ( $\mathrm{Li}$ et al, 2007). The combined effects of climate variability and increased human unsustainable water projects led to significant shrinkage of the lake (Coe and Foley 2001).

This problem of drought and water shortage has a devastating implication on the natural resources of the LCB with great consequence on food security, poverty reduction and quality of life of the inhabitants (Babamaaji and Lee, 2013).

As much as the project was created to satisfy the economic need of the community, the problem created also requires economic intervention. Apart from the environmental issue that would have occurred, the social problem on the community cannot be overemphasized as made evident on their quality of life making this project unsustainable socially and economically. 
Figure 1: A collection of image map showing shrinkage of the lake (Source: Sierra Club 2015 report)

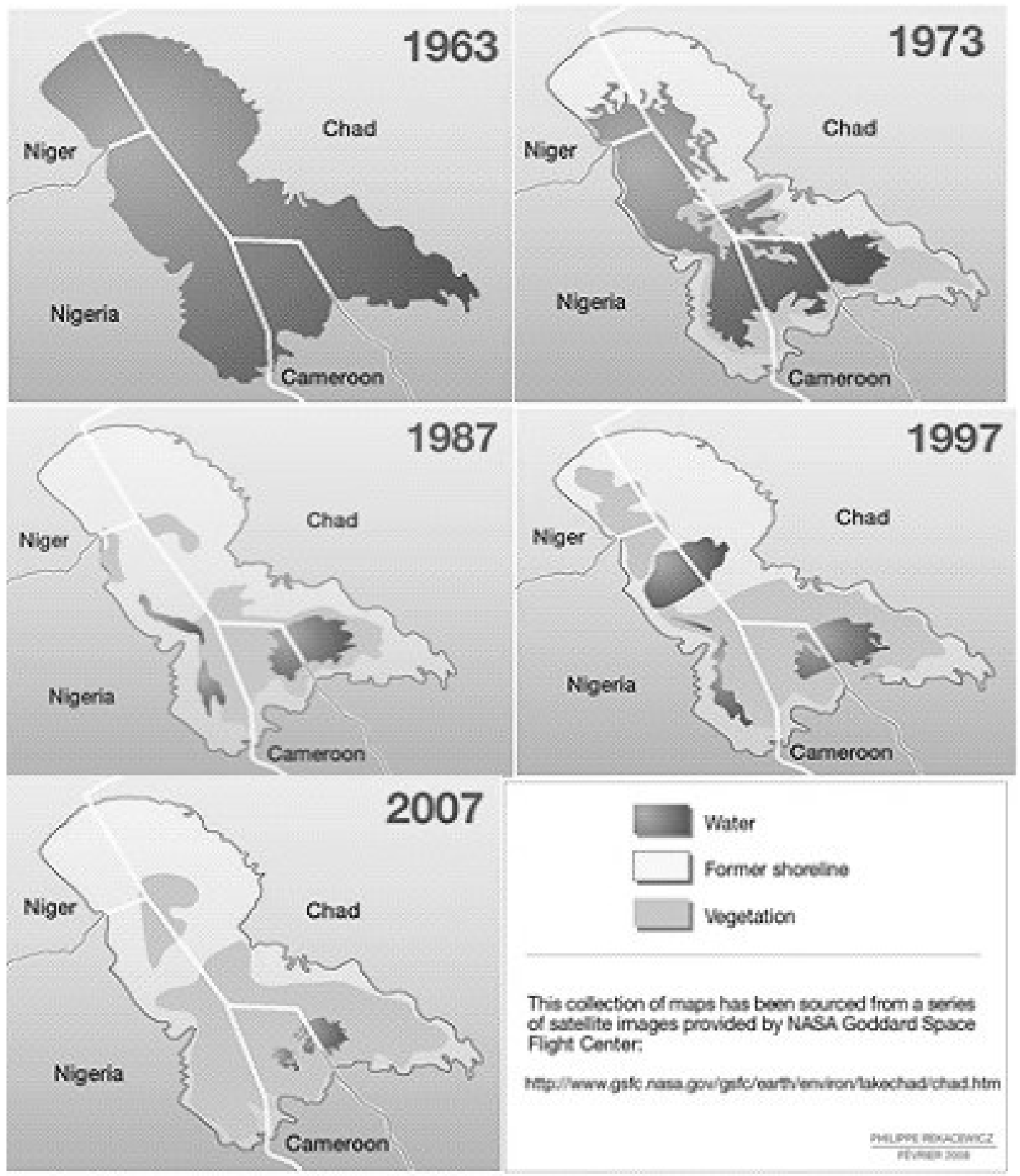

In Canada, Tar sands production, wastes and contaminates tremendous amounts of water. Every barrel of oil produced requires four barrels of water. In this process, water is pumped into toxic waste reservoirs large enough to be seen from space. This mega project which consists of network of refineries and pipelines is creating a catastrophic impact on human health. The mercury, lead and arsenic in tar sands waste threaten human health, even at small levels of exposure (Sierra, 2015). The economic driven motive of oil 
exploration created an unsustainable environment. This could cost the government lot of money to fix and in turn defeating the initial economic motive.

The major purpose of asset creation is to satisfy the economic need of the asset owner.

This vested interest in most cases is the major cause of the unsustainability problem we face in our built environment today. No designer in his right frame of mind would create a time bomb in a bid to create an asset. A review of all the cases aforementioned indicated an oversight in the design stage. The cost of exploring outside the system boundary is high but the long term cost of managing the consequences of not exploring is higher. For assets to be economically sustainable, it is crucial to identify the asset design that requires exploring outside the boundary before doing so, hence the need for risk management assessment.

\section{RISK MANAGEMENT}

In the management of these risks, the system boundary must first and foremost be defined and the key potential risks outside this boundary must be identified, their potent impacts analyzed and eventually outlining the most appropriate procedures that can be applied in response to their occurrence in the design. Analysis of risks form a very basic component of management of such risks as it defines as well as dissolves them, whereas the risk management seeks to establish the solution to such shortcomings that may be caused.

\section{APPROACH TO SYSTEM ANALYSIS}

In an approach to analyze the asset and identify if there is need to carry out a very intensive theoretical and conceptual study.

Figure 2: Approach to system analysis (Source: Author's own creation)

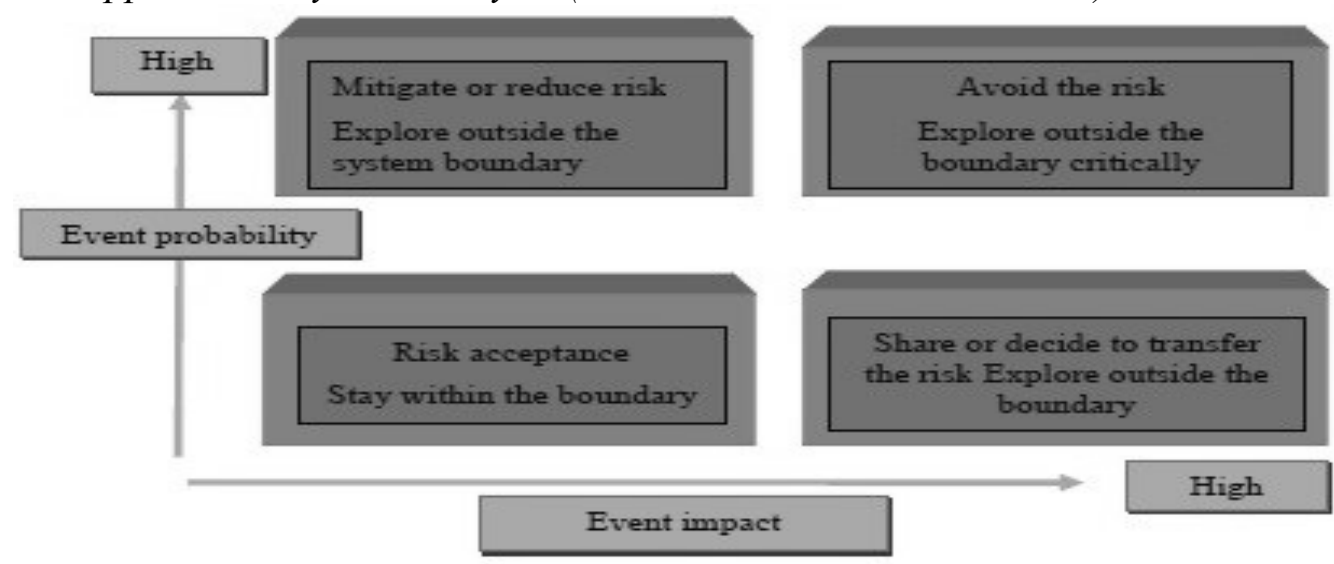




\section{RELATIONSHIP BETWEEN DESIGN, AMP AND AM COST}

It is important to take advantage of the relationship existing between design and AMC to either reduce the construction cost or the AMC. In the initial design of the aforementioned cases, it was not envisaged that the asset would require retrofitting to be sustainable. On the cost side, it is advantageous to consider the AMP with the initial design to achieve the sustainability target rather than considering after design. This in most cases requires retrofitting of the asset to achieve the sustainability target which increases the construction cost which could sometimes be a costly retrofitting.

Figure 3: Annotation showing the relationship between design, asset and AMP (Source: Author's creation)

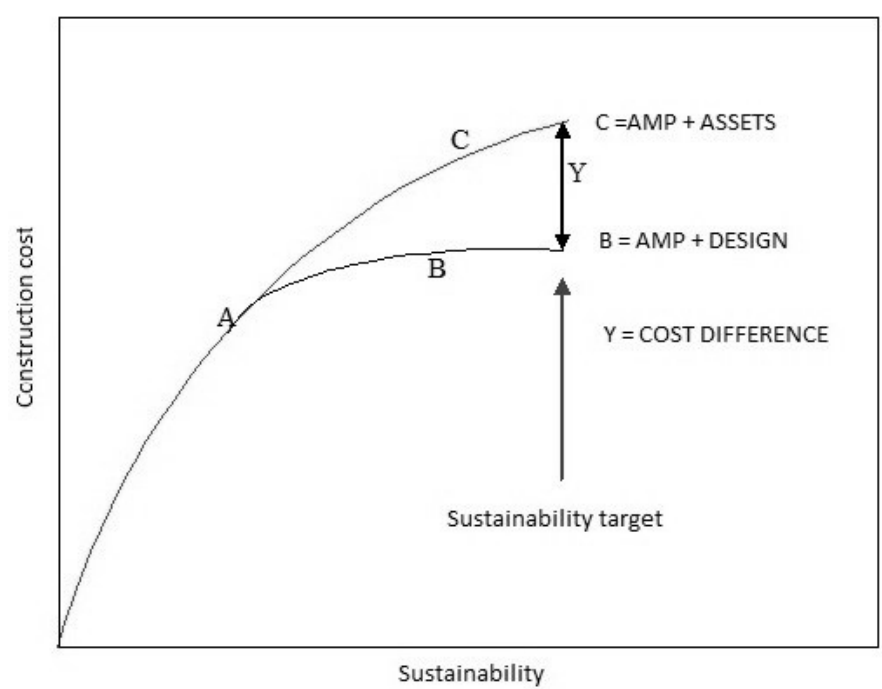

Figure 3 shows the relationship between design, asset and AMP. Y is the construction cost difference between the curve B and C. This difference occurred because AMP wasn't considered in the design phase resulting in an additional cost to achieve the same sustainability target.

\section{Role of environmental impact assesment (EIA)}

According to the EIA classification all the aforementioned cases fall under SCHEDULE 1. This implies that EIA is required. The purpose of EIA as stated in paragraph: 002 Reference ID: 4-002-20140306 is to identify projects which is likely to have significant impact on the environment. However, literature review conducted across some case studies has indicated that failure still occur in some projects after EIA has been carried out. EIA identifies the impact or consequences of the proposed asset within the boundary of the proposed design whereas literature review showed the failure occurred outside the proposed design boundary. 


\section{Role of construction design and management REgulations (CDM)}

The role of designer as stated in the CDM regulation manual 2015 No. 51, Part 3, and Regulation 9(CDM, 2015) are:

To make sure identified health and safety risk is reduced to the possible minimum and where it is not possible to eliminate the risk the designer must try as much as possible to reduce the risk in the subsequent design and communicate the risk information to the contractor.

In order to achieve the low carbon targets of cities such as London for both buildings and infrastructure, it will be necessary to up-skill existing designers and asset managers with knowledge at a detail level and across discipline and space boundaries to avoid the style of mistakes identified in the four case studies described. Using a BIM based model, incorporating photographic or 3D rendered representations as routine, and linked to a Knowledge based system (KBS) with design rules identifying concept clashes in the way current BIM identifies space clashes, we are investigating how to optimise a design and an AMP.

To do this we are using SNAKE software to compute local parametric values of interest, and link to an open source database holding concept rules. The assembly is described in the block diagram as presented in Figure 4.

Figure 4: Annotation showing the building block diagram for the snake eye (Source: Author's creation)

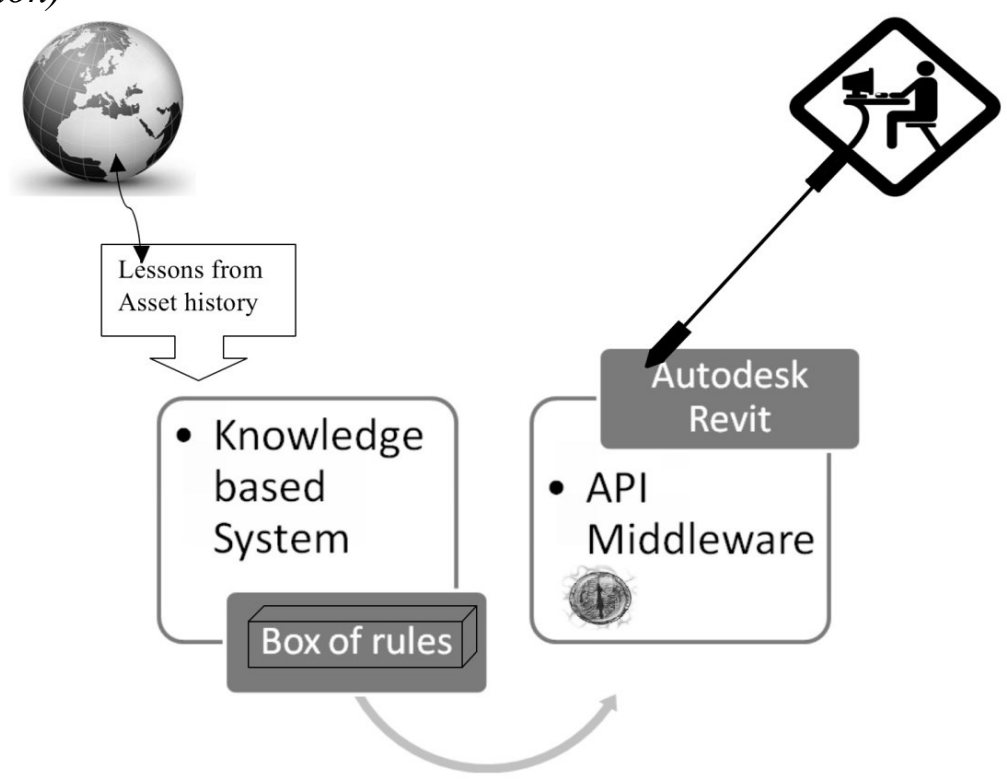

The lessons learnt from asset history are feed into a knowledge based system (KBS). This KBS is filtered with a set of rules into Autodesk Revit via the application program interface (API). Currently there are over 150 add-on software applications that access the Revit platform building information model using API (Revit BIM, 2008). It identifies concept clash the same way Revit identify geometry clash. The API sits at the designers 
elbow and uses AM analytics to inform design rules, which pop up with cold bridge identified such as dissimilar metals identified warnings for a repetition of past mistakes from asset failure for the detail to be updated or designed afresh. This API creates a form of leadership for designers, a relationship through which one person influences the behaviour or actions of other people (Egbu, 2013).

The analytics available at the moment lets us see the big data and what matters in a big system. It looks at failure rates but fails to close the cycle.

The snake eye is looking at the new build and major maintenance intervention as a seamless link and the necessary improvement. It fills the gap by closing the forensic cycle control loop at the BIM operator's level. It creates meaningful engineering rules from the data. It is focusing on the low carbon objective and knowledge gap by improving the KBS-BIM interface.

The major challenge facing systems like this is the lack of rigorous validation and verification $(\mathrm{V} \& \mathrm{~V})$. Although there have been vast improvements in the field of $\mathrm{V} \& \mathrm{~V}$ methodology, studies indicates that KBS industry still lacks rigorous validation methods (Batarseh \& Gonzalez, 2015).

Most end users believe they are not novices and that they have more practical experience than systems like the SnakeEye that is not taken into account by knowledge engineers. As a consequence, end users preferred to consult other people or any other conventional help rather than rely on the Expert systems (Brezillon, 1997).

The authors will identify all possible implementation challenges and perceived weaknesses of the SnakeEye such as identified above and use a similar approach to system analysis shown in figure 2 to profound a solution.

\section{CONCLUSIONS}

The review conducted across a range of disciplines and international data base has indicated the need to assess assets at the design phase for failures that could occur outside the boundary and act accordingly. The scope of knowledge base required should be widened where required by considering the system dynamics of our ecosystem in relation to the design. This would meet the low carbon agenda as a result of longer design lives.

The benefit of adopting this method is impressing as it does not only reduce the risk of catastrophic sustainability issue but also eliminates the need for additional construction cost or a high AMC.

The comparison of these cases establishes the need for the question of the asset system boundary to be revisited by designers and the scope of the Asset Management Plan to be developed alongside the initial design brief in the same way that site safety issues are considered under CDM Regulations. These research observations have led us to commence the development of Snake based modules as add-ons to BIM packages to 
assist inexperienced designers upgrading existing assets or designing new ones from a sustainable viewpoint.

\section{ACKNOWLEDGMENT}

The authors want to thank Andy Ford of LSBU, Dr Hwee See and Richard Shennan of Mott Macdonald, Prof Gbenga Aribisala of University of Ado Ekiti for useful discussions. We wish to thank Engr Tunde Ajanaku of TUNS Consult, Nigeria, for matched funding support within the research development programme initiated by Prof Paul Ivey, PVC for Research at LSBU.

\section{REFERENCES}

- $\quad$ ALJAZERA MEDiA NETWORK. (19 November 2014, 10:13 GMT). River of Hope: Can prawns stop a massive outbreak of the killer schistosomiasis (bilharzia) parasite in Senegal?.

- $\quad$ AN, S., LI, H., GUAN, B. ZHOU, C. WANG, Z. DENG, Z. ZHI, Y. LIU, Y. XU, C. FANG, S. JIANG, J. and HONGLi, H. (2007) China's Natural Wetlands: Past problems, current status and future challenges. Ambio, 34 (4): 335-342.

- $\quad$ BABANAAJI, R. A., LEE, J. (2013) Land use/Land cover classification of the vicinity of Lake Chad using NigeriaSat-1 and Landsat data. Environmental Earth Sciences.

- BATARSEH, F. and GONZALEZ, A. (2015). Validation of knowledge-based systems: a reassessment of the field. Artificial Intelligence Review, 43(4), pp. 485-500

- BIRDLIFE INTERNATIONAL (2014) Habitat destruction in the Yellow Sea is impacting migratory waterbirds. Presented as part of the BirdLife State of the world's birds website. Available from: http://www.birdlife.org/datazone/sowb/casestudy/606. (Accessed: 8th April 2015).

- $\quad$ BREZILLON, P (1997) Successes and failures of KBSs in real-world applications: Report on the international conference.

- CHOI, M., HAN, S. (2013) Remote sensing imageries for land cover and water quality dynamics on the west coast of Korea.

- $\quad$ EGBU, C. (2013) The Role of Leadership in Improved Knowledge Management Practices in Complex Construction Projects: University of Salford.

- H. GAO, T. J. BOHN, E. PODEST, K. C. MCDONALD, and D. P. LETTENMAIERL. (2011) "On the causes of the shrinking of Lake Chad," Environmental Research Letters, vol. 6, no. 3, Article ID 034021, 2011

- LAND USE. (2013) Land cover classification of the vicinity of Lake Chad using NigeriaSat-1 and Landsat data Rakiya A. Babamaaji - Jejung Lee Received: 31 January 2013 / Accepted: 23 September 2013 / Published online: 11 October 2013 Springer-Verlag Berlin Heidelberg 2013

- $\quad$ LI KY, COE MT, RAMANKUTTY N, DE JONG R (2007). Modelling the hydrological impact of land-use change in West Africa. J Hydrol 337:258-268

- $\quad$ MACKINNON, J., YVONNE, I., VERKUIL, M., NICHOLAS, M. (2012) IUCN situation analysis on East and Southeast Asian intertidal habitats, with particular reference to the Yellow Sea (including the Bohaisea). IUCN Species survival commission Report No 47

- ODADA, E O., OYEBADE, L. OGUNTOLA, J A. (2006). Lake Chad. Experience and Lessons Learned Brief. Lake Basin Management Initiative (LBMI).

- PETER BOSSHARD., BERNE DECLARATION. (1999) A case study on the Manatali Dam Project (Mali, Mauritania. Senegal). 
- $\quad$ REVIT BUILDING INFORMATION MODELING. (2008) A white paper: BIM and API Extensions. (Online) Available from: http://images.autodesk.com/latin_am_main/files/revit_bim_and_api_extensions_mar08.pdf . (Accessed:14th July 2015).

- Sierra Club. (2015) Toxic Tar Sands: Profiles from the front line. Available from: http://vault.sierraclub.org/dirtyfuels/tar-sands/faces/TarSands.pdf . [Accessed: 16th May 2015].

- SOUTHGATE, V.R. (1997) Schistosomiasis in the Senegal River Basin: before and after the construction of the dams at Diama, Senegal and Manantali, Mali and future prospects. Journal of Helminthology (1997) 71,125-132.

- $\quad$ STEINMANN, P., KEISER, J. BOS, R. TANNER, M. (2006) Schistosomiasis and water resources development systematic review, meter-analysis, and estimates of people.

- THE CONSTRUCTION (DESIGN AND MANAGEMENT) REGULATIONS 2015 and come into force on the $6^{\text {th }}$ April 2015 immediately after the Mines Regulations 2014(e).Available from: http://www.legislation.gov.uk/uksi/2015/51/pdfs/uksi 20150051 en.pdf

- THURLBY, R. (2012). R. (2012) Managing the asset time bomb: a system dynamics approach? Proceedings of the institute of civil engineers Forensic Engineering volume 166 Issue FE3.

- VINNARI, J., and HUKKA, J. (2009). An International Comparison of the Institutional Governance of Water Utility Asset Management and Its Implications for Finland. Water Policy, 1-18.

- WORLD HEALTH ORGANISATION (2001). Water-related Diseases Prepared for World Water Day 2001. Reviewed by staff and experts from the cluster on Communicable Diseases (CDS), and Water, Sanitation and Health unit (WSH), World Health Organization (WHO). 


\title{
REDUCING THE ENVIRONMENTAL IMPACT AND IMPROVING THE EFFICIENCY OF CONSTRUCTION TRANSPORT
}

\author{
Vrijhoef, R. ${ }^{1}$
}

\begin{abstract}
:
Last few years the hindrance, accidents, pollution and other negative side effects of construction projects and namely construction transport have become an issue particularly in urban areas across Europe such as in London, and in the Netherlands as well, including the cities of Utrecht, Rotterdam and Amsterdam. Municipalities have issued new legislation and stricter conditions for vehicles to be able to access cities and city centres in particular and accessibility of older and polluting vehicles. Considerate clients, public as well private, have started developing tender policies to encourage contractors to reduce the environmental impact of construction projects. Contractors and third party logistics providers have started applying consolidation centres. These developments have shown considerable reductions of number of vehicles needed to deliver goods and to transport workers to site. In addition these developments have led to increased transport efficiency, labour productivity and cost reductions on site as well as down the supply chain. Besides these developments have led to increased innovations in the field of logistics planning software, use of ICT , and handling hardware and equipment. This paper gives an overview of current developments and applications in the field of construction logistics in the Netherlands, and in a few project cases in particular. Those cases are underway as part of an ongoing applied research project and studied by using an ethnographic participative action research approach. The case findings and project results show initial advantages how the projects, the firms involved and the environment can profit from the advancement of logistics management leading to reduced environmental impact and increased efficiencies of construction transport.
\end{abstract}

KEYWORDS: CONSTRUCTION TRANSPORT, ENVIRONMENTAL IMPACT, LOGISTICS MANAGEMENT, PRODUCTIVITY, TRANSPORT EFFICIENCY.

\section{INTRODUCTION}

In the Netherlands construction activities are changing from development projects to construction and reconstruction projects in cities. About half of the building activities already take place in cities. These construction activities are causing safety and environmental problems, especially when taking the environmental goals of the local authorities into account. Companies that are operating in the construction chains need to contribute to the reduction of these safety and environmental issues, for instance through $\mathrm{CO} 2$ reductions. These companies encounter various problems in the way construction chains operate. Suppliers are faced with unpredictability in the supply because of a lack of detail in planning. Because of the frequent last minute planning, adjusting production and stock levels to the provided demand of goods is difficult. The biggest problem for the carriers is the low utilization rate of the vehicles. This is mostly caused by last minute or dedicated supplies to various construction sites in cities, and notably in city centres.

\footnotetext{
${ }^{1}$ Faculty of Nature and Technology, Utrecht University of Applied Sciences, The Netherlands. Email ruben.vrijhoef@hu.nl
} 
Decoupling the delivery process by means of a construction consolidation Construction Consolidation Centre (CCC) is seen by all parties involved in the supply chain as a potentially liable solution to organize construction chains within cities in a more effective, efficient and sustainable way.

\section{Relevance and potential of construction transport}

Last few years particularly cities have restrained the entering of polluting vehicles and improving the inner-city climate and air quality in general. Particularly construction transport is relevant to this aim while typically 30 to $40 \%$ of all transport is related to construction. This represents some $40 \%$ of vehicle emissions and road congestions. On the other hand studies on load factors indicate a need to act, while these tend to remain structurally under $50 \%$, in few cases down to $15 \%$, and far lagging behind other sectors of transport (Sullivan et al 2010). In the UK and notably London local government and the industry have shifted to action some years ago with demonstrable results.

The London Construction Consolidation Centre (LCCC) claims that the number of construction vehicles entering the City of London, and delivering to the sites being served by the LCCC is reduced with 68\% (Brett 2007). Also LCCC claims that a reduction in supplier journey times, by going direct to the LCCC rather than driving into the City of London, (including loading / unloading time) of an average of two hours is reached (MVA 2006). LCCC claims that the delivery performance of goods delivered the first time right is $97 \%$ and that there is an availability of goods of $100 \%$ within 24 hours (Constructing Excellence 2007). LCCC claims that a reduction of materials waste is generated of up to $15 \%$ by reduced damages, less shrinkage and less theft. LCC claims that there is an increase in productivity of the labour force by up to 30 minutes per worker per day (Transport and Travel 2010). Also improvements of site safety through reduction of materials and packaging on site are reported (Department for Transport 2007). To conclude LCCC claims that a reduction of CO2 emissions, as a direct result of the reduction in vehicles, of about 75\% (Transport for London 2008).

\section{BACKGROUND AND METHOD}

This paper reports an ongoing research project in the Netherlands aimed at the advancement of innovative logistical solutions and demonstrating the effects in construction practice. The first year of the project four projects have been observed in close collaboration between firms involved, researchers and students. In the projects novel kinds of solutions have been applied and tested, and the effects have been measured via a set of Key Performance Indicators (KPIs). The research project is both aimed at gaining academic insights and advancing logistic in construction solutions such the use of Construction Consolidation Centres (CCC) in the Netherlands, and thus increasing the efficiency of construction as well as reducing the negative effects of construction transport for society. 
Based on projects studied in London, discussions and group sessions that were held and earlier research a basic construction supply chain in the Netherlands, using a CCC is set up. Within this supply chain, the Logistics Service Provider is seen as a Cross Chain Control Centre (4C). The description of these solutions applied and the effects envisaged has been based on the GreenSCOR model (SCC 2010).

\section{Ethnographic participative research approach}

We aimed to investigate the SCOR dimensions and how they actually occurred in the projects as experiments. Therefore, we have taken an participative observation approach in which the researchers took part in the project teams. The participative observer collected data by participating in practice in a few projects for a particular period of time (Bryman, 2008). This particular study can be considered to be an ethnographic research i.e. 'interactive-inductive research involving direct and sustained contact with human agents, within the context of their daily lives, watching what happens, listening to what is said, asking questions, and producing a richly written account' (Pink et al. 2013). To guide us in our study, we used prior research on supply chain integration and logistics such as Vrijhoef (2011). We used these insights as input constructs to provide a starting point for this study. The analyses were undertaken in a ethnographic and participative way in close collaboration with practitioners in the projects studied. This was done via interviews, document studies, experiments and interventions in the projects, modelling exercises of $\mathrm{xD}$ planning using $\mathrm{BIM}$, and finally effect measurements of logistics measures taken using the KPI framework, and validation of the outcomes with practitioners from the firms in the project cases.

\section{Case selection}

To increase our understanding and also uncover areas for further application and research, multiple cases were analysed to explore differences and conformities within and between the four cases (Table 1). We were able to participate in four projects. The projects differ in type, size and location. This has enabled to focus on the differences and conformities how logistics solutions were implemented. The differences give insight how project characteristics affect the dimensions of logistics and the effects of the measures taken. 
Table 1: Project cases

\begin{tabular}{|c|c|c|c|c|}
\hline & Project A & Project B & Project C & Project D \\
\hline Type of project & $\begin{array}{l}\text { Newly built } \\
\text { housing blocks } \\
\text { incl commercial } \\
\text { spaces and } \\
\text { parking basement }\end{array}$ & $\begin{array}{l}\text { Newly built hotel, } \\
\text { incl parking } \\
\text { basement }\end{array}$ & $\begin{array}{l}\text { Newly built } \\
\text { multifunctional } \\
\text { expansion of } \\
\text { shopping centre, } \\
\text { incl. hotel and } \\
\text { apartments, and } \\
\text { parking basement }\end{array}$ & $\begin{array}{l}\text { Internal } \\
\text { refurbishment of } \\
\text { office buildings of } \\
\text { a larger trade } \\
\text { centre incl. the } \\
\text { entrance of the } \\
\text { centre }\end{array}$ \\
\hline Location & Nearby city centre & $\begin{array}{l}\text { Urban area close } \\
\text { to motorway }\end{array}$ & In city centre & In city centre \\
\hline Duration of the project & 2014-2016 & $2013-2015$ & 2013-2019 & 2014 \\
\hline Size of the building & $\begin{array}{l}255 \text { small } \\
\text { apartments, } 1,500 \\
\text { m2 commercial } \\
\text { space, parking } \\
\text { basement }\end{array}$ & $\begin{array}{l}18,500 \mathrm{~m} 2 \text { hotel, } \\
4,000 \mathrm{~m} 2 \text { parking } \\
\text { for } 136 \text { spaces }\end{array}$ & $\begin{array}{l}35,000 \mathrm{~m} 2 \\
\text { shopping, } 5 \text { level } \\
\text { parking basement } \\
\text { for } 1,300 \text { spaces }\end{array}$ & $65,000 \mathrm{~m} 2$ \\
\hline
\end{tabular}

\section{Data collection and analysis}

The researchers are present as observers in the project team. During construction the Logistics Service Provider coordinates the logistics activities based on the agreements that were set up during the purchasing processes with suppliers and subcontractors. During construction the main constructor sets up a six week planning. This planning is shared with the Logistics Service Provider in the CCC so they can call off goods at the suppliers.

Next to the above mentioned planning a more detailed, weekly planning is set up. This planning gives insight into the day-to-day operation. Also this planning is shared with the Logistics Service Provider. Based on this planning delivery plans are set up for delivery of the goods to the construction site. Also this planning is leading in the call off at the supplier of goods that need to delivered directly to the construction site. These goods then are directly delivered to the construction site. If there are goods that need to be shipped directly to the construction site, these goods will be called off by the CCC.

Based on the KPI framework the personnel of the firms and the researchers involved have measured and reported the deliveries and the transport movement of the project both taking place at the CCC and on site. These measurements and reports have systematically been put in a database and thus produced the input data to calculate the formulas that represent the KPIs.

\section{FOUR FACTORS OF INFLUENCE ON CONSTRUCTION TRANSPORT}

Construction transport and the effect on process efficiency and the environment can be influenced by different kind of factors. First, transport can be influenced by the way the logistics are managed. More specifically this concerns the extent to which the logistics process can be decoupled and optimised in process parts and load factors of vehicles can 
be maximised by means of consolidation. Second, the information management of the construction process and the logistics in particular influence the efficiency of construction transport. Third, the packaging and integration of materials into bundles, kits or prefabricated modules that can be shipped and moved in a smart way to the place of installation on site influence the efficiency of transport. Fourth, the extent to which project tendering and purchase contracts consider transport and the effects of it such as $\mathrm{CO} 2$ emission as variables or criteria influence the effort contractors, suppliers and logistics service providers put into transport efficiency. At the end of this section these four factors of influence are projected on the four cases, including the logistics measures that were taken in the four projects (Table 2).

\section{Logistics management; decoupling and consolidation}

Decoupling the construction chain can be done by using CCCs. The CCC functions as a decoupling point between supplier and construction site. These centres functions as hubs in a few cases already used in construction as a temporary storage at or near the construction site. The CCC then functions as a decoupling point at which supplies to the CCC are controlled in a 'push' way, while goods to the construction site from the CCC are supplied based on the project planning, based on the real and actual need and so controlled in a 'pull' way. There is also a possibility that goods are shipped from the CCC, where the CCC is used as a crossdock. By organizing the supply in this way the supplies are more time-independent than deliveries that are directly shipped to the construction site traditionally (Figure 1).

Figure 1: Traditional supply process to a construction site

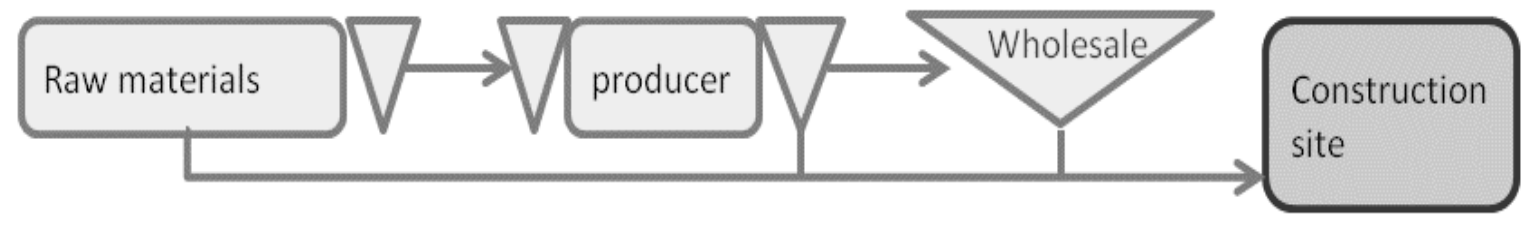

Materials are not just transported in a JIT manner through the CCC to one site. If required the CCC can be bypassed by supplying goods directly to the construction site, for instance in the case of liquid concrete, full truckloads of heavy material, or supplies that require direct handling on site. Besides multiple sites can be serviced by the same CCC. To concludes, a CCC can also handle return flows from the construction site including recycling of debris, packaging and equipment. 
Figure 2: Supply process using a CCC

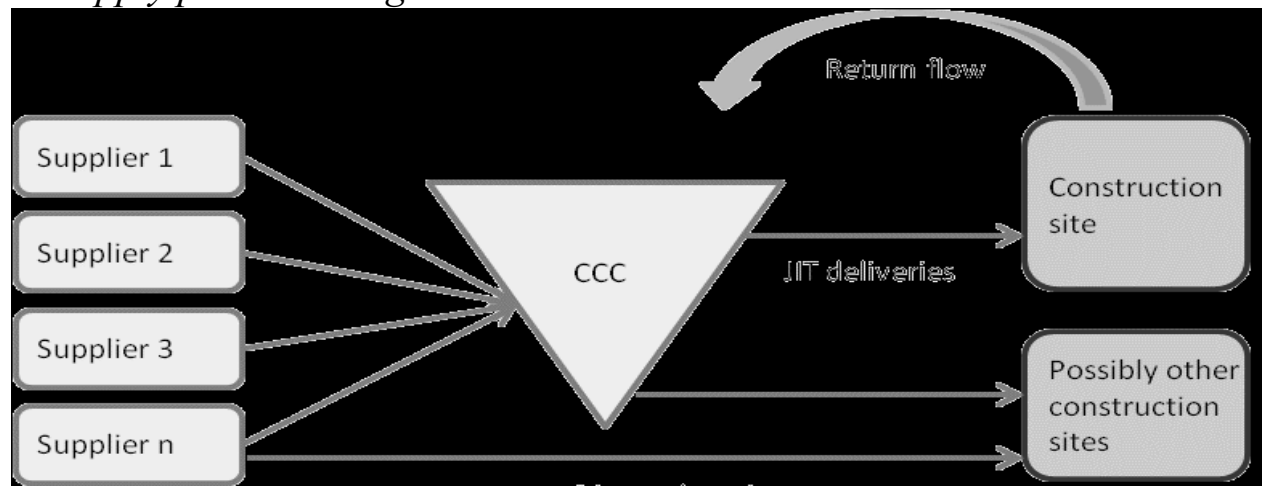

\section{Information management; integrated planning and delivery}

The planning of the delivery to the construction site is done by the Logistics Service Provider in collaboration with the contractor and subcontractors. Also the suppliers are active in planning the deliveries, particularly the (time-)critical products and the direct deliveries. The overall planning is finalised and controlled by the main contractor at the construction site.

The resources needed at the construction site are called off at the CCC by the responsible person at the construction site through the Warehouse Management Systems (WMS) functioning at the CCC. This request for resources is at minimum one day before the goods are needed at the construction site. The goods can be picked based on this signal and be transported in consolidated shipments to the construction site controlled by the connected Transport Management Systems (TMS).

The balancing of supply chain resources with supply chain requirements is done by the site manager. Orders that are placed come from the project planning. The information in an order generally contains an article code and name, construction part, the planning, location on site. To organize the information about goods to the construction site in a situation with the CCC a so called 'building ticket' can be used. This ticket is a form with which the supplier presents a supply beforehand. Based on the ticket a logistics coordinator can plan deliveries to the construction site.

\section{Prefabrication; off-site construction and kitting}

Particularly at small construction sites there is no space for subcontractors to assemble materials. Therefore it can be a solution that these assembly activities can take place at the CCC. The subcontractor can then assemble goods at the warehouse and have them shipped through regular service to the construction site for installation. This means that goods need to be pulled from stock, taken to the working area where the subcontractor does the assembly work after which the assembled product is put back to stock, meaning 
new product codes must be generated in the system. Based on the weekly schedule the goods are then shipped to the construction site in a consolidated shipment.

It might happen after assembly modules are becoming hard to handle or kits of material are completely and exactly filled at the supplier's location. In this case a decision can be made that the modules or kits are shipped to the construction site by dedicated deliveries. This means the modules or kits do not pass the CCC and are not put in stock to be called off from there.

This particularly concerns engineered modules, large customized subassemblies, large bulky materials or complete materials packs to finish an entire room in the building for instance. These deliveries are put on site directly and are usually too unpractical to be handled at the CCC. The goods may travel quite a distance from various places. The planning and the time of arrival of those transports needs to be accurate, planned well ahead, to avoid long waiting times once arriving to the site. Vehicle marshalling and control towering are the means to achieve this in particular. If needed the transports are held outside city limits before being called into the city to the site.

\section{Procurement; MEAT tender and strategic purchasing}

Local government have installed restrictions to enter cities and want to keep vehicles out. Also clients who care about sustainability tender via innovative routes and include and reward CO2 reduction as a MEAT criterion (Most Economically Advantageous Tender) in contracts and contractors need to comply to these requirements in their bids in order to win it. This often includes reduction of hindrance for traffic and keeping driving lanes open around and to construction sites. Local governments reward transport and deliveries outside rush hours and even stimulate nightly transport.

In turn some contractors stress the importance and stimulate their suppliers and transport firms to achieve logistics efficiencies. Few studies on supply chain costs rate logistics costs at 10 to $20 \%$ of sales prices (https://www.instituteforsupplymanagement.org/). However adversarial procurement by clients tends to lead to adversarial purchasing of subs and suppliers. In turn subs have generally included logistics costs in their prices and contractors have often bargained a good purchase price from suppliers before the discussion about logistics costs would normally start in projects. Therefore contractors shift to strategic and long-term kinds of purchasing and collaboratively with subs and suppliers drive down logistics costs structurally.

\section{EMPIRICAL FINDINGS AND RESULTS}

In this section we explore the differences within and between the four projects using the KPI framework as a guide (Table 3). The findings are partly qualitative and partly quantitative. The description of the findings partly focus on elements that are not present in the framework or that might deepen our understanding on how to operationalise its dimensions. Within the ongoing research reported the KPI framework is subject of continual development, which is also true for the projects and solutions applied. The 
fieldwork done at the projects is therefore input for further advancement of the logistics management of the projects (Table 4).

\section{KPI framework}

The KPI framework presented below is based on the GreenSCOR model (SCC 2010) adapted to a construction context. The indicators and measurements are also based on the construction practices in the UK and the Netherlands applying advanced logistics solutions. The KPIs are formulated to monitor the construction and logistics processes, and also to gain data to measure the effect of logistics measures taken, such as the use of a CCC.

Table 2: Logistics measures taken in projects

\begin{tabular}{|c|c|c|c|c|}
\hline & Project A & Project B & Project C & Project D \\
\hline Logistics management & $\begin{array}{l}\text { CCC, Buffering, } \\
\text { consolidation, } \\
\text { waste disposal in } \\
\text { same loop, group } \\
\text { transport of } \\
\text { workers and } \\
\text { equipment }\end{array}$ & $\begin{array}{l}\text { Buffer location } \\
\text { for trucks close } \\
\text { to site }\end{array}$ & $\begin{array}{l}\text { CCC, Buffering, } \\
\text { consolidation, } \\
\text { waste disposal in } \\
\text { same loop }\end{array}$ & $\begin{array}{l}\text { CCC, Buffering, } \\
\text { consolidation, } \\
\text { waste disposal in } \\
\text { same loop, } \\
\text { public/ group } \\
\text { transport of } \\
\text { workers and } \\
\text { equipment }\end{array}$ \\
\hline Information management & $\begin{array}{l}\text { Input from BIM, } \\
\text { Solibri into TMS }\end{array}$ & $\begin{array}{l}\text { Online transport } \\
\text { tickets per } \\
\text { delivery, online } \\
\text { WMS and TMS }\end{array}$ & $\begin{array}{l}\text { Online transport } \\
\text { tickets per } \\
\text { delivery, online } \\
\text { WMS and TMS }\end{array}$ & $\begin{array}{l}\text { Printed transport } \\
\text { tickets per } \\
\text { delivery }\end{array}$ \\
\hline Prefabrication, kitting & $\begin{array}{l}\text { Prefabricating } \\
\text { e.g. of rebar } \\
\text { modules at CCC, } \\
\text { kitting of daily } \\
\text { batches }\end{array}$ & $\begin{array}{l}\text { Kitting of daily } \\
\text { batches at CCC, } \\
\text { all fit-out } \\
\text { material per } \\
\text { room per kit }\end{array}$ & $\begin{array}{l}\text { Kitting of daily } \\
\text { batches at CCC }\end{array}$ & $\begin{array}{l}\text { Kitting of daily } \\
\text { batches at CCC }\end{array}$ \\
\hline Procurement, purchasing & $\mathrm{n} / \mathrm{a}$ & $\begin{array}{l}\text { LEED tender } \\
\text { with implications } \\
\text { for reduced } \\
\text { vehicle } \\
\text { movements }\end{array}$ & $\mathrm{n} / \mathrm{a}$ & $\begin{array}{l}\mathrm{CO} 2 \text { criteria in } \\
\text { MEAT tender } \\
\text { aimed at reduced } \\
\text { vehicle } \\
\text { movements }\end{array}$ \\
\hline
\end{tabular}


Table 3: KPI framework

\begin{tabular}{|c|c|c|}
\hline & Indicators & Measurement \\
\hline Reliability & $\begin{array}{l}\text { Percentage deliveries on time, } \\
\text { and complying to quality and } \\
\text { requirements }\end{array}$ & $\begin{array}{l}\text { Amount of deliveries on time and } \\
\text { complying to requirements, and reason why } \\
\text { not if not, and consequences/costs to fix }\end{array}$ \\
\hline Responsiveness & $\begin{array}{l}\text { Offloading and waiting times } \\
\text { of deliveries on site }\end{array}$ & $\begin{array}{l}\text { Waiting time of trucks before being } \\
\text { offloaded on site, and waiting time of } \\
\text { personnel and equipment on site before } \\
\text { being able to offload }\end{array}$ \\
\hline Agility & $\begin{array}{l}\text { Lead times of orders delivered } \\
\text { from CCC to site, and from } \\
\text { suppliers to CCC }\end{array}$ & $\begin{array}{l}\text { Time needed to place and process an order } \\
\text { from the CCC and suppliers, and being } \\
\text { delivered to the site }\end{array}$ \\
\hline Costs & $\begin{array}{l}\text { Productivity gains on site, } \\
\text { purchase price reductions, } \\
\text { transport costs reductions }\end{array}$ & $\begin{array}{l}\text { Less time wasted by workers on site, } \\
\text { eliminating logistics cost elements by } \\
\text { suppliers, reduction of travel distance and } \\
\text { time or bundling of deliveries of suppliers }\end{array}$ \\
\hline Assets & $\begin{array}{l}\text { transport efficiency, load } \\
\text { factor of trucks, consolidation } \\
\text { factor of CCC, days of stock } \\
\text { at CCC }\end{array}$ & $\begin{array}{l}\text { Transport volume and weight of trucks to } \\
\text { and from site; Amount of trucks from } \\
\text { supplier to CCC vs CCC to site }\end{array}$ \\
\hline Environment & $\begin{array}{l}\text { environmental impact, } \mathrm{CO} 2 \\
\text { emission, waste reduction, } \\
\text { noise, hindrance, health, safety }\end{array}$ & $\begin{array}{l}\text { Amount of fuel use, amounts of waste, } \\
\text { packaging, debris, numbers of complaints, } \\
\text { incidents, accidents, traffic jams caused }\end{array}$ \\
\hline
\end{tabular}

\section{Project A}

In this specific case the site is located at a canal and thus the potential of water transport had been studied and the consequences for costs, emission and planning. It remained unclear what exactly the extra costs and time use would be of the transfer to water transport. $\mathrm{CO} 2$ would reduce but other emissions such as NOx and $\mathrm{SO} 2$ would increase because of the fuel used for the boats. Also the materials need to be packed in specific ways to be able to be transported by boat. On site specific equipment had been tried such as floor extensions to be able to easily pull in material and kits from the building elevator onto the floor.

For the information management and support of optimised transport all data needed from suppliers were analysed and validated in the BIM model of the project. This data contained all product specific details, location, time and transport and handling equipment. This data was connected to the planning software on site and the TMS of the transport firm. The data were printed on 'building tickets' that functioned as an order form from site to the CCC and suppliers, which could contain QR codes or tagging via RFID would be possible in later stage.

\section{Project B}

In this case, the building of an new hotel, the logistics management had been concentrating on the tower crane efficiency; the materials supply onto floors and carrying off debris from the floors. The aim was to balance and increase the efficiency of the arrival of deliveries on site, subsequent offloading by the crane, storage on site, the crane 
taking the materials up to the floor, and installing the materials on the floor. This project did not work with a CCC but was supplied directly from the suppliers plants, particularly concrete, rebar and formwork. This was followed by the HVAC firm whose factory functioned as a place where the materials kits of all materials per hotel room were bundled including all ductwork and finishing.

The site used an online TMS and 'building tickets' including registration of all arriving deliveries from the suppliers and the HVAC firm's location. This led to a continuous information flow to be able to manage the deliveries more accurately, and plan the tower crane's capacity more efficiently. This also reduced the amount of waiting vehicles and traffic jams around the site. As a safeguard, once trucks approached the site they were able to use a buffering location if needed, in case they would arrive untimely.

\section{Project C}

This case is logistically comparable to case B although in this case a CCC was used. Since the project is that large there were dedicated logistics personnel on site as well as at the hub. This personnel was equipped with portable computers with applications to access the online TMS and WMS platform, also including the planning of all cranes, and all entrance and storage locations on site. These integrated systems enabled suppliers and transport firms driving up and down from the site to the CCC to deliver materials and carry off debris in a highly accurate manner. However the size of the project and the amount of suppliers and subcontractors caused quite a bit of improvisation and deliveries that evaded the online system and still caused traffic jams and inefficiencies on the site and around.

Since the project site is located in the very city centre next to the central railway station all disruptions caused quite a bit of congestions. The city is keen to prevent this and reduce emissions caused by vehicles. As an extra measure most of the deliveries were planned outside rush hours and particularly in the early mornings and in the evenings. As a consequence these deliveries took less time and produced less emission.

\section{Project D}

This project had been contracted as a MEAT tender (Most Economically Advantageous Tender) applying $\mathrm{CO} 2$ emissions of supplies, travel of personnel and carrying off debris as criteria to the bids of contractors and rewarded this in the appraisal of the bids, besides the price, planning and quality. The winning bid managed to offer the lowest $\mathrm{CO} 2$ emission. In the tender a traditional calculation of the emission was given of $42,000 \mathrm{~kg}$ the project would produce when executed applying traditional logistics management. The winning bid offered to do the project applying a CCC for all deliveries and carrying off debris, and group and public transport of personnel, resulting in 17,000 kg emission i.e. a reduction of $60 \%$. Based on the registration of all vehicle movements the real emission of the project appeared to be $22,500 \mathrm{~kg}$ i.e. a reduction of $46 \%$. This was caused by displacement of the CCC on further distance from the site, and lower load factors than offered in the bid. 
Table 4: Empirical findings and results

\begin{tabular}{|c|c|c|c|c|}
\hline & Project A & Project B & Project C & Project D \\
\hline Reliability & $\begin{array}{l}\text { Most deliveries } \\
\text { arriving on time } \\
\text { from CCC to site }\end{array}$ & $\begin{array}{l}\text { More than } \\
\text { traditional } \\
\text { deliveries } \\
\text { arriving on time } \\
\text { from suppliers to } \\
\text { site }\end{array}$ & $\begin{array}{l}\text { With online } \\
\text { transport ticket } \\
\text { deliveries within } \\
10 \text { min time } \\
\text { frame; without } \\
\text { ticket } 1: 30 \text { hrs }\end{array}$ & $\begin{array}{l}\text { Most deliveries } \\
\text { arriving on time } \\
\text { from CCC to site }\end{array}$ \\
\hline Responsiveness & $\begin{array}{l}\text { TMS gives } \\
\text { insight in } \\
\text { deliveries, taking } \\
\text { less time for site } \\
\text { personnel to } \\
\text { offload }\end{array}$ & $\begin{array}{l}\text { Offloading of all } \\
\text { deliveries strictly } \\
\text { planned via } \\
\text { online tickets } \\
\text { and followed up } \\
\text { by personnel }\end{array}$ & $\begin{array}{l}\text { Offloading of all } \\
\text { deliveries strictly } \\
\text { planned via } \\
\text { online tickets } \\
\text { and followed up } \\
\text { by personnel }\end{array}$ & $\begin{array}{l}\text { In most cases } \\
\text { site personnel is } \\
\text { aware of } \\
\text { deliveries } \\
\text { planned and take } \\
\text { less time for } \\
\text { offloading }\end{array}$ \\
\hline Agility & $\begin{array}{l}\text { Orders from site } \\
\text { to CCC come } \\
\text { few days to week } \\
\text { in advance based } \\
\text { on online } \\
\text { planning }\end{array}$ & $\begin{array}{l}\text { Online WMS } \\
\text { allows orders } \\
\text { from site to CCC } \\
\text { till two days in } \\
\text { advance }\end{array}$ & $\begin{array}{l}\text { Online WMS } \\
\text { allows orders } \\
\text { from site to CCC } \\
\text { till two days in } \\
\text { advance }\end{array}$ & $\begin{array}{l}\text { Local WMS at } \\
\text { CCC allow } \\
\text { orders from site } \\
\text { few days in } \\
\text { advance }\end{array}$ \\
\hline Costs & $\begin{array}{l}\text { Prefabrication of } \\
\text { rebar and kitting } \\
\text { resulted in faster } \\
\text { working, less } \\
\text { time wasted on } \\
\text { site }\end{array}$ & $\begin{array}{l}\text { Bundled } \\
\text { deliveries, kitting } \\
\text { resulted in faster } \\
\text { working, less } \\
\text { time wasted on } \\
\text { site }\end{array}$ & $\begin{array}{l}\text { Bundled } \\
\text { deliveries, kitting } \\
\text { resulted in faster } \\
\text { working, less } \\
\text { time wasted on } \\
\text { site }\end{array}$ & $\begin{array}{l}\text { Lower bid } \\
\text { caused by lower } \\
\text { transport costs } \\
\text { and higher } \\
\text { productivity } \\
\text { based on firms' } \\
\text { previous } \\
\text { experiences }\end{array}$ \\
\hline Assets & $\begin{array}{l}\text { Less vehicles to } \\
\text { and from site, } \\
\text { than traditional, } \\
\text { bundling, debris } \\
\text { in same loop }\end{array}$ & $\begin{array}{l}\text { Less vehicles to } \\
\text { and from site, } \\
\text { than traditional, } \\
\text { bundling, debris } \\
\text { in same loop }\end{array}$ & $\begin{array}{l}\text { Consolidation of } \\
\text { deliveries at } \\
\text { CCC leading up } \\
\text { to } 60 \% \text { less } \\
\text { vehicles from } \\
\text { CCC to site }\end{array}$ & $\begin{array}{l}\text { Consolidation of } \\
\text { deliveries at } \\
\text { CCC leading up } \\
\text { to } 70 \% \text { less } \\
\text { vehicles to site } \\
\text { and no return }\end{array}$ \\
\hline Environment & $\begin{array}{l}\text { Less emission } \\
\text { due to less } \\
\text { vehicles, less } \\
\text { annoyance in } \\
\text { neighbourhood } \\
\text { of workers not } \\
\text { taking parking } \\
\text { space }\end{array}$ & $\begin{array}{l}\text { Less emission } \\
\text { due to less } \\
\text { vehicles, less } \\
\text { hindrance around } \\
\text { site due to } \\
\text { stricter planned } \\
\text { deliveries and } \\
\text { faster offloading }\end{array}$ & $\begin{array}{l}\text { Deliveries } \\
\text { avoiding rush } \\
\text { hours took } 25 \% \\
\text { less travel time, } \\
11 \% \text { less } \\
\text { emission as a } \\
\text { result }\end{array}$ & $\begin{array}{l}\text { Reduced CO2 } \\
\text { emission } 22,500 \\
\text { kg during project } \\
\text { i.e. } 46 \% \text { less } \\
\text { than traditional } \\
\text { as based on } \\
\text { contract }\end{array}$ \\
\hline
\end{tabular}

\section{CONCLUSIONS}

In this paper we observed four project cases applying advanced logistics solutions. The effects of these applications were assessed based on the KPI framework which was constructed for the research project reported. In the six dimensions of the framework all four projects performed better logistically than what the projects would do traditionally. 
This implied improved transport efficiency and reduced environmental impact of the transport. The observations supported the applicability and usefulness of the framework and the benefits of improved transport and logistics management in construction.

The KPI framework appeared to be quite useful in describing the level of performance of the projects and the four factors of influence on the construction transport of the projects. Although the scope of the performance and the factors covered a wider range of issues than the framework could assess directly, the framework was able to accommodate also those influences on the projects and the construction transport.

The application of a CCC and other efforts to decouple and consolidate construction transport have been found to play a key role in the logistics solutions and to achieve the effects reported. Second, applications of information management, notably Warehouse Management Systems (WMS) and Transport Management Systems (TMS), are playing an increasingly important role to coordinate the stocks at the $\mathrm{CCC}$ and ensure accurate deliveries from the CCC to site. The coordination is starting to extend to the design phase via BIM applications such as Solibri in order to determine daily materials packages to construction sites efficiently. Modularisation and kitting of material packages is a way forward in which much is to be gained in terms of production. Fourth, tendering and purchasing based on MEAT criteria rewarding $\mathrm{CO} 2$ reductions by clients and governments, and also construction firms towards suppliers and transport firms will likely encourage further efforts to improve transport efficiencies and reduce the environmental impact of construction transport.

Notwithstanding the benefits and potential, the scope of these improvements focus mainly on the 'last mile', notably the transport from the CCC to the site. In most cases though the deliveries from suppliers to the CCC are not acted upon, although there is an improvement potential here too. Further, and this goes for the application of the KPI framework as for ICT instruments mentioned, firms and individuals along the supply chain must be aware and systematically use and keep up those tools to be effective and cause the desired impact.

\section{REFERENCES}

- Brett, P. (2007). Construction Consolidation Centres; An Assessment of the Potential for London wide use. Project Ref: 17321/004, May, 2007.

- Bryman, A. (2008). Of methods and methodology. Qualitative Research in Organizations and Management: An International Journal, 3(2), 159-168.

- Constructing Excellence (2007). London Construction Consolidation Centre. Interim Report May 2007. Transport for London. In partnership with Bovis Lend Lease, Constructing Excellence, Stanhope.

- Department for Transport (2007). London Construction Consolidation Centre. Freight Best Practice. Department for Transport, October 2007.

- MVA (2006). Overview on Consolidation Centres, 20 October 2006, MVA Consultancy.

- $\quad$ Pink, S., Tutt, D. and Dainty, A. (2013). Ethnographic Research in the Construction Industry. Routledge, Abingdon. 166 p. 
- SCC (2010) SCOR Supply Chain Operations Reference (SCOR®) model Overview - Version 10.0. Supply Chain Council, Cypress, TX USA, supply-chain.org.

- Sullivan, Barthorpe and Robbins (2010). Managing Construction Logistics. Wiley-Blackwell, Chichester.

- Transport and Travel (2010). Freight Consolidation Centre Study. Main Report. Prepared for Department for Transport. Transport and travel research Ltd. Version 1.0 14th July 2010.

- Transport for London (2008). London Construction Consolidation Centre. Final Report April 2008 rev October 2008. Transport for London, In partnership with Bovis Lend Lease, Constructing Excellence, Stanhope, Wilson James, University of Westminster

- Vrijhoef, R. (2011). Supply chain integration in the building industry: The emergence of integrated and repetitive strategies in a fragmented and project-driven industry. $\mathrm{PhD}$ Thesis. Ios Press, Amsterdam. 


\section{Theme 4 Construction Industry and Global Economy}

1. Building Sustainability And Building Health: An Inextricable Synergy

2. Research Trend Of Sustainability In Construction Journals

3. Corporate Factors Influencing Sustainable Construction Enterprise

4. A Framework For Growth Of Small And Medium-Size Construction Firms: A Literature Review

5. A New Theory-Based Typology For Construction Projects

6. Organizational Identification And Turnover Intention Of Employees In The Turkish Construction Industry

7. Research Programme On Innovative Learning Spaces And Their Development

8. Radical Circular Economy

9. Use Of Social Media In Construction Industry: A Case Study 


\title{
BUILDING SUSTAINABILITY AND BUILDING HEALTH: AN INEXTRICABLE SYNERGY
}

\author{
Ajayi, S. O. ${ }^{1}$; Oyedele, L. O. ${ }^{2}$; Kadiri, K. O. ${ }^{3}$ and David S.A. ${ }^{4}$
}

\begin{abstract}
:
There have been speculations as to whether environmental friendly buildings are always healthy. Using Life Cycle Assessment (LCA) methodology, this study investigates relationship between building health and lifecycle environmental impacts. In order to achieve this, a block of classroom was modelled with the aid of Revit, and its lifecycle environmental and health impacts were analysed using Green Building Studio and Athena Impact Estimator. Sensitivity analyses of the block of classrooms were then carried out by varying the building materials and energy use pattern of the original typology. The lifecycle assessment was performed for seven alternative typologies that were achieved through variation in the building materials and energy use patterns. The human health impacts was evaluated by measuring amount of particulate matter (PM2.5) produced by the buildings while environmental impact was evaluated by measuring global warming (KgCO2) potentials of the buildings throughout its lifecycle. For all the eight building typologies, the study shows a direct relationship between global warming potentials and human health impacts. This confirms that the more sustainable a building, the less its tendency for having negative health effects on building operatives, occupants and the wider environment. Again, the more green a building in terms of its materials and energy use pattern, the healthier the building becomes.
\end{abstract}

KEYWORDS: ACIDIFICATION, BUILDING AND HEALTH, GLOBAL WARMING, LCA, SUSTAINABILITY.

\section{INTRODUCTION}

As a result of its contribution of substantial portion of $\mathrm{CO} 2$ in the atmosphere (Baek et al. 2013), consumption of large mineral resources (Anink et al., 1996) and generation of largest proportion of landfill waste (Oyedele et al., 2014), construction industry has remained under pressure to improve its environmental sustainability. It has often been stated that the achievement of global sustainability agenda and prevention of impending negative environmental impacts depends on how well the construction industry is able to reduce its $\mathrm{CO} 2$ emission, virgin materials consumption and waste to landfill (Ajayi et al., 2015). Owing to these needs, substantial legislative and research efforts have been made to curb waste generation and carbon emission from the industry. This has led to significant improvement in the industry's sustainability.

\footnotetext{
${ }^{1}$ Bristol Enterprise, Research and Innovation Centre, University of the West of England, Bristol; UK. Email: saheed2.ajayi@live.uwe.ac.uk;

${ }^{2}$ Bristol Enterprise, Research and Innovation Centre, University of the West of England, Bristol; UK. Email: L.oyedele@uwe.ac.uk

3 Department of Architecture, Obafemi Awolowo University, Ile-Ife, Nigeria. Email: imamkadiri@yahoo.com;

4 Department of Architecture, Obafemi Awolowo University, Ile-Ife, Nigeria. Email: davidsaderemi@yahoo.com
} 
Apart from environmental sustainability, the design and method of construction of the built environment have great impacts on human health. It has been argued that "the connection between health and dwelling of the populace is one of the most important that exist" (Hood, 2005, p. A317). Evidence shows that several diseases, deaths and ultimate damage to the wider environment have been associated with building health and safety hazards. These are as a result of poor design and construction techniques, improper ventilation system as well as wrong materials and products selection (Ajayi et al., 2014). However, unlike issues relating to environmental sustainability, health aspects of the built environment has received less attention.

This negligence has often been defended with an assumption that reducing global warming potential of built infrastructure could amount to reducing its negative health impacts. While this claim is becoming the norms of the industry and justification for lack of holistic efforts for improving building health (Poland and Dooris, 2010), there is lack of empirical research substantiating such claim. Conversely, some study have even suggested that naturally ventilated building might contribute to ingestion of polluted outdoor air (Boldi, 2014). This is against the common notion that as naturally ventilated buildings are energy efficient and more sustainable, they are equally meant to be healthier (Redlich et al., 1997).

With the growing controversies and unsubstantiated opinion regarding the relationship between building health and building sustainability, it is important that empirical evidence be provided. In order to understand the impacts of building sustainability on the health of building occupants, operatives and the general environment, this study investigates the relationship between building sustainability and building health. As such, the study seek to test a hypothesis, which claims that the more sustainable a building, the healthier it is. The study adopts methodology in Lifecycle Assessment (LCA) to evaluate environmental and health impacts of eight building typologies. The results are then compared to establish relationship between sustainability and health.

As a theoretical insight for this study, the next section review literatures on LCA methodology. Methodological approach employed in the study, which includes description of case study models and analytical process is justified and discussed. Findings of the study are then presented and discussed before culminating the study with implication for practices and conclusion. All arguments relating to the relationship between building sustainability and health are laid to rest by the paper.

\section{LITERATURE REVIEW}

Based on Lifecycle methodology, impact of buildings on the environment ranges from its materials extraction to its end of life. As such, it is important that each of the stages of building lifecycle be adequately considered in order to estimate its holistic impacts. Whole building Lifecycle usually cover five stages, which are raw materials and manufacturing, construction, operation, maintenance, and demolition stages (Wang et al., 2011). As result of simplifications suggested for successful implementation of LCA, 
some studies neglect one stage or the other. For instance, while carrying out BIM-based LCA of whole building, Wang et al. (2011) neglected demolition stage as a result of its insignificance in reference to Sartori and Hestnes (2007).

The raw material and manufacturing phases encompasses environmental burden as a result of extraction and refinement of the raw material and production process, while construction stage accounts for not only site based construction activities, but also transportation of the materials and workers to the site (Wang et al, 2011; Ramesh et al, 2010). Few studies estimated material transportation as separate stage in the life cycle of whole building (e.g. Scheuer et al, 2003). Several studies also neglected maintenance stages due to level of uncertainty involved (e.g. Adalberth et al., 1997), while many others (e.g. Rossi et al, 2012) neglected transportation stage. Nevertheless, all known studies identified material and manufacturing, construction and operation stages as crucial stages for evaluating impacts of buildings. Stages covered or omitted in each study is determined by the goal and scope of the study.

Basically, studies investigating environmental impacts of buildings are carried out within the ISO14040 framework for lifecycle assessment. However, combination of LCA tools and other external analysis tools have been used. For instance, Ooteghem and $\mathrm{Xu}$ (2012) used ATHENA Impact Estimator for estimating other impacts than operational impacts of the building, while eQUEST assisted in calculating lifecycle operational impacts of the building. Ghattas et al., (2013) also employed Eco invent LCA tool based on an argument that it is one of the commonly used LCA data source. Other databases that have been used in various studies include inventory prepared by Japan Building Construction (Baek et al., 2013), Finnish building classification (Wang et al, 2011), Bath University Inventory of Carbon and Energy (ICE) (Hammond and Jones, 2008), and so on. Irrespective of the variation in methods and tools of assessment, studies estimating holistic impacts of buildings are required to be in four phases, which are goal and scope definition, inventory analysis, impact assessment and result interpretation.

\section{METHODOLOGY}

The study aims at comparing health and environmental impacts of buildings. In order to achieve this aim, a case study of a block of classrooms was modelled with the aid of Revit, with the building detailed at BIM level 2. This section describes the methodological framework, case study model, and the processes used in the study.

\section{Lifecycle Analysis Methodological Framework}

The scope of this study is limited to lifecycle evaluation of health and environmental impacts of a classroom block over a lifecycle duration of 30 years as recommended by Saynajoki et al. (2012). The analysis covered the whole building structure as well as whole life duration, which encompasses material extraction and transportation, manufacturing (regarded as product), construction, operation and replacement, and end of life stages. Inventory analysis of the building was carried out with the aid of Revit using 
volume estimates. This was then entered into ATHENA impact estimator, which is a LCA software designed to estimate environmental impact of a built facility through the volume of materials used in its construction. As the ATHENA Impact estimator lacks capacity for evaluating operational impacts of a building, the tool was corroborated with Green Building Studio, which was used in evaluating operational impacts of the building. The unit of operational energy were later converted into such impacts as acidification, global warming potential, etc. by the impact estimator.

Based on the aim of this study, the two major impacts that were assessed in this study were health impacts and global warming potential (GWP) of the buildings. The health impacts was measured in terms of the volume of particulate matters (PM2.5) likely to be present in the air as a result of materials manufacturing, construction, operation and end of life demolition of the buildings. It is suitable for measuring health impacts of building as evidence shows that it is capable of causing such diseases as bronchitis, asthma and acute pulmonary diseases (Ajayi et al., 2014). The GWP was particularly used in measuring environmental impacts as a study by BRE suggests that it is the most potent of the impacts categories (Hamilton et al., 2007). To enhance comparison of the health and environmental impacts of the building, materials specification and energy used pattern were varied across eight cases. Lifecycle impacts of the main case study was then interpreted and compared with alternative cases.

\section{Case Studies}

A case study of a block of classroom, with seven-sensibility analyses, was used for the study. The case study is characterised by the following. Building Type: Academic; Number of floor: 2; Ground Floor area (used for the study): 1319m2; First floor area (used for the study): 938m2; Lighting control: All manual; Green roof area: 258m2; First floor roof area: $1050 \mathrm{~m} 2$; Lower roof: $183 \mathrm{~m} 2$.

Figure 1: Simulated energy use pattern for the building
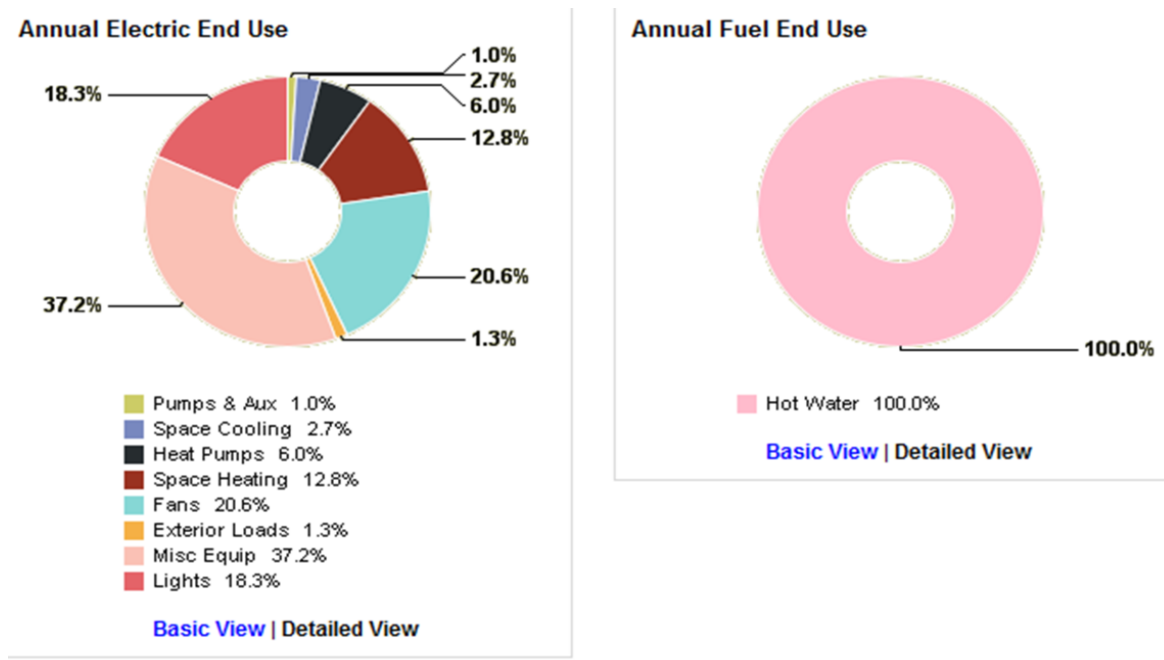
In order to enhance comparison of the model, materials specification was varied for other three alternatives (2, 3 and 4). Amount of energy that could be generated for the building through the use of PV panel was calculated through Green Building Studio (GBS). In addition, lifecycle environmental and health impacts were analysed for energy efficient alternatives of typologies 1-4, which resulted into typologies 1A, 2A, 3A and 4A. For each of the energy efficient alternatives, embodied impacts of the PV panel was added to the overall embodied impacts of the buildings, while operational energy required for lighting, fans and other miscellaneous equipment were subtracted from operational impacts of the main typologies (1-4). The embodied value of PV panel was taken at an average value of $60 \mathrm{~g}$ of $\mathrm{CO} 2 / \mathrm{Kwh}$ based on the works of Zhong et al. (2011) and Sherwani et al. (2010). Figure 2 shows energy use pattern for the building, while Table 1 presents specific characteristics of each of the typologies.

\section{Table 1: Materials and energy use variation across the typologies}

\begin{tabular}{|c|c|}
\hline Building Systems & Specific characteristics of the typologies $(1-4 \mathrm{~A})$ \\
\hline Exterior Walls & $\begin{array}{l}\text { 1. Brick/block cavity wall. } \\
\text { 2. Cladded timber cavity wall filled with cellulose insulation. } \\
\text { 3. ICF with expanded Polystyrene. } \\
\text { 4. Gypframe steel framed wall with polystyrene insulation. }\end{array}$ \\
\hline Interior Walls & $\begin{array}{l}\text { 1. Hardwood structural post as main beam, and glue lamp as secondary frame. } \\
\text { 2. Hardwood structural post as main beam, and glue lamp as secondary frame. } \\
\text { 3. Reinforced Concrete column structure } \\
\text { 4. Steel frame }\end{array}$ \\
\hline Structures & $\begin{array}{l}\text { 1. Hardwood structural post as main beam, and glue lamp as secondary frame. } \\
\text { 2. Hardwood structural post as main beam, and glue lamp as secondary frame. } \\
\text { 3. Reinforced Concrete column structure } \\
\text { 4. Steel frame }\end{array}$ \\
\hline Ground Floor & $\begin{array}{l}\text { 1-3 Timber raised floor insulated with blown cellulose, on CMU structure. } \\
\text { 4. Steel plate raised on CMU, and finished with synthetic resin }\end{array}$ \\
\hline First Floor & $\begin{array}{l}\text { 1. Timber boards with I-section timber frame and resin floor finish } \\
\text { 2. Timber frame and timber board finished with synthetic resin } \\
\text { 3. Precast concrete floor } \\
\text { 4. Gypframe steel flooring }\end{array}$ \\
\hline Windows & $\begin{array}{l}\text { 2. Timber-frame, double-glazed, argon-filled, U-value } 1.55 \mathrm{~W} / \mathrm{m} 2 \mathrm{~K} \\
\text { 1, } 3 \& 4 \text {. Aluminium-frame, double-glazed, argon-filled, U-value } 1.55 \mathrm{~W} / \mathrm{m} 2 \mathrm{~K}\end{array}$ \\
\hline Roofs & $\begin{array}{l}\text { 1. Slate roofing sheet with wood frame } \\
\text { 2. Insulated timber plate flat roof with EPDM cover } \\
\text { 3. Reinforced concrete flat roof with } 40 \% \text { GGBS/recycled aggregate } \\
\text { 4. Insulated steel plate flat roof covered with EPDM }\end{array}$ \\
\hline HVAC & $\begin{array}{l}\text { 1-4. Gas fired boiler, steam from Central Power plant. } \\
\text { 1A, 2A, 3A \& 4A: Renewable source with lower percentage of fossil fuel. }\end{array}$ \\
\hline Electricity & $\begin{array}{l}\text { 1-4. 100\% from external regional utility } \\
1 \mathrm{~A}, 2 \mathrm{~A}, 3 \mathrm{~A} \& 4 \mathrm{~A}: \text { Renewable/non-renewable sources }\end{array}$ \\
\hline Ceiling & All: Suspended gypsum ceiling with steel grid \\
\hline Column & $\begin{array}{l}\text { 1-3. Pressure treated sawn hardwood } \\
\text { 4. Steel column. }\end{array}$ \\
\hline
\end{tabular}

Note: 1 is a typical Brick/block building; 2 is a timber structure; 3 is ICF building and 4 is a steel structure. 1A, 1B, 1C $\& 1 \mathrm{D}$ are energy efficient alternatives of $1,2,3 \& 4$ respectively. 


\section{Process Description}

The figure below illustrates the methodological processes involved in carrying out environmental/health impacts analyses for each of the eight case studies.

Figure 3: A typical simulation flow pattern

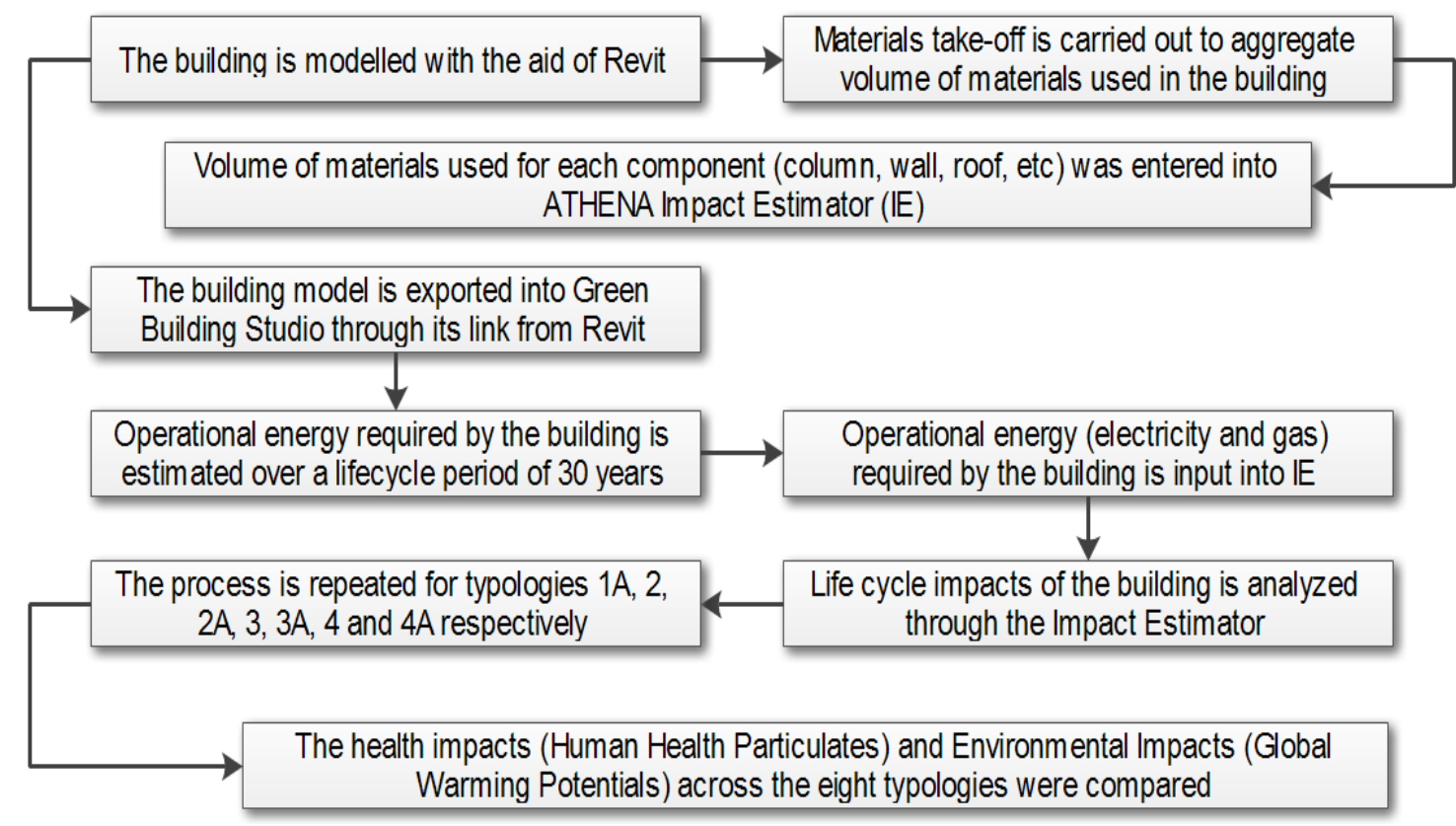

\section{FINDINGS}

Table 2 and 3 below shows the global warming potential (GWP) and human health impacts for each of the eight building typologies.

Table 2: Global Warming Potential of the typologies (measured in KgCO2)

\begin{tabular}{lllllllll}
\hline Impacts/Stages & Type 1 & $\begin{array}{l}\text { Type } \\
\text { 1A }\end{array}$ & Type 2 & $\begin{array}{l}\text { Type } \\
\text { 2A }\end{array}$ & Type 3 & Type & Type 4 & $\begin{array}{l}\text { Type } \\
\text { 3A }\end{array}$ \\
\hline End of Life Stage & 23200 & 23200 & 6840 & 6840 & 50900 & 50900 & 9760 & 9760 \\
Operational Stage & 438000 & 580000 & 439000 & 59610 & 440000 & 599871 & 454000 & 740320 \\
& 0 & & 0 & 5 & 0 & & 0 & \\
Replacement/maintena & 3840 & 3840 & 13745 & 13745 & 10424 & 10424 & 83200 & 83200 \\
nce & & & & & & & & \\
$\begin{array}{l}\text { Construction Stage } \\
\text { Product Stage }\end{array}$ & 84400 & 84400 & 26540 & 26540 & 128000 & 128000 & 72800 & 72800 \\
& 716000 & 727027 & 235500 & 24652 & 108090 & 109193 & 659000 & 670030 \\
TOTAL IMPACT & 520744 & 141846 & 467262 & 88975 & 567022 & 188112 & 536476 & 157611 \\
& 0 & 7 & 5 & 7 & 4 & 5 & 0 & 0 \\
\hline
\end{tabular}


Table 3: Lifecycle Health Impacts of the typologies (measured in KgPM2.5)

\begin{tabular}{lllllllll}
\hline Impacts/Stages & Type & Type & Type & Type & Type 3 & Type & Type 4 & Type \\
& 1 & 1A & 2 & 2A & & 3A & & $4 \mathrm{~A}$ \\
\hline End of Life Stage & 7 & 7 & 2 & 2 & 14 & 14 & 3 & 3 \\
Operational Stage & 4135 & 612 & 4130 & 607 & 4140 & 617 & 4290 & 767 \\
Replacement/maintenance & 7 & 7 & 46 & 46 & 26 & 26 & 188 & 188 \\
Construction Stage & 72 & 72 & 26 & 26 & 109 & 109 & 37 & 37 \\
Product Stage & 1465 & 1540 & 26 & 101 & 2993 & 3068 & 1201 & 1276 \\
TOTAL IMPACT & 5686 & 2238 & 4230 & 782 & 7282 & 3834 & 5719 & 2271 \\
\hline
\end{tabular}

\section{ANALYSIS AND DISCUSSION}

As shown in table 2, global warming potential of the building varies from one typologies to another. It was evident from the table that building that employed renewable technology (Type 1A, 2A, 3A and 4A) are more environmental friendly compared to the same building that employed fossil fuel for building operation (Type 1, 2, 3 and 4). For instance, while brick/block building (Type 1) will generate 5,207,440kgCO2 over its lifecycle, it will only generate $1418467 \mathrm{KgCO} 2$ when it employed PV for its electricity, fans and miscellaneous equipment (Type 1A). This is in line with earlier studies, which posit that the more energy efficient a building, the less its impacts on the environment (Dodoo et al., 2012). Similarly, the table shows that operational stage of a building could contribute about $80 \%$ of its environmental impacts. The stage contributes $84 \%$ for Type 1 (brick/block building), 94\% for Type 2 (cladded timber building), 78\% for Type 3 (ICF building) and $85 \%$ for Type 4 (steel building). This further buttresses the need for increased stringency of legal requirements that stipulate the use of renewable technology for buildings operation.

On the other hand, the lifecycle health impact of the building typologies also range from one typology to another, with buildings employing renewable technology having lesser health impacts than those using fossil fuel (see table 2). Similarly, operational stage of the buildings have more health impacts than other stages of the building lifecycle. This suggests that the use of fossil fuel is not only having negative environmental impacts, it also affects human health as a result of its release of particulate matters capable of affecting respiratory system. As the buildings employ renewable technology (Type 1A, $2 \mathrm{~A}, 3 \mathrm{~A}$ and $4 \mathrm{~A}$ ), environmental and health impacts due to their operational stage significantly reduced, while there are non-significance increase in embodied impacts. Albeit small magnitude of the increment, it suggests that as buildings become energy efficient during their operational stage, embodied impacts need to be reduced. According to Ajayi et al. (2015), this could be tackled by allocating eco-pints to different materials so that designers would be encouraged to specify environmental friendly materials for their designs.

\section{Environmental Impacts of different typologies}

As evident in figure 4 below, negative environmental impacts of the building typologies ranges from ICF building, steel building, brick/block building, timber building, ICF 
building (with PV panel), steel building (with PV panel), brick/block building (with PV panel) to timber building (with PV panel). This corresponds with types 3, 4, 1, 2, 3A, 4A, $1 \mathrm{~A}$ and $2 \mathrm{~A}$ respectively. It means that while building constructed with Insulated Concrete Forms (ICF building - type 3) has the highest negative environmental impacts, timber building (with PV panel - type 2A) is the most environmental friendly. With lifecycle emission of $5670224 \mathrm{KgCO} 2$, the ICF building has CO2 equivalent of 573SUVs over a 30-year lifecycle or 19SUVs per year, while brick/block, steel and cladded timber building have $\mathrm{CO} 2$ equivalent of $17 \mathrm{SUVs} /$ year, $18 \mathrm{SUVs} /$ year and 16SUVs/year respectively.

Figure 4: Lifecycle environmental impacts of the typologies (measured in KgCO2).

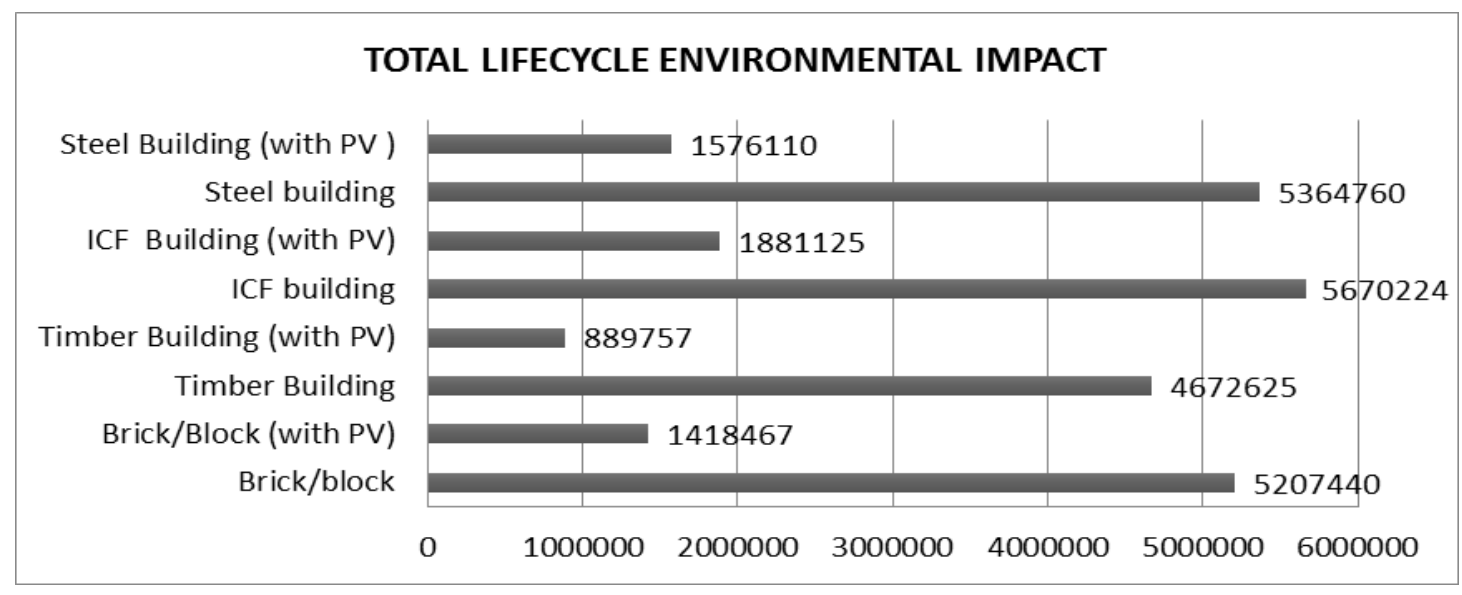

\section{Health Impacts of different typologies}

Figure 5 shows the distribution of health impacts of the different building typologies. By health impacts, the study refers to the proportion of particulate matters (PM2.5) that would be present in the air as a result of lifecycle activities of the building typologies. The US Environmental Protection Agency (USEPA, 1997) posits that PM2.5 have tendency of causing serious health problems when present in the atmosphere. Some of these health problems are lung diseases, non-fatal heart attack, decrease lung function, aggravated asthma and several respiratory problems such as coughing, irritation and difficulty in breathing. From the figure, it is evident that the building constructed with ICF has the highest health impacts, while timber building has the least impacts on human health. Generally, the health impacts of the building typologies improve from types 3,4 , $1,2,3 \mathrm{~A}, 4 \mathrm{~A}, 1 \mathrm{~A}$ to $2 \mathrm{~A}$ in descending order. 
Figure 5: Lifecycle health impacts of the typologies (measured in KgPM2.5).

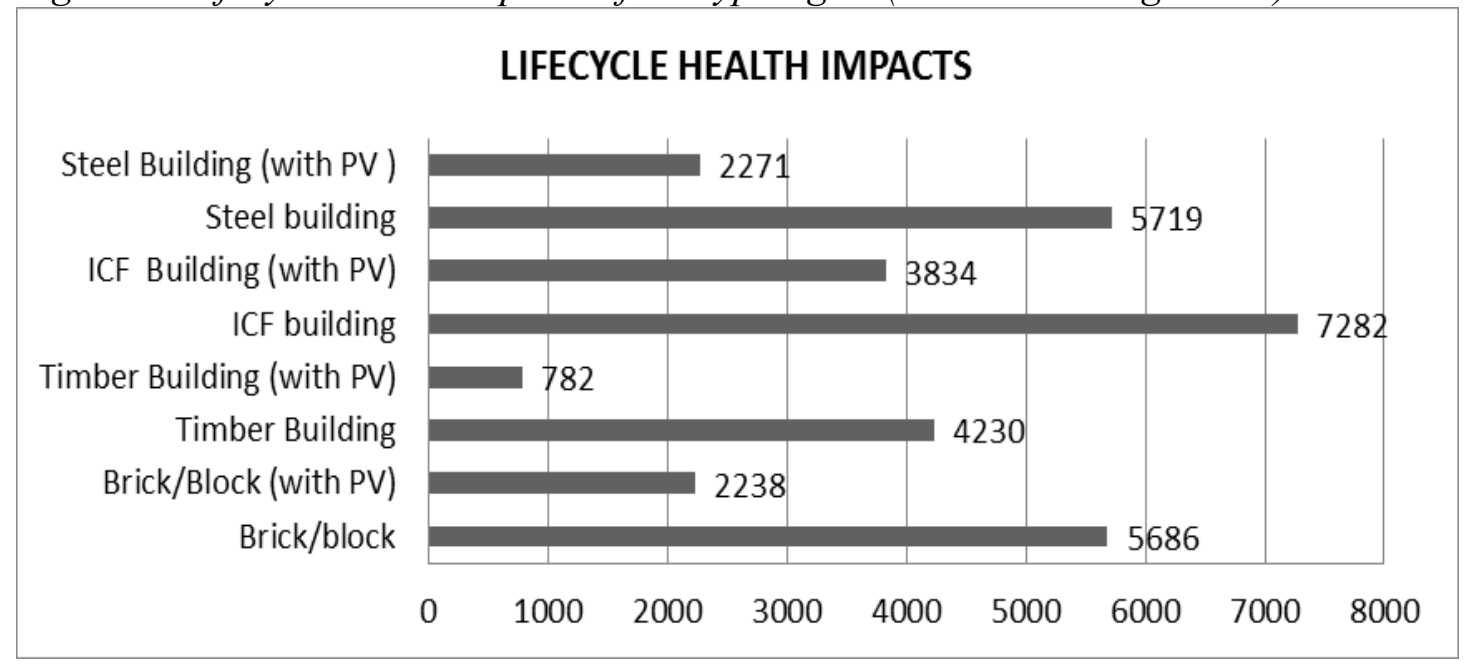

\section{Relationship between Environmental and Health Impacts}

A direct relationship is observed between building sustainability and building health. As shown in Figure 6, the more the global warming potential of a building typology, the more its health impacts. This ranges equally for all the eight building typologies used in this study, thereby suggesting that by tackling environmental impacts of a building, negative health impact of such building has also been prevented.

Figure 6: Comparison of health and environmental impacts of the eight typologies

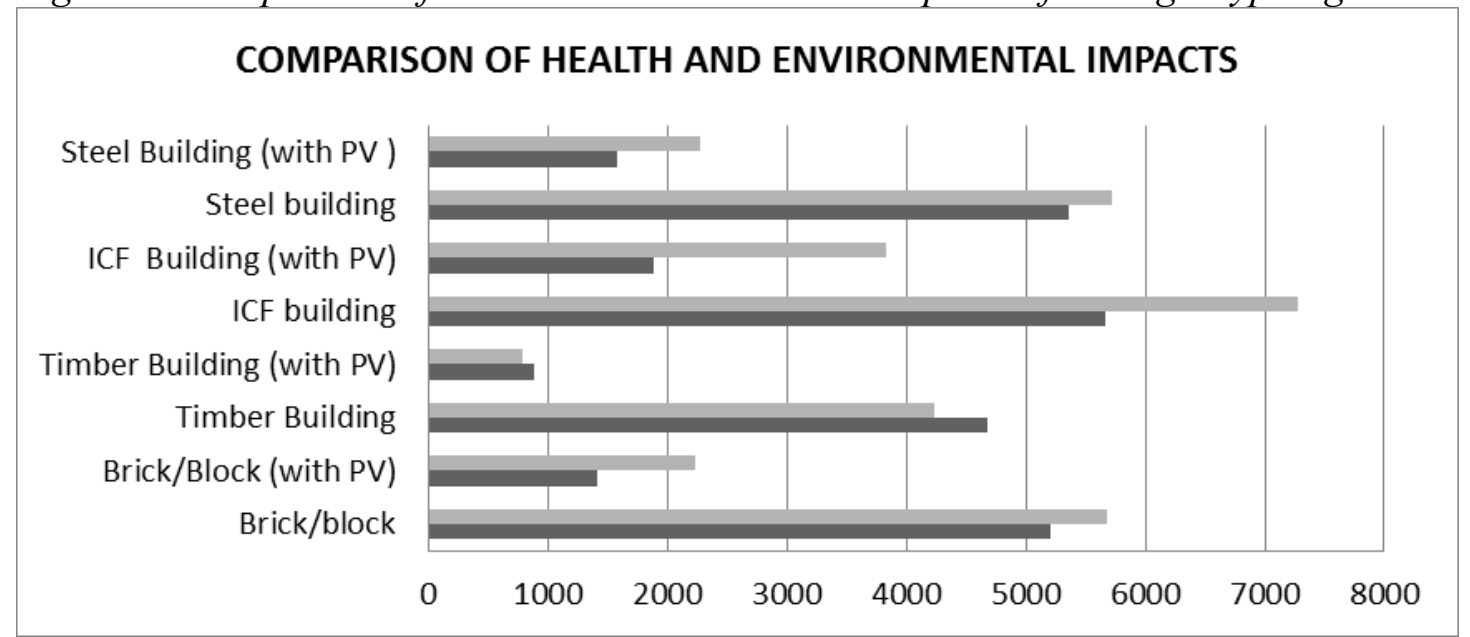

As shown in the figure above, the ICF building (Type 3) has the highest environmental and health impacts, this was followed by steel building, brick/block building and timber building respectively. The energy efficient alternatives for each typology also follow the same pattern. This means that for both environmental and health impacts of the eight typologies, the lifecycle impacts ranges from ICF building, steel building, brick/block 
building, timber building, ICF building (with PV panel), steel building (with PV panel), brick/block building (with PV panel) to timber building (with PV panel). This corresponds with types $3,4,1,2,3 \mathrm{~A}, 4 \mathrm{~A}, 1 \mathrm{~A}$ and $2 \mathrm{~A}$ respectively. This thus confirms the hypothesis that the more sustainable a building, the healthier it becomes.

\section{CONCLUSION}

The overall goal of this study was to determine the relationship between building sustainability and building health. Whole lifecycle environmental and health impacts of building were evaluated through the use of a case study of academic block. In order to enhance comparison of health and environmental impacts of the case study model, materials specification and energy used pattern were varied across eight typologies. The study suggests that operational stage of building lifecycle contributes the highest impacts over the building lifecycle. This suggests that buildings that are based on renewable technology during its operational stage are more sustainable and healthy than those that are based on fossil fuel. In terms of materials, buildings constructed with timber are found to be more sustainable and healthier than brick/block building, which is also better than steel buildings in terms of environmental and health impacts. Building constructed with ICF is the least sustainable of all materials typologies considered in the study. Importantly, the same pattern was observed in terms of healthiness and environmental friendliness of all the eight cases used in the study. This confirms that the more sustainable a building, the healthier it becomes. Thus, by addressing sustainability of the built environment, negative health impacts of the buildings are also prevented.

The environmental impacts of buildings in this study have been estimated based on a single measure, which is the global warming potential (climate change). Other studies could investigate the relationship between health impacts (toxicity) of buildings and other measures of environmental impacts such as acidification potentials, materials depletion and ozone depletion, among others.

\section{REFERENCES}

- ADALBERTH K. (1997). Energy use during the life cycle of buildings: A method. Building and Environment, 32(4), pp. 317-320.

- $\quad$ AJAYI, S. O., OYEDELE, L. O., BILAL, M., AKINADE, O.O., ALAKA, H.A., OWOLABI, H.A., \& KADIRI, K.O., (2015). Waste Effectiveness of the Construction Industry: Understanding the Impediments and Requisites for Improvement. Resource, Conservation and Recycling. DOI: 10.1016/j resconrec.2015.06.001.

- AJAYI, S.O., OYEDEle, L.O., AlAKA, H.A., OWOLABI, H.A., BILAL, M., \& AKINADE, O.O. (2014). Expository Study of Building Related health Issues: Need for Safety Measures. In: M. Okeil (Ed.). Smart, sustainable and healthy city, proceeding of the first international conference of the CIB Middle East and North Africa Research Network, CIBMENA, Abu Dhabi, UAE; 12/2014, pp. 521 - 532.

- ANINK, D., MAK, J., \& BOONSTRA, C. (1996). Handbook of sustainable building: An environmental preference method for selection of materials for use in construction and refurbishment. London: James and James. 
- $\quad$ BAEK, C., PARK, S., SUZUKI, M., \& LEE, S. (2013). Life cycle carbon dioxide assessment tool for buildings in the schematic design phase. Energy and Buildings, 61(2013), pp. 275-287

- BOLDI, R. A. (2014). A comparison of the indoor and outdoor concentrations of fine particulate matter in various locations within Dubai, UAE. In: Okeil, M. (Ed). Smart, sustainable and healthy city, proceedings of the First International Conference of the CIB Middle East and North Africa Research Network (CIB-MENA 2014), December 14 -16, 2014, pp. $511-520$.

- DODOO, A., GUSTAVSSON, L., \& SATHRE, R. (2012). Lifecycle primary energy analysis of conventional and passive houses. International Journal of Sustainable Building Technology and Urban Development, 3(2), pp. 105-111.

- Ghattas, R., GRegory, J., OLIVETTI, E., \& GREENE, S. (2013). Life cycle assessment for residential buildings: A literature review and gap analysis (online). Available from: http://web.mit.edu/cshub/news/pdf. [Accessed: May, 2013]

- HAMilTON, L., EDWARDS, S., AIZLEWOOD, C., SHIERS, D., THISTLETHWAITE, P., \& STEELE, K. (2007). Creating environmental weightings for construction products. Bracknell: BRE Press

- HAMMOND, G., \& JONES, C., (ed.) (2008). Inventory of Carbon and Energy (ICE), version $1.6 \mathrm{a}$

- HOOD, E. (2005). Dwelling disparities: How poor housing leads to poor health, environmental health perspectives, 113(5), pp. A310-A317.

- OOTEGHEM, K.V., \& XU, L. (2012). The life-cycle assessment of a single-storey retail building in Canada. Building and Environment, 49(2012), pp. 212-226

- OYEDELE, L. O., AJAYI, S. O., \& KADIRI, K. O. (2014). Use of recycled products in UK construction industry: An empirical investigation into critical impediments and strategies for improvement. Resources, Cons. and Recycling, 93(2014), pp. 23-31.

- POLAND, B., \& DOORIS, M. (2010). A green and healthy future: The settings approach to building health. Critical Public Health, 20(3), pp. 281-298.

- RAMESH, T., PRAKASH, R., \& SHUKLA, K. K. (2010). Life cycle energy analysis of buildings: An overview. Energy and Buildings, 42 (2010), pp. 1592-1600.

- REDLICH, C. A., SPARER, J., \& CULLEN, M. R. (1997). Sick-building syndrome. The Lancet, 349(9057), pp. 1013-1016.

- ROSSI, B., MARIQUE, A.F., GLAUMANN, M., \& REITER, S. (2012). Life-cycle assessment of residential buildings in three different European locations, basic tool. Building and Environment, 51(2012), pp. 395 - 401.

- SARTORI, I., \& HESTNES, A. G. (2007). Energy use in the life cycle of conventional and low-energy buildings: A review article. Energy and Buildings, 39(3), pp. 249-257.

- SÄYNÄJOKI, A., HEINONEN, J., \& JUNNILA, S. (2012). A scenario analysis of the life cycle greenhouse gas emissions of a new residential area. Environmental Research Letters, 7(3), 034037.

- SCHEUER, C., KEOLEIAN, G.A., \& REPPE, P. (2003). Life cycle efnergy and environmental performance of a new university building: modelling challenges and design implications. Energy and Buildings, 35 (10) pp. 1049-1064.

- SHERWANI, A.F., USMANI, J.A., \& VARUN, (2010). Life cycle assessment of solar PV based electricity generation systems: A review. Renewable and Sustainable Energy Reviews, 14(1) pp. 540-544.

- USEPA (1997). Health and environmental effects of particulate matter, OAQPS Fact Sheet, July 17, 1997.

- WANG, E., SHEN, Z., \& BARRYMAN, C. (2011). A building LCA case study using Autodesk Ecotect and BIM model. Papers in construction management. Paper 6, University of Nebraska - Lincoln

- ZHONG, Z.W., SONG, B., \& LOH, P.E. (2011). LCAs of a polycrystalline photovoltaic module and a wind turbine. Renewable Energy, 36 (8), pp. 2227 - 2237. 


\title{
RESEARCH TREND OF SUSTAINABILITY IN CONSTRUCTION JOURNALS
}

\author{
Akgul, G. ${ }^{1}$ and Giritli,F.H. ${ }^{2}$
}

\begin{abstract}
:
Sustainability has become a subject of increasing concern to academics and practitioners in recent years. Significant literature has been dedicated to research studies on sustainability and related issues. Factors such as consumption of energy resources, environmental pollution and global warming make sustainability increasingly an important issue especially in the construction industry. The purpose of this study is to conduct an examination of the popularity and trend of sustainability research topics in construction. The central questions that form the basis of this paper are: How many research studies on sustainability have been published in construction journals in recent years? Based on what have been done so far, what do we know? Finally, what do we need to know more about from future research?

The study to be presented in the paper will carry out a two-stage literature review to determine the nature and extent of attention to sustainability issues in construction journals. In Stage 1, a comprehensive literature review will be conducted using the search engine "Scopus. The results of Stage 1 will be used for identifying target journals to be included in the second stage too. In Stage 2, a visual and more comprehensive search of all target journals will be carried out instead of via the search engine. Based on a two-stage literature review, construction-related sustainability articles from 1997 to 2015 were analyzed in terms of the number of papers published annually, country and institution contributions, research methods and data analysis methods adopted, and research topics covered.

It is hoped that this study will provide information on current sustainability practices in the construction industry and will identify some strengths and weaknesses of the field that can form a sound basis for future research.
\end{abstract}

KEYWORDS: CONSTRUCTION PUBLICATIONS, CONSTRUCTION, GREEN, RESEARCH TREND, REVIEWS, SUSTAINABILITY

\section{INTRODUCTION}

Sustainability is a difficult concept to define; it is also continually evolving, which makes it difficult to define. There are more than 500 definitions of sustainability. Accordingly, sustainability means different things to different people. The Oxford English Dictionary defines sustainability as "the property of being sustainable". It also defines "sustainable" as "to be capable of enduring". Sustainability initially meant environmental sustainability, but today it can be applied to refer to all aspects of social and environmental impacts. The world has become familiar with this notion through the acceptance of Kyoto Protocol in 1997. Most of the countries have agreed on controlling the global warming and climate changing.

"Sustainability is said to be based on five pillars: conservation of nature, health and safety, reduced use of materials, social ecology, and cultural ecology" (Cywinski 2001, p.

\footnotetext{
${ }^{1}$ Institute of Science and Technology, Istanbul Technical University, Turkey. Email: gizakgul@gmail.com

${ }^{2}$ Faculty of Architecture, Istanbul Technical University, Turkey. Email: giritli@itu.edu.tr
} 
13). The last two issues are dedicated to education and knowledge, ethics and culture, and values of heritage. The remaining issues are geared to "management and business practices, design technology and procedures, construction methods and equipment, materials and systems, and public and government policy. A list of sustainability linked environmental factors includes: energy, building ecology, air-water landscaping, waste management, cultural change, and behavioural issues" (Cywinski 2001, p. 15; Myers ,2005; Yates, 2014)

The term Sustainable Construction implies holistic thinking as regards construction and management of the built environment, taking a lifecycle perspective. In 1994, CIB defined the concept of sustainable construction as "the creation and responsible management of a healthy built environment based on resource efficient and ecological principles" (CIB, UNEP-IETC, \& CSIR,2002; Kibert, 2008). It was then added to the common triple objectives: time, cost, and quality. Almost all scholars have focused on the concept of sustainable construction as one of the most important CSR issues in case of the construction sector. It has been pointed out that due to fierce competition in the construction industry, companies need to consider environmental aspects of their business in order to remain competitive. (Griffits and Bhutto,2008). Some examples of sustainable approaches to building are: green building, sustainable design, high performance building, whole building design, sustainable building, and integrated design.

The growing awareness of environmental issues has encouraged the take-up of sustainable practices in the construction industry. As a result, sustainability studies have gained considerable momentum among construction scholars. The aim of this paper is to find research gaps and trends on this field in the literature. A systematic analysis of academic studies could help the researchers to gain a wider perspective of the field quickly and make further advancement in the chosen topic. For this reason, it would be valuable to use trend analysis as a research methodology in order to answer in which construction journals the most relevant articles on the sustainability are published. How the trends of publication have been over the last decade (1997 to 2015), and which of the publication year that have produced the greatest amount of new results to the research area?

\section{METHODOLOGY}

This study was carried out with a two-stage literature review to analyze trends in sustainability research topics in construction, using the Scopus Database. We utilized the time period 1997-2015, representing the last decade of the 20th century and the initial decade of the 21st century. Coincidentally, 1997 also was the year in which Kyoto Protocol was accepted. Search keywords included sustainability and construction. Publications with these specific terms in the title, abstract, or keywords were considered to meet the requirements of this study. The search was also limited to research papers in English language. The literature sources included articles, reviews, conference paper, article in press, short survey conference reviews and etc... The number of the publications 
referred to the 18 year period is 6504 . More than $50 \%$ of the publications in the sample (3588) were published in journals.

Information from the documents published was extracted and the following aspects were coded: (1) number of publications (2) Source of publications (3) Number of publications by affiliation (4) Number of publications by country/territory (5) Percentage of publications by type, and (6) Percentage of publications by subject area. Figure 1 shows that the average trend of publication rate is slowly increasing in the period from 1997 to 2002. Looking at the "middle period" starting in 2006, the number of publications is increasingly growing. In particular, peak can be identified in the year 2013, due to the publication of the first edited volume on the topic (Silvius \& Tharp, 2013). Finally, the year 2014 is the year where the publication rate remains steady. It should be noted that the data for 2015 are only up to July 2015, i.e., only contain information for the partial year. Hence, this year was excluded from any

calculations unless otherwise mentioned.

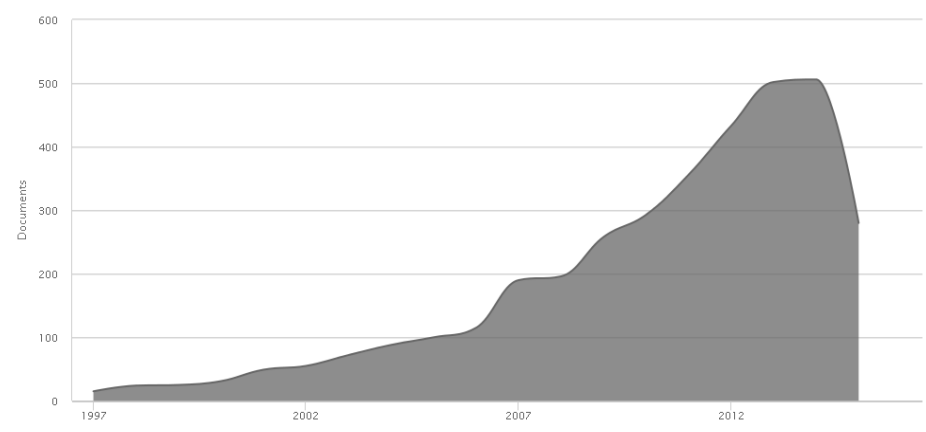

Figure 1: Number of publications between 1997 and 2015

Figure 2 shows the institutions of higher education that are ranked the top ten for total contributions of papers over the 18 years. As indicated by Figure 2, the Hong Kong Polytechnic University was ranked first, while Loughborough University and Delft University of Technology were ranked as second and third respectively.

Figure 2: Number of publications by affiliation (top 10)

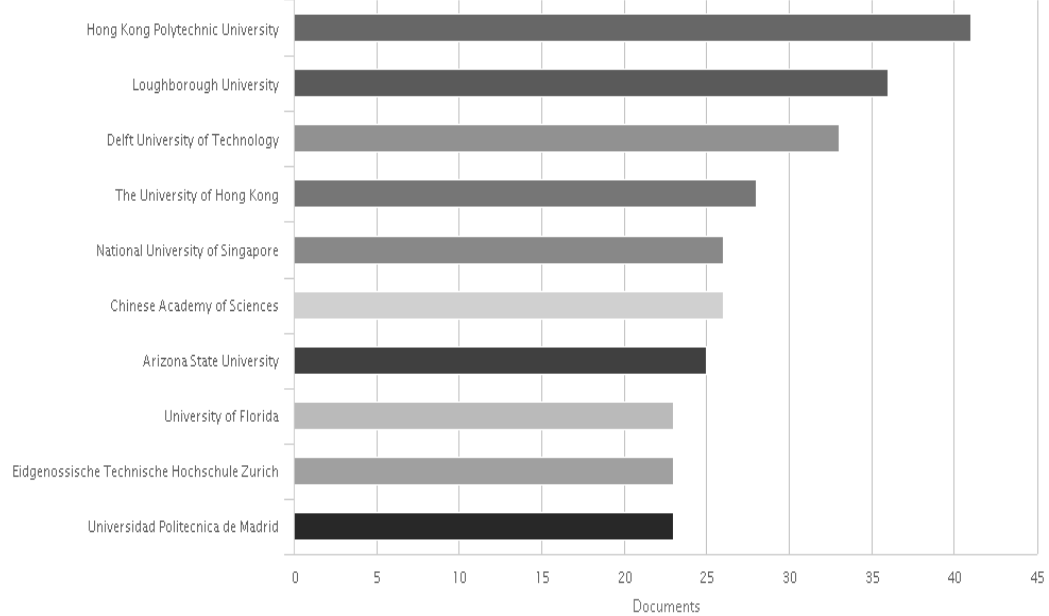


Figure 3 represents the top contributing countries. The US was ranked first. The next two countries were the UK and China. Contributions of the US (LEEDS) and the UK(BREEAM) may be attributed to the fact that both of these countries have their own certification systems.

Figure 3: Number of publications by country/territory (top 10)

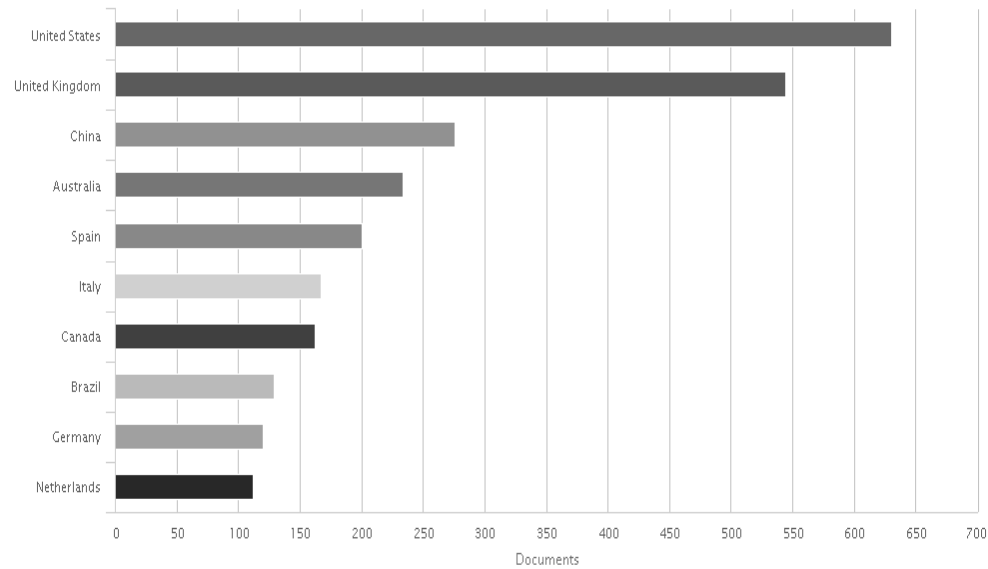

Figure 4 illustrates the separation of publications by type. It is noticeable that journal articles remain the predominant publication type $(82.63 \%)$. Next comes papers published in conference proceedings which account for only 8.2 percent of total publications.

Figure 4: Percentage of publications by type

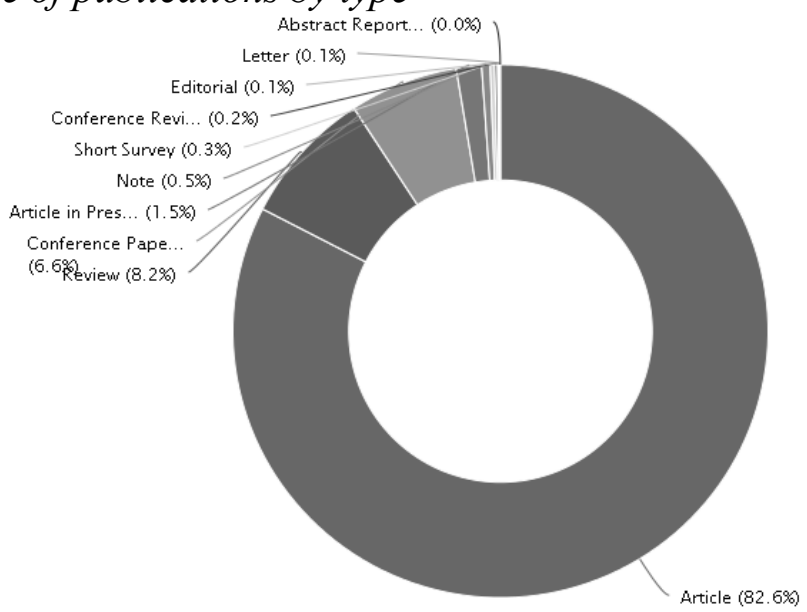

Sustainability research is not yet an autonomous field or discipline, but rather a multidisciplinary research area that is bringing together global and local perspectives, and various disciplines (Clark and Dickson, 2003). This is also the case for constructionrelated research (Xia et.al.2015). Figure 5 identifies ten domains of sustainability-related research: agriculture, engineering, forestry, water, energy, economics, sociology, and all other sciences This categorization was developed by examining the contents of the 
selected set of articles. Figure 5 also shows the percentage of papers assigned to each domain. Environmental science includes the largest percentage of papers $(39.0 \%)$, and economics, econometrics and finance has the smallest percentage of papers $(4.7 \%)$.

Figure 5: Percentage of publications by subject area

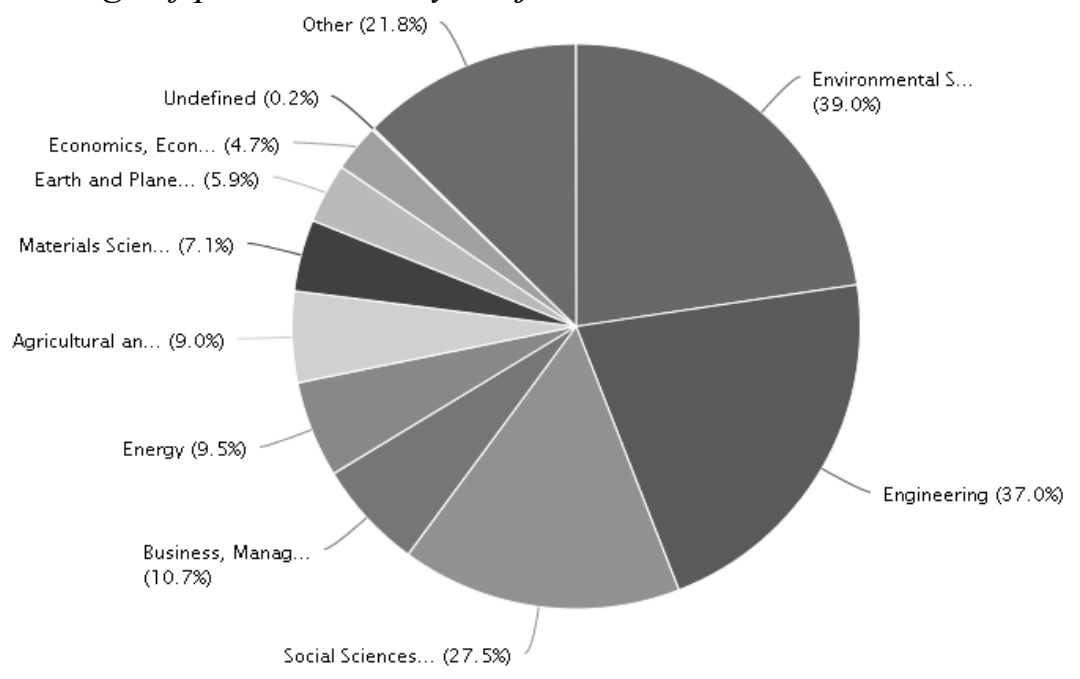

In the second stage of the literature review, the search was narrowed based on the document type of the article or review. It was found that top-five journals, namely Wit Transactions on Ecology and the Environment, Construction and Building Materials, Proceedings of the Institution of Civil Engineers Engineering Sustainability, Building and Environment and Journal of Green Building have published sustainability related articles from 1997 to 2015. These journals are examined with their SJR (SCImago Journal Rank), IPP, SNIP and number of citation values.

Figure 6 shows the total number of papers published in the five selected journals during 1997-2015. These five journals were selected as the target journals for the data collection in Stage 2, as described in the "Research Methodology" section. Among the five selected journals, Wit Transactions on Ecology and the Environment published 91 documents, followed by 65 in Construction and Building Materials, 53 in Proceedings of the Institution of Civil Engineers Engineering Sustainability, 51 in Building and Environment, and 50 in Journal of Green Building. 
Figure 6: Yearly publication of papers in the selected journals

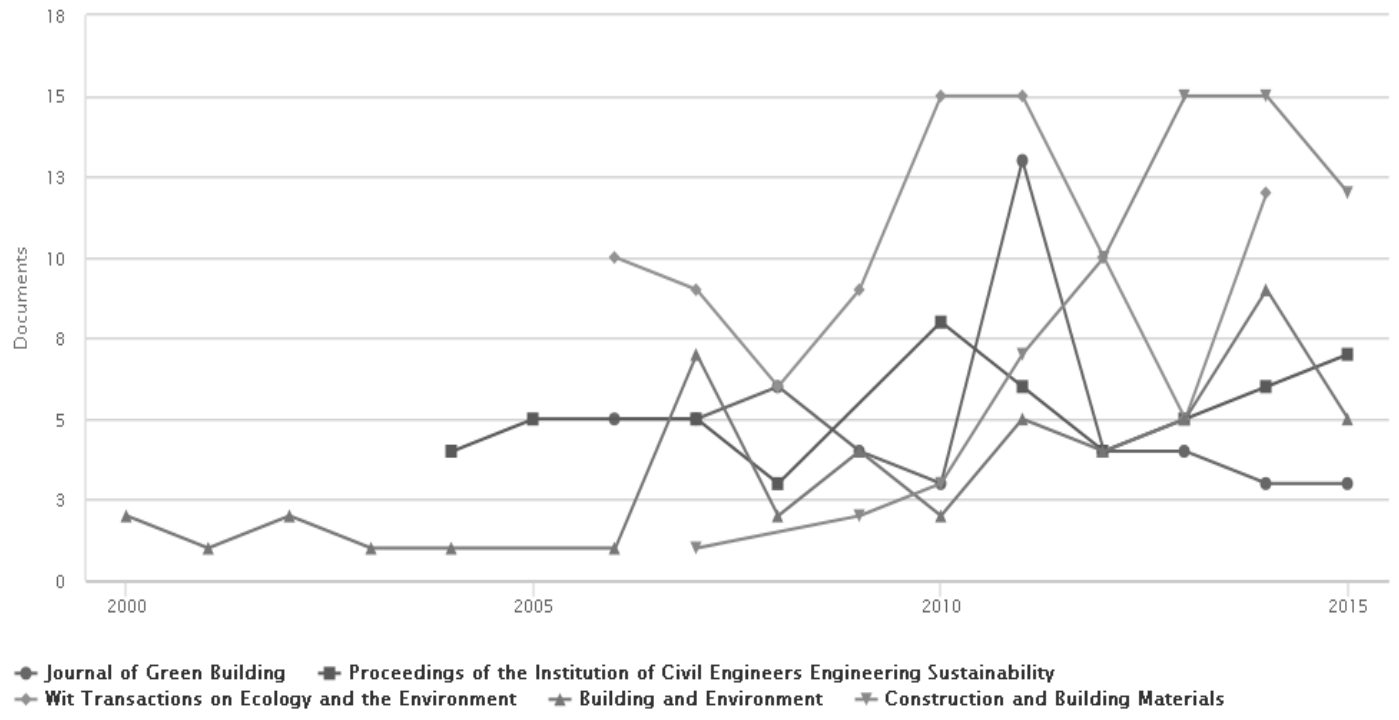

SJR (SCImago Journal Rank) is weighted by the prestige of a journal. Subject field, quality and reputation of the journal have a direct effect on the value of a citation. As it shown in figure 7 the journals named Construction and Building Materials and Building and Environment's SJR rank increased while the other journals' stayed the same. Therefore, Construction and Building Materials and Building and Environment journals gained more reputation year by year and become more respectful.

Figure 7: SCImago journal rank by year (top 5)

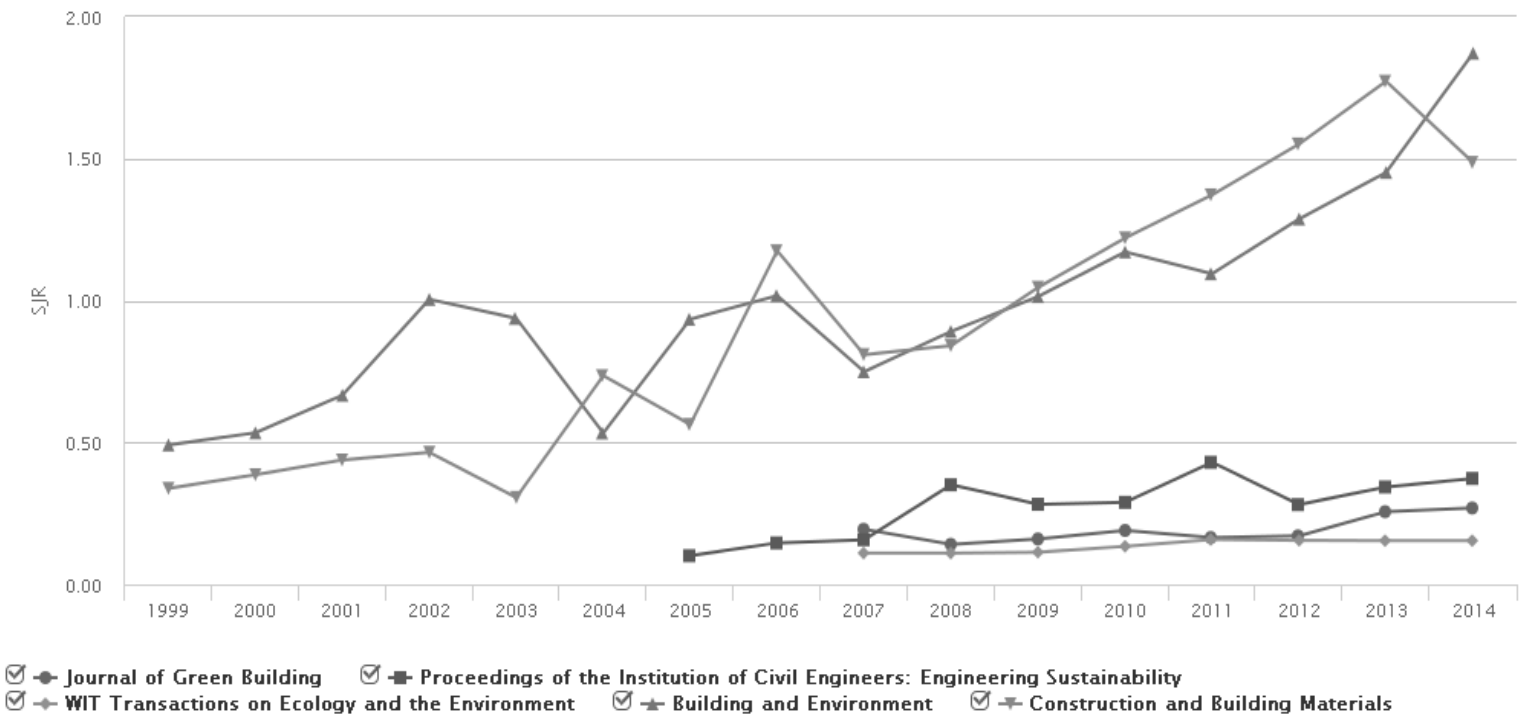

IPP: Compare the ratio of citations per article published in a journal. The Impact per Publication metric is using a citation window of three years which is considered to be the optimal time period to accurately measure citations in most subject fields. In figure 8 , it is 
obvious that SJR rank is related with IPP because the same growth have observed in the same journals.

Figure 8: Impact per publication by year (top 5)

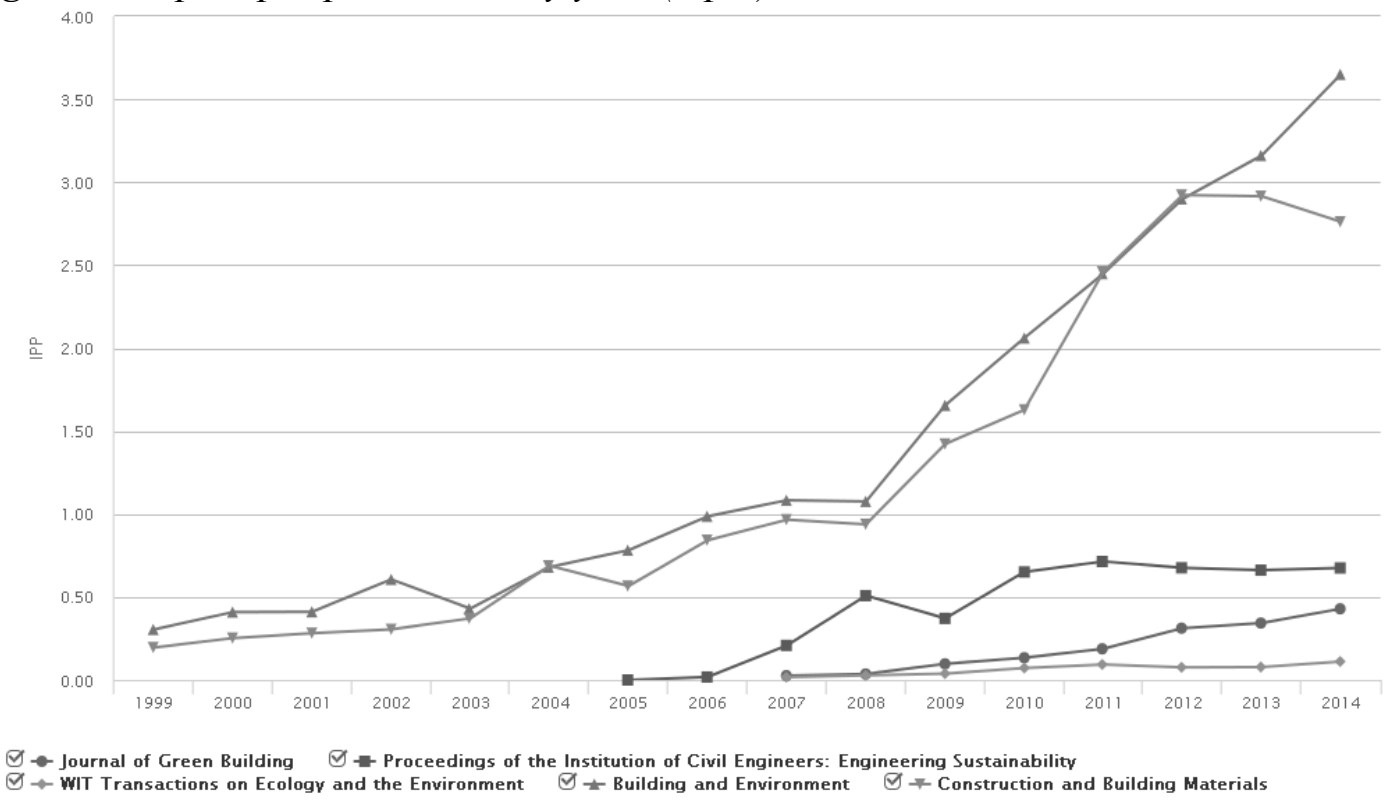

SNIP measures a source's contextual citation impact by weighting citations based on the total number of citations in a subject field. According to the figure 9, the SNIP value for Construction and Building Materials journal has increased until 2011. Also the same value for Building and Environment journal has increased until 2012. On the other hand, these two journals' quality is clearly ahead than other three journals.

Figure 9: Source normalized impact per paper by year (top 5)

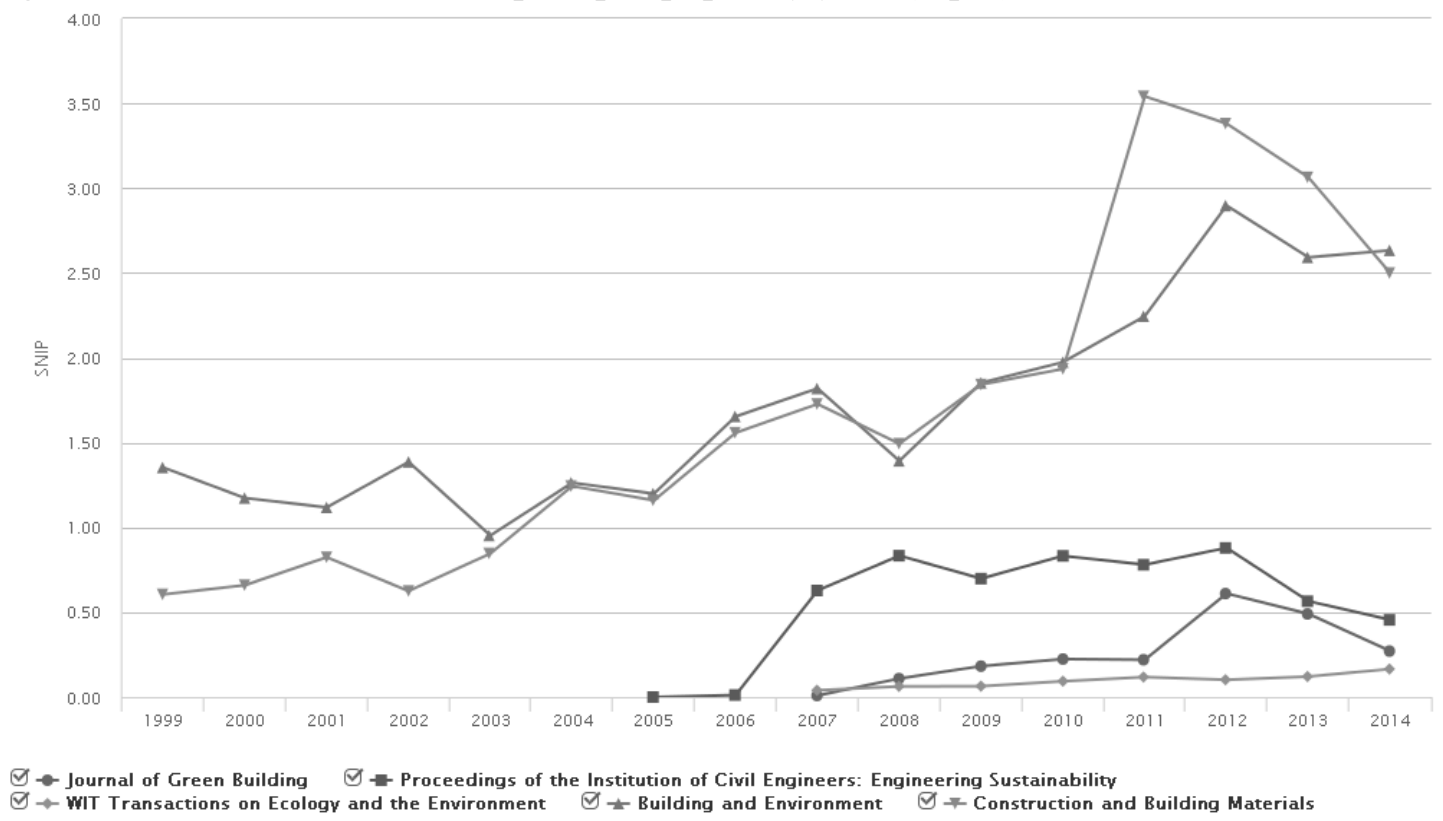


As is seen from figure 10, Construction and Building Materials and Building and Environment journals' articles have the higher number of citations that bring their sources reputation. That is why these two journal become more and more popular and respectful.

Figure 10: Source citations by year (top 5)

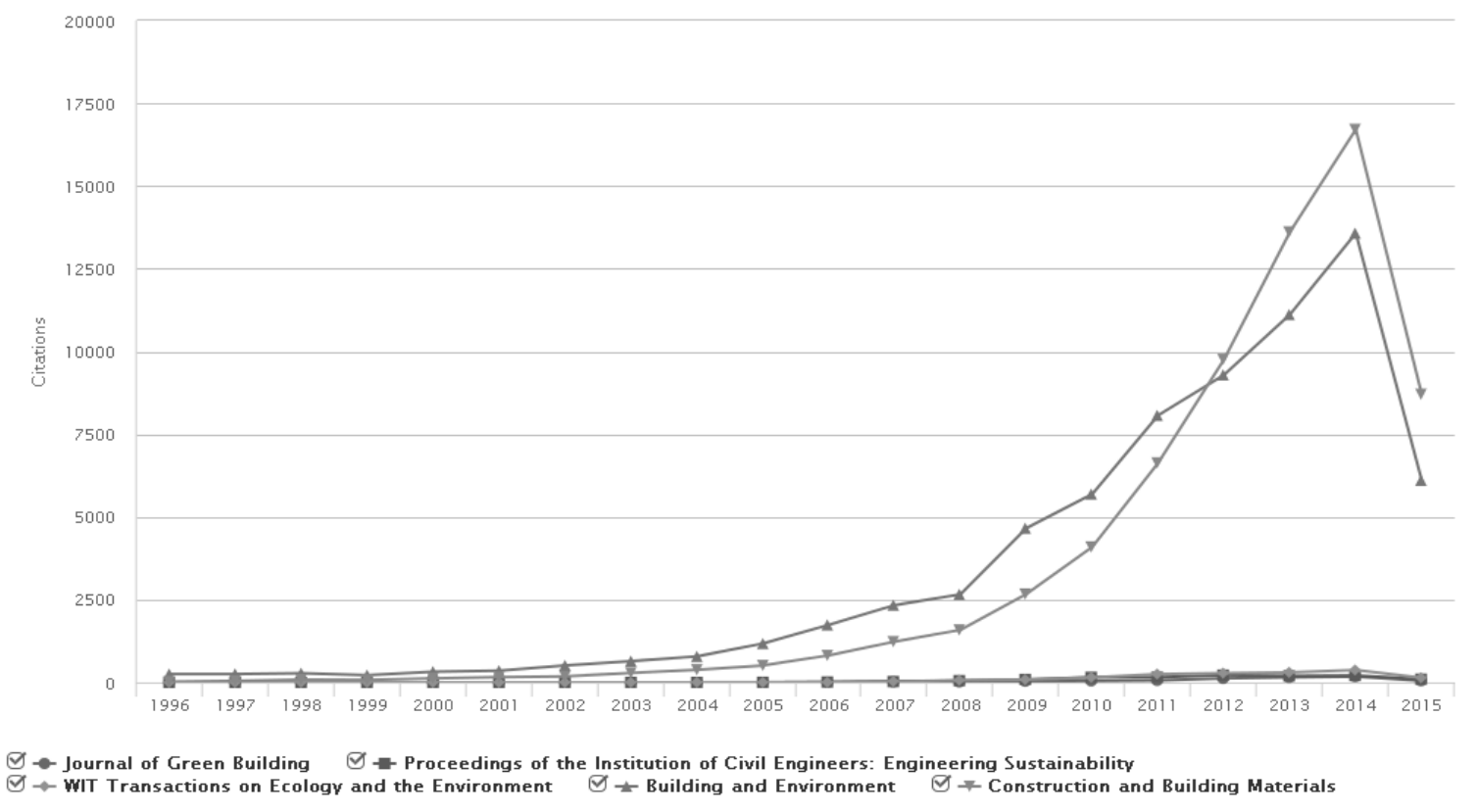

\section{CONCLUSIONS}

This study has uncovered the main research directions on sustainability in the field of construction, and has reflected what was published in the construction related literature across an eighteen year period. There is evidence that the trend in the literature for the theme of sustainability in construction has been linearly increasing from the beginning of 2005 through the end of 2013. It reaches a peak value in 2013 during the 18-year period and then stays the same. This increase may connote the popularity of constructionrelated sustainability.

The U.SA. researchers were found to be the originators of most sustainability papers, followed by the United Kingdom, China, Australia, Spain, Italy, Canada, Brazil, Germany, and Netherlands. In the academic community, Hong Kong Polytechnic University, Loughborough University in the U.K., Delft University of Technology, the University of Hong Kong, National University of Singapore, Chinese Academy of Sciences, Arizona State University, University of Florida, Eidgenossische Technische Hochschule Zurich and Universidad Politechnica de Madrid have been identified as active in pursuing sustainability research in the field of construction. 
Furthermore, the noteworthy aspect of trend analysis in this paper is that Building \& Environment, and Building \& Construction Materials can be considered as the flagship journals which publish high-quality papers.

From the percentages of subject area, it is clearly seen that, more researches have been made in environmental science (39\%), engineering(37\%), and social sciences $(27,5 \%)$. This might reflect increasing interest in these domains.However, that would also suggest that some domains overlap and some articles must be categorized as belonging to more than one domain.Further researches should take this determination into consideration while making a study on sustainability in construction.

In summary, the information provided here was written to provide information on current sustainability practices in the construction industry. Future research should further explore the explanations offered in this study.

\section{REFERENCES}

- $\quad$ CIB \& UNEP-IETC (2002). Agenda 21 for sustainable construction in developing countries: a discussion document, prepared by Du Plessis, C. (CSIR Boutek Report No Bou/E0204)

$\bullet$

- CLARK,W.C. \&DICKSON, N.M. (2003) Sustainability science: the emerging research program. Proc Natl Acad Sci USA 100(14):8059-8061

- CYWINSKI, Z. (2001). "Current philosophy of sustainability in civil engineering." Journal of Professional Issues Engineering Education and Practice, ASCE, 127:1(12), 12-16.

- GRIFFITS,A \& BHUTTO, K. (2008). "Improving environmental performance through integrated management systems (IMS) in the UK", Management of Environmental Quality: An International Journal, 19 (5), 565-578.

- KIBERT, C. J. (2008) Sustainable Construction: Green Building Design and Delivery, John Wiley \& Sons, second edition, New Jersey

- RAFINDADI,A.D., MIKIĆ,M., KOVAČIĆ,I. \& CEKIĆ, Z. (2014). "Global Perception of Sustainable Construction Project Risks", Procedia - Social and Behavioral Sciences, 119, 456465

- $\quad$ SILVIUS, A.J.G., \& THARP, J. [Eds.] (2013). Sustainability Integration for Effective Project Management. Hershey, PA: IGI Global Publishing

- XIA,B., ZUO,J.,WU,P. \& KE, Y. (2015). Sustainable Construction Trends in Journal Papers, Proceedings of the 19th International Symposium on Advancement of Construction Management and Real Estate, Springer Berlin Heidelberg

- YATES, J.K. (2014). "Design and Construction for Sustainable Industrial Construction", Journal of \& Construction Engineering Management, ASCE, 140 (4). 


\title{
CORPORATE FACTORS INFLUENCING SUSTAINABLE CONSTRUCTION ENTERPRISE
}

\author{
Alaka, H.A. ${ }^{1}$; Oyedele, L. O. ${ }^{2}$; Kadiri, K.O. ${ }^{3}$; \\ Owolabi, H.A. ; Ajayi, S.O. ${ }^{5}$; Akinade, O.O. ${ }^{6}$; Bilal, M. ${ }^{7}$
}

\begin{abstract}
:
While many studies are still focusing on sustainability in construction in terms of greening or resource consumption reduction, the construction industry (CI) has been struggling more with the sustainability of construction firms in terms of survival. For example, more than 1,500 construction firms went bust at the start of 2012 alone, with the industry leading the liquidated companies in England and Wales chart at the end of 2013. Despite many studies into the causes of failure of firms, the firms in the CI have continued to perform poorly. On the world scale, the CI has consistently been the second worst industry in terms of corporate failure. The objective of this study is hence to identify the key factors that determinelaffect the sustainability of a construction enterprise. The methodology used is mainly phenomenology. Phenomenology, otherwise known as interpretivism, is known for its suitability for discovering root causes of events comprehensively. Ten comprehensive unstructured interviews were carried out to identify the factors using convenience and snowballing sample methods. The target respondents were mainly managerial level employees, directors and owners of failed construction firms. Target construction firms were only small and medium enterprise (SMEs). The interviews were analysed qualitatively using Nvivo. The results showed that cash flow; investment in operation/assets; immigration; over reliance on certain source(s) for project; multiple responsibilities; lack of construction business knowledge; bid pricing; and firm's age are the most important factors affecting the sustainability of construction firms.
\end{abstract}

KEYWORDS: CONSTRUCTION FIRMS, CONSTRUCTION INDUSTRY, CORPORATE FAILURE, KEY FACTORS, SMES, SUSTAINABILITY

\section{INTRODUCTION}

While many studies are still focusing on sustainability in construction in terms of greening and/or resource consumption reduction, the construction industry (CI) has been struggling more with the sustainability of construction firms in terms of survival. For example, more than 1,500 construction firms went bust at the start of 2012 alone (Daily Mail Reporter, 2012), with the industry leading the liquidated companies in England and Wales chart at the end of 2013 (Figure 1). Despite many investigative studies into failure of firms, the firms in the CI have continued to perform poorly and the multiple failure problem has not dwindled.

\footnotetext{
1 University of the West of England, Bristol, United Kingdom Emails: Hafiz2.Alaka@live.uwe.ac.uk 2 University of the West of England, Bristol, United Kingdom Emails: L.Oyedele@uwe.ac.uk 3 Obafemi Awolowo University, Ile-Ife, Nigeria. Email: imamkadiri@yahoo.com 4 University of the West of England, Bristol, United Kingdom Emails: Hakeem2.Owolabi@live.uwe.ac.uk 5 University of the West of England, Bristol, United Kingdom Emails: Saheed2.Ajayi@live.uwe.ac.uk 6 University of the West of England, Bristol, United Kingdom Emails: Olugbenga2.Akinade@live.uwe.ac.uk

7 University of the West of England, Bristol, United Kingdom Emails: Muhammad2.Bilal@live.uwe.ac.uk
} 
Figure 1: Total Company Liquidations in England and Wales by Broad Industry Sector, year ending 2013 Q2 (The Insolvency service 2013)

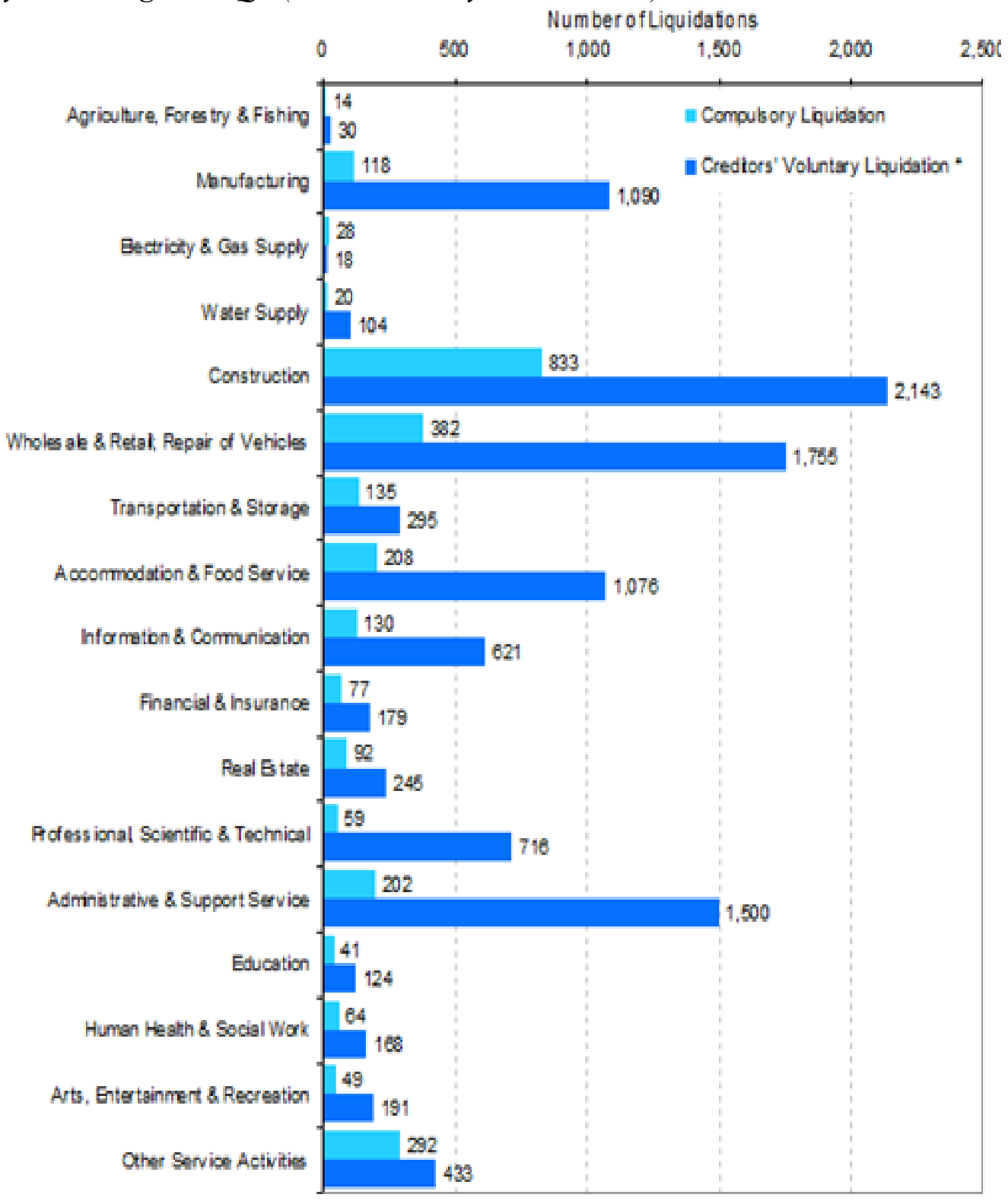

The CI continues to witness high number of firm failure partly because most studies have generally focused of failed big construction firms, when majority of construction firms that fail are small, reflecting not only the heavily skewed distribution of company size in the sector, but also the strong negative correlation of incidence of failure with size. The statistics are clear: at the start of 2014 there were 950,000 small and medium enterprise (SME) operating in the Construction sector; $18 \%$ of all SMEs in the UK private sector, making it the sector with the highest percentage of SME firms (Department for Business Innovation and Skills, 2014); 96\% of UK construction firms as at 2001 had below 10 employees (Jaunzens, 2001); more than $86 \%$ of the construction industry employees 
work in the SMEs and bring about over $75 \%$ of the turnover. It is thus impossible to find a real solution to the problem without properly involving SME construction firms.

Also, most studies tend to use only information from financial statements of firms when studying their failure and especially when developing a form of failure prediction model (Abidali and Harris, 1995; Chen, 2012; Bal et al., 2013; and more) which can be used as an early warning system to avoid failure. This act has a number of consequences. First, a lot of SMEs do not have a good accounting system and hence only produce/submit very incomplete and inadequate financial statements; this automatically nullifies the possibility of their involvement in financial statement based studies therefore causing underrepresentation of SMEs which are the majority. Another problem is that some SMEs do outsource their account management to independent accounting firms with the sole intention of ensuring annual production of their financial statement in order to satisfy legal/government requirements. This sometimes leads to misrepresented financial statements based solely on the amount of information provided to the accounting firm by the construction firm. Similarly firms generally, large and SMEs, tend to want to disguise their distress by 'window dressing' their financial statements to show good health. All these mean the sole use of financial statement in the study of failed firms can result in inaccurate results.

Still on the problem of the sole use of financial statements, it has been noted in various studies that, even if the financial statements were always true representation of the firms' financial situation, financial ratios cannot solely predict their failure. For example, knowing a construction firm has repeatedly recorded losses over a period of time does not particularly reveal why the firm is failing as different factors can be responsible for the losses. Likewise, heavy borrowing may be as a result of a desperate attempt to keep a failing firm afloat and does not actually reveal what led to the situation in the first place. As such assailants of the sole use of financial information have insisted that, and rightly so, financial distress only tends to be noticeable when the failure process is almost complete (Hall, 1994; Abidali, 1990; Abidali and Harris, 1995). As Argenti (1976, p.138) rightly said: "while these (financial) ratios may show that there is something wrong. I doubt whether one would dare to predict collapse or failure on the evidence of these ratios alone."

Accordingly, the aim of this study is to uncover the main factors that affect/lead to failure of SME construction firms across UK. The objectives are:

- To identify factors that led to the failure of a number SME construction firms across the UK

- To group all the factors into representative categories

- To analyse the factors to find out the most important ones

This study will contribute to knowledge by exposing the key factors that affect/lead to failure of SME construction firms across UK. The scope of this work is limited to factors affecting SME construction firms only; large firms will not be considered. The next 
section describes the methodology used for this study. This is followed the results and, finally, the conclusion of the study

\section{METHODOLOGY}

The owners/managers of failed SME construction firms are usually involved in the firm operation from inception until its failure hence understand a lot about what happened (not necessarily what went wrong) during the failure process and hence can provide 'rich insights into this complex' failure process; the situation of talking to social actors that can provide rich insights falls under the interpretivism/phenomenology paradigm (Saunders et al., 2009). The target respondents in this study are thus owners/managers of failed SME construction firms. One of the issues identified with finding out insolvency factors that lead to failure of firms is that researchers tend to concentrate on asking respondents to identify the actual factors that led to the failure of their firms. Normally, the respondent has more tendency to associate the main influence to personal leadership traits. This study hopes to get a better understanding of the complex failure process of SME construction firms by asking the respondents to relay the story of their firms from before distress periods to the final closure day, or throughout the life time of the firm where the lifespan of the firm was very short. By using the story telling method, which in itself is an open-ended form of interview, the author of this study has shunned any form of priori guesses about what factors really lead to the failure of SME construction businesses.

A popular challenge for researchers looking into failed firms is how to identify and get access to owners/employees of failed firms as they are very hard, if not impossible, to trace (Everett and Watson 1998; Stokes and Blackburn 2002; Harada 2007). The use of interview in this study thus offers an exclusive resource. Due to the challenge, sampling was based on the easiest subjects to find. This conforms to convenient sampling ideology since it is known to be used when target respondents are hard to find for surveying questioning (interview) purposes (Latham, 2007). Babbie (1990) also described convenient sampling as a method that depends on availability of subjects. Since the author hails from the construction background, friends and colleagues were asked to help with contacts of known owners/managers of failed construction firms. The convenience sampling method was supported with the snowball sampling method by asking successfully gotten respondents for contacts of similar respondents. A total of ten respondents were gotten for the study.

As initially noted, the interviews were open-ended to avoid any predetermined responses. The storytelling method in qualitative research is getting progressively popular in the social sciences (e.g. Steyaert and Bouwen 1997; Rae 2000) and it has been said that studies that do not employ the narrative method in understanding the performance of firms can only provide partial or false account of the firms (Denning, 2005).

The storytelling method, when used properly, is believed to be especially fitting for research on sensitive topic areas like insolvency of firms since it might be perceived by 
some respondents to be a touching/embarrassing aspects of their business life (Johansson, 2004). As such, in the interviews in this study, only non-judgemental questions that stimulated plenty of narrations were asked. An example question is 'Can you explain the series of event that took place in your firm before you decided to stop operations?'

The whole methodology is seen as a success as respondents responded well and some even expressed happiness at having the chance to share their experience. No wonder Saunders et al. (2009) noted that this area of research, i.e. understanding the complex process of construction firms' failure, can be best studied using the interpretivism paradigm. The interviews were fully transcribed and analysed qualitatively using the Nvivo software. A word frequency analysis of all transcribed interviews was carried out with Nvivo. All words that related to a potential factor in the word frequency query search were noted and coded. Each factor was categorised according to literature. Five major categories were identified and coded namely: internal strategic factor, management/owner characteristic, budgetary, firm characteristics, and government policy. Sub-coding was used for the factors to be identified (see Table 1 in result section). The analysis was able to show the frequency at which each factor was mentioned and the context in which it was mentioned

\section{RESULTS}

The findings of the interviews are presented in this section. One disadvantage of the storytelling method is that it comes with a sizeable amount of unrelated/irrelevant stories. However, a careful analysis was used to decipher the key factors. A number of factors were identified in the analysis with some receiving more emphasis than the other. The number of respondents that spoke about each factor are indicated in Table 1.The importance attached to each factor by the respondents are also presented in Table 1 . The importance is judged by how much the respondent links the factor to the insolvency of his/her firm despite not being specifically asked to do so.

Table 1: The results of the interviews

\begin{tabular}{|c|c|c|c|}
\hline Factor Identified & Category & $\begin{array}{l}\text { Number of } \\
\text { respondent }\end{array}$ & $\begin{array}{l}\text { Importance } \\
\text { attached by } \\
\text { respondent }\end{array}$ \\
\hline Cash flow & Budgetary & 10 & Very high \\
\hline $\begin{array}{l}\text { Over reliance on certain source(s) for } \\
\text { project }\end{array}$ & Internal strategic factor & 8 & High \\
\hline $\begin{array}{l}\text { Multiple responsibilities e.g. accounting, } \\
\text { bid pricing, etc. }\end{array}$ & $\begin{array}{l}\text { Management/owner } \\
\text { characteristic }\end{array}$ & 8 & Very high \\
\hline Bid pricing & Internal strategic factor & 7 & Very high \\
\hline Investment in operation/assets & Budgetary & 7 & Very high \\
\hline Firm's age & Firm characteristics & 7 & \\
\hline Lack of construction business knowledge & Internal administrative & 6 & High \\
\hline Immigration & Government policy & 5 & High \\
\hline
\end{tabular}




\section{Cash-Flow}

'Studies of patterns of business failure in the UK, US, Canada and Australia found that companies with ineffective control procedures and poor cash flow planning are more vulnerable to financial distress' (Charitou et al., 2001). For a construction firm to be more sustainable financially, a reasonable size of the firm's cash flow should be employed in operations with a reduced cash flow in investment (Arditi et al., 2000).A key problem construction firms face with cash flow is that

- Client only pays for completed work that has been financed by the firm, usually on a periodic basis

- A fraction (usually 10\%) of payment is withheld by client for possible omissions and/or defects

This arrangement normally makes it nigh on impossible for construction firms to fully recover expenses talk less of make profit hence making them less sustainable financially. This is always harsh on especially small firms that do not always have large capital available for operations. It even gets worse when a small construction firm is involved in two projects and is being owed for completed works on both thereby making them less sustaianble. Interest on loans keep growing during this period, and payment to staff/subcontractors become difficult:

'They want all the good features in their converted loft when it is done.... but they struggle to pay for completed works all the time. So much stories are told that I now hate stories' (respondent nine)

'You are happy to get multiple projects and think you are borrowing to make your company bigger..... these people simply kill others dream by not paying on time.... You fear the court will take forever, plus the legal fees. Its al really upsetting' (respondent six)

The whole scenario makes construction firms prefer to delay payments to suppliers, subcontractors, etc. in order to have more cash for project execution. Although this sounds reasonable, research has shown that such arrangement is detrimental to the survival of small firms as it deteriorates relationships with suppliers, subcontractors, etc. (Hall and Fulshaw, 1993). In fact, 'early payment of bills was found to be strongly and positively associated with high levels of performance' (Hall, 1994, p.750)

\section{Over reliance on certain source(s) for project}

There were respondents whose stories showed that their firms were built to respond to only certain sources for projects. In fact, the firm was started simply because of their accessibility to such sources for projects.

'I was always sure of getting projects from ......... I hardly got projects from other sources and I was not too bothered' (respondent four)

'Unfortunately, I never thought _ _ could close down. That affected us massively as we got $90 \%$ of our projects from them. They actually encouraged me to start this construction business of a thing' (respondent 10) 
A few other respondents also made statements that showed their over reliance on certain sources for projects. This type of set up is a very unsustainable one as the death of the source will easily mean the death of the construction firm. Accounting experts have clearly expressed that though there could be a main source, there should always be other multiple sources from which projects are gotten (Klein and Kumar, 2015). The thought of the author here, based on multiple readings, is that any firm with more than $40 \%$ of its projects coming from a single source is at a high risk and is therefore not sustainable. The more the sources, the more sustainable it becomes.

\section{Multiple responsibilities and Bid pricing:}

All the firms sampled had owners that performed multiple functions. Performing multiple function in itself is not the main problem but the type of function being performed. It was found that a number of owners did bid pricing and prepared accounts, despite not being a professional nor having vast experience in the areas. This in itself will normally mean less effectiveness as time is created for all these things. Most respondent firms practised lowest price bidding and did some radical cutting. For example, respondents moaned some spoke in a resigned tone:

'I always make extra effort to cut our bid price to a minimum yet we barely win' (respondent eight)

'I wonder if these bid prices are really looked at....... We once even cut our bid to an unrealistically low price but did not win' (respondent seven)

Although low prices are key to staying competitive, bidding with overly low prices generally results in losses that can be unsustainable. As desperation to win bids set in, bids prices get lower and this is responsible for the insolvency of many small construction firms in (Arditi et al., 2000) as they will not come to profiting if they ever win. They might also end up doing some shoddy works to try to make profit; such jobs either result in expensive legal conflicts and/or make them lose that customer and potential referred customers. Professional and experienced quantity surveyors would have known better and avoid such desperations in pricing bids.

\section{Investment in operation/assets}

This factor is quite related to the cash flow factor as the main issue here is that of tying down cash in investments in properties. Although respondent five in particular alluded that investment in properties was a good idea, others disagreed and respondent seven even indicated that investment in properties actually led to firm failure

'I always buy properties because I am sure they will appreciate.... I am always relaxed I am in some form of business even when contracts are not coming in' (respondent five)

'The pieces of land I bought from the firm's proceeds suddenly devalued and I could not sell them for the price at which I bought them. My bank went after me as I was worth below my loan.... I was forced to sell the lands at a loss when money was needed for projects.... as I ended up with losses that eventually made us (i.e. the firm) close down' (respondent seven) 
Two other respondents also explained how money tied up in property investment caused serious operational problems and led to more unavoidable loans and interest. This property investment problem was identified in Arditi et al's., (2000) study which declared that if a construction firm is to have a more sustainable cash, a reasonable size of the firm's cash flow should be employed in operations with a reduced cash flow in investment

\section{Firm's Age}

Eight of the ten respondents spoken to represented construction firms that closed down in less than six years of operation while none operated successfully for ten years; a pattern which correlates newness positively with failure of construction firms. This corroborates Kale and Arditi's (1999) study which found that the possibility of insolvency of construction firms initially increases with age, reaches a peak at some point in time, and then decreases. According to them (i.e. Kale and Arditi 1999), newness of construction firms is solely responsible for this pattern due to their lack of organizational learning. Newness caused different types of problems for different respondents.

'We just bought materials from where it was cheapest......, this hunted us during periods of scarcity as we were not the favourites of any supplier' (respondent one)

This clearly shows lack of organizational learning as the firm simply went for cost advantage all over the place without thinking of other factors. A better strategy to make the firm more sustainable would have been to have a few particular suppliers that they dealt with, and to have communicated any cheaper prices to them first to see if they can match the price before opting for an unusual supplier.

'The supplier always preferred to supply the old and trusted customers before us...... And we barely ever got the a bargain as compared to other customers' (respondent two)

Because it takes time to build trust, new construction firms are usually relegated when there is time competition on who to supply first. Also, bargain is mostly given to old customers as repeat business is almost certain and suppliers want to display loyalty.

\section{Lack of construction business knowledge}

Respondents spoke about their desire to have a construction firm despite not having much knowledge about the industry. The motivation behind starting the firm ranged mainly from making profit to knowing a particular source for projects. The poor knowledge of the industry however affected them.

'I never knew there were so many firms involved in loft conversion in the area... it was like magic the number of people after each job that came up' (respondent three)

'You sometimes begin to wonder why there is no supplier of such materials in the whole city... you even wonder if that was not a better business opportunity than this one' (respondent three).

'These suppliers need to be regulated to stop them from stupidly increasing prices' (respondent five). 
Clearly these respondents did not understand how construction industry operated and this, as expected, caused them more harm than good. This is partly a problem of newness as the firm has not gone through a good period of organizational learning (Arditi et al., 2000), causing them to struggle with the norms of the industry. It is generally thought that the longer a firm exists the more sustainable it becomes

\section{Immigration}

About five respondents highlighted immigration as an issue in that a lot of immigrants that came into the country had the skills to carry out some of the repair works the frim normally engaged in and they did so at a much cheaper price. Respondent two moaned

'The works dried out because people now prefer to give the jobs to some European immigrants that will do a shoddy job for a token' (respondent two)

The problem is mainly that of the very low, or lack of, barrier to entry into the construction industry as in Porter's theory of five competitive forces. This problem, though there are many studies on the need for a barrier to entry (e.g. De Valence, 2012), has continued to cause problems for the construction industry, and highlights the fierce competition that exist for small construction firms. This reduces the corporate sustainability of many of the small firms in the construction firms.

\section{CONCLUSIONS}

While many studies are still focusing on sustainability in construction in terms of greening or resource consumption reduction, the construction industry (CI) has been struggling more with the sustainability of construction firms in terms of survival. Though $96 \%$ of the UK construction firms have below 10 employees, and more than $86 \%$ of the construction industry employees work in the SMEs and bring about over $75 \%$ of the turnover, majority of construction firm insolvency studies have focused on large construction firms and have thus not made huge impact. This study therefore focuses on identifying factors associated with the insolvency of SME construction firms.

Knowing that many small construction firms do not produce up to date financial reports, and that financial statements can be deliberately tinkered with, the interpretivism approach was adopted for this study, especially as it excels in providing 'rich insights into complex (failure) processes. Open ended interview was thus carried out with ten owner/managers of failed small construction firms. A qualitative analysis revealed cash flow; investment in operation/assets; immigration; over reliance on certain source(s) for project; multiple responsibilities; lack of construction business knowledge; bid pricing; and firm's age as the eight main factors that influence the failure/survival of small construction firms.

The results show that some factors (e.g. immigration; like lack of construction business knowledge; bid pricing) which are not known to affect big construction firms do affect small construction firms. The implication of this study on practice is that it allows prospective small construction firms owners to have a chance of looking into the right 
factors properly before venturing into the business. It also contributes to knowledge by giving potential qualitative variables for insolvency prediction of small construction firms. Future works should endeavour to conduct a higher number of interviews with a view to identifying more factors and increasing reliability of study. Also there is need to look into which survival/failure influencing factors that are very common to both big and small construction firms

\section{REFERENCES}

- ABIDALI, A. F., and HARRIS, F. (1995). A methodology for predicting failure in the construction industry. Construction Management and Economics, 13 (3), pp. 189-196.

- ARDITI, D., KOKSAL, A. and KALE, S. (2000). Business failures in the construction industry. Engineering, Construction and Architectural Management, 7 (2), pp. 120-132

- $\quad$ ARGENTI, J. (1976). Corporate collapses: The causes and symptoms. London: McGraw Hill.

- BABBIE, E. (1990). Survey Research Methods. 2nd ed. Belmont, California: Wadsworth Publishing Company.

- BAL, J., CHEUNG, Y. and WU, H. (2013). Entropy for business failure prediction: an improved prediction model for the construction industry, Advances in Decision Sciences, 2013, pp. 1-14

- Charitou, A., NeOphytou, E. and CHARAlAmBOUS, C. (2004). Predicting corporate failure: empirical evidence for the UK. European Accounting Review, 13 (3), pp. 465-497.

- CHEN, J. H. (2012). Developing SFNN models to predict financial distress of construction companies. Expert Systems with Applications, 39 (2012), pp. 823-827

- DAILY MAIL REPORTER (2012). Building gloom hits economy as more than 1,500 construction firms close this year. Daily Mail This is Money, 30 July 2012.

- DENNING, S. (2005). The role of narrative in organizations. In J.S. Brown, S. Denning, K. Groh and L. Prusack (Eds.), Storytelling in organizations: why storytelling is transforming 21 st century organizations and management (pp. 165-182). Oxford: Elsevier ButterworthHeinemann.

- DEPARTMENT FOR BUSINESS INNOVATION and SKILLS (2014). Statistical release, business population estimates for the UK and regions 2014. National Statistics, URN 14/92

- DE VALENCE, G. (2012). The Significance of Barriers to Entry in the Construction Industry. Construction Economics and Building, 7 (1), pp.29-36.

- EVERETT, J. and WATSON, J. (1998). Small business failure and external risk factors. Small Business Economics, 11(4), pp. 371-390.

- HALL, G. (1994). Factors distinguishing survivors from failures amongst small firms in the UK construction sector. Journal of Management Studies, 31 (5), pp. 737-760.

- HALL, G. and FULSHAW, S. (1993). 'Success in the instrumentation sector'. In Landt, A. (Ed.), Entrepreneurship and Business Development. Aveb

- HARADA, N. (2007). Which firms exit and why? An analysis of small firm exits in Japan. Small Business Economics, 29 (4), pp. 401-414.

- JAUNZENS, D. (2001). Influencing small businesses in the construction sector through research. BRE Informing and Influencing Small to Medium Enterprises.

- JOHANSSON, A.W. (2004). Narrating the entrepreneur. International Small Business Journal, 22 (3), pp. 273-293.

- $\quad$ KALE, S., and ARDITI, D. (1999). Age-dependent business failures in the US construction industry. Construction Management and Economics, 17 (4), pp. 493-503.

- KLEIN, G. and KUMAR, N. (2015). Ethics in Accounting: A Decision-Making Approach. New Jersey: Wiley 
- LAThaM, B. (2007). Sampling: What is it? Quantitative Research Methods [online]. Available

from:http://webpages.acs.ttu.edu/rlatham/Coursework/5377(Quant))/Sampling_Methodology_ Paper.pdf [Accessed 27 April 2015]

- RAE, D. (2000). Understanding entrepreneurial learning: a question of how? International Journal of Entrepreneurial Behaviour and Research, 6 (3), pp. 145-159.

- SAUNDERS, M., LEWIS P. and THORNHILL, A. (2009). Research Methods for Business Students, 5th ed. Essex: Pearson Education Limited.

- STEYAERT, C. and BOUWEN, R. (1997). Telling stories of entrepreneurship - towards a narrative contextual epistemology for entrepreneurial studies. In R. Donckels and A. Mietten (Eds.), Entrepreneurship and SME research (pp. 47-62). Aldershot, UK: Ashgate.

- STOKES, D. and BLACKBURN, R. (2002). Learning the hard way: the lessons of ownermanagers who have closed their businesses. Journal of Small Business and Enterprise Development, 9 (1), pp. 17-27

- THE INSOLVENCY SERVICE (2013). Statistics Release: Insolvencies in the Third Quarter 2013. London: 2013 


\title{
A FRAMEWORK FOR GROWTH OF SMALL AND MEDIUM-SIZE CONSTRUCTION FIRMS: A LITERATURE REVIEW
}

\author{
Arthur-Aidoo B. M. ${ }^{1}$, Aigbavboa C. O. ${ }^{2}$ and Thwala W. D. ${ }^{3}$
}

\begin{abstract}
:
Small and medium-sized firms (SMEs) are considered as the engine of growth in most economies due to their significant contribution in terms of employment and natural development. SMEs growth within an economy is, therefore, paramount. Growth of SMEs firms has been deliberated in literature as an expansion. This development is classified as either organic (internal expansion) or inorganic (expansion by integration). Literature has also stressed on the eased at which these construction SMEs enter the market environment and quickly exit due to peculiar challenges including growth. Therefore, this study seeks to establish a framework for SMEs in the construction industry in order to foster their growth. The study adopted the use of extensive use of literature. This was supported by informal semi-structured interviews which involved construction industry professionals as the population. The research focused on the determinants of growth and how these factors will be established The study concludes that for growth to be ascertained in a firm, there must be an integration of both the internal and external variables to influence growth.
\end{abstract}

KEYWORDS: CONSTRUCTION FIRM, FRAMEWORK, GROWTH, SUSTAINABLE, SMALL AND MEDIUM-SIZE,

\section{INTRODUCTION}

The significant contribution of small and medium size firms in terms of employment and development in most economize have characterized them as an engine of growth. Most literature on the growth of firm have not paid much attention to small and medium-size firms within the construction sector. Nevertheless, the construction industry in most countries facilitates infrastructure development such nations. As a result, when there is sustainable growth among the firms particularly the SMEs that operate within the construction sector them there be a tremendous increment in the infrastructure development of the nation. However, lack of such growth among SMEs will impact the entire economy of a country. Undoubtedly, the SMEs that operate within the construction sector easily sprang up as a result of the tender request of a client. These SME firms that usually expressed interest in the bid package normally concentrate so much on the profits to be attained after executing the project. This obviously affects their growth and

\footnotetext{
${ }^{1}$ Department of Construction Management and Quantity Surveying, Faculty of Engineering and Built Environment, University, of Johannesburg, South Africa, Email: bernardmartins@hotmail.com.

2 Department of Construction Management and Quantity Surveying, Faculty of Engineering and Built Environment, University, of Johannesburg, South Africa, Email: calgbavboa@uj.ac.za

3 Department of Construction Management and Quantity Surveying, Faculty of Engineering and Built Environment, University, of Johannesburg, South Africa, Email: didibhukut@uj.ac.za.
} 
therefore, they exit the market after some time in operation. In addition, these construction SME firms are mostly family owned business with self-styled managerial structures which targets profits predominantly without any mechanism to ensure their growth. This may be due to unfamiliarity or lack of an established framework available to be considered as a benchmark by these SMEs firms in order to facilitate their growth. Therefore, this study seeks to establish a sustainable growth framework for small and medium-sized construction firms in the built environment.

\section{Definition of Small and Medium-Size firms}

The subject of what constitutes a small and medium enterprise is a primary concern in the literature. Attempt have been made by some to define SME's using their capital assets while others use the skill of labor and turnover level. Similarly, others define SMEs in terms of their legal status and method of production. Definition of small and mediumsized firms varies from the industrial sector and the country as such there is no accepted standard definition (Ward 2005). The literature on small and medium construction firms SME's have defined it in line with their function. Further definition of these SME's could be categorized in two ways: based on the number of employees in an enterprise and or the enterprise's fixed assets. According to Boon (1989), the size of the enterprises employment is the most important criterion used in Ghana. But one must be cautious when defining SMEs based on fixed assets because of the continuous depreciation in the exchange rates, which often makes such definition out-dated. UNIDO defines SMEs in developing countries based on the number of employees in an enterprise. A small company has between 5 and 19 workers and takes the example of the ubiquitous small shops in the cities. A medium enterprise has 20 to 99 workers, and these include manufacturing firm and exporting companies. As early as 1971, The Bolton Committee first formulated an "economic" and "statistical" definition of a small firm. Under the economic definition, a firm is regarded as small if it meets the following three criteria: (i) it has a relatively small share of their marketplace; (ii) it is managed by owners, or part owners, in a personalized way and not through the medium of a formalized management structure; and (iii) it is independent in that it is not part of a larger enterprise. Similarly under the "statistical" definition on the other hand, the committee proposed these in three main areas: (i) quantifying the size of the small firm sector and its contribution to GDP, employment and exports; (ii) comparing the extent to which the small firm sector's economic contribution has changed over time; and (iii) in a cross-country comparison of the small firms' economic contribution. The Bolton Committee applied different definitions of the small firm to various sectors. Whereas firms in manufacturing, construction and mining were defined in terms of number of employees (in which case, 200 or less qualified the firm to be a small firm), those in the retail, services, wholesale, etc. were defined in terms of monetary turnover (in which case the range is 50,000200,000 British Pounds to be classified as small firm). Firms in the road transport industry are categorized as small if they have 5 or fewer vehicles. The European Commission (EC) however defined SMEs largely in terms of the number of employees as 
follows: firms with 0 to 9 employees - microenterprises; (i) 10 to 99 employees - small enterprises; (ii) 100 to 499 employees - medium enterprises.

\section{Definition of growth}

The term 'growth' is used in discourse with two different connotations. It sometimes denotes merely increase in an amount such as sales, outputs, etc. At other times, however, it is used in its primary meaning implying an increase in size or an improvement in quality as a result of a process development, biological processes (Penrose, 1980). According to Kirkwood (2009), firm's growth has long been a focus attention among researchers in entrepreneurship. This is because growth is seen as synonymous with entrepreneurship Sexton (1989) cited in (Kirkwood, 2009). Growth in the firm has however been recognized as a complex process through studies (Baum et al., 2001). Massey et al. (2006) supported that firm's growth is not homogenous amongst SME's. As a result, the growth trend can change over time. s. It can also be measured in the form of qualitative features like market position, quality of the product and goodwill of the customers. In addition, Moreno and Casillas (2007) postulated that the growth of firms vary and may be measured by various levels of sales and employees growth over a particular period. Sales volumes of firms that are considered as the standard feature of growth measure also depend on some external factors such as inflation and exchange rates. Growth has been used as a modest measure of success and performance in business and as Delmar et al. (2003) points out that it is the appropriate indicator for surviving small and medium businesses. Firms grow in two ways; by internal expansion (organically) and through integration (inorganic) (Miriam 2006). Organic growth is the rate of an enterprise expansion through a company's business activity while inorganic growth means that the company has grown by merger, acquisitions or takeovers. Growth and performance of small and medium-sized construction firms have been found to be hampered by several impediments. When a company with the aid of its efficient management enhances its growth rate it is referred to as organic growth which is also known as Internal growth whereas inorganic growth is attained when a company acquires a technology developing company in order to enhance its competitive advantage and growth rate and is also known as external growth. Most business enterprises are always faced with the challenge of prospering and growing their business. Growth is measured in terms of increased revenue, profits or assets. Companies can choose to build their inhouse competencies, invest to create competitive advantages, differentiate and innovate in the product or service line (Organic Growth) or leverage upon the market, products and revenues of other companies (Inorganic Growth). Simply put, business expansion with the help of the businesses' core competencies and sales refers to organic growth and is in contrast with Inorganic growth approach where expansion objectives are met through Mergers and Acquisition (M \&A). There is an increasingly growing recognition of the important role Small and Medium Enterprise (SME's) play in economic development.

The needs of SMEs in the construction industry are similar to those of their counterparts (SMEs) in all sectors of the economy, and include: access to market information; work 
opportunities; access to finance and other resources; opportunities to develop technical and managerial capabilities; and opportunities to form mutually beneficial networks with potential business partners within the industry and in related sectors such as supply and manufacturing. In addition, construction SMEs have to contend with the peculiar features of their industry and their products. In the developing economies, the small and mediumsized construction firms (SME) sector is seen as the source of indigenous economic development to match the growth achieved inward investment activity.

\section{Significance of growth in firms}

Growth within firms ensues in order for firms to achieve their objectives including increasing sales, maximizing profits or increasing market share. Barringer et al. (2005) remarked that regardless of the exact definition of what firms entails, it is often realized that very few firms accomplished it. Barringer et al, (2005) further stressed that firm's growth is not an automatic event to happen and as such managers and owners must endeavour to institute schemes and measures that will bring in growth within firms.

\section{Determinants of Growth in firms}

According to Coad (2009) cited in Gopinath (2012), firm's growth depends on the prevailing macroeconomic conditions affecting the firm and the macroeconomic issues such as its organizational outcome resulting from the combinations of firm-specific resources and capabilities. Similarly, Zhou and Wit (2009) postulates that determinants of firm's growth are classified into three integrated themes namely: organizational, environmental and individual determinants. Beck et al. (2006): Triki et al. (2011) suggests that one of the key drivers of sustainable growth in developing countries is firm growth and productivity. As a result, comprehending firm's growth has now become a great concern for researchers and policy makers. Therefore identifying the channel that promotes small and medium-sized firm's growth in will provide the basis to influence policy direction to create the environment and required initiatives to help other informal sectors. Further, this will contribute to building the right platform for SME's firms to grow. Hashi and Kransnigi (2011), on the other established that the determinants of SME's growth are grouped into four categories including those related to the entrepreneurial features of that firm, secondly, those linked to other characteristics of the firm and thirdly, those related to the business environment that the firm operates, Lastly stakeholder's involvement.

\section{Entrepreneurial features}

According to Kritikos (2014), Entrepreneurial features do not only impact on the internal growth of a business but the economic growth of a nation. This is because entrepreneurs often create new technologies, develop new products or process innovation, and open new markets that drive growth in their firms and the entire economy. Growth and development of SME's depend entirely on the motivation and ambition of the owner of the firm personality behavior. The personality trait of entrepreneurs is a key factor that affects motivation (Delmar, 1996). Zhou and Wit (2009) supported that willingness and 
ability of owner with the addition of growth motivation play a significant role in entrepreneurial ventures. Approaches to growth depend on the expected consequences of growth (Wiklund et al., 2003) and what the entrepreneur is comfortable managing (Cliff, 1998). Financial gain has not been found to be a large determinant of attitudes toward growth but other important non-economic outcomes exist, such as those around keeping control and independence, and the effect on employee well-being (Cassar, 2007; Wiklund et al., 2003). The presence of an entrepreneurial team has also been shown to influence positively firm growth (Ensley et al., 2002; Ruef et al., 2003). An important function of SME's entrepreneurial is their ability to innovate and challenge incumbents firms with their creative products service offerings (Shane, 2003). Goedhuys and Veugelers (2012) stress that combining product and process innovation is vital for significantly improving the success and growth of SMEs. Empirical evidence suggests that a firm belonging to an entrepreneurial family augments the probability of survival (Cooper et al., 1994, Papadaki et al., 2000). However, firm's performance is found to be positively affected by the prior entrepreneurial experience.

\section{Firm's characteristics}

According to Kolveried and Davidsson (1989) cited in Kirkwood (2009), owners and entrepreneurs of SME's desire growth within their firms, however, needed skills are required to accomplish it. Firm's characteristics can include the growth strategies the growth strategies for management personnel and the entire firm Hutchinson et al. (2006). Firm's characteristics determinants are found to have the greatest influence on firm growth. These strategies regarding the features of the firm such as size, age, human capital and ownership amongst may also affect the growth pattern of the firm. The correlation of age, size and growth is major recognized issues in literature under the Law of proportionate effect also known as the Gibrat's Law, which was formulated by Robert Gibrat in as early as 1931(Kirkwood, 2009). Gibrat's Law affirmed that firm's growth is independent of the size of the (Sutton 1997). The Law further stressed that all firms, whatever their size, are likely to reach a certain growth rate. Some firms grow and survive while others do not grow and end up leaving the market. Dobbs and Hamilton (2006) established that growth on SME's could be better understood using stochastic models that emanate from the law of proportionate effect. Gibrat's Law affirmed that there was no relationship between the size of a firm and its growth. Further firm's growth is the result of a multiplication process that affects the initial size. Ownership influence, SME's that are partly owned by or wholly belonging to foreigners are likely to be engaged likely to be engaged in activity on the international market with the possibility of experiencing a higher growth rate in the market. Kirkwood (2009) supported that SME's with the knowledge of the foreign market will enable the firm to learn from competitors regarding technology and quality. 


\section{Business environment of firm}

Gopinath (2012) affirmed that the environmental determinants of dynamism, hostility and heterogeneity determine the growth potential of SME's firms. To some extent, growth is externally determined by the environment in which the firm operates. The external environment where firms play is considered as a crucial issue in their growth (Hashi and Kransniqi, 2010). This is because the business climate is, of course, a multi-dimensional environment with prevailing institutional and regulatory framework. According to Stiglitz and Weiss (1981) cited in Serrasqueiro (2010) pointed that if capital markets are perfect, then all firms would have access to alternative sources of finance (internal and external would be considered excellent substitute. As a consequence, firms finance decision would be significant for carrying out their strategies of investment and growth of the entire firm. Market orientation of the SME's firms is also a determinant of its growth. According to Gudlaugsson and Schalk (2009) market orientation is defined as a form of organizational culture where employees in an organization are committed and dedicated to continuously creating superior customer value, through a sequence of marketing activities that can enhance the performance of a business. Reijonen, et al. (2012) supported that market orientation gives small businesses a potential competitive advantage over their counterparts operating on a large scale. That is because the proximity of SME firms and their customers is usually closer, and this facilitates able quickly and flexibly respond to their needs, experience less organizational bureaucracy and thus can distribute customer information and implement marketing plans quickly. Studies by (Gronroos, 2006; Gudlaugsson and Schalk, 2009) have affirmed that marketoriented firms turn to perform better than firms that are less market-oriented as they focus on adapting their products and services based on the needs and expectations of their customers. Market orientation has been identified as the key to successful business performance and growth (Dauda and Akingbade, 2010; Grönroos, 2006). Similarly, other studies by Pulendran et al., (2003); Matsuno et al., (2002) established that market orientation enhances the market share, profitability, return on investment.

\section{METHODOLOGY}

In order to achieve the purpose of this study a rigors literature review was embarked on using existing literature. This research focused primarily on literature on the growth of small and medium-size firms including their growth determinants. Semi-structured interviews were also adopted as a supplement to the review of the literature. The targeted interviewees were professionals from the construction industry namely Architects, Project Managers, Quantity Surveyors, Planners, and Construction managers as the study population who were engaged with small and medium sized firms working around the Gauteng Province in Johannesburg in South Africa. The study area was selected because the majority of the small and medium-size constructions firms are based within that environ. All the interviewees had equal time to respond to the questions which was guided by an interview schedule and was transcribed. The interviewees allotted time to respond to the semi-structure interviews due to the prior arranged site and office visits for 
the interviews by the researcher. In all a total of twelve professionals were interviewed via the semi-structured interview.

Figure 1 Framework of determinants offirm's growth

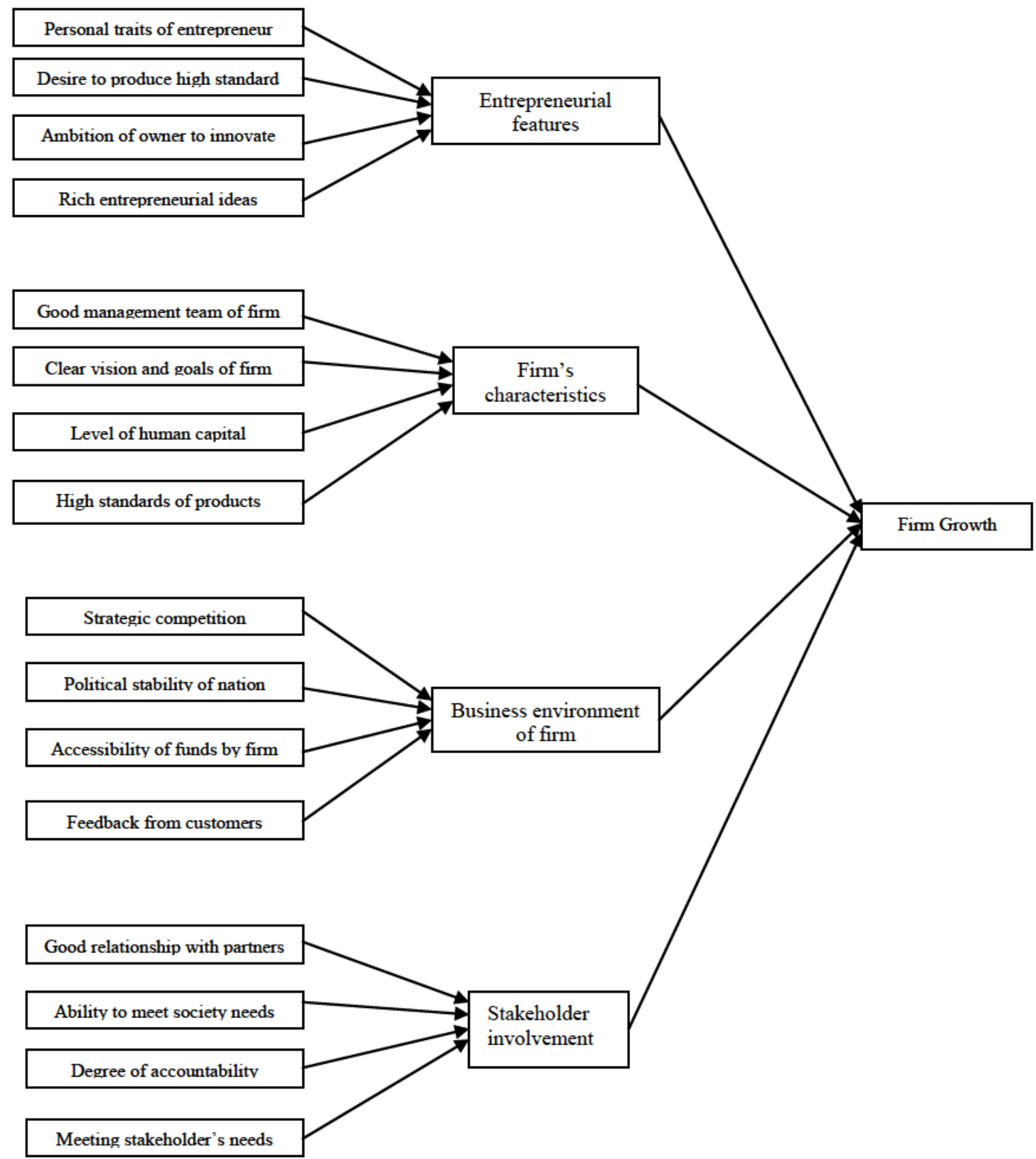




\section{DISCUSSION}

Growth in firms has been found to have an impact not only on the construction industry but also the entire nation. Findings transcribed from the interviews shown that growth is defined in various perspectives as such; increased in employees, turnovers, products, sales, amongst others. As a result, there is no definite definition for growth. Firm's growth is dependent on the following variables including entrepreneurial features, firm characteristics, business environment and stakeholder's involvement. Entrepreneurial features as a dependent variable are affected by the personal traits of an entrepreneur and the vibrant entrepreneurial ideas will drive owners of the firm to grow. Also, the desire to produce high standards by entrepreneurs will drive the firm to establish mechanisms to growth. Firm characteristics have demonstrated to impact firm's growth due to its unique factors including good management team and their level of experience and skills that enable the firm to achieve sustainable growth. Further, the the study established that growth of a firm would be enhance when the vision and goals of a firm are clear. This will enable all the team to work towards achieving a common target with a mutual understanding. Also, when a firm set a high standard of its services and products, the firm will be obliged to put in a continuous effort in accomplishing the set standard this is likely to foster growth. In addition, a business environment that the firm operates mostly inspire the firm to act in a manner which promotes growth. This is because when competitors in the market are innovating and improving on their products and services, the firm will be compelled to towards archiving growth. Likewise when the business environment paves the way for the firm to have access to credit facilities from banks and other financial institutions, it will enable the firm to leverage on the accessed funds and grow. Similarly, political stability of the nation that a firm operates affect their growth in a situation where there is political turbulent with the severity of war, this would force the firms to fold-up thereby affecting their growth. However, where the environment is conducive, it will drive firms to operate well and grow. Equally, stakeholder's involvement impacts on firm's growth. Stakeholders are individual or group of institutions with an interest in the firm. They include someone who contributes to the firm's growth or success or who benefits from its success. Stakeholder's needs of a firm are met when they are involved. This involvement will seek to establish collaboration between all the partners and suppliers. Further, it will enable the needs of the community to be addressed socially and environmentally. Also, the vital needs of customers are met. This s because the firm will tailor their services and products towards customers needs thereby facilitating growth.

\section{CONCLUSIONS}

The purpose of the study was to establish a sustainable growth framework for small and medium-sized construction firms. The study proved that the determinants of SME's growth are grouped into four categories including those related to the entrepreneurial features of that firm, Entrepreneurial features do not only impact on the internal growth of a business but the economic growth of a nation. This is because entrepreneurs often 
create new technologies, develop new products or process innovation, and open new markets that drive growth in their firms and the entire economy.

The study secondly concludes that firm's growth is also linked to other characteristics of the firm. Further, the growth of a firm would enhance when the vision and goals of a firm are clear. This will enable all the team to work towards achieving a common target with a mutual understanding.

Thirdly, firms grow due to factors that are related to the business environment that the firm operates. This is because when competitors in the market are innovating and improving on their products and services, the firm will be compelled to towards archiving growth. Likewise when the business environment paves the way for the firm to have access to credit facilities from banks and other financial institutions, it will enable the firm to leverage on the accessed funds and grow. Also, unstable political stability of a nation does affect the growth of a firm.

Lastly, Stakeholder's needs of a firm are met when they are involved firm's operation. This involvement will seek to establish collaboration between all the partners and suppliers. Further, it will enable the needs of the community to be addressed socially and environmentally. The study finally concludes that for growth to be ascertained and be sustainable within small and medium-sized construction firm, there must be an integration of both the internal and external variables the influence growth.

\section{REFERENCES}

- $\quad$ BARRINGER, B., JONES, F. and NEUBAUM, D. (2005), "A quantitative content analysis of the characteristics of rapid-growth firms and their founders", Journal of Business Venturing, Vol. 20 No. 5, pp. 663-87.

- $\quad$ BAUM, J. R., LOCKE, E.A., and SMITH, K.G. (2001), "A multidimensional model of venture growth", Academy of Management Journal, Vol. 44 No. 2, pp. 292-303.

- BAUM, J. R. and E. A. LOCKE, E. A., 2004, - The Relationship of Entrepreneurial Traits, Skill, and Motivation to Subsequent Venture Growth,॥ Journal of Applied Psychology, 89, 587-598.

- CASSAR, G. (2007), "Money, money, money? A longitudinal investigation of entrepreneur career reasons, growth preferences and achieved growth", Entrepreneurship \& Regional Development, Vol. 19, pp. 89-107.

- CLIFF, J.E. (1998), "Does one size fit all? Exploring the relationship between attitudes towards growth, gender, and business size", Journal of Business Venturing, Vol. 13, pp. 523 42.

- DAUDA, Y.A. and AKINGBADE, A.W. (2010). Employee's Market Orientation and Business Performance in Nigeria: Analysis of Small Business Enterprises in Lagos State, International Journal of Marketing Studies, 2 (2), pp. 134-143.

- DAVIDSSON, P. (1989), "Entrepreneurship - and after? A study of growth willingness in small firms", Journal of Business Venturing, Vol. 4 No. 3, pp. 211-26.

- ENSLEY, M., PEARSON, A. and AMASON, A. (2002), "Understanding the dynamics of new venture top management teams: cohesion, conflict and new venture performance", Journal of Business Venturing, Vol. 17 No. 4, pp. 365-86.

- GOPINATH, R., C. (2012) Understanding the determinants of firm growth in young Reits, Singapore. 
- GRÖNROOS, C. (2006). On defining marketing: finding a new roadmap for marketing, Management theory, 6 (4),pp. 395-41

- GUDLAUGSSON, T. and SCHALK, A.D. (2009). Effects of Market Orientation on Business Performance: Empirical Evidence from Iceland, The European Institute of Retailing and Services Studies Recent Advances in Retailing and Service Science, July 6-9.

- HASHI, I. and KRASNIQI, A. B. (2011) Entrepreneurship and SME growth: evidence from advanced and laggard transition economies, International Journal of Entrepreneurial Behaviour \& Research Vol. 17 No. 5.

- HUTCHINSON, J., QUINN, B. and ALEXANDER, N. (2006), "The role of management characteristics in the internationalisation of SMEs: evidence from the UK retail sector", Journal of Small Business and Enterprise Development, Vol. 13 No. 4, pp. 513-34.

- KIRKWOOD, J. (2009), To grow or not? Growing small service firms Journal of Small Business and Enterprise Development Vol. 16 No.3, pp. 485-503

- KRITIKOS, A., S. (2014) Entrepreneurs and their impact on jobs and economic growth, World of Labor Evidence-based policy making, IZA, Germany.

- MATSUNO, K., MENTZER, J.T. and ÖZSOMER, A. (2002). The Effects of Entrepreneurial Proclivity and Market Orientation on Business Performance, Journal of Marketing, 66, pp.1832.

- MASSEY, C., LEWIS, K., WARRINER, V., HARRIS, C., TWEED, D., CHEYNE, J. and Cameron, A. (2006), "Exploring firm development in the context of New Zealand SMEs", Small Enterprise Research, Vol. 14 No. 1, pp. 1-13.

- MIRIAM J. (2006) organic Vs Inorganic Growth: A case study, Dissertation Presentation for the Degree of MA in Finance and investment.

- MORENO, A. and CASILLAS, J. (2007), "High-growth SMEs versus non-high-growth SMEs: a discriminant analysis", Entrepreneurship \& Regional Development, Vol. 19 No. 1, pp. 69-88.

- OECD, (2002). Small and Medium Enterprise Outlook, Paris, 63-74.

- PENROSE, E (1959). The theory of the growth of the firm. Oxford: Oxford University Press

- PUlENDRAN, S., SPEED, R. and WIDING, R.E. (2003). Marketing Planning, Market Orientation and Business Performance, European Journal of Marketing, 37, pp. 476-497.

- REIJONEN, H., LAUKKANEN, T., KOMPPULA, R. and TUOMINEN, S. (2012). Are Growing SMEs More Market-Oriented and Brand-Oriented? Journal of Small Business Management, 50 (4), pp. 699-716.

- RUEF, M., ALDRICH, H. and CARTER, N. (2003), "The structure of organizational founding teams: homophily, strong ties, and isolation among US entrepreneurs", American Sociological Review, Vol. 68 No. 2, pp. 195-222.

- SEXTON, D.L. (1989), "Growth decisions and growth patterns of women-owned enterprises", in HAGAN, O., RIVCHUM, C. and SEXTON, D. (Eds), Growth Decisions and Growth Patterns of Women-Owned Enterprises, Praeger, New York, NY.

- SERRASQUEIRO, Z., NUNES, P. M., JOA O LEITA, O. J. and MANUEL ARMADA, M. (2010), Are there non-linearities between SME growth and its determinants? A quantile approach Industrial and Corporate Change, Volume 19, Number 4, pp. 1071-1108 doi:10.1093/icc/dtp053 Advance Access published.

- STIGLITZ, J. and A. WEISS (1981), 'Credit rationing in markets with imperfect information,' The American Economic Review, 71, 393-410.

- SUTTON, J. (1997), 'Gibrat's Legacy', Journal of Economic Literature 35, 40-59.

- United Nations Industrial Development Organization (2010) UNIDO Report

- WIKLUND, J., DAVIDSSON, P. and DELMAR, F. (2003), "What do they think and feel about growth? An expectancy-value approach to small business managers' attitudes toward growth", Entrepreneurship Theory \& Practice, Vol. 26 No. 2, pp. 247-70.

- ZHOU, H. and de WIT, G. (2009), SCALES, Scientific Analysis of Entrepreneurship and SME's, Netherlands Ministry of Economic Affairs 


\title{
A NEW THEORY-BASED TYPOLOGY FOR CONSTRUCTION PROJECTS
}

\author{
Brockmann, C. ${ }^{1}$ and Brezinski, $\mathrm{H}^{2}$
}

\begin{abstract}
:
Existent systematic orders of construction projects assign structures to categories such as residential, building, civil engineering, and industrial construction by the use of the owners. Such a concept is informative but not useful. What we need is a typology based on theory that can provide solutions for a multitude of problems. We have identified four salient dimensions (complexity, difficulty, novelty and specificity) after a literature review. Contingency theory is in most cases the underlying theory. With the help of these four dimension, we can build seven different combinations that occur in reality and these again define seven different types of construction projects. Three types belong to routine projects and two each to innovation and special projects. This is an exercise in theory building, where logic replaces data. We have also identified applications to test the usefulness of the typology: market entry, optimum firm size, strategic planning, marketing, construction technology and project organisation, all topics that cannot be explained with existing orders. The results for market entry and optimum firm size provide an explanation for the fragmented structure of the construction industry. The results for strategic planning by contractors offer normative advice. With the help of the applications, we are able to demonstrate the usefulness and simplicity of the typology. Governance of rules (versus arbitrary assignment) is a consequence of establishing the typology based upon theory.
\end{abstract}

KEYWORDS: COMPLEXITY, DIFFICULTY, NOVELTY, SPECIFICITY, TYPOLOGY.

\section{INTRODUCTION}

The goal for developing a new typology is to provide a framework that allows us to explain and understand phenomena in the construction industry. Looking into a systematic order of construction projects is of a conceptual nature and it means advancing a theoretical contribution. Systematic orders are fundamental elements in the development of a scientific body of knowledge (McKelvey, 1975). The lack of a theoretical background of existing orders provided the impetus. A simple example of an existing categorisation is the well-known differentiation between residential, industrial, building, and civil engineering projects (Barrie and Paulson, 1992; similar Langford and Male, 2001). The group of building projects comprises offices, churches, sports arenas, opera houses, and universities. What do they have in common? Theoretical contributions need to identify building blocks (what), relations (how) and underlying dynamics (why). The reasoning (why) is of special importance because logic replaces data as the basis for an evaluation (Whetten, 1989).

There are four forms of systematic orders on hand: nomenclature, classification, taxonomy and typology. Nomenclatures in science describe systems of designations. An

\footnotetext{
1 Department of Civil and Environmental Engineering, UAS Bremen, Germany, Email: christian.brockmann@hs-bremen.de

${ }^{2}$ Department of Economics, TU Freiberg, Germany, Email: horst.brezinski@vwl.tu-freiberg.de
} 
example is NACE (French: Nomenclature statistique des activités économiques dans la Communauté européenne), the statistical framework in the EU. Nomenclature as a system of designation is nothing more than a series of nominalist definitions. Theory is not the base of nomenclatures, they have neither truth values nor empirical content but they can be practical. We create classification systems by assigning objects or phenomena to specific classes according to predetermined criteria (similarity or relationships) and decision rules; a hierarchy (Doty and Glick, 1994) characterizes them and they are precise, complete and disjunctive. If natural laws provide the basis of a classification, then it becomes a taxonomy. The most widely known one is the systematic order of plants (Linnaean taxonomy). Archetypes are the components of typologies. Categories of typologies are precise (however, the assignment is imprecise), complete but not clearly disjunctive. Unambiguous decision rules for the assignment are not possible. We can distinguish different characteristics for these four systematic orders (table 1).

Table 7: Characteristics of systematic orders

\begin{tabular}{lllll}
\hline & Nomenclature & Classification & Taxonomy & Typology \\
\hline Ontological base & Definitions & Rationality & Natural laws & Rationality \\
Assignment by & Definitions & Decision rules & Decision rules & $\begin{array}{l}\text { Similarity with } \\
\text { archetypes }\end{array}$ \\
Truth values & No & Yes & Yes & Yes \\
Empirical content & No & Yes & Yes & Yes \\
Precise & Yes & Yes & Yes & Yes \\
Complete & Yes & Yes & Yes & Yes \\
Disjunctive & No & Yes & Yes & No \\
\hline
\end{tabular}

Clearly, either a classification or a taxonomy would be preferable as they are most stringent. Unfortunately, construction projects do not follow the order of natural laws: establishing a taxonomy is indefensible. A classification, on the other hand, poses problems when the population that it tries to capture is continuous. Project size measured in monetary units would result in distinguishing two construction projects that differ by the amount of one dollar: establishing a classification is undesirable. Some fuzziness about the categories will prove beneficial.

\section{RESEARCH METHODOLOGY}

In a wider sense, the typology that we are trying to establish is an explication. Carnap (1956) defined explications as the process of replacing unclear or defective pretheoretical concepts (explanandum) with clear ones (explicatum). The method to achieve this comprises analysis and replacement. In the end, the explicatum must satisfy the conditions of adequacy (similarity with the explanandum, governance of rules, usefulness, and simplicity).

First, we will analyse the existing literature to establish dimensions for the typology. These are the building blocks of our theory (what). In a second step, we scrutinise the relationships between the dimensions (how). During the analysis, we will give reasons for the choices referring to the underlying concepts. Rules of use for the dimensions also 
follow from the analysis and from industry practise. This is clearly an exercise in theory building and it does not include theory testing (Dubin, 1969).

What can a typology achieve? In the best case, they are complex theories. Doty and Glick (1994) provide five guidelines for building a typological theory: (1) make the underlying grand theoretical assertions explicit; (2) define the set of archetypes completely; (3) use the same set of dimensions when describing archetypes; (4) explain the constructs used as dimensions and (5) operationalise and empirically test the typological theory.

\section{CONCEPTUALIZATION}

In construction, it is fundamental to differentiate between product and process. The client typically designs the product (building, structure) with the help of architects and engineers. The contractor develops the construction process. Product and process planning are interdependent; both are part of construction projects.

\section{Choice of dimensions}

Starting point for the selection of possible dimensions for the construction industry are publications analysing organisations and their tasks. In this business context, authors distinguish between task and resource dimensions. Tasks can be difficult, variable, interdependent, complex and novel or easy, routine, independent, simple and repetitive. Resources can be specific or generic.

Difficulty: It is not easy to analyse a difficult task. Algorithms for solutions are unknown (Van de Ven and Delbecq, 1974). Perrow (1967) describes difficulty as the degree of complexity of the search process in performing the task, the amount of thinking time required, and the body of knowledge that provides guidelines for performing the tasks. The underlying theory is task contingency - a special form of contingency theory - , i.e. the idea that tasks determine the structure of an organization (Fiedler, 1964). This holds also true for the next two dimensions, variability and interdependency.

Variability: Tasks with a great variability demand use of a multitude of different approaches (Perrow, 1967).

Interdependency: We can differentiate between interdependency within and between teams. It is high when either many members of a team or many teams need to interact for the solution of a problem. A high interdependency increases the demands for coordination (Tushman, 1979).

Complexity: Complex tasks can be broken down into many parts and there are many connections between the parts possible. A third component of complexity is the crossimpact of decisions, the question of consequences for the system. When many decisions entail important consequences, we face a high complexity. Multiple parts, interactions, and consequences create uncertainty when solving a problem (Tushman and Nadler, 1978). Complexity belongs to a theory that interprets organizations mainly as information 
processing and decision making entities. It also plays an important role in systems theory (Luhmann, 2013).

Novelty: Novel tasks are the opposite of repetitive tasks; the degree of newness to the actor defines the dimension (Puddicombe, 2012). For their solution, we first need to develop new structures and then new algorithms. Repetitive tasks are already prestructured. The construct of novelty also belongs into the realm of contingency theory.

Resource specificity: Of high importance are human, asset, location, and temporal specificity. High resource specificity describes high quality demands in these areas (Williamson, 1991). Using the concept of opportunity cost, we can state that resources are very specific if the difference to the second best alternative is especially high (Williamson, 1985). He introduced this term as part of the theory of governance costs.

We have now identified six dimensions of construction projects. Difficulty, complexity, novelty and resource specificity are rather independent of each other. However, variability and interdependence are strongly affecting complexity with regard to the number of parts and their interrelationships. If we subsume these two dimension under complexity, we get a scheme with four dimensions determining a construction project (fig. 1.)

Figure 8: conceptualisation of construction projects

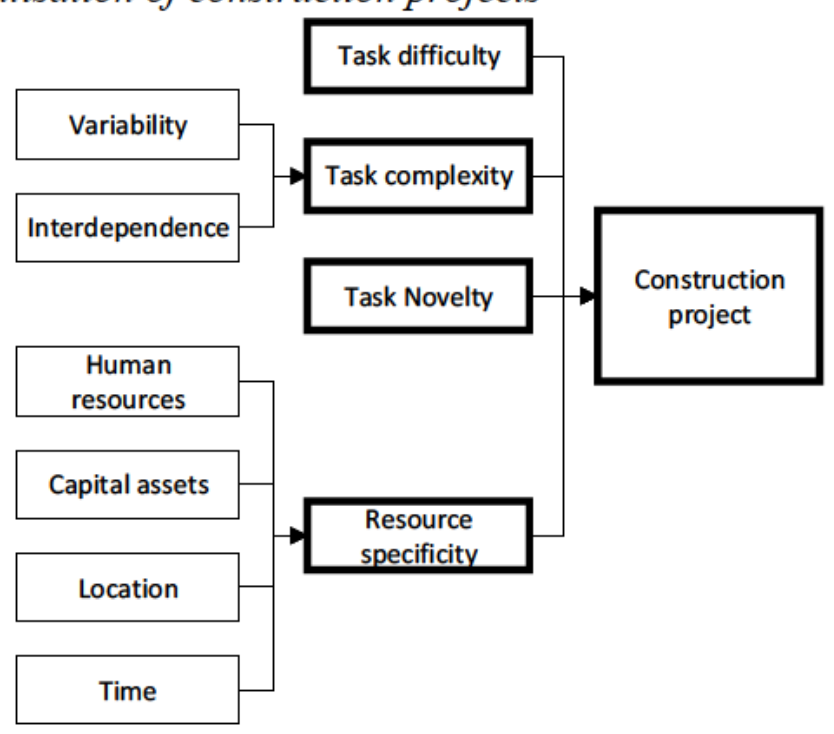

\section{Typical cases}

The four chosen dimensions represent each a continuum with values ranging from "high" to "low". To simplify the typology, we will only consider the extreme values of the continuum. In this way, we can designate the variables by discrete attributes. Difficulty has the extremes of very difficult and very easy; complexity ranges from very complex to very simple; novelty spans from very novel to very routine and resources can be very specific or very generic. An array of four dimensions with two possible values each generates 16 solutions. However, some of these are not possible. It is impossible to 
combine high difficulty with routine novelty and low complexity. We cannot solve highly novel tasks with ease. Routine tasks do not require specific resources. These practical exclusions reduce the possibilities to seven cases (table 2).

Table 8: Existing combinations of dimensions

\begin{tabular}{lllll}
\hline & Difficulty & Specificity & Novelty & Complexity \\
\hline Case 1 & easy & generic & routine & simple \\
Case 2 & easy & generic & routine & complex \\
Case 3 & difficult & generic & routine & complex \\
Case 4 & difficult & generic & novel & simple \\
Case 5 & difficult & generic & novel & complex \\
Case 6 & difficult & specific & novel & simple \\
Case 7 & difficult & specific & novel & complex \\
\hline
\end{tabular}

\section{Typology}

We can develop the typology by further condensing the information of table 2 . Generic resources and routine tasks typify cases 1,2 and 3; they differ only with regard to difficulty and complexity. Taking generic resources as defining dimension, we can distinguish three types of tasks defining a group of projects (fig. 2). Rule tasks describe the simplest construction projects, traditional rules are sufficient for a solution (example: one family house). Repetitive tasks differ from rule tasks by their increased complexity, managers and engineers must apply the rules repetitively (example: pipeline). If not only the complexity is increased but also the difficulty we face reflection tasks, repetitive use of rules will not generate a solution (example: tunnel in a difficult geology). These types form the R-projects.

Figure 9: R-projects with generic resources

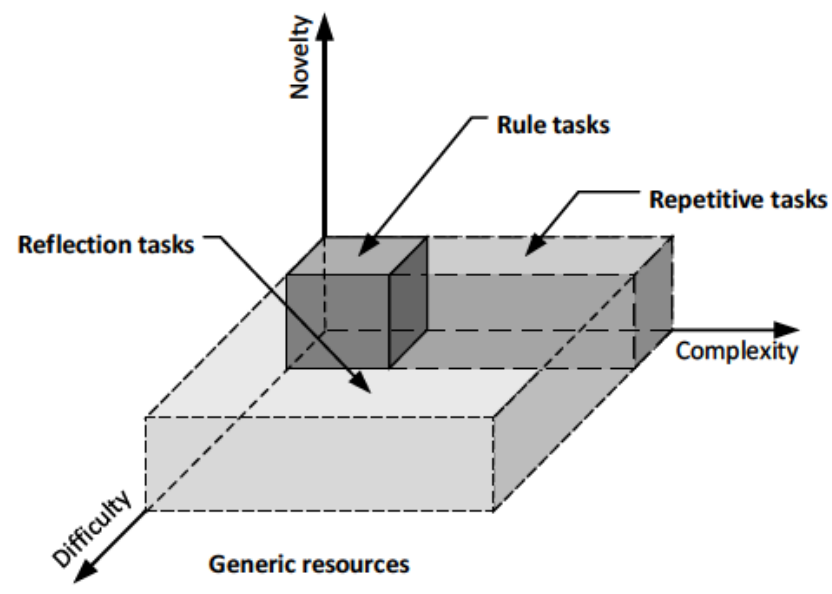

Small companies are well suited to implement rule tasks because such projects do not require a sophisticated overhead. The resources are available on the markets the implementation poses no unwarranted problems and financing is no hurdle. Such 
boundary conditions allow for an easy market entry and that again is a reason for the large number of companies in this sector.

For repetitive tasks, there is a need for an iterative approach to the problems and the observance of impacts of decisions on other parts in order to solve the structural complexity. New is the interdependence of partial solutions, not the general approach. Repetitive tasks provide the natural growth path for companies that master rule tasks.

A further horizontal task enlargement characterises reflection tasks and it entails the development of new solution algorithms in planning. This requires reflection based on previous experience. Planning becomes more important and the necessary engineering resources must be available. There exists a possibility to create a niche market, based on the competence to solve difficult problems.

Generic resources can also appear together with high novelty and high difficulty, with complexity being the only variable. These tasks are innovation driven but no backing by specific resources is required with the exception of highly qualified personnel.

Innovation tasks are novel and difficult to solve (example: Frank Gehry's Dancing House in Prague). This is the ideal setting for companies with a strong engineering background; they can be of smaller or large size.

Integration tasks add to novelty and difficulty the dimension of complexity, thus increasing the size of the tasks (example: modern sports stadia). In such cases, expertise most likely comes from different sources and there must be a system leader to integrate all the efforts. The ideal company must have command of superior project management and engineering competences. This can still be a specialised company or a large one.

Figure 10: I-tasks with generic resources

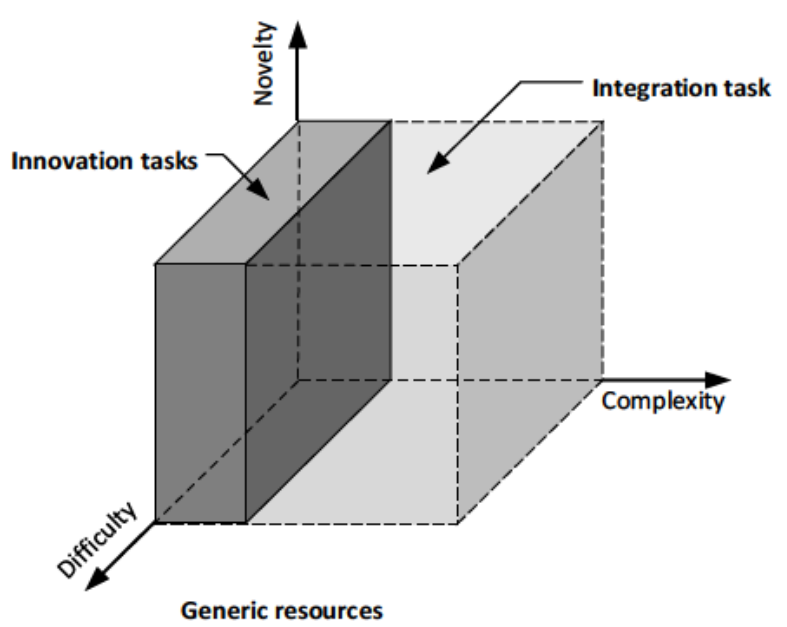

Special tasks (S-tasks) combine high degrees of novelty and difficulty with specific resources. Specific resources are expensive, so companies that attack such problems must possess the necessary capital. 
Smaller high-tech buildings pose specific tasks (difficult, novel, specific): An example is the Sydney Opera House. There are high demands on engineering and financing.

Megaprojects are examples of select tasks; they have the highest requirements in all four dimensions. An example is the Doha Metro Project with $350 \mathrm{~km}$ of metro lines and 100 stations. A company tackling such a task must have many highly qualified managers and engineers with megaproject experience. Access to financing is also of greatest importance.

Figure 11: S-tasks

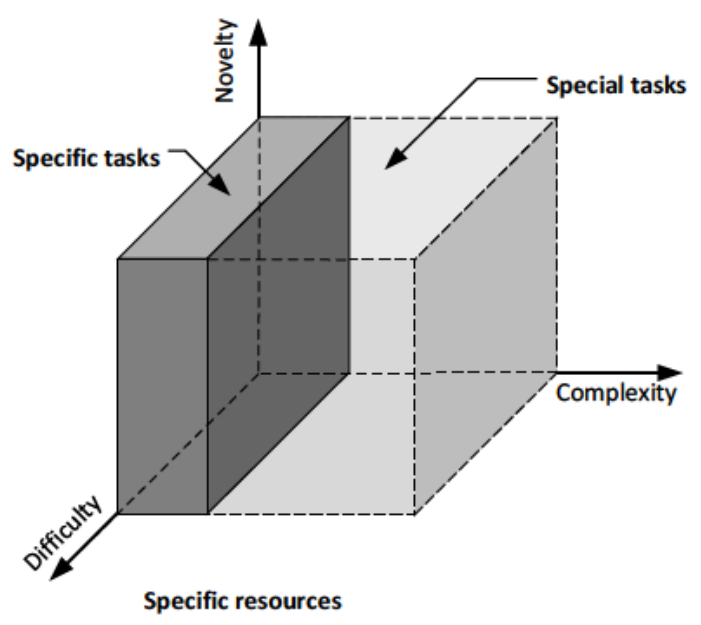

We have developed a typology of construction projects by logical deduction. Starting from a review of the relevant business and construction literature, we were able to identify for independent dimensions. There exist seven possible combinations based on the four dimensions. A discussion of these seven cases resulted in the identification of three project groups:

7. R-tasks or routine projects; they are derived from rule, repetitive and reflection tasks

8. I-projects or innovation projects; they are driven by innovation and integration tasks

9. S-projects or special projects: they are results of specific and select tasks

\section{APPLICATIONS}

The starting point for this paper was dissatisfaction with existing systematic orders of construction projects. Therefore, we must provide some proof how the new typology can be applied in a useful way. The following chapters analyse the impact of this typology for the understanding of some different topics. We have chosen a number pertaining to contractors (market entry, optimum firm size, strategic planning). Other possible topics 
for contractors could be marketing or construction technology, one concerning clients could be project organisation. The theory helps enterprise and project planning, not so much implementation.

\section{Market entry}

In all industrialized countries, the number of construction companies is large. However, small companies seldom compete with large ones for the same project. We can interpret the seven different project types of the typology as different markets that require different competences. Rule tasks need the least amount of capital and expertise; they are the typical entry projects for small companies. Special tasks, on the other hand, require considerable capital and a very high amount of expertise. Repetitive, reflection, and innovation tasks require approximately the same amount of capital but increasing and differentiated skills. Integration, specific and select tasks depend of ever-increasing amounts of capital and knowledge (fig. 5).

Typically, many companies will seek entry with little money and little know-how; these form the bulk of all construction companies. At other levels, a direct start-up is still possible but mergers and acquisitions are more likely. For performing s-tasks either longterm growth or an acquisition that poses a high investment are options.

Figure 12: Market entry and required resources

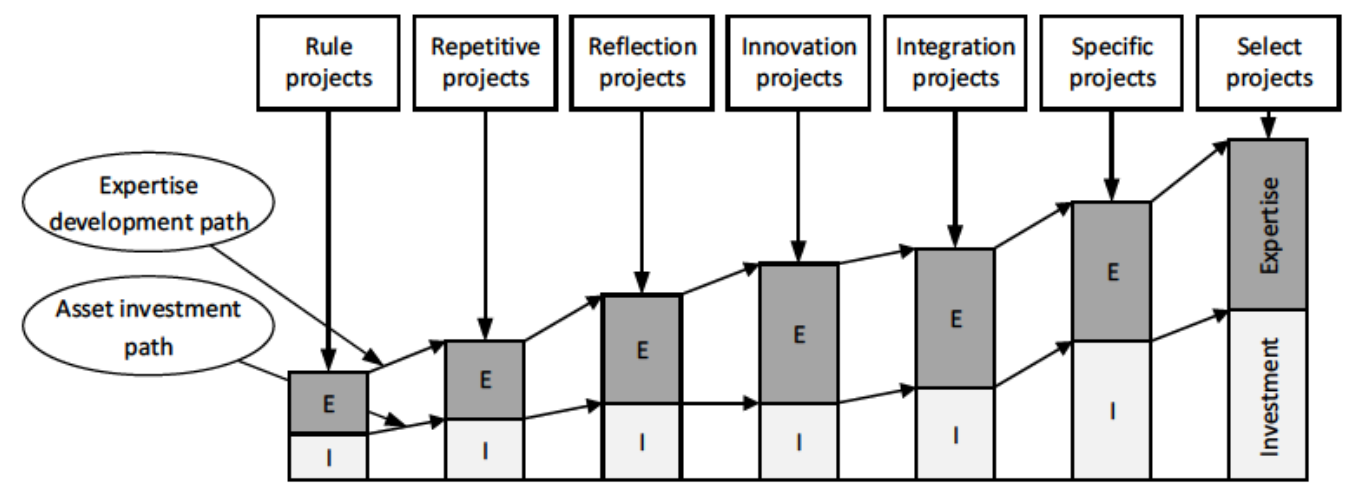

\section{Optimum firm size}

The optimum firm size is an economic concept. Williamson (1967) describes it as a management problem but one can also interpreted it as a microeconomic problem. When considering the management factor the optimum size is determined on a continuum between hierarchical and market organization. R-tasks would rather rely on a market solution and S-tasks on a hierarchy.

Microeconomics defines the optimum firm size as the minimum of the long-term average cost curve given a certain amount of capital. The curve has a U-shape because of increasing returns to scale up to the minimum costs and decreasing returns to scale 
thereafter, which raise the costs. The use of all resources is efficient only at the point of the optimum firm size (fig. 6).

Figure 13: Optimum firm size based on long-run average cost curve

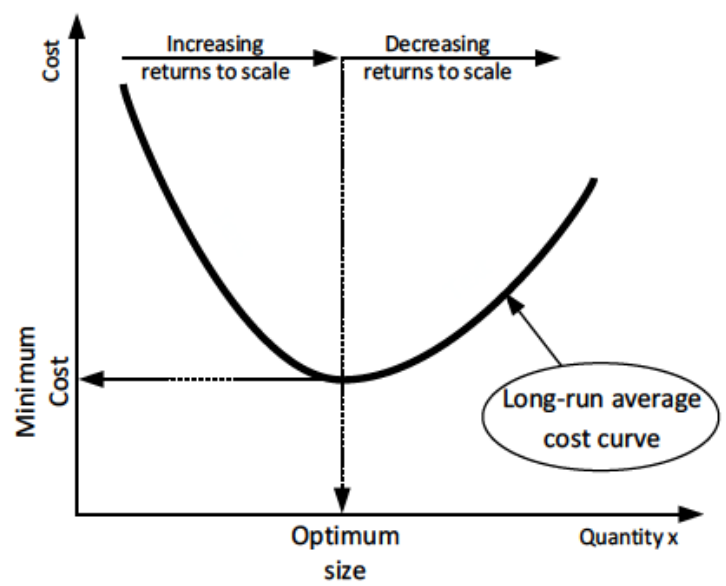

Since the construction industry is highly competitive, firms must produce close to minimum cost or they will fail. Looking at the seven different tasks and the associated levels of required capital in figure 6 , we can conclude that there are different optimum firm sizes in construction because different levels of capital are required. This separates the construction market in different submarkets. If we take a one-family home as an example, we face a rule task. A small company (with little capital) can get the work done efficiently while a larger company produces to the left of the optimum size and way above minimum costs.

\section{Strategic planning}

Strategic planning often starts with a SWOT-analysis and moves on to generating options; decision-making and implementation are the final steps. If we choose a resourcebased approach to the problem, figure 6 provides already qualitative data on two types of resources: capital and expertise. These two resources can plotted in a two-dimensional graph (fig. 7). 
Figure 14: Strategic planning

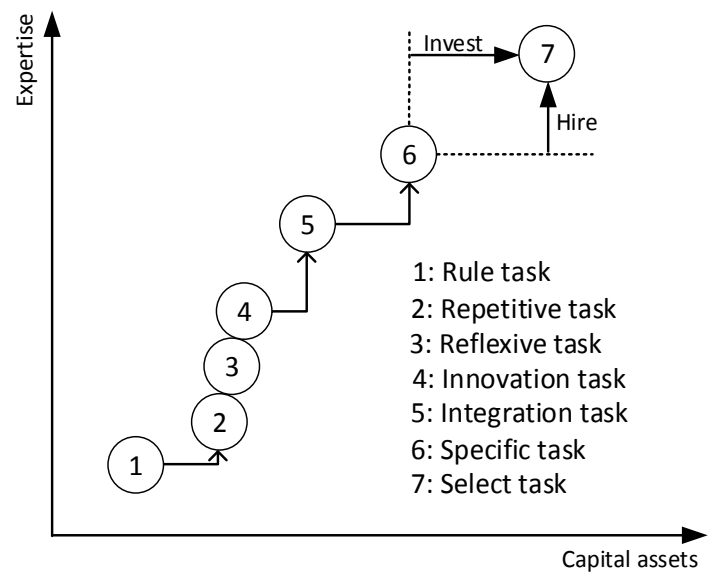

A contractor can decide from his starting point where he wants to move and whether that means investing and / or hiring and an appreciation of the magnitude for both actions. Another option is of course to acquire expertise and capital assets by mergers and acquisition.

\section{CONCLUSION}

By building the typology, we have fulfilled most of the demands formulated by Doty/Glick (1994).

1. We have explicitly described the underlying theoretical assertions when choosing dimensions for the construct "construction project". Most belong to contingency theory.

2. We have defined a complete set of archetypes by R-, I- and S-tasks.

3. We consistently employed the dimensions of complexity, difficulty, novelty and specificity when describing the archetypes.

4. We have explained the constructs used as dimensions.

5. We have not operationalised and tested the typological theory. However, we have offered examples to check plausibility. It remains open to further research to check the validity of the concept. Blismas et al. (2004) have validated a typology for clients' multi-project environments by taking the clients' project database and checking off the dimensions for each project. This is a possible approach.

The typology fulfils the conditions of adequacy as formulated by Carnap (1956) to a large degree. The developed terms are not similar to current custom. This was impossible because we do not have a similar systematic order available in construction. On the other hand, we were able to show the governance of rules, the usefulness for applications and the simplicity of the use. 
In practical terms, we have shown that the explanatory power of the typology is high. Market entry, optimum firm size and strategic planning are just three applications that we discussed, three others we have mentioned (marketing, construction technology and project organisation). Whether we can explain further phenomena of the construction industry with the typology is a question of further research.

Use of the typology will help the industry to achieve better sustainability for the construction enterprise and society.

\section{REFERENCES}

- BARRIE, D. and PAULSON, B. (1992) Professional Construction Management. New York: McGraw-Hill.

- CARNAP, R. (1956) Meaning and Necessity: A Study in Semantics and Modal Logic. Chicago: University of Chicago Press.

- DOTY, D. and GLICK, W. (1994) Typologies as a Unique Form of Theory Building: Toward Improved Understanding and Modelling. Academy of Management Review, 19, 230-251.

- DUBIN, R. (1969) Theory Building. New York: The Free Press.

- FIEDLER, F. (1964) A Contingency Model of Leadership Effectiveness. Advances in Experimental Social Psychology, 1, 149-190.

- LANGFORD, D. and MALE, S. (2001) Strategic Management in Construction. Osney-Mead: Blackwell Science.

- LUHMANN, N. (2013) Introduction to Systems Theory. Cambridge: Polity.

- MCKELVEY, B. (1975) Guidelines for the Empirical Classification of Organizations. Administrative Science Quarterly, 20, 509-521.

- PERROW, C. (1967) A Framework for the Comparative Analysis of Organizations. American Sociological Review, 32, 194-208.

- PUDDICOMBE, M. (2011). Novelty and Technical Complexity: Critical Constructs in Capital Projects. Journal of Construction Engineering and Management, 138, 613-620.

- TUSHMAN, M. (1979) Work Characteristics and Subunit Communication Structure: A Contingency Analysis. Administrative Science Quarterly, 24, 82-98.

- TUSHMAN, M. and NADLER, D. (1978) Information Processing as an Integrated Concept in Organizational Design. Academy of Management Review, 3, 613-624.

- VAN DE VEN, A. and DELBECQ, A. (1974) A Task-Contingent Model of Work-Unit Structure. Administrative Science Quarterly, 19, 183-195.

- WHETTEN, D. (1989) What Constitutes a Theoretical Contribution? Academy of Management Review, 14, 490-495.

- WILliamSON, O. (1967) Hierarchical Control and Optimum Firm Size. Journal of Political Economy, 75, 123-138.

- WilliamsON, O. (1991) Comparative Economic Organization: the Analysis of Discrete Structural Alternatives. Administrative Science Quarterly, 36, 269-296. 


\title{
ORGANIZATIONAL IDENTIFICATION AND TURNOVER INTENTION OF EMPLOYEES IN THE TURKISH CONSTRUCTION INDUSTRY
}

\author{
Demircioglu, Y. ${ }^{1}$ and Giritli, F.H. ${ }^{2}$
}

\begin{abstract}
:
Organizational identification is an important work attitude that affects performance and job satisfaction. Hence, exploring antecedents of organizational identification in organization settings within the construction industry is vital in understanding the role of organizational identification in performance outcomes.

Organizational identification, which refers to an individual's psychological attachment to the organization, has gained increasing attention because of its assumed link with behavior associated with enhanced organizational performance. Yet little work has been done on what fosters organizational identification, particularly within the context of construction industry.

The main aim of this study is to determine the relationships among organizational communication, selfconstrual, perceived external prestige, organizational communication, turnover intention and organizational identification within the context of Turkish Construction Industry. A research model, which incorporates these relationships will be developed and tested. It is proposed that collectivistic aspects of Turkish culture may influence the strength of an employee's identification with the organization.

A questionnaire accessible through Internet has been developed to collect information for measuring the study variables. Respondents in the present study are employees working in the construction industry. The questionnaire survey will be conducted through standardized assessment instruments. It is hoped that the findings will enhance our understanding of the nature and consequences of organizational identification among employees in the construction sector.
\end{abstract}

KEYWORDS: CONSTRUCTION INDUSTRY, ORGANIZATIONAL COMMUNICATION, ORGANIZATIONAL IDENTIFICATION, PERCEIVED EXTERNAL PRESTIGE, TURNOVER INTENTION

\section{INTRODUCTION}

Over the past decades, a growing body of research has been dedicated to the relationship between employees and their employing organization. This psychological relationship has been conceptualized in terms of both organizational identification and organizational commitment. Traditionally, employee attachment to the organization has been examined with regards to commitment (Meyer \& Allen, 1997; Morrow, 1993). However, organizational scholars now are showing a keen interest to assess this relation with the concept of organizational identification (Ashforth \& Mael, 1989; Ashforth, Harrison \&

1 Institute of Science and Technology, Istanbul Technical University, Turkey. Email: demirciogluy@itu.edu.tr

2 Faculty of Architecture, Istanbul Technical University, Turkey. Email:

giritli@itu.edu.tr 
Corley, 2008). This may be attributed to the fact that an individual's identification with and involvement in a particular organization is likely to be associated with a number of outcomes that have the potential to significantly affect the organization's ability to sustain itself over time. And hence, it is to be expected that the importance given to organizational identification will reduce work withdrawal and turnover. Moreover, low levels of work withdrawal which generate work force continuity is supposed to be a path leading to increased employee green behaviour (Jackson et.al.,2011). In their study, Ones et.al. (2010) reported that employees with the lowest levels of withdrawal performed the most green behaviours in their organization which was committed to enviromental sustainability.

As such, organizational identification is an important work attitude that may exert on a wide range of organizational outcomes. Previous studies have found that positive identification with the organization improves motivation, job satisfaction and commitment. Positive identification also decreases turnover and reduces conflict within an organization (Pratt, 1998; Van Dick et al., 2004). Many authors also argue that strong identification feelings can offer sustainable competitive advantage to the firm. Yet, important questions regarding its nature, the factors that fosters identification feelings, and the consequences of identification still require further exploration. This is also the case for the construction industry.

The aim of this study is to provide employers in the construction industry with information designed to reduce the potential for turnover of employees. To that end, the following research question was examined in this study:

'Are there identifiable factors that increase or decrease an employee's level of organizational identification and intention to stay with her/his current employer?'

\section{THEORETICAL BACKGROUND}

\section{Organizational identification and communication}

There exist various studies which emphasize the importance of communication as an antecedent of organizational identification (DiSanza \& Bullis, 1999; Riordan \& Weatherly, 1999; Scott, 1997). Although these studies show that frequent organizational communication strengthen organizational identification, they are lack of explaining the effects of different communication types on the concept of organizational identification.

Although there are many communication types in the literature, "Horizontal communication" and "Vertical Communication" types are examined in this study. Horizontal communication refers to the informal interpersonal and socio-emotional interaction with proximate colleagues and others in the organization who are at the same level. In contrast, vertical communication refers to work-related communications up and down the organizational hierarchy. Although vertical and horizontal communication styles in organizations include formal messages among employees, supervisors etc., vertical communication is only taken by its formal side, and horizontal communication is considered only by its informal side. 
Empirical evidence from a prior meta-analysis of the literature suggests that communication is an important predictor of identification, but that horizontal communications are less strongly related to levels of organizational identification, than are vertical communications.

\section{Organizational identification and perceived external prestige}

A number of studies have shown that among variables influencing organizational identification, perceived external prestige of the organization is the most influential one (Dutton and Dukerich, 1991; Dutton et al., 1994; Dukerich et al., 2002; Lipponen, Delkama, Olkkonen \& Justlin, 2005; Mael \& Ashforth, 1992; Smidts et al., 2001, Wan Huggins et al., 1998; Karabey \& Đscan, 2007).

Perceived external prestige concerns employees' perception of how the outside world views their organization. In line with social identity theory, if employees see their organization as more respected or prestigious by important outsiders, organizational identification is more likely to take place (Dutton et al., 1994). This would also enhance their personal identity and contribute positively to their self-esteem. Moreover, organizational image has become of prime importance for many firms because their performance and survival today depend in large part on their reputation with respect to numerous stakeholders (Roberts \& Dowling, 2002).

\section{Organizational identification and turnover intention}

Over the past few years, several papers have been published indicating the relationship between organizational identification and employees' reported turnover intentions (Van Dick et. al., 2004; Wan Huggins et al. 1998). Meta analytic studies have reported that organizational identification exhibits strong, negative correlations with turnover intention (e.g., Meyer et al., 2002; Riketta, 2005).

This paper thus addresses the question of the relationships among the variables which form the basis of the study findings within the context of construction industry.

\section{METHODOLOGY}

\section{Sample and procedure}

A questionnaire accessible through Internet has been developed to collect information for measuring the study variables. Respondents in the present study are employees working in the construction industry. There are 103 returned questionnaires from a total of 499 contacted survey sample; giving a response rate of $20.60 \%$. Of the 103 returned questionnaires, 5 were unusable due to missing information. Although a response rate of 20-40 per cent has been claimed to be accurate for representing the target group (Badger $\&$ Werret, 2005), we were disappointed with the high non-response rate.

The questionnaire survey has been conducted through standardized assessment instruments. It is hoped that the findings will enhance our understanding of the nature and 
consequences of organizational identification among employees in the construction sector.

\section{Measurements}

Organizational identification (OID)

Organizational Identification was assessed with the Turkish translation of Mael and Ashforth's (1992) 6-item organizational identification scale. Although there are a wide variety of organizational identification scales, the Mael and Ashforth measure is the most frequently used one. Examples of items are: "When someone criticizes this firm, I feel like a personal insult", "When I talk about this firm I usually say "we' rather than 'they" and "This firm's successes are my successes'.

\section{Organizational communication}

Organizational communication is measured with its two directions as; vertical communication and horizontal communication. The scale is adapted from Postmes et al.'s (2001) study. Horizontal communication scale has 3 items and it measures both the quantity and quality of the horizontal communication between employees. Sample items are; "I also communicate with my colleagues informally" and "The communication between me and my peers is qualified." etc. Vertical communication scale has 12 items and it measures both the quantity and quality of the vertical communication between employees. Sample items are; "Senior management gives information about the changes in the organization." and "Senior management gives information about the strategy that the company is following." etc.

\section{Perceived external prestige (PEP)}

In order to measure the perceptions of the employees regarding the prestige of the company that they work for, Dutton and Dukerich's (1991) perceived external prestige scale is used. Sample items are; "My company has a good reputation in the society.", "My company generally has a good image" and "My company has a good reputation on its clients" etc... The higher the score, the more prestigious the employees perceive their company.

\section{Turnover intentions}

Turnover intention was measured by five items adapted from a meta-analysis by Cotton and Tuttle (1986). In this scale, subjects were asked to assess the last year of their experience on turnover intentions. Examples of item: "I often think of leaving my current job", I don't want to leave my current job within five years (reversed), "I look for other jobs".

Unless indicated, all items had a response scale ranging from 1 (strongly disagree) to 5 (strongly agree). Higher scores indicated higher levels of endorsement of the construct.

Age, gender and organizational tenure were included as control variables in line with prior research (Meyer et al., 2002; Snape et al., 2006). 


\section{RESULTS AND DISCUSSIONS}

Statistical Package for the Social Sciences (SPSS) was used to analyze data.

Descriptive and inferential statistics were used to analyze the data. Descriptive findings include the following: (1) respondents ranged in age from 23 to 55 years old, with $46.8 \%$ of the respondents being between 23 and 29 years old, $44.7 \%$ between 30 and 39 years old, $6.4 \%$ between 40 and 49 years old, and $2.1 \%$ between 50 and 55 years old, In terms of the age composition of the sample 55.3 percent represented those below 30 years, 41.5 percent were in the 31-45 age bracket, and 3,2 percent were above the 46 years age bracket. Bachelor and master degrees were the highest educational degree received for approximately 53.2 and $40.4 \%$ of respondents respectively.

Table 1 presents the means, standard deviations, and internal consistency alphas for the study variables. The Cronbach alpha coefficients of the scales used in the study meet Van de Ven and Fry's (1979) minimum criteria of 0.55 or above. Relative to the scale midpoint of 3 (neutral), the sample's means for the focal variables were high and the mean for turnover intention was low.

Table 1. Means, Standard Deviations, and Cronbach Alpha Coefficients

\begin{tabular}{llll}
\hline & \multicolumn{3}{c}{ Descriptive Statistics } \\
\cline { 2 - 4 } Variables & Mean & $\begin{array}{l}\text { Standard } \\
\text { Deviation }\end{array}$ & $\begin{array}{l}\text { Cronbach Alpha } \\
\text { Coefficients }\end{array}$ \\
\hline Age & 31.26 & 6.31 & NA \\
Gender $^{\text {a }}$ & 1.49 & 0.50 & NA \\
Organizational tenure $_{\text {Vertical communication }}$ & 4.21 & 4.68 & NA \\
Horizontal communication & 3.01 & 0.93 & 0.93 \\
Prestige (PEP) & 4.19 & 0.78 & 0.85 \\
Organizational Identification (OID) & 3.89 & 0.91 & 0.93 \\
Turnover Intention & 3.43 & 0.92 & 0.87 \\
\hline S-poin & 2.77 & 1.18 & 0.93 \\
\hline
\end{tabular}

5-point Likert scales were used for all scales

${ }^{\text {a }}$ Coding: 1 , male; 2 , female

Because it fits the purposes of the present study better, a hierarchical multiple regression analysis was used in the study. Table 2 next presents the results of hierarchical multiple regression analyses which aim to analyze the predictors of organizational identification and turnover intentions. In hierarchical regression analysis, variables are entered into the model in stages: first, a group of independent variables are evaluated in terms of how much information they provide about the dependent variable, and then, another group of variables are entered into the model.

The hierarchical ordering of the independent variables in the study is as follows: the first set includes the control variables (i.e. age, gender, organizational tenure); the second set includes the predictor variables. These sets are entered into the analysis through two steps.

Statistical analysis was conducted separately for OID (termed Model A) and turnover intention (termed Model B). Firstly, organizational identification was put into regression 
as the dependent variable. The value of the adjusted R-squared was $15.5 \%$, which meant that organizational identification can be partially explained by the predictors included. There are two possible reasons for this. First, the model constructed was not comprehensive enough to incorporate all possible predictors of organizational identification. Second, this study was exploratory and its sample was not large enough.

Table 2. Hierarchical regression analyses of the predictors of organizational identification and turnover intentions. The entries are standardized betas

\begin{tabular}{lll}
\hline Predictors & Model A & Model B \\
\hline Step 1 & Organizational Identification & Turnover Intention \\
\hline Gender & -.101 & .062 \\
Age & .168 & $-.404^{*}$ \\
Tenure in the organization & $.270^{*}$ & .085 \\
Adjusted R2 & .115 & .087 \\
\hline Step 2 & & \\
\hline Gender & -.052 & .002 \\
Age & .094 & $-.192^{*}$ \\
Tenure in the organization & $.272^{*}$ & .007 \\
Vertical communication & $.169^{*}$ & $-.177^{* *}$ \\
Horizontal communication & .089 & $-.208^{* *}$ \\
Prestige (PEP) & .129 & $-.470^{* * *}$ \\
Adjusted R2 & .155 & .427 \\
$\Delta \mathrm{R} 2$ & .040 & .034 \\
$\Delta \mathrm{F}$ & $5.017^{* *}$ & $8.343^{* *}$ \\
\hline${ }^{*} \mathrm{p}<.05, * * \mathrm{p}<.01, * * * \mathrm{p}<.001$ & &
\end{tabular}

The only statistically significant variables at $p<0.05$ were vertical communication and organizational tenure, which had positive coefficients of 0.169 and 0.272 respectively. These findings provide evidence that horizontal communication is a weak predictor of organizational identification, whereas vertical communication is a stronger predictor (Bartels et.al., 2009; Postmes et al., 2001; Smidts et al., 2001; Bartels et al., 2006, see among others). On the basis of this explanation, one may venture that a clearly positive relationship between vertical communication and organizational identification thus appears to exist within the contruction context.

Furthermore, the findings are also consistent with prior research findings which confirm the direct impact of length of tenure on organizational identification (Hall and Schneider, 1972; Hall et al., 1970; Mael and Ashforth, 1992). This indicates that employee identification are stronger for highly tenured employees as opposed to employees who had been working at the organization for a shorter period of time.

According to multiple regression analysis, perceived external prestige is not an antecedent of organizational identification, contrary to expectations. The results highlight that the contribution of PEP is not large enough to have statistically significant predictive capability, meaning that individuals high in OID are not necessarily those who perceive their company as prestigious. This evidence is in contrast with previous studies which have indicated that PEP influences organizational identification (Mael and Ashforth, 1992; Dutton et al., 1994; Smidts et al., 2001; Riketta, 2005; Carmeli et al., 2006; Fuller 
et al., 2006; Bartels et al., 2007; Carmeli and Freund, 2009; Cohen-Meitar et al., 2009). These studies have showed that employees preferred to enter into a contract with a firm that has a favorable reputation. However, the findings presented here contribute by showing that a low prestige organization has little negative impact on construction professionals' well-being and sense of self. In other words, PEP does not have a statistically significant effect on organizational identification among construction employees. This may be due to the fact that their professional and work-team identities may offset the negative impact of low prestige on organizational identification. Furthermore, the participants selected for this study were prestigious professionals working in back-end, positions.

Secondly, turnover intention was put into regression as the dependent variable. The same variables - age, perceived external prestige (PEP), horizontal communication and vertical communication - emerged as significant predictors of turnover intention. The full model has an exploratory power of $42.7 \%$ and change in F value statistically important $(\mathrm{p}<.01)$. Standardized regression coefficients (beta) indicate that most of the contribution to the exploratory power of the model is provided by the variables "perceived external prestige (PEP)", age, horizontal communication and vertical communication.

Perceived External Prestige, as being the strongest predictor of turnover is thought to have the strongest differentiative contribution between organizational identification and turnover. The difference between organizational identification and turnover intention was also explained by organizational tenure. Some scholars have found that tenure is not a predictor for turnover intention (Griffeth et al., 2000). The finding of a relationship between age and turnover intention supports earlier research stating that younger employees show higher turnover intention than older employees (Cho \& Lewis, 2011; Smith \& Hoy, 1992). Also, gender was significantly associated with none of the dependent variables in Model A and B.

In addition to the results above, organizational identification was put into regression as the independent variable and turnover intention was put into regression as the dependent variable in order to see the contribution of organizational identification on turnover intention.

Table 3. Simple Regression Analysis: Turnover Intention

\begin{tabular}{llllll}
\hline Predictor & $\mathrm{R} 2$ & $\mathrm{~B}$ & $\begin{array}{l}\text { Standard } \\
\text { Error }\end{array}$ & $\beta$ & $\mathrm{F}$ \\
\hline $\begin{array}{l}\text { Organizational } \\
\text { identification }\end{array}$ & .142 & -.501 & .124 & $-.389^{* * *}$ & $16.413^{* * *}$ \\
\hline$* * * \mathrm{p}<.001$ & & & & &
\end{tabular}

As is seen from Table 3, the relation between construction employees' identification and turnover intention reaches statistical significance $(p<.001)$, as expected. This finding is consistent with the idea that identification is a more proximal predictor of turnover intention, and offers a sting psychological anchor that discourages turnover intention within the context of construction industry (Randsley de Moura et. al., 2009). This 
suggests that higher levels of organizational identification among construction employees will lead to lower levels of turnover intentions.

In the context of construction industry, these results are interesting because there have not been many studies on the predictors of organizational identification and turnover intentions.

\section{CONCLUSION}

The results of this study suggest some important recommendations for construction firms to enhance their performance outcomes leading to competitive advantage. Organizational identification was found to influence employees' attitude towards turnover intention in a negative way. Therefore, fostering identification will contribute to the long-term success of an organization.

In contrast to the majority of prior studies on OID that have been conducted in the Western countries (Chughtai \& Buckley, 2010; Edwards, 2005), this study has been conducted in Turkey in general and construction industry in particular.

It is suggested that a detailed conceptual model relating to the antecedents of organizational identification be tested by means of structural equations modelling based on larger scale data collection. The present regression analysis provides a basis to support the relationship of identification and turnover intention, but further model development is required to take into account other possible antecedents of organizational identification. Accordingly, future research can replicate the present study's findings, implications for theorizing on hierarchical status and its influence on organizational identification and turnover intention may be realized.

\section{REFERENCES}

- ASHFORTH, BLAKE E. and FRED MAEL (1989) Social Identity Theory and The Organization. Academy of Management Review, 14 (1), 20-39.

- ASHFORTH, B., \& HARRISON, S. H., \& CORLEY, K. G. (2008) Identification in Organizations: An Examination of Four Fundamental Questions. Journal of Management, 34(3), 6

- $\quad$ BADGER, F., \& WERRETT, J. (2005). Room for improvement? Reporting response rates and recruitment in nursing research in the past decade. Journal Advanced Nursing, 51, 502510

- $\quad$ CHO, Y. J. \& LEWIS, G.B. (2012) Turnover Intention and Turnover Behavior: Implications for Retaining Federal Employees. Review of Public Personnel Administration 32(1): 4-23

- $\quad$ COTTON, J. L. \& TUTTLE, J. M. (1986) Employee Turnover: A Meta-Analysis and Review with Implications for Research, The Academy of Management Review, Vol. 11, No. 1, 55-70.

- DISANZA, J. R., \& BULLIS, C. (1999) Everybody Identifies with Smokey The Bear: Employee Responses to Newsletter Identification Inducements at The U.S. Forest Service. Management Communication Quarterly, 12(3), 348.

- $\quad$ DUTTON, J. E., \& DUKERICH, J. M. (1991) Keeping an Eye On The Mirror: Image and Identity In Organizational Adaptation. Academy of Management Journal,34(3), 517-554 
- DUTTON, J. E., DUKERICH, J. M., \& HARQUAIL, C. V. (1994) Organizational Images and Member Identification. Administrative Science Quarterly, 39, 239-263.

- DUKERICH, J. M., GOLDEN, B. R., \& SHORTELL, S. M. (2002) Beauty Is In The Eye of The Beholder: The Impact of Organizational Identification, Identity and Image On The Cooperative Behaviors of Physicians. Administrative Science Quarterly, 47, 507-534.

- JACKSON, S.E., ONES, D.S. \& DILCHERT, S. ( 2011) Managing Human Resources for Enviromental Sustainability, John Wiley \& Sons

- KARABEY, C. N. \& ISCAN, Ö. F. (2007) The Relationship Between Organizational Identification, Organizational Image and Organizational Citizenship Behaviour: An Application. Atatürk University Journal of Economic and Administrative Sciences, 21 (2), 231-241.

- LIPPONEN, J., HELKAMA, K., OLKKONEN, M. E. \& JUSTLIN, M., (2005) Predicting The Different Profiles of Organizational Identification: A Case of Shipyard Subcontractors, Journal of Occupational and Organizational Psychology, 78(1), 97-112.

- MAEL, F. \& ASHFORTH, B. (1992) Loyal from One Day: Biodata Organizational Identification, and Turnover Among Newcomers, Personnel Psychology, vol.48, 103-123.

- MEYER, JOHN P. and NATALIE J. ALLEN (1997) Commitment In The Workplace: Theory, Research and Application. Thousand Oaks, London, New Delhi: ATOB SAGE.

- MEYER, J. P., STANLEY, D. J., HERSCOVITCH, L., \& TOPOLNYTSKY, L. (2002) Affective, Continuance, and Normative Commitment to The Organization: A Meta-Analysis of Antecedents, Correlates, and Consequences. Journal of Vocational Behavior, 61(1), 20-52.

- ONES, D. S., DILChERT, S., BIGA, A., \& GIBBY, R. E. (2010). Managerial level differences in eco-friendly employee behaviors, paper presented at the Annual Conference of the Society for Industrial and Organizational Psychology,Atlanta, Georgia.

- POSTMES, TOM, MARTIN TANIS and BOUDEWIJN DE WIT (2001) Communication and Commitment In Organizations: A Social Identity Approach. Group Processes \& Intergroup Relations, 4(3), 227-246.

- PRATT, G. MICHAEL (1998) To Be or Not to Be? Central Question In Organizational Identification. In WHETTEN, D. A. and P. C. GODFREY (eds.). Identity In Organizations: Building Theory Through Conversations. SAGE: Thousand Oaks, London, New Delhi.

- RANDSLEY DE MOURA, G., Abrams, D. RETTER C., GUNNARSDOTTIR, S. \& ANDO K. (1998) 'Identification as an organizational anchor: How identification and job satisfaction combine to predict turnover intention', European Journal of Social Psychology, 39(4). Pp. 540-557.

- RIKETTA, M. (2005) Organizational Identification: A Meta-Analysis. Journal of Vocational Behavior, 66, 358-384.

- RiORDAN, C. M. \& WEATHERLY, E. W. (1999) Defining and Measuring Employees' Identification with Their Work Groups, Educational and Psychological Measurement, 59, 310-324.

- $\quad$ ROBERTS, P. W. \& DOWLING, G. R. (2002) Corporate Reputation and Sustained Superior Financial Performance. Strategic Management Journal, 23, 1077-1093.

- SCOTT, C. R. (1997) Identification with Multiple Targets in a Geographically Dispersed Organization. Management Communication Quarterly, 10(4), 491-522.

- SMIDTS, A., PRUYN, A. T. H. and VAN RIEL, C. B. M. (2001) "The Impact of Employee Communication and Perceived External Prestige on Organizational Identification", Academy of Management Journal, Vol. 49 No. 5, pp. 1051-62.

- SMITH, P. L., \& HOY, F. (1992). Job Satisfaction and Commitment of Older Workers in Small Businesses. Journal of Small Business Management, 30(4). 106-118.

- SNAP, E., CHAN, A. W. \& REDMAN, T. (2006) Multiple Commitments In The Chinese Context: Testing Compatibility, Cultural, and Moderating Hypotheses, Journal of Vocational Behaviour, 69, 302-314.

- VAN DICK, ROLF, ULRICH WAGNER, JOST STELLMACHER and OLIVER CHRIST (2004) The Utility of a Broader Conceptualization of Organisational Identification: Which 
Aspects Really Matter?, Journal of Occupational and Organisational Psychology, 77(2), 17192.

- WAN-HUGGINS, V. N., RIORDAN, C. M. and GRIFFETH, R. W. (1998) "The Development of Longitudinal Test of a Model of Organizational Identification”, Journal of Applied Social Psychology, Vol. 28, pp. 724-49. 


\title{
RESEARCH PROGRAMME ON INNOVATIVE LEARNING SPACES AND THEIR DEVELOPMENT
}

\author{
Kähkönen, K. ${ }^{1}$, Keinänen, M. $^{2}$, Naaranoja, M. ${ }^{3}$, Niemi, O. ${ }^{4}$ and Savolainen, J. ${ }^{5}$
}

\begin{abstract}
:
The "Indoor Environments" (IE) research program was a highly ambitious research program coordinated by the Strategic Centre for Science, Technology and Innovation for Built Environment (RYM). The overall target of this four year research effort is built around a rather radical vision where we see conditions, where humans will go from outdoor spaces into the indoor environment to grasp fresh air, to refresh them and to get inspired. The IE program's research agenda through far-reaching, collaborative and multidisciplinary research work is carried of jointly by companies, universities and research centres. The research work was carried out by the consortium which included 26 industrial partners and 10 research partners. The main targets of IE research program were i) user-centric spaces and their energy-efficient management, ii) revenue models for good indoor environment, and iii) design and implementation of innovative learning environments. The authors of this paper were involved in the main research activities addressing new learning environments. The research included design of pilot projects, demonstration projects and pop-up projects for testing possible organizational solutions. In this work it was collaborative design with end-users, their engagement, relating processes and their testing which all together represent the chosen research direction. The end-user centric operations provide a way towards service oriented construction and renovation operations. This paper shall present the overall body of that research work, examples of the gained results and conclusions based on these contributions.
\end{abstract}

\section{KEYWORDS: BUILDING DESIGN, EDUCATIONAL ENVIRONMENTS, DESIGN MANAGEMENT, PROPERTY DEVELOPMENT, USER EXPERIENCE, VALUE MANAGEMENT}

\section{INTRODUCTION}

Real estate and construction has been often named as a traditional fragmented sector where the sector wide innovations are very difficult to achieve (Aranda-Mena et al, 2009; Bernstein \& Pittman, 2004). Generally, the construction industry is a very heterogeneous combination of localised needs, various crafts, services, products and their professional providers. Each service or product supplier can be seen as a business line of its own inside the construction sector due to its specific characteristics, culture and terms of business. It is obvious that specific measures and instruments are needed for introducing systemic changes and improvements in this kind of business conditions. For example, new procurement models and their wide use have generated a lot of interest which has been very popular research and development approach. Recently the main attention has

\footnotetext{
${ }^{1}$ Tampere University of Technology, Department of Civil Engineering, Finland. Email: kalle.e kahkonen@tut fi

${ }^{2}$ Tampere University of Technology, Department of Civil Engineering, Finland. Email: marko.keinanen@tut fi

${ }^{3}$ Vaasa University, Finland. Email: marja naaranoja@uwasa fi

${ }^{4}$ University Properties of Finland Ltd, Finland. Email: olli niemi@sykoy.fi

${ }^{5}$ Sumplia Workshop Ltd, Finland. Email: jussi.savolainen@sumplia.fi
} 
been towards relational contracting solutions such as Integrated Project Delivery Matthews \& Howell, 2005).

Another potential approach is to have sector wide key promoters which are extensively acknowledged and have thus full potential for advancing the desired major changes. Accordingly, the Strategic Centres for Science, Technology and Innovation (SHOKs) were established in 2007 as a policy concept to accelerate the process of innovation and renew Finland's industrial clusters. This includes also Strategic Centre for Science, Technology and Innovation for Built Environment i.e. RYM Ltd (later RYM) that is a private company owned by industry, research centres and universities as shareholders. RYM operates as a broker which is initiating and forming research programmes for achieving the innovation targets. Further information from the SHOK centres can be found from Lähteenmäki-Smith et al (2013).

This paper shall present some key results of a research program "Indoor Environments" (IE) initiated by RYM. New innovative learning spaces, what their can be and how they can be achieved were one of the key objectives of this research programme.

\section{IE RESEARCH PROGRAMME}

The RYM's vision is to create the superior world-class competences and competitiveness for the whole life-cycle of built environment through a top-ranking joint strategic research of the real estate and construction sector. Accordingly the built environment will be developed with a user- and customer-oriented approach so that it will improve people's health and well-being, and create good conditions for competition as well as respond to changing needs of industry, business, habitation and consumption in the best possible way. New user-oriented thinking and operations models are needed in design, construction and use of buildings and built environment. The spaces shall be adaptable and versatile. Spaces will also grow toward platforms of virtual services, and intelligent learning systems will overcome in their control. User-oriented thinking will also change for example understanding about a school or hospital as a functional environment.

This Indoor Environments research program (2011-2015) was the second major research programme initiated by RYM. The IE programme addressed the indoor environment research from multiple perspectives (Figure 1). The overall goal of the research program was the gain improved understanding of the physiological and psychological basis of perceived indoor environmental quality (IEQ) and IEQ targets when user is comfortable, healthy and productive. The focus areas were user-centric spaces, energy-efficient management of the indoor environment, revenue models for good indoor environments, and design and implementation of inspiring learning environments. Energy-efficiency refers to the ecologically sustainable solutions that can meet successfully tightening energy-saving requirements which also still represent good and healthy indoor environments. The IE research consortium consisted of 26 companies and 10 research institutes. For further information look at http://rym.fi/programs/ 
Figure 1. The three main drivers and research questions formed the main starting points and objectives of the Indoor Environments research program.

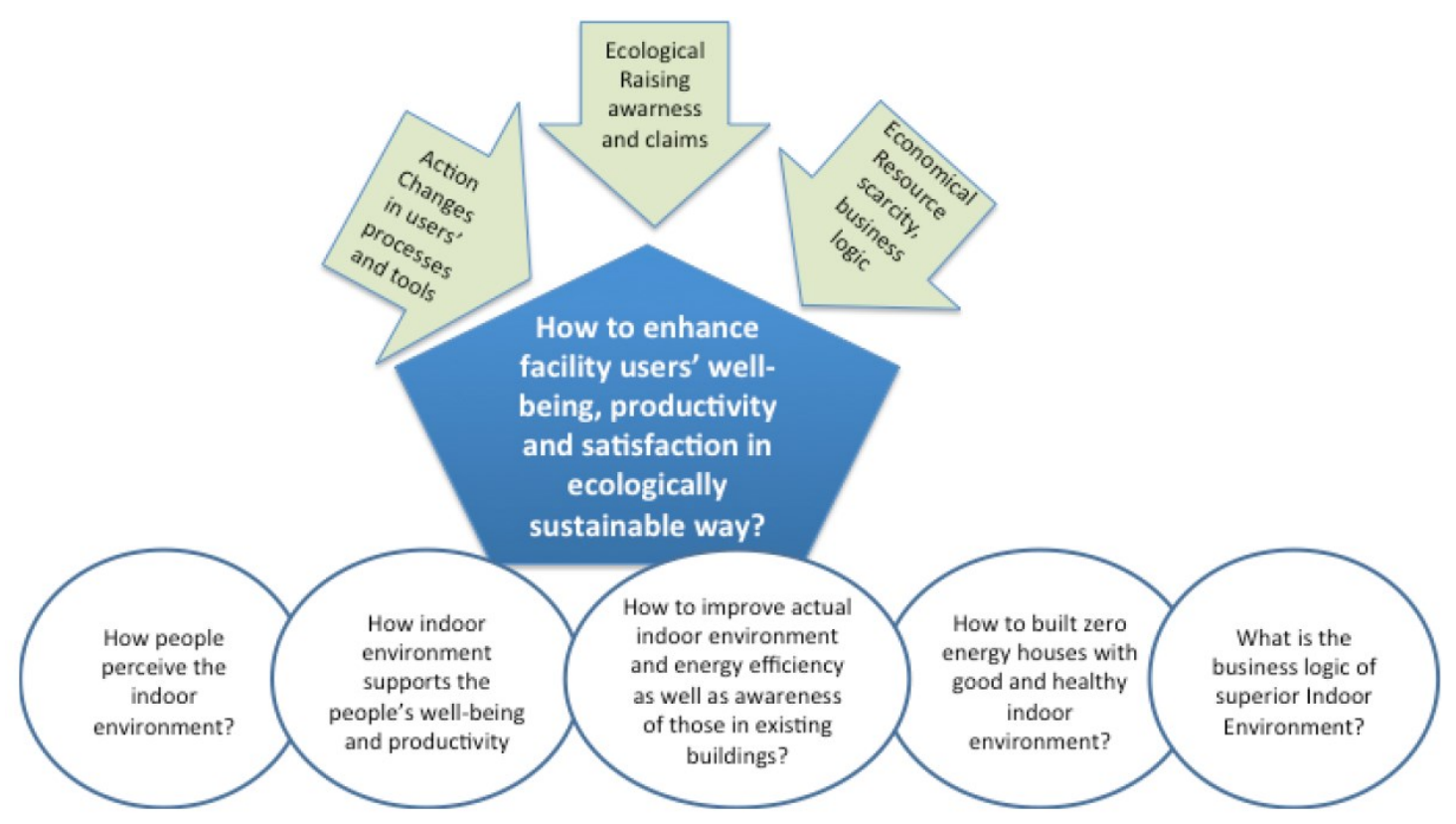

\section{RESEARCH ADDRESSING NEW LEARNING SPACES}

Real estate form a central part of universities property. At the same time, the facilities and buildings form the main place for learning and knowledge creation. Optimizing and tailoring the facilities according to users' needs is essential. Investments in renovations and building projects must be based on the owner's and users' needs. For instance, in designing libraries or laboratories, we have to be aware of the current practices and ways people use these spaces, and further, to be able to see in which direction the business is going. It is therefore imperative to carry out intensive research and find out the human perspective, before making big investments for designing something that is not useful. Furthermore, the challenge is to design spaces that are functional for different groups of people including undergraduates, graduates, $\mathrm{PhD}$ students, and faculty staff. New technologies are opening new possibilities for organizing learning and research at the workplace. This is not only a challenge, but provides new business opportunities for technology industry, construction, design and pedagogical innovations.

The IE research program included a work package where the focus of research was on the future learning environments. The interest was to understand how to support the goals of university renewal by providing appropriate facilities and services. The support of efficient performance of the organization, creation of rapid and agile innovations and development of competitive edge were amongst the main research interests. The shift towards more social and interactive, constructive processes as learning vehicle comprised important viewpoints. The identified learning philosophy supports learning that is 
embedded in a hybrid curricula containing different teaching and learning activities, is inter professional, interactive, flexible, collaborative and enforces peer-learning. Lifelong learning is a strong value which can be reinforced by physical environment. The future learning environments work package included four main research tasks (Figure 2). Important parts of the research were pilot studies over novel designs of learning environment and their implementation (Naaranoja et al, 2014. The following chapter presents results from these pilot studies. Each pilot study description includes presentation of the used research methods.

Figure 2. The main research tasks of the future learning environments work package.

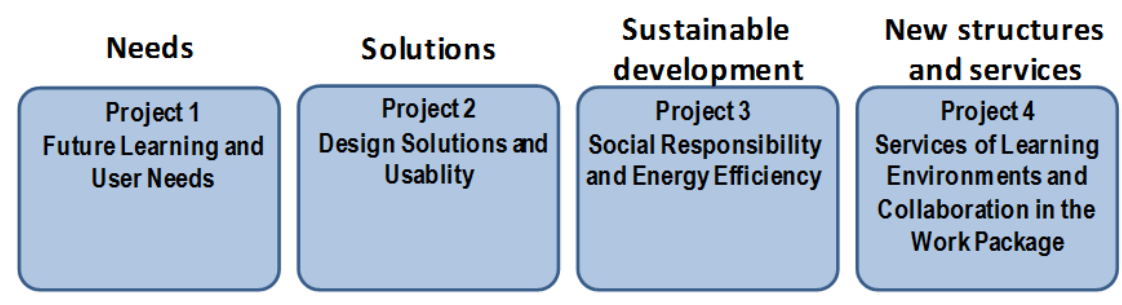

\section{RESULTS FROM PILOT STUDIES}

\section{Case Motivaattori: a designed third place as social learning space in higher education}

(Case introduction based on Poutanen, 2013)

\section{General introduction}

Generally, expectations concerning learning as a process or experience have changed clearly during the past decade. Demand for learning solutions that are more collaborative, blended with other activities, can happen anywhere and anytime comprise the most important needs faced increasingly by campus planners (Dugdale, 2009). Case Motivaattori is an example of a transformation of existing supporting function area into primary functions as a social informal learning place in Tampere University of technology (TUT) premises.

\section{Resulting object}

Café Motivaattori is existing informal and the social third place in university campus. Near areas, former entrance hall, coat rack area and a corridor were transformed into the use of primary functions with novel spatial solutions: the "Platforms", the "Glass Boxes" and the "Table Groups" (Figure 3). The case areas are in near connection with this third place function and it can be seen exemplifying of a Designed Third Place. These case areas are examples of easy-access spaces: reservations are not required, and the novel areas are not part of curriculum. The novel learning spaces were designed in an architectural design course arranged for architecture students. The design, implementation and research of the case study were conducted over the year 2012 . 
Figure 3. Observation areas and target spaces in plan (Figure: Poutanen, 2013).

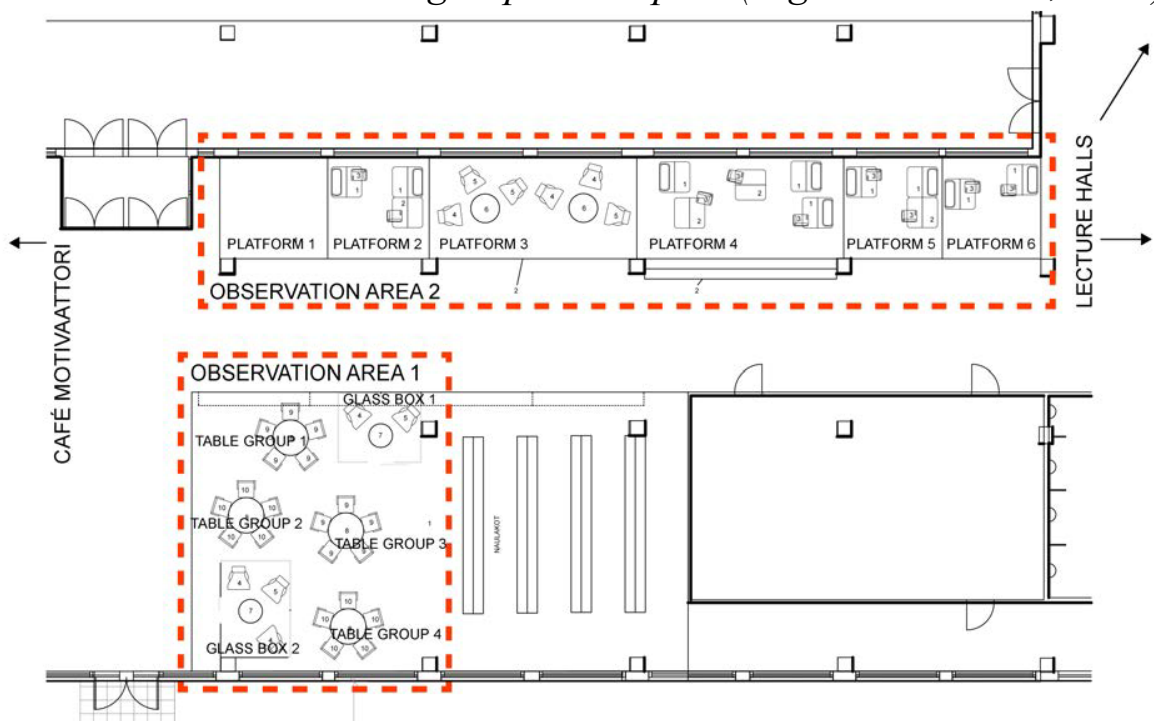

\section{Research method and results}

The used research method was Direct Systematic Observation on two observation areas. In the observation it was examined how many people use spaces and to what function. Altogether fifteen of two hour sessions were taken into account in the final analysis. Number of users is shown in Figure 4.

Figure 4. Total amount of users in the whole case area during the observation sessions. (Figure: Poutanen, 2013).

TOTAL AMOUNT OF USERS

(sum of users of all the observation sessions)

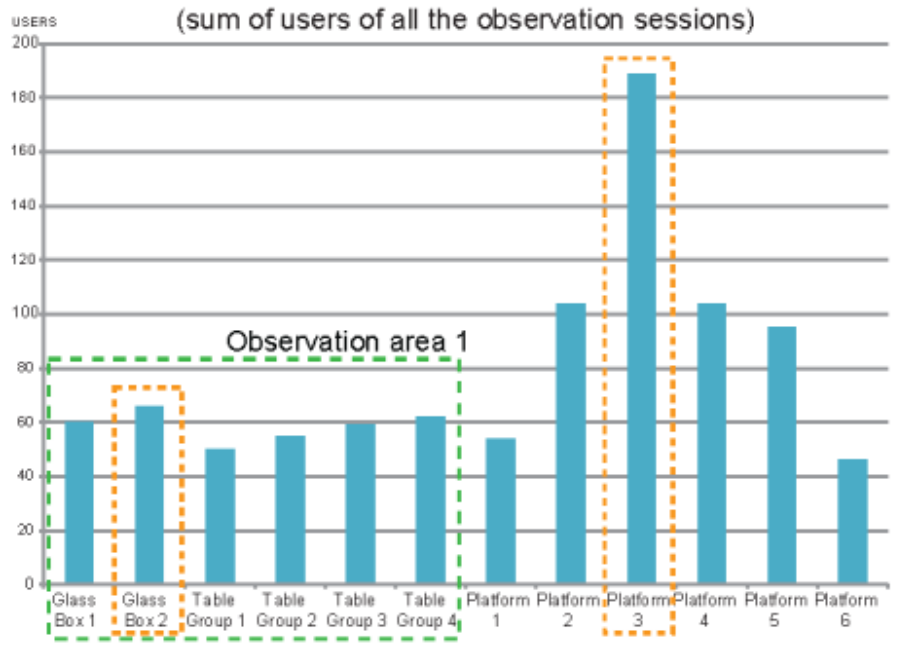

The use of the target spaces was observed by dividing the use in work or in leisure. Results are shown in Figure 5. The comparison between of the target spaces indicates that the Glass Boxes were preferred for working, the Table Groups come in second and the use of the Platforms was almost half work and half leisure (Figure 5). 
Figure 5. Comparison of uses in Target Spaces. (Figure: Poutanen, 2013).
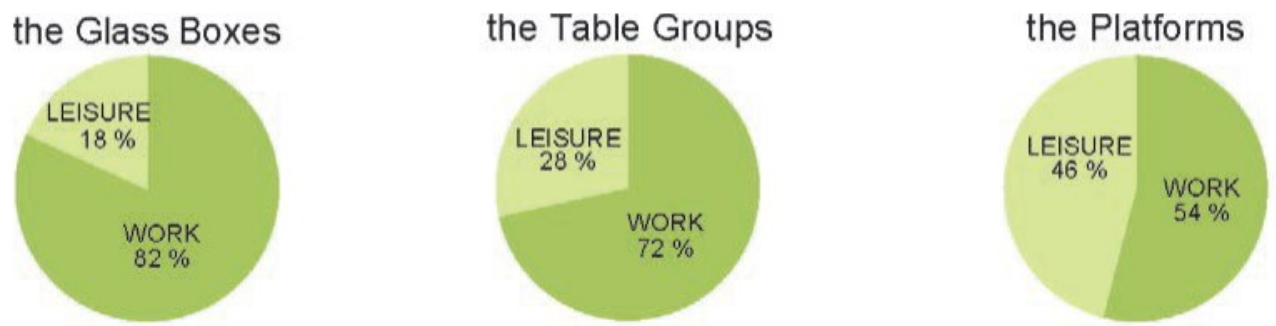

Results show that the new places are actively used. Users also seem to study or work rather than just spend time. These results indicate that these kinds of places are needed and learning and/ or working can also happen in a noisy and active place.

\section{Case Jyväskylä - co-creative process in renewing university spaces}

\section{General introduction}

In this case study a $400 \mathrm{~m} 2$ location was re-designed at the University of Jyväskylä, Finland to better support the core activities of the organization. The co-creation process was part of a national Indoor Environment research project that aimed at designing evidence-based educational spaces for knowledge creation. The charrette approach formed starting point for designing and running the co-creation processes (Lindsey et al, 2009). The co-creation project began in November 2013 and ended in March 2015. The process is divided into five phases that follow each other. Each phase has its own mission and involves various tasks and activities. In this case study approximately 50 individuals participated in a five-day design workshop charrette, to analyze and propose new spatial solutions for higher education. The charrette was organized in two parts: the first part encompassed two days in December and the second part encompassed three days in January. Participants represented different user-groups - students, teachers, researchers, facility management, campus developers and musicians. Designers, architecture and construction professionals were also involved in the co-creation process. Workshops included drawings, discussions, handicrafts and the testing of proposed spatial solutions with cardboard and paper. Additionally, professionals from different fields were invited to give inspirational speeches, and visits were made to spaces significant to the design. All the workshops took place in the space that was to be renewed.

\section{Resulting object}

During the visioning phase (here: the first phase of the charrette process) the project goals and the guidelines for design were set by the central stakeholders and implementers of the project. Goals for the project were increased use of space, sense of ownership through participation, improving the image of the discipline and research. The first draft drawing of renewing the location was completed by the architect (Figure 6). In the drawing, the space is divided into five smaller spaces, each with a different design concept: Stage, 
Club, Studio, Showroom and Lobby. This presented a novel conceptualisation and sectioning of the location.

Figure 6. The first draft from the architect.

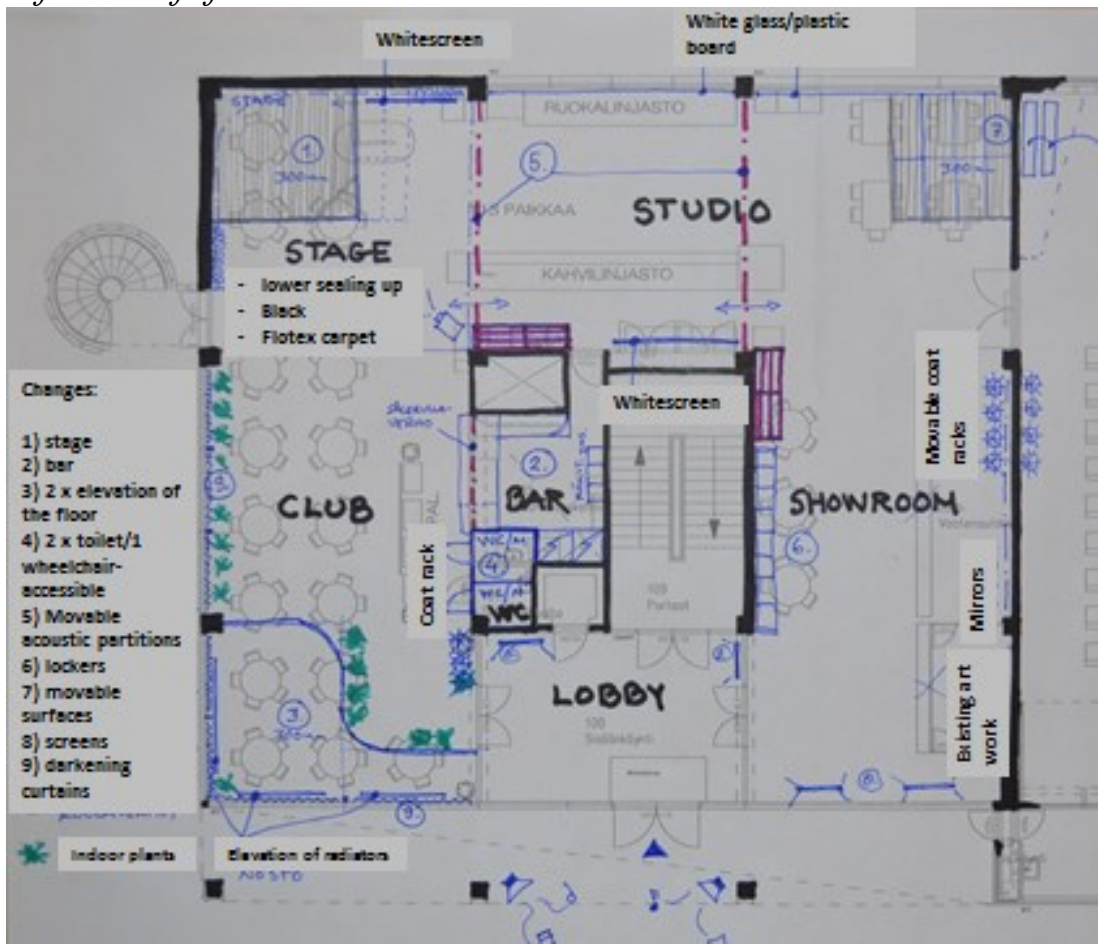

\section{Research method and results}

Various forms of data were gathered systematically throughout the project. The data comprises all the memos and minutes from the project meetings and materials produced during charrette. Charrette materials comprise designs in writing and drawings, expertevaluations, summaries of discussions, concept designs and the first draft of the architect's drawing. In addition, video recordings and a user-experience survey were conducted. The gained results are providing basis for the following conclusions: i) The active role of the owner seems to lead to opportunities to co-create value-in-use with users in the concept design phase, ii) If users are not actively involved in the creation process, the new premises are designed for the prevailing activities of the users and the new culture will remain undeveloped, iii) The co-creation produces positive expectations and the readiness of end-users for swift commissioning.

\section{Case Kampusareena}

General introduction

The 21 st century has changed many things about modern society. New technologies and social developments affect the way in which we communicate and work together. Many traditional offices do not offer environments which support this. Kampusareena is a new kind of working environment for universities and enterprises that support communality, learning and business. Kampusareena is a major new building investment by Tampere 
University of technology. The inauguration ceremony of this building took place in September 2015

\section{Resulting object}

A hub of science, research and technology called Kampusareena is a full scale pilot project in the campus of the Tampere University of Technology in Finland (Figure 7). The preplanning of the building was started in 2011 and actual project planning in 2012 . This over 15000 gross square meter building was finished on August 2015. The eight floor building consists of bigger three floor base and five floor tower. $60 \%$ of the premises are used by the university and $40 \%$ is rented to an office and business premises.

\section{Figure 7. Kampusareena (source TUT, photographer Jalonen A.)}

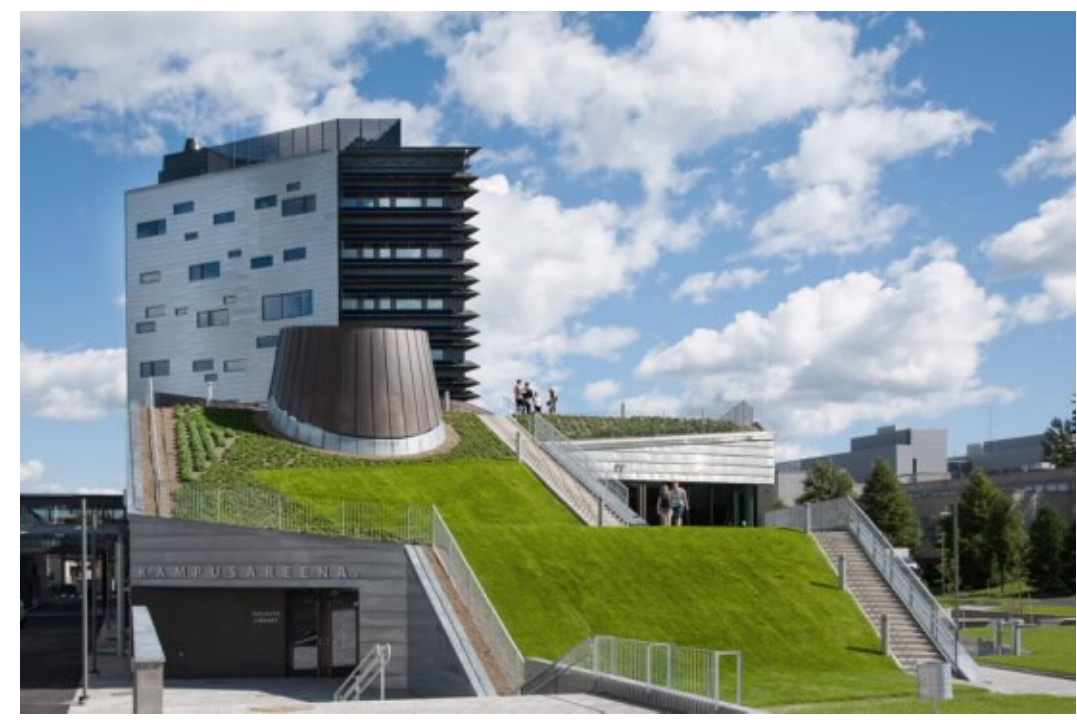

The concept behind of Kampusareena was formed during the "Indoor Environment" research program. The leading idea was to create a service platform students, researchers and other professionals that enables their collaboratively work, study and create with the specialists of enterprises in the campus area. A service platform is a working environment that provides the entire infrastructure to this kind of operation. Kampusareena can be considered as an innovative, a different stakeholders integrative, protean multipurpose building to support learning and businesses. In this case it is justified to talk about more a service platform rather than a building.

\section{Research potential}

At present, in September 2015, Kampusareena is a "test lab" for a new kind project closing operations, building handover procedures and the start of building use. Data has been collected but the research results are still waiting to come. The recently completed service platform, which will be brought into use in the autumn 2015, will offer interesting opportunities for various ways of research also in the future. The great interest is directed to it how the building is able to support the functions that have been invested in it. At first 
it is planned to carry out a research on a utilization of separated spaces and services along with the flow of people.

\section{CONCLUSIONS}

The presented case studies represent prototyping towards new kind of building premises concerning learning spaces. This prototyping included variety of research interest: i) organizational solutions for the design process and actual experimenting with those in case projects, ii) end product solutions, iii) end user oriented processes. The gained results are demonstrating the benefits that can gained from early involvement, and that in a high activity level, of end users in co-operative design processes. However, this requires thoughtful facilitation where the thinking over the needs-of-future-services and their realization requires main attention. It is of importance to make distance to the traditional thinking models where the discussions are typically focusing on area spaces and technical utilities. Heterogeneity of project partners in person and their commitment levels can clearly be challenging aspects.

Based on the gained experiences the early involvement of end users together with cooperative project processes are seen as imperative ways to develop building construction project processes to a new performance and service level.

\section{ACKNOWLEDGEMENTS}

The Finnish Funding Agency for Innovation (TEKES) was the main financing sponsor behind the Indoor Environments. University Properties of Finland Ltd was the main financing sponsor behind the future learning environments work package.

\section{REFERENCES}

- $\quad$ ARANDA-MENA, G., CRAWFORD, J., CHEVEZ, A. and FROESE, T. (2009), "Building information modeling demystified: does it make business sense to adopt BIM?", International Journal of Managing Projects in Business, Vol. 2 No. 3, pp. 419-34.

- BERNSTEIN, P.G. and PITTMAN, J.H. (2004), "Barriers to the adoption of building information modelling in the building industry", White paper, Autodesk Building Solutions, USA.

- BRADBURY, I., BOYLE, J. and MORSE, A. (2002) Scientific Principles for Physical Geographers. Harlow: Prentice Hall.

- DUGDALE, S. (2009) Space strategies for new Learning Landscape. Educause Review. March/April 2009 pp.51-63. Available through: http://www.educause.edu/ero/article/spacestrategies-new-learning-landscape [Accessed 31 August 2012].

- $\quad$ FONTANA-GIUSTI, G. (ed.) (2008) Designing Cities for People: Social, Environmental and Psychological Sustainability. London: Earthscan.

- $\quad$ LAHTEENMÄKI-SMITH, K., HALME, K., LEMOLA, T., PIIRAINEN, K., VILJAMAA, K., HAILA, K., KOTIRANTA, A., HJELT, M., RAIVIO, T., POLT, W., DINGES, M., PLODER, M., MAYER, S., LUUKKONEN, K. AND GEORGIHIOU, L. (2013) "Licence to 
SHOK?" External evaluation of the strategic centres for science, technology and innovation, Publications of the Ministry of Employment and the Economy, Finland.

- $\quad$ LINDSEY, G., TODD, J. A., HAYTE, S. J., \& ELLIS, P. G. (2009). A handbook for planning and conducting charrettes for high-performance projects (2nd ed.). Golden, CO: National Renewable Energy Laboratory. [Adobe Digital Editions version]. Retrieved from http://www.nrel.gov/

- MARSHALL, W. A. (1975) The Child as a Mirror of his Brain's Development. In SANTS, J. \& BUTCHER, H. J. (eds.). Development Psychology. Aylesbury, Bucks: Hazell Watson \& Viney Ltd.

- MATTHEWS, O., \& HOWELL, G. (2005). Integrated project delivery: An example of relational contracting. Lean Construction Journal, 2(1), 46-61.

- $\quad$ NAARANOJA, M., KÄHKÖNEN, K. and KEINÄNEN, M. (2014) Construction Projects as research objects - different research approaches and possibilities, Procedia - Social and Behavioral Sciences 119 ( 2014 ) p. 237-246.

- $\quad$ NEVILlE, C. (2010) The Complete Guide to Referencing and Avoiding Plagiarism. 2nd Ed. Maidenhead: Open University Press.

- $\quad$ POUTANEN, J. 2013. A designed third place as social learning space in higher education case motivaattori. INTED 2013 Proceedings: 7th International technology, Education and Development Conference, Valencia, Spain, 4th - 6th March, 2013. pp 688-697.

- SADLER, P. (2003) Strategic Management. [Online] Sterling. VA Kogan Page. Available from: http://www.netlibrary.com/reader/. [Accessed: 6th May 2012]. 


\title{
RADICAL CIRCULAR ECONOMY
}

\author{
Mohammadi, S. ${ }^{1}$; Prins, M. ${ }^{2}$, and Slob, N. ${ }^{3}$
}

\begin{abstract}
:
Recently the Circular Economy (CE) concept has gained momentum in the Netherlands, propounding that environmental impact reduction can provide a significant positive economical impulse. The government, larger parts of the industry as a whole, as well as the construction industry, has warmly received this approach. At first sight the CE concept connects over two centuries of sustainability thinking together in a relatively seen rather coherent framework. So, CE in its constituent elements doesn't provide anything new. It is the economic framework uniting the elements, which makes CE a new and challenging approach. Insofar the Dutch construction industry is concerned, based on the extensive experiences of the authors over the past years, the CE concept gets a fragmented, incoherent and eclectic interpretation. In the paper, departing from the concept of the 'homo-economicus' (Mill, 1836), and the free market theory (Malthus, 1826) $C E$, is re-defined into 'Radical $C E$ ' attempting to constitute a CE theory and terminology, appropriate for the construction industry and addressing the core of the CE concept in terms of a sustainable industry and society, behaving as such because of economic incentives. Based on the concept of 'Radical CE', the paper describes and evaluates several CE cases. The paper concludes with some guidelines and strategies for implementing CE.
\end{abstract}

KEYWORDS: RADICAL CIRCULAR ECONOMY, SUSTAINABILITY, HOMOECONOMICUS, FREE MARKET THEORY, CIRCULAR ECONOMY THEORY, CRADLE 2 CRADLE, RAW MATERIALS, ENVIRONMENTAL IMPACT REDUCTION

\section{INTRODUCTION}

The current and future developments indicate that the demand for natural resources will radically increase due to the growth of the world population from 7 billion persons today to 9 billion in 2050 (UNEP, 2011). At the same time, 3 billion people will be added to the middle class (OECD, 2012). This will lead to an increase in consumption and by further use of natural resources at the current pace two similar planets will be required in 2050 to meet the needs and aspirations of the people (EMF, 2012). As our society and economy are constantly changing, the unsustainable process of production, which contains a takemake-dispose model, has not changed since the beginning of the industrial revolution two centuries ago. This unsustainable development has resulted in scarcity of raw materials, depletion and waste of resources, global warming, environmental pollution, greenhouse gas, climate change and unfair distribution of wealth (IPCC, 2013). McKinsey (2011) reported that 'resource-scarcity' risks are increasing, leading to more 'volatile prices.' Continuing 'business as usual,' will likely impose increasing threats to the environment, welfare, wellbeing, competitiveness, profits and business continuity (Wijkman, and

\footnotetext{
1 Delft University of Technology, Faculty of Architecture, The Netherlands / Reborn BV. Email: S.Mohammadi@tudelft.nl

${ }^{2}$ Delft University of Technology, Faculty of Architecture, The Netherlands. Email: m.prins@tudelft.nl

${ }^{3}$ Delft University of Technology, Faculty of Architecture, The Netherlands / Reborn BV. Email: N.Slob@tudelft nl
} 
Skånberg 2015). Moreover, recent debates have focussed on the challenges and complexities associated with meeting the resource demand (Barlow, 2013). Chatham House (2012) reported "new models are required to de-link rising prosperity from resource consumption growth." Due to these current developments, the quality of life for many is in jeopardy (EMF, 2013).

The construction industry is an important economic engine and makes intensive use of resources extracted from the earth, which generates a significant amount of the earth's environmental pollution (UNEP, 2011; BAM, 2013). Change in the construction industry is urgently required because the construction industry consumes $40 \%$ of the natural resources (Roodman and Lenssen, 1995). This means each year, approximately three billion tonnes of raw materials (European Commission, 2014) and a further $40 \%$ of the total flow in the global economy are used in the manufacturing of building products and components globally (BAM, 2013). Moreover, the built environment is responsible for $40 \%$ of the total use of energy (UNEP, 2011; European Commission, 2014).

Recently the Circular Economy (CE) concept gained momentum in the Netherlands, propounding that environmental impact reduction through $\mathrm{CE}$ can provide a significant positive economical impulse, this following EMF's (2012) report produced together with McKinsey. CE, although it's dates back much earlier, since 2012 became rather popular within the industry at governmental levels and by the EU (DG Environment, 2014). Circular economy is assumed to boost innovation and to generate profits for businesses as supply chains are better managed. In turn companies will be less sensitive to price volatility of resources, and additionally, adapting $\mathrm{CE}$ will build longer and better relationship with customers (Kok, et al., 2013). The Ellen Macarthur Foundation and TNO estimated the combined benefits to be around $€ 500$ billion over a ten year period for the European Union (3,6\% growth cumulative) and around $€ 7$ billion for the Dutch economy $(1,4 \%$ growth cumulative over a ten year period as the Dutch already have much higher recycling rates than other European countries) (Bastein et al., 2013; ING, 2015).

$\mathrm{CE}$ can be defined as an economic system. Within CE thinking predominantly (-neo liberal vision) the economic system is assumed to result in a sustainable industrial production. CE takes the reusability of products and materials and the protection of natural resources as a starting point and pursues value at every stage of the system (TNO, 2013). In a CE, the aim is to maximize value creation in each link in the system hence products must be designed for ease of reuse, disassembly and remanufacturing or recycling to keep material flows circulating at a high rate. So to achieve true sustainability, CE pursue value through design of the reusability of products and raw materials, and the restorative capacity of natural resources (in terms of quality, property, function, range of use) without the materials entering the biosphere, unless they are biological nutrients. Additionally a fundamental part of the CE concept (following Stahels' (1976) thinking) is the transition from product consumption to product services. 


\section{SUSTAINABILITY AND CIRCULAR ECONOMY}

At first sight the CE concept connects over two centuries of sustainability thinking together in a relatively seen rather coherent framework. Malthus ("An Essay on the Principle of Population') -and later on Marx- already in 1798, warned that population growth would exceed resource growth, leading to catastrophic checks on overpopulation. At the turn of the century, Arrhenius (1896) noted the phenomenon of 'greenhouse gas emissions' and the 'warming of the Earth. Boulding (1966) described the earth as a 'closed system' and illustrated that the economy and the environment are interlinked. The publication "The Limits to Growth" by Meadow et al. (1972) distributed by the Club of Rome led to a huge impact on public opinion. The publication, predicted the beginning of the 21 st century resource depletion. Commoner (1971) suggested that economy should be remodelled to adapt the unbending "laws of ecology." Commoners' approach of materialloops, was further developed by Stahel (1976) introducing 'the Looped Economy'. In the 1980s, "Our Common Future," the report of World Commission on Environment and Development (WCED, 1987) radically influenced the modern view by defining the concept of sustainable development as a holistic concept (People, Planet, Profit), claiming that the environmental degradation is linked to social as well as economic developments. The Rio Summit (1992) again addressed the fact that we can no longer think of environment and economic and social development as isolated fields. From 1990s onwards, the perception gradually shifted away from single products and processes towards a more integrated, holistic systems thinking approach (Lyle, 1994; Lyle Center 2011). Benyus (1997) introduced the 'Biomimicry' concept, stating that nature's best 'ideas' needs to be imitated to solve human problems'. Industrial Ecology' was introduced in the 1970s, partly based on biomimicry thinking, and gained mainstream attention since 1990 (Frosch \& Gallopoulos). Industrial Ecology adopts a systemic point of view and focuses on material and energy flows. Waste within industrial models and symbioses are linked to develop closed ecological loop systems within industries (Graedel, 2002). Cradle to Cradle' (C2C) was introduced by Braungart (1999) and since became a rather dominant concept. The $20^{\text {th }}$ century remarked the further development of so called 'integrated theories'. Stahel (2006), continuing his earlier thinking, and created the concept of the 'Performance Economy' a concept based on usage instead of ownership; the ownership is kept by the producers and the user pays a fee for the performance of a product. Pauli (2010) introduced the 'Blue Economy' concept, which is a design philosophy, where the cascading system is developed to use the waste of one product as the input to create new cash flows.

\section{Circular Economy}

At first sight the CE concept connects over two centuries of sustainability thinking together uniting the various schools of thoughts. New however is the accent on sustainability in terms of economic profit for all as a core concept. CE is most often visualised in the 'circular system interactive diagram' also known as the so-called 'butterfly-diagram' (EMF, 2012). The system diagram shows how -raw or virginorganic materials, and technical materials behave in different circles or 'loops' flowing 
through and constituting the economic system. Within the technical cycle, materials must remain within that circuit, by means of maintenance, re-cycling, refurbishing and re-use. In the biological cycle, the materials are returned to the biosphere or directly used as nutrient for new cycles by composting and anaerobic digestion through non-toxic, restorative loops. Essential in the butterfly model is the idea of Stahels' product service concept in which the ownership of materials stays with the suppliers responsible to keep them in the circles. CE assumes an economic system resulting in sustainable industrial production. So in comparison to traditional sustainability thinking CE proposes a certain reversal of means and goal. However, due to the variety of concepts applied to (re-) define the $\mathrm{CE}$ concept it has become difficult to correctly address the definition and identify the challenges and obstacles, as there is relatively little critical analysis of the concept (Barlow, 2013). At least, as far as the Dutch construction industry is concerned, the $\mathrm{CE}$ concept gets a fragmented, incoherent and eclectic interpretation. Besides, there is a lack of solid theory and connected-empirical- evidence, in general and within the construction industry more specifically. The question at stake is, 'how do we know if CE works,' or 'how do we know what it is', if there are no common proven and accepted definitions and measurement scales.

The aim of this paper is to re-define CE into 'Radical CE', attempting to constitute a CE theory and terminology, appropriate for the construction industry and addressing the core of the CE concept. To achieve this, the concept and theories from the different publications and the extensive practical experiences of the authors over the past years are developed into a priori specification of constructs. This is the first step in Eisenhardt's methodology on theory-building. This method is assumed to be appropriate in the early stages of research on a topic or to provide freshness in perspective to an already existing topic (Eisenhardt, 1989). Although this type of specification is not common in theorybuilding studies to date, it is valuable because it permits researchers to measure constructs more accurately. If these constructs prove important as the study progresses, then researchers have a firmer empirical grounding for the emergent theory (Eisenhardt, 1989). As is typical for theory building, such approaches have to find a balance between generalization and specialization. Generalization makes them applicable in a wider range of settings. Specialization allows being detailed enough to yield insights on the individual case level. Next the constructs are thought through to identify opportunities, challenges, issues or obstacles. In this paper an attempt is made to measure new developed CE constructs in a few cases on building and product level within the Dutch construction industry.

\section{RADICAL CIRCULAR ECONOMY}

\section{A priori constructs}

Within Radical CE, CE is foremost seen as an economical system resulting in a more sustainable -industrial- production. Sustainability is defined as preserving the earth for future generations, with regard to global population growth, growing prosperity, social justice and fairness. The willingness of society to morally adapt this sustainability 
concept is axiomatically assumed within Radical CE. Radical CE departs distinguishing the natural world (mother earth with raw/virgin materials and natural resources), and an artificial (man-made) world with materials/parts (extracted from the earth), products (assembled parts) and components (more complex or and assembled products). Within the artificial world there are two cycles or loops namely a biological and a technical one. Within Radical CE in principle all materials stay as much and as long as possible, within one of the loops. Preferably as one can assume the regenerative capacity of the earth has its limits, materials have to be kept in the technical loop. Switching between the loops is part of CE. The technical materials that degrade during their period of use (lifecycle), or when they are no longer usable within the technical cycle, must be returned to the biological cycle (this assumes axiomatically that no $\mathrm{CE}$ materials without an economic $\mathrm{CE}$ act can be given back to the earth). In order to close cycles, energy is needed (Joustra et al., 2013). Within Radical CE axiomatically assumed there is an endless amount of clean energy available (EMF, 2012). The human within Radical CE is axiomatically a 'Homo-economicus' (Mill, 1836), which assumes a particular 'theory of life' as the 'foundation of morals'. According to Mill, A homo economicus within a Radical CE "does not treat the whole of man's nature as modified by the social state, nor of the whole conduct of man in society. It is concerned with him solely as a being who desires to possess wealth, and who is capable of judging the comparative efficacy of means for obtaining a wished end." Alongside, Radical CE is based on the free market theory (Malthus, 1826). This theory is based on a system where the forces of supply and demand are allowed to reach their point of equilibrium without intervention by government policy, and it typically entails support for highly competitive markets and private ownership of productive enterprises in which the prices for goods and services are set freely by consent between vendors and consumers. The end-users or consumer as 'Homo economicus' within Radical CE are not the (legal) owners of the products but they buy services in the form of a user right for a certain period of time. This means that consumers cannot, or only limited (only the services products contain), trade products. As due to scarcity, prices of materials will continue to rise this service concept is assumed to be in the benefit of suppliers as well as consumers. The supplier, as 'Homo economicus' within Radical CE always remains the owner of products. So by definition products are only traded by suppliers and in between suppliers. Supply chain partners who trade products in terms of a stock of services for a certain period of time to end-users (services market) are service providers. It is in the economic interest of suppliers to guarantee that products can be kept and traded within the loops. For the same reason complex products (components, especially those compiled out of products with different life spans) are designed for disassembly, so they can be dismantled and traded in parts within the supply chain market. A product that has reached the end of its economic lifecycle, which cannot be traded within the supply chain market nor on the service market is returned to earth via the biological loops. Within a Radical CE every transaction between the supply chain and service market is in the form of 'operational lease' or 'pay-per-use' (the more impure forms imply: financial lease, buyback and take-back). 


\section{Radical CE, some reflections}

Radical CE has consequences for the definition of a sustainable product. Within a Radical $\mathrm{CE}$ a product is sustainable if the product as a whole or in its constituent parts remains to be traded on the service market, or while cycling in the technical loop on the supply chain market or alternatively is given back to the natural world trading it through the biological loops. As within Radical CE clean energy is endlessly available, so nor maintenance, nor designing for durability makes a product more sustainable. Also the so-called 'functional degradation' at the end of a service life span has in principle no influence on the sustainability of a product, unless degradation implies shortening cycling within the technical loop. Finally, within Radical CE products require no assurance in terms of being kept in the loops. It is axiomatically assumed that the scarcity of resources and the resulting inflation ensures an economic incentive for supply chain partners to trade the (assembled) products sustainably at the service or supply chain market. So, designing a truly Radical CE product/component requires a systemic approach and will need new forms of cooperation among multiple actors operating in different parts of the supply chain, between producer and end-user.

Radical CE implies a decomposition of complex products, primarily in parts compiling a marketable stock of services of which the constituent products have also validity within the business models of the supply chain partners owning these parts. For such a product in form of a complex component not only the strategic assembly of the products is of great importance but also the junctions and fittings between the constituent parts. In Radical CE every junction needs to be modelled with its' own life span, maybe even its' own supply chain partner(s) and requires an investment decision, which cannot always be taken by a single responsible supply chain partner. As a complex product ought to be designed, engineered and constructed as a stock of services, composed in terms of materials, products and components from a CE perspective, new types of value models have to be developed to steer belonging the processes of decision making.

A building as manifest on a Radical CE services market can be characterised as a complex component existing out of subcomponents/products with different functional life spans in relation to the economic lifespan of the whole. The subcomponents might be owned by different supply chain partners and are traded, whether or not separately, as services by service providers. So design for disassembly needs to be incorporated in the business models. If constituent products within the complex component have shorter functional life spans as the whole, then these parts must be removable, replaceable and tradable. Furthermore, the above mentioned replacements asks for new forms of regulations between service providers and supply chain partners, as well regulations between service providers and end-users. The more products (subcomponents) that are owned by different supply chain partners, especially in case of different life spans, the more complex these regulations will be. Removal of products with a shorter life span within a complex component preferably has to be done without harming the connected parts. The mitigation of risks concerning the continuity of the services might be performed by the service provider on behalf of the supply chain partners acting together in a kind of cooperative company. 
A service provider/lessor holds a 'pay-per-use' or 'operational lease' contract with the end-users as a lessee. Under current regulations, this implies that the service provider owns the products in the form of company assets. In case of capital-intensive assets, this has wide implications for the business model and the companies funding structure (funding, liquidity, solvability). In terms of balance sheet management, risk mitigation, asset management, depreciation method, the income statement and taxation, the various measures of $\mathrm{CE}$ have far-reaching consequences that cannot be adequately addressed within the current market conditions and regulations. The implementation of Radical CE therefore requires adjustment in enterprise strategy and business finance models, funding mechanisms, governance structures, regulations and government policy. This relates to the level of supra-national-building-regulations-within the construction industry as whole as well as individual building projects. For instance, at he moment it seems rather impossible to get a 'product inflation swap' (compare with interest rate swaps, day trading and options and futures on the commodity futures market) on products with a duration of lets say 20 years.

In a Radical CE market it makes sense to disassemble the custom made one off buildings, which after their first use period might be assumed to have limited tradability as a whole, after the first contract period, where the disassembled products are then traded on the supply chain or service market. This is also because within 'Radical CE', consumers of $\mathrm{CE}$ goods are not the (legal) owners but only own a user right. The question remains whether consumers can trade user rights in the consumer market because of the lack in legal ownership of the goods. User rights are not without legal clauses, but are contractually agreed between the suppliers (rights-giving) and consumer (rights-getting). When these user rights are traded by consumers, a supplier should be able to claim its rights when needed in a chain of consumers over time. This doesn't seem really realistic at the moment. So the real estate market as existing today, for larger parts will disappear while implementing Radical CE.

In 'Radical CE' the identity of materials/parts, products and components should be registered in the form of a passport. Identity represents the embedded value and provides a tool for the service provider to trace the products.

Radical CE implies the assessment of a product being CE can only be measured in $\mathrm{Kg}$ of materials used under in essence the condition $-100 \%$ non virgin- materials at the start of a cycle, equals the amount of materials marketable on the service or suppliers market, out at the end.

\section{DUTCH CE CASES EVALUATED}

In this paragraph the Radical CE construct is applied to a few cases on building and product level within the Dutch construction industry. To do so the research relies on theoretical sampling (i.e., cases are chosen for theoretical, not statistical, reasons, Glaser \& Strauss, 1967). 
The 'Town-Hall of Brummen' (2014), which is often mentioned as one of the first and most famous CE project in the Netherlands, is a project designed for disassembly, implies a bio-degradable construction and several $\mathrm{C} 2 \mathrm{C}$ products. However, this project has no proof for incentives for the suppliers for even one loop after its first use-cycle (for instance in the form of a buy-back guarantee) hence it's not really circular according to the Radical CE concept.

The renovation of the headquarters of 'Tennet' (2014) is an example that comes closer to reach Radical CE. In this project a take-back guarantee is incorporated, within the procurement process, for all its furniture and infill. This relates to one single loop after its first use-cycle. This however is not primarily realised through financial incentives within the business model of the supply chain partners but forced through procurement pressures in the form of take-back guarantees. It's still not evident that the taking back of components by the suppliers is done primarily from out their circular business model. The case is much presented within the 'Dutch CE circuit' but till so far not described in the literature. According to the presentations on this case the resulting effect of the special procurement method used (the so called PRP method of the firm Rendemint) it was calculated that only $7 \%$ (in $\mathrm{kg}$ ) of all materials were really circular (in PRP terms, could be re-used without waste and with equal functionality).

Within the Netherlands two product related cases are most often provided as famous CE examples: the pay per lumen concept of Philips and the carpet tiles as produced by Interface and Desso.

The pay per lumen -LED- light concept (2013) is developed by 'Philips' for the office of RAU Architects in corporation with 'TurnToo' (TurnToo, 2015). The Pay per lumen idea seems to have an ideal CE fit but its unlikely, and nowhere documented, Philips having changed neither the product nor its business model according to CE principles because of this project. Thus as the incentive for even one loop after its first use-cycle is missing, the product is not yet really circular.

Interface and later on Desso have entered the market with carpet tiles, which can be operationally- leased, or bought. Both firms also have incorporated the take back of already existing carpet tiles in their business model for recycling them into new ones. So instead of paying for the discharge, one could say owners get paid for their waste of carpeting (Desso, 2015). There are no formal guarantees the tiles will be re-used to manufacture new ones which sometimes is criticised by those wanting to regulate $\mathrm{CE}$, but form a Radical CE perspective these manufacturers fulfil all necessary CE demands as recycling old tiles into new ones is incorporated into their business model.

The Gilde opleidingen project concerns an educational building, which had to be renovated. The project is done with professional participation of this papers' authors, trying to implement Radical CE principles. Every supply chain partners took back the demolished materials/parts and products, resulting from the renovation, this related to their own business model, for reuse and recycling. The firms selected were asked in their proposal to translate their-assumed-financial benefits in form of the embedded value of these materials and products, in the form of a discount on the new products provided by 
the same supply chain partner. Finally, a take- and/or buy-back guarantee, captured in a resource passport, is incorporated for all the new products that supply chain partners have provided. The resource passport has the form of a digital Building Information Model (BIM). Hence this project is realised through financial incentives within the business model of the supply chain partners, which they have to prove in terms of discounts for the client. The firms were not ask to prove their business model was circular, they were forced to act as such by making profits explicit in forms of discounts for the client. As the service concept is not implemented, also this case isn't fully compliant to the rules of Radical CE.

\section{CONCLUSION AND REFLECTIONS}

The aim of this paper was to re-define CE into 'Radical CE', attempting to constitute a $\mathrm{CE}$ theory and terminology, appropriate for the construction industry and addressing the core of the CE concept in terms of a resulting sustainable society, behaving as such because of economic incentives.

As described 'Radical CE' in its pure form will have consequences for the definition of sustainability. It's not the long life span of a product whether or not realised by making it adaptable, which make it sustainable but its potential to be endlessly kept within the technical cycle. In other words buildings, more especially custom made one off buildings, don't need to be designed for 'eternity', but for demolishing after the -first- functional live span has ended.

Buildings need to be designed and constructed as a stock of services, composed in terms of products and more complex components from a CE perspective. This implies the constituent parts of a building must have validated economic value in terms of tradability on the supply chain market or services market. So, design for disassembly or demolition needs to be incorporated in the business model of the suppliers involved.

If constituent products within a complex component like a building have shorter functional life spans as the whole then these parts must be removable and replaceable. A building has to been seen as a composition/system of components and connections between them which are economically meaningful within the business models of suppliers who owns them and keep them circulating. While doing so Radical CE asks for new forms of regulations between service providers and supply chain partners, as well as between service providers and end-users and requires adjustment in enterprise strategy and business finance models, funding mechanisms, governance structures, regulations and government policy.

In a 'Radical CE' Market the question remains this especially for real estate, whether or not consumers can trade user rights in the consumer market because of the lack in legal ownership of the goods. When trading these user rights by consumers a supplier should be able to track (resource passport) and claim its rights when needed in a chain of 
consumers over time. This doesn't seem really realistic at the moment. So the real estate market as existing today, for larger parts will disappear while implementing Radical CE.

Axiomatic for $\mathrm{CE}$ is the availability of -endlessly- available clean energy, and rising prices, due to scarcity, of materials. Radical CE is developed as a concept for pushing CE to the limits in terms of endlessly riding the 'loops' based on a rather neo-liberal interpretation. CE then is an economic system, which logically (free market) results in a sustainable industrial production. If one interprets $\mathrm{CE}$ as an economic system, which has sustainability as a goal, then a more -centrally- planned economy is needed. In both cases however to a large extend new regulations at all levels seem unavoidable, supply chains needs to reorganized, and new business models needs to be developed. Essential for the construction industry is the remodelling of a building in terms of an ensemble of components with each on their own have endless economic value within the technical loop or and can be traded separately to clients and end users providing housing services.

\section{REFERENCES}

- BARLOW, D. (2013) A Circular Economy. The information Centre. Scottish Parliament Briefing

- $\quad$ BASTEIN, T., RIETVELD, E. ROELOFS, E. and HOOGENDOORN, A.(2013) Kansen voor de circulaire economie in Nederland (Opportunities for a circular economy in the Netherlands). TNO-rapport

- $\quad$ BAM (2013) Duurzaamheidsverslag. Koninklijke BAM Group nv. Bunnik

- BRAND, S. (1994) How Buildings Learn: What Happens After they're Built. Tennessee: Quebecor

- BÖRLIN, (1987) 'Utilitarianism.' Bentham, J. (2002) Available at: http://en.wikipedia.org/wiki/Utilitarianism BRADBURY, I., BOYLE, J. and MORSE, A. (2002) Scientific Principles for Physical Geographers. Harlow: Prentice Hall.

- BRUNDTLAND (1987) Our Common Future, Report of UN World commission on Environment and DAMEN, M.A. (2012). A resource passport for a circular economy: An assessment of the possible content and format of a resources passport in order to successfully contribute to the achievement of the circular economy. Master Thesis. University of Utrecht.

- DESSO (2015): http://www.desso-businesscarpets.com/products/product-search/

- DIJK S van, Tenpierik M. and Dobbelsteen AAJF van den (2013) Continuing the building's cycles: A literature review and analysis of current systems theories in comparison with the theory of Cradle to Cradle. Proceedings of the 4th CIB international conference on smart and sustainable built environments.

- EISENHARDT K. M. (1989). Building theories from case study research. Academy of Management Review,14:

- $\quad$ ELLEN MACARTHUR FOUNDATION (EMF) (2012, 2013, 2014) Towards the Circular Economy. http://www.ellenmacarthurfoundation.org/

- EUROPEAN COMMISSION (2014) Towards a circular economy: A zero waste programme for Europe. Brussels (2011)

- GRAEDEL, T. and GREENVILLE, J. (2005) Greening the Industrial Facility. Perspectives, approaches and tools. New York: Springer.

- $\quad$ HABRAKEN, J. (1972) Dragers en de mensen. MIT Press: Cambridge

- ING Economics Department (2015) 'Rethinking finance in a circular economy; Financial implications of circular business models.' 
- IPCC. (2013) Fifth Assessment Report. Summery for Policy makers. Available at: http://www.climatechange2013.org

- JOUSTRA, D.J., DE JONG, E., and ENGELAER, F. (2013) Guided Choices towards a Circular Business Model. Eindhoven: SRE/C2C-BIZZ.

- LYLE, J. (1994) Regenerative Design for Sustainable Development. John Wiley and Sons Inc: Canada, West Sussex.

- MCDONOUGH W and BRAUNGART M, (2002) Cradle to Cradle: remaking the way we make things. New York: North Point Press

- MALTHUS T. (1798) An Essay on the Principle of Population. London: John Murray

- MEADOWS, D., MEADOWS, RANDERS, J., Behrens W. (1972). The Limits to Growth. New York: Universe Books

- OECD. (2008) Measuring material flows and resource productivity. Synthesis report. Paris: OECD,(2012) An Emerging Middle Class. Available at: http://www nispnetwork.com/aboutnisp (09.09.2013)

- PAULI, G. (2010). The Blue Economy - 10 Years, 100 Innovations and 100 Million Jobs a Report to the Club of Rome, Taos, New Mexico: Paradigm Publications.

- PRESTON, F. (2012) 'A Global Redesign? Shaping the Circular Economy.' Chatham House: London.

- ROODMAN, D. M. and LENSSEN, N. 1995. A Building Revolution: How Ecology and Health Concerns are Transforming Construction. Washington D.C., Worldwatch Paper 124.

- STAHEL W.R., (2010) The Performance Economy. 2nd ed. Hampshire: Palgrave Macmillan.

- TURNTOO (2015) Available at: http://turntoo.com/en/

- WiJKMAN, A. and SKÅNBERG K, (2015) The Circular Economy and Benefits for Society. Club of Rome. http://www.clubofrome.org/?p=8260

- UNEP (2007) Towards a Low Carbon Economy. http://www.unep.org/

- UNEP (2009) Seizing the Green Opportunity, Green Economy; Pathways to Sustainable Development and Poverty Eradication. http://www.unep.org/

- UNEP (2010), Decoupling natural resource use and environmental impacts from economic growth. http://www.unep.org/ 


\title{
USE OF SOCIAL MEDIA IN CONSTRUCTION INDUSTRY: A CASE STUDY
}

\author{
Perera, S. ${ }^{1}$; Victoria, M. F. ${ }^{2}$ and Brand, S. ${ }^{3}$
}

\begin{abstract}
:
Social media evolved in the early 2000's with the birth of Facebook and Flickr in 2004. It is hard to ignore the current influence of social media upon modern lifestyle with the continuous development of many social media platforms over the past decade. On the other hand, the construction industry is often criticised for lack of communication and poor uptake of technology and innovation. Hence, this study reviewed and analysed the usage of social media in the UK construction industry focusing on quantity surveying practices. Three Quantity Surveying practices were selected for the study. Of the three cases, one organisation was selected as the principal case study within which a comprehensive questionnaire survey was conducted to investigate the level of understanding and knowledge of employees about social media within the organisation. The other two organisations were used for verification of findings from the main case study. The case study findings revealed a very low usage of social media within the organisations. Even though there was a mixture of positive and negative views on the commercial potential of social media for construction business, the questionnaire findings suggested that the social media platforms were poorly understood by the employees and its potential is underestimated.
\end{abstract}

KEYWORDS: CASE STUDY, CONSTRUCTION INDUSTRY, QUANTITY SURVEYING, SOCIAL MEDIA

\section{INTRODUCTION}

Social media can be defined briefly as a web-based platform where conversations can take place between two or more people in light of information exchange (Andrews, 2012). However, there are multiple views on what social media is and how it should be defined. Social media is defined using either an information model or a communication model. Information model suggest that all media are social while communication models claims that media becomes social when communication takes place (Fuch, 2014). Social media can take different forms and leaves the users with a personal experience. Ahlqvist et al. (2008) define three key elements of social media namely: content, community and Web 2.0. Web 2.0 technology serves as the foundation of the whole social media platform development (see, O'Reilly, 2005), where content is shared within the community. Therefore, one without the other two will not form a social media platform.

Social media platforms are classified in different ways. Golden (2010) classifies social media platforms into two types based on ownership such as: firm sponsored or individual publications (e.g. blogs) and third-party forums (e.g. Facebook, Twitter and LinkedIn).

\footnotetext{
${ }^{1}$ Department of Architecture and Built Environment, Northumbria University, England UK. Email: srinath.perera@northumbria.ac.uk

${ }^{2}$ Department of Architecture and Built Environment, Northumbria University, England UK. Email: michele f.victoria@northumbria.ac.uk

${ }^{3}$ Department of Architecture and Built Environment, Northumbria University, England UK. Email: sam.brand@northumbria.ac.uk
} 
On the other hand, few others (Grahl, 2015, Scott, 2014, SEOPressor, 2015) classify social media into six types based on the main activity of the platform, such as:

6. Social networks: Facebook, LinkedIn, Google+

7. Media sharing: YouTube, Instagram, Pinterest, Flickr

8. Microblogging: Twitter, Tumblr

9. Blog Comments and Forums: Blogger

10. Social news: Reddit

11. Bookmarking site: Delicious, StumbleUpon

Each type is intended for a specific purpose. Social networking platforms allow users to connect to people all over the word and share messages and media files with personalised settings. Media sharing platforms enable distribution of various media types including videos, audios and images. Microblogging platforms designed for concise posts where the user can update short messages and link to other sites. Blog Comments and Forum platforms engage users in a public conversation. Social news sites allow registered members to submit content from external sources. Finally, bookmarking sites enable users to save links, add bookmarks or tag webpages.

Use of social media has extended beyond personal use in present era and it is not uncommon to see active business participation in social media. However, social media implementation in a business setting is distinctly different from personal usage. More than a leisure medium social media can bring commercial benefits in a business setting when it is implemented effectively which can highly influence the sustainability of the business, especially, economic and social sustainability. Therefore, this paper presents a literature review of the role of social media in a business environment and its potential benefits, and then, exploring it further through case study approach focusing on construction organisations.

\section{LITERATURE REVIEW}

\section{Social media in businesses}

Social media can provide wide range of benefits to businesses including: fast specialist feedback/better communication; capable of reaching global audience; improve networks; improve awareness of a brand; enhance knowledge on current issues and initiatives/innovations; facilitate knowledge management; drive traffic to website; raise company profile; increase online visibility of the organisation, the products and the services; allows consumers to engage with company; improve work efficiency; increase PR opportunities with industry publications; help monitor competitors and act on negative comments (Brown, 2012, Salcido, 2011, Pauley, 2014, Bradwell and Reeves, 2008, Patten, 2007).

On the other hand, not all business functions are equally benefitted, and in fact, it can be expected that some business functions are hugely benefited or impacted by social media usage while other functions have less or no impact. According to Smith et al. (2011) 
information technology, sales, marketing, services and human resources are highly affected by social media while research and development and supply chain are moderately affected and legal and finance are less affected. Apparently, this claim is supported by the benefits listed above that most impacts are attributed to the information technology, sales, marketing and human resources functions.

Specialist on social media suggests that social media must be encouraged in working environment for better results (Broughton et al., 2010). However, this has to be implemented in a systematic way by. In addition to that it is also believed that a successful social business strategy will integrate social media in to business goals and objectives (Altimeter, 2015, Li and Solis, 2015, Myers, 2012). This calls for a sound usage guideline or protocol and awareness among the employees.

\section{Social media in different industries - case studies}

\section{Health and beauty industry - L'Oreal}

Famous beauty company L'Oreal uses various forms of social media to attract job seekers. Company vacancies webpage is linked directly to company profile in Facebook, LinkedIn and twitter. In addition to that L'Oreal provides a link in Facebook profile on an internship programme which is linked to an application called 'Work for Us'. This targets candidates and allows collation of important information. Through this method L'Oreal was able to reach inactive candidates as well as improve the brand image. It was also reported that L'Oreal Australia saved nearly 20,000 Australian dollars in recruitment process (LinkedIn, 2012, Hebberd, 2015).

Case study of L'Oreal showcases effective recruitment process through social media platforms which helps to identify potential candidates at a lower cost and time than the conventional method of recruitment.

\section{Food and drink industry - Coca-cola}

Coca-cola is a world famous drink company and well-known for its brand. Moth (2013) reported that coca-cola to have over 63 million fans to its main Facebook page, over 700,000 followers in Twitter and also seemed to be active in Pinterest and Google+. Case study also reveals that coca cola is able to attract more fans and followers and improve the brand image by active participation in social media.

This case study conveys the message that social media serves as a good marketing tool and helps improve brand image of businesses.

However, Myers (2012) alarms small businesses to not to be deceived by all social media platforms, since there is a tendency of being active in all platforms while not reaping huge benefits (Myers, 2012).

\section{Social media in construction industry}

Construction industry is a distinctly different industry compared to manufacturing industry. Generally, construction clients get the project done from the industry according 
to their needs. Hence, the products are tailor made with different prices and the business is highly competitive. So the industry produces low volumes of output with high margin in contrast to manufacturing industry. Therefore, usage of social media in construction industry can be expected to be different than the previously reported case studies and there is a lack of reported case studies within construction organisations.

Construction industry is often criticised for its slow adoption of ICT and innovation. The Office for National Statistics (2013) report findings affirms the above claim in terms of social media adoption. Findings show that up to $77 \%$ of companies in information and communication sector are leaders in social media adoption in 2012 whereas only $20 \%$ of construction companies reported to have implemented social media within business. A different survey of top 15 construction companies in the UK reported that over $90 \%$ of the construction companies holding a Twitter account and LinkedIn account and 65\% having a Facebook account for the company. Further, more than half of the companies have linked the website with social media accounts while all having the capability to analyse internet traffic (Pauley, 2014). In addition to that another study reported that the most popular social media platform used by construction professionals is LinkedIn followed by Twitter, Facebook, YouTube, Blogs, Google+ and Pinterest (Whiston Solutions, 2015).

Literature findings demonstrate that smaller number of construction companies is using social media and that percentage consists of primarily large construction companies. However, majority of the construction industry is composed of Small and Medium Enterprises (SME). Michaelidou, Siamagka, and Christodoulides (2011) reported about the usage of social media in SMEs in the UK. Findings identified Facebook as the popular social media with $77 \%$ users followed by Twitter (55\%), and LinkedIn (46\%). Therefore, social media usage is evident in both large and SME construction organisations.

Furthermore, CIC Group construction industry survey 2014 outlines the expectable key benefits for the construction industry by social media usage such as: collaboration, innovation and promotion and improved image (Construction Industry Council, 2014). Another potential benefit of social media to construction industry is knowledge management. Knowledge management becomes important to construction industry due to the fragmented nature of the industry (Dave \& Koskela, 2009). However, social media has the potential to bridge the fragmentation between stakeholders of the project which is demonstrated by the case study presented by Porkka, Jung, Päivänen, Jäväjä, and Suwal (2012).

Despite the benefits, reluctance of top management, lack of understanding and encouragement from top management (Brown, 2012), unfamiliarity of staff/lack of technical skills in handling social media platforms, perceived unimportance, lack of use by the competitors (Michaelidou et al., 2011) are reported to be the barriers of social media implementation in construction organisations. While some feel that social media should not be encouraged in a working environment as it is highly unregulated, unmanageable and perceived to be of high risk to reputation, others think that it is a good 
medium of marketing, attracting younger generation and disseminating knowledge through interactive forums, video blogs and the like (Construction Industry Council, 2014).

In summary, the reported studies on social media usage suggest that the social media usage within the construction industry is very low. The role of social media is overlooked and sometime social media is considered as a risk to the business operations. Further, the expected benefits of social media usage are not fully entertained by the industry and there is a huge scope for potential development.

\section{METHODOLOGY}

Case study method was adopted to explore the use of social media in construction organisation as case study is considered suitable when an in-depth (Fellows and Lieu, 2003) and holistic inquiry to be done to investigates a contemporary phenomenon within its natural setting (Harling, 2002).

The case study was designed to combine both qualitative and quantitative methods. Three Quantity Surveying organisations were selected as the cases. Of the three cases, one organisation was selected as the principal case study within which a survey (quantitative analysis) was conducted. The other two cases served as a verification and in-depth review of findings emanating from the main study. While qualitative approach helps to gain deeper understanding of the situation from managerial level people of the selected cases, quantitative approach investigates the level of understanding and knowledge of employees about social media within the principal case study organisation.

Semi-structured interviews were employed to capture qualitative data while questionnaire survey was employed to capture quantitative data. Semi-structured interviews were conducted with three managerial level personnel from each case (total of 9 interviews). Questionnaire survey was conducted within the principal case study organisation with a sample size of 91 employees (out of approximately 800 employees) which fulfils the requirement of a minimum sample size at $\alpha 0.10$ (Kotrlik and Higgins, 2001). Then, key themes and patterns from interviews were identified using content analysis and survey results were analysed using descriptive statistics. Finally, conclusions were derived based on both the findings and comparisons made with the literature findings.

\section{FINDINGS}

\section{Case A}

Case A is a large professional Quantity Surveying (QS) organisation registered under the RICS with over 800 employees and has several branches over the UK. The organisation maintains accounts in various social media platform such as: Blog, LinkedIn, Twitter, YouTube and Facebook. Frequent emails are circulated among employees about the news 
feeds in social platforms as a result of active participation of the organisation in social platforms. However, employees demonstrated very low level of awareness about internet/social media usage protocol.

Social media implementation within the organisations is viewed positively as it is believed that social media helps to connect targeted audiences like clients, contractors as well as prospective employees; encourage co-operation within groups; enable fast specialist feedback; has potential to reach global audience; improves networks; improves brand image; and could facilitates knowledge management. However, it was also highlighted that the construction business is not greatly influenced by promotions and marketing like other businesses.

Nevertheless, social media is perceived to be surrounded by negative stigmas making it difficult to be encouraged within the organisation. Especially, it is considered to be difficult to convince top management regarding its usage and implementation within the organisation. Some of the barriers in social media implementation within the organisation includes: age of employees, more of personal usage, lack of control, conflict of interest, and lack of encouragement to use.

\section{Survey findings}

Figure 1 illustrates the age profile of the survey respondents. Accordingly, majority of the respondents are between 20 to 29 age group (38\%), representing younger generation in the sample. Also it is clear that sample represents fair proportion of employees in all age groups which gives a clear account from all age groups.

Figure 15: Age profile of the respondents

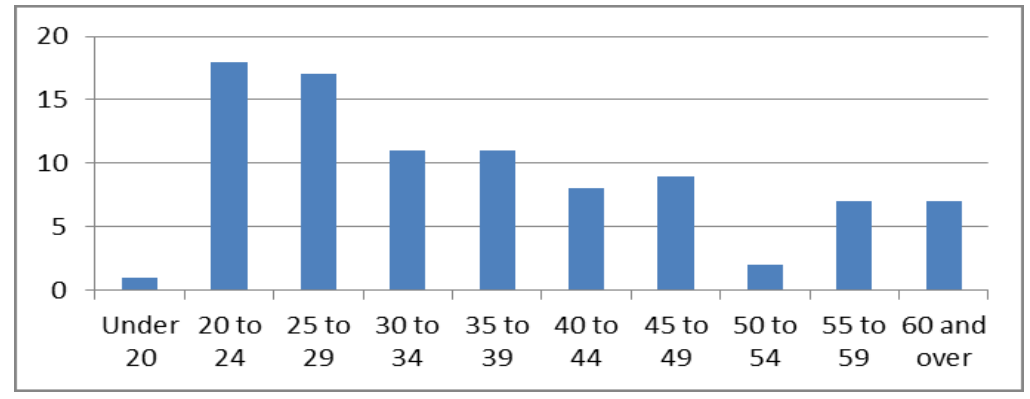


Figure 16: Users of social media platforms for different purposes

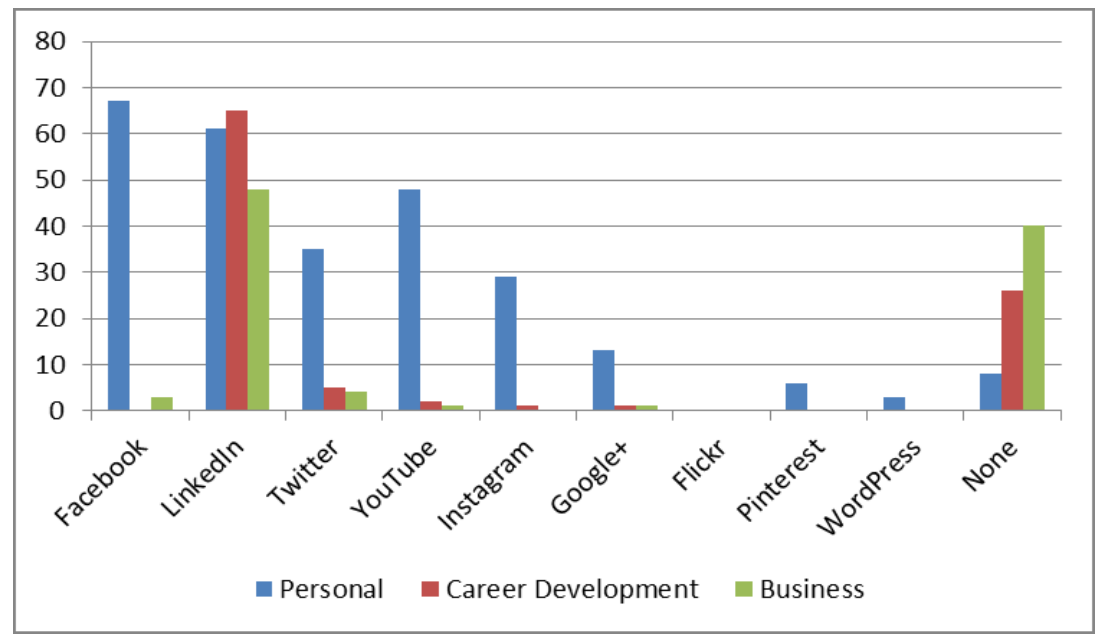

Findings suggest that $91 \%$ of the respondents use social media platforms for personal purposes. Facebook is identified as the most popular platform used by the respondents for personal purposes followed by LinkedIn and YouTube. Further, Flickr found to be unpopular among the respondents. Only $56 \%$ of the respondents claimed to be using social media for business purposes indicating limited application of social media in business functions. Mainly, LinkedIn is used for business purposes while Twitter, Facebook, YouTube and google+ are also used at a very lower rate. On the other hand, $67 \%$ respondents reported to be using social media for career development purposes in which LinkedIn is used by $71 \%$ while few others use Twitter, YouTube, Instagram and Google+ (see, Figure 2).

Majority of the respondents (71\%) confirmed that social media usage is not encouraged within the organisation. Further, half of the respondents confirmed that they are unaware of the internet usage policy of the organisation. Also employees demonstrated lack of clear understanding about level of integration of social media with business goals and objectives.

Out of five identified potential areas of benefits of social media implementation (business development, knowledge management, marketing/advertising, competitive advantage and brand and industry awareness) respondents consider that social media is most beneficial in terms of gaining competitive advantage and for knowledge management, followed by business development, brand or industry awareness and marketing.

\section{Case B}

Case B is a North East England based professional QS practice that operates locally employing approximately 15 QSs. The organisation maintains only a Twitter account which is occasionally updated. Further, lack of awareness about internet/social media usage protocol was evident. 
Social media is considered as a potential recruitment tool which acquires less cost and time while reaching more targeted audiences. Also it is believed that social media platforms are a medium of meeting prospective clients and attracting new projects. However, there is a general opinion that social media work well for large organisation than small organisations. In fact, the commercial potential of social media implementation is considered to be low for construction organisations. Furthermore, age of employees and reduced employee productivity are identified as potential barriers of social media implementation.

\section{Case C}

Case C is a professional QS practice with over 1000 employees operating across the UK. The organisation maintains accounts in LinkedIn, Twitter, YouTube, Facebook and Yammer. Further, knowledge of internet/social media usage protocol seems to be moderate in the organisation.

Social media is said to be providing competitive advantage over inactive competitors; raise awareness of the brand; facilitates promotions; circulates job opportunities; and help to reach large audience. Organisation believes that the social media implementation has commercial potential and thus, a specialist is appointed in the marketing department to mange social platforms for the organisation.

On the other hand, organisation experiences other obstacles in social media implementation such as: age of the employees, reduced employee productivity, restricted internet use, and cost of additional resources like employment of a specialist to maintain platforms.

\section{DISCUSSION}

\section{Popular social media platforms among construction organisations}

Table 1 compares the findings of the study with other studies. Findings of the study exclude social media usage for personal purposes while other studies do not clearly state the scope of the analysis. LinkedIn, Twitter and Facebook are identified as popular platforms used by construction professionals by all presented studies while the case study identified LinkedIn to be the most popular platform used for business and career development purposes in the case study organisation. Reason for this could be Twitter and Facebook are more inclined towards personal usage rather than for business and career development purposes. Apparently, LinkedIn has become a very popular platform for job hunting where well-presented profiles attract competitive opportunities, leading to career development. Nevertheless, Twitter, Facebook, YouTube, Blogs, Google+ and Pinterest are also used at a smaller percentage. 
Table 1: Comparison of study findings with literature findings

\begin{tabular}{lllll}
\hline & The study & Pauley (2014) & $\begin{array}{l}\text { Whinston } \\
\text { Solutions (2015) }\end{array}$ & $\begin{array}{l}\text { Michaelidou et al. } \\
(2011)\end{array}$ \\
\hline Study Sample & $\begin{array}{l}\text { Construction } \\
\text { professional of the case } \\
\text { study organisation }\end{array}$ & $\begin{array}{l}\text { Top 15 construction } \\
\text { companies }\end{array}$ & $\begin{array}{l}\text { Construction } \\
\text { professionals }\end{array}$ & SME's in the UK \\
& $71 \%$ & $90 \%$ & $91 \%$ & $46 \%$ \\
\hline LinkedIn & $5 \%$ & $95 \%$ & $84 \%$ & $55 \%$ \\
Twitter & $3 \%$ & $65 \%$ & $83 \%$ & $77 \%$ \\
Facebook & $2 \%$ & & $68 \%$ & \\
YouTube & & $47 \%$ & \\
Blogs & $1 \%$ & $40 \%$ & \\
Google + & $0 \%$ & & & \\
Pinterest & & & & \\
\hline
\end{tabular}

Internet and social media usage policy

Findings reveal that half of the employees in the sample are unaware of the internet usage policy. According to the literature this can be a threat as the literature suggests that there should be protocols in place to govern social media usage in a business environment. This is a key problem in many organisations which needs to be given serious attention where social media usage is allowed and encouraged. Knowledge of protocol and boundaries of usage is very important to prevent any damage to the brand image and maintain the reputation of the organisation.

\section{Potential benefits of social media for construction organisations}

Identification of knowledge management as a major potential benefit of social media, over business development, marketing/advertising, and brand and industry awareness, demonstrate evolving role of social media from primarily being a marketing tool to other areas. The identified benefits showcase the ability of social media in achieving economic and social sustainability in business environments. It is interesting to note that employees scored high for knowledge management. However, potential for knowledge management is not explored much and the role of social media in organisational knowledge management could be an interesting area to explore further.

\section{Issues in social media implementation}

Key barriers identified includes: age of the employees, more of personal usage/reduced productivity, lack of control, conflict of interest, lack of encouragement, restricted internet usage, and additional cost of resources. Therefore, findings suggests that construction organisations are still reluctant to implement social media in a business environment as it is perceived as a risk to business and potential benefits are overlooked. Even if it is implemented, lack of effective communication of protocols to employees can be a potential threat to the business. Furthermore, integrating social media in to business goals and objectives is crucial for a successful social business strategy. 


\section{CONCLUSIONS}

Social media is now proving to be having commercial potential for businesses use more than being as a personal entertainment medium. However, social media implementation within construction business is not explored in-depth. Therefore, the study aimed at exploring the use of social media in the case study organisations, employees understanding of social media, potential benefits, and barriers of implementation through semi-structured interviews as well as a questionnaire survey. Findings suggested that LinkedIn is the most popular platform used for business $\mathrm{s}$ and career development purposes while Twitter, Facebook, YouTube, Blogs, Google+ and Pinterest are also used at a smaller percentage. While there is some form of social media usage for business purposes, employees demonstrated lack of awareness of usage protocol which according tot the literature is a potential threat and can even damage brand image. Therefore, it is important that businesses that use social media for business functions take necessary precautions to eliminate such threats due to ineffective communication of usage protocol to employees.

Social media usage in construction organisation claims to yield many benefits including: business development, knowledge management, marketing/advertising, competitive advantage and brand and industry awareness. Out of which respondents presume social media use will highly benefit knowledge management functions. Nevertheless, as with any choice, social media implementation in construction organisations also has pros and cons. Age of the employees, more of personal usage/reduced productivity, lack of control, conflict of interest, lack of encouragement, restricted internet usage, and additional cost of resources are the identified barriers for social media implementation in case study organisations and which are in fact the key concerns for most of the organisations. Also some people consider that social media implementation benefits large organisations than small. Effective implementation of social media can disprove all the criticisms about social media implementation in a business environment and also integrating social media in to business goals and objectives is crucial for a successful social business strategy. Further, potential benefits of social media implementation pave the way for economic and social sustainability in a business environment. However, construction industry is slow in social media adoption and further researches and case studies are needed to give assurance of successful social media usage in construction organisations.

\section{REFERENCES}

- $\quad$ AHLQVist, T., BÄCK, A., HALONEN, M. \& HEINONEN, S. 2008. Social Media Roadmaps: exploring the futures triggered by social media. Espoo, Finland.

- ALtiMETER. 2015. Social Business Strategy [Online]. Available: http://www.altimetergroup.com/work-with-us/challenges-we-solve/social-business-strategy/.

- $\quad$ ANDREWS, C. 2012. Social media recruitment. Applied Clinical Trials, 21, 32-42.

- $\quad$ BRADWELL, P. \& REEVES, R. 2008. Network citizens power and responsibility at work, UK, Demos. 
- $\quad$ BROUghtON, A., HigGins, T., HiCKS, B. \& COX, A. 2010. Workplaces and Social Networking: The Implications for Employment Relations. The Institute for Employment Studies.

- $\quad$ BROWN, M. 2012. Why the construction sector should engage with social media [Online]. Available: http://www.theguardian.com/sustainable-business/construction-sector-social-media [Accessed 17 May 2015].

- COLEMAN, V. 2013. Social media as a primary source: A coming of age. EDUCAUSE Review, 48, 60-61.

- CONSTRUCTION INDUSTRY COUNCIL 2014. CIC 2050 Group Construction Industry Survey 2014. UK: CIC 2050 Group.

- DAVE, B. \& KOSKELA, L. 2009. Collaborative knowledge management-A construction case study. Automation in Construction, 18, 894-902.

- FELlOWS, R. \& LIEU, A. 2003. Research methods for construction, USA, Blackwell publishing.

- GOLDEN, M. 2010. Social media strategies for professionals and their firms: the guide to establishing credibility and accelerating relationships, Hoboken, N.J, Wiley.

- GRAHL, T. 2015. The 6 types of social media [Online]. Available: http://timgrahl.com/the-6types-of-social-media/ [Accessed 17 May 2015].

- HARLING, K. 2002. Annual meeting of the american agricultural economics association, case studies: Their future role in agricultural and resource economics. California.

- HEBBERD, L. 2015. How L'Oreal use social media for recruitment [case study] [Online]. Available: $\quad$ http://linkhumans.com/case-study/how-loreal-use-social-media-for-recruitment [Accessed 20 May 2015].

- KOTRLIK, J. \& HIGGINS, C. 2001. Organizational research: Determining appropriate sample size in survey research appropriate sample size in survey research. Information technology, learning, and performance journal, 19, 43.

- LI, C. \& SOLIS, B. 2015. The 7 success factors of social business strategy [Online]. Available: http://www.briansolis.com/2015/04/7-success-factors-social-business-strategyinfographic/ [Accessed 17 May 2015].

- LINKEDIN. 2012. Case study L'Oreal [Online]. Available: http://www.slideshare net/linkedineurope/loreal-case-studyv5 [Accessed 17 May 2015].

- MiCHAElidoU, N., SiAMAGKA, N. T. \& CHRISTODOUlidES, G. 2011. Usage, barriers and measurement of social media marketing: An exploratory investigation of small and medium B2B brands. Industrial Marketing Management, 40, 1153-1159.

- $\quad$ MOTH, D. 2013. How Coca-Cola uses Facebook, Twitter, Pinterest and Google+ [Online]. Available: $\quad$ https://econsultancy.com/blog/62548-how-coca-cola-uses-facebook-twitterpinterest-and-google/\#! [Accessed 20 May 2015].

- MYERS, A. 2012. 13 types of social media platforms and counting [Online]. Available: http://decidedlysocial.com/13-types-of-social-media-platforms-and-counting/ [Accessed 17 May 2015].

- O'REILly, T. 2005. What Is Web 2.0 [Online]. Available: http://www.oreilly.com/pub/a/web2/archive/what-is-web-20.html.

- OFFICE FOR NATIONAL STATISTCS. 2013. Business use of social media [Online]. Available: http://www.ons.gov.uk/ons/rel/rdit2/ict-activity-of-uk-businesses/2012/sty-ecom2012.html [Accessed 20 May 2015].

- PATTEN, J. 2007. Blogging in the workplace: Building a safe culture [Online]. Available: http://www.personneltoday.com/hr/blogging-in-the-workplace-building-a-safe-culture/ [Accessed 17 May 2015].

- PAUlEY, N. 2014. How the top UK construction companies are using social media marketing in 2014 [Online]. Available: http://www.pauleycreative.co.uk/2014/01/how-thetop-construction-companies-are-using-social-media-in-2014/ [Accessed 17 May 2015].

- $\quad$ PORKKA, J., JUNG, N., PÄIVÄNEN, J., JÄVÄJÄ, P. \& SUWAL, S. Role of social media in the development of land use and building projects. Proceedings of ECPPM, 2012. 
- SALCIDO, M. 2011. Benefits and advantages of using social media | advantages of social media [Online]. Available: http://www.organicseoconsultant.com/advantages-of-using-socialmedia/ [Accessed 17 May 2015].

- SCOTT, M. 2014. Understanding the basic categories of social media marketing [Online]. Available: https://blog.ahrefs.com/understanding-basic-categories-social-media-marketing/ [Accessed 17 May 2015].

- SEOPRESSOR. 2015. The 6 Types of Social Media [Online]. Available: http://seopressor.com/social-media-marketing/types-of-social-media/ [Accessed 17 May 2015].

- WHISTON SOLUTIONS. 2015. Social media benefits for the property and construction industry [Online]. Available: http://www.whiston-solutions.com/industrydevelopments/social-media-benefits-property-and-construction-industry [Accessed 17 May 2015]. 


\section{Theme 5 Construction Technology, Research and Development}

1. Fibrous Concrete For Sustainable Construction

2. Asbestos Free Fibrecement Components - Fifteen Years Of Joint Activities Between Industry And University

3. Using Life Cycle Assessment To Illustrate The Benefits Of Blinds As Passive And Sustainable Energy Saving Products In The Domestic Environment In The UK

4. A BIM-Centred System For Buffer Management

5. RE-Designing Project Management: Steps Towards A Project Management Curriculum For A Sustainable Built Environment

6. BIM Awareness And Readiness Of Postgraduate Built Environment Students In West Midlands Universities, $U K$

7. The Extent Of Integrating Sustainability Topics Into An MSc Quantity Surveying Course At London South Bank University In UK

8. Building Refurbishment Site Managers' Waste Management Practices

9. Challenges Of BIM Implementation In Sustainable Residential Projects In The UK And Future Perspective

10. Feasibility Study On Integration Of Low Carbon Technologies To Existing Domestic Dwellings In The UK

11. A Novel Dry Air Ground Source (DAGS) System For Heating And Cooling Buildings 


\title{
FIBROUS CONCRETE FOR SUSTAINABLE CONSTRUCTION
}

\author{
Abdulle, F. A. ${ }^{1}$ and Xiao, R. Y. ${ }^{2}$
}

\begin{abstract}
:
Concrete has been extensively used in the construction industry for buildings, bridges, dams and tunnels for many decades. It has relatively high compressive strength and its use is economic. However, it is brittle with low tensile strength and requires the use of other reinforcing materials to enhance its tensile and crack resistance properties. Cement production (one of the main constituents of concrete) also accounts for large volume of carbon-dioxide (CO2) emission into the environment, which makes the sustainability aspect of concrete questionable. This has led to the benefits of using micro fibres as a CO2 reduction and crack controlling measure for concrete to be realised and encouraged their widespread use in the construction industry in recent years, for applications ranging from industrial flooring to tunnel lining. The main focus of this research has been to carry out experimental testing and numerical simulations of single fibres, with different geometrical and mechanical properties, embedded in cementitious matrix and subjected to pull-out loading. It aimed to create and validate a Finite Element (FE) model that could be used to predict the performance of such fibres under pull-out loading as an alternative to laboratory testing. This allows the better understanding of the positive contribution that micro fibres can make to the sustainability of concrete as a construction material and the extent to which the overall cost, weight and manual handling risk (associated with steel reinforcements) of conventional reinforced concrete can be reduced, without compromising the structural performance of concrete. Comparisons of results revealed close agreements between the experimental tests and numerical simulations, and have led to the conclusion that the proposed FE model is capable of being used as an alternative to experimental investigations of single-fibre-reinforced matrix.
\end{abstract}

KEYWORDS: CONSTRUCTION, CONVENTIONAL REINFORCED CONCRETE, FIBRES, FIBROUS CONCRETE, SUSTAINABLE MATERIAL

\section{INTRODUCTION}

Concrete is the most widely used structural material in the construction industry internationally, due to its durability and ability to be mixed and moulded into any shape on site as well as its excellent resistance against compressive forces. However, it is well known for its weakness in tension and shear and requires steel reinforcing bars to take these forces (BSI, 2004), (The Concrete Society, 2007a). In addition to the reinforcing bars, steel mesh or micro fibres may be incorporated into the concrete to provide it with significant post cracking capacity and inhibit crack propagation due to serviceability conditions (The Concrete Society, 2007a), (The Concrete Society, 2007b), (Propex Concrete Systems, 2014), (Dramix, 2010).

The use of micro fibres is preferred over other secondary reinforcing materials due to their lower cost and ability to be added into the concrete during the mixing process, which removes the manual handling risk associated with the installation of steel mesh

\footnotetext{
${ }^{1}$ School of the Built Environment and Architecture, London South Bank University, England UK. Email: abdullf8@1sbu.ac.uk

${ }^{2}$ School of the Built Environment and Architecture, London South Bank University, England UK. Email: xiaor2@1sbu.ac.uk
} 
(Elasto Plastic Concrete, 2013), (CENTONZE, G., 2012). They also contribute to the sustainability of the concrete as a structural material through reduction in the cementitious materials in the mix, weight and overall cost of the fibrous concrete. However, their performance is not fully understood, despite being the subject of extensive research over a long period. This is due to their random distribution and orientation characteristics when added to the concrete mix (The Concrete Society, 2007a). It has been generally accepted, however, that single fibre pull-out testing is the most effective way of investigating fibre-matrix interface bond behaviour. It allows the adhesion quality of fibrous concrete to be investigated and characterised, enabling the effectiveness of fibres to be determined (XIAO, R., Y., and CHIN, C., S., 2009), (ZILE, E., Zile, O., 2012).

Therefore, the aim of this research was to carry out testing, numerical modelling and simulation of individual fibres, with different shapes, dimensions and mechanical properties, embedded in cementitious matrix and subjected to pull-out loading. The objective was to develop a Finite Element (FE) model capable of predicting the pull-out strength and failure mechanisms of such fibres, in order that their performance is better understood and to allow the constant development of new and more effective fibres with minimal costly and time consuming laboratory testing. ANSYS (finite element analysis software) has been used in this study for the numerical analysis.

\section{DESIGN AND TESTING OF EXPERIMENTAL SPECIMENS}

Three different grades of mortar matrix were designed from Ordinary Portland Cement (grade $52.5 \mathrm{~N}$ ), beach sand and water according to BRE (1997). Six cubes (100 x $100 \mathrm{x}$ $100 \mathrm{~mm})$, three cylinders $(150 \times 300 \mathrm{~mm})$ and nine pull-out test specimens $(65 \times 65 \times 200$ $\mathrm{mm})$, three for each type of fibre, were cast from each mortar mix in accordance with BSI (2009a). The cubes and cylinders were tested to determine the compressive and tensile strengths of the specimens according to BSI (2009b and 2009c). These properties were needed for the numerical modelling of the fibre-reinforced matrix. The pull-out tests were carried out in order to verify the accuracy of the results from the numerical simulations.

Three different types of fibres used in the research are shown in Figure 1. Two of the fibres are steel, but have different shapes (hooked end - HE and undulated - UD) and dimensions. The third fibre is micro-synthetic polymer fibre (polypropylene - PP), which also has different shape (fibrillated) and dimension as well as mechanical properties from the steel fibres. 
Figure 1: Fibres used in the research

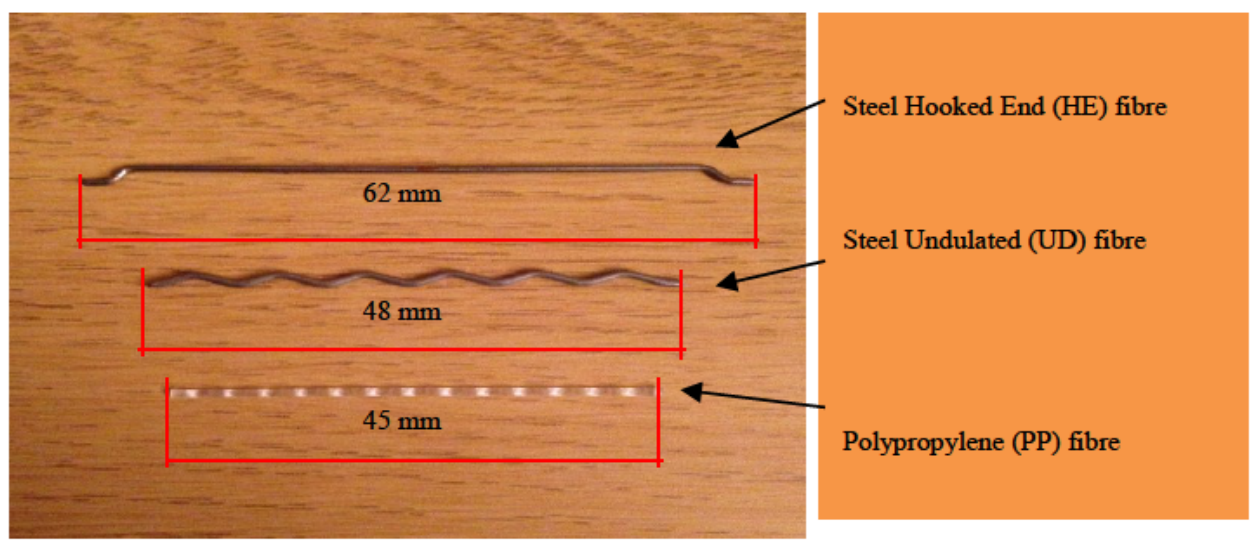

The fibres were clamped to the centre of the moulds before the first half of the test specimens were cast. A thin plastic membrane was then placed in the moulds to from an artificial crack across the middle of the specimens. This was to ensure that the only connection between the two halves of the matrix (being pulled apart) was through the single fibres, as can be seen in Figure 2 .

Figure 2: Fibre pull-out test specimen moulds ready for casting the first half

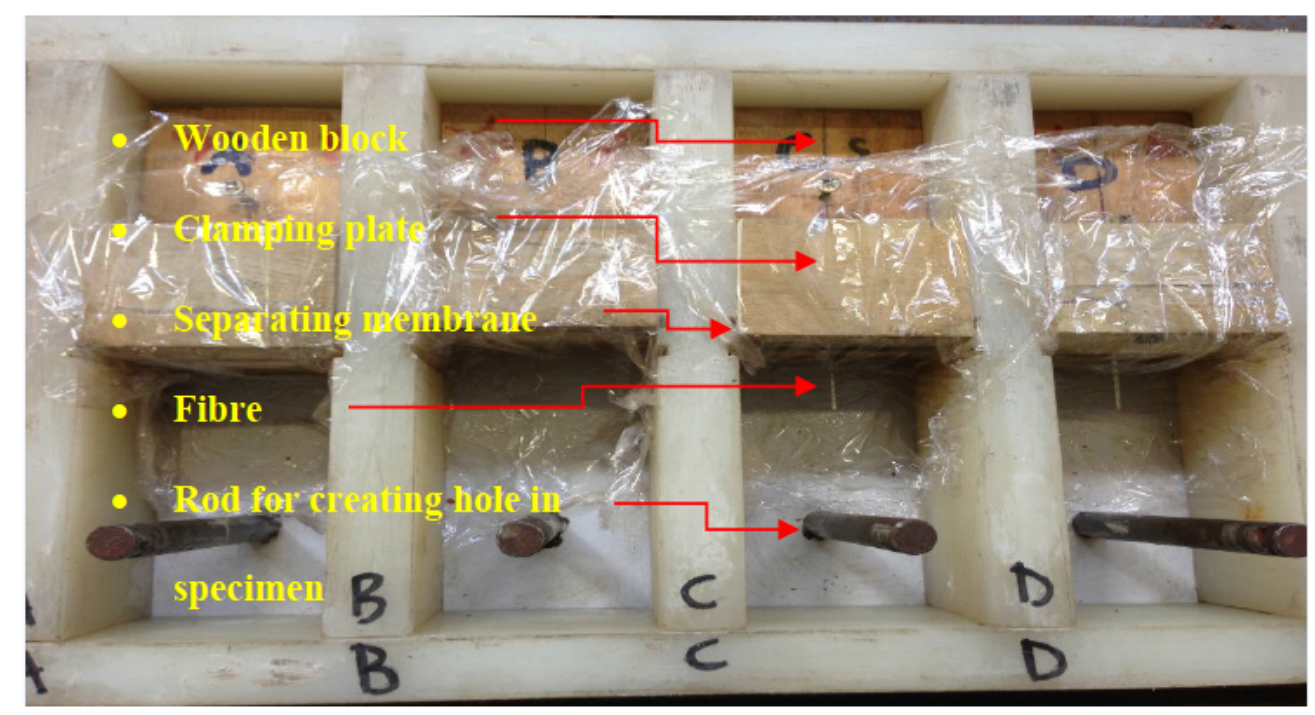

\section{NONLINEAR NUMERICAL MODELLING}

Nonlinear finite element modelling was carried out to simulate the behaviour of the tested specimens under the pull-out loading. The following is a summary of the numerical techniques used. 


\title{
Element types
}

In ANSYS there are various elements available for modelling different structural elements. The suitability of these elements depends on the nature of the problem and shape of the elements to be analysed. For this study Solid 65 has been used for the matrix and Solid 185 for the fibres.

Solid65 is capable of cracking in tension and crushing in compression and is suitable for both linear and nonlinear analysis of concrete, with or without reinforcing bars (ANSYS, Inc., 2011a). It has eight nodes with three degrees of freedom (DOF) at each node, translations X, Y and Z (Figure 3). In contrast, Solid185 is suitable for modelling general $3 \mathrm{D}$ solid structures. This element is also defined by eight nodes with three DOF at each node, translations $\mathrm{X}, \mathrm{Y}$ and $\mathrm{Z}$ (Figure 4). It allows plasticity, large deformation, stress stiffening and large strains and supports degenerate shapes, such as pyramid as well as prism and tetrahedral, in irregular regions where the option of meshing with regular elements is not available (ANSYS, Inc., 2011a).

In addition to the solid elements, Contact174 and the associated Target170 elements have been used to model the interfacial bond between the matrix and fibre (Figure 5). The contact and target elements represent contact and sliding between deformable and target surfaces (i.e. fibre and matrix surfaces, respectively) and allow simulation of interface delimitation, which is of paramount importance for the investigation of bond behaviour at the fibre-matrix interface (ANSYS, Inc., 2011b).

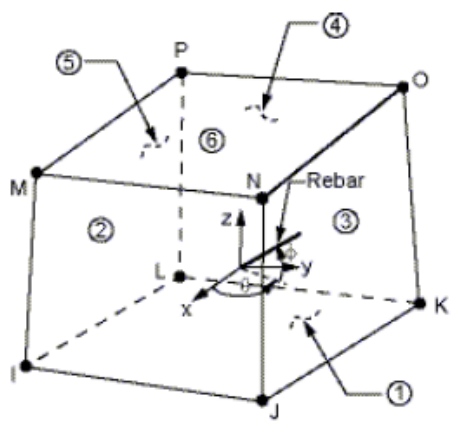

Figure 3: Geometry of Solid65
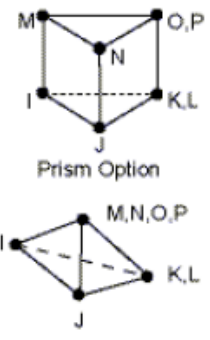

Tetrahedral Option (not recommended)

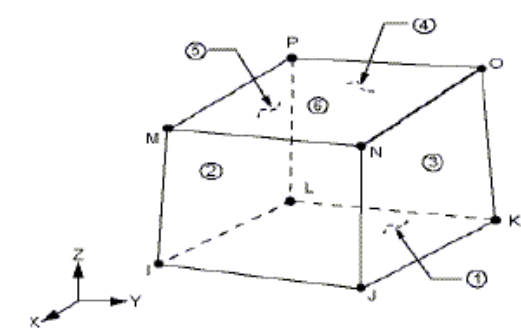

Figure 4: Geometry of Solid18.5

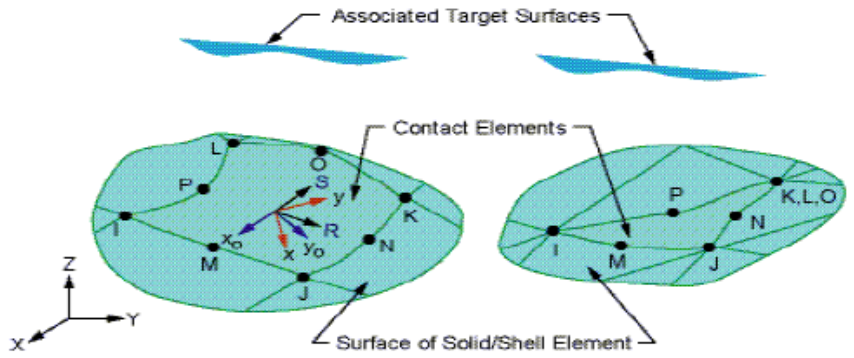

Figure 5: Geometry of Contact174 and Target170 Elements

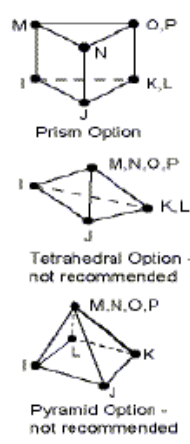

Pyramid option -

\author{
.
}


Cohesive Zone Material (CZM) model has been introduced to the contact element to activate debonding of fibres from the matrix using Mode II dominated Bilinear CZM Law, since the separation of the material interfaces is tangent to the interface (ANSYS, Inc., 2011c). Arc-Length nonlinear technique has been employed to overcome the convergence difficulties experienced when materials reach their capacity limit and start to soften, which allows the analysis to continue beyond the peak load until complete failure of the fibres occurs.

\section{Material properties}

The properties shown in Table 1 and 2 have been used for the modelling of the specimens. The compressive and tensile strength values of the matrix were obtained from the experimental testing of the mortar cubes and cylinders, while the elastic modulus values for the different strengths of matrix were derived according to BSI (2004). The material properties of the fibres were obtained from their manufacturers (Propex Concrete Systems, 2014), (Dramix, 2010).

Multilinear Isotropic (MISO) Hardening material model found in ANSYS has been used to model numerically the nonlinear behaviour of the matrix, and for the fibres Bilinear Isotropic (BISO) Hardening material model has been employed (ANSYS, Inc., 2011d). The fibre models and the complete proposed FE model are illustrated in Figure 6 and 7, respectively.

Table 1: Material properties of matrix

\begin{tabular}{lllll}
\hline Design Mix & $\begin{array}{l}\text { Compressive strength } \\
\text { No. }\end{array}$ & $\begin{array}{l}\text { Tensile strength } \\
(\mathrm{MPa})\end{array}$ & $\begin{array}{l}\text { Elastic modulus } \\
(\mathrm{MPa})\end{array}$ & Poisson's ratio \\
\hline 1 & 26.41 & 2.03 & 26561 & 0.2 \\
2 & 41.23 & 2.72 & 29574 & 0.2 \\
3 & 64.12 & 4.03 & 33163 & 0.2 \\
\hline
\end{tabular}

Table 2: Material and geometrical properties of fibres

\begin{tabular}{llll}
\hline Properties & UD steel fibre & HE steel fibre & PP polypropylene \\
\hline Elastic modulus (MPa) & 210000 & 210000 & 10000 \\
Tensile strength (MPa) & 1050 & 1050 & 600 \\
Poisson's ratio & 0.3 & 0.3 & 0.3 \\
Length $(\mathrm{mm})$ & 48 & 62 & 45 \\
Diameter $(\mathrm{mm})$ & 1.04 & 0.98 & Equiv. 1.08 \\
\hline
\end{tabular}


Figure 6: Fibre models

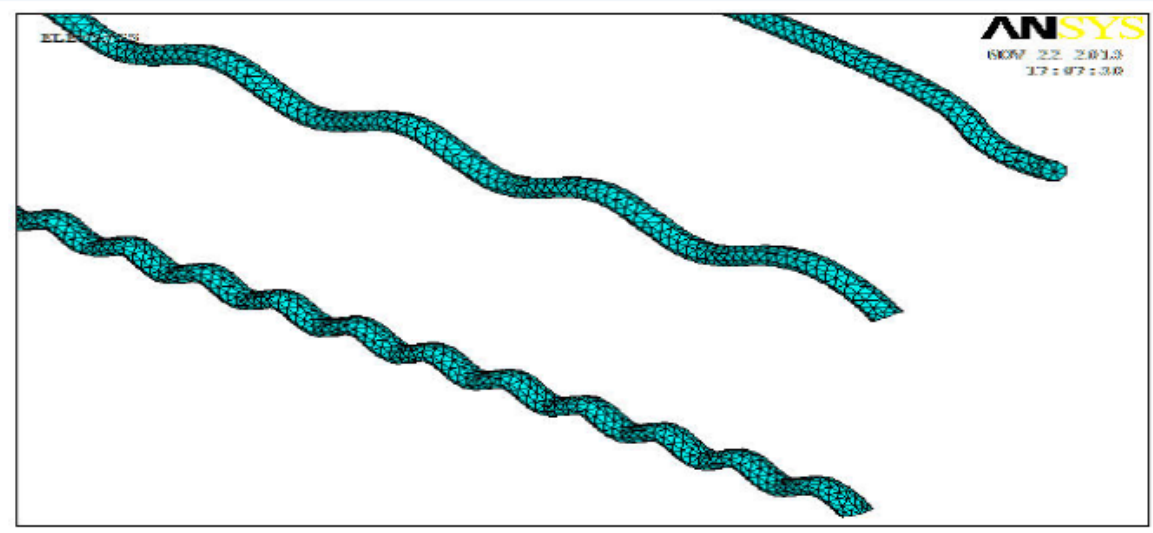

Figure 7: Proposed FE model

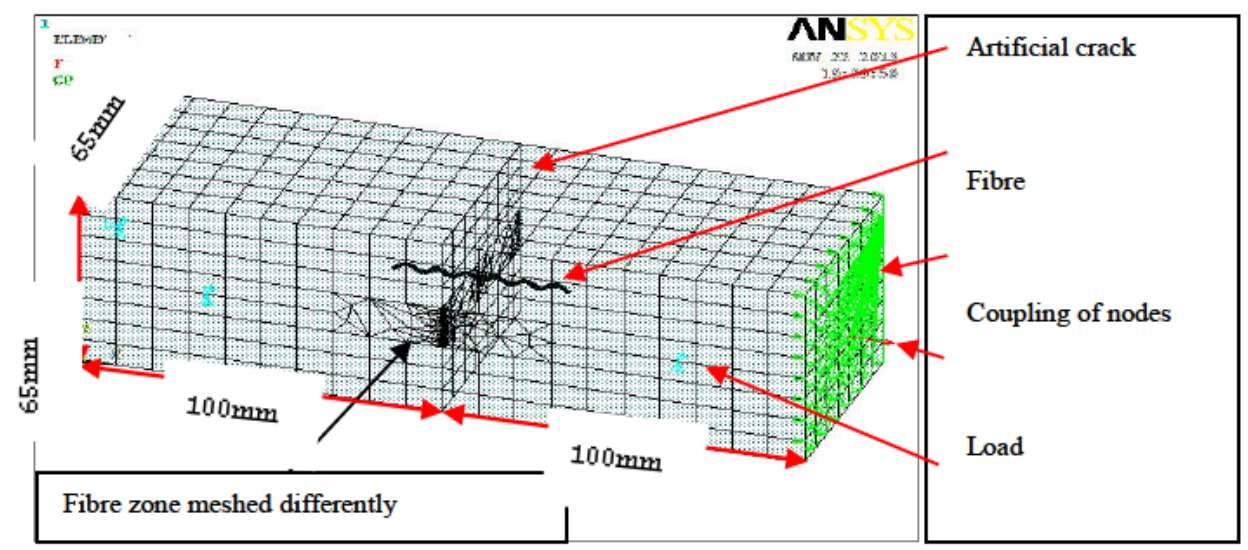

\section{COMPARISON OF FEA AND EXPERIMENTAL RESULTS}

\section{Pull-out strength of fibres}

Twenty seven pull-out specimens, with three different design strengths (30 MPa, $40 \mathrm{MPa}$ and $60 \mathrm{MPa}$ ) and incorporating three different types of fibres, have been tested in total. Two different failure modes were observed from the testing, i.e. pull-out failure and rupture failure. The pull-out failure mode is associated with loss of bond between the fibre and matrix at the fibre-matrix interface. This type of failure occurred when test specimens with lower strengths were tested.

The mechanically deformed fibres were pulled out before reaching their ultimate strengths but straightened up in the process, as can be seen in Figure 8. This failure was classified as matrix failure. However, rupture failure occurred when the tensile strength of fibres were exceeded, as shown in Figure 9. The failures were sudden and occurred just after peak loads. This type of failure was observed when mortar specimens with higher strengths were subjected to pull-out loading, which indicates that the bond 
strength of the matrix was greater than the strength of the failed fibres. This is classified as fibre failure.

Figure 8: Pull-out failure of fibres

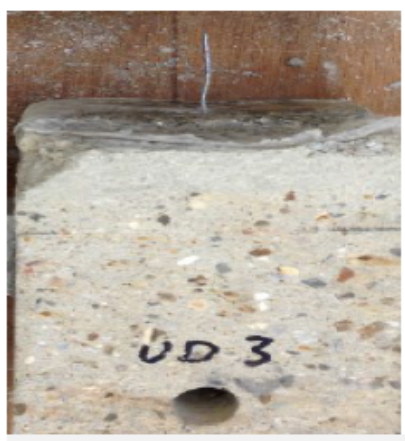

UD fibre

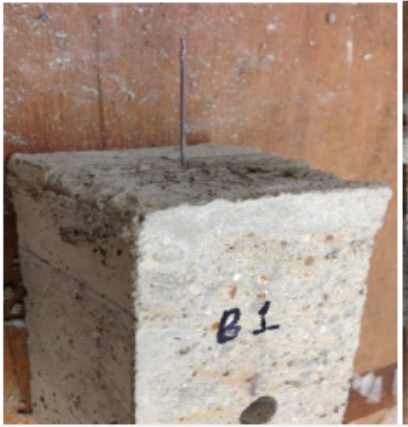

HE fibre

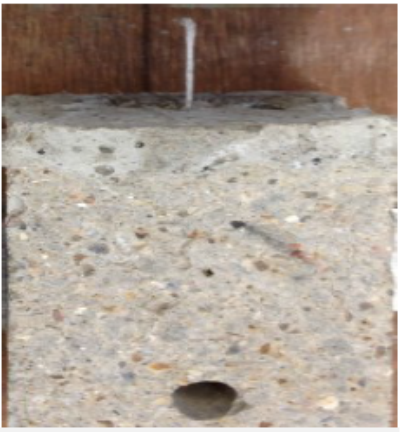

PP fibre

Figure 9: Rupture failure of fibres

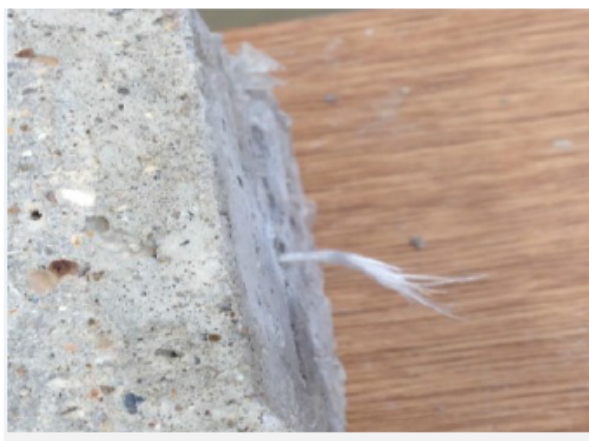

PP fibre

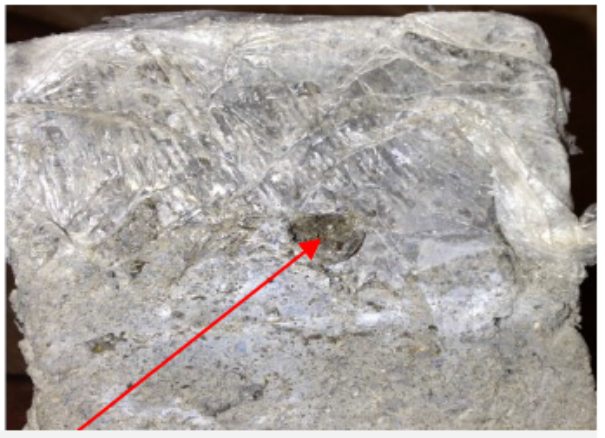

UD fibre

The load-displacement data from the FEA are compared with the experimental (EXP) test results in Figures 10 to 12 . As can be seen in Figure 10 there is a very good agreement between the EXP and FEA results for the UD and PP fibres, with the ascending and descending slopes of the curves following similar path. In fact the only difference between these curves is where there is a sudden increase in load in the descending region of the curves, due to bending/unbending of the fibres. However, the curves relating to the HE fibre are somewhat different. The biggest difference occurred during the pull-out process, where the resistance of the fibre is largely due to the mechanical anchorage of the hooks.

The experimental results show considerable fluctuation of pull-out force beyond the peak load, accounting for the fibre being pulled through hardened curved ducts. In comparison the FEA results show a smooth curve, indicating the only resistance of the HE fibre at 
this stage is frictional resistance, and do not capture well the additional energy required to bend/straighten the fibre hooks.

Figure 11 shows a similar trend with the FEA curves relating to the UD and PP fibres closely matching the EXP curves. The FEA curve for the PP fibre, however, shows larger displacement at the beginning of loading than the EXP curve, with maximum difference of around $37 \%$ at $133 \mathrm{~N}$ pull-out load. It seems that minor difference in material properties is responsible for the slight deviation of the FEA results, as far as displacement is concerned. In the case of the HE fibre, there is about $20 \%$ difference in peak load between the EXP and FEA results. However, closer agreements between the FEA and EXP data relating to the HE fibre can be seen in Figure 12.

Figure 10: Load-displacement curves of different fibres: Test 1 (EXP vs. FEA)

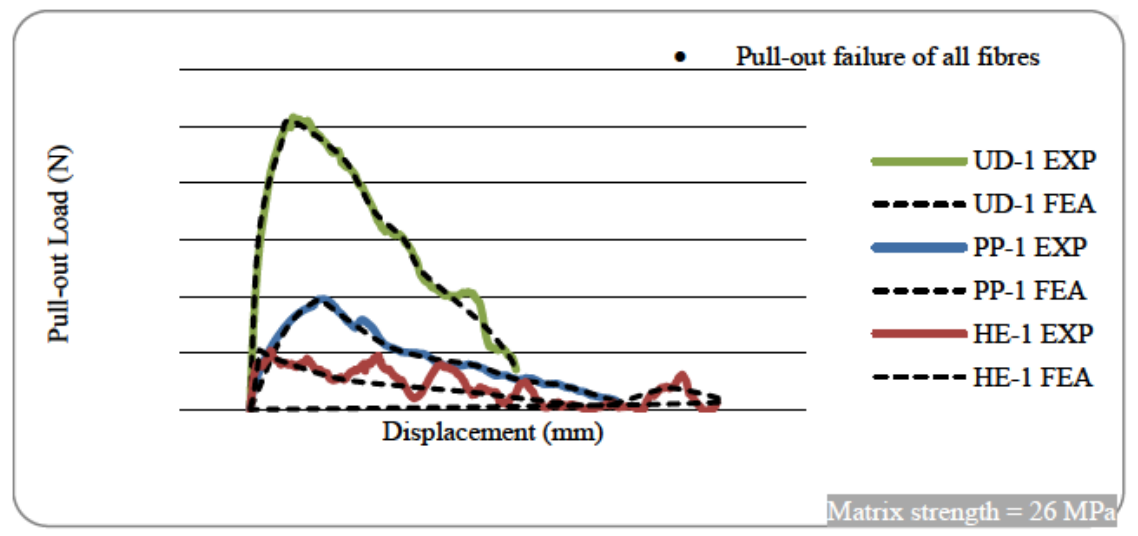

Figure 11: Load-displacement curves of different fibres: Test 2 (EXP vs. FEA)

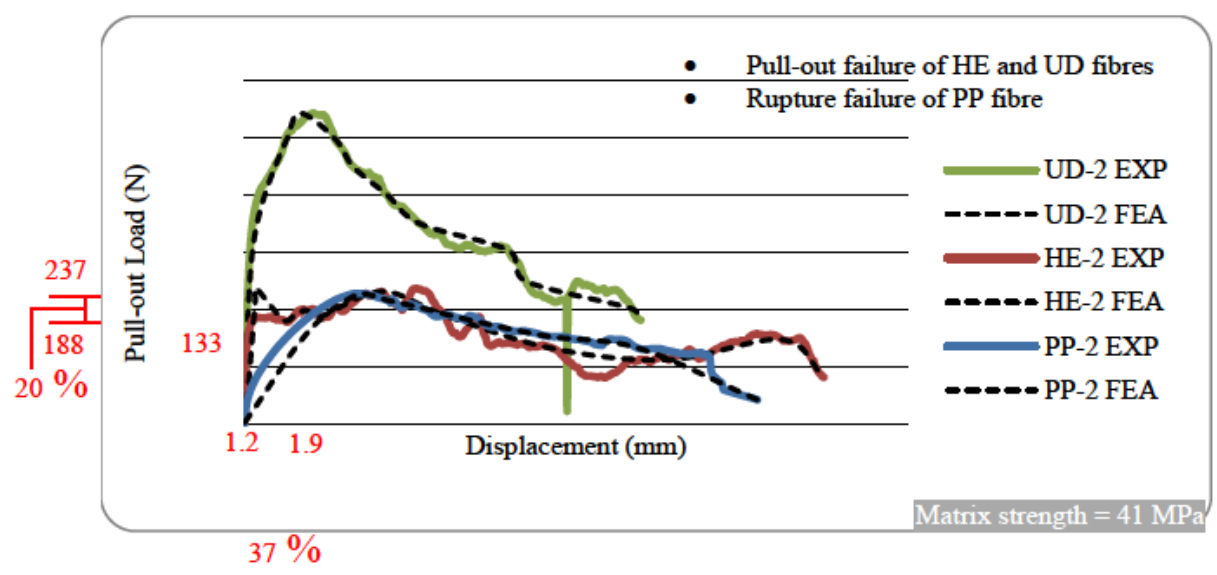


Figure 12: Load-displacement curves of different fibres: Test 3 (EXP vs. FEA)

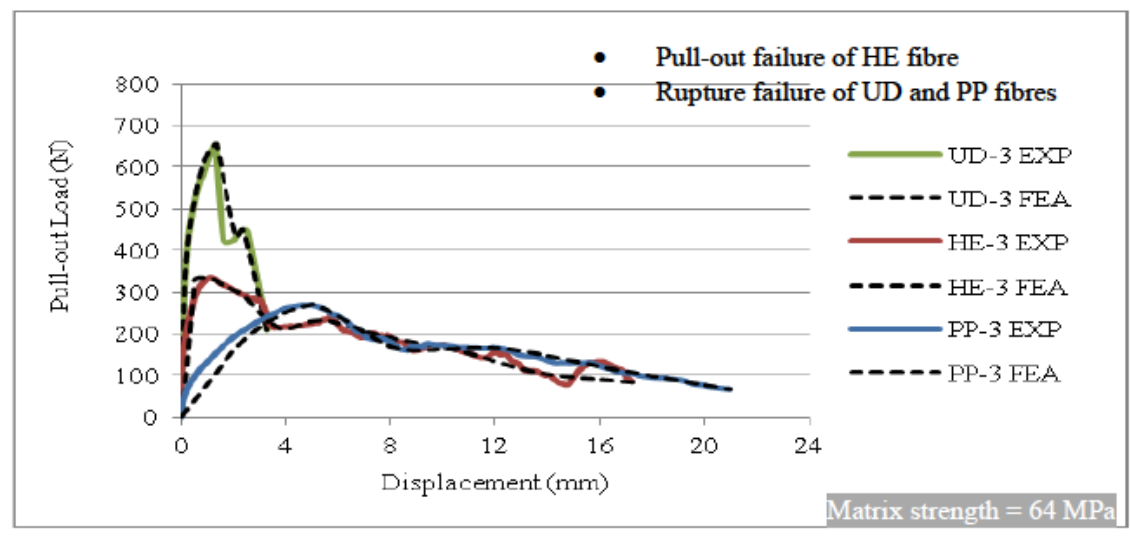

Figures 10 to 12 demonstrate how well the FE model predicted the increased pull-out load for each fibre when the matrix strengths were increased. They also demonstrate the predicted superior performance of the UD fibre compared with the HE and PP fibres, as well as the pull-out failure mode of the HE fibre in all the cases which has been linked to poor geometrical proportions of this fibre. These trends were observed from the EXP tests and have been confirmed by the numerical simulations.

\section{Graphical simulation of interfacial fracture and fibre deformation}

Figures 13a and 13b illustrate the damage sustained by the UD fibre when it failed. For comparison purposes, the state of the fibre is shown before and after the loading. It is clear from Figure 13b that the UD fibre had experienced the necking phenomenon (i.e. the cross-sectional area of the fibre decreased considerably due to plastic strains disproportionately localising in a relatively small area) as well as frictional sliding before the sudden failure shown in Figure 12 occurred. As the cross-sectional area decreased considerably, the increased pull-out load due to bending and straightening of the fibre was enough to cause the failure of the fibre.

In an effort to show the plastic deformation that the UD fibre had undergone as well as the fracture to the matrix along the interface, the FE model consisted of this fibre has been sliced through the middle and the fibre (still attached to one half of the matrix) is exposed, as can be seen in Figure 14. Since the fibre is very small relative to the size of the matrix, the pull-out load did not have much of an effect on the matrix. Only the region immediately adjacent to the fibre was affected. 

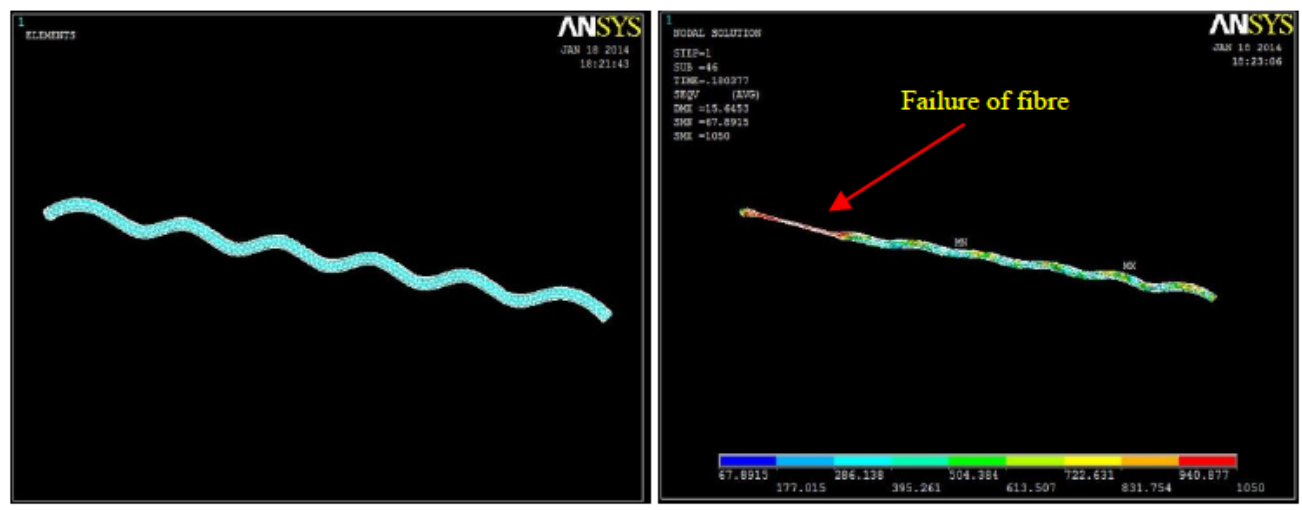

Figure 14: UD fibre-matrix model sliced through the middle
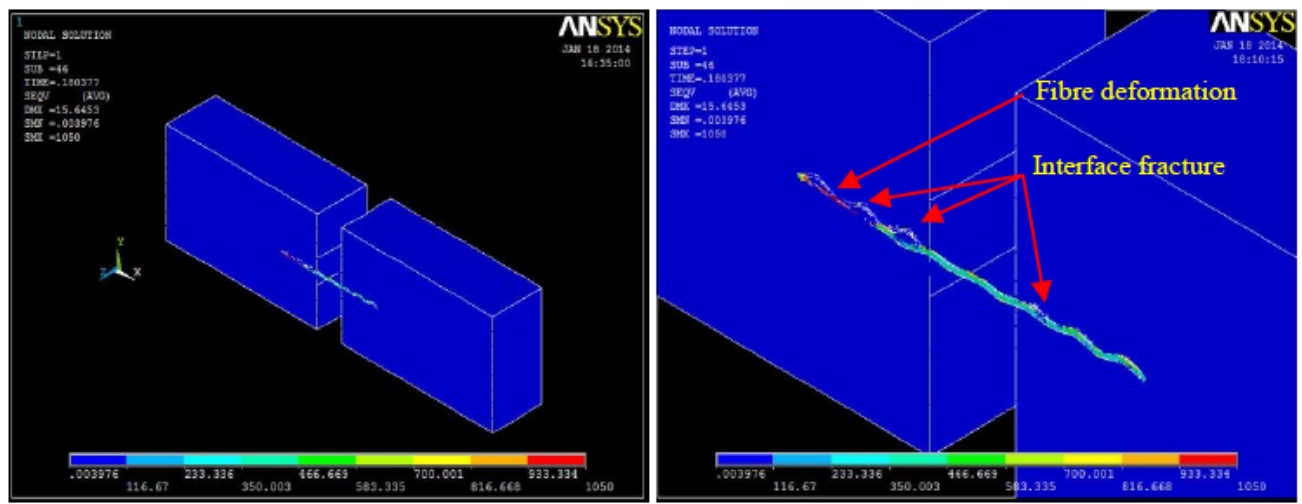

\section{SIGNIFICANCE OF THIS STUDY}

The proposed FE model is a convenient and useful tool that can be utilised for the research and development of micro fibres with different shapes, dimensions and mechanical properties, and can be used as an alternative to laboratory investigations. It can also be used for parametric studies where the influence of embedment length, diameter and shape of fibre, as well as the strength of matrix, on the pull-out strength and failure mechanisms of fibres can be investigated, which can lead to the optimisation of fibres.

The addition of high performance fibres in concrete can significantly enhance the post cracking performance of concrete, whilst reducing the cement content in the mix, weight and overall cost of the fibrous concrete, thereby contributing to the sustainability of concrete as a construction material. Therefore, the development of the FE model is quite 
significant. Further development could make it possible for the FE model to undertake even more complex tasks involving cementitious materials incorporating multiple fibres.

\section{CONCLUSIONS}

The following conclusions can be drawn from this study:

Pull-out load increases with the increase in matrix strength due to improved interfacial bond between the fibre and matrix.

Increase in length and diameter of fibre also increases the load required to cause the failure of fibres. However, it is more effective to increase the fibre diameter than length, as this increases the annular contact between the fibre and matrix, which in turn increases the pull-out load significantly.

The HE fibre was found to be poorly proportioned and an increase in diameter is recommended.

The Arc-Length nonlinear method used in the FEA allowed the full behaviour of the test specimens to be simulated and overcame the convergence instabilities encountered when materials reach their limit.

It can be concluded that the proposed FE model is capable of predicting the load capacities and behaviour of the subject fibres with reasonable accuracy, and that it can be utilised for the research and development of micro fibres. This can lead to the production of high performance fibres and can contribute to the sustainability of concrete as a construction material.

\section{REFERENCES}

- $\quad$ ANSYS, Inc. (2011a) Modelling Composites. USA: ANSYS Release 14.0.

- ANSYS, Inc. (2011b) Modelling Interface Delamination with Contact Elements. USA: ANSYS Release 14.0.

- $\quad$ ANSYS, Inc. (2011c) Cohesive Zone Material Model. USA: ANSYS Release 14.0.

- $\quad$ ANSYS, Inc. (2011d) Modelling Material Nonlinearities. USA: ANSYS Release 14.0.

- $\quad$ Building Research Establishment, BRE (1997) Design of Normal Concrete Mixes. (2nd ed.). Watford: Construction Research Communications Ltd.

- British Standards Institute, BSI (2004) Design of concrete structures - Part 1-1: General rules and rules for buildings. London: BSI Publications.

- British Standards Institute, BSI (2009a) Testing Hardened Concrete - Part 2: Marking and Curing Specimens for Strength Tests. London: BSI Publications.

- $\quad$ British Standards Institute, BSI (2009b) Testing Hardened Concrete - Part 3: Compressive Strength of Test Specimens. London: BSI Publications.

- $\quad$ British Standards Institute, BSI (2009c) Testing Hardened Concrete - Part 3: Tensile Splitting Strength of Test Specimens. London: BSI Publications.

- CENTONZE, G. (2012) Steel Fibres from Waste Tyres as Reinforcement in Concrete: A Mechanical Characterization, Construction \& Building Materials, no 36, pp. 46 - 57. 
- Dramix (2010) Data Sheet. [Online] Sterling. Available from: http://www.bekaert.com/ /media/Files/Download\%20Files/Construction/Concrete\%20reinfor cement/Dramix\%20General/Datasheet\%20Dramix\%20RC-6535-BN.ashx/. [Accessed:15th January 2014].

- Elasto Plastic Concrete (2013) The History of Fibre Reinforcement. [Online] Sterling. Available from: http://www.elastoplastic.com/index.php/the-history-of-fibre-reinforcement/. [Accessed: 25th October 2013].

- Propex Concrete Systems (2014) Enduro 600 Product Data Sheet. [Online] Sterling. Available from: http://www.fibermesh.com/downloads/Enduro\%20600.pdf/. [Accessed: 15th January 2014].

- The Concrete Society, TR63 (2007a) Guidance for the Design of Steel-fibre-reinforced Concrete. Surrey: The Concrete Society.

- The Concrete Society, TR65 (2007b) Guidance on the Use of Micro-Synthetic-fibrereinforced Concrete. Surrey: The Concrete Society.

- $\quad$ XIAO, R., Y., and CHIN, C., S. (2009) Finite Element Modelling of Fibrous Concrete Structures: Trends in Civil and Structural Engineering Computing, no 6, pp. 131 - 148.

- ZILE, E., Zile, O. (2012) Effect of the Fibre Geometry on the Pull-out Response of Mechanically Deformed Steel Fibres: Cement and Concrete Research, no 44, pp. 18 - 24. 


\title{
ASBESTOS FREE FIBRECEMENT COMPONENTS - FIFTEEN YEARS OF JOINT ACTIVITIES BETWEEN INDUSTRY AND UNIVERSITY
}

\author{
Agopyan, V. ${ }^{1}$ John; V. M. ${ }^{2}$ and Savastano Jr., H. ${ }^{3}$
}

\begin{abstract}
:
At the end of last century the fibrecement producers in Brazil had the great issue of replacing asbestos in the production of flat and corrugated sheets for construction applications. The local fibrecement industry had two options: to buy a foreign technology or develop a local product. The first option was the easy one, as the technology of PVA fibre reinforced cement was well developed and several players were pleased to offer technological packages. However, this option had limitations as the industry would not have the control of the acquired technology. A solution economically feasible in the reach market might be difficult in the Brazilian conditions, moreover the knowledge on durability of PVA reinforced components in hot and humid climate was very limited at that time. University of S. Paulo (USP) made a call for the entire fibrecement industry to discuss a new research consortium. After one year of negotiation, in 2000, two Brazilian-controlled companies decided to sign a joint research long term agreement with USP. To speed up the process the companies bought a turn-key solution. Research has been therefore focused on durability and cost reduction strategies, which included innovation in both process and raw materials. Thanks to this agreement new durable and competitive products were developed and introduced in the Brazilian market. Results include a patent on graded fibrecement sheet, a first commercial application of functionally graded materials with cement. Moreover, it was possible to reduce the amount of Portland cement in all formulations, improving durability and making the solution more compatible with consumers' budget. These components are sustainable because their cost is adequate to the market, have no asbestos and have lower $\mathrm{CO} 2$ emissions. Nowadays the focus of the ongoing research includes improved graded materials and $\mathrm{CO} 2$ curing, which increases durability and dimensional stability of these components.
\end{abstract}

KEYWORDS: COMPOSITES, DURABILITY, FAST CURING, FIBRECEMENTS, FUNCTIONALLY GRADED MATERIALS, SUSTAINABLE BUILDING MATERIALS

\section{INTRODUCTION}

Estimated as several millions of tons per year (Heinricks et al., 2000), consumption of fibre-reinforced cement building components is rapidly increasing, especially in developing countries. This is because such materials allow one to produce lightweight building components with excellent mechanical performance and acceptable thermalacoustic insulation properties, while being economically attractive (Moslemi, 2000).

Fibrecement production started in Brazil just before the Second War and the consumption has increased continuously since then. The main products are the corrugated roof sheets $50 \%$ of market share; residential water tanks - a market that was recently lost to plastic;

\footnotetext{
${ }^{1}$ Escola Politecnica, University of S. Paulo, S. Paulo-SP, Brazil. Email: Vahan.agopyan@usp.br

${ }^{2}$ Escola Politecnica, University of S. Paulo, S. Paulo-SP, Brazil. Email: vanderley.john@lme.pcc.usp.br

${ }^{3}$ Faculty of Animal Science and Food Engineering, University of S. Paulo, Pirassununga-SP, Brazil. Email: holmersj@usp.br
} 
and flat sheets for partitions, which is today the most promising market. Until today, this industry relies heavily on chrysotile asbestos fibres, largely available in Brazil.

The health concerns on the use of asbestos in the Brazilian society have started after eighties. A strict health and safety regulation to protect industry workers was adopted by the federal government in 1991, banning all asbestos fibres except for chrysotile ones, limiting the maximum amount of fibre concentration in air, among other aspects. Public concern on the subject increased and, by the end of the century, producers in Brazil had started searching for competitive technologies to replace asbestos in their production.

The local fibrecement industry had two options: to buy a foreign technology or develop a local product. The first option was the easy one, as the technology of PVA fibre reinforced cement was well developed and several international players were pleased to offer technological packages. However, this option had limitations as the industry would not have the control of the acquired technology. A solution economically feasible in the reach market might be difficult in the Brazilian conditions, moreover the knowledge on durability of PVA reinforced components in hot and humid climate was very limited at that time.

\section{The options of fibre reinforcement}

The purpose of fibre reinforcement is to improve mechanical properties of a given brittle matrix, which would be otherwise unsuitable for several practical applications (Agopyan et al., 2005). Examples of brittle matrices were fibre reinforcement reached market applications include: (i) Portland cement (Tonoli et al., 2010 and 2011) and (ii) gypsum (Mármol et al., 2013). A major advantage of fibre reinforcement of a brittle material is the resulting composite behaviour after cracking. Post-cracking toughness, produced even by adding low modulus of elasticity fibres in the brittle matrix, allow the production of lightweight thin components that can withstand bending and impact (Agopyan et al., 2005). Reinforcement is distributed into the composite, reinforcing the matrix and bridging cracks during bending or tensile tests.

Cement matrix is strongly alkaline. Besides asbestos, other alkali resistant synthetic fibres are available, such as AR glass, polypropylene (PP) and polyvinyl-alcohol (PVA) ones are commonly used as main reinforcement in cement based composites subjected to normal temperature curing. Cellulose fibres can only be used in autoclaved components, a technology with higher costs. Steel fibres, subject to corrosion, were not an option for thin sheets.

\section{University \& Industry: Collaboration framework}

At the end of last century University of S. Paulo (USP) invited all Brazilian fibre cement producers to discuss a research consortium to develop a technology economically feasible and environmentally safer for fibrecement production in the Brazilian market. The research will be funded by a combination of companies' own money and public funds for industry innovation. 
After one year of negotiation, in 2000, two Brazilian-controlled companies, Infibra and Imbralit, representing $15-20 \%$ of the market, decided to sign a joint research long-term agreement with USP. To speed up the process the companies bought a turn-key industrially proven but somehow expensive PVA fibre reinforced solution. By that time, the largest player in the market had already begun replacing the asbestos by PVA fibres and, as was found out later, it was in advanced stage of development its own technology, based on PP fibres.

The initial purpose of the research agreement was to improve durability in Brazilian environment and reduce production cost of the PVA corrugated sheets for roofing. This development should be done keeping the available upgraded infrastructure in the plants, mainly equipment prepared for Hatcheck production process.

However since the beginning of the agreement, it has been clearly perceived that additional improvements on the composites and components design and production could be possible achieved, so further benefits for the industry could be feasible. Actions for reduction of cement consumption and the volume of fibres in the composites, the durability validation of the components and their production with faster curing process make the components more competitive in the market and at the same time far more sustainable in comparison with the conventional ones.

Figure 1 - Conceptual framework of the research, from motivation to achievement of durable and cost effective fibrecement in cooperation between the industry and the academic research group.

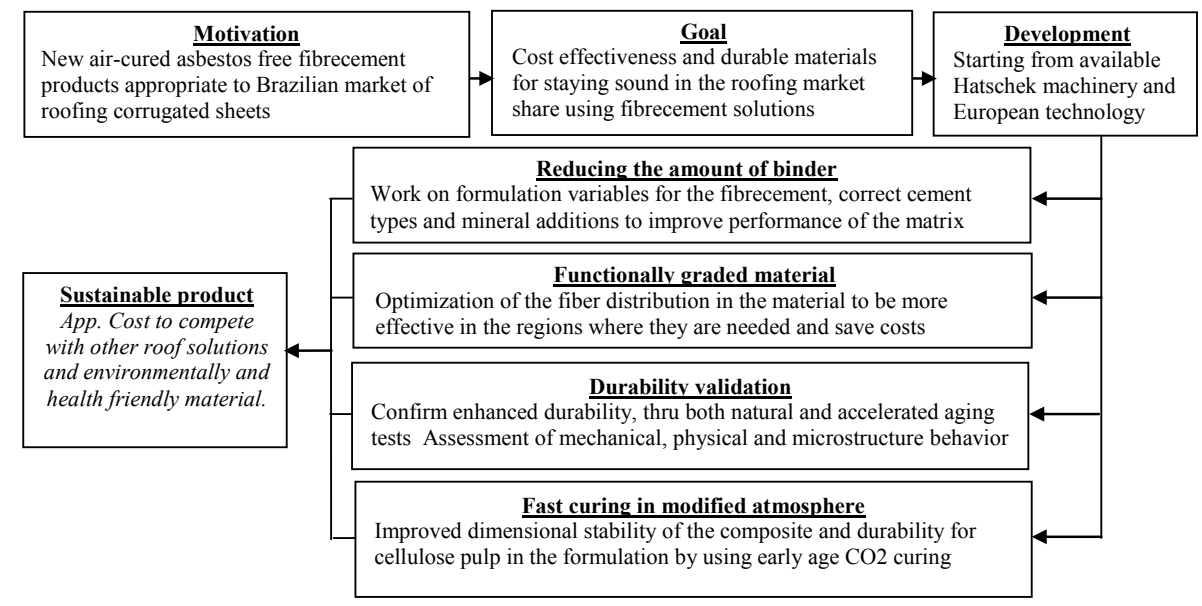

In the Figure 1, the conceptual framework of the research carried on in this project is presented. Research results have been extensively published by the team on fibre replacement (e. g. Bezzera et al., 2006, Nita et al., 2004) and on other topics, including shrinkage and edge cracking (Souza, 2013). 


\section{MAIN TOPICS OF THE COLLABORATIVE WORK}

\section{Reduction of the binder consumption}

The efficient use of cement has a great impact on the world's $\mathrm{CO} 2$ emissions and consumption of natural resources. Binder - Portland cement and pozzolans - content can be above $80 \%$ of the dry formulation and it is the most important cost item for fibrecement products. Therefore, fibrecement eco-efficiency demands cement reduction.

For the industry, strength of the composite was associated with high amount of cement. The reduction of ordinary Portland cement (OPC) fraction was achieved by a combination of mix design and particle size distribution optimization. As an example (Table 1), the Portland cement fraction of a given formulation can be reduced from $75 \%$ (value after initial optimization studies) to approximately $65 \%$ (industrial trials) without major changes in the mechanical behaviour. The modulus of rupture (MOR) in bending test was maintained unchanged and the toughness was significantly enhanced due to improved bonding between the matrix and the fibres and pore size control. A significant improvement of the matrix performance can be achieved by properly selecting the material. The limit of proportionality (LOP) - the point where the matrix cracks, can be raised by excess of $30 \%$ at the same time water absorption is reduced, improving the system.

Table 1. Formulations of fibrecement with different content amount of OPC. Mechanical behaviour in bending test and physical properties at 28 days (average followed by standard deviation values)

\begin{tabular}{|c|c|c|c|c|c|c|}
\hline Formulation & $\begin{array}{l}\text { OPC content } \\
(\mathrm{w} \%)\end{array}$ & $\begin{array}{l}\text { MOR } \\
(\mathrm{MPa})\end{array}$ & $\begin{array}{l}\text { LOP } \\
(\mathrm{MPa})\end{array}$ & $\begin{array}{l}\text { Toughness } \\
(\mathrm{kJ} / \mathrm{m} 2)\end{array}$ & WA (w\%) & $\begin{array}{l}\text { BD } \\
(\mathrm{g} / \mathrm{cm} 3)\end{array}$ \\
\hline $01-y 2002$ & 75.2 & $\begin{array}{l}11.7 \\
(0.5)\end{array}$ & $\begin{array}{l}8.6 \\
(1.0)\end{array}$ & $2.31(0.37)$ & $19.6(0.4)$ & $\begin{array}{l}1.55 \\
(0.02)\end{array}$ \\
\hline $02-y 2006$ & 64.6 & $\begin{array}{l}11.4 \\
(0.5)\end{array}$ & $\begin{array}{l}7.7 \\
(0.6)\end{array}$ & $4.77(0.38)$ & $22.9(0.9)$ & $\begin{array}{l}1.61 \\
(0.03)\end{array}$ \\
\hline $03-y 2006$ & 66.5 & $\begin{array}{l}13.5 \\
(1.9)\end{array}$ & $\begin{array}{l}10.3 \\
(1.2)\end{array}$ & $4.75(1.35)$ & $18.2(0.6)$ & $\begin{array}{l}1.71 \\
(0.03)\end{array}$ \\
\hline
\end{tabular}

Key: OPC type: CP2F (OPC with addition of carbonate filler); CP5 (OPC with low content of mineral addition); $\mathrm{MOR}=$ modulus of rupture; $\mathrm{LOP}=$ limit of proportionality; $\mathrm{WA}=$ water absorption; $\mathrm{BD}=$ bulk density.

\section{FUNCTIONALLY GRADED MATERIAL (FGM) DESIGN}

The higher cost of producing asbestos free cement based components as compared with the asbestos reinforced ones is both a social and economical problem in developing countries. PVA fibres, the standard replacement for asbestos fibres in air cured asbestos cement, is an expensive raw material (as much as $40 \%$ of the raw materials cost in the Brazilian marketplace) and a reduction of the fibre content will potentially reduce production costs. As demonstrated by Dias et al. (2010), the FGM concept can be a tool 
for optimizing fibre content distribution in such products and therefore improve the competitiveness of asbestos free products in such markets. In two series of the study developed as part of the collaborative project, the distribution of PVA fibre was inhomogeneous (GFC $0.2 \_1.8 \%$ and GFC 1.8_0_1.8\%), as seen in Table 2. This table also shows two additional series that present homogeneous PVA fibre content distributions (FC 1.8\% and FC 1.07\%). PVA fibre content averages and distributions per layer of all series are equally presented in Table 2 .

Table 2 - PVA fibre content $w / w(\%)$ of different layers for all experimental series.

\begin{tabular}{lllllll}
\hline Series & Layer 1 & Layer 2 & Layer 3 & Layer 4 & Layer 5 & Average \\
\hline FC_1.80\% & 1.80 & 1.80 & 1.80 & 1.80 & 1.80 & 1.80 \\
\hline FC_1.07\% & 1.07 & 1.07 & 1.07 & 1.07 & 1.07 & 1.07 \\
\hline GFC 0.2 to $1.8 \%$ & 0.20 & 0.60 & 1.00 & 1.40 & 1.80 & 1.00 \\
\hline GFC $1.8 \_0 \_1.8 \%$ & 1.80 & 0.90 & 0.00 & 0.90 & 1.80 & 1.07 \\
\hline
\end{tabular}

Figure 2 presents a backscattered electron (BSE) image of a transversal section of sample GFC 1.8_0_1.8\% showing different concentrations of fibre (dark points in the micrographs) by thickness. Layer 1 , which was projected to contain $1.8 \mathrm{wt} \%$ of PVA fibre, is in the edge of the cross-section, and layer 3, which is in the core, does not contain PVA fibre. Layer 2 is located between layer 1 and 3 and presents $0.9 \mathrm{wt} \%$ of PVA fibre. PVA distribution is easily observed with BSE imaging.

Figure 2-Backscatter image of cross-section of a specimen GFC 1.8_0_1.8\%. From Dias et al. (2010)

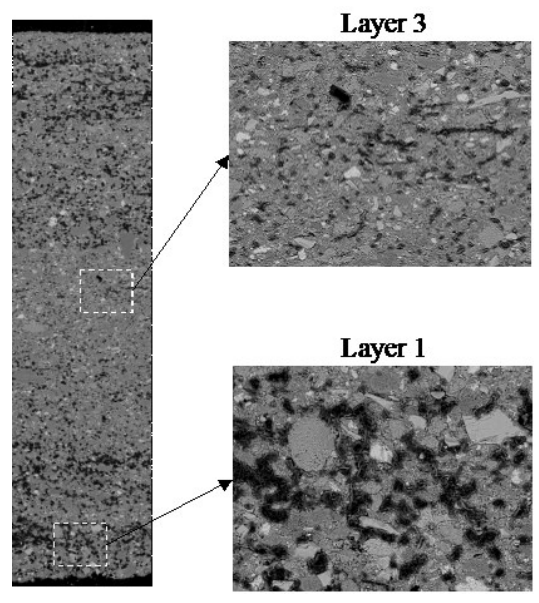

Typical curves of flexural stress versus specific deflection are presented in Figure 3. Different performances were observed for the different series, although some of those series present the same PVA fibre content. This shows that the performance of graded fibrecement under bending solicitations depends on the fibre content distribution. It is possible to reduce the fibre content from a conventional $1.8 \%$ to around $1.0-1.07 \%$ 
without much effect on MOR, depending on how the load is applied. When FGM specimens were submitted to the bending with the layers having the highest fibre content (1.8\%) positioned down (GFC $0.2 \_1.8 \%$ fibres down) they performed results similar to a regular FC $1.8 \%$, despite having fibre content $56 \%$ lower than a regular FC $1.8 \%$. The formulation GFC $1.8 \_0 \_1.8 \%$ (no fibres in the middle layer) and regular FC $1.07 \%$, which have the same average fibre content (1.07\%), presented almost the same average MOR, but the graded fibrecement presented specific energy significantly higher than the homogeneous series.

Both MOR and toughness are strongly influenced by fibre distribution. Preliminary results from the bending tests show that in functionally graded cement based material products, the amount of fibre below the neutral axis, which is the fraction submitted to tensile stress in the beginning of the test, greatly influences MOR and toughness.

The results confirm the potential of the FGM concept in reducing the costs of cement based composite materials. For composites with the same MOR, a reduction in raw materials costs of up to $18.3 \%$ was estimated.

Figure 3. Typical curves of flexural strength versus deflection: a) FC1.8\% and GFC0.2_1.8\% and b)FC1.07\% and GFC $1.8 \_0 \_1.8 \%$

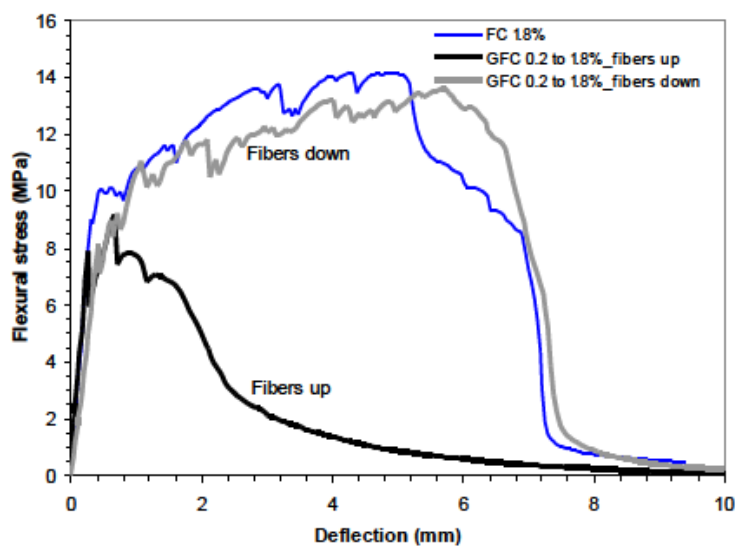

a)

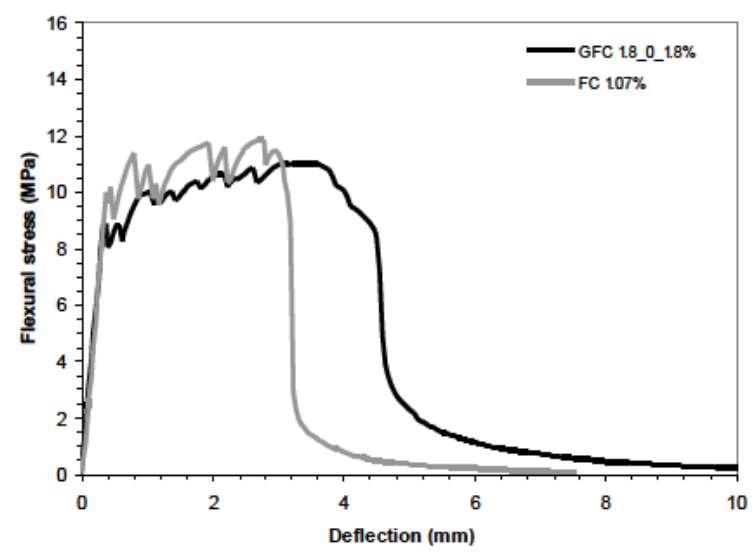

b)

\section{DURABILITY VALIDATION}

The specimens of cement based composites were produced in laboratory by slurring the raw material in water solution ( $20 \%$ of solids) followed by a vacuum drainage of the excess of water and pressing (3.2 MPa). This procedure of preparation is described in details elsewhere (Savastano Jr. et al., 2001). Twenty specimens for each formulation were submitted to wet curing for seven days followed by air cure until the age of 28 days 
when the mechanical and physical performances were assessed. Other twenty specimens for each formulation were submitted to the accelerated aging test (soak-dry cycles). This test consists of submerging the specimens into the water for $18 \mathrm{~h}$; after they are put into an oven at $60 . \mathrm{C}$ of temperature during $6 \mathrm{~h}$, to complete the cycle of $24 \mathrm{~h}$. The aging test is composed by 50 cycles and it is based on the methodology of the European Standards EN -494 section 7.3.5.

The Figure 4 shows the stress-strain curves relative of the composite with fly ash after 28 days of curing. The modulus of rupture, the modulus of elasticity and the toughness values showed only some small alterations due to the variation in the content of synthetic PVA fibre from 1-3\%. According to the Figure 5, the formulation MFA3 presented the best mechanical behaviour after accelerated aging test, because of the higher concentration ( $3 \%$ by mass) of PVA fibres. The cellulose fibres are particularly sensitive to alkali attack (Singh, 1985) what can be better identified in the series with lower content of synthetic fibre. The peeling and the hydrolytic reactions can be responsible for the loss of polysaccharides and reduction of the chain length of cellulose in alkaline environment ( $\mathrm{pH}$ 12-13). Besides, the fly ash particles presented lower values of specific surface area. As a result the mechanical properties of the composites were affected in the initial ages. The higher amount of fibres led to the reduction of the bulk density of the composite. This reduction can be associated with two factors: (1) change in the phase composition, due to modifications in the concentration by mass of the reactive particles and (2) reduction of the packing factor of the particles.

Figure 4. Matrix with fly ash: stress-strain curves of the composite reinforced with synthetic (1, 2 and 3\% by mass) and cellulose (4\% by mass) fibres after 28 days of cure.

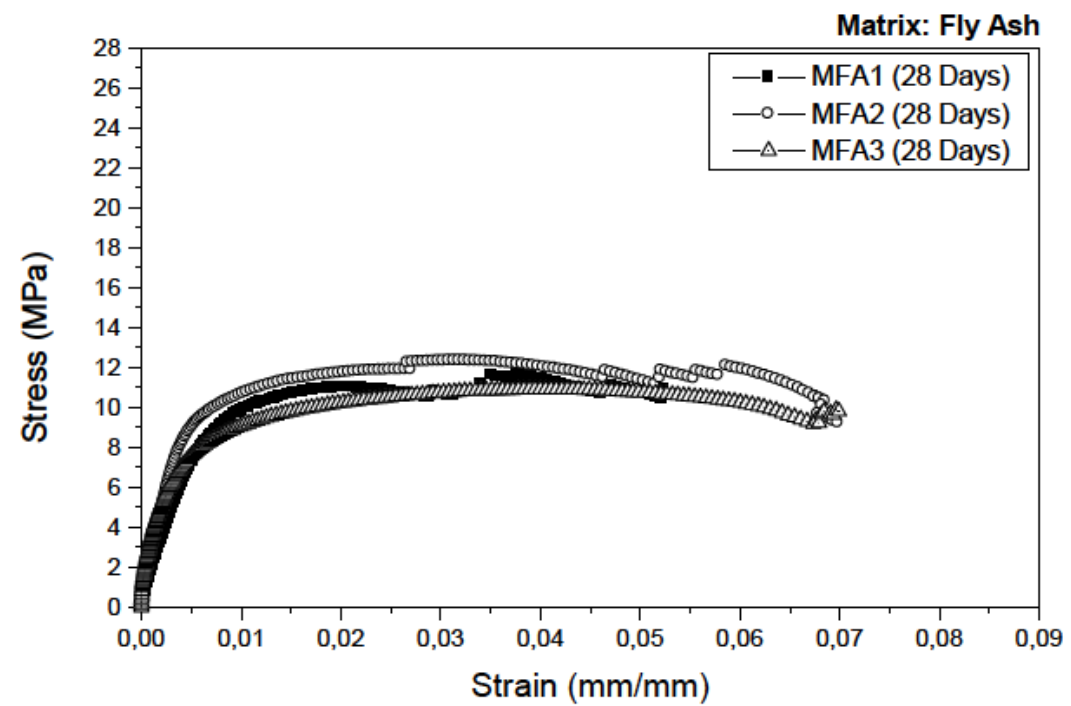

Figure 5. Matrix with fly ash: stress-strain curves of the composite reinforced with synthetic (1, 2 and $3 \%$ by mass) and cellulose (4\% by mass) fibres after accelerated aging test. 


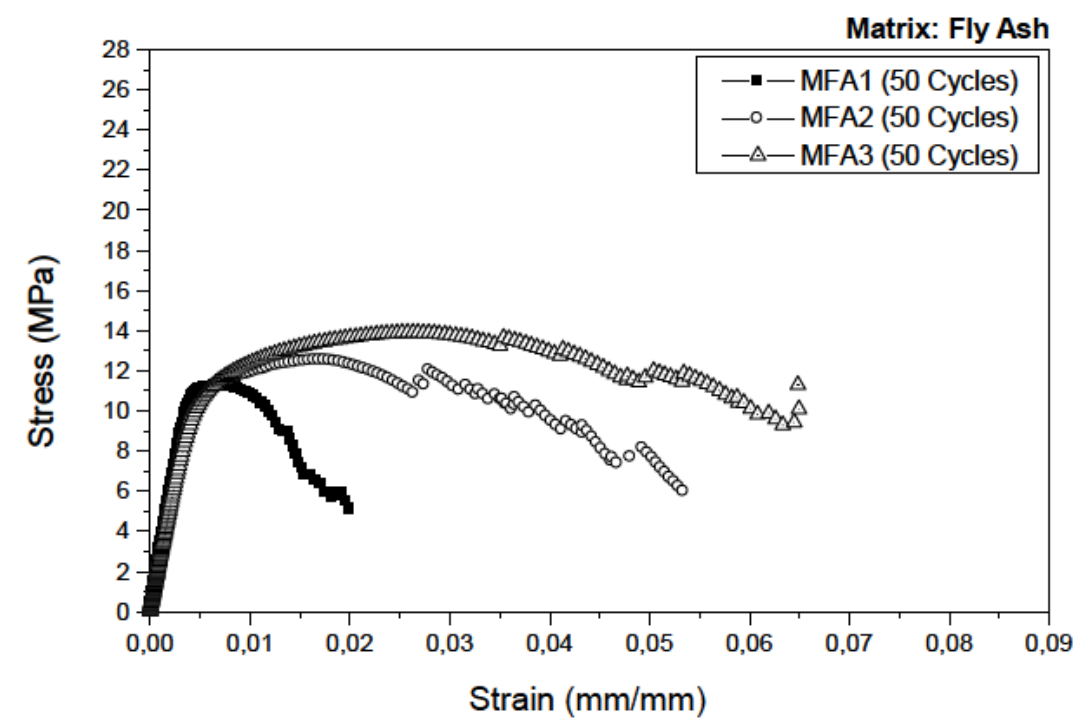

The reduction in the flexural strength after 50 soak-dry cycles was more abrupt to the formulations containing lower concentration ( $1 \%$ by mass) of the PVA fibres. This behaviour can be mainly understood by the degradation of cellulose fibre and its more significant effect in the behaviour of the composite with lower content of PVA fibre. The research also included long-term natural ageing tests.

\section{NEWS PERSPECTIVES ON FAST CURING IN MODIFIED ATMOSPHERE}

When the relative humidity decreases the porous materials undergo a so-called drying shrinkage. Indeed, the evaporation of the interstitial liquid water and the consequent decrease of the liquid saturation give rise to capillary pressure effects that lead to contraction of the solid structure of the composite (Coussy et al., 2004). Carbonation, the reaction of hydrated cement phases with CO2, also leads further shrinkage (Souza, 2013).

Figure 6 presents the drying shrinkage $(\mathrm{mm} / \mathrm{m})$ of the composites cured in a conventional environment and cured in a $\mathrm{CO} 2$ rich environment. Specimens were submitted to drying after 10 days of total curing.

Besides accelerating cement curing, carbonated composites presented lower drying shrinkage than control composites due to changes both in mineralogy and porosity. Their lower water absorption (WA) is an asset in roofing technology. The higher bulk density (BD) is associated to higher bending strength.

Figure 6 - Drying shrinkage, water absorption (WA) and bulk density (BD) of the control (non-carbonated) and carbonated composites 


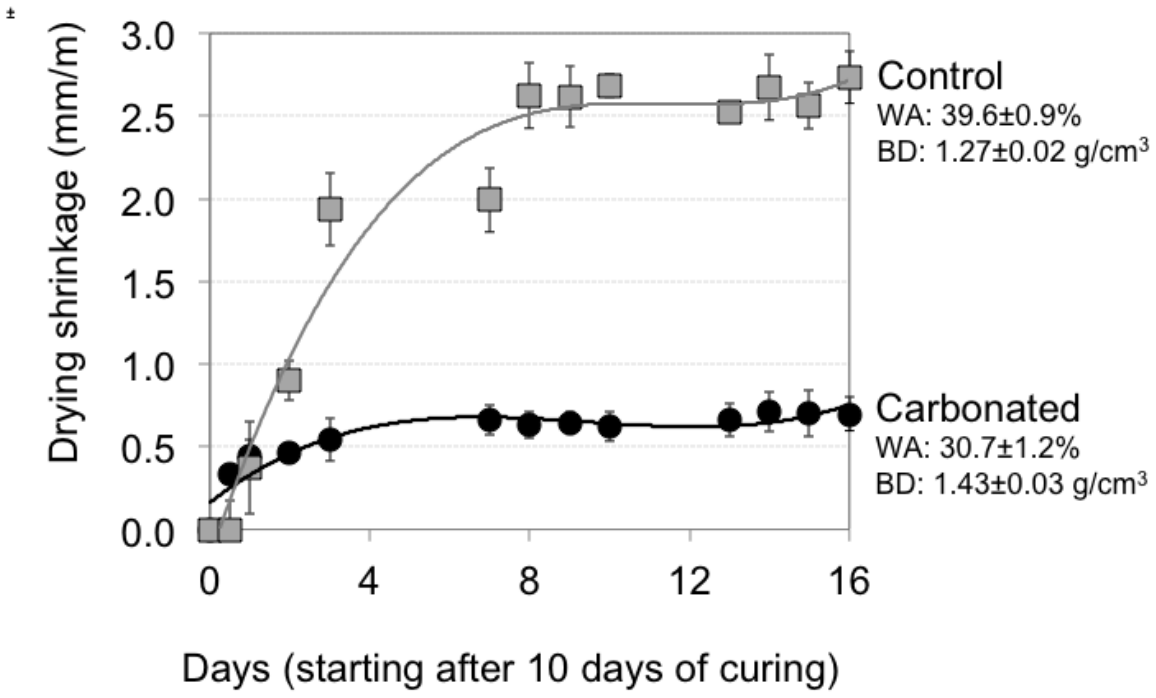

\section{CONCLUSIONS}

In a short paper like this it is not possible to describe properly the advances achieved during this collaborative research work between the industry and the university. Further information is available in the papers prepared by the authors and presented here as references. It is possible to confirm that the two companies have been getting more benefits than they expected, and they are very competitive in the market with new sustainable and economically feasible products. Thanks to the success of this joint research work, the agreement has just been renewed for a further five year period.

The main output of this joint research work is to prove that it is possible to produce sustainable and economically feasible building components, even in developing countries. In this research the sustainability has been achieved by the following steps:

a) replacement of the asbestos fibres, reducing the health risks of the workers and consumers;

b) reduction of Portland cement consumption, therefore decreasing the amount of energy and raw materials expenditure and also the $\mathrm{CO} 2$ emission;

c) application of FGM design, which implies in the reduction of the volume of man-made fibres in the components with similar outcomes of the previous item.

Our experience shows the potential of long-term research collaboration between academy and industry in solving society problems. In many developing countries such collaboration is rather an exception. It also shows that it is possible for companies that compete in the market to join forces to develop pre-competitive research, reducing the investment and sharing the risks, therefore affording to finance a much larger $R \& D$ project. University, on the other side, has the opportunity to conduct research at international level, thanks to the financial and technical support from the industry. The 
collaboration also made possible to educate graduate students in the art of using science based research to solve practical problems.

\section{ACKNOWLEDGEMENTS}

The authors are in debt with the industries INFIBRA S.A. and IMBRALIT Ltda. for their long-term collaboration and also FAPESP (PITE Program) and FINEP (Habitare Program) for their financial support to the University research group. They also express their gratitude to numerous research partners, including Cleber M. R. Dias (UFBA), Gustavo Tognoli (UFV), Juliano Fiorelli (FZEA USP), Leila M. C. Motta (UEL), Maria Alba Cincotto (Poli USP), Rafael G Pileggi (Poli USP), Rui B de Souza (FEI).

\section{REFERENCES}

- AgOPYAN, V., SAVAStanO JR., H, JOHN, V. M., CINCOTTO, M. A. (2005) Developments on vegetable fibre-cement based materials in São Paulo, Brazil: an overview. Cement \& Concrete Composites, 27, p. 527-536.

- BEZERRA, E. M.; JOAQUIM, A. P.; SAVASTANO JR, H.; JOHN, V. M.; AGOPYAN, $\underline{\mathrm{V}}$. (2006) The effect of different mineral additions and synthetic fiber contents on properties of cement based composites. Cement \& Concrete Composites, v. 28, n.6, p. 555-563.

- DiAS, C. M. R., SAVASTANO JR., H., JOHN, V. M. (2010) Exploring the potential of functionally graded materials concept for the development of fiber cement. Construction and Building Materials, 24, p. 140-146.

- $\quad$ HEINRICKS, H., BERKENKAMP, R., LEMPFER, K., FERCHLAND, H. F (2000) In MOSLEMI, A. A.(ed.) Proceedings of the 7th International Inorganic-Bonded Wood and Fiber Composite Materials Conference. Siempelkamp Handling Systems Report; University of Idaho: Moscow, 2000; 12 p.

- MÁrmOL, G., SANTOS, S. F., SAVASTANO JR., H., BORRACHERO, M. V., MONZÓ, J. M., PAYÁ, J. J. (2013) Mechanical and physical performance of low alkalinity cementitious composites reinforced with recycled cellulosic fibres pulp from cement kraft bags. Industrial Crops and Products, 49, p. $422-427$.

- $\quad$ MOSLEMI, A. A. (ed.) (2000). Proceedings of the 7th International Inorganic-Bonded Wood and Fiber Composite Materials Conference. University of Idaho: Moscow.

- NITA, C.; JOHN, V. M.; DIAS, C. M. R.; SAVASTANO JR, H. ; TAKEASHI, M. (2004). Effect of metakaolin in the performance of PVA and cellulose fibers reinforced cement. In: 9th International Conference on Inorganic-bonded Composite Materials, 2004, Vancouver. Proceedings of the 9th International Conference on Inorganic-bonded Composites Materials. Moscow: University of Idaho. p. 1-11.

- ODLER, I., COLÁN-SUBAUSTE, J. (1999) Investigations on cement expansion associated with ettringite formation. Cement and Concrete Research, 29, p. 731-735.

- $\quad$ PAVOINE, A., BRUNETAUD, X., DIVET, L. (2012) The impact of cement parameters on Delayed Ettringite Formation. Cement \& Concrete Composites, 34, P. 521-528.

- $\quad$ SAVASTANO JR., H., WARDEN, P. G., COUTTS, R. S.P. (2001) Ground iron blast furnace slag as a matrix for cellulose-cement materials, Cement \& Concrete Composites, 23, p. 389397.

- SINGH, S. M. (1985) Alkali resistance of some vegetable fibers and their adhesion with Portland cement, Research and Industry, 15, p. 121-126.

- $\quad$ SOUZA, R.B. Study of shrinkage of polymer fiber reinforced cement. Dr. Eng. Thesis. Escola Politécnica da USP, 2013. (in Portuguese) 
- $\quad$ TONOLI, G. H. D., SANTOS, S. F., JOAQUIM, A. P., SAVASTANO JR., H. (2010) Effect of accelerated carbonation on cementitious roofing tiles reinforced with lignocellulosic fibre. Construction and Building Materials, 24, p. 193-201.

- TONOLI, G. H. D., SANTOS, S. F., SAVASTANO JR., H., DElVASTO, S., MEJía DE GUTIÉRREZ, R., LOPEZ DE MURPHY, M. M. (2011) Effects of natural weathering on microstructure and mineral composition of cementitious roofing tiles reinforced with fique fibre. Cement \& Concrete Composites, 33, p. 225-232. 


\title{
USING LIFE CYCLE ASSESSMENT TO ILLUSTRATE THE BENEFITS OF BLINDS AS PASSIVE AND SUSTAINABLE ENERGY SAVING PRODUCTS IN THE DOMESTIC ENVIRONMENT IN THE UK
}

\author{
Andrews, D. ${ }^{1}$; De Grussa, Z. ${ }^{2}$, Chalk, A. ${ }^{3}$, and Bush D. ${ }^{4}$
}

\begin{abstract}
:
Blinds and shutters create privacy during the day and night in residential and commercial buildings. They are also widely used in warm locations to keep rooms cool when sunny and to reduce heat loss at night or in winter; in turn this reduces use of air conditioning, heating, associated energy, carbon and costs. Although these benefits have not been fully recognised in the UK, some can be assessed via 'Shade Specifier' (an online tool developed by the British Blind and Shutters Association and London South Bank University), to promote their wider and more correct use. Recent research has confirmed the importance of blinds and shutters in passive temperature control, which indicates that they contribute positively to sustainable living; their overall level of sustainability has not been fully determined however because to date the majority of research has only considered operational energy savings and/or carbon equivalent inputs and outputs.

This paper seeks to present a more holistic and accurate evaluation of the environmental impact of blind use as an aid to sustainable living in a typical domestic setting in the UK. Life Cycle Assessment is used to model the overall product life and associated impacts of 4 different types of blind, different product life spans, levels of energy consumption and potential savings during the heating season in order to demonstrate the real benefits of this type of window covering in the UK.
\end{abstract}

KEYWORDS: BLINDS AND SHUTTERS, ENERGY SAVING, LIFE CYCLE ASSESSMENT, OVERALL ENVIRONMENTAL IMPACT

\section{INTRODUCTION}

Global energy consumption has increased exponentially since the Industrial Revolution and almost 9,000 Mtoe energy were consumed in 2012 alone. It is predicted that consumption will continue to rise by between $37 \%$ (EIA, 2014) and 56\% (IEA, 2014) by 2040 concurrently with development in non-OECD countries and population increase. Although a very efficient source of energy, fossil fuels also produce $\mathrm{CO} 2$ and other greenhouse gases during combustion, many of which have been shown to have direct and indirect detrimental impacts on the environment, human populations and ecosystems in general.

\footnotetext{
${ }^{1}$ School of the Engineering, London South Bank University, England UK. Email: andrewsd@1sbu.ac.uk

${ }^{2}$ School of the Engineering, London South Bank University, England UK. Email;; degrussz@1sbu.ac.uk

${ }^{3}$ British Blind and Shutters Association, PO Box 232, Stowmarket, Suffolk, IP14 9AR England UK Email: andrew@bbsa.org.uk

${ }^{4}$ British Blind and Shutters Association, PO Box 232, Stowmarket, Suffolk, IP14 9AR England UK Email: dnbushhallmarkblinds@hotmail.com
} 
As a naturally occurring substance $\mathrm{CO} 2$ has always been present in the atmosphere and prior to the Industrial Revolution the concentration was about 250ppm. Since then the level has increased to 400ppm as a direct result of human activity. At 450ppm however it is unlikely that humans will be able to reverse climate change, the impacts of which could be catastrophic (IPCC, 2007). The need to reduce the level of CO2 and similar emissions therefore is of paramount importance and could be achieved in part by reducing energy consumption. It is equally important to consider other inputs, outputs and their contribution overall environmental impact to ensure that carbon reduction in one area does not lead to or increase damage to another. Therefore this paper assesses the overall environmental impact of one particular energy saving product, namely window blinds, to find out how sustainable or otherwise this type of product really is.

\section{ENERGY CONSUMPTION AND THERMAL COMFORT IN UK HOMES}

In the UK energy is consumed across 4 main sectors, namely transport, industry, services and domestic and consumption by each sector is $38 \%, 17 \%, 13 \%$ and $27 \%$ respectively (DECC, 2015). Energy is used in the domestic sector for lighting and appliances, water heating, cooking and space heating and in 2012 accounted for 502 TWh energy. Although the number of homes in the UK has increased by $40 \%$ since 1970 , overall energy use by this sector has only increased $16 \%$ because individual household energy use has fallen from 23,800 to $18,600 \mathrm{kWh}$ per year. The decrease in household energy consumption is mainly due to more efficient lighting, appliances, space and water heating systems, and insulation. Space heating currently accounts for about $60 \%$ of domestic energy use because consumer expectations have changed with the widespread installation of central heating and internal temperatures are 4oC higher than they were in 1970 (DECC, 2013).

Improved insulation has helped to reduce heat loss through roofs (by approximately $20 \%$ ), floors and walls and typically a contemporary insulated cavity wall has a U-value of $0.2 \mathrm{~W} / \mathrm{m} 2 \mathrm{~K}$. Heat loss through windows has also been reduced from $5.8 \mathrm{~W} / \mathrm{m} 2 \mathrm{~K}$ in a single glazed window to $2.9 \mathrm{~W} / \mathrm{m} 2 \mathrm{~K}$ in a double glazed window, from which about $90 \%$ of homes in the UK now benefit. Use of special coatings (that reduce emissivity and increase solar gain), optimum cavity width, inert gas (e.g. argon), warm edge spacers, and triple glazing can further reduce heat lost to $1 \mathrm{~W} / \mathrm{m} 2 \mathrm{~K}$ although the number of homes with this type of window is very limited. These figures clearly show that even through the most technically advanced windows heat loss is greater than other building elements.

Windows also contribute to thermal gain, which is becoming an increasingly important factor in the UK due to changes in weather, climate, and building design (specifically larger windows, glazed walls, doors, and roofs). A number of studies show that in the workplace productivity increases when employees have individual temperature control (World Green Building Council, 2013). In the home the effects of temperature are also very dramatic particularly in the case of babies and people over the age of 65. Living room and bedroom temperatures should be no lower than $18 \mathrm{oC}$ (to reduce risk of heart 
attack and strokes in older people) (Wookey et al, 2014) and no higher than 25oC (to avoid thermal stress and dehydration) (ODPM, 2006). Babies should also sleep in rooms between $16-20 \mathrm{oC}$ to reduce the risk of Sudden Infant Death Syndrome, which has been linked to overheating (Lullaby Trust, 2014).

In the UK numerous commercial buildings have heating and cooling systems but, unlike many other countries, domestic electro-mechanical cooling systems are comparatively rare. Nevertheless a number of studies illustrate the value of blinds and shutters to both control internal temperature and reduce demand on electro-mechanical cooling systems. The benefits vary according to glazing type and size, building aspect and construction but range from 30-70\% (Dolmans, 2006) and (Hutchens, 2015). Blinds and shutters and their correct use will of course become more important in the UK as climate changes and temperatures rise (CIBSE, 2015).

\section{BLINDS AND SHUTTERS IN UK HOMES}

The above data relating to heat-loss through windows is based on uncovered windows but blinds and other window coverings have been shown to be a very important means of reducing U-value and heat loss (BBSA, 2011); the same prior studies show that correct use of window coverings during the heating season (where they are open during the day and fully closed at night) can reduce energy consumption by at least $25 \%$ in the case of single glazed windows and by at least $15 \%$ in the case of double glazed windows (Dolmans, 2006) and (Hutchens, 2015).

Although window coverings can help to control thermal loss and gain it is of course essential that windows are not covered permanently to allow natural light into buildings; in addition to reducing Seasonal Affective Disorder studies show that this type of light improves mental function and memory, learning speed and test scores, workplace productivity, helps patient recovery in hospital, and increases retail sales (World Green Building Council, 2013). Occupants' requirements vary according to activity but light levels should be between 20-500 lux on average (CIBSE, 2015).

Unlike roller blinds and curtains other than semi-transparent sheer curtains, slatted blinds and shutters can of course be adjusted to allow natural light into buildings; it is therefore unsurprising that venetian blinds are the most popular type of domestic blind in the UK and account for $30 \%$ of sales. All types of domestic window covering are important to residents and in 2103 in the UK alone sales of all window coverings and associated products exceeded $£ 1.1$ billion, over $51 \%$ of which ( $£ 565$ million) were for blinds (AMA Research, 2014). These sums highlight the importance of blinds and shutters as part of the domestic interior as do the energy saving benefits discussed above. 


\section{CARBON FOOTPRINT STUDIES AND THEIR LIMITATIONS}

To date analysis of the overall environmental impact of blind and shutter use has been very limited and studies have only measured carbon and its equivalents (as carbon footprints) rather than overall environmental impact. One such study considered use of external slatted roller blinds in the UK (Ylitalo et al, (2011) and another use of motorised external venetian blinds (Würzburg Schweinfurt Institute, 2013). In both cases use of blinds was found to be reduce carbon and its equivalents. More specifically the earlier study showed that, providing that the blind is recycled at end of life, the payback for life cycle greenhouse gas emissions is only 6 months but 3 years if it is not recycled. The later study showed that with a 20 year product life, carbon savings ( 8.5 tonnes) were 57 times greater than the carbon embodied in the blind $(150 \mathrm{~kg})$.

'Carbon footprint' studies are a popular guide to environmental impact but, as previously stated, they only measure one type of substance and its associated impacts and consequently results can be misleading. Life Cycle Assessment (LCA) is a far more comprehensive means of measuring environmental impact and includes hundreds of material, gas and liquid inputs and outputs including emissions to land, air and water, the impact on ecosystems, resource supply and human health. A recent study that compared a Life Cycle Assessment and a Carbon Footprint of the same supermarket refrigerated display cabinet clearly illustrated the limitations of carbon footprints. It is appreciated that the majority of impacts related to this type of product derive from use (because the unit almost continually consumes energy); however a typical cabinet is comprised of 1.5 tonnes materials which produce many impacts in addition to carbon. The results of this carbon footprint study show that $97.5 \%$ of impacts derive from operational energy and only $2.5 \%$ impacts from product manufacture and treatment at end-of-life. The ratio of impacts measured by the LCA results were somewhat different however and show that $80 \%$ of impacts derive from operational energy and $20 \%$ from product manufacture and disposal (Bibalou et al, 2013).

To date even though some manufacturers state that they have LCAs of window coverings the published results only show CO2 (Velux, 2015). There is a therefore a definite need to present a more comprehensive assessment of the overall impacts, benefits and otherwise of window coverings.

\section{LIFE CYCLE ASSESSMENT (LCA) AND RESEARCH METHODOLOGIES IN THIS STUDY}

The stages of a Life Cycle Assessment include extraction of raw materials, bulk materials processing, component manufacture and assembly, use, treatment at end-of-life (landfill, reuse, remanufacture, recycle) and transport. In this study all of the numerous inputs, outputs, and impacts are assessed using the Eco-indicator 99 method and Ecoinvent Database in SimaPro LCA software. This is a simplified LCA in which weighted results are presented as Ecopoints so that dissimilar impacts can be easily compared. The datum for this unit (1000 Ecopoints) derives from the average impact of 1 European person per 
year. Uncertainties in this study are also limited by weighting the results with the default Hierarchist weighting set in which the effect of impacts are considered over a medium timescale, it is predicted that many problems can be avoided through proper policies, and inclusion of evidence / data is based on expert consensus.

Figure 1: Life cycle processes for blinds

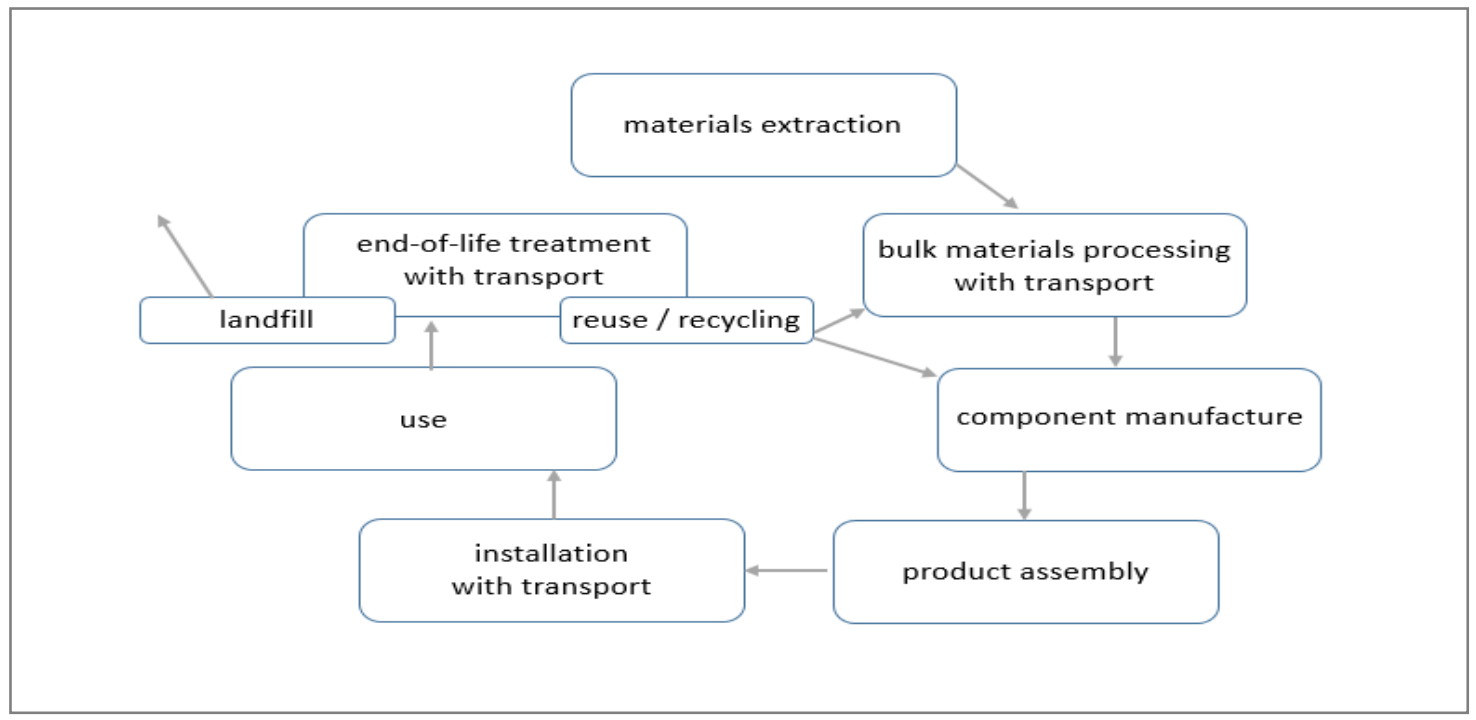

At present it is unknown how domestic blinds are treated at end of life in the UK. If they are not disassembled they may be combusted with energy recovery (in an energy from waste plant) or in the case of metal blinds, the polymeric parts could be combusted as waste during the metals recycling process. Two end-of-life scenarios have been modelled to address some of these uncertainties: in the best case it is assumed that $100 \%$ materials are either recycled or reused and a worst case end-of-life scenario it is assumed that $100 \%$ materials are sent to landfill.

There are so many variables that affect energy saving through blind use including operational type, materials, and colour of blind, which affect the transmittance, absorption and reflection of light (and therefore the U-value); building orientation, type of glazing (Dolmans, 2006 and Hutchens, 2015) and occupant behaviour (Bennett et al, 2014) also have a considerable impact on energy saving. It has already been stated that the average energy savings for single glazed windows can exceed $25 \%$ and those for double glazed windows $15 \%$ providing that blinds are open all day and fully closed at night during the heating season. Energy savings of $5 \%, 10 \%, 15 \%$, and $20 \%$, are modelled in this simplified LCA study to account for variation in the above criteria and to determine the point at which use of blinds becomes environmentally advantageous. It is also assumed that all windows are double glazed because this is the most predominant type of glazing in the UK.

The functional unit in the model is one average house which has 7 blinds that cover a total of $14.5 \mathrm{~m} 2$. Annual average annual energy consumption for space heating is $60 \%$ of 
the total of domestic energy use (although it varies according to external temperature); this is therefore calculated as 11,160 kWh per household (DECC, 2015).

The life cycle impacts of 4 typical types of blind are calculated to ascertain whether there is much difference in the impact of these individual products. It is not untypical for different types of blind to be installed in the same house so the average impact of these blinds will be calculated to create a representative product. The 4 blinds could be used in either a residential or commercial context but in this study they are used in the former.

The models are based on real products and each blind was reverse engineered in order to and identify and quantify all materials and manufacturing processes, details of which were discussed with a manufacturer. The blinds are a polyester blackout roller blind, a linden (basswood) wood venetian blind (50mm slats), an aluminium venetian blind (25mm slats) and a vertical blind ( $89 \mathrm{~mm}$ polyester vanes). While the materials for the window covering components obviously differ, the materials in the mechanisms are more similar and include polymers (nylon 6, acetal, PVC, and polyester) and metals (aluminium, brass, nickel plated, mild and stainless steel). Associated manufacturing processes include wood cutting and machining, injection moulding, extrusion, sheet and bar production, metal forming and machining, yarn production and braiding, paint and powder coating. Materials selection has been optimised for function: for example polyester is widely use because it does not stretch and or deteriorate in sunlight like natural fibres. Similarly engineering polymers (nylon 6 and acetal) are wear and abrasion resistant and consequently are used for bearings and other moving parts. The specific type and quantity of components varies according to blind type and operation method and in this case the roller blind has the lowest and the vertical blind the highest number of components.

The UK blind industry currently employs about 16,000 people and although the largest companies employ over 500 people a significant majority (73\%) of businesses employ 15 people (Experian, 2014) and many blinds are assembled by hand; mechanisms and components are designed accordingly and most push-fit, which also facilitates disassembly and therefore reuse and recycling. Not all materials and components are produced in the UK however and the model therefore assumes that $25 \%$ by mass are shipped from China where components are also manufactured.

In addition to life cycle stages product life span is considered in the model because this also affects overall environmental impact. The carbon footprint studies discussed above (Ylitalo et al, (2011) and Würzburg Schweinfurt Institute, (2013)) are based on a 20 year life, which is realistic because external blinds are more expensive, durable and difficult to install than internal blinds; in both models blinds are raised and lowered automatically. Internal blinds may be subject to misuse or damage because they tend to be raised and lowered manually; they are also seen as interior furnishings and may be changed in conjunction with other interior decoration activities. Anecdotal evidence shows that product life is often less than 20 years and that some residents decorate as frequently as every 3 years; many more residents decorate every 5 years and others every $10-15$ years 
((Graham \& Brown, (2015) and Kingfisher Group, (2012)). These different time periods are also included in the model to address uncertainty about length of product life.

\section{RESULTS}

\section{Comparative LCA of 4 blinds}

As stated above the 4 blinds that were assessed are a polyester blackout roller blind, an aluminium venetian blind, a linden wood blind, and a polyester vertical blind. Assessment of the product only (materials and manufacturing processes) shows that the roller blind has the lowest impact followed by the wood venetian, the vertical and the metal venetian. In fact the impact of the materials and manufacture in the metal venetian is more than twice that of the roller because of the high energy inputs required for the aluminium parts even though the model is based on a typical standard production mix which includes recycled as well as virgin material. The wood blind includes painted slats; the impact of painting is higher than that of embedding colour in the polyester fabrics but there is a trade-off and the impact of wood is reduced during the growing stage when it absorbs $\mathrm{CO} 2$ during photosynthesis. The vertical blind uses slightly more polyester fabric than the roller and the impact is higher due to this and to additional processing such as cutting. The impact of the vertical blind is also increased by the inclusion of distinctive ballast weights and stainless steel spacers. These results usefully illustrate the differences between the impacts of materials and manufacture but the end-of-life stage must be included for assessment of a complete life cycle.

The two different end-of-life scenarios make a significant difference to the overall life cycle impact and, predictably, all products that are sent to landfill have a higher impact than those that are reused / recycled. This is partly because in the LCA method it is assumed that materials are not stockpiled after disassembly but are recycled and reused in the manufacture of new products. Furthermore in addition to being wasted, the materials that are sent to landfill can produce emissions to air, water and soil as they break down, which in turn increases environmental load.

When recycled at end of life the blind with the lowest impact is the wood venetian, followed by roller, metal venetian and vertical. When sent to landfill however that with the lowest impact is the roller followed by the vertical, the wood venetian and the metal venetian. On average the impact of sending the blinds to landfill is more than twice that of recycling at end-of-life which highlights the benefit of recycling. Although technically possible it can be difficult to find markets for some of the recyclate materials however; this is particularly true in the case of polymers so reuse could be a preferred option proving that the components are not worn or damaged.

\section{Combined LCA of energy consumption of blinds}

Prior research shows that use of blinds can save in excess $15 \%$ of energy for space heating in the UK. The original intent of this paper was to measure the overall 
environmental impact of blinds and to compare this with the reduced environmental impact of related energy savings. A typical UK generation mix that includes various fossil fuel and renewable technologies was used for the model and the results are summarised in figures 2 and 3.

Figure 2: The benefits of blind use when recycled at end-of-life space heating energy savings of 5\%,10\%,15\% and 20\% and 3, 5, 10, 15 and 20 year product (blind) life spans

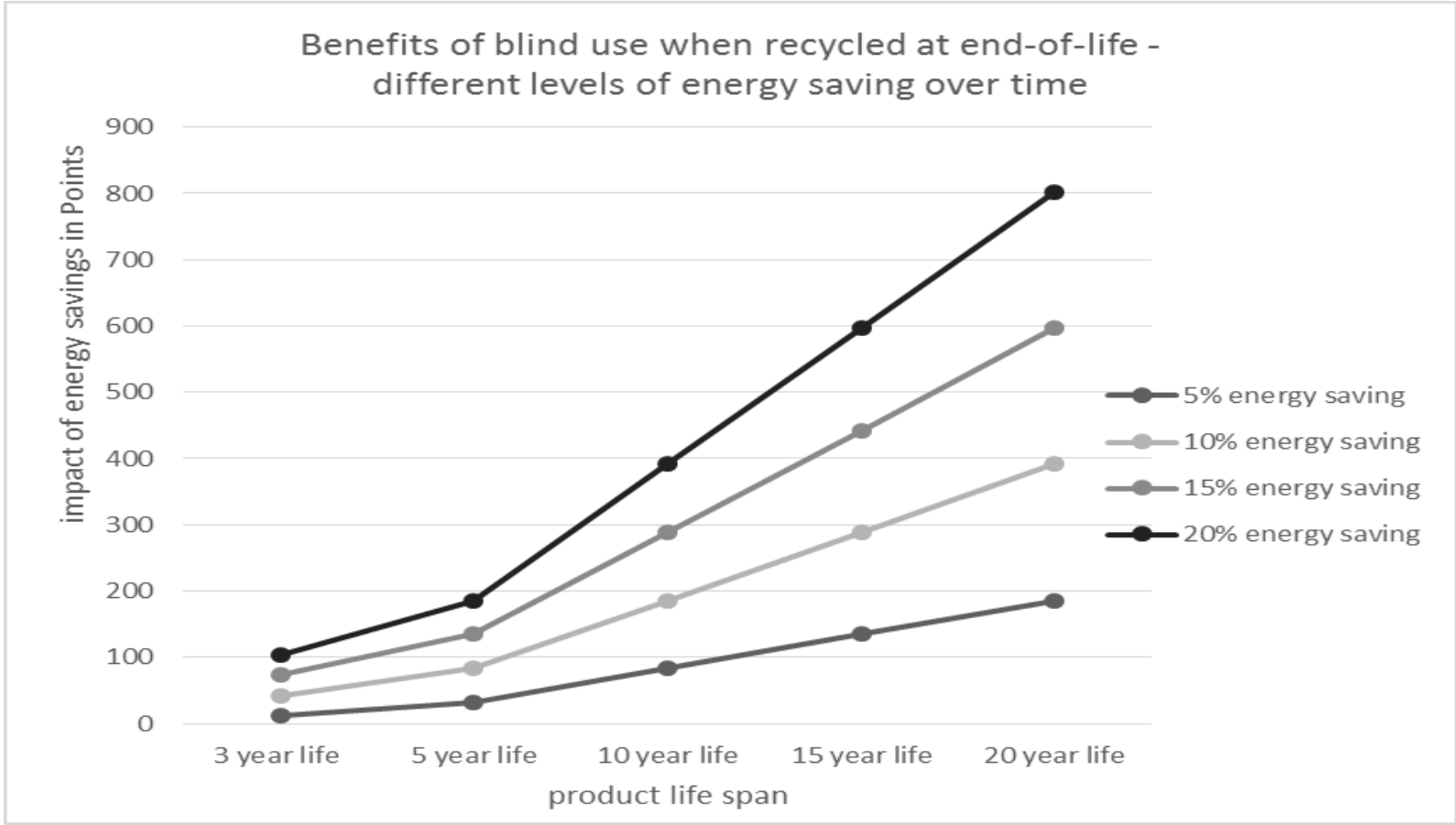

Figure 2 shows that, providing the blinds are recycled at end-of-life the overall environmental impact will be reduced through energy saving. After 3 years with 5\% energy saving the benefits are very limited and overall environmental impact is reduced by less than $2 \%$. As time progresses benefits becomes more apparent however and after 5 years with $15 \%$ energy savings or 10 years with $10 \%$ energy savings overall impact is about $13 \%$ lower than it would have been in a house without blinds. Over time the impact of the blinds themselves obviously becomes less significant so that by 15 years with $15 \%$ energy savings impact is reduced by more than $14 \%$ and at 20 years with $20 \%$ energy saving impact is almost $20 \%$ lower than it would have been without use of blinds.

The results in Figure 3 - where the blinds are sent to landfill - follow a similar pattern to those in figure 2 although the benefits are slightly less notable. After 5 years with $15 \%$ energy saving, use of blinds has only reduced environmental impact by about $10 \%$. Over time the ratio of blind-energy changes and by 20 years with $20 \%$ energy saving it is almost $19 \%$. The most dramatic difference however occurs if product life is very short and the blinds are sent to landfill after 3 years and only 5\% of energy has been saved: in this case the impact of blind use is higher than not using a blind. Hopefully disposal of 
blinds after such a short time period is limited and residents either pass them on to other users or disassemble and recycle parts.

Figure 3: The benefits of blind use when sent to landfill at end-of-life space heating energy savings of $5 \%, 10 \%, 15 \%$ and $20 \%$ and $3,5,10,15$ and 20 year product (blind) life spans

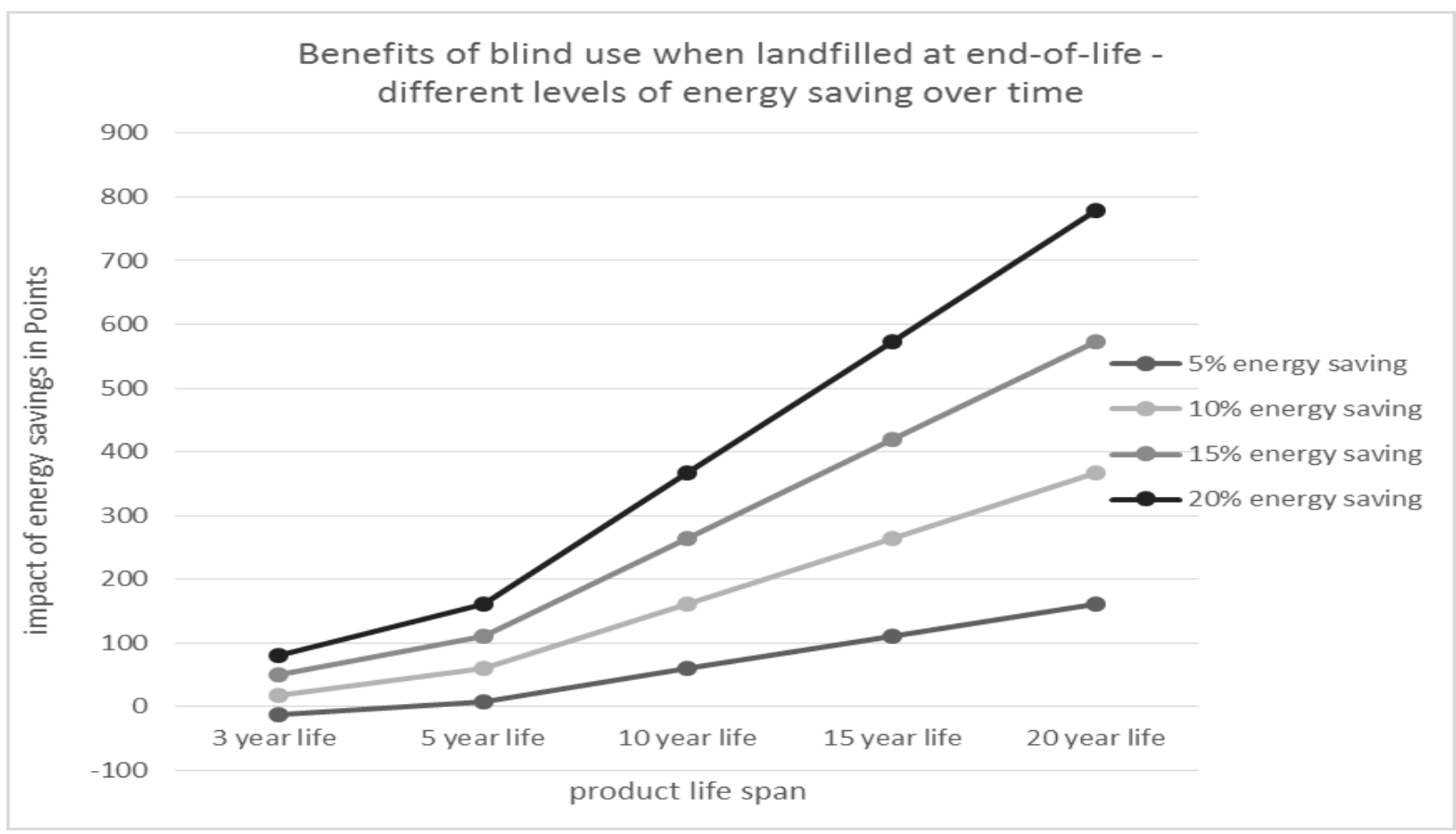

Conclusions and discussion

The research undertaken and the simplified LCA studies clearly show that in a typical UK household use of blinds during the heating season is environmentally beneficial. Even if the blinds are not used 'correctly' (i.e. are fully open during the day and fully closed at night and therefore energy savings are below the potential maximum of $15 \%$ ), the installation of blinds will reduce overall environmental impact as long as they are used for at least 3 years and are recycled at end-of-life. If blinds are sent to landfill use will still be environmentally beneficial as long as product life is at least 5 years and energy savings are above $10 \%$.

It is important to note that the carbon savings recorded in the studies of the two external blinds appear to be higher than the overall savings calculated in these Life Cycle Assessment studies. This is due to the fact that carbon footprint studies only measure one type of substance whereas the LCA studies consider the impacts of hundreds of substances and are therefore more accurate; furthermore the blinds in these studies are external and are more efficient (i.e. reduce thermal gain and loss) more than internal blinds. A full LCA of an external blind should be undertaken to compare like with like. Similarly other types of interior and exterior blind in addition to the 4 blinds in this study should also be modelled and compared to identify the optimum product(s). 
It is acknowledged that the data used in this study is generic and future studies should include more specific data about the origin of materials and how blinds are treated at endof-life including reuse and energy from waste scenarios for example. A more comprehensive LCA that conforms to ISO 14040 standards should also be carried out.

It is essential to undertake real world studies of blind use for domestic solar shading during the summer months in the UK in order to assess its effect on interior temperature and overall environmental impact. Solar shading will become increasingly important in the UK for thermal comfort, health and well being in anticipation of future climate change and the need to continually reduce carbon emissions and overall environmental impact. These studies must also include consider the differing effects and impacts of natural and artificial light levels associated with use of blinds as well as variables in user behaviour.

Finally sustainability includes environmental, economic and social factors; the emphasis of this LCA is environmental impact however, and at present economic considerations are excluded. Similarly the Eco-indicator 99 LCA method includes some impacts on human health (e.g. damage to the ozone layer and respiratory substances) but it does not include a comprehensive assessment of social factors such as ethical and safe working conditions, child labour and its impact on education etc. Social LCA is an emerging process which, in conjunction with economic factors should be included in future studies of blinds from cradle-to-cradle and operational energy in order to determine their complete level of sustainability.

\section{REFERENCES}

- BENNETT I, O’BRIAN AND BURAK HG, (2014) Effect of Window Blind Use in Residential Buildings: Observation and Simulation Study, International Building Performance Simulation Association; accessed $20 \quad$ July 2015 from http://www.ibpsa.org/proceedings/eSimPapers/2014/3A.3.pdf

- BIBALOU D, ANDREWS D,CHAER I, MAIDMENT G AND LONGHURST M, (2013) A Carbon Footprint Study and a Life Cycle Assessment of an identical Refrigerated Display Cabinet: comparative analysis of the respective ratios of embodied and operational impacts; proceedings of the 3rd International Congress on Life Cycle Assessment, Lille, 4-5 Nov 2013.

- BBSA (2011) AND BAKER (2009) Improving the thermal performance of traditional windows with blinds and shutters; Guidance notes based on Research into the thermal performance of traditional windows: timber sash windows. Glasgow Caledonian University and English Heritage. http://www.englishheritage.org.uk/professional/research/buildings/energy-efficiency/thermalperformance-of-traditional-windows/

- CIBSE (Chartered Institution of Building Services Engineers) (2015) Environmental design guide; 8th edition. Lavenham Press, UK.

- DECC, (2015) Energy Consumption in the UK; accessed 20 July 2015 from https://www.gov.uk/government/uploads/system/uploads/attachment_data/file/449102/ECUK _Chapter_1_-_Overall_factsheet.pdf

- $\quad$ DECC, (2013) United Kingdom Housing Energy Fact File; accessed 20 July 2015 from https://www.gov.uk/.../united-kingdom-housing-energy-fact-file-2013 
- DOLMANS, D., (2006) Energy saving and CO2 Reduction Potential from Solar Shading Systems and Shutters in the EU-25; accessed 20 July 2015 from http://www.esso.com/images/downloads/ESCORP-EU25\%20volledig.pdf

- $\quad$ EIA (Energy Information Administration) International Energy Outlook (2014); accessed 20 July 2015 from http://www.eia.gov/forecasts/ieo/

- EXPERIAN BUSINESS DATABASE (2014); accessed 20 July 2015 from http://www.experian.co.uk/assets/businessinformation/brochures/National_Business_Database_Guide.pdf

- $\quad$ GRAHAM AND BROWN (2015) How often should you redecorate? (2015) accessed 20 July 2015 from https:/www.grahambrown.com/uk/blog/inspirations/how-often-should-youredecorate

- HUTCHENS, M G (2015) HIGH Performance Dynamic Shading Solutions for Energy Efficiency in Buildings; accessed 20 July 2015 from http://www.esso.com/images/downloads/Downloads\%20presentations/ES-SO_RT-2015_Hutchins-

M_V6_final.pdf

- $\quad$ IEA (International Energy Agency) World Energy Outlook (2014); accessed 20 July 2015 from

https://www.iea.org/publications/freepublications/publication/WEO_2014_ES_English_WEB .pdf

- $\quad$ KINGFISHER GROUP, European home report 2012, Better Homes Better Lives; (2012) $\begin{array}{llll}\text { accessed } & 20 & \text { July } & 2015\end{array}$ http://www.kingfisher.com/files/reports/2012/european_home_report/european_home_report. pdf

- LULLABY TRUST Fact Sheet on Temperature; accessed 20 July 2015 from http://www.lullabytrust.org.uk/file/Fact-Sheet-Temperature.pdf

- ODPM (Office of the Deputy Prime Minister) (2006) Housing Health and Safety Rating System (HHSRS): Operating Guidance, London, ODPM.

- VELUX (2015) Life Cycle Assessments; accessed 20 July 2015 from http://crreport.velux.com/products-and-services\#Life_Cycle_Assessments

- WOOKEY R, BONE A, CARMICHAEL AND CROSSLEY A, (2014) Public Health England; Minimum home temperature thresholds for health in winter: A systematic literature review; Public Health England 2014; accessed 20 July 2015 from https://www.gov.uk/government/uploads/system/uploads/attachment_data/file/365755/Min_te mp_threshold_for_homes_in_winter.pdf

- WORLD GREEN BUILDING COUNCIL, (2013) The Case for Green Building, A Review of the Costs and Benefits for Developers, Investors and Occupants; accessed 20 July 2015 from http://www.worldgbc.org/files/1513/6608/0674/Business_Case_For_Green_Building_Report WEB_2013-04-11.pdf

- WURZBRG SCHWEINFURT INSTITUTE (2013) in ES-SO A New Vision on Solar Shading; $\quad$ accessed $\quad 20 \quad$ July $\quad 2015$ from http://www.verozo.be/sites/verozo/files/files/Brochure_SolarShading_screen_LR.pdf

- $\quad$ YLITALO H, IP, K AND MARSHALL D, (2011), Environmental performance of external roller blinds in the UK ; accessed 2 July 2015 from about.brighton.ac.uk/ccp/index.php/download_file/view/462/306 


\title{
A BIM-CENTRED SYSTEM FOR BUFFER MANAGEMENT
}

\author{
Chen, K. ${ }^{1}$ and Lu, W. S. ${ }^{2}$
}

\begin{abstract}
:
Buffer is critical for project managers to accommodate uncertainties in construction projects. However, buffer is costly and may undermine the final productivity if not being properly managed. Previous studies have investigated modern technologies to achieve a "Just-in-Time (JIT)" buffer management, but it is too costly and thus impractical. As Building Information Modelling (BIM) is now increasingly used, an innovative extension to BIM is of high probability to improve output of buffer management with much less additional cost. The aim of this study is to propose a BIM-centred system to facilitate a relative-dynamic buffer management. Proceed from literature review, buffers in construction projects are categorized as inventory buffer, time buffer, and capacity buffer. Then, based on the exploration of archived literature and academic studies on related technologies, a four-layered system is designed, which consists of Auto-ID technologies, gateway, database server, BIM model and decision-making modules. The proposed system will enable more efficient and effective buffer management by enhancing ubiquitous and automatic information collection, visualization, communication and integration. These will be validated in case studies in future research.
\end{abstract}

KEYWORDS: BUILDING INFORMATION MODELLING; BUFFER MANAGEMENT; RFID; DECISION-SUPPORT SYSTEM

\section{INTRODUCTION}

As defined by Horman and Kenley (1998), buffer is an allowance to absorb unexpected influences and other difficulties. In a construction project, different types of buffer, such as time buffer and inventory buffer, act as the "shield" for accommodating various uncertainties throughout the project life-cycle (Lee et al., 2006; Hopp and Spearman, 2008).

Nowadays, both the economic efficiency and the development sustainability have been receiving increasing attentions, in order to achieve win-win situations. As an indirect cost, the buffer in construction projects should be properly managed (Horman et al., 2003). Otherwise, a waste of resources and a decrease of project efficiency will happen (Bertelsen, 2004). As a result, continuous improvements of buffer management are pursued by both the industry and the academia.

To date, two major deficiencies existing in the buffer management have hindered the evolutionary process for the construction industry to develop in a sustainable way. The first one is a lack of real-time information. Conventional paper-based methods for

\footnotetext{
1 Department of Real Estate and Construction, The University of Hong Kong, Hong Kong. Email: leochen@connect.hku hk

${ }^{2}$ Department of Real Estate and Construction, The University of Hong Kong, Hong Kong. Email:

wilsonlu@hku.hk
} 
information collection and exchange are time-consuming, labour-intensive, and errorprone (Ergen and Akinci, 2008). Project managers cannot have sufficient information, but have to rely on their own experience when determining buffers. Another problem is the complexity in considering the interrelationship between different types of buffer. Generally, the adjustment of one buffer would affect arrangements on others. For example, the increased inventory buffer needs more area for storage, although it can reduce the time buffer allocated. These two deficiencies, as having been argued above, impede the progress towards sustainable construction. Therefore, it is of key importance to improve the collection, visualization, communication and integration of buffer-related information (Howell and Ballard, 1994), so as to balance different buffers within the project context.

Recent development of building information modelling (BIM) provides opportunities to break the constraints faced by current construction buffer management-it is by definition the resource of life-cycle information of buildings in terms of an indispensable information platform, facilitating communication and collaborative decision-making among various disciplines (NIBS, 2007). Further, advanced technologies, such as AutoID and scanning, have been explored in depth to ensure the sufficiency and accuracy of information contained in the BIM (e.g. Shin et al., 2011; Flanagan et al., 2014). Nevertheless, it is surprisingly rare for previous studies to take advantages of BIM in their analyses of various buffers in construction projects, and thereof a research gap exists.

Inspired by the BIM's capabilities, this study aims at developing a BIM-centred system, in which, inventory buffer, time buffer, and capacity buffer are managed but coordinated by three individual modules respectively. These three modules share a single database to ensure the information consistency. Auto-ID technologies which are administered by the gateway are adopted to continuously collect the real-time information needed for managing the buffers. By creating the four breakthroughs, progressive management of buffers could be realized: (1) accurately collecting the necessary information for determining the buffers, (2) providing real-time status of the construction project for timely adjustment of buffers, (3) systematically integrating the information of correlated buffers; and (4) flexibly communicating among stakeholders in charge.

In remaining contents, Section 2 introduces the research method in this study, and Section 3 reviews previous studies on buffer management. Section 4 builds the architecture of the BIM-centred system, and Section 5 describes how the system supports buffer management. Section 6 presents the conclusion and the further studies.

\section{RESEARCH METHOD}

In this study, a mixed research method in forms of empirical observations and literature review was applied to design the BIM-centred system for buffer management. 
The first step was to propose the research question, the buffer management issues, by empirical observation on what are happening in the construction industry. The authors conducted ten times of site visits, containing two construction projects in Mainland China and two in Hong Kong, to observe the current buffer management practices.

Then, the authors carried out a literatures review to: (1) rationally categorize construction buffers; (2) identify the ideology of buffer management; and (3) explored the technologies supporting buffer management. As a systematic and explicit method for identifying, evaluating, and interpreting existing studies, literature review helped to connect related studies, and highlight important issues in a specific field. After a screening of previous studies on buffer management in construction projects, several peer-reviewed journal papers, conference papers, and books are reviewed to correspondingly address the three specified aspects.

Based on the empirical observations and literature review, the multi-layered system was designed. Without omitting the specific characteristics of construction projects, details on the constitution of the proposed system and how it works were given. Through the steps, the BIM-centred system for buffer management is accomplished and future studies are finally proposed.

\section{LITERATURE REVIEW}

\section{Buffers in construction}

It is fundamental to categorize construction buffers since it serves for structuring the database of the proposed BIM-centred system. Hitherto, universal category of buffer is missing, which is largely due to that the definition has to serve their proposed buffer management framework. This study will follow Hopp and Spearman's (2008) view to divide buffers to inventory buffer, time buffer, and capacity buffer, in view of the fact that other categorizations of buffers are more or less add-ups to Hopp and Spearman's. For example, Russell et al. (2013) add plan and financial buffers. Another distinguished view of buffer types is defined by Goldratt (1997), he divides buffers into project buffer, feeding buffer, and resource buffer, and builds a dynamic buffer management to ensure the critical path for completing a project. Admitting that his idea is inspiring, Goldratt (1997) fails to analyse how to merge all three types of buffers into the dynamic buffer management.

\section{Ideology of buffer management}

Facing continuous uncertainties, the buffer exists here and there throughout a project life cycle in almost all industries (e.g. Thomas et al., 2004; Russell et al., 2009). A more accurate buffer thus is critical for economic growth in that buffer is by nature a nonvalue-adding item and should be retained at its minimum level (Shingo, 1988). Despite a minimum buffer is desired, a commonly agreed ideology is that the buffer management is to decrease the negative impacts caused by uncertainties instead of eliminating them 
altogether (Sarker et al., 2012). Even the lean principle which supports buffer elimination acknowledges that it is more critical and practical to optimize buffers (Tommelein, 2003). Simulation and modelling have been widely utilized for determining an optimal buffer. However, no matter the fixed buffer or the dynamic buffer, their methods are specifically designed for certain cases and, very often too costly to practice (e.g., Polat et al., 2007; González et al., 2009).

\section{Technologies for buffer management}

When analogizing the buffer management ideology to the construction industry, the uniqueness of building projects cannot be overlooked. Compared to the manufacturing industry, construction is highly dynamic and resource paced. Any reduction in buffers' size should be carefully managed since the shortage of supply can cause great loss (Brodetskaia, et al., 2013). As repeatedly stressed above, technologies facilitating information collection, visualization, communication and integration are crucial in outreaching the constraints of conventional buffer management.

The utilization of BIM, the central technology innovation in the proposed system, has been proved in enabling a better inventory planning (Fischer et al., 2000). More innovatively, 4D model can simulate the construction processes, streamline the onsite management practices (Chau et al., 2004), ensure sufficient labour force and equipment (Sacks et al., 2010), and eliminate potential workspace conflicts (Moon et al., 2014). Besides, technologies to collect the real-time information throughout a construction project are developed in advance, which includes photographs (Golparvar-Fard et al., 2009), Auto-ID technologies (e.g. RFID) (Lu et al., 2011), and global positioning system (GPS) (Young et al., 2011). A summary of efforts on integrating the virtual BIM and physical project processes to develop a cyber-physical system has been summarized by Chen et al. (2015). Despite the utilization of those technologies being able to achieve better planning, the management of buffers is highly fragmented (Tommelein and Ballard, 2005). A new and systematic buffer management system based on better information management is highly desired.

\section{Architecture overview}

The proposed BIM-centred buffer management system is constituted by four layers as shown in Figure 1, which are, from the bottom layer to the top, (1) the traceable smart construction objects (SCO) and labour for information collection, (2) the database server for information storage, (3) the BIM-centred data processing for information visualization and integration, and (4) decision-making layer for relative dynamic buffer management. Prior to the further introduction of its architecture, several concepts in technical terms need to be addressed primarily.

\section{Auto-ID technologies}

Auto-ID technologies are those technologies for automatic identification. They facilitate tracking object, collecting data, and ubiquitous computing with low cost and without 
human intervention (Schuster, 2005). Examples of Auto-ID technology include barcode, QR code, and radio frequency identification (RFID). Compared with barcode and QR code, RFID is less vulnerable under dynamic and dirty environment, and has relatively long reading distance.

\section{Smart construction objects (SCOs)}

Typical objects in a construction project include raw materials (e.g. cement, rebar), semifinished or end products (e.g. precast facade, precast slab), facilities (e.g. passages, gates), and machinery (e.g. truck, digger). In order to achieve their real-time visibility and traceability, they are made to be "smart" by smart technologies such as RFID, sensing, and the server employed in the BIM-centred buffer management system. It is worth mentioning that, workers conducting a certain task will also be attached with RFID tags even they have subjective initiative. This helps to temporarily link the person to the task that he/she is working on or the machine that he/she is operating. Hence, in the system, the status of SCOs can be automatically updated to reflect the overall construction progress.

\section{Database server}

A database is basically a structured collection of data, and the database server is a computer program that stores data and provides data to other computer programs. In this case, it is actually a BIM, which is defined as a centralised, shared platform of information that is relating to the building project. Compared with conventional paperbased method, the database server has the following advantages: (1) it can hold a vast amount of data; (2) it accelerates the speed of information exchange; (3) it eases the analysis of data; and (4) it improves information security.

\section{Gateway}

The fundamental precondition of the system is that, throughout a building project lifecycle, real-time information of construction objects and labour should be continuously collected and transferred to the database, and thereafter integrating information to enable informed buffer management. However, in the design of the system, project-relevant information is very often collected from different sources and in various formats. Hence a gateway is employed to manage all RFID-attached objects and labour, with the aim to ensure information consistency and ubiquitously recording the information dynamics.

\section{The four-layered BIM-centred buffer management system}

The first layer of the system is constituted by SCOs and labour. In the first layer, materials, machines, and workers are attached by RFID tags with unique identifications (IDs). Readers and personal digital assistants (PDA) are used to scan the RFID tags, and add information linked to the tags. Then the information will be sent to the server through either wired or wireless communication network. 
The second layer is the database server. It stores information of SCOs and that of labour, which could include the quantity, quality, position, time, and status, from the physical environment. Here, the status of an object refers to whether it has been produced, delivered, or stored on the construction site, and the status of machine and labour refers to whether the machine is being used and whether the worker is working respectively. Besides, when any information is changed, the change and the time when such change takes place will be updated in the database. Therefore, it is convenient for project managers to identify the most updated information.

The third layer is the BIM for information processing, feedback, and visualization. Here, BIM is also the central platform augmented with algorithms and logics to aid buffer decision-making. It has mainly three functions: (1) visualizing the real-time information about the project; (2) detecting useful information for managing specific buffer; and (3) applying rule-based methods to adjust the buffer based on the model, the project plan, and the real-time information.

In the fourth layer, the multi-aspects of information is connected to the corresponding buffer modules, which are the inventory buffer module, the time buffer module, and the capacity buffer module. The three modules are the direct sources for a project manager to make informed decisions. Since the decision-making is based on the BIM with real-time information from the physical life-cycle, in-time and appropriate reaction can be taken in case of construction uncertainties emerging. Besides, when the project manager is planning to adjust one type of buffer, they will review any possible affecting consequences on other buffers. Only through interrelated information review and integration, a final decision on buffer management is made and carried out.

\section{Figure 1. System Architecture}

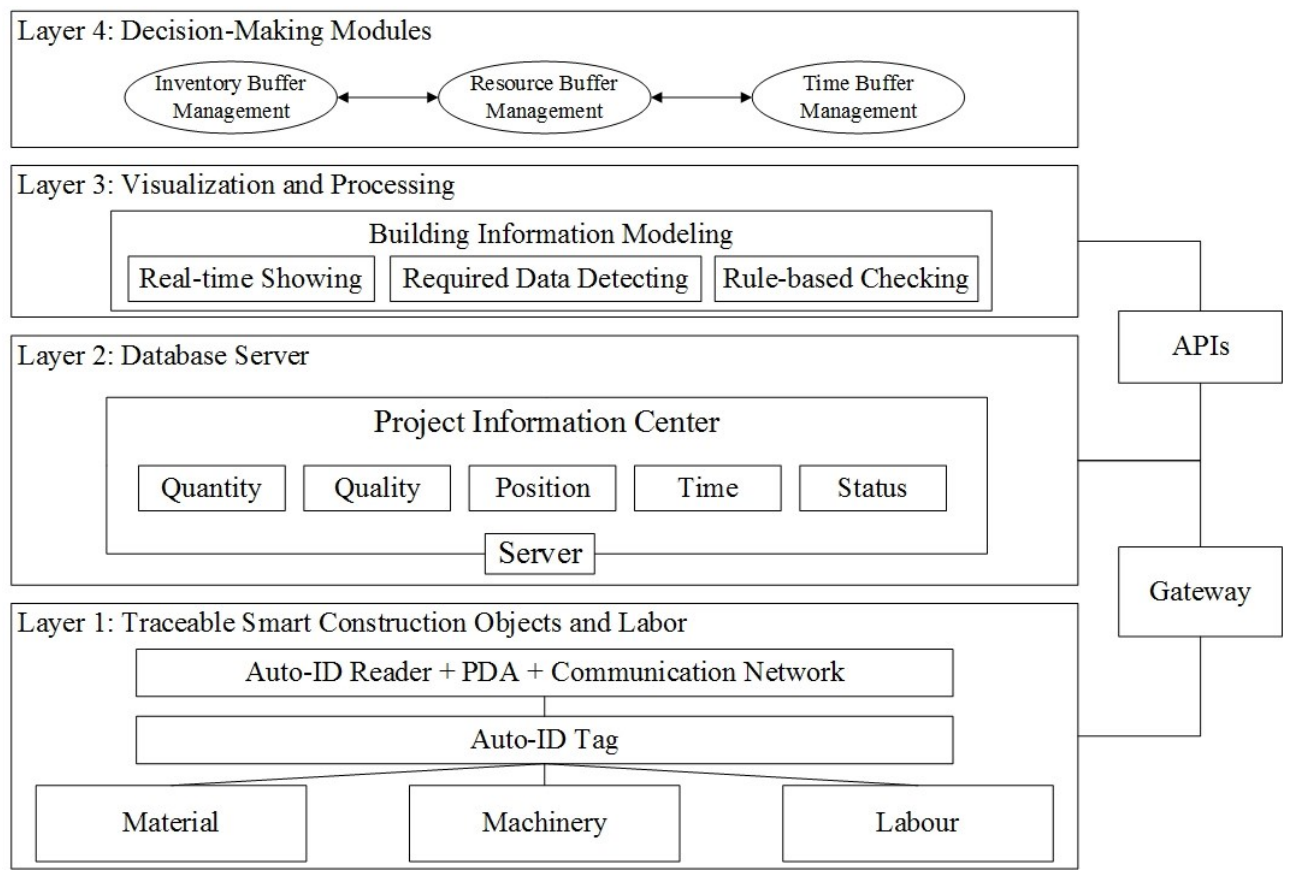




\section{MANAGING THE BUFFER}

While the connection between SCOs, labour and database is realized by RFID, the BIMcentred buffer system can only bring into function after BIM is equipped with real-time information through the connection with the database, i.e. an as-built BIM. Some commercial BIM software, such as Autodesk Revit, provides Application Programming Interface (API) for achieving this goal. Each component in the BIM has a unique name that distinguishes it from others. The name will then be used to match the tag ID of the corresponding physical construction component (e.g. beam, facade). When the RFID tag of a physical component is scanned, its digital representation in BIM can be easily identified. Simultaneously, the name, attributes and parameters of each digital component are extracted from the model and stored in the database. Therefore, the information of each individual component, either collected during physical construction processes or originally stored in BIM, can be firmly integrated.

Noticing that some physical objects, such as trucks, have no digital representation in BIM, their information can still be indirectly integrated with the model. For instance, when a truck is assigned to carry a batch of precast facades to the construction site, they are bound through the RFID tags. As those facades have been linked with their digital presentations in BIM, the information of that truck can be shared by all corresponding facades in the model.

In the proposed BIM-centred buffer management system, each construction task is assigned with a unique task ID. The task to be conducted is linked with components in BIM. Since a single task may involve a number of components, the one-to-many relationship is generated (shown in Figure 2). When there is any change in project design or task schedule during the construction process, the information of task and components in BIM will be simultaneously updated to reflect the latest information. There are three advantages in connecting the BIM with the database through this way: firstly, the project task, in addition to independent component, can be displayed in the 3D virtual environment; secondly, the requirements on materials can be calculated based on the attributes and parameters of each component in BIM; thirdly, it is convenient to compare the designed schedule and actual construction process in BIM. Thereafter, any lead or delay in terms of time, capacity or material can be checked to support buffer management. 
Figure 2. Binding the construction task with components in BIM

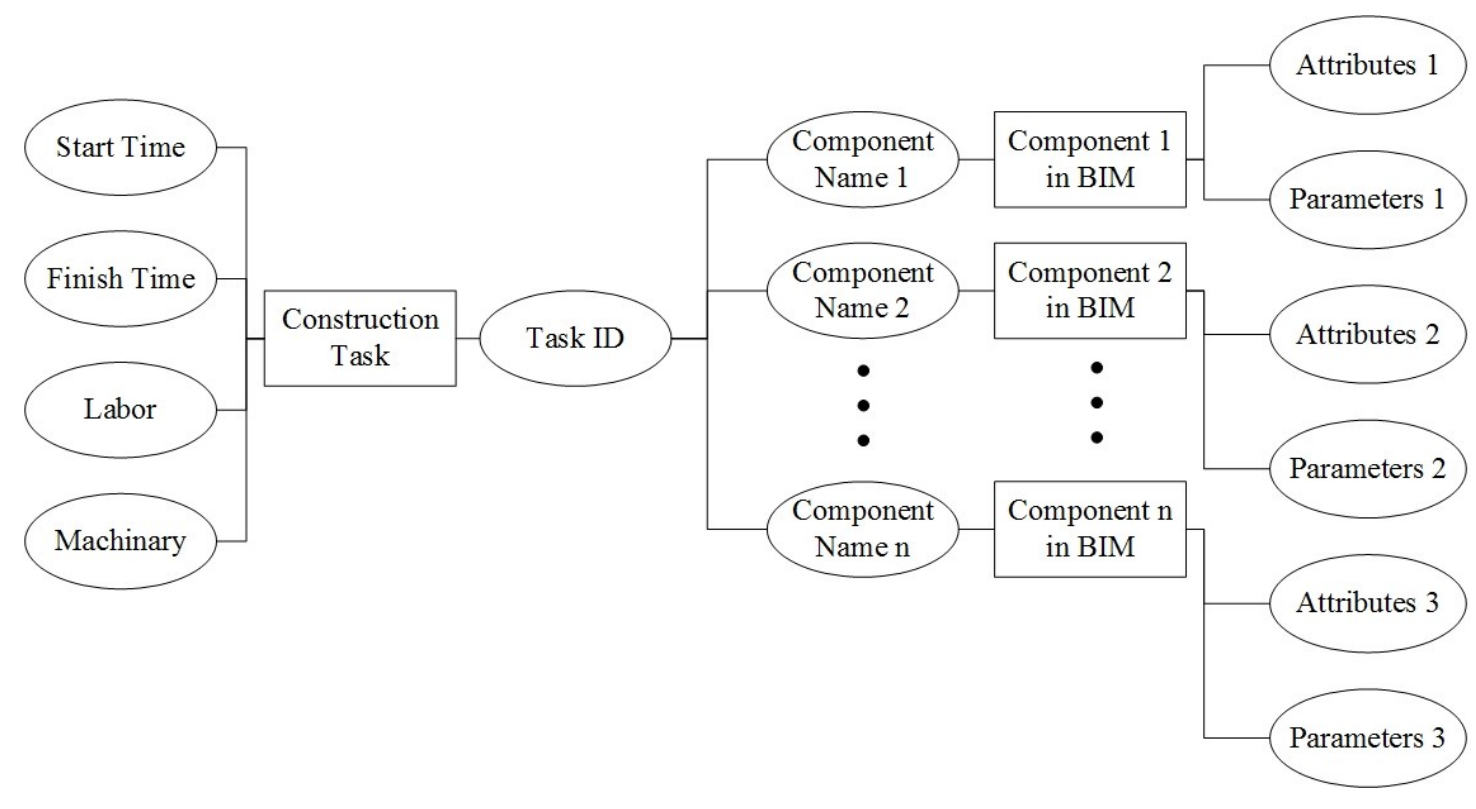

\section{CONCLUSIONS}

Construction projects involved resources of time, space, labour and materials, all of which are facing perpetual uncertainties. In current practice of construction projects, the allocation of construction resources is designed with constant buffers to reduce undesirable consequences due to uncertainties as much as possible. However, the buffer itself requires substantial cost, a huge amount of waste hence would bring adverseness to resources-saving. To manage construction buffer more efficiently, this study proposed a BIM-centred buffer management system, which aims at facilitating managers to determine and manage the buffers.

Given the information-rich BIM recording the real-time data overall the project life cycle, the buffer decided by the system ensures a buffer size being able to accommodate uncertainties, and at the same time diminish both economic waste and disturbs to the environment. It can also help managers to develop their own experiential knowledge on buffer management in future works, which implicates that the more the proposed system is practiced, the more efficiencies will there be. Consequently, the proposed BIMcantered system expands and complements the traditional approach of buffer management, concerning of labour-attendance, cost-efficiency, adaptation and mitigation to environments and production durability. Above all things, it contributes to the achievement of the sustainable construction.

Limited by page, the more detailed analyses and introduction of the BIM-centred buffer management system are obviously not exhaustive in the existing paper. At the time of writing this paper, the following works, although not being contained in this paper, have already been accomplished: the user interface (UI) design and functioning of three 
modules of time buffer, inventory buffer and the capacity buffer, the workflow of how these three buffers is determined. Additionally, a field study will be conducted to validate the proposed system.

\section{ACKNOWLEDGMENT}

This study is jointly supported by the Innovation and Technology Fund (Project No.: ITP/045/13LP) of the Hong Kong Innovation and Technology Commission (ITC), and the General Research Fund (Project No.: 17205614) of the Hong Kong Research Grant Council (RGC).

\section{REFERENCES}

- BERTELSEN, S. (2004). Lean Construction: Where are we and how to proceed. Lean Construction Journal, 1(1), 46-69.

- $\quad$ BRODETSKAIA, I., SACKS, R., and SHAPIRA, A. (2013). Stabilizing Production Flow of Interior and Finishing Works with Reentrant Flow in Building Construction. Journal of Construction Engineering and Management ASCE, 139(6), 665-674

- CHAU, K. W., ANSON, M., and ZHANG, J. P. (2004). Four-dimensional visualization of construction scheduling and site utilization. Journal of Construction Engineering and Management ASCE, 130(4), 598-606.

- $\quad$ CHEN, K., LU, W. S., PENG, Y., ROWLINSON, S., and HUANG, G.Q (2015). Bridging BIM and building: From a literature review to an integrated conceptual framework. International Journal of Project Management. 33(6), 1405-1416.

- $\quad$ ERGEN, E., AKINCI, B., and SACKS, R. (2007). Tracking and locating components in a precast storage yard utilizing radio frequency identification technology and GPS. Automation in Construction, 16(3), 354-367

- $\quad$ Fischer, M., HAYMAKER, J., KNUTSON, G., LiSTON, K., SCHWEGLER, B., and STAUB-FRENCH, S. (2000). Integrating CAD, scheduling, cost, and document management. In Computers for Construction 2000 and A/E/C Systems Fall Conference.

- $\quad$ FlanAGAN, R., JEWELL, C., LU, W.S., PEKERICli, K. (2014). Auto-ID — Bridging the Physical and the Digital on Construction Projects. Chartered Institute of Building (ISBN 1853800191).

- $\quad$ GOLdRATT, E. M. (1997). Critical chain. Great Barrington, MA: North River Press.

- GOlPARVAR-FARD, M., PEÑA-MORA, F., ARBOlEDA, C. A., and LEE, S. (2009). Visualization of construction progress monitoring with 4D simulation model overlaid on timelapsed photographs. Journal of Computing in Civil Engineering ASCE, 23(6), 391-404.

- GONZÁleZ, V., ALARCÓN, L. F., and MOLENAAR, K. (2009). Multiobjective design of Work-In-Process buffer for scheduling repetitive building projects. Automation in Construction, 18(2), 95-108.

- HOPP, W. J. and SPEARMAN, M. L. (2008). Factory physics. New York: McGrawHill/Irwin.

- HORMAN, M. and KENLEY, R. (1998). Process dynamics: Identifying a strategy for the deployment of buffers in building projects. International Journal of Logistics Research and Applications, 1(3), 221-237.

- HORMAN, M. J., MESSNER, J. I., Riley, D. R., and Pulaski, M. H. (2003). Using buffers to manage production: A case study of the Pentagon renovation project. In Proceedings of the 11 th Annual Conference of the International Group for Lean Construction (IDLC-11). 
- HOWELL, G. and BALLARD, G. (1994). Implementing Lean Construction: Reducing Inflow Variation, In Proceedings of the 2nd Annual Conference of the International Group for Lean Construction, IGLC 2, Santiago, Chile.

- LEE, S., PEÑA-MORA, F., and PARK, M. (2006). Reliability and stability buffering approach: Focusing on the issues of errors and changes in concurrent design and construction projects. Journal of Construction Engineering and Management ASCE, 132(5), 452-464.

- LU, W., HUANG, G. Q., and LI, H. (2011). Scenarios for applying RFID technology in construction project management. Automation in Construction, 20(2), 101-106.

- MOON, H., DAWOOD, N., and KANG, L. (2014). Development of workspace conflict visualization system using 4D object of work schedule. Advanced Engineering Informatics, 28(1), 50-65.

- NATIONAL INSTITUTE OF BUILDING SCIENCES (NIBS) (2007). National Building Information Modeling Standard Part-1: Overview. Principles and Methodologies. US National Institute of Building Sciences Facilities Information Council. BIM Committee.

- POLAT, G., ARDITI, D., and MUNGEN, U. (2007). Simulation-based decision support system for economical supply chain management of rebar. Journal of Construction Engineering and Management ASCE, 133(1), 29-39.

- RUSSELL, M. M., HOWELL, G., HSIANG, S. M., and LIU, M. (2013). Application of Time Buffers to Construction Project Task Durations. Journal of Construction Engineering and Management ASCE, 139(10), 04013008.

- RUSSELL, A., STAUB-FRENCH, S., TRAN, N., and WONG, W. (2009). Visualizing highrise building construction strategies using linear scheduling and 4D CAD. Automation in Construction, 18(2), 219-236.

- $\quad$ SACKS, R., KOSKELA, L., DAVE, B. A., and OWEN, R. (2010). Interaction of lean and building information modeling in construction. Journal of Construction Engineering and Management ASCE, 136(9), 968-980.

- SARKER, B. R., EGBELU, P. J., LiAO, T. W., and YU, J. (2012). Planning and design models for construction industry: A critical survey. Automation in Construction, 22, 123-134.

- SCHUSTER, E. W. (2005). Auto-ID technologies: creating an intelligent infrastructure for business. The Data Center Massachusetts Institute of Technology Cambridge.

- SHIN, T. H., CHIN, S., YOON, S. W., and KWON, S. W. (2011). A service-oriented integrated information framework for RFID/WSN-based intelligent construction supply chain management. Automation in Construction, 20(6), 706-715.

- SHMANSKE, S. (2003). JIT and the Complementarity of Buffers and Lot Size. American Business Review, 21(1), 100.

- SHINGO, S. (1988). Non-stock production: the Shingo system of continuous improvement. Productivity Press.

- THOMAS, H. R., HORMAN, M. J., and de Souza, U. E. L. (2004). Symbiotic crew relationships and labor flow. Journal of Construction Engineering and Management ASCE, 130(6), 908-917.

- TOMMELEIN, I. D. (2003). Acknowledging Variability and Uncertainty in Product and Process Development. In 4D CAD and Visualization in Construction: Developments and Applications. A. A. Balkema Publishers.

- TOMMELEIN, I. D. and Ballard, G. (2005). Restructuring the rebar supply system. In Proceedings Construction Research Congress 2005, ASCE, San Diego, California.

- YOUNG, D. A., HAAS, C. T., GOODRUM, P., and CALDAS, C. (2011). Improving construction supply network visibility by using automated materials locating and tracking technology. Journal of Construction Engineering and Management ASCE, 137(11), 976-984. 


\title{
RE-DESIGNING PROJECT MANAGEMENT: STEPS TOWARDS A PROJECT MANAGEMENT CURRICULUM FOR A SUSTAINABLE BUILT ENVIRONMENT
}

\author{
Heintz, J.L. ${ }^{1}$; Lousberg, L.H. ; Prins, M.
}

\begin{abstract}
:
Sustainability concerns add a wide range of both stakeholders and performance expectations to building projects. The transition of a circular economy will also have a significant impact on the way in which building projects are carried out. This in addition to an already established escalation of stakeholder involvement and performance expectations. Even simple projects are acquiring a substantial degree of complexity. Taken together these factors (and others) suggest that we need to move beyond classic project management to an alternative approach to project management education which prioritizes outputs over outcomes (Morris, 2013b), placing the emphasis on project sponsors business strategies, and the social and environmental ambitions, and focussing on the early stages, the social aspects, and the problems solving activity of project management. The scope of this paper is to propose a framework for an alternative approach to project management education for built environment professionals. The framework will make use of principles of Practical Pluralism, Project Management as Design, Project Management Design Cycle. The intention of the framework is to facilitate graduate project managers is making use of the wide range of recent project management scholarship.
\end{abstract}

KEYWORDS: SUSTAINABLE PROJECT MANAGEMENT, PROJECT MANAGEMENT EDUCATION

\section{INTRODUCTION}

Sustainability concerns add a wide range of both stakeholders and performance expectations to building projects. The transition of a circular economy will also have a significant impact on the way in which building projects are carried out. This in addition to an already established escalation of stakeholder involvement and performance expectations. Even simple projects are acquiring a substantial degree of complexity.

Taken together these factors (and others) suggest that we need to move beyond classic project management to an alternative approach to project management education which prioritizes outputs over outcomes (Morris, 2013b), placing the emphasis on project sponsors business strategies, and the social and environmental ambitions, and focussing on the early stages, the social aspects, and the problems solving activity of project management.

The scope of this paper is to propose a framework for an alternative approach to project management education for built environment professionals. The framework will make use of principles of Practical Pluralism, Project Management as Design, Project

\footnotetext{
${ }^{1}$ Department of Management in the Built Environment, Delft University of Technology, Netherlands. Email: j.1.heintz@tudelft nl
} 
Management Design Cycle. The intention of the framework is to facilitate graduate project managers is making use of the wide range of recent project management scholarship.

\section{Sustainability and Circular Economy change Everything}

Sustainability, and the transition to a circular economy will add additional layers of both performance expectations and project complexity. The successful determination and implementation of the appropriate sustainability measures requires close cooperation with stakeholders throughout the project in order to maintain a "willing-ness-to-pay" (Kaatz, 2005), and to ensure that sustainability measures survive the inevitable cycles of cost cutting through which most building projects pass (Doorn, 2012). The transition to a circular economy will require that new business plans are developed, often transgressing what we now conceive of as the boundaries of the project. Further the gradual adoption of $\mathrm{CE}$ will mean that the business practices in the built environment continue to change radically for the foreseeable future.

The implementation of existing and the development of new sustainability technologies also requires a close multi-disciplinary collaboration between project members (Robichaud, 2010). Such collaboration requires that the project team develop shares conceptual frameworks reference which will facilitate the development and maintenance of the project mission, and make possible the translation of this mission into inter-related courses of action for each project member. (Kaatz, 2005). Without this projects are likely to revert to the competitive and self-interested behaviour that is already a common problem in building projects (Groák, 1992).

All of these issues lie outside the Iron Triangle of cost, quality, and time. These are not issues of efficiency, but rather issues of holding together a team, in a productive relationship with it's context, and maintaining focus on the mission while overcoming the inevitable difficulties which occur along the way.

\section{MOVING BEYOND CLASSIC PROJECT MANAGEMENT}

Recent research has shown that despite the application of project management techniques and practices, many projects underperform, failing to deliver the original objectives of the project while running over budget and over time. Attempts to identify the factors leading to project failure have generally drawn attention to early stage factors such as "unclear success criteria, changing sponsor strategy, poor project definition, technology (the fascination with, uncertainty of, and design management), concurrency, poor quality assurance, poor linkage with sales and marketing, inappropriate contracting strategy, unsupportive political environment, lack of top management support, inflation, funding difficulties, poor control, inadequate manpower, and adverse geophysical conditions)." (Morris, 2013a) While this is presented as a critique of Classical Project Management, one might also see it as a measure of the success. The classical tool set has proved itself capable of addressing issues of coordination, planning and cost control, thus exposing the 
more complex social issues typically associated with the early and pre-project phases. Issues of program and process management. Many of these factors not only lie outside the conventionally determined time boundaries of projects. Further, many are not addressed by measures addressing issues of control and efficiency.

These findings are reflected in a shift in focus within project management research. For more than 10 years researchers have been rethinking of project management (Cicmil, 2006; Winter, 2006; Svejvig, 2015), reconstructing project management (Morris, 1994; Morris, 2013a; Morris, 2013b), making projects critical (Hodgson, 2006), making projects Scandinavian (Sahlin-Andersson, 2002; Lundin, 1995; Packendorff, 1995), and recasting projects as practices (Blomquist, 2010). This work has been motivated by the widely shared belief that project management theory is not adequate to the task of helping projects managers carry out their work (Koskela, 2002). All of the above authors find that what is variously called classical -, main stream -, systems -, or type 1 - project management is too limited in perspective, and does not capture or address many of the most important issues or problems facing project managers. In general all of the new approaches make a "social turn", acknowledging projects as primarily social phenomena and apply a variety of theories and methodologies drawn from social science to the study of projects. Other turns have taken place as well, such as the practice turn, and a complexity turn (Cooke-Davies, 2008). In addition, many scholars have shifted from an engineering perspective to a 'critical' perspective (Cicmil, 2006) seeking not so much to propose improvements to project management tools, but to challenge beliefs, theories, and "bodies of knowledge" about projects and how they are managed. This has led to a large body of research rich with new insights and observations. However, many of the leaders of these movements have also come to the conclusion that as yet little of this research has led to significant advances in project management tools, practice, or education (Svejvig, 2015; Morris, 2013a).

This may, in part be due to the diversity of focus, research methods, theoretical foundations, and findings. Given this diversity, it has not bee possible for authors to present project management as a single coherent body of knowledge or underlying theory. The frequent citation of Koskela and Howell's paper (Koskela, 2002) is a clear enough signal of this. A new approach will be required to present this material in such a way that graduate project managers can draw upon its richness and diversity.

\section{NEED FOR AN ALTERNATIVE PROJECT MANAGEMENT CURRICULUM}

Taken together, the emergence of sustainability and circular economy along with the critique of classical project management amount to a call for a new approach to project management education. This alternative approach should, as Morris proposes (Morris, $2013 \mathrm{~b}$ ), focus on the sponsor's strategy and goals. It should also place environmental and social needs central to the practice and understanding of project management. This means that project management must focus on early stages in the project - and even on preproject stages. The clarification of sponsor strategy, defining objectives, understanding 
what value means, and developing the scope and the brief are key to the eventual success of projects - as is the choice of contract / project organization form/ and tendering method. These choices can lock in incentives that make it very difficult for a client to see their goals realized through the project.

We further suggest that this alternative curriculum should be built around the notion of project management as problem solving, rather than the acquisition of competence in the use of project management tools. The core of this approach should be a framework which provides project managers the ability to understand the situation in which they find themselves, and to draw upon the entire repertory of project management research, knowledge and tools to craft an effective course of action.

We have observed that many student interested in the management of design and construction projects gravitate to positions in organizations that are traditionally seen as clients or sponsors, or into organizations which advice them. This has drawn our attention to the need to prepare these young professionals for a project management role outside the classical bounds of the project - acknowledging the existence of a project manager distinct from the construction project manager working for a general contractor. These new project managers are as much concerned with the administration of projects from the client side as with the conduct of projects from the supply side.

Project managers, or professionals describing themselves as project managers can now be found in many roles in building projects, focussing on many different aspects of the project. The tools and insights of classical project management remain important, especially in construction management, but other project managers working for clients, or as consultants, or for consortia will focus on other aspects of the project. Sharing many of the concerns of what is often called program or process management.

Finally, in the present and future dynamic environment, graduate project managers will have to continue to learn throughout their careers. Project managers must be able to use a wide range of approaches to project management (incorporating the latest research) to solve a wide range of problems, and to continue to learn to adapt and improve their skills throughout their careers. The alternative curriculum should emphasis an approach to project management that incorporates learning as a fundamental element.

\section{The Project Design School}

The goal of the Project Design School is just this, to draw on this body of research lessons to assemble a ne alternative approach to the education of future project managers, and to prepare materials that can be used for this purpose.

Our intention is to lay the groundwork for the development of just such a new approach to project management education. It is not our intention to reinvent from scratch, but to create a framework which will facilitate project managers to be opportunistic, and eclectic in their approach to project management science, able to take up and apply the insights, tools and techniques that seem likely to be of service in a given situation, to equip them to address unclear problems, and to continue to learn. 
At the heart of the Project Design School we propose to place a framework for project management practice. This framework will incorporate several fundamental approaches to project management practice:

Practical Pluralism

Project Management as Design

Project Management Design Cycle

This framework governs the basic approach to how one might act as a project manager, it does not pretend to unify the contemporary understandings of project management into a single theory. Rather, by remaining epistemologically agnostic, it leaves the graduate project manager free to choose from the entire range of project management research, knowledge and tools to determine a course of action at any particular moment.

\section{Practical Pluralism}

Leading researchers in both built environment research and project management research have made clear their view that a pluralism of approaches is required to address the many facets of project management and their complicated relationships. (Sage, 2014; Söderlund, 2011). The new lines of research into project management have made it clear that project management can be usefully viewed from a number of different viewpoints. Whether it is 5 (Anbari, 1985) or 7 (Söderlund, 2002) or 9 (Anbari, 2008) schools of research into project management, it is clear that researchers, using different tools drawn from difference sciences and professions, have illuminated different aspects of projects, described, diagnosed, and prescribed solutions for different problems, and proposed a wide variety of tools. What is challenging about this variety of research approaches is that on either an ontological or an epistemological basis they are incommensurable, incompatible. What counts as an object of unit of research, what counts as knowledge and what counts as proof varies dramatically between these different research approaches. Supply chain systems based on systems theory describe a fundamentally different world from that described by research into the performance of anger in project management (Lindebaum, 2011). The result of this plurality of research approaches is an undoubtedly rich, but potentially bewildering range of research and recommendations that cannot be reduced to a single theory or picture of projects and project management.

Our claim is that the need for pluralism applies not just to research but also to the practice of project management, especially in the built environment. Gareth Morgan suggests that one way to understand how to make use of fundamentally different theories in management is through understanding theory as metaphor (Morgan, 2006). Metaphors are necessarily distortions of reality, but these distortions can be useful, creating "constructive falsehoods" which help managers to read situations, and to act in them, more effectively. The different schools of project management research provide practicing project managers with a set of powerful metaphors, complete with tool sets, through which they can read situations, and with which they can design courses of action to address them. For this reason it is important to recognize a substantial range of theories 
or metaphors. It is important to provide project managers with multiple metaphors through which they can have new points of view on their projects and generate new insights. No single metaphor will be 'right', i.e. useful, all the time. Each will be helpful in filtering out the significant from the insignificant in different situations. The advantage, though, is that once a project manager has found a view or metaphor that makes clear what is happening in a given situation, that metaphor comes with theory and tools to intervene.

This is often a process of recognition. Experienced project managers relate their current situations to past situations, and choose courses of action based on what has worked well in the past. This way of thinking has been shown to be very effective, but is only available to project managers with a large repertoire of previous situations. Through providing young project managers with a range of metaphors through which they can understand current situations, they are enabled to make better use of the collective experience and research available to them through books, courses, and other modes of knowledge.

The education of building project managers should focus in particular on the actions of individuals in the project management context. This focus on personal awareness, design, performance and reflection makes the approach ideal for the education project management professionals.

In addition, thinking in terms of a range of metaphors provides project managers with additional tools to deal with conflicts. Disagreements are often specific to the frame through which they are viewed. By changing metaphor, project managers can change the frame through which the problem is viewed, and create new possibilities for designing courses of action that will be agreeable to the parties to the conflict (Schön, 1994).

\section{PROJECT MANAGEMENT AS DESIGN}

It is possible to view project management as a form of problem solving (Ahern, 2014), where problem is the determination of courses of action to change present states into more desirable states, then it follows that design and design thinking are necessary tools. For at its most general design can be described as "defin[ing] courses of action aimed at changing existing situations into preferred ones." (Simon, 1969) Projects present managers with design problems at several scales. The overall organization of the project, selection of partners, forms of contracts and tendering, structures of reporting and meeting is a large scale design problem facing any project manager at the outset. One might call this the strategic level. Resolving a scheduling conflict between two agents or a question of how to structure a BIM database would be examples of tactical problem solving.

While one may consider these issues as matters of choice, the interrelation between the different choices to be made (each representing a different frame), and the multiplicity and ambiguity of project goals and resources (typically seen differently by different 
stakeholders) raises the complexity of the network of choices to the level of a wicked problem (Coyne, 2005; Rittel, 1973) - i.e. a problem where there is no possibility of optimization or algorithmic approaches to decision making. This is a problem type for in which design thinking has been found to be very useful.

A variety of researchers have proposed that these sorts of problems are best addressed by design. Among them Boland and Collopy describe the advantages of design thinking in management contexts as follows:

"A decision attitude toward problem solving is used extensively in management education. It portrays the manager as facing a set of alternative courses of action from which a choice must be made. The decision attitude assumes it is easy to come up with alternatives to consider, but difficult to choose among them. The design attitude toward problem solving, in contrast, assumes that it is difficult to design a good alternative, but once you have developed a truly great one, the decision about which alternative to select becomes trivial. The design attitude appreciates that the cost of not conceiving of a better course of action than those that are already being considered is often much higher than making the 'wrong' choice among them." (Boland, 2004)

Projects provide their managers with one big design problem - designing the project (process, etc.) - and many smaller ones, designing interventions to keep it moving towards success. In designing the project the manager must (in collaboration with others) shape the project team through selection, contracting, governance, planning, and scope (the list is incomplete) to set out on the process of fulfilling (a subset of) the sponsors business goals through the provision of a building. But the greater portion of the project manager's time is spent on dealing with the project as an evolving series of situations. Each situation calls upon the project manager to make an intervention that will further the project. Some situations, such as stage-gate reviews, are clearly outlined in project management literature. Others, probably the more important category, consist of unpredictable events caused either by members of the project team or by exogenous events that must be dealt with somehow. Some of these are normal challenges to a project, some are clearly problems to be solved, but all can be treated as design problems.

One of the values of approaching such problems in a designerly way is the practice of problem seeking - the process of finding what the 'real' problem is. Situations, as they present themselves to project members, are not transparent, and the solutions offered are perhaps not solutions at all. The designer seeks to understand the situation first, determining it's underlying nature, and who would be the best 'problem owner', and only then seeks to craft a solution. Thus, transgressions of schedule of budget, or loss of control of the scope would not be treated as a problem to be solved, but as an indication of perhaps larger problems that need to be addressed before control can be regained over budget, schedule or scope. Similarly the failure of a project member to comply with some aspect of the project specification need not simply be seen as recalcitrance, but possibly as an indication of hidden coordination problems. This process takes place within a project management design cycle. 


\section{Project Management design Cycle}

The simplest description of the design cycle is as a cycle of generate and test, but the design cycle also bears similarity to Deming's Plan-Do-Check-Act cycle and the Kolb Learning Cycle: Concrete Experience - Reflective Observation - Abstract Conceptualization - Active Experimentation. These similarities are not coincidental, design and management both rely on learning and feedback from the situation to arrive at better outcomes than might otherwise be realized. For the purposes of illuminating the role of design thinking in building project management the following formulation of the cycle may be most helpful:

\section{Awareness / Recognition - Design - Performance - Reflection}

\section{Awareness}

The cycle begins with establishing awareness of the current situation. This awareness encompasses not only the formal project as captured in so called "project information", but also, and importantly, the social situation (situational awareness), including the status and state of the various actors and stakeholders in the project. Awareness has a very significant component of sense-making. It is at this stage that the project manager considers which metaphor - which project management perspective - best illuminates the situation. Using this metaphor and its terminology, the project manager can then describe the situation.

\section{Design}

Out of this awareness comes an understanding of both the current state and a desired outcome. Also, out of the choice of metaphor, comes a tool set which can be used to design a course of action to effect the change from the current to the desired state. Having determined that action is required, design refers to the shaping of a course of action. This course of action will consist a set of actions the project manager him- or her-self must to in order to initiate and guide the other actors in the actions they must carry out.

\section{Performance}

This set of actions must then be performed by the project manager. It is not just a matter of carrying out the design. A Performance is required in that management, requires that one changes people's minds and actions.

\section{Reflection}

Finally, there is a reflection upon the outcome, attempting to draw any lessons about the designed course of action or its performance that may be useful in the future. At this stage the project manager may, for example, choose to reconsider the choice of metaphor, and the description of the situation.

The cycle thus incorporates reflection and learning into the normal course of project management. This provides the graduate project manager with the opportunity to both improve their knowledge and skills over time, and in gain increased insight into the current project. 


\section{CONCLUSIONS}

The framework proposed there is merely a skeleton upon which a project management course or curriculum could be built. It is intended to provide a means of re-centring project management education around the practice of project management rather than around the acquisition of knowledge and skill isolated from the reasons and contexts in which they will be implemented. Further it is intended that such an approach will open up building project management to permit project managers to foreground, not the project specification, but the business, social and environmental goals driving the project.

We intend this paper to invite discussion of the ideas presented here, and to further the development of a project management curriculum which can ore easily incorporate recent research results.

\section{REFERENCES}

- AHERN, T., LEAVY, B. and BYRNE, P. J. (2014). Complex project management as complex problem solving: A distributed knowledge management perspective. International Journal of Project Management, 32(8), 1371-1381

- ANBARI, F. T. (1985). A systems approach to project evaluation. . Project Management Journal, 16(3), 21-26.

- $\quad$ ANBARI, F. T., BREDILlET, C. N., \& TURNER, J. R. (2008). Exploring research in PM: nine schools of PM thought. Academy of Management Conference.

- $\quad$ BLOMQUiST, T., HÄLlGREN, M., NILSSON, A., and SÖDERHOLM, A. (2010). Projectas-practice: In search of project management research that matters. Project Management Journal, 41(1), 5-16.

- $\quad$ BOLAND, R. J., and COLlOPY, F. (2004). Managing as Designing. Palo Alto: Standford University Press.

- CICMIL, S., and HODGSON, D. (2006). New possibilities for project management theory: A critical engagement. Project Management Journal, 37(3), 111.

- $\quad$ CICMIL, S., WILliaMS, T., THOMAS, J., and HODGSON, D. (2006). Rethinking Project Management: Researching the actuality of projects. International Journal of Project Management, 24(8), 675-686.

- COOKE-DAVIES, T., CICMIL, S., CRAWFORD, L., and RICHARDSON, K. (2008). We're Not in Kansas Anymore, Toto: Mapping the Strange Landscape of Complexity Theory, and Its Relationship to Project Mangement. IEEE Engineering Management Review(36), 5-21.

- COYNE, R. (2005). Wicked Problems Re-Visited. Design Studies, 26(1), 5-17.

- $\quad$ DOORN, A. van (2012). Het Duurzame Ontwerp Project. Amsterdam: SUN.

- GROÁK, S. (1992). The idea of building : thought and action in the design and production of buildings (1st ed.). London; New York: E \& FN Spon.

- HODGSON, D. E., and CICMIL, S. (2006). Making projects critical. Basingstoke: Palgrave Macmillan.

- $\quad$ KAATZ, E., ROOT, D., \& BOWEN, P. (2005). Broadening project participation through a modified building sustainability assessment. Building Research \& Information, 33(5), 441454.

- KOSKELA, L., and HOWELL, G. (2002). The underlying theory of project management is obsolete. Paper presented at the Proceedings of the PMI Research Conference.

- LINDEBAUM, D., and FIELDEN, S. (2011). 'It's good to be angry': Enacting anger in construction project management to achieve perceived leader effectiveness. Human Relations, 64(3), 437-458. 
- LUNDIN, R. A., and SÖDERHOLM, A. (1995). A theory of the temporary organization. Scandinavian Journal of Management, 11(4), 437-455.

- MORGAN, G. (2006). Images of organization (Updated ed. ed.). London: SAGE.

- MORRIS, P.W.G. (1994). The management of projects. London: Thomas Telford.

- MORRIS, P.W.G. (2013a). Reconstructing Project Management Reprised: A Knowledge Perspective. Project Management Journal, 44(5), 6-23.

- MORRIS, P.W.G. (2013b). Reconstructing project management: John Wiley and Sons.

- PACKENDORFF, J. (1995). Inquiring into the temporary organization: New directions for project management research. Scandinavian Journal of Management, 11(4), 319-333.

- $\quad$ RITTEL, H. J., and WEBBER, M. (1973). Dilemmas in a general theory of planning. Policy Sciences, 4(2), 155-169.

- $\quad$ ROBichaud, L., \& ANANTATMUlA, V. (2010). Greening Project Management Practices for Sustainable Construction. Journal of Management in Engineering, 27(1), 48-57.

- SAGE, D., DAINTY, A., \& BROOKES, N. (2014). A critical argument in favor of theoretical pluralism: Project failure and the many and varied limitations of project management. International Journal of Project Management, 32(4), 544-555.

- SAHLIN-ANDERSSON, K., and SÖDERHOLM, A. (2002). Beyond project management: New perspectives on the temporary-permanent dilemma.

- SCHÖN, D. A., and REIN, M. (1994). Frame reflection : toward the resolution of intractable policy controversies. New York, N.Y.: BasicBooks.

- $\quad$ SIMON, H. A. (1969). The sciences of the artificial. Cambridge, Mass.: MIT Press.

- SÖDERLUND, J. (2002). On the development of project management research: schools of thought and critique. Project Perspectives(8), 20-31.

- SÖDERLUND, J. (2011). Pluralism in Project Management: Navigating the Crossroads of Specialization and Fragmentation. International Journal of Management Reviews, 13(2), 153176.

- SÖDERLUND, J. (2012). Theoretical Foundations of Project Management: Suggestions for a Pluralistic Understanding. In MOORIS, P.W.G., J. K. PINTO, J.K., and SÖDERLUND, J. (Eds.), The Oxford handbook of project management. Oxford: Oxford University Press.

- SVEJVIG, P., and ANDERSON, P. (2015). Rethinking project management: A structured literature review with a critical look at the brave new world. International Journal of Project Management, 33(2), 278-290.

- $\quad$ WINTER, M., SMITH, C., COOKE-DAVIES, T., and CICMIL, S. (2006). The importance of 'process' in Rethinking Project Management: The story of a UK Government-funded research network. International Journal of Project Management, 24(8), 650-662. 


\title{
BIM AWARENESS AND READINESS OF POSTGRADUATE BUILT ENVIRONMENT STUDENTS IN WEST MIDLANDS UNIVERSITIES, UK
}

\author{
Kugbeadjor W. ${ }^{1}$, Suresh S. and Renukappa S.
}

\begin{abstract}
:
Several reports and studies have been conducted on Building Information Modelling (BIM) awareness and readiness of the construction industry in UK ever since the directive by the UK Government for the use of fully collaborative $3 D$ BIM at Level 2 as a minimum by 2016. These reports and studies revealed that the industry is not yet ready to implement BIM at maturity Level 2 because of lack of training and lack of professionals who can work in a BIM enabled environment. Key to the implementation of BIM is education and training of all affected people. However, a significant number of organisations are reluctant to invest and develop in BIM capability mainly because of the cost involved. There is a growing and urgent demand for higher educational institutions to provide specialised training for students to meet the current needs of the industry because most companies are finding it difficult to find existing employees who have the experience to implement BIM. Researchers have highlighted the need for building information modelling to be an integral part of the curricula of higher educational institutions. Some universities have responded by incorporating BIM into their curricula. However, not much is known about BIM awareness and readiness of built environment students who are required by the industry and employers to fill the skill gaps.

This paper investigated BIM awareness and readiness of postgraduate built environment students of universities in the West Midlands, UK. To achieve the aims and objectives of this research, a positivist research approach was adopted. The population of the study consists of postgraduate built environment students in the West Midlands universities. Data was collected using a self-completion online survey. The results indicated that students have heard about BIM but do not understand its concepts. It also indicated that the respondents were not ready to work in a BIM enabled environment because their courses have not prepared them well. However, most of the respondents would like to explore BIM as part of their course. Training will be required for all affected staff in order to prepare students for successful careers in the built environment industry.
\end{abstract}

KEYWORDS: AWARENESS, BUILDING INFORMATION MODELLING, POSTGRADUATE STUDENTS, READINESS, AND UNIVERSITIES

\section{INTRODUCTION}

After several years of using paper and lately Computer Aided Design (CAD) to create plans and drawings, a process seen to be error-prone, the UK construction industry appears to be preparing for the adoption of building information modelling (BIM). The UK government, the industry's biggest client in 2011 mandated for the use of fully collaborative 3D BIM at Level 2 as a minimum on all centrally procured government construction projects by 2016. This is to enable stakeholders on a project collaborate for an efficient, productive, sustainable, and competitive industry (Cabinet Office, 2011). All organisations (either small or large) are likely to be affected and will be engaged in the

\footnotetext{
${ }^{1}$ University of Wolverhampton, s.subashini@wlv.ac.uk
} 
BIM process because of their involvement with a supply chain partner or a government department (BIM Task Group, 2013).

Key to the implementation of BIM is education and training of all affected people (Building Smart 2010; McGraw-Hill Construction, 2008; Khosrowshahi and Arayici, 2012). Though education and training play a big role in the BIM adoption process, a significant number of organisations are reluctant to invest and develop in BIM capability mainly because of the cost involved. For instance, small and medium sized enterprises (SMEs) which form a significant portion of the UK construction industry are far behind with only 1 in 10 planning to train their staff whilst 1 in 2 larger organisations were planning to do so (NFB, 2012). The lack of training and development activity in the industry (BIS, 2013) is seen as a major barrier to BIM adoption (Building Smart, 2010; Becerik-Gerber et al., 2011; McGraw-Hill Construction, 2008; Khosrowshahi and Arayici, 2012). There is a growing and urgent demand for higher educational institutions to provide specialised training for students to meet the current needs of the industry (Göransson and Brundeniu, 2011; Hardin, 2009). This is because most companies are finding it difficult to find existing employees who have the experience to implement BIM (Kymmell, 2008). Race (2013) and Wong et al. (2011) highlight the need for BIM to be an integral part of the curricula of higher educational institutions. Khosrowshahi and Arayici (2012) mentions that there is a necessity for an up skilling of the current workforce but since such standards are rare, there is currently a growing need for academic organisations to host such educational programmes. Johnson and Gunderson (2010) highlights that not much is known about how educational institutions are moving to address these changes through their courses to prepare their students. Students on construction management programmes should be taught BIM because most construction organisations will consider employing graduates with BIM skills over those who do not have the knowledge of BIM (Dean, 2007; Hardin, 2009). This papers seeks to investigate the level of awareness and readiness of built environment graduates on BIM implementation.

\section{THE UK CONSTRUCTION INDUSTRY AND THE NEED FOR BIM}

In spite of the contributions the construction industry makes to the UK economy, several researches and reports on the state of the industry in the last 80 years have highlighted its inefficiencies, waste, adversarial and fragmented nature (e.g. Banwell, 1964; Bossom, 1934, in Cain 2004; Egan, 1998; Emmerson, 1962; Latham, 1994; Simon, 1944). These reports revealed that collaboration among stakeholders and the modernisation of the industry are the way forward to overcome its challenges in order to deliver value to its clients as well as make reasonable profit. The recommendations for improvement from these reports were also ignored by the industry due to poor client involvement and a lack of legislation to reinforce them (Cain, 2003; Cain, 2004; Potts, 2008). However, the UK Government mandate for the industry to embrace 3D BIM at Level 2 as a minimum on all 
centrally procured government contracts from 2016 will change the way the industry works.

The agenda of the UK government on construction for several years has been to improve efficiency (Wolstenholme, 2009). The HM Government (2013) report on the industrial strategy for the construction sector set out a clear vision for the sector to deliver $33 \%$ lower costs in the initial cost of construction and the whole life cost of built assets. It also called for a $50 \%$ faster delivery of construction project for new build and refurbished assets; $50 \%$ lower emissions, and halving the export trade gap for construction products and materials by 2025. In the UK, there is an increasing demand for construction as the economy emerges from the recession of 2008. This has led to an increasing demand for a capable workforce that can deliver transformational changes (HM Government, 2013). There is also a major opportunity for UK-based construction business to win in the expanding markets especially in the developing world. To achieve this will require that the sector is BIM ready to gain a competitive edge (Saxon, 2013b).

The UK construction sector faces a challenge of recruiting skilled workforce (CITB, 2014) to meet these future demands and take advantage of the global and domestic market opportunities. A report by the UK Commission for Employment and Skills (2012) highlights the need for employers to invest in the skills of its workforce over the skills shortage. There is little training and development activity within the construction sector compared to other sectors (BIS, 2013; Egan, 1998). The total spending on training has fallen by $£ 2.5$ billion since 2011 (UKCESS, 2014). The report also forecast a higher future demand for construction managers and professionals especially for new job opening. A survey by the Office for National Statistic indicates that the number of graduates leaving higher education into the industry is promising. Employees with degrees or equivalent in the construction contracting sector moved up from $12 \%$ to $22 \%$ between 2001 and 2012 (HM Government, 2013). These graduates are expected to keep abreast with the current development in the industry because recruiters expect graduates from the universities to be BIM ready (Kymmell, 2008). Wong et al. (2011) points out that BIM integration in higher education would serve the high demand for BIM capable professionals whiles producing fresh opportunities for students to deal with fresh challenges with high efficiency achieved by BIM application.

\section{THE ROLE OF HEIS IN PROMOTING BIM ADOPTION}

The growth and prosperity of nations depends on their universities because they serve as the providers of human capital as well as incubators for entrepreneurial activities (Göransson and Brundeniu, 2011). According to Lamond et al. (2013), higher education (HE) courses are the main providers of future built environment professionals for the construction industry. Educators are expected to equip the future design and construction professionals with the knowledge and skills needed by industry in a collaborative environment to create and construct the built environment (McCuen and Pober, 2013; Ngo, 2012). Göransson and Brundeniu (2011) and Hardin (2009) maintained that there is a growing and urgent demand on HE institutions (HEIs) to adjust to the changing needs 
of society and economy by providing specialised training to students. HEIs are required to develop and transfer technologies to industry for a smooth transition to BIM. The NBS (2011, p. 20) mentions that "Educational establishments clearly have a major role to play in this transition, they should and will seed the next generation of professionals who understand BIM as a technology that supports collaborative working." For this reason, curricula of HEIs are to be designed to ensure it mirrors the needs of the industry (Morton, 2012; Becerik-Gerber et al., 2011).

Some universities around the world have started incorporating BIM into their built environment curricula either through seminars, workshops, presentations or through the development of a specific course for BIM at undergraduate and postgraduate levels to prepare students for the industry in response to the lack of BIM knowledge and skills. This includes universities in countries such as Australia, Canada, Finland, Hong Kong, New Zealand, Norway, UK and the U.S. (Becerik-Gerber et al., 2011; Rooney, 2014; Sabongi, 2009). In the UK, some universities have incorporated BIM courses into their built environment curricula at postgraduate level whiles at undergraduate level BIM has become a feature (Rooney, 2014). Evidence suggests that there are barriers to BIM integration into the curriculum of HEIs (Becerik-Gerber et al., 2011; Sabongi, 2009). Kymmell (2008) mentioned that the barriers that HEIs face in introducing BIM into their curriculum may be one or more of the following factors: conceptual issues (a lack of understanding); technical issues (inability to use the required tools); and environmental issues (circumstances). Sabongi (2009) conducted a survey of 119 institutions in the US, which offered built environment undergraduate programmes. The results indicated that the main barriers to the introduction of BIM in higher education included: lack of time and resources to prepare a new curriculum; lack of room in the curriculum to include new courses to existing curriculum; the limited number of courses (requirements and electives) that can be taken by students within the period they are expected to complete their courses; and a lack of appropriate materials and educational resources to teach BIM. Other barriers identified by the research include: BIM complexity; lack of interest or willingness to explore new technology by students; lack of support from faculty colleagues and/or administrators; unwillingness to change curriculum to add BIM when BIM itself may be replaced by another technology program in a few years; and uncertainty about which BIM platform (Revit, Bentley or something else) will become dominant. Becerik-Gerber et al. (2011) in their survey of 101 Architecture, Civil Engineering and Construction Management programs in the U.S. also identified lack of trained personal in BIM; the time it takes for the implementation of BIM; and a lack of curriculum focus on BIM as barriers. Although a lack of interest or willingness to explore new technology by students is seen as one of the barriers to the integration of BIM into HEIs, Hardin (2009) argued that students will study software if chosen to be part of the curriculum. Table 1.1 below presents the barriers to BIM integration in HEIs found in the literature.

\section{BIM Awareness}

For the purpose of this study, the following definition of awareness from the Cambridge Advanced Learner's Dictionary (2008) is used. It defines awareness as the "knowledge 
that something exists, or understanding of a situation or subject at the present time based on information or experience" was used. In establishing BIM awareness of built environment students, the survey questionnaire examine whether the student had heard about BIM; how they heard about BIM; what their basic understanding of BIM is and their knowledge on current development in the UK construction industry with regards to BIM adoption.

\section{BIM Readiness}

The definition of readiness has been discussed (Aziz and Salleh 2011; Subramaniam et al., 2013; Othman et al., 2012). Aziz and Salleh (2011) mentioned that the concept of readiness cannot be defined but depends on contexts, situations and the individuals involved. For instance, the Harvard University Centre for International Development (2001) in a report on 'Readiness for the networked world' defined readiness as "the degree to which a community is prepared to participate in the Networked World." Othman et al. (2012) in studying the readiness of students towards entrepreneurship education defined readiness as "the willingness and ability to do something." Subramaniam et al. (2013) in their study of 'E-Content Development in Engineering Courses: Students Needs and Readiness', used the Cambridge Advanced Learner's Dictionary (2008) which defines readiness as "willingness or a state of being prepared for something." It can be deduced from all the definitions that readiness measures willingness and capability (ability) therefore the survey used these two elements to inform the student's BIM readiness. For the purpose of this study, BIM readiness is defined as the student's willingness to explore BIM and their ability to work in a BIM enabled environment. The research therefore intend to establish the willingness of built environment students to explore BIM as part of their courses and their ability to work in a BIM enabled environment. 
Table 1: Barriers to BIM integration in higher educational institute

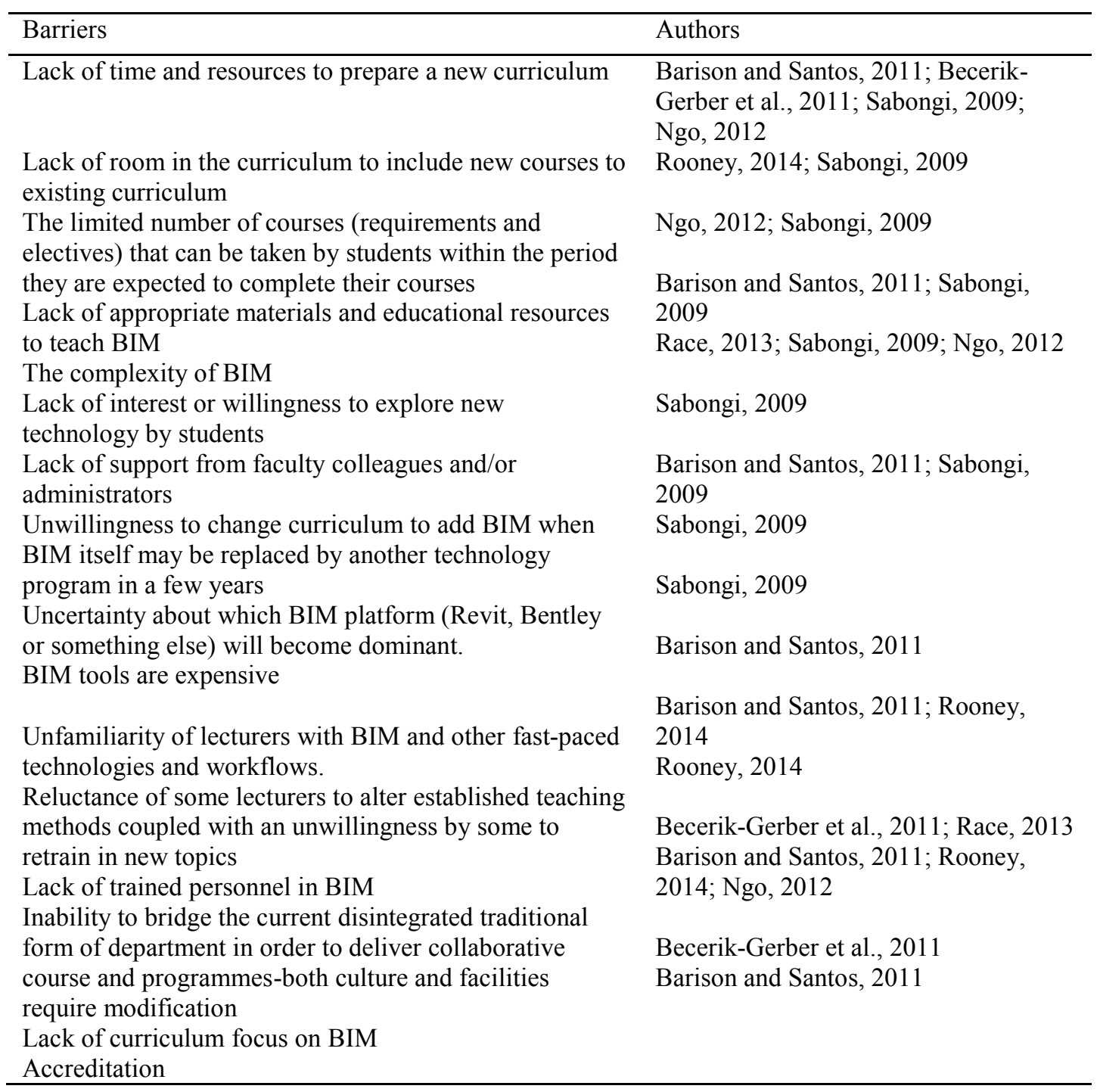

\section{METHODOLOGY}

This study investigated BIM awareness and readiness of postgraduate students of the six (6) universities in the West Midlands, namely Aston University, University of Birmingham, Birmingham City University, Coventry University, University of Warwick and University of Wolverhampton using purposive sampling. These universities offer built environment courses such as Architecture, Architectural Technology, Building Services Engineering, Building Surveying, Civil/Structural Engineering, Civil Engineering Surveying, Quantity Surveying, Construction related programmes (Construction/Project management), BIM related programmes and other built environment courses. The study adopted a positivist (quantitative) research approach. Data was collected by means of a self-completion online survey questionnaire consisting 
of twenty items divided into three sections. The first section had ten items to ascertain BIM awareness, followed by five (5) items on BIM readiness (Section 2). Section 3 consists of five (5) items on the respondent's profile. Closed ended questions were used to make it easier and quicker for the respondents to answer. It also enabled easier comparison of answers from different respondents. Most of the questions were 5 point Likert-like items based on a scale from "strongly agree" to "strongly disagree" where a score of 5 means strongly agree and 1 means strongly disagree. The names of the universities were coded from 1 to 6 for confidentiality. A variety of statistical analysis were used to analyse the data using statistical package for social sciences (SPSS). Descriptive analysis was performed to provide insight of the data and a summary of the results. A more detailed analysis was performed to compare the results of different samples using Spearman's rank correlations. In all, thirty-five students from three out of the six universities responded to the survey.

\section{ANALYSIS AND DISCUSSION OF RESULTS}

Respondents to the survey were from Architectural Technology, Civil/Structural Engineering, Construction related programmes (Construction/Project management), BIM related programmes and other built environment courses. All respondents answered that they had heard about BIM. However, more than half (51.4\%) answered that BIM was not introduced as part of their modules. Sixty percent $(60 \%)$ of the respondent answered that they either heard about BIM through Trade journals, seminars, at work or other sources. The data suggests that most of the students may have heard about BIM before it was introduced on their courses. This could be attributed to the high level of reports and journal papers on BIM in the last 5 years. BIM has become one of the most discussed and written about topics in the construction industry within the last 5 years (Crotty, 2012; Harding et al., 2014). A google scholar search on Building Information Modelling returns $3,170,000$ results.

To ascertain the understanding of BIM among the students, the questionnaire asked whether BIM is a synonym for 3D CAD drawing. Of the total respondents, almost threequarters $(74.3 \%)$ answered 'Yes' or 'Did not know' to the question. The results suggest that although all the respondents had heard about BIM, many of them did not understand what BIM is. This could be attributed to the unlimited number of BIM definitions in circulation which leads to the tendency for misinterpretation by readers because most publications attempt to define BIM in their own terms (Barlish and Sullivan, 2012). Many people perceive BIM as the file that is created using 3D CAD software programs (Reddy, 2012). The level of BIM awareness of built environment lecturers will impact on the students they teach. However, Rooney (2014) highlighted that some lecturers are unwilling to retrain in new topics such as BIM. Many of the lecturers in the respondents' institutions may have touched on BIM without adequately explaining what BIM was to their students. A lack of trained BIM personnel, lack of curriculum focus on BIM in higher educational institutions (Becerik-Gerber et al., 2011; Race, 2013), the lack of materials and educational resources to teach BIM (Barison and Santos, 2011; Sabongi, 2009), and unfamiliarity with BIM among lecturers (Barison and Santos, 2011; Rooney, 
2014) could be affecting the delivery of BIM to students in the higher educational institutions. This situation calls for the training of the affected built environment lecturers to ensure that they are better able to deliver BIM topics.

The results to ascertain postgraduate (MSc) built environment students' knowledge of current developments in the UK construction industry suggest that $62.9 \%$ were aware that BIM will become mandatory across all centrally procured UK Government construction projects by 2016 . However, almost two-third (65.7\%) were not aware of the maturity levels of BIM whilst 71.4\% were not aware of the maturity level expected as a minimum for the UK construction industry. A cross-tabulation was performed to compare the relationship between respondents' awareness that BIM will become mandatory across all centrally procured UK government construction project with respondents' awareness of the BIM maturity levels. The results indicated that of the total respondents $(62.9 \%)$ who answered that BIM will become mandatory across all centrally procured UK government construction project, $45.4 \%$ answered that they were not aware (strongly disagree, disagree or neither agree nor disagree) of the BIM maturity levels. Those who answered that they were aware of the maturity levels of BIM add up to $54.6 \%$. Of the total respondents $(5.7 \%)$ who answered (No) that BIM will not become mandatory across all centrally procured UK government construction project, all $(100 \%)$ answered that they were unaware (strongly disagree) of the BIM maturity levels. Of the total respondents (31.4\%) who answered that they do not know BIM will become mandatory across all centrally procured UK government construction project, $100 \%$ answered that they were unaware (strongly disagree, disagree or neither agree nor disagree) of the maturity levels of BIM. The results shows that majority of the respondents who answered that they were aware BIM will become mandatory across all centrally procured UK government construction project were also aware of the BIM maturity levels. The relationship between 'I am aware of the BIM maturity levels and What BIM maturity level is expected of the UK construction industry by 2016' was investigated using Spearman's rank correlation coefficient. To ensure that there was no violation of the assumption of normality, linearity and homoscedasticity, preliminary analyses were performed. The results revealed a significant and negative correlation $(\mathrm{r}=-0.47, \mathrm{~N}=35, \mathrm{p}=0.04)$ between the two variables with high levels of BIM maturity level awareness associated with lower levels awareness of mandatory BIM by 2016. The correlation was moderate in strength.

Sixty percent $(60 \%)$ of the survey's respondents answered that collaboration is needed by teams on a BIM project for better results. The remaining respondents disagreed or were not sure. The results suggest a lack of awareness of the central principle of BIM among some postgraduate (MSc) built environment students. The National BIM Standard-United States (2013) points out that a vital principle of BIM is collaboration by all the teams for an efficient industry. The concept of BIM is collaboration to create a single integrated model (McGough et al., 2013). BIM therefore thrives in a collaborated multidisciplinary environment from project inception. BIM would ensure that several companies work in a fully collaborated 3D environment so that the teams involved in the project can work on a common platform to reduce the costs of transaction and errors (Cabinet Office, 2011). 
Overall, only $14.3 \%$ answered that they were satisfied with the level of BIM knowledge they have received through their courses. This result clearly suggest that 6 out of 7 respondents $(85.7 \%)$ were not satisfied with the BIM knowledge received through their university courses.

\section{BIM READINESS}

The questionnaire asked the respondents whether their courses have prepared them well enough to perform within a BIM enabled environment. Of the total respondents, only $11.4 \%$ or almost 1 in 9 respondents answered "Yes" to the question. The results of students overall satisfaction with the BIM knowledge received through their courses and their ability to perform in a BIM enabled environment because their course has prepared them well paints a gloomy picture considering that the construction industry is counting on professionals from the higher educational institutions to fill the skills gap (Kymmell, 2008, McCuen and Pober, 2013). This suggests that majority of respondents were not fully aware of current developments in the industry.

The relationship between 'Overall satisfaction with BIM knowledge received through my course' and 'My course has prepared me well to perform within a BIM enabled environment' was investigated using Spearman's rank correlation coefficient. The results revealed a moderate, positive correlation $(r=0.37, \mathrm{~N}=35, \mathrm{p}=0.03)$ between the two variables with higher levels of overall satisfaction with BIM knowledge received through their courses being associated with higher levels of My course has prepared me well to perform within a BIM enabled environment.

Further to the above question, respondents were asked whether they could perform well in a BIM enabled environment. About 1 in 7 (14.3\%) of the respondents answered that they could perform well in a BIM enabled environment. It is interesting to note that the result was $2.9 \%$ more than those who answered that their course had prepared them well to perform in a BIM enabled environment. Of all the respondents to the survey, $28.6 \%$ answered that they could use one or more BIM tools (software) as shown in Figure 1.1. The result indicate that Revit (Arch, Struct, MEP), was the most common BIM tool that respondent answered they could use.

The results of the survey indicated that more than three quarters $(77.2 \%)$ of the respondents were willing to explore BIM as part of their course. Almost three quarters (71.4\%) of the respondent answered that they will willingly add BIM to their course if it were an elective module. The results from this survey differ from Sabongi (2009) who conducted a survey of built environment undergraduate programmes in US institutions and concluded that a lack of interest or willingness by student to explore new technology such as BIM was a barrier to BIM integration in the undergraduate courses. It must however be noted that respondents to this survey were on postgraduate (Masters) programmes. The UK government mandate for the industry to adopt level 2, fully collaborative 3D BIM, or higher on all public sector contracts by 2016 could account for 
respondents' interest and willingness to explore BIM as part of their courses in order to gain a competitive edge during their job search.

Figure 1.1 Ability to use one or more of the following BIM tools (software) in a BIM enabled environment

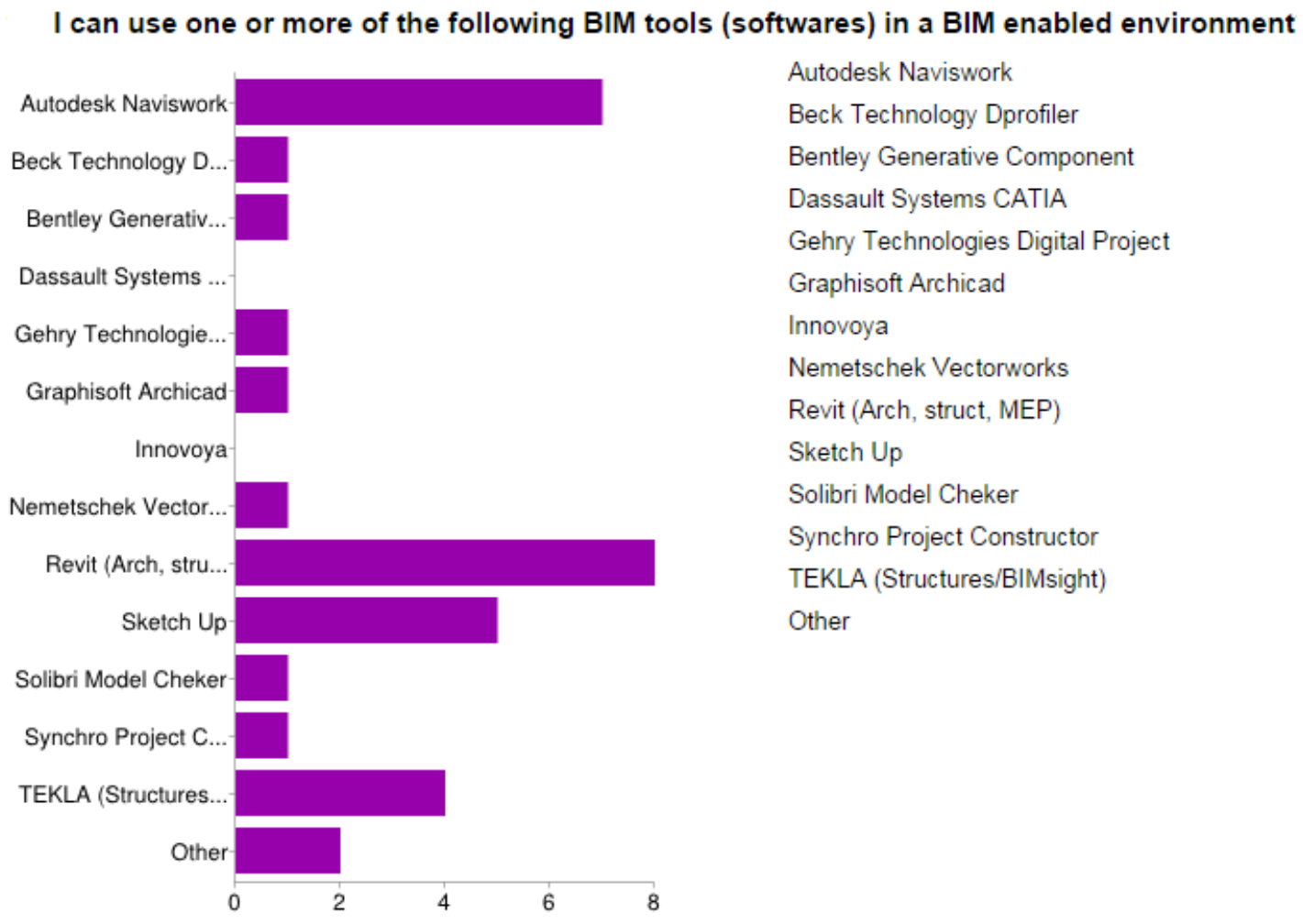

\section{CONCLUSION}

The adoption of BIM by the UK construction industry will ensure efficiency in projects delivery predictably to the required quality, time and budget. It will also enable the industry to gain a competitive edge in the expanding global market. UK firms that adopt BIM at level 2 as a minimum by 2016 will gain a competitive edge over those that do not. A lack of in-house expertise and training of the affected employees will mean that many organisations, especially SME's will lose out. Most of these organisations will be counting on HEIS to equip their graduates from the built environment schools to fill the skill gaps. However, the results of the research suggest that HEIS are far behind in preparing their postgraduate (MSc) built environment students to be enable them work in a BIM enabled environment. This situation must be addressed by higher educational institutions to ensure that their students are equipped with the essential BIM knowledge to succeed in a BIM enabled environment. Ngo (2012) points out that educational institutions have a crucial role to equip the next generations of graduates with the necessary BIM knowledge to perform their task in the BIM enabled environment. 
Institutions that integrate BIM into their built environment curricula early stand to gain a competitive edge in that students will be attracted to them. The current situation calls for the training all affected lecturers in the built environment schools to enable them deliver BIM topics. HEIS are seen by many as the solution for a smooth transition from 2D CAD to BIM.

\section{REFERENCES}

- AZIZ, N. M. AND SALLEH, H. (2011) A readiness model for IT investment in the construction industry. African Journal of Business Management, 5(7), pp. 2524-2530.

- BANWELL, H. (1964) Report of the Committee on the Placing and Management of Contracts for Building and Civil Engineering work. UK: HMSO.

- BARISON, M. B. AND SANTOS, E. T. (2011) BIM teaching: current international trends, Design Management, 6(2), pp. 67-80.

- $\quad$ BARLISH, K. AND SULLIVAN, K. (2012) How to measure the benefits of BIM - A case study approach. Automation in Construction, 24(2012), pp. 149-159.

- BECERIK-GERBER, B., GERBER, D. AND KU, K. (2011) The pace of Technological Innovation in Architecture, Engineering and Construction Education: integrating recent trends into the curricula, Electronic Journal of Information Technology in Construction, 16(2011), pp. 411-432.

- $\quad$ BIM TASK GROUP (2013) Education and Training [online]. [Accessed 10 March 2014]. Available at: <http://www.bimtaskgroup.org/education-and-training/>.

- BUILDING SMART (2010) Constructing the business case: Building Information Modelling. London: British Standards Institution and Building SMART UK.

- CABINET OFFICE (2011) Government construction strategies. London: Cabinet Office.

- CAIN, C. T. (2003) Building down barriers- A guide to construction best practice. London: Spon Press.

- CAIN, C. T. (2004) Performance Measurement for Construction Profitability. Oxford: Blackwell Publishing Ltd.

- CAMBRIDGE (2008) Cambridge Advanced Learner's Dictionary. Cambridge University Press.

- CONSTRUCTION INDUSTRY TRAINING BOARD (CITB) (2014) Construction: the war for talent and driving growth. The House: Parliament's Magazine, [online] 2 May [Accessed 14 July 2014]. Available at:< http://www2.warwick.ac.uk/fac/soc/cei/news/the_house_may_2_2014_low_res-2.pdf>.

- CROTTY, R. (2012) The Impact of Building Information Modelling: Transforming Construction. Oxon: SPON Press.

- $\quad$ DEAN, R. (2007) Building Information Modeling (BIM): Should Auburn University Teach BIM to Building Science Students? Graduate Capstone, Department of Building Science, Auburn University.

- DEPARTMENT FOR BUSINESS, INNOVATION AND SKILLS (BIS) (2013) UK Construction: An economic analysis of the sector. London: Department for Business, Innovation and Skills.

- $\quad$ EGAN, A. (1998) Rethinking Construction. London: Department of Trade and Industry.

- $\quad$ EMMERSON, H. (1962) Survey of Problems before the Construction Industries. HMSO.

- GÖRANSSON, B. AND BRUNDENIU, C. (eds.) (2011) Universities in Transition: The Changing Role and Challenges for Academic institution. Ottawa: International Development research Centre.

- HARDIN, B. (2009) BIM and construction management: proven tools, methods, and workflows. Chichester: John Wiley. 
- HARDING, J., SURESH, S. RENUKAPPA, S. AND MUSHATAT, S. (2014) Do building information modelling applications benefit design teams in achieving BREEAM accreditation? Journal of Construction Engineering, (2014), pp.1-8.

- HARVARD UNIVERSITY CENTRE FOR INTERNATIONAL DEVELOPMENT (CID 2001) Readiness for the networked world: A Guide for developing countries world. Cambridge: Harvard University Centre for International Development.

- HM GOVERNMENT (2013) Construction 2025. Industrial strategy: government and industry in partnership. London: Department of Business, Innovation and Skills.

- JOHNSON B. T. AND GUNDERSON D. E. (2010) Educating students concerning recent trends in AEC: A survey of ASC member programs. Associated Schools of Construction Annual International Conference, and CIB Workgroup 89 [online]. Wentworth institute of Technology, Boston 7-10 April. [Accessed 1 August 2014]. Available at: $<$ http://ascpro0.ascweb.org/archives/cd/2009/paper/CERT144002009.pdfs.

- KHOSROWSHAHI, F. AND ARAYICI, Y. (2012) Roadmap for implementation of BIM in the UK construction industry. Engineering, Construction and Architectural Management, 19(6), pp. 610-635.

- KYMMELL, W. (2008) Building Information Modeling: Planning and Managing Construction Projects with 4D CAD and Simulations. New York: McGraw Hill.

- LAMOND, J., PROVERBS, D AND WOOD, T. (2013) What matters to built environment students. York: The Higher Education Academy.

- $\quad$ LATHAM, M. (1994) Constructing the Team. London: HSMO.

- MCCUEN, T. AND POBER, E. (2013) BIMSTORM: a platform facilitating integrated design and construction processes [online]. [Accessed 9 November 2013]. Available at: $<$ http://www.nibs.org/?conference bim>.

- MCGOUGH, D., AHMED, A. AND AUSTIN, S. (2013) Integration of BIM in higher education: case study of the adoption of BIM into Coventry University's department of civil engineering, architecture and building. Integrated Approaches to Sustainable Building: Sustainable Building Conference 2013. Coventry University, Coventry 3-5 July. Coventry University: Department of Built Environment, Coventry University, pp. 394-403.

- MCGRAW-HILL CONSTRUCTION (2008) Smart market report: Building Information Modelling (BIM) - Transforming design and construction to achieve greater industry productivity. New York: The McGraw-Hill Companies.

- MORTON, D. E. (2012) BIM: a transformative technology within the architectural curriculum in schools of architecture. 1st UK academic conference on BIM: conference proceedings. Northumbria University, Newcastle 5-9 September, pp. 47-66.

- NATIONAL BIM STANDARD-UNITED STATES (2013) What is BIM [online]. [Accessed 26 July 2014]. Available at: $<$ http://www nationalbimstandard.org/faq.php\#faq1 $>$.

- NATIONAL BUILDING SPECIFICATION (NBS) (2011) Building Information Modelling Report March 2011. Newcastle upon Tyne: RIBA Enterprises Ltd.

- NATIONAL FEDERATION OF BUILDERS (NFB) (2012) BIM: ready or not? The NFB BIM-readiness survey 2012. Crawley: National Federation of Builders. [Accessed 6 July 2014]. $\quad$ Available

$<$ http://www.builders.org.uk/resources/nfb/000/318/333/NFB_BIM_Survey_BIMready_or_not.pdf $>$.

- NGO, M. H. (2012) UK Construction Industry's responses to Government Construction Strategy BIM deadline and applications to civil engineering education. 1st Civil and Environmental Engineering Student Conference [online]. Imperial College, London 25-26 June. [Accessed 18 July 2014]. Available at:

- $\quad<\mathrm{https} / /$ workspace.imperial.ac.uk/civilengineering/Public/technical\%20paper\%20group\%20 A/18A-Ngo UK\%20Construction\%20Ind.\%20Responses\%20to\%20Governm't\%20Construction\%20Strate gy\%202.pdf $>$. 
- OTHMAN, N., HASHIM, N. AND WAHID, H. A. (2012) Readiness towards entrepreneurship education. Education \& Training, 54(8), pp. 697-708.

- POTTS, K. (2008) Construction cost management: learning from case studies. Oxon: Taylor and Francis.

- RACE, S. (2013) BIM demystified. An architect's guide to building information modelling/ management (BIM). 2nd ed. London: RIBA Publishing.

- REDDY, K. P. (2012) BIM for building owners and developers: Making a business case for using BIM on projects. New Jersey: John Wiley \& Sons.

- ROONEY, K. (2014) BIM education - global - summary report - 2013. Sydney: Construction Information Systems Limited.

- SABONGI, F. J. (2009) The Integration of BIM in the Undergraduate Curriculum: an analysis of undergraduate courses. Proceedings of the 45th Annual Conference of Associated School of Construction [online]. University of Florida, Florida 1-4 April. [Accessed 10 August 2014]. Available at: <http://ascpro0.ascweb.org/archives/cd/2009/paper/CEUE90002009.pdf $>$.

- SIMON, E. (1944) Report of the Council for Works and Buildings: The Placing and Management of Building Contracts. HMSO.

- SUbRAMANIAM, T. S., NORDIN, N. AND KRISHNAN, M. (2013) E-Content Development in Engineering Courses: Students Needs and Readiness. International Journal of Business and Social Science, 4(6), pp.282-289.

- UK COMMISSION'S EMPLOYER SKILLS SURVEY (UKCESS) (2014) UK Commission's Employer Skills Survey 2013: UK Results. London: UKCESS.

- UK COMMISSION FOR EMPLOYMENT AND SKILLS (2012) Sector Skills Insights: Construction. Rotherham: UK Commission for Employment and Skills.

- WOLSTENHOLME, A. (2009) Never waste a good crisis: a review of progress since rethinking construction and thoughts for our future. London: Constructing Excellence.

- WONG, A. K. D., WONG, F. K. W. AND NADEEM, A. (2011) Building Information Modelling for tertiary construction education in Hong Kong. Journal of Information Technology in Construction, 16(2011), pp. 467-476. 


\title{
THE EXTENT OF INTEGRATING SUSTAINABILITY TOPICS INTO AN MSC QUANTITY SURVEYING COURSE AT LONDON SOUTH BANK UNIVERSITY IN UK
}

\author{
Opoku, A. ${ }^{1}$ and Egbu, C.
}

\begin{abstract}
:
The concept of Education for Sustainable Development (ESD) is gaining interest and importance in the field of educational policy, practice and research. It is argued that educational institutions have a key role to play in educating future generations of citizens, consumers, investors, entrepreneurs, leaders, and decision-makers and should embed sustainability principles in the curricula to empower students and graduates to contribute towards achieving a more sustainable society. Sustainable development could be embedded in the curriculum by fully integrating it into courses or embedding in a particular module of a course. This research aims to investigate the extent of integration and students' experience on how sustainable development has been embedded in the MSc Quantity Surveying (QS) course at the London South Bank University (LSBU). It critically examines how sustainable development is embedded in teaching and learning of the MSc Quantity Surveying course. This paper adopts a qualitative approach to data collection and analysis. A detailed content analysis of module guides and course materials were undertaken. An audit of modules currently available within the MSc Quantity Surveying course is conducted using module guides held electronically. This was followed by interviews with 15 current MSc Quantity Surveying students. The results revealed that students value sustainable development knowledge and skills. Most students believe that they need the right sustainable development skills to be competitive in the job market. There were mixed responses on the extend of integrating sustainable development in the MSc QS course, however the general consensus was that students are not happy with how sustainable development is being embedded in the QS course and argues that more needs to be done to fully integrate sustainable development in the programme. It is recommended that a separate module on sustainable development would be the best way to integrate sustainable development into the QS course.
\end{abstract}

KEYWORDS: CURRICULUM, EDUCATION, QUANTITY SURVEYING, SUSTAINABLE DEVELOPMENT

\section{INTRODUCTION}

The role of education in achieving the sustainable development goals need to be continuously promoted. The concept "Education for sustainability" (ESD) is used to describe learning for sustainability where graduates take responsibility for creating a sustainable society. Students are increasing being aware and concern about the issues of sustainable development, the environment, and climate change and this is encouraging academics to embed sustainability into their teaching (Bone and Agombar, 2011). It is believed that a growing proportion of employers want to attract recent graduates with responsible values on sustainable development (Hanover Research, 2011). It is argued that Universities plays a key role in educating future generations of citizens, consumers, investors, entrepreneurs, leaders, and decision-makers and should embed sustainability

\footnotetext{
1 School of Built Environment \& Architecture, London South Bank University, England UK. Email: opokua@1sbu.ac.uk
} 
principles in the curricula to empower students and graduates to contribute towards achieving a more sustainable society. Martin and Jucker (2005) describe universities as the most important organization to help the drive towards achieving sustainable development by addressing the sustainability agenda through the curriculum. EAUC (2009) describe Education for Sustainable Development (ESD) as finding and using opportunities to include environmental, economic and social issues in the curriculum. There is a rise in sustainability-related educational programs across the world currently due to the increasing student interest in learning more about the field of sustainability and employers desire to hire graduates with sustainability backgrounds (Hanover Research, 2011).

ESD seeks to develop student's behaviour to respect environmental, social and cultural differences which are the central part of our world; appreciation that we are all part of society and humanity depends on the environment for their wellbeing (EAUC, 2009). The United Nations realised the essential role of teaching, learning and research in promoting sustainability and declared 2005 to 2014 as the decade for Education for Sustainable Development (UNESCO, 2005). Subsequently, the UK developed a sustainable development strategy in 2005; "Securing the Future: delivering the UK sustainable development strategy". The strategy pointed out the important role of education in providing the youth of today with the skills and the knowledge toward achieving sustainable development. It argues that sustainability literacy should be a core competence among graduates (DEFRA, 2005).

This paper aims to examine the extent of integrating sustainable development into the MSc QS course and students' experience on how the concept of sustainability is being embedded in the course at LSBU. The next part of the paper provides an overview of the MSc QS course. Relevant and current literature on education for sustainable development and its delivery is examined in the third section. The final part discusses the qualitative data on students' experience on how sustainable development is being integrated in the course. It also presents conclusions and recommendations for academics with the desire to embed sustainable development in higher education curriculum.

\section{MSC QUANTITY SURVEYING COURSE AT LONDON SOUTH BANK UNIVERSITY IN UK}

The MSc Quantity Surveying course at the London South Bank University (LSBU) is accredited by the Royal Institution of Chartered Surveyors (RICS). The course is completed in 2 semesters for full-time students or 4 semesters for part time students plus dissertation. The course consist of three (3) supplementary level 6 modules at the beginning of the course bringing non-cognate students up to speed in relation to construction technology, law and contract documentation and administration before they embark on the masters level modules. The main master's programme consist of six (6) level 7 core modules plus one (1) level 7 optional module. 


\section{Limitations}

The concept of Education for sustainable development is broad and impractical to fully deal with it in in this paper. This paper is therefore very concise and only looks at the key themes relevant to the research questions due to the 10 page limit restrictions. Data collection was based on 15 interviews and content analysis only which could affect generalization of the research findings.

\section{THE CONCEPT OF SUSTAINABLE DEVELOPMENT}

The concept of Sustainable development (SD) has been defined in many ways but the most commonly used definition is the one in Brundtland's commission 1987 report of the United Nations World Commission on Environment and Development: Our Common Future which defines sustainable development as:

"Meeting the needs of the present without compromising the ability of future generations to meet their own needs... A process of change in which the exploitation of resources, the direction of investments, the orientation of technological development, and institutional change are all in harmony and enhance both current and future potential to meet human needs and aspirations" (Brundtland, 1987:43).

Opoku and Ahmed (2013:141) however address the concept of need and human behaviour in achieving sustainability by defining Sustainable development as:

"The adjustment of human behaviour to address the needs of the present, without compromising the ability of future generations to meet their own needs" (Opoku and Ahmed, 2013:141).

Sustainable development ensures a better quality of life for everyone, now and future generations through the protection of the environment to meet our social needs and the promotion of successful economies. Sustainable development could be embedded in the curriculum by fully integrating it into courses or embedding in a particular module of a course (EAUC, 2009). Education for sustainable development involves the development of student who believes in the promotion of global citizenship, environmental stewardship, social justice, ethics and wellbeing to ensure sustainable futures (Longhurst et al., 2014). Graduates should be well prepared with the appropriate sustainable development knowledge and skills to deal with the problems society faces today.

\section{EDUCATION FOR SUSTAINABLE DEVELOPMENT}

Education for Sustainable Development describes the process of teaching and learning that studies the long term future of the environment, the economy and the society (UNESCO, 2005). Longhurst et al. (2014:5) define Education for sustainable development (ESD) as: 
"The process of equipping students with the knowledge and understanding, skills and attributes needed to work and live in a way that safeguards environmental, social and economic wellbeing, both in the present and for future generations".

A person is said to be Sustainability literate when he/she "combines an understanding of the need for change with appropriate knowledge and skills, and is able to recognise and reward sustainable actions in others. Sustainability literacy is seen by its proponents as important for employability, effective professionalism, economic performance and social wellbeing" (Murray et al., 2007:83). Parkin et al., (2004) however add that sustainability literacy develop the knowledge and skills to decide to act towards achieving sustainable development; recognising the need for change to a sustainable way of doing things both individually and collectively as society. Sustainability literacy should develop knowledge and skills that embraces the adoption of social, environmental and economic aspects of Sustainable development (Dyer and Selby, 2004). Educational institutions have a major role to play in building the intellectual capital required by the future generation in supporting society's respond to the sustainable development challenge. This can be achieved by integrating sustainable development in the content and the delivery of the curriculum (EAUC, 2009). Education for sustainable development (ESD) is more about providing students with the skills to think creatively and critically, working with others and acting positively; this can only be achieved through the development of curricula and pedagogy that provide students the knowledge and skills to exhibit a more sustainable behaviour (HEFCE, 2009). The United Nations realised the essential role of teaching, learning and research in promoting sustainability and declared 2005 to 2014 as the Decade for Education for Sustainable Development (UNESCO, 2005). Subsequently, the UK developed a sustainable development strategy in 2005; "Securing the Future: delivering the UK sustainable development strategy". The strategy pointed out the important role of education in providing the youth of today with the skills and the knowledge toward achieving sustainable development. It argues that sustainability literacy should be a core competence among graduates (DEFRA, 2005). ESD seeks to integrate the beliefs, principles and practices of sustainable development into all aspects of teaching and learning.

\section{DELIVERING EDUCATION FOR SUSTAINABLE DEVELOPMENT}

Universities are key actors in the delivery of the relevant skills for sustainable development (Longhurst et al., 2014). The concept of Sustainability literacy is very important for graduates in terms of employability, effective professionalism, economic performance and social wellbeing (Murray et al., 2007). In terms of the delivery of sustainable development education (sustainability literacy), Rowe (2002) support the view that sustainable development should be integrated right across higher education curriculum so that every student on every course is provided with the knowledge and skills needed to promote a sustainable society. Sustainability literacy should be a core 
competency for all graduates in order to compete in the current job market (Longhurst et al., 2014).

In a joint study by the UK National Union of Students (NUS) and Higher Education Academy (HEA) to discover opinions on how education for sustainable development should be delivered, students argue that sustainability literacy should be embedded into the existing content of the curriculum (Drayson et al., 2013). They were however open to other approaches such as the addition of content to the course, studying a specific module or taking part in extracurricular activities that promotes teaching and learning of sustainable development (Drayson et al., 2013). Pedagogical, teaching and learning approaches that develop stimulus activities, simulation, experiential project work and problem-based are effective for education for sustainable development. These methods enable students to relate their learning to real-life problems and situations (Longhurst et al., 2014). Education for sustainable development enhances student's ability to understand and appreciate the impact of their activities and decisions on the society. The teaching of the concept of sustainability literacy in higher education is essential for students of all discipline. Graduates currently leaving higher education should have the ability to think and describes a learning exercise that can help them understand how complex systems can form mutually beneficial relationships because graduates require the knowledge and the skill of sustainable development in all careers of endeavour. It is important that graduates acquire sustainability knowledge and skills needed in the current job market. The drive towards achieving sustainable development demand a change in behaviour and mindset and education plays a major role.

\section{RESEARCH APPROACH}

This study adopts the interpretivist/constructivist philosophical stance that argues that reality can fully be understood only through the subjective interpretation and intervention in reality (Creswell, 2003). The constructivist researcher is most likely to rely on qualitative data collection methods and analysis (Mackenzie and Knipe, 2006). In the qualitative research paradigm, the most important focus is for researchers to capture accurately the existing experiences and perceptions of participants involved in the phenomenon or process under investigation (Onwuegbuzie and Johnson, 2006). Qualitative method is concerned with words and images out of which the researcher seeks to interpret meanings and explanations as to the way people behave and to develop an understanding of social constructs. This study therefore adopts a qualitative research approach for data collection and analysis. A desktop study focusing on literature review on the main theme of Education for sustainable development (ESD) in the higher education was carried out. A detailed content analysis of module guides and course materials was also undertaken. An audit of modules currently available within the MSc Quantity Surveying course was conducted using module guides held electronically. Module guides are written by module teams to a university template and guidance and are validated through the university quality assurance structures. They include identification of aims and learning outcomes, core content, the learning and teaching and assessment methods and key learning resources associated with the module. 
Semi-structured interviews were used for primary data collection; interviews are useful to obtain detailed information about personal feelings, perceptions and opinions. Fellow and Liu (2003) argue that, interviews are useful tools to obtain detailed information about personal feelings, perceptions and opinions. A semi-structured interview involves the implementation of a number of predetermined questions. The interviewer prepares some questions or a topic frame for the interview and is also free to probe to greater depth when necessary. A primary risk of using interviews is interviewer bias and its associated subjectivity due to quite different lines of questioning depending on the experience of the interviewer (De Silva, 2009). The focus of this study is to seek the understanding and experience of full time and part time MSc Quantity Surveying students at the school of built environment when integrating sustainable development into the course.

\section{RESEARCH FINDINGS AND DISCUSSIONS}

\section{Content Analysis of MSc QS Modules}

A content analysis of the MSc Quantity Surveying programme modules a very low level of integration of sustainable development in the course. Only the Construction module; one (1) module out of the three (3) Level 6 supplementary modules has sustainable development content covering the environmental dimension of sustainability. However, there are two (2) level 7 modules with sustainable development topics integrated; these are Project Evaluation and Procurement \& management of Construction modules. Project Evaluation module has topics covering the social, economic and the environmental dimensions of sustainability. The Procurement \& Management of Construction module however cover only the environmental dimension of sustainability. In terms of the optional modules, two (2) out of the five (7) optional modules have certain level of sustainable development embedded in the topics. The Building control has topics such new technologies associated with sustainable construction while the BIM and the collaborative working module has topics with sustainable development integrated in the delivery. A content analysis of all the MSc QS modules is presented in Table 1.

Table 1: MSc Quantity Surveying modules content analysis and Sustainable Development

\begin{tabular}{|c|c|c|c|c|}
\hline Level & Module & 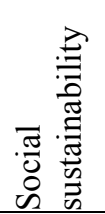 & 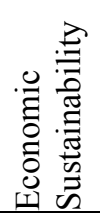 & 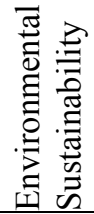 \\
\hline & Core Modules & & & \\
\hline 6 & Measurement, Documentation \& Estimating & & & \\
\hline 6 & Construction & & & $\checkmark$ \\
\hline 6 & Institutional \& Legal Context for Construction & & & \\
\hline 7 & Economics \& Finance for Construction & & & \\
\hline 7 & Procurement \& Management of Construction & & & $\checkmark$ \\
\hline
\end{tabular}




\begin{tabular}{|c|c|c|c|c|}
\hline 7 & Construction Contract Administration & \multirow{5}{*}{$\checkmark$} & \multirow{5}{*}{$\checkmark$} & \multirow{4}{*}{$\checkmark$} \\
\hline 7 & Construction Law & & & \\
\hline 7 & Project Evaluation & & & \\
\hline 7 & Dissertation & & & \\
\hline & Optional Modules & & & \\
\hline 7 & Advanced Measurement \& Documentation & & & \multirow{4}{*}{$\checkmark$} \\
\hline 7 & Building Control & & & \\
\hline 7 & International Real Estate \& Construction & & & \\
\hline 7 & Legal Resolution of Property \& Construction Disputes & & & \\
\hline 7 & BIM \& Collaborative Working & $\checkmark$ & $\checkmark$ & $\checkmark$ \\
\hline
\end{tabular}

\section{INTERVIEW DATA ANALYSIS}

Semi-structured interviews with open-ended questions were used for the qualitative data collection. The use of semi-structured interviews requires the interviewer to approach the conversation with an overarching topic and go through general themes and specific questions. The aim of the interviews was to provide an in-depth understanding of the student's opinion and experiences of the extent of integration of the sustainable development into the MSc QS course. Semi-structured interviews were carried out with fifteen (15) students from the MSc QS course. The interview data were analysed by transcribing, identifying and coding the themes, interpreting and providing an explanatory accounts through a review of the content. A profile of students who were interviewed is shown in Table 2.

Table 2: Profile of students who were interviewed

\begin{tabular}{lll}
\hline Student & Study Route & Gender \\
\hline A & Part time & Male \\
B & Full time & Female \\
C & Part time & Female \\
D & Full time & Male \\
E & Part time & Female \\
F & Full time & Female \\
G & Full Time & Female \\
H & Part time & Male \\
I & Full time & Male
\end{tabular}


Part time

Female

K

Part time

Male

L

Full time

Male

M

Full time

Female

$\mathrm{N}$

Part time

Male

$\mathrm{O}$

Part time

Male

All interview data were transcribed and analysed to identify common messages and themes. Students were asked about their understanding of sustainable development; generally interviewed student understand the concept of sustainable development but more biased towards the environmental dimension of sustainability. For example student ' $\mathrm{B}$ ' describes sustainable development as: "The development of buildings that are more efficient with less waste and less damage to the environment". Student 'E' however understands sustainable development as; "Caring about the environment, recycling of waste, improving what is available or keeping it for the future generation".

In addition, student ' $\mathrm{J}$ ' describes sustainable development as: "The development that does not harm the environment and doesn't use more natural resources". While student ' $\mathrm{K}$ ' believes that sustainable development is "an approach to design that seeks to maximise the quality of the built environment whilst minimising the negative impact to the environment".

In terms of the importance of the knowledge and skills of sustainable development to students and their career, the general consensus was that the knowledge and skills of sustainability is very important to the interviewed students and their career. For instant, student ' $G$ ' said that: "The sustainable development knowledge is very important to me and my career because our company (Skanska) stand for sustainable development". Student ' $F$ ' added that: "the knowledge of sustainable development is relevant to my career. Clients sometimes ask for sustainability. It is very important part or our job due to regulations and future for the environment and the society we live". According to student ' $\mathrm{D}$ ' 'the knowledge of sustainable development is important, however I don't think that it necessarily translates into a better career path as yet, however, with time this may change".

However student ' $\mathrm{C}$ ' comments that: "the knowledge of sustainable development is not a requirement for her job but an advantage because sustainability is at the core of the construction industry in terms of lean construction and more efficient methods of construction". Contrary to the above statements, Student 'E' argued that the knowledge and skills of sustainable development is not important to her by saying: "Sustainability knowledge is not important to me; I don't have passion for the environment". 
In terms of how happy students are with the integration of sustainable development into the MSc QS course at the LSBU, it is clear that student are not happy with how the knowledge of sustainable development is being embedded in the QS course. Most students argued that emphasis is not being made on sustainable development during lectures or the concept of sustainable development is not mentioned at all. Student ' $\mathrm{N}$ ' for example said that: "How sustainable development is embedded in the course is bad and not mentioned at all; a stand-alone module on sustainable development will be better than embedding just small topics into various modules on the course".

Student ' $\mathrm{J}$ ' highlighted her opinion by saying: "Not really happy as there hasn't been much emphasis on sustainability throughout the course". According to student 'B' "project Evaluation is the only module that covered sustainable development; the other core modules did not talk about sustainable development". However the module content analysis showed that the Procurement and Management in Construction module should cover some level of sustainable development. Student ' $E$ ' confirmed the above statement by saying that: "I can't remember how sustainable development was embedded in the QS course because it was not mentioned; not much of sustainable development was taught". Student ' $F$ ' however comments that: "Bits of sustainable development are embedded in the Procurement and management in construction module. However I would have preferred a separate module on sustainability which could help students to concentrate on it more".

Finally, interviewed students were asked about how satisfied they are in terms of the extent of integration of sustainable development in the QS course. The results were mixed from "not satisfied" through "fairly satisfied" to being "satisfied". However, only two (2) out of the fifteen (15) interviewees were satisfied with the extent of integration of sustainable development in the QS Course. Student ' $M$ ' commented that: 'I'm not satisfied with the extent of integration of sustainable development; there should be a separate module on sustainability, preferably a core module".

In the words of student ' $G$ ' "Fairly satisfied because sustainable development is not well covered. Had basic knowledge but would have been better with more on sustainability". Student 'B' however said that: "I'm fairly satisfied but other modules did not cover sustainable development. The Procurement \& management in construction module should cover more on sustainability due to the current requirements for sustainable procurement in construction industry".

\section{CONCLUSIONS}

The MSc QS module content analysis shows that only one (1) module out of the three (3) Level 6 supplementary modules has sustainable development content covering the environmental dimension of sustainability. However, there are two (2) level 7 modules with sustainable development topics integrated into the content. There are also two (2) out of the seven (7) optional modules that have certain level of sustainable development embedded in the delivery. Primary data from the interview with the 15 students revealed 
that, students generally understand the concept of sustainable development but are more biased towards the environmental dimension of sustainability. Students interviewed acknowledged the importance of the knowledge and skills of sustainable development to their career; the general consensus was that the knowledge and skills of sustainability is very important if they are to compete well in the current job market. In terms of how happy students are with the delivery and the integration of sustainable development into the MSc QS course at the London South Bank University, it is clear that student are not happy with how the knowledge of sustainable development is being embedded in the QS course. Most students argued that emphasis is not being made on sustainable development during lectures or the concept of sustainable development is not mentioned at all. There were mixed responses on the extend of integration of sustainable development in the MSc QS course, however the general view was that, students are not satisfied with the extent of integration of sustainable development into the QS course and argues that more needs to be done to fully integrate sustainable development in the programme. It is recommended that a separate module on sustainable development would be the best way to integrate sustainable development into the QS course. Alternatively, sustainable development could be embedded in all the core modules and emphasis on the link or the importance of sustainable development should be made clear in each module during its delivery. Curriculum designers of courses in the built environment and relevant professional bodies should consider therefore considers sustainability knowledge and skill as core for graduates and professional membership.

\section{REFERENCES}

- Bone, E. and Agombar, J. (2011), First-year attitudes towards and skills in, sustainable development. A report from the Higher Education Academy. Available online at: http://www.heacademy.ac.uk/assets/York/documents/ourwork/sustainability/FirstYearAttitiud es_FinalReport.pdf (Accessed June 2014)

- Brundtland, G. H. (1987), Our Common Future: Report of the world Commission in Environment and Development, Oxford University Press, Oxford

- Creswell, J. W. (2003), Research design: Qualitative, quantitative, and mixed methods approach (2nd edition). Thousand Oaks, CA: Sage

- DEFRA (2005), Securing the future - delivering UK sustainable development strategy, [Online], available at: https://www.gov.uk/government/publications/securing-the-futuredelivering-uk-sustainable-development-strategy, Department for Environment, Food \& Rural Affairs (DEFRA), (Accessed June 2014)

- De Silva, T. (2009), Benefits of Mixed Methods in Environmental Reporting Research, Christchurch: Lincoln University

- $\quad$ Dyer, A. and Selby, D. (2004), Centre of Excellence for Teaching and Learning. Education for Sustainable Development, Stage 2 Bid; University of Plymouth

- $\quad$ Drayson, R., Bone, E., Agombar, J. and Kemp, S. (2013), Student attitudes towards and skills for sustainable development. York: HEA

- EAUC (2009), Embedding Sustainable Development in the Curriculum, available at: http://www.eauc.org.uk/sorted/embedding_sustainable_development_in_the_curric, Environmental Association for Universities \& Colleges (EAUC), (Accessed June 2014)

- Fellows, R. and Liu, A. (2003), Research Methods for construction students, 2nd edition, Oxford: Blackwell publishing 
- Hanover Research (2011), Embedding Sustainability into University Curricula, [Online], Academy Administration Practice, Available at: http://www.niu.edu/ese/images/attachments/Embedding\%20Sustainability\%20into\%20Univer sity\%20Curricula.pdf, (Accessed June 2014)

- Higher Education Funding Council for England (HEFCE) (2009), Sustainable development in higher education: Update to strategic statement and action plan. Available online from: http://www. hefce.ac.uk/pubs/hefce/2009/09_03/\#exec (Accessed June 2014)

- $\quad$ Longhurst, J. W. S., Bellingham, L., Cotton, D., Isaac, V., Kemp, S., Martin, S., Peters, C., Robertson, A., Ryan, A., Taylor, C. and Tilbury, D. (2014), Education for sustainable development: Guidance for UK higher education providers, Technical Report. QAA: Gloucester

- Martin, S and Jucker, R. (2005), Educating Earth-literate Leaders, Journal of Geography in Higher Education, Vol. 29 No. 2, pp.19-29

- Mackenzie, N. and Knipe, S. (2006), Research dilemmas: Paradigms, methods and methodology. Issues in Educational Research, 16(2) 193-205

- Murray, P., Brown, N. and Murray, S. (2007), Deconstructing Sustainability Literacy: The cornerstone of Education for Sustainability? The Role of Values, The International Journal of Environmental, Cultural, Economic and Social Sustainability, 2 (7), pp 83-92

- Onwuegbuzie, A. J. and Johnson, R. B. (2006), The validity issue in Mixed Research, Research in the schools, Vol. 13, No. 1, 48-63

- Opoku, A. and Ahmed, V. (2013), "Understanding Sustainability: A View from Organizational leadership within UK construction organizations", International Journal of Architecture, Engineering and Construction, Vol. 2 No.2, pp. 133-143

- Parkin S; Johnson A; Buckland H; White E; (2004) Learning and Skills for Sustainable Development: Developing a sustainability Literate Society, HEPS, London

- $\quad$ Rowe, D. (2002), Environmental Literacy and Sustainability as Core Requirements: Success Stories and Models; Teaching and Learning at Universities; Editor Peter Lang, New York

- UNESCO (2005), UN Decade of Education for Sustainable Development 2004-2014, [Online, available at: http://www.unesco.org/new/en/education/themes/leading-the-internationalagenda/education-for-sustainabledevelopment/, (Accessed June 2014) 


\title{
BUILDING REFURBISHMENT SITE MANAGERS' WASTE MANAGEMENT PRACTICES
}

\author{
Sezer, A. A ${ }^{1}$
}

\begin{abstract}
:
Waste management in refurbishment projects can be costly and harmful to the environment. Legislation on waste management sets limits, but the construction industry remains among the top contributors to waste generation. Well planned waste management can drive improvements in productivity and environmental sustainability. Site managers' waste management strategies might include reducing waste generation, reuse, recycling and disposal. The aim is to analyse the administrative and physical factors influencing refurbishment site managers' attitudes and behaviours towards waste management. Eight semi-structured interviews were held with site managers, two with project managers and two with environmental staff belonging to large contractors involved in housing and office refurbishment projects in Sweden. Waste management practices on refurbishment sites were found to differ. Influences on site managers arise at three organisational levels: top management (sustainability policies), local level (project budgets), and site level (physical factors including limited space). Disposal of waste is the last choice of most site managers given cost and company policies. Site managers devise waste management strategies based on environmental inventories and project size. In smaller projects, waste contractors are employed only for physical support and site managers have less flexibility due to limited physical space. Design-build procurement is viewed by site managers as more efficient for waste management; partnering is promoted for greener refurbishment projects. Client demand and company policy heavily influence practices. Unlike new construction, refurbishment clients seldom require green waste management to a higher standard than is typical of large contractors.
\end{abstract}

KEYWORDS: BUILDING, LARGE CONTRACTORS, REFURBISHMENT, SITE MANAGERS, WASTE MANAGEMENT

\section{INTRODUCTION}

Energy efficiency and increased indoor environmental quality are common client aims in recent refurbishment projects in Sweden. However, the construction industry is one of the top contributors to waste generation. Management of waste in the refurbishment process is important for contractors; if badly done, it is costly, harms the work environment and is less environmentally sustainable. Earlier studies have developed methods for quantification of waste and developed technologies to support waste management plans (Banias et al., 2011; Cheng and Ma, 2013). They focus on waste management methods, but there has been little interest in refurbishment site managers' views on waste management practices and influences. Refurbishment organisations are decentralised which gives refurbishment site managers flexibility and allows quick decisions to respond to the higher risks and uncertainties associated with the refurbishment works

\footnotetext{
1 Department of Technology Management and Economics, Chalmers University of Technology, Gothenburg, Sweden. Email: ahmeta@,chalmers.se
} 
(Egbu, 1999). Decentralisation thus means varieties in site managers' waste management practices and highlights the need for understanding site managers' practices.

This paper aims to analyse the administrative and physical factors influencing refurbishment site managers' attitudes and behaviours towards waste management. The study is based on a literature review and 12 semi-structured interviews in two large contractor organisations, mainly with refurbishment site managers.

The next section discusses the methods followed by the literature review and interview results. The paper concludes with a discussion and policy recommendations.

\section{Methods}

The paper is based on a literature review and semi-structured interviews. A review of the literature on waste management was conducted in order to formulate the survey questions. Two large Swedish contractors were chosen, involved in housing and office refurbishment projects and familiar with certification schemes such as BREEAM, LEED and the Sweden Green Building Council's Miljöbyggnad (Brown et al., 2013). Twelve semi-structured interviews were conducted with site managers (8), project managers (2) and environmental staff (2). The focus is on site managers and their practices since (regardless of the type of project) it is they who make the decisions at refurbishment sites. Project managers and environmental staff were interviewed to obtain views from other levels of these organisations on company policies and relationships with clients, subcontractors and waste logistics firms.

The initial interviewees were nominated by the representative of the companies and were asked to identify another potential interviewee based on the criteria of at least two years' experience in residential and commercial refurbishment projects, and location in southwest Sweden, experience of working in different sized projects. Requiring two years' experience would ensure that interviewees would have participated in at least one refurbishment project.

Interviews were conducted between February and June 2015. Interviewees were given a short text describing the research project and a list of interview questions at least 24 hours in advance. Interviews lasted for 30-60 minutes, were conducted in Swedish and taped. Interviews were face-to-face and except for one interview were conducted in the interviewee's office. Interviewees were promised anonymity. The interview guide began by asking about years of experience, occupation in the company and types and sizes of refurbishment projects. It comprised a mix of open-ended and closed questions, including questions about experiences from earlier projects, such as "What actions do you take on site to deal with waste?", "How do waste management practices differ on refurbishment sites compared to new construction?" and "Do you see a link between the contract type (traditional or design-build) and waste management practices on refurbishment sites?"

Interviews were first transcribed verbatim and then summarised for each question. Responses were categorised and relevant passages coded. The data were subjected to qualitative content analysis. 


\section{LITERATURE REVIEW}

Earlier studies of construction waste management are dominated by new construction, but there is also a small but growing number of studies in a refurbishment context.

Waste in new construction

The new construction literature focuses mainly on management of the waste generated rather than its reduction. Waste can be generated in several ways including bad materials handling practices, design changes and inaccurate documents (Fadiya et al., 2014). Construction industry solid waste includes concrete, metal, wood and hazardous chemicals. Wang et al. (2015) argue that a good multi-design strategy can reduce waste by $14 \%$ more than the sum of the strategies involved.

Site managers have a crucial role in construction projects. According to Styhre and Josephson (2006), the role of site managers has broadened due to adding administrative work activities to their production related activities. These administrative activities are due to head office requirements and force site managers to prioritise among different tasks. In their study of site operatives' behaviour towards waste management, Teo and Loosemore (2001) used the theory of planned behaviour, investigated attitudinal forces and concluded that operatives see waste as an inevitable by-product of construction activity and that its management is low priority. Lack of managerial commitment, facilities, resources and incentives inhibit waste management practices among supervisors, leading hands, tradesmen and labourers, it was found.

Many actors with different attitudes to waste management are involved in construction projects. Udawatta et al. (2015) study designers, clients, contractors, subcontractors and waste companies and argue that most construction industry decisions are based on financial returns rather than environmental considerations. Private clients in particular are thought to be more price-driven than public clients. There are no major incentives for contractors to implement waste management practices, and Udawatta et al. (2015) propose stricter legislation, whereas designers do include provisions for waste management if it is a special requirement, or is required to comply with a sustainable rating system. Osmani et al. (2008) argue that many architects ignore waste generation due to lack of financial rewards related to its inclusion, lack of client demand, and the belief that contractors are responsible for waste management.

The relation between designers and contractors is clearly influenced by the procurement path. Withana-Gamage (2011) argues that design-build systems encourage waste minimisation by early contractor involvement, competitive design at the tendering stage, ability to work with a wholly integrated supply chain from the beginning, fixed contract sums and minimum flexibility for variations. Design-build based to a considerable extent on client-provided design will exclude early contractor involvement, involves incomplete concept design, tight tender process, poor communication and relationships between concept design team and design-build contractors and therefore generates more waste, according to Withana-Gamage (2011). 


\section{WASTE IN REFURBISHMENT PROJECTS}

There are only a few earlier studies concentrating on managing waste in refurbishment. Small packages of refurbishment projects are carried out by subcontractors, often SMEs (small and medium enterprises). In a study of office refurbishment projects, Li (2012) identifies limited site space and uncertain project nature as problems for SMEs and points to their lacking awareness and capabilities and their need for financial and technical support to plan waste management. Recycling in office refurbishment sites does not reach its full potential due to the existence of asbestos in the building, continued occupation of the building by users and the splitting of large projects into small sub-projects (Hardie et al., 2011).

Quantification and estimation of waste is crucial in the early project stage to enable planned waste management activities. Cheng and Ma (2013) developed a BIM (building information modelling) based system, and DeconRCM (Banias et al., 2011) is a webbased decision support system enabling optimal management of building demolition and renovation waste based on information on the building including construction year, dimensions and type of heating to estimate the quantity of waste.

Li and Yang (2014) discuss factors influencing waste management practices for top level decision makers and site practitioners. Strategic factors related to job delivery and waste management processes such as lack of knowledge, training in waste minimisation, small packages of work undertaken by subcontractors and problems discovered during the project are the most important factors for top level decision makers, while last minute changes demanded by the client and incomplete or inaccurate contract documents have to be dealt with by site managers.

Clients often appear to be involved more in refurbishment projects than in new construction. More recent versions of client oriented building certification schemes such as BREEAM Refurbishment Domestic Buildings and LEED for New Construction and Major Renovations include waste management during refurbishment. Client reliance on such certification schemes may not only influence contractors waste management performance but also encourage architects to involve waste management in earlier phases of refurbishment projects (cf. Moore, 2013). Collaboration between client and contractor is an important issue, and therefore design-build contracts are better suited to refurbishment projects (Ali, 2010).

Earlier studies suggest that refurbishment site managers' attitudes and behaviours towards waste management are influenced by factors at different levels, including incentives, clients, subcontractors, designers, procurement type, use of sustainability rating systems, legislation and available site space. 


\section{RESULTS}

The waste management activities on refurbishment sites include waste reduction, reuse, recycling, and disposal. In refurbishment projects, waste is generated by demolition and bad ordering and processing. Compared to new construction, refurbishment contractors are more likely to encounter hazardous substances. According to the interviewees, before a project starts, an environmental inventory is conducted to identify the quantity and type of waste expected. Based on the inventory and the size of the project, site managers meet with a waste contractor to discuss waste management including number of containers and their location on site. At most refurbishment sites, waste is sorted into two or more containers, or so-called big bags, depending on the space available. The containers or bags are collected by the waste contractor for recycling. Gypsum, wood, metal, concrete and combustibles are the most frequent materials. Hazardous substances, such as asbestos and PCB, have to be removed by special subcontractors and receipts filed for legal reasons. Removal of hazardous materials is the first activity in a refurbishment project to preserve on-site safety.

\section{Refurbishment phase}

\section{Site level influences on waste management}

Interviewees identified a set of influences at the site level. Limited physical space within and around the building due to occupation in adjacent buildings, bicycle and car parks were frequently cited by site managers along with problems related to separating aggregate materials, lack of specially adapted containers for different types of waste, absence of clear labelling and materials such as gypsum becoming heavier and thus their disposal costing more if they are not sheltered from rain. Ensuring good logistics for removing old materials and receiving new ones and ensuring a good work environment for refurbishment workers and tenants by reducing dust and keeping the work environment clean and tidy to avoid any accidents, were highlighted as important.

Reducing waste was considered difficult since the quantity of waste from a demolition activity cannot be changed. However, four interviewees felt that more accurate ordering of new building materials and use of prefabricated materials would reduce waste generation and release space on site. Excessive packaging by logistic companies and materials producers was considered a source of waste.

Refurbishment usually involves replacing old materials with new ones which inhibits reuse of materials on site. Also, reuse is considered time consuming, expensive and in the case of old residential buildings built using cheap, low quality materials, it is not an attractive option. An interviewee said they tried to reduce the extent of demolition by repairing a wall or moving it rather than completely replacing it.

Services from waste contractors include physical help and advice. The contractors interviewed had price arrangements with waste contractors, providing site managers with financial incentives. Site managers rent waste containers and bags from the waste contractors who regularly collect or empty them. In the case of large projects, the waste 
contractor will meet the site manager to agree the number of containers and their location on site and offer advice about the removal of waste from the building based on the space available for sorting, the size of the project, and the quantity and type of waste. Planning of on-site traffic to unload containers is important also from a safety perspective. In smaller projects, waste contractor services are limited to physical removal of the sorted waste.

Subcontractors have varying responsibilities. The rules are stricter for demolition subcontractors because of the larger quantities of waste and possibility of hazardous substances such as asbestos. Demolition subcontractors, unlike electricians, ventilation and insulation subcontractors, use their own containers to sort their waste. Site managers generally were unhappy about subcontractors' waste management performance. According to an interviewee, a waste contractor told him that they discovered cardboard in the concrete container, which meant that the container was reclassified as a mixed load and cost much more to dispose of. The site manager felt that this was due to one of the subcontractors. Site managers check the demolition subcontractors' receipts for the quantity of waste, how it was handled, and in particular how hazardous substances were handled. These receipts have to be filed for legal reasons. Some subcontractor waste practices were difficult to monitor since they used the same containers as the main contractor. Two site managers were strict and imposed financial penalties for bad sorting of waste. One site manager however said that it is difficult to apply penalties: "...it also happens to be a theoretical bit coming from back office and then you are supposed to put that into practice in the workplace, that isn't easy because ... are you creating enemies, you get an incredibly bad cohesion and a poor working atmosphere". Site managers try to inform subcontractors about the costs and consequences of bad waste sorting.

\section{Local level influences}

Project location (city centre or not), project size, project type, time and cost were cited as influences by site managers. City centre projects involve measures such as working at night to avoid disruption to traffic, applying for access and exit permits, getting permission for placing a combustible waste container (at least six metres away from a building). One site manager noted that waste containers in city centre projects were abused by members of the public.

According to interviewees, waste management is lower priority in smaller project and less time is devoted to sorting because of smaller quantities of waste and the relative cost of sorting. The type of waste can be estimated based on the type of project - e.g. whether it is housing built in the 1970s, or a sports hall. Site managers stated that they were under time pressures for refurbishment projects to be completed quickly, which means a risk that less time is devoted to waste management. Most site managers agreed that waste could be costly if managed badly.

\section{Top level influences}

Company policy, client demand and legislation were cited as the main factors affecting site managers' waste management practices. Site managers generally acknowledged the importance of the company's environmental goals, standards and guidelines, ISO 
standards and municipalities with different requirements. It seems that company policy is well developed and based on legislation. Half of the site managers found the company policy easy to apply since it was aimed at reducing the amount of waste sent to disposal; others argued that each project involved different problems such as location and lack of physical space which made it difficult to comply with company policy. Interviewees from one of the contractors said that project environmental performance was recorded on a colour scale ranging from dark green, to green and to beige. Waste management goals get stricter when moving to dark green from beige. The environmental specialist from the same contractor said that refurbishment projects were less prestigious than new office construction explaining why almost all refurbishment projects were beige. Government regulation of waste management was considered very strict, and therefore was an important factor for the group of site managers. In refurbishment projects, the client is more closely involved and might have higher waste management goals than required by either the legislation or company policy. In these cases, site managers comply with the client's requirements.

There are site managers who stress that support for their waste management is largely informal, including guidelines, company policy, company intranet, company external web pages, the company's purchasing system, company goals, municipal web pages, and internal e-mails. A few site managers said they are supported by a work environment engineer, an environmental specialist, quality-environment-work environment staff and in large projects a project engineer. However, in the case of smaller projects they only received basic administrative support. Environmental specialists said that their support of site managers was limited to providing documentation and reminders about environmental inventories before the start of a project.

\section{Design phase}

Client requirements can play a large part in improving waste management efforts. Site managers mentioned that today's clients are more aware and have higher environmental requirements, and that public clients such as municipalities and central and regional authorities require more than private clients. However, a project manager said: "...the client demanded that I should have various plans and so I produced a moisture safety plan, a quality plan, an environmental plan, a work environment plan, a demolition plan; the only one they approved immediately without problems was "Yes environmental plan is approved!" it didn't matter much, and for the other four "Yes, but that and that and that!", which in his view, showed the client's lack of interest in sustainability issues.

Environmental specialists acknowledged the importance of client demand but added that refurbishment clients were focused on keeping costs down and do not favour green projects. One of the environmental specialists highlighted that communicating with clients can be difficult if the client has no experience of an environmental inventory. Nevertheless, some calls for tenders require the contractor to submit documentation on quantities and types of waste sent to disposal. 
Views on procurement types, design-build or design-bid-build, and their effects on waste management differed significantly. Five site managers claimed that there is no difference, and they aim for high levels of sorting and recycling regardless of procurement type. Others maintain that waste management performance is better in design-build compared to design-bid-build because the client is more involved in the latter case, and then sometimes directly purchases materials to be used on site, or provides detailed drawings and conducts an environmental inventory, giving site managers less flexibility to make decisions. One of the site managers preferred the client to provide detailed demolition plans and an environmental inventory because it reduced uncertainties. In design-build contracts, site managers have more flexibility and can choose replacement materials that are produced locally and are more sustainable, or choose insulation materials that can be recycled. In design-build, decisions are based mainly on company policy and legislation. In the case of unexpected discoveries that imply refurbishment design changes, contractors are responsible. The two environmental specialists, as well as one of the site managers and one of the project managers considered partnering a good alternative to achieve greener projects and cost related concerns.

It is common for the building involved in a refurbishment project to have undergone previous refurbishment which often has not been well documented including the quality and quantities of the materials used. Site managers believe that waste management is a practical issue and can be managed only during the refurbishment phase, and rejected the idea that architects' and consultants' involvement in earlier phases might reduce waste generation. One interviewee thus felt that greater involvement in the early project phase of architects and consultants in waste management would not help: "I do not think those who do the design think much about waste management. [...] Because it is usually a practical thing that the site manager will take care of. Our consultants do not work with it, because it's probably only site managers doing that".

\section{DISCUSSION AND CONCLUSIONS}

The sustainability imperative requires firms to develop their strategies, visions, value propositions and performance measures (Lubin and Esty, 2010). Firms will soon understand what it means to manage sustainability as a megatrend, linking negative environmental impact to financial terms, to sustain or improve their market position. Resource efficiency, reducing waste generation and managing generated waste are obvious sustainability activities, which reduce environmental impact as well as costs.

Construction and demolition waste management thus involves reducing waste generation, reusing, recycling and disposal. Reducing waste generation at refurbishment sites is thought to be difficult and according to site managers is made possible by correct ordering of new materials, using prefabricated materials and avoiding excessive packaging. Site managers' general view was that waste is generated due to demolition activities and therefore they failed to recognize waste generated during production. According to Fadiya et al. (2014), sources of waste are procurement (ordering excessive materials), changes to design, material handling, rework (wrong installation and 
removal), weather, vandalism and misplacement. Except for late design changes, sources of waste can be influenced by site managers. Although site managers claimed that they prioritised reuse of old materials, most ongoing refurbishment projects in Sweden are aimed at improving energy performance in buildings built between the 1960s and 1980s, which requires use of new materials. The opportunities for reuse and reduction are limited.

Most influences cited by the site managers are related to each other. Quantity of waste and time pressure depend on the size of the project. Size of the project determines the level of services that will be bought from the waste contractor. Waste contractors mainly engage in waste sorting and recycling activities on refurbishment sites. They use environmental inventories and information about the available space on site when suggesting the number of containers and their location on site. Simple practical issues including lack of specially adapted containers for different types of waste, absence of clear labelling on containers, materials such as gypsum becoming heavier and thus their disposal costing more if they are not sheltered from rain, and difficulties of separating aggregate materials could be solved with support from waste contractors or from someone in the organisation such as a designated internal consultant. It seems that more waste is sorted in large projects since the larger quantities of waste make this more feasible and financially rewarding.

Most interviewees considered clients to have more involvement in refurbishment projects compared to new construction. Public clients are considered to be more demanding, but also usually more experienced and clearer about their demands, which facilitates waste management. Findings support the claim by Udawatta et al. (2015) that private clients are more price-driven than public clients and less concerned about the environment. Views varied about type of procurement, some referred to reduced flexibility in design-bid-build procurement due to the high involvement of the client while, as Withana-Gamage (2011) has suggested, design-build contracts empowered site managers to employ their company policies more fully, allowing reduced waste generation and good management of waste. Partnering with clients was seen as an advantage by project managers and environmental specialists in the case of green projects, suggesting that in these projects, clients are less cost driven.

Although site managers here did not believe that designers could reduce waste, it is probable that there is a potential for improving waste management by creating stronger links between refurbishment design and site operations, as proposed by Osmani et al. (2008).

Subcontractors other than demolition subcontractors are considered by the interviewees to have bad waste management performance, which clearly influences the main contractor. Subcontractors do not consider that there are benefits from improving waste management performance $(\mathrm{Li}, 2012)$. Monetary penalties imposed on subcontractors are believed to have a negative effect on the work atmosphere. Main contractors could encourage better waste management by subcontractors through provision of clear 
incentives, demonstration of the cost consequences and including good waste management as a selection criterion for subcontractors.

The case contractors are large, decentralised organisations, and site managers indicated a gap between the management and the sites, confirming Li and Yang's (2014) findings. For site managers it is crucial to have full control and authority over a construction project (Styhre and Josephson, 2010). This clearly explains the different practices of site managers belonging to the same organisation.

Company policies in the two organisations generally recommend reducing the quantity of waste sent to disposal. These policies could be stricter and should take account of refurbishment projects and different sized projects, as when BREEAM Refurbishment Domestic Buildings (BRE, 2014) splits projects into three size categories with different waste management standards and measures.

Greater use of technologies for quantifying and managing waste has been proposed by researchers. None of the site managers mentioned using IT to manage waste, suggesting that they still use traditional methods. However, technical consultants could use more technology to estimate quantities and types of waste during environmental inventories, and many waste contractors have software to facilitate planning. Since cost reduction is an important project incentive, these softwares should include cost comparisons for different waste management strategies and clearly show profits that can be gained. Considering only the responses from the interviewees, factors that influence site managers' waste management behaviour are unlikely to be reduced by utilisation of IT tools.

Collaboration between site managers and waste logistics firms, and developing specific methods for refurbishment projects of different sizes should be useful to reduce waste and facilitate sorting. Large refurbishment projects with no space limitations and located outside city centres, clear but not too specific client demands, design-build procurement and waste conscious subcontractors are the best conditions for improving waste management efforts by site managers. Reducing the gap between refurbishment sites and offices might be beneficial while standard approaches to waste management may fail to respect the heterogeneous nature and needs of projects. Waste management should be included among the performance criteria for refurbishment projects, be monitored and rewarded. Policies and guidelines in large contractors should be developed for projects in different sizes, considering that scale affects important factors influencing site managers' waste strategies.

\section{REFERENCES}

- ALI, A.-S. (2010) Design information in managing refurbishment projects in Malaysia. International Journal of the Physical Sciences, 5(6), pp.768-773.

- BANiAS, G., ACHillas, C., VlaCHOKOSTAS, C., MOUSSIOPOUlOS, N. and PAPAIOANNOU, I. (2011) A web-based Decision Support System for the optimal 
management of construction and demolition waste. Waste Management, 31(12), pp.24972502.

- BRE (2014) BREEAM Refurbishment Domestic Buildings. [Online] Available from: http://www.breeam.org/domrefurbmanual/ [Accessed: 31 July 2015].

- BROWN, N. W., MALMQVIST, T., BAI, W. and MOLINARI, M. (2013) Sustainability assessment of renovation packages for increased energy efficiency for multi-family buildings in Sweden. Building and Environment, 61, pp.140-148.

- CHENG, J. C. P. and MA, L. Y. H. (2013) A BIM-based system for demolition and renovation waste estimation and planning. Waste Management, 33(6), pp.1539-1551.

- EGBU, C. O. (1999) Skills, knowledge and competencies for managing construction refurbishment works. Construction Management and Economics, 17(1), pp.29-43.

- FADIYA, O. O., GEORGAKIS, P. and CHINYIO, E. (2014) Quantitative Analysis of the Sources of Construction Waste. Journal of Construction Engineering, doi:10.1155/2014/651060.

- HARDIE, M., MILlER, G. and KHAN, S. (2011) Waste minimisation in office refurbishment projects: an Australian perspective. Open Waste Management Journal, 4, pp.21-27.

- LI, M. (2012) A waste management system for small and medium enterprises engaged in office building retrofit projects. $\mathrm{PhD}$ thesis presented at the School of Civil Engineering and Built Environment, Queensland University of Technology, Brisbane.

- LI, M. and YANG, J. (2014) Critical factors for waste management in office building retrofit projects in Australia. Resources, Conservation and Recycling, 93, pp.85-98.

- LUBIN, D. A. and ESTY, D. C. (2010) The sustainability imperative. Harvard Business Review, 88(5), pp.42-50.

- MOORE, J. (2013) Renovation/Expansion of Administration Building Offers Successful Paradigm for Integrated Planning and Collaborative Design. Planning for Higher Education, 41(4), pp.126-131.

- OSMANI, M., GLASS, J. and PRICE, A. D. (2008) Architects' perspectives on construction waste reduction by design. Waste Management, 28(7), pp.1147-1158.

- STYHRE, A. and JOSEPHSON, P. E. (2006) Revisiting site manager work: stuck in the middle? Construction Management and Economics, 24(5), pp.521-528.

- TEO, M. M. M. and LOOSEMORE, M. (2001) A theory of waste behaviour in the construction industry. Construction Management and Economics, 19(7), pp.741-751.

- UdAWATTA, N., ZUO, J., CHIVERAlLS, K. and ZILlANTE, G. (2015) Attitudinal and behavioural approaches to improving waste management on construction projects in Australia: benefits and limitations. International Journal of Construction Management, 15(2), pp.137-147.

- WANG, J., LI, Z. and TAM, V. W. Y. (2015) Identifying best design strategies for construction waste minimization. Journal of Cleaner Production, 92(1), pp.237-247.

- WITHANA-GAMAGE, I. S. 2011. A waste minimisation framework for the procurement of design and build construction projects. $\mathrm{PhD}$ thesis presented at the Dept of Civil and Building Engineering, Loughborough University, Loughborough. 


\title{
CHALLENGES OF BIM IMPLEMENTATION IN SUSTAINABLE RESIDENTIAL PROJECTS IN THE UK AND FUTURE PERSPECTIVE
}

\author{
Silverio K. A. ; Suresh S.; Renukappa S. and Eason M.
}

\begin{abstract}
:
Globally, there is a concern about the environmental damages caused by human's activities, especially from the construction industry. Sustainable construction is becoming more demanding in order to diminish these impacts. However, the tendency is more focused on large-scale projects, mostly commercial, rather than residential buildings, which have been acknowledged to cause more environmental impacts than any other type of building, mainly during its life cycle. The UK government has expressed its interest in building more sustainable residential buildings through the creation of standards and policies. Along with sustainable construction, the implementation of BIM in the construction field is increasing worldwide. Due to the advantages offered by BIM, its implementation is considered important in the development of sustainable projects. The UK is known as a BIM leader country, having set a deadline to implement level 2 of BIM in public projects by 2016. This context suggests the possibility of implementing BIM in sustainable residential projects. This paper aims to investigate the current implementation of BIM in sustainable residential projects in the UK; analyse its challenges, which were several and significant; and give a perspective of how its implementation is likely to be in the future. The methodology proposed includes a literature review and the analysis of four sustainable residential projects developed with BIM in the UK, Finland, and the USA, which were selected from different countries due to the difficulties of finding good examples of these type of projects in the UK. The results suggested that there is still an immature knowledge of BIM implementation for sustainable residential buildings not only in the UK, but worldwide. This research may be beneficial to any professional of the construction who has worked or is interested in BIM implementation and sustainable construction.
\end{abstract}

KEYWORDS: BIM, RESIDENTIAL BUILDINGS, SUSTAINABILITY, UK GOVERNMENT, ZERO CARBON HOMES

\section{INTRODUCTION}

Commercial and residential buildings in the UK are responsible of almost $50 \%$ of the carbon dioxide emissions which mostly come from heating and their operation. Additionally, it is estimated that three million of houses will be built by 2020 . Due to the government's purpose of reducing to an $80 \%$ the emissions of carbon, it has become really important to guarantee that, both, new and already built homes meet the sustainable requirements necessary to diminish the climate changes and adapt to the changing climate (Seyfang, 2010). In another context, the UK government, through the document "Construction 2025", has set out its vision to position the UK at the vanguard of the global construction in the coming years. Among the commitments of this strategy are included the topics of sustainable design and BIM implementation. The government states that there will be a big demand to enhance the energy performance of the existing

\footnotetext{
${ }^{1}$ University of Wolverhampton, s.subashini@wlv.ac.uk
} 
building stock. In order to give to the industry enough confidence to get involved in these innovative markets, it is considered a must to build a low-carbon construction industry and promote with more clarity and certainty the emerging sustainable and low-carbon construction practices. As to BIM implementation, it is exposed that the BIM strategy has had a good start and that the industry must meet the target to implement BIM in all centrally procured Government contracts from 2016. It is considered that only with the implementation of BIM will be possible to develop more sustainable buildings, in less time and with more efficiency. Moreover, BIM is seen as crucial in the development of offsite manufacturing (HM Government, 2013).

The government has the urge to develop a more sustainable housing stock and has proposed BIM as a method to build more sustainably. However, is it the UK residential sector focusing on sustainable construction? And, moreover, are they currently implementing BIM for these purposes?

\section{LITERATURE REVIEW}

\section{BIM implementation}

BIM is a combination of technologies, communications, methods and procedures which connect together in order to create a plan that can be used to supervise digitally the most important aspects about the design of a project as well as the information related to it during the building's life-cycle (Succar, 2009).

The benefits of BIM in the construction industry have been exposed by many authors and proved in numerous real-life projects. Eastman et al. (2008) give an explanation that covers very well the benefits of implementing BIM in every phase of the construction process: Preconstruction benefits to the owner: Conceptualisation, feasibility and design of the project; the increment of the building quality and performance; the enhancement of the collaboration between designer and client thanks to the implementation of Integrated Project Delivery for project procurement. Design benefits: Precise and early visualisations of the design; automatic corrections in the design process; production of precise and logical 2D drawings at any phase of the design process; collaborative work with other disciplines at the early stages of the process; easy confirmation of the uniformity of the design; cost estimations in the design stage; energy efficiency and sustainability. Construction and manufacturing advantages: Usage of the design model for fabrication of elements; fast solutions in case of design changes; detections of any design mistakes and omissions before the construction phase; coordination between the design and construction strategy; more successful incorporation of lean construction practices; coordination of the design and construction with the procurement of the project. Post construction benefits: Enhancement in the commissioning and delivery of the project's facilities; improved administration and performance of the facilities; unification of the project (model) with facility operation and management procedures. On the other hand, the literature also indicates that there are multiple challenges in the implementation of BIM. Arayici et. al (2011) identified some aspects that hinder BIM 
adoption which include change the position some people have about BIM adoption and make them realise how important BIM and the advantages it offers compared to 2D drafting; adjust the current workflows to lean architecture and construction systems; instruct people to use BIM and get a project team with the skills to manage and comprehend how BIM works; the comprehension of all the conditions needed in order to manage proficiently BIM applications and tools, such as high-end hardware resources and networking facilities; unification, cooperation and interoperability among the MEP (Mechanical, electrical and plumbing) and structural designers/engineers; and the comprehension from the construction lawyers and insurers about all the responsibilities that the stakeholders have in this new way of work. Moreover, Khosrowshahi and Arayici (2012) mention other important challenges such as the high costs that implies the investment in hardware, software and training and the lack of demand of projects developed with BIM.

Regarding sustainability, Kriegel and Nies (2008) identify that BIM can help in different sustainable aspects of a project, which comprehend the orientation of the project thanks to its modelling properties; building massing, to examine the building shape and its surroundings in order to optimise the building envelope; daylighting evaluation; water harvesting, to decrease the need of water in a building; energy modelling, to decrease the costs and minimise the use of energy by the exploring possible ways to use renewable energy; sustainable materials, which helps to reduce the need of materials by the use of recycled materials; and site and planning management for the reduction of waste and carbon footprints. Despite all these benefits, BSI (2010) reported that the sustainable aspects of BIM are underused. It is cited the 2009 McGraw-Hill survey taken place in the US in 2009 , where only $15 \%$ of the BIM users were getting the best performance of energy analysis in BIM.

\section{BIM OUTLOOK IN THE UK}

The UK government has been an important driver of the implementation of BIM. The Cabinet Office of the United Kingdom issued a document in 2011 called The Government Industry Strategy whose aim is to decrease the cost of the activities involved in the construction process up to a $20 \%$ by 2016 . A condition specified in this document is the usage of Building Information Modelling for projects whose budget exceeds the 5 million pounds (Ngo, 2012). In this document is also stated the government's plan of implementing collaborative 3D BIM (BIM Level 2) on projects from the central government department by 2016 (NBS, 2012). 
Figure 17 Awareness and BIM adoption in the UK, (NBS, 2015).

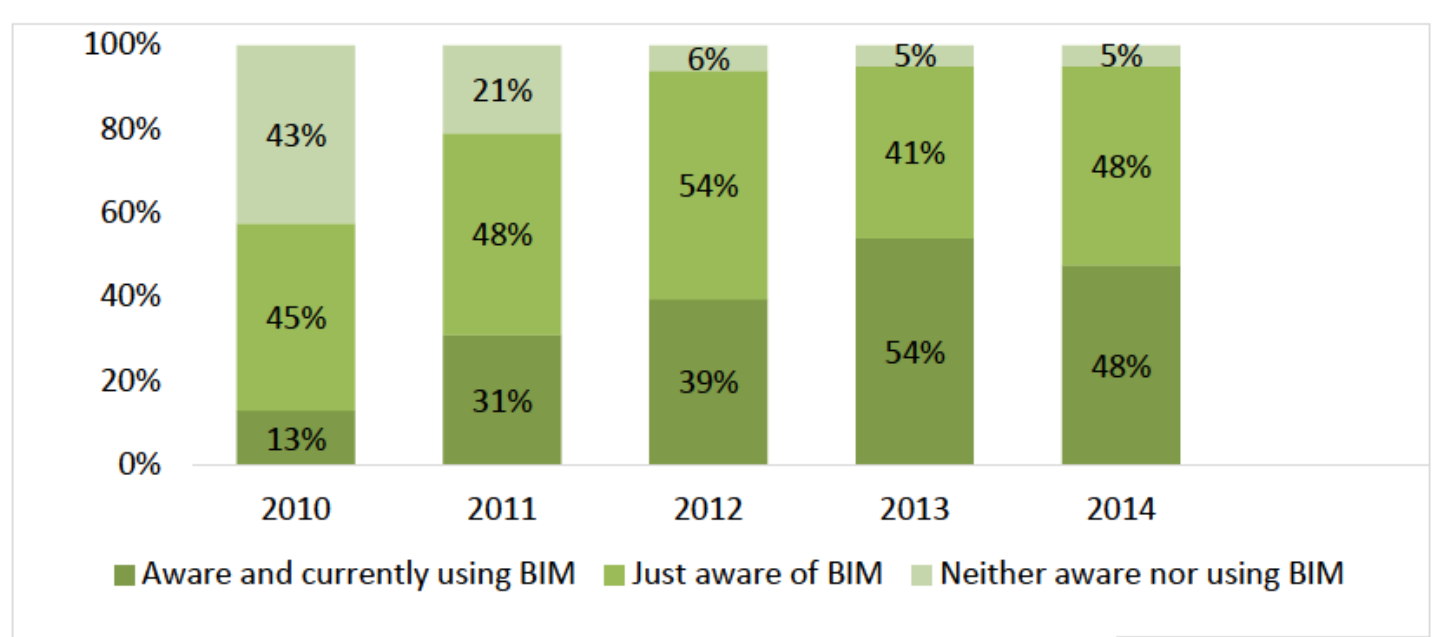

Regarding BIM awareness and adoption, the last National BIM report presents a significant increase since 2010 (See figure 1). However there was registered a small decrease of its implementation in 2014. Despite these results, the report considers that $\mathrm{BIM}$ adoption in the UK is still increasing and it will grow faster in the last years (NBS, 2015). In contrast, it has been identified that BIM is not widely implemented in the residential sector in the UK. According to the report of the NHBC Foundation (2013), only an $11 \%$ of house builders were using BIM by 2013 and a $24 \%$ did not have any knowledge about BIM. A 64\% were aware of BIM but were not implementing it.

\section{SUSTAINABILITY OUTLOOK IN THE UK'S RESIDENTIAL SECTOR}

Residential buildings are considered as the major contributors of $\mathrm{CO} 2$ emissions in the UK. In 2005 was reported that $27 \%$ of these emissions (about 150 million tonnes yearly) were related to the operation, heating and lighting of domestic buildings (Seyfang, 2010). Furthermore, Palmer et al. (2013) presented, in a study about the energy performance of different sectors in the UK, that the residential sector was the highest energy consumer of the UK by 2012 with an energy consumption value of $502 \mathrm{TWh}$, surpassing road transport (459 TWh), industry (293 TWh), commercial and public administration (197 TWh) and air transport (144 TWh).

Facing that situation, the UK Government created the Zero Carbon Home Policy in which was demanded new homes to be Zero Carbon from 2016, following the specifications of a standard named Code for Sustainable Homes (Lester, 2013). However, in the document "Fixing the foundations: creating a more prosperous nation", published the 10th of July, the government announced the cancelation of this scheme (Oldfield, 2015). Several environmentalists and house builders have reacted against this decision, mainly alleging the confidence it gave to the industry as to energy efficiency and low-carbon solutions 
(UK-GBC, 2015). Nevertheless, this end was expected to happen due to aspects related to its general acceptance in the construction industry and effectiveness. According to Graham (2014) Zero Carbon Homes plan received many critics from house builders who considered this goal would imply higher costs in the residential building sector affecting, specially, small builders. Regarding is effectiveness, the target of the scheme did not include the existing housing stock, which is very important in the government's goal of reducing carbon emissions: "There's slow progress in the construction sector in tackling the carbon agenda. We are starting to address matters in the new build housing market, but the commercial sector is faced with a confusing non-mandatory code. The focus is also on the new build market, rather than the existing stock - which is where the real issue is" (Hammerson, in GVA, 2011, p.3). The CIOB (2013) states that 50\% of the UK dwellings are 50 years old and a $5 \%$ are more than 100 years old. The process of renovating or modernising, which is undertaken approximately every 20 and 30 years of a building lifecycle, helps significantly in the objective of reducing the emissions of carbon produced by the building. According to Boardman (2007) new homes within the domestic construction sector are not a significant element due to the turnover's slowness. Despite the advancements achieved in the construction sector, they will represent from a quarter to a third part of the building stock by 2050. Even though they can be considered as a solution when the old ones are demolished due to inefficiencies, a new building implies more carbon emissions, while refurbishment is a saving.

\section{METHODOLOGY}

The research technique applied in this research was the analysis of case studies. As several case studies were required, it was implemented a type of collective/multiple case studies named case study of "structured, focused comparison", which is defined by George and Bennett (2005, p.67) as follows: "The method is "structured" in that the researcher writes general questions that reflect the research objective and that these questions are asked of each case under study to guide and standardize data collection, thereby making systematic comparison and cumulation of the findings of the cases possible. The method is "focused" in that it deals only with certain aspects of the historical cases examined". It was first intended to search and analyse case studies exclusively from the UK, however, there were some obstacles in finding case studies of this type of projects. Due to these difficulties, the research had to change, expanding its scope and including case studies from overseas. This decision did not interfere with the purposes of this study, otherwise it made possible to give another perspective to the investigation. The inclusion of international case studies helped to attain the following aspects: a perception of the status of the UK compared to other BIM leader countries in regard the implementation of BIM in sustainable residential projects; analyse every case and make comparisons among them in order to see which of these projects implemented BIM more successfully; and, depending on the results of every case, give recommendations to the UK construction sector on how to address the issues encountered in the research.

Table 9 Variables and weighting of the performance matrix 
SUSTAINABLE CATEGORIES $\quad$ Weight

Mandatories: Energy and CO2 emissions, Water, Materials, Surface Water 2

Run-off, Waste and Health, and Wellbeing

Flexibles: Pollution, management and ecology

BIM IMPLEMENTATION

Fully implemented (including facilities and life cycle management) 4

Implementation in the design and construction phase with all the parties 3 involved

Implementation in the design and pre-construction phase. Eg. Mechanical, 2 electrical and plumbing services (MPE)

Implementation in the design process

The analysis of the cases studies was divided into two phases. The first phase consisted in answering the general questions as part of the case study of "structured, focused comparison". A total of 6 general questions were formulated: 1. How BIM was implemented in this project? 2. Which environmental sustainable benefits were obtained with the implementation of BIM? 3. Were there any other environmental sustainable benefits not intrinsically related to BIM? If yes, which ones? 4. Which other benefits could be obtained with the implementation of BIM? 5. Did the project follow any sustainable standard? If yes, which one? Was the implementation of BIM useful to comply with the standard(s)? 6. Has the project been assessed for any sustainable assessment tool? If yes, which ones? Did BIM help in the assessment process? The second phase of the data analysis consisted in a performance matrix where two aspects, the implementation of BIM and the sustainable benefits related to its implementation, were measured in every project. For this analysis, the variables to be weighted in these two aspects were identified (See table 1). Regarding BIM, the variables comprehended different levels of BIM implementation, which are described in table 1 along with their weight. On the other hand, the sustainable variables were the sustainable features contained in the Code for Sustainable Homes $(\mathrm{CSH})$, which are divided into two sections: mandatories and flexibles (BREEAM, 2014). The maximum weight of " 2 " was assigned to the mandatories and the minimum " 1 " to the flexible, indicating that the first are more significant than the latter. After checking the variables in every project, the variables of BIM were multiplied with the total sum of the variables of the sustainable features, giving a value to the project. It should be noted that in every project were only checked the variables that could be identified according to the information gathered. None assumptions were taken. 


\section{CASE STUDIES}

For the case studies search, an investigation of BIM implementation around the world was undertaken. In this manner, the most influent countries in BIM were identified (USA, Finland, Norway, Sweden, Denmark, Germany, Singapore, South Korea, United Arab Emirates, Australia) and the case studies were specifically searched in these countries. In total, eight cases studies were found: two from the UK, five from the United States, one from Finland and another one from Sweden.

These cases were reviewed with the questions formulated in the first data analysis and the ones that could give most significant information were selected. The selection comprised four projects: 1. UK: A pair of 3-Storey Victorian terraces, Liverpool (refurbishment) 2. USA: Loblolly House, Taylor's island, Maryland (new-built) 3. USA: Ross Street house, Madison, Wisconsin (new-built) 4. Finland: Härmälänranta neighborhood, Tampere (combination of new-built and regeneration of an urban area, compound by residential buildings).

\section{FINDINGS}

First of all, through the analysis it was noticed that most of the projects were not implementing BIM as a working process. This confirms that there is still a misunderstanding of what BIM is. In the case studies, some of the developers considered and presented their projects as a "BIM product". However, BIM was actually implemented in specific tasks. For instance, in the neighborhood Härmälänranta is only specified that BIM was used for the carbon footprinting estimation of the residential buildings. There is not a description of BIM being implemented as a process. Secondly, it could be noted that the implementation of BIM with sustainable purposes is translated to the use of a software rather than a process: e.g., "thanks to ArchiCAD", "With the use of Revit", "With the model" etc. Furthermore, the underuse of sustainable aspects of BIM was evident in one of the projects analysed: Härmälänrant, where many sustainable aspects were accomplished, but the implementation of BIM was limited. The project was developed in two phases and a BIM model was only used to measure the carbon footprinting of the first phase and to conduct a LCC (Life Cycle Costing) analysis for the energy efficiency of the second phase. In contrast, the sustainable benefits obtained without BIM were more in quantity (See figure 2).

Due to the general concern about energy efficiency, projects' developers tend to centre their attention in energy performance when developing a sustainable project, although this is not the only feature to take into account in a sustainable building. In most sustainable projects, not only residential, the implementation of BIM is translated to the use of energy analysis tools/software implemented in the early stages of the design process. This could be exemplified in the case study of the pair of 3-storey houses were the only sustainable benefits that could be attained were related to energy efficiency. There was not attempted any other sustainable approach in this project. 
On the other hand, the project of Ross Street House showed how beneficial can be the implementation of BIM in the sustainable assessment with rating systems. This house had several sustainable benefits thanks to the use of BIM: daylighting and ventilation; energy efficiency; and ecology, which helped them significantly to achieve 102 LEED points and get a Home Platinum Certification.

Figure 18 Summary of the general questions of each case study

\begin{tabular}{|c|c|c|c|c|c|c|}
\hline Project & Question 1 & Question 2 & Question 3 & Question 4 & Question 5 & Question 6 \\
\hline 1 & $\begin{array}{l}\text { 1. Conceptualisation; } \\
\text { 2. Later phases of the } \\
\text { design process; } \\
\text { 3. Energy analysis; } \\
\text { 4. Design of plumbing } \\
\text { runs with the heating } \\
\text { engineer; } \\
5 \text {. Collaborative work } \\
\text { among the different } \\
\text { parties of the team } \\
\text { by sharing } \\
\text { information about the } \\
\text { project. }\end{array}$ & $\begin{array}{l}\text { 1. Building's } \\
\text { orientation. } \\
2 \text {. Energy } \\
\text { efficiency }\end{array}$ & 1. Not specified & $\begin{array}{l}\text { 1. Communication; } \\
\text { 2. Coordination; } \\
\text { 3. Collaborative } \\
\text { work; } \\
\text { 4. Clash detection; } \\
\text { 5. Cost } \\
\text { management }\end{array}$ & $\begin{array}{l}\text { The Standard } \\
\text { Assessment } \\
\text { Procedure } \\
\text { (SAP) }\end{array}$ & Not specified \\
\hline 2 & $\begin{array}{l}\text { 1. Early stages of the } \\
\text { design process: } \\
\text { design every element } \\
\text { of the house } \\
\text { accurately and the } \\
\text { coordination among } \\
\text { them. } \\
\text { 2. The procurement } \\
\text { of materials; } \\
3 \text {. Prefabrication } \\
\text { process of the house's } \\
\text { elements; } \\
4 \text {. Collaborative work } \\
\text { among the different } \\
\text { parties of the team } \\
\text { by sharing } \\
\text { information about the } \\
\text { project. }\end{array}$ & $\begin{array}{l}\text { 1. Energy } \\
\text { savings and } \\
\text { reduction of } \\
\text { carbon dioxide } \\
\text { emissions; } \\
2 \text {. Sustainable } \\
\text { materials. } \\
3 \text {. Site's ecology } \\
\text { preservation; } \\
4 \text {. Waste } \\
\text { management; } \\
5 \text {. Reduction of } \\
\text { the construction } \\
\text { process to a } \\
\text { period of } 6 \\
\text { weeks }\end{array}$ & $\begin{array}{l}\text { All the sustainable } \\
\text { aspects developed } \\
\text { in the project } \\
\text { were intrinsically } \\
\text { related with the } \\
\text { implementation of } \\
\text { BIM. }\end{array}$ & $\begin{array}{l}\text { 1. Communication } \\
\text { 2. Collaborative } \\
\text { work } \\
\text { 3. Cost savings in } \\
\text { the construction } \\
\text { process. } \\
\text { 4. Clash detection }\end{array}$ & Not specified & Not specified \\
\hline 3 & $\begin{array}{l}\text { 1. Design process; } \\
2 \text {. Collaborative work } \\
\text { among the different } \\
\text { parties of the team by } \\
\text { sharing information } \\
\text { about the project. }\end{array}$ & $\begin{array}{l}\text { 1. Day lighting } \\
\text { and ventilation } \\
2 \text {. Energy } \\
\text { efficiency } \\
\text { 3. Ecology } \\
\text { preservation }\end{array}$ & $\begin{array}{l}\text { 1. Energy } \\
\text { efficiency; } \\
\text { 2. Sustainable } \\
\text { materials; } \\
\text { 3. Water } \\
\text { efficiency; } \\
\text { 4. Water } \\
\text { harvesting; } \\
\text { 5. Water } \\
\text { management }\end{array}$ & $\begin{array}{l}\text { 1. Communication; } \\
\text { 2. Collaborative } \\
\text { work }\end{array}$ & Not specified & $\begin{array}{l}\text { Yes, it has been } \\
\text { assessed by two } \\
\text { different assessment } \\
\text { systems: The house } \\
\text { received a rating of } 42 \\
\text { in the Home Energy } \\
\text { Rating System (HERS), } \\
\text { being } 0 \text {, a zero energy } \\
\text { home. LEED for Home } \\
\text { Platinum certification } \\
\text { with a total of } 102 \\
\text { points, the highest } \\
\text { within this assessment } \\
\text { rating system. }\end{array}$ \\
\hline 4 & $\begin{array}{l}\text { 1. First phase of the } \\
\text { project: carbon } \\
\text { footprinting } \\
\text { calculation; } \\
\text { 2. Second phase of } \\
\text { the project: to } \\
\text { conduct a LCC (Life } \\
\text { Cycle Costing) } \\
\text { analysis in order to } \\
\text { determine the lowest } \\
\text { lifecycle energy } \\
\text { design alternatives } \\
\text { for the project. }\end{array}$ & $\begin{array}{l}\text { 1. Carbon } \\
\text { footprinting; } \\
\text { 2. Energy } \\
\text { efficiency }\end{array}$ & $\begin{array}{l}\text { 1. Energy } \\
\text { efficiency; } \\
\text { 2. Environmental } \\
\text { materials; } \\
\text { 3. Waste } \\
\text { management; } \\
\text { 4. Water } \\
\text { efficiency; } \\
\text { Urban sustainable } \\
\text { benefits: } \\
\text { 1. Stormwater } \\
\text { management; } \\
\text { 2. Green spaces; } \\
\text { 3. Reuse of } \\
\text { existing buildings; } \\
\text { 4. Sustainable } \\
\text { lifestyle }\end{array}$ & $\begin{array}{l}\text { 1. Cost savings } \\
\text { 2. Visualisation }\end{array}$ & $\begin{array}{l}\text { In this project } \\
\text { were } \\
\text { implemented } \\
\text { three } \\
\text { sustainable } \\
\text { standards, two } \\
\text { of them } \\
\text { created by the } \\
\text { company } \\
\text { Skanska: } \\
\text { 1. LAD } \\
\text { Methodology } \\
\text { (Skanska's } \\
\text { Living Area } \\
\text { Design). } \\
\text { 2. Finnish M1 } \\
\text { standards. } \\
\text { 3. The Skanska } \\
\text { Finland's } \\
\text { standard waste } \\
\text { management }\end{array}$ & $\begin{array}{l}\text { The project has not } \\
\text { been assessed with } \\
\text { any sustainable } \\
\text { assessment tools, } \\
\text { however the company } \\
\text { made an evaluation of } \\
\text { the project using a } \\
\text { system called "the } \\
\text { Skanska color palette". }\end{array}$ \\
\hline
\end{tabular}


Based on the questions, the best example is undoubtedly the Loblolly house. This is an example of a project that received multiple benefits thanks to a coordinated and integrated design. This house was the only project that did not centre its attention in energy efficiency. When this project was designed, the project team did not have tools available to undertake an energy analysis, however some of the benefits obtained could help in the energy efficiency of the construction process.

These projects showed a variety of benefits a sustainable building can offer. It could be noted that some of the sustainable benefits obtained with the implementation of BIM were not explicitly defined by the developers and some were obtained as a result of others. Furthermore, some benefits were not sustainable in the first place, but could help in attaining environmental targets. To conclude, a common factor observed was that none of the projects utilised BIM for lifecycle management, which is another aspect ascribed to BIM that can help significantly in maintaining the sustainable attributes of a building, considering that most of the environmental damages are caused when a building is used.

Figure 19 Performance matrix of the case studies

\begin{tabular}{|l|l|l|l|l|l|}
\hline $\begin{array}{l}\text { Sustainable } \\
\text { category }\end{array}$ & $\begin{array}{l}\text { Sustainable } \\
\text { category weight }\end{array}$ & $\begin{array}{l}\text { Project } \\
\mathbf{1}\end{array}$ & $\begin{array}{l}\text { Project } \\
\mathbf{2}\end{array}$ & $\begin{array}{l}\text { Project } \\
\mathbf{3}\end{array}$ & $\begin{array}{l}\text { Project } \\
\mathbf{4}\end{array}$ \\
\hline $\begin{array}{l}\text { Energy and } \\
\text { carbon dioxide } \\
\text { emissions }\end{array}$ & 2 & $\checkmark$ & $\checkmark$ & $\checkmark$ \\
\hline $\begin{array}{l}\text { Water } \\
\text { Materials }\end{array}$ & 2 & $\checkmark$ & & \\
\hline $\begin{array}{l}\text { Surface water- } \\
\text { run off }\end{array}$ & 2 & & & \\
\hline Waste & 2 & $\checkmark$ & & \\
\hline Pollution & 2 & & & \\
\hline $\begin{array}{l}\text { Health and Well- } \\
\text { being }\end{array}$ & 1 & & $\checkmark$ & \\
\hline Management & 1 & 1 & $\checkmark$ & & \\
\hline $\begin{array}{l}\text { Ecology } \\
\text { Total of sustainable categories weight }\end{array}$ & 2 & 8 & 4 & 2 \\
\hline BIM implementation weight & 3 & 3 & 3 & 1 \\
\hline Product of both weights & 6 & 24 & 12 & 2 \\
\hline
\end{tabular}

Legend:

Project 1: A pair of 3-Storey Victorian terraces, Liverpool

Project 2: Loblolly House, Taylor's island, Maryland. 
Project 3: Ross Street house, Madison, Wisconsin

Project 4: Härmälänranta neighborhood, Tampere.

The second data analysis also revealed that Loblolly house was the project that had more sustainable features thanks to the use of BIM: five in total (See figure 3). In addition, this project, along with two others, were the ones that more implemented BIM as a process of work, getting a weight of 3 in the BIM implementation category. An aspect that helped this project in attaining all these sustainable characteristics was the decision to use prefabrication as a method of construction. This method is environmentally friendly and BIM made its execution easier, faster and more accurate. The project with the lowest sustainable performance related to BIM was Härmälänrant, basically due to the underuse of BIM for sustainable purposes.

\section{CONCLUSIONS}

The shortage of information in the literature review and the difficulties arose in the methodology indicated how immature the topic of implementing BIM in sustainable residential projects still is even in the UK, a country that has been widely recognised in the field of BIM implementation. The research showed that the total spread of this practice in this type of projects is not likely to happen in a near future. Undoubtedly, more time is needed for the UK industry to clearly see the benefits obtained after meeting the BIM mandatory target for public projects in 2016, thus its implementation can be spread in, both, private and public sectors and in different types of projects. Furthermore, more time is needed for the residential sector to increase the use of BIM. The implementation of BIM is still seen as a challenge in the construction sector in general, more in the residential sector where BIM adoption is relatively limited. The barriers of BIM implementation tend to be bigger in this sector for several reasons: Most of the residential buildings developed in the UK are dwellings, which means they are small projects. The high cost that implies the adoption of BIM does not look very attractive to companies that develop small projects. Furthermore, it is difficult for the small builders involved in this sector to make such investments taking into account the quantity and size of projects they normally develop. Another aspect is the client's demand in this sector. For the economic implications of implementation of BIM, it is not likely that clients ask for sustainable residential projects to be developed with BIM.

From this research could be drawn several recommendations for the UK industry:

The government must act quickly and propose a substitute of Zero Carbon Homes Scheme and create new and less severe standards in order to drive the construction of sustainable residential buildings.

The government must also implement standards that cover the refurbishment of residential projects, which is very important due to the low rate of new-built residential projects compared to the high need of refurbishment in this sector. 
Spread the implementation of more environmentally friendly methods of construction that could be implemented in residential buildings and also be developed by the use of BIM. As shown in one of the case studies, it can be suggested the use of off-site technologies, for example the prefabrication, which is not widely adopted in the UK.

This study suggests further investigation of the topic and also of the development of projects of this type in the UK. It is also suggested to follow the future government's actions regarding this area.

\section{REFERENCES}

- $\quad$ ARAYICI, Y, COATES, P., KOSKELA, L. and KAGIOGLOU, M. (2011) BIM adoption and implementation for architectural practices. Structural Survey, 29(1) pp. 7-25.

- BOARDMAN, B., BANK, C. and BRITAIN G. Boardman, B., Bank, C. and Britain, G. (2007) Home truths: a low-carbon strategy to reduce UK housing emissions by $80 \%$ by 2050. [Online] Friends of the earth. Available from: http://www.foe.co.uk/sites/default/files/downloads/home truths.pdf. [Accessed: 16th July, 2014].

- BREEAM (2014) Code for Sustainable Homes. [Online] BREEAM webpage. Available from: http://www.breeam.org/page.jsp?id=86 [Accessed: 19th Aug., 2014].

- BSI (2010) Constructing the business case. Building Information Modelling. London: British Standards Institution.

- $\quad$ CIOB (2013) Sustainable Construction and the Green Deal. [Online] CIOB website. Available from:

http://www.ciob.org/sites/default/files/Sustainable\%20Construction\%20and $\% 20$ the $\% 20$ Green \%20Deal.pdf. [Accessed: 3rd of August 2014].

- $\quad$ EASTMAN, C., TEICHOLZ, P. SACKS, R. and LISTON, K. (2008) BIM Handbook. A guide to Building Information Modeling for owners, managers, designers, engineers and contractors. New Jersey: John Wiley and \& Sons, Inc.

- GEORGE, A.L. and BENNETT A. (2005) Case studies and theory development in the social sciences. Massachusetts: MIT Press.

- GRAHAM, G. (2014) Small housing developers exempt from 'zero carbon' home regulations. [Online] The telegraph. Available from: http://www.telegraph.co.uk/news/politics/liberaldemocrats/10868579/Small-housingdevelopers-exempt-from-zero-carbon-home-regulations.html. [Accessed: 20th Aug, 2014].

- GVA (2011) Stimulating sustainable construction in the UK. Do we need a scrappage scheme for buildings? [Online]. GVA website. Available from:

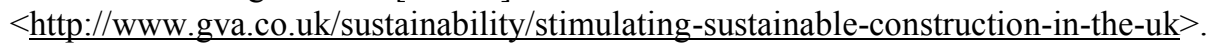
[Accessed: 18th July, 2014].

- HM GOVERNMENT (2013) Industrial Strategy: Government and Industry partnership. Construction 2025. [Online] UK government website. Available from: https://www.gov.uk/government/publications. [Accessed: 15th July, 2014].

- $\quad$ KHOSROWSHAHI, F. and ARAYICI, Y. (2012) Roadmap for implementation of BIM in the UK construction industry. Engineering, Construction and Architectural Management, 19(6) pp. 610-635.

- $\quad$ KRIEGEL, E. and NIES, B. (2008) Green BIM. Successful sustainable with design building information modelling. Indianapolis: Wiley Publishing, Inc.

- LESTER, P. (2013) Zero Carbon Homes. [Online] UK Parliament. Available from: http://researchbriefings.parliament.uk/. [Accessed: 15th July, 2014]. 
- NBS (2012) BIM a year on. [online] NBS website. Available from: http://www.thenbs.com/topics/bim/articles/bimAYearOn.asp. [Accessed: 16th Aug, 2014].

- NBS (2015) NBS National BIM Report. [Online] NBS website. Available from: http://www.thenbs.com/topics/bim/articles/nbs-national-bim-report-2014.asp. [Accessed: 16th Aug. 2014].

- NGO, M.H. (2012) UK Construction Industry's responses to Government Construction Strategy BIM deadline and applications to civil engineering education. [Online] 1st Civil and Environmental Engineering Student Conference. Available from: https://workspace.imperial.ac.uk/civilengineering/Public/technical\%20paper\%20group\%20A/ 18A-Ngo-

UK\%20Construction\%20Ind.\%20Responses\%20to\%20Governm't\%20Construction\%20Strate gy\%202.pdf. [Accessed: 13th July, 2014].

- NHBC (2013) Building Information Modelling. An introduction for house builders [Online]. Available from: $\quad$ http://bsria files.wordpress.com/2013/02/nf49-building-informationmodelling.pdf. [Accessed: 22nd Aug. 2014].

- OLDFIELD, P. (2005) UK scraps zero carbon homes plan. [Online] The Guardian. Available from: $\quad$ http://www.theguardian.com/environment/2015/jul/10/uk-scraps-zero-carbon-hometarget. [Accessed: 28th July, 2015].

- PALMER, J. and COOPER, I. (2013) United Kingdom housing energy fact file. [Online] Department of Energy and Climate Change. Available from: https://www.gov.uk/government/uploads/system/uploads/attachment data/file/201167/uk ho using fact file 2012.pdf. [Accessed: 20th July, 2014].

- SEYFANG, G. (2010) Community action for sustainable housing: Building a low-carbon future. Energy Policy, 38(2010), pp. 7624-7633.

- SUCCAR, B. (2009) Building information modelling framework: A research and delivery foundation for industry stakeholders. Automation in Construction, 18(3), pp. 357-375.

- UK-GBC (2015) Over 200 businesses urge Chancellor to reconsider scrapping zero carbon. [Online]. Available from: http://www.ukgbc.org/press-centre/press-releases/over-200businesses-urge-chancellor-reconsider-scrapping-zero-carbon. [Accessed: 28th July, 2015]. 


\title{
FEASIBILITY STUDY ON INTEGRATION OF LOW CARBON TECHNOLOGIES TO EXISTING DOMESTIC DWELLINGS IN THE UK
}

\author{
Ye, Z. ${ }^{1}$ Tann, D. B. ${ }^{2}$; Chaer, I. ${ }^{3}$; and Beasley, P. ${ }^{4}$
}

\begin{abstract}
:
In 2013, the dwelling stocks for England were estimated to be 23.2 million. This is $0.54 \%$ higher than the 23.1 million estimated in 2012 of which 19.1 million were privately owned and 4 million were social rented accommodation either by local authorities or privately registered providers. This demonstrates that the ratio of new dwellings to existing ones is rather small and hence dwellings that utilise technologies and construction methods that are inferior to new building regulations still exist on a large scale. Those existing dwellings will continue to produce excessive levels of $\mathrm{CO} 2$ until major retrofitting work is carried out. Bearing the above in mind, it is necessary to find a solution to enhance the building fabric and use a high efficiency low-carbon heating source. At this moment in time, there has been no research carried out on the optimization of retrofitting existing building fabric together with the application of a high efficiency low-carbon heating source. The objective of this paper is to find an economical and technical solution which reduces the energy consumption of existing dwellings by applying a low-carbon heating source and improving building fabrics. In this study, extensive modelling work was carried out using the IES VE® software to simulate the energy consumption of dwellings. Firstly, the $U$-values of the building fabric have been improved by using high level insulation and double or triple glazed windows. Secondly, various low carbon heating sources were investigated. It was found that by improving the wall U-values of the dwellings, the optimal energy savings can be achieved by adding internal or external wall insulation to dwellings originally constructed with solid walls. The hybrid air source heat pump is suitable for all existing dwellings and will not require replacement of the heat emitters, this will achieve a good overall saving as the control strategy can be set to accommodate the incorporation of the hybrid system.
\end{abstract}

This work opens up the possibility of retrofitting existing domestic dwellings with a high efficiency heating source and improved building fabric without interruption of the existing heating system.

KEYWORDS: BUILDING FABRICS, ENERGY EFFICIENT HEATING TECHNOLOGIES, LOW CARBON, RETROFITTING

\section{INTRODUCTION}

The building services industry traditionally concentrates mainly on large industrial and commercial buildings along with larger scale domestic heating schemes, where it is possible to make substantial emissions and energy savings on individual projects. However, the residential sector has a significant part to play in reducing the UK's $13 \%$ of total emissions that are attributed to fossil fuels being used for both space heating and

\footnotetext{
${ }^{1}$ School of the Built Environment and Architecture, London South Bank University, England UK. Email: zhihuiy@1sbu.ac.uk

${ }^{2}$ School of Engineering and Computing, University of the West Scotland, Scotland, UK. Email: david.tann@uws.ac.uk

${ }^{3}$ School of the Built Environment and Architecture, London South Bank University, England UK. Email: chaeri@1sbu.ac.uk

${ }^{4}$ School of the Built Environment and Architecture, London South Bank University, England UK. Email: beasley@1sbu.ac.uk
} 
cooking (DECC [Department of Energy and Climate Change], 2014) and substantial CO2 emission savings could also be achieved by introducing innovative measures into domestic dwellings with potentially up to $11 \mathrm{Mt}$ of CO2 reduction by 2020 , and $73 \mathrm{Mt}$ by 2050 (LCICG [Low Carbon Innovation Coordination Group], 2012).

There are already strong policy ambitions in the UK affecting domestic buildings. The Climate Change Act 2008 requires an $80 \%$ cut in emissions by 2050, and a significant part of this must come from the domestic buildings sector.

Research on retrofitting the 1930's and 1980's dwellings has been carried out by insulating the external wall, floor and roof, using double glazing windows (Simpson et al. 2012). However, there are no published results relating to the savings due to the use of high efficiency heating generators with original (as built) heating infrastructure.

In this work a notional dwelling, semi-detached, has been chosen to represent one of the typical domestic housing in the UK. Extensive building simulation has been carried out to investigate the improvement level required to the building fabric of two typical houses which were constructed in the 1930's and 1980's. The high efficiency heat generator which can be retrofitted into existing dwellings without altering the existing heating infrastructure, i.e. heat emitters and pipework, are discussed in great detail. The suitability of existing heat emitters and pipework to the retrofitted heat generator has been verified.

Review of heat generator technologies

To establish the best technology suited for retrofitting in existing privately owned dwellings in the UK, eight different heat generator technologies were considered in the original study, Beasley (2014). This included review of technologies such as:

Gas Condensing Boilers

Micro Combined Heat and Power

Air Source Heat Pumps

Ground Source Heat Pumps

Gas Absorption Heat Pumps

Gas Adsorption Heat Pumps

Biomass Boilers

Hybrid Air Source Heat Pumps

The DECC report (DECC, 2013) was also reviewed with regard to future technologies which could meet the United Kingdom's carbon reduction targets. 


\section{RESEARCH METHODOLOGY}

After the detailed analysis of each heat generator technology and the content of the DECC report (DECC, 2013), the air source heat pump (ASHP) and hybrid air source heat pump (Hybrid ASHP) have been selected as those that are recognised by the government to be the technologies of the future. Also the gas driven heat pumps (GAHP) have been selected due to their potential high efficiency and low carbon emissions due to gas being the main source of energy, although it is currently being researched. The most suitable technologies for retrofitting into existing dwellings were then used, in the IES VE® thermal model of the two dwellings, in order to ascertain what carbon and energy savings each could potentially deliver.

\section{PROPOSED CONSTRUCTION IMPROVEMENTS}

The thermal transmittance ( $\mathrm{U}$ value, $\mathrm{W} / \mathrm{m} 2 \mathrm{~K}$ ) of the building envelope is determined by the construction material. The building envelope with a higher $U$ value will result in a greater heating requirement in winter. Thus, to reduce the heat energy consumption, the $\mathrm{U}$ value of the building envelope has to be reduced. To achieve this, it is proposed to improve the fabrics of the notional dwelling to the levels of the enhanced construction and advanced construction. With the enhanced construction, the notional dwelling is retrofitted to fit 2010 Building Regulation Part L existing dwellings requirement (HM [Her Majesty's] Government, 2010). With the advanced construction, the notional dwelling is retrofitted to fit 2010 Building Regulation Part L new dwellings requirement (HM Government, 2010). The notional dwelling with its original fabrics as it was constructed is defined as the standard construction.

Improvement to the notional dwelling is carried out by two methods:

Changing windows from single glazed to double/triple glazed.

Adding insulation to external wall and roof.

The main characteristic of the 1930 's standard construction is the $225 \mathrm{~mm}$ solid brick wall, single glazed window and $100 \mathrm{~mm}$ insulated roof. To upgrade the 1930's standard construction to the proposed enhanced construction, $50 \mathrm{~mm}$ insulation is added to the external wall, double glazed windows are used to replace single glazed windows and $270 \mathrm{~mm}$ thick insulation is added to the roof. The upgrade of the 1930's standard construction to the proposed advanced construction is carried out by adding $100 \mathrm{~mm}$ insulation to the external wall, using triple glazed windows and adding $300 \mathrm{~mm}$ insulation to the roof.

The main characteristic of the 1980's standard construction is the cavity wall, single glazed window and 130mm insulated roof. To upgrade the 1980's standard construction to the proposed enhanced construction, $50 \mathrm{~mm}$ blown glass insulation is filled in the cavity of the external wall. The improvements to the windows and roof are the same as the proposed windows and roof improvements done to 1930's dwellings. Based on the 
1980's proposed enhanced construction, the improvement of the 1980's proposed advanced construction is carried out by adding 50mm PIR insulation, and $9.5 \mathrm{~mm}$ plaster to the external wall. The improvements to the windows and roof are the same as the proposed windows and roof improvements done to 1930's dwellings.

For the purpose of comparing how the thermal performance of the building envelopes has improved against 2010 and 2013 approved Building Regulations Part L requirement (HM Government, 2013), the 2010 and 2013 standard construction are given below.

The 2010 standard construction consists of the $100 \mathrm{~mm}$ PIR insulated wall, double glazed window and $270 \mathrm{~mm}$ insulated roof.

The 2013 standard construction consists of the $120 \mathrm{~mm}$ PIR insulated wall, triple glazed windows and $300 \mathrm{~mm}$ insulated roof.

The $U$ values of the above building structure have been calculated using the individual construction element based on the thermal conductivity and thickness of the elements, further detail could be found in CIBSE guide A (CIBSE, 2006). The improvement of the building fabrics will improve the $U$ values significantly. The typical $U$ values of the building components are summarised in Tables 1. The $U$ values of the floor are unchanged due to practical constrains.

Table 1: Dwellings U value ( $\mathrm{W} / \mathrm{m} 2 \mathrm{~K})$

\begin{tabular}{lccccc}
\hline Construction type & Walls & Window & Roof & Doors & Floor \\
\hline 1930's Standard & 2.0 & 4.3 & 0.35 & 4.3 & 0.8 \\
1930's Enhanced & 0.35 & 1.6 & 0.13 & 1.8 & 0.8 \\
1930's Advanced & 0.2 & 1.1 & 0.11 & 1.6 & 0.8 \\
1980's Standard & 0.6 & 3.0 & 0.35 & 3.0 & 0.45 \\
1980's Enhanced & 0.35 & 1.6 & 0.13 & 1.8 & 0.45 \\
1980's Advanced & 0.2 & 1.1 & 0.11 & 1.6 & 0.45 \\
2010 Part L & 0.2 & 1.5 & 0.13 & 1.5 & 0.25 \\
2013 Part L & 0.15 & 1.0 & 0.11 & 1.0 & 0.13 \\
& & & & & \\
\hline
\end{tabular}

\section{MODELLING OF NOTIONAL DWELLING}

IES VE® (IES Virtual Environment) is a building simulation software. The semidetached notional dwelling is modelled using IES VE® software as set in the Thames Valley area. The dwelling is modelled using construction methods from the 1930's, 1980's and 2010 or 2013 Part L Building Regulation requirements. A level of thermal improvement to reflect the currently available upgrades that are commonly used will then be applied to update the 1930's and 1980's dwellings.

The semi-detached dwelling has two floors with $5.5 \times 8.7 \mathrm{~m} 2$ for each floor. The dining room, lounge, kitchen, are located on the ground floor. There are three bedrooms and one bathroom on the first floor. 


\section{Design criteria}

The internal design condition of temperature and air chance rate is determined based on the CIBSE Domestic Heating Design Guide (CIBSE, 2008) and given in Table 2.

The external design temperature for the selected location is $-4.7^{\circ} \mathrm{C}$ dry bulb and $-6.9^{\circ} \mathrm{C}$ wet bulb, taken from the Heathrow area.

\section{IES models}

The notional dwelling was constructed in several steps. Firstly, the 3D models were drawn by using the Model-IT function as shown in Figure 1. Secondly, room temperatures and air change rates were assigned to each room within the dwelling by using the Apache function. Thirdly, the models were assigned to the proposed location which determined the external design condition. Fourthly, the building elements were assigned to the models for the first level of construction of $U$ values detailed in Table 1 to represent the dwellings with the standard level of construction improvement. Fifthly, each model was assigned the selected heating plant and its seasonal efficiency. Finally, thermal calculations and simulations were carried out using the CIBSE loads and Apache-Sim dynamic simulation functions.

Table 2: Internal design condition

\begin{tabular}{|c|c|c|c|}
\hline Room type & $\begin{array}{l}\text { Room temperature } \\
\left({ }^{\circ} \mathrm{C}\right)\end{array}$ & $\begin{array}{l}\text { Dwelling constructed } \\
\text { before } 2006(\mathrm{ACH})\end{array}$ & $\begin{array}{l}\text { Dwelling constructed } \\
\text { after } 2006(\mathrm{ACH})\end{array}$ \\
\hline Lounge/TV room & 21 & 1.5 & 0.5 \\
\hline Dining room & 19 & 1.5 & 0.5 \\
\hline Kitchen/Utility & 21 & 2.0 & 1.5 \\
\hline Hall & 21 & 2.0 & 0.5 \\
\hline Bathroom/Toilet & 22 & 3.0 & 1.5 \\
\hline Bedroom & 18 & 1.0 & 0.5 \\
\hline
\end{tabular}

Figure 1: Model of the notional dwelling

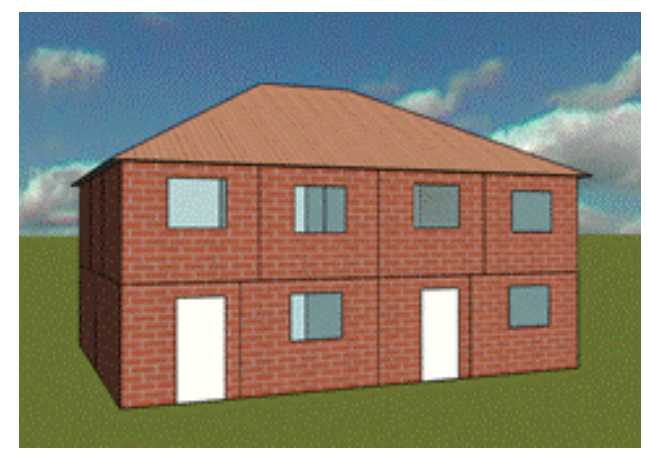

The initial simulations were carried out by using the standard construction structure with condensing boiler as this represents a realistic option. This was used as the base model, so the heat energy savings from both construction improvement and the high efficiency 
heating plant could be obtained. Afterwards, the simulation was repeated with varying construction improvement and keeping the original heat generator. Therefore, it was possible understood how the construction improvement affected the heat energy consumption. In order to understand how different types of heating plant affect the heat energy consumption of the building, the simulations were repeated with varying heating plants which represented a selection of low carbon heating solutions, i.e. gas condensing boiler, air source heat pump, gas driven heat pump, hybrid air source heat pump. The enhanced construction structure was used in these simulations.

\section{IES RESULTS}

\section{Predicated heat load calculation}

The predicted heat loads of the notional dwelling are given in Table 3. It can be seen that the heat load is great reduced by construction improvement, especially for the enhanced construction used in 1930's dwellings. The heat load can be further reduced by using advanced construction; however, it is not significant.

Although the predicted heat load is greatly reduced through the construction improvement, the heat load is still significantly different to the 2010 and 2013 construction periods; this is partly due to some of the $U$ values of the construction elements not being upgraded due to practical constraints such as the ground floor not being upgraded. The other main area that differs in the existing dwellings is the air change rate per hour that has been applied to the existing dwellings, is higher than those that will be found in newly built dwellings, this is due to the improvements that have been made in construction details reducing the air infiltration rates.

Table 3: Dwelling predicted heat load calculated

\begin{tabular}{lllllrc}
\hline \multicolumn{2}{l}{ Predicted heat load $(\mathrm{kW})$} & & & & \multicolumn{2}{c}{ Potential heat load reduction (\%) } \\
\hline $\begin{array}{l}\text { Construction } \\
\text { period }\end{array}$ & Standard & & Enhanced & Advanced & Enhanced & Advanced \\
construction & & construction & construction & construction & construction \\
1930 's & & 18.1 & 11.7 & 11.3 & 35.4 & 37.6 \\
1980 's & 12.8 & 11.3 & 10.6 & 11.7 & 17.2 \\
2010 & 6.0 & N/A & N/A & N/A & N/A \\
2013 & 5.2 & N/A & N/A & N/A & N/A \\
\hline
\end{tabular}

Annual heat energy savings due to fabric improvements

The annual heat energy used by the notional dwelling is shown in Table 4. As could be seen from the table, the annual heat energy is greatly reduced when enhanced construction is applied to the notional dwelling, especially for the 1930's dwelling. The annual heat energy consumption can be further reduced by using advanced construction; however, it is not significant. 
Table 4: Dwelling annual heat energy consumption with varied building fabrics

\begin{tabular}{|c|c|c|c|c|c|c|}
\hline \multicolumn{4}{|c|}{$\begin{array}{l}\text { Annual heat energy } \\
\text { consumption (MWh) }\end{array}$} & \multicolumn{3}{|c|}{$\begin{array}{l}\text { Reduction of heat energy } \\
\text { consumption }(\%)\end{array}$} \\
\hline $\begin{array}{l}\text { Construction } \\
\text { period }\end{array}$ & $\begin{array}{l}\text { Standard } \\
\text { construction }\end{array}$ & & $\begin{array}{l}\text { Enhanced } \\
\text { construction }\end{array}$ & $\begin{array}{l}\text { Advanced } \\
\text { construction }\end{array}$ & $\begin{array}{r}\text { Enhanced } \\
\text { construction }\end{array}$ & $\begin{array}{r}\text { Advanced } \\
\text { construction }\end{array}$ \\
\hline 1930 's & & 36.0 & 23.3 & 22.3 & 35.3 & 38.1 \\
\hline 1980's & & 24.9 & 22.1 & 20.8 & 11.2 & 42.7 \\
\hline 2010 & & 11.0 & $\mathrm{~N} / \mathrm{A}$ & $\mathrm{N} / \mathrm{A}$ & N/A & N/A \\
\hline 2013 & & 9.2 & $\mathrm{~N} / \mathrm{A}$ & $\mathrm{N} / \mathrm{A}$ & N/A & N/A \\
\hline
\end{tabular}

Annual heat energy savings due to the use of improved heat generators

The annual heat energy savings for the notional dwelling due to the use of improved heat generators were obtained from IES VE® by running the simulation with the different heating plants, these are selected from Apache systems and applied to each dwelling, and the original design and operating conditions remain unchanged.

The calculation of annual heat energy used for the 1930's and 1980's notional dwellings was also carried out with a $65 \%$ efficient non-condensing boiler as this represents an old heating appliance that is likely to be exchanged for a low carbon heat generator, then this is used as the base to determine the savings that can be achieved when replacing an old inefficient heat generator. As a non-condensing boiler is not allowed in a newly built dwelling, a condensing boiler is used as the base to determine the savings for 2010 and 2013 dwellings.

The annual heating energy consumption and reduction of the notional dwellings are shown in Tables 5 and 6 . The air source heat pump is the most energy efficient heating source. However, its carbon savings are lower than other selected heating sources, the details of carbon savings will be reported in a separate paper.

Table 5: Dwelling annual heat energy consumption (MWh )with varied heat generators

\begin{tabular}{llllcc}
\hline Construction period & Boiler A & Boiler B & ASHP & GAHP & Hybrid ASHP \\
\hline 1930 's & 35.9 & 23.3 & 8.9 & 13.9 & 17.4 \\
1980 's & 31.7 & 22.1 & 8.4 & 13.1 & 16.2 \\
2010 & N/A & 11.0 & 4.7 & 7.2 & 10.7 \\
2013 & N/A & 9.2 & 4.0 & 6.1 & 9.1
\end{tabular}

Note: Boiler A is the non-condensing boiler, boiler B is the condensing boiler.

Table 6: Dwelling annual heat energy consumption reduction (\%) with varied heat generators

\begin{tabular}{lllcc}
\hline Construction period & Boiler B & ASHP & GAHP & Hybrid ASHP \\
\hline 1930 's & 35.1 & 75.2 & 61.3 & 51.5 \\
1980 's & 30.3 & 73.5 & 58.7 & 48.9 \\
2010 & N/A & 57.3 & 34.5 & 2.7 \\
2013 & N/A & 56.5 & 33.7 & 1.1 \\
\hline
\end{tabular}

Note: boiler B is the condensing boiler. 


\section{ANALYSIS OF RESULTS FOR ANNUAL HEAT ENERGY SAVINGS}

From the data above, it can be seen that the 2010 and 2013 notional dwellings have significantly lower energy consumption than the dwellings that have been improved. This is partly due to the lower air change rate applied to these dwellings, and also due to the ground floor $\mathrm{U}$ values on the existing dwellings having not been reduced.

By applying air source heat pump, the annual heat energy consumption can be reduced by up to $70 \%$ for 1930 's and 1980's dwellings and up to 50\% for 2010 and 2013 dwellings. In addition, its carbon savings are higher than other technologies. The gas driven air source heat pump has achieved a higher efficiency, although it is currently being researched. The hybrid air source heat pump is an energy-efficient heat generator that is suitable for existing dwellings.

\section{suitability of existing heat emitters}

A high efficiency heat generator such as an air source heat pump is suitable for low temperature water heating. Thus, when using a low-temperature heat generator, the suitability of existing heat emitters should be examined.

The heat emitter's suitability will be determined by using conversion factors that have been obtained from the BRE Design of Low-temperature Heating (Young et al. 2013). The conversion factors are 1.132, 1.000, 0.872, 0.748, 0.629, 0.515, 0.406 which correspond to temperature differences between the room and heat emitter of $55^{\circ} \mathrm{C}, 50^{\circ} \mathrm{C}$, $45^{\circ} \mathrm{C}, 40^{\circ} \mathrm{C}, 35^{\circ} \mathrm{C}$ and $30^{\circ} \mathrm{C}$. By applying the conversion factors to heat emitters, their heat output when the mean water temperature is below the original design criteria can be determined.

The manufacturers' data tables for heat emitter output is based on a $50^{\circ} \mathrm{C}$ difference between the room design temperature and the mean emitter water temperature, where the mean water temperature is above or below $50^{\circ} \mathrm{C}$, a conversion factor is applied as required by BSEN 422-1 1996: Specification for Radiators and Convector.

In this work, the heat emitter suitability of the notional dwelling with the enhanced construction structure is examined by applying the temperature differences of room to heat emitter water of $45^{\circ} \mathrm{C}, 40^{\circ} \mathrm{C}, 35^{\circ} \mathrm{C}$ and $30^{\circ} \mathrm{C}$ with suitable heat generators of condensing boilers, GAHP/Hybrid, ASHP/GAHP and ASHP/GAHP respectively.

\section{0 's dwelling heat emitter suitability}

The data in Table 7 shows the room heat load requirements for the dwelling originally constructed in the 1930's, that has been improved to achieve the U values of the enhanced construction. It would be feasible for a selected design criterion of $35^{\circ} \mathrm{C}$ room to emitter temperature differential to be used; this would allow a MWT of $55^{\circ} \mathrm{C}$. To achieve this, the kitchen, hallway and landing heat emitters would require upgrading; alternatively a number of smaller additional emitters could be added. 
Table 7: 1930's dwelling adjusted emitter outputs ( $\mathrm{kW})$

\begin{tabular}{|c|c|c|c|c|c|c|c|}
\hline \multicolumn{3}{|c|}{$\begin{array}{l}\text { Emitter outputs at original } \\
\text { design MWT } 65^{\circ} \mathrm{C}\end{array}$} & \multicolumn{5}{|c|}{$\begin{array}{l}\text { Emitter output with varied room to emitter } \\
\Delta \mathrm{t}\left({ }^{\circ} \mathrm{C}\right)\end{array}$} \\
\hline Room & $\begin{array}{l}\text { Standard } \\
\text { construction }\end{array}$ & $\begin{array}{l}\text { Enhanced } \\
\text { construction }\end{array}$ & 45 & 40 & 35 & & \\
\hline Lounge & 4.3 & 2.6 & 3.8 & 3.2 & 2.7 & & \\
\hline Kitchen & 3.0 & 1.7 & 2.6 & 2.2 & 1.9 & & \\
\hline Hallway & 2.5 & 1.4 & 2.2 & & 1.9 & 1.6 & 1.3 \\
\hline Landing & 1.5 & 0.85 & 1.3 & & 1.1 & 0.9 & 0.8 \\
\hline Bathroom & 2.6 & 1.4 & 2.3 & & 2.0 & 1.7 & 1.4 \\
\hline Bedroom 1 & 1.7 & 0.7 & 1.5 & & 1.3 & 1.1 & 0.9 \\
\hline Bedroom 2 & 1.6 & 0.9 & 1.4 & & 1.2 & 1.0 & 0.8 \\
\hline Bedroom 3 & 1.6 & 0.8 & 1.4 & & 1.2 & 1.0 & 0.8 \\
\hline
\end{tabular}

1980's dwelling heat emitter suitability

The data in Table 8 shows the room heat load requirements for the dwelling originally constructed in the 1980's, which has been improved to achieve the U values of the enhanced construction. It would be feasible for a selected design criterion of $40^{\circ} \mathrm{C}$ room to emitter temperature difference to be used; this would allow a MWT of $60^{\circ} \mathrm{C}$. To achieve this, the lounge, kitchen, hallway, lobby, bathroom and landing heat emitters would require upgrading; alternatively a number of smaller additional emitters could be added.

\section{ANALYSIS OF RESULTS FOR HEAT EMITTER SUITABILITY}

From the data above it can be seen that for the 1930's dwellings a greater number of the existing emitters are able to be retained, this is due to the greater reduction in $U$ values obtained by the improvement. It can be seen that the lowest flow temperature that can be used is between 55 and $60^{\circ} \mathrm{C}$, this temperature is at the upper limits of air source heat pump suitability, and will result in a low COP, both the hybrid and gas driven heat pump will operate with a reasonable efficiency at these flow temperatures. 
Table 8: 1980's dwelling adjusted emitter outputs ( $\mathrm{kW})$

\begin{tabular}{|c|c|c|c|c|c|c|c|}
\hline \multicolumn{3}{|c|}{$\begin{array}{l}\text { Emitter outputs at original } \\
\text { design MWT } 65^{\circ} \mathrm{C}\end{array}$} & \multicolumn{5}{|c|}{$\begin{array}{l}\text { Emitter output with varied room to emitter } \Delta t \\
\left({ }^{\circ} \mathrm{C}\right)\end{array}$} \\
\hline Room & $\begin{array}{l}\text { Standard } \\
\text { construction }\end{array}$ & $\begin{array}{l}\text { Enhanced } \\
\text { construction }\end{array}$ & 45 & 40 & 35 & 30 & \\
\hline Lounge & 3.10 & 2.4 & 2.7 & 2.3 & 1.9 & & .6 \\
\hline Kitchen & 1.95 & 1.6 & 1.7 & 1.5 & 1.2 & 1.0 & \\
\hline Hallway & 1.72 & 1.4 & 1.5 & & 1.3 & 1.1 & 0.9 \\
\hline Landing & 1.15 & 0.9 & 1.0 & & 0.9 & 0.7 & 0.6 \\
\hline Bathroom & 1.95 & 1.6 & 1.7 & & 1.5 & 1.2 & 1.0 \\
\hline Bedroom 1 & 1.03 & 0.7 & 0.9 & & 0.8 & 0.6 & 0.5 \\
\hline Bedroom 2 & 1.15 & 0.9 & 1.0 & & 0.9 & 0.7 & 0.6 \\
\hline Bedroom 3 & 1.03 & 0.8 & 0.9 & & 0.8 & 0.6 & 0.5 \\
\hline
\end{tabular}

\section{Existing pipe sizing suitability}

To establish the suitability of the existing heat network including existing pipework circuits, and their ability to deliver the required flow rates to the heat emitters, initial calculations were carried out on the dwellings' existing pipework size requirements and then compared against the requirements for the same building with improved level of construction. The calculations have been carried out on a selected section of the detached dwelling as the principles and results hold for all sections and both dwellings. From the calculation, it can be ascertained if the existing pipe size is suitable for the retrofitted heat generator.

\section{CONCLUSIONS}

This current work has investigated the levels of improvements that are commonly applied to existing domestic dwellings which would allow the installation of low carbon heating solutions into existing dwellings whilst retaining the existing heating circulation network and heat emitters. It explored the potential energy savings that could be achieved by existing and emerging technologies.

It has been found from the modelling work carried out in IES VE® that by improving the wall $U$ values of the dwellings, the optimal energy savings can be achieved by adding internal or external wall insulation to dwellings originally constructed with solid walls.

It has also been found that when the next level of insulation is applied, the added costs do not add much more energy savings. This level of improvement would only be suitable when the whole dwelling is being renovated due to high capital investment and disruption.

For the 1930's dwellings that have received the required fabric improvement, calculations have shown that the majority of the original heat emitters could still be suitable to deliver 
the heat from a low carbon heat generator that delivers a flow temperature in the region of $55^{\circ} \mathrm{C}$ to $60^{\circ} \mathrm{C}$. For the 1980 's dwellings, the higher original design temperatures of the existing heat emitters (hence lower surface area of some of the emitters) do not provide enough surfaces to compensate for the lower heat output temperature from a low carbon source even when there is slight reduction in the demand due to the fabric improvement.

The existing pipework was suitable for all of the low carbon heating technologies that were considered, this would minimise disruption and could be a deciding factor when an owner occupier is deciding to upgrade their heat generator.

The hybrid air source heat pump is suitable for all existing dwellings and will not require replacement of the heat emitters, in order to achieve a good overall saving as the control strategy can be set to accommodate the incorporation of the hybrid system.

\section{REFERENCES}

- BEASLEY, P. (2014) Integration of Low Carbon Technologies into Existing Domestic Dwellings, BEng Final Year Report, London South Bank University.

- $\quad$ BSEN 422-1 1996: Specification for Radiators and Convector. Technical specifications and requirements.

- $\quad$ CIBSE. (2010) CIBSE Guide A, Environmental Design. London: CIBSE.

- $\quad$ CIBSE. (2008) Domestic Heating Design Guide. 10th ed. London: CIBSE.

- $\quad$ DECC. (2013) The Future of Heating Meeting the Needs, London: Department of Energy and Climate Change.

- DECC. (2014) 2012 UK Greenhouse Gas Emissions, Final Figures Statistical, London: Department of Energy and Climate Change.

- HM Government. (2010) Building Regulations 2010 Part L Conservation of Fuel and Power, Approved Document, HM Government.

- HM Government. (2013) Building Regulations 2013 Part L Conservation of Fuel and Power, Approved Document, HM Government.

- LCICG. (2012) Technology Innovation Need Assessments, London: Low Carbon Innovation Coordination Group 2012.

- $\quad$ SIMPSON, S. and BANFILL, P. (2012) The Importance of the Order of Insulation of Retrofit Measures in Optimising Long Term Energy and CO2 Reductions. Available from: http://www.salford.ac.uk/ data/assets/pdf file/0005/142376/006-Simpson.pdf [Accessed: 6th July 2015]

- YOUNG, B., SHIRET, A., HAYTON, J. and GRIFFITHS, W. (2013) Design of Lowtemperature Domestic Heating Systems. Bracknel: HIS BRE Press. 


\title{
A NOVEL DRY AIR GROUND SOURCE (DAGS) SYSTEM FOR HEATING AND COOLING BUILDINGS
}

\author{
Yebiyo, $\mathrm{M}^{1}{ }^{1}$; Maidment, $\mathrm{G}^{2}$. Paurine, $\mathrm{A}^{3}$. and Day, A. ${ }^{4}$
}

\begin{abstract}
:
Based on a number of studies carried out; it has been identified that, Ground Source Heat Pump (GSHP) systems are widely used as one of the preferred low carbon technologies in the UK. The use of these systems is due to their economic advantages and potential reduction of carbon footprint. However, a number of the studies have highlighted that the systems are either installed incorrectly or operated and controlled improperly and therefore result in poor performance. GSHP performance is affected by the temperature of the ground and when thermally saturated its efficiency reduces significantly.

This paper investigates the potential to reduce the level of thermal saturation by rejecting heat via a Dry Air Cooler (DAC) when the ground and ambient temperatures favour this. DACs are often fitted to GSHP systems to reject heat during extreme conditions to protect the system, rather than improve performance. In this investigation, an empirical Transient System Simulation (TRNSYS) model has been developed and used to investigate the control algorithms so as to identify the optimal operation and control strategies for DAGS system for enhancing the system efficiency.

Specifically, the paper investigates the effect of using a DAC in conjunction with a GSHP system. This includes investigating the (i) energy input into the GSHP system, (ii) ground temperatures and (iii) Coefficient of Performance (COP). The results show significant savings can be achieved.
\end{abstract}

KEYWORDS: CONTROL STRATEGY, DRY AIR COOLER, GROUND SOURCE HEAT PUMP, TRNSYS, GROUND TEMPERATURE VARIATION

\section{INTRODUCTION}

It is widely accepted that global climate change is predominantly due to the emissions of greenhouse gases (GHG), 75\% of which are attributable to CO2 (Pachauri and Reisinger, 2007). In the UK, $47 \%$ of $\mathrm{CO} 2$ emissions are due to the production of heat with a significant contributor to the total emissions from heat generation in the domestic sector (Karl, 2008; UK Office of Climate Change, 2007). The heat pump stock in 2013 contributed to $20 \mathrm{Mt}$ of greenhouse gas emission savings. The current European installed base of heat pumps (HPs) produces 35 TWh of renewable energy from the air, water and the ground and is responsible for the abatement of $8 \mathrm{Mt}$ of $\mathrm{CO} 2$ per annum (European Heat Pump Association and Delta Energy and Environment, 2013).

\footnotetext{
${ }^{1}$ The School of the Built Environment and Architecture, London South Bank University, 103 Borough Road, London SE10AA; email: yebiyom2@1sbu.ac.uk

${ }^{2}$ School of the Built Environment and Architecture, London South Bank University, 103 Borough Road, London SE1 $0 \mathrm{AA}$

${ }^{33}$ School of the Built Environment and Architecture, London South Bank University, 103 Borough Road, London SE1 $0 \mathrm{AA}$

${ }^{4}$ International Energy Research Centre Tyndall National Institute Lee Maltings Dyke Parade Cork e: tony.day@ierc.ie
} 
The performance of GSHP systems is intrinsically related to the ground and load temperatures. It is unavoidable that ground temperatures will change to some degree in response to extraction of heat from, or rejection of heat to, the ground. However, it is important to recognise that the ground is not an infinite source or sink of energy, and that excessively large net rates of extraction or rejection of heat to the ground must be avoided. If excessive rates of heat extraction from, or rejection to, the ground are allowed for prolonged periods, then it is likely that significant changes in ground temperature will occur; such ground temperature changes can have significant detrimental impact on overall system efficiency or COP (Coefficient of Performance), as well as large environmental impact. Zoi and Constantinos (2012) proposed a GSHP system controlled with only cooling tower and investigated three control strategies to minimise this significant change in ground temperature by using simpler heat rejection or 'free cooling'. The first one determines the set point at which a cooling tower starts its operation according to the fluid temperature exiting HP and ambient air wet bulb temperature exceeds a given set point. The second one activates the cooling tower when the fluid temperature exiting the ground heat exchanger (GHX) is greater than a certain value. The third one sets the cooling tower on when the fluid temperature exiting the HP is greater than a given value.

This paper investigates the use of a DAC rather than a cooling tower to reduce the level of ground temperature saturation by rejecting heat via a DAC when the ground and ambient temperatures favour this. DACs are often fitted to GSHP systems to reject heat during extreme conditions to protect the system, rather than improve performance. Opportunities exist to control the performance of the GSHP using a DAC and also the predicted seasonal or daily ground temperature as well as predicted/available energy demand of the building. However these control systems are not reported in the literature.

This paper includes the description of the new system and its operation, the simulation setup, the investigation of new control strategies using a DAC and the conclusions.

\section{DESCRIPTION OF THE NEW SYSTEM AND ITS OPERATION}

The proposed system employs the existing London South Bank University's (LSBU) GSHP installation and components but operates it differently to how it was originally configured. The GSHP system within the K2 building at LSBU uses four WaterFurnace EKW130 reversible HP units. Each has a nominal capacity of $120 \mathrm{~kW}$ for heating and $125 \mathrm{~kW}$ for cooling. The heat is transferred from and to the ground through a closed loop system with the aid of 159 vertical energy piles which are built into the foundations of the structure and bored into the London clay. The building's heating and cooling generation is fully provided for by the GSHP system. The source-side of the system consists of energy piles and header pipes to which the HPs add or extract heat using a heat transfer fluid which is pumped and exchanges energy between the building and the ground.

The original system utilised a DAC designed to operate when the heat sink temperatures were either too high or too low. The DAC was therefore employed as a safety device to 
protect the heat pump from operating outside its safe envelope. In the proposed system the DAC was used tactically to improve the efficiency and performance of the heat pump and therefore system. The system simulated is shown in Figure 1 below. This shows the system controlled to provide heat rejection via the DAC rather than the ground loop to achieve the best COP. This relies on the principle that heat pump efficiency or COP is affected significantly by its temperature lift with a $1 \mathrm{~K}$ reduction giving typically a $3 \%$ rise in COP. The DAC can therefore be employed selectively when it will produce more favourable heat sink temperatures (and therefore higher COP) compared to those generated by the ground sink. The proposed system has the potential to save energy, however should not require additional components compared to the existing system, although it will be controlled differently. The performance improvement of the proposed system is investigated in the following sections.

Figure 20 Schematic of the System Simulated.

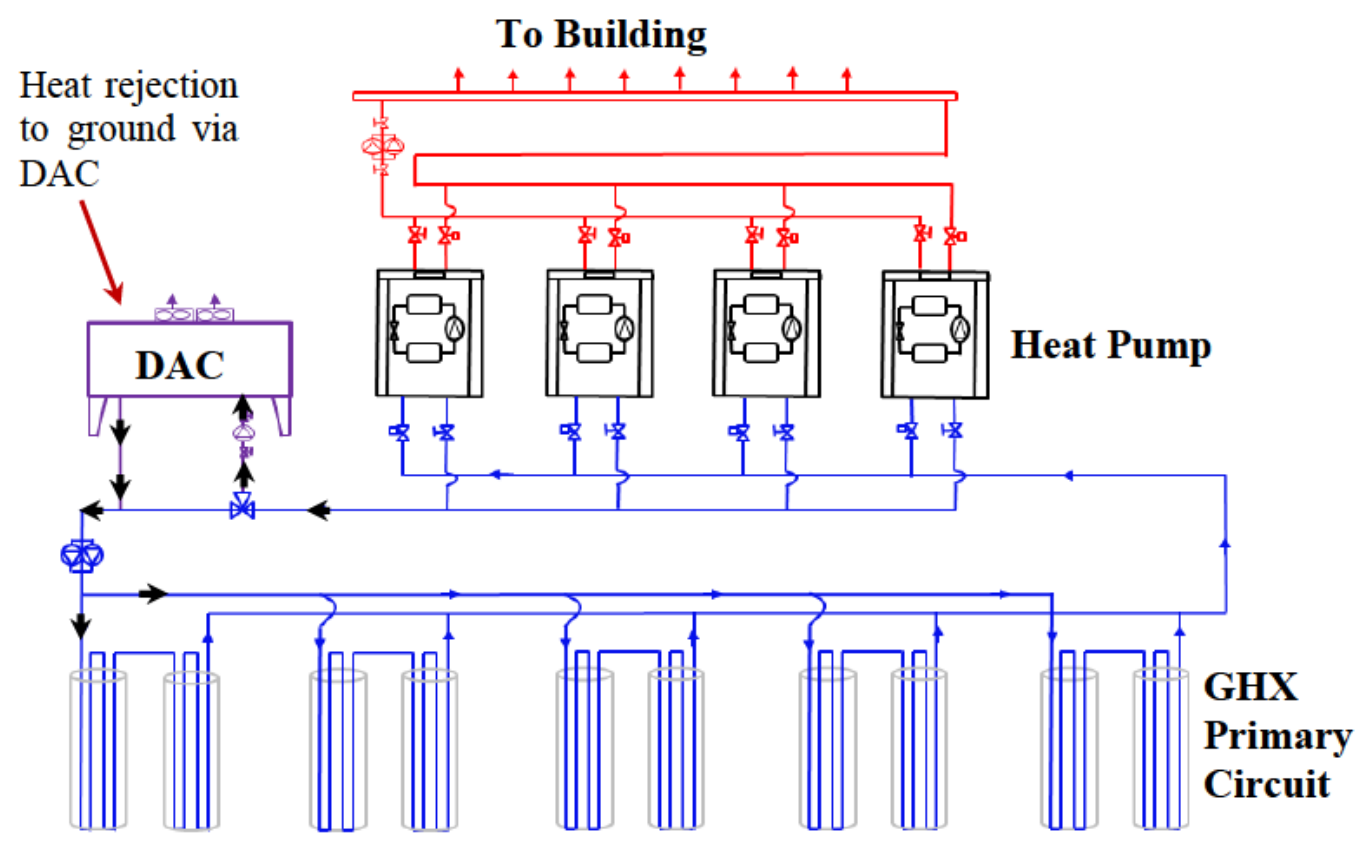

\section{THE SIMULATION SETUP}

The following section presents a description of the operation of the different components of the system which is replicated by interconnecting a set of models. In order to simulate the experimental observations, a model has been built using the TRNSYS 17 simulation software (TRNSYS, 2010). This allows the construction of a GSHP system simulator that closely resembles and simulates the actual HP installation. The main parts of the GSHP system that have been used in building the simulation model are: the ground heat exchanger (Type 557), the HP model (Type 668), the circulating pumps, flow stream loads (Type 682), DAC (Type 511), tempering valve (Type 11) and tee piece (Type 511). 


\subsection{Ground Heat Exchanger (Type 557a)}

The ground heat exchanger component (Type 557a) was set up with the appropriate geometrical configuration and relevant ground thermal properties some of which were derived from the thermal response testing carried out in the GSHP design stage. In the current work 159 energy piles are used to exploit the ground's heating and cooling capacity. Type 557a models a set of equal vertical U-tube heat exchangers which thermally interact with the ground. This ground heat exchanger model is most commonly used in GSHP applications. A heat carrier fluid is circulated through the ground heat exchanger and either rejects heat to, or absorbs heat from the ground depending on the temperatures of the heat carrier fluid and the ground.

\subsection{Heat Pump Model (Type 688)}

The HP model (Type668) relies upon catalogue data readily available from HP manufacturers for the performance measurement related to the HP that is being simulated. At the heart of the component are two data files: a file containing cooling performance data, and a file containing heating performance data. Both data files provide capacity and power draw of the HP (whether in heating or cooling mode) as functions of entering source fluid temperature and entering load fluid temperature these establish the performance envelope of the HP over a range of ground source side temperatures and a range of load side temperatures.

The data used to build this HP model were obtained from the manufacturer WaterFurnace. The Type668 HP is equipped with two control signals, one for heating and one for cooling. However, heating mode takes precedence over cooling mode. If the heating and cooling control signals are both $\mathrm{ON}$, the model will ignore the cooling control signal and will operate in heating mode.

The HP's COP in heating is given by equation 1.

$\mathrm{COP}=\frac{\mathrm{Q}_{\mathrm{HP}}[\mathrm{kW}]}{\mathrm{W}_{\mathrm{HP}}[\mathrm{kW}]}$

The amount of energy absorbed from the source fluid stream in heating is given by equation 2

$Q_{\text {absorbed }}=$ Cap $_{\text {heating }}-P_{\text {heating }}$

The outlet temperatures of the two liquid streams can then be calculated using equations 3 and 4.

$T_{\text {Source,out }}=T_{\text {source, in }}-\frac{Q_{\text {absorbed }}}{m_{\text {source } C p_{\text {source }}}}$

$T_{\text {load,out }}=T_{\text {load,in }}-\frac{\text { Cap }_{\text {heating }}}{m_{\text {load }} C p_{\text {load }}}$

The HP's COP in cooling mode is given by equation 5 . 
$\mathrm{COP}=\frac{\mathrm{Q}_{\mathrm{HP}}[\mathrm{kW}]}{\mathrm{W}_{\mathrm{HP}}[\mathrm{kW}]}$

The amount of energy rejected by the source fluid stream in cooling mode is given by equation 6

$Q_{\text {absorbed }}=$ Cap $_{\text {cooling }}+P_{\text {cooling }}$

The outlet temperatures of the two liquid streams can then be calculated using equations 7 and 8.

$$
\begin{aligned}
& T_{\text {Source,out }}=T_{\text {source,in }}+\frac{Q_{\text {rejected }}}{m_{\text {source }} C p_{\text {source }}} \\
& T_{\text {load,out }}=T_{\text {load,in }}+\frac{\text { Cap } p_{\text {cooling }}}{m_{\text {load }} C p_{\text {load }}}
\end{aligned}
$$

\subsection{Circulation Pumps (Type 741)}

There are two circulation pumps. In reality each pump represents a series of pumps; Type 741 models a variable speed pump that is able to produce any mass flow rate between zero and its rated flow rate. The pump's power draw is calculated from pressure rise, overall pump efficiency, motor efficiency and fluid characteristics. As with most pumps and fans in TRNSYS, Type741 takes mass flow rate as an input but ignores the value except in order to perform mass balance checks. Type741 sets the downstream flow rate based on its rated flow rate parameter and the current value of its control signal input.

\subsection{DAC (Type 511)}

Type511 models a dry air cooler; a device used to cool a liquid stream by blowing air across coils containing the liquid. This model assumes that the device can be modeled as a single-pass, cross-flow heat exchanger.

\subsection{Tempering valve (Type 11b)}

The use of pipe or duct 'tee-pieces', mixers, and diverters, which are subject to external control, is often necessary in thermal systems. This valve allows the system to be controlled in response to temperature of the fluid leaving the heat pump.

\subsection{Tee piece (Type 511h)}

This instance of the Type11 model uses modes 1 and 6 to simulate the function of a teepiece that completely mixes two inlet streams of the same fluid at different temperatures and or humidities.

The system model which is used in this study is shown in Figure 2 below. A list of assumptions is shown in table 1 . 
Figure 21 Schematics of the DAC simulation setup connected to GSHP system

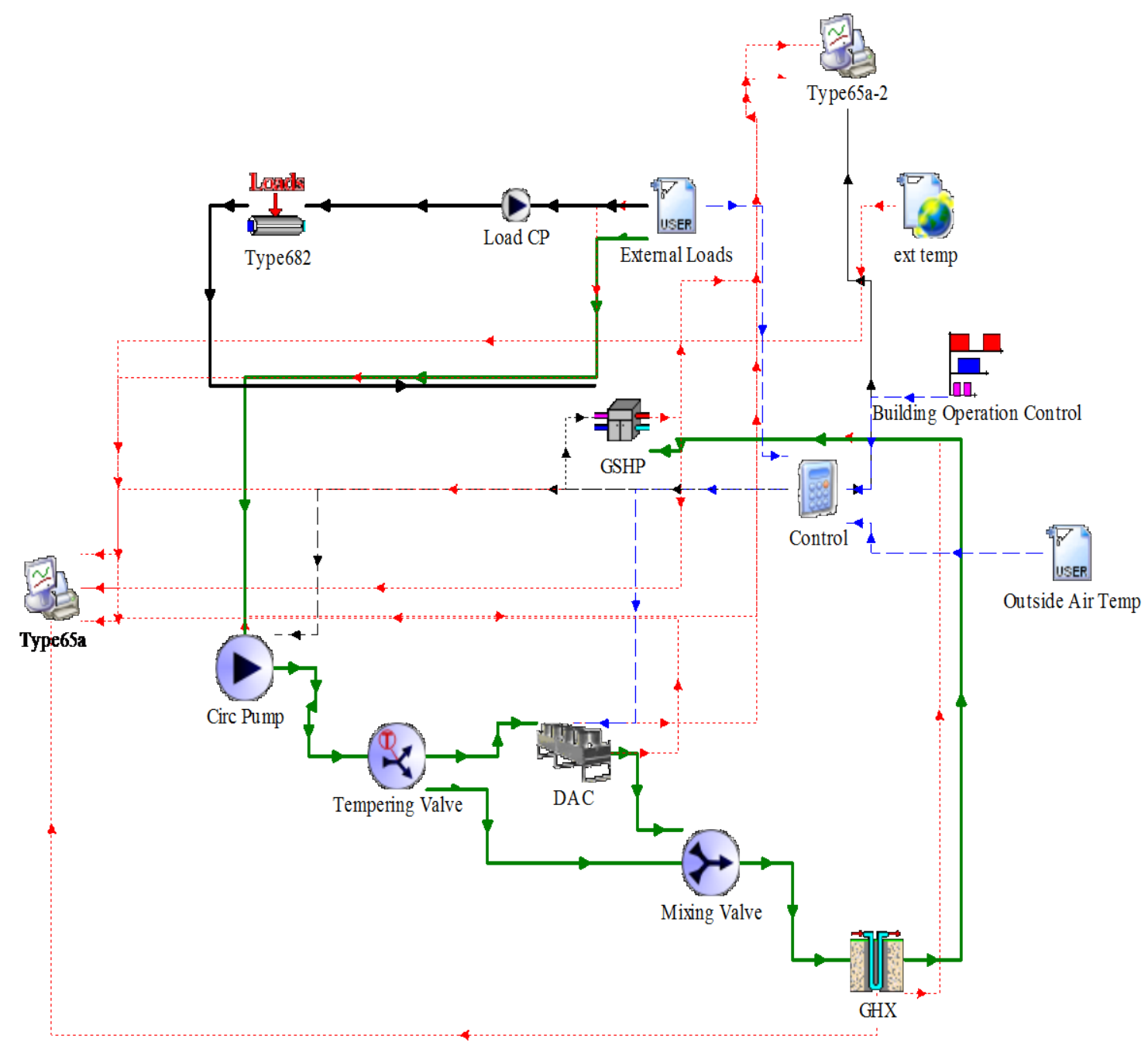

Table 1 list of model inputs and assumptions

List of Model Inputs and Assumptions

Occupancy period 13 hours every day except weekends

Historical outside air temperature (OAT)

Flow and return fluid temperatures on both source and load side of the system

Heating and cooling performance data of the heat pump model

Heat pump and Circulation pumps to operate in heating mode if the $\mathrm{OAT}>18^{\circ} \mathrm{C}$

Heat pump and Circulation pumps to operate in heating mode if the $\mathrm{OAT}<14^{\circ} \mathrm{C}$ 


\section{MODEL VALIDATION}

The empirical TRNSYS model developed was validated using experimental data from London South Bank University's actual GSHP system installation. For validation of the model, several tests have been conducted, the various physical components of the system have been kept as close to reality as possible. A comparison between model predicted and independently determined COP values for both the actual and predicted test shows a very reasonable agreement. Figure 3 shows that a maximum deviation of about $\pm 7 \%$ is observed.

Figure 22 Comparison of actual and predicted COP

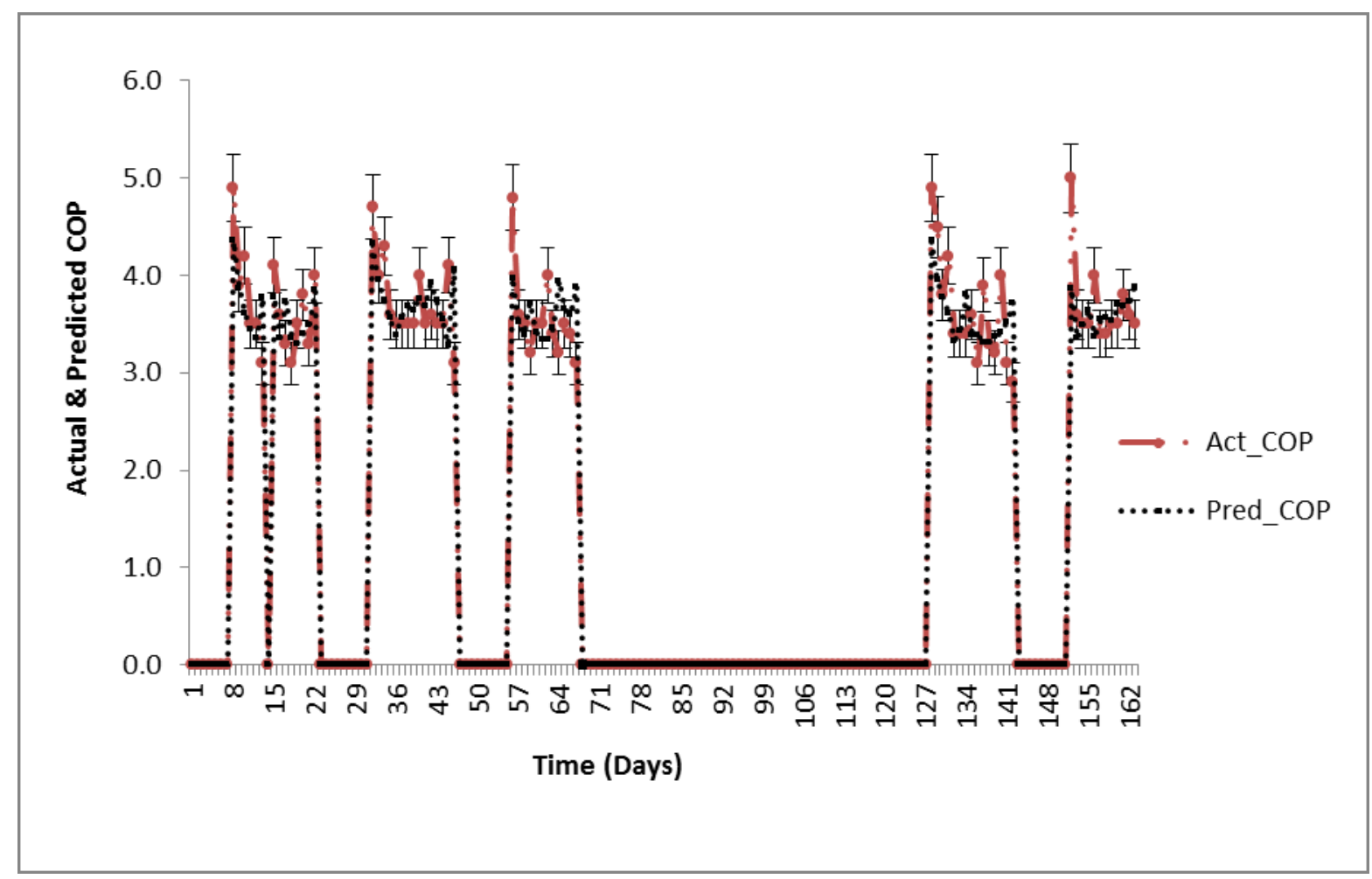

\section{Investigating New Control Strategies Using DAC}

The current control strategy of $\mathrm{K} 2$ is designed to operate the DAC only in the event that the temperature of the water returning from the ground loop exceeds $38{ }^{\circ} \mathrm{C}$. The control system enables the dry air cooler shunt pump which is positioned in the loop supplying the DAC and circulates the water to the already enabled DAC. The DAC has its own internal PID based control system which controls the temperature of the water leaving the dry coolers to $22{ }^{\circ} \mathrm{C}$.

The existing system model was reconfigured to reject heat into the ground to ease ground saturation which has consequences on the performance of the system. Therefore having built and established a validated empirical TRNSYS system model the opportunity was 
taken to investigate the effects of different control strategy approaches using the DAC on HP performance and ground temperature variation.

Control strategies utilized in this study define when and how the DAC circuit, circulation pumps and the HP should be turned on or off. The system's electrical power consumption is the sum of three terms: HP power, power of each circulating pump and DAC fan power.

Figure 2 shows a schematic of the empirical GSHP system model used for investigating the control strategies. The control strategies set DAC on when the fluid temperature exiting HP is greater than a given value. Different desired outlet fluid temperatures of 22, 24,26 and $28{ }^{\circ} \mathrm{C}$ are examined and hence the normal operating condition of the system has been compared to these four different scenarios to investigate the impact of running the DAC at different temperature set points. Scenarios CS1, CS2, CS3 and CS4 are being used instead of the four desired control temperatures. In these comparisons the following parameters have been investigated:

\section{COP OF THE SYSTEM.}

\section{Ground temperature variation}

\section{Heat Pump Energy Consumption}

These results are presented on the following sections 5.1 to 5.4 and compared against the normal operating control scenario.

\subsection{Effect of DAC on COP}

The cooling COP value of the GSHP system under different temperature set points is illustrated in Figure 4. It can be noted that at the beginning of the season between April and June 2013 the COP values for all the four set temperature scenarios were very close to each other. This is when the DAC is not running and this is labelled Time Period A. In Time Period B the DAC is operating partially or fully between the periods of June to October 2013 and there is a variation in COP between the options. This COP differences is purely because the DAC has been utilised in lowering the leaving fluid temperature from the HP by rejecting the heat back to the ground at a lower temperature compared to the normal operating leaving fluid temperature.

It is clear that the GSHPs COP value decreases continuously with increasing set point temperature. For the first year's operation of the GSHP system, the COP values for cooling is highest for the lowest set point temperature.

Compared to the normal operating scenario in which the COP value for cooling is decreased to 5.2 while setting the temperature set point control to $22{ }^{\circ} \mathrm{C}$ achieves a lower cooling COP of 6.2 which is $19.2 \%$ higher than the normal operating scenario. 
Figure 23 Average Monthly system COP

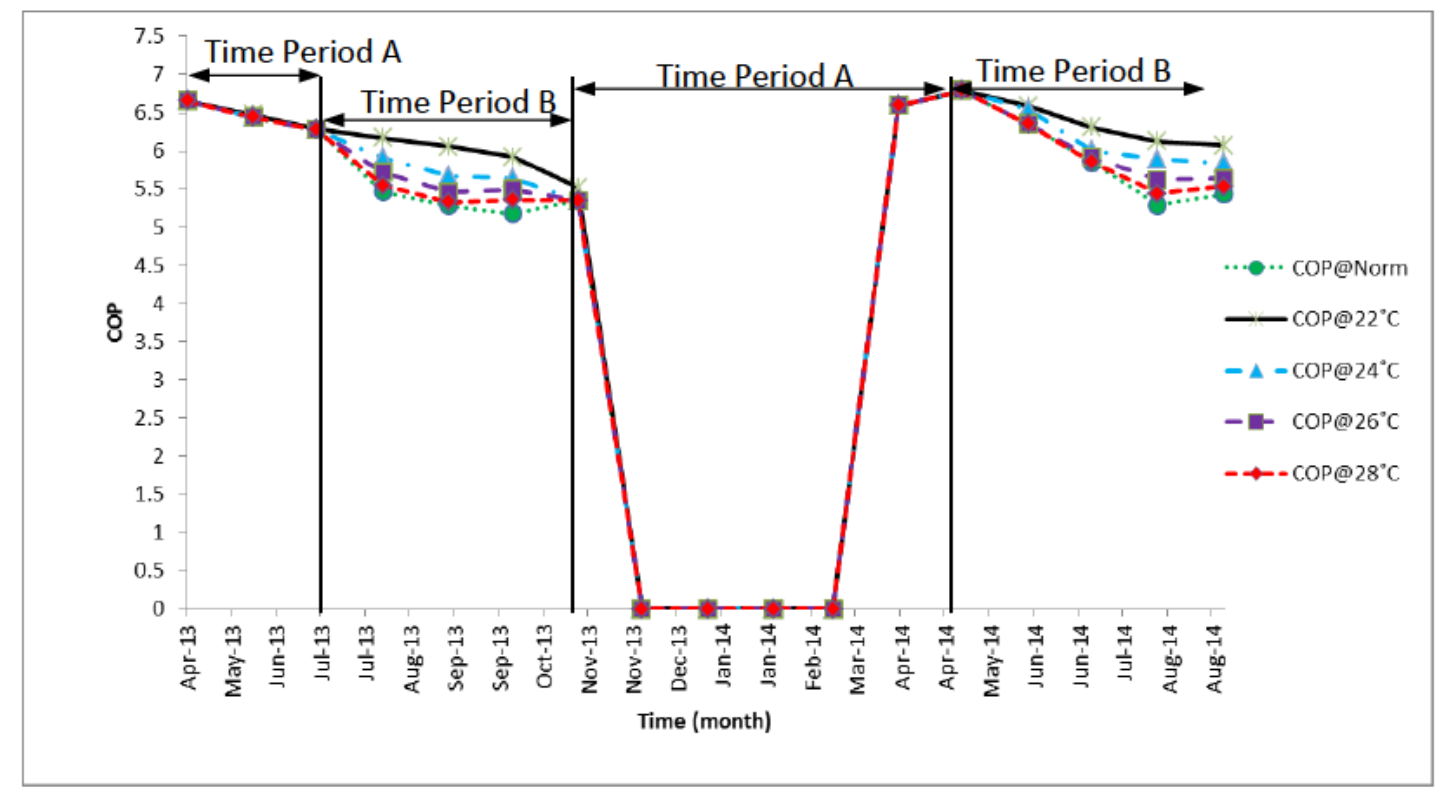

\subsection{Effect of DAC on Ground Temperature}

As well as investigating the effect of operating period of the DAC on the performance of the system, the effect on the ground temperature is also investigated. The simulation results of ground temperature for 1 year's operation are presented in Figure 5. The results show that the four different set point operation temperatures of the DAC leads to differences in the ground temperature variation when the set point temperature varies. In Time Period A when the DAC is not operating at the beginning of the cooling season the ground temperature is similar and hence varying the ground temperature set points has no effect at all. Therefore the ground temperature for all scenarios remain constant. However in Time Period B the temperature variation between the scenarios becomes clear that the more the DAC is running the lower the ground temperature variation is. The highest ground temperature after 1 year's operation in cooling mode is $23{ }^{\circ} \mathrm{C}$ for normal operation period, compared to $20^{\circ} \mathrm{C}$ for the lowest set point temperature which is $15 \%$ lower than the normal operation. This impacted on COP and therefore by reducing the ground temperature from 23 to $20^{\circ} \mathrm{C}$, the overall system performance has improved by approximately $9 \%$ and this can be seen clearly in Figure 4 above.

With the decrease of average ground temperature around the ground heat exchanger, the temperature difference between the ground and the circulated heat carrier fluid decreases, this phenomena has both advantages and disadvantages on the system. Although this incremental temperature change improves the $\mathrm{COP}$ value during cooling season, however it also reduces the COP value of the system in heating season. 
Figure 24 Monthly ground temperature variations

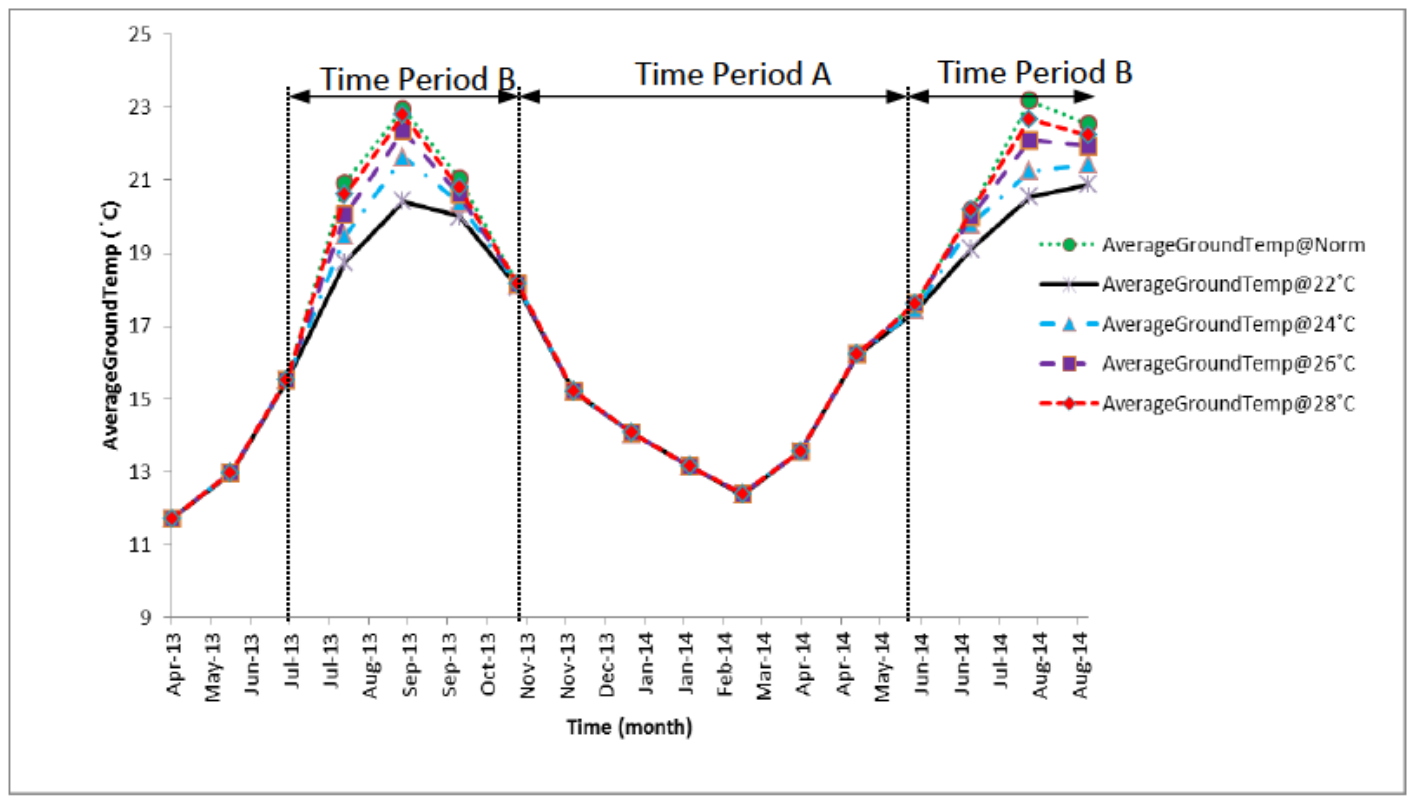

\subsection{Effect of DAC on Heat Pump Energy Consumption}

The total monthly HP energy consumption for scenarios CS1, CS2, CS3 and CS4 is presented in Figure 6. The operation cycle of the DAC can determine whether the GSHP system consumes more energy, compared to a GSHP system without DAC. Figure 6 shows that between the periods of April 2013 and August 2014 the highest energy consumption of the HP was $7923 \mathrm{kWh}$ and $7669 \mathrm{kWh}$ respectively and this has occurred at both when the system was running without the aid of the DAC and also when the DAC was controlled at the highest set point temperature of $28^{\circ} \mathrm{C}$, this dynamics can be shown clearly in Figure 6 during Time Period B. Time Period A shows that when the DAC is off the output of the four set points remain unchanged. Time Period B shows that when the DAC was operating at different set points, this zone also highlights the benefits of reducing the ground temperature as shown in Figure 5 to the energy input of the system. Reducing the ground temperature helps to reduce the temperature difference between the ground loop heat exchanger leaving temperature and HP leaving temperature and hence increasing COP of the system.

Similarly the lowest energy consumption of the system during the transition period to heating mode was $267 \mathrm{kWh}$. In Time Period B between the periods of July and September 2013, comparisons of the four scenarios revealed that the energy consumption of the system has decreased by $8 \%$ when the lowest control set point of $22{ }^{\circ} \mathrm{C}$ (CS4) was compared to the normal operating conditions of the system. 
Figure 25 Monthly HP energy consumption

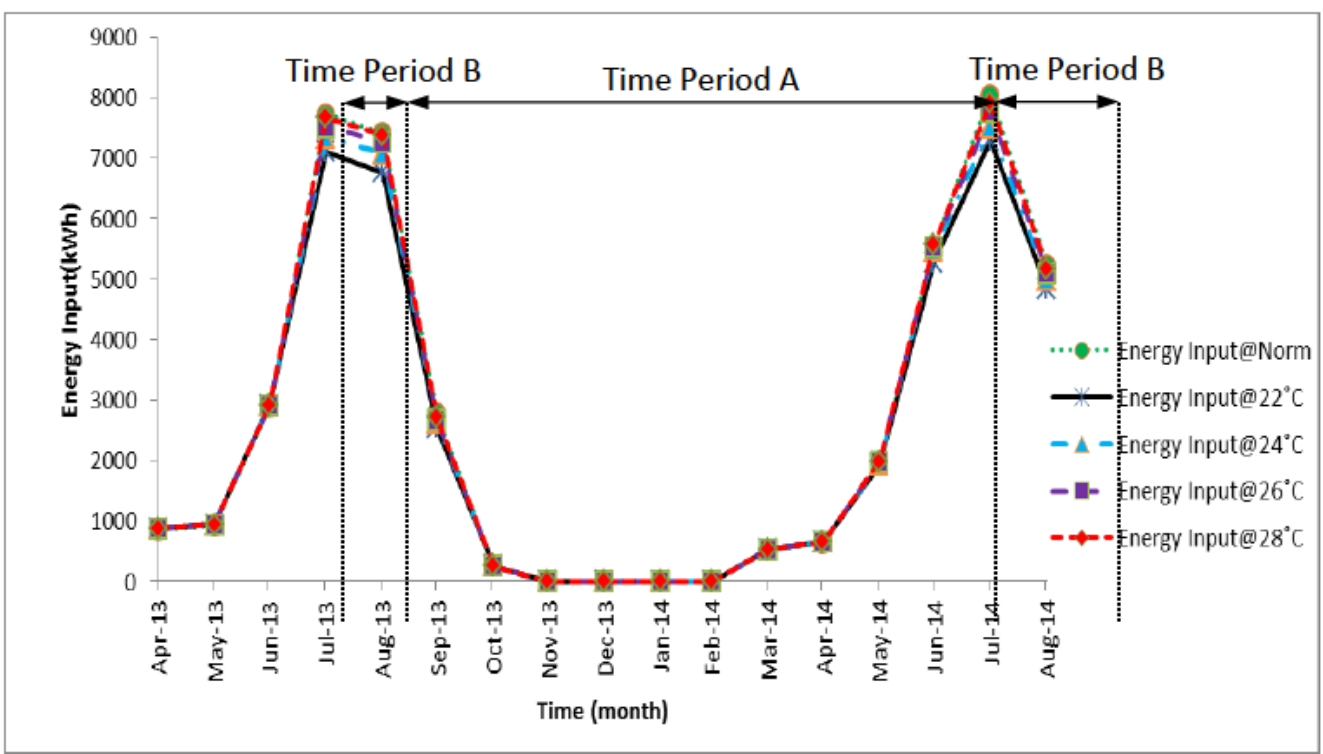

\subsection{Economics of The Control Strategy 1}

In this section the financial and $\mathrm{CO} 2$ emission savings of each temperature set point have been compared to the normal operation of the system. Figure 7 shows the additional monthly $\mathrm{CO} 2$ emission savings $(\mathrm{kgCO} 2)$ that can be achieved by implementing the different temperature control set points. The graph shows that in July 2014 a maximum $\mathrm{CO} 2$ emission saving of $420 \mathrm{kgCO} 2$ was achieved. Relating this to Figures 4 and 5 this is also the point at which the highest COP and highest ground temperature was recorded. Notably this has occurred at the lowest temperature set point of $22{ }^{\circ} \mathrm{C}$. Moreover the lowest $\mathrm{CO} 2$ emission saving was approximately $20 \mathrm{kgCO} 2$ and this has occurred at the highest temperature set point of $28{ }^{\circ} \mathrm{C}$. As can be seen the lowest temperature set point can yield a saving of approximately $17 \%$ compared to the highest temperature set point. In addition the lowest temperature set point can achieve cost savings of approximately 18 $\%$ compared to the highest temperature set point.

Figure 26 Monthly CO2 emission savings from different control strategy

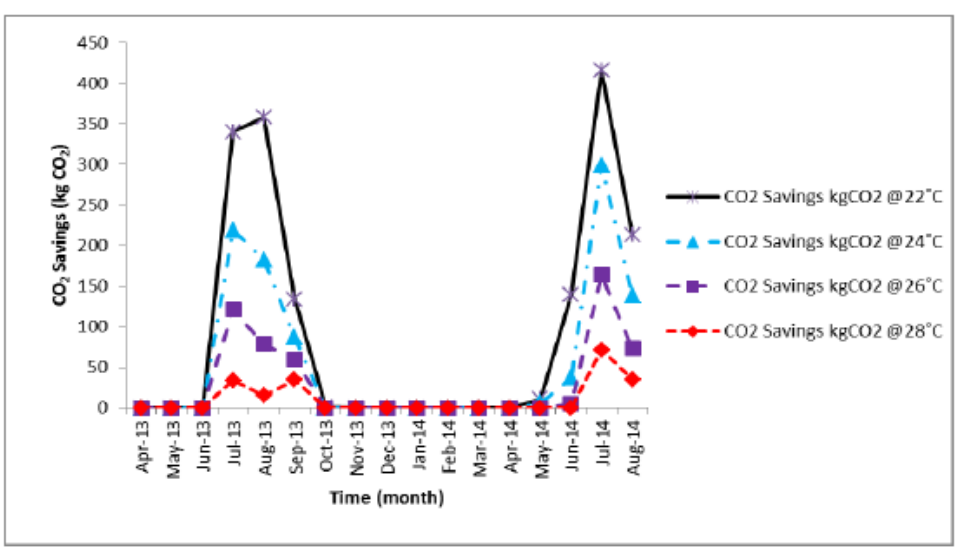




\section{CONCLUSION}

This paper has described the current different control strategies for DAGS system optimization during the net cooling period to a university building. The investigation has focused on the effect of DAC on heat rejection to the ground, COP of the system, ground temperature variation, minimization of electric power consumption of the compressor and circulation pump, assuming certain values for the building load, the HP and DAC maximum cooling capacity. Therefore, it might not be considered as a full system optimization but it still could be considered as a determining improvement in system's operation.

This paper has shown that by utilising and controlling a DAC using different temperature set points, a significant reduction to GSHP operating cost, the electric power consumption and an improvement to performance of the system could be achieved. However, it is difficult to claim that this is the most economically beneficial scenario, not only because the heating period is not examined but, also because the investment and maintaining cost have not been considered in unit selection. This is subject of further work.

This paper has identified that the lowest temperature set point control is the best of the examined so as to regulate DAC's operation in the GSHPs. A comparison of these four scenarios illustrates that there are significant cost and carbon savings that can be made and all new control strategies achieve a better regulation to system operation which leads to an extra reduction in the energy consumption, carbon and cost savings. These remarks can be used as guidance to future GSHP designers.

\section{ACKNOWLEDGMENTS}

The research of the GSHP was financially sponsored by UK Energy Research Centre (UKERC); their sponsorship is gratefully acknowledged.

\section{REFERENCES}

- Karl, O. (2008). Geothermal Heat Pumps, A guide for Planning \& installing: London, UK, pp.15. ISBN 9781844074068.

- Pachauri, R.K., Reisinger, A. (2007). Climate Change 2007: Synthesis Report. Contribution of Working Groups I, II and III to the Fourth Assessment Report of the Intergovernmental Panel on Climate Change, IPCC: Geneva, Switzerland; pp. 301-320.

- TRNSYS, (2010). Version 17. Transient system simulation program solar energy engineering laboratory Madison: University of Wisconsin. Available from: http://sel me.wisc.edu/trnsys/features/features html. [Accessed: 6th August 2015].

- UK Office of Climate Change OCC (2007). Household Emissions Project-Analysis Pack, London, UK.

- Zoi, S. and Constantinos, R. (2012). Control Strategy for minimizing the electric power consumption of Hybrid Ground Source Heat Pump System. Proceeding of ECOS JUNE 2629, 2012, PERUGIA, ITALY. 


\section{Theme 1 - Procurement and Construction Economics}

\begin{tabular}{|c|c|c|}
\hline Authors & Title & Keywords \\
\hline $\begin{array}{l}\text { ABDULAZEEZ A.D., } \\
\text { OWOICHO M.E. \& DAHIRU } \\
\text { D. }\end{array}$ & $\begin{array}{l}\text { Developers' Compliance to the Delivery } \\
\text { of Basic Infrastructure to Housing } \\
\text { Estates under the Public Private } \\
\text { Partnership Arrangement in Abuja }\end{array}$ & $\begin{array}{l}\text { Developers, Housing, Infrastructure, } \\
\text { Estates, Public Private Partnership. }\end{array}$ \\
\hline $\begin{array}{l}\text { AWUZIE B.O., EMUZE F.A. } \\
\& \text { NGOWI A. }\end{array}$ & $\begin{array}{l}\text { Towards Sustainable Procurement Of } \\
\text { Infrastructure At A South African } \\
\text { University Of Technology }\end{array}$ & $\begin{array}{l}\text { Case Study, Higher Education } \\
\text { Institutions, Infrastructure, South Africa, } \\
\text { Sustainability. }\end{array}$ \\
\hline $\begin{array}{l}\text { KAYODE, O., AKHAVAN } \\
\text { FARSHCHI, M. \& FORD, A. }\end{array}$ & $\begin{array}{l}\text { Analysis of Households Energy } \\
\text { Consumption in Nigeria }\end{array}$ & $\begin{array}{l}\text { Energy Modelling, Black Economy, } \\
\text { Households, Theory }\end{array}$ \\
\hline $\begin{array}{l}\text { CHIURUGWI T., UDEAJA } \\
\text { C., BABATUNDE S.O. \& } \\
\text { EKUNDAYO D. }\end{array}$ & $\begin{array}{llr}\text { Life cycle } & \text { costing in } & \text { construction } \\
\text { projects: } & \text { professional } & \text { quantity } \\
\text { surveyors' perspective } & \end{array}$ & $\begin{array}{l}\text { Barriers, Construction Organisations, } \\
\text { LCC, Professional Quantity Surveyors, } \\
\text { UK. }\end{array}$ \\
\hline $\begin{array}{l}\text { FARAG F. \& MCDERMOTT, } \\
\text { P. }\end{array}$ & $\begin{array}{l}\text { Using Soft System Methodology To } \\
\text { Approach Social Value Outcomes In } \\
\text { Public Procurement }\end{array}$ & $\begin{array}{l}\text { Public Clients, Public Procurement, } \\
\text { Sustainable Procurement, Soft System } \\
\text { Methodology, Social Value }\end{array}$ \\
\hline $\begin{array}{l}\text { GERAEDTS R.P. \& PRINS } \\
\text { M. }\end{array}$ & $\begin{array}{l}\text { The CE Meter; An instrument to assess } \\
\text { the circular economy capacity of } \\
\text { buildings }\end{array}$ & $\begin{array}{lcr}\text { Adaptable, } \quad \text { Flexible, } & \text { Assessment } \\
\text { Instrument, } \quad \text { Circular } & \text { Economy, } \\
\text { Sustainable, Open Building. } & \end{array}$ \\
\hline $\begin{array}{l}\text { JEFFERIES M.C., DAVIS } \\
\text { P.R. \& KE, Y. }\end{array}$ & $\begin{array}{l}\text { An Investigation of Psychological } \\
\text { Contracts in Construction Procurement }\end{array}$ & $\begin{array}{ll}\text { Psychological } & \text { Contracts; Traditional } \\
\text { Procurement; } & \text { Alliance Contracting; } \\
\text { Focus Groups. } & \end{array}$ \\
\hline $\begin{array}{l}\text { KOOLWIJK J.S.J., OEL VAN } \\
\text { C.J. \& WAMELINK J.W.F. }\end{array}$ & $\begin{array}{l}\text { Supply Chain Partnership in } \\
\text { construction A field study on project } \\
\text { team level factors }\end{array}$ & $\begin{array}{l}\text { Supply Chain Partnership, Project Team } \\
\text { Level, Participative Observation, } \\
\text { Construction Industry }\end{array}$ \\
\hline $\begin{array}{l}\text { KORAYEM I.M., } \\
\text { OGUNLANA S.O. \& } \\
\text { BOATENG P. }\end{array}$ & $\begin{array}{l}\text { Development Of The "Water-Specific } \\
\text { P3 Risk Model", Risks Identified }\end{array}$ & $\begin{array}{l}\text { Public-Private Partnerships, Water } \\
\text { Infrastructure, PPP Water Projects, Risk } \\
\text { Assessment, Value For Money, Analytic } \\
\text { Network Process. }\end{array}$ \\
\hline OBI L.I. \& ARIF M. & $\begin{array}{l}\text { A case for Target Value Design towards } \\
\text { Effective Low-cost Housing Project } \\
\text { Cost Management and Performance in } \\
\text { South-East zone Nigeria }\end{array}$ & $\begin{array}{l}\text { Cost Management, Low-Cost Housing, } \\
\text { Project Cost Performance, } \\
\text { Sustainability, Target Value Design }\end{array}$ \\
\hline $\begin{array}{l}\text { OWOLABI H.A., OYEDELE } \\
\text { L.O.C., ALAKA A.H., AJAYI, } \\
\text { O.S., AKINADE O.O., \& } \\
\text { MUHAMMAD BILAL }\end{array}$ & $\begin{array}{l}\text { Stimulating The Bankability Of PFI/PPP } \\
\text { Infrastructures Through The UK } \\
\text { Government Guarantees: Prospects And } \\
\text { Challenges. }\end{array}$ & $\begin{array}{l}\text { Construction Industry, Government } \\
\text { Guarantee Scheme, Private Finance } \\
\text { Initiative (PFI), Project Finance, Public } \\
\text { Private Partnerships (PPP). }\end{array}$ \\
\hline $\begin{array}{l}\text { POTTS M., MCDERMOTT P. } \\
\text { \& STEPHENSON, A. }\end{array}$ & $\begin{array}{l}\text { Strategic change in the delivery of } \\
\text { infrastructure }\end{array}$ & $\begin{array}{l}\text { Change Management, Infrastructure } \\
\text { Delivery, Participatory Research, Socio } \\
\text { Technical Systems. }\end{array}$ \\
\hline
\end{tabular}




\section{Theme 2 - Culture and Human Resources}

\begin{tabular}{|c|c|c|}
\hline Authors & Title & Keywords \\
\hline AKGUL G. \& GIRITLI F.H. & $\begin{array}{l}\text { Perceptions Of Different } \\
\text { Stakeholders Towards Sustainability: } \\
\text { A Case Example From The Turkish } \\
\text { Construction Industry }\end{array}$ & $\begin{array}{ll}\text { Construction, LEED, } & \text { Management, } \\
\text { Perception, } & \text { Stakeholders, } \\
\text { Sustainability. } & \end{array}$ \\
\hline AHUJA V. \& KUMARI S. & $\begin{array}{l}\text { Women Professionals' Participation } \\
\text { In The Construction Industry - Indian } \\
\text { Scenario }\end{array}$ & $\begin{array}{l}\text { Indian Construction Industry, Issues } \\
\text { And Challenges, Women Workforce }\end{array}$ \\
\hline $\begin{array}{l}\text { AJAYI S. O., OYEDELE L. O., } \\
\text { KADIRI K. O., MUHAMMAD B., } \\
\text { AKINADE O.O., OWOLABI H.A., } \\
\text { \& ALAKA H.A. }\end{array}$ & $\begin{array}{l}\text { Industry Culture As Causative } \\
\text { Agents Of Construction Waste: A } \\
\text { Need For Cultural Change }\end{array}$ & $\begin{array}{l}\text { Construction Waste, Collaboration, } \\
\text { Make-Do Waste, Waste Behaviour, } \\
\text { Landfill. }\end{array}$ \\
\hline $\begin{array}{l}\text { HUA Y.Y., LIU A.M.M. \& TIJHUIS } \\
\text { W. }\end{array}$ & $\begin{array}{l}\text { Interactions Of Culture And Person- } \\
\text { Technology Fit }\end{array}$ & $\begin{array}{l}\text { Construction, Information And } \\
\text { Communication Technology, } \\
\text { Innovation, Task-Technology Fit, } \\
\text { Technology-Culture Fit. }\end{array}$ \\
\hline $\begin{array}{l}\text { LESAILANE M.P., AIGBAVBOA } \\
\text { C.O. \& THWALA W.D. }\end{array}$ & $\begin{array}{l}\text { Determinants Of Employee Job } \\
\text { Satisfaction In The Gauteng Province } \\
\text { Of South Africa }\end{array}$ & $\begin{array}{l}\text { Absenteeism, Construction, } \\
\text { Employee Turnover, Job Satisfaction, } \\
\text { Job Dissatisfaction }\end{array}$ \\
\hline $\begin{array}{l}\text { LOUSBERG L.H., HEINTZ J.L. \& } \\
\text { PRINS M. }\end{array}$ & $\begin{array}{l}\text { Sustainability In Projects Requires } \\
\text { Training In Managing As Designing }\end{array}$ & $\begin{array}{l}\text { Sustainability, Training, Reflection- } \\
\text { In-Action, Design-Thinking, Project } \\
\text { Management }\end{array}$ \\
\hline OLOWOAKE M.A. & $\begin{array}{l}\text { Influence Of Host Organisation } \\
\text { Culture In The Execution Of } \\
\text { Construction Projects: A Case Study } \\
\text { Of Selected Higher Education } \\
\text { Institutions In Nigeria. }\end{array}$ & $\begin{array}{l}\text { Project Budget, Country Culture, } \\
\text { Sustainable Environment, Sustainable } \\
\text { Programme, Quality Control. }\end{array}$ \\
\hline RWELAMILA P.D. \& BROWN S.T. & $\begin{array}{l}\text { Implementation Of Early Conflict } \\
\text { Management Measures In } \\
\text { Construction Projects - The Case Of } \\
\text { South Africa" }\end{array}$ & $\begin{array}{l}\text { Early Conflict Management, Projects, } \\
\text { Disputes, Construction Industry, } \\
\text { South Africa }\end{array}$ \\
\hline
\end{tabular}




\section{Theme 3 - Infrastructure Development and Management}

\begin{tabular}{|c|c|c|}
\hline Authors & Title & Keywords \\
\hline $\begin{array}{l}\text { ADEYINKA B.F., JAGBORO G.O. } \\
\& \text { OJO, G.K. }\end{array}$ & $\begin{array}{l}\text { An Evaluation Of Factors Influencing } \\
\text { Compliance Of Construction } \\
\text { Professionals To Ethical Standards }\end{array}$ & $\begin{array}{lcr}\text { Professional } & \text { ethics, } & \text { construction } \\
\text { industry, } & \text { compliance; } & \text { ethical } \\
\text { standards } & & \end{array}$ \\
\hline $\begin{array}{l}\text { ABDUL-RASHID A.A. \& CHOW } \\
\text { W.W. }\end{array}$ & $\begin{array}{l}\text { An Exploration Of Malaysian Public } \\
\text { Listed Companies Diversifying Into } \\
\text { Property Development }\end{array}$ & $\begin{array}{l}\text { Diversification, Housing } \\
\text { Development, Liability Of Newnes, } \\
\text { Serendipity. }\end{array}$ \\
\hline $\begin{array}{l}\text { AIGBAVBOA C.O. \& THWALA } \\
\text { W.D. }\end{array}$ & $\begin{array}{l}\text { Beneficiary Housing Participation } \\
\text { Defined - A South Africa Perspective }\end{array}$ & $\begin{array}{l}\text { Beneficiary Participation, Housing, } \\
\text { Housing Policy, Low-Income, Low- } \\
\text { Income Housing, }\end{array}$ \\
\hline $\begin{array}{l}\text { CHILVERS. S. CHAER, I. \& } \\
\text { FORD A. }\end{array}$ & $\begin{array}{l}\text { Environmental Impact And Energy } \\
\text { Management Of Sports Stadia }\end{array}$ & $\begin{array}{l}\text { Energy Management, Regulations, } \\
\text { Sports Stadia, Stadium Design, } \\
\text { Sustainability. }\end{array}$ \\
\hline GILLICH A. \& FORD A. & $\begin{array}{l}\text { Performance In Use: The Great } \\
\text { Externality Of The Built Environment }\end{array}$ & $\begin{array}{l}\text { Building Performance, Evaluation, } \\
\text { Externality, Innovative Procurement, } \\
\text { Social Responsibility. }\end{array}$ \\
\hline HUOVINEN P. & $\begin{array}{lrr}\text { Leveraging } & \text { Concepts } & \text { For } \\
\text { Environmentally } & \text { Sustainable } \\
\text { Business } & \text { Management } & \text { In }\end{array}$ & $\begin{array}{l}\text { Business Management, Concept } \\
\text { Design, Construction, Environmental } \\
\text { Sustainability, Research Review }\end{array}$ \\
\hline LONDON K. \& PABLO Z. & $\begin{array}{l}\text { Construction - A Focused Review } \\
\text { Innovation In Offsite Manufacturing } \\
\text { In The Field Of Housing: A Case } \\
\text { Study Using Bourdivian And Actor- } \\
\text { Network Approaches }\end{array}$ & $\begin{array}{l}\text { Actor-Network Theory, Bourdieu, } \\
\text { Capital, Innovation, } \\
\text { Manufacturing }\end{array}$ \\
\hline $\begin{array}{l}\text { MADUKA N.S.1, UDEAJA C. \& } \\
\text { GREENWOOD D. }\end{array}$ & $\begin{array}{l}\text { Exploring Knowledge Management } \\
\text { Principles For Decision-Making In } \\
\text { Low-Energy Building For } \\
\text { Sustainability In Construction }\end{array}$ & $\begin{array}{l}\text { Climate Change, Existing Buildings, } \\
\text { Knowledge Management, Low- } \\
\text { Energy Retrofits, Decision Support. }\end{array}$ \\
\hline $\begin{array}{l}\text { MALTESE S., KAMARA J. M., } \\
\text { DEJACO M.C. \& RE CECCONI F. }\end{array}$ & $\begin{array}{l}\text { Towards An Adaptability Rating For } \\
\text { Buildings }\end{array}$ & $\begin{array}{l}\text { Adaptability, Change, Flexibility, } \\
\text { Function, Key Performance Indicator, } \\
\text { New Construction, Real Estate }\end{array}$ \\
\hline $\begin{array}{l}\text { MOREIRA D.A. COSTA J. \& } \\
\text { CORVACHO M. H. }\end{array}$ & $\begin{array}{l}\text { Improving Housing Quality } \\
\text { Through Client-Focused Information }\end{array}$ & $\begin{array}{l}\text { Client, Design, Evaluation Methods, } \\
\text { Quality, User }\end{array}$ \\
\hline PERSSON M. \& LYVALL A-C. & $\begin{array}{l}\text { Knowledge In The Decision-Making } \\
\text { Process For Sustainable Renovation } \\
\text { Of Multifamily Houses }\end{array}$ & $\begin{array}{l}\text { Basis For Decision, Knowledge } \\
\text { Management, Knowledge Transfer, } \\
\text { Renovation Decision, Renovation } \\
\text { Alternatives, Sustainable Renovation }\end{array}$ \\
\hline $\begin{array}{l}\text { TADE O.S., SMITH K., ALI A. \& } \\
\text { OPOKU A. }\end{array}$ & $\begin{array}{l}\text { Lessons For Specifying The System } \\
\text { Boundaries Of An Asset Management } \\
\text { Plan From Four Case Studies Of } \\
\text { Failure }\end{array}$ & $\begin{array}{l}\text { Asset Management, Environmental, } \\
\text { Design, Risk Management, } \\
\text { Sustainability }\end{array}$ \\
\hline
\end{tabular}


Reducing The Environmental Impact Construction Transport, And Improving The Efficiency of Environmental Impact, Logistics Construction Transport

Management, Productivity, Transport Efficiency 


\section{Theme 4 - Construction Industry and Global Economy}

\begin{tabular}{|c|c|c|}
\hline Authors & Title & Keywords \\
\hline $\begin{array}{lrrr}\text { AJAYI } & \text { S.O., } & \text { OYEDELE } & \text { L.O. } \\
\text { KADIRI, K.O. \& DAVID S.A. } & \end{array}$ & $\begin{array}{l}\text { Building Sustainability And Building } \\
\text { Health: An Inextricable Synergy }\end{array}$ & $\begin{array}{l}\text { Acidification, Building and Health, } \\
\text { Global Warming, } \\
\text { Sustainability }\end{array}$ \\
\hline AKGUL G \& GIRITLI F.H. & $\begin{array}{l}\text { Research Trend Of Sustainability In } \\
\text { Construction Journals }\end{array}$ & $\begin{array}{l}\text { Construction Publications, } \\
\text { Construction, Green, Research Trend, } \\
\text { Reviews, Sustainability }\end{array}$ \\
\hline $\begin{array}{l}\text { ALAKA H.A., OYEDELE L. O., } \\
\text { KADIRI K.O., OWOLABI H.A., } \\
\text { AJAYI S.O., AKINADE O.O. \& } \\
\text { BILAL M. }\end{array}$ & $\begin{array}{l}\text { Corporate Factors Influencing } \\
\text { Sustainable Construction Enterprise }\end{array}$ & $\begin{array}{l}\text { Construction Firms, Construction } \\
\text { Industry, Corporate Failure, Key } \\
\text { Factors, SMEs, Sustainability }\end{array}$ \\
\hline $\begin{array}{l}\text { ARTHUR-AIDOO B.M., } \\
\text { AIGBAVBOA, C.O. \& THWALA } \\
\text { W.D. }\end{array}$ & $\begin{array}{l}\text { A Framework For Growth Of Small } \\
\text { And Medium-Size Construction } \\
\text { Firms: A Literature Review }\end{array}$ & $\begin{array}{l}\text { Construction Firm, Framework, } \\
\text { Growth, Sustainable, Small And } \\
\text { Medium-Size }\end{array}$ \\
\hline $\begin{array}{l}\text { BROCKMANN C. \& BREZINSKI } \\
\text { H. }\end{array}$ & $\begin{array}{l}\text { A New Theory-Based Typology For } \\
\text { Construction Projects }\end{array}$ & $\begin{array}{l}\text { Complexity, Difficulty, Novelty, } \\
\text { Specificity, Typology }\end{array}$ \\
\hline DEMIRCIOGLU Y. \& GIRITLI F.H. & $\begin{array}{l}\text { Organizational Identification And } \\
\text { Turnover Intention Of Employees In } \\
\text { The Turkish Construction Industry }\end{array}$ & $\begin{array}{lr}\text { Construction } & \text { Industry, } \\
\text { Organizational } & \text { Communication, } \\
\text { Organizational } & \text { Identification, } \\
\text { Perceived External } & \text { Prestige, } \\
\text { Turnover Intention } & \end{array}$ \\
\hline $\begin{array}{l}\text { KÄHKÖNEN K., KEINÄNEN M., } \\
\text { NAARANOJA M., NIEMI O. \& } \\
\text { SAVOLAINEN J. }\end{array}$ & $\begin{array}{l}\text { Research Programme On Innovative } \\
\text { Learning Spaces And Their } \\
\text { Development }\end{array}$ & $\begin{array}{l}\text { Building Design, Educational } \\
\text { Environments, Design Management, } \\
\text { Property Development, User } \\
\text { Experience, Value Management }\end{array}$ \\
\hline $\begin{array}{l}\text { MOHAMMADI S. PRINS M. \& } \\
\text { SLOB, N. }\end{array}$ & Radical Circular Economy & $\begin{array}{l}\text { Radical Circular Economy, } \\
\text { Sustainability, Homo-Economicus, } \\
\text { Free Market Theory, Circular } \\
\text { Economy Theory, Cradle } 2 \text { Cradle, } \\
\text { Raw Materials, Environmental } \\
\text { Impact Reduction }\end{array}$ \\
\hline $\begin{array}{l}\text { PERERA S., VICTORIA M.F. \& } \\
\text { BRAND S. }\end{array}$ & $\begin{array}{l}\text { Use Of Social Media In Construction } \\
\text { Industry: A Case Study }\end{array}$ & $\begin{array}{l}\text { Case Study, Construction Industry, } \\
\text { Quantity Surveying, Social Media }\end{array}$ \\
\hline
\end{tabular}




\section{Theme 5 - Construction Technology, Research and Development}

\begin{tabular}{|c|c|c|}
\hline Authors & Title & Keywords \\
\hline ABDULLE F.A. \& XIAO R.Y. & $\begin{array}{l}\text { Fibrous Concrete For Sustainable } \\
\text { Construction }\end{array}$ & $\begin{array}{l}\text { Construction, } \quad \text { Conventional } \\
\text { Reinforced Concrete, Fibres, Fibrous } \\
\text { Concrete, Sustainable Material }\end{array}$ \\
\hline $\begin{array}{l}\text { AGOPYAN V., JOHN V.M. \& } \\
\text { SAVASTANO JR. H. }\end{array}$ & $\begin{array}{l}\text { Asbestos Free Fibrecement } \\
\text { Components }- \text { Fifteen Years Of Joint } \\
\text { Activities Between Industry And } \\
\text { University }\end{array}$ & $\begin{array}{l}\text { Composites, Durability, Fast Curing, } \\
\text { Fibrecements, Functionally Graded } \\
\text { Materials, Sustainable Building } \\
\text { Materials }\end{array}$ \\
\hline $\begin{array}{l}\text { ANDREWS D., DE GRUSSA Z., } \\
\text { CHALK A. \& BUSH D. }\end{array}$ & $\begin{array}{l}\text { Using Life Cycle Assessment To } \\
\text { Illustrate The Benefits Of Blinds As } \\
\text { Passive And Sustainable Energy } \\
\text { Saving Products In The Domestic } \\
\text { Environment In The UK }\end{array}$ & $\begin{array}{l}\text { Blinds And Shutters, Energy Saving, } \\
\text { Life Cycle Assessment, Overall } \\
\text { Environmental Impact }\end{array}$ \\
\hline CHEN K. \& LU W.S. & $\begin{array}{l}\text { A BIM-Centred System For Buffer } \\
\text { Management }\end{array}$ & $\begin{array}{llr}\text { Building Information } & \text { Modelling; } \\
\text { Buffer } & \text { Management; } & \text { RFID; } \\
\text { Decision-Support System } & \end{array}$ \\
\hline $\begin{array}{l}\text { HEINTZ J.L., LOUSBERG L.H., \& } \\
\text { PRINS M. }\end{array}$ & $\begin{array}{l}\text { RE-Designing Project Management: } \\
\text { Steps Towards A Project } \\
\text { Management Curriculum For A } \\
\text { Sustainable Built Environment }\end{array}$ & $\begin{array}{l}\text { Sustainable Project Management, } \\
\text { Project Management Education. }\end{array}$ \\
\hline $\begin{array}{l}\text { KUGBEADJOR W., SURESH S. \& } \\
\text { RENUKAPPA S. }\end{array}$ & $\begin{array}{l}\text { BIM Awareness And Readiness Of } \\
\text { Postgraduate Built Environment } \\
\text { Students In West Midlands } \\
\text { Universities, UK }\end{array}$ & $\begin{array}{l}\text { Awareness, Building Information } \\
\text { Modelling, Postgraduate Students, } \\
\text { Readiness, And Universities }\end{array}$ \\
\hline OPOKU A. \& EGBU C. & $\begin{array}{l}\text { The Extent Of Integrating } \\
\text { Sustainability Topics Into An MSc } \\
\text { Quantity Surveying Course At } \\
\text { London South Bank University In } \\
\text { UK }\end{array}$ & $\begin{array}{l}\text { Curriculum, Education, Quantity } \\
\text { Surveying, Sustainable Development. }\end{array}$ \\
\hline SEZER A.A. & $\begin{array}{llr}\text { Building } & \text { Refurbishment Site } \\
\text { Managers' } & \text { Waste Management } \\
\text { Practices } & & \end{array}$ & $\begin{array}{l}\text { Building, Large } \\
\text { Refurbishment, Site } \\
\text { Waste Management }\end{array}$ \\
\hline $\begin{array}{l}\text { SILVERIO K.A., SURESH S., } \\
\text { RENUKAPPA S. \& EASON M. }\end{array}$ & $\begin{array}{l}\text { Challenges Of BIM Implementation } \\
\text { In Sustainable Residential Projects In } \\
\text { The UK And Future Perspective }\end{array}$ & $\begin{array}{l}\text { BIM, Residential Buildings, } \\
\text { Sustainability, UK Government, Zero } \\
\text { Carbon Homes. }\end{array}$ \\
\hline $\begin{array}{l}\text { YE Z., TANN D.B., CHAER I. \& } \\
\text { BEASLEY P. }\end{array}$ & $\begin{array}{l}\text { Feasibility Study On Integration Of } \\
\text { Low Carbon Technologies To } \\
\text { Existing Domestic Dwellings In The } \\
\text { UK }\end{array}$ & $\begin{array}{l}\text { Building Fabrics, Energy Efficient } \\
\text { Heating Technologies, Low Carbon, } \\
\text { Retrofitting }\end{array}$ \\
\hline $\begin{array}{l}\text { YEBIYO M., MAIDMENT G., } \\
\text { PAURINE A. \& DAY A. }\end{array}$ & $\begin{array}{l}\text { A Novel Dry Air Ground Source } \\
\text { (DAGS) System For Heating And } \\
\text { Cooling Buildings }\end{array}$ & $\begin{array}{l}\text { Control Strategy, Dry Air Cooler, } \\
\text { Ground Source Heat Pump, } \\
\text { TRNSYS, Ground Temperature } \\
\text { Variation }\end{array}$ \\
\hline
\end{tabular}

